\title{
MANUAL
}

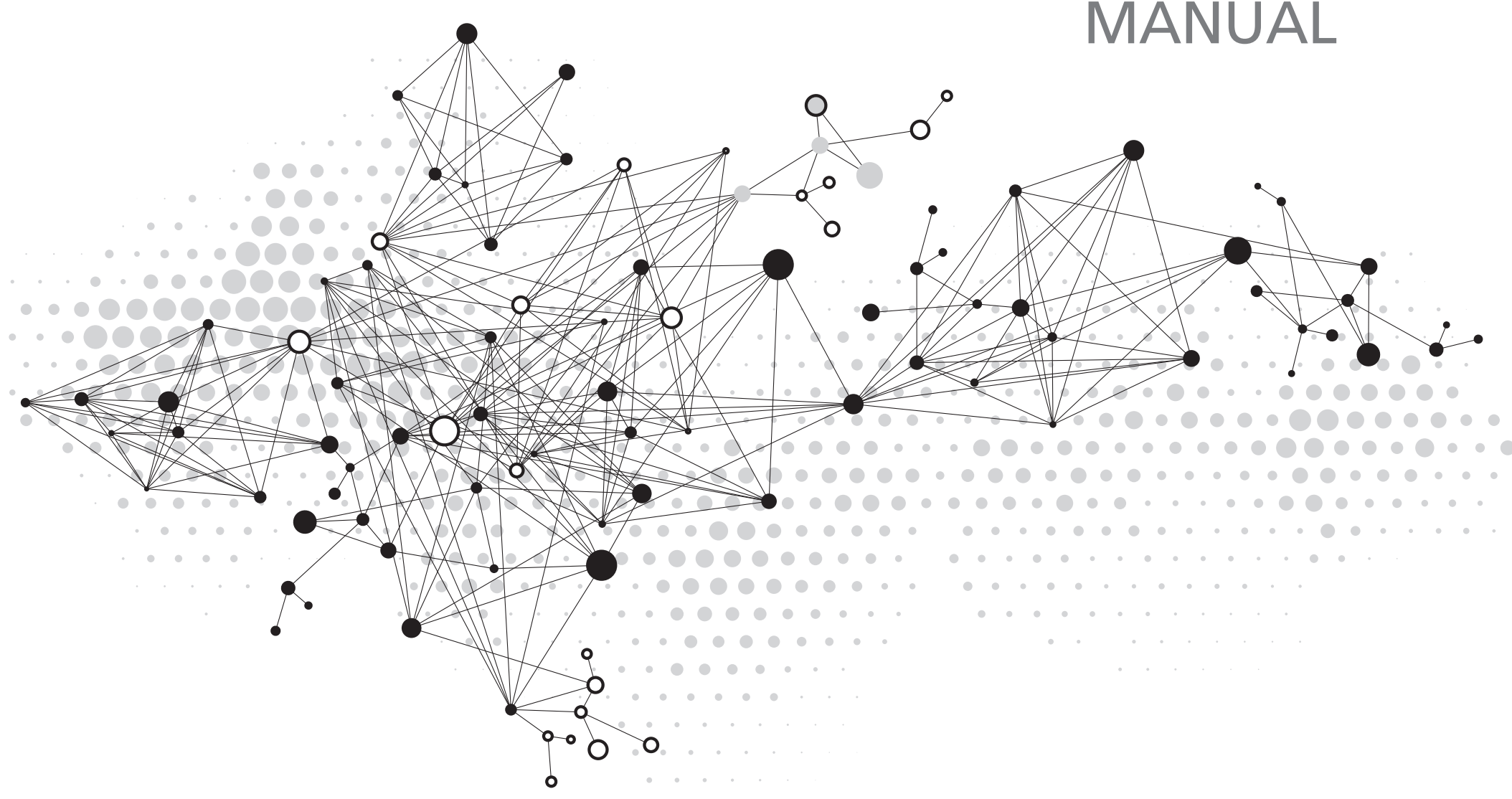

\section{GOVERNMENT FINANCE}

STATISTICS MANUAL 2014

2014

I NTER NATIONAL MONETARY FUND 
(c) 2014 International Monetary Fund

\section{Cataloging-in-Publication Data}

Joint Bank-Fund Library

Government finance statistics manual 2014. - Washington, D.C. : International Monetary Fund, 2014.

pages; $\mathrm{cm}$.

Includes bibliographical references and index.

ISBN: 978-1-49834-376-3

1. Finance, Public - Statistics - Handbooks, manuals, etc. I. International Monetary Fund.

HJ131.M26 2014

ISBN: 978-1-49834-376-3 (paper)

978-1-49837-921-2 (ePub)

978-1-49836-697-7 (Mobi pocket)

978-1-49837-916-8 (web PDF)

Disclaimer: The views expressed in this book are those of the authors and should not be reported as or attributed to the International Monetary Fund, its Executive Board, or the governments of any of its member countries.

Please send orders to:

International Monetary Fund, Publication Services

P.O. Box 92780, Washington, DC 20090, U.S.A.

Tel.: (202) 623-7430 Fax: (202) 623-7201

E-mail: publications@imf.org

Internet: www.elibrary.imf.org

www.imfbookstore.org 


\section{Contents}

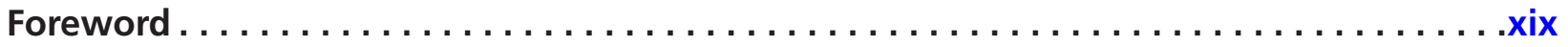

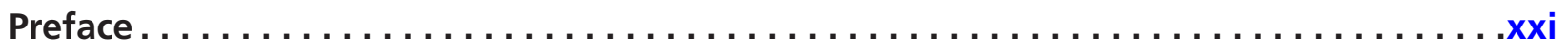

\section{Chapters}

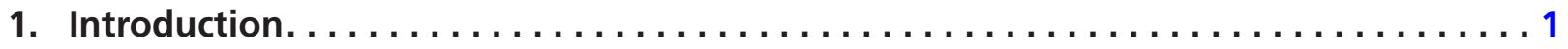

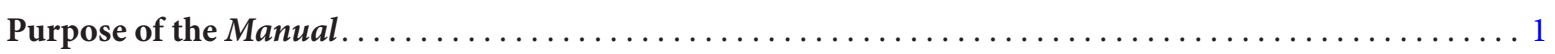

The Evolution of International Statistical Guidelines on GFS $\ldots \ldots \ldots \ldots \ldots \ldots \ldots \ldots \ldots \ldots \ldots \ldots \ldots \ldots$

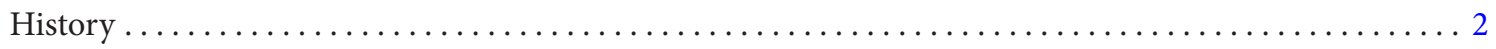

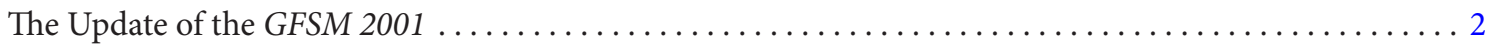

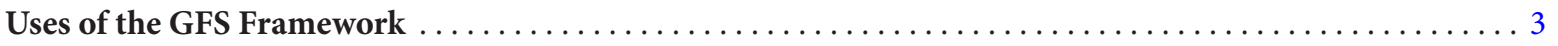

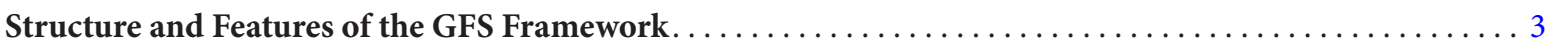

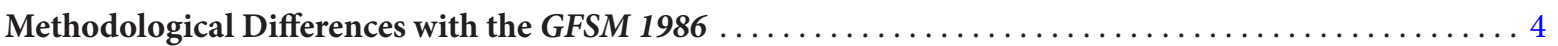

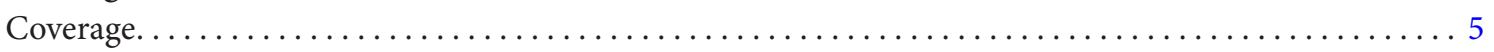

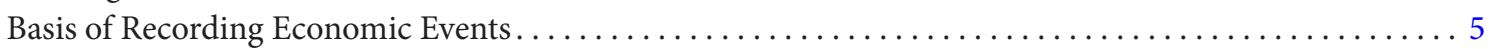

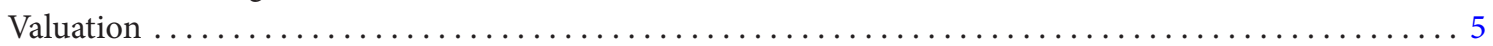

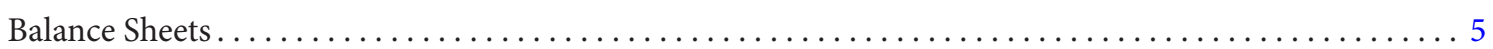

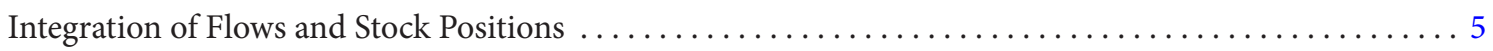

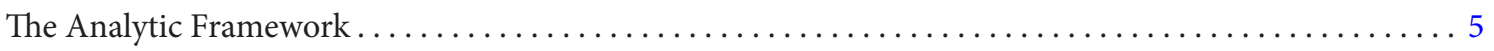

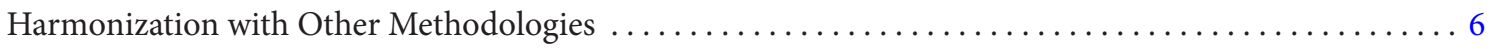

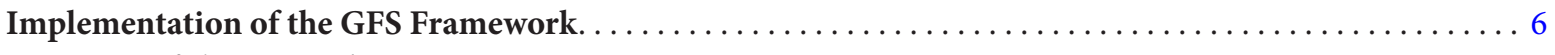

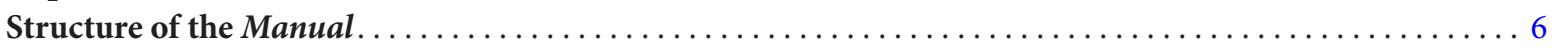

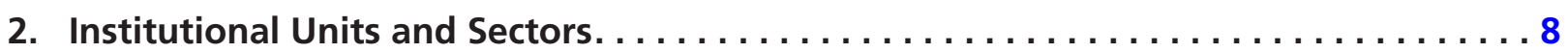

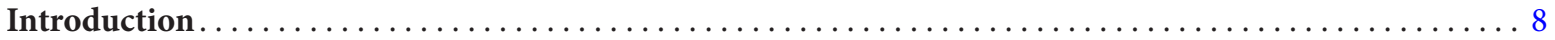

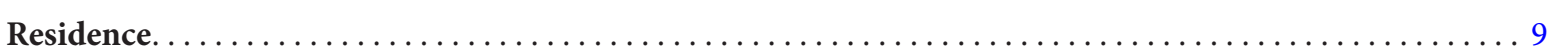

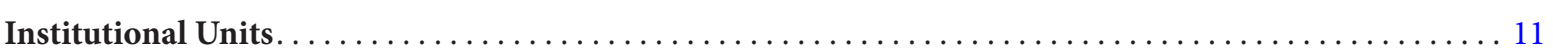

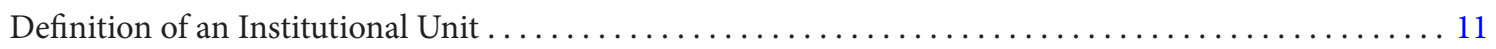

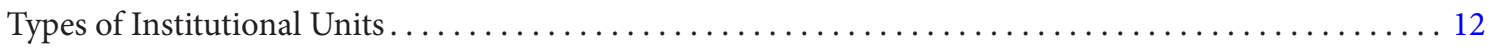

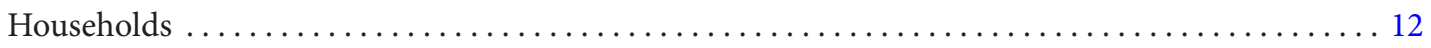

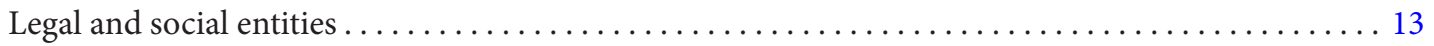

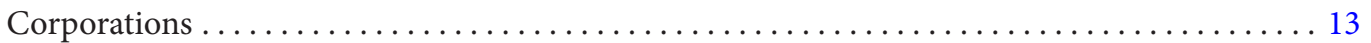

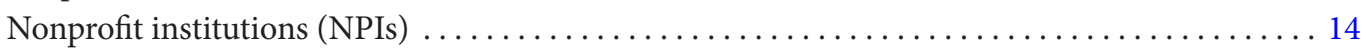

Government units........................... $\overline{14}$

Application of the Definition of an Institutional Unit to Government $\ldots \ldots \ldots \ldots \ldots \ldots \ldots \ldots \ldots \ldots$

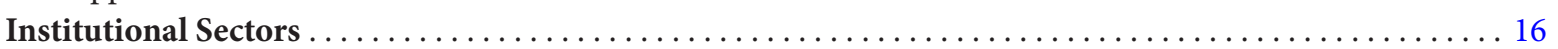

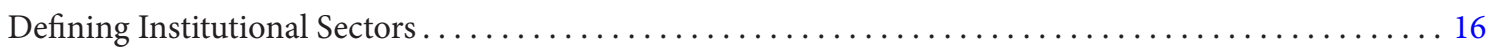

Nonfinancial corporations sector $\ldots \ldots \ldots \ldots \ldots \ldots \ldots \ldots \ldots \ldots \ldots \ldots \ldots \ldots \ldots \ldots \ldots$

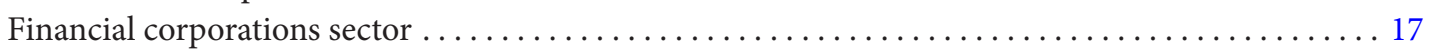

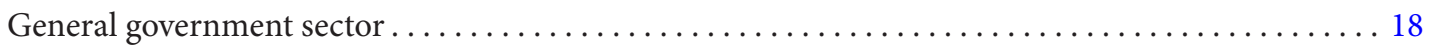


Households sector. ................................................. 18

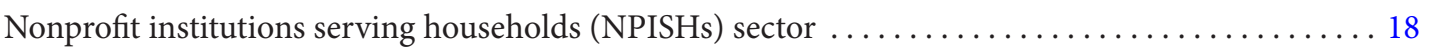

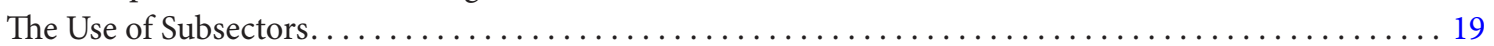

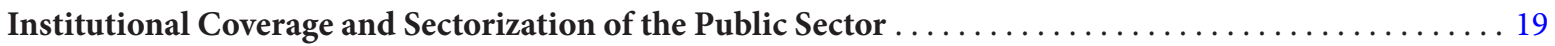

Delineating General Government and Public Corporations . . . . . . . . . . . . . . . . . . . . . 19

The General Government Sector and Its Subsectors . . . . . . . . . . . . . . . . . . . . . . . . $\frac{22}{24}$

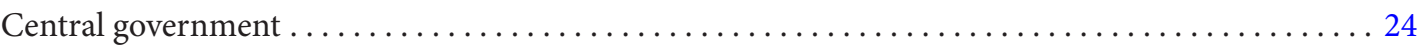

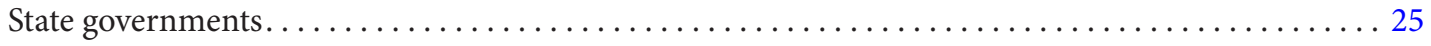

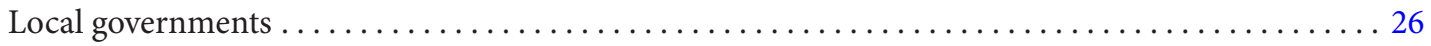

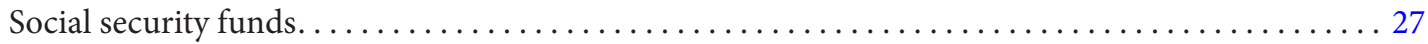

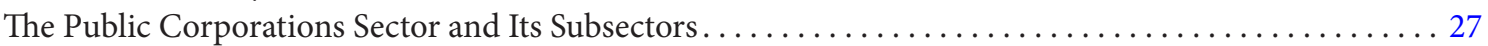

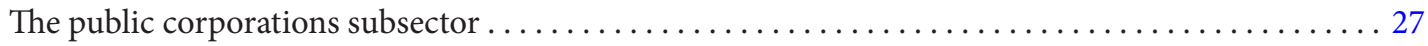

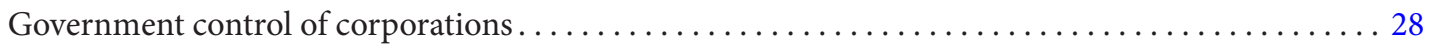

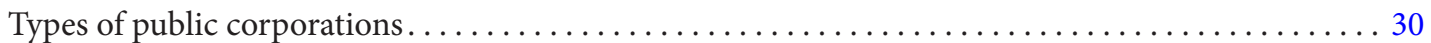

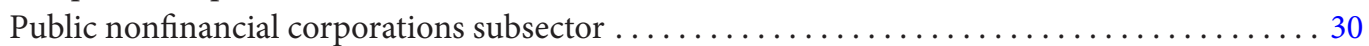

Public financial corporations subsector. . . . . . . . . . . . . . . . . . . . . . . . . .

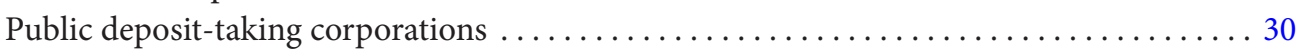

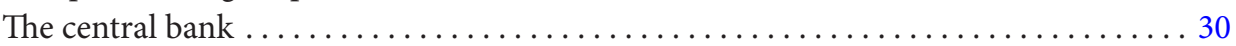

Public deposit-taking corporations except the central bank..............

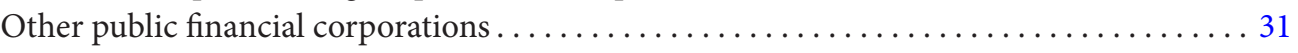

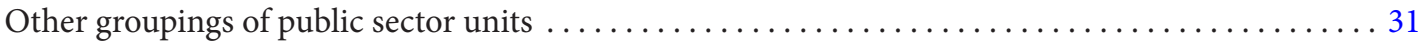

Decision Tree for Sector Classification of the Public Sector..........................

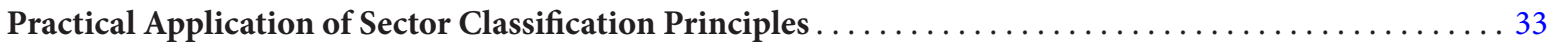

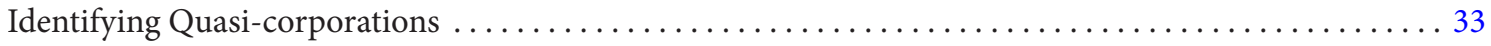

Distinguishing Head Offices and Holding Companies ..........................

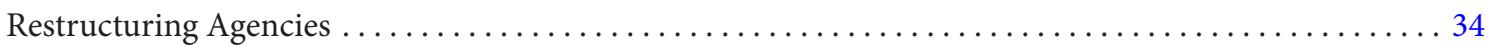

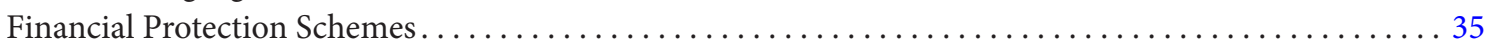

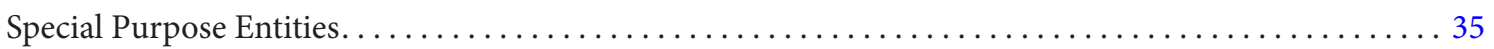

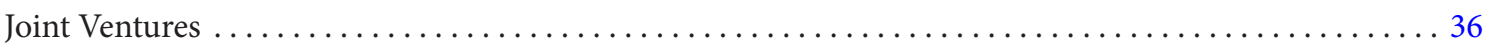

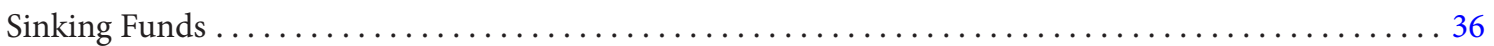

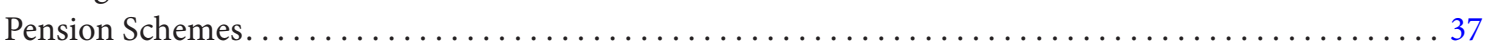

Provident Funds ......................................................... $\frac{37}{37}$

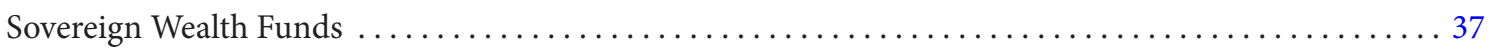

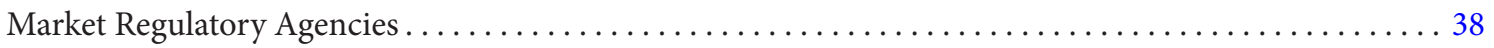

Development Funds and/or Infrastructure Companies or Entities.....................

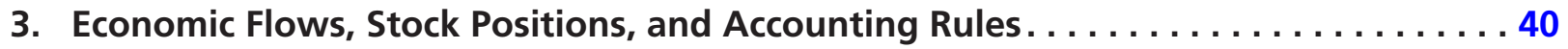

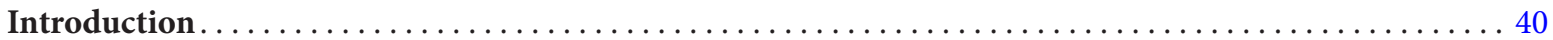

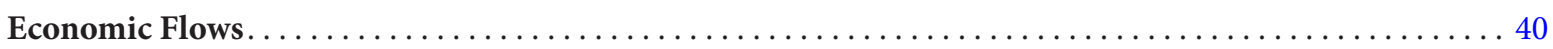

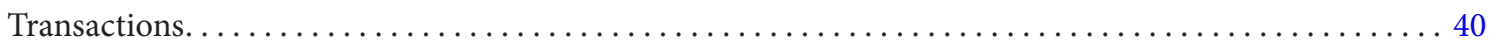

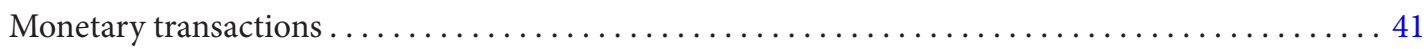

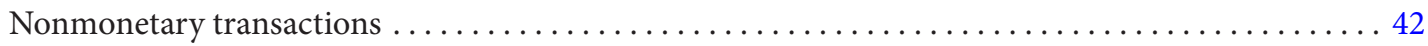

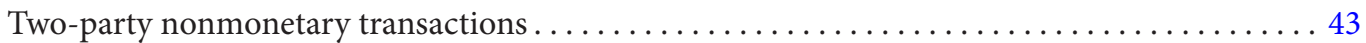

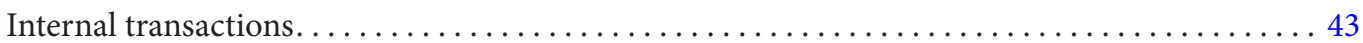

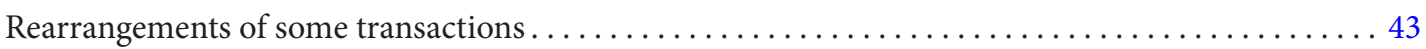

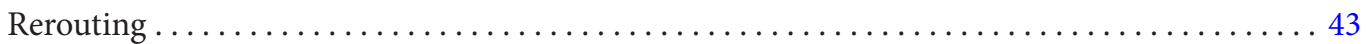

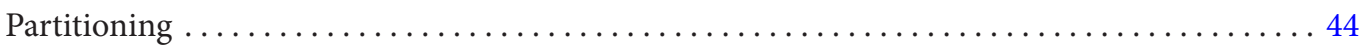

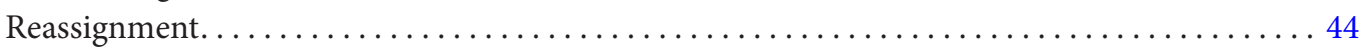

Other Economic Flows. . . . . . . . . . . . . . . . . . . . . . . . . . . . . . . . . . . . . . . . .

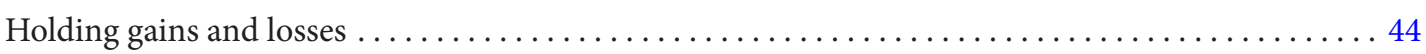

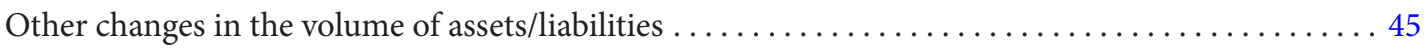




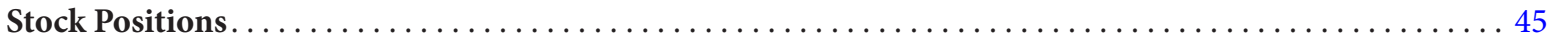

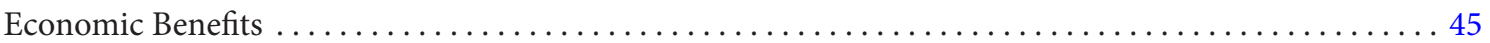

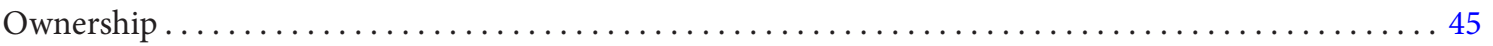

Definition of Assets and Liabilities. . . . . . . . . . . . . . . . . . . . . . . . . . . . . . . . . $\frac{46}{46}$

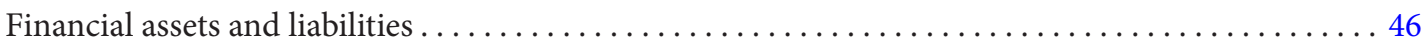

Nonfinancial assets . . . . . . . . . . . . . . . . . . . . . . . . . . . . . . . . . . . .

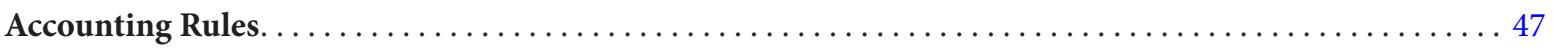

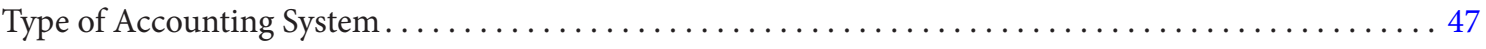

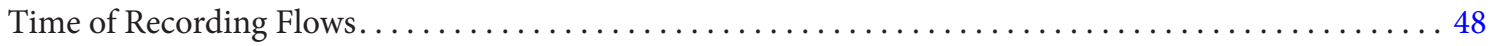

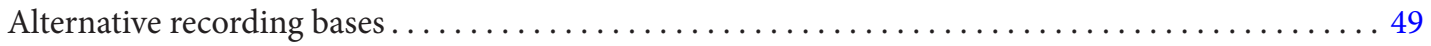

Using the accrual basis of recording in the Statements of Operations and

Other Economic Flows, and Balance Sheet of the GFS framework................... 50

Application of the accrual principles .....................................

Time of recording and measurement of taxes and other compulsory transfers.......... 51

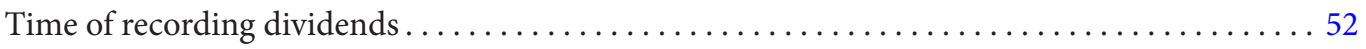

Time of recording transactions in goods, services, and nonfinancial assets $\ldots \ldots \ldots \ldots \ldots \ldots \frac{52}{53}$

Time of recording transactions in financial assets and liabilities.................

Time of recording other economic flows. . . . . . . . . . . . . . . . . . . . . . . .

Using the cash basis of recording in the Statement of Sources and Uses of Cash . . . . . . . . . .

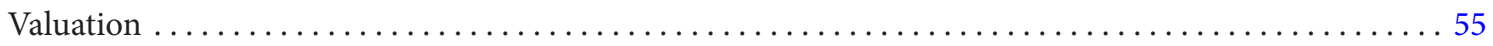

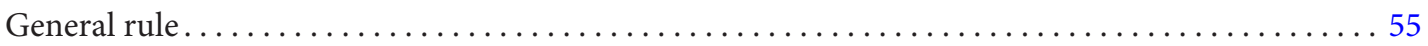

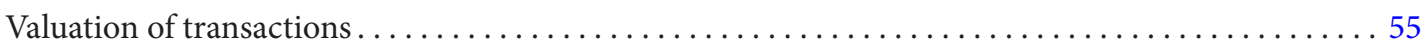

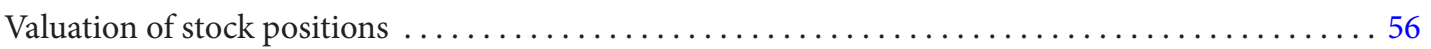

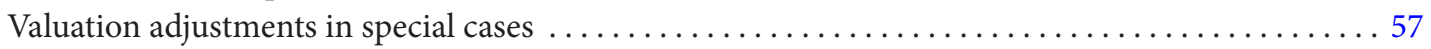

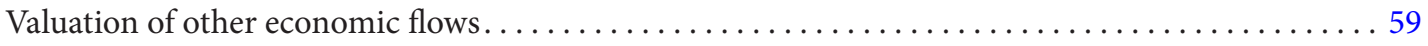

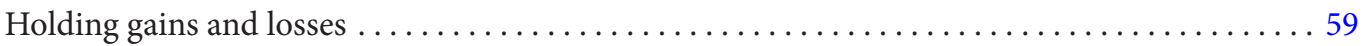

Other changes in the volume of assets ..............................

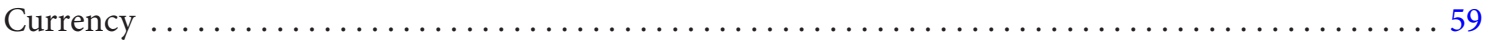

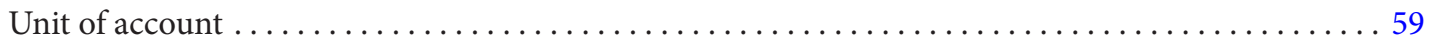

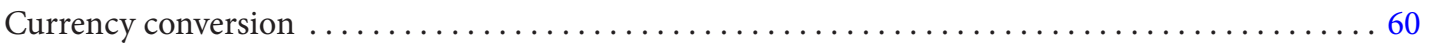

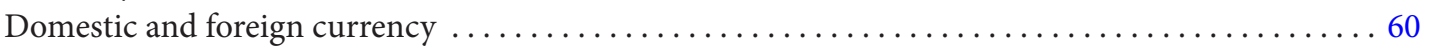

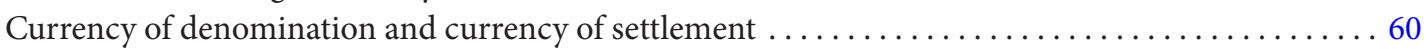

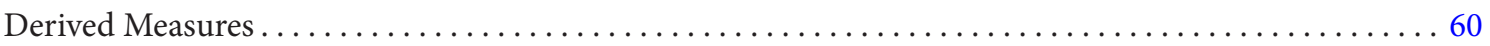

Netting of Flows and Stock Positions. . . . . . . . . . . . . . . . . . . . . . . . . . . . . .

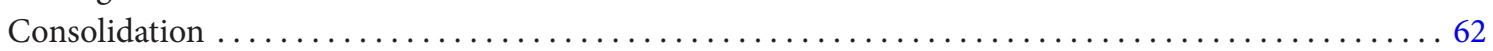

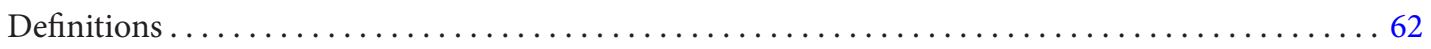

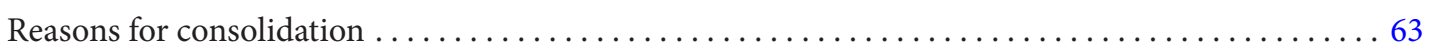

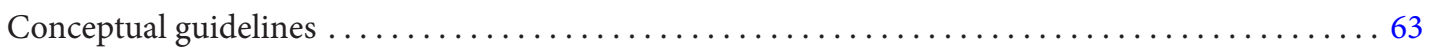

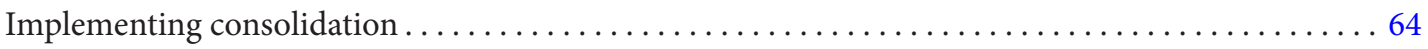

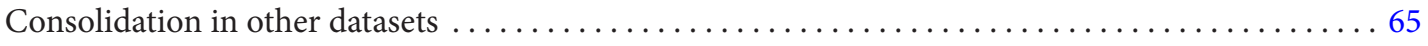

2008 System of National Accounts .................................... $\frac{65}{65}$

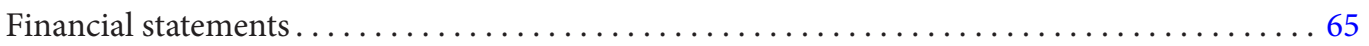

4. The Government Finance Statistics Analytic Framework $\ldots \ldots \ldots \ldots \ldots \ldots \ldots$

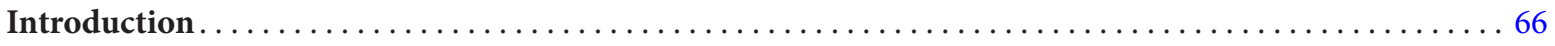

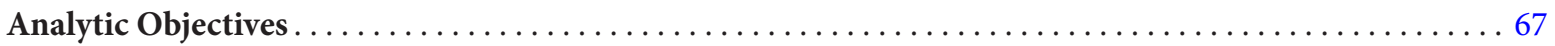

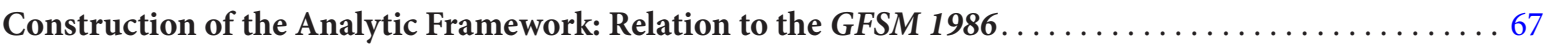

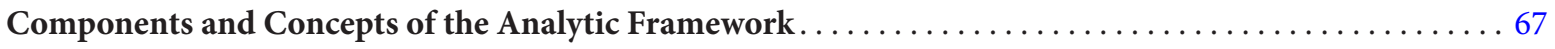

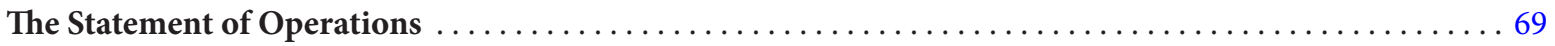

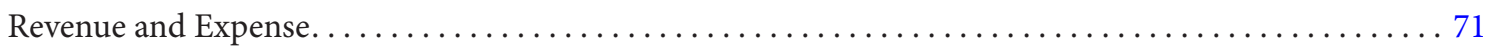




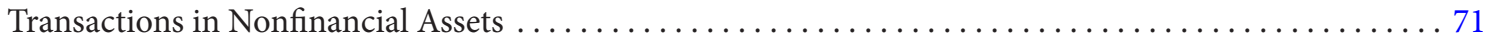

Transactions in Financial Assets and Liabilities................................ $\frac{71}{73}$

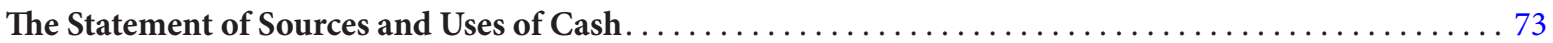

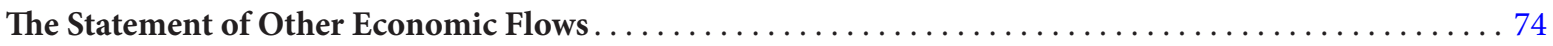

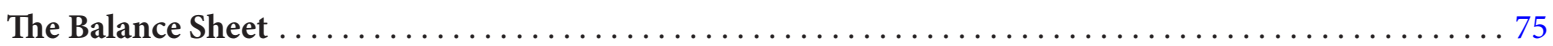

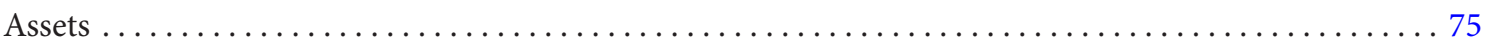

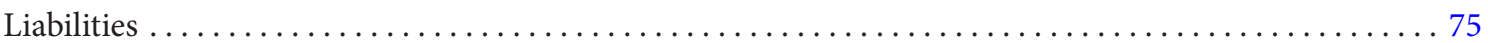

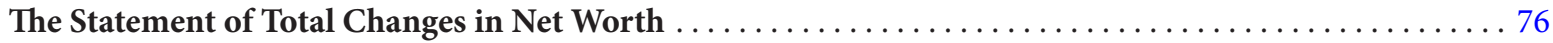

The Summary Statement of Explicit Contingent Liabilities and Net Implicit Obligations for

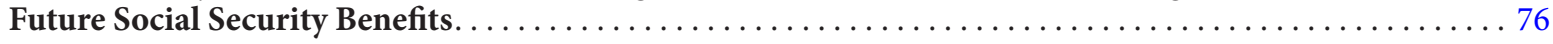

Annex: Using GFS for Fiscal Analysis. . . . . . . . . . . . . . . .

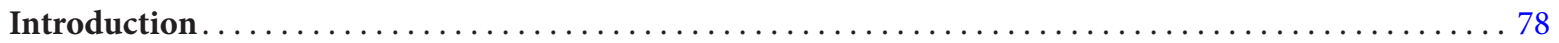

Fiscal Indicators Available from the GFS Framework. $\ldots \ldots \ldots \ldots \ldots \ldots \ldots \ldots \ldots \ldots \ldots \ldots$

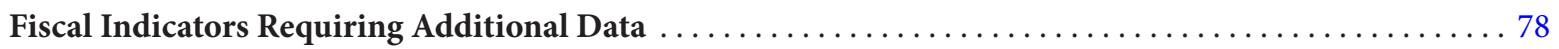

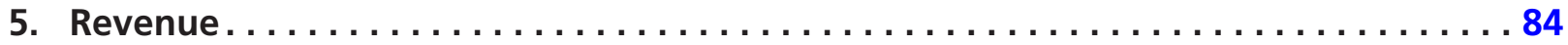

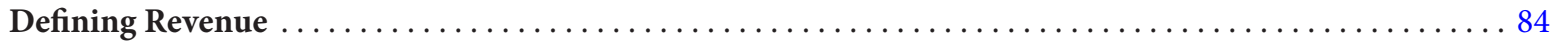

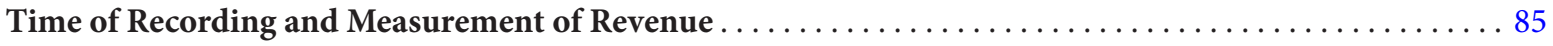

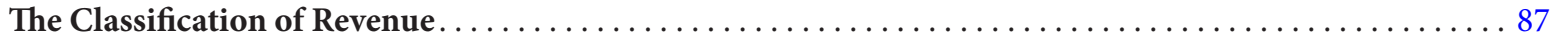

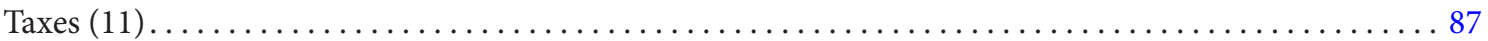

GFS tax classifications in comparison with other statistical databases $\ldots \ldots \ldots \ldots \ldots \ldots \ldots \ldots \frac{87}{89}$

Treatment of tax refunds and tax relief . . . . . . . . . . . . . . . . . . . . . . . . . .

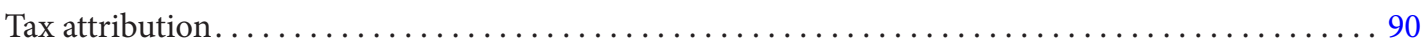

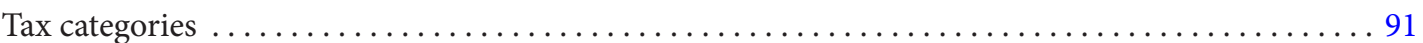

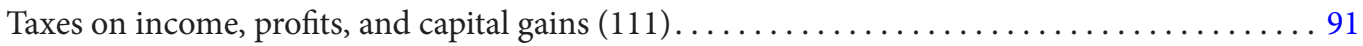

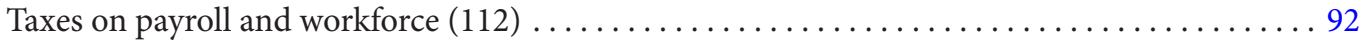

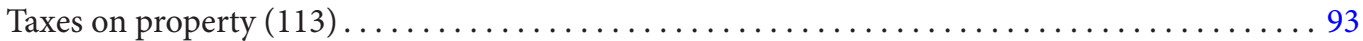

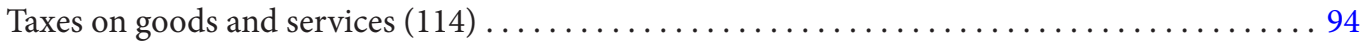

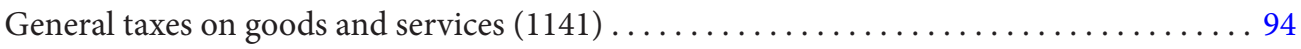

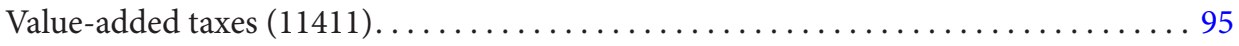

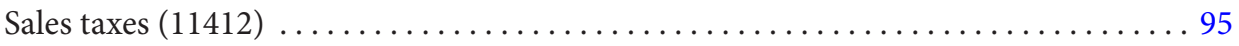

Turnover and other general taxes on goods and services $(11413) \ldots \ldots \ldots \ldots \ldots, \frac{95}{95}$

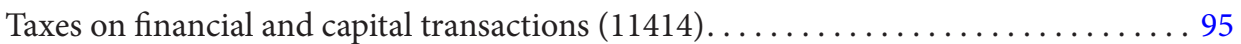

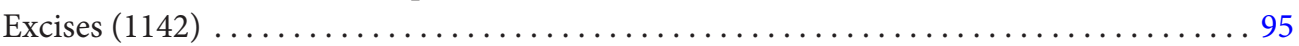

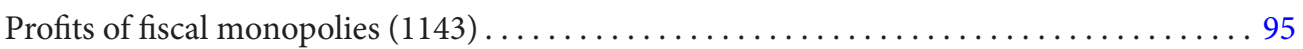

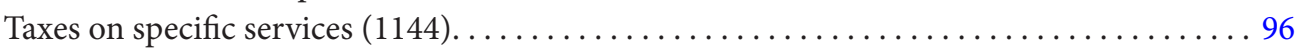

Taxes on use of goods and on permission to use goods or perform activities $(1145) \ldots \ldots \overline{\frac{97}{97}}$

Boundary with administrative fees........................

Boundary with taxes on business activities levied on different bases . . . . . . . . $\frac{98}{98}$

Boundaries with other tax categories .........................

Boundary with the acquisition or use of an asset ..................

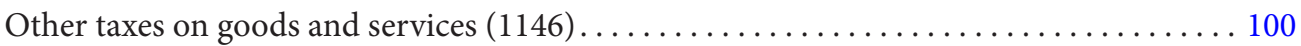

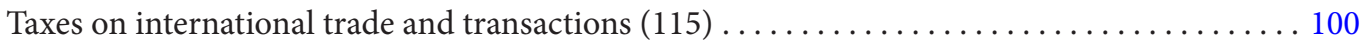

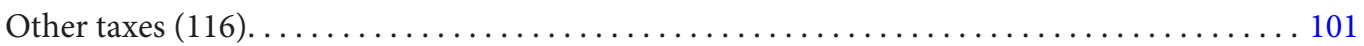

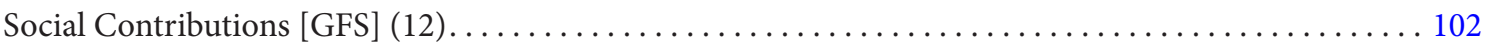

The boundary between social contributions and other categories of taxes $\ldots \ldots \ldots \ldots \ldots \ldots \ldots . .102$

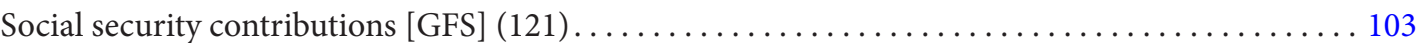

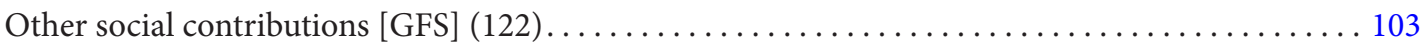

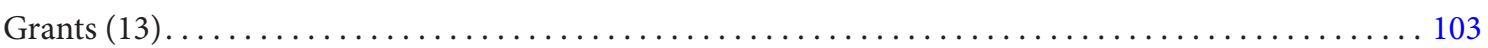

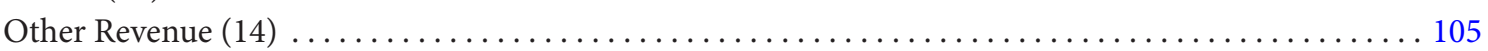




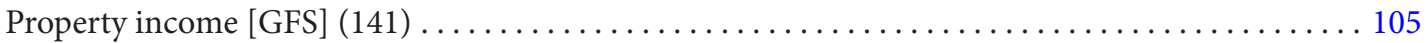

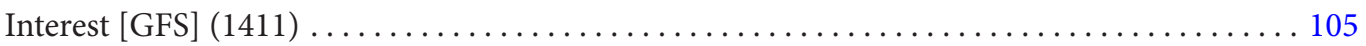

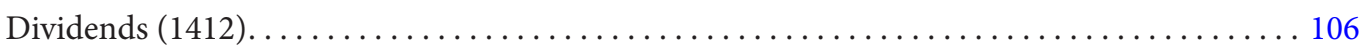

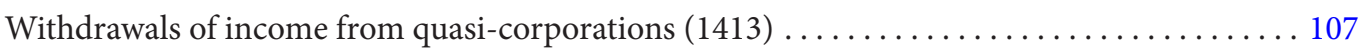

Property income from investment income disbursements $(1414) \ldots \ldots \ldots \ldots \ldots \ldots \ldots . .107$

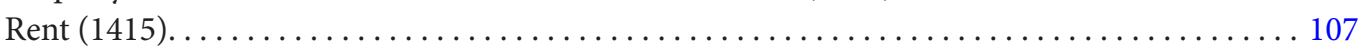

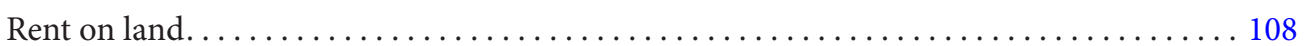

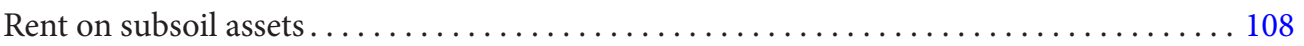

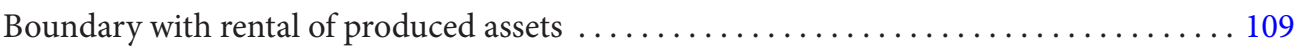

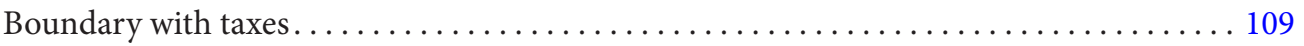

Reinvested earnings on foreign direct investment $(1416) \ldots \ldots \ldots \ldots \ldots \ldots \ldots \ldots \ldots \ldots$

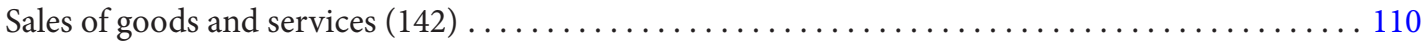

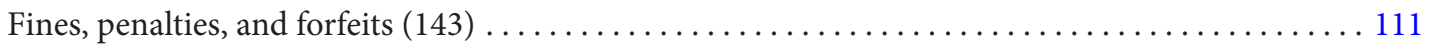

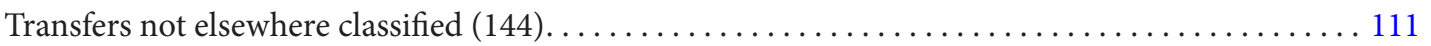

Premiums, fees, and claims receivable related to nonlife insurance and

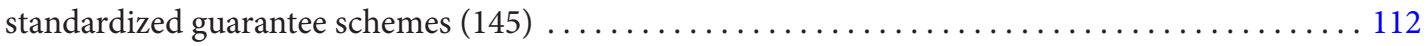

6. Expense $\ldots \ldots \ldots \ldots \ldots \ldots \ldots \ldots \ldots \ldots \ldots \ldots \ldots \ldots \ldots \ldots \ldots \ldots \ldots \ldots \ldots \ldots \ldots \ldots \ldots \ldots, 114$

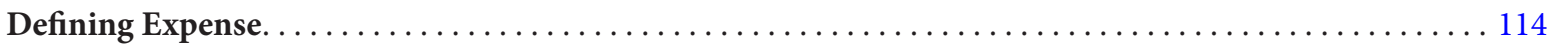

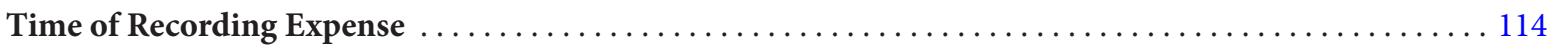

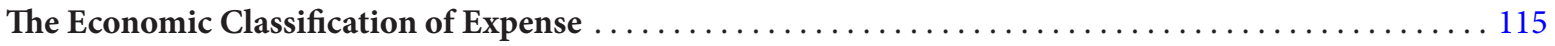

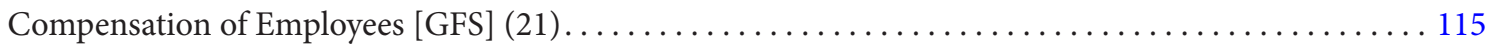

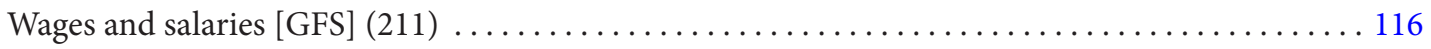

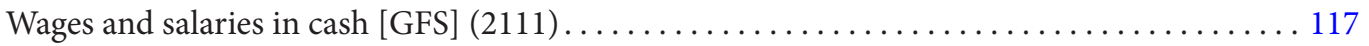

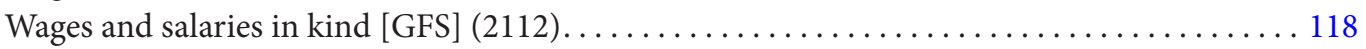

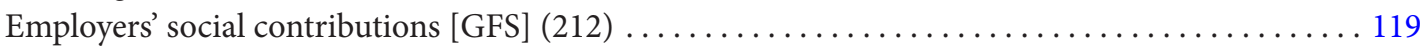

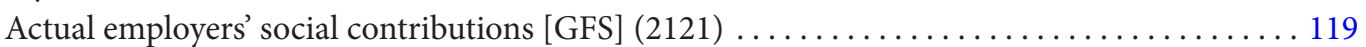

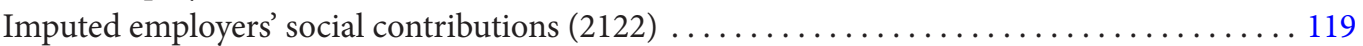

Imputed employers' social contributions related to nonpension benefits. .........

Imputed employers' social contributions to employment-related pension benefits . . . . $\frac{120}{120}$

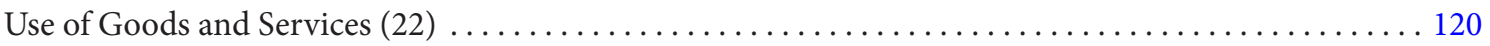

The boundary between use of goods and services and compensation of employees $\ldots \ldots \ldots \ldots \ldots \frac{121}{122}$

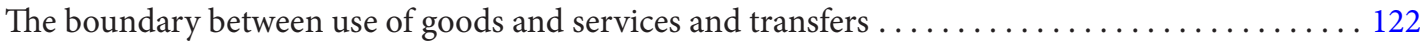

The boundary between use of goods and services and the acquisition of nonfinancial assets ....

Other boundaries related to use of goods and services.........................

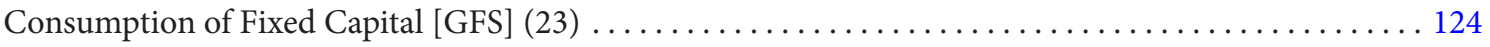

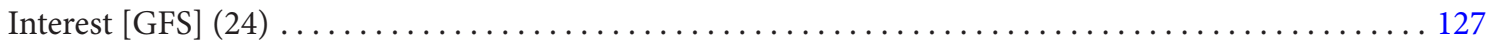

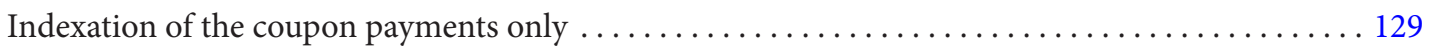

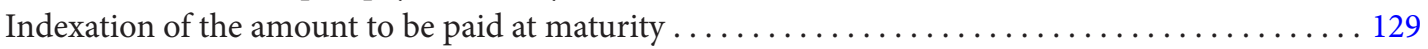

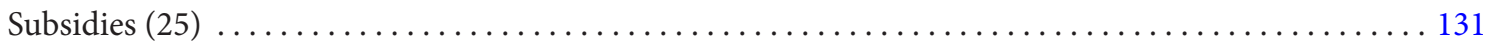

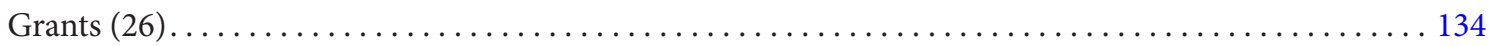

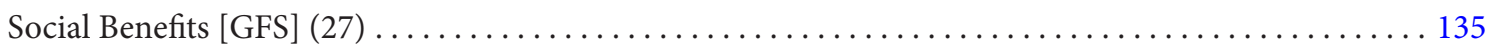

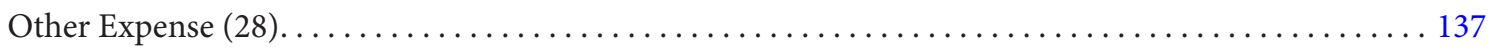

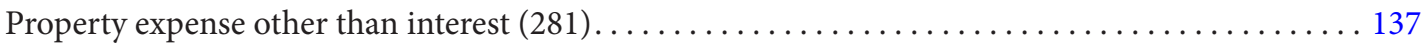

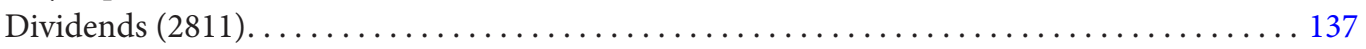

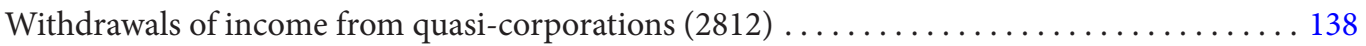

Property expense for investment income disbursements $(2813) \ldots \ldots \ldots \ldots \ldots \ldots \ldots \ldots \ldots \ldots \ldots$

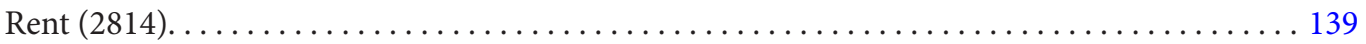

Reinvested earnings on foreign direct investment $(2815) \ldots \ldots \ldots \ldots \ldots \ldots \ldots \ldots \ldots \ldots \ldots \ldots \ldots \ldots$

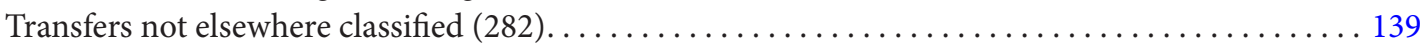




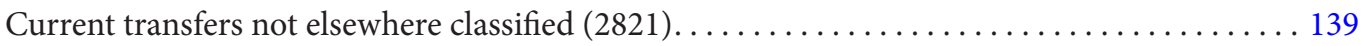

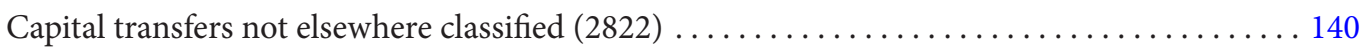

Premiums, fees, and claims payable related to nonlife insurance and standardized

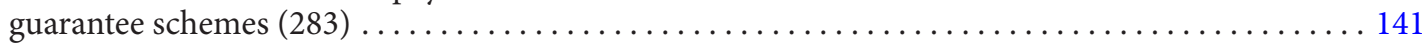

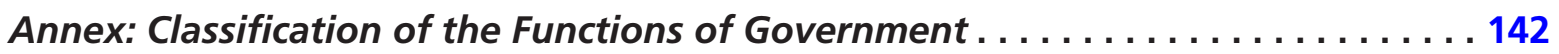

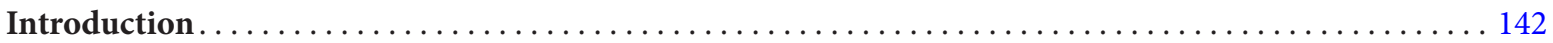

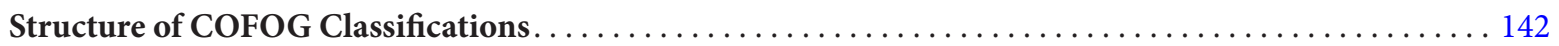

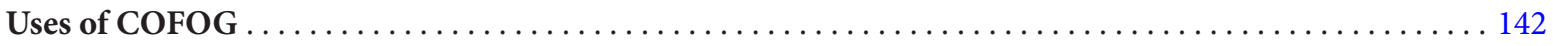

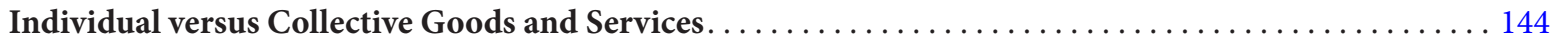

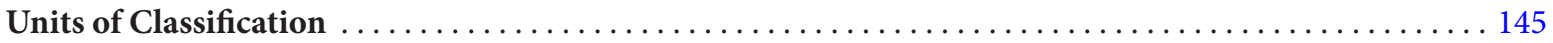

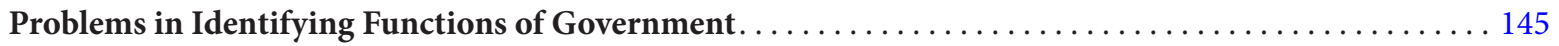

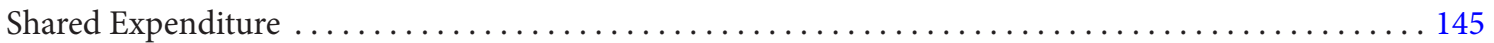

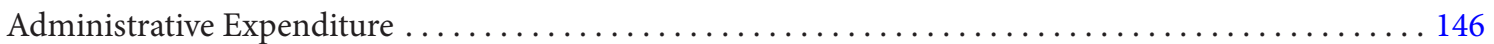

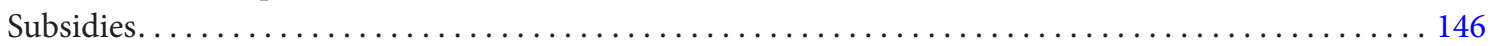

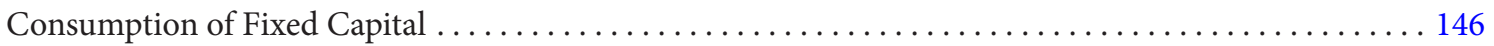

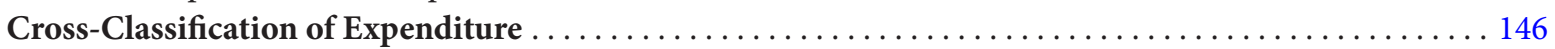

Detailed Classification of the Functions of Government $\ldots \ldots \ldots \ldots \ldots \ldots \ldots \ldots \ldots \ldots \ldots \ldots$

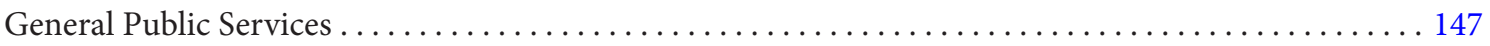

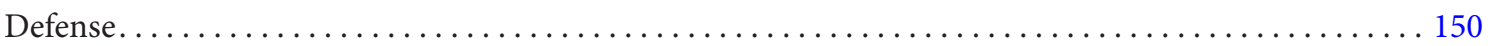

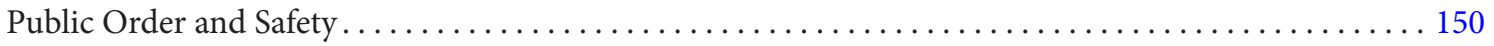

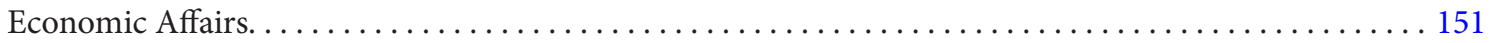

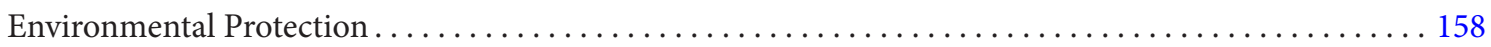

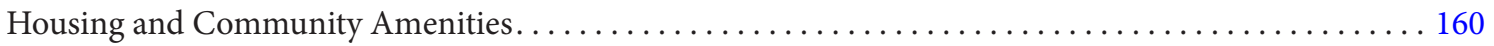

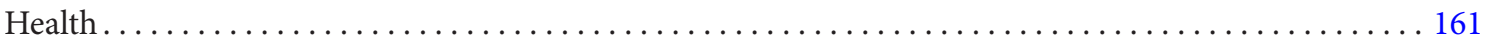

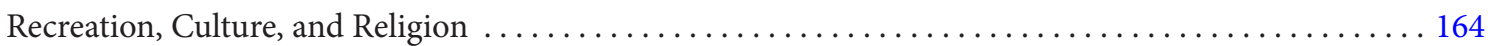

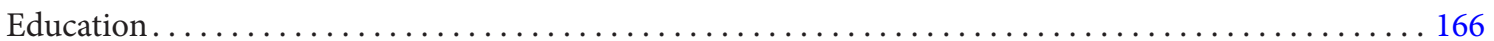

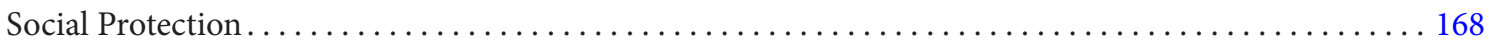

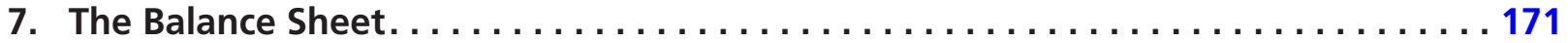

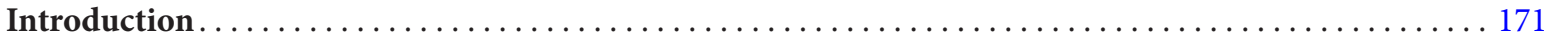

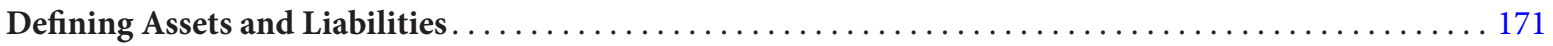

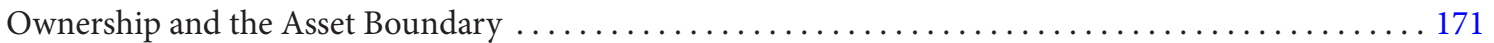

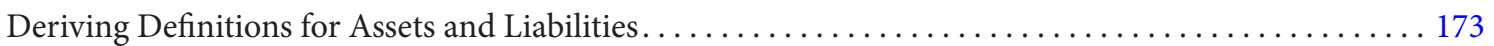

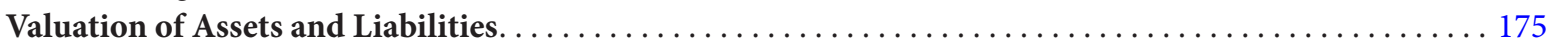

Value Observed in Markets . . . . . . . . . . . . . . . . . . . . . . . . . . . . . . $\frac{175}{175}$

Value Obtained by Accumulating and Revaluing Transactions . . . . . . . . . . . . . . .

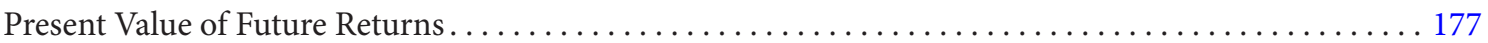

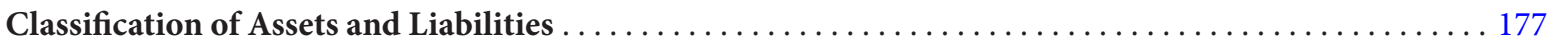

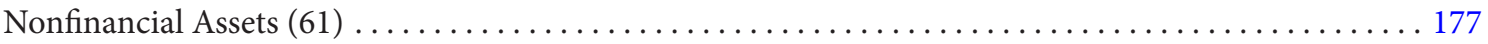

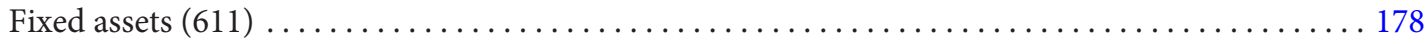

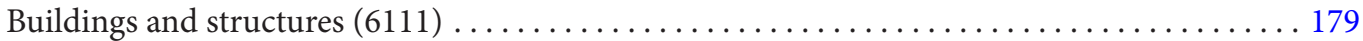

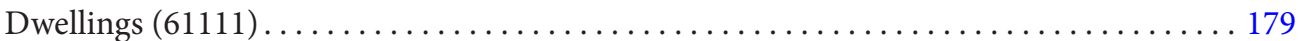

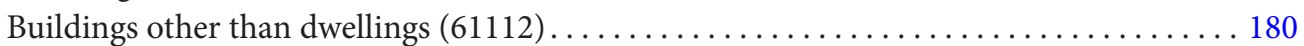

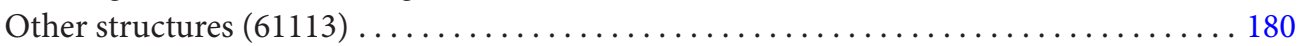

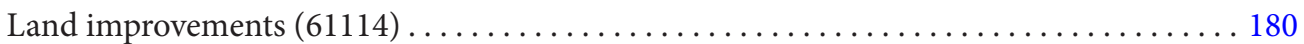

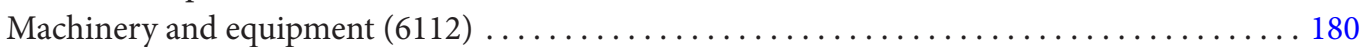

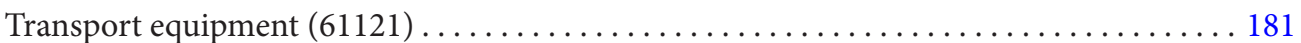

Machinery and equipment other than transport equipment $(61122) \ldots \ldots \ldots \ldots \ldots 1$

Information, computer, and telecommunications equipment (ICT) (611221) . . $\overline{181}$

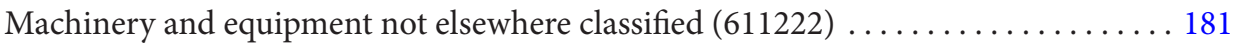




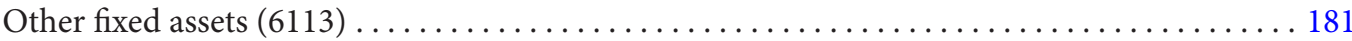

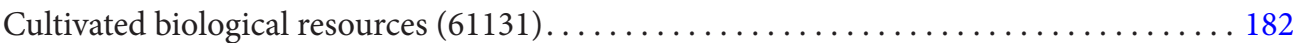

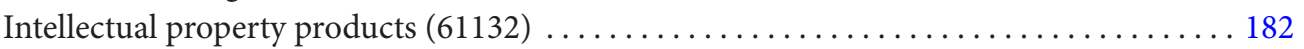

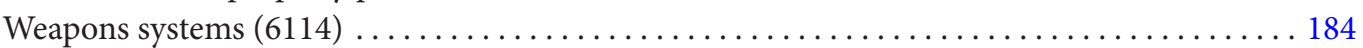

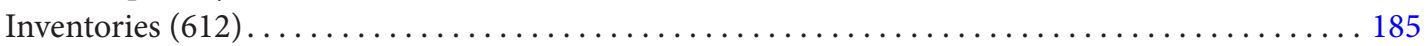

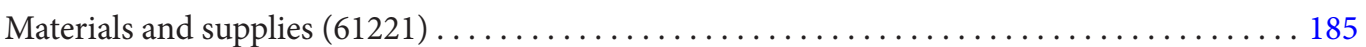

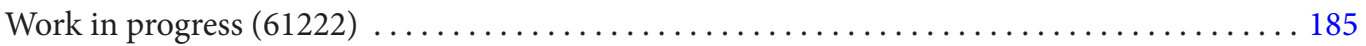

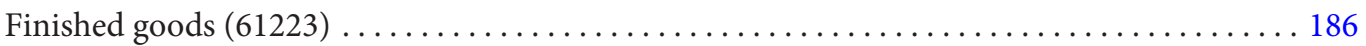

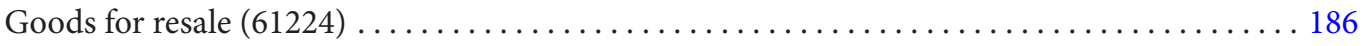

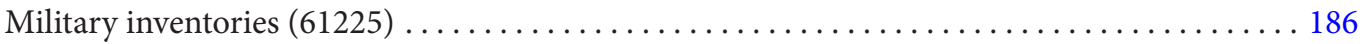

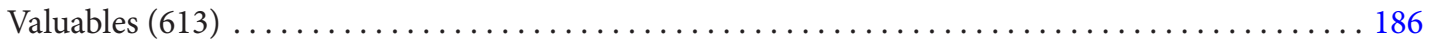

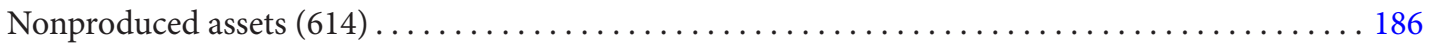

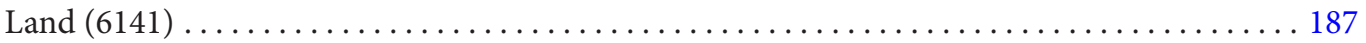

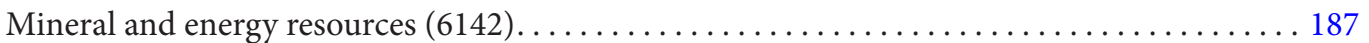

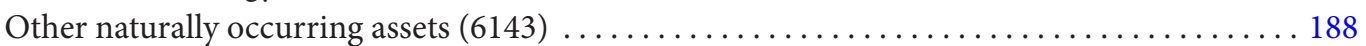

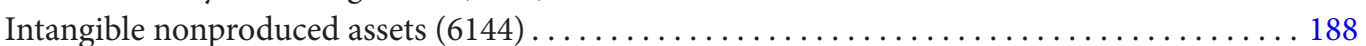

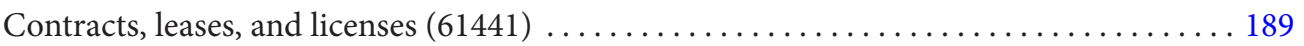

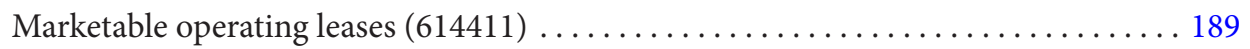

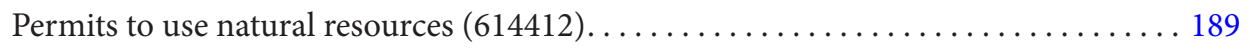

Permits to undertake specific activities $(614413) \ldots \ldots \ldots \ldots \ldots \ldots \ldots \ldots \ldots \ldots \ldots \ldots$

Entitlement to future goods and services on an exclusive basis $(614414) \ldots \ldots \ldots \ldots 190$

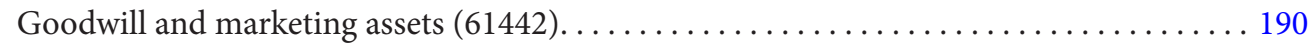

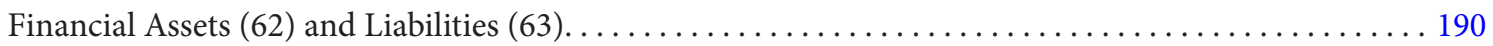

Monetary gold and Special Drawing Rights (SDRs) $(6201,6221,6301,6321) \ldots \ldots \ldots \ldots \ldots \ldots 191$

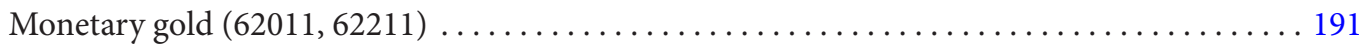

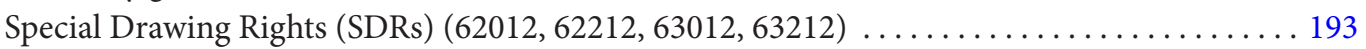

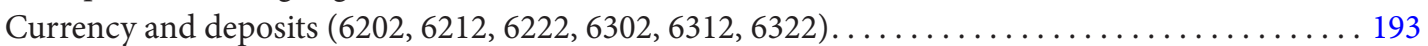

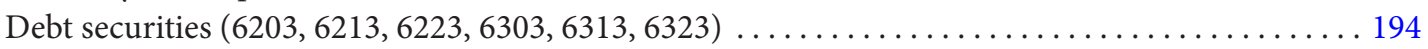

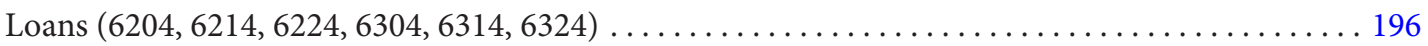

Equity and investment fund shares $(6205,6215,6225,6305,6315,6325) \ldots \ldots \ldots \ldots \ldots \ldots \ldots \frac{197}{197}$

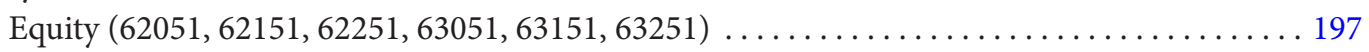

Investment fund shares or units $(62052,62152,62252,63052,63152,63252) \ldots \ldots \ldots \ldots \ldots \underline{198}$

Insurance, pension, and standardized guarantee schemes [GFS] $(6206,6216,6226$,

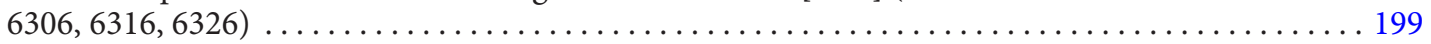

Nonlife insurance technical reserves $(62061,62161,62261,63061,63161,63261) \ldots \ldots \ldots \ldots \underline{199}$

Life insurance and annuities entitlements $(62062,62162,62262,63062,63162,63262) \ldots \ldots \underline{200}$

Pension entitlements [GFS] $(62063,62163,62263,63063,63163,63263) \ldots \ldots \ldots \ldots \ldots \ldots \frac{200}{202}$

Claims of pension funds on pension manager $(62064,62164,62264,63064,63164,63264) \ldots \underline{202}$

Provisions for calls under standardized guarantee schemes $(62065,62165,62265,63065$,

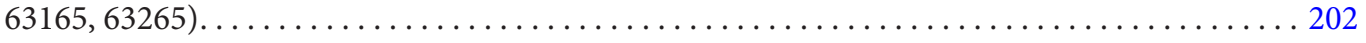

Financial derivatives and employee stock options $(6207,6217,6227,6307,6317,6327) \ldots \ldots \ldots \underline{202}$

Financial derivatives $(62071,62171,62271,63071,63171,63271) \ldots \ldots \ldots \ldots \ldots \ldots \ldots 202$

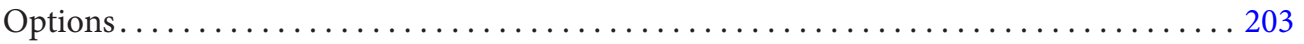

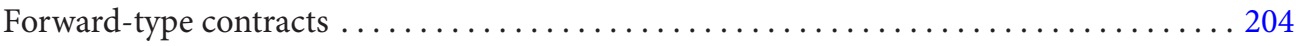

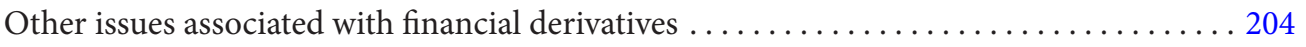

Swap contracts.......................................

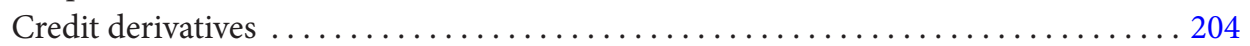

Margins.........................................

Employee stock options $(62072,62172,62272,63072,63172,63272) \ldots \ldots \ldots \ldots \ldots \ldots \underline{\underline{205}}$

Other accounts receivable/payable $(6208,6218,6228,6308,6318,6328) \ldots \ldots \ldots \ldots \ldots \ldots \ldots \underline{205}$ 


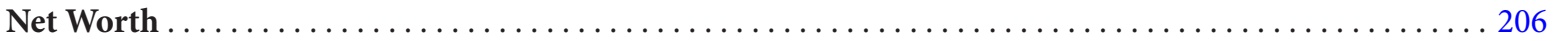

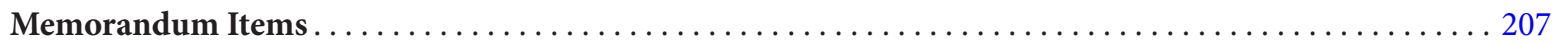

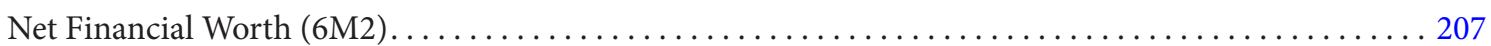

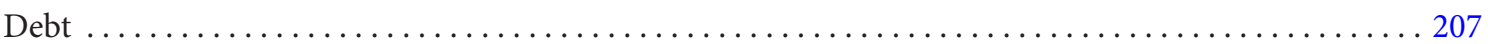

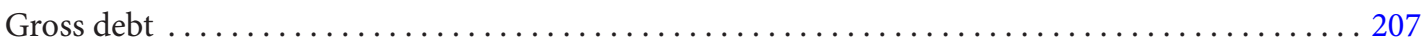

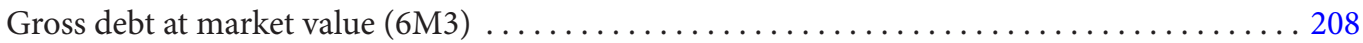

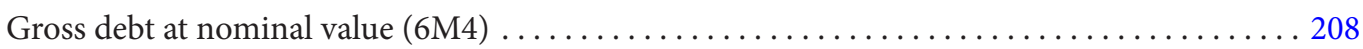

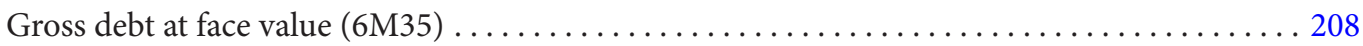

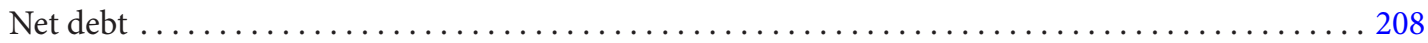

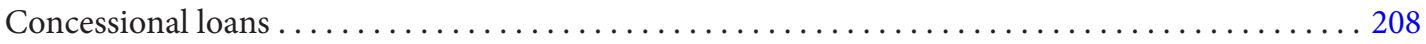

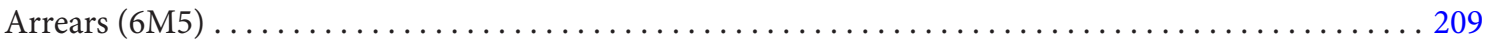

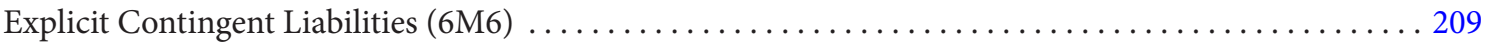

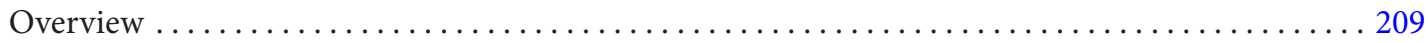

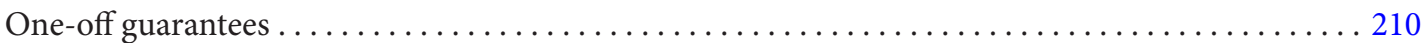

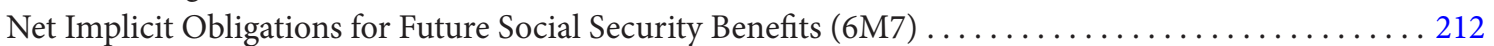

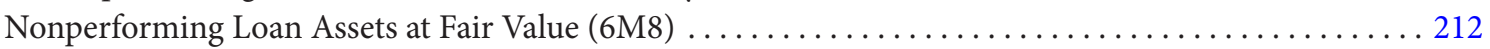

Classification of the Counterparty of Financial Assets and Liabilities by Institutional Sector ....... $\overline{213}$

Classification of Debt Liabilities and Financial Assets Corresponding to Debt Instruments by Maturity ... $\underline{213}$

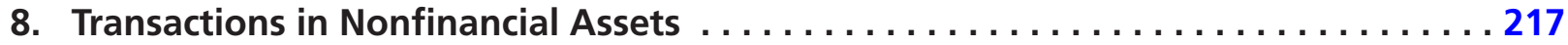

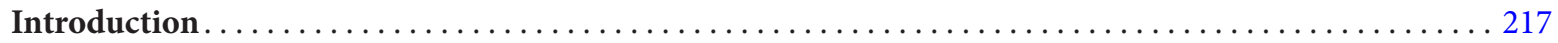

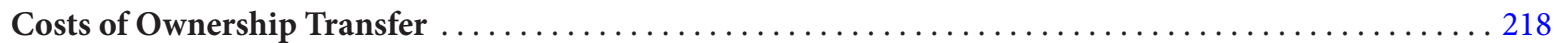

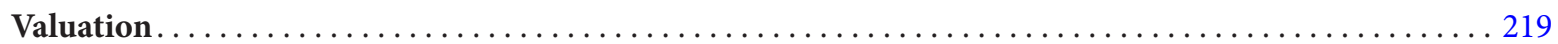

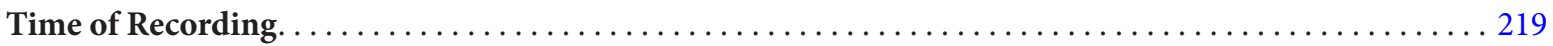

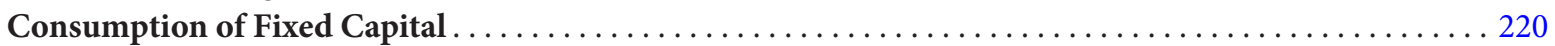

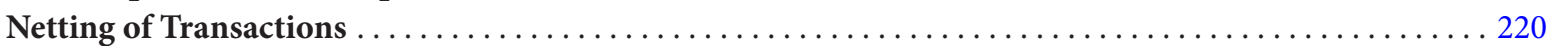

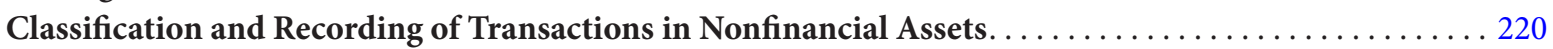

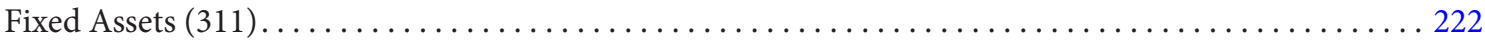

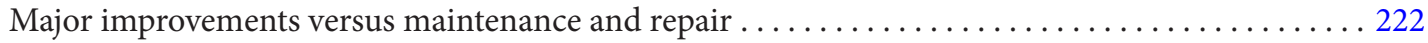

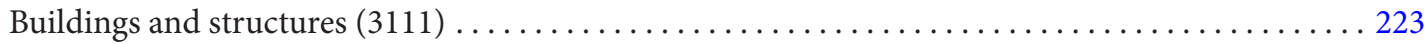

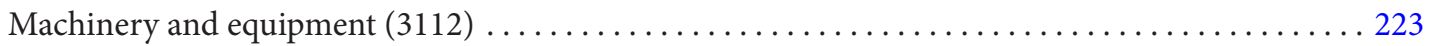

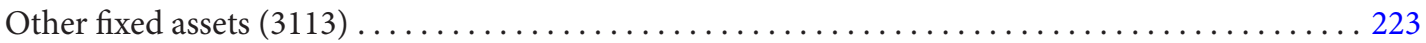

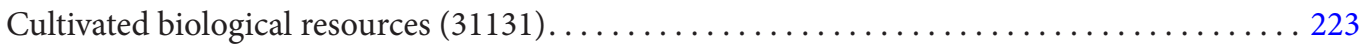

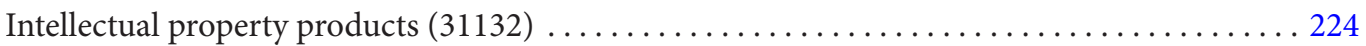

Costs of ownership transfer on nonproduced assets other than land (31133) $\ldots \ldots \ldots \ldots \ldots .225$

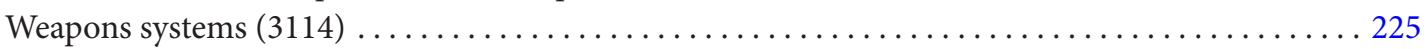

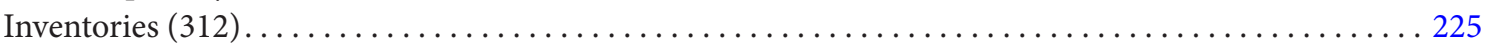

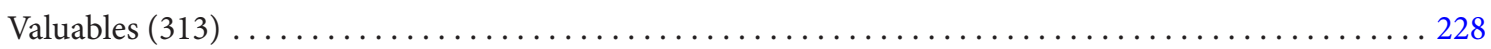

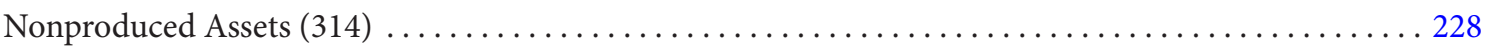

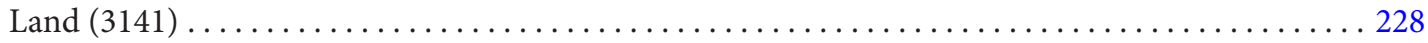

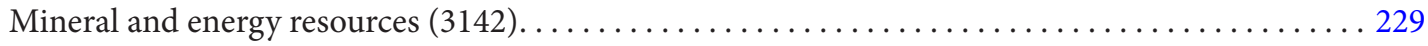

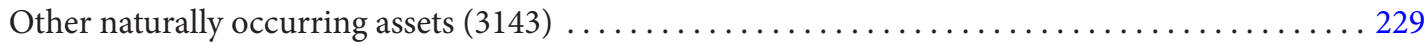

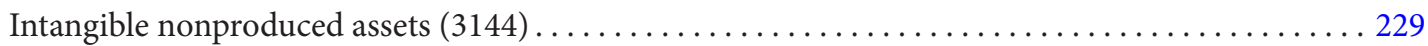

9. Transactions in Financial Assets and Liabilities. . . . . . . . . . . . . . . 230

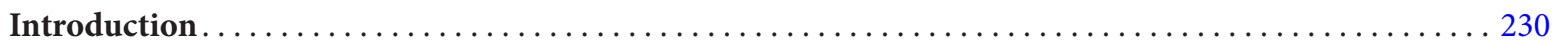

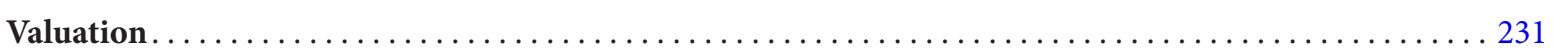

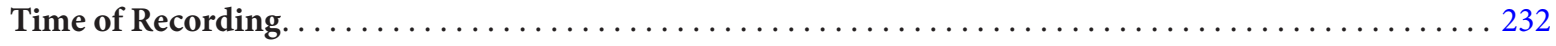

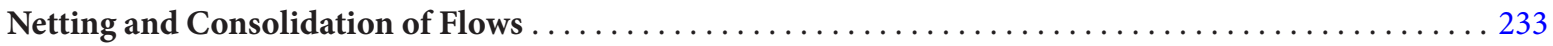

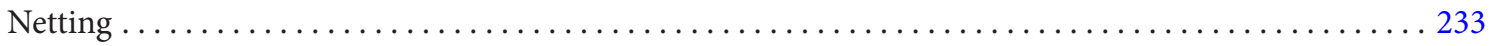

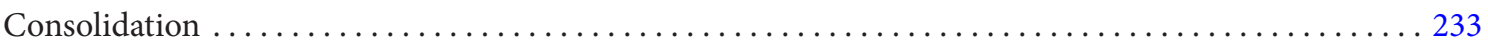


Arrears. 233 Classification of Transactions in Financial Assets and Liabilities by Type of Financial Instrument and Residence. .234

Monetary Gold and Special Drawing Rights (SDRs) $(3201,3221,3301,3321) \ldots \ldots \ldots \ldots \ldots \ldots$

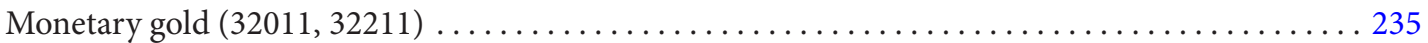

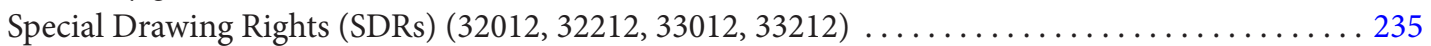

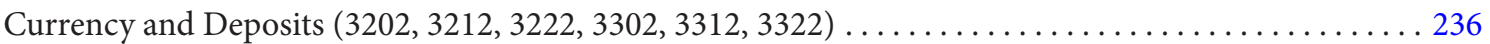

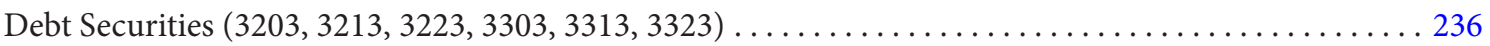

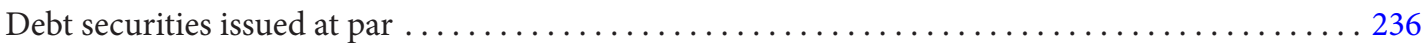

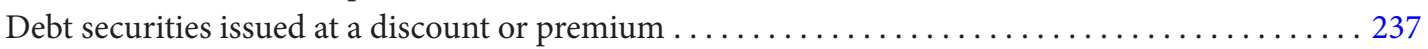

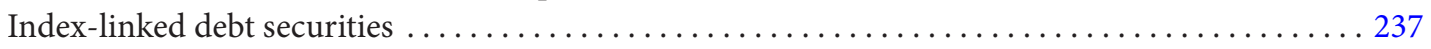

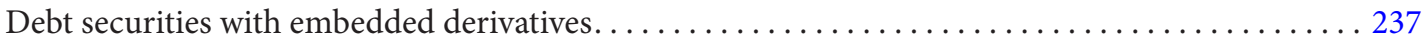

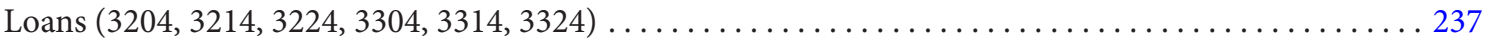

Equity and Investment Fund Shares $(3205,3215,3225,3305,3315,3325) \ldots \ldots \ldots \ldots \ldots$

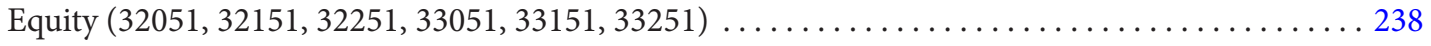

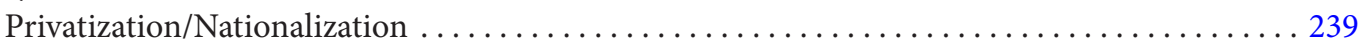

Investment fund shares $(32052,32152,32252,33052,33152,33252) \ldots \ldots \ldots \ldots \ldots \ldots \ldots \ldots \ldots$

Insurance, Pension, and Standardized Guarantee Schemes [GFS] $(3206,3216,3226,3306$,

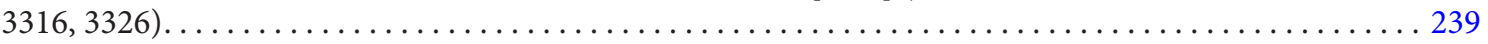

Nonlife insurance technical reserves [GFS] $(32061,32161,32261,33061,33161,33261) \ldots \ldots .240$

Life insurance and annuities entitlements $(32062,32162,32262,33062,33162,33262) \ldots \ldots 240$

Pension entitlements [GFS] $(32063,32163,32263,33063,33163,33263) \ldots \ldots \ldots \ldots \ldots \ldots$

Claims of pension fund on pension manager $(32064,32164,32264,33064,33164,33264) \ldots .241$

Provision for calls under standardized guarantee schemes $(32065,32165,32265,33065$,

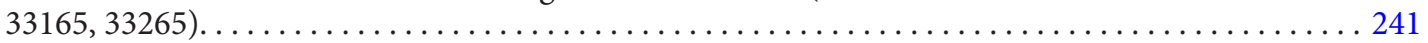

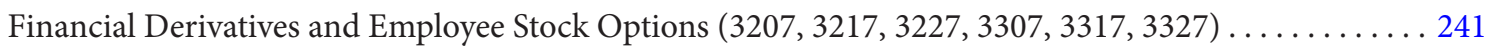

Financial derivatives $(32071,32171,32271,33071,33171,33271) \ldots \ldots \ldots \ldots \ldots \ldots \ldots \ldots \ldots$

Employee stock options $(32072,32172,32272,33072,33172,33272) \ldots \ldots \ldots \ldots \ldots \ldots \ldots . \ldots .242$

Other Accounts Receivable/Payable $(3208,3218,3228,3308,3318,3328) \ldots \ldots \ldots \ldots \ldots \ldots$

Classification of Transactions in Financial Assets and Liabilities by Sector and Residence. . . . . . . 243 Classification of Debt Liabilities and Financial Assets Corresponding to Debt Instruments

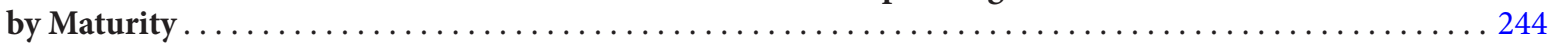

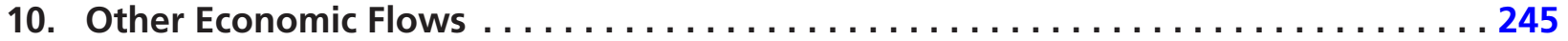

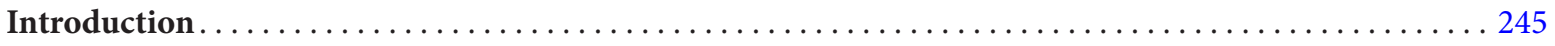

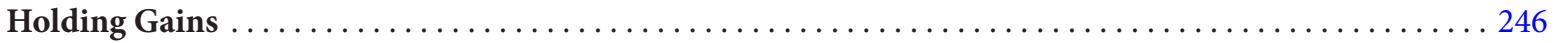

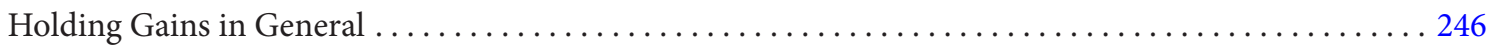

Holding Gains for Particular Types of Assets . . . . . . . . . . . . . . . . . . . . . . . 249

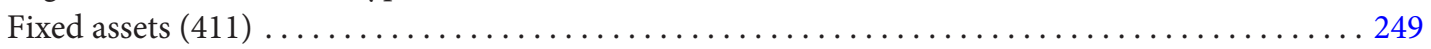

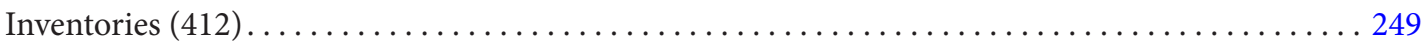

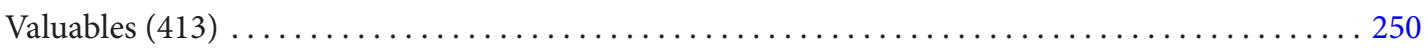

Nonfinancial assets disposed of during the reporting period. . . . . . . . . $250 \ldots \ldots \ldots \ldots$

Monetary gold and Special Drawing Rights (SDRs) $(4201,4221,4301,4321) \ldots \ldots \ldots \ldots \ldots$

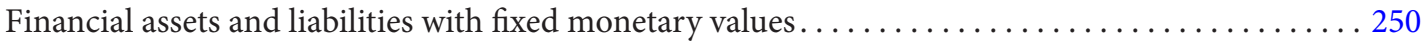

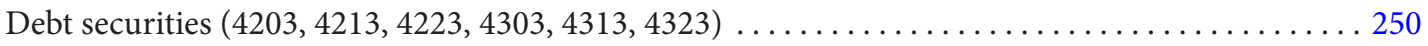

Equity and investment fund shares $(4205,4215,4225,4305,4315,4325) \ldots \ldots \ldots \ldots \ldots \ldots$

Insurance, pension, and standardized guarantee schemes $(4206,4216,4226,4306$,

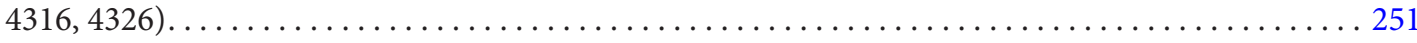

Financial derivatives and employee stock options $(4207,4217,4227,4307,4317,4327) \ldots \ldots .252$

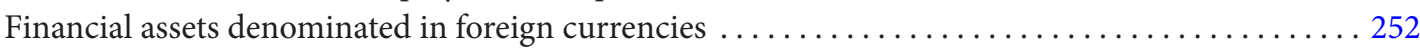

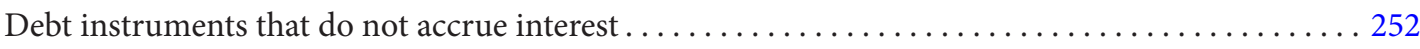




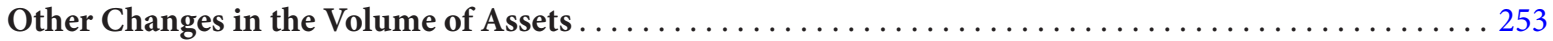

Appearance or Disappearance of Existing Economic Assets . . . . . . . . . . . . . . . . 253

The Effect of External Events on the Value of Assets...............................

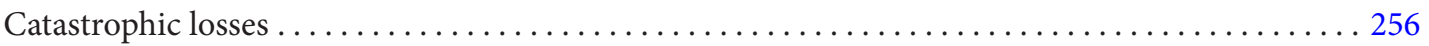

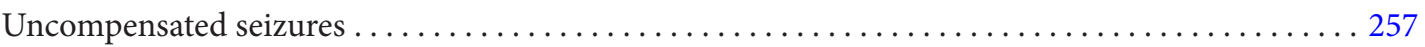

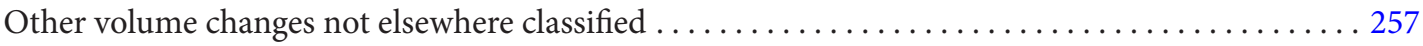

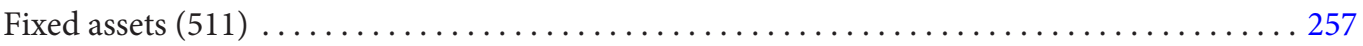

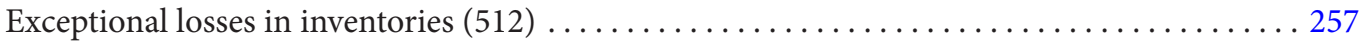

Life insurance and annuities entitlements $(52062,52162,52262,53062,53162,53262) \ldots \ldots .258$

Pension entitlements $(52063,52163,52263,53063,53163,53263) \ldots \ldots \ldots \ldots \ldots \ldots \ldots \ldots \ldots$

Provisions for calls under standardized guarantee schemes (52065, 52165, 52265, 53065,

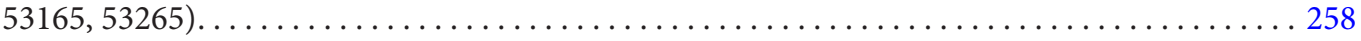

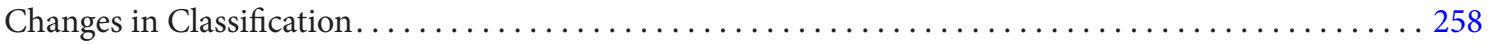

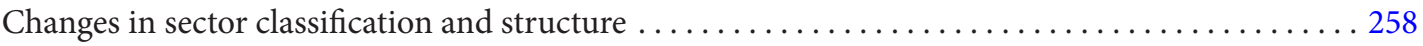

Changes in classification of assets and liabilities ...............................

\section{Appendixes}

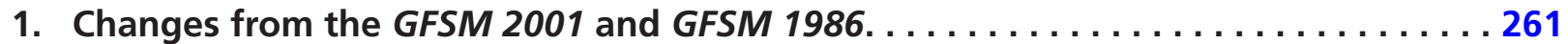

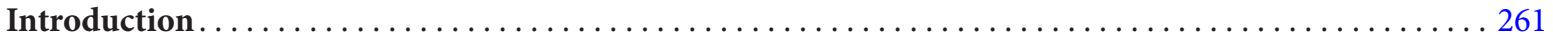

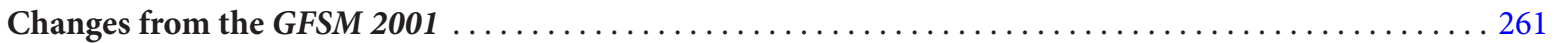

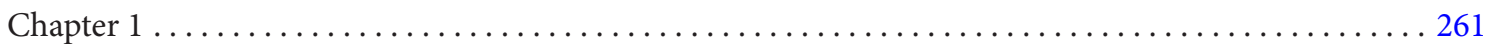

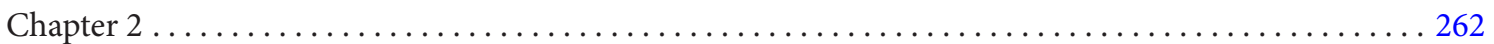

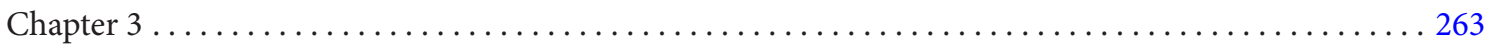

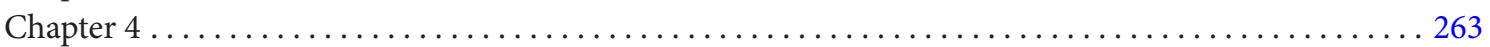

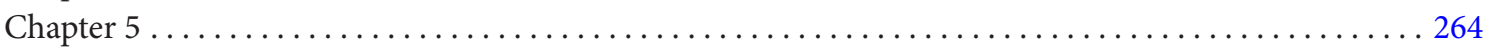

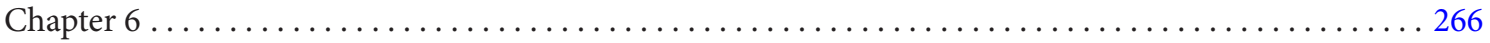

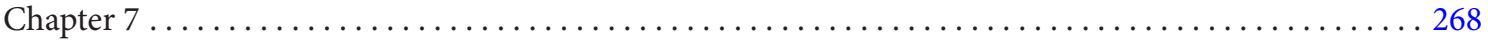

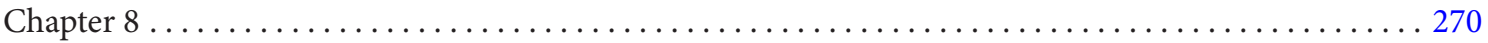

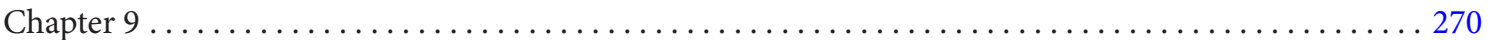

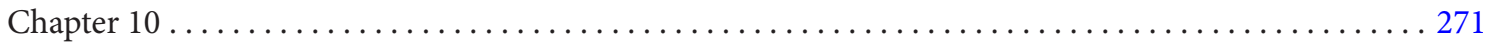

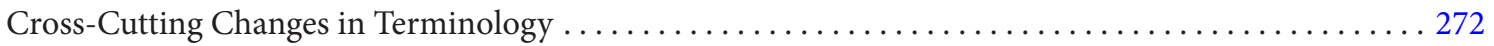

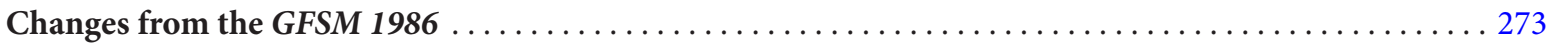

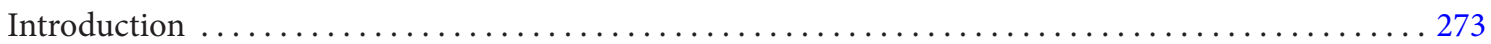

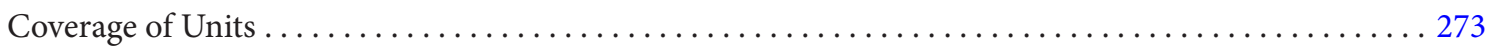

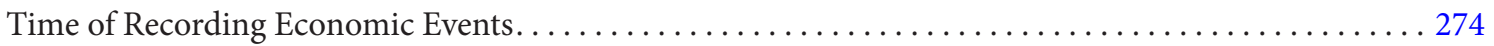

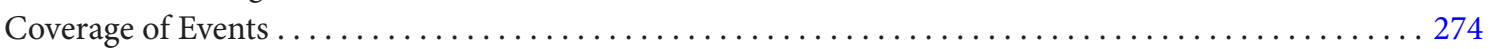

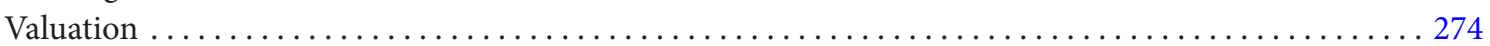

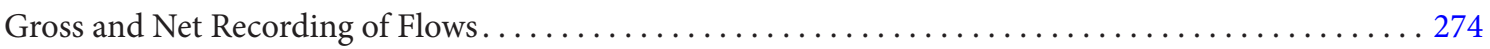

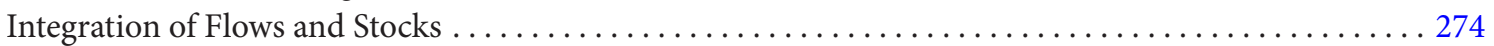

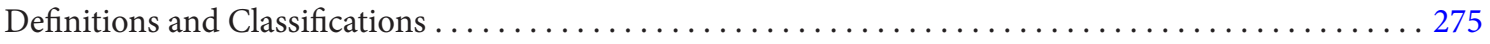

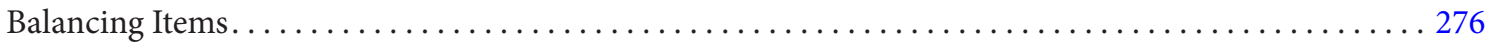

Harmonization with Other Statistical Systems................................ 276

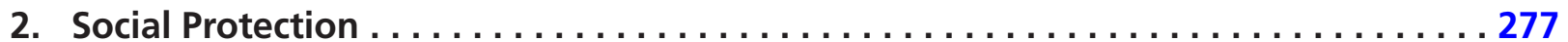

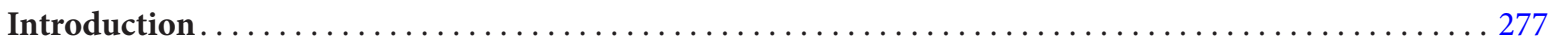

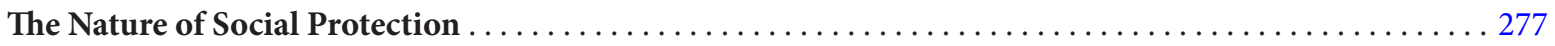

Boundary between Social Protection and Private Insurance. . . . . . . . . . . . . . . . . . . . 279

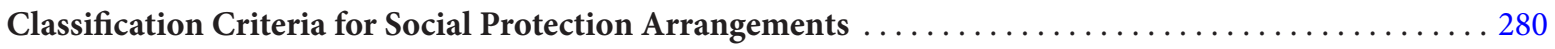

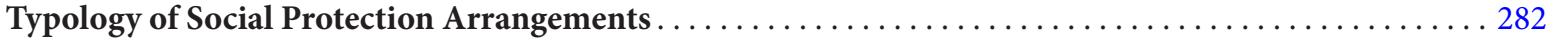

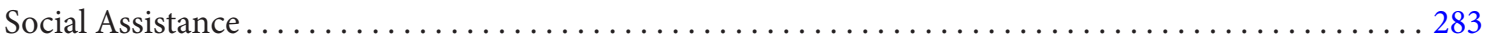




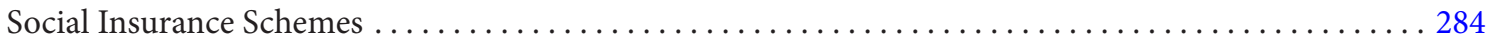

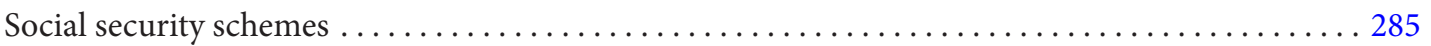

Other employment-related social insurance schemes .......................

Employment-related pensions and other retirement benefit schemes .............. $\frac{286}{287}$

Nonautonomous employment-related pension schemes ................. $\frac{287}{289}$

Autonomous employment-related pension schemes..................... $\frac{289}{290}$

Defined-benefit pension schemes............................

Defined-contribution pension schemes......................... 290

Government assumption of employment-related pension obligations of

other institutional units . ......................................

Employment-related nonpension social insurance schemes .................

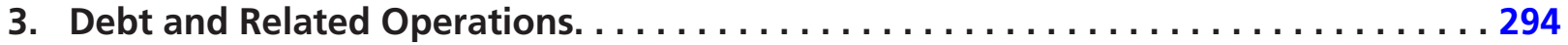

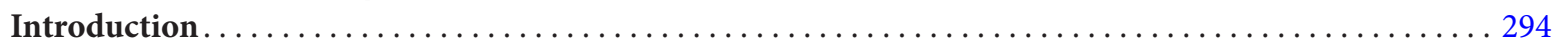

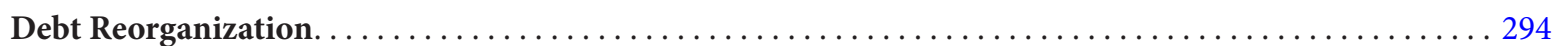

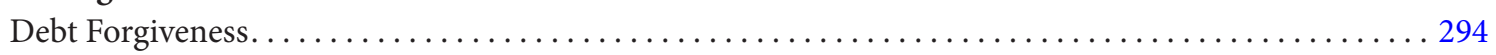

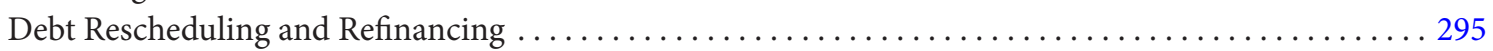

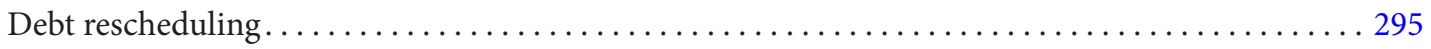

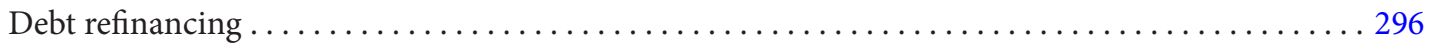

Debt Conversion and Debt Prepayment ...................................

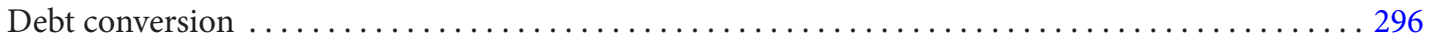

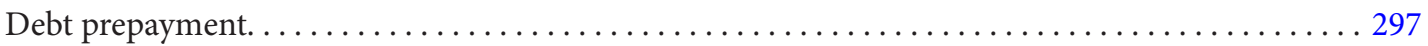

Debt Assumption and Debt Payments on Behalf of Others ......................... $\frac{297}{297}$

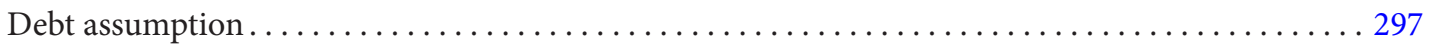

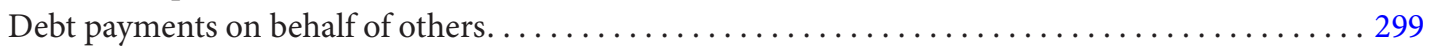

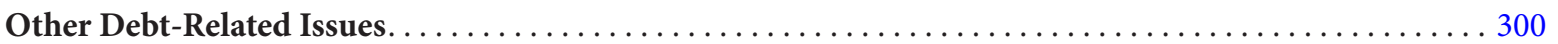

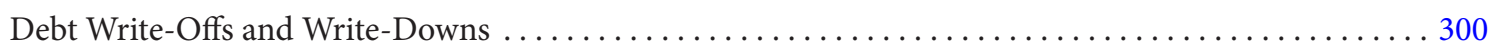

New Money Facilities . . . . . . . . . . . . . . . . . . . . . . . . . . . . . . . . . . .

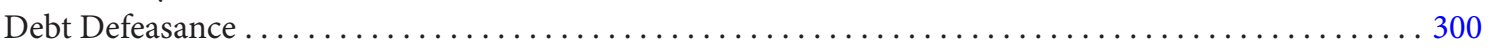

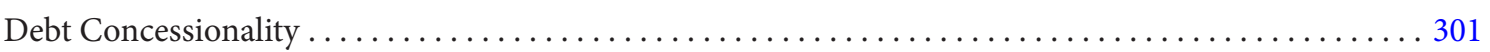

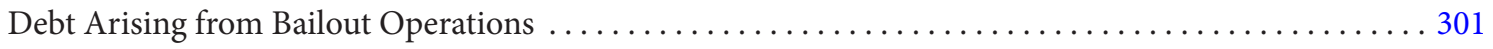

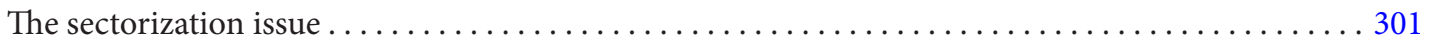

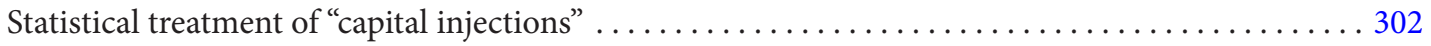

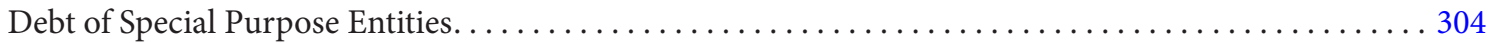

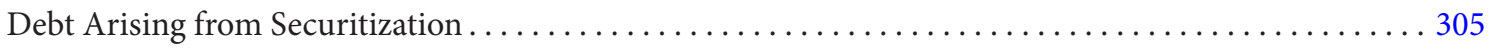

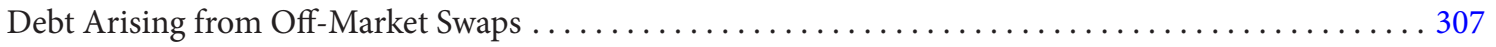

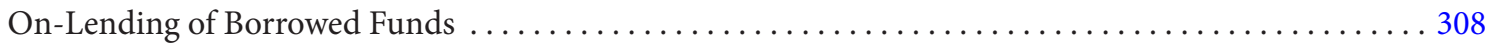

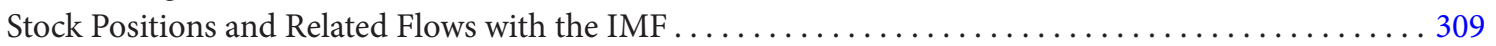

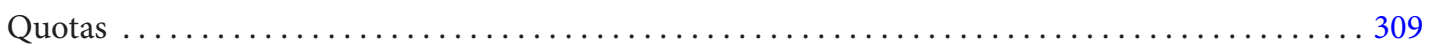

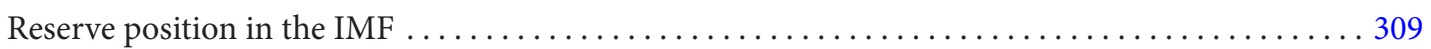

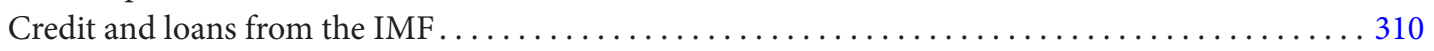

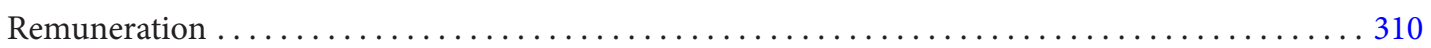

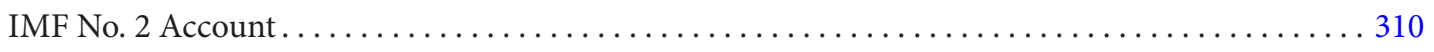

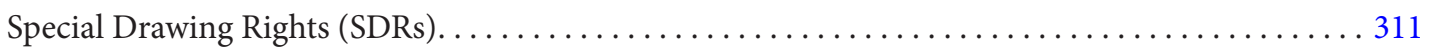

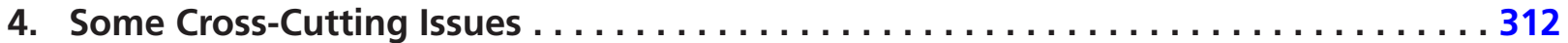

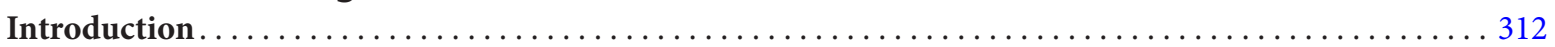

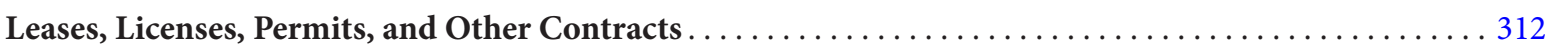

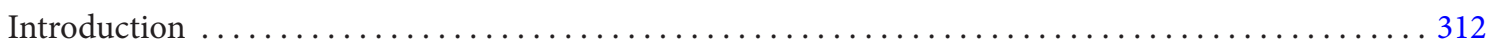

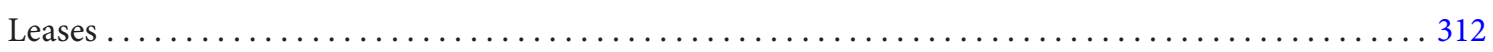

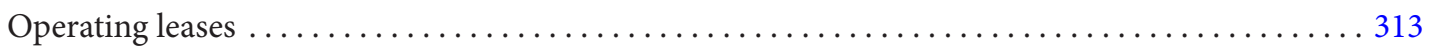




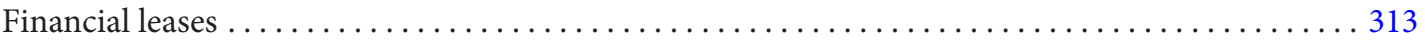

Resource leases .................................................

Licenses and Permits to Use a Natural Resource . . . . . . . . . . . . . . . . . . . . . . . . . $\frac{315}{316}$

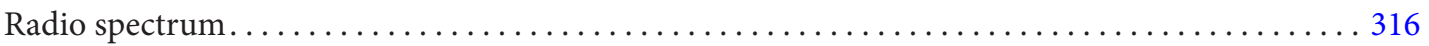

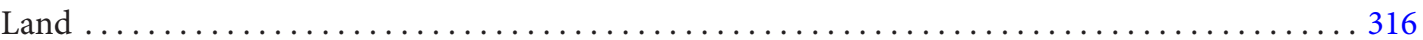

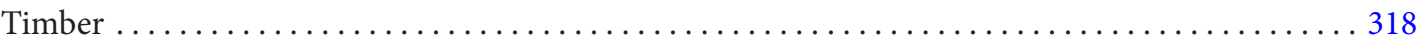

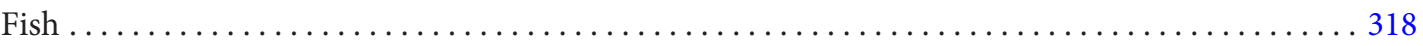

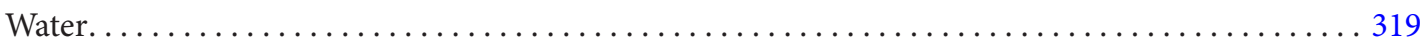

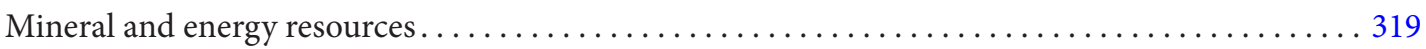

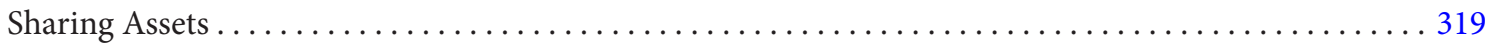

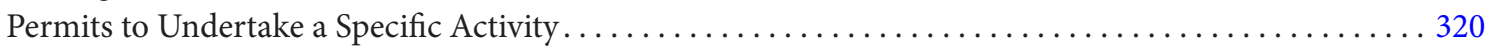

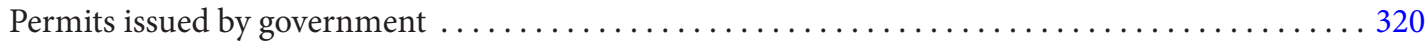

Conditions for government permits recognized as assets......................

Permits to use natural resources as sinks. . . . . . . . . . . . . . . . . . . . . . . . .

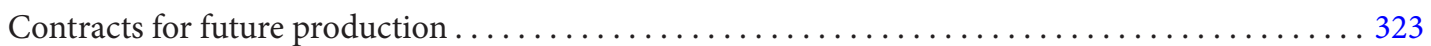

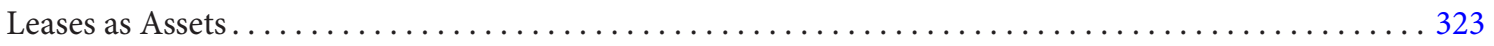

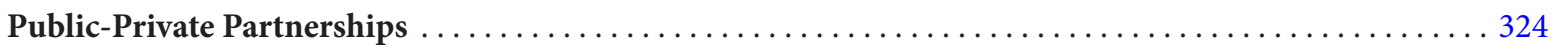

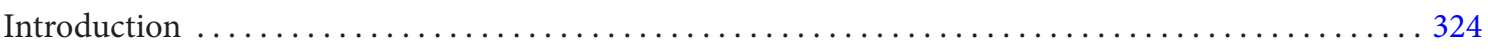

Determining Economic Ownership of PPP-Related Assets . . . . . . . . . . . . . . . .

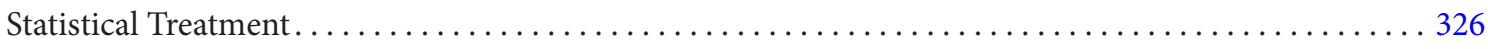

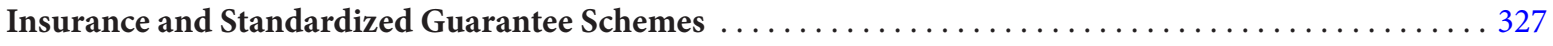

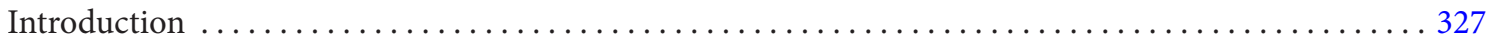

Types of Insurance and Standardized Guarantee Schemes......................... 327

Defining Terminology Used in Insurance . . . . . . . . . . . . . . . . . . . . . . . . . . .

Statistical Treatment of Nonlife Insurance and Standardized Guarantees ...............

Flows and stock positions recorded by public sector units as nonlife insurers or guarantors . . . . .

Flows and stock positions recorded by public sector units as nonlife policyholders and

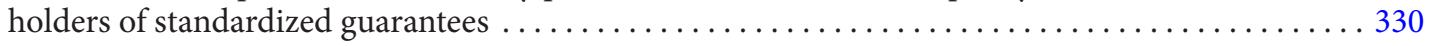

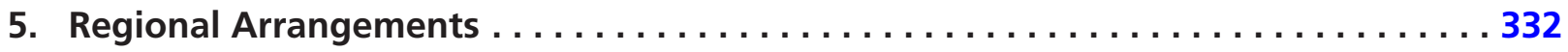

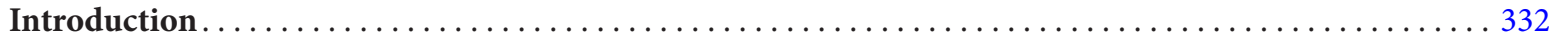

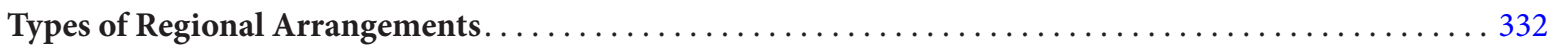

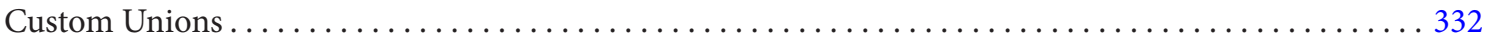

A designated agency levies, collects, and distributes the proceeds from the duties .......... 333

A designated agency levies and distributes duties but member governments collect duties on

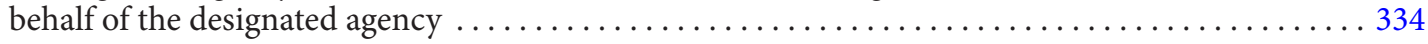

Member governments have collective rights to levy, collect, and distribute the duties ......... 334

Member governments have collective rights to levy the duty, but only one member collects

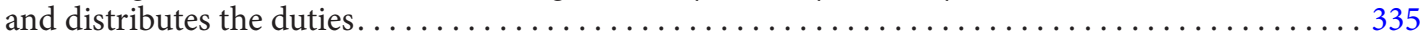

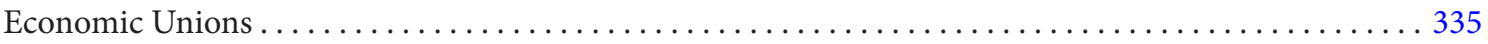

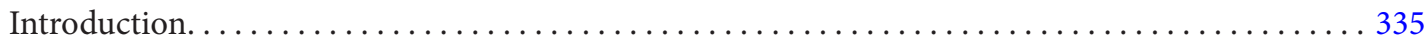

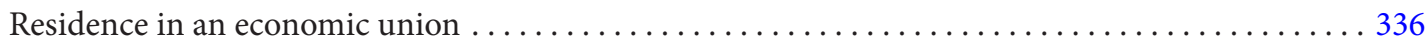

Recording some specific transactions related to regional organizations...............

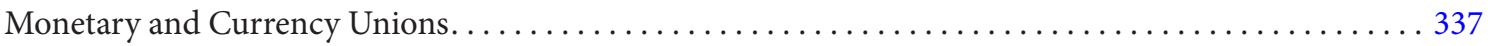

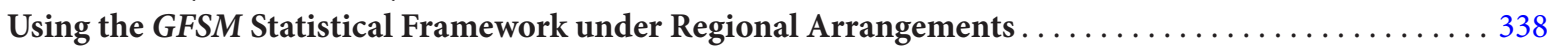

Harmonization Requirements for GFS in Economic or Monetary Unions . . . . . . . . . . . . 339

6. GFS and International Public Sector Accounting Standards . . . . . . . . 341

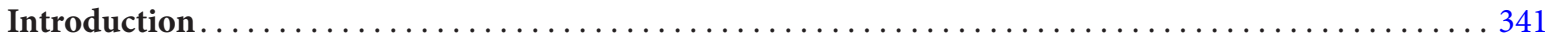

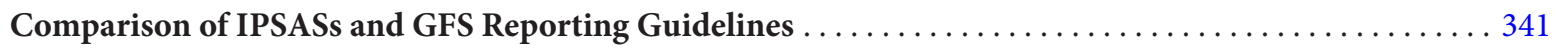

Conceptual Differences between IPSASs and GFS Reporting Guidelines .................

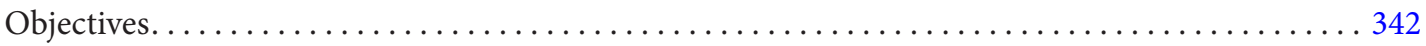




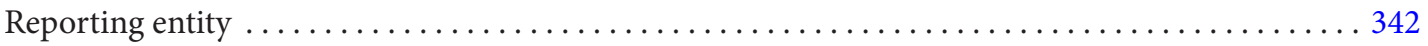

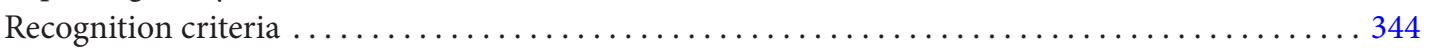

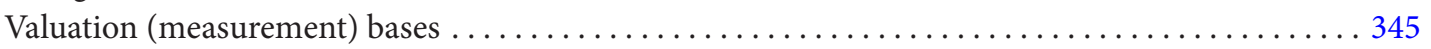

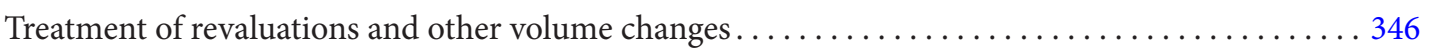

Presentation and Terminology Differences. ............................

Different names for statements . . . . . . . . . . . . . . . . . . . . . . . . . . . . . . . $\frac{347}{347}$

Classification structures........................................... $\frac{347}{348}$

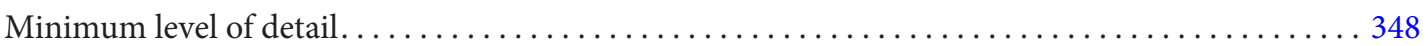

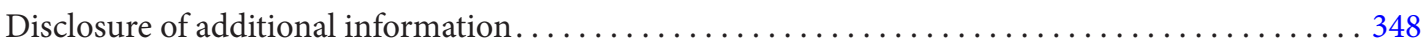

Mapping from IPSAS financial statement aggregates to GFS aggregates $\ldots \ldots \ldots \ldots \ldots \ldots \ldots .3 \frac{349}{349}$

Total assets and total liabilities . . . . . . . . . . . . . . . . . . . . . . . . . . . . . $\frac{349}{349}$

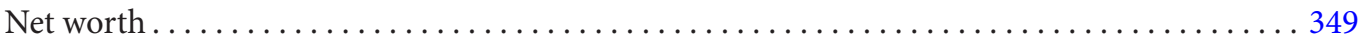

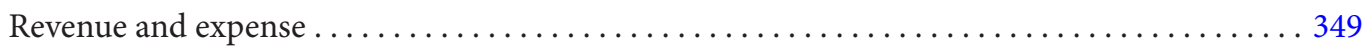

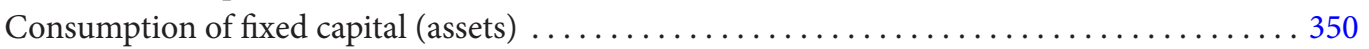

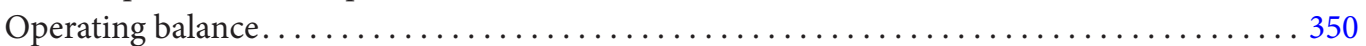

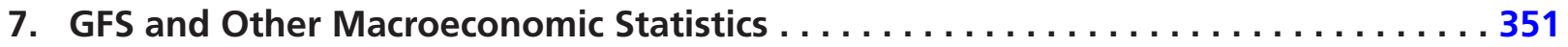

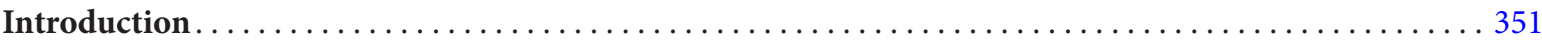

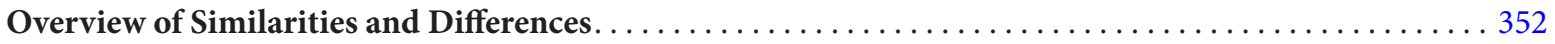

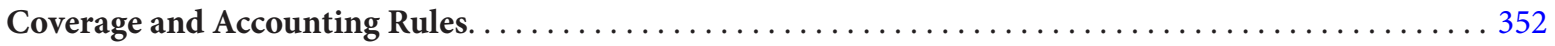

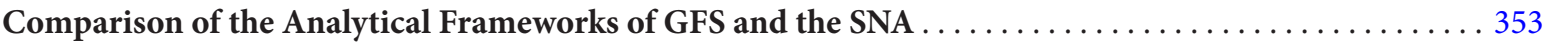

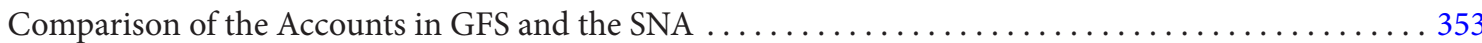

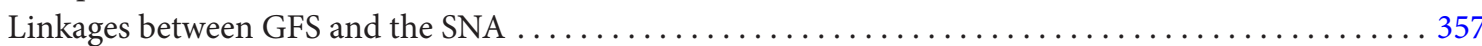

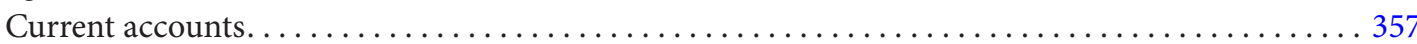

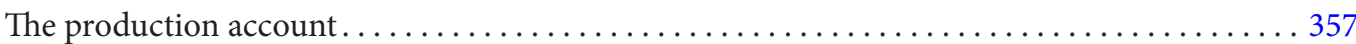

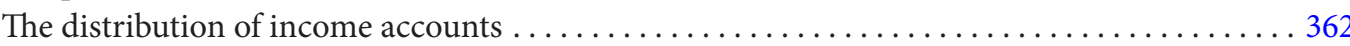

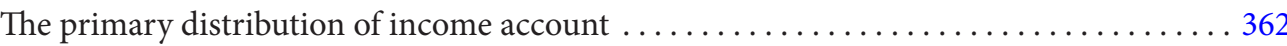

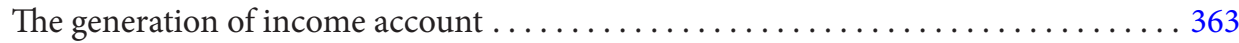

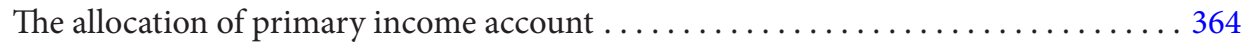

The secondary distribution of income account. . . . . . . . . . . . . . .

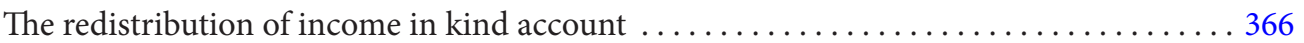

The use of disposable income account ..............................

The accumulation accounts ....................................

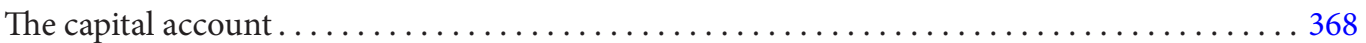

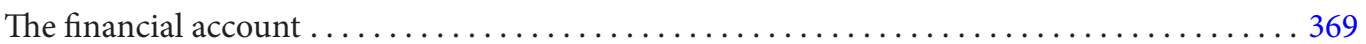

The other changes in the volume of assets accounts ....................... $\overline{369}$

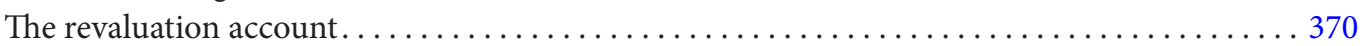

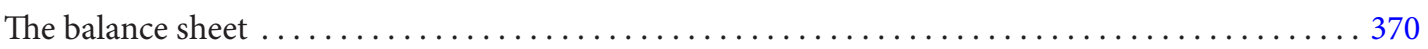

Comparison of the Analytical Frameworks of the GFS and the Balance of Payments and the

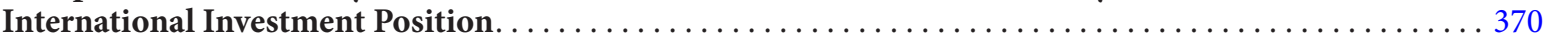

Comparison of the Accounts in GFS and Balance of Payments and the International

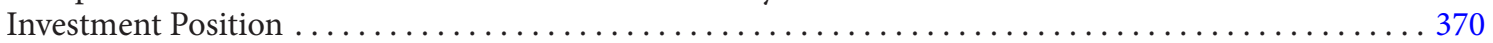

Linkages between GFS and Balance of Payments and the International Investment Position ...... $\frac{\overline{372}}{372}$

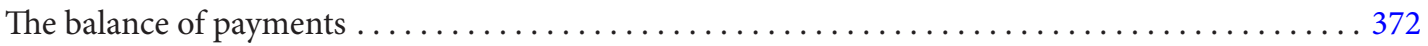

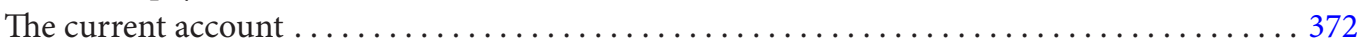

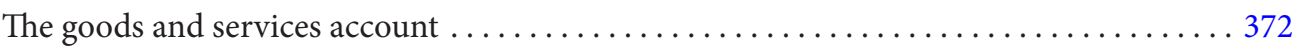

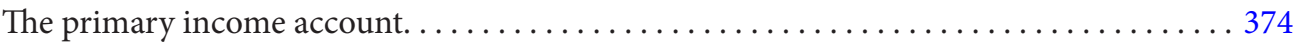

The secondary income account. . . . . . . . . . . . . . . . . . . . . . . . .

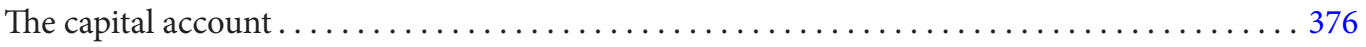

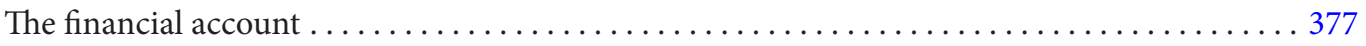


The other changes in financial assets and liabilities account $\ldots \ldots \ldots \ldots \ldots \ldots \ldots \ldots \ldots \ldots$

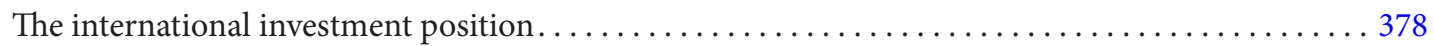

Comparison of the Analytical Frameworks of the GFS and the Monetary and Financial Statistics ....

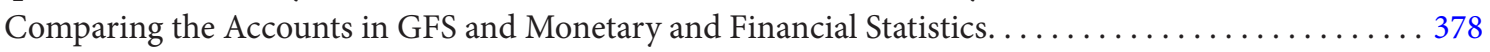

Linkages between GFS and Monetary and Financial Statistics . . . . . . . . . . . . . .

Comparison of the Analytical Framework of the GFS and the System of Environmental-Economic

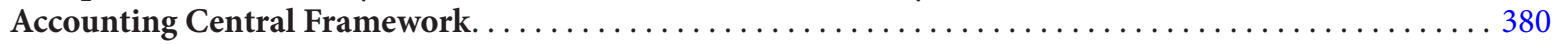

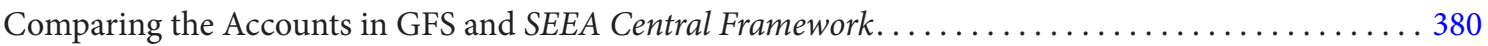

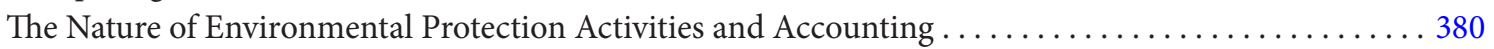

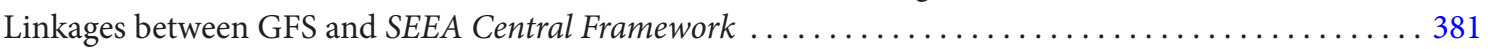

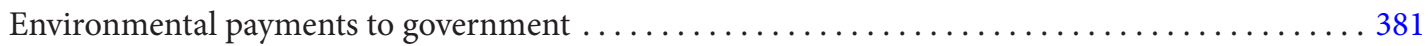

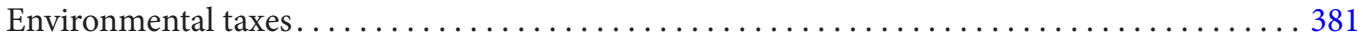

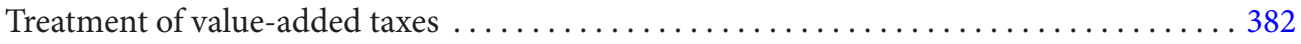

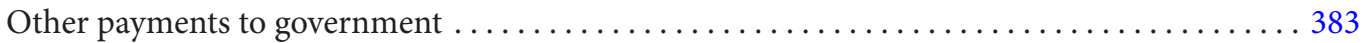

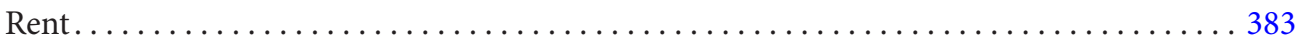

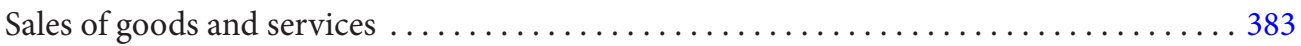

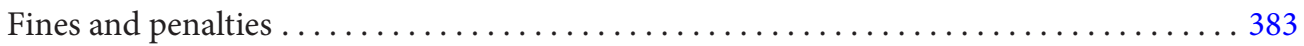

Environmental transfers by nongovernment institutional units $\ldots \ldots \ldots \ldots \ldots \ldots \ldots \ldots 383$

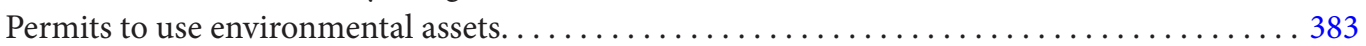

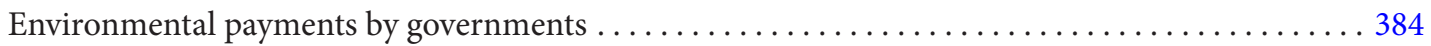

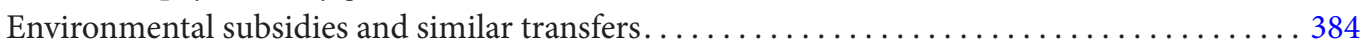

8. GFS Classifications......................

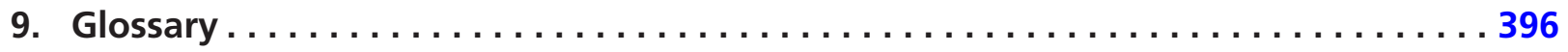

\section{Tables}

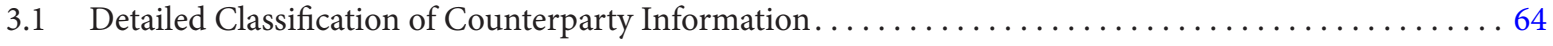

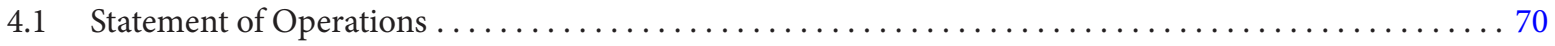

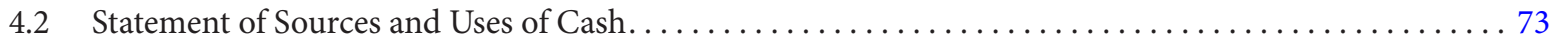

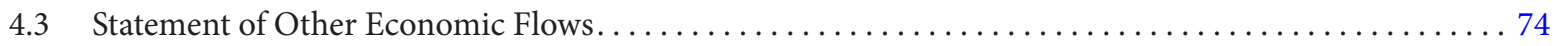

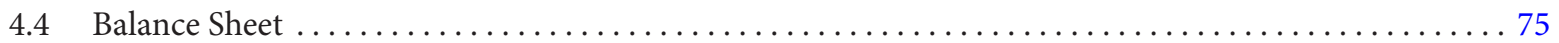

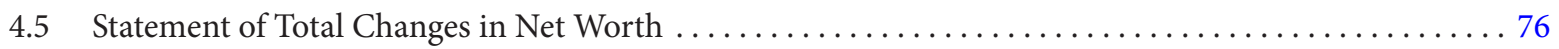

4.6 Summary Statement of Explicit Contingent Liabilities and Net Implicit Obligations for

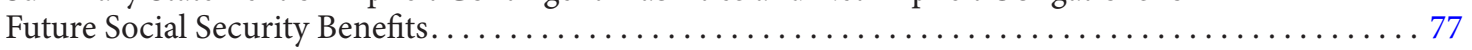

4A.1 Fiscal Indicators Available from the GFS Framework $\ldots \ldots \ldots \ldots \ldots \ldots \ldots \ldots \ldots \ldots \ldots \ldots$

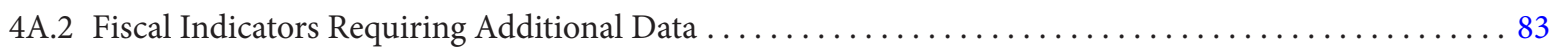

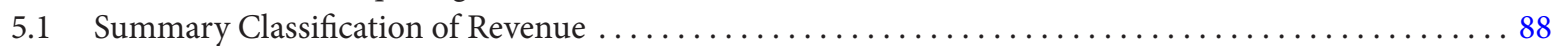

5.2 Detailed Classification of Taxes on Income, Profits, and Capital Gains $(111) \ldots \ldots \ldots \ldots . \ldots . . . \ldots 92$

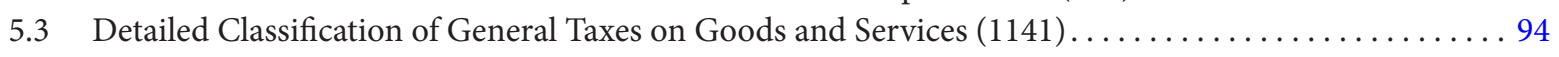

5.4 Detailed Classification of Taxes on Use of Goods and on Permission to Use Goods or

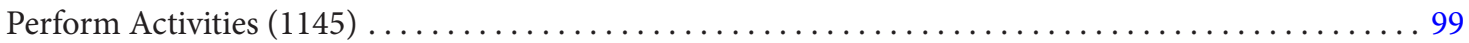

5.5 Detailed Classification of Taxes on International Trade and Transactions $(115) \ldots \ldots \ldots$

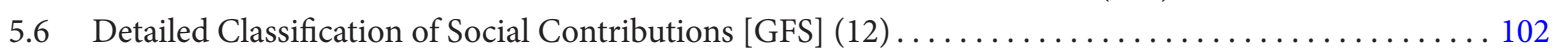

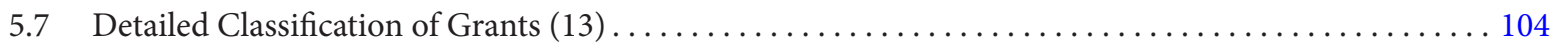

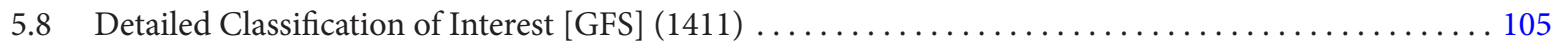

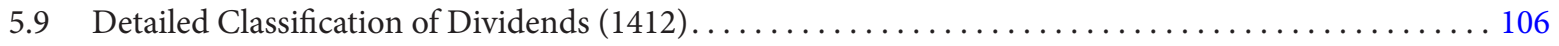

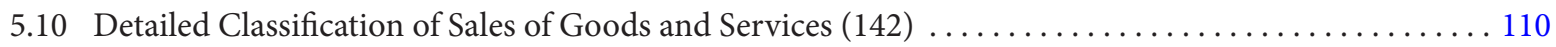

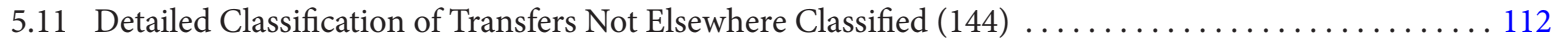

5.12 Detailed Classification of Premiums, Fees, and Claims Receivable Related to Nonlife

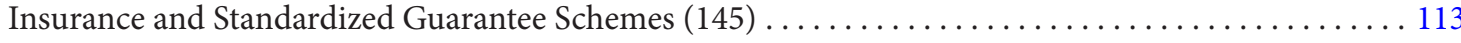




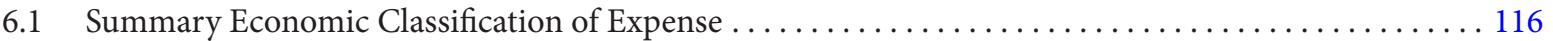

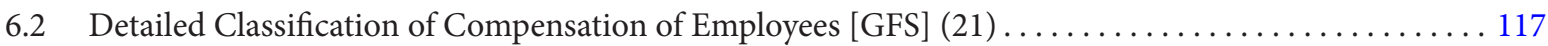

6.3 Relationship between Inventories (612) and Use of Goods and Services (22) . . . . . . . . . . . $\frac{121}{121}$

6.4 Detailed Classification of Consumption of Fixed Capital [GFS] (23) $\ldots \ldots \ldots \ldots \ldots \ldots \ldots \ldots \ldots \ldots \ldots \ldots \ldots \ldots$

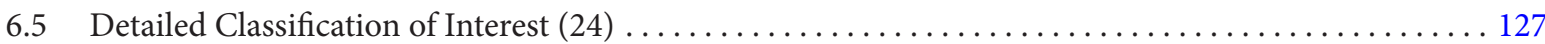

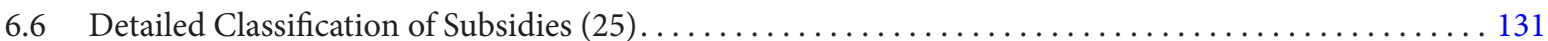

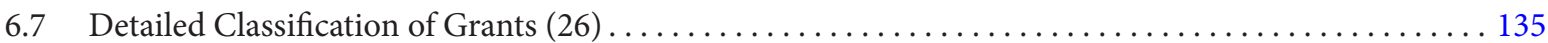

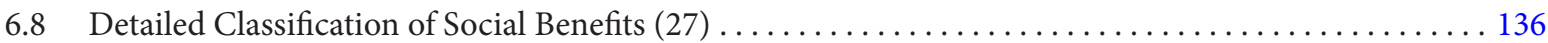

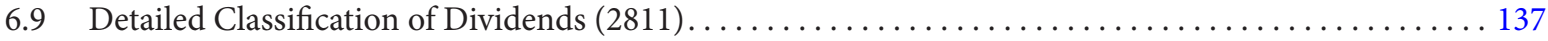

6.10 Detailed Classification of Transfers Not Elsewhere Classifieds $(282) \ldots \ldots \ldots \ldots \ldots \ldots \ldots \ldots \ldots \ldots \ldots \ldots \ldots$

6.11 Detailed Classification of Premiums, Fees, and Claims Payable Related to Nonlife Insurance

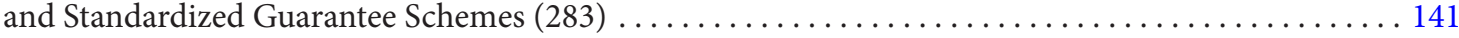

6A.1 Classification of Expenditure by Functions of Government According to Divisions

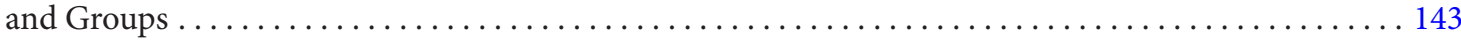

6A.2 Cross-Classification of Expenditure by Functional and Economic Classifications $\ldots \ldots \ldots \ldots \ldots \ldots 147$

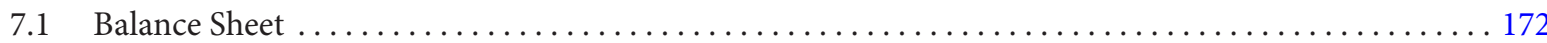

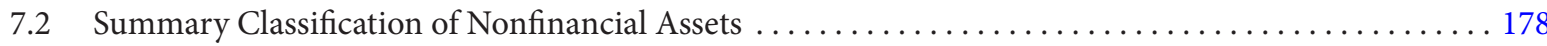

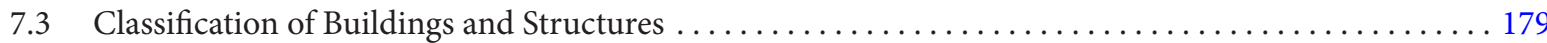

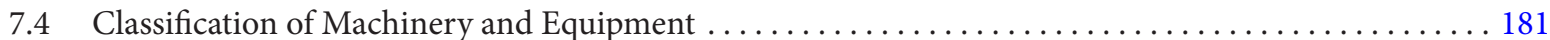

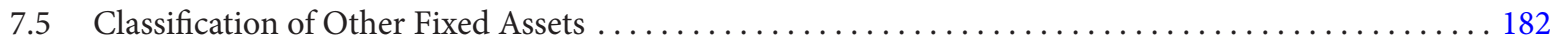

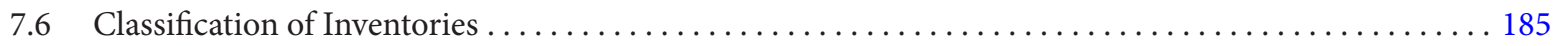

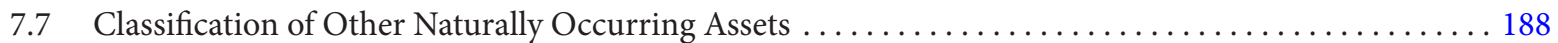

7.8 Classification of Intangible Nonproduced Assets . . . . . . . . . . . . . . . . . . . . . . . . $\frac{189}{189}$

7.9 Classification of Financial Assets and Liabilities by Instrument and Residence of

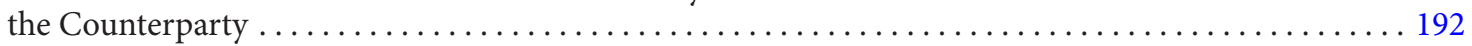

7.10 Classification of Memorandum Items to the Balance Sheet. . . . . . . . . . . . . . . . .

7.11 Cross-Classification of Financial Assets and Liabilities by the Institutional Sector of

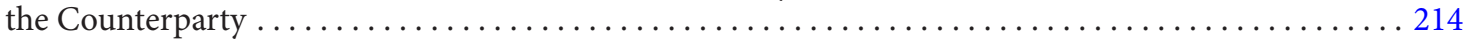

7.12 Classification of Debt Liabilities and Financial Assets Corresponding to Debt Instruments

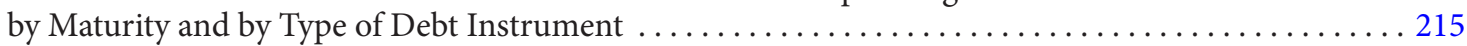

8.1 Classification of Transactions in Nonfinancial Assets . . . . . . . . . . . . . . . . . . . . 221

9.1 Net Acquisition of Financial Assets and Net Incurrence of Liabilities Classified by Instrument

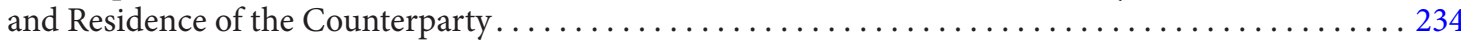

9.2 Net Acquisition of Financial Assets and Net Incurrence of Liabilities Classified by Residence

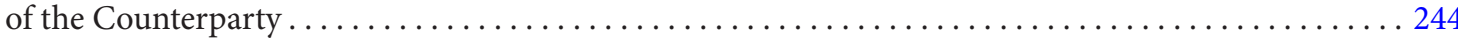

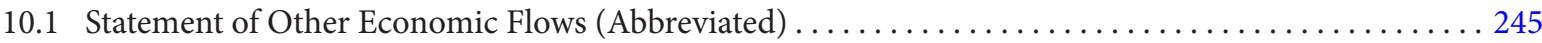

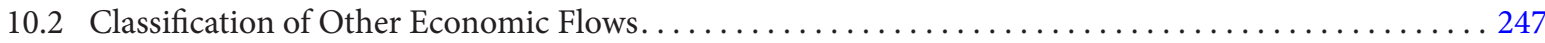

A2.1 Illustrative Recording of Flows Related to Social Assistance . . . . . . . . . . . . . . . . . . 283

A2.2 Illustrative Recording of Flows Related to Social Security Schemes................... 287

A2.3 Illustrative Recording of Flows Related to Employment-Related Pension Schemes. . . . . . . . . . . 288

A2.4 Illustrative Recording of Flows Related to Employment-Related Nonpension Social Insurance Schemes ............................................. 293

A3.1 Summary of the Statistical Treatment of On-Lending of Borrowed Funds by Institutional

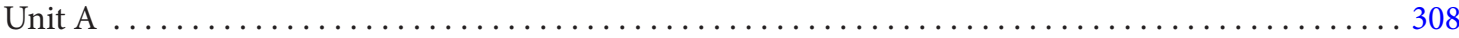

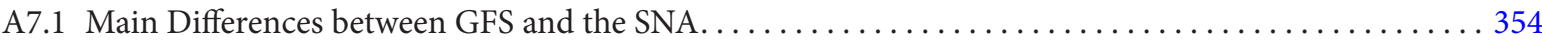

A7.2 Linkages of the Statement of Operations in GFS with Sequence of SNA Transaction Accounts ....... 356

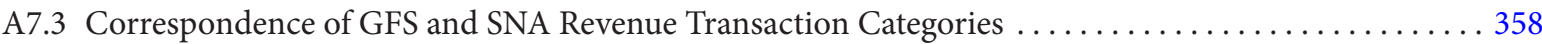

A7.4 Correspondence of GFS and SNA Expense Transaction Categories...................

A7.5 Correspondence of GFS and SNA Transactions in Nonfinancial Asset Categories . . . . . . . . . $\frac{371}{377}$

A7.6 Correspondence of GFS and SNA Financial Assets and Liabilities. . . . . . . . . . . . . . . . . $\frac{373}{373}$

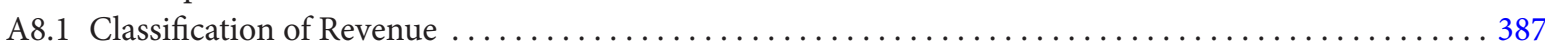




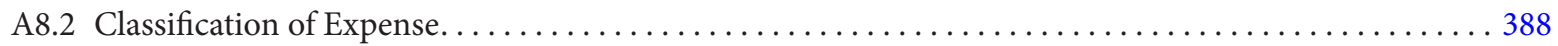

A8.3 Classifications of Flows and Stock Positions in Assets and Liabilities . . . . . . . . . . . . 389

A8.4 Classifications of the Counterparty of Transactions and Stock Positions in Financial

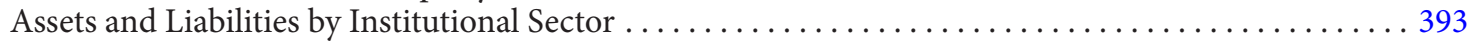

A8.5 Classification of Debt Liabilities and Financial Assets Corresponding to Debt Instruments

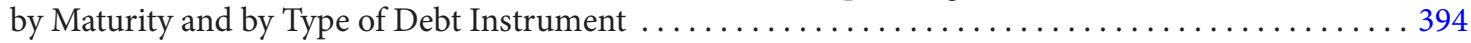

A8.6 Classification of Expenditure by Functions of Government According to Divisions and Groups..... $\underline{395}$

\section{Figures}

2.1 Types of Institutional Units and Their Relation to Sectors of the Economy $\ldots \ldots \ldots \ldots \ldots \ldots$

2.2 The Public Sector and Its Relation to Other Institutional Sectors of the Economy . . . . . . . . . . 19

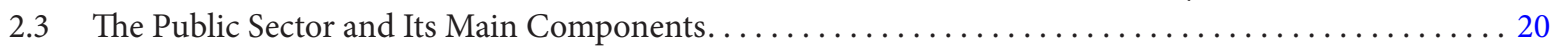

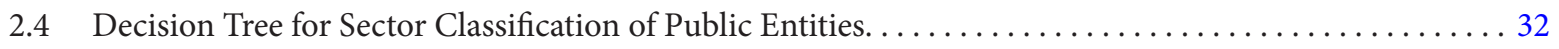

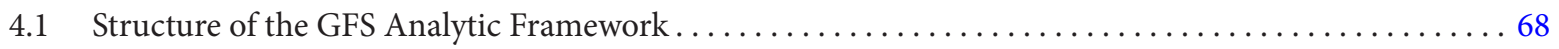

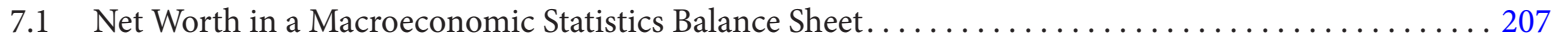

7.2 Overview of Liabilities and Contingent Liabilities in Macroeconomic Statistics . . . . . . . . . . . 211

8.1 Illustrating the Treatment of Costs of Ownership Transfer on Nonproduced Assets . . . . . . . . 226

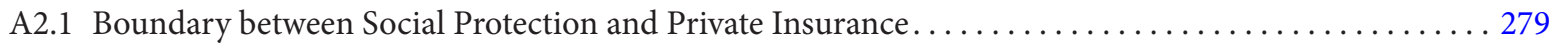

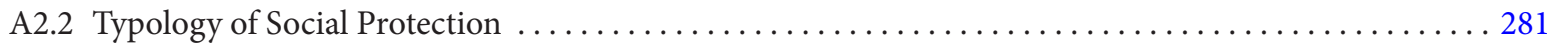

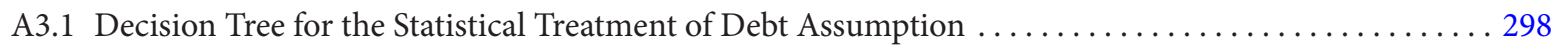

A3.2 Decision Tree for the Statistical Treatment of "Capital Injections" . . . . . . . . . . . . . 303

A4.1 Illustrating the Treatment of Licenses and Permits to Use a Natural Resource. . . . . . . . .

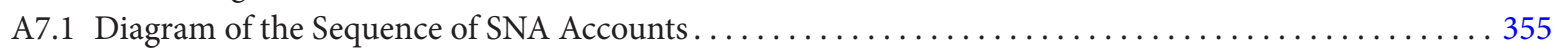

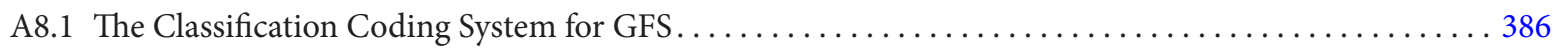

\section{Boxes}

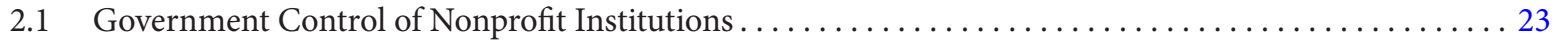

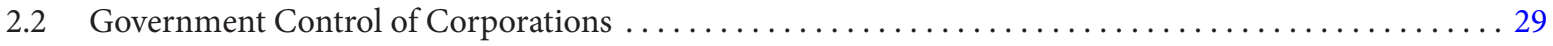

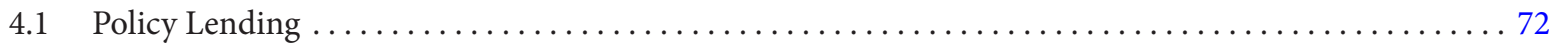

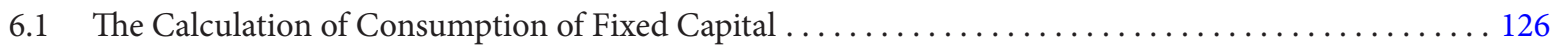

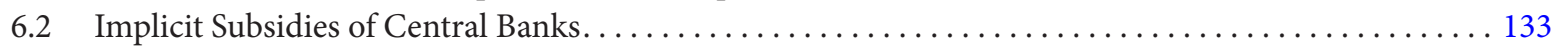

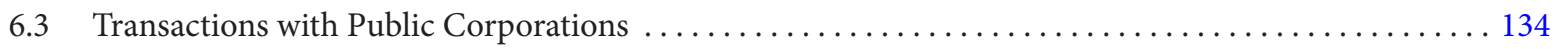

A4.1 Criteria to Determine Whether a License Represents and Asset Sale or Rent ........... 317

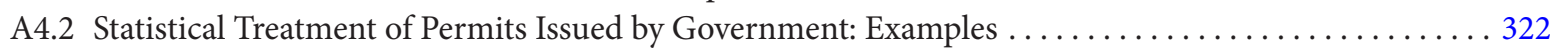

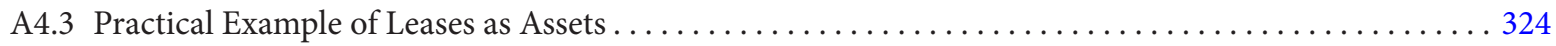

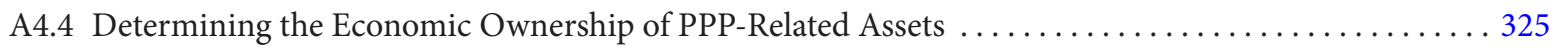

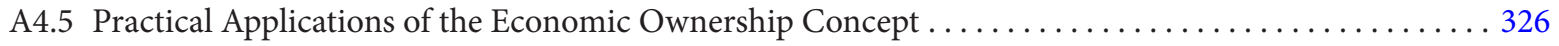

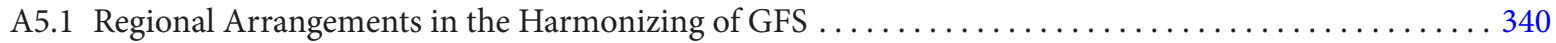

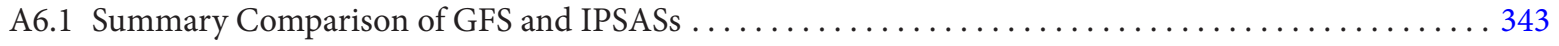

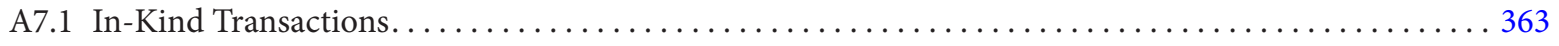

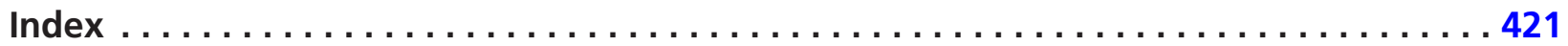


This page intentionally left blank 
The work was supervised by Mr. Robert Heath (Deputy Director), Ms. Claudia Dziobek (Chief, Government Finance Division), and Mr. Robert Dippelsman (former Deputy Chief, Government Finance Division), all from the Statistics Department. Ms. Sagé De Clerck (Senior Economist, Government Finance Division, Statistics Department) was the primary drafter and also coordinated and edited contributions to the Manual. Many staff in the Government Finance Division contributed to the project, in particular, Mmes. Majdeline El-Rayess, Viera Karolova, Phebby Kufa, and Kara Rideout, and Messrs. Miguel Alves, Alberto Jiménez de Lucio, Gary Jones, Mike Seiferling, Philip Stokoe, Deon Tanzer, and Tobias (Murto) Wickens. Contributions were also made by former staff members and experts in GFS including Mmes. Brigitte Batschi, Paola De Rita, Irina Dubinina, and Betty Gruber, and Messrs. Ismael Ahamdanech-Zarco, Johann Bjorgvinsson, Paul Cotterell, Jean-Pierre Dupuis, Cor Gorter, Carlos Gutierrez, Héctor Hernández, Ciaran Judge, Leonard Haakman, Brooks Robinson, and Vincent Marie. Mmes. Katy Hurston and Sheridan Parsonson supported the preparation of discussion papers and prepared drafts for publication. Current and former staff from other divisions of the Statistics Department also contributed to the project, including the Balance of Payments Division (Ms. Rita Mesias and Mr. Marcelo Dinenzon); Financial Institutions Division (Messrs. Jose Cartas, Thomas Elkjaer, and Richard Walton); and Real Sector Division (Messrs. Manik Shrestha and Daniel Smith).

Current and former staff from other departments of the IMF also contributed to the Manual. In particular, collaboration between the IMF's Statistics and Fiscal Affairs Departments is acknowledged. Contributors from the Fiscal Affairs Department included Mmes. Adrienne Cheasty, Chita Marzan, Delphine Moretti, Isabel Rial, and Christine Richmond, and Messrs. Sanjeev Gupta, Richard Hughes, Tim Irwin, Kris Kaufman, Abdul Khan, Geremia Palomba, and Shamsuddin Tareq. Contributors from the Finance Department included Mmes. Sheila Basset, Elena Budras, Mary Hoare, and Jane Mburu, and Messrs. Preet Bhullar, Claudio De Luca, Carlos Janada, and Barry Yuen. A contribution was also received from the Research Department (Mr. Manmohan Singh).

\section{Government Finance Statistics Advisory Committee}

The GFSM 2014 greatly benefited from meetings of the Government Finance Statistics Advisory Committee that were convened in February 2011 and May 2012. The GFSM 2014 benefited from the discussions, written contributions, and comments of members of the committee and the organizations they represented.

Country Members

$\begin{array}{ll}\text { Australia } & \text { Michael Davies, Australian Bureau of Statistics } \\ \text { Brazil } & \text { Felipe Bardella, Ministry of Finance } \\ \text { Fanada } & \text { Kabiana Magalhães Almeida Rodopoulos, Ministry of Finance } \\ \text { Chile } & \text { Héctor Hernández, Ministry of Finance } \\ \text { Côte d'Ivoire } & \text { Nicolas Kacou, Ministry of Finance } \\ \text { Denmark } & \text { Søren Brodersen, Statistics Denmark } \\ \text { Georgia } & \text { Pridon Aslanikashvili, Ministry of Finance } \\ \text { Ghana } & \text { Nelly Mireku, Ministry of Finance and Economic Planning } \\ \text { Japan } & \text { Hidehiko Futamura, Cabinet Office } \\ & \text { Kosuke Suzuki, Cabinet Office } \\ \text { Philippines } & \text { Teresa Habitan, Department of Finance } \\ \text { Qatar } & \text { Rifaat Basanti, Ministry of Economy and Finance } \\ \text { South Africa } & \text { Michael Adams, South African Reserve Bank } \\ \text { Switzerland } & \text { André Schwaller } \\ \text { United Kingdom } & \text { Philip Stokoe, Office for National Statistics } \\ \text { United States } & \text { Pamela Kelly, Bureau of Economic Analysis }\end{array}$


Representatives of International Organizations

Commonwealth Secretariat of the UK

European Central Bank

Eurostat

\author{
Arindam Roy \\ Julia Catz \\ Reimund Mink \\ Gabriel Quiros \\ Hans Olsson \\ Luca Ascoli \\ Denis Besnard \\ Francois Lequiller \\ Alexandre Makaronidis \\ Lena Frej Ohlsson \\ John Verrinder
}

Andreas Bergmann

Ian Carruthers

Nadim Ahmad

Maurice Nettley

Balliram Baball

Benson Sim

Mohamed Dhehby

Shaida Badiee

Neil Fantom

Ibrahim Levent

Evis Rucaj

An earlier draft of the GFSM 2014 was circulated for worldwide comments and the final text benefited from the comments received from experts in member countries and other international organizations. The IMF Statistics Department gratefully acknowledges the important contribution by comments received in the process of finalizing the GFSM 2014.

Louis Marc Ducharme

Director

Statistics Department International Monetary Fund 
This page intentionally left blank 
Public corporations, nonfinancial as well as financial, can carry out government fiscal policies in a variety of ways, and analysis of their fiscal activities frequently requires statistics on all of their activities rather than statistics on specific transactions. Even when statistics are compiled for only the general government sector, some information on public corporations is required. To reflect transactions with public corporations, the change in the level of equity ownership held by units of the general government sector and the exposure to risks associated with guarantees provided to these corporations should be recorded.

1.5 The basic concepts, classifications, and definitions employed in this Manual reflect economic principles that should be universally valid regardless of the circumstances in which they are applied. Therefore, the GFS framework is applicable to all types of economies regardless of the institutional or legal structure of a country's government, the sophistication of its statistical development, the financial accounting system of government, or the extent of public ownership of for-profit entities. Nevertheless, the fact that the institutional and economic structures of countries differ greatly means that the various parts of this Manual will not be equally relevant.

\section{The Evolution of International Statistical Guidelines on GFS History}

1.6 The evolution of international statistical guidelines for compiling GFS started in the early 1970s, with a draft of A Manual on Government Finance Statistics. This draft was circulated in English, Spanish, and French to governments, central banks, central statistical offices, and international organizations for comments, and was also discussed at several regional seminars. Based on comments received and the application of the earlier draft in compiling data for the IMF's Government Finance Statistics Yearbook, A Manual on Government Finance Statistics, 1986 (GFSM 1986) was published. The GFSM 1986 provided guidance to compile GFS but was not directly aligned with other macroeconomic statistics.

1.7 The Government Finance Statistics Manual 2001 (GFSM 2001) updated the internationally recognized guidelines for compiling statistics required for fiscal analysis that were established by the GFSM 1986. The revised guidelines were harmonized with the corresponding standards of other internationally recognized macroeconomic statistical guidelines to the extent possible, consistent with the goal of supporting fiscal analysis. Also, the revised guidelines incorporated, for the first time, an integrated balance sheet approach to compiling and presenting GFS.

\section{The Update of the GFSM 2001}

1.8 The GFSM 2014 updates the internationally recognized guidelines for compiling statistics required for fiscal analysis that were established by the GFSM 2001. The revised guidelines are harmonized with the updates in other macroeconomic statistical manuals and guides. The other statistical manuals are the overarching System of National Accounts 2008 $(2008 \text { SNA })^{4}$ and two specialized manuals: the sixth edition of the Balance of Payments and International Investment Position Manual (BPM6) ${ }^{5}$ and the Monetary and Financial Statistics Manual (MFSM). ${ }^{6}$ The updates to these manuals draw on the text of the 2008 SNA to avoid an inference that a different meaning is intended. ${ }^{7}$ For debt-related issues, the GFSM 2014 is supplemented with the Public Sector Debt Statistics: A Guide for Compilers and Users (PSDS Guide) and the External Debt Statistics: Guide for Compilers and Users, 2013 (2013 EDS Guide).

1.9 The revised manuals and guides address important international economic developments in recent years and take into account improved recording and methodological treatments of various types of events. Furthermore, the development of International Public Sector Accounting Standards and continued efforts to harmonize statistical reporting and financial reporting have led to additional changes incorporated in the

\footnotetext{
${ }^{4}$ Commission of the European Communities, International Monetary Fund, Organisation for Economic Co-operation and Development, United Nations, World Bank, System of National Accounts 2008 (Brussels/Luxembourg, New York, Paris, Washington, 2009).

${ }^{5}$ International Monetary Fund, Balance of Payments and International Investment Manual, 6th ed. (Washington, 2009).

${ }^{6}$ Monetary and Financial Statistics Manual (Washington, 2000)_revision of the MFSM, 2000 edition, to also align with the 2008 SNA, is pending at the time of publication of GFSM 2014.

${ }^{7}$ This manual also draws on United Nations, Classifications of Expenditure According to Purpose (New York, 2000) for the Classification of Functions of Government introduced in Chapter 6.
} 
GFSM 2014. The changes incorporated in GFSM 2014 can broadly be summarized as ${ }^{8}$

- Methodological changes in the 2008 SNA

- Clarifications of existing methodological guidelines

- Presentational changes

- Editorial changes.

\section{Uses of the GFS Framework}

1.10 The GFS framework is designed to provide statistics that enable policymakers and analysts to study developments in the financial operations and financial position of government. GFS also allow an assessment of the liquidity and sustainability of the finances of the general government sector or the public sector in a consistent and systematic manner. The GFS framework can be used to analyze the operations of a specific level of government, transactions between levels of government, and the public sector.

1.11 The GFS framework produces summary information on the overall performance and financial position of the general government or public sector through the use of balancing items, such as the net operating balance, net lending/net borrowing, and the change in net worth. These balancing items are defined and measured within the integrated and comprehensive GFS reporting framework.

1.12 In contrast to summary measures, the detailed data of the GFS framework can be used to examine specific areas of government operations. For example, one might want information about particular forms of taxation, the level of expense incurred on a type of social service, or the amount of government borrowing from deposit-taking corporations.

1.13 The harmonization of the GFS framework with other macroeconomic datasets means that data from GFS can be utilized as source data, or can be combined with data from other datasets to assess general government or public sector developments in relation to the rest of the economy. Similarly, the establishment of internationally recognized statistical guidelines permits GFS to be used in crosscountry analyses of government operations and stock

${ }^{8}$ The major changes are described in more detail in Appendix 1. positions, such as comparisons of ratios of taxes, expense, or debt to gross domestic product.

\section{Structure and Features of the GFS Framework}

1.14 The GFS framework pertains to the general government and public sectors as defined in the 2008 SNA and Chapter 2 of this Manual. These sectors are defined in terms of institutional units, which are economic entities that are capable, in their own right, of owning assets, incurring liabilities, and engaging in economic activities and transactions with other entities.

1.15 Stock positions and economic flows are integrated in the GFS framework and are presented in several statements, as described in Chapter 4. Two types of economic flows are recorded in the GFS framework: transactions and other economic flows. ${ }^{9}$ For the most part, transactions are interactions between two institutional units that take place by mutual agreement. The Statement of Operations and the Statement of Sources and Uses of Cash record the results of all transactions during a reporting period. They are classified as revenue, expense, net investment in nonfinancial assets, net acquisition of financial assets, or net incurrence of liabilities. Transactions that generate revenue or expense result in a change in net worth. All other types of transactions result in equal changes to assets and/or liabilities and do not result in a change to net worth.

1.16 Other economic flows include price changes and a variety of other economic events that affect the holdings of assets and liabilities, such as debt writeoffs and catastrophic losses. The Statement of Other Economic Flows summarizes these changes in assets, liabilities, and net worth.

1.17 The Balance Sheet for the general government or public sector is a statement of the stock positions of nonfinancial and financial assets owned, the stock positions of claims of other units on the general government or public sector in the form of liabilities, and the sector's net worth, equal to the total value of all assets minus the total value of all liabilities.

\footnotetext{
${ }^{9}$ Economic flows reflect the creation, transformation, exchange, transfer, or extinction of economic value. Transactions and other economic flows are defined and described in more detail in Chapter 3 .
} 
1.18 In addition to the core statements in the GFS framework, two supplementary statements are included due to their analytic usefulness. To provide a clear statistical explanation of the factors causing changes in net worth, the Statement of Total Changes in Net Worth combines the results of the Statement of Operations and the Statement of Other Economic Flows in one statement.

1.19 Contingencies, such as loan guarantees and implicit guarantees to provide social benefits when various needs arise, can have important economic influences on the general economy but do not result in transactions or other economic flows recorded in the GFS framework until the event or condition referred to actually occurs. A second supplementary statement, the Summary Statement of Explicit Contingent Liabilities and Net Implicit Obligations for Future Social Security Benefits, summarizes the explicit and some implicit contingent liabilities.

1.20 The comprehensive treatment of transactions and other economic flows in the GFS framework provides a full explanation of the changes between the opening and closing balance sheet stock positions. That is, the stock position of a given type of asset or liability at the beginning of a reporting period plus the changes in that asset or liability indicated by transactions and other economic flows equals the stock position at the end of the period. Such an integrated statistical framework permits the effects of policies and specific economic events to be described and analyzed fully.

1.21 Various classifications are applied to the economic flows and stock positions recorded in the GFS framework. For example, each revenue transaction is classified according to whether it is a tax or another type of revenue; expense transactions are classified by purpose (functional classification) and by economic type (economic classification); assets are classified according to whether they are financial or nonfinancial; and financial assets and liabilities are classified by type of instrument, maturity, and the sector of the unit that issued the asset or that holds the liability.

1.22 Despite harmonization of the GFS framework with the 2008 SNA, there are differences between the two statistical frameworks because of the different analytic purposes they serve. The most important difference is that the focus of the GFS framework is the impact of economic events on government financestaxing, spending, borrowing, and lending-while the 2008 SNA also focuses on the production and consumption of goods and services. As a result, the treatment of government production activities in GFS differs from the treatment of those activities in the 2008 SNA. Significant differences relate to the treatment of own-account capital formation, and the degree of consolidation. In addition, the recording of pension schemes for government employees may be different from the 2008 SNA in some circumstances (see Appendix 7 for more details on the relationship between GFS and other macroeconomic statistics).

1.23 In many cases, compiling GFS will be the first step in compiling statistics for the general government sector of the national accounts. For this reason, some data that normally would not appear in a standard GFS presentation should be maintained in underlying source data because they are needed for the national accounts. For example, the detailed classification of subsidies in GFS is based on the nature of the recipient of the subsidy, while classification in the 2008 SNA is based on whether the subsidy is on a product or production.

1.24 Definitions of concepts in the GFS framework are the same as in the 2008 SNA, but the coverage of a particular category of transactions may be slightly different. For example, compensation of employees recorded as an expense in GFS does not include the compensation of employees engaged in own-account capital formation, but can be reconciled with compensation of employees in the 2008 SNA that includes the compensation of all employees. The definition and composition of compensation of employees, however, are identical in both frameworks. To note where the coverage or some other aspect of a concept differs from the same concept in the 2008 SNA, the indicator "[GFS]" is added after the GFS title and an explanation of the difference is provided.

\section{Methodological Differences with the GFSM 1986}

1.25 The methodology for compiling GFS described in this Manual differs substantially from the methodology of the GFSM 1986. The following paragraphs summarize the major differences. Details are provided in Appendix 1. 


\section{Coverage}

1.26 The coverage of the GFS framework is the general government sector as defined in the 2008 $S N A$, which is defined on the basis of institutional units. To capture the fiscal transactions and activities taking place outside the general government sector, the GFS framework should also be used to compile statistics for the public sector and its subsectors. The coverage of the GFSM 1986 is defined on a functional basis under which general government data include all the relevant transactions of any unit carrying out a function of government. Therefore, some transactions of units of the broader public sector carrying out functions of government are included in general government data, unlike GFSM 2014. In addition, some transactions are excluded from general government data in GFSM 1986 as they relate to production or market trading activities.

\section{Basis of Recording Economic Events}

1.27 The GFS framework records economic flows on an accrual basis, which means that flows are recorded at the time economic value is created, transformed, exchanged, transferred, or extinguished. However, the framework also encompasses the traditional cash-based reporting. In the GFSM 1986, transactions are recorded only when cash is received or paid.

1.28 Using the accrual basis of recording also means that nonmonetary transactions are fully integrated in the GFS framework. In the GFSM 1986, only selected nonmonetary transactions are recorded as memorandum items.

\section{Valuation}

1.29 Economic flows as well as assets, liabilities, and net worth are valued at current market prices in the GFS framework. While current market prices are readily available for assets and liabilities that are traded in active markets, valuation according to market-value equivalents is used for valuing assets and liabilities that are not traded in markets, or are traded only infrequently. In the GFSM 1986, debt securities are valued at the amount the government is obligated to pay when the debt matures (face value), which may differ from both the nominal value and the current market value.

\section{Balance Sheets}

1.30 Complete balance sheets, which include all stock positions of nonfinancial and financial assets, liabilities, and net worth, are included in the GFS framework. The GFSM 1986 reports only on the stock positions of certain debt liabilities.

\section{Integration of Flows and Stock Positions}

1.31 The comprehensive recording of transactions and other economic flows permits a full integration of economic flows and stock positions and the reconciliation of differences between the opening and closing balance sheets. In the GFSM 1986, such a reconciliation of the stock positions of the debt liabilities is not possible without collecting additional information.

\section{The Analytic Framework}

1.32 In the GFS framework, several balancing items are introduced. The multiple balancing items facilitate analysis of the general government sector or the public sector based on a variety of considerations rather than a single measure. In the GFSM 1986, the emphasis of the analytic framework is focused on a single balancing item, the overall deficit/surplus.

1.33 The GFS framework's use of definitions of revenue and expense as transactions that bring about changes in net worth leads to a different treatment of transactions in nonfinancial assets. The GFSM 1986 treats cash transactions in nonfinancial assets as capital revenue and expenditure, which affected the overall deficit/surplus. In the GFS framework, the difference between revenue and expense is a balancing item, the net operating balance, measuring the change in net worth resulting from transactions-it is a sustainability measure before considering the net investment in nonfinancial assets.

1.34 In the GFS framework, all transactions involving the acquisition or disposal of financial assets are treated as financing transactions, and net lending (+) / net borrowing (-) is a balancing item calculated as the net operating balance minus the net investment in nonfinancial assets. Net lending/net borrowing is also equal to the net acquisition of all financial assets minus the net incurrence of all liabilities from transactions. In the GFSM 1986, the net acquisition of financial assets for policy purposes is designated as lending minus repayments and treated like expenditure in deriving the overall deficit/surplus. In the GFSM 2014 framework, the 
supplementary fiscal indicators include the calculation of an overall fiscal balance that treats the net acquisition of selected financial assets similarly to the net acquisition of financial assets for policy purposes in the GFSM 1986 (see the annex to Chapter 4).

\section{Harmonization with Other Methodologies}

1.35 Recognizing the important linkages between GFS and other macroeconomic datasets, this Manual is more closely harmonized with the 2008 SNA and BPM6 than was the case for the GFSM 1986. Where differences exist due to the different analytic purposes of various datasets, guidance is provided on the reconciliation between datasets to ensure consistency (see Appendix 7). Also, recognizing the close relationship that exists between GFS and accruals-based public sector accounting standards, the systematic documentation of similarities and differences between statistical guidelines and accounting standards has informed changes in both. Therefore, the GFSM 2014 is also more closely harmonized with accounting standards than was the case with the GFSM 1986 (see Appendix 6).

\section{Implementation of the GFS Framework}

1.36 Some countries may be able, at least initially, to compile only a part of the integrated GFS framework. It is not feasible to lay down general priorities for data collection when economic circumstances may vary widely from one country to another. In practice, priorities usually are best established by national authorities that are familiar with the situation, needs, and challenges of their countries.

1.37 It is recognized that the implementation of the fully integrated GFS framework presented in this Manual will take some time. In particular, many countries will need to revise their underlying accounting systems to accommodate the accrual basis of reporting and fully reflect the revised classifications of the GFS framework. ${ }^{10}$

1.38 Nonetheless, it is likely that many countries will follow a similar path as they implement the GFS

\footnotetext{
${ }^{10}$ Although the GFS framework uses some accounting terms, it is important to remember that it is a statistical reporting framework that might differ in important ways from the underlying financial accounting system from which most of GFS will be derived (see Appendix 6).
}

framework. For example, a possible first step on the migration path could be that countries would adopt the classification structure of the Statement of Operations or the Statement of Sources and Uses of Cash and adjust their cash-based statistics to address known deficiencies, such as by incorporating information on revenue or expense arrears. Another step could be the assembly of balance sheet information on financial assets and liabilities that would allow estimates to be made of the other economic flows as they relate to these financial instruments. A more difficult step is likely to be the collection of a complete set of information about the stock positions of nonfinancial assets held at a given time and their valuation at current market prices. Finally, a fully developed accrual accounting system could be introduced that provides for complete and fully integrated balance sheets to be prepared.

1.39 Good dissemination practices are essential in addition to good data compilation. As well as provision of metadata, aspects of good dissemination practices include a predictable release schedule, readily accessible published data, and identification of internal government access to statistics before public release. In recent years, international guidelines have been developed on good data dissemination practices-namely, the IMF's General Data Dissemination System, Special Data Dissemination Standard, and Special Data Dissemination Standard Plus. ${ }^{11}$

\section{Structure of the Manual}

1.40 The remainder of this Manual can be divided into two general topics. Chapters 2 through 4 develop the concepts used in the framework, and Chapters 5 through 10 describe the classifications used and the types of economic flows or stock positions included in each classification category.

1.41 Chapter 2 describes the coverage of the general government and public sectors, and their subsectors. Chapter 3 first explains the concepts of transactions, other economic flows, and stock positions of assets and liabilities. It then describes the accounting rules governing their recording, including timing, valuation, and consolidation. Chapter 4 presents the analytic framework, which is the integrated presentation of transactions, other economic flows, and stock

\footnotetext{
$\overline{{ }^{11} \mathrm{http}: / / \text { dsbb.imf.org. }}$
} 
positions in a manner that permits the calculation of aggregates and balancing items as summary measures of the activities of the general government and public sectors.

1.42 Chapters 5 through 10 describe the classifications of transactions, other economic flows, and stock positions of assets and liabilities. Chapter 5 is devoted to revenue transactions, which increase net worth. Chapter 6 is devoted to expense transactions, which decrease net worth. Chapter 7 describes the balance sheet and the classification of stock positions of assets and liabilities. Chapter 8 provides a classification of transactions in nonfinancial assets, while Chapter 9 provides a classification of transactions in financial assets and liabilities. Chapter 10 covers other economic flows.

1.43 An annex to Chapter 4 describes the use of GFS to build well-defined indicators for fiscal analysis, while an annex to Chapter 6 describes the Classification of the Functions of Government (COFOG).
1.44 This Manual includes nine appendixes. Appendix 1 lists the methodological changes from the GFSM 2001 to this Manual, and the differences of the GFSM 2014 framework from the GFSM 1986. Appendix 2 describes the various organizational structures used to provide social protection and the associated statistics compiled for the general government and public sectors. Appendix 3 provides guidance on selected public sector debt issues. Appendix 4 covers a description of cross-cutting issues such as the recording of leases, licenses, permits and other contracts, public-private partnerships, and insurance and standardized guarantee schemes. Appendix 5 elaborates on the implications of regional arrangements for GFS compilation. In Appendix 6 , a description of the relationship between GFS and International Public Sector Accounting Standards is provided, while Appendix 7 describes the relationship between GFS and other macroeconomic statistics. Appendix 8 provides the classification codes used in the GFS framework. Appendix 9 contains a glossary of terms used in the GFS framework. 


\section{Institutional Units and Sectors}

This chapter defines and describes the concepts of residence, institutional units, and sectors, and then uses those concepts to delineate the general government and public sectors, and to discuss practical applications of sector classification principles.

\section{Introduction}

2.1 In principle, GFS should cover all entities that materially affect fiscal policies. Normally, fiscal policies are carried out by entities, established by political processes, wholly devoted to the economic functions of government (see paragraph 2.38), such as government ministries or municipal councils. The term "government" is often used as a collective noun for various combinations of entities in a country involved in the functions of government, or reference is made to the various individual governments of a country. For example, a country may have one central government; several state, provincial, or regional governments; and many local governments. Nonprofit institutions under government control may also exist. In addition to those entities, government-owned or controlled enterprises that engage in some commercial activities may be instruments of fiscal policy (see paragraphs 2.104-2.105). These government-owned enterprises, such as the central bank, post office, or railroad, which are often referred to as public corporations, state-owned enterprises, or parastatals in a legal sense, may be part of the general government or public sector, and statistics should be compiled for all of them.

2.2 Determining the coverage of the entities included in GFS requires determining economic territory, using the residence criteria (see paragraph 2.6), before considering two questions. First, what is the statistical unit for which it is feasible and meaningful to collect statistics? Second, which of those statistical units should be included in GFS?
2.3 The statistical unit employed in the institutional sector classification in GFS is the institutional unit, the same unit that is the foundation of the 2008 SNA and other macroeconomic datasets. ${ }^{1}$ This chapter therefore defines (see paragraph 2.22), and describes, types of institutional units (see paragraph 2.26).

2.4 Regarding the coverage of GFS, two principal constructs are used in macroeconomic datasets. First, the general government sector, which is primarily engaged in nonmarket activities, is defined (see paragraph 2.58). Second, the public sector is defined to also capture the market activities and the quasi-fiscal operations of public corporations (see paragraph 2.63) such as the central bank and other public corporations. Quasi-fiscal operations are government operations carried out by institutional units other than general government units. These quasi-fiscal operations have the same fiscal policy impact on the economy as those of government units (see paragraph 2.38). A number of subsectors of the general government and public sectors are also defined because of their analytical usefulness.

2.5 The remainder of this chapter defines the concept of residence to delineate an economy, and describes institutional units and the types of institutional units that exist in macroeconomic statistics before defining the institutional sectors. The chapter applies these concepts to delineate the general government sector and the public sector. Finally, a decision tree to assist with the classification of public sector entities and the application of sector classification principles to some examples are discussed.

\footnotetext{
${ }^{1}$ Maintaining a list or register of these units and their sector classification will ensure consistent classification in all macroeconomic datasets.
} 


\section{Residence}

2.6 An economy consists of a set of resident institutional units. As is the case for other macroeconomic statistics, the concept of residence is important for determining the coverage of institutional units and the classification of transactions. Also, as described in later chapters (see paragraphs 5.101-5.103, 6.93, and 7.264-7.265), some types of flows and stock positions of assets and liabilities of general government and public sector units are classified in GFS on the basis of the counterparty to a financial instrument, where one of the classification criteria is the residence of the counterparty.

2.7 The residence of each institutional unit is the economic territory with which it has the strongest connection (i.e., its center of predominant economic interest). ${ }^{2}$ According to international statistical guidelines, residence is not based on nationality or legal criteria, although it may be similar to the concepts of residence used in many countries for exchange control, taxes, or other purposes. Nonresidents are units that are resident in any other economic territory, and for convenience they are referred to as the "rest of the world."

2.8 Economic territory, in its broadest sense, can be any geographic area or jurisdiction for which statistics are required. The most commonly used concept of economic territory is the area under the effective economic control of a single government. The concept of economic territory in GFS is the same as that used in other macroeconomic datasets. The connection of entities to a particular economic territory is determined from aspects such as physical presence and being subject to the jurisdiction of the government of the territory. However, economic territory need not be identical to its physical or political borders, and may be larger or smaller than this, as in a currency or economic union, or as part of an economy, region, or the world as a whole.

2.9 Economic territory includes:

- The land area

- Airspace

${ }^{2}$ Residence is primarily defined in the BPM6, paragraphs 4.1134.144 , and also discussed in the 2008 SNA, paragraphs 4.10-4.15, and Chapter 26.
- Territorial waters, including areas over which jurisdiction is exercised over fishing rights and rights to fuels or minerals

- In a maritime territory, islands that belong to the territory

- Territorial enclaves in the rest of the world (such as embassies, consulates, military bases, scientific stations, information or immigration offices, aid agencies, central bank representative offices with diplomatic status).

2.10 Territorial enclaves are physically located in other territories and used by governments that own or rent them for diplomatic, military, scientific, or other purposes with the formal agreement of governments of the territories where the land areas are physically located. These areas may be shared with other organizations, but the operations must have a high degree of exemption from local laws to be treated as an enclave. Government operations that are fully subject to the laws of the host economy are not treated as enclaves, but as residents of the host economy. Conversely, the economic territory of a country does not include the territorial enclaves that are physically located within the geographical boundaries of that country that are used by foreign governments or international organizations and are not subject to the laws of that host country.

2.11 Sometimes a government has a separate physical or legal zone that is under its control, but for which, to some degree, separate laws are applied. For example, a free trade zone or offshore financial center may be exempt from certain taxation or other laws. Because of the need to view the whole economy, to have comprehensive global data, and to be compatible with counterpart data, these special zones should always be included in the economic statistics of the economy that exercises control over the separate physical or legal zone. ${ }^{3}$

2.12 An institutional unit has a center of predominant economic interest in an economic territory when there exists, within the economic territory, some location, dwelling, place of production, or other premises on which, or from which, the unit engages

\footnotetext{
${ }^{3}$ Where analytically useful, data for these zones could be presented separately, before they are consolidated with those of the remainder of the economy.
} 
and intends to continue engaging, either indefinitely or over a finite but long period of time, in economic activities and transactions on a significant scale. The location need not be fixed so long as it remains within the economic territory. Actual or intended location for one year or more is used as an operational definition; while the choice of one year as a specific period is somewhat arbitrary, it is adopted to avoid uncertainty and facilitate international consistency.

2.13 A notional resident unit is a unit identified for statistical purposes to be the resident owner of immovable assets legally owned by nonresidents. Immovable assets, such as land, other natural resources, buildings, and structures, are always treated as being owned by resident units. If the legal owner of these types of assets is a nonresident, a notional resident unit is created. The notional resident unit is recorded as owning the asset and receiving the rent or rentals that accrue to the asset. The legal owner is deemed to hold equivalent equity in the notional resident unit and then receives income from the notional resident unit in the form of property income paid abroad. If a building or structure is owned in part by a resident unit and in part by one or several nonresidents, there is one notional resident unit established. Each of the owners has a proportionate share of the equity of the notional resident unit. Land and buildings in extraterritorial enclaves of foreign governments (such as embassies, consulates, and military bases) that are subject to the laws of the home territory and not those of the territory where they are physically situated are part of the economic territory of the home economy (home territory).

2.14 On the basis of the definition of residence, all general government units are considered to be residents in their own country regardless of their physical location. Public corporations, however, are considered to be residents of the economies in whose territories they operate. Thus, a general government unit resident in one country can own a corporation resident in a second country. Corporations subject to the control of a government that is resident in a different economy are not classified as public corporations; these are classified as private corporations in the economy in which they are resident. This is because they are not public corporations related to the government of their economy of residence.
2.15 The case of "special purpose entities" (SPEs), "brass plate companies," or "shell companies" requires particular consideration. These entities may have little or no physical presence in the economy in which they are legally constituted or legally domiciled (e.g., registered or licensed), and any substantive work of the entity may be conducted in another economy. In such circumstances, residence is attributed to the economy in which the entity is legally constituted, or in the absence of legal incorporation, is legally domiciled. However, the fiscal activities of nonresident government-controlled SPEs should be reflected in GFS (see paragraphs 2.136-2.139).

2.16 The economic territory of an international organization that has all the essential attributes of an institutional unit (see paragraph 2.22) consists of the territorial enclaves over which it has jurisdiction. International organizations have the following special characteristics:

- The members of an international organization are either national states or other international organizations whose members are national states; they thus derive their authority either directly from the national states that are their members or indirectly from them through other international organizations.

- They are entities established by formal political agreements between their members that have the status of international treaties; their existence is recognized by law in their member countries.

- Because they are established by international agreement, they are accorded sovereign statusthat is, international organizations are not subject to the laws or regulations of the country, or countries, in which they are located.

- They are created for various purposes, such as international financial organizations (e.g., the International Monetary Fund, World Bank, and Bank for International Settlements) or to provide nonmarket services of a collective nature for the benefit of their member states (e.g., peacekeeping, health, and governing certain aspects of the economic relationships or integration processes among the region's economies).

As a result, international organizations are not considered residents of any national economy, including the country in which they are located or conduct their affairs. 
2.17 International organizations may be global or regional. Regional organizations arise from regional arrangements such as customs unions, economic unions, and monetary and currency unions. ${ }^{4}$ Regional organizations consist of those institutions whose members are governments or monetary authorities ${ }^{5}$ of economies that are located in a specific region of the world. They can be financial, such as regional development banks, or nonfinancial, such as entities involved in the governance of economic unions. Regional organizations are not resident units of any country.

2.18 Some regional organizations have been endowed with the authority to raise taxes or other compulsory contributions within the territories of the countries that are members of the organization. These are sometimes described as "supranational authorities." Despite the fact that they fulfill some of the functions of government within each member country, they are not resident units of any country.

2.19 Financial positions between the regional organization and resident institutional units outside the general government or public sectors are not included in the public sector statistics of a member country because these organizations are not residents of that country. When GFS are compiled for regional organizations as if they constituted a separate government, this Manual recommends that financial positions be classified according to the member country that is the counterparty to allow individual countries to evaluate the impact of regional organizations on their economy.

2.20 In contrast to regional organizations, which perform governmental functions, there may be regional enterprises that are owned by two or more governments and that operate as market producers. If the enterprise has legal entities or separate branches in each economy in which it operates, then identification of these units and determination of their resi-

\footnotetext{
${ }^{4}$ The regional central decision-making body in a currency union is usually the currency union central bank (see paragraph 2.21). For a discussion of currency unions and other regional arrangements, see Appendix 5, and the BPM6, Appendix 3.

${ }^{5}$ Monetary authorities encompass the central bank (which subsumes other institutional units included in the central bank subsector, such as currency boards) and certain operations usually attributed to the central bank but sometimes carried out by other government institutions or commercial banks, such as government-owned commercial banks.
}

dence in the host economy of each of the branches are obvious. However, if they operate as a seamless entity in several economies, then the enterprise's operations are prorated between the economies, so that they are included in the public sector statistics in the national economies in which they operate. The procedures should be applied consistently with the recording in other macroeconomic statistics. ${ }^{6}$

2.21 A currency union central bank is an international financial organization that acts as a common central bank for a group of member countries. A currency union central bank is an institutional unit in its own right, owning assets and liabilities on own account, and is nonresident of any currency union member economy but resident in the currency union. Such a bank typically has the headquarters located in one country of the currency union and maintains national offices in each of the member countries to conduct some central bank functions. Each national office acts as the central bank for that country and is treated as a resident institutional unit in that country. The headquarters, however, is an international organization.

\section{Institutional Units ${ }^{7}$ \\ Definition of an Institutional Unit}

2.22 An institutional unit is an economic entity that is capable, in its own right, of owning assets, incurring liabilities, and engaging in economic activities and in transactions with other entities. Some important features of institutional units are:

- The ability of an institutional unit to own goods or assets in its own right means that it is also able to exchange the ownership of goods or assets in transactions with other institutional units.

- An institutional unit is able to take economic decisions and engage in economic activities for which it is itself held directly responsible and accountable by law.

- An institutional unit is able to incur liabilities on its own behalf, to take on other obligations or future commitments, and to enter into contracts.

\footnotetext{
${ }^{6}$ See the 2008 SNA, paragraph 4.13 , and the BPM6, paragraphs 4.41-4.44.

${ }^{7}$ The definitions and descriptions of institutional units are fully consistent with the corresponding definitions and descriptions in the 2008 SNA, Chapter 4. Hereafter, "unit" is used as a short form for "institutional unit" in some instances.
} 
- Either a complete set of accounts, including a balance sheet of assets, liabilities, and net worth, exists for an institutional unit, or it would be possible and meaningful, from both an economic and legal viewpoint, to compile a complete set of accounts if they were required.

2.23 Identifying the institutional unit is important for GFS compilation since it allows the sectorization of the economy, the identification of the counterparty to transactions and stock positions, and consolidation. ${ }^{8}$ There are several reasons for choosing the institutional unit to work with:

- Statistics for the general government or public sector can be harmonized with the national accounts, balance of payments, international investment position, and monetary and financial statistics because the institutional units and sectors for which statistics are compiled are defined identically (see Appendix 7).

- These institutional units have legal responsibility for their actions, and are centers of decisionmaking in their own right.

- Statistics can be based on information from entities for which complete sets of accounts can be compiled, including balance sheets.

- The source data required for compiling statistics are usually readily available or can be made available.

2.24 An establishment is an enterprise, or part of an enterprise, that is situated in a single location and in which only a single productive activity is carried out or in which the principal productive activity accounts for most of the value added. There is a hierarchical relationship between institutional units and establishments. An institutional unit may contain one or more entire establishment(s), while an establishment can belong to only one institutional unit. The definition of an establishment implies that, at a minimum, complete accounting records about its production activities are available, including the value of its output and the cost of producing that output. An establishment can be an institutional unit if it satisfies

${ }^{8}$ Consolidation is a method of presenting statistics for a set of institutional units (or entities) as if they constituted a single unit (see paragraphs 3.152-3.168). the criteria as set out in paragraph $2.22 .{ }^{9}$ Identifying establishments may be of particular interest in determining the market production of general government units (see paragraph 2.76).

2.25 An enterprise is the view of an institutional unit as a producer of goods and services. The term enterprise may refer to a corporation, a quasicorporation, a nonprofit institution, or an unincorporated enterprise. ${ }^{10}$

\section{Types of Institutional Units}

2.26 In compiling macroeconomic data the classification of an institutional unit is determined by its objectives and functions and cannot always be inferred from its legal status or name. It is therefore necessary to closely examine the objectives and functions of the institutional unit before deciding which type of unit it is.

2.27 There are two main types of institutional units:

- Persons or groups of persons in the form of households

- Legal or social entities.

\section{Households}

2.28 A household is a group of persons who share the same living accommodation, who pool some, or all, of their income and wealth, and who consume certain types of goods and services collectively, mainly housing and food. A household can be an individual household, or an institutional household. The latter comprises groups of persons staying for a very long or indefinite period of time, or who may be expected to reside for a very long or indefinite period of time in institutions such as hospitals, retirement homes, prisons, or religious communities such as convents, monasteries, and nunneries.

2.29 A household can have one member or could be a multiperson household. In a multiperson household, individual members are not treated as separate institutional units. Many assets are owned, or liabilities incurred, jointly by two or more members of the same household, while some or all of the income received

\footnotetext{
${ }^{9}$ If the establishment charges economically significant prices and meets the criteria to be classified as an institutional unit, it would be treated as a quasi-corporation (see paragraph 2.33).

${ }^{10}$ See the 2008 SNA, paragraphs 5.1-5.2, for a detailed description of enterprises.
} 
by individual members of the same household may be pooled for the benefit of all members. Moreover, many expenditure decisions, especially those relating to the consumption of food or housing, may be made collectively for the household as a whole. It may be impossible, therefore, to draw up meaningful balance sheets or other accounts for individual members of a multiperson household. For these reasons, the household as a whole rather than the individual persons in it must be treated as the institutional unit.

\section{Legal and social entities}

2.30 A legal or social entity is one whose existence is recognized by law or society independently of the persons or other entities that may own or control it. Three types of legal or social entities are recognized as institutional units: corporations and nonprofit institutions are primarily created for purposes of production of goods or services; and government units are created by political processes.

\section{Corporations}

2.31 Corporations are defined as entities that are capable of generating a profit or other financial gain for their owners, are recognized by law as separate legal entities from their owners, and are set up for purposes of engaging in market production. The key to classifying a unit as a corporation in macroeconomic statistics is not its legal status but rather the economic substance of the nature of the entity. The laws governing the creation, management, and operations of legally constituted corporations and other entities may vary from country to country, so that it is not feasible to provide a legal definition of a corporation that would be universally valid. Therefore, in macroeconomic statistics, the term corporation is not necessarily used in the same way as in the legal sense. ${ }^{11}$

2.32 The key to classifying a unit as a corporation in macroeconomic statistics is the notion of being a market producer (see paragraph 2.65). Of particular importance are the characteristics to produce goods and services for the market at economically significant prices as explained in paragraph 2.66, and the potential to be a source of profit or other financial

${ }^{11}$ For a full discussion on the features of corporations, also see the 2008 SNA, paragraphs 4.38-4.50. gain to the owners. Some nonprofit institutions and government units have the legal status of a corporation, but are not considered corporations for the purposes of macroeconomic statistics because they are not market producers. Other nonprofit institutions are legal corporations that produce for the market but they are not allowed to be a source of financial gain to their owners. Conversely, some entities with different legal titles, such as partnerships or a jointstock company, could be considered corporations for economic statistics when they satisfy the definition of corporations.

2.33 A quasi-corporation is either (i) an unincorporated enterprise owned by a resident institutional unit that has sufficient information to compile a complete set of accounts, that is operated as if it were a separate corporation, and whose relationship to its owner is effectively that of a corporation to its shareholders, or (ii) an unincorporated enterprise owned by a nonresident institutional unit that is deemed to be a resident institutional unit because it engages in a significant amount of production in the economic territory over a long or indefinite period of time. ${ }^{12}$ These entities are not incorporated or otherwise legally constituted, but function as if they were corporations. They are treated as corporations in GFS (see paragraphs 2.125-2.127).

2.34 An establishment or group of establishments engaged in the same kind of production activities should be treated as a quasi-corporation if the following criteria hold:

- The establishment charges prices for its outputs that are economically significant (see paragraph 2.66).

- The establishment is operated and managed in a similar way to a corporation.

- The establishment has a complete set of accounts, or is able to construct a complete set of accounts, that enable its stock positions and flows to be separately identified and measured.

\footnotetext{
${ }^{12}$ Unincorporated enterprises, such as some post offices or national railways, may exist in government ministries. When these unincorporated enterprises produce goods and services for the market at economically significant prices, and have separate sets of accounts, they are quasi-corporations and classified as part of public corporations. If not, they may be market establishments as discussed in paragraph 2.75 .
} 
2.35 All corporations are part of the nonfinancial corporations sector or the financial corporations sector, depending on the nature of their primary activity. Institutional units that qualify as corporations and are controlled by government units or other public corporations are classified as public corporations (see paragraph 2.104).

\section{Nonprofit institutions (NPIs)}

2.36 Nonprofit institutions (NPIs) are legal or social entities created for the purpose of producing or distributing goods and services, but they cannot be a source of income, profit, or other financial gain for the institutional units that establish, control, or finance them. In practice, their productive activities generate either surpluses or deficits, but the surpluses cannot be appropriated by other institutional units. The articles of association by which they are established are drawn up in such a way that the institutional units that control or manage them are not entitled to a share in any profits or other income they generate.

2.37 NPIs may engage in market or nonmarket production, and may be created by households, corporations, or governments (see paragraph 2.83).

- NPIs engaged in market production charge economically significant prices for their services (see paragraph 2.66). Schools, colleges, universities, clinics, hospitals, etc. constituted as NPIs are market producers when they charge fees that are based on the majority of their production costs and that are sufficiently high to have a significant influence on the demand for their services. There are no shareholders with a claim on the profits or equity of the NPI. Because of their status as NPIs, they are also able to raise significant additional funds through donations from persons, corporations, or governments. Nevertheless, NPIs engaged in market production and controlled by government units must be treated as public corporations so long as they produce goods and services for the market at economically significant prices.

- Some market NPIs restrict their activities to serving a particular subset of other market producers. They consist of chambers of commerce, agricultural, manufacturing or trade associations, employers' organizations, research or testing laboratories, or other organizations or institutions that engage in activities that are of common interest or benefit to the group of enterprises that control and finance them. These NPIs are usually financed by contributions or subscriptions from the group of enterprises concerned. Such subscriptions are treated not as transfers but as payments for services rendered, and these NPIs are, therefore, classified as market producers. These market NPIs are, like corporations and quasicorporations, members of either the nonfinancial corporations sector or the financial corporations sector.

- NPIs that are engaged in nonmarket production and are controlled by government are treated as government units (see paragraph 2.38 and Box 2.1). Therefore, schools, colleges, universities, clinics, hospitals, etc. constituted as NPIs are nonmarket producers when they charge fees that are not economically significant.

- The remaining NPIs, those that produce goods and services but do not sell them at economically significant prices and are not controlled by government, are classified as a special group of units called NPIs serving households.

\section{Government units}

2.38 Government units are unique kinds of legal entities established by political processes that have legislative, judicial, or executive authority over other institutional units within a given area. The principal economic functions of government units are to:

- Assume responsibility for the provision of goods and services to the community or individual households primarily on a nonmarket basis

- Redistribute income and wealth by means of transfers

- Engage primarily in nonmarket production ${ }^{13}$

- Finance their activities primarily out of taxation or other compulsory transfers. ${ }^{14}$

\footnotetext{
${ }^{13}$ The concepts of market and nonmarket producers are described in paragraph 2.65.

${ }^{14}$ The requirement of financing activities by compulsory transfers is necessary to differentiate a government from a nonprofit institution, which may carry out the same functions as a government but obtains its funds from voluntary transfers, property income, or sales. The receipt of compulsory transfers may be indirect. For example, a local government may finance its activities with grants receivable from the central government.
} 
A government unit may also finance a portion of its activities in a specific period by borrowing or by acquiring funds from sources other than compulsory transfers-for example, interest revenue, incidental sales of goods and services, or the rent of subsoil assets. All government units are part of the general government sector.

\section{Application of the Definition of an Institutional Unit to Government}

2.39 Depending on the complexity of a government's organization, the identification of government units may require careful consideration. Ministries, departments, agencies, boards, commissions, judicial authorities, legislative bodies, and other entities that make up a government are not institutional units if they do not have the authority to own assets, incur liabilities, or engage in transactions in their own right. In general, all entities funded by appropriations made in accordance with a budget controlled by the legislature are not separate institutional units and are treated as constituting a single institutional unit.

2.40 The geographic location of a government unit is not always limited to one location within the economic territory-for example, individual ministries or departments of a particular government may be deliberately dispersed throughout the area of the government's jurisdiction. They remain, nevertheless, part of the same institutional unit. Similarly, a given ministry or department may maintain branch offices or agencies in many different locations to meet local needs. These offices and agencies are part of the same institutional unit.

2.41 There may, however, be government entities with a separate legal identity and substantial autonomy, including discretion over the volume and composition of their expenditures and a direct source of revenue, such as earmarked taxes. Such entities are often established to carry out specific functions, such as road construction or the nonmarket production of health or education services. These entities should be treated as separate government units (often referred to as extrabudgetary units) if they satisfy the criteria to be an institutional unit (see paragraphs 2.22 and 2.80).

2.42 Sometimes governments establish legal entities that cannot act independently and are simply a passive holder of assets and liabilities. Such an entity is referred to as an artificial subsidiary and is not treated as a separate institutional unit, unless it is resident in an economy different from that of its parent unit (see paragraphs 2.6-2.20). Resident artificial subsidiary entities are classified as components of the level of government that controls them (i.e., as part of their parent unit or extrabudgetary units of the parent unit).

2.43 Government resident artificial subsidiaries are sometimes set up as SPEs. Although these resident artificial subsidiaries are often legally constituted corporations, to the extent that these entities are nonmarket producers and are controlled by another government unit, they should be classified within the general government sector, either as an extrabudgetary government unit, or with the parent government unit that controls the SPE. Resident SPEs acting independently, acquiring assets and incurring liabilities on their own behalf, and accepting the associated risk, are treated as separate institutional units and are classified by sector according to their principal activity. All nonresident SPEs are treated as separate institutional units resident in the economy where they are established, but the fiscal activities they carry out are reflected in the accounts of the government that controls them (see paragraphs 2.136-2.139).

2.44 Another example of a resident artificial subsidiary is where government establishes a central borrowing authority that appears to be a public financial corporation but is in fact part of a general government unit. These central borrowing authorities borrow on the market and then lend only to the parent unit or other general government units. However, because such entities are not treated as separate institutional units, and merely facilitate government borrowing, they should be classified in general government, either as an extrabudgetary unit, or with the government unit that controls the central borrowing authority. Where such a central borrowing authority is created as a resident in an economy different from that of its parent, it should be classified as a captive financial institution (see paragraphs 2.14 and 2.54) in the financial corporation sector of the host economy.

2.45 An ancillary activity is a supporting activity providing services within an enterprise in order to create the conditions within which the principal 
or secondary activities can be carried out. ${ }^{15}$ The type of services referred to include keeping records, managing and paying employees, cleaning, maintenance, transportation, and security. An entity undertaking only ancillary activities will, in general, not satisfy the criteria to be an institutional unit. ${ }^{16}$

2.46 Many governments allocate substantial resources to social protection through the provision of social benefits (see paragraphs 6.96-6.105 and Appendix 2), to protect the entire population or specific segments of it against certain social risks. Social risks are events or circumstances that may adversely affect the welfare of the households concerned either by imposing additional demands on their resources or by reducing their income. Examples of social benefits are the provision of medical services, unemployment compensation, and social security pensions. Because of the large scale of social protection programs in many countries and the various organizational structures of such programs, Appendix 2 describes the institutional units involved in these programs and their effects on statistics of the general government sector.

2.47 Government usually comprises two or more institutional units, and there normally is one unit that controls the other units. The controlling unit most likely includes the legislature, head of state, and judiciary. In contrast to corporations (see paragraph 2.107), one government unit controls another government unit by appointing its managers and/or determining the laws and regulations that provide its finance rather than through equity ownership. Generally, government units do not issue shares. SPEs, wealth funds, or other entities of government that are legally constituted as corporations but do not satisfy the statistical definition of a corporation should be classified as government units in one of the subsectors of the general government. As a result, a liability for equity and investment fund shares could appear in the consolidated general government's balance sheet (see paragraphs 2.137 and $2.152-2.155) .{ }^{17}$

\footnotetext{
${ }^{15}$ Ancillary activities produce mainly services, but, as exceptions, goods that do not become a physical part of the marketable products produced by an enterprise.

${ }^{16}$ See the 2008 SNA, paragraphs 5.35-5.45, for more details.

${ }^{17}$ Because of consolidation, GFS are not highly sensitive to the institutional unit borderline among the subsectors of the general government sector, as long as all general government units are fully covered.
}

2.48 Public corporations, in contrast to general government units, are institutional units that are potential sources of financial gains or losses to the government units that own or control them. In some cases, the corporation issues shares, and thus the financial gain or loss is clearly allocated to the shareholders. In other cases, no shares are issued, but it is clear that a specific government unit controls the corporation's activities and is financially responsible for it. In those cases, the responsible government unit also owns equity and investment fund shares (see paragraphs 7.164-7.177).

\section{Institutional Sectors ${ }^{18}$}

2.49 An economy can be divided into institutional sectors. ${ }^{19}$ It is therefore necessary to define institutional sectors and identify the type of sectors that exist.

\section{Defining Institutional Sectors}

2.50 An institutional sector groups together similar kinds of institutional units according to their economic objectives, functions, and behavior. Each sector consists of a number of institutional units that are resident in the economy and is intrinsically different from the other sectors. An economy is divided into five mutually exclusive institutional sectors. All resident institutional units are allocated to one of these institutional sectors. The five institutional sectors are:

- Nonfinancial corporations sector

- Financial corporations sector

- General government sector

- Households sector

- Nonprofit institutions serving households sector.

2.51 The relationship between these sectors of the economy and the types of institutional units (discussed in paragraphs 2.26-2.48) is depicted in Figure 2.1.

\section{Nonfinancial corporations sector}

2.52 The nonfinancial corporations sector consists of resident institutional units that are principally engaged in the production of market goods or

\footnotetext{
$\overline{{ }^{18} \text { The definitions and }}$ descriptions of institutional sectors are fully consistent with the corresponding definitions and descriptions in the 2008 SNA, Chapter 4.

${ }^{19}$ Hereafter, "sector" will often be used as a short form for "institutional sector."
} 
Figure 2.1 Types of Institutional Units and Their Relation to Sectors of the Economy

\begin{tabular}{|l|c|c|c|c|c|}
\hline Sector & $\begin{array}{c}\text { Nonfinancial } \\
\text { corporations } \\
\text { sector }\end{array}$ & $\begin{array}{c}\text { Financial } \\
\text { corporations } \\
\text { sector }\end{array}$ & $\begin{array}{c}\text { General } \\
\text { government } \\
\text { sector }\end{array}$ & $\begin{array}{c}\text { Households } \\
\text { sector }\end{array}$ & $\begin{array}{c}\text { Nonprofit } \\
\text { institutions } \\
\text { serving } \\
\text { households } \\
\text { sector }\end{array}$ \\
\hline Households & $\checkmark$ & $\checkmark$ & & $\checkmark$ & \\
\hline Corporations & $\checkmark$ & $\checkmark$ & $\checkmark$ & & $\checkmark$ \\
\hline Nonprofit institutions & & & $\checkmark$ & & \\
\hline Government units & & & & \\
\hline
\end{tabular}

$\sqrt{ }$ Units included in sector

nonfinancial services. The sector includes public and private corporations and is composed of:

- All resident nonfinancial corporations (as defined in paragraphs 2.31-2.32), regardless of the residence of their owners

- The branches of nonresident enterprises that are engaged in nonfinancial production in the economic territory on a long-term basis

- All resident NPIs that are market producers of goods or nonfinancial services.

\section{Financial corporations sector}

2.53 The financial corporations sector consists of resident corporations that are principally engaged in providing financial services, including insurance and pension fund services, to other institutional units. The production of financial services is the result of financial intermediation, financial risk management, liquidity transformation, or auxiliary financial activities. In addition, the sector includes NPIs engaged in market production of a financial nature, such as those financed by subscriptions from financial enterprises whose role is to promote and serve the interest of those enterprises.

2.54 Financial corporations can be divided into three broad classes: financial intermediaries, financial auxiliaries, and captive financial institutions and money lenders.

- Financial intermediaries are institutional units that incur liabilities on their own account for the purpose of acquiring financial assets by engaging in financial transactions on the market. The assets and liabilities of financial intermediaries are transformed or repackaged with respect to maturity, scale, risk, and the like, in the financial intermediation process. The financial intermediation process channels funds between third parties with a surplus of funds and those with a demand for funds. A financial intermediary not only acts as an agent for these other institutional units, but also places itself at risk by acquiring financial assets and incurring liabilities on its own account. Financial intermediation is limited to acquiring assets and incurring liabilities with the general public or specified and relatively large groups thereof. Where the activity is limited to small groups, no intermediation takes place. Financial intermediaries include deposit-taking corporations, insurance corporations, and pension funds.

- Financial auxiliaries consist of financial corporations that are principally engaged in activities associated with transactions in financial assets and liabilities or with providing the regulatory context for these transactions but in circumstances that do not involve the auxiliary taking ownership of the financial assets and liabilities being transacted. They include brokers, managers of pension funds, mutual funds, etc. (but not the funds they manage), foreign exchange bureaus, and central supervisory authorities.

- Captive financial institutions and money lenders are institutional units providing financial services other than insurance, where most of their assets or liabilities are not available on open financial markets. These entities transact within only a limited group of units (such as with subsidiaries) or subsidiaries of the same holding 
corporations or entities that provide loans from own funds provided by only one sponsor. Captive insurance is the exception and is classified as an insurance corporation.

2.55 Financial intermediaries can be divided into seven subsectors according to the intermediary's activity in the market and the liquidity of its liabilities. These seven subsectors are: central bank; deposit-taking corporations except the central bank; money market funds; nonmoney market investment funds; other financial intermediaries except insurance corporations and pension funds; insurance corporations; and pension funds.

2.56 As indicated in Figure 2.3 and Table 7.11, in GFS the financial corporations are presented as follows for analytic purposes:

- The central bank

- Deposit-taking corporations except the central bank

- Other financial corporations-including all financial intermediaries except deposit-taking corporations, financial auxiliaries, and captive financial institutions and money lenders.

2.57 The financial corporations sector includes public and private financial corporations comprising:

- All resident financial corporations (as defined in paragraphs 2.31-2.35), regardless of the residence of their shareholders

- The branches of nonresident enterprises (see paragraph 2.20) that are engaged in financial activity in the economic territory on a long-term basis

- All resident NPIs that are market producers of financial services (see paragraph 2.36 - 2.37).

\section{General government sector}

2.58 The general government sector consists of resident institutional units that fulfill the functions of government as their primary activity. These institutional units perform the principal economic functions of government, as described in paragraph 2.38, in addition to fulfilling their political responsibilities and their role of economic regulator. The general government sector comprises:

- All government units of central, state, provincial, regional, and local government, and social security funds (see paragraphs 2.76-2.103) imposed and controlled by those units

- All nonmarket NPIs that are controlled by government units (see paragraph 2.83).
2.59 The general government sector does not include public corporations, even when all the equity of such corporations is owned by government units, nor quasicorporations that are owned and controlled by government units. However, unincorporated enterprises owned by government units that are not quasi-corporations remain integral parts of those units and, therefore, must be included in the general government sector.

\section{Households sector}

2.60 The households sector consists of all resident households (see paragraphs 2.28-2.29). Households may be of any size and take a variety of different forms in different societies or cultures. All physical persons in the economy must belong to one and only one household. Households supply labor, undertake final consumption, and, as entrepreneurs, produce market goods and nonfinancial (and possibly financial) services.

\section{Nonprofit institutions serving households (NPISHs) sector}

2.61 The nonprofit institutions serving households (NPISHs) sector consists of resident nonmarket nonprofit institutions (NPIs) that are not controlled by government. They provide goods and services to households for free or at prices that are not economically significant. One type of NPISHs is created by associations of persons to provide goods or, more often, services primarily for the benefit of the members themselves. For example, professional or learned societies, political parties, trades unions, consumers' associations, churches or religious societies, and social, cultural, recreational, or sports clubs. They do not include bodies serving similar functions that are controlled by government units. Religious institutions are usually excluded from general government and classified as NPISHs even when mainly financed by government units if this majority financing is not seen as empowering control by government. Political parties in countries with one-party political systems that are controlled by government units by means of providing the necessary finance are included in the general government sector. A second type of NPISHs consists of charities, and relief or aid agencies that are created for philanthropic purposes, while a third type provides collective services, such as research institutions that make their results freely available, environmental groups, etc. By convention, nonmarket NPIs controlled by foreign governments are classified as NPISHs in the host economy. 
Figure 2.2 The Public Sector and Its Relation to Other Institutional Sectors of the Economy

\begin{tabular}{|l|c|c|c|c|}
\hline $\begin{array}{c}\text { General } \\
\text { Government } \\
\text { Sector }\end{array}$ & $\begin{array}{c}\text { Nonfinancial } \\
\text { Corporations } \\
\text { Sector }\end{array}$ & $\begin{array}{c}\text { Financial } \\
\text { Corporations } \\
\text { Sector }\end{array}$ & $\begin{array}{c}\text { Households } \\
\text { Sector }\end{array}$ & $\begin{array}{c}\text { Nonprofit } \\
\text { Institutions } \\
\text { Serving House- } \\
\text { holds Sector }\end{array}$ \\
\hdashline $\begin{array}{c}\text { Central government } \\
\text { State governments } \\
\text { Local governments }\end{array}$ & $\begin{array}{c}\text { Public corporations } \\
\text { corporations }\end{array}$ & $\begin{array}{c}\text { Public corporations } \\
\text { corporations }\end{array}$ & Private & Private \\
\hline
\end{tabular}

$\mid \begin{aligned} & \text { Public } \\ & \text { sector }\end{aligned}$

\section{The Use of Subsectors}

2.62 Each of the sectors of the economy may be divided into subsectors, and the subsectors can be combined in different ways to form other sectors. No single method of combining subsectors may be optimal for all purposes. Dividing the total economy into sectors and subsectors enhances the usefulness of the data for purposes of economic analysis and enables targeted monitoring of particular groups of institutional units for policy purposes. For example, the general government sector can be divided into central, state, and local government subsectors, while social security funds could be presented as a separate subsector or could be included in the subsector that organizes and manages them. The nonfinancial corporations subsector can be divided into public nonfinancial corporations, foreign-controlled nonfinancial corporations, and national private nonfinancial corporations. ${ }^{20}$ The division of sectors into subsectors depends upon the type of analysis to be undertaken, the needs of policymakers, the availability of data, the economic circumstances, and the institutional arrangements within a country. Figure 2.2 shows the relationship between the general government sector, the public sector, and the other main sectors of the domestic economy.

\section{Institutional Coverage and Sectorization of the Public Sector}

2.63 The public sector consists of all resident institutional units controlled directly, or indirectly, by resident government units-that is, all units of the

\footnotetext{
${ }^{20}$ Similarly, financial corporations can be divided into public, foreign-controlled, and national private financial corporations.
}

general government sector and resident public corporations. Figure 2.3 illustrates the main components of the public sector. Statistics should be compiled for the general government and public sectors, as well as for all the subsectors of the general government and the public corporations subsector.

\section{Delineating General Government and Public Corporations}

2.64 The general government sector consists of all government units and all resident nonmarket NPIs that are controlled by government units, while the public corporations subsector (see paragraph 2.104) consists of all corporations controlled by government units or other public corporations. General government also includes public enterprises, legally constituted as corporations, but that do not satisfy the statistical criteria to be treated as corporations (see paragraphs $2.31-2.35$ ). ${ }^{21}$ To determine which public enterprises are treated as general government units and which as public corporations, it is necessary to delineate nonmarket and market producers .

2.65 A market producer is an institutional unit that provides all or most of its output to others at prices that are economically significant. A nonmarket producer provides all or most of its output to others for free or at prices that are not economically significant.

2.66 Economically significant prices are prices that have a significant effect on the amounts that producers

\footnotetext{
${ }^{21}$ Public enterprises are often also referred to as state-owned enterprises or parastatals.
} 


\section{Figure 2.3 The Public Sector and Its Main Components}

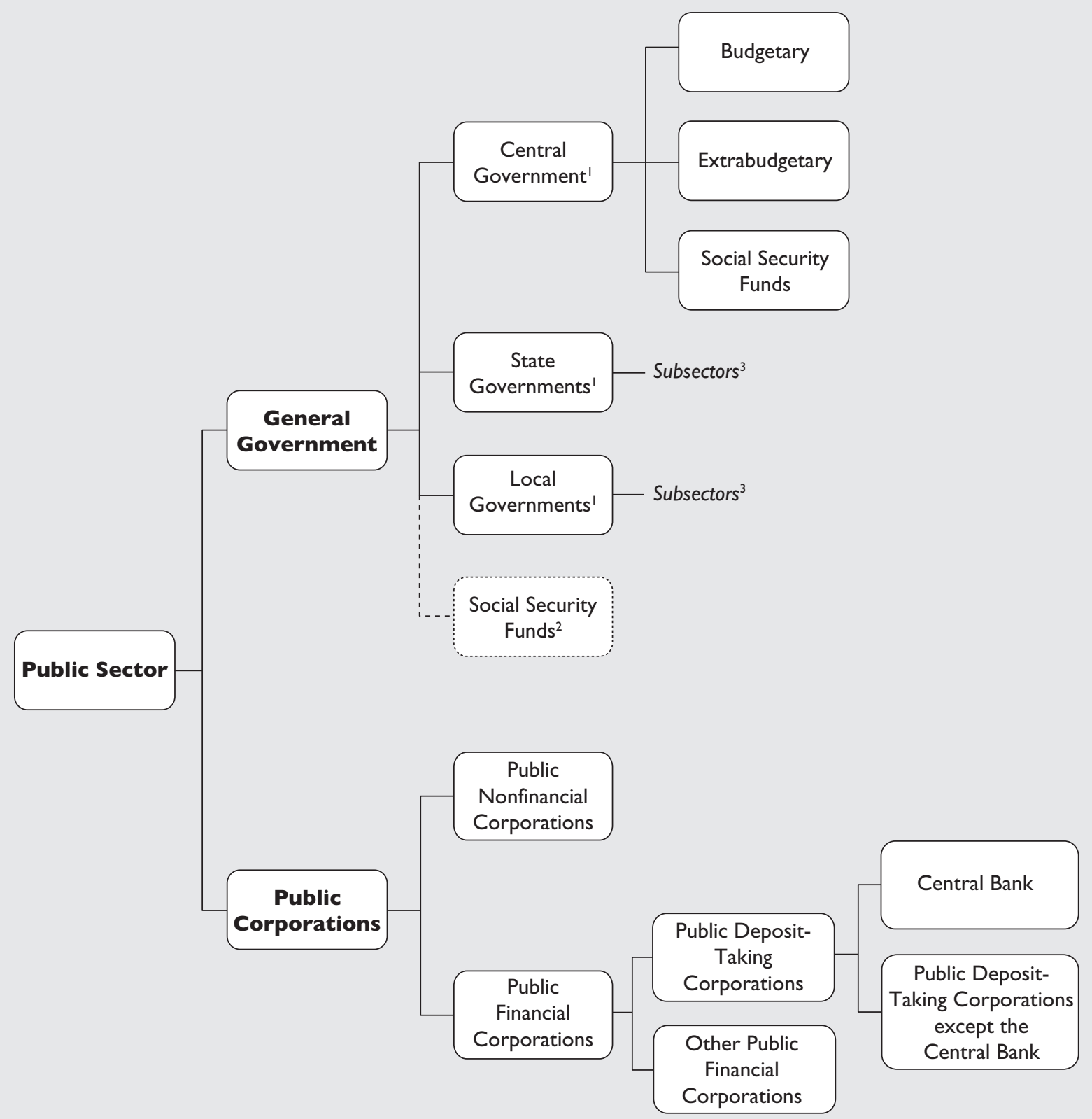

${ }^{1}$ Includes social security funds.

${ }^{2}$ Alternatively, social security funds can be combined into a separate subsector, as shown in the box with dashed lines.

${ }^{3}$ Budgetary units, extrabudgetary units, and social security funds may also exist in state and local governments.

are willing to supply and on the amounts purchasers wish to buy. These prices normally result when:

- The producer has an incentive to adjust supply either with the goal of making a profit in the long run or, at a minimum, covering capital and other costs.
- Consumers have the freedom to purchase or not purchase and make the choice on the basis of the prices charged.

These conditions usually mean that prices are economically significant if sales cover the majority of the 
producer's costs and consumers are free to choose whether to buy, and how much to buy, on the basis of the prices charged.

2.67 A price is not economically significant when it has little or no influence on how much the producer is prepared to supply and on the quantities demanded. Economically insignificant prices may be charged in order to raise some token revenue and/ or reduce, but not eliminate, excessive demand that may occur if goods and services are provided free of charge. An economically insignificant price may be set on administrative, social, or political grounds for goods or services for which the amount to be supplied is fixed.

2.68 It can be presumed that prices are economically significant when the producers are private corporations. When there is public control, however, the unit's prices may be modified for public policy purposes. This may cause difficulties in determining whether the prices charged are economically significant. Public corporations are often established to provide goods and services in larger quantities than a private corporation would provide at the same selling price. Even when the sales of public corporations may cover a large portion of their costs, one can expect that they respond to market forces quite differently than would private corporations.

2.69 Although there is no prescriptive numerical relationship between the value of sales (excluding both taxes and subsidies on products) and the production costs, one would expect the value of the sales by public corporations to average at least half of the production costs over a sustained multiyear period.

2.70 In principle, the distinction between market and nonmarket producers should be made on a case-by-case basis. The classification of a producer as a market or nonmarket producer should be considered over a range of years. ${ }^{22}$ Once classified, only if a change in pricing holds for several years or is expected to hold for several years should a reclassification of the entity be considered.

2.71 It is likely that corporations receiving substantial government financial support, or enjoying other

\footnotetext{
${ }^{22}$ When a newly established unit needs to be classified to a sector, the classification as a market or nonmarket producer should be based on its intent regarding the prices it is to charge for its goods and services.
}

risk-reducing factors such as substantial government guarantees, will respond to changes in the economic conditions differently from corporations without such advantages because their budget constraints are softer, and so are more likely to be classified as nonmarket producers.

2.72 The question arises whether governmentowned entities supplying goods and services to government should be treated as market or nonmarket producers. The producer of these goods and services is not a market producer if it is a dedicated provider of ancillary services (see paragraph 2.45). These entities will, in general, not satisfy the criteria to be an institutional unit. Similarly, it can often be assumed that the producer is not a market producer if the unit provides the goods and services in the absence of competition ${ }^{23}$ with private producers, and when the choice of supplier to government is not based on price. This is true regardless of whether the supplier is the only supplier and whether the government is the only customer of the supplier.

2.73 To assess whether a producer is a market producer, it is necessary to carry out a comparison between the receipts from sales and the production costs of the goods and services sold. Sales are measured before any taxes applicable to the products are added. Sales exclude all payments receivable from government unless they would be granted to any producer undertaking the same activity. Production for own use, known as own-account production, does not generate receipts from sales, and so it is not considered as part of sales in this context.

2.74 Production costs are calculated as the sum of compensation of employees, use of goods and services, consumption of fixed capital, and other taxes on production. ${ }^{24}$ These concepts used in the calculation of production costs exclude all costs associated with ownaccount capital formation. Further, a return to capital is included in production costs if the unit is to be treated as a market producer. Subsidies receivable on production are not deducted from the production costs.

2.75 As a nonmarket producer, a general government institutional unit will have mostly nonmarket establishments (see paragraph 2.24), but it may have

\footnotetext{
${ }^{23}$ Prices determined in a competitive market are highly likely to be economically significant prices.

${ }^{24}$ For a detailed breakdown of other taxes on production, see paragraph A7.41 and Table A7.3.
} 
one or more market establishments. ${ }^{25} \mathrm{~A}$ market establishment is an establishment that charges economically significant prices. Where a general government unit sells some of its output at prices that are economically significant, it may be possible to identify market producers. Market establishments within government that satisfy the criteria to be separate institutional units are quasi-corporations (see paragraph 2.22), and are treated in the same way as corporations. The remaining market establishments would remain an integral part of the general government sector.

\section{The General Government Sector and Its Subsectors}

2.76 The general government sector consists of resident institutional units that fulfill the functions of government as their primary activity. This sector includes all government units and all nonmarket NPIs that are controlled by government units. For analytic purposes, it is often necessary or desirable to disaggregate the general government sector into subsectors.

2.77 Depending on the administrative and legal arrangements, there may be more than one level of government within a country, and statistics should be compiled for each level (also referred to as subsectors). However, because of these different arrangements, international comparison of data for each subsector of general government should be undertaken with some caution. In macroeconomic statistics, provision is made for three subsectors of general government: central, state, and local. Not all countries have all three levels; some may have only a central government or a central government and one level below. Other countries may have more than three levels. In that case, the various units should all be classified as one of the three subsectors suggested here. In addition to levels of government, the existence of social security funds and their role in fiscal policy may require that statistics for all social security funds be compiled as a separate subsector of the general government sector.

2.78 A full classification of the subsectors of the general government would allow for both NPIs and social security funds to be distinguished for each of

\footnotetext{
${ }^{25}$ The sales of goods and services (142) include sales of market establishments and sales by nonmarket establishments, and are identified as specific categories of revenue (see paragraphs 5.136-5.141).
}

central, state, and local government subsectors. In practice, though, it is usual to present social security funds in one of two alternative sets of subsectors, as illustrated in Figure 2.3. ${ }^{26}$

- All social security funds could be combined into a separate subsector and all other general government units could be classified according to their level. In that case, the central, state, and local government subsectors would comprise all government units other than social security funds; or

- Social security funds could be classified according to the level of government that organizes and manages them and therefore be combined with the other general government units at the respective subsectors. Thus, the general government would consist of central, state, and local governments, assuming that all three levels of government exist. To facilitate analysis of social security funds as a whole, separate statistics for them may be provided within the statistics for each level of government.

Countries may choose either presentation.

2.79 Classification problems may arise when government operations are carried out by a general government unit jointly accountable to two levels of government. ${ }^{27}$ This classification decision may be especially difficult if the agency has its own source of funding, such as earmarked taxes. In some cases, an NPI might be controlled by two or more government units at different levels of government. For example, a state government unit might have the right to appoint the majority of officers managing an NPI but the financing might be provided mainly by the central government. General government units subject to dual control should be classified to the level of government that predominates in terms of control in accordance with all the indicators of control (see Boxes 2.1 and 2.2).

2.80 The central, state, and local government subsectors of general government are each made up of

\footnotetext{
${ }^{26}$ The alternative methods of subsector classification are designed to accommodate different analytic needs. The decision as to which method is more appropriate in a given country depends on how significant social security funds are and on the extent to which they are managed independently of the government units with which they are associated.

${ }^{27}$ Also see the discussion on joint ventures in paragraphs $2.140-2.143$.
} 


\section{Box 2.1 Government Control of Nonprofit Institutions}

Control of an NPI is defined as the ability to determine the general policy or program of the NPI. To determine if an NPI is controlled by the government, the following five indicators of control would be the most important and likely factors to consider:

- The appointment of officers-The government may have the right to appoint the officers managing the NPI under the NPI's constitution, its articles of association, or other enabling instrument.

- Other provisions of the enabling instrument-The enabling instrument may contain provisions other than the appointment of officers that effectively allow the government to determine significant aspects of the general policy or program of the NPI. For example, the enabling instrument may specify or limit the functions, objectives, and other operating aspects of the NPI, thus making the issue of managerial appointments less critical or even irrelevant. The enabling instrument may also give the government the right to remove key personnel or veto proposed appointments, require prior approval of budgets or financial arrangements by the government, or prevent the NPI from changing its constitution, dissolving itself, or terminating its relationship with government without government approval.

- Contractual agreements-The existence of a contractual agreement between a government and an NPI may allow the government to determine key aspects of the NPI's general policy or program. As long as the NPI is ultimately able to determine its policy or program to a significant extent, such as by being able to fail to comply with the contractual agreement and accept the consequences, to change its constitution, or to dissolve itself without requiring government approval other than that required under the general regulations, then it would not be considered controlled by government.

- Degree of financing by government-An NPI that is mainly financed by government may be controlled by that government. Generally, if the NPI remains able to determine its policy or program to a significant extent along the lines mentioned in the previous indicator, then it would not be considered controlled by government.

- Risk exposure-If a government openly allows itself to be exposed to all, or a large proportion of, the financial risks associated with an NPI's activities, then the arrangement constitutes control.

A single indicator could be sufficient to establish control in some cases, but in other cases, a number of separate indicators may collectively indicate control. A decision based on the totality of all indicators will necessarily be judgmental in nature but clearly similar judgments must be made in similar cases.

institutional units. For each of these subsectors, it is often analytically useful to group its entities according to administrative, legislative, or funding arrangements. For example, governments may create specialized boards, commissions, or agencies either as part of their budgetary accounts or as separate units. It may be possible to create subsectors at each level of government based on whether the units in the subsector are financed by the legislative budgets of that level of government or by extrabudgetary sources-that is, distinguishing between budgetary and extrabudgetary units (irrespective of the treatment of social security funds-see paragraph 2.78). The budgetary component may comprise only the main (or general) budget, and the extrabudgetary component the remaining entities that constitute that level of government, excluding social security funds. Such a grouping of the subsectors allows for a more direct comparison between budget data and GFS. Whether units are clas- sified as budgetary or extrabudgetary depends on country circumstances. What is important, though, is full coverage of the general government sector-that is, the statistics compiled for each level of government should cover all units that constitute that subsector of government (central, state, or local).

2.81 In all countries, there is an institutional unit of the general government sector particularly important in terms of size and power, in particular the power to exercise control over many other units and entities. The budgetary central government is often a single unit of the central government that encompasses the fundamental activities of the national executive, legislative, and judiciary powers. This component of general government is usually covered by the main (or general) budget. The budgetary central government's revenue and expense are normally regulated and controlled by a ministry of finance, or its functional equivalent, by means of a budget approved by 
the legislature. Most of the ministries, departments, agencies, boards, commissions, judicial authorities, legislative bodies, and other entities that make up the budgetary central government are not separate institutional units. This is because they generally do not have the authority to own assets, incur liabilities, or engage in transactions in their own right (see paragraph 2.42). The state or local government subsectors each have a budgetary state/local government component that includes the principal executive, legislative, and judicial powers for these levels of government.

2.82 General government entities with individual budgets not fully covered by the main (or general) budget are considered extrabudgetary. ${ }^{28}$ These entities operate under the authority or control of a central, state, or local government. Extrabudgetary entities may have their own revenue sources, which may be supplemented by grants (transfers) from the general budget or from other sources. Even though their budgets may be subject to approval by the legislature, similar to that of budgetary accounts, they have discretion over the volume and composition of their spending. Such entities may be established to carry out specific government functions, such as road construction, or the nonmarket production of health or education services. Budgetary arrangements vary widely across countries, and various terms are used to describe these entities, but they are often referred to as "extrabudgetary funds" or "decentralized agencies."

2.83 Nonmarket NPIs controlled by government are typically classified as extrabudgetary units when they satisfy the criteria to be an institutional unit. More specifically, they are classified with the level of government that controls them-namely, central, state, or local governments. The most important and likely factors to consider in determining government control of NPIs are discussed in Box 2.1. All NPIs allocated to the general government sector should retain their identity as NPIs in statistical records, to facilitate the analysis of a complete set of NPIs.

2.84 The following sections further define the subsectors of government. These definitions apply whether social security funds are included with the

\footnotetext{
${ }^{28}$ These entities are institutional units if they satisfy the criteria to be a separate institutional unit (see paragraph 2.22). If an entity does not qualify as a unit, it is considered as part of the unit that controls it.
}

level of government that organizes and manages them, or as a separate subsector of general government.

\section{Central government}

2.85 The central government subsector consists of the institutional unit(s) of the central government plus those nonmarket NPIs that are controlled by the central government. The political authority of the central government extends over the entire territory of the country. Central government has, therefore, the authority to impose taxes on all resident institutional units and on nonresident units engaged in economic activities within the country. Its political responsibilities include national defense, the maintenance of law and order, and relations with foreign governments. It also seeks to ensure the efficient working of the social and economic system by means of appropriate legislation and/or regulation. It is responsible for providing collective services for the benefit of the community as a whole, and for this purpose incurs expenditure on defense, public administration, etc. In addition, it may incur expenditure on the provision of services, such as education or health, primarily for the benefit of individual households, and it may make transfers to other institutional units, including other levels of government.

2.86 Compiling statistics for the central government is particularly important because of the special impact it has on monetary policy and economic growth. For example, it is mainly through central government finances that fiscal policy impacts on inflationary or deflationary pressures within the economy. It is generally at the central government level alone that a decision-making body can formulate and carry out public policies directed toward nationwide economic objectives. Other levels of government have neither national economic policies as their objective nor the central government's access to central bank credit.

2.87 In most countries, central government is a large and complex subsector. Nonetheless, as described in paragraph 2.80 , based on administrative arrangements in a country, it is generally composed of a budgetary central government, extrabudgetary units, and social security funds (unless a separate subsector is used for social security funds, as described in paragraph 2.78). 
2.88 While the central government may also control nonfinancial or financial corporations, these corporations are classified outside of the central (and general) government sector(s), but are part of the public sector. However, if institutional units controlled by central government are legally constituted as corporations but are not market producers, they should be classified as part of the central government sector, not the public corporations sector. Similarly, unincorporated enterprises controlled by central government units that do not satisfy the criteria to be quasi-corporations (see paragraph 2.34) should remain integral parts of those units and, therefore, would be included in the central government subsector.

2.89 In some countries, central government may include units that engage in financial transactions that in other countries would be performed by central banks. In particular, units of central government may be responsible for the issue of currency, the maintenance of international reserves, the operation of exchange stabilization funds, and transactions with the International Monetary Fund. When the units in question remain financially integrated with central government and under the direct control and supervision of central government, they cannot be treated as separate institutional units. Accordingly, these monetary authority functions carried out by central government are recorded in the general government sector and not the financial corporations sector. However, because of the analytic importance of obtaining accounts covering the monetary authorities as a whole, and in order to provide links with other macroeconomic statistics such as the 2008 SNA, the BPM6, and the MFSM, it is recommended that the transactions of central government agencies carrying out monetary authority and deposit-taking functions be separately identified, so that they can be combined with those of the central bank and other deposit-taking corporations in special tabulations if desired.

\section{State governments}

2.90 State governments consist of institutional units exercising some of the functions of government at a level below that of central government and above that of the government institutional units existing at a local level. State governments are distinguished by the fact that their fiscal authority extends over the largest geographical areas into which the country as a whole may be divided for political or administrative purposes. They are institutional units whose fiscal, legislative, and executive authority extends only to individual "states" into which the country as a whole may be divided. These states may be described by different names in different countries and the subsector may consist of state, provincial, or regional governments. For ease of expression, this level of government will be referred to hereafter as state governments. In many countries, especially smaller countries, state governments may not exist. However, in geographically large countries, especially those that have federal constitutions, considerable powers and responsibilities may be assigned to state governments.

2.91 A state government may consist of many institutional units and usually has the fiscal authority to levy taxes on institutional units that are resident in, or engage in economic activities or transactions within, its area of jurisdiction (but not other areas). It must also be entitled to spend or allocate some, or possibly all, of the taxes or other revenue that it receives according to its own policies, within the general rules of law of the country, although some of the transfers it receives from central government may be tied to certain specified purposes. It should also be able to appoint its own officers, independently of external administrative control. On the other hand, if a regional unit is entirely dependent on funds from central government, and if the central government also determines the ways in which these funds are to be spent at the regional level, it should be treated as an agency of central government for statistical purposes, rather than as a separate level of government.

2.92 In a few countries, more than one level of government exists between the central government and the smallest governmental institutional units at a local level; in such cases, for purposes of sector classification, these intermediate levels of government are grouped with the level of government-either state or local - with which they are most closely associated.

2.93 If a state government exists, then its principal departments and ministries will generally constitute a single institutional unit in a manner similar to the budgetary unit of the central government. In addition, there may be extrabudgetary agencies operating under the authority of a state government with a separate legal identity and enough autonomy to form 
additional institutional units (see paragraph 2.39). There may also be institutional units whose authority extends over two or more states, but are responsible to the respective state governments. Such units should also be included in the state government subsector.

2.94 State governments may control corporations in the same way as central government. They may also have unincorporated units that engage in market production. Such institutional units should be treated as quasi-corporations in line with the principles in paragraph 2.33. These corporations and quasicorporations should be classified outside of the state government subsector (and general government sector) as part of public corporations.

\section{Local governments}

2.95 Local government units are institutional units whose fiscal, legislative, and executive authority extends over the smallest geographical areas distinguished for administrative and political purposes. The local government subsector consists of local governments that are separate institutional units plus those nonmarket NPIs that are controlled by local governments. The scope of their authority is generally much less than that of central government or state governments, and they may, or may not, be entitled to levy taxes on institutional units resident in their areas. They are often heavily dependent on grants (transfers) from higher levels of government, and they may also act, to some extent, as agents of central or regional governments. They should also be able to appoint their own officers, independently of external administrative control. Even when local governments act as agents of central or state governments to some extent, they can be treated as a separate level of government, provided they are also able to raise and spend some funds on their own initiative and own responsibility.

2.96 Local governments are in closest contact with institutional units occupying their localities. They typically provide a wide range of services to local residents, some of which may be financed out of grants (transfers) from other levels of government. Statistics for the local government subsector may cover a wide variety of governmental units, such as counties, municipalities, cities, towns, townships, boroughs, school districts, and water or sanitation districts. Often, local government units with different functional responsibilities have authority over the same geographic areas. For example, separate government units representing a town, a county, and a school district may have authority over the same area. In addition, two or more contiguous local governments may organize a government unit with regional authority that is accountable to the local governments. Such units should also be included in the local government subsector.

2.97 Some of the most typical functions of local governments provide services for which users' fees are small in relation to the main costs borne by the local government. Local governments are typically involved in:

- Educational establishments

- Hospitals and social welfare establishments, such as kindergartens, nurseries, and welfare homes

- Public sanitation and related entities, such as water purification systems and plants, refuse collection and disposal agencies, cemeteries, and crematoria

- Culture, leisure, and sports facilities, such as theaters, concerts, music halls, museums, art galleries, libraries, parks, and open spaces.

2.98 The same rules governing the treatment of the production of goods and services by central and state government units are applied to local governments. If a market producer can be identified within a local government unit that satisfies the criteria to be a corporations or a quasi-corporation (see paragraph 2.34), it is classified as a public corporation. When market establishments ${ }^{29}$ do not satisfy the criteria to be a quasi-corporation, they are included within local government. Units supplying services on a nonmarket basis, such as education or health, remain an integral part of the local government unit that controls them.

2.99 Government units serving both a state government and one or more local governments should be included with the level of government that predominates in its operations and finances. In some countries, more than one level of government exists between the central government and the smallest governmental institutional units at a local level. In such cases, these intermediate levels of government are grouped together with the level of government, either

\footnotetext{
${ }^{29}$ See paragraph 2.75 for a definition of market establishments.
} 
state or local, with which they are most closely associated. For some analyses, it may be useful to combine the statistics for state and local governments.

\section{Social security funds}

2.100 A social security fund is a particular kind of government unit that is devoted to the operation of one or more social security schemes. ${ }^{30}$ In macroeconomic statistics, a social security fund is recognized if it meets the criteria to be an institutional unit and if it:

- Is organized and managed separately from the other activities of government units

- Holds its assets and liabilities separately from other government units

- Engages in financial transactions on its own account.

2.101 Social security schemes are social insurance schemes covering the community as a whole, or large sections of the community, and are imposed and controlled by government units. Social insurance schemes provide social protection and require formal participation by the beneficiaries, evidenced by the payment of contributions (actual or imputed). Participation in social security schemes is therefore also evidenced by the payment of contributions (actual or imputed) by the beneficiaries. These schemes cover a wide variety of programs, providing benefits in cash or in kind for old age, invalidity or death, survivors, sickness and maternity, work-related injury, unemployment, family allowance, health care, etc. There is not necessarily a direct link between the amount of the contributions payable by an individual and the benefits receivable.

2.102 However, not all social security schemes are organized and managed by social security funds; for example, a social security scheme for sickness may be operated by a national health ministry. If there is an autonomous employment-related pension fund (i.e., a separate institutional unit) to provide government employee pensions, this fund should be excluded from social security funds and be classified as a public financial corporation if under control of government, or otherwise as a private financial corporation (see paragraphs A2.47-A2.53). A nonautonomous employment-related pension scheme

\footnotetext{
${ }^{30}$ Appendix 2 provides a detailed description of the nature of social protection, including social security.
}

for government employees that is administered by a social security fund remains part of social security funds. However, if the conditions for participation and benefits payable, as determined by the employment contract, differ from those of the social security scheme for nongovernment employee participants, an employment-related pension scheme exists. GFS recognizes liabilities for employment-related pension entitlements. Therefore, economic flows and stock positions related to this pension scheme should be distinguished within the social security fund (see paragraphs 6.25 and 7.194).

2.103 Consistent with the 2008 SNA, this Manual allows for social security funds to be accommodated in two alternative sets of subsectors of general government, as described in paragraph 2.78 .

\section{The Public Corporations Sector and Its Subsectors}

\section{The public corporations subsector}

2.104 The public corporations subsector consists of all resident corporations controlled by government units or by other public corporations. It is possible that some entities that are legally constituted as corporations may not be classified as corporations for statistical purposes if they do not charge economically significant prices. Public corporations may be involved in quasi-fiscal operations (i.e., they carry out government operations at the behest of the government units that control them-see paragraph 2.4). As such, public corporations may exist to serve as an instrument of public (or fiscal) policy for government. Most directly, a public corporation can engage in specific transactions to carry out a government operation, such as lending to particular parties at a lower-than-market interest rate or selling their product, such as electric power, to selected customers at reduced rates. More generally, however, a public corporation can carry out fiscal policy by employing more staff than required, purchasing extra inputs, paying above-market prices for inputs, or selling a large share of its output for prices that are less than what the market price would be if only private producers were involved.

2.105 Public corporations may be created to: generate profits for general government; protect key resources; provide competition where barriers to entry may be large; and provide basic services where costs are prohibitive. These public corporations are often 
large and/or numerous, and may have a significant economic impact-for example:

- Public corporations may be of significance to government because of the effects their magnitude or strategic position may have on macroeconomic objectives, such as bank credit, aggregate demand, borrowing abroad, and the balance of payments.

- Many public corporations may represent a sizeable investment of national resources, at considerable opportunity costs.

- Public corporations are a potential source of fiscal risk to the extent that their liabilities could be explicitly or implicitly guaranteed by government, or may hold reputational risks for government.

- Public corporations may over time become nonmarket units reclassified to the general government sector and vice versa; compilation of statistics on the public sector avoids the series breaks in general government data that may result from changes in the way they operate.

2.106 Statistics on public corporations are also likely to be needed to compile comprehensive statistics for the general government sector. GFS for the general government sector should reflect all transactions with public corporations, and changes in the net worth of public corporations are reflected in the value of the equity of those corporations owned by general government units. The accounts of public corporations will help explain the source of changes in these assets, and that information will be useful for an analysis of sustainability and other aspects of fiscal policy.

\section{Government control of corporations}

2.107 A corporation is a public corporation if a government unit, another public corporation, or some combination of government units and public corporations controls the entity. Control of a corporation is defined as the ability to determine general corporate policy of the corporation. The expression "general corporate policy" as used here is understood in a broad sense to mean the key financial and operating policies relating to the corporation's strategic objectives as a market producer.

2.108 Because the arrangements for the control of corporations can vary considerably, it is neither desirable nor feasible to prescribe a definitive list of factors to be taken into account. Although a single indicator could be sufficient to establish control, in other cases, a number of separate indicators may collectively indicate control. A decision based on the totality of all indicators must necessarily be judgmental in nature, but clearly similar judgments must be made in similar cases. Box 2.2 presents the most important and likely factors to consider.

2.109 Because governments exercise sovereign powers through legislation, regulations, orders, and other arrangements, care needs to be applied in determining whether the exercise of such powers amounts to a determination of the general corporate policy of a particular corporation, and therefore control of the corporation. Laws and regulations applicable to all units as a class or to a particular industry should not be viewed as amounting to control of these units.

2.110 The ability to determine general corporate policy does not necessarily include the direct control of the day-to-day activities or operations of a particular corporation. The officers of such corporations would normally be expected to manage these in a manner consistent with and in support of the overall objectives of the particular corporation. Nor does the ability to determine the general corporate policy of a corporation include the direct control over any professional, technical, or scientific judgments, as these would normally be viewed as part of the core competence of the corporation itself. For example, the professional or technical judgments exercised by a corporation set up to certify aircraft airworthiness would not be considered controlled with respect to individual approvals and disapprovals. However, its broader operating and financial policies, including the airworthiness criteria, may well be determined by a government unit as part of the corporation's corporate policy.

2.111 Corporations subject to the control of a nonresident government unit (or a nonresident public corporation) are not classified as public corporations in the host economy, but would be part of the private corporations in that economy. ${ }^{31}$

2.112 Quasi-corporations and market NPIs (i.e., NPIs engaging in market production) under the control of government are classified as public corporations.

\footnotetext{
${ }^{31}$ Also see the discussion of residence in paragraphs 2.6-2.21 of this chapter and definitions of corporations in paragraphs 2.31-2.32.
} 


\section{Box 2.2 Government Control of Corporations}

Control of corporations is defined as the ability to determine the general corporate policy of the corporation. To determine if a corporation is controlled by the government, the following eight indicators of control would be the most important and likely factors to consider:

- Ownership of the majority of the voting interest-Owning a majority of shares will normally constitute control when decisions are made on a one-share, one-vote basis. The shares may be held directly or indirectly, and the shares owned by all other public entities should be aggregated. If decisions are not made on a one-share, one-vote basis, the classification should be based on whether the shares owned by other public entities provide a majority voice.

- Control of the board or other governing body-The ability to appoint or remove a majority of the board or other governing body as a result of existing legislation, regulation, contractual, or other arrangements will likely constitute control. Even the right to veto proposed appointments can be seen as a form of control if it influences the choices that can be made. If another body is responsible for appointing the directors, it is necessary to examine its composition for public influence. If a government appoints the first set of directors but does not control the appointment of replacement directors, the body would then be part of the public sector until the initial appointments had expired.

- Control of the appointment and removal of key personnel-If control of the board or other governing body is weak, the appointment of key executives, such as the chief executive, chairperson, and finance director, may be decisive. Nonexecutive directors may also be relevant if they sit on key committees, such as the remuneration committee determining the pay of senior staff.

- Control of key committees of the entity-Subcommittees of the board or other governing body could determine the key operating and financial policies of the entity. Majority public sector membership on these subcommittees could constitute control. Such membership can be established under the constitution or other enabling instrument of the corporation.

- Golden shares and options-A government may own a "golden share," particularly in a corporation that has been privatized. In some cases, this share gives the government some residual rights to protect the interests of the public by, for example, preventing the company selling off some categories of assets or appointing a special director who has strong powers in certain circumstances. A golden share is not of itself indicative of control. If, however, the powers covered by the golden share do confer on the government the ability to determine the general corporate policy of the entity in particular circumstances and those circumstances currently existed, then the entity should be in the public sector from the date in question. The existence of a share purchase option available to a government unit or a public corporation in certain circumstances may also be similar in concept to the golden share arrangement discussed earlier. It is necessary to consider whether, if the circumstance in which the option may be exercised exists, the volume of shares that may be purchased under the option and the consequences of such exercise mean that the government has "the ability to determine the general corporate policy of the entity" by exercising that option. An entity's status in general should be based on the government's existing ability to determine corporate policy exercised under normal conditions rather than in exceptional economic or other circumstances, such as wars, civil disorders, or natural disasters.

- Regulation and control-The borderline between regulation that applies to all entities within a class or industry group and the control of an individual corporation can be difficult to judge. There are many examples of government involvement through regulation, particularly in areas such as monopolies and privatized utilities. It is possible for regulatory involvement to exist in important areas, such as in price setting, without the entity ceding control of its general corporate policy. Choosing to enter into or continue to operate in a highly regulated environment suggests that the entity is not subject to control. When regulation is so tight as to effectively dictate how the entity performs its business, then it could be a form of control. If an entity retains unilateral discretion as to whether it will take funding from, interact commercially with, or otherwise deal with a public sector entity, the entity has the ultimate ability to determine its own corporate policy and is not controlled by the public sector entity.

- Control by a dominant public sector customer or group of public sector customers-If all of the sales of a corporation are to a single public sector customer or a group of public sector customers, there is clear scope for dominant influence. The presence of a minority private sector customer and/or open competition from private producers to supply goods and services to the public sector usually implies an element of independent decisionmaking by the corporation so that the entity would not be considered controlled. In general, if there is clear evidence that the corporation could not choose to deal with nonpublic sector clients because of the public sector influence, then public control is implied.

- Control attached to borrowing from the government-Lenders often impose controls as conditions of making loans. If the government imposed controls through lending or issuing guarantees that are more than would be typical when a healthy private sector entity borrows from a bank, control may be indicated. Similarly, control may be implied if only the government was prepared to lend to the corporation.

Although a single indicator could be sufficient to establish control, in other cases, a number of separate indicators may collectively indicate control. A decision based on the totality of all indicators must necessarily be judgmental in nature, but clearly similar judgments must be made in similar cases. 


\section{Types of public corporations}

2.113 Public corporations are classified as nonfinancial or financial corporations, depending on the nature of their primary activity.

\section{Public nonfinancial corporations subsector}

2.114 All resident nonfinancial corporations controlled by general government units or other public corporations are part of the public nonfinancial corporations subsector. Nonfinancial corporations are corporations whose principal activity is the production of market goods or nonfinancial services. Typical examples of public nonfinancial corporations are national airlines, national electricity companies, and national railways, if those entities charge economically significant prices. This category could also include public nonprofit institutions engaging in market production (such as hospitals, schools, or colleges) if they are separate institutional units and charge economically significant prices. However, entities that receive financial aid from government but are not controlled by government are not public corporations, but are classified as private corporations or NPISHs.

\section{Public financial corporations subsector}

2.115 All resident financial corporations controlled by general government units or other public corporations are part of the public financial corporations subsector. Financial corporations are corporations that are principally engaged in providing financial services, including insurance and pension fund services, to other institutional units (see paragraphs 2.53-2.57).

2.116 The financial corporations subsector can further be divided into subsectors according to the financial corporations' activity in the market and the liquidity of its liabilities. ${ }^{32}$ However, for GFS purposes, the public financial corporations subsector can broadly be grouped into public deposit-taking corporations (central bank and public deposit-taking corporations except the central bank) and other public financial corporations. Relative to other subsectors of the public sector, public financial corporations may tend to have relatively large values of financial assets and liabilities because of their role in financial intermediation. Ac-

\footnotetext{
${ }^{32}$ See paragraphs $2.53-2.57$, and in the 2008 SNA, paragraphs 4.98-4.116, for a detailed breakdown of these subsectors.
}

cordingly, separate data for public financial corporations may be useful in addition to the data consolidated with other components of the public sector.

\section{Public deposit-taking corporations}

2.117 Public deposit-taking corporations are financial corporations controlled by general government units or other public corporations whose principal activity is financial intermediation and who have liabilities in the form of deposits or financial instruments that are close substitutes for deposits. Two types of public deposit-taking corporations can be distinguished: the central bank and public deposittaking corporations except the central bank.

\section{The central bank}

2.118 The central bank is the national financial institution that exercises control over key aspects of the financial system. In general, the following financial intermediaries are classified in this subsector:

- The national central bank, including where it is part of a system of central banks ${ }^{33}$

- Currency boards or independent currency authorities that issue national currency that is fully backed by foreign exchange reserves

- Central monetary agencies of essentially public origin (e.g., agencies managing foreign exchange or issuing banknotes and coins) that keep a complete set of accounts but are not classified as part of central government.

2.119 As long as the central bank is a separate institutional unit, it is always part of the financial corporations subsector, even if a case can be made that it is primarily a nonmarket producer. While a central bank may have a high degree of operational independence, it is a public corporation. Supervisory authorities that are mainly engaged in supervision of financial units and are separate institutional units from the central bank are included with financial auxiliaries.

\section{Public deposit-taking corporations except the central bank}

2.120 Public deposit-taking corporations except the central bank consist of all resident depository

\footnotetext{
${ }^{33}$ In a currency union, in each member economy the monetary authority functions may be carried out by a national (resident) monetary authority (see paragraph 2.21).
} 
corporations, except the central bank, that are controlled by general government units or other public corporations. Examples are commercial banks, "universal" banks, "all purpose" banks, savings banks, post office giro institutions, ${ }^{34}$ post banks, rural credit banks, agricultural credit banks, export-import banks, and specialized banks if they take deposits or issue close substitutes for deposits.

\section{Other public financial corporations}

2.121 Other public financial corporations comprise all resident financial corporations, except public deposit-taking corporations, controlled by general government units or other public corporations. This subsector includes units that raise funds in financial markets other than by deposits and use them to acquire financial assets. Examples of units in this subsector are money market funds, nonmoney market investment funds, insurance corporations, pension funds, and other financial intermediaries (except insurance corporations and pension funds). In addition, this subsector includes financial auxiliaries (including supervisory authorities that are separate institutional units), and captive financial institutions and money lenders.

\section{Other groupings of public sector units}

2.122 When compiling statistics of public corporations, various groupings-or subsectors of the public sector-may be desirable for analytical purposes. The four groupings of public corporations as illustrated in Figure 2.2 will likely form the foundation from which other groupings can be created. Other possible groupings include:

- The nonfinancial public sector-The general government sector plus public nonfinancial corporations

- The general government sector plus the central bank

- The central government public sector-The central government subsector plus public corporations controlled by the central government. ${ }^{35}$

\footnotetext{
${ }^{34}$ Giro institutions enable money to be transferred quickly and cheaply between accounts or between financial institutions. ${ }^{35} \mathrm{GFS}$ for the central government public sector will be comparable to the consolidated financial statements prepared in accordance with accounting standards for the central government in cases where central government does not control state and local governments.
}

2.123 The term "sovereign" is often used by financial markets and fiscal analysts in the context of fiscal operations, borrowing, and debt. Unlike groupings of the public sector described earlier, which are based on institutional units, "sovereign" is defined on a functional basis and may be used in varying ways. To avoid confusion and, as a service to users, the presentation of "sovereign statistics" should indicate the institutional coverage of the statistics, and how this relates to the standard definitions of general government and/ or public sector statistics.

\section{Decision Tree for Sector Classification of the Public Sector}

2.124 Using the concepts of residence, institutional unit, control, and market versus nonmarket producers, the decision tree presented in Figure 2.4 facilitates the appropriate delineation of the public sector. In order to determine which entities belong to the general government sector and which to the public corporations subsector, the decision tree should be followed, using sequential questions:

- Is the entity a resident or a nonresident? Data for nonresident entities are recorded in data for the rest of the world (see paragraph 2.7).

- Is the entity an institutional unit? If it is resident but not an institutional unit, it is treated as an integral part of the institutional unit that controls it. If it satisfies the criteria to be an institutional unit, move on to the next decision point (see paragraph 2.22).

- Is the institutional unit controlled by government or another public corporation? The answer to this question will place the institutional unit in the public or private sector (see Boxes 2.1 and 2.2).

- Is the institutional unit a market or nonmarket producer? The answer to this question will place the institutional unit in the general government sector or the public corporations subsector (see paragraphs 2.65-2.75).

- If the institutional unit is in the general government sector, could any market establishments that satisfy the criteria to be an institutional unit be identified within the general government unit? Such market establishments should be classified as quasi-corporations in the public corporations subsector (see paragraphs 2.33-2.34). 


\section{Figure 2.4 Decision Tree for Sector Classification of Public Entities}

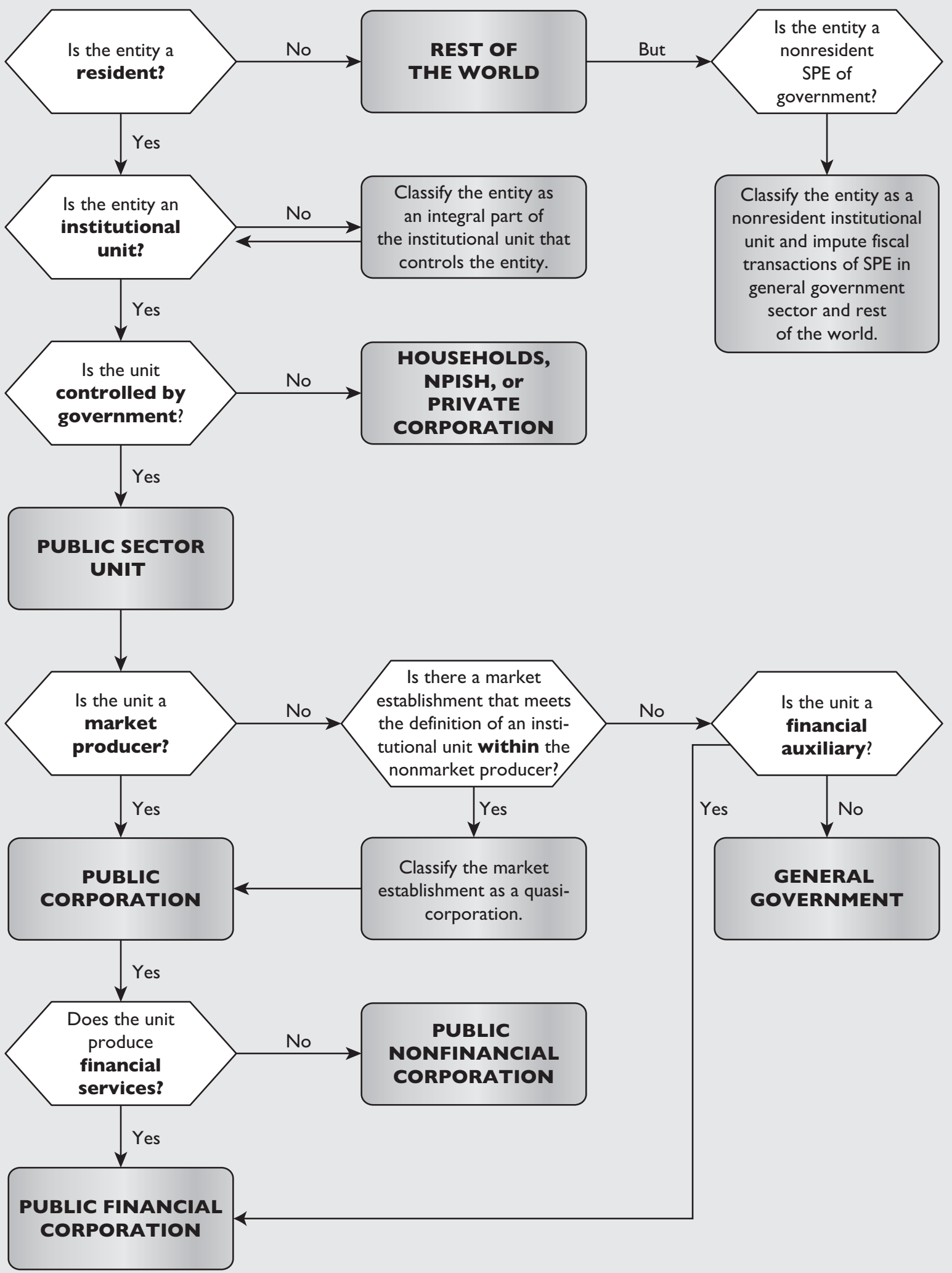


- Is the institutional unit providing financial auxiliary services, such as supervisory authorities of financial intermediaries and financial markets? A positive answer to this question will place the institutional unit in the public financial corporations subsector (see paragraph 2.54).

- Is the public corporation involved in producing financial services? The answer to this question will place the institutional unit in the public financial or public nonfinancial corporations subsector (see paragraphs 2.114-2.121).

\section{Practical Application of Sector Classification Principles Identifying Quasi-corporations}

2.125 Quasi-corporations (as defined in paragraph 2.33) satisfy the criteria to be separate institutional units and function as if they were corporations. They are treated in macroeconomic statistics as if they were corporations-that is, as institutional units separate from the units to which they legally belong. Thus, quasi-corporations owned or controlled by government units are grouped with public corporations in the public nonfinancial or public financial corporations sectors.

2.126 The existence of, or possibility to construct, a complete set of accounts, including balance sheets, for the enterprise is a necessary condition for the entity to be treated as a separate institutional unit. Also, the government must grant management of the enterprise discretion to operate as if it were a separate corporation. In practice this should apply with respect to both the management of the production process and the use of funds, including maintaining their own working balances and business credit, and being able to finance some or all of their capital formation out of their own saving, financial assets, or borrowing. The ability to distinguish flows of income and finance between quasi-corporations and general government units implies that, in practice, their operating and financing activities must be separable from government revenue or financing statistics, despite the fact that they are not separate legal entities.

2.127 Entities such as national railways, port authorities, post offices, government publishing offices, public theaters, museums, swimming pools, hospitals, education centers, and other entities that provide goods and services on a market basis should be treated as public corporations if these units satisfy the criteria to be quasi-corporations. Similar market producers that do not satisfy the requirements to be recognized as quasi-corporations are treated as market establishments integrated with the general government unit that controls them. In cases where government producers of similar goods and services sell their products at nonmarket prices, they remain a part of the nonmarket activities of general government.

\section{Distinguishing Head Offices and Holding Companies}

2.128 Large groups of corporations may be created whereby a parent corporation (or government in the case of public corporations) controls several subsidiaries, some of which may control subsidiaries of their own. Each individual corporation that satisfies the criteria to be an institutional unit should be classified as a separate institutional unit, regardless of whether it forms part of a group. The parent corporation in such circumstances is often referred to as a holding company. There are two different types of holding companies:

- The first type is the head office that is actively engaged in production by exercising some aspects of managerial control over its subsidiaries. This class of corporations includes overseeing and managing other units of the company or enterprise; undertaking the strategic or organizational planning and decision-making role of the company or enterprise; exercising operational control; and managing the day-to-day operations of their related units. Such units are allocated to the nonfinancial corporations subsector unless all or most of their subsidiaries are financial corporations, in which case they are treated by convention as financial auxiliaries in the financial corporations sector.

- The second type is a unit that holds the assets of subsidiary corporations but does not undertake any management activities. This class of corporations includes the activities of holding companies-that is, units that hold the assets (owning controlling-levels of equity) of a group of subsidiary corporations and whose principal activity is to own the group. The holding companies in this case do not provide any other service to the enterprises in which the equity is held- 
that is, they do not administer or manage other units. Such units are allocated to the financial corporations subsector and treated as captive financial institutions even if all the subsidiary corporations are nonfinancial. However, these holding companies should be distinguished from artificial subsidiaries and restructuring agencies (see paragraphs 2.42 and 2.129, respectively).

\section{Restructuring Agencies}

2.129 Restructuring agencies are entities set up to sell corporations and other assets, and for the reorganization of companies. They may also serve for defeasance of impaired assets or repayment of liabilities of insolvent entities, often in the context of a banking crisis. These entities are known by various names, such as restructuring corporations, privatization vehicles, asset management companies, liquidation corporations, bridge banks, or bad banks.

2.130 Some institutional units specialize in the restructuring of corporations, either nonfinancial or financial. These corporations may or may not be controlled by government. Restructuring agencies may be long-standing or created for this special purpose. Governments may fund the restructuring operations in various ways, either directly, through capital injections (capital transfer, loan, or acquisition of equity), or indirectly, through granting guarantees. If the restructuring agency is controlled by government or another public corporation, it is classified in the public sector (see Box 2.2). Whether a restructuring unit is part of the general government sector or is a public corporation is determined by whether it is a market or nonmarket producer. Given that the economically significant price criteria may be insufficient for this purpose, the following general criteria should be considered: ${ }^{36}$

- A unit that serves only government, or primarily government, is more likely to be included as a nonmarket producer within the general government sector than one that serves other units as well.

- A unit that sells or buys financial assets at a value other than market values is more likely to be in the general government sector than not.

- A unit that takes on low risks because it acts with strong public financial support and, by law or ef-

\footnotetext{
${ }^{36}$ This is because restructuring units have, by nature, little output.
}

fectively, on behalf of the government, is likely to be included within the general government sector.

2.131 The following are two frequently observed examples that provide further guidance in the classification of restructuring agencies:

- A restructuring agency may undertake the reorganization of public or private sector entities or the indirect management of privatization. Two cases may be considered:

- The restructuring unit is a genuine holding company controlling and managing a group of subsidiaries, and only a minor part of its activity is dedicated to channeling funds from one subsidiary to another on behalf of the government and for public policy purposes. This unit is more likely to be a market producer and classified as a financial corporation, and the transactions made on behalf of the government rerouted through the general government unit using the service provided. ${ }^{37}$

- The restructuring unit, whatever its legal status, acts as a direct agent of the government and is not a market producer. Its main function is to redistribute national income and wealth, channeling funds from one unit to the other. The restructuring unit should be classified in the general government sector.

- Another example of a restructuring agency is one mainly concerned with impaired assets, mainly in the context of a banking or other financial crisis. Such a restructuring agency must be analyzed according to the degree of risk it assumes, considering the degree of financing provided by the government. Again, two cases may be considered:

- The restructuring agency borrows on the market at its own risk to acquire financial or nonfinancial assets that it actively manages. In this case the unit is more likely to be a market producer and classified as a financial corporation.

- The restructuring agency deliberately purchases assets at above-market prices with direct or indirect financial support from the government. It is primarily engaged in the redistribution of national income (and wealth), does not act independently

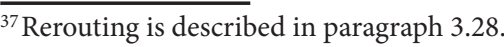


of government or place itself at risk, and therefore is not a market producer and should be classified in the general government sector.

\section{Financial Protection Schemes}

2.132 The financial infrastructure of an economy may include financial protection schemes to protect the assets of financial institutions' clients. These schemes are often referred to as deposit guarantee schemes or deposit insurance schemes. The main types of schemes provide protection of deposits or protect policyholders against failing life and nonlife insurance schemes. These entities are known by various names, but to determine their sector classification, the nature of their activities should be considered on a case-by-case basis.

2.133 A financial protection scheme is classified as part of the general government, a public financial corporation, or a private financial corporation outside the public sector according to the same sectorization principles that apply to any other entity, as described earlier in this chapter (see paragraph 2.124).

2.134 A resident financial protection scheme may or may not satisfy the criteria to be an institutional unit. If it is not an institutional unit, it is treated as an integral part of the institutional unit that controls it.

2.135 If the fees are set by government, or when the government or a public corporation has control over the financial protection scheme through other means, the scheme is to be included in the public sector. The following criteria should be considered in determining whether the scheme is part of the general government sector:

- If fees payable to government for such a protection scheme are compulsory-that is, if beneficiaries cannot opt out of the scheme-the scheme is to be included in general government sector (see paragraph 5.74).

- If fees payable to government are clearly out of proportion to the service provided (fees are not determined based on the associated risks covered), the scheme is to be included in general government sector (see paragraph 5.74).

- If fees payable to government are not set aside in a fund, or can be used for other purposes, the scheme is to be included in general government sector.
- If the fees are proportional to the cost of the service provided, and the scheme is an institutional unit, it is classified as an insurance corporation; operating a fund that functions on insurance rules may indicate proportionality and the existence of a standardized guarantee scheme.

\section{Special Purpose Entities}

2.136 While there is no internationally agreedupon definition of an SPE, some typical features are that it has little physical presence, is related to another corporation or government, and is often resident in a territory other than the territory of residence of its parent unit. ${ }^{38}$

2.137 Governments may set up SPEs for financial convenience. For example, the SPE may be involved in fiscal or quasi-fiscal activities (including securitization of assets, borrowing, etc.). Resident ${ }^{39}$ SPEs that function only in a passive manner relative to general government and that carry out fiscal and quasi-fiscal activities do not satisfy the criteria to be institutional units and are therefore not treated as separate institutional units in macroeconomic statistics; they are treated as part of general government regardless of their legal status. Resident SPEs acting independently, acquiring assets and incurring liabilities on their own behalf, accepting the associated risk, are treated as separate institutional units and are classified to a sector according to their principal activity.

2.138 SPEs that are resident in a different country than their controlling government are always classified as separate institutional units in the economy where they are established. When such entities exist, care must be taken to reflect the fiscal activities of government accurately. All flows and stock positions between the general government unit and the nonresident SPE should be recorded in the accounts for general government and the rest of the world when they occur. ${ }^{40}$

2.139 A government may create a nonresident SPE to undertake government borrowing or incur

\footnotetext{
${ }^{38}$ SPEs are also discussed in the 2008 SNA, paragraphs 4.55-4.58.

${ }^{39}$ For a definition of resident and nonresident units, see paragraphs 2.6-2.15.

${ }^{40}$ Examples of these imputations are described in the PSDS Guide, Box 4.12.
} 
government outlays abroad for fiscal purposes. Even if there are no actual economic flows recorded between the government and the SPE related to these fiscal activities, flows and stock positions should be imputed in the accounts of both the government and the rest of the world to reflect the fiscal activities of the government undertaken by the SPE.

\section{Joint Ventures}

2.140 Many public sector units enter into arrangements with private entities (e.g., a public-private partnership) or other public sector units to undertake a variety of activities jointly. The joint venture could be a market or nonmarket producer. Joint operations can be structured broadly as one of three types: jointly controlled units, referred to here as joint ventures; jointly controlled operations; and jointly controlled assets.

2.141 A joint venture involves the establishment of a corporation, partnership, or other institutional unit in which, legally, each party has joint control over the activities of the joint venture unit. The joint venture unit operates in the same way as other units except that a legal arrangement between the parties establishes joint control over the unit. As an institutional unit, the joint venture may enter into contracts in its own name and raise finance for its own purposes. Such a joint venture maintains its own accounting records.

2.142 The participants to a joint venture may be public sector and/or private sector units. To properly decide the sector classification of the joint venture in macroeconomic statistics, it must be determined which unit has economic control of the joint venture. Given the nature of a joint venture (created legally with joint control), the principal question to be considered here is whether the effective economic control of the joint venture establishes a public or a private unit:

- If a joint venture operates as a nonmarket producer, then government is in effective control and it is classified as part of the general government sector.

- If the joint venture is a market producer, it is treated as a public or private corporation according to whether it is controlled by a government unit. Normally, the percentage of ownership will be sufficient to determine control. If the public and private units own an equal percentage of the joint venture, the other indicators of control must be considered (see Box 2.2).

2.143 Joint operating arrangements can be in the form of jointly controlled operations or jointly controlled assets. When public sector units enter into joint operating arrangements without establishing separate institutional units, there are no units requiring classification; however, the recording should reflect the proper economic ownership of assets. Also, any sharing arrangements of revenue and expense should be recorded in accordance with their economic nature as determined by the provisions of the governing contract. For example, two units may agree to be responsible for different stages of a joint production process or one unit may own an asset or a complex of related assets, but both units agree to share revenue and expense.

\section{Sinking Funds}

2.144 A sinking fund is a separate account, which may, or may not be an institutional unit. A sinking fund is made up of segregated contributions provided by the unit(s) that makes use of the fund (the "parent" unit) for the gradual redemption of the parent unit's debt. A sinking fund may also be established to provide for major repairs or replacements. Aside from eventually extinguishing all government debt in a prudent and orderly manner, sinking funds may be meant to inspire confidence, supporting the market for government securities.

2.145 Public sector sinking funds are classified to sectors according to whether they are separate institutional units ${ }^{41}$ and, if so, whether they provide their services at economically significant prices.

- Sinking funds that are separate institutional units and provide services as market producers are classified as public financial corporations.

- Sinking funds that are separate institutional units and provide services as nonmarket producers are classified as general government units. In particular, such sinking funds will be classified as extrabudgetary units of the unit that controls them (e.g., central government).

- Sinking funds that are not separate institutional units are classified with the unit that controls them (i.e., the "parent" unit).

\footnotetext{
${ }^{41} \mathrm{An}$ institutional unit is defined in paragraph 2.22.
} 
2.146 A variety of practices exist among sinking funds as to both their operation and the degree of control exercised by the "parent" unit (such as government):

- Some sinking funds retire or purchase only the parent unit's securities for which they are established. Such sinking funds are normally not separate institutional units and are classified with the unit that controls them.

- Some sinking funds may have been assigned other responsibilities, such as the conduct of government lending programs or even the collection of earmarked taxes. Such sinking funds are normally not separate institutional units and are classified with the unit that controls them.

- Other sinking funds may purchase and sell securities of other governments or institutions-domestic or external debtors and creditors-usually seeking securities that have similar maturity dates. Such sinking funds may well be institutional units providing services on a market basis and are classified as public financial corporations.

\section{Pension Schemes}

2.147 The means by which pensions are provided to persons in retirement varies from country to country. Various types of pensions are provided by public sector units to individuals via social assistance, social security schemes, and employment-related schemes other than social security. Due to the complexities involved in the classification and sectorization of these arrangements, a detailed discussion is provided in Appendix 2.

\section{Provident Funds}

2.148 Provident funds are compulsory saving schemes that maintain the integrity of the contributions for individual participants. Some governments create provident funds rather than providing social insurance benefits. Under provident fund arrangements, the compulsory contributions of each participant and of their employer on behalf of each participant are kept in a separate account and could be withdrawn under specified circumstances, such as retirement, unemployment, invalidity, and death. These contributions are then managed and invested to obtain a return for each participant.

2.149 The establishment of a provident fund raises the issue of whether this fund is classified as a social security scheme elsewhere in the general government, as a public corporation, or outside the public sector. Provident fund arrangements as defined in the preceding paragraph are different from social security schemes insofar as for each contributor segregated assets exist and it is not foreseen for government to be able to alter the benefits. These provident funds thus are excluded from social security schemes.

2.150 The classification of a provident fund controlled by government in the general government sector or financial corporations subsector is determined by the same sectorization principles that apply to any other entity, as described earlier in this chapter:

- A resident provident fund controlled by government that satisfies the definition of an institutional unit is classified as a public financial corporation. Individual contributions determine individual benefits, and the entity is involved in financial intermediation by pooling the contributions from many households and investing them on their behalf similar to the case of investment funds and defined-contribution pension funds (see paragraphs 2.53-2.54). Therefore, these units are classified in the public financial corporations subsector as market producers.

- A resident provident fund controlled by government that does not satisfy the criteria to be an institutional unit is classified with the government unit that controls it.

2.151 It is possible that a provident fund may be established in such a way that it includes aspects of a social security scheme (social insurance) as well as aspects of a compulsory saving scheme. In such cases, the fund would be classified according to the scheme that predominates while still applying the sectorization principles outlined in this chapter.

\section{Sovereign Wealth Funds}

2.152 Some governments create special purpose government funds, usually called sovereign wealth funds (SWFs). ${ }^{42}$ Created and owned by the general government for macroeconomic purposes, SWFs hold, manage, or administer assets to achieve financial objectives, and employ a set of investment strategies that include investing in foreign financial assets. The funds are commonly established out of balance of

\footnotetext{
${ }^{42}$ While these funds may have various names, this section refers to them as "sovereign wealth funds" for ease of reference.
} 
payments surpluses, official foreign currency operations, the proceeds of privatization, fiscal surpluses, and/or receipts resulting from commodity exports.

2.153 The establishment of an SWF raises the issue of whether this fund is classified as part of the general government, as a public corporation, or outside the public sector. The classification of a sovereign wealth fund controlled by government in the general government sector or financial corporations subsectors is determined by the same sectorization principles that apply to any other entity, as described earlier in this chapter (see paragraph 2.124).

2.154 A resident SWF controlled by government may, or may not satisfy the definition of an institutional unit:

- If the SWF is not an institutional unit, it is classified with the unit that controls it.

- If the resident SWF is an institutional unit, it is classified as:

- A public financial corporation if it is providing financial services on a market basis

- A general government unit (an extrabudgetary fund or social security fund ${ }^{43}$ ) if it satisfies the definition of a government unit (see paragraph 2.38) and is simply a passive holder of assets and liabilities (see paragraph 2.42).

2.155 If the SWF is an entity incorporated abroad or quasi-corporation located abroad, it is classified as a separate institutional unit in the financial corporations subsector of the economy in which the entity is legally constituted, or in the absence of legal incorporation, is legally domiciled. In such circumstances, all general government transactions and stock positions with the SWF should be reflected in the general government account with the rest of the world as the counterparty.

\section{Market Regulatory Agencies}

2.156 Market regulatory agencies act on behalf of a government (or a regional organization with governments as its members), and influence the market for specific goods or services directly and/or indirectly. These agencies may influence the market directly by acting as buyers and sellers of the goods or services and may influence the market indirectly through

\footnotetext{
${ }^{43}$ SWFs that hold and manage wealth designated to provide social benefits will be included in social security funds.
}

regulations, rulings, compliance laws, or standards, to impact the production, price, and marketing of specific products. The regulations may cover the terms and conditions of supplying the goods and services and in particular the price allowed to be charged and/ or to whom the goods and services are distributed. It is most common for a regulatory agency to control agricultural products, monopolistic markets, or, in some cases, natural resources.

2.157 The nature of these market regulatory agencies may differ. The nature of each agency should be investigated to decide the sector classification according to sectorization principles. At one end of the spectrum, some agencies are merely distributing subsidies, while others may have an administrative, advisory, standard or price setting, or collective advertising function. At the other end of the spectrum, the agency may have total control over all aspects of the production and distribution process, including being the only legal buyer/seller of the products.

2.158 Following the residence principle, those market regulatory agencies that meet the definition of an international or regional organization are not included in the statistics of the individual member countries, but their activities should be reflected in regional data (see Appendix 5). By convention, financial regulatory (supervisory) bodies are considered as financial corporations, specifically as financial auxiliaries when they are separate institutional units. For those resident market regulatory agencies involved with nonfinancial goods and services, the following guidance applies:

- Those agencies that do not satisfy the criteria to be an institutional unit remain an integral part of the general government unit that controls them. This would usually be the case for those agencies exclusively or principally involved in the distribution of subsidies on behalf of government.

- Those agencies that satisfy the criteria to be institutional units, and that are mainly nonmarket producers, such as performing some administrative functions, setting standards, or overseeing and regulating the production process, should be classified in the general government sector. Although the agency may have active participation of members from the market it serves, government 
control is established by the enabling instruments and nonmarket nature of these entities.

- Those agencies that satisfy the criteria to be an institutional unit and that are mainly a market producer should be classified in the nonfinancial corporations subsector. These market regulatory agencies' sole or principal activity is to buy, hold, and sell the goods or services at economically significant prices.

2.159 Where market regulatory agencies are involved in a mixture of activities, such as distributing subsidies and buying, holding, and selling goods and services, the sector classification may require careful consideration. If it is possible to separately identify a quasi-corporation that is undertaking market activities, it should be classified in the nonfinancial corporations subsector. The nonmarket activities should be classified in the general government sector. If it is not possible to distinguish two institutional units, the majority of the activities of the entity should determine the sector classification.

\section{Development Funds and/or Infrastructure Companies or Entities}

2.160 Some governments create special entities/funds to finance and develop the economy in general, develop specific sectors of the economy, or upgrade specific facilities, such as infrastructure. These types of agencies/ funds may be involved in various aspects of development, ranging from only providing the finances for development activities to being involved in all aspects of the actual development and construction of the infrastructure or facilities. Various terms, such as "development banks," "investment funds," "fiscal stabilization funds," or "infrastructure companies", are used to describe these agencies. Whatever they are called, the sector classification should be based not on their description but rather on the economic nature of the entities.

2.161 Using the usual criteria (see paragraph 2.22), compilers should determine whether the entity is a separate institutional unit in the public sector, or whether it is not an institutional unit and should be classified as an integral part of the unit that controls it.
2.162 These entities may be established in the legal form of a corporation, but it is necessary to decide whether to classify them as institutional units. The financing arrangements of these entities usually involve the issuance of debt instruments, but could also include some other sources of financing. The customers that they serve, the financing arrangements, and the economic ownership of the assets created by these entities could often be indicative of the risks assumed by these entities, and could help to determine their status as an institutional unit. The following guidance applies:

- If the entity cannot act independently from its parent and is a passive holder of assets and liabilities, it is an artificial subsidiary. If it is a resident unit, it is classified as a component of the level of government that controls it (i.e., as part of the parent unit). These entities are not treated as separate institutional units, unless they are resident in an economy different from that of their parent unit (see paragraphs 2.6-2.15).

- If the entity borrows on the market and then lends only to general government units, it is not involved in financial intermediation and should be regarded as a resident artificial subsidiary (see paragraphs 2.42-2.44).

- If government assumes economic ownership of the nonfinancial assets created, it is an indication that the development fund is just a device to borrow and acquire the assets, and the entity should be treated as a resident artificial subsidiary.

- If these entities meet the definition of an institutional unit (see paragraph 2.22) and are government-controlled market producers of goods or services, they should be classified as a corporation. More specifically, they will be a public financial corporation only if they are involved in providing financial services (see paragraph 2.53). ${ }^{44}$ They will be public nonfinancial corporations only if they produce and sell the infrastructure assets at economically significant prices in market transactions.

\footnotetext{
${ }^{44}$ Providing concessionary loans does not necessarily mean that an institutional unit is not a market producer (e.g., some development banks are providing concessionary loans but are still considered financial intermediaries).
} 


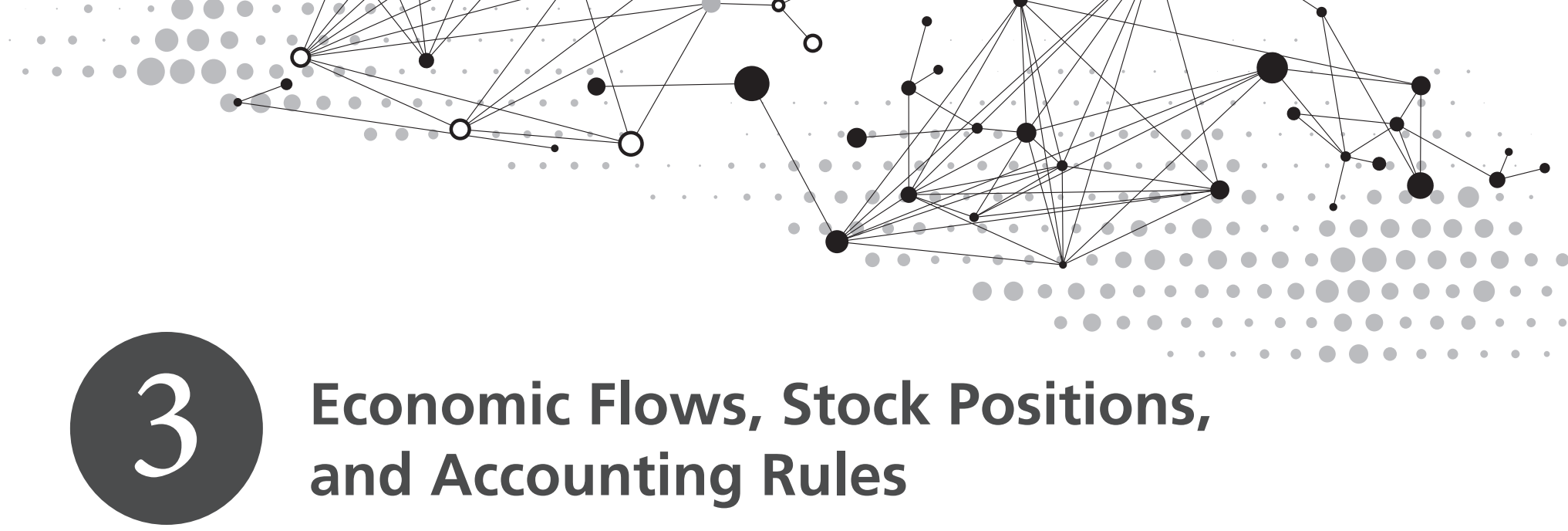

This chapter describes the economic flows and stock positions of the government finance statistics framework and the accounting rules used to determine all aspects of their recording.

\section{Introduction}

3.1 Entries recorded in GFS are either economic flows or stock positions. ${ }^{1}$ Flows are monetary expressions of economic actions and effects of events that result in changes in economic value within a reporting period. Stock positions measure economic value at a point in time. More specifically, stock positions refer to a unit's holdings of assets and liabilities at a specific time and the unit's resulting net worth, equal to total assets minus total liabilities.

3.2 The flows and stock positions recorded in the GFS framework are integrated, which means that all changes in stock positions can be fully explained by the flows. In other words, the following relationship is valid for each stock position:

$$
\mathrm{S}_{0}+\mathrm{F}=\mathrm{S}_{1}
$$

where $S_{0}$ and $S_{1}$ represent the values of a specific stock position at the beginning and end of a reporting period, respectively, and $\mathrm{F}$ represents the net value of all flows during the period that affected that particular stock. More generally, the value of any stock position held by a unit at a given time is the cumulative value of all flows affecting that stock position that have occurred since the unit first acquired the particular type of asset or liability.

3.3 The GFS framework includes a great diversity of economic flows. This chapter first describes several important characteristics of economic flows that

\footnotetext{
${ }^{1}$ In macroeconomic statistics, the term "flows" will often be used as a short form for "economic flows," and "stocks" will often be used as a short form for "stock positions."
}

underlie their classification and treatment. It then describes in a general way the accounting rules used for recording these flows and stock positions in GFS. Descriptions of specific categories of flows and stock positions and the application of the general rules to their recording are discussed in Chapters 5 through 10.

\section{Economic Flows}

3.4 Economic flows reflect the creation, transformation, exchange, transfer, or extinction of economic value; they involve changes in the volume, composition, or value of a unit's assets, liabilities, and net worth. A flow can be a single event, such as the purchase of goods, or the cumulative value of a set of events occurring during a reporting period, such as the continuous accrual of interest expense on a government bond. All flows are classified as transactions or as other economic flows. The following sections describe these two types of economic flows.

\section{Transactions}

3.5 A transaction is an economic flow that is an interaction between institutional units by mutual agreement or through the operation of the law, or an action within an institutional unit that is analytically useful to treat like a transaction, often because the unit is operating in two different capacities. ${ }^{2}$ This definition of a transaction stipulates that an interaction between institutional units occurs by mutual agreement. $\mathrm{Mu}-$ tual agreement means that there was prior knowledge and consent by the units, but it does not mean that both units entered into the transaction voluntarily. Some transactions, such as the payment of taxes, are imposed by force of law. Although individual units are not free to determine the amount of taxes they pay,

\footnotetext{
${ }^{2}$ For example, consumption of fixed capital (23) and the use of inventories in the production of goods and services (22) (see paragraphs 6.27 and 6.53, respectively).
} 
there is collective recognition and acceptance by the community of the obligation to pay taxes. Thus, payments of taxes are considered transactions despite being compulsory. Similarly, the actions necessary to comply with judicial or administrative decisions may not be undertaken voluntarily, but they are taken with prior knowledge and consent of the parties involved.

3.6 The treatment of some activities in GFS takes a different perspective from the treatment of the same activities in the 2008 SNA. GFS is focused on the impact of economic events on the finances of government. In contrast, the 2008 SNA is focused on measuring production, consumption, distribution of income, and investment. Appendix 7 contains a complete description of the implications of these different perspectives. Despite different treatments of some activities, both frameworks include all flows that change stock positions so that all changes in the balance sheet can be explained by the flows.

3.7 Transactions may take on many different forms. In GFS, all transactions are classified according to their economic nature, while transactions in expenditure are also classified according to their functions (see Chapters 5, 6, 8, and the annex to Chapter 6). To give more precision to the classification of transactions, the characteristics of transactions have to be systematically described.

\section{Monetary transactions}

3.8 A monetary transaction is one in which one institutional unit makes a payment (receives a payment) or incurs a liability (acquires an asset) to (from) another institutional unit stated in units of currency. In GFS, all flows are recorded in monetary terms, but the distinguishing characteristic of a monetary transaction is that the parties to the transaction express their agreement in monetary terms. For example, goods or services are usually purchased or sold at a given number of units of currency per unit of the good or service, social security benefits are often payable in fixed amounts of currency, and taxes receivable are measured and payable in units of currency. All monetary transactions are interactions between two institutional units, recorded as either an exchange or a transfer.

3.9 An exchange is a transaction in which one unit provides a good, service, asset, or labor to a second unit and receives a good, service, asset, or labor of the same value in return. ${ }^{3}$ Compensation of employees, purchases of goods and services, the incurrence of interest expense, and the sale of an office building are all exchanges.

3.10 A transfer is a transaction in which one institutional unit provides a good, service, or asset to another unit without receiving from the latter any good, service, or asset in return as a direct counterpart. This kind of transaction is also referred to as being unrequited, a "something for nothing" transaction, or a transaction without a quid pro quo. Transfers can also arise where the value provided in return for an item is not economically significant or is much below its value. Typically, general government units engage in a large number of transfers, which may be compulsory or voluntary. Taxes and most social security contributions are compulsory transfers imposed by government units on other units. Subsidies, grants, and social assistance benefits are transfers from general government units to other units. Public corporations are, to a lesser extent, involved in transfers-they may receive subsidies or capital transfers from government and may also be involved in transfers payable resulting from their quasi-fiscal activities.

3.11 Some transactions appear to be exchanges but are actually combinations of an exchange and a transfer. In such cases, the actual transaction should be partitioned and recorded as two transactions, one that is only an exchange and one that is only a transfer. For example, a general government unit might sell an asset at a price that is clearly less than the market value of the asset, or may buy an asset at a price that is clearly above the market value of the asset. The transaction should be divided into an exchange at the asset's market value and a transfer equal in value to the difference between the actual transaction value and the market value (see paragraph 3.107) of the asset. ${ }^{4}$

3.12 Exchange transactions do not include entitlements to collective services or benefits-these are

\footnotetext{
${ }^{3}$ The term "provides a good, service, asset ..." is meant to include one unit allowing a second unit to use an asset owned by the first unit or a change in the ownership of an asset. Interest and other property income transactions are exchanges because they are receivable by a unit in return for putting assets at the disposal of another unit.

${ }^{4}$ See paragraph 3.29 for a general statement on partitioning of transactions.
} 
considered transfers. The amount of collective service or benefit that may eventually be receivable by an individual unit is not proportional to the amount payable. Taxes and nonlife insurance premiums are examples of such transactions classified as transfers due to the collective nature of the benefits (see paragraphs 5.23 and 5.149, respectively).

3.13 Taxes are treated as transfers even though the units making these payments may receive some benefits from services provided by the government unit receiving the taxes. For example, in principle, no one can be excluded from sharing in the benefits provided by collective services such as public safety. In addition, a taxpayer may even be able to consume certain individual services provided by government units. However, it is usually not possible to identify a direct link between the tax payments and the benefits received by individual units. Moreover, the value of the services received by a unit usually bears no relation to the amount of the taxes payable by the same unit.

3.14 Nonlife insurance premiums and claims are also treated as transfers in GFS. ${ }^{5}$ This type of premium entitles the units making the payment to benefits only if one of the events specified in the insurance contract occurs. That is, one unit pays a second unit for accepting the risk that a specified event may occur to the first unit. These transactions are considered transfers ${ }^{6}$ because in the nature of the insurance business, they distribute income between policyholders to those who claim, as opposed to all policyholders who contribute. There is uncertainty whether the contributing unit will receive any benefits and, if it does receive benefits, they may bear no relation to the amount of the premiums previously paid. Nonlife insurance includes social security schemes and employer social insurance schemes for government employees that do not provide retirement benefits. Thus, social security contributions receivable and social security benefits payable by government units, which are not for employmentrelated pensions, are treated as transfers in GFS.

3.15 Transfers may be either current or capital. To distinguish current transfers from capital transfers, it

\footnotetext{
${ }^{5}$ The prepayment of a premium is the acquisition of a financial asset by the insured (see paragraph A4.76), which reduces as insurance coverage is provided.

${ }^{6}$ In the 2008 SNA, nonlife insurance premiums are partitioned into a sale of a service and a transfer. In GFS, the entire premium is considered a transfer (see paragraph 5.149).
}

is preferable to focus on the special characteristics of capital transfers.

3.16 Capital transfers are transfers in which the ownership of an asset (other than cash or inventories) changes from one party to another, or that oblige one or both parties to acquire or dispose of an asset (other than cash or inventories), or where a liability is forgiven by the creditor. Cash transfers involving disposals of noncash assets (other than inventories) or acquisition of noncash assets (other than inventories) are also capital transfers. A capital transfer results in a commensurate change in the stock position of assets of one or both parties to the transaction. Capital transfers are typically large and infrequent, but capital transfers cannot be defined in terms of size or frequency. A transfer in kind without a charge is a capital transfer when it consists of: the transfer of ownership of a nonfinancial asset (other than inventories); and the forgiveness of a liability by a creditor when no corresponding value is received in return. Major nonrecurrent payments in compensation for accumulated losses or extensive damages or serious injuries not covered by insurance policies are also capital transfers. A transfer of cash is a capital transfer when it is linked to, or conditional on, the acquisition or disposal of an asset by one or both parties to the transaction.

3.17 Current transfers consist of all transfers that are not capital transfers. Current transfers directly affect the level of disposable income and influence the consumption of goods or services. That is, current transfers reduce the income and consumption possibilities of the donor and increase the income and consumption possibilities of the recipient. For example, social benefits, subsidies, and food aid are current transfers.

3.18 It is possible that some cash transfers may be regarded as capital by one party to the transaction and as current by the other party. So that a donor and a recipient do not treat the same transaction differently, a transfer should be classified as capital for both parties even if it involves the acquisition or disposal of an asset, or assets, by only one of the parties. When there is doubt about whether a transfer should be treated as current or capital, it should be treated as a current transfer.

\section{Nonmonetary transactions}

3.19 Nonmonetary transactions are transactions that are not initially stated in units of currency. These 
include all transactions that do not involve any cash flows, such as barter, in-kind transactions, and certain internal transactions. They must be assigned a monetary value as GFS record flows and stock positions expressed in monetary terms. The entries therefore represent values that are indirectly measured or otherwise estimated. The values assigned to nonmonetary transactions have a different economic implication than do monetary payments of the same amount, as they are not freely disposable sums of money. Nevertheless, to have a comprehensive and integrated set of accounts, it is necessary to assign the best estimate of market values to the items involved in nonmonetary transactions.

3.20 Nonmonetary transactions can be either twoparty transactions or actions within an institutional unit that are used to construct an internal transaction.

\section{Two-party nonmonetary transactions}

3.21 These nonmonetary transactions can be exchanges or transfers. Barter, remuneration in kind, and other payments in kind are nonmonetary exchanges. Transfers in kind are nonmonetary transfers.

3.22 In a barter transaction, two units exchange goods, services, or assets other than cash of equal value. For example, a government unit may agree to trade a parcel of land in an industrial area to a private corporation for a different parcel of land that the government will use as a national park. Between nations, governments may trade strategic natural resources for another kind of product or service.

3.23 Remuneration in kind occurs when an employee is compensated with goods, services, or assets other than money. Types of compensation that employers commonly provide without charge or at reduced prices to their employees include meals and drinks, uniforms, housing services, transportation services, and child care services (see paragraph 6.17-6.18).

\subsection{Payments in kind other than remuneration}

in kind occur when any of a wide variety of payments is made in the form of goods and services rather than money. A payment to settle a liability can be made in the form of goods, services, or noncash assets rather than money. For example, a government unit may agree to settle a claim for past-due taxes if the taxpayer transfers ownership of land or fixed assets to the government, or inheritance taxes may be payable by making donations of paintings or other valuables to government.

3.25 Transfers in kind may be used to increase efficiency, or to insure that the intended goods and services are consumed. For example, aid after a natural disaster may be delivered faster and be more effective if it is provided in the form of medicine, food, and shelter instead of money. Also, a general government unit might provide medical and educational services in kind to ensure that the need for those services is met.

\section{Internal transactions}

3.26 Internal or intra-unit transactions take place when a single unit acts in two different capacities, and it is analytically useful to record this act as a transaction. The choice of which internal actions to treat as transactions is subjective to the purpose of recording these actions. GFS follows the 2008 SNA by treating consumption of fixed capital as an internal transaction to allow the calculation of the operating costs of government. Similarly, the transfer of materials and supplies from inventories to use of goods and services and other internal changes in inventories are treated as internal transactions (see paragraph $8.46-8.47)^{7}$

\section{Rearrangements of some transactions}

3.27 Some transactions are not recorded in the form in which they appear to take place. Instead, they are modified in macroeconomic statistics to bring out their underlying economic relationships more clearly. There are three kinds of rearrangements employed in GFS: rerouting, partitioning, and reassignment.

\section{Rerouting}

3.28 Rerouting records a transaction as taking place through channels that differ from the actual ones, or as taking place in an economic sense when no actual transactions take place. Rerouting is often required when a unit that is a party to a transaction does not appear in the actual accounting records because of

\footnotetext{
${ }^{7}$ Internal transactions are described in the 2008 SNA, paragraphs 3.85-3.90. GFS does not record all the internal transactions that relate to production processes.
} 
administrative arrangements. Two kinds of rerouting occur:

- In the first kind of rerouting, a direct transaction between unit $\mathrm{A}$ and unit $\mathrm{C}$ is recorded as taking place indirectly through a third unit B. For example, if government employees are enrolled in a social security or retirement scheme, accounting records may show the government unit making contributions directly to the social security fund or retirement scheme on behalf of its employees. However, these contributions are part of the compensation of employees and should be recorded as being paid to the employee. In such a case, it is necessary to reroute the payments so that the government is seen as paying the employees, who then are deemed to make payments of the same amount to the social security or retirement scheme (see paragraph 6.19). As a result of the rerouting, these contributions are included as part of the labor cost of government. Rerouting may also be necessary when recording the distribution of profits of fiscal monopolies (see paragraph 5.68).

- In the second kind of rerouting, a transaction of one kind from unit $\mathrm{A}$ to unit $\mathrm{B}$ is recorded with a matching transaction of a different kind from unit $\mathrm{B}$ to unit A. For example, when a nonresident special purpose entity (SPE) of government borrows abroad for fiscal purposes, transactions should be imputed in the accounts of both the government and the nonresident SPE as if the SPE has extended a loan to government and government has invested the corresponding amount in the SPE (see paragraphs 2.136-2.139). This rearrangement of the transactions reflects government's involvement in the nonresident SPE, which would otherwise not be captured in government accounts.

\section{Partitioning}

3.29 Partitioning records a transaction that is a single transaction from the perspective of the parties involved as two or more differently classified transactions. For example, when a general government unit acquires an asset below or above its current market price, the division of the actual transaction into an exchange and a transfer is an example of partitioning (see paragraph 3.11).

\section{Reassignment}

3.30 Reassignment records a transaction arranged by a third party on behalf of others as taking place directly by the two principal parties involved. Reassignment is required when one unit arranges for a transaction to be carried out between two other units, generally in return for a fee from one or both parties to the transaction. In this case, one unit acts as an agent for another unit. In such a case, the transaction is recorded exclusively in the accounts of the two parties engaging in the transaction and not in the accounts of the third party facilitating the transaction. The accounts of the agent show only the fee charged for the facilitation services rendered. For example, reassignment may occur when one government unit collects taxes and then transfers some or all of the taxes to another government unit. In some arrangements of this nature, the collecting unit retains a small portion of the tax collected in return for its collection efforts. The amount retained is treated as the sale of a service by the collecting unit, while the total amount of taxes collected is shown as revenue for the beneficiary government unit. For guidelines on the reassignment or attribution of taxes to collecting or beneficiary governments, see paragraphs 5.33-5.38.

\section{Other Economic Flows}

3.31 Other economic flows are changes in the volume or value of assets or liabilities that do not result from transactions. These other economic flows are not transactions because they do not meet one or more of the characteristics of transactions. For example, the institutional units involved may not be acting by mutual agreement, as in the case of an uncompensated seizure of assets, or changes due to natural events, such as an earthquake or a flood. Alternatively, the value of an asset expressed in foreign currency may change as a result of exchange rate changes, or the value of an asset may change due to the passing of time.

3.32 There are two major categories of other economic flows, described as holding gains and losses, and other changes in the volume of assets and liabilities. ${ }^{8}$

\section{Holding gains and losses}

3.33 A holding gain or loss $^{9}$ is a change in the monetary value of an asset or liability resulting from changes in the level and structure of prices, excluding qualitative or quantitative changes in the asset or liability. Holding gains and losses on assets and

\footnotetext{
${ }^{8}$ References to changes in the valuation or volume of assets also apply to liabilities.

${ }^{9}$ Holding gains and losses are also referred to as revaluations in the 2008 SNA and in generally accepted accounting standards.
} 
liabilities include changes resulting from exchange rate movements. In concept, holding gains and losses are continuously recorded as market prices change.

3.34 A holding gain or loss accrues continuously, purely as a result of holding an asset or liability over time without transforming it in any way. Holding gains/losses can apply to virtually any type of asset or liability, and they may accrue on an asset held for any length of time during the reporting period. (See paragraphs $10.05-10.45$ for a complete discussion.)

\section{Other changes in the volume of assets/ liabilities}

3.35 Other changes in the volume of assets are any changes in the value of an asset or liability that do not result from a transaction or a holding gain/loss. Other changes in the volume of assets cover a wide variety of specific events. These events are divided into three main categories: ${ }^{10}$

- The first category consists of events that involve the appearance or disappearance of economic assets other than by transactions. In other words, certain assets and liabilities enter and leave the GFS balance sheet through events other than by transactions. (See paragraphs $10.48-10.58$ for a complete discussion.)

- The second group consists of the effects of external events-exceptional and unexpected-on the economic benefits derivable from assets and corresponding liabilities. (See paragraphs 10.5910.75 for a complete discussion.)

- The final group is made up of changes in classifications. (See paragraphs 10.76-10.84 for a complete discussion.)

\section{Stock Positions}

3.36 A stock position is the total holdings of assets and/or liabilities at a point in time. Stock positions are recorded in the balance sheet of the GFS framework (see Chapter 7). The integrated GFS framework shows stock positions at the beginning and end of a reporting period. Stock positions at these two points in time are connected by flows during that period because changes in positions are caused by transactions and other economic flows. In order to discuss

${ }^{10}$ The distinctions made are only for purposes of description; the GFS framework and classification system does not allow for this breakdown. stock positions, it is necessary to determine the asset boundary in macroeconomic statistics from which the definition of assets and liabilities is derived. The coverage of assets in GFS is limited to economic assets from which economic benefits may flow to the owners.

\section{Economic Benefits}

3.37 Economic benefits arise from owning and using economic assets. The economic benefits of ownership usually include the right to use, rent out, or otherwise generate income, or to sell the asset. Different kinds of economic benefits that may be derived from an asset include:

- The ability to use assets, such as buildings or machinery, in production

- The generation of services (e.g., renting out produced assets to another entity)

- The generation of property income (e.g., interest and dividends received by the owners of financial assets)

- The potential to sell and thus realize holding gains.

\section{Ownership}

3.38 Two types of ownership can be distinguished in macroeconomic statistics: legal ownership and economic ownership. The legal owner of resources such as goods and services, natural resources, financial assets, and liabilities is the institutional unit entitled by law and sustainable under the law to claim the benefits associated with the resource. Sometimes government may claim legal ownership of a resource on behalf of the community at large. To be recognized in the GFS framework, a resource must have a legal owner, on either an individual or a collective basis.

3.39 The economic owner of resources such as goods and services, natural resources, financial assets, and liabilities is the institutional unit entitled to claim the benefits associated with the use of these resources by virtue of accepting the associated risks. In most cases, the economic owner and the legal owner of a resource are the same. Where they are not, the legal owner has passed responsibility for the risk involved in using the resource in an economic activity to the economic owner as well as associated benefits. In return, the legal owner accepts another package of risks and benefits from the economic owner. In GFS, when the expression "ownership" or "owner" is used and the 
legal and economic owners are different, the reference should generally be understood to be to the economic owner. Appendix 4 discusses a number of cases where legal and economic ownership are different.

3.40 Sometimes government may claim legal ownership of a resource on behalf of the community at large, such as territorial waters. If so, the benefits also accrue to the government on behalf of the community at large. Thus, government is both the legal and economic owner of these resources. However, governments may share the benefits with other entities but, by virtue of accepting the majority of the risks, become the economic owner of a resource. For example, in the case of public-private partnerships, economic ownership can be vested with government when government accepts the majority of the risks (see paragraphs A4.58-A4.65).

3.41 The benefits inherent in financial assets and liabilities are seldom transferred from a legal owner to an economic owner in exactly the same state. They are usually transformed to new forms of financial assets and liabilities by the intermediation of a financial institution that assumes some of the risk and benefits while passing the financial instrument on to other units.

\section{Definition of Assets and Liabilities}

3.42 An asset is a store of value representing a benefit or series of benefits accruing to the economic owner by holding or using the resource over a period of time. It is a means of carrying forward value from one reporting period to another.

3.43 Only economic assets are recorded in the macroeconomic statistical systems (i.e., included within the asset boundary) and they appear in the balance sheet of the unit that is the economic owner of the asset. Economic assets are resources over which ownership rights are enforced and from which economic benefits may flow to the owners. Personal attributes such as reputation or skill, which are sometimes described as an asset, are not recognized as such in GFS because they are not economic assets as defined earlier. A distinction is made between nonfinancial and financial assets. All financial assets have liabilities as counterparts, except for gold bullion held as a reserve asset, which, by convention, is a financial asset (7.128).

\section{Financial assets and liabilities}

3.44 A particularly important mechanism in the economy is the device whereby one economic unit exchanges a particular set of benefits with another economic unit for future payments. From this a financial claim, and hence a liability, can be defined. There are no nonfinancial liabilities recognized in the GFS framework, and thus the term liability necessarily refers to a liability that is financial in nature. ${ }^{11}$

3.45 A liability is established when one unit (the debtor) is obliged, under specific circumstances, to provide funds or other resources to another unit (the creditor). Normally, a liability is established through a legally binding contract that specifies the terms and conditions of the payment(s) to be made and payment according to the contract is unconditional. These are typically established through the provision of economic value by one institutional unit, the creditor, to another, the debtor, normally under a contractual arrangement. Liabilities can also be created by the force of law, and by events that require future transfer payments. In many cases, liabilities (and their corresponding financial claims) are explicitly identified by formal documents expressing the debtor-creditor relationship. In other cases, liabilities are imputed to reflect the underlying economic reality of a transaction, such as the creation of a notional loan when an asset is acquired under a financial lease.

3.46 Liabilities created by the force of law include those arising from taxes, penalties (including penalties arising from commercial contracts), and judicial awards at the time they are imposed. Liabilities established by events that require future transfer payments include claims on nonlife insurance companies, claims for damages not involving nonlife insurance companies, and claims arising from winnings from lottery and gambling activities.

3.47 Whenever a liability exists, the creditor has a corresponding financial claim on the debtor. A financial claim is an asset that typically entitles the owner of the asset (the creditor) to receive funds or other resources from another unit, under the terms of a liability. Like liabilities, financial claims are unconditional. A financial claim provides benefits to the creditor, such as by acting as a store of value, or by generating

\footnotetext{
${ }^{11}$ In contrast, accounting standards recognize nonfinancial liabilities under certain conditions.
} 
interest, other property income, or holding gains. Financial claims consist of equity and investment fund shares, debt instruments, financial derivatives and employee stock options, and monetary gold in the form of unallocated gold accounts (see paragraphs $7.15,7.127$, and 7.139).

3.48 Financial assets consist of financial claims and gold bullion held by monetary authorities as a reserve asset. For a complete discussion of financial assets and liabilities, see paragraphs 7.118-7.227.

3.49 This Manual follows the 2008 SNA by not treating guarantees other than derivatives and the provision for calls under standardized guarantee schemes as financial assets or liabilities. However, it is recommended to report these guarantees as memorandum items to the balance sheet. (See paragraphs 4.48 and 7.251-7.261.)

\section{Nonfinancial assets}

3.50 Nonfinancial assets are economic assets other than financial assets. Nonfinancial assets are further subdivided into those that are produced (fixed assets, inventories, and valuables) and those that are nonproduced (land, mineral and energy resources, other naturally occurring assets, and intangible nonproduced assets). For a complete description of the nature of nonfinancial assets, see paragraphs 7.34-7.117.

\section{Accounting Rules}

3.51 All entries in GFS have to be measured in monetary terms. In some cases, the amounts entered are the actual payments that form part of flows, and in other cases the amounts entered are estimated by reference to monetary values. Money is thus the unit of account in which all stocks and flows are recorded.

3.52 In principle, a reporting period can cover any period of time. Periods that are too short have the disadvantage that statistical data are influenced by incidental factors, while long periods may not adequately portray changes in the economy in a timely manner. Merely seasonal effects can be avoided by having the reporting period cover a whole cycle of regularly recurrent economic phenomena. In general, calendar years, financial years, and quarters are well suited for drawing up a complete set of GFS for the consolidated general government or public sectors, while monthly data with the broadest institutional coverage possible provide a good high-frequency indicator of fiscal per- formance. Country-specific circumstances will influence the coverage, frequency, and periodicity of fiscal reporting. However, in deciding these, data reporting guidelines and standards, such as the General Data Dissemination System (GDDS), Special Data Dissemination Standard (SDDS), SDDS Plus, and Code on Good Practices on Fiscal Transparency, should also be considered. ${ }^{12}$

3.53 The GFS framework is well suited to cover all economic activities in such a way that it is possible to compile GFS statements for individual units, groups of units, or all units in the general government or public sectors. To permit this, the accounting rules for recording flows and stock positions in the GFS framework are designed to ensure consistency in the data generated, and to conform to accepted standards for compiling other macroeconomic statistics. With the exception of consolidation, as noted later in this chapter, the accounting rules of the GFS framework are the same as those of the 2008 SNA (see Appendix 7). There are also many similarities between the rules used in the GFS framework and those applied by businesses and governments in their financial statements. ${ }^{13}$ The following sections describe the type of accounting system used, the accounting rules governing topics such as the time of recording, and the valuation of flows and stock positions.

\section{Type of Accounting System}

3.54 The recording of economic events underlying GFS derives from general bookkeeping principles. Double-entry recording is used for recording all flows. In a double-entry system, each transaction gives rise to at least two equal-value entries, traditionally referred to as a credit entry and a debit entry. This principle ensures that the total of all credit entries and that of all debit entries for all transactions are equal, thus permitting a check on consistency of the GFS accounts for a unit, subsector, or sector. Other economic flows also lead to debit and credit entries. These flows have their corresponding entries directly in changes in net worth. As a result, double-entry recording ensures the fundamental identity of a balance sheet-that

\footnotetext{
${ }^{12} \mathrm{http}: / /$ dsbb.imf.org.

${ }^{13}$ Appendix 6 presents a broad description of linkages with financial accounting standards. It is recommended that the financial statements of government entities compiled in accordance with international accounting standards for governments be harmonized to the extent possible, and where differences remain, be reconciled with the equivalent GFS statements.
} 
is, the total value of assets equals the total value of liabilities plus net worth.

3.55 A debit entry is an increase in an asset, a decrease in a liability, or a decrease in net worth. A credit entry is a decrease in an asset, an increase in a liability, or an increase in net worth. Revenue entries result in an increase in assets or decrease in liabilities, which ultimately increase net worth; therefore, revenue entries are recorded as credits. Conversely, expense entries result in a decrease in assets or increase in liabilities, which ultimately decrease net worth; therefore, expense entries are recorded as debits. Other economic flows can increase or decrease assets and liabilities, thereby directly impacting net worth. In the case of the reclassification of assets or liabilities, a change occurs in the stock positions of two categories of assets or liabilities with no impact on net worth (e.g., an increase in one category of asset is paired with a decrease in another category of asset).

3.56 A balance sheet is a statement of the values of the stock positions of assets owned and of the liabilities owed by an institutional unit or group of units, drawn up in respect of a particular point in time. The fundamental identity of the balance sheet and of accounting in general is that the total value of the assets always equals the total value of the liabilities plus net worth. Use of the double-entry recording ensures that this identity is maintained. There are several possible combinations of debits and credits affecting assets, liabilities, and net worth. For example, the purchase of a service by a general government unit with payment to be made in 30 days would be recorded on an accrual basis as an expense (debit) and an increase in the liability, other accounts payable (credit). Thus, net worth, through the expense, decreases by the same amount that liabilities increase, and assets are not affected. The subsequent payment at the end of the 30 days would be recorded on an accrual basis as a decrease in currency and deposits (credit) and a decrease in other accounts payable (debit). In this case, both assets and liabilities decrease by the same amount and net worth is unaffected.

\section{Time of Recording Flows}

3.57 Once a flow has been identified, the time at which it occurred must be determined so that the results of all flows within a given reporting period can be reported. Although this section is concerned with the time assigned to flows, the integrated nature of the GFS framework means that the stock positions recorded on the balance sheet are also influenced by the timing of flows.

3.58 One of the problems in determining the timing of transactions is the frequent existence of a long period between the initiation of an action and its final completion. For instance, many purchases of goods commence with the signing of a contract between a seller and a buyer, followed by the initiation and completion of production of the item ordered, shipment from the seller's location, arrival at the buyer's location, preparation and mailing the invoice, receipt of the invoice, approval of payment, the beginning of interest accruing on a late payment or the expiration of a discount for prompt payment, signing a check for payment, mailing of the check by the buyer, receipt of the check by the seller, deposit of the check in the seller's bank, and finally the check is paid by the buyer's bank. Even then, the transaction may not be complete as there may be rights of return or warranty claims. Each of these distinct moments is to some extent economically relevant and may result in multiple transactions being recorded in GFS, but only one time can be attributed to each transaction.

3.59 Similarly, in analyzing government expense and acquisition of nonfinancial assets, one can distinguish the day that a budget is voted upon by the legislature, the day on which the ministry of finance authorized a department to pay out specified funds, the day a particular commitment is entered into by the departments, the day deliveries take place, and finally, the day payment orders are issued and checks are paid. With regard to taxes, for example, important moments are the day or the period in which the liability arises, the moment the tax liability is definitively assessed, the day that it becomes due for payment without penalty, and the day the tax is paid or refunds are made.

3.60 In summary, when using the accrual basis of recording, transactions are recorded when economic ownership changes hands for goods, nonproduced nonfinancial assets and financial assets and liabilities, when services are provided, and for distributive transactions when the related claims arise. On the other hand, when using the cash basis of recording, flows are recorded when cash is received and disbursed. 
These alternative recording bases are discussed in more detail in paragraphs 3.61-3.68.

\section{Alternative recording bases}

3.61 While making entries for all successive stages discernible within the activities of institutional units may be possible, it could severely overburden compilers, so a choice has to be made. Broadly, the time of recording could be determined on four bases: the accrual basis, the commitments basis, the due-for-payment basis, and the cash basis. In practice though, many variations on these bases of recording may exist. Accounting systems may use a mixed basis of recording; for example, tax revenue may be recorded on a cash basis while other transactions are recorded on an accrual basis.

3.62 In the accrual basis of recording, flows are recorded at the time economic value is created, transformed, exchanged, transferred, or extinguished. In other words, the effects of economic events are recorded in the period in which they occur, irrespective of whether cash was received or paid, or was due to be received or paid. Nevertheless, the time at which the economic events occur is not always clear. In general, the time attributed to events is the time at which economic ownership of goods changes, services are provided, the obligation to pay taxes is created, the claim to a social benefit payment is established, or other unconditional claims are established.

3.63 If an economic event requires a subsequent cash flow, such as purchases of goods and services on an installment plan, then the length of time between the time attributed to an event with the accrual basis and the time of the cash flow is bridged by recording other accounts receivable/payable. For example, when a general government unit purchases goods on credit, it records a debit to an inventory account and a credit to other accounts payable when ownership of the goods shifts. When the cash payment is made, the general government unit records a debit to other accounts payable and a credit to currency and deposits.

3.64 All events that result in the creation, transformation, exchange, transfer, or extinguishment of economic value are recorded on an accrual basis in the GFS Statement of Operations or Statement of Other Economic Flows (see paragraphs 4.16-4.31 and 4.36-4.38). Thus, all monetary and nonmonetary transactions are included in statistics compiled on the accrual basis.
3.65 In the commitments basis of recording, flows are recorded when an institutional unit has committed itself to a transaction. This basis often applies only to purchases of assets, goods, services, and to compensation of employees. The time of recording generally is when approval for the purchase was issued, which results in funds being earmarked for a specific transaction. Flows for which the commitments basis is not applicable, such as revenue, must be recorded using one of the other three bases of recording. In kind transactions may or may not be recorded.

3.66 In the due-for-payment basis of recording, flows that give rise to cash payments are recorded at the latest times they can be paid without incurring additional charges or penalties or, if sooner, when the cash payment is made. ${ }^{14}$ The period of time (if any) between the moment a payment becomes due and the moment it is actually made is bridged by recording other accounts receivable/payable, just as with the accrual basis. If a payment is made before it is due, then no receivable is necessary. Although due-for-payment recording furnishes a more comprehensive description of monetary flows than cash accounting, recording is limited to monetary flows and therefore does not capture all economic events.

3.67 In the cash basis of recording, flows are recorded when cash is received or disbursed. The cash basis of recording provides analytically useful information on the liquidity position of government, which allows for liquidity management. All events resulting in a cash flow are recorded in the GFS Statement of Sources and Uses of Cash (see paragraphs 4.32-4.35). Nonmonetary flows are not recorded, since no cash flows are involved in these transactions. Therefore, the cash basis of recording does not fully record all economic activity and resource flows.

3.68 Cash flows determine the government's ability to pay its bills and, by influencing the liquidity of the community, activate or validate the demand for goods and services in the rest of the economy. Traditionally, payments data form the basis for most government accounting systems and often represent the most readily available estimates generated by the

\footnotetext{
${ }^{14}$ Another basis of recording is when flows are recorded at the time legal controls that are necessary to authorize a payment have been completed. This basis of recording is entitled "due-and-payable."
} 
administrative accounting system. For instance, data on payments for the delivery of goods and services may frequently be more readily available than data on the time of delivery. But while statistics based on cash flows are of analytical value in their own right they do not fully meet the government's reporting needs. Therefore, the statistics on the accrual basis should be seen as necessary for the proper recording of all governments' operations.

\section{Using the accrual basis of recording in the Statements of Operations and Other Economic Flows, and Balance Sheet of the GFS framework}

3.69 Using the accrual basis of reporting provides the most comprehensive information because all economic events and resource flows are recorded, including internal transactions, in-kind transactions, and other economic flows. Moreover, it is only this comprehensive recording framework that permits the full integration of all flows with stock positions in the balance sheet. In general, accounts using the commitment, due-for-payment, or cash basis are restricted to monetary transactions.

3.70 The integrated framework of GFS uses the accrual basis, primarily because the time of recording matches the time of the actual resource flows and economic events. As a result, the accrual basis provides the best estimate of the macroeconomic impact of government fiscal policy. With the cash basis, the time of recording may diverge significantly from the time of the economic activities and the transactions to which they relate. For example, the interest accrued on a zero-coupon bond would not be recorded until the bond matures, which could be many years after the expense was incurred. The due-for-payment basis will frequently record transactions after the resource flows have taken place, although the very long delays permitted by the cash basis would, in most cases, be reduced. The timing of the commitments basis will precede the actual resource flow.

3.71 The accrual basis of recording also fully captures all amounts receivable or payable in arrears. Arrears are defined as amounts that are both unpaid and past the due date for payment. Because the duefor-payment date is always the same or later than the date attributed to a flow under the accrual basis, all arrears will be included in statistics compiled using the accrual basis. Without supplementary information, however, it may be difficult to estimate the share of total accounts payable that is in arrears as opposed to the share that exists because of normal payment delays. By definition, the due-for-payment basis will clearly show the arrears arising from purchases on installment plans, but arrears from the failure to repay debt obligations as scheduled, such as loans and debt securities, will not always be apparent without supplemental information. With the commitments basis, the availability of information on arrears will be the same as with the accrual basis. With the cash basis, there is no impact on the accounts when a unit does not pay for purchases made or comply with the terms for the repayment of debt. Thus, there will be no information on arrears unless special compilation effort is made.

3.72 In accrual accounting systems, provision is usually made for a separate statement of cash flows to be prepared as part of the comprehensive suite of statements-implementing accruals accounting systems therefore usually maintains some information on cash flows. Managing liquidity is crucial for the operation of any unit, and information on cash flows helps meet this need. Moreover, it may be difficult to assess solvency and future cash flows without an accrual-based system because information on arrears and on other accounts payable/receivable, such as trade credits and advances, is missing.

3.73 Accounts using the due-for-payment, commitments, or cash basis normally do not differentiate between the time of payment, acquisition, and use of resources. With the accrual basis, acquisitions of nonfinancial assets are recorded separately and the expense of using those assets in operating activities is matched with the period of their use through the consumption of fixed capital.

3.74 Additionally, the other major macroeconomic statistical frameworks (national accounts, balance of payments, and monetary and financial statistics) use the accrual basis. Thus, the consistency of statistics from the different systems is facilitated greatly by sharing the use of the accrual basis for all the macroeconomic frameworks.

3.75 Despite the advantages of the accrual basis of recording, its implementation is likely to be more complex than the other bases of recording and may require additional estimates. For example, it may 
be difficult for a government unit to know the full amount of tax revenue to which it is entitled because these amounts may depend on transactions and other events to which the government is not a party.

\section{Application of the accrual principles}

3.76 As a general rule, a flow is recorded under the accrual basis of recording when economic ownership changes or another economic event has occurred. More specific guidelines for the application of the accrual recording basis are described in the following paragraphs.

\section{Time of recording and measurement of taxes and other compulsory transfers}

3.77 The general principle is that taxes and other compulsory transfers should be recorded when the underlying activities, transactions, or other events occur that give rise to the liability to pay (i.e., the moment when it creates the government's unconditional claim to the taxes or other payments) (see paragraphs 5.10 5.20). This time is not necessarily the time at which the event being taxed occurred. For example, the obligation to pay tax on capital gains normally occurs when an asset is sold, not when the asset's value appreciated.

3.78 Estimating the revenue from taxes and compulsory social insurance contributions must take many uncertainties into account. The primary uncertainty is that the government unit receiving the revenue is usually not a party to the transaction or other event that creates the obligation to pay the taxes or social insurance contributions. Consequently, many of these transactions and events permanently escape the attention of the tax authorities. The amount of revenue from taxes and social insurance contributions should exclude the amounts that possibly could have been received from such unreported events, had the government learned about them. In other words, only those taxes and social insurance contributions that are evidenced by tax assessments and declarations, customs declarations, and similar documents are considered to create revenue for government units.

3.79 In addition, it is typical that some of the taxes and social insurance contributions that have been assessed will never be collected. Uncollectable taxes include amounts deemed uncollectable due to noncompliance with tax laws or insolvency of taxpayers. Taxes should also exclude contested tax assessments, which are treated as contingencies. It would be inappropriate to accrue revenue for an amount that the government unit does not realistically expect to collect. Thus, the difference between assessments and expected collections represents a claim that has no real value and should not be recorded as revenue (see paragraph 5.20). The amount of taxes and social insurance contributions that is recorded as revenue should be the amount that is realistically expected to be collected. The actual collection, however, may be in a later period, possibly much later.

3.80 To ensure that the amount of taxes and social contributions recorded on an accrual basis is equivalent to the corresponding amounts actually received over a reasonable amount of time, the following possibilities for the accrual recording of taxes could be considered:

- Amounts to be recorded are assessed amounts adjusted by coefficients reflecting the assessments not likely to be collected. The coefficients are estimated on the basis of past experience and current expectations in respect of assessed amounts never collected.

- Cash amounts are recorded in the accounts, but they are time-adjusted so that they are attributed to the period when the activity took place to generate the liability.

3.81 If taxes are imposed on specific transactions or events, they are recorded at the time the underlying transaction or event occurs, even though these times may not coincide with the actual payment of the tax to the government. This implies that taxes on products and imports are recorded at the time the products in question are produced, imported, or sold, depending on the basis of the taxation. Examples include sales taxes, value-added taxes, import duties, and estate and gift taxes.

3.82 In principle, income taxes and social contributions based on income should be attributed to the period in which the income is earned, even though there may be a significant delay between the end of the reporting period and the time at which it is feasible to determine the actual liability. In practice, however, some flexibility is permitted. In particular, as a practical deviation from the general principle, income taxes deducted at source, such as pay-as-youearn taxes and regular prepayments of income taxes, 
may be recorded in the periods in which they are paid, and any final tax liability on income may be recorded in the period in which it is determined.

3.83 Income taxes are normally imposed on the income earned during an entire year. If monthly or quarterly statistics are compiled in the absence of monthly accrual administrative records, indicators of seasonal activity or other appropriate indicators may be utilized to allocate the annual totals.

3.84 Taxes on the ownership of specific types of property may be based on the value of the property at a particular time, but are deemed to accrue continuously over the entire year or the portion of the year that the property was owned, if less than the entire year. Similarly, taxes on the use of goods or the permission to use goods or perform activities usually relate to a specific time period, such as a license to operate a business during a specific period.

3.85 Some compulsory transfers, such as fines, penalties, and property forfeitures, are determined at a specific time. These transfers are recorded when the government has an unconditional legal claim to the funds or property, which usually is when a court renders judgment or an administrative ruling is published. If such judgment or ruling is subject to further appeal, then the time of recording is when the appeal is resolved.

3.86 Determining the time of recording for grants and other voluntary transfers is influenced by a wide variety of eligibility conditions that have varying legal powers. In some cases, a potential grant recipient has a legal claim when it has satisfied certain conditions, such as the prior incurrence of expenses for a specific purpose or the passage of legislation. These transfers are recorded by recipient and donor when all conditions are satisfied. In other cases, the grant recipient never has a claim on the donor, and the transfer should be attributed to the time at which the cash payment is made, or when the goods or services are delivered (see paragraph 5.105).

\section{Time of recording dividends}

3.87 Dividends and withdrawals of income from quasi-corporations are distributive transactions for which the time of recording depends on the unit's decision regarding when to distribute income (see paragraphs 5.111-5.119). The level of dividends is not unambiguously attributable to earnings of a particular period, and dividends are to be recorded as of the moment the associated share starts to be quoted "ex-dividend." Withdrawals of income from quasicorporations are recorded on the date the payment actually occurs.

\section{Time of recording transactions in goods, services, and nonfinancial assets}

3.88 The time of recording transactions (including by barter, payment in kind, or transfer in kind) ${ }^{15}$ in goods and nonfinancial assets is, in principle, when economic ownership changes, which depends on the provisions in the sales contract (see paragraphs 8.138.17). When change of ownership is not obvious, the time of recording by the transaction partners ${ }^{16}$ may be a good indication and, failing that, the moment when there is a change in physical possession or control. For example, a change of ownership is imputed to have taken place under a financial lease when the lessee takes control of the asset.

3.89 Transactions in services normally should be recorded when the services are provided. If a service, such as transportation, is provided at a specific time, then the transaction is recorded at that time. Some services are supplied or take place on a continuous basis. For example, insurance, and rental of housing services are continuous flows and should be recorded continuously for as long as they are being provided. More practically, the value of the services attributed to a reporting period is based on the quantity supplied during the period rather than the payments required.

3.90 Several other transactions also relate to flows that take place continuously or over extended periods. For example, operating leases and consumption of fixed capital accrue continuously over the whole period a fixed asset is used and interest ${ }^{17}$ accrues continuously over the period that the financial claim exists. These flows are recorded as being provided

\footnotetext{
${ }^{15}$ These transactions are excluded from a pure cash basis of recording.

${ }^{16}$ To maintain symmetry in the macroeconomic statistical system, the time of recording should be the same for both parties to the transaction.

${ }^{17}$ The counterpart entry to accruing interest expense is a simultaneous increase in the amount of liability outstanding. Periodic payments reduce the liability that has accrued and are not expense transactions.
} 
continuously over the whole period the contract lasts or the asset is available for use.

3.91 Inventories may be materials and supplies held as input for producing goods and services, workin-progress, or finished goods held for resale or distribution. Additions to inventories are recorded when products are purchased, produced, or otherwise acquired. Withdrawals from inventories are recorded when products are sold, used up in production, or otherwise relinquished. Additions to work-in-progress inventories are recorded continuously as work proceeds. When production is completed, the goods valued at costs accumulated to that point are transferred to inventories of finished goods.

3.92 Use of goods and services is recorded when the good or service enters the process of production, as distinct from the time it was acquired. For goods, this time may be quite different from the time they were acquired. In the meantime, they are classified as inventories.

\section{Time of recording transactions in financial assets and liabilities}

3.93 Transactions in many types of financial assets and liabilities, such as debt securities, loans, currency, and deposits, are recorded when economic ownership changes (see paragraphs 9.13-9.16). This date may be specified according to a contract to ensure matching entries in the books of both parties. If no precise date is fixed, the date on which the creditor receives payment, or some other financial claim, is the determining factor. For example, loan drawings are entered in the accounts when actual disbursements are made and financial claims are established, which is not necessarily when an agreement is signed. On practical grounds, public sector liabilities may have to take account of the time of recording from the viewpoint of the public sector unit.

3.94 In some cases, the parties to a transaction may perceive ownership to change on different dates because they acquire the documents evidencing the transaction at different times. This variation usually is caused by the process of clearing, or the time checks are in the mail. The amounts involved in such a "float" may be substantial in the case of transferable deposits and other accounts receivable or payable. If there is disagreement on a transaction between two units, the date on which the transaction is fully completed, which is the day the creditor regards change of ownership to have taken place, is the date of record; this date could be when the creditor receives payment or some other financial claim.

3.95 Some financial claims or liabilities, in particular the various types of other accounts payable and receivable, such as trade credit and advances, general accounts payable, and wages payable, are the result of a nonfinancial transaction and are not otherwise evidenced. In these cases, the financial claim is created when the counterpart transaction (such as the purchase of a good on credit or provision of labor) occurs.

3.96 For securities, the transaction date (i.e., the time of the change in ownership of the securities) may precede the settlement date (i.e., the time of the delivery of the securities). Both parties should record the transactions at the time ownership changes, not when the underlying financial asset is delivered. Any significant difference between transaction and settlement dates gives rise to other accounts payable or receivable. In practice, when the delay between the transaction and settlement is short, the time of settlement may be considered an acceptable proxy.

3.97 According to the accrual basis of recording, repayments of debts are recorded when they are extinguished (such as when they are paid, or rescheduled, or forgiven by the creditor). When arrears occur, no transactions should be imputed, but the arrears should continue to be included in the same instrument until the liability is extinguished. If the contract provided for a change in the characteristics of a financial instrument when it goes into arrears, this change should be recorded as a reclassification in the other changes in volume of the financial assets and liabilities account. The reclassification applies to situations where the original contract remains, but the terms within it change (e.g., interest rates, repayment periods, etc.). ${ }^{18}$ If a new contract is negotiated or the nature of the instrument changes from one instrument category to another (e.g., from bonds to equity), transactions should be recorded to reflect the redemption of the old instrument and to create a new instrument.

\footnotetext{
${ }^{18}$ Charging a penalty interest rate on arrears that was stipulated in the original contract is not in itself a reason to reclassify the debt.
} 


\section{Time of recording other economic flows}

3.98 Other changes in the volume of assets are usually discrete events that occur or accrue at particular moments or within fairly short periods of time (see paragraphs 10.46-10.47). For example, the destruction of an asset by fire happens at a specific time, and the impact of a natural disaster can be allocated to a specific period.

3.99 Changes in prices often have a more continuous character, particularly in respect of assets for which active markets exist. In practice, holding gains or losses will be computed between two points in time. The starting point will be the moment at which:

- The reporting period begins

- Ownership is acquired from other units (through purchase or a transaction in kind)

- An asset is produced.

The end point in time will be the moment at which:

- The reporting period ends

- Ownership of an asset is relinquished (through a sale or a transaction in kind)

- An asset is consumed in the production process.

3.100 Holding gains and losses are not calculated over a period beginning the moment two units agree to a mutual exchange of assets. Instead, the calculation of the holding gains and losses starts when economic ownership of the assets is acquired. The signing of the contract fixes the market price for the transaction. A unit can incur holding gains and losses only on the assets or liabilities over which it has economic ownership. This implies that during the period between the signing of a contract and the date on which the first party delivers, the second party cannot incur any price risks on this contract; the second party neither owns the assets to be delivered nor owns a claim on the first party to be recorded in the financial accounts. ${ }^{19}$

3.101 Other changes in volume, including reclassifications, are recorded as these changes occur. An integrated stock-flow framework requires that both

\footnotetext{
${ }^{19}$ For example, a sales contract to the value of 100 is agreed on day 1 , when the market price of the transaction is 100 , for delivery on day 5 . On day 5 , the price of the item prevailing on the market is 102 -the buyer records a transaction of 100 and immediately revalues the item.
}

the removal of an existing asset or liability from the original category and its inclusion in the new category are recorded at the same time.

3.102 Reclassifications should be recorded when the change in the nature of the asset, liability, or entity occurs. Although one might be tempted to stockpile major reclassifications for a number of years and enter them as one block at the end of this period, this procedure does not conform to the accrual principles of GFS, which aim for correct estimates at all times. Keeping records of reclassifications makes it possible to reconstruct supplementary time series based on the situation before the reclassification, if needed.

\section{Using the cash basis of recording in the Statement of Sources and Uses of Cash}

3.103 GFS includes a Statement of Sources and Uses of Cash. For this statement, statistics on monetary flows should be based on transactions as close to the payment/receipt stage as possible. These statistics, based on cash payments/receipts, measure in aggregate the government's impact on the liquidity conditions in the economy (see paragraph 3.67). Although these cash-based data lack an integration of flows with stock positions, they are complementary to the accrual data and form an integral part of the complete GFS framework.

3.104 For expense and the acquisition of nonfinancial assets, data at the stage of payment by cash disbursed, or checks or warrants issued, represent the most desirable basis on which to record the cashbased data. ${ }^{20}$ For revenue, data representing the tax payments received by government, net of refunds paid out during the period covered should be reported. These data will include taxes paid after the original assessment, taxes paid or refunds deducted from taxes after subsequent assessments, and taxes paid or refunds deducted after any subsequent reopening of the accounts. In the reporting of tax revenue, the use of payment basis data is often the first best estimate for a cash statement.

3.105 In the case of government borrowing, the cash basis of recording will report borrowing when funds are received by government, or when lenders

\footnotetext{
${ }^{20}$ Cash accounting that allows back-dated transactions (known as complementary periods), may distort actual cash flows. Recording of cash transactions in such a manner should be disclosed.
} 
pay government suppliers on behalf of government. Government lending should be recorded when the government makes payment, or when funds are provided to a borrower.

3.106 However, payments data must be adjusted to an accrual basis to permit the measurement of production, income, consumption, capital accumulation, and finance in the national accounts. To reconcile data extracted from cash-based data and data maintained on an accrual basis, the cash flows must be adjusted for accrued revenue not yet received and accrued expense not yet paid, respectively.

\section{Valuation}

\section{General rule}

3.107 All flows and stock positions should be measured at market prices. Market prices refer to current exchange value-that is, the value at which goods, services, labor, or assets are exchanged or else could be exchanged for cash (currency or transferable deposits). Flows recorded in the Statement of Operations should be valued at the market prices at which these flows take place, while flows recorded in the Statement of Sources and Uses of Cash should be valued at the monetary value of the cash flows. Stock positions should be valued at the market prices prevailing on the balance sheet date. Valuation of specific types of flows and stock positions are discussed in further detail in the remainder of this section.

\section{Valuation of transactions}

3.108 Market prices for transactions are defined as amounts of money that willing buyers pay to acquire something from willing sellers; the exchanges are made between independent parties and on the basis of commercial considerations only, sometimes called "at arm's length." Thus, according to this strict definition, a market price refers only to the price for one specific exchange under the stated conditions. A second exchange of an identical unit, even under circumstances that are almost exactly the same, could result in a different market price. A market price defined in this way is to be clearly distinguished from a price quoted in the market, a world market price, a going price, a fair market price, or any price that is intended to express the generality of prices for a class of supposedly identical exchanges rather than the price actually applying to a specific exchange. Furthermore, a market price should not necessarily be construed as equivalent to a free market price; that is, a market transaction should not be interpreted as occurring exclusively in a purely competitive market situation. In fact, a market transaction could take place in a monopolistic, monopsonistic, or any other market structure. Indeed, the market may be so narrow that it consists of a sole transaction of its kind between independent parties.

3.109 When a price is agreed to by both parties in advance of a transaction taking place, this agreed or contractual price is the market price for that transaction regardless of the prices that prevail when the transaction takes place.

3.110 Actual exchange values, expressed in monetary terms, are presumed to be the market prices in most cases. Paragraph 3.122 describes those cases where actual exchange values do not represent market prices. Transactions that involve dumping and discounting represent market prices. Transaction prices for goods and services are inclusive of appropriate taxes and subsidies. A market price is the price payable by the buyer after taking into account any rebates, refunds, adjustments, etc., from the seller.

3.111 Transactions in financial assets and liabilities are recorded at the prices at which they are acquired or disposed of. Transactions in financial assets and liabilities should be recorded exclusive of any service charges, commissions, fees, taxes, and similar payments for services that would be necessary to require the asset or incur the liability. These costs of ownership transfers are excluded regardless of whether these are charged explicitly, included in the purchaser's price, or deducted from the seller's proceeds. This is because both debtors and creditors should record the same amount for the same financial instrument. The commissions, fees, and/or taxes should be recorded separately from the transaction in the financial asset and liability, under appropriate categories of revenue or expense. The valuation of financial instruments, which excludes commission charges, differs from the valuation of nonfinancial assets (excluding land), which includes any costs of ownership transfer. Costs of ownership transfer on land are included in the value of land improvements (see paragraphs 8.6-8.8).

3.112 When market prices for transactions are not observable, such as for some barter or transfersin-kind transactions, valuation according to market 
price-equivalents provides an approximation to market prices. In such cases, market prices of the same or similar items, when such prices exist, will provide a good basis for applying the principle of market prices. Generally, market prices should be taken from the markets where the same or similar items are currently traded in sufficient numbers and in similar circumstances. If there is no appropriate market in which a particular good or service is currently traded, the valuation of a transaction involving that good or service may be derived from the market prices of similar goods and services by making adjustments for quality and other differences.

\section{Valuation of stock positions}

3.113 Stock positions should be valued at market value - that is, as if they were acquired in market transactions on the balance sheet reporting date (reference date). Market prices are readily available for assets and liabilities that are traded in active markets, most commonly certain financial assets and their corresponding liabilities. Market values of other assets and liabilities need to be estimated in a manner similar to nonmonetary flows, as described in paragraphs $3.118-3.125$ and 7.20-7.33.

3.114 Valuation according to market-value equivalent is needed for valuing assets and liabilities that are not traded in markets or are traded only infrequently. For these assets and liabilities, it will be necessary to estimate values that, in effect, approximate market prices (see paragraph 3.125). ${ }^{21}$

3.115 It may also be analytically useful and appropriate, in some circumstances, to use alternative valuation methods and to compare these with market values. Market values, fair values, and nominal values should be distinguished from such notions as amortized values, face values, book values, and historic cost.

- Fair value is a market-equivalent value defined as the amount for which an asset could be ex-

\footnotetext{
${ }^{21}$ International statistical manuals consider that for nonnegotiable instruments, nominal value is an appropriate proxy for market value (see paragraph 7.30). Nonetheless, the development of markets, such as for credit derivatives linked to the credit risk of individual entities, is increasing the likelihood that market prices can be estimated even for nonnegotiable instruments. As these markets extend, consideration might be given to compiling additional information on market values of nonnegotiable debt.
}

changed, or a liability settled, between knowledgeable, willing parties in an arm's-length transaction. It thus represents an estimate of what could be obtained if the owner sold the asset or the debtor settled the liability.

- Nominal value at any moment in time is the amount that the debtor owes to the creditor. It reflects the value of the instrument at creation and subsequent economic flows, such as transactions, exchange rate and other valuation changes other than market price changes, and other volume changes. For financial instruments other than debt securities, equity, and financial derivatives, the lack of generally available market values means that these values are estimated by using the nominal value.

- The amortized value of a loan reflects the gradual elimination of the liability by regular payments over a specified period of time. On the date of each scheduled payment, the amortized value is the same as the nominal value, but it may differ from the nominal value on other dates because the nominal value includes interest that has accrued.

- The face value of a debt instrument is the undiscounted amount of principal to be repaid at (or before) maturity. ${ }^{22}$ The use of face value as a proxy for nominal value in measuring the gross debt position can result in an inconsistent approach across all instruments and is not recommended. For example, the face value of deep-discounted bonds and zero-coupon bonds includes interest not yet accrued, which runs counter to accrual principles.

- Written-down replacement cost is the current acquisition price of an equivalent new asset minus the accumulated consumption of fixed capital, amortization, or depletion.

- Book value generally refers to the value recorded in the entities' records. Book values may have different meanings because their values are influenced by accounting standards, rules, and policies, as well as the timing of acquisition, company

\footnotetext{
${ }^{22}$ In some statistical databases, face value is also called nominal value. However, in GFS, nominal value is understood to be different from face value, except on the date of maturity of the instrument.
} 
takeovers, frequency of revaluations, and tax and other regulations.

- Historic cost, in its strict sense, reflects the cost at the time of acquisition, but sometimes it may also reflect occasional revaluations.

3.116 The valuation of assets and liabilities based on accounting standards may not fully reflect the market prices of the assets and liabilities. In such cases, the source data for GFS should be adjusted to reflect, as closely as possible, the market value of the assets and liabilities. ${ }^{23}$

3.117 Some financial assets and liabilities, such as bonds, have a nominal value, face value, and market value, and for some purposes, supplementary data on the nominal and face values of stock positions may be useful. ${ }^{24}$ However, transactions in these assets and liabilities should be valued at the prices actually paid. Similarly, to attain integration between stock positions and flows, the stock positions of debt securities should be valued at their market value when recorded on the balance sheet.

\section{Valuation adjustments in special cases}

3.118 When a unit sells an item and does not expect to receive payment, or the corresponding payment is not due for an unusually long time, ${ }^{25}$ the value of the principal (recorded in other accounts payable/ receivable) is reduced by an amount that reflects the time to maturity using an appropriate discount rate, such as the contractual rate for similar debt instruments. If payment is not due for an unusually long period of time, this reduction is by partitioning the market price of the item purchased, which equals the reduced principal amount, and accrued interest, the assumption being that the amount to be paid includes an allowance for interest. If payment is not expected for an unusually long period of time, such as due to the circumstances of the debtor, a reduction in the principal to be paid is recorded through a valuation change in other accounts

\footnotetext{
${ }^{23}$ More information on the valuation rules and numerical examples are in the PSDS Guide, paragraphs 2.115-2.123, and the 2013 EDS Guide.

${ }^{24}$ The PSDS Guide recommends that debt instruments should be valued at nominal value, while debt securities should be valued at market value as well.

${ }^{25}$ What constitutes an unusually long time in this context will depend on the circumstances. For example, for any given time period, the higher the level of interest rates or the longer the delay in payment, the greater is the opportunity cost of delayed payment.
}

payable/receivable, with interest accruing on the reduced principal amount, reflecting the time delay in payment. In both the circumstances described in this paragraph, interest should accrue until payment is made, at the rate used to discount the principal.

3.119 Flows and stock positions expressed in a foreign currency are converted to their value in the domestic currency at the rate prevailing at the moment they are entered in the accounts-that is, the moment the transactions or other flow takes place, and stock positions are converted at the rate prevailing on the balance sheet date. The midpoint between the buying and selling spot rates should be used so that any service charge is excluded. When a multiple exchange rate system is in operation, the valuation should be based on the rate applicable to the type of asset in question. The valuation in the domestic currency of a purchase or sale on credit expressed in a foreign currency may differ from the value in domestic currency of the subsequent cash payment because the exchange rate changed in the interim. Both transactions should be valued at their market values as of the dates they actually occurred, and a holding gain or loss resulting from the change in the exchange rate should be recorded for the period or periods in which it occurs.

3.120 For some transactions in goods, contracts establish a quotation period often months after the goods have changed hands. In such cases, market value at the time of the change of ownership of the goods should be initially estimated, and revised with the actual market value, when known. Market value is given by the contract price even if it is unknown at the time of change of ownership.

3.121 Transfers in kind should be valued at the market prices that would have been receivable if the resources had been sold in the market. In the absence of a market price, the donor's view of the imputed value of the transaction will often be quite different from that of the recipient. The suggested rule of thumb is to use the value assigned by the donor as the basis of recording.

3.122 In some cases, actual exchange values may not represent market prices. Examples are transactions involving transfer prices between affiliated units, manipulative agreements with third parties, and certain noncommercial transactions. Prices may be under- or overinvoiced, in which case an assessment 
of a market-equivalent price needs to be made. Although, conceptually, adjustment should be made when actual exchange values do not represent market prices, this may not be practical in many cases. In some cases, transfer pricing may be motivated by income distribution or equity buildups or withdrawals. Replacing book values with market-value equivalents is desirable in principle, when the distortions are large and when the availability of data (such as adjustments by customs or tax officials or from partner economies) makes it feasible to do so. Selection of the best marketvalue equivalents to replace book values is an exercise calling for cautious and informed judgment. In many cases, compilers may have no choice other than to accept valuations based on explicit costs incurred in production or any other values assigned by the unit.

3.123 While some nonmarket transactions, such as grants in kind, have no market price, other nonmarket transactions may take place at implied prices that include some element of grant or concession so that those prices also are not market prices (see paragraphs 3.10-3.11). Examples of such transactions could include negotiated exchanges of goods between governments and governments' concessional lending. While there is no precise definition of concessional loans, it is generally accepted that they occur when units lend to other units and the contractual interest rate is intentionally set below the market interest rate that would otherwise apply. The degree of concessionality can be enhanced with grace periods (see paragraph 6.69), frequencies of payments, and a maturity period favorable to the debtor. Since the terms of a concessional loan are more favorable to the debtor than market conditions would otherwise permit, concessional loans effectively include a transfer from the creditor to the debtor. However, except for the case of concessional lending to government employees (see paragraph 6.17 and Chapter 6, footnote 11) and concessional lending by central banks (see Box 6.2), the means of incorporating the impact of concessional lending into GFS have not been fully developed. Accordingly, until the appropriate treatment of concessional debt is resolved, information on concessional debt should be provided as supplementary information (see paragraph 7.246).

3.124 Where a single amount payable/receivable refers to more than one transaction category, the individual flows should be partitioned and recorded sepa- rately (see paragraph 3.29). In such a case, the total value of the individual transactions after partitioning must equal the market value of the exchange that actually occurred.

3.125 The value of flows that are not already expressed at their market value, such as barter transactions, must be estimated. In addition, market values for many stock positions will not be readily available and must be estimated. The following list suggests several estimation possibilities. The choice of which method to use in a given circumstance depends on the information available.

- It may be possible to estimate the values of transactions based on values taken from markets in which similar transactions take place under similar conditions. The value of certain stock positions, primarily financial assets, may also be estimated using market transactions involving similar assets that take place at the end of the reporting period.

- Flows and stock positions involving existing fixed assets can be valued using the market price for similar new goods, properly adjusted for consumption of fixed capital and other events that may have occurred since they were produced.

- If there is no appropriate market in which a particular good or service is currently traded, the valuation of a flow involving that good or service may be derivable from the market prices of similar goods and services by making adjustments for quality and other differences.

- The value of flows and stock positions of assets may be estimated on the basis of the historic or acquisition cost of the item, adjusted for all changes that have occurred since it was purchased or produced, such as consumption of fixed capital, holding gains or losses, depletion, exhaustion, degradation, unforeseen obsolescence, and exceptional losses. ${ }^{26}$

- Goods and services can be valued by the amount that it would cost to produce them in the current reporting period. For market producers, the market value of a nonfinancial asset valued in this way should include a mark-up that reflects the net operating surplus attributable to

\footnotetext{
${ }^{26}$ This estimate is also referred to as the "written-down current acquisition" value.
} 
the producer. For nonmarket goods and services produced by general government units or nonprofit institutions serving households (NPISHs), however, no allowance should be made for any net operating surplus in the calculation of the market price.

- Assets can be valued at the discounted present value of their expected future returns. This method is particularly prominent for a number of financial assets, natural assets, and intangible assets. For some financial assets, the present market value is established by discounting future payments or receipts to the present, using the market interest rate. In principle, therefore, if a reasonably robust estimate of the stream of future earnings to come from an asset can be made, along with a suitable discount rate, this method allows an estimate of the present value. However, it may be difficult to determine the future earnings with the appropriate degree of certainty, given that assumptions are also needed about the asset's life span and the discount factor to be applied. Because of these uncertainties, the other possible sources of valuation described in the preceding paragraphs should be exhausted before resorting to this method.

\section{Valuation of other economic flows}

3.126 Apart from transactions, the change in the value of assets and liabilities between two end-periods also results from holding gains and losses, and other changes in volume of assets and liabilities. The valuation of these other economic flows is discussed in the remainder of this section.

\section{Holding gains and losses}

3.127 Holding gains and losses accrue continuously and apply to both nonfinancial and financial assets and liabilities. Since all financial assets, except gold bullion, are matched by liabilities either within the domestic economy or with the rest of the world, it is important that holding gains/losses are recorded symmetrically. A holding gain occurs when an asset increases in value or a liability decreases in value; a holding loss occurs when an asset decreases in value or a liability increases in value. Holding gains and losses during a reporting period are shown separately for assets and liabilities. In practice, the value of holding gains and losses is calculated for each asset and liability between two points in time: the beginning of the period or when the asset or liability is acquired or incurred, and the end of the period or when the asset or liability is sold or extinguished.

\section{Other changes in the volume of assets}

3.128 In order to determine the valuation of the other changes in the volume of nonfinancial assets, it is usually necessary to determine the market value of the asset before and after the economic event, such as its appearance, disappearance, catastrophic loss, or reclassification (see paragraphs 10.46-10.84). The value of the other change in volume is calculated as the difference in the market value of the asset immediately before and after the event.

3.129 Other changes in the volume of financial assets and liabilities are recorded at the market or market-equivalent prices of similar instruments. For writing-off of marketable financial instruments that are valued at their market values, the value recorded in the other changes in the volume of asset account should correspond to their market values prior to being written off. For nonmarketable financial instruments that are recorded at nominal values, the value recorded in the other changes in the volume of assets account should correspond to their nominal value prior to being written off. For all reclassifications of assets and liabilities, values of both the new and old instruments should be the same.

\section{Currency \\ Unit of account}

3.130 The compilation of GFS, particularly transactions and stock positions with nonresidents, is complicated by the fact that the values may be expressed initially in a variety of currencies or perhaps in other standards of value, such as Special Drawing Rights (SDRs). The conversion of these transactions and stock positions expressed in another currency, or a commodity into a reference unit of account, is a requisite for the construction of consistent and analytically meaningful statistics. If financial assets or liabilities are in foreign currency units, data in a single currency unit are needed for compiling meaningful statistics.

3.131 From the perspective of the national compiler, the domestic currency unit is the obvious choice for measuring transactions and stock positions. Denominating government finance transactions and 
stock positions in such a way is compatible with the national accounts and most of the economy's other economic statistics. Where a foreign currency is used to settle domestic transactions, such as with "dollarized" economies, this foreign currency may be the relevant currency unit for the compilation of GFS.

\section{Currency conversion}

3.132 The most appropriate exchange rate to be used for conversion of transactions and stock positions is the market (spot) rate prevailing on the transaction or balance sheet date. The midpoint between buying and selling rates should be used.

3.133 For debt transactions, in principle, the actual exchange rate applicable to each transaction should be used for currency conversion. The use of a daily average exchange rate for transactions usually provides a good approximation. If daily rates cannot be applied, average rates for the shortest period should be used. Some transactions occur on a continuous basis, such as the accrual of interest over a period of time. For such flows, therefore, an average exchange rate for the period in which the flows occur should be used for currency conversion. More details on currency conversion are given in the BPM6, paragraphs 3.104-3.108.

\section{Domestic and foreign currency}

3.134 For an economy, a domestic currency is distinguished from foreign currency. Domestic currency is that which is legal tender in the economy and issued by the monetary authority for that economy-that is, either that of an individual economy or, in a currency union, that of the common currency area to which the economy belongs. All other currencies are foreign currencies.

3.135 Under this definition, an economy that uses as its legal tender a currency issued by a monetary authority of another economy-such as U.S. dollarsor of a common currency area to which it does not belong should classify the currency as a foreign currency, even if domestic transactions are settled in this currency. Unallocated gold accounts and other unallocated accounts in precious metals giving title to claim the delivery of gold or precious metal are treated as denominated in foreign currency.
3.136 SDRs are considered to be foreign currency in all cases, including for the economies that issue the currencies in the SDR basket. Any other currency units issued by an international organization, except in the context of a currency union, are considered foreign currency.

\section{Currency of denomination and currency of settlement}

3.137 For debt statistics, a distinction should be made between the currency of denomination and the currency of settlement. The currency of denomination is determined by the currency in which the value of flows and stock positions is fixed as specified in the contract between the parties. Accordingly, all cash flows are determined using the currency of denomination and, if necessary, converted to the domestic currency or another unit of account for the purpose of settlement or compilation of accounts. The currency of denomination is important for distinguishing transaction values and holding gains and losses.

3.138 The currency of settlement may be different from the currency of denomination. Using a currency in settlement that is different from the currency of denomination simply means that a currency conversion is involved each time a settlement occurs. The currency of settlement is important for international liquidity and measurement of potential foreign exchange drains.

3.139 A financial instrument may be settled in domestic currency with both the amount to be paid at maturity and all periodic payments (such as coupons) linked (or indexed) to a foreign currency. In this instance, the currency of denomination is the foreign currency. Some instruments are denominated in more than one currency. However, if the amounts payable are linked to one specific currency, then the liability should be attributed to that currency.

\section{Derived Measures}

3.140 Derived measures consist of aggregates and balancing items. They are important analytic tools that summarize the values of selected flows or stock positions that have been individually recorded in the GFS framework. These derived measures are the sum or the balance of two or more flows or stock positions.

3.141 Aggregates are summations of individual entries and elements in a class of flows or stock positions. They allow for these data to be arranged in a 
manageable and analytically useful way. For example, tax revenue is the sum of all flows that are classified as taxes, and data for social security funds are the aggregations of the data for all institutional units in the economy that are classified as social security funds. Aggregates and classifications are closely linked in that classifications are designed to produce the aggregates thought to be most useful. Conceptually, the value for each aggregate is the sum of the values for all items in the relevant category. However, estimates of some aggregates may be needed due to deficiencies in source data, such as missing information on individual transactions, other economic flows, and asset and liability positions that may be incomplete or even nonexistent.

3.142 Balancing items are economic constructs obtained by subtracting one aggregate from a second aggregate. For example, the net operating balance is obtained by subtracting the total expense aggregate from the total revenue aggregate. Net worth is the balancing item equal to total assets minus total liabilities (see Chapter 4).

\section{Netting of Flows and Stock Positions}

3.143 It is feasible to present many categories of flows and stock positions on a gross or net basis. An item presented on a net basis is calculated as the sum of one set of flows or stock positions minus the sum of a second set of a similar kind. For example, total tax revenue could be presented on a gross basis as the total amount of all taxes accrued, or on a net basis as the gross amount minus tax refunds. Similarly, interest can be presented on a gross basis as interest revenue and interest expense, respectively, while it is feasible to calculate the net interest. The choice depends on the category of flows or stock positions, the nature of the items that might be subtracted to obtain the net value, and the analytic utility of the gross and net values. The choices for gross and net presentations as used in the GFS framework are discussed in paragraphs 3.144-3.151.

3.144 In GFS, revenue categories are presented gross of expense categories for the same or related category and likewise for expense categories. In particular, interest revenue and interest expense are presented gross rather than as net interest expense or net interest revenue. Similarly, social benefits and social contributions, grant revenue and expense, and rent revenue and expense are presented gross. Also, sales of goods and services are presented gross of the expenses incurred in their production.

3.145 In the case of the correction of erroneous or unauthorized transactions, revenue categories are presented net of refunds of the relevant revenue, and expense categories are presented net of inflows from the recovery of the expense. For example, refunds of income taxes may be paid when the amount of taxes withheld or otherwise paid in advance of the final determination exceeds the actual tax due. Such refunds are recorded as a reduction in tax revenue. Similarly, if social benefits that were paid in error are recovered, then such recoveries are recorded as a reduction in expense.

3.146 Acquisitions and disposals of nonfinancial assets other than inventories are presented gross. For example, acquisitions of land are presented separately from disposals of land. For analytic presentations, the net acquisition of each category of nonfinancial asset may be preferable and can be derived easily.

3.147 Netting is implicit in the presentation of some specific transactions categories in GFS-for example, changes in inventories. Changes in each type of inventories are presented net rather than tracking daily additions and withdrawals. That is, the change in materials and supplies is presented in the GFS framework as the net value of additions minus withdrawals. Nonetheless, full inventory accounting could allow for the gross recording of all the movements in inventories in the underlying administrative records. Similarly, tax revenue is presented net of nonpayable tax credits (see paragraphs 5.29-5.32).

3.148 Acquisitions and disposals of each category of financial assets/liabilities are also presented net in the GFS framework, to reflect the nature of the financial flows. For example, only the net change in the holding of assets related to currency and deposits is presented, not gross receipts and disbursements. Similarly, additions to liabilities in the form of loans are presented net of repayments. However, for analytical and administrative reasons, it may be useful to develop source data on the gross acquisitions and the gross disposals of each financial instrument as separate data categories.

3.149 Other economic flows are presented net. That is, the net holding gain for each asset and liability is presented, not gross holding gains and gross 
holding losses. Similarly, other changes in the volume of assets and liabilities are presented net, rather than recording increases and decreases in volume changes on a gross basis.

3.150 Stock positions held for the same type of financial instrument, both financial assets or liabilities, are presented gross. For example, a unit's holding of debt securities as financial assets is presented separately from its liabilities for debt securities issued.

3.151 In the GFS framework the terms "gross" and "net" are used in a very specific manner. Apart from the balancing items net worth, net operating balance, and net lending/net borrowing, the GFS classifications employ the word "gross" and "net" to indicate the value of the operating balance and investment in nonfinancial assets before or after deduction of consumption of fixed capital. The framework also uses the term "net" to indicate that the net acquisition of financial assets represents both acquisition and disposal of assets, while the net incurrence of liabilities represents both incurrence and repayment of liabilities.

\section{Consolidation}

3.152 A consolidated set of accounts for a group of units, subsectors, or sectors, is produced by, first, an aggregation of all flows and stock positions within the GFS analytical framework, followed by the elimination, in principle, of all flows and stock positions that represent relationships among the units or entities being consolidated. In other words, consolidation eliminates the double-count because a flow or stock position of one unit is paired with the corresponding flow or stock position recorded for the second unit with which it is being consolidated, and both flows and/or stock positions are eliminated. For example, if one general government unit owns a bond issued by a second general government unit, and data for the two units are being consolidated, then the stock positions of bonds held as assets and liabilities of the consolidated unit are reported as zero (i.e., as if the bond position between them did not exist). At the same time, the interest related to this bond is consolidated, so that the interest revenue and expense of the consolidated account exclude the interest paid by the debtor general government unit to the creditor general gov- ernment unit. Similarly, sales of goods and services between consolidated units are also eliminated. ${ }^{27}$

\section{Definitions}

3.153 Consolidation is a method of presenting statistics for a set of units (or entities) as if they constituted a single unit. In the GFS framework, the data presented for a group of units are consolidated. In particular, statistics for the general government sector and each of its subsectors are presented on a consolidated basis. When units of the public sector are included in a presentation, the data for public corporations should be presented in two ways: as separate subsectors for the financial public corporations and for the nonfinancial public corporations; and together with general government units for the consolidated public sector. In both cases, the statistics should be presented on a consolidated basis within each group.

3.154 When compiling general government or public sector statistics, two types of consolidation may be necessary-namely, intrasectoral consolidation and intersectoral consolidation.

3.155 Intrasectoral consolidation is consolidation within a particular subsector to produce consolidated statistics for that particular subsector-for example, within the central government subsector or within the public nonfinancial corporations subsector. This consolidation may be required at two stages. A single institutional unit may require consolidation when the unit has multiple funds and accounts to carry out its operations and there are flows and stock positions among those funds. For example, a country may have a core central government institutional unit that has one or more departmental accounts, as well as special funds and accounts established for specific purposes. There are often flows and stock positions held between these accounts and funds that are recorded on a gross basis in the respective accounts. Failure to eliminate these transfers would yield aggregates that result from the accounting device, and not from interaction with units outside of the central government.

3.156 Intersectoral consolidation is consolidation between subsectors of the public sector to produce consolidated statistics for a particular grouping of public

\footnotetext{
${ }^{27}$ See PSDS Guide, Box 8.1 and Table 8.2, for examples of consolidation.
} 
sector units-for example, consolidation between central, state, and local governments, and between general government and public nonfinancial corporations.

3.157 Intrasectoral consolidation is always done before intersectoral consolidation-for example, where more than one central government social security fund exists, the data for all social security funds should be consolidated before the consolidated social security data is presented as a subsector of the central government. Subsequently, data for all the subsectors of the central government will be subject to intersectoral consolidation to produce data for the consolidated central government.

\section{Reasons for consolidation}

3.158 The main reason for consolidation lies in the analytical usefulness of the consolidated statistics: consolidation eliminates the distorting effects on aggregates of differing administrative arrangements across countries or over time. The main impact of consolidation on the statistics is on the magnitude of aggregates. To relate government aggregates to the economy as a whole (e.g., revenue, expense, or debt to gross domestic product (GDP) ratios), it is better to eliminate the internal movement of economic value and include only those flows and stock positions that actually cross the boundaries with other sectors or nonresidents. The same arguments apply to why public corporations and public sector statistics should be consolidated.

3.159 By eliminating all reciprocal flows and stock positions among the units being consolidated, consolidation has the effect of measuring only flows or stocks of the consolidated units versus units outside the boundary. Consolidation excludes the economic interaction within the grouping of institutional units, and presents only those flows or stocks that involve interactions with all other institutional units in the economy, and the rest of the world.

3.160 Consolidation avoids double-counting of flows or stock positions among a grouping of institutional units, thus producing statistics that exclude these internal flows or stock positions. It is the avoidance of double-counting that produces the increased analytical usefulness of consolidated statistics in cases where it makes sense to view the consolidated group as acting as if it were a single entity.

\section{Conceptual guidelines}

3.161 Conceptually, consolidation entails the elimination of all intra- and intergovernmental flows and all debtor-creditor relationships among the units or entities that are combined. Consolidation requires a review of the accounts to be consolidated to identify inter- and intrasectoral flows and stock positions. The goal is to eliminate, in a consistent manner, flows and stock positions that will have a significant effect on the final derived measures. However, two types of transactions that appear to take place between two government units are never consolidated because they are rerouted in GFS (see paragraph 3.28):

- Employer social contributions, whether paid to social security or government pension funds, are treated as being payable to the employee in the household sector as part of compensation and then payable by the employee to the social security scheme.

- Taxes withheld by government units from the compensation of their employees, such as payas-you-earn taxes, and paid to other government units should be treated as being paid directly by the employees. The government employer is simply the collecting agent for another government unit, and is acting on behalf of the employees in the household sector.

3.162 Consolidation covers a range of categories of flows that may vary greatly in importance. The major transactions, in likely order of importance, cover:

- Grants (current and capital) among general government units or entities

- Interest income/expense

- Taxes paid by one government unit or entity to another (except those taxes withheld on behalf of the household sector)

- Purchases/sales of goods and services

- Acquisitions/disposals of nonfinancial assets.

3.163 The following major transactions, other economic flows, and stock positions in financial assets and liabilities, in likely order of importance, should be consolidated:

- Loans

- Debt securities

- Other accounts receivable/payable. 
3.164 For the public sector, in addition to the foregoing financial instruments, the following flows and stock positions should also be eliminated-in principle-in both intra- and intersectoral consolidation:

- Equity and investment fund shares

- Currency and deposits

- Insurance, pension, and standardized guarantee schemes.

\section{Implementing consolidation}

3.165 This Manual recommends that, based on Table 3.1, counterparty flows and stock position information be identified that will be eliminated in consolidation. But practicality should be kept in mind: the resources devoted to consolidation and the level of detail applied in consolidation should be in direct proportion to their fiscal significance. Suggestions for the sequence of analysis are:

- Begin all consolidation exercises with an analysis of the accounts involved to determine whether there are flows or stock positions internal to the unit(s) to be consolidated. This will depend on knowledge of the relationships among the units involved. Do some of the units incur expense or receive revenue from the other units? Do some units extend loans to the other units? Do they buy debt securities issued by the other units? Do they have currency and deposits held by the other units?

- Once these relationships are established, compilers must determine whether the intra- and/or intersectoral flows and stock positions can be measured or estimated, and whether the amounts will be significant in terms of analytical importance.

- If the amounts are likely to be significant, are they large enough to justify the effort to collect the data and other information for consolidation purposes? The effort and cost to identify an amount to be consolidated should be directly proportional to the expected amount and its impact on the aggregates.

- The "one-side" rule of thumb is commonly used. That is, if there is convincing evidence from the one institutional unit that a flow or stock position exists, it should be imputed to the counterparty. The imputation should be recorded even if there is no record of the flow or stock position in the counterparty's accounts. When such an adjust-

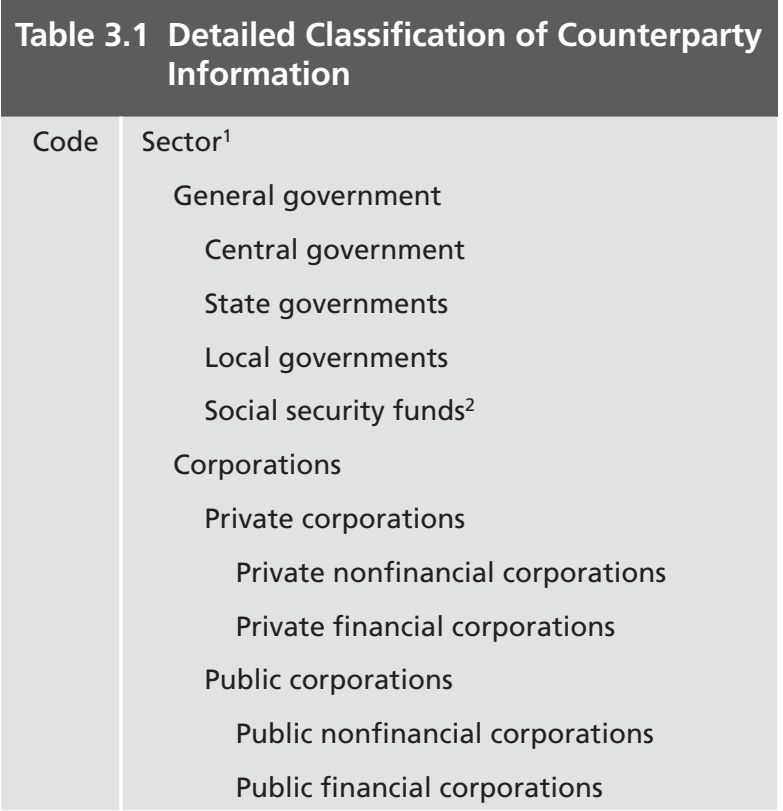

${ }^{1}$ Further breakdown/"of which" lines could allow for the identification of subsectors and individual units.

${ }^{2}$ Social security funds are presented as a subsector only if their data are excluded from the data of the government level at which they are organized (see paragraph 2.78).

ment is made in the data for a unit where the flow or stock position cannot be directly identified, it will be necessary to ensure that the records for that unit are properly modified.

- For flows and stock positions in financial assets and liabilities, normally the creditor can be expected to maintain the most reliable records. For loans, the creditor unit usually maintains the most complete records, but, with the international emphasis on proper debt recording, the debtor unit may be equally reliable. For debt securities, especially bearer instruments, only the creditor may have the information needed for consolidation. For example, when a central government issues bearer securities, some of which are acquired by public corporations, the central government may have no direct information on who is holding the securities, especially if they can be acquired on secondary markets. It is therefore necessary to rely on the creditor's records.

- Sometimes discrepancies exist between data for two units that are being consolidated. There are many reasons for such discrepancies, such as coverage, time of recording, valuation, and classification. Resolving these discrepancies will promote proper consolidation and improve the overall 
quality of GFS compiled. However, where a discrepancy cannot be resolved, decisions need to be made about which unit or group of units has the most reliable source data. Generally, the higher level of government is considered to have more reliable records than the lower levels of government.

- To create consistency with other macroeconomic datasets, components of the data for the public sector should be presented in such a way that they show the data before consolidation and after consolidation. This will allow for the unconsolidated data to be consistent with the data required in the national accounts and other datasets that are presented before consolidation (see paragraph 3.168).

3.166 Consolidation does not affect balancing items. In other words, the balancing items that are produced by simple aggregation are the same as those produced by consolidation. This is a result of the symmetry of the consolidation process, wherein the two sides of the consolidation adjustment fall within the same section of the analytical framework. When consolidated data produce different balancing items from the unconsolidated data, recording errors have been made. Therefore, when intra- or intersectoral flows and stock positions to be consolidated are not measured in the same amount by the units or subsectors involved, a consolidation method must be chosen that does not affect balancing items (see paragraph 3.165).

\section{Consolidation in other datasets 2008 System of National Accounts}

3.167 The 2008 SNA recommends, as a matter of principle, that statistics of institutional units should not be consolidated in the national accounts, but that consolidated accounts may be compiled for complementary presentations and analyses. Even then, transactions appearing in different accounts of the national accounts are never consolidated. The difference between the 2008 SNA and this Manual reflects the different uses of the statistics. The GFS framework is designed to produce statistics suitable for use in the analysis of the net relations between government and the rest of the economy. In particular, assessing the overall impact of government operations on the total economy or the sustainability of government operations is more effective when the measure of government operations is a set of consolidated statistics rather than unconsolidated statistics. The GFS framework also is not intended to produce a measure of production. The 2008 SNA, on the other hand, serves a range of other uses, including a comprehensive measure of production and relations among all the sectors of the economy.

\section{Financial statements}

3.168 In financial statements, compiled in accordance with accounting standards, accounting entries are often presented on a consolidated basis for the reporting entity and all of its controlled entities. This is done without regard to whether the controlled entities are general government units or public corporations, as those terms are used in this Manual, or whether the controlled entities are residents or nonresidents. This use of consolidation attempts to portray the operations and financial position of a parent and its subsidiaries as though the group of enterprises were a single unit. For example, a financial report for a state government unit would include all public corporations controlled by that government unit but would not include the statistics of any other state governments. In contrast, the consolidated statistics of the state government subsector in the GFS framework would include all state government units of the country, but would exclude all public corporations owned or controlled by those state governments. 


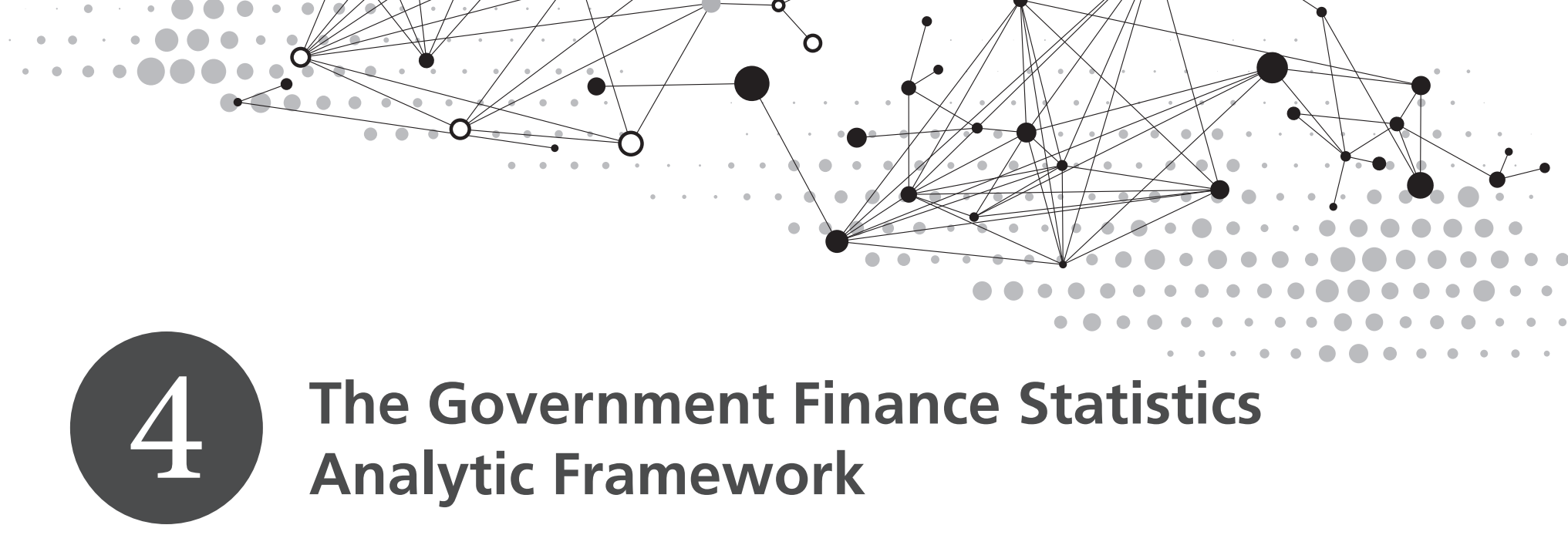

This chapter introduces the government finance statistics analytic framework ${ }^{1}$ and describes the relationships among its elements and use of government finance statistics in fiscal analysis.

\section{Introduction}

4.1 Government units and public corporations carry out a multitude of activities. To manage the internal operations of government and assess their impact on the economy, these activities-resulting in transactions and other economic flows-must be organized into a framework within which they can be summarized and analyzed. For accountability purposes, these activities may be organized according to the government unit that carries them out. For managerial or planning purposes, these activities may be organized by the kind of item purchased/sold or service provided/acquired. For billing or control purposes, these activities may be organized by the particular transactors with whom the government deals. The GFS framework, on the other hand, is designed to facilitate fiscal analysis in a broader macroeconomic context. While there is clearly a close link between accounting data and macroeconomic statistics, they do not serve the same objectives and may differ in the treatment of particular items. ${ }^{2}$

4.2 Traditionally, governments have recorded their activities on a cash basis; this is reflected in the analytic framework of the GFSM 1986. Including only cash revenue and expenditure has the advantage of focusing the government's attention on its financing/

\footnotetext{
${ }^{1}$ The GFS analytic framework refers to the structure of accounts and their relationships as a body of thought, while the term GFS framework more generally refers to the framework for the compilation and dissemination of GFS data.

${ }^{2}$ See Appendix 6 for a detailed description of the linkages between GFS and international accounting standards, and see Appendix 7 for linkages between GFS and other macroeconomic statistics.
}

liquidity constraint, which has traditionally been viewed as its most binding priority. However, governments have become less liquidity-constrained in carrying out fiscal policy and have become more adept at separating the time of a fiscal action from the time it is paid for, so that cash transactions do not adequately capture either the timing of activities or their economic impact. In consequence, there has been increasing recognition worldwide of the need to adopt the accrual system of recording, which includes a cash-flow statement for assessing fiscal policy. ${ }^{3}$

4.3 The GFS analytic framework introduced in the GFSM 2001, and as updated in this Manual, reflects these developments and is presented in the form of a set of interrelated accrual-based statements. These statements are harmonized with the 2008 SNA, that integrate flows and stock positions, and are supplemented with a cash-flow statement. The GFS analytic framework facilitates a more comprehensive assessment of the economic impact of government activity and the resulting changes on liquidity and the implications for the sustainability of fiscal policy. More specifically, the use of accrual-based statements and the integration of balance sheets with flows are consistent with the need for government behavior to be determined in the context of its intertemporal budget constraint. For example, a government's policies will not be sustainable if they significantly reduce its net worth. The framework also provides an improved basis for monitoring efficiency in the allocation and use of all government resources. The analytic framework set out in this Manual encompasses the traditional cash-based fiscal reporting, to support liquidity analysis.

\footnotetext{
${ }^{3}$ For example, see Study 11, Part III of International Federation of Accountants, Government Financial Reporting: Accounting Issues and Practices (New York, 2000), and IFAC Recommendations to G-20 meeting, New York, 2010 and 2012.
} 


\section{Analytic Objectives}

4.4 The GFS analytic framework is a quantitative tool that supports fiscal analysis. To permit effective analysis of fiscal policy, the GFS framework must facilitate the identification, measurement, monitoring, and assessment of the impact of a government's economic policies and other activities on the economy.

4.5 To achieve the analytic objectives, the GFS framework should generate data that:

- Are sufficiently detailed and effectively organized to allow an assessment of management and policy decisions

- Are closely linked to other macroeconomic statistical frameworks (national accounts, balance of payments and international investment position, and monetary and financial statistics)

- Enable analysts to assess the financial soundness of the general government and public sectors in ways commonly applied to other organizations in the economy ${ }^{4}$

- Enable assessment of sustainability over the long term

- Enable assessment of liquidity constraints and financing needs.

\section{Construction of the Analytic Framework: Relation to the GFSM 1986}

4.6 The analytic framework of this Manual builds on the GFSM 1986 framework, and extends it by incorporating additional elements that are useful in assessing fiscal policy. There are three types of modifications:

- The definitions of individual statistical variables are closely aligned with economic concepts. An important example is the treatment of nonfinancial assets, where the sale of such assets is no longer included in revenue and their purchase is no longer included in expense.

- Concepts are harmonized with the 2008 SNA. These include: the shift from a functional-based definition of general government and public sectors to one built on institutional units (see paragraphs 2.22-2.48); a switch from using only

${ }^{4}$ Organizations in other sectors of the economy record their operations in the form of integrated accounting systems that include income statements, balance sheets, and cash-flow statements. the cash basis of recording to a framework of accounts using the accrual basis of recording, while maintaining a cash-flow statement (see paragraphs 3.70-3.72); and the complete integration of flows and stock positions (see paragraphs 3.2-3.3).

- The GFSM 1986 framework has been extended to include nonmonetary transactions, such as inkind and imputed transactions (see paragraphs 3.19-3.20), flows other than transactions (see paragraphs 3.31-3.35), and a balance sheet (see paragraphs 3.36-3.50).

4.7 In principle, the coverage of GFS encompasses all institutional units that materially affect fiscal policies. Therefore, two principal constructs are used for which GFS should be compiled. The general government sector captures those institutional units primarily involved in nonmarket activities of government, while the public corporations sector captures all the activities of public corporations, including their market and quasi-fiscal activities (see Chapter 2). Once an institutional unit has been classified to a sector, all its flows and stock positions are recorded in that sector. Thus, statistics for the general government sector as well as for the public sector should be compiled. The analytic framework described in this chapter can be applied to both sectors, and their subsectors.

\section{Components and Concepts of the Analytic Framework}

4.8 The core of the analytic framework is a set of four financial statements. Three of the statements can be combined to show that all changes in stock positions result from flows (see Figure 4.1 and paragraph 3.4). These are the:

- Statement of Operations

- Statement of Other Economic Flows

- Balance Sheet.

In addition, the core framework includes a Statement of Sources and Uses of Cash to provide key information on liquidity.

4.9 The Statement of Operations is a summary of the transactions of a sector or subsector in a given reporting period. In essence, transactions represent changes to stock positions that arise from mutually agreed interactions between institutional units, such 


\section{Figure 4.1 Structure of the GFS Analytic Framework}

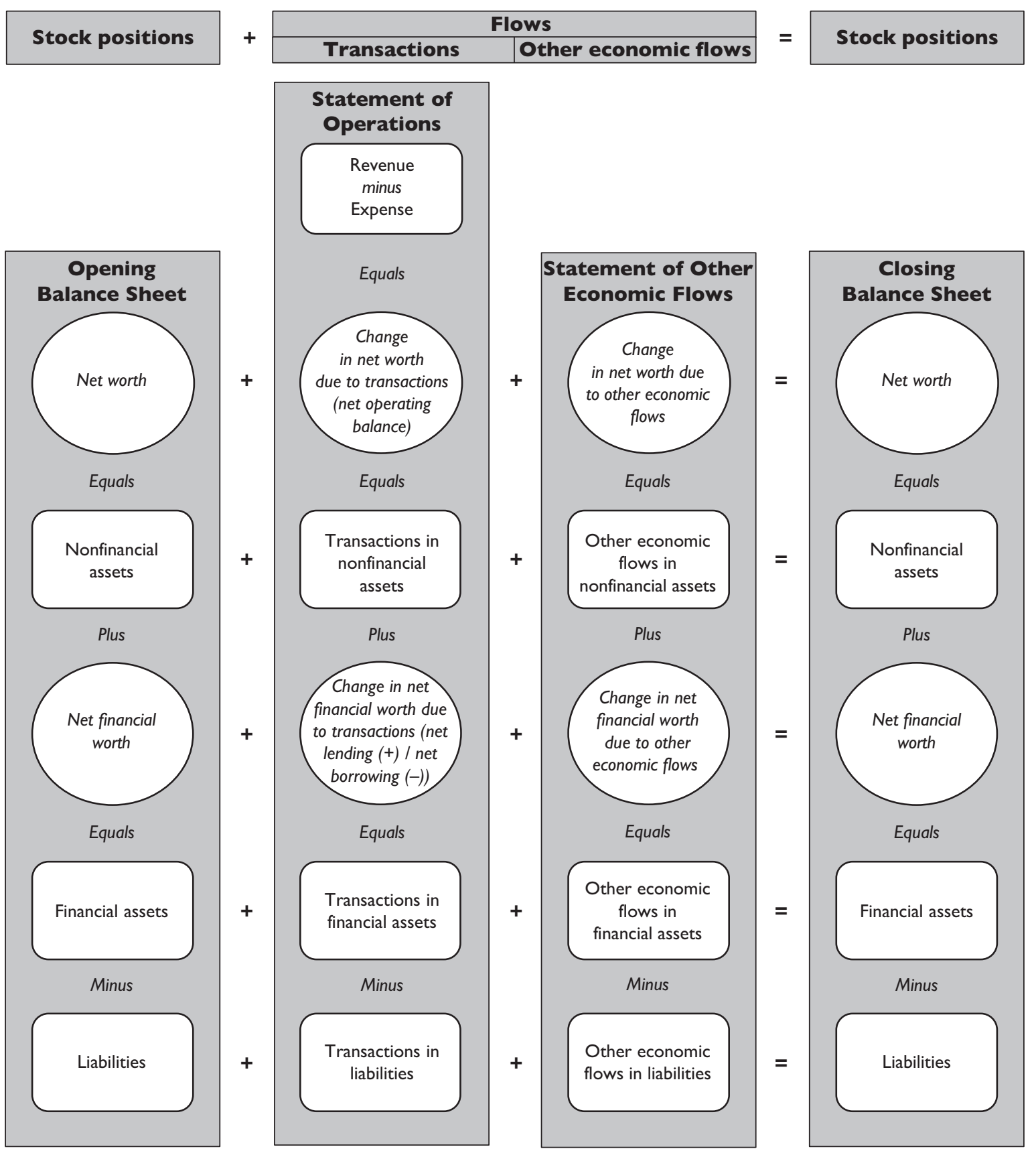

as the sale of a good or service by one unit and its purchase by another (see paragraph 3.5 ). The framework also recognizes that a unit can act in two capacities of economic interest and includes as transactions some items that do not involve another institutional unit. For example, consumption of fixed capital recognizes that a unit is both the owner of a fixed asset and the consumer of the services provided by the asset. Taken together, transactions constitute the largest share of the flows associated with the implementation of fiscal policy. As described in the following section, transactions are classified to demonstrate how general government and public sector units raise revenue and spend it, and to show the effects of fiscal 
policy decisions on the net worth of the sector, on its demand for credit, and on its ability to invest in assets.

4.10 The Statement of Other Economic Flows tabulates changes to stock positions of assets, liabilities, and net worth that come about for reasons other than transactions. More specifically, holding gains and losses represent changes to stock positions that arise from price movements, including exchange rate movements. ${ }^{5}$ Other changes in the volume of assets represent changes to stock positions arising from events such as the discovery of new assets/liabilities (e.g., mineral deposits), depletion or destruction of assets, or reclassification of assets/liabilities.

4.11 The Balance Sheet records the stock positions of assets, liabilities, and net worth of the sector or subsector at the end of each reporting period.

4.12 The Statement of Sources and Uses of Cash records cash inflows and outflows using a classification similar to that of the Statement of Operations, but with a focus on the net change in cash flows arising from transactions during the reporting period.

4.13 In addition to the core statements of the GFS framework, two supplementary statements are included in the framework due to their analytic usefulness. These statements are the:

- Statement of Total Changes in Net Worth

- Summary Statement of Explicit Contingent Liabilities and Net Implicit Obligations for Future Social Security Benefits.

4.14 The Statement of Total Changes in Net Worth combines the revenue and expense transactions from the Statement of Operations with the Statement of Other Economic Flows in one statement. In its summary format, this supplementary statement serves to highlight the total changes in net worth of government.

4.15 The Summary Statement of Explicit Contingent Liabilities and Net Implicit Obligations for Future Social Security Benefits summarizes the explicit and implicit guarantees outstanding. Contingent liabilities create fiscal risks and may arise from deliberate public policy or from unforeseen events. The stock positions of explicit and some implicit contingent liabilities are recorded as memorandum items to the GFS balance sheet (see paragraphs 7.251-7.261). For details on

\footnotetext{
5 "Holding gains" is used as a short form of the more general term "holding gains and losses."
}

the recording of contingent liabilities, also see paragraphs 7.251-7.259 and the PSDS Guide, paragraphs $4.3-4.26$.

\section{The Statement of Operations}

4.16 The Statement of Operations (see Table 4.1) presents details of transactions in revenue and expense, as well as the net investment in nonfinancial assets, the net acquisition of financial assets, and the net incurrence of liabilities. ${ }^{6}$ Revenue is defined as the increase in net worth resulting from transactions, and expense as the decrease in net worth resulting from transactions. The net investment in nonfinancial assets equals the acquisitions minus disposals of fixed assets, minus consumption of fixed capital, plus changes in inventories, plus the net acquisition (acquisitions minus disposals) of valuables and nonproduced assets.

4.17 Two important analytic balances are derived in the Statement of Operations. Revenue minus expense equals the net operating balance, reflecting the total change in net worth due to transactions. The subsequent deduction of the net investment in nonfinancial assets results in net lending (+)/ net borrowing (-), which is also equal to the net result of transactions in financial assets and liabilities. In addition to these balances, the annex to Chapter 4 describes a number of other important fiscal indicators that could be derived from GFS and that are used in fiscal analysis.

4.18 The net operating balance is a summary measure of the sustainability of the reporting sector or subsector's operations. It is comparable to the national accounts concept of saving plus net capital transfers receivable. The net operating balance as defined here excludes gains and losses resulting from changes in price levels and other changes in the volume of assets. The component of the change in net worth that

\footnotetext{
${ }^{6}$ As explained in paragraph 3.69, the Statement of Operations is intended to be compiled using the accrual basis of recording transactions. It is recognized, however, that many governments may be able to compile statistics only on the cash or partial accrual basis for some time. If only cash data are available, the classification of cash flows shown in Table 4.2 should be used. Otherwise, with accrual or partial accrual (noncash) source data, the classification of transactions shown in Table 4.1 should be used. With the exception of consumption of fixed capital, in-kind and imputed transactions, and other accounts receivable/payable, all of the line items in Table 4.1 can be applied to both cash and accrual data. However, the benefits of the fully integrated GFS framework can be derived only when using the accrual basis of recording.
} 
is due to transactions can largely be attributed directly to government policies since governments have direct control over the decisions that lead to the interaction with other units by mutual agreement. The same cannot always be said for the other components of the total change in net worth. For example, changes in the market prices or events that impact on the volume of assets or liabilities are not in the direct control of government. Still, these risks need to be monitored so that governments can manage them proactively to minimize their potential fiscal impact.

4.19 Net lending (+) / net borrowing (-) is a summary measure indicating the extent to which government is either putting financial resources at the disposal of other sectors in the economy or abroad, or utilizing the financial resources generated by other sectors in the economy or from abroad. It may therefore be viewed as an indicator of the financial impact of government activity on the rest of the economy and the rest of the world. While this balancing item is conceptually the same as in the 2008 SNA, amounts reported as net lending/net borrowing may differ to the extent that a government maintains an unfunded pension scheme for its employees (see paragraphs 5.95, 7.192-7.193 and Appendixes 2 and 7).

4.20 The gross operating balance as presented in the Statement of Operations differs from the net operating balance in that it does not include consumption of fixed capital as an expense. Consumption of fixed capital can be difficult to measure in practice and a satisfactory estimate may not be available. If so, the gross operating balance may be more practical for analysis than the net operating balance. ${ }^{7}$ The net operating balance is, however, preferred in principle because it captures all costs of operations during the reporting period.

4.21 Expenditure is the sum of expense and the net investment in nonfinancial assets and is presented as an additional aggregate in the Statement of Operations. This aggregate is not influenced by the level of consumption of fixed capital and is therefore suitable for international comparisons between countries even if they cannot reliably measure consumption of fixed capital.

\footnotetext{
${ }^{7}$ The availability of data on consumption of fixed capital has no influence on net lending/net borrowing. The counterpart entry for the expense recorded for consumption of fixed capital reduces the value of investment in fixed assets-thereby neutralizing the impact on net lending/net borrowing.
}

\section{Table 4.1 Statement of Operations}

\begin{tabular}{|c|c|}
\hline \multicolumn{2}{|c|}{ Transactions Affecting Net Worth: } \\
\hline 1 & Revenue \\
\hline 11 & Taxes \\
\hline 12 & Social contributions [GFS] \\
\hline 13 & Grants \\
\hline 14 & Other revenue \\
\hline 2 & Expense \\
\hline 21 & Compensation of employees [GFS] \\
\hline 22 & Use of goods and services \\
\hline 23 & Consumption of fixed capital [GFS] \\
\hline 24 & Interest [GFS] \\
\hline 25 & Subsidies \\
\hline 26 & Grants \\
\hline 27 & Social benefits [GFS] \\
\hline 28 & Other expense \\
\hline NOB/GOB & Net/gross operating balance $(1-2)^{1}$ \\
\hline \multicolumn{2}{|c|}{ Transactions in Nonfinancial Assets: } \\
\hline 31 & $\begin{array}{l}\text { Net/gross investment in nonfinancial } \\
\text { assets }^{2}\end{array}$ \\
\hline 311 & Fixed assets \\
\hline 312 & Inventories \\
\hline 313 & Valuables \\
\hline 314 & Nonproduced assets \\
\hline $2 M$ & Expenditure $(2+31)$ \\
\hline NLB & $\begin{array}{l}\text { Net lending (+)/ Net borrowing (-) [GFS] } \\
(1-2-31=1-2 \mathrm{M}=32-33)\end{array}$ \\
\hline \multicolumn{2}{|c|}{ Transactions in Financial Assets and Liabilities (Financing): } \\
\hline 32 & Net acquisition of financial assets \\
\hline 321 & Domestic $^{3}$ \\
\hline 322 & External $^{3}$ \\
\hline 33 & Net incurrence of liabilities \\
\hline 331 & Domestic $^{3}$ \\
\hline 332 & External $^{3}$ \\
\hline
\end{tabular}

${ }^{1} T$ The net operating balance equals revenue minus expense. The gross operating balance equals revenue minus expense other than consumption of fixed capital.

${ }^{2}$ The net investment in nonfinancial assets equals acquisitions minus disposals minus consumption of fixed capital. The gross investment in nonfinancial assets equals acquisitions minus disposals.

${ }^{3}$ Classified by instrument and/or sector of the counterparty (see Tables 9.1 and 9.2).

4.22 As illustrated in Table 4.1, the Statement of Operations is divided into three sections that present: revenue and expense transactions; transactions in nonfinancial assets; and transactions in financial assets and liabilities. The following paragraphs follow this structure in providing an overview of the various categories of transactions. These definitions and descriptions are not intended to be comprehensive. 
In each section, reference is made to the chapter that contains more detailed information.

\section{Revenue and Expense}

4.23 Revenue is an increase in net worth resulting from a transaction. ${ }^{8}$ The major types of revenue are taxes (11), social contributions (12), grants (13), and other revenue (14). ${ }^{9}$ The detailed classification of revenue is described in Chapter 5. The disposal of a nonfinancial asset by sale or barter is not revenue because it has no effect on net worth. Rather, it changes the composition of the balance sheet by exchanging one asset (the nonfinancial asset) for another (the proceeds of the sale). Similarly, amounts receivable from loan repayments and loan disbursements are not revenue. These are transactions in assets or liabilities as described in Chapters 8 and 9.

4.24 Expense is a decrease in net worth resulting from a transaction. ${ }^{10}$ The major types of expense are compensation of employees (21), use of goods and services (22), consumption of fixed capital (23), interest (24), subsidies (25), grants (26), social benefits (27), and other expense (28). In addition, expense can be classified according to the functions of government, such as health or social protection. The economic and functional classifications of expense are described in Chapter 6. The acquisition of a nonfinancial asset by purchase or barter is not an expense because it has no effect on net worth. Rather, it changes the composition of the balance sheet by acquiring one asset (the nonfinancial asset) against the disposal/reduction in another asset or by incurring a liability (the payable for the asset). Similarly, amounts payable on loans extended and repayments on loans incurred are not classified as expense. These are transactions in assets or liabilities as described in Chapter 8 and 9.

\footnotetext{
${ }^{8}$ In general, transactions that increase net worth result from current operations. Capital transfers are an exception. Capital transfers are defined in paragraph 3.16. In GFS, capital transfers receivable are classified as revenue because they increase the recipient's net worth and they are often indistinguishable from current transfers in their effect on government operations. ${ }^{9}$ The numbers in parentheses after each classification category are the GFS classification codes. Appendix 8 provides all classification codes used in the GFS system.

${ }^{10}$ As with revenue, transactions that decrease net worth result mainly from current operations. Capital transfers payable or otherwise obligated are an exception. See footnote 8.
}

\section{Transactions in Nonfinancial Assets ${ }^{11}$}

4.25 The second section of the Statement of Operations (see Table 4.1) records transactions that change a government's net investment in nonfinancial assets. Nonfinancial assets are economic assets other than financial assets. Nonfinancial assets are stores of value and provide benefits either through their use in the production of goods and services or in the form of property income and holding gains. These assets are classified as fixed assets (311), inventories (312), valuables (313), and nonproduced assets (314). The classification of nonfinancial assets is described in Chapter 7 and transactions in nonfinancial assets are discussed in Chapter 8.

\section{Transactions in Financial Assets and Liabilities}

4.26 The third section of the Statement of Operations (see Table 4.1) records financing transactions, which are transactions that change a government's holdings of financial assets and liabilities (financial assets and liabilities are defined in paragraphs 3.48 and 3.45 , respectively). The classification of financial assets and liabilities is described in Chapter 7 and transactions in financial assets and liabilities are discussed in Chapter 9.

4.27 Transactions in financial assets can be classified in multiple ways; for ease of presentation, Table 4.1 indicates a classification of financial assets according to whether the counterpart liability was incurred by a resident (indicated by "domestic" in the table) or a nonresident (indicated by "external") and similarly for the classification of liabilities.

4.28 There are additional classifications of transactions in financial assets and liabilities in GFS. The first classification is based on the type of financial instruments involved in the transactions. The instruments are: monetary gold and SDRs; currency and deposits; debt securities; loans; equity and investment fund shares or units; insurance, pension, and standardized

\footnotetext{
${ }^{11}$ This section deals only with the net investment in nonfinancial assets (acquisitions minus disposals of nonfinancial assets, minus consumption of fixed capital) by the reporting unit or sector. Government or public sector institutional units may also facilitate public capital formation by transferring funds to other governments or to public corporations with a requirement that the funds be used to acquire nonfinancial assets. Rather than being considered transactions in nonfinancial assets, these transactions are included in capital transfers, either as capital grants or other expense, as relevant.
} 


\section{Box 4.1 Policy Lending}

Whether to consider the acquisition of a financial asset or assumption of a liability as being for public policy purposes, for liquidity management, or for other purposes rests largely on an assessment of the particular purpose for acquiring the instrument. ${ }^{1}$

Some fiscal policies that may lead to the ownership of financial claims include fostering new industries, assisting ailing government corporations, or helping particular businesses that are experiencing economic adversity. For example, a government unit may provide loans at favorable rates to particular economic sectors, acquire shares in a corporation active in a particular geographical region or in a function that the government wishes to promote, or sell shares in a public corporation for less than their market value.

Liquidity management, on the other hand, refers to actions taken to ensure the availability of financial assets to fulfill requirements for short-term funds and to ensure that such funds earn the best available rate of return. Prudent financial management requires that government units acquire and dispose of financial assets in the process of their financing operations. The motive underlying these transactions is the effective management of finances.

Other purposes for acquiring financial assets, and perhaps incurring related liabilities, include the need to make a longterm provision for society, such as acquiring financial assets derived from the sale of natural resource assets to hold in a special-purpose government fund.

Some factors that should be considered when identifying policy-related financial instruments are as follows:

- Nonnegotiable financial assets are usually held for policy-related purposes, as are negotiable financial claims issued by a lower level of government and held by a higher level of government.

- Financial assets issued by a public corporation-for example, shares and other equity, debt securities, or loans-and held by government are typically held for public policy purposes.

- A government statement about the acquisition of a financial asset may indicate that the purpose is policy-related.

- Noncommercial terms favoring the borrower generally indicate a policy-related purpose, such as concessional interest rates on loans or arrangements for repayment that do not meet normal commercial standards.

- Assets acquired as a result of government units acting as guarantors are likely to be policy-related.

- Assets acquired through nationalization are policy-related.

- Holdings of monetary gold, SDRs, currency, and nonlife insurance technical reserves are always liquidity-related.

- Deposits may be acquired for policy or liquidity purposes.

${ }^{1}$ As explained in paragraph 6.91 and Box 6.3, under some circumstances, "capital or equity injections" are considered to be expense (i.e., when they do not result in an effective financial claim on the debtor).

guarantee schemes; financial derivatives and employee stock options; and other accounts receivable/payable (see Table 9.1). The second classification is based on the sector of the counterparty of the transactions in financial instruments. That is, transactions in liabilities are classified according to the sector of the institutional unit conducting the counterpart transaction in financial assets, such as financial corporations, nonfinancial corporations, households, and nonprofit institutions serving households (see Table 9.2).

4.29 Another possible classification of transactions in financial assets and liabilities is whether they were acquired or disposed of for the purpose of public pol- icy or liquidity management. This distinction is not included in the Statement of Operations, but is used to define the overall fiscal balance, as described in the annex to Chapter 4, Table 4A.2.

4.30 Public policy-related assets or liabilities (also called policy lending-see Box 4.1) may be acquired for a variety of reasons, such as fostering new industries, assisting ailing government corporations, or helping particular businesses suffering economic adversity. Such transactions can take a variety of forms, including loans, equity securities, and debt securities. Given that there is often a concessional element to such transactions, it is useful to identify them in a 
separate category so that for some analyses the fiscal impact of these policy-related transactions in assets could be assessed separately. ${ }^{12}$

4.31 All other transactions in financial assets are assumed to be for liquidity management or other purposes. That is, the assets are acquired to earn a market rate of return while keeping sufficient funds on hand to finance day-to-day operations, or to meet the long-term needs of society, such as through a specialpurpose government fund.

\section{The Statement of Sources and Uses of Cash}

4.32 Information on the sources and uses of cash is important for assessing the liquidity of the general government and public sectors. The Statement of Sources and Uses of Cash (see Table 4.2) shows the total amount of cash generated or absorbed by current operating activities, transactions in nonfinancial assets, and transactions involving financial assets and liabilities other than the financial asset currency and deposit (cash) itself. The net change in the stock of cash is the sum of the net cash received from these three sources.

4.33 The net change in the stock of cash refers to the financial asset currency and deposits (3202). Currency consists of notes and coins that are of fixed nominal values and are issued or authorized by the central bank or government. Deposits are all claims, represented by evidence of deposit, on the deposittaking corporations (including the central bank) and, in some cases, general government or other institutional units. The classification of this financial asset is described in Chapter 7 and transactions are discussed in Chapter 9.

4.34 The Statement of Sources and Uses of Cash (Table 4.2) reflects transactions when using the cash basis of recording. This, in effect, means that transactions are captured only when cash is received or when cash payments are made (see paragraphs 3.67 and 3.103-3.105).

\footnotetext{
${ }^{12}$ The net acquisition of financial assets for policy purposes was called "lending minus repayments" in the GFSM 1986 and was often referred to as "net lending." These terms should not be confused with the term "net lending/net borrowing" used in this Manual.
}

\author{
Table 4.2 Statement of Sources and Uses of \\ Cash \\ Cash Flows from Operating Activities: \\ C1 Revenue cash flows \\ C11 Taxes \\ C12 Social contributions \\ C13 Grants \\ C14 Other receipts \\ C2 Expense cash flows \\ C21 Compensation of employees \\ C22 Purchases of goods and services \\ C24 Interest \\ C25 Subsidies \\ C26 Grants \\ C27 Social benefits \\ C28 Other payments \\ ClO Net cash inflow from operating activities \\ (C1-C2)
}

Cash Flows from Transactions in Nonfinancial Assets:

C31 Net cash outflow from investment in nonfinancial assets ${ }^{1}$

C311 Fixed assets

C312 Inventories ${ }^{2}$

C313 Valuables

C314 Nonproduced assets

C2M Expenditure cash flows $(\mathrm{C} 2+\mathrm{C} 31)$

CSD Cash surplus (+) / Cash deficit (-) (C1-C2$\mathrm{C} 31=\mathrm{C} 1-\mathrm{C} 2 \mathrm{M}=\mathrm{C} 32-\mathrm{C} 33)$

Cash Flows from Transactions in Financial Assets and Liabilities (Financing):

C32x Net acquisition of financial assets other than cash

C321x Domestic ${ }^{3}$

C322x External ${ }^{3}$

C33 Net incurrence of liabilities

C331 Domestic ${ }^{3}$

C332 External ${ }^{3}$

NFB Net cash inflow from financing activities (C33-C32x)

NCB Net change in the stock of cash $(C S D+N F B=C 3202=$ C3212 + C3222)

${ }^{1}$ The net cash outflow from investment in nonfinancial assets equals purchases minus sales.

${ }^{2}$ On a cash basis, the category inventories (C312) is limited to changes in strategic stocks. Other inventories are, by definition of the cash basis of recording, considered an expense when acquired.

${ }^{3}$ Classified by instrument and/or sector of the counterparty (see Tables 9.1 and 9.2).

4.35 Additional useful information for fiscal analysis is obtained from an analysis of the differences between amounts reported in the Statement of Operations and the Statement of Sources and Uses of Cash. 
There are some broad types of transactions that are recorded in Table 4.1 but not in Table 4.2:

- Expense transactions that will be settled in cash in the future-With accrual recording, a purchase of goods and services is recognized when the ownership of goods changes hands or services are provided. The associated cash payment may not take place until a subsequent reporting period, in which case it would not be included in Table 4.2 in the same period as it appears in Table 4.1. The fiscal implication of such differences in amounts reported may indicate a larger need for liquidity in the future to provide for the payments of accrued expense.

- Revenue transactions that were settled in cash but will be earned in the future-Revenue can be received in cash before it is earned by the delivery of goods or provision of services to the purchaser. In addition, taxes and other compulsory revenue may be earned, but may be unpaid and will be settled in the future. The fiscal implication of such differences may indicate a larger demand for service delivery in the future, or a need to assess the efficiency of tax collection efforts.

- There may also be transactions in assets and liabilities that will be settled in cash in future periods, such as the interest accruing from the amortization of the discount on a zero-coupon or other discounted bond. There may be fiscal implications for liquidity management.

- There are transactions that are not in cash by their nature. Consumption of fixed capital, imputed transactions, barter, other transactions in kind, and debt forgiveness and write-off are noncash transactions and would therefore not be recorded in a Statement of Sources and Uses of Cash. The difference between the two statements in this case will be an indication of the size of economic activities not measured in cash.

\section{The Statement of Other Economic Flows}

4.36 The Statement of Other Economic Flows (see Table 4.3) presents changes in assets, liabilities, and net worth that are not the result of transactions. They are classified as changes either in the value or volume of assets, liabilities, and net worth. The balancing item of this statement, the change in net worth due to other economic flows, is defined as the sum of the

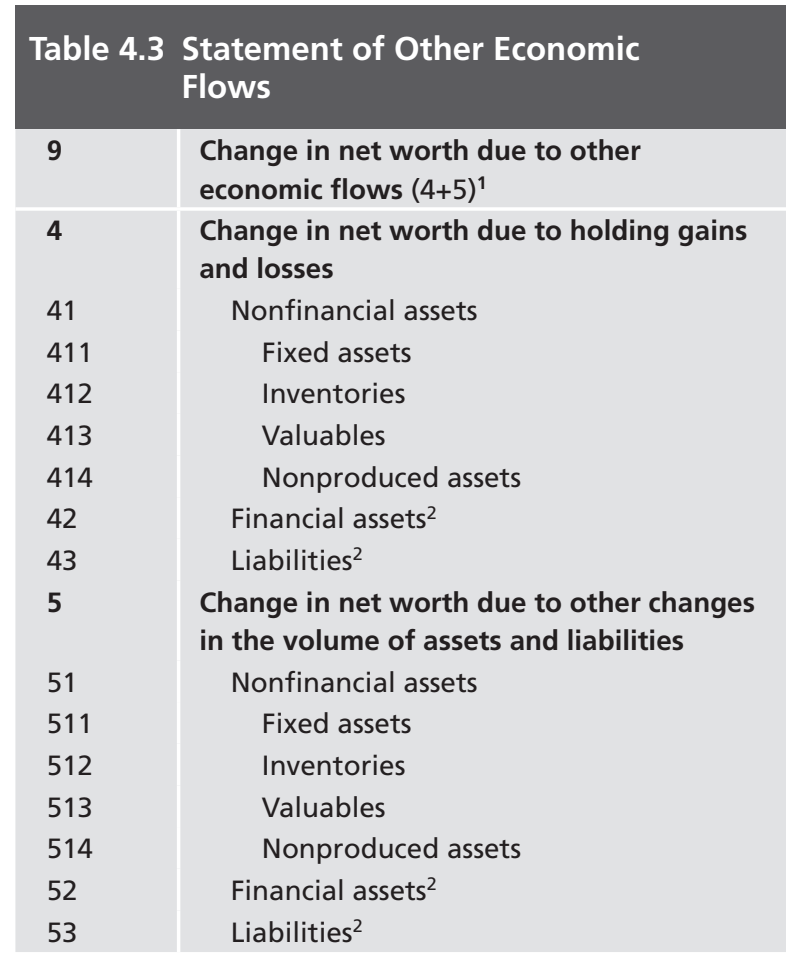

'See Table 10.2 for a detailed classification of other economic flows.

${ }^{2}$ Classified by residence, instrument, and/or sector of the counterparty (see Tables 9.1 and 9.2).

change in net worth due to holding gains or losses and the change in net worth due to other changes in the volume of assets. In line with the integrated approach, these other economic flows are classified by the type of asset or liability affected. Other economic flows are described in Chapter 10.

4.37 Change in net worth due to holding gains or losses is defined as the sum of the positive or negative holding gains and holding losses on all assets and liabilities. These include all changes in the value of assets, liabilities, and net worth due solely to price effects. They can result from changes in the general price level or in relative prices. Changes in the exchange rate cause holding gains or losses in financial assets and liabilities denominated in a foreign currency (see paragraph 10.44).

4.38 Change in net worth due to other changes in the volume of assets and liabilities is defined as the sum of the positive and negative other changes in the volume of assets and liabilities. These changes in the volume of assets and liabilities, other than from transactions and price effects, may arise for a variety of reasons. They can be described as resulting from 
the appearance or disappearance of existing resources as economic assets, effects of external events that are exceptional and unexpected, and changes in classification (see paragraphs 10.46-10.84).

\section{The Balance Sheet}

4.39 A balance sheet is a statement of the values of the stock positions of assets owned and of the liabilities owed by an institutional unit or group of units, drawn up in respect of a particular point in time. The Balance Sheet, shown in Table 4.4, presents the stock positions of assets and liabilities at the end of the reporting period in comparison to the stock positions at the beginning of the reporting period..$^{13}$ The main balancing item on the balance sheet is net worth. The net worth of an institutional unit (or grouping of units) is the total value of its assets minus the total value of its liabilities. The change in net worth (comprising the change in net worth due to transactions in revenue and expense and the change in net worth due to other economic flows) is a fiscal indicator for assessing the sustainability of fiscal activities.

4.40 For public corporations, using changes in net worth as a fiscal indicator for assessing sustainability should be approached with caution. Because of the inclusion of shareholders' equity as a liability in the calculation of net worth, the interpretation of net worth may be counterintuitive for public corporations. In cases where the market value of a public corporation's shares and equity is increasing by more than the market value of the recognized assets minus liabilities, the net worth of the public corporations will decrease in GFS (and in other macroeconomic statistics). Thus, for public corporations' own funds (including the value of shares and other equity and net worth) may provide a more useful fiscal indicator than net worth alone (see paragraphs 7.229-7.232 for more details on own funds).

4.41 Where market values of some nonfinancial assets are not available or are unreliable, net financial worth is another fiscal indicator of sustainability. The net financial worth of an institutional unit (or grouping of units) is the total value of its financial assets minus the total value of its liabilities.

4.42 The Balance Sheet shows the stock positions in assets and liabilities. (The definitions and classifications of assets and liabilities are described in Chapter 7.)

\footnotetext{
${ }^{13}$ Table 7.1 presents the balance sheet in another format.
}

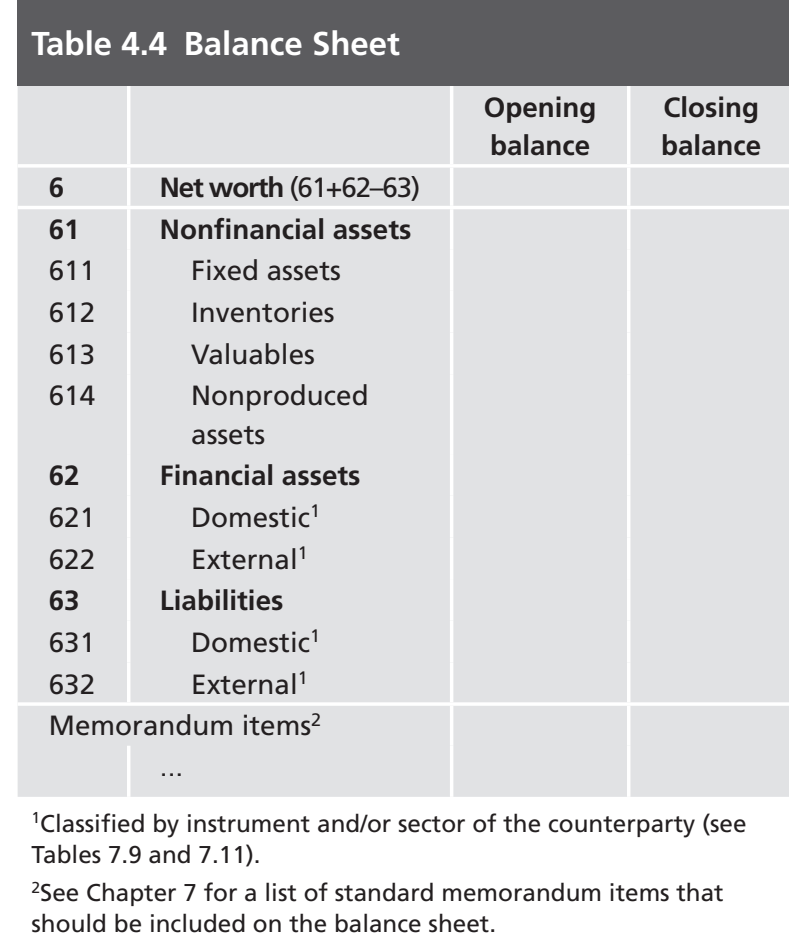

\section{Assets}

4.43 The assets included in the Balance Sheet are economic assets, defined as resources over which ownership rights are enforced and from which economic benefits may flow to the owners. Economic benefits arise from owning and using economic assets over a period of time. Assets not owned and controlled by a reporting unit or sector and assets that have no economic value are excluded.

4.44 As shown in Table 4.4, stock positions in assets are classified in the same way that transactions and other economic flows in assets are classified. Assets are either nonfinancial or financial. Nonfinancial assets are further classified as fixed assets, inventories, valuables, or nonproduced assets. Financial assets are classified by residence of the counterparty and by type of instrument. Financial assets can also be classified by sector of the counterparty and maturity.

\section{Liabilities}

4.45 A liability is established when one unit (the debtor) is obliged, under specific circumstances, to provide funds or other resources to another unit (the creditor). Most classifications that apply to financial assets also apply to liabilities. Liabilities are classified by the residence of the counterparty and by type of 
instrument. Liabilities can also be classified by sector of the counterparty and maturity.

\section{The Statement of Total Changes in Net Worth}

4.46 The Statement of Total Changes in Net Worth (see Table 4.5) combines the results from the Statement of Operations for revenue and expense transactions with the Statement of Other Economic Flows in one statement. The statement provides a clear statistical explanation of the factors causing the change in the net worth of government. It explains the sources of changes in assets and liabilities from one reporting period to another in terms of transactions in revenue and expense and other economic flows. In its summary format, this supplementary statement serves to highlight the total change in net worth of government. ${ }^{14}$

\section{The Summary Statement of Explicit Contingent Liabilities and Net Implicit Obligations for Future Social Security Benefits}

4.47 The Summary Statement of Explicit Contingent Liabilities and Net Implicit Obligations for Future Social Security Benefits records the explicit and some implicit contingent liabilities. Contingent liabilities are obligations that do not arise unless a particular, discrete event(s) occurs in the future. These contingencies create fiscal risks and may arise from deliberate public policy or from unforeseen events. The stock positions of contingent liabilities are recorded as a memorandum item to the balance sheet (see paragraph 7.255). Some details on the nature and composition of these contingencies are recorded in this statement (see Table 4.6). ${ }^{15}$

4.48 In GFS, the net implicit obligations for future social security benefits (other than employment-related retirement benefits) are not recognized as liabilities (see Appendix 2$).{ }^{16}$ Social security contributions are clas-

\footnotetext{
${ }^{14}$ This format brings the statistical presentation closer to the presentation used in financial statements compiled in accordance with International Public Sector Accounting Standards (see Appendix 6).

${ }^{15}$ For more details, see the PSDS Guide, paragraphs 4.3-4.26.

${ }^{16}$ These implicit obligations exclude amounts that become overdue after all criteria for benefits have been met-GFS include these as liabilities in other accounts payable.
}

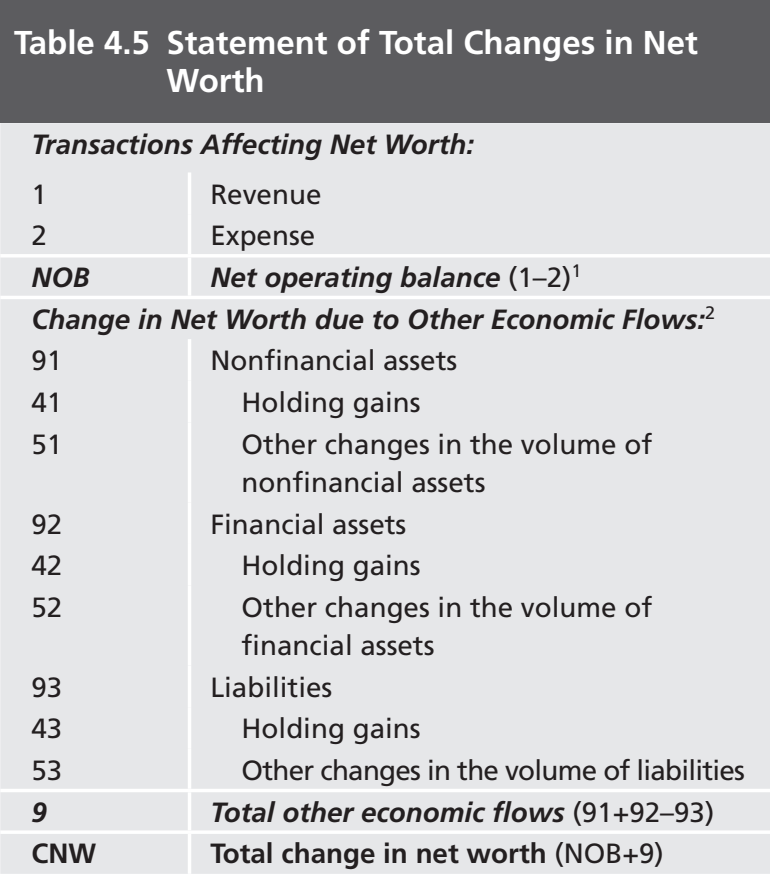

${ }^{1}$ The net operating balance equals revenue minus expense. ${ }^{2}$ Classified by categories of assets and liabilities as needed.

sified as revenue (and therefore as an increase in net worth), and social security benefits payable as expense (a decrease in net worth). This treatment is in line with conventional fiscal analysis. Alternatively, in a full intertemporal framework, social security contributions may be seen more appropriately as akin to a buildup of assets (arising from contributions made) associated with future liabilities of the government. Likewise, many social security benefit payments may be seen as the extinction of previously incurred government liabilities. This approach is not taken in the main tables of GFS because it is considered that social security schemes, other than employment-related pension schemes, do not result in a contractual liability for the government-that is, there is no direct link between the contributions made and the benefits eventually payable.

4.49 Indeed, it is not uncommon for governments to change unilaterally the structure of benefits of social security schemes (e.g., by changing the circumstances under which the benefits become payable or the amount of the benefit). Moreover, in most cases, these benefits become payable only when certain contingent events occur, such as sickness or unemployment. Nonetheless, it is important for a government to be aware of the implicit contingent liability that 
arises from its social security programs. Such a contingency recognizes the present value of future benefits that have already been earned according to the existing laws and regulations, net of the present value of future contributions to the scheme according to existing laws and regulations. As a result, a memorandum item is included in the Balance Sheet, with more details on these net obligations disclosed in this Statement (see Table 4.6).

4.50 The implicit contingent liabilities related to social security schemes exclude the liabilities associated with employment-related pension schemes, including in cases where the employment-related pensions are provided through the social security scheme. In GFS, imputed obligations incurred for unfunded government employee retirement schemes are considered to involve a contractual liability for a government or public sector unit to its employees. As a result, the actual or imputed contributions receivable to such employment-related schemes are considered to give rise to an incurrence of a liability, and the payment of retirement benefits is considered to be a reduction in the same liability (see paragraph 6.25).

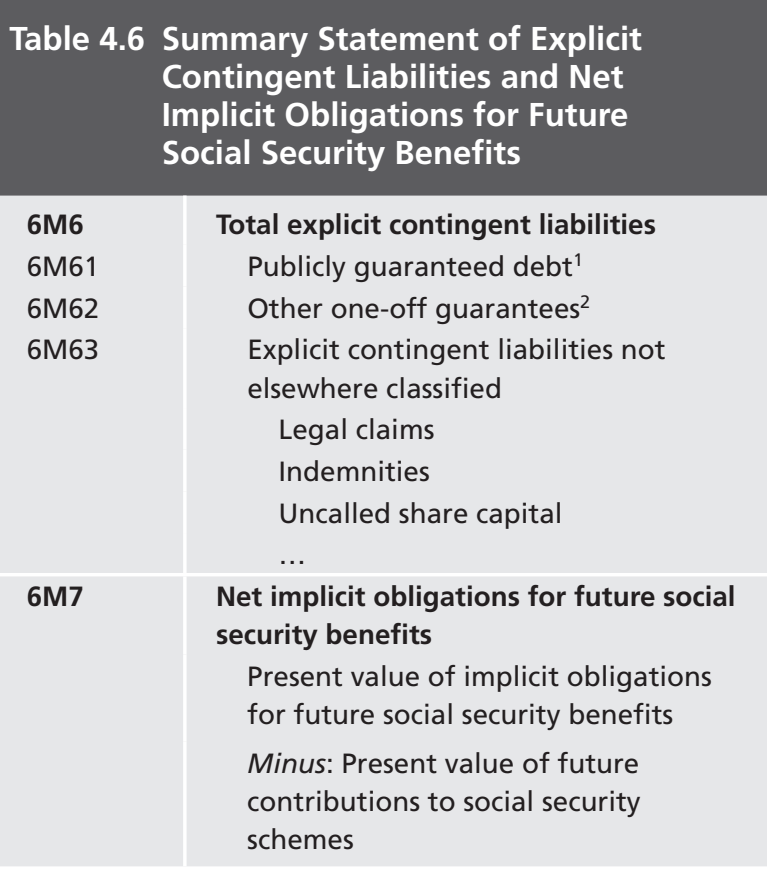

${ }^{1}$ It is recommended that details of publicly guaranteed debt (i.e., loan and other debt instrument guarantees) are shown by maturity and type of debt instrument, at nominal values.

${ }^{2}$ For example, credit guarantees and other similar contingent liabilities (such as lines of credit and loan commitments), contingent "credit availability" guarantees, and contingent credit facilities. 


\section{Annex: Using GFS for Fiscal Analysis}

This annex describes the use of GFS in creating fiscal indicators.

\section{Introduction}

4.51 This annex offers an overview of the application of the GFS framework in creating commonly used fiscal indicators. ${ }^{1}$ Some of these indicators can be observed or derived directly from the GFS framework, while others can be derived using a combination of GFS with other macroeconomic data.

4.52 Fiscal indicators may be produced for the general government and public sectors (see Chapter 2). Fiscal indicators for the subsectors of general government and the public sector can also be produced to take account of the decentralized nature of fiscal responsibilities in an economy. Using data from the GFS framework enhances the comparability of data across countries (see paragraph 1.13), which is important in establishing robust analytical findings.

\section{Fiscal Indicators Available from the GFS Framework}

4.53 The GFS framework produces fiscal indicators from the transactions, other economic flows, stock positions, aggregates, or balancing items. For example, in the Statement of Operations, net lending/ net borrowing is the basic indicator of the fiscal balance, measured from "above-the-line" as revenue minus expenditure (with expenditure comprising expense plus the net investment in nonfinancial assets). This fiscal balance can alternatively be measured from "below-the-line" as the difference between transactions in financial assets and liabilities, also referred to as financing transactions. From an above-the-line

\footnotetext{
${ }^{1}$ The International Financial Statistics and the Government Finance Statistics Yearbook contain a large and comprehensive database of macroeconomic statistics, including GFS. See also the IMF's Fiscal Transparency Code at www.imf.org/external/ $\mathrm{np} / \mathrm{fad} /$ trans/. First published in 1998 and updated in 2007 and 2014, the IMF's Code of Good Practices on Fiscal Transparency and accompanying Manual and Guide are centerpieces of the global architecture of fiscal transparency norms and standards.
}

perspective, GFS provide detailed information on revenue sources, and the composition of expenditure, while the "below-the-line" approach provides detailed information on how governments invest surpluses or finance deficits.

4.54 The Balance Sheet offers data on regularly used fiscal stock position indicators, such as the gross and net debt, and the stock position and composition of various categories of assets and liabilities (see paragraphs 7.14-7.19). Additional aggregates, such as the stock position of cash and the maturity breakdown of other financial instruments, are useful for an analysis of liquidity. Balancing items such as net worth and net financial worth allows for an analysis of the wealth of government.

4.55 An analysis of gross debt sustainability requires calculating a primary balance, which can be calculated by excluding interest expense from the calculation of net lending/net borrowing or cash surplus/ deficit. When net debt is considered in the analysis, the primary balance should be calculated excluding the impact of interest expense and interest revenue. Similarly, the fiscal burden-an indicator of the compulsory contributions to the government-can be derived from transactions related to taxes and social contributions.

4.56 Table 4A.1 presents a list of some fiscal indicators that are directly available from GFS or that can be derived from GFS.

\section{Fiscal Indicators Requiring Additional Data}

4.57 Some fiscal indicators require additional information. The overall fiscal balance, for example, reflects the net lending/net borrowing after transactions in assets and liabilities are adjusted for transactions that are deemed to be for public policy purposes (also called "policy lending"). Notably, all proceeds under privatization (including proceeds from the sale of fixed assets) are included as financial items, while policy lending is treated as if it is an expense rather than a transaction in financial assets. 
For example, privatization proceeds or the repayment of policy lending is treated as financing while capital injections or loans to public corporations (policy lending) are added to expense in calculating the overall fiscal balance. Calculating the overall fiscal balance requires therefore a distinction between transactions in financial assets/liabilities undertaken for public policy purposes and those undertaken for liquidity management (see paragraph 4.29 and Box 4.1).

4.58 Cyclically adjusted and structural balances are other examples of fiscal indicators where information from various datasets must be assembled. These more complex fiscal balances attempt to measure fiscal positions net of cyclical and other transitory effects by taking into consideration the effects of exogenous factors on the fiscal balance. Examples of these more complex balances are also provided in Table 4A.2. Cyclically adjusted balances are measures of the government's fiscal position in an economy as if the economy was operating at potential gross domestic product (GDP). These balances can be calcu- lated by adjusting the GFS concept of net lending/net borrowing (or other fiscal balances in the GFS framework) for the effect on revenue and expense of the difference between actual and potential GDP. Structural balances are an extension of cyclically adjusted balances, by adjusting for a broader range of factors, such as commodity prices, which may over- or understate fiscal performance.

4.59 In resource-rich countries, analysts often take into account the volatility of commodity prices (which affects fiscal balances but is outside of the direct control of government) when assessing fiscal performance. Calculating nonresource balances requires removing from net lending/net borrowing (or other fiscal balances) net resource-related revenue and expenditure. These resource-related items are not available in the core classifications of GFS, but could be provided in underlying source data.

4.60 Table 4A.2 presents a list of fiscal indicators that are built using GFS with additional data. These fiscal indicators are usefully expressed as a percentage change or as ratios of aggregates, such as GDP.

\section{Table 4A.1 Fiscal Indicators Available from the GFS Framework}

\begin{tabular}{|c|c|c|}
\hline Fiscal Indicator & Equivalent Term in Statistical Methodologies & GFS Codes \\
\hline \multicolumn{3}{|c|}{ Fiscal balances } \\
\hline $\begin{array}{l}\text { Cash balance } \\
\text { (also referred } \\
\text { to as deficit/ } \\
\text { surplus) }\end{array}$ & $\begin{array}{l}\text { Cash surplus (+) / Cash deficit (-) (CSD) equal to the net cash inflow from } \\
\text { operating activities minus the net cash outflow from investment in } \\
\text { nonfinancial assets. } \\
\text { Cash surplus/cash deficit is also equal to total cash flows from financing } \\
\text { transactions. }\end{array}$ & $\begin{array}{l}\mathrm{C} 1-\mathrm{C} 2-\mathrm{C} 31 \text {, or } \\
\mathrm{C} 1-\mathrm{C} 2 \mathrm{M} \text {, or } \\
\mathrm{NFB}+\mathrm{NCB}\end{array}$ \\
\hline $\begin{array}{l}\text { Net operating } \\
\text { balance (NOB) }\end{array}$ & $\begin{array}{l}\text { Revenue minus expense. } \\
\text { Net operating balance is also equal to change in net worth due to } \\
\text { transactions. }\end{array}$ & $1-2$ \\
\hline $\begin{array}{l}\text { Gross operating } \\
\text { balance (GOB) }\end{array}$ & Revenue minus expense, excluding consumption of fixed capital. & $1-2+23$ \\
\hline $\begin{array}{l}\text { Net lending/net } \\
\text { borrowing (NLB) }\end{array}$ & $\begin{array}{l}\text { Revenue minus expense minus net investment in nonfinancial assets; or } \\
\text { Revenue minus expenditure; or } \\
\text { Net operating balance minus net investment in nonfinancial assets; or } \\
\text { Gross operating balance minus gross investment in nonfinancial assets. } \\
\text { Net lending/net borrowing is also equal to total financing. }\end{array}$ & $\begin{array}{l}1-2-31 \text {, or } \\
1-2 \mathrm{M} \text {, or } \\
\text { NOB-31, or } \\
\text { GOB-31.1+31.2 } \\
32-33\end{array}$ \\
\hline $\begin{array}{l}\text { Primary cash } \\
\text { balance }\end{array}$ & $\begin{array}{l}\text { Cash surplus/cash deficit excluding interest expense or net interest expense. } \\
\text { For gross debt sustainability analysis, use cash surplus/cash deficit excluding } \\
\text { interest expense. } \\
\text { For net debt sustainability analysis, use cash surplus/cash deficit excluding } \\
\text { net interest expense. }\end{array}$ & $\begin{array}{l}\mathrm{CSD}+\mathrm{C} 24 \\
\mathrm{CSD}+\mathrm{C} 24-\mathrm{C} 1411\end{array}$ \\
\hline
\end{tabular}




\section{Table 4A.1 Fiscal Indicators Available from the GFS Framework (continued)}

\begin{tabular}{|c|c|c|}
\hline Fiscal Indicator & Equivalent Term in Statistical Methodologies & GFS Codes \\
\hline \multicolumn{3}{|c|}{ Fiscal balances (continued) } \\
\hline $\begin{array}{l}\text { Primary } \\
\text { operating } \\
\text { balance }\end{array}$ & $\begin{array}{l}\text { Net operating balance excluding interest expense or net interest expense. } \\
\text { For gross debt sustainability analysis, use net operating balance excluding } \\
\text { interest expense. } \\
\text { For net debt sustainability analysis, use net operating balance excluding net } \\
\text { interest expense. }\end{array}$ & $\begin{array}{l}\mathrm{NOB}+24 \\
\mathrm{NOB}+24-1411\end{array}$ \\
\hline Primary balance & $\begin{array}{l}\text { Net lending/net borrowing excluding interest expense or net interest } \\
\text { expense. } \\
\text { For gross debt sustainability analysis use net lending/net borrowing } \\
\text { excluding interest expense. } \\
\text { For net debt sustainability analysis use net lending/net borrowing excluding } \\
\text { net interest expense. }\end{array}$ & $\begin{array}{l}\text { NLB }+24 \\
N L B+24-1411\end{array}$ \\
\hline \multicolumn{3}{|c|}{ Other Macroeconomic Fiscal Indicators } \\
\hline $\begin{array}{l}\text { Above-the-line } \\
\text { transactions }\end{array}$ & $\begin{array}{l}\text { All transactions in revenue, expense, and net investment in nonfinancial } \\
\text { assets. } \\
\text { (The main balancing items, such as cash surplus/cash deficit or net lending/ } \\
\text { net borrowing, serve as the "line.") }\end{array}$ & $\begin{array}{l}1,2 \text {, and } 31 \text {, or } \\
\mathrm{C} 1, \mathrm{C} 2 \text {, and } \mathrm{C} 31\end{array}$ \\
\hline $\begin{array}{l}\text { Below-the-line } \\
\text { transactions }\end{array}$ & $\begin{array}{l}\text { All transactions in the net acquisition of financial assets, and the net } \\
\text { incurrence of liabilities-also referred to as financing transactions. } \\
\text { (The main balancing items, such as cash surplus/cash deficit or net lending/ } \\
\text { net borrowing, serve as the "line.") }\end{array}$ & $\begin{array}{l}32 \text { and } 33, \text { or } \\
\text { NFB and NCB }\end{array}$ \\
\hline Fiscal burden & $\begin{array}{l}\text { Revenue in the form of taxes plus social contributions. } \\
\text { (In principle, only compulsory social contributions should be included- } \\
\text { where voluntary social contributions are significant, these need to be } \\
\text { excluded to calculate the fiscal burden, in which case this indicator becomes } \\
\text { a fiscal indicator requiring additional data.) }\end{array}$ & $\begin{array}{l}11+12, \text { or } \\
11+121+122\end{array}$ \\
\hline Tax burden & Revenue in the form of taxes. & 11 \\
\hline Direct taxes & $\begin{array}{l}\text { Taxes that take into account individual circumstances of taxpayers (e.g., } \\
\text { taxes on individual and corporate income). }\end{array}$ & $111+1131+1132+1136$ \\
\hline Indirect taxes & $\begin{array}{l}\text { Taxes that do not take into account individual circumstances of taxpayers } \\
\text { (e.g., taxes imposed on goods and services). }\end{array}$ & $112+114+115+116$ \\
\hline Capital taxes & $\begin{array}{l}\text { Capital taxes are taxes levied at irregular and infrequent intervals on } \\
\text { the values of the assets or net worth owned by institutional units or on } \\
\text { the values of assets transferred between institutional units as a result of } \\
\text { legacies, gifts, or other transfers. }\end{array}$ & $1133+1135$ \\
\hline $\begin{array}{l}\text { Government } \\
\text { final } \\
\text { consumption } \\
\text { expenditure }\end{array}$ & $\begin{array}{l}\text { Approximated by compensation of employees, plus the use of goods and } \\
\text { services, plus consumption of fixed capital, plus purchases of goods and } \\
\text { services for direct transfer to households (mainly social benefits in kind), } \\
\text { minus the sales of goods and services. }\end{array}$ & $21+22+23+282-142$ \\
\hline Gross saving & $\begin{array}{l}\text { Gross operating balance excluding net capital transfers receivable (capital } \\
\text { transfers including net capital grants and capital taxes); or } \\
\text { Net lending/net borrowing excluding gross investment in nonfinancial } \\
\text { assets, and excluding net capital transfers receivable (capital transfers } \\
\text { including net capital grants and capital taxes). }\end{array}$ & $\begin{array}{l}\text { GOB- }(1133+1135+1312+ \\
1322+1332+1442+1452- \\
2612-2622-2632-2822- \\
2832), \text { or } \\
\text { NLB+31+23- } \\
(1133+1135+1312+ \\
1322+1332+1442+ \\
1452-2612-2622-2632- \\
2822-2832)\end{array}$ \\
\hline
\end{tabular}




\section{Table 4A.1 Fiscal Indicators Available from the GFS Framework (continued)}

\begin{tabular}{|c|c|c|}
\hline Fiscal Indicator & Equivalent Term in Statistical Methodologies & GFS Codes \\
\hline \multicolumn{3}{|c|}{ Other Macroeconomic Fiscal Indicators (continued) } \\
\hline Capital spending & $\begin{array}{l}\text { Net investment in nonfinancial assets equals acquisition of nonfinancial } \\
\text { assets minus disposal of nonfinancial assets minus consumption of fixed } \\
\text { capital. }\end{array}$ & $31.1-31.2-31.3$ \\
\hline $\begin{array}{l}\text { Gross investment } \\
\text { in nonfinancial } \\
\text { assets }\end{array}$ & $\begin{array}{l}\text { Net acquisition of nonfinancial assets equals acquisition of nonfinancial } \\
\text { assets minus disposal of nonfinancial assets. } \\
\text { Net investment in nonfinancial assets plus consumption of fixed capital. }\end{array}$ & $\begin{array}{l}31.1-31.2, \text { or } \\
31+23\end{array}$ \\
\hline $\begin{array}{l}\text { Gross capital } \\
\text { formation }\end{array}$ & $\begin{array}{l}\text { Acquisition minus disposals of produced nonfinancial assets, which comprise } \\
\text { fixed assets, inventories, and valuables. }\end{array}$ & $311.1-311.2+312+313$ \\
\hline $\begin{array}{l}\text { Gross fixed } \\
\text { capital } \\
\text { formation }\end{array}$ & Acquisitions minus disposals of fixed assets. & $311.1-311.2$ \\
\hline $\begin{array}{l}\text { Net interest } \\
\text { expense }\end{array}$ & Interest expense minus interest revenue. & 24-1411 \\
\hline Social spending & $\begin{array}{l}\text { Approximated by functional classification of expenditure on housing, } \\
\text { health, education, and social protection. }\end{array}$ & $706+707+709+710$ \\
\hline $\begin{array}{l}\text { Total } \\
\text { expenditure or } \\
\text { outlays }\end{array}$ & Expense plus net investment in nonfinancial assets; or expenditure. & $2+31$, or $2 \mathrm{M}$ \\
\hline $\begin{array}{l}\text { Transfer } \\
\text { payments } \\
\text { excluding grants }\end{array}$ & $\begin{array}{l}\text { Transfers to corporations, households, and nonprofit institutions serving } \\
\text { households, which comprise subsidies, social benefits, transfers not } \\
\text { elsewhere classified, and premiums, fees, and claims related to nonlife } \\
\text { insurance and standardized guarantee schemes. }\end{array}$ & $25+27+282+283$ \\
\hline \multicolumn{3}{|c|}{ Financing Indicators } \\
\hline Total financing & Transactions in financial assets minus transactions in liabilities. & $32-33$, or $82-83$ \\
\hline $\begin{array}{l}\text { Domestic } \\
\text { financing }\end{array}$ & $\begin{array}{l}\text { Transactions in financial assets minus transactions in liabilities, both with } \\
\text { resident institutional units (domestic debtors/creditors). }\end{array}$ & $321-331$, or $821-831$ \\
\hline $\begin{array}{l}\text { Foreign } \\
\text { financing }\end{array}$ & $\begin{array}{l}\text { Transactions in financial assets minus transactions in liabilities, both with } \\
\text { nonresident institutional units (external debtors/creditors). }\end{array}$ & $322-332$, or $822-832$ \\
\hline $\begin{array}{l}\text { Domestic bank } \\
\text { financing }\end{array}$ & $\begin{array}{l}\text { Transactions in financial assets and liabilities with the central bank and } \\
\text { resident deposit-taking corporations other than the central bank. }\end{array}$ & $8212+8213-8312-8313$ \\
\hline $\begin{array}{l}\text { Domestic } \\
\text { nonbank } \\
\text { financing }\end{array}$ & $\begin{array}{l}\text { Transactions in financial assets and liabilities with resident institutional } \\
\text { units other than the central bank and resident deposit-taking corporations } \\
\text { other than the central bank; or } \\
\text { Transactions in financial assets and liabilities with general government } \\
\text { units, and resident other financial corporations, nonfinancial corporations, } \\
\text { and households and nonprofit institutions serving households. }\end{array}$ & $\begin{array}{l}(821-8212-8213)-(831- \\
8312-8313), \text { or } \\
8211+8214+8215+8216- \\
8311-8314-8315-8316\end{array}$ \\
\hline \multicolumn{3}{|c|}{ Wealth and Debt Indicators } \\
\hline $\begin{array}{l}\text { Accounts } \\
\text { payable }\end{array}$ & $\begin{array}{l}\text { Stock position in other accounts payable, which comprise trade credit and } \\
\text { advances, and miscellaneous other items due to be paid. }\end{array}$ & 6318 \\
\hline Arrears & Stock position in amounts unpaid and past the due date for payment. & $6 \mathrm{M} 5$ \\
\hline $\begin{array}{l}\text { Contingent } \\
\text { liabilities }\end{array}$ & $\begin{array}{l}\text { Obligations that do not arise unless a particular, discrete event(s) occurs in } \\
\text { the future. }\end{array}$ & $6 \mathrm{M} 6$ \\
\hline $\begin{array}{l}\text { Total pension } \\
\text { and insurance } \\
\text { liabilities }\end{array}$ & $\begin{array}{l}\text { Stock position in insurance, pension, and standardized guarantee scheme } \\
\text { liabilities plus net obligations for social security benefits. }\end{array}$ & $6306+6 \mathrm{M} 7$ \\
\hline Gross debt & $\begin{array}{l}\text { Stock position in financial claims that require payment(s) of interest and/ } \\
\text { or principal by the debtor to the creditor at a date, or dates, in the future. } \\
\text { Includes all liabilities held in debt instruments (i.e., total liabilities excluding } \\
\text { equity and investment fund shares and financial derivatives and employee } \\
\text { stock options). }\end{array}$ & $\begin{array}{l}63-6305-6307, \text { or } \\
6301+6302+6303+6304+ \\
6306+6308\end{array}$ \\
\hline
\end{tabular}


Table 4A.1 Fiscal Indicators Available from the GFS Framework (concluded)

\begin{tabular}{|c|c|c|}
\hline Fiscal Indicator & Equivalent Term in Statistical Methodologies & GFS Codes \\
\hline \multicolumn{3}{|c|}{ Wealth and Debt Indicators (concluded) } \\
\hline Net debt & $\begin{array}{l}\text { Gross debt minus stock position in financial assets corresponding to debt } \\
\text { instruments. Includes all financial assets/liabilities held in debt instruments } \\
\text { (i.e., financial assets/liabilities excluding equity and investment fund shares } \\
\text { and financial derivatives and employee stock options). }\end{array}$ & $\begin{array}{l}(63-6305-6307)-(62- \\
6205-6207), \text { or } \\
6301+6302+6303+6304+ \\
6306+6308-6201-6202- \\
6203-6204-6306-6308\end{array}$ \\
\hline $\begin{array}{l}\text { Gross debt, net } \\
\text { of highly liquid } \\
\text { assets }\end{array}$ & $\begin{array}{l}\text { Gross debt minus financial assets held in the most liquid financial } \\
\text { instruments. In most countries, liquid assets would primarily comprise } \\
\text { currency and deposits. (Where other financial assets are partly considered } \\
\text { highly liquid financial assets, this indicator becomes a fiscal indicator } \\
\text { requiring additional data.) }\end{array}$ & $\begin{array}{l}63-6305-6307-6201, \text { or } \\
6301+6302+6303+6304+ \\
6306+6308-6201\end{array}$ \\
\hline $\begin{array}{l}\text { Net financial } \\
\text { wealth }\end{array}$ & $\begin{array}{l}\text { Net financial worth equals the stock position in financial assets minus stock } \\
\text { position in liabilities. }\end{array}$ & $62-63$, or $6 \mathrm{M} 1$ \\
\hline Net worth & $\begin{array}{l}\text { Stock position in assets minus stock position in liabilities at end of reference } \\
\text { period. }\end{array}$ & $61+62-63$, or 6 \\
\hline $\begin{array}{l}\text { Total change in } \\
\text { net worth }\end{array}$ & $\begin{array}{l}\text { Net worth at the end of the current reporting period minus net worth at } \\
\text { the end of the previous reporting period. (A split between change in net } \\
\text { worth due to transactions [i.e., net operating balance] and change in net } \\
\text { worth due to other economic flows is also analytically useful.) }\end{array}$ & $\begin{array}{l}6_{t 1}-6+0, \text { or }(61+62-63)_{t 1-} \\
(61+62-63)_{t 0} \text {, or NOB+9 }\end{array}$ \\
\hline
\end{tabular}


Table 4A.2 Fiscal Indicators Requiring Additional Data

\begin{tabular}{|c|c|}
\hline Fiscal Indicator & Related Term in Statistical Methodologies \\
\hline Resource revenue & $\begin{array}{l}\text { Revenue receivable that is related to natural resources. These receivables may be related to } \\
\text { various types of taxes, subsidies, dividends, contracts, leases, and licenses, rent, or other transfers. }\end{array}$ \\
\hline Resource expense & $\begin{array}{l}\text { Expense payable that is related to natural resources. These payables may be related to various } \\
\text { types of expense such as subsidies, property expense, and transfers. }\end{array}$ \\
\hline $\begin{array}{l}\text { Nonresource } \\
\text { operating balance }\end{array}$ & $\begin{array}{l}\text { Total revenue excluding natural resource-related revenue minus total expense excluding natural } \\
\text { resource-related expense. }\end{array}$ \\
\hline $\begin{array}{l}\text { Nonresource } \\
\text { primary operating } \\
\text { balance }\end{array}$ & $\begin{array}{l}\text { Nonresource operating balance excluding interest expense for gross debt sustainability analysis or } \\
\text { excluding net interest expense for net debt sustainability analysis. }\end{array}$ \\
\hline $\begin{array}{l}\text { Nonresource } \\
\text { net lending/net } \\
\text { borrowing }\end{array}$ & Nonresource operating balance minus net investment in nonresource related nonfinancial assets. \\
\hline $\begin{array}{l}\text { Nonresource } \\
\text { primary net } \\
\text { lending/net } \\
\text { borrowing }\end{array}$ & $\begin{array}{l}\text { Nonresource net lending/net borrowing excluding interest expense for gross debt sustainability } \\
\text { analysis or excluding net interest expense for net debt sustainability analysis. }\end{array}$ \\
\hline $\begin{array}{l}\text { Overall fiscal } \\
\text { balance }\end{array}$ & $\begin{array}{l}\text { Net lending/net borrowing adjusted through the rearrangement of transactions in assets and } \\
\text { liabilities that are deemed to be for public policy purposes (also called policy lending/borrowing). } \\
\text { Policy lending is added to expense. Privatization proceeds from the sale of nonfinancial assets } \\
\text { and repayments on policy lending (see Box 4.1) are included as transactions in financial items in } \\
\text { calculating the overall fiscal balance. }\end{array}$ \\
\hline $\begin{array}{l}\text { Overall primary } \\
\text { balance }\end{array}$ & $\begin{array}{l}\text { Overall fiscal balance excluding interest expense or net interest expense. } \\
\text { For gross debt sustainability analysis, use overall fiscal balance excluding interest expense. } \\
\text { For net debt sustainability analysis, use overall fiscal balance excluding net interest expense. }\end{array}$ \\
\hline $\begin{array}{l}\text { Cyclically adjusted } \\
\text { balance }\end{array}$ & $\begin{array}{l}\text { Trend balance through an economic cycle, which is the fiscal balance, stripped of the impact of } \\
\text { cyclical movements in revenue and expenditure (for government, usually only unemployment } \\
\text { benefits payable are eliminated). }\end{array}$ \\
\hline $\begin{array}{l}\text { Cyclically adjusted } \\
\text { primary balance }\end{array}$ & $\begin{array}{l}\text { Trend balance through an economic cycle, which is primary fiscal balance, stripped of the impact } \\
\text { of cyclical movements in revenue and expenditure (for government, usually only unemployment } \\
\text { benefits payable are eliminated). }\end{array}$ \\
\hline Structural balance & $\begin{array}{l}\text { Underlying or permanent fiscal balance, which is the fiscal balance, stripped of the impact of } \\
\text { cyclical movements in revenue, expenditure, and the effects of unusual or one-off events. }\end{array}$ \\
\hline $\begin{array}{l}\text { Structural primary } \\
\text { balance }\end{array}$ & $\begin{array}{l}\text { Underlying or permanent primary fiscal balance, which is the primary fiscal balance, after } \\
\text { removing the impact of cyclical movements in revenue, expenditure, and the effects of unusual or } \\
\text { one-off events. }\end{array}$ \\
\hline Fiscal impulse & $\begin{array}{l}\text { Change in the structural primary balance between two reporting periods. (Often also calculated } \\
\text { using the [overall] structural balance, or the cyclically adjusted [primary] balance.) }\end{array}$ \\
\hline $\begin{array}{l}\text { Gross financing } \\
\text { needs }\end{array}$ & $\begin{array}{l}\text { Net lending/net borrowing during a particular reporting period plus debt maturing within that } \\
\text { reporting period. (This concept is a forward-looking indicator and should not be confused with } \\
\text { total financing.) }\end{array}$ \\
\hline Concessional loans & $\begin{array}{l}\text { Loans that provide to the borrower some concessional benefits. An estimate of the one-off } \\
\text { benefit at the point of loan origination can be calculated as equal to the difference between the } \\
\text { nominal value of the debt and its present value using a relevant market discount rate. }\end{array}$ \\
\hline $\begin{array}{l}\text { Development } \\
\text { spending }\end{array}$ & $\begin{array}{l}\text { Represents government's expenditure on national development and encompasses transactions in } \\
\text { the acquisition of nonfinancial assets, usually related to infrastructure. Development spending is } \\
\text { often financed from specific designated sources (e.g., foreign loans, foreign grants, privatization } \\
\text { proceeds, one-off tax levies). }\end{array}$ \\
\hline $\begin{array}{l}\text { Quasi-fiscal } \\
\text { operations }\end{array}$ & $\begin{array}{l}\text { Quasi-fiscal operations are government operations carried out by institutional units other than } \\
\text { government units (e.g., central banks and other public corporations). Quasi-fiscal operations } \\
\text { encompass a broad array of activities that have the same fiscal policy impact on the economy as } \\
\text { government operations. }\end{array}$ \\
\hline
\end{tabular}



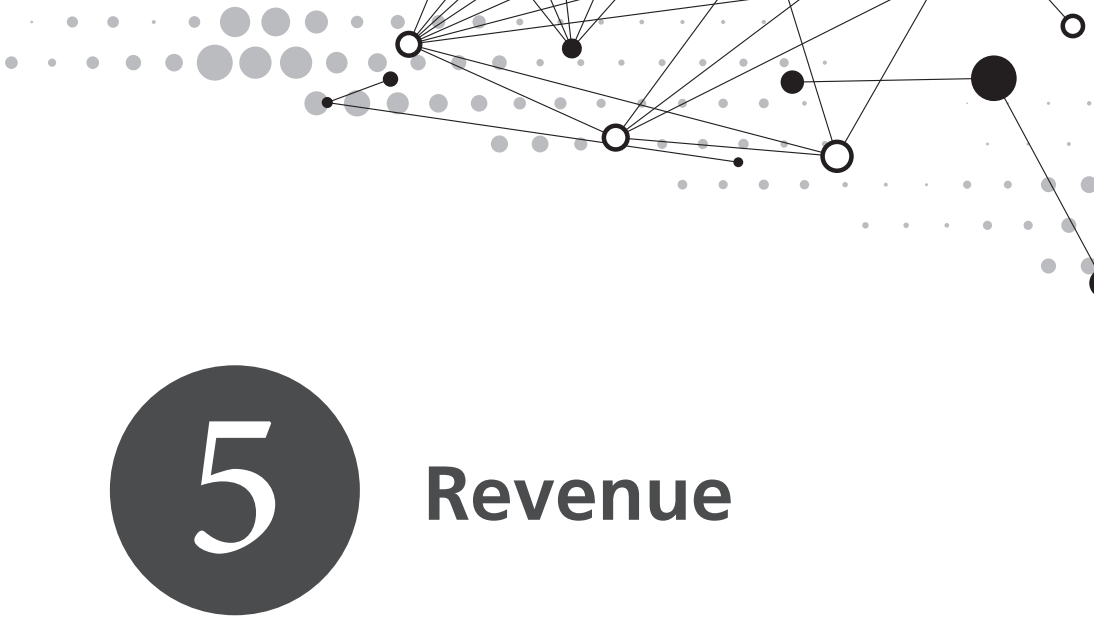

\section{Revenue}

This chapter defines the concept of revenue and describes the manner in which revenue is classified.

\section{Defining Revenue}

5.1 Revenue (1) is an increase in net worth resulting from a transaction. Revenue transactions, as defined in GFS, have counterpart entries either in an increase in assets or in a decrease in liabilitiesthereby increasing net worth. General government units have four types of revenue: (i) compulsory levies in the form of taxes and certain types of social contributions; (ii) property income derived from the ownership of assets; (iii) sales of goods and services; and (iv) other transfers receivable from other units. Of these, compulsory levies and transfers are the main sources of revenue for most general government units. Public corporations do not levy taxes, but derive their revenue from all the other sources-of these, property income and the sales of goods and services are the main sources of revenue.

5.2 Taxes $(11)^{1}$ are compulsory, unrequited amounts receivable by government units from institutional units. Taxes can be receivable in cash $^{2}$ or in kind. ${ }^{3}$ By its nature, only a government unit can receive revenue in the form of taxes. When an institutional unit other than a government unit collects taxes, the tax should be attributed in accordance with tax attribution guidelines (see paragraphs 5.33-5.40). Tax revenue is considered to be unrequited because the government provides nothing directly to the individual unit in exchange for the payment. Governments may use the tax revenue

\footnotetext{
${ }^{1}$ The numbers in parentheses after each classification category are the GFS classification codes. Appendix 8 provides all classification codes used in the GFS framework.

${ }^{2}$ The use of the term "cash" here does not refer to the cash basis of recording, but rather refers to the monetary nature of the settlement.

${ }^{3}$ Revenue receivable in kind will not be recorded when using the cash basis of recording - no cash flows are involved (see paragraph 3.67).
}

to provide goods or services to other units, either individually or collectively, or to the community as a whole. Certain compulsory receivables, such as fines, penalties, and most social security contributions, are not considered taxes (see paragraph 5.23). These types of revenue have, under certain conditions, an element of exchange and are therefore not classified as taxes.

5.3 All other types of revenue are frequently combined into a heterogeneous broad category: revenue other than taxes (also sometimes referred to as nontax revenue). In this manual, however, the various other types of revenue are separately identified and classified as social contributions, grants, and other revenue.

5.4 Social contributions $[G F S]^{4}(12)$ are actual or imputed revenue receivable by social insurance schemes to make provision for social insurance benefits payable. ${ }^{5}$ Social contributions may be from employers on behalf of their employees, from employees, or from self-employed or unemployed persons on their own behalf. These contributions secure entitlement to social benefits payable to the contributors, their dependents, or their survivors when certain social risks arise. The contributions may be compulsory or voluntary (see paragraph 5.94 and Appendix 2).

5.5 Grants (13) are transfers receivable by government units from other resident or nonresident government units or international organizations, and that do not meet the definition of a tax, subsidy, or social contribution. When statistics are compiled for the general government sector, grants from other domestic government units would be

\footnotetext{
${ }^{4}$ [GFS] indicates that an item has the same name but different coverage in the 2008 SNA.

${ }^{5}$ Social contributions [GFS](12) revenue excludes amounts receivable as employment-related pension and other retirement contributions that create a liability for future benefits payable (see paragraphs 4.50 and 5.95).
} 
eliminated in consolidation so that only grants from foreign governments and international organizations would remain in the general government accounts. Grants may be classified as capital or current and can be receivable in cash or in kind (see paragraphs 5.103-5.105).

5.6 Other revenue (14) is all revenue receivable excluding taxes, social contributions, and grants. Other revenue comprises: (i) property income; (ii) sales of goods and services; (iii) fines, penalties, and forfeits; (iv) transfers not elsewhere classified; and (v) premiums, fees, and claims related to nonlife insurance and standardized guarantee schemes (see paragraphs 5.106-5.151).

5.7 Refunds (see paragraph 5.27) and corrections of erroneously collected revenue are transactions that decrease the net worth of the recipient government unit. More accurately, they are adjustments that allow the excessive increase in net worth previously recorded to be corrected. These refund transactions are recorded as a reduction in revenue, with a corresponding reduction in financial assets or an increase in liabilities. ${ }^{6}$

5.8 Some transactions are exchanges in assets and/or liabilities and should not be recorded as revenue. The disposal of a nonfinancial asset, other than inventories, ${ }^{7}$ by sale or barter does not affect net worth and these transactions are not revenue. They are transactions in nonfinancial assets as described in paragraphs 8.3-8.4. However, when ownership of an asset is acquired without having to give up anything of commensurate value in return, the net worth of the unit increases. This increase in assets has a counterpart entry in an increase in revenue and should be recorded as a type of capital transfer receivable, such as a capital grant. Repayments on loans previously extended to other institutional units, and loan disbursements, are not revenue. These are transactions in financial assets or liabilities as described in paragraphs 9.3-9.4.

5.9 For the purposes of fiscal analysis, additional aggregations of revenue could be calculated, such as the fiscal burden, direct versus indirect taxes, and

\footnotetext{
${ }^{6}$ Similarly, refunds of expense are recorded as a reduction in expense, rather than revenue (see paragraph 6.4).

${ }^{7}$ For a description of the treatment of inventories, see paragraphs 8.44-8.47.
}

revenue related to natural resources. A discussion of these supplementary fiscal indicators and their uses in fiscal analysis is presented in the annex to Chapter 4.

\section{Time of Recording and Measurement of Revenue}

5.10 In the Statement of Operations, revenue should be recorded according to the accrual basis of recording. In the accrual basis of recording, transactions are recorded when the underlying activities, transactions, or other events occur that create the unconditional claims to receive the taxes or other types of revenue (see paragraphs 3.69-3.102). The application of the general rule to various types of revenue is indicated in each section of the classification as needed.

5.11 In the Statement of Sources and Uses of Cash, cash receipts from operating activities are recorded in accordance with the cash basis of recording. In the cash basis of recording, transactions are recorded when cash payments for the respective revenue categories are received (see paragraph 3.103-3.104).

5.12 According to the accrual principles of GFS, income taxes and social contributions based on income should be attributed to the period in which the income is earned, even though there may be a significant delay between the end of the reporting period and the time at which it is feasible to determine the actual liability of the taxpayer.

5.13 Conceptually, when using the accrual basis of recording, the time between the moment a revenue transaction accrues and the payment is received (or made in the case of refunds) is bridged by recording a transaction in financial assets or liabilities (see paragraph 7.224). In cases where a prepayment of revenue covering two or more reporting periods is made to government, government should record an increase in liabilities, usually recorded in other accounts payable (3308), for the revenue that falls due in future periods. In effect, this is a financial advance made to government by the payee. It constitutes a liability of the government and an asset of the payee. This liability is extinguished as the revenue falls due in future periods.

5.14 In practice, however, some flexibility is permitted as the accrual recording of revenue can be difficult to implement because government accounting 
systems often record revenue only on a cash basis. This is especially the case for taxes. Further, even when accrued taxes are estimated from assessments of taxes due, there may be a risk of over- or understatement of tax revenue. The remainder of this section provides additional practical guidance on the appropriate time of recording for taxes.

5.15 As a practical deviation from the general principle, income taxes deducted at source, such as pay-as-you-earn taxes, and regular prepayments of income taxes may be recorded in the periods in which they are paid and any final tax liability on income may be recorded in the period in which the liability is determined.

5.16 It is also possible that governments receive cash amounts before having an unconditional claim on them. ${ }^{8}$ Such circumstances include advances for provision of goods and services to be delivered in the future, and grants for the construction of fixed assets over several periods. When using the accrual basis of recording, these cash receipts cannot be recognized as revenue until such time as the government acquires the unconditional claim on the amount. However, when using the cash basis of recording, the full amount of revenue will be recognized in the period in which the cash amounts were received, irrespective of whether the service, delivery, or compliance with the conditions were met in the past or will be met in the future.

5.17 With the exception of taxes and social contributions, the amount of revenue to be recorded on the accrual basis is the entire amount to which the general government unit has an unconditional claim. In the case of taxes and social insurance contributions, only those amounts that are evidenced by assessments and declarations, customs declarations, and similar documents are considered to constitute revenue for government units.

5.18 As indicated in paragraph 3.78, the amount of taxes and social contributions recorded must take into account that the government unit receiving the revenue is usually not a party to the transaction or other event that creates the obligation to pay the taxes or social insurance contributions. Consequently, many

\footnotetext{
${ }^{8}$ These receipts are also referred to as "deferred revenue" or "advances" (see also paragraph 7.225).
}

of these transactions and events permanently escape the attention of the tax authorities. The amount of revenue from taxes and social insurance contributions should exclude the amounts that possibly could have been received from such unreported events had the government learned about them, but instead permanently escape the attention of the tax authorities.

5.19 Furthermore, in some countries, and for some taxes, the amounts of taxes eventually paid may diverge substantially and systematically from the amounts due to be paid. It would be inappropriate to accrue revenue for an amount that the government unit does not realistically expect to collect. The amount that is realistically expected to be collected may sometimes be influenced by tax amnesties. Governments use tax amnesties to capture some of the taxes accrued but unpaid, to speed up payment of taxes, and to capture revenue from transactions or events that have previously escaped the attention of the tax authorities. The time of recording and measurement of revenue arising from such tax amnesties depends on the exact nature of the amnesty granted and whether the revenue has been previously accrued. The case of adjusting for underestimation or overestimation of tax revenue is discussed later.

5.20 It is typical that some of the taxes and social insurance contributions that have been assessed and accrued will never be collected. Thus, the difference between estimates based on these assessments and expected collections represents a claim that has no real value and should not be recorded as revenue. If transactions are recorded for such taxes (and other revenue) that overestimate the amount of revenue receivable, a correction should be recorded in the GFS framework. This requires an adjustment that allows the excessive increase in net worth previously recorded to be corrected. ${ }^{9}$ In keeping with the accrual basis of recording (see paragraph 3.79), such an adjustment should occur in the period in which the overestimation of receivables occurred. However, in cases where it is not possible to identify the time of the overestimation, the adjustment is recorded when the need for the adjustment is identified. As such, a correction to reduce revenue, with a corresponding correction

\footnotetext{
${ }^{9}$ These corrections in transactions recorded for revenue receivables should be distinguished from the case where a specific debtor is deemed bankrupt and amounts receivable are deemed to be uncollectable (see paragraph 10.57).
} 
(reduction) in other accounts receivable (3208), should be recorded. The amount of taxes and social insurance contributions that is recorded as revenue should be the amount that is realistically expected to be receivable. The actual collection, however, may be in a later period, possibly much later.

\section{The Classification of Revenue}

5.21 Revenue comprises heterogeneous elements, classified according to different characteristics depending on the type of revenue. For taxes, the classification scheme is determined mainly by the base on which the tax is levied. Revenue other than taxes is classified by the nature of the economic flow, and in some cases by the source from which the revenue is derived. The summary classification of revenue in the GFS framework is shown in Table 5.1, and the remainder of this chapter describes each category in detail.

5.22 While the summary GFS revenue classification structure provides guidance on the minimum requirements for internationally comparable classifications of revenue, analytical needs may necessitate further detailed classifications to be added as subitems in national data presentations. Additional subitems, presented either as a comprehensive breakdown of the standard item or as "of which" lines, could be used to identify items required:

- To facilitate consolidation-for example, a breakdown of items according to the subsectors and institutional units of general government (see paragraph 3.152)

- As input into other macroeconomic datasets to enhance consistency with these data-for example, a breakdown of interest to identify recipients according to residence and sectors (see paragraph 7.264)

- To facilitate the calculation of supplementary aggregates or balances used as fiscal indicators in fiscal analysis-for example, identifying all revenue related to a particular resource could allow the calculation of government balances without such resource revenue (see paragraph 4.59), or identifying all environment-related revenue and payments to government could facilitate the compilation of environmental accounts (see paragraph A7.107).

\section{Taxes (11)}

5.23 Taxes are compulsory, unrequited amounts receivable by government units from institutional units. In GFS, taxes are classified mainly according to the base on which the tax is levied. Normally, designating a tax for a particular use does not affect its classification. An exception is the distinction between taxes on payroll and workforce and social security contributions. If a tax on payroll or workforce is designated for use in a social security scheme, then it is classified as a social security contribution (see paragraphs 5.45 and 5.96). Otherwise, it is classified under taxes on payroll and workforce. Taxes also exclude compulsory payments receivable by government, as contributions to employment-related pension schemes. Since these compulsory contributions are associated with the expectation of future benefits payable, they are not tax revenue receivable, but rather recorded as the incurrence of a pension entitlement liability (see paragraphs 9.63-9.67).

5.24 In principle, interest charged on overdue taxes or fines and penalties imposed for the attempted evasion of taxes should be recorded as interest (1411), or fines, penalties, and forfeits (143) and not as taxes. However, it may not be possible to separate receivables of interest, fines, or other penalties from the taxes to which they relate, so in practice they are usually grouped with the relevant tax receivable (see also paragraph 6.82).

\section{GFS tax classifications in comparison with other statistical databases}

5.25 The coverage, timing, and valuation of tax revenue in GFS and the 2008 SNA are identical, but the classification systems differ. The 2008 SNA classifies taxes according to their role in economic activitiesnamely: (i) taxes on production and imports (D2); (ii) current taxes on income, wealth, etc. (D5); and (iii) capital taxes (D91). The result is that some categories of taxes in GFS need to be allocated between two of the SNA tax categories according to whether they are payable by producers or final consumers, or whether they are current or capital taxes. ${ }^{10}$ In GFS, taxes are classified into six major categories: (i) taxes on income, profits, and capital gains; (ii) taxes on

\footnotetext{
${ }^{10}$ For a detailed description of the linkages between the GFS and the 2008 SNA categories of taxes, see Appendix 7.
} 


\section{Table 5.1 Summary Classification of Revenue}

\begin{tabular}{|c|c|c|c|}
\hline 1 & Revenue & 12 & Social contributions [GFS] \\
\hline 11 & Taxes & 121 & Social security contributions [GFS] \\
\hline 111 & Taxes on income, profits, and capital gains & 1211 & Employee contributions [GFS] \\
\hline 1111 & Payable by individuals & 1212 & Employer contributions [GFS] \\
\hline 1112 & $\begin{array}{l}\text { Payable by corporations and other } \\
\text { enterprises }\end{array}$ & 1213 & $\begin{array}{l}\text { Self-employed or unemployed contributions } \\
\text { [GFS] }\end{array}$ \\
\hline \multirow[t]{2}{*}{1113} & \multirow{2}{*}{$\begin{array}{l}\text { Other taxes on income, profits, and } \\
\text { capital gains }{ }^{1}\end{array}$} & 1214 & Unallocable contributions [GFS] \\
\hline & & 122 & Other social contributions [GFS] \\
\hline 112 & Taxes on payroll and workforce & 1221 & Employee contributions [GFS] \\
\hline 113 & Taxes on property & 1222 & Employer contributions [GFS] \\
\hline 1131 & Recurrent taxes on immovable property & 1223 & Imputed contributions [GFS] \\
\hline 1132 & Recurrent taxes on net wealth & 13 & Grants \\
\hline $\begin{array}{l}1133 \\
1135\end{array}$ & Estate, inheritance, and gift taxes & 131 & From foreign governments \\
\hline 1136 & Other recurrent taxes on property & 1311 & Current \\
\hline 114 & Taxes on goods and services & 1312 & Capital \\
\hline 1141 & General taxes on goods and services & 132 & From international organizations \\
\hline 11411 & Value-added taxes & 1321 & Current \\
\hline 11412 & Sales taxes & 1322 & Capital \\
\hline 11413 & $\begin{array}{l}\text { Turnover and other general taxes on } \\
\text { goods and services }\end{array}$ & $\begin{array}{l}133 \\
1331\end{array}$ & $\begin{array}{l}\text { From other general government units }{ }^{1} \\
\text { Current }\end{array}$ \\
\hline 11414 & Taxes on financial and capital transactions & 1332 & Capital \\
\hline 1142 & Excise & 14 & Other revenue \\
\hline 1143 & Profits of fiscal monopolies & 141 & Property income [GFS] \\
\hline 1144 & Taxes on specific services & 1411 & Interest [GFS $]^{1}$ \\
\hline 1145 & $\begin{array}{l}\text { Taxes on use of goods and on permission } \\
\text { to use goods or perform activities }\end{array}$ & 1412 & Dividends $^{1}$ \\
\hline 11451 & $\begin{array}{l}\text { to use goods or perform activities } \\
\text { Motor vehicle taxes }\end{array}$ & 1413 & $\begin{array}{l}\text { Withdrawals of income from } \\
\text { quasi-corporations }\end{array}$ \\
\hline \multirow[t]{2}{*}{11452} & \multirow{2}{*}{$\begin{array}{l}\text { Other taxes on use of goods and on } \\
\text { permission to use goods or perform } \\
\text { activities }^{1}\end{array}$} & 1414 & $\begin{array}{l}\text { Property income from investment income } \\
\text { disbursements }\end{array}$ \\
\hline & & 1415 & Rent \\
\hline 1146 & Other taxes on goods and services & 1416 & Reinvested earnings on foreign direct investment \\
\hline 115 & Taxes on international trade and transactions & 142 & Sales of goods and services \\
\hline 1151 & Customs and other import duties & 1421 & Sales by market establishments \\
\hline 1152 & Taxes on exports & 1422 & Administrative fees \\
\hline 1153 & Profits of export or import monopolies & 1423 & Incidental sales by nonmarket establishments \\
\hline 1154 & Exchange profits & 1424 & Imputed sales of goods and services \\
\hline 1155 & Exchange taxes & 143 & Fines, penalties, and forfeits \\
\hline 1156 & $\begin{array}{l}\text { Other taxes on international trade and } \\
\text { transactions }\end{array}$ & $\begin{array}{l}144 \\
1441\end{array}$ & $\begin{array}{l}\text { Transfers not elsewhere classified } \\
\text { Current transfers not elsewhere classified }\end{array}$ \\
\hline 116 & Other taxes & 14411 & Subsidies $^{1}$ \\
\hline 1161 & Payable solely by business & 14412 & Other current transfers not elsewhere classified ${ }^{1}$ \\
\hline \multirow[t]{4}{*}{1162} & \multirow{4}{*}{$\begin{array}{l}\text { Payable by other than business or } \\
\text { unidentifiable }\end{array}$} & 1442 & Capital transfers not elsewhere classified \\
\hline & & 145 & $\begin{array}{l}\text { Premiums, fees, and claims related to nonlife } \\
\text { insurance and standardized guarantee schemes }{ }^{1}\end{array}$ \\
\hline & & 1451 & Premiums, fees, and current claims ${ }^{1}$ \\
\hline & & 1452 & Capital claims \\
\hline
\end{tabular}

IIndicates that a further breakdown may be analytically useful and is presented in detailed tables. 
payroll and workforce; (iii) taxes on property; (iv) taxes on goods and services; ( $v$ ) taxes on international trade and transactions; and (vi) other taxes. These categories are described in the various sections on the respective tax categories.

5.26 The classification of taxes in this manual is quite similar to the classification employed in Revenue Statistics, which is published annually by the Organisation for Economic Co-operation and Development. The two primary differences in the classification structure are that in Revenue Statistics, compulsory social security contributions are treated as taxes and the categories of taxes on goods and services, and taxes on international trade and transactions are combined into a single category. In addition, at a detailed classification level, Revenue Statistics differs in the following aspects: (i) payable tax credits are recorded as negative taxes to the extent that the payable tax credit offsets existing income tax receivable; (ii) imputed taxes or subsidies resulting from the central bank imposing a rate of interest other than the market rate are excluded from Revenue Statistics; and (iii) imputed taxes or subsidies resulting from the operation of multiple exchange rate systems are excluded from Revenue Statistics.

\section{Treatment of tax refunds and tax relief}

5.27 Tax refunds are adjustments for overestimation of taxes payable or the return of amounts to taxpayers due to overpayments. Tax refunds generally are recorded as a reduction in the appropriate tax category. When using the accrual basis of recording, refunds are attributed to the period in which the event occurred that generated the overassessments or overpayments. However, in cases where it is not possible to identify the time of the overestimation, the adjustment is recorded at the time when the need for the adjustment is identified. When using the cash basis of recording, such refunds should be recorded at the time the payment occurs. In the case of a value-added tax, taxpayers other than final consumers normally are allowed a refund of taxes paid on purchases. Even if this refund exceeds the taxes payable by an individual taxpayer, the net refund is recorded as a reduction in that category of tax.

5.28 Tax relief measures are incentives that reduce the amount of tax owed by an institutional unit. Tax relief can take the form of a tax allowance, an exemp- tion, a deduction, or a tax credit. Tax allowances, exemptions, and deductions are subtracted from the tax base before the tax liability is computed-it reduces the taxable amount before assessing the tax. These tax relief measures are also known as tax expenditures. Tax expenditures are concessions or exemptions from a "normal" tax structure that reduce government revenue collection. No tax expenditures are recorded as flows in the GFS. However, because the government policy objectives could be achieved alternatively through a subsidy or other direct outlays, for fiscal transparency purposes, all tax expenditures should be reported in supplementary reports.

5.29 A tax credit is an amount subtracted directly from the tax liability due by the beneficiary household or corporation after the liability has been computed. Tax credits can be payable or nonpayable. Tax credits can be payable, in the sense that any amount of the credit that exceeds the tax liability is paid to the beneficiary. Under a payable tax credit system, the credits payable can be awarded to nontaxpayer beneficiaries, as well as taxpayers. In contrast, tax credits that are nonpayable (sometimes called "wastable") are limited at most to the size of the tax liability of the taxpayer.

5.30 Tax relief that is embedded in the tax system reduces the taxes receivable from the taxpayer and therefore reduces government tax revenue. This is the case for tax allowances, exemptions, and deductions because they enter directly into the calculation of the tax liability. Tax relief granted in this form of nonpayable tax credits should also be recorded as a reduction in the relevant tax category.

5.31 However, when tax relief is granted in the form of payable tax credits, it should be recorded on a gross basis: the total amount of tax receivable should be recorded as tax revenue of government and the total amounts due as payable tax credits should be recorded as expense. Payable tax credits are often not connected with the assessment of the taxable event, and should be shown as a current transfer classified according to the purpose of the credit and the nature of the recipient:

- The transfer is a subsidy (25) if receivable by an enterprise on the basis of the level of its production activities or the quantities or values of the goods or services it produces, sells, exports, or imports (see paragraph 6.84). 
- The transfer is an implicit social assistance benefit (272) if receivable by households intended to provide for the needs that arise from certain events or circumstances (see paragraph 6.101), or

- The transfer is classified as transfers not elsewhere classified (282) if receivable by individuals, private nonprofit institutions, nongovernmental foundations, corporations, or government units, and the nature of the transfer is not such that it could be included in the other categories of transfers (see paragraph 6.122).

5.32 Payable tax credits should be recorded for the full amount when the tax claim is recognized by government regardless of the time when it is paid in cash by government or used to decrease the amount of taxes to be paid to government. Gross recording of the payable tax credit allows GFS to reflect the economic substance of government intervention in the economy. ${ }^{11}$ This treatment differs from the treatment of the imputation system of corporate income tax (see paragraph 5.44).

\section{Tax attribution ${ }^{12}$}

5.33 In some cases, one government unit collects taxes and then transfers some or all of them to another government unit or international organization. Depending on the arrangement, the taxes passed on to the second government unit may be reassigned as tax revenue of that unit or they can be recorded as tax revenue of the collecting unit and a grant from that unit to the second government unit.

5.34 A tax is attributed to the government unit that: (i) exercises the authority to impose the tax (either as a principal or through the delegated authority of the principal); and (ii) has final discretion to set and vary the rate of the tax.

5.35 Where an amount is collected by one government for and on behalf of another government, and the latter government has the authority to impose the tax, and to set and vary its rate, then the former is acting as an agent for the latter. The full amount of tax

\footnotetext{
${ }^{11}$ For example, when tax credits on customs and other import duties (1151) on raw materials are used to support producers of exports, the full amount of customs and other import duties (1151) should be reflected, as well as the subsidy (25) to the producers of the exports.

${ }^{12}$ Similar attribution principles could be applied to subsidies or social benefits.
}

raised is assigned as tax revenue to the government on whose behalf the collection was made. Any amounts retained by the collecting government as a collection charge should be recorded as a payment for a service, classified as the relevant category of sales of goods and services (142). The same amount is recorded as an expense for use of goods and services (22) by the counterparty. Any other amounts retained by the collecting government, such as under a tax-sharing arrangement, should be recorded as current grants (1331) receivable while the counterparty will record current grants (2631) payable. If the collecting government was delegated the authority to set and vary the rate, then the amount collected should be recorded as tax revenue of the collecting government.

5.36 Where different governments jointly and equally set the rate of a tax, with no individual government having ultimate overriding authority, then the tax revenues are attributed to each government according to its respective share of the proceeds. ${ }^{13}$ If an arrangement allows one government unit to exercise ultimate overriding authority, then all of the tax revenue is attributed to that unit.

5.37 There may also be circumstances where a tax is imposed under the constitutional or other authority of a government unit or an international organization, ${ }^{14}$ but participating governments individually set the tax rate in their jurisdictions. The proceeds of the tax generated in each respective government's jurisdiction are attributed as tax revenues to the individual government units.

5.38 When taxes are collected by an institutional unit other than a government unit, the tax is always reassigned to the government unit that permitted the nongovernment unit to act as a collecting agent (see paragraph 5.2). For example, a public corporation may act as an agent to collect a specific tax on behalf of government. In this case, the taxes collected by the public corporations should be recorded as transactions in financial assets and liabilities for the collecting agent, and the full amount collected should be

\footnotetext{
${ }^{13}$ These respective shares of the proceeds should reflect the underlying taxable economic event. If, under the revenue sharing arrangement, these shares amount to more or less than the underlying taxable economic event, a transfer for the difference should be recognized.

${ }^{14}$ For a discussion on the tax attribution in the case of supranational authorities and regional cooperation, see Appendix 5.
} 
recorded as tax revenue receivable by the government unit. Amounts retained by the collecting unit as a collection charge should be recorded as a payment for a service receivable by the collecting unit and payable by the government unit.

5.39 The attribution of church or "zakat" taxes requires some further consideration. The treatment of these taxes depends on the sector classification of the religious institutional units (see paragraph 2.61). In countries where some of the activities of the religious organizations are funded from earmarked taxes raised by general government, such as church or zakat taxes, these are included in the tax component of government revenue, provided they meet the definition of taxes set out in paragraphs 5.2 and 5.23. The base on which such religious taxes are levied can vary from country to country (the most usual cases are income, property, or net wealth). These taxes should be classified in the tax category that best describes the tax base on which they are levied.

5.40 When the religious organizations are not part of general government, ${ }^{15}$ historical and administrative reasons may still determine that contributions to religious organizations are collected through the tax authorities. In this case, the contributions should be recorded as financial transactions classified in other accounts payable (3308). Amounts retained by the tax authority as a collection charge should be recorded as sales of goods and services (142) receivable from the religious organizations. The collected amounts are not taxes and are therefore not included in tax revenue if any of the following conditions apply:

- Individuals may opt out of the "tax" payment by formally declaring to the tax authorities their wish to leave the religious organizations.

- Government is acting in a collection agency capacity on behalf of the religious organizations.

- Government does not exercise the authority to impose a compulsory contribution, or

- Government has limited or no discretion to set and vary the rate of the contributions. ${ }^{16}$

\footnotetext{
${ }^{15}$ The authority to raise taxes is an exclusive right of government units. As a result, when religious organizations are not part of general government, religious "taxes" are classified as transfers from households to religious organizations when compiling national accounts.

${ }^{16}$ If the individuals may not opt out of the liability for the payment of the tax, or where the government imposes and sets the rates of such contributions, it may be a sufficient indication that such contributions to the religious organizations are indeed a tax.
}

\section{Tax categories}

\section{Taxes on income, profits, and capital gains (111)}

\subsection{Taxes on income, profits, and capital gains}

(111) consist of taxes assessed on the actual or presumed incomes of institutional units. They include taxes assessed on holdings of property, land, or real estate when these holdings are used as a basis for estimating the income of their owners. These taxes, often referred to as income taxes, include:

- Taxes on individual or household income-These consist of personal income taxes, including those deducted by employers (pay-as-you-earn taxes) and surtaxes. Such taxes are usually levied on the total declared or presumed income from all sources of the person concerned: compensation of employees (e.g., wages, salaries, tips, fees, commissions, fringe benefits), property income (e.g., interest, dividends, rent, royalty incomes), and pensions (taxable portions of social security, pension, annuity, life insurance, and other retirement benefit distributions), etc., after deducting certain allowances in accordance with tax laws. Taxes on the income of the owners of unincorporated enterprises ${ }^{17}$ are included here. Also included are income taxes on the income of family estates and trusts where the beneficiaries are individuals.

- Taxes on the income of corporations-These consist of corporate income taxes, corporate profits taxes, corporate surtaxes, etc. Such taxes are usually assessed on the total incomes of corporations-with corporations understood as in macroeconomic statistics. This item includes taxes on the income of units such as partnerships, sole proprietorships, estates, ${ }^{18}$ and some trusts that are recognized as corporations. This covers income from all sources and not simply profits generated by production. Also included are income taxes on trusts where the beneficiaries are corporations.

- Taxes on capital gains-These consist of taxes on the capital gains (including capital gains distributions of investment funds) of persons or

\footnotetext{
${ }^{17}$ For a definition and discussion of unincorporated enterprises, see paragraphs $2.32-2.33$.

${ }^{18}$ These types of estates are recognized as quasi-corporations and generally classified as captive financial institutions.
} 
corporations that become payable during the current reporting period, irrespective of the periods over which the gains have accrued. They are usually payable on nominal, rather than real, capital gains and on realized, rather than unrealized, capital gains.

- Taxes on winnings from lotteries or gamblingThese are taxes payable on the amounts receivable by winners. They do not include taxes on the turnover of producers that organize gambling or lotteries, which are recorded as taxes on goods and services.

5.42 Taxes on income, profits, and capital gains are attributed as being payable by either individuals (1111) or corporations and other enterprises (1112). These individuals, corporations, and other enterprises may be resident or nonresident institutional units. Taxes on income, profits, and capital gains are classified as other taxes on income, profits, and capital gains (1113) when these taxes are payable by general government units, or when information needed to determine whether taxes should be attributed to individuals, corporations, or general government units is not available. In the event that general government units are subject to this tax category, these taxes should be classified under this category, identifiable according to the subsector of the taxpayer to allow for consolidation (see paragraphs 6.122-6.123). Similarly, taxes payable by public corporations are subject to consolidation and should be identified as a subcategory of taxes payable by corporations (see Table 5.2). Income taxes on trusts,

\section{Table 5.2 Detailed Classification of Taxes on Income, Profits, and Capital Gains (111) \\ 111 Taxes on income, profits, and capital gains \\ $1111 \quad$ Payable by individuals \\ 1112 Payable by corporations and other enterprises ${ }^{1,2}$ \\ 1113 Other taxes on income, profits, and capital gains \\ 11131 \\ Payable by general government ${ }^{1,2}$ \\ $11132 \quad$ Unallocable taxes on income, profits, and capital gains}

"Further breakdown/" of which" lines could allow for the identification of subsectors and individual units (see Table 3.1).

"Further breakdown/" of which" lines could allow for the identification of those taxes related to specific natural resources or environmental taxes. estates, capital gains, or winnings from lotteries and gambling may fall under income taxes payable by individuals (1111), payable by corporations and other enterprises (1112), or other taxes on income, profits, and capital gains (1113), depending on the institutional unit that benefited from the income (see paragraph 5.41). Income taxes payable by nonprofit institutions serving households or corporations are recorded as taxes on corporations. These taxes may be levied on actual or presumed income and profits, and usually only on realized capital gains. The amount of income subject to tax is usually less than gross income because various deductions are permitted. A profits tax is levied on revenue minus allowable deductions.

5.43 When using the accrual basis of recording, income taxes are normally imposed on the income earned during an entire year. In the absence of highfrequency source data, indicators of seasonal activity or other appropriate indicators may be used to allocate the annual totals when monthly or quarterly statistics are compiled. When using the cash basis of recording, income taxes are recorded when the tax payment is received.

5.44 Under imputation systems of corporate income tax, shareholders are wholly or partially relieved of their liability for an income tax on dividends paid by the corporation out of income or profits liable to corporate income tax. The relief is usually called a tax credit, although it actually is a means of allocating a tax among taxpayers. If the relief exceeds a shareholder's total tax liability, the excess may be payable to the shareholder. Because this "tax credit" is an integral part of the imputation system of corporate income tax, any net payment to shareholders is recorded as a negative tax rather than expense. This treatment differs from the general treatment of tax credits described in paragraph 5.29. The total tax paid by the corporation is attributed to corporations and other enterprises (1112). The associated tax credit is for the benefit of the shareholders.

\section{Taxes on payroll and workforce (112)}

5.45 Taxes on payroll or workforce (112) are taxes payable by enterprises assessed either as a proportion of the wages and salaries paid or as a fixed amount per person employed. They do not include: 
- Payments earmarked for social security schemes, which are classified as social security contributions (121)

- Taxes paid by the employees themselves out of their wages or salaries, which are classified as taxes on income, profits, and capital gains, payable by individuals (1111).

\section{Taxes on property (113)}

5.46 Taxes on property (113) are taxes payable on the use, ownership, or transfer of wealth. The taxes may be levied at regular intervals, one time only, or on a change in ownership.

5.47 Taxes on the ownership or use of specific types of property often are based on the value of the property at a particular time but, when using the accrual basis of recording, are deemed to accrue continuously over the entire year, or the portion of the year that the property was owned, if less than the entire year. ${ }^{19}$ Taxes on the transfer of wealth are recorded at the time of the transfer, and some taxes on the ownership or use of property are recorded at a specific time, such as a one-time tax on net wealth. When using the cash basis of recording, these property taxes are recorded when the cash is received.

5.48 Taxes on property are divided into five categories: (i) recurrent taxes on immovable property; (ii) recurrent taxes on net wealth; (iii) estate, inheritance, and gift taxes; (iv) capital levies; and (v) other recurrent taxes on property.

5.49 Recurrent taxes on immovable property (1131) cover taxes levied regularly on the use or ownership of immovable property, which includes land, buildings, and other structures. The taxes can be levied on proprietors, tenants, or both. The amount of the taxes is usually a percentage of an assessed property value that is based on a notional rental income, sales price, capitalized yield, or other characteristics, such as size or location. Unlike recurrent taxes on net wealth (1132), liabilities incurred on the property are usually not taken into account in assessment of these taxes.

5.50 Recurrent taxes on net wealth (1132) cover taxes levied regularly on net wealth. Net wealth is usu-

\footnotetext{
${ }^{19}$ In compiling high-frequency GFS, the application of the accrual basis of recording would require the distribution of the tax receivable throughout the whole period of the taxable ownership (see paragraph 3.84)
}

ally defined as the value of a wide range of movable and immovable property minus liabilities incurred on that property.

5.51 Estate, inheritance, and gift taxes $(1133)^{20}$ cover taxes on transfers of property at death and on gifts, including gifts made between living members of the same family to avoid, or minimize, the payment of inheritance taxes. Taxes on the transfer of property at death include estate taxes, which are usually based on the size of the total estate, and inheritance taxes, which may be determined by the amount received by beneficiaries and/or their relationship to the deceased.

5.52 Capital levies $(1135)^{21}$ cover taxes on the values of the assets or net worth owned by institutional units levied at irregular and very infrequent intervals of time. Capital levies are recorded as exceptional both by units concerned and by the government. They may be payable by households or enterprises. They include taxes on net wealth levied to meet emergency expenditures or to effect a redistribution of wealth; taxes on property, such as betterment levies, that are taxes on the increase in the value of agricultural land due to planning permission being given by government units to develop the land for commercial or residential purposes; taxes on the revaluation of capital; and any other exceptional taxes on particular items of property.

5.53 Other recurrent taxes on property (1136) include all recurrent taxes on property other than immovable property or net wealth. This category includes recurrent gross taxes on personal property, jewelry, cattle, other livestock, other particular items of property, and external signs of wealth. Taxes on the use of particular types of movable property, such as motor vehicles and guns, are classified in taxes on use of goods and on permission to use goods or perform activities (1145).

\footnotetext{
${ }^{20}$ Estate, inheritance, and gift taxes (1133) are one of the two categories of taxes that are considered to be capital taxes in the 2008 SNA. The other category is capital levies (1135). Capital taxes are taxes levied at irregular and very infrequent intervals on the values of the assets or net worth owned by institutional units or on the values of assets transferred between institutional units as a result of legacies, gifts, or other transfers.

${ }^{21}$ To maintain consistency with codes used in the GFSM 2001, this code does not follow directly the code of the previous category of taxes. Taxes on capital and financial transactions (1134 in the GFSM 2001) were reclassified as 11414, one of the categories of taxes on goods and services (114), to improve consistency with the 2008 SNA.
} 
5.54 While sharing certain characteristics with taxes on property, the following taxes are classified elsewhere:

- Taxes on immovable property that are levied on the basis of a presumed net income should be recorded as taxes on income, profits, and capital gains (111).

- Taxes on the use of property for residence, where the tax is payable by either proprietor or tenant and the amount payable is a function of the user's personal circumstances, such as net income or the number of dependents, are recorded as taxes on income, profits, and capital gains (111).

- Taxes on construction, enlargement, or alteration of all buildings, or those whose value or use density exceeds a certain threshold, are included in taxes on use of goods and on permission to use goods or perform activities (1145).

- Taxes on use of one's own property for special trading purposes, such as selling alcohol, tobacco, or meat, should be recorded under taxes on use of goods and on permission to use goods or perform activities (1145).

- Taxes on exploitation of natural resources, such as land and subsoil assets not owned by government units, including taxes on extraction and exploitation of minerals and other resources, should be recorded in other taxes on goods and services (1146). Payments to a government unit as the owner of land and subsoil assets for the exploitation of such natural resources (often referred to as royalties) should be recorded in rent (1415). Payments for licenses that allow the beneficiary to carry out the business of exploitation of land and subsoil assets are classified in taxes on use of goods and on permission to use goods or perform activities (1145).

- Taxes on capital gains resulting from the sale of property are included in taxes on income, profits, and capital gains (111).

\section{Taxes on goods and services (114)}

5.55 Taxes on goods and services (114) are taxes that become payable as a result of the production, sale, transfer, leasing, or delivery of goods and rendering of services, or as a result of their use for own consumption, or own capital formation. Taxes on goods and services are divided into six categories, as described in paragraphs 5.57-5.82:
- General taxes on goods and services (1141), whether levied at manufacturer/producer, wholesale, or retail level-including single-stage taxes and cumulative multistage taxes, where "stage" refers to stage of production or distribution

- Excises (1142)

- Profits of fiscal monopolies (1143)

- Taxes on specific services (1144)

- Taxes on the use of goods and on permission to use goods or perform activities (1145), comprising various types of licenses to use motor vehicles and other goods, or to perform specific activities

- Other taxes on goods and services (1146) that include taxes levied on the extraction, processing, or production of minerals and other products.

5.56 This category does not include taxes levied on international trade and transactions (115) but does include taxes levied upon importation, or at the border, if the tax liability does not result solely from the fact that the goods have crossed the border and is applicable to domestic goods or transactions as well.

\section{General taxes on goods and services (1141)}

5.57 General taxes on goods and services (1141) are levied on the production, leasing, delivery, sale, purchase, or other change of ownership of a wide range of goods and the rendering of a wide range of services (see Table 5.3). General taxes on goods and services may be levied regardless of whether the goods or services are produced domestically or imported, and they may be imposed at any stage of production or distribution. Adjustments made in connection with these taxes when goods cross a border are included

\section{Table 5.3 Detailed Classification of General Taxes on Goods and Services (1141) \\ 1141 General taxes on goods and services \\ 11411 Value-added taxes ${ }^{1,2}$ \\ 11412 Sales taxes ${ }^{1,2}$ \\ 11413 Turnover and other general taxes on goods and services ${ }^{1,2}$ \\ 11414 Taxes on financial and capital transactions ${ }^{1,2}$}

'Further breakdown/" of which" lines could allow for the identification of subsectors and individual units (see Table 3.1).

2Further breakdown/" of which" lines could allow for the identification of these taxes related to specific natural resources or environmental taxes. 
in this tax category. Conversely, refunds of these taxes when goods are exported are recorded as a reduction of the taxes within this category. This item excludes customs and other import duties (1151) and taxes on exports (1152). When taxes are levied on a limited range of goods rather than a wide range, they are included in excises (1142). Borderline cases are resolved on the basis of the predominant character of the tax.

\section{Value-added taxes (11411)}

5.58 Value-added taxes (VAT) (11411) are taxes on goods or services collected in stages by enterprises but that are ultimately charged in full to the final purchasers. This tax is described as a deductible tax because producers are not usually required to pay the government the full amount of the tax they invoice to their customers, as they are permitted to deduct the amount of tax they have been invoiced on their own purchases of goods or services intended for intermediate consumption or fixed capital formation (i.e., only the net amount of VAT is recorded after deducting refunds-see paragraph 5.27). VAT is usually calculated on the price of the good or service, including any other tax on the product. VAT may also be payable on imports of goods or services in addition to any import duties or other taxes on the imports.

\section{Sales taxes (11412)}

5.59 Sales taxes (11412) are all general taxes levied on sales at one stage only, whether at manufacturing or production stages or on wholesale or retail trade.

\section{Turnover and other general taxes on goods and services (11413)}

5.60 Turnover and other general taxes on goods and services (11413) are multistage cumulative taxes and taxes where elements of consumption taxes are combined with multistage taxes. These taxes are levied each time a transaction takes place without deduction for taxes paid on inputs. Multistage taxes can be combined with elements of value-added or sales taxes.

\section{Taxes on financial and capital transactions $(11414)^{22}$}

5.61 Taxes on financial and capital transactions (11414) are taxes levied on the change in ownership of

${ }^{22}$ This item was classified as 1134 in the GFSM 2001 (see footnote 21). property, except those classified as gifts, inheritance, or estate transactions. These taxes are recorded as taxes on the services of the unit selling the asset. Included are taxes on the purchase and sale of nonfinancial or financial assets (including foreign exchange or securities), taxes on checks and other forms of payment, and taxes levied on specific legal transactions, such as the validation of contracts and the sale of immovable property. This category does not include taxes on the use of goods (part of 1145); taxes on capital gains (part of 111); recurrent taxes on net wealth (1132); capital levies (1135); fees paid to cover court charges or for birth, marriage, or death certificates that are included in administrative fees (1422); sales taxes (11412); or general stamp taxes (part of 116).

\section{Excises (1142)}

5.62 Excises (1142) are taxes levied as a productspecific unit tax on a predefined limited range of goods. Excises are usually levied at differentiated rates on nonessential or luxury goods, alcoholic beverages, tobacco, and energy. Excises may be imposed at any stage of production or distribution and are usually assessed as a specific charge per unit based on characteristics by reference to the value, weight, strength, or quantity of the product. Included are special taxes on individual products such as sugar, sugar beets, matches, and chocolates; taxes levied at varying rates on a certain range of goods; and taxes levied on tobacco goods, alcoholic drinks, motor fuels, and hydrocarbon oils. If a tax collected principally on imported goods also applies, or would apply, under the same law to comparable domestically produced goods, then the revenue from this tax is classified as arising from excises rather than from import duties. This principle applies even if there is no comparable domestic production or no possibility of such production. Taxes on the use of utilities such as water, electricity, gas, and energy are regarded as excises rather than taxes on specific services (1144). Excises exclude those taxes that are levied as general taxes on goods and services (1141); profits of fiscal monopolies (1143); customs and other import duties (1151); or taxes on exports (1152).

\section{Profits of fiscal monopolies (1143)}

5.63 Profits of fiscal monopolies (1143) cover that part of the profits of fiscal monopolies that is 
transferred to the government. Fiscal monopolies are public corporations, public quasi-corporations, or government-owned unincorporated enterprises that have been granted a legal monopoly over the production or distribution of a particular kind of good or service in order to raise revenue and not in order to further the interests of public economic or social policy. Such monopolies are typically engaged in the production of goods or services that may be heavily taxed in other countries-for example, alcoholic beverages, tobacco, matches, petroleum products, salt, playing cards, lotteries, gambling, etc. The exercise of monopoly powers is simply an alternative way for the government to raise revenue instead of the more overt procedure of taxing the private production of such products. In such cases the sales prices of the monopolies are deemed to include implicit taxes on the products sold.

5.64 In principle, only the excess of the monopoly profits over some notional "normal" profits should be recorded as taxes, while the "normal" profits are regarded as dividends (1412) or withdrawals of income from quasi-corporations (1413). However, it is recognized that it may be difficult to estimate this amount, and, in practice, the value of the taxes should be taken as equal to the amount of the profits actually payable from fiscal monopolies to government. Any reserves retained by fiscal monopolies are excluded. This tax is recorded when the payment takes place rather than when the profits were earned.

5.65 When a public enterprise is granted monopoly powers as a matter of deliberate economic or social policy because of the special nature of the good or service or the technology of production (e.g., public utilities, post offices and telecommunications, railways), it should not be treated as a fiscal monopoly. Property income payable to government from such public enterprises is recorded as dividends (1412) or withdrawals of income from quasi-corporations (1413). Export and import monopoly profits receivable from marketing boards or other enterprises dealing with international trade are similar to fiscal monopoly profits, but are classified as profits of export or import monopolies (1153).

5.66 The treatment of lotteries and other gambling activities deserves special mention. The concept of fiscal monopoly applies to state lotteries and other gambling to the extent that they are devices to raise revenue rather than further the interests of pub- lic economic or social policy, even though they may compete with other privately organized lotteries and other gambling. As is the case with other fiscal monopolies (see paragraph 5.64), in principle, the "normal" profits should be regarded as dividends (1412) or withdrawals of income from quasi-corporations (1413), while the excess should be recorded as a tax classified as profits on fiscal monopolies (1143). However, in practice it may be difficult to estimate the "normal" profits, and the taxes should be taken as equal to the amount of profits actually payable to government.

5.67 Governments that have monopoly powers over lotteries and other gambling activities often delegate the organization of these activities to nonprofit institutions serving households, with a view to a final distribution of the profits earned, through social transfers. This delegation of functions normally requires the nonprofit institution to organize those activities through a specialized department. When such departments have the attributes of an institutional unit (as described in paragraph 2.22), they may be classified as public corporations (see paragraph 2.104) that constitute a fiscal monopoly.

5.68 Depending on the administrative arrangements, the distribution of the profits earned may be done in two ways: (i) the fiscal monopoly transfers its profits to a government unit (classified as a tax in profits of fiscal monopolies (1143)), and the government unit then transfers the profits to the population; or (ii) the fiscal monopoly transfers the profits directly to the population (normally through criteria determined by law). In the latter case, a rerouting treatment is required because the government does not appear as a party to the transaction in the actual accounting records. Rerouting means the transaction is recorded as if the monopoly transferred its profits to government as described in (i) (see paragraph 3.28).

\section{Taxes on specific services (1144)}

5.69 Taxes on specific services (1144) are levied on payments for specific services. These taxes are levied on services such as transportation (including airport and other passenger taxes), ${ }^{23}$ insurance, banking, entertainment, restaurants, and advertising. Also

\footnotetext{
${ }^{23}$ If these taxes are based exclusively on international travel, they are classified as other taxes on international trade and transactions (1156) (see paragraph 5.92).
} 
included in this item are taxes levied on gambling and betting stakes for horse races, football pools, lotteries, and so forth. Taxes on entry to casinos, races, etc. are also classified as taxes on specific services.

5.70 This category also includes the implicit taxes resulting from the central bank imposing a rate of interest other than the market rates. The central bank's main responsibility is to formulate and carry out monetary policy as part of economic policy. It therefore often acts differently than other financial corporations and generally has received the authority from government to impose its policies. In cases where the central bank uses its special powers to set interest rates that are out of line with market rates, the difference gives rise to an implicit tax and subsidy (see paragraph 6.89 and Box 6.2 for an illustration of recording these implicit taxes and subsidies). This procedure is analogous to and consistent with the practice of treating the difference between the market exchange rate and an alternative exchange rate imposed by the central bank as an implicit tax or subsidy (see paragraph 5.89).

5.71 This category does not include:

- Taxes that are included in general taxes on goods and services (1141)

- Taxes on individual gains from football pools or other gambling proceeds, classified in taxes on income, profits, and capital gains (111)

- Profits transferred to government from state lotteries and other gambling enterprises regarded as profits of fiscal monopolies (1143), dividends (1412), or withdrawals of income from quasi-corporations (1413)

- Taxes on checks and on the issue, transfer, or redemption of securities, classified as taxes on financial and capital transactions (11414)

- Stamp tax revenues that cannot be assigned to taxes on services or other transactions, classified as other taxes (116)

- Taxes on the use of utilities, such as water, electricity, gas, and energy, which are included under excises (1142).

Taxes on use of goods and on permission to use goods or perform activities (1145)

5.72 Taxes on use of goods and on permission to use goods or perform activities (1145) are fees levied for the issuance of a license or permit that are not commensurate with the cost of the control function of government. There are cases where the government provides something to the individual unit directly in return for a payment in the form of the granting of a permit or authorization. In such instances, the payment is part of a mandatory process that ensures proper recognition of ownership or ensures that activities are performed under the authorization of the law. The boundary between when such payments are to be recorded as a tax and when they are to be recorded as the sale of a service or as the sale of an asset by the government requires additional guidance.

\section{Boundary with administrative fees}

5.73 One of the regulatory functions of governments is to prohibit the ownership or use of certain goods or the pursuit of certain activities, unless specific permission is granted by issuing a license or other certificate for which a fee is demanded. To decide whether such a fee constitutes this tax category or administrative fees (1422), the following recommendations apply:

- The payment is recorded as a tax when a license or a permit is automatically granted by the government as a mandatory condition to perform an activity or acquire an asset. The government unit performs little or no work other than a minimum control of the legal capacity of the acquirer to receive the permit (e.g., to confirm the applicant has not been convicted of a crime). The payment of the fee in such a case is not commensurate with the control function that the government exercises.

- The payment is recorded as the sale of a service when, for instance, issuing the license or permit involves a proper regulatory function of the government by exercising control on the activity, checking the competence or qualifications of the persons concerned, etc. In such a case, the payment is taken to be proportional to the costs of producing the service for all or any of the entities benefiting from the services and is borne by those benefiting. The payment is recorded as a tax only if it is out of proportion to the costs of producing the services.

5.74 More specifically, the following types of fees are considered taxes:

- Fees where the payer of the levy is not the receiver of the benefit, such as a fee collected from 
slaughterhouses to finance a service provided to farmers

- Fees where government is not providing a specific service commensurate with the levy even though a license may be issued to the payer, such as a hunting, fishing, or shooting license that is not accompanied by the right to use specific government-owned natural resources

- Fees where benefits are received only by those paying the fee but the benefits received by each individual are not necessarily in proportion to the payments, such as a milk marketing levy paid by dairy farmers and used to promote the consumption of milk

- Fees paid to government for deposit insurance and other guarantee schemes if they are compulsory-that is, if beneficiaries cannot opt out of the scheme, if the payment is clearly out of proportion to the service provided, if the payment is not set aside in a fund, or if it can be used for other purposes. ${ }^{24}$

5.75 Although taxes in this category are levied on the use of goods rather than on the ownership or transactions in goods, registration of the ownership of goods may generate the tax claim. For example, registration of the ownership of animals or motor vehicles may be the event that causes a tax on the use of these items to be assessed. Taxes on the use of goods may apply even to functionally unusable goods, such as antique motor vehicles or guns.

\section{Boundary with taxes on business activities levied on different bases}

5.76 Boundary cases arise with taxes on business activities, which are levied on a combined income, payroll, or turnover base. If it is possible to estimate receipts related to each base, then the total should be allocated among the bases. If sepa-

\footnotetext{
${ }^{24}$ If the fees are proportional to the cost of the service provided, they constitute a payment for an insurance-type transaction, in which case it will be classified as a premium in the category premiums, fees, and claims related to nonlife insurance and standardized guarantee schemes (145). The criterion of proportionality between payments and provision of an insurance-type of service (including payments for the risk element) should be examined on a case-by-case basis. The existence of an institutional unit with a full set of accounts operating a fund that functions on insurance rules may indicate that the payment is for an insurancetype of service.
}

rate amounts cannot be estimated, but it is known that most of the receipts are derived from one base, then the whole of the receipts are classified according to that base.

\section{Boundaries with other tax categories}

5.77 Boundary cases arise with taxes on the ownership or use of property that could be classified as recurrent taxes on immovable property (1131), recurrent taxes on net wealth (1132), or other recurrent taxes on property (1136). Unlike the taxes under this item (category 1145), category 1131 is confined to taxes on the ownership or tenancy of immovable property and such taxes are usually a percentage of the assessed property value. The taxes included in categories 1132 and 1136 are confined to ownership rather than use of assets, apply to groups of assets rather than particular goods, and are based on the value of assets.

\section{Boundary with the acquisition or use of an asset}

5.78 Boundary cases arise with the payments for licenses to make use of a natural resource. If the natural resource qualifies as an asset and the government controls it on behalf of the community, payments for the license could be recorded as the disposal of the asset when government surrenders economic control of the asset and the life span of the license and the life span of the asset are the same. If the license agreement is recorded as the sale of an asset in its own right, it should be recorded as the disposal of an asset in the category of contracts, leases, and licenses (31441). A license for the use of the natural resource itself for a finite period does not reflect a disposal of an asset and should be classified as rent (see paragraph 5.124). Licenses to permit the use of natural resources not under the control of government will be treated as a tax (classified under this item) in all other cases except if the license is legally and practically transferable to a third party, in which case it should be classified as an asset in the category of contracts, leases, and licenses (see paragraphs A4.54-A4.55).

5.79 Taxes on use of goods and on permission to use goods or perform activities (1145) are subdivided into motor vehicle taxes (11451) and other taxes on the use of goods and on the permission to use goods or perform activities (11452), while several subcategories of taxes are identifiable in the latter (see Table 5.4). 


\begin{tabular}{|c|c|}
\hline lole 5.4 & $\begin{array}{l}\text { Detailed Classification of Taxes on Use } \\
\text { of Goods and on Permission to Use } \\
\text { Goods or Perform Activities (1145) }\end{array}$ \\
\hline 1145 & $\begin{array}{l}\text { Taxes on use of goods and on permission to } \\
\text { use goods or perform activities }\end{array}$ \\
\hline 11451 & Motor vehicle taxes ${ }^{1}$ \\
\hline 11452 & $\begin{array}{l}\text { Other taxes on use of goods and on } \\
\text { permission to use goods or perform } \\
\text { activities }^{1}\end{array}$ \\
\hline 114521 & Business and professional licenses ${ }^{1}$ \\
\hline 114522 & Pollution taxes ${ }^{1}$ \\
\hline 114523 & Radio and television licenses ${ }^{1}$ \\
\hline 114524 & Licenses and permits for households ${ }^{1}$ \\
\hline 114525 & $\begin{array}{l}\text { Other taxes on the use of goods and } \\
\text { on permission to use goods or perform } \\
\text { activities not elsewhere classified }{ }^{1}\end{array}$ \\
\hline
\end{tabular}

"Further breakdown/" of which" lines could allow for the identification of specific goods or activities, and how these taxes relate to specific natural resources or environmental taxes.

5.80 Motor vehicle taxes (11451) include taxes on the use of motor vehicles or permission to use motor vehicles. It does not include taxes on motor vehicles as property or net wealth or tolls for use of roads, bridges, and tunnels.

5.81 Other taxes on use of goods and on permission to use goods or perform activities (11452) include business and professional licenses that consist of taxes paid by enterprises in order to obtain a license to carry on a particular kind of business or profession and taxes payable by individuals to perform certain activities. Included in this tax category are the following:

- General business taxes or licenses levied in a fixed amount, on a schedule according to the kind of business, or on the basis of various indicators such as floor space, installed horsepower, capital, or shipping tonnage would be included. It would not cover business taxes levied on gross sales, which would be classified under general taxes on goods and services (1141).

- Taxes or licenses for particular kinds of businesses including permission to sell goods or provide services may be levied at regular intervals, on a one-time basis, or each time goods are used. Business licenses payable by enterprises are included, such as for taxi, casino, mining, exploitation of land and subsoil assets, or broadcasting. This category also includes all cases where government issues licenses to limit the number of units operating in a particular field where the limit is fixed arbitrarily and is not dependent on qualifying criteria. When government restricts the number of cars entitled to operate as taxis or limits the number of casinos permitted by issuing licenses, they are in effect creating monopoly profits for the approved operators and recovering some of the profits as the fee. These license fees should also be recorded as taxes in this category. In principle, if the license is valid for several years, the payment should be recorded on an accrual basis with an entry in other accounts payable (3308) for the amount of the prepayment of license fees covering future years. However, if government does not recognize a liability to repay the licensee in the case of a cancellation, the whole of the fee payable is recorded as a single tax payment at the time it is paid.

- Taxes on pollution levied on the emission or discharge into the environment of noxious gases, liquids, or other harmful substances are included. On an accrual basis, the revenue receivable for emission permits, issued by governments under cap and trade schemes, should be recorded in this category at the time the emissions occur. No revenue should be recorded for permits that government issues free of charge. The timing difference between the cash received by government for the permits and the time the emission occurs constitutes a prepaid tax and gives rise to a financial liability (other accounts payable) for government. The difference between the prepaid tax value of the permit and the market value of the permit represents a marketable contract (nonproduced nonfinancial asset) for the holder (see paragraphs A4.48-A4.49). Amounts payable to government for the collection and disposal of waste or noxious substances are excluded from this tax category as they constitute a sale of services, recorded as sales of goods and services (142).

- Taxes in this category other than business and professional licenses include taxes payable by persons or households for licenses for recreational hunting, shooting, or fishing, and taxes on the ownership of pets when the amount payable is not commensurate with the administrative cost. They also include radio and television licenses payable by viewers, unless the public authorities provide general broadcasting services, in which case a service payment, rather than a tax, is recorded. 


\section{Other taxes on goods and services (1146)}

5.82 Other taxes on goods and services (1146) include taxes on the extraction of minerals, fossil fuels, and other exhaustible resources from deposits owned privately or by another government and any other taxes on goods or services not included in categories 1141 through 1145. Taxes on the extraction of exhaustible resources usually are a fixed amount per unit of quantity or weight, but can be a percentage of value. The taxes are recorded when the resources are extracted. Payments for timber felling and the extraction of exhaustible natural resources from deposits owned by the government unit receiving the payment are classified as rent (1415) (see paragraph 5.129).

\section{Taxes on international trade and transactions (115)}

5.83 Taxes on international trade and transactions (115) are taxes that become payable when goods cross the national or customs frontiers of the economic territory, or when transactions in services exchange between residents and nonresidents. These taxes are classified into various subcategories according to the nature of the exchange and whether the exchange is related to imports or exports (see Table 5.5).

5.84 Customs and other import duties (1151) cover revenue from all levies and duties payable on goods of a particular kind because they are entering the country or services because they are delivered by nonresidents to residents. The levies may be imposed with the intention to raise revenue or discourage imports in order to protect resident producers of the same goods or services. The duties may be determined on a specific or ad valorem basis, but they must be restricted by law to imported products. Included are duties levied under the customs tariff schedule and its annexes, including surtaxes that are based on the tariff schedule, consular fees, tonnage charges, statistical taxes, fiscal duties, and surtaxes not based on the customs tariff schedule. This category covers taxes that fall on imports only. Imports that fall into a wider category of goods that are subject to the tax should be recorded under general taxes on goods and services (1141) or excises (1142). If excises are levied on imported goods under the same law to comparable domestically produced goods, then the revenue from the tax should be classified as arising from excises rather than from import duties (see paragraph 5.62).

\section{Table 5.5 Detailed Classification of Taxes on International Trade and Transactions (115) \\ 115 Taxes on international trade and transactions \\ 1151 Customs and other import duties \\ 1152 Taxes on exports \\ 1153 Profits of export or import monopolies \\ $1154 \quad$ Exchange profits \\ $1155 \quad$ Exchange taxes \\ 1156 Other taxes on international trade and transactions}

'Further breakdown/" of which" lines could allow for the identification of specific goods or activities, and how these taxes relate to specific natural resources or environmental taxes.

5.85 Taxes on exports (1152) include all levies that become payable on goods that are transported out of the country, or services that are provided to nonresidents by residents. Rebates on exported goods that are repayments of previously paid general consumption taxes, excises, or import duties are deducted from the gross amounts receivable from the respective taxes, not from amounts receivable in this category.

5.86 Profits of export or import monopolies (1153) include the profits from government-established enterprises with the domestic monopoly right to export or import particular goods and/or control services provided to or received from nonresidents. The exercise of the monopoly powers is an alternative way of raising revenue through taxes on exports, imports, or dealings in foreign exchange. When such export or import monopolies exist, the profits remitted to government by the monopolistic enterprises or marketing boards are considered to be taxes, classified as profits of export or import monopolies (1153). While in principle only the excess of the monopoly profits over some notional "normal" profits should be treated as taxes, it is difficult to estimate this amount, and in practice the value of the taxes should be taken as equal to the amount of the profits actually payable from the export or import monopolies to government. This tax is recorded when the payment to the government takes place rather than when the profits were earned and does not include the retained reserves of the enterprises or marketing boards. ${ }^{25}$

\footnotetext{
${ }^{25}$ If an enterprise of this type generates profits from its exports or imports of products, and a government unit provides a subsidy on other products, then the taxes and subsidies should be separately recorded to the extent possible rather than recording only the net value of taxes minus subsidies.
} 
5.87 Property income receivable from export or import enterprises or marketing boards that do not represent monopoly profits should be recorded as dividends (1412) or withdrawals of income from quasicorporations (1413). Fiscal monopoly profits receivable from public enterprises or marketing boards dealing in commodities domestically, outside of international trade, should be recorded under profits of fiscal monopolies (1143).

5.88 Exchange profits (1154) include the profits generated when the monopoly powers of government or monetary authorities are exercised to extract a margin between the purchase and sale prices of foreign exchange, other than to cover administrative costs. The revenue derived constitutes a compulsory levy extracted from both purchaser and seller of foreign exchange. Similarly, an implicit tax results from the operation of a multiple exchange rate regime by the central bank or other official agency. It is the common equivalent of an import duty and export duty levied in a single exchange rate system or of a tax on the sale or purchase of foreign exchange. As in the case of the profits of export or import monopolies, the revenue represents the exercise of monopoly powers for tax purposes and is included in tax revenue when received by government.

5.89 Under a multiple exchange rate regime, two or more exchange rates are applicable to different categories of transactions; the rates favor some categories and discourage others. The net proceeds as a result of these transactions are calculated as implicit taxes or subsidies (see paragraph 6.89). The amount of the implicit tax or subsidy for each transaction can be calculated as the difference between the value of the transaction in domestic currency at the actual exchange rate applicable and the value of the transaction at a unitary rate that is calculated as a weighted average of all official rates used for external transactions.

5.90 Exchange profits are often included in a lumpsum payment from the monetary authorities to government. Such a lump-sum payment should be disaggregated according to the economic nature of the components, and each component classified according to its nature. These lump-sum payments may include components of dividends, exchange profits, interest, and/or equity withdrawals. This category for exchange profits should not include any payments to government of exchange profits realized other than as a result of maintenance of an exchange rate differential. Also excluded from this category are any payments to government of unrealized revaluation profits, which are in the nature of a book entry resulting from revaluation of foreign exchange or gold holdings for the owner. As discussed in paragraph 5.115 , such payments to government based on holding gains are classified as a withdrawal of equity rather than a tax. Any operational profits transferred to government should be classified as dividends (1412) (see paragraph 5.111).

5.91 Exchange taxes (1155) cover taxes that are levied upon the sale or purchase of foreign exchange, whether at a unified exchange rate or at different exchange rates. Included are taxes on remittances abroad if the taxes are levied on the purchase of foreign exchange that is to be remitted. Remittance taxes that are not levied on the purchase of foreign exchange should be recorded under other taxes on international trade and transactions (1156).

5.92 Other taxes on international trade and transactions (1156) include other taxes levied on various aspects of international trade and transactions, except those payable by producers. This item includes taxes levied exclusively on international travel, taxes on insurance or investment abroad, and taxes on foreign remittances, excluding taxes levied on the purchase of foreign exchange to be remitted abroad, which are included in exchange taxes (1155).

\section{Other taxes (116)}

5.93 Other taxes (116) cover revenue from taxes levied predominantly on a base or bases not elsewhere classified, and unidentified taxes. The item is subdivided into other taxes payable solely by business (1161) and other taxes payable by other than business or unidentifiable (1162). The item includes taxes on persons that are not based on income or presumed income, sometimes referred to as poll taxes, head taxes, or capitation taxes. Personal taxes based on actual or presumed income should be recorded as taxes on income, profits, and capital gains (111). Also included are stamp taxes that do not fall exclusively or predominantly on a single class of transactions or activities covered by taxes on financial and capital transactions (11414). Examples would be revenues from the sale of stamps required to be affixed to contracts. Revenues from the sale of 
stamps assignable to a single category, such as liquor and cigarettes, would be shown as taxes on those products, either excises (1142) or taxes on specific services (1144). Similarly, stamp duties on financial transactions would be shown as taxes on financial and capital transactions (11414). Also included in other taxes (116) would be an expenditure tax that is levied on purchases but is personalized by the application of personal deductions and exemptions. Revenue from taxes levied on a combination of several tax bases, or on multiple tax bases, where the revenue cannot be readily allocated to each tax base or to one predominant tax base is also reported in this category of taxes.

\section{Social Contributions [GFS] (12)}

5.94 Social contributions [GFS] (12) are actual or imputed revenue receivable by social insurance schemes to make provision for social insurance benefits payable. Social contributions [GFS] (12) exclude contributions receivable under employment-related pension and other retirement schemes that create a liability for future benefits payable. Social contributions are further classified according to the nature of the payee and the nature of the scheme that received these contributions (see Table 5.6). These receipts are from employers on behalf of their employees, from employees, or from self-employed or unemployed persons on their own behalf to secure entitlement to social benefits, payable in cash and in kind, to the contributors, their dependents, or their survivors. ${ }^{26}$ The contributions are usually compulsory, but may also be voluntary. Voluntary contributions are usually made in arrangements where a means test determines whether contributors are exempted from compulsory contributions, but are eligible to participate by choice. If any contributions are voluntary, a memorandum item of their total amount would be useful for computing the fiscal burden and other analytical uses. Social contributions are classified as social security contributions (121) or other social contributions (122) depending on the type of scheme receiving them.

5.95 The coverage of social contributions in GFS is more restricted than in the 2008 SNA. In GFS, only amounts that constitute revenue are included in social contributions [GFS] (12)-that is, those transactions

\footnotetext{
${ }^{26}$ The institutional units involved, classification, and recording of flows and stock positions related to social protection are described in Appendix 2.
}

\author{
Table 5.6 Detailed Classification of Social \\ Contributions [GFS] (12)

\begin{tabular}{l|c}
12 & Social contributions [GFS] \\
121 & Social security contributions [GFS] \\
1211 & Employee contributions [GFS] \\
1212 & Employer contributions [GFS] \\
1213 & Self-employed or unemployed \\
& contributions [GFS] \\
1214 & Unallocable contributions [GFS] \\
122 & Other social contributions [GFS] \\
1221 & Employee contributions [GFS] \\
1222 & Employer contributions [GFS] \\
1223 & Imputed contributions [GFS]
\end{tabular}

"Further breakdown/" of which" lines could allow for the identification of the contributions in cash and in kind, and make a distinction between compulsory and voluntary contributions.

that create a recognized liability are not part of revenue. In GFS, social contributions exclude contributions to autonomous and nonautonomous pension funds and to unfunded employment-related schemes that provide pension and other retirement benefits. These transactions should be recorded in GFS as incurrence of liabilities for future pension and other retirement benefits payable. The 2008 SNA records them both as social contributions and incurrence of liabilities, with the double recording being neutralized by recording an adjustment in the use of income account for the change in pension entitlements. ${ }^{27}$

\section{The boundary between social contributions and other categories of taxes}

5.96 Compulsory transfers can be classified as either a tax or a social contribution. Social contributions include payments made by insured persons, or their employers, to secure entitlement to social benefits. The contributions are levied as a function of earnings, payroll, or the number of employees. When income is used as a proxy for gross wages, as for the self-employed, the receipts are included as social contributions. Compulsory payments levied as a tax

\footnotetext{
${ }^{27}$ The 2008 SNA allows some flexibility regarding the recording of pension entitlements of unfunded pension schemes sponsored by government for all employees. Given the different institutional arrangements in countries, and using this flexibility, only some of these pension entitlements may be recorded in the main sequence of accounts (core accounts). However, in such instances, a supplementary table is to be presented that discloses the proportion of pension provision covered in the core accounts with some approximate estimates of the liability arising from the remaining schemes (see the 2008 SNA, paragraph 17.193).
} 
assessed on a different base and earmarked for funding social protection schemes are classified in the respective tax category and not as social contributions. In particular, receipts based on net income personalized by adjustments for personal deductions and exemptions are classified as taxes on income, profits, and capital gains (111), even if earmarked for the payment of social benefits. Compulsory payments levied on enterprises as a function of earnings, payroll, or the number of employees that do not make provision for entitlement to social security benefits are classified as taxes on payroll or workforce (112). Similarly, compulsory levies on the use of fuel are classified as excises (1142), even though some of it could be earmarked to finance social benefits to victims of motor vehicle accidents. In these cases, if the government unit that levies the tax and the unit providing the social benefits are not the same, a subsequent grant should be recorded to the unit providing the social benefit.

\section{Social security contributions [GFS] (121)}

5.97 Social security contributions [GFS] (121) are actual revenue receivable by social security schemes organized and operated by government units, for the benefit of the contributors to the scheme. These contributions are classified by the source of the contribution, which may be the employers or the household sector (separated according to whether they are employees, self-employed, or unemployed). Employee contributions (1211) are either payable directly by employees or deducted from employees' wages and salaries and transferred on their behalf by the employer. Employer contributions (1212) are payable directly by employers on behalf of their employees. Self-employed or unemployed contributions (1213) are paid by contributors who are not employees. Unallocable contributions (1214) are those contributions whose source cannot be determined. Amounts payable by general government employers are not eliminated by consolidation when the paying and receiving units are in the same sector or subsector because the contributions are considered to be rerouted as described in paragraph 3.28.

\section{Other social contributions [GFS] (122)}

5.98 Other social contributions [GFS] (122) are actual and imputed contributions receivable by social insurance schemes operated by employers on behalf of their employees. Unlike social security schemes, social insurance schemes for employees generally tie the level of benefits directly to the level of contributions. Such schemes usually are operated by general government units for their own employees, but they can be operated by one unit on behalf of the employees of many government units or even public corporations. These contributions can be receivable from employees or from employers.

5.99 Employee contributions (1221) include amounts payable directly by employees or deducted from wages and salaries and transferred by employers on behalf of employees. Employer contributions (1222) include amounts payable by employers on behalf of their employees. As with employer contributions to social security schemes, these contributions are not eliminated by consolidation when the paying and receiving governments are in the same sector or subsector.

5.100 Imputed contributions (1223) are revenue that arises when government employers provide nonpension benefits directly to their employees, former employees, or dependents out of their own resources without involving an insurance enterprise and without creating a special fund or segregated reserve for the purpose. ${ }^{28}$ As described in detail in paragraphs A2.64-2.66, in this situation, existing employees may be considered as being protected against various specified needs or circumstances, even though no reserves are built up to provide for future entitlement. Compensation of employees (2122) is therefore imputed (see paragraph 6.22) equal to the amount of social contributions that would be needed to secure the de facto entitlements to the social benefits they accumulate. A simultaneous transaction is recorded between the household sector and government, for the household imputed contributions (1223) receivable.

\section{Grants (13)}

5.101 Grants (13) are transfers receivable by government units, from other resident or nonresident government units or international organizations, that do not meet the definition of a tax, subsidy, or social contribution. As indicated in paragraph 3.10, a transfer is a transaction in which one institutional unit provides a

\footnotetext{
${ }^{28}$ Revenue from imputed contributions excludes imputed contributions to employment-related pension and retirement schemes, which are recorded as the incurrence of a liability.
} 
good, service, or asset to another unit without receiving from the latter any good, service, or asset in return as a direct counterpart. Grants are normally receivable in cash, but may also take the form of the receipt of goods or services (in kind). Grants receivable are classified first by the type of unit providing the grant and then by whether the grant is current or capital.

5.102 Three sources of grants are recognized in GFS: grants from foreign governments (131), grants from international organizations (132), and grants from other general government units (133). For the general government sector, these transactions should be eliminated in consolidation. Therefore, grants from other general government units (133) will have a nonzero value only when statistics are compiled for a subsector of the general government sector. To allow for consolidation, it may be useful to identify grants receivable from other general government units also according to the subsector of the counterparty (see Table 5.7).

5.103 Current grants (1311/1321/1331) are current transfers receivable by government units, from other resident or nonresident government units or international organizations, that do not meet the definition of a tax, subsidy, or a social contribution. Current grants are those transfers (see paragraph 3.17) receivable that are not capital transfers. Capital grants (1312/1322/1332) are capital transfers receivable by government units, from other resident or nonresident government units or international organizations, that do not meet the definition of a tax, subsidy, or a social contribution (see paragraph 3.16). If doubt exists regarding the character of a grant, it

\begin{tabular}{|c|c|}
\hline 13 & Grants \\
\hline 131 & From foreign governments \\
\hline 1311 & Current \\
\hline 1312 & Capital \\
\hline 132 & From international organizations \\
\hline 1321 & Current \\
\hline 1322 & Capital \\
\hline 133 & From other general government units \\
\hline 1331 & Current \\
\hline 1332 & Capital \\
\hline
\end{tabular}

"Further breakdown/" of which" lines could allow for the identification of subsectors and individual units (see Table 3.1). should be classified consistently by both parties (see paragraph 3.18).

5.104 A grant in kind concerns a good or service provided free of charge or the change of ownership of an existing nonfinancial asset in the accounts of the donor without receiving anything of commensurate value in return. Goods and services that are consumed, such as food contributions, blankets, and medical and rescue services and supplies, are classified as current grants. Aid of a capital nature receivable from resident and nonresident general governments and international organizations is classified as capital grants. Grants in kind should be valued at current market prices. If market prices are not available, then the value should be the explicit costs incurred in providing the resources or the amounts that would be received if the resources were sold. A capital grant in kind necessarily concerns the change of ownership of a product previously recorded as a nonfinancial asset in the accounts of the donor government. In this case, there is no effect in the net lending/net borrowing, because the counterpart entry for the positive effect in the net worth (the transfer of wealth implied by the grant revenue) is a transaction in nonfinancial assets (the acquisition of the asset being transferred by the donor). In some cases, the donor and the recipient may view the value of the nonfinancial asset quite differently. To maintain consistency in the macroeconomic statistical system, the valuation from the viewpoint of the donor should be used for recording transactions. If the market value of the asset in the balance sheet of the recipient of the asset is different, the recipient would then record a subsequent holding gain or loss on this asset (see paragraph 10.5).

5.105 When using the accrual basis for recording, the time at which a grant is recorded is dependent on whether the recipient has a claim on the donor. In many cases, the grant recipient never has a claim on the donor and the grant should be attributed to the time at which the cash payment is made or the goods or services are delivered by the donor. When a claim is involved, grants are recorded when all requirements and conditions for receiving them are satisfied and the receiving unit has an unconditional claim recorded under other accounts receivable (3208). In some cases, a potential grant recipient has 
a legal claim when it has satisfied certain conditions, such as the prior incurrence of expenses for a specific purpose or when a certain event has occurred, such as the passage of legislation. Determining this time can be complex because there could be a wide variety of eligibility conditions that have varying legal powers, and so grants are most commonly recorded when received. When using the cash basis of recording, grants are recorded when cash is received. Grants in kind will not be recorded in a cash system.

\section{Other Revenue (14)}

5.106 Other revenue (14) is all revenue receivable excluding taxes, social contributions, and grants. This category of revenue includes property income, sales of goods and services, and miscellaneous other types of revenue.

\section{Property income [GFS] (141)}

5.107 Property income [GFS] (141) is the revenue receivable in return for putting financial assets and natural resources at the disposal of another unit. ${ }^{29}$ Revenue in this category may take the form of interest, distributed income of corporations, investment income, and rent. Distributed income of corporations includes dividends, withdrawals of income from quasi-corporations, and reinvested earnings on foreign direct investment. Investment income includes property income from investment income disbursements, and holders of investment fund shares.

\section{Interest [GFS] (1411)}

5.108 Interest [GFS] (1411) is a form of investment income that is receivable by the owners of certain kinds of financial assets (SDRs, deposits, debt securities, loans, and other accounts receivable) for putting these financial assets and other resources at the disposal of another institutional unit. ${ }^{30}$ The financial assets giving rise to interest are all claims of creditors over debtors. Under the accrual basis of recording,

\footnotetext{
${ }^{29}$ Property income [GFS] (141) differs due to the treatment of financial intermediation services indirectly measured (FISIM) in interest [GFS] (1411).

${ }^{30}$ Interest [GFS] (1411) differs due to the treatment of FISIM (see paragraph 6.81 and Appendix 7).
}

the amount of outstanding debt increases as interest accrues continuously over the period that the financial asset exists, and the amount due to the creditor declines as the payments are made on the debt by the debtor. The amount that the debtor owes to the creditor is referred to as the principal amount. Interest revenue also includes imputed interest that originates from interest forgone by employers when they provide loans to employees at reduced or even zero rates of interest as part of the remuneration in kind of government and public sector employees (see paragraph 6.17).

5.109 Interest may be a predetermined sum of money or a fixed or variable percentage of the principal outstanding. If some or all of the interest accruing to the creditor is not paid during the period in question, it should be added to the amount of the principal outstanding. However, the interest may not necessarily be due for payment until a later date and sometimes not until the loan or other financial instrument matures. To the extent that interest has accrued without being paid, the debtor's total liability to the creditor has increased. On an accrual basis, any periodic or other payments reduce the total liability but are not revenue transactions.

5.110 Many considerations must be taken into account when determining the amount of interest revenue to record, or to eliminate, in consolidation. To avoid repetition, interest is described in more detail in paragraphs 6.62-6.83. Interest should also be recorded according to the subsector of the counterparty, to allow for consolidation of the general government and public sectors (see Table 5.8).

\section{Table 5.8 Detailed Classification of Interest [GFS] (1411)

\begin{tabular}{|c|c|}
\hline \multirow[t]{3}{*}{1411} & Interest [GFS] \\
\hline & Interest [SNA] \\
\hline & Minus: FISIM \\
\hline 14111 & From nonresidents \\
\hline 14112 & $\begin{array}{l}\text { From residents other than general } \\
\text { government }{ }^{1}\end{array}$ \\
\hline 14113 & From other general government units ${ }^{1}$ \\
\hline
\end{tabular}

"Further breakdown/"of which" lines could allow for the identification of subsectors and individual units (see Table 3.1). 


\section{Dividends (1412)}

5.111 Dividends (1412) are the distributed earnings allocated to government or public sector units, as the owners of equity, for placing funds at the disposal of corporations. ${ }^{31}$ Raising equity through the issue of shares is an alternative way of raising funds compared to borrowing. Equity does not give rise to a liability that is fixed in monetary terms and it does not entitle the holders to a fixed or predetermined income. Instead, the board of directors or other managers of the corporation must declare a dividend payable on their own volition. Dividends exclude issues of bonus shares that simply represent a reclassification between own funds, reserves, and undistributed profits.

5.112 Although dividends represent a part of income that has been generated over a substantial period of time, often 6 or 12 months, dividends are not recorded in GFS at the time the economic value is generated. For public corporations where government or another public corporation is the only shareholder and the shares are not publicly traded, the dividends are recorded at the time they are payable. Quoted shares go "ex-dividend," meaning that the dividend is payable to the owner at that date. In other words, the owner of the equity at the ex-dividend date, and not the owner on the date dividends became payable, has the right to the dividend. A share sold "ex-dividend" is therefore worth less than one sold without this constraint. In this case, the time of recording of dividends is the point at which the share price starts to be quoted on an "ex-dividend" basis rather than at a price that includes the dividend.

5.113 General government units may receive dividends from resident or nonresident private or public corporations (see Table 5.9). In exceptional cases, legally constituted corporations that are classified as a general government unit may also distribute dividends, so that dividends may also be receivable from other general government units (though subject to consolidation). The sector of the counterparty to dividends receivable should be identified separately to allow for consolidation of the general government and public sectors.

5.114 Distributions of profits by public corporations may take place irregularly and may not be ex-

\footnotetext{
${ }^{31}$ Government or public sector units, in their capacity as shareholders, may in some cases also acquire equity by transferring nonfinancial assets to a corporation.
}

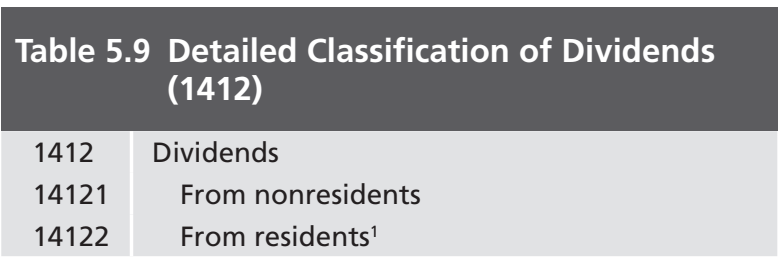

"Further breakdown/" of which" lines could allow for the identification of subsectors and individual units (see Table 3.1).

plicitly labeled as dividends. Nevertheless, dividends include all distributions of profits by corporations to their shareholders or owners, by whatever name they are called, including profits of central banks transferred to government units, profits transferred or distributed from the operation of monetary authority functions outside the central bank, and profits transferred by state lotteries that compete with other privately organized lotteries. Distributions of profits of fiscal monopolies (1143) and profits of export or import monopolies (1153), however, are classified as taxes, as described in paragraphs 5.63 and 5.86.

5.115 Dividends are notionally paid out of the current period's operating surplus. However, corporations often smooth the payments of dividends, sometimes paying out rather less than their operating surplus but sometimes paying out a little more, especially when the operating surplus itself is very volatile. For practical reasons, no attempt is made to align dividend payments with earnings except in one circumstance. The exception occurs when dividends are disproportionately large relative to the recent level of dividends and earnings. Such disproportionally large and irregular payments, often referred to as "super-dividends," are often based on accumulated reserves, privatization receipts, other sales of assets, or holding gains. Any dividends declared greatly in excess of the recent level of dividends and earnings should be recorded as a transaction in financial assets, specifically the withdrawal of owners' equity from the corporation (see paragraph 9.49).

5.116 To determine whether "super-dividends" are disproportionately large, it is helpful to introduce the concept of distributable income. Distributable income of a corporation is equal to entrepreneurial income, plus all current transfers receivable, minus all current transfers payable, and minus the adjustment for the change in pension entitlements relating to the pension scheme of that corporation (see also 2008 SNA 7.131). From this it is possible to look at 
the ratio of dividends to distributable income over the recent past and assess the plausibility that the current level of dividends declared is in line with past practice. In practice, a proxy for distributable income can be measured by the net operating balance (NOB), excluding dividends payable and net capital transfers. Determining whether dividends are in line with past practice is recommended for all corporations, including the central bank.

5.117 Interim dividends are dividend payments during a reporting period, before the final operating result of a corporation is known. If evidence exists that such dividends are not from the current period's operating surplus, interim dividend payments should be recorded as a financial advance to the shareholder in transactions in financial assets and liabilities.

\section{Withdrawals of income from quasi- corporations (1413)}

5.118 Withdrawals of income from quasi-corporations (1413) consist of that part of distributable income ${ }^{32}$ that the owner withdraws from the quasi-corporation. By definition, quasi-corporations ${ }^{33}$ cannot distribute income in the form of dividends, but the owner may choose to withdraw some or all of the distributable income. Conceptually, the withdrawal of such income is equivalent to the distribution of corporate income through dividends and is recorded the same way. The amount of income that the owner of a quasicorporation chooses to withdraw will depend largely on the size of its disposable income before taxes. All such withdrawals are recorded on the date the payment actually occurs.

5.119 As with dividends, withdrawals of income from quasi-corporations do not include withdrawals of funds realized from the sale or other disposal of the quasi-corporation's assets. Withdrawals based on such sales should be recorded as disposals of nonfinancial assets in the accounts of the quasi-corporation and the reduction of the equity of quasi-corporations owned by government sector units. Similarly, funds withdrawn by liquidating large amounts of accumulated retained earnings or other reserves of the quasicorporation are recorded as withdrawals from equity.

\footnotetext{
${ }^{32}$ See paragraph 5.116 for a discussion on distributable income.

${ }^{33}$ The criteria to identify quasi-corporations are described in paragraph 2.33 .
}

\section{Property income from investment income disbursements (1414)}

5.120 Property income from investment income disbursements (1414) includes property income attributed to insurance policyholders and holders of investment fund shares. ${ }^{34}$ Insurance enterprises hold technical reserves in the form of prepayments of premiums, reserves against outstanding claims, and actuarial reserves against outstanding risks with respect to life insurance policies. These reserves are liabilities toward the beneficiaries, including any government or other public sector units that are policyholders. Any income receivable from the investment of the corresponding assets should also be attributed as the property income of the policyholders or beneficiaries. However, for government sector units as the holder of policies, the revenue related to this item is likely to be unknown and would probably be calculated only in the context of the whole of the economy; therefore this revenue item is excluded from GFS and so is an adjustment item between GFS and national accounts (see Appendix 7). This type of property income is described in greater detail in paragraphs 6.113-6.119 in the context of the corresponding expense.

5.121 Investment income attributed to holders of shares or units in investment funds includes two separate items. The first of these is the dividends distributed to investment fund shareholders. The second is retained earnings attributed to investment fund shareholders. The increase in value of investment fund shares or units other than from holding gains and losses is recorded as distributed to the share- or unit holders and reinvested by them in the financial instrument.

\section{Rent (1415)}

5.122 Rent (1415) is the revenue receivable by the owners of a natural resource (the lessor or landlord) for putting the natural resource at the disposal of another institutional unit (a lessee or tenant) for use of the natural resource in production. Rent receivable is typically related to a resource lease on land, subsoil resources, and other natural resources. In terms of the

\footnotetext{
${ }^{34}$ Investment income disbursements by definition also include investment income attributed to participants in pension schemes. However, public sector institutional units are not entitled to pension benefits, and therefore this subcategory of investment income disbursement is not applicable as a GFS revenue category.
} 
agreement, the owner can extend or withhold permission for continued use of the asset from one year to the next. It constitutes an agreement whereby the legal owner of a natural resource that is considered to have an infinite life makes it available to a lessee in return for a regular payment recorded as property income and described as rent. ${ }^{35}$

5.123 On the accrual basis of recording, rent accrues continuously to the asset's owner throughout the period of the contract. The rent recorded for a particular reporting period is, therefore, equal to the value of the accumulated rent that becomes payable over the reporting period and may differ from the amount of rent that becomes due for payment or is actually paid during the period.

5.124 Rent excludes payments receivable by the owners of natural resources if such payments permit the resource to be used to extinction-such activity is regarded as a sale (see paragraphs 8.54 and A4.19) and possibly depletion (see paragraph 10.52) of the nonproduced asset. Also excluded from rent are amounts receivable by owners of natural resources when they allow the resource to be used for an extended period of time in such a way that, in effect, the user controls the use of the resource during this time with little, if any, intervention from the legal owner. This option leads to recording a transaction in an asset, classified as contracts, leases, and licenses (31441), for the user, distinct from the resource itself (see paragraphs 8.56 and A4.19).

5.125 Two types of resource rent are described ahead in detail: rent on land and rent on subsoil resources. Resource rent on other natural resources follows the pattern laid out by these two types. The boundary between resource rent and the rental of produced assets is discussed in paragraphs 5.131-5.132.

\section{Rent on land}

5.126 Rent on land is recorded as accruing continuously to the landowner throughout the period of the contract. Rent may be paid in cash or in kind. Under sharecropping or similar schemes, the value of the rent payable is not fixed in advance in monetary

\footnotetext{
${ }^{35} \mathrm{~A}$ more detailed discussion on the boundary between alternative uses of natural resources is presented in the context of the discussion on leases, licenses, permits, and other contracts to use a natural resource in Appendix 4.
}

terms and is measured by the value at basic prices $^{36}$ of the crops that the tenants are obliged to provide to the landowner government unit under the contract between them.

5.127 Rent on land also includes the rent payable to general government sector units for the use of inland waters and rivers (for the right to exploit such waters for recreational or other purposes, including fishing) or noncultivated land (for the right to cut timber on such land). In the case of permits that allow timber felling in a natural forest, it is common for these fellings to be allowed under strict limits with a fee payable per unit volume of timber felled (stumpage). The limits are usually such that the harvest of timber is sustainable and so these payments should also be recorded as rent (1415). However, if a unit is given permission to fell an area of natural forest, or to fell at its discretion without any restriction in perpetuity, the payments made to the owner constitute the sale of an asset. For those forests that are produced assets, the extraction of timber is treated as the sale of a product.

5.128 A landowner may be liable to pay land taxes or incur certain maintenance expenses solely as a consequence of owning the land. By convention, such taxes or expenses are recorded as payable by the tenant who is deemed to deduct them from the rent that he would otherwise be obliged to pay to the landowner. Rent reduced in this way by taxes or other expenses for which the landowner is liable is described as "after-tax rent." The adoption of this convention reflects the true economic nature of the transactions involved in the accounts of both parties.

\section{Rent on subsoil assets}

5.129 The ownership of subsoil assets in the form of deposits of minerals or fossil fuels (coal, oil, or natural gas) depends upon the way in which property rights are defined by law and also on international agreements in the case of deposits below international waters. In some cases the assets may belong to the owner of the ground below which the deposits are located, but in other cases they may belong to a local or central government unit.

\footnotetext{
${ }^{36}$ Basic prices are prices before taxes on products are added and subsidies on products are subtracted.
} 
5.130 General government units may grant leases to other institutional units that permit them to extract these deposits over a specified period of time in return for a payment or series of payments. These payments are often described as "royalties," but they are essentially rent that accrues to owners of natural resources in return for putting these assets at the disposal of other units for specified periods of time. The rent may take the form of periodic payments of fixed amounts, irrespective of the rate of extraction, or, more commonly, they may be a function of the quantity, volume, or value of the asset extracted. Enterprises engaged in exploration on government land may make payments to general government units in exchange for the right to undertake test drilling or otherwise investigate the existence and location of subsoil assets. Such payments are also recorded as rents even though no extraction may take place.

\section{Boundary with rental of produced assets}

5.131 Rent should not be confused with the rental of produced assets, which is recorded as sales of goods and services (142) ${ }^{37}$ Rentals are payments made under an operating lease to use a fixed asset belonging to a unit where the owner maintains and replaces as necessary, and makes available the fixed asset on demand to lessees. The difference in treatment arises because lessors of produced assets are engaged in a production process whereby they provide services to the lessees, such as maintaining inventories of fixed assets available for lease at short notice and repairing and maintaining the leased assets. In particular, the rentals payable by government units as tenants are recorded as payments for the provision of building or housing services. Rent is revenue receivable by owners of natural resources for placing these assets at the disposal of other units.

5.132 A single payment may cover both rent and rentals when an institutional unit rents land that consists of land improvements and land and buildings situated on the land in a single contract, or lease, in which the two kinds of payments are not differentiated from each other. If there is no objective basis on which to split the payment between rent on land and rental on the produced assets, it is recommended to

\footnotetext{
${ }^{37}$ The rentals paid by tenants of buildings are treated as payments for the provision of real estate activities or housing services.
}

treat the whole amount as rent when the value of the land is believed to exceed the value of the buildings and other produced assets, and as a rental otherwise.

\section{Boundary with taxes}

5.133 Rent should also not be confused with severance taxes, business licenses, or other taxes. Severance taxes are imposed on the extraction of minerals and fossil fuels from reserves owned privately or by another government. If the payment counts toward the taxes on profits, then it should be classified as taxes on income, profits, and capital gains (111). Payments related to the gross value of production should be classified as other taxes on goods and services (1146). Payments for a license or permit to conduct extraction operations should be classified as taxes on use of goods and on permission to use goods or perform activities (1145).

\section{Reinvested earnings on foreign direct investment (1416)}

5.134 Reinvested earnings are the direct investor's share of the retained earnings of the direct investment ${ }^{38}$ enterprise. A general government unit or public corporation may have foreign direct investment in nonresident special purpose entities (SPEs), or nonresident branches or subsidiaries of public corporations. Actual distributions receivable from such nonresident units out of their distributable income should be recorded as dividends (1412) or withdrawals of income from quasi-corporations (1413). In addition, these entities may have retained some of their earnings. Retained earnings of a corporation or quasi-corporation are equal to the distributable income $\mathrm{e}^{39}$ minus the dividends payable or withdrawal of income from the corporation or quasi-corporation, respectively.

5.135 Retained earnings of a foreign direct investment enterprise are to be recorded as if they were distributed to foreign direct investors in proportion to their ownership of the equity of the enterprise and then reinvested by them. ${ }^{40}$ The imputed remittance

\footnotetext{
${ }^{38}$ Direct investment is a category of cross-border investment associated with a resident in one economy having control or a significant degree of influence on the management of an enterprise that is resident in another economy (see the BPM6, paragraphs 6.8 and $11.40-11.47$ )

${ }^{39}$ Distributable income is discussed in paragraph 5.116.

${ }^{40}$ See paragraph 10.33 for the treatment of retained earnings of other corporations.
} 
of these retained earnings should be recorded as reinvested earnings on foreign direct investment, while the counterpart entry for the imputed reinvestment should be recorded as the acquisitions of equity and investment fund shares (3205). The rationale behind this treatment is that, because a direct investment enterprise is, by definition, subject to control or influence by the direct investor or investors, the decision to retain some of its earnings within the enterprise represents an investment decision on the part of the investor(s) (see paragraph 6.120). ${ }^{41}$

\section{Sales of goods and services (142)}

5.136 Sales of goods and services (142) consist of the sales by market establishments, administrative fees charged for services, incidental sales by nonmarket establishments, and imputed sales of goods and services. Sales of goods and services are recorded as revenue without deduction of the expenses incurred in generating that revenue. Sales of goods and services are further classified according to whether they relate to market or nonmarket production (see Table 5.10). It is quite possible for general government sector units to sell their output at prices that are less than the cost of production (which is calculated as the sum of compensation of employees, use of goods and services, consumption of fixed capital, and taxes (minus subsidies) on production). Indeed, as nonmarket producers, most general government units distribute their output without charge, or for prices that are not economically significant. These prices defray some of the costs or may eliminate some of the excess demand that otherwise would exist. In contrast, corporations sell their output at prices that are economically significant.

5.137 Sales by market establishments (1421) are the sales of an establishment that is a part of an enterprise (see paragraph 2.75) situated in a single location and at which only a single productive activity is carried out or the principal productive activity accounts for most of the value added. A market establishment within a government unit is an establishment that sells or otherwise disposes of all or most of its output at prices that are economically significant. This category consists of the sales of all market establishments that are part of the units for which statistics are being compiled. Because public corporations comprise primarily

\footnotetext{
${ }^{41}$ The 2008 SNA research agenda includes a proposal to extend the treatment of distributing retained earnings to the owners of other corporations, in particular of public corporations.
}

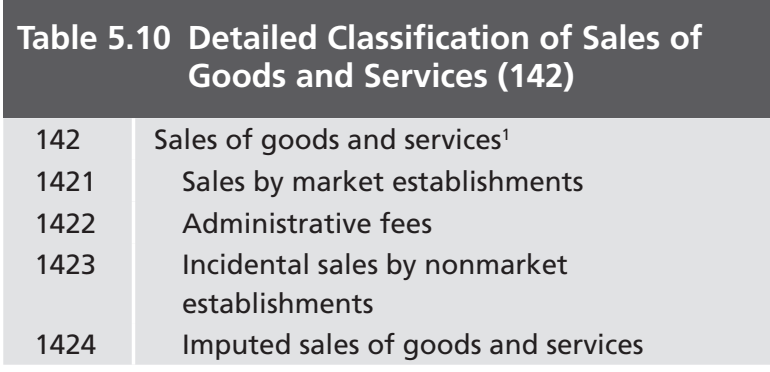

'Detailed data about the sectors of the counterparty may not be available. Where such data are available, further breakdown/" of which" lines could identify the subsectors to allow consolidation. For analytical purposes, it may also be useful to separately identify the nature of the respective goods or services that were sold.

market establishments, their sales are included in this category when compiling statistics for the public sector, unless the sales are of a specific type that are to be recorded elsewhere, such as under insurance premiums and administrative fees. Rentals of produced assets are recorded as sales of services and are included in this category. Sales of nonfinancial assets other than inventories are disposals of nonfinancial assets (as described in Chapter 8) and are not sales of goods and services.

5.138 Administrative fees (1422) include fees for compulsory licenses and other administrative fees that are sales of services. Examples are drivers' licenses, passports, visas, court fees, and radio and television licenses when public authorities provide general broadcasting services. Also included are fees payable for voluntary participation in deposit insurance or other guarantee schemes that do not qualify to be a standardized guarantee scheme. These fees are considered a sale of a service when, for instance, issuing the license or permit implies a proper regulatory function of the government. In this case, the payment is taken to be proportional to the cost of producing the service. For a detailed description on the boundary between taxes and the purchases of services, see paragraph 5.74. If a payment is clearly out of all proportion to such cost, then the fee is classified as taxes on use of goods and on permission to use goods or perform activities (1145).

5.139 Incidental sales by nonmarket establishments (1423) cover sales of goods and services by nonmarket establishments of general government units other than administrative fees. Included are sales incidental to the usual social or community activities of government departments and agencies, such as sales of 
products made at vocational schools, seeds from experimental farms, postcards and art reproductions by museums, fees at government hospitals and clinics, tuition fees at government schools, and admission fees to government museums, parks, and cultural and recreational facilities that are not public corporations.

5.140 Imputed sales of goods and services (1424) are recorded when a unit produces goods and services for the purpose of using them as compensation of employees in kind. The unit is acting in two capacities: as an employer and as a general producer of goods and services. In order to indicate the total amount paid as compensation of employees, it is necessary to treat the amount paid in kind as if it had been paid in cash as wages and salaries and then the employees had used this income to purchase the goods and services. This category includes the total value of these imputed sales. Wages and salaries in kind are explained in greater detail in paragraphs 6.17-6.18. For a defined-contribution pension scheme, this category also includes an imputed sale for the services rendered if the employer operates the scheme itself. In that case, the value of the costs of operating the scheme is recorded as an imputed contribution payable to the employee as part of compensation of employees. The counterpart of this amount should be recorded as an imputed sale of a financial service to the household sector (see paragraph 6.25).

5.141 On the accrual basis of recording, sales of goods are recorded when legal ownership changes. If that time cannot be determined precisely, recording may take place when there is a change in physical ownership or control. Transactions in services normally are recorded when the services are provided. Some services are supplied or take place on a continuous basis. For example, rentals are continuous flows and, in concept, are recorded continuously as long as they are being provided.

\section{Fines, penalties, and forfeits (143)}

5.142 Fines and penalties are compulsory current transfers imposed on units by courts of law or quasijudicial bodies for violations of laws or administrative rules. Out-of-court agreements are also included. Forfeits are amounts that were deposited with a general government unit pending a legal or administrative proceeding and that have been transferred to the general government unit as part of the resolution of that proceeding.
5.143 In principle, fines and penalties charged on overdue taxes or penalties imposed for the evasion of taxes should be recorded in this category and not as taxes. However, it may not be possible to separate payments of fines or other penalties from the taxes to which they relate. In this case, the fines and penalties relating to a particular tax are recorded together with that tax, and fines and penalties related to unidentifiable taxes are classified as other taxes (116).

5.144 Most fines, penalties, and forfeits are determined at a specific time. These transfers are recorded on an accrual basis when the general government unit has an unconditional claim to the funds, which may be when a court renders judgment or an administrative ruling is published, or it may be when a late payment or other infringement automatically causes a fine or penalty. Fines also include bail set by courts, when bail conditions have been violated. When bail is set, repayable amounts received should be recorded as other accounts payable (3308), and should be recorded as revenue only once the conditions for the bail were violated. In cases where no actual payment is made when bail is set, government acquires a conditional claim. Such a conditional claim is not recorded in GFS until the conditions are fulfilled.

\section{Transfers not elsewhere classified (144)}

5.145 Transfers not elsewhere classified (144) receivable include subsidies, as well as gifts and transfers from individuals, private nonprofit institutions, nongovernmental foundations, corporations, or sources other than governments and international organizations. These transfers could be classified according to the sector of the counterparty and whether they are current or capital transfers (see Table 5.11). If doubt exists regarding the character of a transfer, it should be classified consistently by both parties (see paragraph 3.18). Transfers not elsewhere classified (144) comprise current transfers not elsewhere classified (1441) (comprising subsidies (14411) and other current transfers not elsewhere classified (14412)), as well as capital transfers not elsewhere classified (1442).

5.146 Subsidies (14411) are current unrequited transfers that government units make to enterprises on the basis of the level of their production activities or the quantities or values of the goods or services they produce, sell, export, or import. As revenue, these are amounts receivable, mainly by public corporations. In rare cases, general government units and 


\section{Table 5.11 Detailed Classification of Transfers Not Elsewhere Classified (144) \\ 144 Transfers not elsewhere classified \\ 1441 Current transfers not elsewhere classified \\ $14411 \quad$ Subsidies ${ }^{1,2,3}$ \\ 14412 Other current transfers not elsewhere classified $^{1,3}$ \\ 1442 Capital transfers not elsewhere classified ${ }^{1,3}$}

"Further breakdown/" of which" lines could allow for the identification of subsectors and individual units (see Table 3.1).

2Further breakdown/"of which" lines could also identify whether these subsidies are subsidies on products or production.

${ }^{3}$ Further breakdown/" of which" lines could also identify whether these transfers are related to specific natural resource or environmental revenue.

nonprofit institutions serving households can receive subsidies when the transfer receivable depends on the general regulations of the subsidy scheme, applicable to all producers-that is, market and nonmarket producers. Subsidies are explained in greater detail in paragraphs 6.84-6.91.

5.147 Other current transfers not elsewhere classified (14412) are gifts and transfers of a current nature (other than grants or subsidies) from individuals, private nonprofit institutions, nongovernmental foundations, or corporations. These transfers could be in cash or in kind-for example, contributions to government of food, blankets, and medical supplies for relief purposes.

5.148 Capital transfers not elsewhere classified (1442) are gifts and transfers of a capital nature (other than grants) from individuals, private nonprofit institutions, nongovernmental foundations, or corporations. Examples of transfers included in this category are:

- Major nonrecurrent payments receivable in compensation for extensive damages or serious injuries not covered by insurance policies. The payments may be awarded by courts of law or settled out of court. They include payments of compensation for damages caused by major explosions, oil spillages, etc.

- International aid of a capital nature receivable after natural disasters from nonresidents other than international organizations and foreign governments ${ }^{42}$

\footnotetext{
${ }^{42}$ International aid receivable from resident and nonresident general government units and international organizations is classified as grants (see paragraph 5.101).
}

- Payments receivable for damage to property other than payments from an insurance settlement (insurance settlements are included in claims receivable (14513 or 1452))

- Transfers receivable by public corporations from government units, to cover large operating deficits accumulated over two or more years ${ }^{43}$

- Legacies or large gifts receivable by government or public sector units, including gifts of land, buildings, or research and development assets such as patents and copyrights

- Exceptionally large donations receivable from households or enterprises to public sector units to finance gross fixed capital formation: for example, transfers for the construction or purchase of hospitals, schools, museums, theaters, and cultural centers, or gifts to universities to cover the costs of building new residential colleges, libraries, laboratories, etc.

- Capital transfers from corporations, quasicorporations, nonprofit institutions serving households, households, and nonresidents other than governments and international organizations (see paragraph 5.103) for the cancelation or assumption of a debt by mutual agreement with the government without the government incurring an effective liability toward them ${ }^{44}$

- Amounts receivable in excess of the expected value of liabilities assumed for the provision of pension entitlements ${ }^{45}$

- Community-built assets where responsibility for maintenance is then assumed by a public sector unit.

\section{Premiums, fees, and claims receivable related to nonlife insurance and standardized guarantee schemes (145)}

5.149 Premiums, fees, and claims receivable related to nonlife insurance and standardized guarantee schemes (145) comprise nonlife insurance premiums

\footnotetext{
${ }^{43}$ Where a realistic expectation exists that such amounts will be repayable, as indicated by certain criteria (see Box 6.3), the transaction should be classified as the acquisition of a financial asset. A regular transfer covering an operating deficit is recorded as a subsidy.

${ }^{44}$ Details on debt cancellation, debt assumption, and other government debt operations can be found in Appendix 3, and in the PSDS Guide, Chapter 4.

${ }^{45}$ Amounts receivable up to the expected value of the liabilities should be recorded as transactions in financial assets and liabilities (i.e., the incurrence of a liability) (see paragraph 9.67).
} 
receivable ${ }^{46}$ by insurance schemes to provide entitlement to insurance against risks; claims receivable from insurance schemes by beneficiaries; and fees receivable for the issuance of standardized guarantees. While premiums and fees are always of a current nature, claims receivable could be of a capital or current nature. The types of insurance and standardized guarantee schemes, terminology used in insurance, and the statistical recording of flows and stock positions related to these are described in Appendix 4. To allow for consolidation of the general government and public sectors, this revenue should be classified according to the sector of the counterparty (see Table 5.12). ${ }^{47}$

5.150 Premiums, fees, and current claims receivable (1451) comprise nonlife insurance premium revenue and fees receivable for the issuance of standardized guarantees, as well as insurance settlement revenue that is not exceptional. On an accrual basis, premiums and fees receivable should include only those that provide insurance coverage in the reporting period. Receipts of prepayment of premiums and fees should not be recognized as revenue, but should

\footnotetext{
${ }^{46}$ In the 2008 SNA, nonlife insurance premiums receivable are partitioned into a sale of a service and a transfer. In GFS, the entire premium is considered a transfer. Fees receivable for one-off guarantees are recorded as administrative fees (see paragraph 5.138).

${ }^{47}$ See Appendix 4 for an illustration of the recording of transactions and stock positions related to insurance, including standardized guarantees.
}

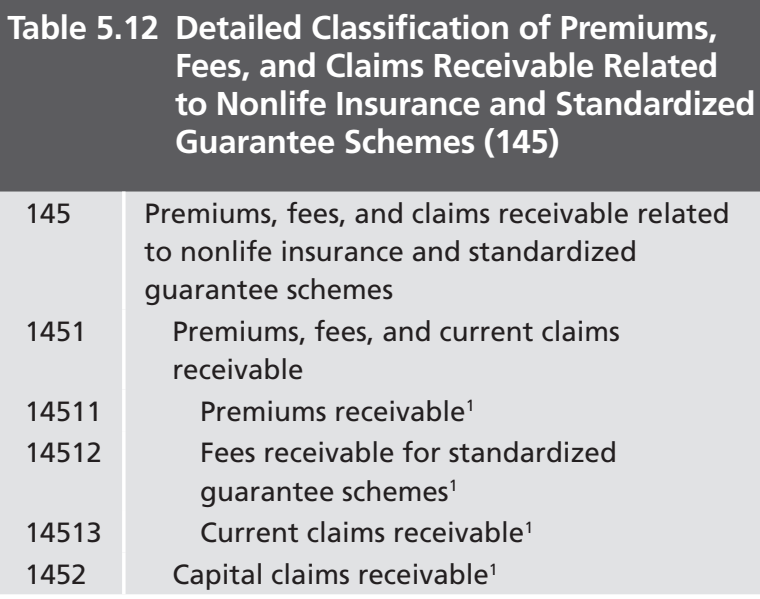
Fees, and Claims Receivable Related to Nonlife Insurance and Standardized Guarantee Schemes (145)

145 Premiums, fees, and claims receivable related to nonlife insurance and standardized guarantee schemes

1451 Premiums, fees, and current claims receivable

14511 Premiums receivable ${ }^{1}$

14512 Fees receivable for standardized guarantee schemes ${ }^{1}$

14513 Current claims receivable ${ }^{1}$

1452 Capital claims receivable ${ }^{1}$

"Further breakdown/" of which" lines could allow for the identification of subsectors and individual units (see Table 3.1)

be recorded as the incurrence of a liability in the form of insurance technical reserves (see paragraphs 7.183 and A4.79).

5.151 Capital claims receivable (1452) comprise exceptionally large insurance settlements receivable in the wake of a catastrophic event or disaster. It may be difficult for the parties to identify these exceptionally large settlements consistently, so as a simplifying convention, all nonlife insurance claims are classified as current transfers, unless it is necessary to record a capital transfer to be consistent with the national accounts. 


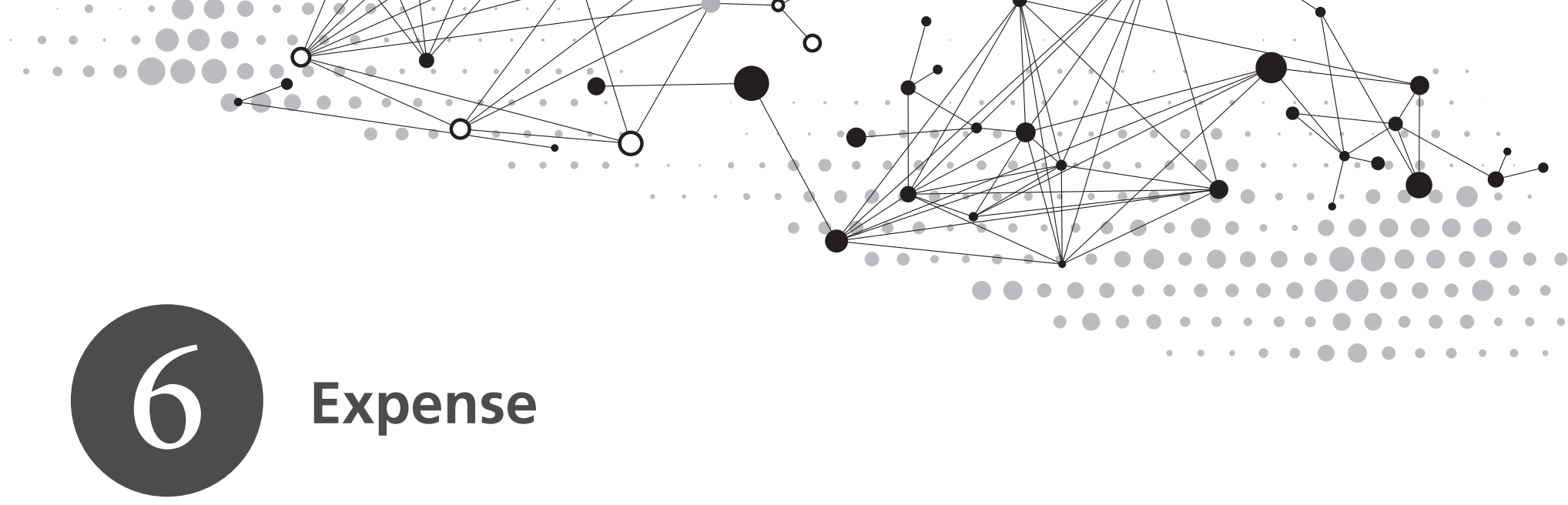

This chapter defines the concept of expense and describes the manner in which expense is classified.

\section{Defining Expense}

6.1 Expense (1) is a decrease in net worth resulting from a transaction. Expense transactions as defined in GFS have counterpart entries either in a decrease in assets or an increase in liabilities-thereby decreasing net worth. The general government sector has two broad economic responsibilities: (i) to assume responsibility for the provision of selected goods and services to the community, primarily on a nonmarket basis; and (ii) to redistribute income and wealth by means of transfers (see paragraph 2.38). These responsibilities are largely fulfilled through expense transactions, which are classified in two ways in GFS: an economic classification and a functional classification.

6.2 The economic classification of expense identifies the types of expense incurred according to the economic process involved. When supplying goods and services to the community, a government unit may produce the goods and services itself and distribute them, purchase them from a third party and distribute them, or transfer cash to households so they can purchase the goods and services directly. For example, compensation of employees, use of goods and services, and consumption of fixed capital all relate to the costs of producing nonmarket (and, in certain instances, market) goods and services by government. Subsidies, grants, social benefits, and transfers other than grants relate to transfers in cash or in kind, and are aimed at redistributing income and wealth.

6.3 The functional classification of expense provides information on the purpose for which an expense was incurred. Examples of functions are education, health, and environmental protection. The functional classification is described in the annex to this chapter. ${ }^{1}$ In addition, the economic and functional classifications can be cross-classified to show the types of transactions engaged in to carry out a given function (see the annex to Chapter 6, paragraphs 6.126-6.148).

6.4 Refunds, recoveries of overpayments, receivables on erroneous payments, and similar transactions are transactions that increase net worth. More accurately, they are adjustments that correct the excessive decrease in net worth previously recorded. These transactions are treated as a reduction in expense, with a corresponding reduction in liabilities or an increase in financial assets.

6.5 Some transactions are exchanges in assets and/ or liabilities and should not be recorded as expense. The acquisition of a nonfinancial asset by purchase or barter does not affect net worth, and such transactions are not an expense. They are transactions in nonfinancial assets, as described in paragraph 8.3. However, when ownership of an asset is given up without receiving anything of commensurate value in return, the net worth of the unit has decreased. This reduction in assets has a counterpart entry in an increase in expense and should be recorded as a type of capital transfer payable, such as a capital grant. Amounts payable on loans extended and repayments on loans incurred are also not an expense. These are transactions in financial assets or liabilities as described in paragraph 9.3 .

\section{Time of Recording Expense}

6.6 In the Statement of Operations, expense should be recorded according to the accrual basis of recording. According to the accrual basis of recording, transactions are recorded when activities, transactions, or other events occur that create the unconditional

\footnotetext{
${ }^{1}$ In GFS, the functional classification is applied to expenditurethat is, the sum of expense transactions and net investment in nonfinancial assets.
} 
obligation to make payments or otherwise give up resources (see paragraph 3.62). In the absence of a complete inventory accounting system (see paragraph 8.46), complications arise with the recording of the acquisition and subsequent use of goods. Conceptually, the purchase of goods that are not immediately used in some manner is an addition to inventories rather than an expense. When the goods are consumed in production or otherwise utilized, a decrease in inventories should be recorded, as well as an expense or an increase in some other category of asset, depending on the manner in which these goods are used. ${ }^{2}$ However, in practice, as described in paragraphs $8.45-8.47$, the change in inventories is often not recorded for each transaction, but rather calculated as a residual from information on stock positions and flows in inventories. Other applications of the accrual basis to specific categories of expense transactions are indicated in each section of the economic classification, as relevant.

6.7 In the Statement of Sources and Uses of Cash, expense transactions should be recorded according to the cash basis of recording, as close to the payment stage as possible (see paragraph 3.103).

\section{The Economic Classification of Expense}

6.8 Table 6.1 shows the summary economic classification of expense, and the remainder of this chapter describes each category in detail. ${ }^{3}$ While the summary GFS expense classification structure provides guidance on the minimum requirements for internationally comparable classifications of expense, analytical needs may necessitate further detailed classifications to be added as subitems in national data presentations. These additional subitems may be presented either as a comprehensive breakdown of the standard item, or presented as "of which" lines. These items usually relate to the need for consolidation of the general government or public sector, input into other macroeconomic datasets, or items that will allow the calculation of supplementary aggregates or balances (see paragraph 5.22).

\footnotetext{
${ }^{2}$ Where these goods are used in own-account capital formation to create another asset, such as a fixed asset or another category of inventories, they would be recorded as part of the cost of the acquisition of such assets. However, where the goods are consumed during the process of providing a service, an expense is recorded. ${ }^{3}$ See also Appendix 8, Table A8.2, for the detailed classifications.
}

\section{Compensation of Employees [GFS] ${ }^{4}(21)^{5}$}

6.9 Compensation of employees is the total remuneration, in cash or in kind, payable to an individual in an employer-employee relationship in return for work performed by the latter during the reporting period. These amounts are payable as an exchange for manual and intellectual labor services of individuals used in the production process of the institutional unit. Compensation of employees [GFS] $(21)^{6}$ excludes amounts connected with own-account capital formation (see Table 6.2). In GFS, compensation of employees payable to employees engaged in own-account capital formation, which is the production of nonfinancial assets for own use, is directly recorded as a component of the cost of the acquisition of nonfinancial assets. Compensation of employees [GFS] (21) also excludes amounts payable when an employer-employee relationship does not exist, such as for contractors and self-employed outworkers. Such amounts payable are classified as use of goods and services (22). For a description of this boundary between compensation of employees and use of goods and services, see paragraph 6.33 .

6.10 When using the accrual basis of recording, compensation of employees is measured by the value of the remuneration in cash and/or in kind that an employee becomes entitled to receive from an employer for work performed during the relevant period, whether paid in advance, simultaneously, or in arrears of the work itself. To the extent that payment has not been made for work performed, the unit should record an entry in other accounts payable (3308) (see paragraphs 7.224-7.227 and 9.83). ${ }^{7}$ On the other hand, to the extent that payment has been made in advance of the work itself, an entry in other accounts receivable (3208) must be recorded until such time as the work is completed. When using the cash basis of recording, compensation of employees is recorded at the time the cash

\footnotetext{
${ }^{4}$ [GFS $]$ indicates that an item has the same name but different coverage in the 2008 SNA.

${ }^{5}$ The numbers in parentheses after each classification category are the GFS classification codes. Appendix 8 provides all classification codes used in the GFS framework.

${ }^{6}$ Compensation of employees is described in the 2008 SNA, paragraphs 7.28-7.70.

${ }^{7}$ To the extent that compensation of employees is not paid on the agreed due for payment date, these other accounts payable will be in arrears from the date they became due (see paragraphs 9.20 and 7.226).
} 
Table 6.1 Summary Economic Classification of Expense

\begin{tabular}{|c|c|c|c|}
\hline 2 & Expense & 27 & Social benefits [GFS ${ }^{1}$ \\
\hline 21 & Compensation of employees [GFS ${ }^{1}$ & 271 & Social security benefits [GFS] \\
\hline 211 & Wages and salaries [GFS] & 2711 & Social security benefits in cash [GFS] \\
\hline 2111 & Wages and salaries in cash [GFS] & 2712 & Social security benefits in kind [GFS] \\
\hline 2112 & Wages and salaries in kind [GFS] & 272 & Social assistance benefits [GFS] \\
\hline 212 & Employers' social contributions [GFS] & 2721 & Social assistance benefits in cash [GFS] \\
\hline 2121 & Actual employers' social contributions [GFS] & 2722 & Social assistance benefits in kind [GFS] \\
\hline 2122 & Imputed employers' social contributions [GFS] & 273 & Employment-related social benefits [GFS] \\
\hline 22 & Use of goods and services & 2731 & Employment-related social benefits in \\
\hline 23 & Consumption of fixed capital [GFS ${ }^{1}$ & & cash [GFS] \\
\hline 24 & Interest [GFS ${ }^{1}$ & 2732 & $\begin{array}{l}\text { Employment-related social benefits in } \\
\text { kind [GFS] }\end{array}$ \\
\hline 241 & To nonresidents [GFS] & 28 & Other expense \\
\hline 242 & $\begin{array}{l}\text { To residents other than general government } \\
\text { [GFS] }\end{array}$ & $\begin{array}{l}281 \\
2811\end{array}$ & $\begin{array}{l}\text { Property expense other than interest } \\
\text { Dividends }{ }^{1}\end{array}$ \\
\hline 243 & To other general government units [GFS] & 2812 & Withdrawals of income from \\
\hline 25 & Subsidies $^{1}$ & & quasi-corporations \\
\hline 251 & To public corporations & 2813 & $\begin{array}{l}\text { Property expense for investment income } \\
\text { disbursements }\end{array}$ \\
\hline 252 & To private enterprises & 2814 & Rent \\
\hline 253 & To other sectors & 2815 & Reinvested earnings on foreign direct \\
\hline 26 & Grants $^{1}$ & & investment \\
\hline 261 & To foreign governments & 282 & Transfers not elsewhere classified \\
\hline 2611 & Current & 2821 & Current transfers not elsewhere classified \\
\hline 2612 & Capital & 2822 & Capital transfers not elsewhere classified \\
\hline 262 & To international organizations & 283 & Premiums, fees, and claims related to \\
\hline 2621 & Current & & nonlife insurance and standardized \\
\hline 2622 & Capital & & guarantee schemes \\
\hline 263 & To other general government units & 2831 & Premiums, fees, and current claims \\
\hline 2631 & Current & 2832 & Capital claims \\
\hline 2632 & Capital & & \\
\hline
\end{tabular}

${ }^{1}$ Indicates that further breakdown may be analytically useful and is presented in detailed tables.

flow occurs, irrespective of when the labor exchange takes place. Wages and salaries in kind are not recorded in the cash basis of recording since no cash flows are involved.

6.11 Compensation of employees comprises wages and salaries (211) and employers' social contributions (212) payable by employers on behalf of employees to social insurance schemes.

\section{Wages and salaries [GFS] (211)}

6.12 Wages and salaries are compensation of employees payable in cash and/or in kind, except for social contributions payable by employers. As indicated in Table 6.2, wages and salaries [GFS] (211) exclude amounts connected with own-account capital formation. They include amounts withheld from wages and salaries by the employer for administrative convenience or other reasons, such as social contributions, income taxes, and other deductibles, payable by the employee. These deductibles are often paid directly to social insurance schemes, tax authorities, etc., on behalf of the employee. Wages and salaries may be payable in various ways, including goods or services provided to employees as remuneration in kind instead of, or in addition to, remuneration in cash. Including remuneration in kind allows GFS to measure the full cost of labor employed. 


\begin{tabular}{|c|c|}
\hline \multirow[t]{3}{*}{21} & Compensation of employees [GFS $]^{1}$ \\
\hline & Compensation of employees [SNA] \\
\hline & $\begin{array}{l}\text { Minus: Related to own-account capital } \\
\text { formation }\end{array}$ \\
\hline \multirow[t]{3}{*}{211} & Wages and salaries [GFS] \\
\hline & Wages and salaries [SNA] \\
\hline & $\begin{array}{l}\text { Minus: Related to own-account capital } \\
\text { formation }\end{array}$ \\
\hline \multirow[t]{3}{*}{2111} & Wages and salaries in cash [GFS] \\
\hline & Wages and salaries in cash [SNA] \\
\hline & $\begin{array}{l}\text { Minus: Related to own-account capital } \\
\text { formation }\end{array}$ \\
\hline \multirow[t]{3}{*}{2112} & Wages and salaries in kind [GFS] \\
\hline & Wages and salaries in kind [SNA] \\
\hline & $\begin{array}{l}\text { Minus: Related to own-account capital } \\
\text { formation }\end{array}$ \\
\hline \multirow[t]{3}{*}{212} & Employers' social contributions [GFS] \\
\hline & Employers' social contributions [SNA] \\
\hline & $\begin{array}{l}\text { Minus: Related to own-account capital } \\
\text { formation }\end{array}$ \\
\hline \multirow[t]{3}{*}{2121} & Actual employers' social contributions [GFS] \\
\hline & $\begin{array}{l}\text { Actual employers' social contributions } \\
\text { [SNA] }\end{array}$ \\
\hline & $\begin{array}{l}\text { Minus: Related to own-account capital } \\
\text { formation }\end{array}$ \\
\hline \multirow[t]{3}{*}{2122} & Imputed employers' social contributions [GFS] \\
\hline & $\begin{array}{l}\text { Imputed employers' social contributions } \\
\text { [SNA] }\end{array}$ \\
\hline & $\begin{array}{l}\text { Minus: Related to own-account capital } \\
\text { formation }\end{array}$ \\
\hline
\end{tabular}

${ }^{1}$ Further breakdown/" of which" lines could allow for the identification of the types of compensation of employees payable.

\section{Wages and salaries in cash [GFS] (2111)}

6.13 Wages and salaries in cash $^{8}$ are the amounts payable in cash, or any other financial instruments used as means of payments, to employees in return for work performed. As indicated in Table 6.2, wages and salaries in cash [GFS] (2111) exclude amounts connected with own-account capital formation. Included are the following kinds of remuneration:

- Basic wages or salaries payable at regular weekly, monthly, or other intervals, including payments by results and piecework payments; enhanced

${ }^{8}$ The use of the term "cash" should not be viewed as denoting the cash basis of recording, but rather denotes monetary remuneration. payments or special allowances for working overtime, at nights, on weekends, or other irregular hours; allowances for working away from home or in disagreeable or hazardous circumstances; expatriation allowances for working abroad, etc.

- Supplementary allowances payable regularly, such as housing allowances or allowances to cover the costs of travel to and from work, but excluding social benefits payable by the employers (see paragraph 6.16)

- Wages or salaries payable to employees away from work for short periods-for example, on vacation or as a result of a temporary halt to production, except during absences due to sickness, injury, etc. (see paragraph 6.16)

- Annual supplementary pay, such as bonuses and "13th month" pay

- Ad hoc bonuses or other exceptional payments linked to the overall performance of the enterprise made under incentive schemes

- Commissions, gratuities, and tips received by employees: these should be included in payments for services rendered by the unit employing the worker, even when they are payable directly to the employee by a third party. They are thus regarded as being paid by the employer to the employee. ${ }^{9}$

6.14 In some instances, an employee benefit, such as a car or extra pension contributions, may not be provided to the employee for free (i.e., not provided without an opportunity cost to the employee). The benefit may be "purchased" from the employer by forgoing some salary. The attraction of such schemes often lies in the tax advantages that an employee may enjoy by restructuring salary packages. In these cases, the full salary should include the employee benefits "purchased" and be recorded as payable in cash-the cost of acquiring the benefit is regarded as an expenditure of the employee.

6.15 Wages and salaries in cash do not include the reimbursement by the government of costs incurred

\footnotetext{
${ }^{9}$ Amounts directly paid to the employee should be rerouted to be included in revenue of the employer related to the service provided, and then expensed as wages and salaries.
} 
by its employees in order to enable them to take up their jobs or to carry out their work-for example:

- The reimbursement of travel, relocation, or related expenses made by employees when they take up new jobs or are required by their employers to move their homes to different parts of the country or to another country

- The reimbursement of costs incurred by employees on tools, equipment, special clothing, or other items that are needed exclusively, or primarily, to enable them to carry out their work. In these cases, the amounts reimbursed are recorded as use of goods and services (22). To the extent that employees who are required by their contract of employment to purchase tools, equipment, special clothing, etc. are not fully reimbursed, the remaining expense they incur should be deducted from the amounts receivable in wages and salaries and the government's use of goods and services increased accordingly.

6.16 Wages and salaries also exclude social benefits payable by governments to their employees in the form of:

- Children's, spouse's, family, education, or other allowances in respect of dependents

- Payments made at full, or reduced, wage or salary rates to workers absent from work because of illness, accidental injury, maternity leave, etc. ${ }^{10}$

- Severance payments to workers or their survivors who lose their jobs because of redundancy, incapacity, accidental death, etc.

These social benefits are recorded as an imputed employers' social contributions (2122) payable to households, and subsequent imputed social contributions (1223) payable by these households to the employer, before including it in employment-related social benefits (273) (see paragraph 6.104).

\section{Wages and salaries in kind [GFS] (2112)}

6.17 Wages and salaries in kind are amounts payable in the form of goods, services, interest forgone, and shares issued to employees in return for work

\footnotetext{
${ }^{10}$ If it is difficult to separate payments of wages and salaries to employees on short periods of absence due to sickness, accidents, etc., from other payments of wages and salaries, the payments during short periods of absence should remain included in wages and salaries.
}

performed. As indicated in Table 6.2, wages and salaries in kind [GFS] (2111) exclude amounts connected with own-account capital formation. This category consists of goods and services provided without charge, or at reduced prices. When provided at reduced prices, the value of the wages and salaries in kind is given by the difference between the full value of the goods and services and the amount payable by the employees. These goods and services provided in kind by the government to its employees are not necessary to enable them to perform their work. They could be used by employees in their own time, and at their own discretion, for the satisfaction of their own needs or wants, or those of other members of their households. Almost any kind of good or service may be provided as wages and salaries in kind. The following are the most common types of goods and services provided without charge, or at reduced prices:

- Meals and drinks provided on a regular basis, including any subsidy element of an office canteen (for practical reasons, it is not necessary to make estimates for meals and drinks consumed as part of official entertainment or during business travel)

- Clothing or footwear that employees may choose to wear frequently outside of the workplace and while at work

- Housing services or accommodation of a type that can be used by all members of the household to which the employee belongs

- The services of vehicles or other durables provided for the personal use of employees

- Goods and services produced by the employer, such as free travel on government airplanes or trains

- Sports, recreation, or holiday facilities for employees and their families

- Transportation to and from work, free or subsidized parking, when it would otherwise have to be paid for

- Child care for the children of employees

- The value of the interest forgone $e^{11}$ by employers when they provide loans to employees at reduced

\footnotetext{
${ }^{11}$ This value may be estimated as the amount the employee would have to pay if the market equivalent interest rates were charged minus the amount of interest actually payable. The sums involved could be large when nominal interest rates are very high, but otherwise they may be too small and too uncertain to be worth estimating.
} 
or even zero rates of interest for purposes of buying houses, vehicles, furniture, or other goods or services (these amounts are also recorded as interest receivable as explained in paragraph 5.108)

- In the case of public corporations, wages and salaries in kind can also include bonus shares or stock options ${ }^{12}$ distributed to employees.

6.18 Some of these services, such as transportation to and from work, parking, and child care may have some of the characteristics of use of goods and services by the employee. However, when governments are obliged to provide these benefits to attract and retain labor, they are similar to other forms of compensation of employees and should be recorded as such. If the same types of benefits are provided because of the nature of the production process or the physical conditions under which employees have to work, they should be recorded as use of goods and services (22) expense of the employer.

\section{Employers' social contributions [GFS] (212)}

6.19 Employers' social contributions are social contributions payable by employers to social security funds, employment-related pension funds, or other employment-related social insurance schemes to obtain entitlement to social benefits for their employees. Employers' social contributions are payable by employers for the benefit of their employees, and are therefore recorded as a component of compensation of employees. Employers' social contributions [GFS] (212) exclude amounts connected with own-account capital formation (see Table 6.2). Social protection is described in Appendix 2.

6.20 Some social contributions are payable directly by the government unit that is the employer to a second public sector unit, often a social security fund or a public financial corporation. It is administratively more efficient for the employer to pay the contributions on behalf of their employees, rather than each employee making individual payments. The administrative arrangement should not obscure the underlying economic realitynamely, that the government unit incurs an expense for compensation of employees payable to households, while the employee contributes to the social insurance

${ }^{12}$ Under a stock option agreement, the employer gives an employee the option to buy stocks or shares at a specified price at a future date (see paragraphs 9.77-9.81). scheme. ${ }^{13}$ These transactions are not eliminated in consolidation because they are rerouted to better show the economic nature of the transaction, as described in paragraph 3.28, first to the employees and then from the employees to the social insurance schemes.

\section{Actual employers' social contributions [GFS] (2121)}

6.21 Actual employers' social contributions consist of actual contributions payable to social security funds, employment-related pension funds, and other employment-related social insurance schemes to obtain entitlement to social benefits for their employees. This category consists of actual contributions payable to insurance enterprises, social security funds, or other institutional units responsible for the administration and management of social insurance schemes, or employment-related pension schemes. As indicated in Table 6.2, actual employer's social contributions [GFS] (2121) also exclude amounts connected with own-account capital formation.

\section{Imputed employers' social contributions [GFS] (2122)}

6.22 Imputed employers' social contributions are the amounts calculated and added to actual contributions, sufficient to exactly match the increases in employees' social benefit entitlements. These imputed employers' social contributions may relate to pension and to nonpension benefits. Imputed employers' social contributions [GFS] (2122) exclude amounts connected with own-account capital formation (see Table 6.2).

\section{Imputed employers' social contributions} related to nonpension benefits

6.23 Some government units provide employmentrelated nonpension social benefits directly to their employees, former employees, or dependents out of their own resources without involving an insurance enterprise (see paragraph 6.16 for examples of the types of benefits payable). In this situation, employees

\footnotetext{
${ }^{13}$ The situation is parallel to one in which income taxes payable by employees are deducted by employers from the wages or salaries and paid directly to the tax authorities. The direct payment of social contributions, or income taxes, by government units as employers to other government units, such as social security schemes, other employment-related social insurance schemes, or tax authorities, is merely a shortcut taken on grounds of administrative convenience and efficiency.
} 
may be considered as being protected against various specified needs or circumstances, even though no reserves are built up to provide for future entitlement to benefits. Compensation of employees in the form of employers' social contributions equal in value to the amount of social contributions that would be needed to secure the de facto entitlements should be imputed. These amounts take into account any actual contributions made by the employer or employee and depend not only on the levels of the benefits currently payable, but also on the ways in which employers' liabilities under such schemes are likely to evolve in the future as a result of factors such as expected changes in the number, age distribution, and life expectancies of their present and previous employees. Thus, the values that should be imputed for the contributions ought, in principle, to be based on the same kind of actuarial considerations that determine the levels of premiums charged by insurance enterprises.

6.24 In practice, however, it may be difficult to decide how large such imputed contributions should be. The government sector unit may make estimates, perhaps on the basis of the contributions payable into similar funded schemes, in order to calculate its likely liabilities in the future, and such estimates may be used when available. Otherwise, the only practical alternative may be to use the unfunded nonpension benefits payable by the unit during the same reporting period as an estimate of the imputed expense that would be needed to cover the imputed contributions (see paragraph 6.104).

\section{Imputed employers' social contributions to employment-related pension benefits}

6.25 The imputation of employers' social contributions related to employment-related pension benefits is influenced by the type of pension scheme the government unit operates:

- In general, in the case of social security schemes, there are no imputed contributions recognized for social insurance. However, in cases where employment-related pensions are administered by such a social security scheme, imputed contributions should be recorded for these pension obligations.

- For a defined-contribution pension scheme, there are no imputed contributions recognized unless the employing unit operates the scheme itself. In that case, the value of the costs of operating the scheme is recorded as an imputed contribution payable to the employee as part of compensation of employees.

- For a defined-benefit pension scheme, there is an imputed contribution recognized, equal to the increase in benefits payable due to current period employment, plus the costs of operating the scheme, minus the sum of the government's actual contribution and the sum of any contributions by the employees. ${ }^{14}$

6.26 Some schemes may be generally described as noncontributory because no actual contributions are ever made by the employee. Nevertheless, in the case of employment-related schemes, an imputed contribution by the employer is calculated and should be imputed for GFS as just described. The fact that the value of imputed contributions for a noncontributory scheme may be set equal to the value of benefits payable does not mean that the benefits themselves are recorded as part of compensation of employees. Rather, the employee has a pension asset that is reduced when benefits are payable. When a pension manager is a unit different from the administrator, and the responsibility for any deficits, or claims on any excess rests with the pension manager, the counterpart entry for such claims is included in imputed social security contributions on a net basis (i.e., an expense to increase the liability and a reduction in the expense when the liability reduces or when government acquires an asset. See paragraph 7.199).

\section{Use of Goods and Services (22)}

6.27 Use of goods and services (22) consists of the value of goods and services used for the production of market and nonmarket goods and services. ${ }^{15} \mathrm{Ex}$ cluded are:

- Consumption of fixed capital (23)

- The use of goods and services in own-account capital formation, which should be recorded as the acquisition of nonfinancial assets (see paragraph 8.3)

\footnotetext{
${ }^{14}$ Some defined-benefit pension schemes may have financial assets that exceed the liabilities of the scheme to present and past employees. It is possible that in this case, the government may take a "contribution holiday" and not make actual contributions for one or more periods. Nonetheless, an imputed contribution by the government should be calculated and recorded (see paragraph A2.46). ${ }^{15}$ Use of goods and services is closely related to intermediate consumption in the 2008 SNA. The relationship between the two concepts is explained in Appendix 7. Intermediate consumption is described in the 2008 SNA, paragraphs 6.213-6.239.
} 
- Goods purchased by government and distributed without transformation, which should be recorded as some type of transfer in kind; these transfers are classified as subsidies (25), grants (26), social benefits (27), or current transfers not elsewhere classified (2821).

6.28 In the Statement of Operations, the value of use of goods or services is recorded when the goods or services are actually used rather than when they were acquired or paid for. In practice, these events often coincide for inputs of services but not for goods, which may be acquired some time in advance of their use. The value of goods purchased and held for resale is recorded as use of goods and services when they are sold.

6.29 In practice, government units do not usually record the actual use of goods in production directly. Instead, they keep records of purchases of materials and supplies intended to be used as inputs and also of any changes in the amounts of such goods held in inventories. An estimate of use of goods and services during a given reporting period can be derived through the indirect method by considering the purchases of goods and services and changes in inventories, ${ }^{16}$ as illustrated in Table 6.3.

6.30 Use of goods and services (22) is recorded on a gross basis. Fees and charges collected for goods and services provided by general government units, such as for certain types of social benefits or administrative services, such as the issuance of licenses and passports, should be shown as revenue rather than deducted from expense.

6.31 In the Statement of Sources and Uses of Cash, the purchases of goods and services are recorded as close to the payment stage as possible. The value of these goods and services will include all cash payments made for goods and services during the reporting period, irrespective of whether the good or service was used during the reporting period. This amount will not include the value of goods paid for in prior periods, but used in the current period.

6.32 The boundaries between use of goods and services and other expenditure items, such as com-

\footnotetext{
${ }^{16}$ As described in paragraph 7.75, inventories may include materials and supplies, work in progress, finished goods, goods for resale, and military inventories. See paragraphs $8.44-8.47$ for a discussion on transactions in inventories.
}

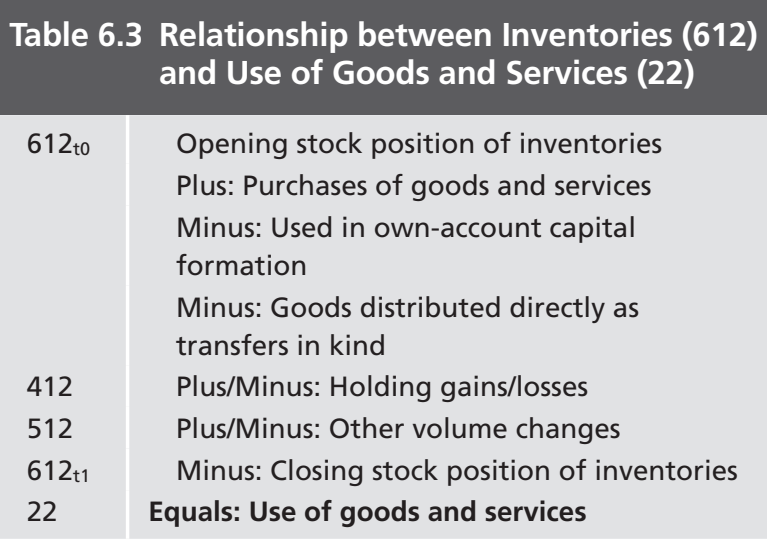

pensation of employees, transfers, or acquisition of nonfinancial assets, are explained in more detail in paragraphs 6.33-6.52.

\section{The boundary between use of goods and services and compensation of employees}

6.33 Compensation of employees excludes amounts payable to contractors, self-employed outworkers, and other workers who are not employees of general government or public sector units. Any such amounts should be recorded under use of goods and services (22). An employer-employee relationship exists when there is a written or oral agreement, which may be formal or informal, between an entity and an individual, normally entered into voluntarily by both parties, whereby the person works for the enterprise in return for remuneration in cash or in kind. The remuneration is normally based on either the time spent at work or another objective indicator of the amount of work performed. If an individual is contracted to produce a single specific task, it suggests that no employer-employee relationship exists, but that a service contract relationship exists between the entity and a self-employed individual.

6.34 An indication of whether an employeremployee relationship exists is that of control. The right to control or to direct work performed and how it shall be performed is a strong indication of an employer-employee relationship. The method of measuring or arranging for the payment is not important as long as the employer has effective control over both the method and the result of the work undertaken by the individual. However, certain control of the work being undertaken may also exist for the purchase of 
a service-for example, when subcontracts are entered into. Therefore, other criteria should also be used to define more clearly the employer-employee relationship. The fact that the individual is solely responsible for social contributions would suggest that the individual is a self-employed service provider. By contrast, payment of social contributions by the employer is an indication of employer-employee relationship. Entitlement by the individual to the same kinds of benefits (e.g., allowances, holidays, and sick leave) generally provided to an entity's employees would also indicate an employer-employee relationship. Payment of taxes on the provision of services (such as sales tax or value-added tax) by the individual is an indication that the individual is a selfemployed service provider.

6.35 Certain goods and services used by governments do not enter directly into the process of production itself but are consumed by employees working on that process. In general, when the goods or services are used by employees on their own time and at their own discretion for the direct satisfaction of their needs or wants, they constitute remuneration in kind (see paragraph 6.17). However, when such use is mandatory in order to enable employees to carry out their work, it should be recorded as use of goods and services. Examples of the latter are:

- Tools or equipment used exclusively, or mainly, at work

- Clothing or footwear of a kind that ordinary consumers do not choose to purchase or wear and that are worn exclusively, or mainly, at work-for example, protective clothing, overalls, or uniforms

- Accommodation services at the place of work of a kind that cannot be used by the households to which the employees belong: barracks, cabins, dormitories, huts, etc.

- Special meals or drinks necessitated by exceptional working conditions, while traveling for business reasons, or meals or drinks provided to employees while on active duty

- Changing facilities, washrooms, showers, baths, etc. necessitated by the nature of the work

- First aid facilities, medical examinations, or other health checks required because of the nature of the work.
6.36 Employees may sometimes be responsible for purchasing the kinds of goods or services just listed and are subsequently reimbursed by the employer. Such reimbursements are recorded as use of goods and services rather than as wages and salaries.

\section{The boundary between use of goods and services and transfers}

6.37 All transfers of goods and services to other institutional units other than goods and services produced by the donor government unit are recorded as grants (26) or transfers not elsewhere classified (282). Such transfers may entail the transfer of governmentowned fixed assets, the transfer of goods held in inventories, the construction of fixed assets, or the purchase and subsequent transfer of either fixed assets or goods and services for current consumption. Examples are transfers of food, clothing, blankets, and medicines as emergency aid after natural disasters; transfers of machinery and other equipment; the direct provision of the construction of buildings or other structures; and transfers of military equipment of all types.

6.38 Goods and services used by a donor government unit to produce nonmarket goods and services consumed by other governments and international organizations are included in use of goods and services. An example would be the goods and services acquired so that government employees can conduct relief operations in a foreign country after a natural disaster. The purpose of this treatment is to show in GFS the reduction in cash, or increase in other accounts payable, with an entry in the respective expense items that made up the cost of producing nonmarket goods and services provided by the government sector unit. ${ }^{17}$

6.39 Use of goods and services also includes all goods and services consumed by a general government unit to produce nonmarket goods and services that are distributed either as social benefits in kind or distributed to households in particular circumstances, such as following a natural disaster. Such social benefits can

\footnotetext{
${ }^{17}$ The treatment in the 2008 SNA differs because national accounts have the purpose to calculate production, transfers, and consumption. Therefore, the SNA treatment is to record the cost of production and the imputed sale of the goods and services to the final recipient as the user of the goods and services. In addition, the SNA also records a transfer that is deemed to be used by the recipient to pay for the imputed sale (see the 2008 SNA, paragraphs $8.43-8.51$ ).
} 
be distributed through social security schemes; social insurance schemes operated for the benefit of government employees, their dependents, or survivors; or social assistance. A common type of social benefit likely to be produced by general government units and distributed in kind is related to health care, such as medical or dental treatments, surgery, hospital accommodation, home care, and similar services. Benefits for government employees and dependents typically include general medical services not related to the employee's work, ${ }^{18}$ convalescent and retirement homes, education services, and access to recreation or vacation facilities. Any nominal payments made by the recipients to the government unit distributing these goods and services should not be deducted from use of goods and services expense, but rather be recorded as the appropriate category of sales of goods and services (142), as relevant.

6.40 Goods and services that were not produced by the donor government unit, but are distributed as social benefits in kind or distributed to households in particular circumstances, are classified as social benefits (27) rather than use of goods and services. Such distributions include transfers of goods held in inventories, the purchase and simultaneous transfer of goods and services from market producers, and the reimbursement by a general government unit for purchases by households of specified goods or services, such as food, education services, medicines, medical or dental treatments, hospital bills, and optometrists' bills.

6.41 On occasion, government units transfer economic value by purchasing goods and services for prices that greatly exceed their market value. As described in paragraph 3.29 , when such transactions can be detected, they should be partitioned into a purchase of goods and services at their true market value and a transfer recorded under the relevant category.

6.42 Membership dues and subscription fees should be recorded as an expense in use of goods and services (22) if there is an exchange of a payment for some form of a service. These include payments by public corporations of membership dues or subscriptions to market nonprofit institutions (NPIs) serving businesses, such as chambers of commerce or trade associations,

\footnotetext{
${ }^{18}$ Should these benefits be related to their employment contract, they will be included in compensation of employees (21).
}

since these are payments for services rendered and are not transfers. In rare cases, market establishments included in the general government sector may have similar membership dues or subscriptions payable to market NPIs serving businesses. Some membership dues and subscription fees are different in nature and are not included in use of goods and services:

- In some cases, membership dues and subscription fees payable to international organizations are recorded as the acquisition of equity (32051) when there is a possibility-even if unlikely-of repayment of the full amount. In these cases, the payee is also entitled to a share of the assets upon windup of the international organization.

- Membership dues and subscription fees are recorded as transfers if the transaction is unrequited; if the recipient is an international organization, foreign government, or another general government unit, the transfer is classified as a grant (26), or otherwise as current transfers not elsewhere classified (2821).

\section{The boundary between use of goods and services and the acquisition of nonfinancial assets}

6.43 Goods acquired for use as fixed assets or valuables, or for use in own-account capital formation, are classified as acquisitions of fixed assets or valuables. Costs incurred on inexpensive durable goods, such as small/hand tools, are recorded as use of goods and services (22) when such expenses are incurred regularly and are small compared with the costs incurred for the acquisition of machinery and equipment (see paragraphs 7.40 and 7.52). This exclusion of small/ hand tools is pragmatic rather than conceptual. Some goods may be used repeatedly, or continuously, in production over many years but may nevertheless be small, inexpensive, and used to perform relatively simple operations. Hand tools such as saws, spades, knives, axes, hammers, screwdrivers, and spanners or wrenches are examples. If expense on such tools takes place at a fairly steady rate and if their value is small compared with amounts payable on more complex machinery and equipment, it may be appropriate to treat the tools as materials or supplies under use of goods and services (22). Some flexibility is needed, however, depending on the relative importance of 
such tools. In countries in which they account for a significant part of the value of the total stock of machinery and equipment, they may be regarded as fixed assets and their acquisition and disposal by public sector units recorded under the net acquisition of nonfinancial assets.

6.44 Goods and services acquired to increase inventories of materials and supplies, work in progress, finished goods, and goods for resale are included in changes in inventories (312), a type of nonfinancial asset (see paragraph 7.75).

6.45 Goods and services consumed for the ordinary maintenance and repair of fixed assets constitute use of goods and services. However, major renovations, reconstructions, or enlargements of existing fixed assets are recorded as acquisitions of fixed assets. See paragraphs $8.25-8.27$ for more information on distinguishing these activities.

6.46 Goods and services used in research and development are recorded as acquisitions of fixed assets in the category intellectual property products (31132), except in cases where it is clear that the activity does not create any future economic benefit for its owner, in which case it is recorded as use of goods and services. For a description of the recognition criteria for intellectual property products, see paragraphs 8.37-8.41.

6.47 Goods and services used in mineral exploration and evaluation are not recorded as use of goods and services. Regardless of whether successful, they are needed to acquire new reserves and so are all classified as acquisitions of fixed assets recorded as intellectual property products (31132).

6.48 Materials to produce coins or notes of the national currency or amounts payable to contractors to produce the currency are included in use of goods and services. The issuance of the coins or notes is a financial transaction that does not involve revenue or expense. Commemorative coins that are not actually in circulation as legal tender are classified as nonfinancial assets (see paragraph 7.135).

6.49 Expenditure on military equipment, including large military weapons systems and armored vehicles acquired by the police and internal security services, are recorded as acquisition of the respective categories of fixed assets, namely weapons systems
(3114) or machinery and equipment (3112). Expenditure on military goods, such as single-use weapons (ammunition, missiles, rockets, bombs, torpedoes) and spare parts, should be recorded as inventories until used, when they are recorded as use of goods and services and a withdrawal from inventories (see paragraphs 7.74 and 7.86).

\section{Other boundaries related to use of goods and services}

6.50 There is a significant conceptual difference between rentals of fixed assets under an operating lease and the acquisition of an asset under a financial lease. Under an operating lease, (see paragraph A4.6) the lessor remains the economic owner of the fixed asset and payments by the lessee are recorded as payments for a service, and therefore recorded as use of goods and services. Under a financial lease (see paragraphs 8.17 and A4.10), the lessee becomes the economic owner of the fixed asset and payments are recorded as payments of interest and repayments of principal by the lessee to the lessor, and thus do not affect use of goods and services (also see paragraphs A4.6-A4.15).

6.51 Amounts payable for the use of nonproduced naturally occurring assets, such as land, are classified as rent (2814) and not as use of goods and services (22). See paragraphs 5.131-5.132 for a description of this boundary.

6.52 Explicit fees for financial services should always be classified as use of goods and services. However, some transactions include an implicit fee for financial services that is not recorded separately in GFS. These implicit fees can be calculated only in the context of an analysis of the whole of the economy or industry. As indicated in paragraph 6.81, financial intermediation services indirectly measured (FISIM) can usually be estimated only indirectly by compilers of the national accounts. Similarly, the service fee implied by nonlife insurance premiums can be estimated only by looking at all the transactions and costs of the insurance industry (see paragraph 6.125).

\section{Consumption of Fixed Capital [GFS] (23)}

6.53 Consumption of fixed capital is the decline, during the course of the reporting period, in the current value of the stock of fixed assets owned and used by a government unit as a result of physical 
Table 6.4 Detailed Classification of Consumption of Fixed Capital [GFS] (23)

23 Consumption of fixed capital [GFS ${ }^{1}$ Consumption of fixed capital [SNA] $]^{1}$ Minus: Related to own-account capital formation

"Further breakdown/" of which" lines could allow for the identification of the category of fixed assets that the consumption relates to. Identifying the type of assets is required for the integration of stocks and flows of each type of asset (see Table 7.2).

deterioration, normal obsolescence, or normal accidental damage. ${ }^{19}$ The concept of consumption of fixed capital is identical to the concept used in the 2008 SNA. However, the amount of consumption of fixed capital [GFS] (23) expense recorded in GFS may differ from the amount recorded in the production account of the 2008 SNA because of the GFS treatment of own-account capital formation (see Table 6.4). When nonfinancial assets are produced on own-account, the consumption of fixed capital related to that production process is recorded in GFS as part of the cost of acquisitions of the fixed assets rather than expense (see paragraph A7.25).

6.54 Consumption of fixed capital may deviate considerably from depreciation as recorded in government financial records. Consumption of fixed capital is a forward-looking measure that is determined by future rather than past events-it is determined by the benefits that institutional units expect to derive in the future from using the asset in production over the remainder of its service life. Consumption of fixed capital is therefore based on the current market value or replacement cost of the asset. Depreciation is normally an allocation of the original costs of fixed assets (historic cost) over subsequent reporting periods. Consumption of fixed capital is calculated on the basis of the estimated opportunity costs of using the assets at the time they are used, as distinct from the prices at which the assets were acquired. Even when the fixed assets used are not actually to be replaced, the amount of consumption of fixed capital charged as a cost of production should be sufficient to enable the assets to be replaced, if desired.

6.55 Consumption of fixed capital is estimated with respect to all fixed assets owned by government

\footnotetext{
${ }^{19}$ Consumption of fixed capital is described in the 2008 SNA in paragraphs 6.240-6.257.
}

units, but not for valuables (precious metals, precious stones, etc.) that are acquired precisely because their value, in real terms, is not expected to decline over time. Consumption of fixed capital does not cover the depletion or degradation of natural assets, such as land, mineral or other deposits, coal, oil, or natural gas, or contracts, leases, and licenses, which are recorded as other changes in the volume of assets (see paragraph 10.52).

6.56 The calculation of the consumption of fixed capital reflects assumptions about normal rates of physical deterioration, obsolescence, and accidental damage. Although some fixed assets, such as roads or railway tracks, may appear to have infinite service lives if properly maintained, their value may nevertheless decline because of a decrease in the demand for their services as a result of technical progress and the appearance of substitutes. Many fixed assets are scrapped or demolished only because they have become obsolete. Consequently, consumption of fixed capital must include an allowance for anticipated obsolescence. Any difference between the normal expected rate of obsolescence and the actual rate of obsolescence within a given period should be recorded as other changes in the volume of assets (see paragraph 10.66).

6.57 Losses of fixed assets due to normal or expected levels of accidental damage (i.e., damage caused to assets used in production resulting from their exposure to the risk of fires, storms, accidents due to human error, etc.) are also included under consumption of fixed capital. When these kinds of accidents occur with predictable regularity, they are taken into account in calculating the average service lives of the goods in question. Any difference between the normal expected and the actual accidental damage within a given period should be recorded as other changes in the volume of assets (see paragraph 10.67).

6.58 Consumption of fixed capital excludes the loss of value when fixed assets are destroyed by acts of war, natural disasters, and other exceptional events that occur very infrequently. Similarly, it excludes losses due to unexpected technological developments that may significantly shorten the service life of an existing fixed asset. These events are recorded as other economic flows and recorded as an other change in the volume of assets (see paragraph 10.66). Holding gains and losses 


\section{Box 6.1 The Calculation of Consumption of Fixed Capital}

Consumption of fixed capital should reflect underlying resource costs and relative demands at the time the production takes place. It should therefore be calculated using the actual or estimated prices and equivalent costs of the rentals of fixed assets prevailing at that time and not at the times the goods were originally acquired. It is recommended that independent estimates of consumption of fixed capital should be compiled in conjunction with estimates of the capital stock. These can be built up from data on the acquisition of fixed assets in the past combined with estimates of the rates at which the efficiency of fixed assets declines over their service lives.

Whenever possible, the initial value of a new fixed asset should be the value at which it was acquired. If assets of all ages and specifications were regularly traded on markets, these prices should be used to value every asset as it ages. However, there is scarce information on the prices of secondhand assets, so a more theoretical approach to determining the price of an asset as it ages must be adopted.

Conceptually, market forces should ensure that the purchaser's price of a new fixed asset is equivalent to the present value of the future benefits that can be derived from it. Therefore, given the initial market price and knowledge of the characteristics of the asset in question, it is possible to project the stream of future benefits and continually update the remaining present value of these. This method of building up estimates of the capital stock and changes in the capital stock over time is known as the perpetual inventory method, or PIM. Estimates of consumption of fixed capital are obtained as a by-product of the PIM.

In the absence of an asset register with appropriate valuations of assets, the PIM requires an estimate to be made of the stock of fixed assets in existence and in the hands of general government or public corporations. The first step is to estimate what proportion of the fixed assets acquired in previous years has survived to the current period. Average service lives, or survival functions, based on observations or technical studies may be applied to past investments for this purpose. Fixed assets purchased at different prices in the past have then to be revalued at the prices of the current period by utilizing appropriate price indices for fixed assets. The construction of suitable price indices covering long periods of time raises difficult conceptual and practical problems, but these technical problems of price measurement must be faced in any case in developing balance sheet values of assets. The stock of fixed assets surviving from past investment and revalued at the purchasers' prices of the current period but before deduction of consumption of fixed capital is often also described as the gross capital stock.

The benefits obtained from the use of a given fixed asset tend to diminish over time. The rate at which the efficiency declines may vary from one type of asset to another. The simplest case to consider is one where the efficiency of the asset remains constant until it disintegrates, like a lightbulb. Other simple cases include the case where the efficiency declines linearly or exponentially over its life. Other methods employ a hyperbolic rate of efficiency loss with relatively little decline in the initial years but increasingly steeper decline as time progresses. However, in practice, calculations are usually not undertaken asset by asset, but for cohorts of assets of similar ages and characteristics. Individual assets within the cohort will retire at different moments, but the age-efficiency profile for the cohort as a whole is typically convex to the origin.

The efficiency profiles of fixed assets determine the profiles of the benefits they command over their service lives. Once the profiles of the benefits over the service lives of the fixed asset have been determined, it becomes possible to calculate the consumption of fixed capital, period by period. Consumption of fixed capital is derived as the reduction in the present value of the remaining benefits, as explained earlier. This reduction, and the rate at which it takes place over time, must be clearly distinguished from the decline in the efficiency of the capital assets themselves. Although the efficiency, and hence the benefit, of an asset may remain constant from period to period until it disintegrates, the value of the asset declines over time. It also follows that the consumption of fixed capital is not constant.

Consumption of fixed capital should not be estimated in isolation from the derivation of a set of data on stock positions of fixed assets. Such data are needed for the balance sheet, as shown in Chapter 7.

due to changes in the price of the asset must also be excluded from consumption of fixed capital. These price changes should be recorded as holding gains or losses, as described in paragraphs 10.5 and 10.15 .

6.59 To compute consumption of fixed capital, the fixed assets purchased in the past and still in use have to be revalued at the average prices of the reference period and assumptions have to be made regarding the remaining service lives of each asset and the rate at which their efficiency is expected to diminish. Consumption of fixed capital should be calculated on the assumption of appropriately long service lives. Linear or geometric patterns of decline, or some combination of them, are the patterns most commonly 
assumed. ${ }^{20}$ Box 6.1 provides a more comprehensive explanation of the calculation of consumption of fixed capital.

6.60 Conceptually, costs of ownership transfer on the acquisition of nonfinancial assets should be written off as consumption of fixed capital over the period the asset is expected to be held by the purchaser rather than over the whole life of the asset. This approach reflects the assumption that the benefits provided by the asset must be sufficient to cover both the cost of the asset and the costs of ownership transfer. Cost of ownership transfer on the disposal of an asset is recorded similarly because it is assumed that the benefit that the asset produced during the time the asset is used in production should cover such costs. Cost of ownership transfer on the disposal of a nonfinancial asset is estimated at the time of the acquisition of the asset and is written off over the period that the owner expects to hold the asset), except for the terminal costs, which should be written off over the whole life of the asset. If an asset is disposed of before the costs of ownership transfer are completely written off, the remainder of these costs should be recorded as an other change in the volume of assets (see paragraph 10.68).

6.61 In the Statement of Sources and Uses of Cash, expense transactions are recorded only when cash flows occurred. Since no cash flows are associated with consumption of fixed capital, no entry for this accrual concept is made in this statement (see paragraph 3.67).

\section{Interest [GFS] (24)}

6.62 Interest is a form of investment income that is receivable by the owners of certain kinds of financial assets (SDRs, deposits, debt securities, loans, and other accounts receivable $)^{21}$ for putting these financial and other resources at the disposal of another institutional unit. Interest [GFS] (24) is not adjusted for the service charge related to FISIM (see paragraph 6.81). The liabilities giving rise to interest expense are all claims of creditors upon debtors. The liabilities generating the

\footnotetext{
${ }^{20}$ Organisation for Economic Co-operation and Development, Measuring Capital-OECD Manual: Measurement of Capital Stocks, Consumption of Fixed Capital and Capital Services (Paris, 2009) contains an extensive discussion of the methods for estimating capital stock and consumption of fixed capital.

${ }^{21}$ Financial assets and their classification are described in Chapter 7.
}

Table 6.5 Detailed Classification of Interest (24)

\begin{tabular}{l|l}
\hline 24 & Interest [GFS $^{1}$ \\
& Interest [SNA] $^{\text {Plus: FISIM }}$ \\
\hline 241 & To nonresidents \\
242 & To residents other than general government \\
& \\
243 & To other general government units $^{1}$
\end{tabular}

"Further breakdown/" of which" lines could allow for the

identification of subsectors and individual units (see Table 3.1).

interest may have arisen from the supply of financial or nonfinancial resources (as in the case of financial leases). As indicated in Table 6.5, interest should be recorded according to the subsector of the counterparty to allow for consolidation of the general government and public sectors. The amount of the liability due to the creditor declines as payments are made on the debt by the debtor and increases as interest accrues.

6.63 Interest is payable by units that incur liabilities by borrowing funds from another unit. Interest is the expense that the debtor unit incurs for the use of the principal outstanding, which represents the economic value that has been provided by the creditor. Interest may be payable in various ways and may not always explicitly be described as interest (see paragraph 6.71). On the other hand, net settlement payments under a swap or forward rate agreement contract (possibly described as "interest" in the contract) are not considered as interest and are to be recorded as transactions in financial derivatives (see paragraphs 6.79 and 9.71).

6.64 Interest is recorded as accruing continuously over time to the creditor on the amount outstanding. Depending on the contractual arrangements, the rate at which interest accrues can be a percentage of the amount outstanding, a predetermined sum of money, a variable sum of money dependent on a defined indicator, or some combination of these. Interest normally is not payable until the expense has accrued. That is, if interest on a loan is payable monthly, the amount paid is usually the expense that has accrued during the previous month. Under the accrual basis of recording, as interest accrues, the debtor's total liability to the creditor has increased by the amount of interest expense accrued but not yet paid. That is, as interest accrues on a government bond, the value of the bond increases. What are commonly referred to as interest payments, 
therefore, from an accrual recording perspective, are reductions of the debtor's existing liability, part of which was created by the accrued interest expense.

6.65 From a cash recording perspective, periodic debt service payments, recorded in the Statement of Source and Uses of Cash, can be distinguished as interest payments ("coupons" or "coupon payments") or principal payments. When using the cash basis of recording, interest payments are recorded as an expense transaction when such cash flows occur. In this case, only principal repayments will reduce the debtor's liability. The amount initially advanced or borrowed is also known as initial principal.

6.66 In macroeconomic statistics, interest is calculated according to the debtor approach. ${ }^{22}$ According to this approach, interest is equal to the amounts the debtors will have to pay to their creditors over and above the repayments of the amounts advanced by the creditor. For fixed rate instruments, this approach assumes that interest expense is determined for the entire life of a financial instrument by the conditions set at inception of the instrument. Interest accrual is therefore determined by using the original yieldto-maturity. A single effective yield, established at the time of security issuance, is used to calculate the amount of accrued interest in each period to maturity. The accrual of interest should be calculated by the compound interest method. ${ }^{23}$

6.67 In the simplest case, a sum of money is borrowed, periodic payments are made equal to the interest expense incurred during the previous period, and at the end of the contract, a final payment of interest is made together with a repayment of the original amount borrowed. The amount of interest expense incurred each period is equal to the interest rate stated in the contract multiplied by the amount borrowed.

6.68 When the end of the reporting period does not coincide with a periodic payment, the total liability at the end of the period will include some amount of interest incurred but not yet paid. As each period passes, the amount of principal outstanding increases

\footnotetext{
${ }^{22}$ There are three approaches for defining and measuring interest for traded debt instruments: debtor approach, creditor approach, and acquisition approach (see the BPM6, paragraphs 11.52-11.53).

${ }^{23}$ Examples of the calculation of interest can be found in the PSDS Guide, Box 2.3, and 2013 EDS Guide, paragraphs 2.65-2.77.
}

as interest expense is incurred. Any periodic payment of the accrued interest reduces the principal to the amount originally borrowed.

6.69 Some debt instruments may have a grace period $^{24}$ during which no interest payments are to be made. For those debt instruments for which the contract requires the accrual of interest during the grace period (i.e., the relevant interest rate that applies during the grace period is greater than zero), the accrual of interest should be recorded as specified in the contract, increasing the value of the principal. On the other hand, if the debtor can repay the same amount of principal at the end of the grace period as at the beginning (i.e., the relevant interest rate applied to the grace period is zero), no interest costs accrue during the grace period..$^{25}$ This remains true even if the rate of interest applied in a second and/or subsequent time period is adjusted (e.g., there is a step up), so that the final yield is roughly similar to what it would have been under normal conditions over the total life of the instrument. This treatment applies to loans and deposits but not to debt securities.

6.70 Loans with step-up interest should accrue at the contractual rate of interest for any period and not at the internal rate of return ${ }^{26}$ of the loan. On the other hand, interest on debt securities with step-up interest should accrue at the original yield-to-maturity rate over the life of the security. ${ }^{27}$

6.71 Certain financial instruments, such as shortterm bills and zero-coupon bonds, do not require the debtor to make payments to the creditor until the liability matures. In effect, the debtor's liability is discharged by a single payment covering both the amount of the funds originally borrowed and the interest accrued and accumulated over the entire life of the liability. Instruments of this type are said to be discounted because the amount initially borrowed is less than the amount to be repaid. The difference

\footnotetext{
${ }^{24}$ The grace period is the period from the disbursement of the loan until the first payment due by the debtor.

${ }^{25}$ If a prepayment fee or a penalty for prepayment is paid, it should be classified as a service fee under use of goods and services (22), and not as interest.

${ }^{26}$ See the 2013 EDS Guide, paragraph 2.98 and Box 2.4, for a discussion on internal rate of return.

${ }^{27}$ The original yield-to-maturity rate is the rate at which the present value of future interest and principal payments equals the issue price of the bond-that is, the yield of the security at issuance.
} 
between the amount to be repaid at the end of the contract and the amount originally borrowed is interest, which on the accrual basis of recording must be allocated over the reporting periods between the beginning and end of the contract. The interest accruing in each period is recorded as if being paid by the debtor and then borrowed as an additional amount of the same liability. Thus, interest expense and an increase in the liability are recorded in each period. When more than one reporting period is involved, there are a number of ways to allocate the total amount of interest among the periods involved. The most common and simple method is to assume that the interest rate is constant throughout the contract period. On the cash basis of recording, the full amount of the difference between the amount to be repaid at the end of the contract and the amount originally borrowed is recorded as interest when the payment is made - that is, at the end of the contract when the liability matures.

6.72 A slightly more complicated case is a deepdiscount bond, which is a discounted instrument that also requires periodic payments. In such cases, the accrued interest expense is the amount of the coupon payable periodically plus the amount of interest accruing each period attributable to the difference between the redemption price and the issue price. Again, the most common assumption is that the interest rate is constant over the entire period of the contract. This interest rate is the one that makes the sum of all future payments equal to the amount initially borrowed when the future payments are discounted by the interest rate.

6.73 In some cases, debt securities are issued at a premium rather than at a discount. The method of determining the accrued interest expense is identical to the case of a discounted instrument except that the premium (the difference between the redemption price and the issue price-see paragraph 9.40) is amortized over the life of the instrument and reduces (rather than increases) the amount of interest accruing in each period. These premiums are therefore recorded as an increase in cash receipts with a corresponding entry in other accounts payable for the unearned portion of the premium. A reduction in interest expense, with a corresponding reduction in the other accounts payable, is subsequently recorded over the period of the contract. On the cash basis of recording, the full amount of premiums will be recognized as a reduction in interest expense at the time the debt instrument is issued.

6.74 Loans are often structured with periodic payments that incorporate both interest and principal payments. The excess of the periodic payment over the interest accrued reduces the original principal. Over time, the share of the payment allocated to the payment of accrued interest decreases and the share allocated to reducing the original principal increases.

6.75 Index-linked securities are instruments for which either the coupon payments (interest) or the principal or both are linked to another item, such as a price index, an interest rate, or the price of a commodity (see paragraph 7.153 ). The item is one that normally changes over time in response to market pressures. The values of the indicators are not known in advance. For debt securities with indexation of the amount to be paid at maturity, these amounts may be known only at the time of redemption. As a result, total interest flows before redemption cannot be determined with certainty. To estimate interest accrued before the values of the reference indicators are known, it is useful to distinguish various arrangements.

\section{Indexation of the coupon payments only}

6.76 When only coupon payments are indexlinked, as with floating-rate notes, the full amount resulting from indexation is recorded as interest accruing during the period covered by the coupon. To the extent that data are compiled after the coupon payment date, the value of the index is known and can be used to estimate that payment. If the data are compiled before the date for the coupon payment, the movement in the index during that part of the reporting period covered by the coupon can be used to calculate the interest accrued.

\section{Indexation of the amount to be paid at maturity}

6.77 When the amount to be paid at maturity is also index-linked, the amount of interest accrued becomes uncertain because the redemption value is unknown; in some cases, the maturity time may be several years in the future. There are two approaches, 
depending on whether the index is based on a broad or narrow reference item. ${ }^{28}$

- When the amount to be paid at maturity and coupon payments are indexed to a broad-based index (e.g., the consumer price index), interest accruing in a reporting period may be calculated by summing two elements:

- The amount resulting from the indexation of the coupon payment (as described in paragraph 6.76) that is attributable to the reporting period

- The change in the value of the amount outstanding between the end and beginning of the reporting period due to the movement in the relevant index.

This approach works well when a broad-based index is used, as such indexation is expected to change relatively smoothly over time.

- When the amount to be paid at maturity or the coupon payments and the amount to be paid at maturity are indexed to a narrow index (e.g., a gold index) that includes a holding gain motive, interest accruing may be determined by fixing the yield-to-maturity (rate of accrual) at the time of issue. Accordingly, interest accrues over the life of the instrument at a rate that reconciles the difference between the issue price and the market expectation, at inception, of all payments that the debtor will have to make over the life of the instrument. Any deviation of the underlying index from the originally expected path leads to holding gains or losses that will not necessarily cancel out over the life of the instrument.

This approach works well when the indexation of the amount to be paid at maturity combines motives for both interest income and holding gains (e.g., a commodity price, stock prices, or gold prices). The treatment of indexation of securities is also discussed in paragraph 9.41.

6.78 Debt instruments with both the amount to be paid at maturity and coupon payments indexed to foreign currency are recorded as though they are denominated in that foreign currency. Interest, other economic flows, and stock positions for these instruments should be calculated using the same principles

\footnotetext{
${ }^{28}$ These approaches are discussed in more detail in the 2008 SNA, paragraphs $17.274-17.282$, and the BPM6, paragraphs 11.59-11.65.
}

that apply to foreign-currency-denominated instruments (see paragraph 9.11).

6.79 For debt securities with embedded derivatives, the recording for accrued interest on the financial instrument is the same as for securities that do not have such features. No interest accrues on the derivative itself (see paragraph 9.43).

6.80 For arrears arising from a debt contract, interest should accrue at the same interest rate as on the original debt, unless a different interest rate for arrears was stipulated in the original debt contract, in which case this stipulated interest rate should be used. The stipulated rate may include a penalty rate in addition to the interest rate on the original debt. If an item is purchased on credit and the debtor fails to pay within the period stated at the time the purchase was made, any extra charges incurred should be regarded as interest and accrue until the debt is extinguished.

6.81 The interest expense payable to financial intermediaries recorded in GFS differs from the amount recorded in the 2008 SNA. Interest [GFS] (24) does not partition interest to separately record a service fee. A financial intermediary sets its interest rates for depositors and borrowers at levels that will provide a margin large enough to at least defray the costs of providing its services to its depositors and borrowers without explicit fees. Interest could be partitioned to separately record the component payable in return for the resources that were put at the disposal of the borrower, as well as an implicit service charge. In concept, the value of the services provided by financial intermediaries to a borrowing unit should be recorded as a use of goods and services expense. To accomplish this treatment, the actual interest expense payable to financial intermediaries would need to be reduced by the value of the fee for the services. ${ }^{29}$ These fees, known as FISIM, can be estimated only indirectly by compilers of the national accounts because data for all depositors and borrowers of financial intermediaries are required.

6.82 In principle, interest payable on overdue taxes should be recorded as interest (24). However, it may not be possible to separate payments of interest, fines, or other penalties from the taxes to which they relate,

\footnotetext{
${ }^{29}$ Similarly, any interest receivable from financial intermediaries would need to be increased by the value of the implicit service fee that has reduced the interest receivable.
} 
so that in practice they are usually grouped with the relevant tax payable (see also paragraph 5.24). If this tax that includes the interest on late payment of taxes is payable by a general government or public sector unit, then it is classified as a tax payable from one government unit to another and classified as a component of transfers not elsewhere classified (282) (see paragraph 6.122). For purposes of consolidation, the relevant government units should be identified as counterparty to the transaction.

6.83 Total interest payable is subdivided into interest payable to nonresidents (241), interest payable to residents other than general government (242), and interest payable to other general government units (243). Interest payable to other general government units will have a nonzero value when statistics are compiled for a subsector of the general government sector or public corporations. For the general government sector, all such transactions are eliminated in consolidation. To allow for consolidation of the general government and public sectors, data could further identify a breakdown according to the recipient of the interest.

\section{Subsidies $(25)^{30}$}

6.84 Subsidies (25) are current unrequited transfers that government units make to enterprises on the basis of the level of their production activities or the quantities or values of the goods or services they produce, sell, export, or import. Subsidies are receivable by resident producers or importers, and in exceptional cases, nonresident producers of goods and services. Subsidies may be designed to influence levels of production, the prices at which outputs are sold, or the profits of the enterprises. Subsidies include payable tax credits receivable by enterprises for these purposes (see paragraph 5.31). By the nature of subsidies, only government units incur an expense in this form. When an institutional unit, other than a government unit, incurs subsidy expense on behalf of a government unit, the subsidy should be attributed in accordance with attribution guidelines, similar to those for tax attribution (see paragraphs 5.32-5.39). When an institutional unit acts on behalf of another unit to distribute subsidies, these should be reported as financial transactions by the distributing agency.

\footnotetext{
${ }^{30}$ Subsidies are described in the 2008 SNA, paragraphs 7.98-7.106.
}

Subsidies payable should be recorded only in the account of the entity that has the control over the subsidy scheme.

6.85 Subsidies are payable to producers only, not to final consumers, and are current transfers only, not capital transfers. Transfers that government units make directly to households as consumers and most transfers to nonprofit institutions serving households are recorded as either social benefits (27) or transfers not elsewhere classified (282), depending on the reason for the payment. Most transfers made to other general government units are included in grants (26).

6.86 In some cases, general government units, nonprofit institutions serving households, and households can receive subsidies in their capacity as producers. To be classified as subsidies, such payments must depend on general regulations of the subsidy scheme applicable to all producers, market and nonmarket. For example, a general government unit may pay a subsidy to all employers (including general government units and/or nonprofit institutions) that employ members of a specified profession or people with a specified disability. Subsidies payable to households include only amounts payable to households as producers - therefore, they will include only amounts payable to those unincorporated household enterprises that do not qualify as a quasi-corporation. In practice, many schemes called "subsidies" provide social benefits to households.

6.87 As indicated in Table 6.6, subsidies may be classified according to the institutional sector of the recipients. Subsidies to public corporations (251) and to private enterprises (252) are further subdivided into nonfinancial or financial corporations and enterprises.

\begin{tabular}{|l|c|}
\hline Table 6.6 & Detailed Classification of Subsidies (25) \\
\hline 25 & Subsidies $^{1}$ \\
251 & To public corporations $^{-}$ \\
2511 & Public nonfinancial corporations \\
2512 & Public financial corporations \\
252 & To private enterprises \\
2521 & Private nonfinancial enterprises \\
2522 & Private financial enterprises \\
253 & To other sectors \\
\end{tabular}

${ }^{1}$ Further breakdown/" of which" lines could identify whether these subsidies are subsidies on products or production.

${ }^{2}$ Further breakdown/"of which" lines could allow for the identification of subsectors and individual units (see Table 3.1). 
Subsidies to other sectors (253) include subsidies payable to other general government units, to nonprofit institutions serving households, and to households, in their capacity as producers. To allow for consolidation of the general government and public sectors, identifying the subsectors of the counterparties is needed.

6.88 Although not specifically used in the GFS classification structure, the 2008 SNA further identifies subsidies according to whether they are payable on specific products or on production in general, depending on how the value of the subsidy is calculated. Further breakdown of GFS codes could allow for this distinction.

6.89 A subsidy on products is a subsidy payable per unit of a good or service. The subsidy may be a specific amount of money per unit of quantity of a good or service, or it may be calculated ad valorem as a specified percentage of the price per unit. A subsidy may also be calculated as the difference between a specified target price and the market price actually paid by a buyer. A subsidy on a product usually becomes payable when the good or service is produced, sold, exported, or imported, but it may also be payable in other circumstances, such as when a good is transferred, leased, delivered, or used for own consumption or own-account capital formation. These subsidies include:

- Direct foreign trade subsidies, such as subsidies on imported or exported goods and services that become payable when the goods cross the frontier of the economic territory or when the services are delivered to resident institutional units (e.g., import subsidies) or to nonresident units (e.g., export subsidies) $)^{31}$

- Implicit subsidies resulting from the operation of an official system of multiple exchange rates (see paragraph 5.89), or resulting from payable tax credits (see paragraph 5.31)

- Losses of government trading organizations whose function is to buy products and then sell them at lower prices to residents or nonresidents,

\footnotetext{
${ }^{31}$ Export subsidies do not include the repayment at the customs frontier of taxes previously paid on goods or services while they were inside the economic territory. They also exclude the waiving of the taxes that would be due if the goods were to be sold or used inside the economic territory instead of being exported. These tax expenditures/credits are not recorded separately in GFS (see paragraph 5.86).
}

when they are incurred as a matter of deliberate government economic or social policy ${ }^{32}$

- Subsidies payable to resident producers in respect of their production that is used or consumed within the economic territory

- Regular transfers payable to corporations and quasi-corporations that are intended to compensate for recurrent losses (i.e., negative operating surpluses) incurred on their productive activities as a result of charging prices that are lower than their average costs of production as a matter of deliberate government economic and social policy ${ }^{33}$

- Subsidies resulting from the central bank accepting interest rates lower than the prevailing market rates (see Box 6.2).

6.90 Other subsidies on production are subsidies that enterprises receive as a consequence of engaging in production but that are not related to specific products. Included are:

- Subsidies on payroll or workforce, which are payable on the total wage or salary bill, the size of the total workforce, or the employment of particular types of persons such as physically handicapped persons or persons who have been unemployed for long periods; the subsidies may also be intended to cover some or all of the costs of training schemes organized or financed by enterprises.

- Subsidies to reduce pollution, which are transfers intended to cover some or all of the costs of additional processing undertaken to reduce or eliminate the discharge of pollutants into the environment.

6.91 Subsidies do not include:

- Payment of interest or other debt service cost on behalf of other producer units without acquiring an effective claim on the original debtor-these payments are recorded as capital transfers, and according to the nature of the recipient, are recorded either as capital grants (26) or capital transfers not elsewhere classified (2822).

- Transfers made by governments to other resident or nonresident units to finance all or part of the

\footnotetext{
${ }^{32}$ In these cases, the subsidy is calculated as the difference between the purchase and the selling price.

${ }^{33}$ Transfers to corporations and quasi-corporations to cover large operating deficits accumulated over two or more years are recorded as capital transfers not elsewhere classified (2822).
} 


\section{Box 6.2 Implicit Subsidies of Central Banks}

The central bank's main responsibility is to formulate and carry out monetary aspects of economic policy. It therefore often acts differently from other financial corporations and generally has the authority from government to enforce its mandate. In cases where the central bank makes payments that are clearly for policy rather than commercial purposesfor example, when it pays above-market rates in a situation where the external value of the currency is under pressure or when it acts as a development bank offering loans at below-market rates to priority industries-it may be argued that implicit subsidies are being provided. This procedure is analogous to and consistent with the practice of treating the difference between the market exchange rate and an alternative exchange rate imposed by the central bank as an implicit subsidy (discussed in paragraph 5.89).

If the central bank interest rates are out of line with those of commercial banks, then the difference between flows calculated using the reference rate and the actual rate set by the central bank should be recorded as implicit taxes receivable (see paragraph 5.70) and subsidies payable by government. These transactions are recorded as follows:

- Below market rates on reserve deposits-Suppose the central bank pays only 3 percent to a commercial bank on reserve deposits when the market rate is 5 percent. The following is recorded in GFS:

- Although the commercial bank actually receives only 3 percent as interest, it is recorded as receiving 5 percent as interest from the central bank and paying 2 percent to government as taxes on specific services (1144) (see paragraph 5.69).

- Government records a subsidy (25) to the central bank.

- Above market rates for currency support-Suppose the central bank pays 7 percent to a commercial bank for a limited period when the currency is under pressure at a time when the market rate is 5 percent. The following is recorded:

- Although the commercial bank actually receives 7 percent as interest, it is recorded as receiving 5 percent as interest and receiving another 2 percent from government as a subsidy (25).

- Government records a tax of 2 percent receivable from the central bank classified as taxes on specific services (1144) (see paragraph 5.69).

- Below market rates to priority industries-Suppose the central bank charges only 3 percent to a priority industry when the market rate is 5 percent. The following is recorded:

- Although the priority industry actually pays only 3 percent as interest, it is recorded as paying 5 percent as interest but receiving 2 percent from government as a subsidy (25).

- Government records a tax of 2 percent receivable from the central bank classified as taxes on specific services (1144) (see paragraph 5.69).

costs of their acquiring nonfinancial assets other than inventories-these payments are recorded either as capital grants (26) or as capital transfers not elsewhere classified (2822).

- Extraordinary payments into social insurance funds, in so far as these payments are designed to increase the actuarial reserves of these funds: These payments are recorded either as capital grants to other general government units (2632) or as capital transfers not elsewhere classified (2822).

- Transfers made by general government units to corporations and quasi-corporations to cover large operating deficits accumulated over two or more years, or exceptional losses due to factors outside the control of the enterprise: These pay- ments are recorded as capital transfers not elsewhere classified (2822) (see Box 6.3).

- The cancellation of debts that institutional units have incurred to government units (resulting, for example, from loans advanced by a government unit to a nonfinancial enterprise that does not have the ability to make repayments due to trading losses accumulated over several financial years): These transactions are recorded as capital grants to other general government units (2632) or as capital transfers not elsewhere classified (2822) if the beneficiary is a unit other than general government.

- Payments made by general government for damage to, or losses of, capital goods as a result of acts of war, other political events or natural disasters: 


\section{Box 6.3 Transactions with Public Corporations}

Owners may inject significant financial support to capitalize or recapitalize a corporation. Such financial support may take various legal forms and its economic substance may also vary (see Figure A3.2). These payments from a government unit, often referred to as "capital injections," could be recorded as:

- An expense, either as a subsidy or capital transfer, or

- A transaction in financial assets/liabilities, either as an addition to equity or an issuance of a loan or securities other than shares.

\section{Recorded as an expense}

If the enterprise is publicly controlled and runs a recurrent deficit each year as a matter of government economic or social policy objectives, and the deficit is covered by a regular transfer receivable from government to match this deficit, the payment is regarded as a subsidy (see paragraph 6.89). If the payment from government is to cover large operating deficits accumulated over two or more years or exceptional losses due to factors outside the control of the enterprise, it is recorded as a capital transfer (see paragraph 6.124). Similarly, if government makes an investment in a public corporation without a reasonable expectation of a realistic rate of return on the investment, or without receiving anything of equal value in exchange, this is also recorded as a capital transfer. The latter includes investments in quasi-corporations with negative imputed equity (see paragraph A3.53).

\section{Recorded as transactions in financial assets/liabilities}

There may be cases where the owners agree to make new financing available to permit expansion, and where such financing establishes an effective claim on the public corporation. Such financing could consist of funds for use by the enterprise according to its need, including purchasing fixed assets, accumulating inventories, acquiring financial assets, or redeeming liabilities. Where evidence of a contractual financing agreement exists, these could constitute the issuance of a specific financial asset, such as loans, for government and the incurrence of a corresponding debt instrument by the public corporations. Without evidence of a specific financing agreement, such payments are to be included as the acquisition of equity in the public corporation even if no new shares are issued in response to the financial contribution. In such a case, government, acting in the same capacity as a private shareholder, provides funds while receiving contractually something of equal value in exchange (i.e., increased value of its equity) and expecting to earn a sufficient rate of return on its investment, in the form of dividends (as a return on equity). Treatment of these payments as the increase in equity depends on evidence of the corporation's profitability and its ability to pay dividends in future.

These payments are recorded as capital grants to other general government units (2632) or as capital transfers not elsewhere classified (2822).

- Transfers to households (often called "subsidies") but intended to supplement household income or defray household expense: These do not relate to production activities and should therefore be included in the relevant category of social benefits (27).

- Increases in equity in corporate enterprises of general government: These are recorded as transactions in the financial instrument equity and investment fund shares (3205) if an effective financial claim is acquired (see Box 6.3).

- Transfers made by a general government unit that has assumed responsibility for pension claims on public enterprises: These payments are recorded as capital transfers not elsewhere classified (2822).
- Payments made by general government to market producers to pay entirely, or in part, for goods and services that those market producers provide directly and individually to households in the context of social risks or needs and to which the households have a right: These payments are recorded as social benefits (27).

\section{Grants (26)}

6.92 Grants (26) are transfers payable by government units to other resident or nonresident government units or international organizations and that do not meet the definition of a tax, subsidy, or social contribution (see paragraph 3.10). Grants are normally payable in cash, but may also take the form of provision of goods or services (in kind). Grants payable are classified first by the type of unit receiving the grant and then by whether the grant is current or capital. 
6.93 Three types of recipients of grants are recognized in GFS: grants to foreign governments (261), grants to international organizations (262), and grants to other general government units (263). The category of grants payable by government units to other general government units has a nonzero value only in the case of statistics compiled for a subsector of the general government sector. For the general government sector, these transactions are eliminated in consolidation. To allow for consolidation, grants payable to other general government units should be identified according to the subsector of the counterparty (see Table 6.7).

6.94 Grants payable distinguish current grants (2611/2621/2631) and capital grants (2612/2622/ 2632). The distinction between current and capital grants is described in paragraph 5.103. If doubt exists regarding the character of a grant, it should be classified as current. The nature of grants in kind, the time at which a grant is recorded, and the valuation are discussed in paragraphs 5.104-5.105.

6.95 In the Statement of Sources and Uses of Cash, the value of grants will be limited to grants paid in cash. Grants in kind will not be recognized in this statement since no cash flows related to the in-kind transaction are recorded. However, any cash payments incurred in the own production of the goods or services provided in kind will be included in the respective expense items (i.e., compensation of employees and purchases of goods and services).

\section{Social Benefits [GFS] (27) 34}

6.96 Social benefits are current transfers receivable by households intended to provide for the needs that arise from social risks-for example, sickness, unemployment, retirement, housing, education, or family circumstances. These benefits are payable in cash or in kind to protect the entire population or specific segments of it against certain social risks. Social risks are events or circumstances that may adversely affect the welfare of the households concerned either by imposing additional demands on their resources or by reducing their income. Examples of social benefits are the provision of medical services, unemployment compensation, and social security pensions. For

\footnotetext{
${ }^{34}$ The institutional units involved, classification, and recording of flows and stock positions related to social protection are described in Appendix 2.
}

\section{Table 6.7 Detailed Classification of Grants (26)}

\begin{tabular}{|c|c|}
\hline 26 & Grants \\
\hline 261 & To foreign governments \\
\hline 2611 & Current \\
\hline 2612 & Capital \\
\hline 262 & To international organizations \\
\hline 2621 & Current \\
\hline 2622 & Capital \\
\hline 263 & To other general government units \\
\hline 2631 & Current $^{1}$ \\
\hline 2632 & Capital $^{1}$ \\
\hline
\end{tabular}

${ }^{1}$ Further breakdown/" of which" lines could allow for the identification of subsectors and individual units (see Table 3.1).

a complete discussion on social protection, see Appendix 2 .

6.97 Not all social benefits as defined in the 2008 SNA are classified in this GFS expense item (see Table 6.8). Social benefits [GFS] (27) exclude:

- The payment of pensions and other retirement benefits through employment-related social schemes, which are recorded in GFS as reductions in liabilities. ${ }^{35}$

- Goods and services produced by government and transferred to households are expense transactions not classified as social benefits. Instead, the expense transactions are recorded as production expenses as part of compensation of employees, use of goods and services, and consumption of fixed capital, as appropriate. ${ }^{36}$

6.98 Social benefits are classified first according to the type of social protection arrangement governing their payment: social security, social assistance, or employment-related social insurance schemes, and

\footnotetext{
${ }^{35}$ In the 2008 SNA, all payments of pension and other retirement benefits are recorded as transfer payments: those paid through social security schemes are solely transfer payments, whereas payments through employment-related schemes, other than social security (defined contributions or defined benefits), are first recorded as transfer payments to households in the use of income account, and then as a change in pension entitlements in the financial account. Subsequently, the reductions in liabilities are recorded as an adjustment entry made to remove any inconsistency between the benefits and the change in liabilities.

${ }^{36}$ In the 2008 SNA, when a general government unit produces goods and services that are distributed as social benefits, the expense items related to the costs of producing them, such as compensation of employees, are the same as in this Manual. However, in the 2008 SNA, unlike this Manual, the value of the goods and services produced is also included as social benefits.
} 


\begin{tabular}{|c|c|}
\hline \multicolumn{2}{|c|}{$\begin{array}{c}\text { Table 6.8 Detailed Classification of Social } \\
\text { Benefits (27) }\end{array}$} \\
\hline 27 & Social benefits [GFS ${ }^{1}$ \\
\hline & $\begin{array}{l}\text { Social benefits [SNA }]^{1} \\
\text { Minus: Social benefits related to reductions in } \\
\quad \text { liabilities } \\
\text { Minus: Cost associated with the own } \\
\text { production of goods and services } \\
\text { transferred to households }\end{array}$ \\
\hline 271 & Social security benefits [GFS] \\
\hline 2711 & Social security benefits in cash [GFS] \\
\hline 2712 & Social security benefits in kind [GFS] \\
\hline 272 & Social assistance benefits [GFS] \\
\hline 2721 & Social assistance benefits in cash [GFS] \\
\hline 2722 & Social assistance benefits in kind [GFS] \\
\hline 273 & Employment-related social benefits [GFS] \\
\hline 2731 & $\begin{array}{l}\text { Employment-related social benefits in } \\
\text { cash [GFS] }\end{array}$ \\
\hline 2732 & $\begin{array}{l}\text { Employment-related social benefits in } \\
\text { kind [GFS] }\end{array}$ \\
\hline
\end{tabular}

${ }^{1}$ A similar breakdown could be applied to other subcategories of social benefits, as relevant.

then by whether the payment was made in cash or in kind. These benefits are divided between pensions and nonpension benefits.

6.99 Social security benefits [GFS] (271) are social benefits expense payable in cash or in kind to households by social security schemes (see paragraph A2.33). Typical social security benefits in cash [GFS] (2711) include extended sickness and invalidity benefits, maternity allowances, children's or family allowances, unemployment benefits, retirement and survivors' pensions, and death benefits.

6.100 Social security benefits in kind [GFS] (2712) typically consist of goods and services purchased from a market producer on behalf of households and benefits related to the reimbursements of costs of goods and services purchased by households in accordance with the rules of the scheme. ${ }^{37}$ These benefits are likely to consist of medical or dental treatments, surgery, hospital accommodation, spectacles or contact lenses, pharmaceutical products, home care, and similar goods or services.

\footnotetext{
${ }^{37}$ Although these reimbursements (partial or in full) are normally paid in cash, they are recorded as social benefits in kind, because they are assumed to be incurred directly by the social security fund at the time the household makes the purchase.
}

6.101 Social assistance benefits [GFS] (272) are transfers payable in cash or in kind to households to meet the same needs as social insurance benefits but that are not made under a social insurance scheme. Eligibility to receive such benefits is not dependent on having elected to participate as demonstrated by the payment of contributions. Social assistance benefits therefore exclude all benefits payable by social security funds.

6.102 Social assistance benefits may include those benefits payable under any one of the following circumstances:

- No social insurance scheme exists to cover the circumstances in question.

- Although a social insurance scheme, or schemes, may exist, the households in question do not participate and are not eligible for social insurance benefits.

- Contributions to social insurance schemes were made on behalf of households who cannot otherwise afford to participate in the scheme, in order to secure entitlement to the benefits of the scheme for them.

- Social insurance benefits are deemed to be inadequate to cover the needs in question, so the social assistance benefits are being paid in addition.

- Implicit social assistance benefits were paid resulting from payable tax credits (see paragraph 5.31).

- As a matter of general social policy.

6.103 Social assistance benefits do not include transfers made in response to events or circumstances, such as natural disasters, which are not normally covered by social insurance schemes. Such transfers are recorded under transfers not elsewhere classified (282).

6.104 Employment-related social benefits [GFS] (273) are social benefits payable in cash or in kind by government or public sector units to their employees or employees of other government or public sector units participating in the scheme (or to survivors and dependents of the employees who are eligible for such payments). The kinds of benefits provided relate to nonpension benefits, and are similar to those listed for social security schemes, such as the continued payment of wages during periods of absence from work as a result of ill health, accidents, maternity, 
etc.; family, education, or other allowances; severance allowances in the event of redundancy, incapacity, or accidental death; general medical expenses not related to the employees' work; and charges for convalescent and retirement homes.

6.105 The payment of employer social benefits is often made out of the government's own resources without involving an insurance enterprise or an autonomous or nonautonomous pension fund. To reflect the true economic nature of the operation and to ensure comparability with similar payments made through social security schemes, an imputation of employers'social contributions [GFS] (2122) (see paragraph 6.22) is made in expense, recorded as compensation of employees (21), and in revenue, recorded as imputed social contributions (1223). These imputed values are equal to the value of the employment-related social benefits payable in this item.

6.106 When using the accrual basis of recording, the payment of pensions and other retirement benefits through these employment-related pension schemes is recorded as reductions in liabilities (see paragraph 7.189). However, when using the cash basis of recording, the liability did not accumulate through imputed contributions recorded in the past, and all payment of these employment-related pensions should be recorded as employment-related social benefits [GFS] (2731).

\section{Other Expense (28)}

6.107 Other expense comprises property expense other than interest (281), transfers not elsewhere classified (282), and amounts payable in respect of premiums, fees, and claims payable related to nonlife insurance and standardized guarantees (283).

\section{Property expense other than interest (281)}

6.108 Property expense (281) is the expense payable to the owners of financial assets or natural resources when they put them at the disposal of another unit. Property expense is the sum of investment expense and rent. One type of investment expense is interest [GFS] (24), which is classified separately in GFS. Property expense other than interest may take the form of dividends (2811); withdrawals of income from quasi-corporations (2812); property expense for investment income disbursements (2813); rent (2814); and reinvested earnings on direct foreign investments

\section{Table 6.9 Detailed Classification of Dividends (2811) \\ 2811 Dividends \\ 28111 To nonresidents \\ 28112 To residents ${ }^{1}$}

${ }^{1}$ Further breakdown/" of which" lines could allow for the

identification of subsectors and individual units (see Table 3.1).

(2815). Dividends and withdrawals of income from quasi-corporations as an expense will primarily apply to public corporations and foreign direct investment of the public sector.

\section{Dividends (2811)}

6.109 Dividends (2811) are the distributed earnings allocated to government or public sector units, as the owners of equity, for placing funds at the disposal of corporations. As shown in Table 6.9, identifying the recipient of dividends from public corporations would allow for consolidation of statistics of the public sector. Dividend payments are not required; the board of directors or other managers of the corporation must declare a dividend payable on their own volition. Distributions of profits by public corporations may take place irregularly and may not be explicitly labeled as dividends. Nevertheless, except for distributions by fiscal, export, or import monopolies, dividends include all distributions of profits by public corporations to their shareholders or owners. ${ }^{38}$ The time of recording of dividends is the point at which the share price starts to be quoted on an "ex-dividend" basis. Dividends are described in more detail in paragraphs 5.111-5.117.

6.110 Dividends are notionally payable out of the current period's operating surplus, although corporations often smooth the payments of dividends, sometimes paying out less than the operating surplus but sometimes paying out more, especially when the operating surplus itself is very low. Dividends that are disproportionately large relative to the recent level of dividends and earnings, often referred to as "superdividends," require special consideration. See paragraphs 5.115-5.116 for a description of the treatment

\footnotetext{
${ }^{38}$ Distributions of profits by fiscal, export, and import monopolies are recorded as taxes payable (see paragraphs 5.63-5.68 and 5.86). Therefore, in expense, these amounts payable are classified as transfers not elsewhere classified (282).
} 
of these "super-dividends" in the context of the corresponding revenue item.

\section{Withdrawals of income from quasi-corporations (2812)}

6.111 Withdrawals of income from quasi-corporations (2812) consists of that part of distributable income that the owner withdraws from the quasi-corporation. By definition, quasi-corporations cannot distribute income in the form of dividends, but the owner may choose to withdraw some or all of the income. Conceptually, the withdrawal of such income is equivalent to the distribution of corporate income through dividends and is recorded in the same way. The amount of income that the owner of a quasi-corporation chooses to withdraw will depend largely on the size of its net income. All such withdrawals are recorded on the date the payment actually occurs. See paragraphs 5.118-5.119 for a description of the recording of the corresponding revenue item.

6.112 As with dividends, withdrawals of income from quasi-corporations do not include withdrawals of funds realized by the sale or other disposal of the quasi-corporation's assets. Funds withdrawn by liquidating large amounts of accumulated retained earnings or other reserves of the quasi-corporation are recorded as withdrawals from equity. The sale of inventories, fixed assets, land, or other nonproduced assets to withdraw funds would be recorded in the accounts of the quasi-corporation as disposals in the appropriate category of assets (see paragraphs 7.347.117), with government recording a withdrawal from equity.

\section{Property expense for investment income disbursements (2813)}

6.113 Property expense for investment income disbursements (2813) includes property income attributed to insurance policyholders, pension entitlements, and holders of investment fund shares (see paragraphs 7.174 and 7.178). Public corporations can be insurance enterprises or may operate pension schemes, in which case they will hold technical reserves in the form of reserves against outstanding risks in respect of nonlife and life insurance policies, as well as reserves to provide for the entitlement on pension and nonpension benefits and calls under standardized guarantee schemes. The reserves are li- abilities toward the policyholders or beneficiaries. Any income receivable from the investment of the corresponding assets should be attributed as the property income of the policyholders or beneficiaries, and therefore a property expense is recorded to reflect the increase in liabilities.

6.114 General government units are less likely to operate an insurance scheme, but if they do and if they maintain separate reserves, the property expense attributed to insurance policyholders would be recorded in the same manner as for a public corporation. If the general government unit does not maintain separate reserves, then no investment income is generated and so no property expense is attributed to the policyholders. ${ }^{39}$

6.115 For government units operating a standardized guarantee scheme against fees, there may also be investment income earned on the reserves of the scheme and this should be shown as a property expense being distributed to the units paying the fees (which may not be the same units that stand to benefit from the guarantees). Appendix 4 describes the recording of transactions related to standardized guarantee schemes.

6.116 As described in Appendix 2, pension entitlements arise from one of two types of pension schemes: defined-contribution schemes and definedbenefit schemes. Under both schemes, the operator of the scheme records a property expense attributed to policyholders to reflect changes in the liability outstanding for the pension entitlements. These changes may arise from investment income and the change in value due to the passage of time.

6.117 With a defined-benefit scheme, the future pension benefits are defined by some formula normally related to participants' length of service and salary. The nominal values of the pension benefits payable in the future are determined actuarially based on estimates of variables, such as expected retirement ages, mortality rates, expected inflation, and expected salary increases. The nominal values can then be converted to present values using an appropriate discount rate. Over time, the total liability of the pension scheme will change because of the receipt

\footnotetext{
${ }^{39}$ For a description of flows and stock positions related to insurance and standardized guarantee schemes, see paragraphs A4.66-A4.80.
} 
of additional contributions and property income, the payment of benefits, changes in the actuarial assumptions, and the passage of time. The property expense attributed to a pension fund's policyholders is equal to the increase in the liability resulting from the property income accruing on the pension fund's assets held on behalf of the beneficiaries and the passage of time, which occurs because the future benefits are discounted over fewer reporting periods.

6.118 With defined-contribution schemes, the level of contributions to the fund, rather than the level of benefits, is guaranteed by the employer. All definedcontribution schemes are funded (see paragraph A2.55), and the liability of a defined-contribution scheme is equal to the current market value of the fund's assets. Therefore, the property expense attributed to insurance policyholders is equal to the property income receivable from the investment of the scheme's assets. Any holding gains on the scheme's assets are equally reflected in holding losses on the scheme's unit's liability to the beneficiaries.

6.119 The increase/decrease in the value of investment fund shares (or units), other than from other economic flows, is recorded as property income, either distributed to the share- (or unit) holders or reinvested by the holders in the shares (or units).

\section{Rent (2814)}

6.120 Rent (2814) is the expense payable to the owners of a natural resource (the lessor or landlord) for putting the natural resource at the disposal of another institutional unit (a lessee or tenant) for use of the natural resource in production. Rent payable is typically related to a resource lease on land, subsoil resources, and on other natural resources. Rent accrues continuously to the asset's owner throughout the period of the contract and may be payable in cash or in kind. The types of resource rent and the boundary between resource rent, rental of produced assets, and taxes are described in detail in paragraphs 5.124-5.132 in the context of the corresponding revenue item.

\section{Reinvested earnings on foreign direct investment (2815)}

6.121 Reinvested earnings are the direct investor's share of the retained earnings of the direct in- vestment enterprise. Public corporations may have foreign direct investors. Actual distributions to such nonresident foreign direct investors may be made out of their distributable income in the form of dividends or withdrawals of income from quasicorporations. However, macroeconomic statistics also require the retained earnings of a foreign direct investment enterprise to be recorded as if they were distributed and remitted to foreign direct investors in proportion to their ownership of the equity in the enterprise and then reinvested by them by means of additions to equity. The imputed remittance of these retained earnings is classified as a form of distributed income that is separate from, and additional to, any actual payments of dividends or withdrawals of income from quasi-corporations. This treatment assumes that the decision to retain some earnings within the enterprise must represent a deliberate investment decision on the part of the foreign direct investor. Reinvested earnings are described in detail in paragraphs 5.134-5.135 in the context of the corresponding revenue item.

\section{Transfers not elsewhere classified (282)}

6.122 Transfers not elsewhere classified (282) payable include a number of gifts and transfers to individuals, private nonprofit institutions, nongovernmental foundations, corporations, or government units that are not included in other categories of transfers and serve quite different purposes. Transfers not elsewhere classified (282) are subdivided into current transfers not elsewhere classified (2821) and capital transfers not elsewhere classified (2822). It may be of analytic interest to classify this group of transactions according to the recipients, such as residents and nonresidents. Among residents, it may also be of interest to classify them according to whether these are households, nonprofit institutions serving households, public nonfinancial corporations, public financial corporations, or private corporations (see Table 6.10).

\section{Current transfers not elsewhere classified (2821)}

6.123 The most important types of current transfers included here are:

- Current transfers to nonprofit institutions serving households: These transfers usually consist of cash 


\section{Table 6.10 Detailed Classification of Transfers Not Elsewhere Classified (282) \\ Transfers not elsewhere classified ${ }^{1}$ \\ 2822 Current transfers not elsewhere classified Capital transfers not elsewhere classified}

"Further breakdown/" of which" lines could allow for the identification of subsectors and individual units (see Table 3.1).

in the form of membership dues, subscriptions, and voluntary donations, whether made on a regular or occasional basis. ${ }^{40}$ Such transfers are intended to cover the costs of the production of nonprofit institutions serving households or to provide the funds out of which current transfers may be made to households in the form of social assistance benefits. This category also covers transfers in kind in the form of food, clothing, blankets, and medicines to charities for distribution to households.

- Current taxes, compulsory fees, and fines imposed by one unit of general government or public corporations on another government unit or public corporation: These transfers are subject to elimination by consolidation.

- Net nonpayable tax credits: When, due to timing differences, the amount of a nonpayable tax credit exceeds the amount of tax otherwise receivable from taxpayers in the reporting period, and the excess is paid to the taxpayer, the net payment should be recorded as expense rather than negative tax.

- Gross payable tax credits other than those classified as subsidies or social benefits: These amounts arise from tax credits payable irrespective of whether taxes are payable, and are recorded on a gross basis so that the total amount payable is recorded as expense (see paragraphs 5.29-5.32).

- Fines and penalties imposed by courts of law or quasi-judicial bodies.

- Payments of compensation for injury to persons or damage to property caused by general government or public sector units, excluding payments of nonlife insurance claims: These payments can be either compulsory payments awarded by

\footnotetext{
${ }^{40}$ Membership dues and subscription fees are recorded as an expense in use of goods and services (22) if there is an exchange of a payment for some form of a service (see paragraph 6.42).
}

courts of law or ex gratia payments agreed out of court.

- Scholarships and other educational benefits payable for households that are not related to social risks.

- Purchases of goods and services from market producers that are distributed directly to households for final consumption other than social benefits.

\section{Capital transfers not elsewhere classified (2822)}

6.124 The most important types of capital transfers included here are:

- Capital taxes (see paragraph 5.51) imposed by one unit of general government on another government unit or public corporation: These transfers are subject to elimination by consolidation.

- Major, nonrecurrent, exceptional payments in compensation for extensive damages or serious injuries such as those arising from catastrophes not covered by insurance policies are included as a capital transfer.

- Capital transfers to corporations, quasicorporations, nonprofit institutions serving households, households, and nonresidents in cash or in kind, to finance all or part of the costs of acquiring nonfinancial assets, to cancel or assume a debt by mutual agreement with the debtor without acquiring an effective financial claim on the original debtor (see Box 6.3). ${ }^{41}$

- Transfers payable to corporations and quasicorporations to cover large operating deficits accumulated over two or more years. ${ }^{42}$

- Payment of interest or other debt service cost on behalf of other producer units without acquiring an effective claim on the original debtor.

- Amounts payable in excess of the value of liabilities for the provision of pension entitlements assumed by other units. ${ }^{43}$

\footnotetext{
${ }^{41}$ This expense category excludes amounts payable for the acquisition of equity (see paragraph 9.49).

${ }^{42}$ Where a realistic expectation exists that such amounts will be repayable, as indicated by certain criteria (see Box 6.3), the transaction should be classified as the acquisition of a financial asset. A regular transfer covering an operating deficit is recorded as a subsidy.

${ }^{43}$ Amounts payable up to the value of the liability assumed should be recorded as transactions in financial assets and liabilities (i.e., the reduction in liabilities) (see paragraphs 9.66-9.67).
} 
Premiums, fees, and claims payable related to nonlife insurance and standardized guarantee schemes (283)

6.125 Premiums, fees, and claims payable related to nonlife insurance and standardized guarantee schemes (283) include nonlife insurance premiums payable to insurance schemes/corporations to secure entitlement to insurance against risks, claims payable by insurance schemes to beneficiaries, and fees payable to obtain standardized guarantees. To allow for consolidation of the general government and public sectors, this expense should also be classified according to the subsector of the counterparty (see Table 6.11). A distinction is made between premiums, fees, and current claims payable (2831) and capital claims payable (2832):

- Premiums, fees, and current claims payable (2831) comprise nonlife insurance premiums expense and fees payable for the issuance of standardized guarantees, as well as insurance settlement expense that are not exceptional. The premiums and fees are payable to insurance schemes and corporations to obtain coverage against various events or accidents. Such amounts are always recorded as current transfers. ${ }^{44}$ Also included are nonlife insurance claims payable by insurance schemes operated by a general government unit or public insurance corporation in settlement of claims that become due during the current reporting period. Claims be-

\footnotetext{
${ }^{44}$ In the 2008 SNA, nonlife insurance premiums payable are partitioned into a purchase of a service and a transfer. In GFS, the entire premium is considered a transfer because the policyholder is not able to partition the service and transfer components.
}

Table 6.11 Detailed Classification of Premiums, Fees, and Claims Payable Related to Nonlife Insurance and Standardized Guarantee Schemes (283)

283 Premiums, fees, and claims payable related to nonlife insurance and standardized guarantee schemes

2831

28311 Premiums, fees, and current claims payable Premiums payable ${ }^{1}$

28312

28313

2832

"Further breakdown/" of which" lines could allow for the identification of subsectors and individual units (see Table 3.1).

come payable when the eventuality occurs that gives rise to a valid claim, regardless of whether paid, settled, or reported during the reporting period. Such insurance claims that are not exceptional are recorded as current transfers (see also paragraph A4.79 for the recording of standardized guarantee schemes).

- Capital claims payable (2832) comprise exceptionally large insurance settlements payable in the wake of a catastrophic event or disaster. For these exceptional large claims payable, such as those following a catastrophe, some part of the claims may be recorded as capital transfers rather than as current transfers. It may be difficult for the parties to identify these events consistently, so as a simplifying convention, all nonlife insurance claims are classified as current transfers, unless it is necessary to record a capital transfer to be consistent with the national accounts. 


\section{Annex: Classification of the Functions of Government}

This annex describes the classification of expenditure according to the functions of government.

\section{Introduction}

6.126 The Classification of Functions of Government (COFOG) is a detailed classification of the functions, or socioeconomic objectives, that general government units aim to achieve through various kinds of expenditure. COFOG is integral to the GFS presentation. It is one of a family of four classifications referred to as classifications of expenditure according to purpose. ${ }^{45} \mathrm{COFOG}$ provides a classification of government outlays by functions that experiences have shown to be of general interest and useful to a wider variety of analytic applications. Statistics on health, education, social protection, and environmental protection, for example, can be used to study the effectiveness of government programs in those areas. In contrast, the Classification of Environmental Activities (CEA) is a functional classification that covers a more limited but specialized activity. ${ }^{46}$

6.127 While the COFOG as used in this Manual fully agrees with the OECD/UN classification, the concept is applied slightly differently in GFS. Final outlays are referred to in a general sense by the OECD/ $\mathrm{UN}$, and therefore include grants, loans, and/or subsidies. In GFS, COFOG is applied only to expenditure, comprising expense and the net investment in nonfinancial assets. Transactions in financial assets and

\footnotetext{
${ }^{45} \mathrm{COFOG}$ was produced by the Organisation for Economic Cooperation and Development (OECD) and was published together with the other three classifications in United Nations (UN), Classifications of Expenditure according to Purpose (New York, 2000). The other classifications are the Classifications of Individual Consumption According to Purpose (COICOP), the Classification of the Purpose of Nonprofit Institutions Serving Households (COPNI), and the Classification of the Outlays of Producers According to Purpose (COPP).

${ }^{46} \mathrm{CEA}$ is one of the classifications and lists contained in the System of Environmental-Economic Accounting Central Framework (SEEA). See Appendix 7 for a description of the linkages between GFS and the SEEA. For more details on CEA, also see the Classification of Environmental Protection Activities and Expenditure (CEPA) (UN, 2000c).
}

liabilities, such as loans, are excluded when compiling COFOG data for GFS reporting purposes. For the general government sector, transactions in financial assets and liabilities are usually fungible, to such an extent that a functional classification of these financing activities may be less useful.

\section{Structure of COFOG Classifications}

6.128 The classification codes of COFOG are somewhat different from the structure of other GFS classification codes. The functions are classified using a three-level scheme. There are 10 first-level, or two-digit, categories, referred to as divisions. Examples are health (Division 07) and social protection (Division 10). Within each division, there are several groups, or three-digit categories, such as hospital services (Group 073) and sickness and disability (Group 101). Within each group, there are one or more classes, or four-digit categories, such as nursing and convalescent home services (Class 0734) and disability (Class 1012). All three classification levels and detailed descriptions of the contents of each class are reproduced in this annex. Table 6A.1 lists the divisions and groups. In the GFS framework, the prefix " 7 " has been added to align the COFOG codes with other GFS classification codes.

6.129 All expenditure on a particular function is aggregated in one category of COFOG regardless of the economic nature of the expenditure. That is, transfers payable in cash designed to be used for a particular function, the purchase of goods and services from a market producer that are transferred to households for the same function, the production of goods and services by a general government unit, and/or the net investment in a nonfinancial asset for that same function are all reported under the same function.

\section{Uses of COFOG}

6.130 COFOG permits trends in government expenditure on particular functions or policy purposes 


\section{Table 6A.1 Classification of Expenditure by Functions of Government According to Divisions and Groups}

\begin{tabular}{|c|c|c|c|}
\hline 7 & Total expenditure & & \\
\hline 701 & General public services & 706 & Housing and community amenities \\
\hline 7011 & Executive and legislative organs, financial and & 7061 & Housing development \\
\hline & fiscal affairs, external affairs & 7062 & Community development \\
\hline 7012 & Foreign economic aid & 7063 & Water supply \\
\hline 7013 & General services & 7064 & Street lighting \\
\hline 7014 & Basic research & 7065 & R\&D Housing and community amenities \\
\hline 7015 & R\&D General public services & 7066 & Housing and community amenities n.e.c. \\
\hline 7016 & General public services n.e.c. & 707 & Health \\
\hline 7017 & Public debt transactions & 101 & Health \\
\hline 7018 & $\begin{array}{l}\text { Transfers of a general character between } \\
\text { different levels of government }\end{array}$ & $\begin{array}{l}7071 \\
7072\end{array}$ & $\begin{array}{l}\text { Medical products, appliances, and equipment } \\
\text { Outpatient services }\end{array}$ \\
\hline 702 & Defense & 7073 & Hospital services \\
\hline 7021 & Military defense & 7074 & Public health services \\
\hline 7022 & Civil defense & 7075 & R\&D Health \\
\hline 7023 & Foreign military aid & 7076 & Health n.e.c. \\
\hline 7024 & R\&D Defense & 708 & Recreation, culture, and religion \\
\hline 7025 & Defense n.e.c. & 7081 & Recreational and sporting services \\
\hline 703 & Public order and safety & 7082 & Cultural services \\
\hline $\begin{array}{l}1031 \\
7032\end{array}$ & $\begin{array}{l}\text { Police services } \\
\text { Fire protection services }\end{array}$ & 7083 & Broadcasting and publishing services \\
\hline 7033 & Law courts & 7084 & Religious and other community services \\
\hline 7034 & Prisons & 7085 & R\&D Recreation, culture, and religion \\
\hline 7035 & R\&D Public order and safety & 7086 & Recreation, culture, and religion n.e.c. \\
\hline 7036 & Public order and safety n.e.c. & 709 & Education \\
\hline 704 & Economic affairs & 7091 & Pre-primary and primary education \\
\hline 7041 & $\begin{array}{l}\text { General economic, commercial, and labor } \\
\text { affairs }\end{array}$ & $\begin{array}{l}7092 \\
7093\end{array}$ & $\begin{array}{l}\text { Secondary education } \\
\text { Postsecondary nontertiary education }\end{array}$ \\
\hline 7042 & Agriculture, forestry, fishing, and hunting & 7094 & Tertiary education \\
\hline 7043 & Fuel and energy & 7095 & Education not definable by level \\
\hline 7044 & Mining, manufacturing, and construction & 7096 & Subsidiary services to education \\
\hline 7045 & Transport & 7097 & R\&D Education \\
\hline $\begin{array}{l}1046 \\
7047\end{array}$ & $\begin{array}{l}\text { Communication } \\
\text { Other industries }\end{array}$ & 7098 & Education n.e.c. \\
\hline 7048 & R\&D Economic affairs & 710 & Social protection \\
\hline 7049 & Economic affairs n.e.c. & 7101 & Sickness and disability \\
\hline 705 & Environmental protection & 7102 & Old age \\
\hline 7051 & Waste management & 7103 & Survivors \\
\hline 7052 & Waste water management & 7104 & Family and children \\
\hline 7053 & Pollution abatement & 7105 & Unemployment \\
\hline 7054 & Protection of biodiversity and landscape & 7106 & Housing \\
\hline 7055 & R\&D Environmental protection & 7107 & Social exclusion n.e.c. \\
\hline 7056 & Environmental protection n.e.c. & 7108 & R\&D Social protection \\
\hline & & 7109 & Social protection n.e.c. \\
\hline
\end{tabular}

Note: R\&D = research and development; n.e.c. $=$ not elsewhere classified .

to be examined over time. Conventional government accounts are not usually suitable for this purpose because they reflect the organizational structures of governments. Not only might time series be distorted by organizational changes, but at a specific time some organizations may be responsible for more than one function, and responsibility for one function might be divided among several organizations. For example, if a government establishes a new department that brings together some of the functions previously 
administered by several departments or at several levels of government, it will not usually be possible to use conventional government accounts to compare expenditure on these purposes over time.

6.131 COFOG is also used for making international comparisons of the extent to which governments are involved in particular economic and social functions. Just as COFOG avoids the problems of organizational changes in a single government, so too does it avoid the problems of organizational differences among countries. In one country, for example, all functions connected with water supply may be undertaken by a single government agency, while in another country, they may be distributed among departments dealing with the environment, housing, or industrial development.

6.132 For particular kinds of analyses, COFOG provides key aggregates that could be used as indicators or measures of results. For example, in studies of social assistance, information on past expenditure on the social protection function could give an indication of changes in the support provided by government for the welfare of the population. Similarly, analyzing the impact of economic growth on the environment may require information on the expenditure on environmental protection.

\section{Individual versus Collective Goods and Services}

6.133 Government services can benefit the community either individually or collectively. COFOG is used to distinguish between individual and collective goods and services provided by general government units. The COFOG functions are defined so that they represent individual or collective consumption, but not both.

6.134 A collective service is a service provided simultaneously to all members of the community or to all members of a particular section of the community, such as all households living in a particular region. Other characteristics of these collective services may be summarized as follows:

- The use of such services is usually passive and does not require the explicit agreement or active participation of all the individuals concerned.

- The provision of a collective service to one individual does not reduce the amount available to others in the same community or section of the community. There is no rivalry in consuming these services.

6.135 An individual consumption good or service is one that is acquired by a household and used to satisfy the needs or wants of members of that household. Individual goods and services are essentially "private" as distinct from "public" goods and services. They have the following characteristics:

- It must be possible to observe and record the acquisition of the good or service by an individual household or member thereof as well as the time at which it took place.

- The household must have agreed to accept the provision of the good or service and to take whatever action is necessary to make it possible-for example, by attending a school or clinic.

- The good or service must be such that its acquisition by one household or person, or possibly by a small, restricted group of persons, precludes its acquisition by other households or persons.

6.136 An important characteristic of an individual good or service is that its acquisition by one household, person, or group of persons brings no (or very little) benefit to the rest of the community. The borderline between individual goods and services and collective services is not always clear. While the provision of certain individual health or education services (e.g., vaccination or immunization) may bring some external benefits to the rest of the community, in general, the individuals concerned derive the main benefit. When a government unit incurs expenditure on the provision of individual goods or services, it must decide not only how much to spend in total but how to allocate, or distribute, the goods or services among individual members of the community. In contrast, in the case of collective services, all members of the community benefit from such services.

6.137 Expenditure incurred by governments in connection with individual services such as health and education are to be treated as collective services when they are concerned with the formulation and administration of government policy, the setting and enforcement of public standards, the regulation, licensing, or supervision of producers, etc. For example, the expenditure incurred by ministries of health or education at a national level are to be included in 
collective consumption expenditure as they are concerned with general matters of policy, standards, and regulation. On the other hand, any overhead expenses connected with the administration or functioning of a group of hospitals, schools, colleges, or similar institutions are to be included in individual expenditure. For example, if a group of private hospitals has a central unit that provides certain common services such as purchasing, laboratories, ambulances, or other facilities, the costs of these common services would be taken into account in the prices charged to patients. The same principle must be followed when the hospitals are nonmarket producers: all the costs that are associated with the provision of services to particular individuals, including those of any central units providing common services, should be included in the value of expenditure on individual services.

6.138 All of classes 701 to 706 are collective services, as are sections 7075 and 7076 of health; sections 7083 to 7086 of recreation, culture, and religion; sections 7097 and 7098 of education; and sections 7108 and 7109 of social protection. These sections cover expenditure on general administration, regulation, research that is not recorded as investment in nonfinancial assets, and so on. The remaining sections of health, recreation, culture and religion, education, and social protection (which dominate each of the classes) are considered to be individual services.

6.139 In this annex, each class is marked "CS" or "IS" to designate it as collective services or individual services, respectively. This distinction is used for the computation of final consumption expenditure and actual final consumption of the general government and household sectors in the national accounts, as described in paragraphs A7.53-A7.62. Purchases of goods and services that are provided to individual households or persons are treated as social transfers in kind in the 2008 SNA so that the actual final consumption of government and households, in addition to their final consumption expenditure, can be computed. Therefore, statistics compiled for each economic type of expenditure by function are needed for compiling national accounts according to the 2008 SNA.

\section{Units of Classification}

6.140 The units of classification are, in principle, individual transactions. Each purchase of goods and services, wages payable, transfer, or other expenditure should be assigned a COFOG code according to the function that the transaction serves. For most expenditure, however, it will generally not be possible to use transactions as the unit of classification and institutional units may also not necessarily be performing a single function. Instead, COFOG codes may best be done at the smallest level of entities, regardless of their status as institutional units. Functions often have to be assigned to all transactions of agencies, offices, programs, bureaus, and similar smaller entities within government departments or ministries.

6.141 When these smaller government entities rather than transactions are used for classification, it may happen that the smallest entity that can be identified in the government accounts may perform more than one COFOG function. If possible, the expenditure of multifunction entities should be allocated among COFOG functions using a relevant physical indicator, such as hours worked by employees. It may be possible only to assign all expenditure by multifunction entities to whichever purpose appears to account for the largest part of expenditure.

6.142 A single classification cannot serve all analytic purposes. The selection of functions in COFOG is based on judgment. The scope of each function could be broader or narrower, and completely different functions could have been included. For example, expenditure for medical schools is classified in COFOG as education rather than health. Also, research and development could be a function of its own, but in COFOG, research and development expenditure is shown separately, classified according to the function the goal of the research and development most closely serves. Thus, COFOG statistics must be used with care to be sure that the desired coverage is obtained for a specific analytic purpose.

\section{Problems in Identifying Functions of Government \\ Shared Expenditure}

6.143 Government ministries generally are responsible for the formulation, administration, coordination, and monitoring of overall policies, plans, programs, and budgets; for the preparation (in some countries) and enforcement of legislation; and for the production and 
dissemination of general information, technical documentation, and statistics. Consequently, the expenditure of these ministries has to be shared across the classes for which they are responsible. For example, the expenditure of a ministry of transport should be divided between road transport (70451), water transport (70452), railway transport (70453), air transport (70454), and pipeline and other transport (70455).

\section{Administrative Expenditure}

6.144 Administrative expenditure on general services, such as personnel services, supply and purchasing services, accounting and auditing services, and computer and data processing services, undertaken by ministries or units within ministries should be classified at the most detailed level possible. If administrative expenditure overlaps two or more classes, an attempt should be made to apportion expenditure between the classes concerned. If this approach is not feasible, the total should be allocated to that class that accounts for the largest part of the total expenditure.

\section{Subsidies}

6.145 Particular difficulties may arise with regard to subsidies. The main objective behind such government support may be, for example, to assure capacity to build naval vessels considered vital to national defense, to maintain living standards of important groups such as farmers or miners, or to provide employment for workers in underutilized hospitals. These political objectives are not to be confused with functions as the term is used in COFOG. Hence, a government subsidy to shipyards is classified under manufacturing (70442), and grants to hospitals are classified under hospital services (7073) regardless of the ultimate purposes. Subsidies and grants designed chiefly to increase employment opportunities in general are an exception to this rule. Because such programs do not focus on any single industry, they are classified under general labor affairs (70412).

\section{Consumption of Fixed Capital}

6.146 It is likely that consumption of fixed capital will be difficult to allocate by function, especially if only aggregated figures for total government capital stock and consumption of fixed capital are compiled. In these circumstances, approximations will have to be used. One possibility may be to distribute consumption of fixed capital according to book value de- preciation, if it is available for detailed organizational units within government. Another approach would be to distribute consumption of fixed capital among functions in proportion to the net acquisition of fixed assets over a number of earlier years.

6.147 Another caution regarding the use of COFOG statistics relates to net investment in nonfinancial assets. Because expenditure classified by COFOG includes consumption of fixed capital as an expense, and includes it in the calculation of net investment in nonfinancial assets (deducted from acquisition minus disposals), the consumption of fixed capital will net out in COFOG data. However, if a functional classification is compiled for expense items only, this will include consumption of fixed capital representing part of the resource cost of using previously acquired fixed assets.

\section{Cross-Classification of Expenditure}

6.148 The economic and functional classifications of expenditure can be cross-classified as illustrated in Table 6A.2. A cross-classification of COFOG with each of the categories of the economic classification of expense is analytically useful. The cross-classification allows an analysis of:

- The inputs, which show how governments perform their functions, and the outputs, which show what governments are doing

- How governments carry out their public expenditure policy functions to meet social objectives

- The changes in the composition of expenditure over time to serve specific policy objectives

- Comparison of how specific functions are carried out by different governments.

6.149 Table 6A.2 includes a column for each major economic type of expense and for net investment in nonfinancial assets. As indicated earlier, this classification is needed to compile data on the actual final consumption of the general government and households (see paragraph 6.139).

\section{Detailed Classification of the Functions of Government}

6.150 As outlined earlier, the complete Classification of the Functions of Government (COFOG) has three levels of detail: Divisions, Groups, and Classes. 
Table 6A.2 Cross-Classification of Expenditure by Functional and Economic Classifications

\begin{tabular}{|c|c|c|c|c|c|c|c|c|}
\hline $\begin{array}{c}\text { Compensation } \\
\text { of employees } \\
\text { [GFS] }\end{array}$ & $\begin{array}{l}\text { Use of } \\
\text { goods } \\
\text { and } \\
\text { services }\end{array}$ & $\begin{array}{c}\text { Consumption } \\
\text { of fixed } \\
\text { capital [GFS] }\end{array}$ & $\begin{array}{c}\text { Interest } \\
\text { [GFS] }\end{array}$ & Subsidies & ants & $\begin{array}{c}\text { Social } \\
\text { benefits } \\
\text { [GFS] }\end{array}$ & $\begin{array}{c}\text { Other } \\
\text { expense }\end{array}$ & $\begin{array}{c}\text { Net } \\
\text { Investment in } \\
\text { nonfinancial } \\
\text { assets }\end{array}$ \\
\hline
\end{tabular}

General public

services

Defense

Public order

and safety

Economic

affairs

Environmental

protection

Housing and

community

amenities

Health

Recreation,

culture, and

religion

Education

Social

protection

${ }^{1}$ Consumption of fixed capital is a cost (expense) for a general government unit and reduces the value of nonfinancial assets. The net effect of consumption of fixed capital on total expenditure is thus zero.

The Divisions could be seen as the broad objectives of government, while the Groups and Classes detail the means by which these broad objectives are achieved. The classification numbers have been modified slightly to conform with the coding system of this Manual. The numeral "7" is prefixed to all codes and the punctuation separating Divisions, Groups, and Classes are deleted. In addition, where appropriate, reference has been made to expenditure rather than outlays. Otherwise, these descriptions are the same as those of the United Nations Statistical Division. ${ }^{47}$

${ }^{47}$ See http://unstats.un.org/unsd/cr/registry/regcst. asp $? \mathrm{Cl}=4 \& \mathrm{Top}=1 \& \mathrm{Lg}=1$.

\section{GENERAL PUBLIC SERVICES}

7011 EXECUTIVE AND LEGISLATIVE ORGANS, FINANCIAL AND FISCAL AFFAIRS, EXTERNAL AFFAIRS

\section{Executive and legislative organs (CS)}

- Administration, operation, or support of executive and legislative organs:

Includes: office of the chief executive at all levels of government-office of the monarch, governor-general, president, prime minister, governor, mayor, etc.; legislative bodies at all levels of government-parliaments, chambers of deputies, senates, assemblies, town councils, etc.; advisory, administrative, and political staffs attached to chief executive offices and legislatures; 
libraries and other reference services serving mainly executive and legislative organs; physical amenities provided to the chief executive, the legislature, and their aides; permanent or ad hoc commissions and committees created by or acting on behalf of the chief executive or legislature.

Excludes: ministerial offices, offices of heads of departments of local governments, interdepartmental committees, etc. concerned with a specific function (classified according to function).

\section{Financial and fiscal affairs (CS)}

- Administration of financial and fiscal affairs and services; management of public funds and public debt; operation of taxation schemes

- Operation of the treasury or ministry of finance, the budget office, the inland revenue agency, the customs authorities, the accounting and auditing services

- Production and dissemination of general information, technical documentation and statistics on financial and fiscal affairs and services.

Includes: financial and fiscal affairs and services at all levels of government.

Excludes: underwriting or flotation charges and interest payments on government loans (70170); supervision of the banking industry (70411).

\section{External affairs (CS)}

- Administration of external affairs and services

- Operation of the ministry of external affairs and diplomatic and consular missions stationed abroad or at offices of international organizations; operation or support of information and cultural services for distribution beyond national boundaries; operation or support of libraries, reading rooms, and reference services located abroad

- Regular subscriptions and special contributions to meet general operating expenses of international organizations.

Excludes: economic aid to developing countries and countries in transition (70121); economic aid missions accredited to foreign governments (70121); contributions to aid programs administered by international or regional organizations (70122); military units stationed abroad (70210); military aid to foreign countries (70230); general foreign economic and commercial affairs (70411); tourism affairs and services (70473).

\section{FOREIGN ECONOMIC AID \\ 70121 Economic aid to developing countries and countries in transition (CS)}

- Administration of economic cooperation with developing countries and countries in transition

- Operation of economic aid missions accredited to foreign governments; operation or support of technical assistance programs, training programs, and fellowship and scholarship schemes

- Economic aid in the form of grants (in cash or in kind) or loans (regardless of interest charged).

Excludes: contributions to economic development funds administered by international or regional organizations (70122); military aid to foreign countries (70230).

\section{Economic aid routed through international organizations (CS)}

- Administration of economic aid routed through international organizations

- Contributions in cash or in kind to economic development funds administered by international, regional, or other multinational organizations.

Excludes: aid to international peacekeeping operations (70230).

\section{GENERAL SERVICES}

This group covers services that are not connected with a specific function and that are usually undertaken by central offices at the various levels of government. It also covers those services connected with a particular function that are undertaken by such central offices. For example, the compilation of industry, environment, health, or education statistics by a central statistical agency is included here.

\section{General personnel services (CS)}

- Administration and operation of general personnel services, including development and implementation of general personnel policies and procedures covering selection, promotion, rating 
methods, the description, evaluation and classification of jobs, the administration of civil service regulations, and similar matters.

Excludes: personnel administration and services connected with a specific function (classified according to function).

\section{Overall planning and statistical services (CS)}

- Administration and operation of overall economic and social planning services and of overall statistical services, including formulation, coordination, and monitoring of overall economic and social plans and programs and of overall statistical plans and programs.

Excludes: economic and social planning services and statistical services connected with a specific function (classified according to function).

\section{Other general services (CS)}

- Administration and operation of other general services, such as centralized supply and purchasing services, maintenance and storage of government records and archives, operation of government-owned or -occupied buildings, central motor vehicle pools, government-operated printing offices, centralized computer and data processing services, etc.

Excludes: other general services connected with a specific function (classified according to function).

\section{BASIC RESEARCH}

Basic research is experimental or theoretical work undertaken primarily to acquire new knowledge of the underlying foundations of phenomena and observable facts, without any particular application or use in view.

\section{Basic research (CS)}

- Administration and operation of government agencies engaged in basic research

- Grants, loans, or subsidies to support basic research undertaken by nongovernment bodies such as research institutes and universities.

Excludes: applied research and experimental development (classified by function).

\section{R\&D GENERAL PUBLIC SERVICES}

Applied research is original investigation undertaken in order to acquire new knowledge, but directed primarily toward a specific practical aim or objective.

Experimental development is systematic work, drawing on existing knowledge gained from research and practical experience that is directed to producing new materials, products, and devices; to installing new processes, systems, and services; or to improving substantially those already produced or installed.

\section{R\&D General public services (CS)}

- Administration and operation of government agencies engaged in applied research and experimental development related to general public services

- Grants, loans, or subsidies to support applied research and experimental development related to general public services undertaken by nongovernment bodies, such as research institutes and universities.

Excludes: basic research (70140).

\section{GENERAL PUBLIC SERVICES N.E.C.}

\section{General public services n.e.c. (CS)}

- Administration, operation, or support of general public services, such as registration of voters, holding of elections and referendums, administration of nonself-governing and trust territories, etc.

Includes: general public services that cannot be assigned to (7011), (7012), (7013), (7014), or (7015).

Excludes: public debt transactions (7017); transfers of a general character between different levels of government (7018).

\section{PUBLIC DEBT TRANSACTIONS \\ 70170 Public debt transactions (CS)}

- Interest payments and expense for underwriting and floating government loans.

Excludes: administrative costs of public debt management (70112). 


\section{TRANSFERS OF A GENERAL CHARACTER BETWEEN DIFFERENT LEVELS OF GOVERNMENT}

\section{Transfers of a general character between different levels of government (CS)}

- Transfers between different levels of government that are of a general character and not allocated to a particular function.

\section{DEFENSE}

\section{MILITARY DEFENSE}

\section{Military defense (CS)}

- Administration of military defense affairs and services

- Operation of land, sea, air, and space defense forces; operation of engineering, transport, communication, intelligence, personnel, and other noncombat defense forces; operation or support of reserve and auxiliary forces of the defense establishment.

Includes: offices of military attachés stationed abroad; field hospitals.

Excludes: military aid missions (70230); base hospitals (7073); military schools and colleges where curricula resemble those of civilian institutions even though attendance may be limited to military personnel and their families (7091), (7092), (7093), or (7094); pension schemes for military personnel (7102).

\section{CIVIL DEFENSE}

\section{Civil defense (CS)}

- Administration of civil defense affairs and services; formulation of contingency plans; organization of exercises involving civilian institutions and populations

- Operation or support of civil defense forces.

Excludes: civil protection services (70320); purchase and storage of food, equipment, and other supplies for emergency use in the case of peacetime disasters (71090).

\section{FOREIGN MILITARY AID}

\section{Foreign military aid (CS)}

- Administration of military aid and operation of military aid missions accredited to foreign governments or attached to international military organizations or alliances
- Military aid in the form of grants (in cash or in kind), loans (regardless of interest charged), or loans of equipment; contributions to international peacekeeping forces, including the assignment of manpower.

\section{R\&D DEFENSE}

Definitions of basic research, applied research, and experimental development are given under (7014) and (7015).

\section{R\&D Defense (CS)}

- Administration and operation of government agencies engaged in applied research and experimental development related to defense

- Grants, loans, or subsidies to support applied research and experimental development related to defense undertaken by nongovernment bodies, such as research institutes and universities.

Excludes: basic research (70140).

\section{DEFENSE N.E.C.}

\section{Defense n.e.c. (CS)}

- Administration, operation, or support of activities such as formulation, administration, coordination, and monitoring of overall policies, plans, programs, and budgets relating to defense; preparation and enforcement of legislation relating to defense; production and dissemination of general information, technical documentation, and statistics on defense; etc.

Includes: defense affairs and services that cannot be assigned to (7021), (7022), (7023), or (7024).

Excludes: administration of war veterans' affairs (7102).

\section{PUBLIC ORDER AND SAFETY}

\section{POLICE SERVICES}

\section{Police services (CS)}

- Administration of police affairs and services, including alien registration, issuing work and travel documents to immigrants, maintenance of arrest records and statistics related to police work, road traffic regulation and control, prevention of smuggling, and control of offshore and ocean fishing

- Operation of regular and auxiliary police forces, of port, border, and coast guards, and of other 
special police forces maintained by public authorities; operation of police laboratories; operation or support of police training programs.

Includes: traffic wardens.

Excludes: police colleges offering general education in addition to police training (7091), (7092), (7093), or (7094).

\section{FIRE PROTECTION SERVICES 70320 Fire protection services (CS)}

- Administration of fire prevention and firefighting affairs and services

- Operation of regular and auxiliary fire brigades and of other fire prevention and firefighting services maintained by public authorities; operation or support of fire prevention and firefighting training programs.

Includes: civil protection services such as mountain rescue, beach surveillance, evacuation of flooded areas, etc.

Excludes: civil defense (70220); forces especially trained and equipped for fighting or preventing forest fires (70422).

\section{LAW COURTS}

\section{Law courts (CS)}

- Administration, operation, or support of civil and criminal law courts and the judicial system, including enforcement of fines and legal settlements imposed by the courts and operation of parole and probation systems

- Legal representation and advice on behalf of government or on behalf of others provided by government in cash or in services.

Includes: administrative tribunals, ombudsmen, and the like.

Excludes: prison administration (70340).

\section{PRISONS}

\section{Prisons (CS)}

- Administration, operation, or support of prisons and other places for the detention or rehabilitation of criminals such as prison farms, workhouses, reformatories, borstals, asylums for the criminally insane, etc.

\section{R\&D PUBLIC ORDER AND SAFETY}

Definitions of basic research, applied research, and experimental development are given under (7014) and (7015).

\section{R\&D Public order and safety (CS)}

- Administration and operation of government agencies engaged in applied research and experimental development related to public order and safety

- Grants, loans, or subsidies to support applied research and experimental development related to public order and safety undertaken by nongovernment bodies, such as research institutes and universities.

Excludes: basic research (70140).

\section{PUBLIC ORDER AND SAFETY N.E.C.} 70360 Public order and safety n.e.c. (CS)

- Administration, operation, or support of activities such as formulation, administration, coordination, and monitoring of overall policies, plans, programs, and budgets relating to public order and safety; preparation and enforcement of legislation and standards for the provision of public order and safety; production and dissemination of general information, technical documentation, and statistics on public order and safety.

Includes: public order and safety affairs and services that cannot be assigned to (7031), (7032), (7033), (7034), or (7035).

\section{ECONOMIC AFFAIRS}

\section{GENERAL ECONOMIC, COMMERCIAL,} AND LABOR AFFAIRS

\section{General economic and commercial affairs (CS)}

- Administration of general economic and commercial affairs and services, including general foreign commercial affairs; formulation and implementation of general economic and commercial policies; liaison among different branches of government and between government and business

- Regulation or support of general economic and commercial activities such as export and import trade as a whole, commodity and equity markets, overall income controls, general trade promotion 
activities, general regulation of monopolies and other restraints on trade and market entry, etc.; supervision of the banking industry

- Operation or support of institutions dealing with patents, trademarks, copyrights, company registration, weather forecasting, standards, hydrologic surveys, geodesic surveys, etc.

- Grants, loans, or subsidies to promote general economic and commercial policies and programs.

Includes: consumer education and protection.

Excludes: economic and commercial affairs of a particular industry (classified to (7042) through (7047) as appropriate).

\section{General labor affairs (CS)}

- Administration of general labor affairs and services; formulation and implementation of general labor policies; supervision and regulation of labor conditions (hours of work, wages, safety, etc.); liaison among different branches of government and between government and overall industrial, business, and labor organizations

- Operation or support of general programs or schemes to facilitate labor mobility, to reduce sex, race, age, and other discrimination, to reduce the rate of unemployment in distressed or underdeveloped regions, to promote the employment of disadvantaged or other groups characterized by high unemployment rates, etc.; operation of labor exchanges; operation or support of arbitration and mediation services

- Production and dissemination of general information, technical documentation, and statistics on general labor affairs and services

- Grants, loans, or subsidies to promote general labor policies and programs.

Excludes: labor affairs of a particular industry (classified to (7042) through (7047) as appropriate); provision of social protection in the form of cash benefits and benefits in kind to persons who are unemployed (71050).

\section{AGRICULTURE, FORESTRY, FISHING, AND HUNTING}

\section{Agriculture (CS)}

- Administration of agricultural affairs and services; conservation, reclamation, or expansion of arable land; agrarian reform and land settlement; supervision and regulation of the agricultural industry

- Construction or operation of flood control, irrigation, and drainage systems, including grants, loans, or subsidies for such works

- Operation or support of programs or schemes to stabilize or improve farm prices and farm incomes; operation or support of extension services or veterinary services to farmers, pest control services, crop inspection services, and crop grading services

- Production and dissemination of general information, technical documentation, and statistics on agricultural affairs and services

- Compensation, grants, loans, or subsidies to farmers in connection with agricultural activities, including payments for restricting or encouraging output of a particular crop or for allowing land to remain noncultivated.

Excludes: multipurpose development projects (70474).

\section{Forestry (CS)}

- Administration of forestry affairs and services; conservation, extension, and rationalized exploitation of forest reserves; supervision and regulation of forest operations and issuance of tree-felling licenses

- Operation or support of reforestation work, pest and disease control, forest firefighting and fire prevention services, and extension services to forest operators

- Production and dissemination of general information, technical documentation, and statistics on forestry affairs and services

- Grants, loans, or subsidies to support commercial forest activities.

Includes: forest crops in addition to timber.

\section{Fishing and hunting (CS)}

This class covers both commercial fishing and hunting, and fishing and hunting for sport. The fishing and hunting affairs and services listed here refer to activities that take place outside natural parks and reserves.

- Administration of fishing and hunting affairs and services; protection, propagation, and rationalized exploitation of fish and wildlife stocks; 
supervision and regulation of freshwater fishing, coastal fishing, ocean fishing, fish farming, wildlife hunting, and issuance of fishing and hunting licenses

- Operation or support of fish hatcheries, extension services, stocking or culling activities, etc.

- Production and dissemination of general information, technical documentation, and statistics on fishing and hunting affairs and services

- Grants, loans, or subsidies to support commercial fishing and hunting activities, including the construction or operation of fish hatcheries.

Excludes: control of offshore and ocean fishing (70310); administration, operation, or support of natural parks and reserves (70540).

\section{FUEL AND ENERGY}

\section{Coal and other solid mineral fuels (CS)}

This class covers coal of all grades, lignite, and peat, irrespective of the method used in their extraction or beneficiation, and the conversion of these fuels to other forms, such as coke or gas.

- Administration of solid mineral fuel affairs and services; conservation, discovery, development, and rationalized exploitation of solid mineral fuel resources; supervision and regulation of the extraction, processing, distribution, and use of solid mineral fuels

- Production and dissemination of general information, technical documentation, and statistics on solid mineral fuel affairs and services

- Grants, loans, or subsidies to support the solid mineral fuel industry and the coke, briquette, or manufactured gas industries.

Excludes: solid mineral fuel transportation affairs (classified to the appropriate class of group 7045).

\section{Petroleum and natural gas (CS)}

This class covers natural gas, liquefied petroleum gases and refinery gases, oil from wells or other sources, such as shale or tar sands, and the distribution of town gas regardless of its composition.

- Administration of petroleum and natural gas affairs and services; conservation, discovery, development, and rationalized exploitation of petroleum and natural gas resources; supervision and regulation of the extraction, processing, distribution, and use of petroleum and natural gas

- Production and dissemination of general information, technical documentation, and statistics on petroleum and natural gas affairs and services

- Grants, loans, or subsidies to support the petroleum extraction industry and the industry refining crude petroleum and related liquid and gaseous products.

Excludes: petroleum or gas transportation affairs (classified to the appropriate class of group 7045).

\section{Nuclear fuel (CS)}

- Administration of nuclear fuel affairs and services; conservation, discovery, development, and rationalized exploitation of nuclear material resources; supervision and regulation of the extraction and processing of nuclear fuel materials and of the manufacture, distribution, and use of nuclear fuel elements

- Production and dissemination of general information, technical documentation, and statistics on nuclear fuel affairs and services

- Grants, loans, or subsidies to support the nuclear materials mining industry and the industries processing such materials.

Excludes: nuclear fuel transportation affairs (classified to the appropriate class of group 7045); disposal of radioactive wastes (70510).

\section{Other fuels (CS)}

- Administration of affairs and services involving fuels, such as alcohol, wood and wood wastes, bagasse, and other noncommercial fuels

- Production and dissemination of general information, technical documentation, and statistics on availability, production, and utilization of such fuels

- Grants, loans, or subsidies to promote the use of such fuels for the production of energy.

Excludes: forest management (70422); wind and solar heat (70435) or (70436); geothermal resources (70436).

\section{Electricity (CS)}

This class covers both traditional sources of electricity, such as thermal or hydro supplies, and newer sources, such as wind or solar heat. 
- Administration of electricity affairs and services; conservation, development, and rationalized exploitation of electricity supplies; supervision and regulation of the generation, transmission, and distribution of electricity

- Construction or operation of nonenterprise-type electricity supply systems

- Production and dissemination of general information, technical documentation, and statistics on electricity affairs and services

- Grants, loans, or subsidies to support the electricity supply industry, including such expenditure for the construction of dams and other works, designed chiefly to provide electricity.

Excludes: nonelectric energy produced by wind or solar heat (70436).

\section{Nonelectric energy (CS)}

- Administration of nonelectric energy affairs and services that chiefly concern the production, distribution, and utilization of heat in the form of steam, hot water, or hot air

- Construction or operation of nonenterprise-type systems supplying nonelectric energy

- Production and dissemination of general information, technical documentation, and statistics on availability, production, and utilization of nonelectric energy

- Grants, loans, or subsidies to promote the use of nonelectric energy.

Includes: geothermal resources; nonelectric energy produced by wind or solar heat.

\section{MINING, MANUFACTURING, AND CONSTRUCTION \\ 70441 Mining of mineral resources other than mineral fuels (CS)}

This class covers metal-bearing minerals, sand, clay, stone, chemical and fertilizer minerals, salt, gemstones, asbestos, gypsum, etc.

- Administration of mining and mineral resource affairs and services; conservation, discovery, development, and rationalized exploitation of mineral resources; supervision and regulation of prospecting, mining, marketing, and other aspects of mineral production
- Production and dissemination of general information, technical documentation, and statistics on mining and mineral resource affairs and services

- Grants, loans, or subsidies to support commercial mining activities.

Includes: issuance of licenses and leases, regulation of production rates, inspection of mines for conformity to safety regulations, etc.

Excludes: coal and other solid fuels (70431), petroleum and natural gas (70432), and nuclear fuel materials (70433).

\section{Manufacturing (CS)}

- Administration of manufacturing affairs and services; development, expansion, or improvement of manufacturing; supervision and regulation of the establishment and operation of manufacturing plants; liaison with manufacturers' associations and other organizations interested in manufacturing affairs and services

- Production and dissemination of general information, technical documentation, and statistics on manufacturing activities and manufactured products

- Grants, loans, or subsidies to support manufacturing enterprises.

Includes: inspection of manufacturing premises for conformity with safety regulations, protection of consumers against dangerous products, etc.

Excludes: affairs and services concerning the coal processing industry (70431), the petroleum refinery industry (70432), or the nuclear fuel industry (70433).

\section{Construction (CS)}

- Administration of construction affairs and services; supervision of the construction industry; development and regulation of construction standards

- Production and dissemination of general information, technical documentation, and statistics on construction affairs and services.

Includes: issuance of certificates permitting occupancy, inspection of construction sites for conformity with safety regulations, etc.

Excludes: grants, loans, and subsidies for the construction of housing, industrial buildings, streets, public 
utilities, cultural facilities, etc. (classified according to function); development and regulation of housing standards (70610).

\section{TRANSPORT}

\section{Road transport (CS)}

- Administration of affairs and services concerning operation, use, construction, and maintenance of road transport systems and facilities (roads, bridges, tunnels, parking facilities, bus terminals, etc.)

- Supervision and regulation of road users (vehicle and driver licensing, vehicle safety inspection, size and load specifications for passenger and freight road transport, regulation of hours of work of bus, coach and lorry drivers, etc.), road transport system operations (granting of franchises, approval of freight tariffs and passenger fares, and of hours and frequency of service, etc.), and road construction and maintenance

- Construction or operation of nonenterprise-type road transport systems and facilities

- Production and dissemination of general information, technical documentation, and statistics on road transport system operations and on road construction activities

- Grants, loans, or subsidies to support the operation, construction, maintenance, or upgrading of road transport systems and facilities.

Includes: highways, urban roads, streets, bicycle paths, and footpaths.

Excludes: road traffic control (70310); grants, loans, and subsidies to road vehicle manufacturers (70442); street cleaning (70510); construction of noise embankments, hedges, and other anti-noise facilities, including the resurfacing of sections of urban highways with noise reducing surfaces (70530); street lighting (70640).

\section{Water transport (CS)}

- Administration of affairs and services concerning operation, use, construction, and maintenance of inland, coastal, and ocean water transport systems and facilities (harbors, docks, navigation aids and equipment, canals, bridges, tunnels, channels, breakwaters, piers, wharves, terminals, etc.)
- Supervision and regulation of water transport users (registration, licensing and inspection of vessels and crews, regulations concerning passenger safety and freight security, etc.), water transport system operations (granting of franchises, approval of freight tariffs and passenger fares, and of hours and frequency of service, etc.), and water transport facility construction and maintenance

- Construction or operation of nonenterprise-type water transport systems and facilities (such as ferries)

- Production and dissemination of general information, technical documentation, and statistics on water transport system operations and water transport facility construction activities

- Grants, loans, or subsidies to support the operation, construction, maintenance, or upgrading of water transport systems and facilities.

Includes: radio and satellite navigation aids; emergency rescue and towing services.

Excludes: grants, loans, and subsidies to shipbuilders (70442).

\section{Railway transport (CS)}

- Administration of affairs and services concerning operation, use, construction, or maintenance of railway transport systems and facilities (railway roadbeds, terminals, tunnels, bridges, embankments, cuttings, etc.)

- Supervision and regulation of railway users (rolling stock condition, roadbed stability, passenger safety, security of freight, etc.), railway transport system operations (granting of franchises, approval of freight tariffs and passenger fares, and of hours and frequency of service, etc.), and railway construction and maintenance

- Construction or operation of nonenterprise-type railway transport systems and facilities

- Production and dissemination of general information, technical documentation, and statistics on railway transport system operations and railway construction activities

- Grants, loans, or subsidies to support the operation, construction, maintenance, or upgrading of railway transport systems and facilities.

Includes: long-line and interurban railway transport systems, urban rapid transit railway transport systems, 
and street railway transport systems; acquisition and maintenance of rolling stock.

Excludes: grants, loans, and subsidies to rolling stock manufacturers (70442); construction of noise embankments, hedges, and other anti-noise facilities, including the resurfacing of sections of railways with noise reducing surfaces (70530).

\section{Air transport (CS)}

- Administration of affairs and services concerning operation, use, construction, and maintenance of air transport systems and facilities (airports, runways, terminals, hangars, navigation aids and equipment, air control amenities, etc.)

- Supervision and regulation of air transport users (registration, licensing, and inspection of aircraft, pilots, crews, ground crews, regulations concerning passenger safety, investigation of air transport accidents, etc.), air transport system operations (allocation of routes, approval of freight tariffs and passenger fares, and of frequency and levels of service, etc.), and air transport facility construction and maintenance

- Construction or operation of nonenterprise-type public air transport services and facilities

- Production and dissemination of general information, technical documentation, and statistics on air transport system operations and on air transport facility construction

- Grants, loans, or subsidies to support the operation, construction, maintenance, or upgrading of air transport systems and facilities.

Includes: radio and satellite navigation aids; emergency rescue services; scheduled and nonscheduled freight and passenger services; regulation and control of flying by private individuals.

Excludes: grants, loans, and subsidies to aircraft manufacturers (70442).

\section{Pipeline and other transport (CS)}

- Administration of affairs and services concerning operation, use, construction, and maintenance of pipeline and other transport systems (funiculars, cable cars, chairlifts, etc.)

- Supervision and regulation of users of pipeline and other transport systems (registration, licens- ing, inspection of equipment, operator skills and training, safety standards, etc.); pipeline and other transport systems operations (granting of franchises, setting tariffs, frequency, and levels of service, etc.), and pipeline and other transport systems construction and maintenance

- Construction or operation of nonenterprise-type pipeline and other transport systems

- Production and dissemination of general information, technical documentation, and statistics on the operation and construction of pipeline and other transport systems

- Grants, loans, or subsidies to support the operation, construction, maintenance, or upgrading of pipeline and other transport systems.

\section{COMMUNICATION \\ 70460 Communication (CS)}

- Administration of affairs and services concerning construction, extension, improvement, operation, and maintenance of communication systems (postal, telephone, telegraph, wireless, and satellite communication systems)

- Regulation of communication system operations (granting of franchises; assignment of frequencies, specification of markets to be served and tariffs to be charged, etc.)

- Production and dissemination of general information, technical documentation, and statistics on communication affairs and services

- Grants, loans, or subsidies to support the construction, operation, maintenance, or upgrading of communication systems.

Excludes: radio and satellite navigation aids for water transport (70452) and air transport (70454); radio and television broadcasting systems (70830).

\section{OTHER INDUSTRIES}

\section{Distributive trades, storage, and warehousing (CS)}

- Administration of affairs and services concerning the distributive trade and the storage and warehousing industry

- Supervision and regulation of wholesale and retail trade (licensing, sales practices, labeling of packaged food and other goods intended for household consumption, inspection of scales and other 
weighing machines, etc.) and the storage and warehousing industry (including licensing and control of government-bonded warehouses, etc.)

- Administration of price control and rationing schemes operating through retailers or wholesalers regardless of the type of goods involved or intended consumer; administration and provision of food and other such subsidies to the general public

- Production and dissemination of information to the trade and to the public on prices, the availability of goods, and other aspects of the distributive trade and the storage and warehousing industry; compilation and publication of statistics on the distributive trade and the storage and warehousing industry

- Grants, loans, or subsidies to support the distributive trade and to the storage and warehousing industry.

Excludes: administration of price and other controls applied to the producer (classified according to function); food and other such subsidies applicable to particular population groups or individuals (710).

\section{Hotels and restaurants (CS)}

- Administration of affairs and services concerning construction, extension, improvement, operation, and maintenance of hotels and restaurants

- Supervision and regulation of hotel and restaurant operations (regulations governing prices, cleanliness, and sales practices, hotel and restaurant licensing, etc.)

- Production and dissemination of general information, technical documentation, and statistics on hotel and restaurant affairs and services

- Grants, loans, or subsidies to support the construction, operation, maintenance, or upgrading of hotels and restaurants.

\section{Tourism (CS)}

- Administration of tourism affairs and services; promotion and development of tourism; liaison with the transport, hotel, and restaurant industries and other industries benefiting from the presence of tourists

- Operation of tourist offices at home and abroad, etc.; organization of advertising campaigns, in- cluding the production and dissemination of promotional literature and the like

- Compilation and publication of statistics on tourism.

\section{Multipurpose development projects (CS)}

Multipurpose development projects typically consist of integrated facilities for generation of power, flood control, irrigation, navigation, and recreation.

- Administration of affairs and services concerning construction, extension, improvement, operation, and maintenance of multipurpose projects

- Production and dissemination of general information, technical documentation, and statistics on multipurpose development project affairs and services

- Grants, loans, or subsidies to support the construction, operation, maintenance, or upgrading of multipurpose development projects.

Excludes: projects with one main function and other functions that are secondary (classified according to main function).

\section{R\&D ECONOMIC AFFAIRS}

Definitions of basic research, applied research, and experimental development are given under (7014) and (7015).

\section{R\&D General economic, commercial, and labor affairs (CS)}

- Administration and operation of government agencies engaged in applied research and experimental development related to general economic, commercial, and labor affairs

- Grants, loans, or subsidies to support applied research and experimental development related to general economic, commercial, and labor affairs undertaken by nongovernment bodies, such as research institutes and universities.

Excludes: basic research (70140).

\section{R\&D Agriculture, forestry, fishing, and hunting (CS)}

- Administration and operation of government agencies engaged in applied research and experimental development related to agriculture, forestry, fishing, and hunting 
- Grants, loans, or subsidies to support applied research and experimental development related to agriculture, forestry, fishing, and hunting undertaken by nongovernment bodies, such as research institutes and universities.

Excludes: basic research (70140).

\section{$70483 R \& D$ Fuel and energy (CS)}

- Administration and operation of government agencies engaged in applied research and experimental development related to fuel and energy

- Grants, loans, or subsidies to support applied research and experimental development related to fuel and energy undertaken by nongovernment bodies, such as research institutes and universities.

Excludes: basic research (70140).

\section{R\&D Mining, manufacturing, and construction (CS)}

- Administration and operation of government agencies engaged in applied research and experimental development related to mining, manufacturing, and construction

- Grants, loans, or subsidies to support applied research and experimental development related to mining, manufacturing, and construction undertaken by nongovernment bodies, such as research institutes and universities.

Excludes: basic research (70140).

\section{R\&D Transport (CS)}

- Administration and operation of government agencies engaged in applied research and experimental development related to transport

- Grants, loans, or subsidies to support applied research and experimental development related to transport undertaken by nongovernment bodies, such as research institutes and universities.

Excludes: basic research (70140).

\section{R\&D Communication (CS)}

- Administration and operation of government agencies engaged in applied research and experimental development related to communication

- Grants, loans, or subsidies to support applied research and experimental development related to communication undertaken by nongovernment bodies such as research institutes and universities.

Excludes: basic research (70140).

\section{R\&D Other industries (CS)}

- Administration and operation of government agencies engaged in applied research and experimental development related to other sectors

- Grants, loans, or subsidies to support applied research and experimental development related to other sectors undertaken by nongovernment bodies, such as research institutes and universities.

Includes: distributive trades, storage, and warehousing; hotels and restaurants; tourism and multipurpose development projects.

Excludes: basic research (70140).

\section{ECONOMIC AFFAIRS N.E.C.} 70490 Economic affairs n.e.c. (CS)

- Administration, operation, or support activities relating to general and sectoral economic affairs that cannot be assigned to (7041), (7042), (7043), (7044), (7045), (7046), (7047), or (7048).

\section{ENVIRONMENTAL PROTECTION}

The breakdown of environmental protection is based upon the Classification of Environmental Protection Activities (CEPA) as elaborated in the European System for the Collection of Economic Information on the Environment (SERIEE) of the Statistical Office of the European Communities (Eurostat).

\section{WASTE MANAGEMENT}

This group covers collection, treatment, and disposal of waste.

Waste collection includes sweeping of streets, squares, paths, markets, public gardens, parks, etc.; collection of all types of waste, whether selective by type of product or undifferentiated covering all waste, and their transport to place of treatment or discharge.

Waste treatment includes any method or process designed to change the physical, chemical, or biological character or composition of any waste so as to neutralize it, to render it nonhazardous, to make it safer for transport, to make it amenable for recovery or storage, or to reduce it in volume. 
Waste disposal includes final placement of waste for which no further use is foreseen by landfill, containment, underground disposal, dumping at sea, or any other relevant disposal method.

\section{Waste management (CS)}

- Administration, supervision, inspection, operation, or support of waste collection, treatment, and disposal systems

- Grants, loans, or subsidies to support the operation, construction, maintenance, or upgrading of such systems.

Includes: collection, treatment, and disposal of nuclear waste.

\section{WASTE WATER MANAGEMENT}

This group covers sewage system operation and waste water treatment.

Sewage system operation includes management and construction of the system of collectors, pipelines, conduits, and pumps to evacuate any waste water (rainwater, domestic, and other available waste water) from the points of generation to either a sewage treatment plant or to a point where waste water is discharged to surface water.

Waste water treatment includes any mechanical, biological, or advanced process to render waste water fit to meet applicable environment standards or other quality norms.

\section{Waste water management (CS)}

- Administration, supervision, inspection, operation, or support of sewage systems and waste water treatment

- Grants, loans, or subsidies to support the operation, construction, maintenance, or upgrading of such systems.

\section{POLLUTION ABATEMENT}

This group covers activities relating to ambient air and climate protection, soil and groundwater protection, noise and vibration abatement, and protection against radiation.

These activities include construction, maintenance, and operation of monitoring systems and stations (other than weather stations); construction of noise embankments, hedges, and other anti-noise facilities including the resurfacing of sections of urban highways or railways with noise reducing surfaces; measures to clean pollution in water bodies; measures to control or prevent the emissions of greenhouse gases and pollutants that adversely affect the quality of the air; construction, maintenance, and operation of installations for the decontamination of polluted soils and for the storage of pollutant products; transportation of pollutant products.

\section{Pollution abatement (CS)}

- Administration, supervision, inspection, operation, or support of activities relating to pollution abatement and control

- Grants, loans, or subsidies to support activities relating to pollution abatement and control.

\section{PROTECTION OF BIODIVERSITY AND LANDSCAPE}

This group covers activities relating to the protection of fauna and flora species (including the reintroduction of extinct species and the recovery of species menaced by extinction), the protection of habitats (including the management of natural parks and reserves), and the protection of landscapes for their aesthetic values (including the reshaping of damaged landscapes for the purpose of strengthening their aesthetic value and the rehabilitation of abandoned mines and quarry sites).

\section{Protection of biodiversity and landscape (CS)}

- Administration, supervision, inspection, operation, or support of activities relating to the protection of biodiversity and landscape

- Grants, loans, or subsidies to support activities relating to the protection of biodiversity and landscape.

\section{R\&D ENVIRONMENTAL PROTECTION}

Definitions of basic research, applied research, and experimental development are given under (7014) and (7015).

\section{R\&D Environmental protection (CS)}

- Administration and operation of government agencies engaged in applied research and 
experimental development related to environmental protection

- Grants, loans, or subsidies to support applied research and experimental development related to environmental protection undertaken by nongovernment bodies, such as research institutes and universities.

Excludes: basic research (70140).

7056 ENVIRONMENTAL PROTECTION N.E.C. 70560 Environmental protection n.e.c. (CS)

- Administration, management, regulation, supervision, operation, and support of activities such as formulation, administration, coordination, and monitoring of overall policies, plans, programs, and budgets for the promotion of environmental protection; preparation and enforcement of legislation and standards for the provision of environmental protection services; production and dissemination of general information, technical documentation, and statistics on environmental protection.

Includes: environmental protection affairs and services that cannot be assigned to (7051), (7052), (7053), (7054), or (7055).

\section{HOUSING AND COMMUNITY AMENITIES}

\section{HOUSING DEVELOPMENT}

\section{Housing development (CS)}

- Administration of housing development affairs and services; promotion, monitoring, and evaluation of housing development activities regardless of whether the activities are under the auspices of public authorities; development and regulation of housing standards

- Slum clearance related to provision of housing; acquisition of land needed for construction of dwellings; construction or purchase and remodeling of dwelling units for the general public or for people with special needs

- Production and dissemination of public information, technical documentation, and statistics on housing development affairs and services

- Grants, loans, or subsidies to support the expansion, improvement, or maintenance of the housing stock.

Excludes: development and regulation of construction standards (70443); cash benefits and benefits in kind to help households meet the cost of housing (71060).

\section{COMMUNITY DEVELOPMENT 70620 Community development (CS)}

- Administration of community development affairs and services; administration of zoning laws and land-use and building regulations

- Planning of new communities or of rehabilitated communities; planning the improvement and development of facilities such as housing, industry, public utilities, health, education, culture, recreation, etc. for communities; preparation of schemes for financing planned developments

- Production and dissemination of general information, technical documentation, and statistics on community development affairs and services.

Excludes: plan implementation-that is, the actual construction of housing, industrial buildings, streets, public utilities, cultural facilities, etc. (classified according to function); agrarian reform and land resettlement (70421); administration of construction standards (70443) and housing standards (70610).

\section{WATER SUPPLY \\ 70630 Water supply (CS)}

- Administration of water supply affairs; assessment of future needs and determination of availability in terms of such assessment; supervision and regulation of all facets of potable water supply including water purity, price, and quantity controls

- Construction or operation of nonenterprise-type of water supply systems

- Production and dissemination of general information, technical documentation, and statistics on water supply affairs and services

- Grants, loans, or subsidies to support the operation, construction, maintenance, or upgrading of water supply systems.

Excludes: irrigation systems (70421); multipurpose projects (70474); collection and treatment of waste water (70520). 
7064 STREET LIGHTING

\section{Street lighting (CS)}

- Administration of street lighting affairs; development and regulation of street lighting standards

- Installation, operation, maintenance, upgrading, etc. of street lighting.

Excludes: lighting affairs and services associated with the construction and operation of highways (70451).

\section{R\&D HOUSING AND COMMUNITY AMENITIES}

Definitions of basic research, applied research, and experimental development are given under (7014) and (7015).

\section{R\&D Housing and community amenities (CS)}

- Administration and operation of government agencies engaged in applied research and experimental development related to housing and community amenities

- Grants, loans, or subsidies to support applied research and experimental development related to housing and community amenities undertaken by nongovernment bodies, such as research institutes and universities.

Excludes: basic research (70140); applied research and experimental development into construction methods or materials (70484).

\section{HOUSING AND COMMUNITY AMENITIES N.E.C. \\ 70660 Housing and community amenities n.e.c. (CS)}

- Administration, operation, or support of activities such as formulation, administration, coordination, and monitoring of overall policies, plans, programs, and budgets relating to housing and community amenities; preparation and enforcement of legislation and standards relating to housing and community amenities; production and dissemination of general information, technical documentation, and statistics relating to housing and community amenities.

Includes: administration, operation, or support activities relating to housing and community amenities that cannot be assigned to (7061), (7062), (7063), (7064), or (7065).

\section{HEALTH}

Government expenditure on health includes expenditure on services provided to individual persons and services provided on a collective basis. Expenditure on individual services is allocated to groups (7071) through (7074); expenditure on collective services is assigned to groups (7075) and (7076).

Collective health services are concerned with matters such as formulation and administration of government policy; setting and enforcement of standards for medical and paramedical personnel and for hospitals, clinics, surgeries, etc.; regulation and licensing of providers of health services; and applied research and experimental development into medical and health-related matters. However, overhead expenditure connected with administration or functioning of a group of hospitals, clinics, surgeries, etc. is considered to be individual expenditure and is classified to groups (7071) through (7074) as appropriate.

\section{MEDICAL PRODUCTS, APPLIANCES, AND EQUIPMENT}

This group covers medicaments, prostheses, medical appliances and equipment, and other health-related products obtained by individuals or households, either with or without a prescription, usually from dispensing chemists, pharmacists, or medical equipment suppliers. They are intended for consumption or use outside a health facility or institution. Such products supplied directly to outpatients by medical, dental, and paramedical practitioners or to in-patients by hospitals and the like are included in outpatient services (7072) or hospital services (7073).

\section{Pharmaceutical products (IS)}

- Provision of pharmaceutical products such as medicinal preparations, medicinal drugs, patent medicines, serums and vaccines, vitamins and minerals, cod liver oil and halibut liver oil, oral contraceptives

- Administration, operation, or support of the provision of pharmaceutical products. 


\section{Other medical products (IS)}

- Provision of medical products such as clinical thermometers, adhesive and nonadhesive bandages, hypodermic syringes, first-aid kits, hotwater bottles and ice bags, medical hosiery items such as elasticized stockings and knee-pads, pregnancy tests, condoms, and other mechanical contraceptive devices

- Administration, operation, or support of the provision of prescribed other medical products.

\section{Therapeutic appliances and equipment (IS)}

- Provision of therapeutic appliances and equipment, such as corrective eyeglasses and contact lenses, hearing aids, glass eyes, artificial limbs and other prosthetic devices, orthopedic braces and supports, orthopedic footwear, surgical belts, trusses and supports, neck braces, medical massage equipment and health lamps, powered and unpowered wheelchairs and invalid carriages, "special" beds, crutches, electronic and other devices for monitoring blood pressure, etc.

- Administration, operation, or support of the provision of prescribed therapeutic appliances and equipment.

Includes: dentures but not fitting costs; repair of therapeutic appliances and equipment.

Excludes: hire of therapeutic equipment (70724).

\section{OUTPATIENT SERVICES}

This group covers medical, dental, and paramedical services delivered to outpatients by medical, dental, and paramedical practitioners and auxiliaries. The services may be delivered at home, in individual or group consulting facilities, dispensaries, or the outpatient clinics of hospitals and the like.

Outpatient services include the medicaments, prostheses, medical appliances and equipment, and other health-related products supplied directly to outpatients by medical, dental, and paramedical practitioners and auxiliaries.

Medical, dental, and paramedical services provided to in-patients by hospitals and the like are included in hospital services (7073).

\section{General medical services (IS)}

This class covers the services provided by general medical clinics and general medical practitioners.

General medical clinics are defined as institutions that chiefly provide outpatient services that are not limited to a particular medical specialty and that are chiefly delivered by qualified medical doctors. General medical practitioners do not specialize in a particular medical specialty.

- Provision of general medical services

- Administration, inspection, operation, or support of general medical services delivered by general medical clinics and general medical practitioners.

Excludes: services of medical analysis laboratories and $\mathrm{x}$-ray centers (70724).

\section{Specialized medical services (IS)}

This class covers the services of specialized medical clinics and specialist medical practitioners.

Specialized medical clinics and specialist medical practitioners differ from general medical clinics and general medical practitioners in that their services are limited to treatment of a particular condition, disease, medical procedure, or class of patient.

- Provision of specialized medical services

- Administration, inspection, operation, or support of specialized medical services delivered by specialized medical clinics and specialist medical practitioners.

Includes: services of orthodontic specialists.

Excludes: dental clinics and dentists (70723); services of medical analysis laboratories and $\mathrm{x}$-ray centers (70724).

\section{Dental services (IS)}

This class covers the services of general or specialist dental clinics and dentists, oral hygienists, or other dental operating auxiliaries.

Dental clinics provide outpatient services. They are not necessarily supervised or staffed by dentists; they may be supervised or staffed by oral hygienists or by dental auxiliaries.

- Provision of dental services to outpatients

- Administration, inspection, operation, and support of dental services delivered by general or 
specialist dental clinics and by dentists, oral hygienists, or other dental auxiliaries.

Includes: fitting costs of dentures.

Excludes: dentures (70713); services of orthodontic specialists (70722); services of medical analysis laboratories and $\mathrm{x}$-ray centers (70724).

\section{Paramedical services (IS)}

- Provision of paramedical health services to outpatients

- Administration, inspection, operation, or support of health services delivered by clinics supervised by nurses, midwives, physiotherapists, occupational therapists, speech therapists or other paramedical personnel and of health services delivered by nurses, midwives, and paramedical personnel in nonconsulting rooms, patients' homes, or other nonmedical institutions.

Includes: acupuncturists, chiropodists, chiropractors, optometrists, practitioners of traditional medicine, etc.; medical analysis laboratories and $\mathrm{x}$-ray centers; hire of therapeutic equipment; medically prescribed correctivegymnastic therapy; outpatient thermal bath or sea-water treatments; ambulance services other than ambulance services operated by hospitals.

Excludes: public health service laboratories (70740); laboratories engaged in determining the causes of disease (70750).

\section{HOSPITAL SERVICES}

Hospitalization is defined as occurring when a patient is accommodated in a hospital for the duration of the treatment. Hospital day care and home-based hospital treatment are included, as are hospices for terminally ill persons.

This group covers the services of general and specialist hospitals, the services of medical centers, maternity centers, nursing homes, and convalescent homes that chiefly provide in-patient services, the services of military base hospitals, the services of institutions serving old people in which medical monitoring is an essential component, and the services of rehabilitation centers providing in-patient health care and rehabilitative therapy where the objective is to treat the patient rather than to provide long-term support.
Hospitals are defined as institutions that offer inpatient care under direct supervision of qualified medical doctors. Medical centers, maternity centers, nursing homes, and convalescent homes also provide in-patient care, but their services are supervised and frequently delivered by staff of lower qualification than medical doctors.

The group does not cover facilities such as military field hospitals (7021), surgeries, clinics, and dispensaries devoted exclusively to outpatient care (7072), institutions for disabled persons and rehabilitation centers providing primarily long-term support (71012), or retirement homes for elderly persons (71020). Neither does it cover payments to patients for loss of income due to hospitalization (71011).

Hospital services include medicaments, prostheses, medical appliances and equipment, and other health-related products supplied to hospital patients. It also includes nonmedical expenditure of hospitals on administration, nonmedical staff, food and drink, accommodation (including staff accommodation), etc.

\section{General hospital services (IS)}

- Provision of general hospital services

- Administration, inspection, operation, or support of hospitals that do not limit their services to a particular medical specialty.

Excludes: medical centers not under the direct supervision of a qualified medical doctor (70733).

\section{Specialized hospital services (IS)}

Specialized hospitals differ from general hospitals in that their services are limited to treatment of a particular condition, disease, or class of patient-for example, diseases of the chest and tuberculosis, leprosy, cancer, otorhinolaryngology, psychiatry, obstetrics, pediatrics, and so forth.

- Provision of specialized hospital services

- Administration, inspection, operation, or support of hospitals that limit their services to a particular medical specialty.

Excludes: maternity centers not under the direct supervision of a qualified medical doctor (70733). 


\section{Medical and maternity center services (IS)}

- Provision of medical and maternity center services

- Administration, inspection, operation, or support of medical and maternity center services.

\section{Nursing and convalescent home services (IS)}

Nursing and convalescent homes provide in-patient services to persons recovering from surgery or a debilitating disease or condition that requires chiefly monitoring and administering of medicaments, physiotherapy, and training to compensate for loss of function or rest.

- Provision of nursing and convalescent home services

- Administration, inspection, operation, or support of nursing and convalescent home services.

Includes: institutions serving old people in which medical monitoring is an essential component; rehabilitation centers providing in-patient health care and rehabilitative therapy where the objective is to treat the patient rather than to provide long-term support.

\section{PUBLIC HEALTH SERVICES}

\section{Public health services (IS)}

- Provision of public health services

- Administration, inspection, operation, or support of public health services, such as bloodbank operation (collecting, processing, storing, shipping), disease detection (cancer, tuberculosis, venereal disease), prevention (immunization, inoculation), monitoring (infant nutrition, child health), epidemiological data collection, family planning services, and so forth

- Preparation and dissemination of information on public health matters.

- Includes: public health services delivered by special teams to groups of clients, most of whom are in good health, at workplaces, schools, or other nonmedical settings; public health services not connected with a hospital, clinic, or practitioner; public health services not delivered by medically qualified doctors; public health service laboratories.
Excludes: medical analysis laboratories (70724); laboratories engaged in determining the causes of disease (70750).

\section{R\&D HEALTH}

Definitions of basic research, applied research, and experimental development are given under (7014) and (7015).

\section{R\&D Health (CS)}

- Administration and operation of government agencies engaged in applied research and experimental development related to health

- Grants, loans, and subsidies to support applied research and experimental development related to health undertaken by nongovernment bodies, such as research institutes and universities.

Includes: laboratories engaged in determining the causes of disease.

Excludes: basic research (70140).

\section{HEALTH N.E.C.}

\section{Health n.e.c. (CS)}

- Administration, operation, or support of activities such as formulation, administration, coordination, and monitoring of overall health policies, plans, programs, and budgets; preparation and enforcement of legislation and standards for the provision of health services, including the licensing of medical establishments and medical and paramedical personnel; production and dissemination of general information, technical documentation, and statistics on health.

Includes: health affairs and services that cannot be assigned to (7071), (7072), (7073), (7074), or (7075).

\section{RECREATION, CULTURE, AND RELIGION}

Government expenditure on recreation, culture, and religion includes expenditure on services provided to individual persons and households and expenditure on services provided on a collective basis. Individual expenditure is allocated to groups (7081) and (7082); expenditure on collective services is assigned to groups (7083) to (7086).

Collective services are provided to the community as a whole. They include activities such as formulation 
and administration of government policy; formulation and enforcement of legislation and standards for providing recreational and cultural services; and applied research and experimental development into recreational, cultural, and religious affairs and services.

\section{RECREATIONAL AND SPORTING SERVICES}

\section{Recreational and sporting services (IS)}

- Provision of sporting and recreational services; administration of sporting and recreational affairs; supervision and regulation of sporting facilities

- Operation or support of facilities for active sporting pursuits or events (playing fields, tennis courts, squash courts, running tracks, golf courses, boxing rings, skating rinks, gymnasia, etc.); operation or support of facilities for passive sporting pursuits or events (chiefly specially equipped venues for playing cards, board games, etc.); operation or support of facilities for recreational pursuits (parks, beaches, camping grounds and associated lodging places furnished on a noncommercial basis, swimming pools, public baths for washing, etc.)

- Grants, loans, or subsidies to support teams or individual competitors or players.

Includes: facilities for spectator accommodation; national, regional, or local team representation in sporting events.

Excludes: zoological or botanical gardens, aquaria, arboreta, and similar institutions (70820); sporting and recreational facilities associated with educational institutions (classified to the appropriate class of Division 709).

\section{CULTURAL SERVICES}

\section{Cultural services (IS)}

- Provision of cultural services; administration of cultural affairs; supervision and regulation of cultural facilities

- Operation or support of facilities for cultural pursuits (libraries, museums, art galleries, theatres, exhibition halls, monuments, historic houses and sites, zoological and botanical gardens, aquaria, arboreta, etc.); production, operation, or support of cultural events (concerts, stage and film productions, art shows, etc.)

- Grants, loans, or subsidies to support individual artists, writers, designers, composers, and others working in the arts or to organizations engaged in promoting cultural activities.

Includes: national, regional, or local celebrations provided they are not intended chiefly to attract tourists.

Excludes: cultural events intended for presentation beyond national boundaries (70113); national, regional, or local celebrations intended chiefly to attract tourists (70473); production of cultural material intended for distribution by broadcasting (70830).

\section{BROADCASTING AND PUBLISHING SERVICES}

\section{Broadcasting and publishing services (CS)}

- Administration of broadcasting and publishing affairs; supervision and regulation of broadcasting and publishing services

- Operation or support of broadcasting and publishing services

- Grants, loans, or subsidies to support the construction or acquisition of facilities for television or radio broadcasting; the construction or acquisition of plant, equipment, or materials for newspaper, magazine, or book publishing; the production of material for, and its presentation by, broadcasting; the gathering of news or other information; the distribution of published works.

Excludes: government printing offices and plants (70133); provision of education by radio or television broadcasting (709).

\section{RELIGIOUS AND OTHER COMMUNITY SERVICES \\ 70840 Religious and other community services (CS)}

- Administration of religious and other community affairs

- Provision of facilities for religious and other community services, including support for their operation, maintenance, and repair

- Payment of clergy or other officers of religious institutions; support for the holding of religious 
services; grants, loans, or subsidies to support fraternal, civic, youth, and social organizations or labor unions, and political parties.

\section{R\&D RECREATION, CULTURE, AND RELIGION}

Definitions of basic research, applied research, and experimental development are given under (7014) and (7015).

\section{R\&D Recreation, culture, and religion (CS)}

- Administration and operation of government agencies engaged in applied research and experimental development related to recreation, culture, and religion

- Grants, loans, and subsidies to support applied research and experimental development related to recreation, culture, and religion undertaken by nongovernment bodies, such as research institutes and universities.

Excludes: basic research (70140).

\section{RECREATION, CULTURE, AND RELIGION N.E.C.}

\section{Recreation, culture, and religion n.e.c. (CS)}

- Administration, operation, or support of activities such as formulation, administration, coordination, and monitoring of overall policies, plans, programs, and budgets for the promotion of sport, recreation, culture, and religion; preparation and enforcement of legislation and standards for the provision of recreational and cultural services; production and dissemination of general information, technical documentation, and statistics on recreation, culture, and religion.

Includes: affairs and services relating to recreation, culture, and religion that cannot be assigned to (7081), (7082), (7083), (7084), or (7085).

\section{EDUCATION}

Government expenditure on education includes expenditure on services provided to individual pupils and students and expenditure on services provided on a collective basis. Expenditure on individual services is allocated to groups (7091) through (7096); expenditure on collective services is assigned to groups (7097) and (7098).
Collective educational services are concerned with matters such as formulation and administration of government policy; setting and enforcement of standards; regulation, licensing, and supervision of educational establishments; and applied research and experimental development into education affairs and services. However, overhead expenditure connected with administration or functioning of a group of schools, colleges, etc. is considered to be individual expenditure and is classified to groups (7091) through (7096) as appropriate.

The breakdown of education is based upon the level categories of the 1997 International Standard Classification of Education (ISCED-97) of the United Nations Educational, Scientific and Cultural Organization (UNESCO).

This division includes military schools and colleges where curricula resemble those of civilian institutions, police colleges offering general education in addition to police training, and the provision of education by radio or television broadcasting. Expenditure so incurred is classified to groups (7091) to (7095) as appropriate.

\section{PRE-PRIMARY AND PRIMARY EDUCATION}

\section{Pre-primary education (IS)}

- Provision of pre-primary education at ISCED-97 level 0

- Administration, inspection, operation, or support of schools and other institutions providing pre-primary education at ISCED-97 level 0.

Excludes: subsidiary services to education (70960).

\section{Primary education (IS)}

- Provision of primary education at ISCED-97 level 1

- Administration, inspection, operation, or support of schools and other institutions providing primary education at ISCED-97 level 1.

Includes: literacy programs for students too old for primary school.

Excludes: subsidiary services to education (70960).

\section{SECONDARY EDUCATION}

\section{Lower-secondary education (IS)}

- Provision of lower-secondary education at ISCED-97 level 2 
- Administration, inspection, operation, or support of schools and other institutions providing lower-secondary education at ISCED-97 level 2

- Scholarships, grants, loans, and allowances to support pupils pursuing lower-secondary education at ISCED-97 level 2.

Includes: out-of-school lower-secondary education for adults and young people.

Excludes: subsidiary services to education (70960).

\section{Upper-secondary education (IS)}

- Provision of upper-secondary education at ISCED-97 level 3

- Administration, inspection, operation, or support of schools and other institutions providing upper-secondary education at ISCED-97 level 3

- Scholarships, grants, loans, and allowances to support pupils pursuing upper-secondary education at ISCED-97 level 3.

Includes: out-of-school upper-secondary education for adults and young people.

Excludes: subsidiary services to education (70960).

\section{POST-SECONDARY NONTERTIARY EDUCATION}

\section{Post-secondary nontertiary education (IS)}

- Provision of post-secondary nontertiary education at ISCED-97 level 4

- Administration, inspection, operation, or support of institutions providing post-secondary nontertiary education at ISCED-97 level 4

- Scholarships, grants, loans, and allowances to support students pursuing post-secondary nontertiary education at ISCED-97 level 4.

Includes: out-of-school post-secondary nontertiary education for adults and young people.

Excludes: subsidiary services to education (70960).

\section{TERTIARY EDUCATION}

\section{First stage of tertiary education (IS)}

- Provision of tertiary education at ISCED-97 level 5

- Administration, inspection, operation, or support of universities and other institutions providing tertiary education at ISCED-97 level 5
- Scholarships, grants, loans, and allowances to support students pursuing tertiary education at ISCED-97 level 5.

Excludes: subsidiary services to education (70960).

\section{Second stage of tertiary education (IS)}

- Provision of tertiary education at ISCED-97 level 6

- Administration, inspection, operation, or support of universities and other institutions providing tertiary education at ISCED-97 level 6

- Scholarships, grants, loans, and allowances to support students pursuing tertiary education at ISCED-97 level 6.

Excludes: subsidiary services to education (70960).

\section{EDUCATION NOT DEFINABLE BY LEVEL}

\section{Education not definable by level (IS)}

- Provision of education not definable by level (i.e., educational programs, generally for adults, that do not require any special prior instruction, in particular, vocational training and cultural development)

- Administration, inspection, operation, or support of institutions providing education not definable by level

- Scholarships, grants, loans, and allowances to support students pursuing education programs not definable by level.

\section{SUBSIDIARY SERVICES TO EDUCATION}

\section{Subsidiary services to education (IS)}

- Provision of subsidiary services to education

- Administration, inspection, operation, or support of transportation, food, lodging, medical and dental care, and related subsidiary services chiefly for students regardless of level.

Excludes: school health monitoring and prevention services (70740); scholarships, grants, loans, and allowances in cash to defray the costs of subsidiary services (7091), (7092), (7093), (7094), or (7095).

\section{R\&D EDUCATION}

Definitions of basic research, applied research, and experimental development are given under (7014) and (7015). 


\section{R\&D Education (CS)}

- Administration and operation of government agencies engaged in applied research and experimental development related to education

- Grants, loans, and subsidies to support applied research and experimental development related to education undertaken by nongovernment bodies, such as research institutes and universities.

Excludes: basic research (70140).

\section{EDUCATION N.E.C.}

\section{Education n.e.c. (CS)}

- Administration, operation, or support of activities such as formulation, administration, coordination, and monitoring of overall educational policies, plans, programs, and budgets; preparation and enforcement of legislation and standards for the provision of education, including licensing of educational establishments; production and dissemination of general information, technical documentation, and statistics on education.

Includes: education affairs and services that cannot be assigned to (7091), (7092), (7093), (7094), (7095), (7096), or (7097).

\section{SOCIAL PROTECTION}

Government expenditure on social protection includes expenditure on services and transfers provided to individual persons and households and expenditure on services provided on a collective basis. Expenditure on individual services and transfers are allocated to groups (7101) through (7107); expenditure on collective services is assigned to groups (7108) and (7109).

Collective social protection services are concerned with matters such as formulation and administration of government policy; formulation and enforcement of legislation and standards for providing social protection; and applied research and experimental development into social protection affairs and services.

The social protection functions and their definitions are based on the 2008 European System of Integrated Social Protection Statistics (ESSPROS) of the Statistical Office of the European Communities (Eurostat).

In ESSPROS, social protection includes health care, but this division does not include health care. Health care is covered by Division 707. Hence, medical goods and services provided to persons who receive the cash benefits and benefits in kind specified in groups
(7101) through (7107) are classified under (7071), (7072), or (7073) as appropriate.

\section{SICKNESS AND DISABILITY}

\section{Sickness (IS)}

- Provision of social protection in the form of cash benefits or benefits in kind that replace in whole or in part loss of earnings during a temporary inability to work due to sickness or injury

- Administration, operation, or support of such social protection schemes

- Cash benefits, such as flat-rate or earningsrelated sick leave payments and miscellaneous payments provided to help persons temporarily unable to work due to sickness or injury

- Benefits in kind, such as assistance with daily tasks provided to persons temporarily unable to work due to sickness or injury (home help, transport facilities, etc.).

\section{Disability (IS)}

- Provision of social protection in the form of cash benefits or benefits in kind to persons who are fully or partially unable to engage in economic activity or lead a normal life due to a physical or mental impairment that is either permanent or likely to persist beyond a minimum prescribed period

- Administration, operation, or support of such social protection schemes

- Cash benefits, such as disability pensions paid to persons below the standard retirement age who encounter a disability that impairs their ability to work, early retirement benefits paid to older workers who retire before reaching the standard retirement age due to reduced capacity to work, care allowances, allowances paid to disabled persons undertaking work adapted to their condition or undergoing vocational training, and other periodic or lump-sum payments paid to disabled persons for social protection reasons

- Benefits in kind, such as lodging and possibly board provided to disabled persons in appropriate establishments, assistance provided to disabled persons to help them with daily tasks (home help, transport facilities, etc.), allowances paid to the person who looks after the disabled person, vocational and other training provided to further the occupational and social rehabilitation of disabled persons, and miscellaneous services and goods provided to disabled persons to enable them to 
participate in leisure and cultural activities or to travel or to participate in community life.

Excludes: cash benefits and benefits in kind paid to disabled persons on reaching the standard retirement age (71020).

\section{OLD AGE \\ 71020 Old age (IS)}

- Provision of social protection in the form of cash benefits and benefits in kind against the risks linked to old age (loss of income, inadequate income, lack of independence in carrying out daily tasks, reduced participation in social and community life, etc.)

- Administration, operation, or support of such social protection schemes

- Cash benefits, such as old-age pensions paid to persons on reaching the standard retirement age, anticipated old-age pensions paid to older workers who retire before the standard retirement age, partial retirement pensions paid either before or after the standard retirement age to older workers who continue working but reduce their working hours, care allowances, and other periodic or lump-sum payments paid upon retirement or on account of old age

- Benefits in kind, such as lodging and sometimes board provided to elderly persons either in specialized institutions or staying with families in appropriate establishments, assistance provided to elderly persons to help them with daily tasks (home help, transport facilities etc.), allowances paid to the person who looks after an elderly person, and miscellaneous services and goods provided to elderly persons to enable them to participate in leisure and cultural activities or to travel or to participate in community life.

Includes: pension schemes for military personnel and for government employees.

Excludes: early retirement benefits paid to older workers who retire before reaching standard retirement age due to disability (71012) or unemployment (71050).

\section{SURVIVORS}

\section{Survivors (IS)}

- Provision of social protection in the form of cash benefits and benefits in kind to persons who are survivors of a deceased person (such as the per- son's spouse, ex-spouse, children, grandchildren, parents, or other relatives)

- Administration, operation, or support of such social protection schemes

- Cash benefits, such as survivors' pensions, death grants, and other periodic or lump-sum payments to survivors

- Benefits in kind, such as payments toward funeral expenditure and miscellaneous services and goods provided to survivors to enable them to participate in community life.

\section{FAMILY AND CHILDREN}

\section{Family and children (IS)}

- Provision of social protection in the form of cash benefits and benefits in kind to households with dependent children

- Administration, operation, or support of such social protection schemes

- Cash benefits, such as maternity allowances, birth grants, parental leave benefits, family or child allowances, and other periodic or lumpsum payments to support households and help them meet the costs of specific needs (e.g., those of the lone parent families or families with handicapped children)

- Benefits in kind, such as shelter and board provided to preschool children during the day or part of the day, financial assistance toward payment of a nurse to look after children during the day, shelter and board provided to children and families on a permanent basis (orphanages, foster families, etc.), goods and services provided at home to children or to those who care for them, and miscellaneous services and goods provided to families, young people, or children (holiday and leisure centers).

Excludes: family planning services (70740).

\section{UNEMPLOYMENT}

\section{Unemployment (IS)}

- Provision of social protection in the form of cash benefits and benefits in kind to persons who are capable of work and available for work but are unable to find suitable employment

- Administration, operation, or support of such social protection schemes

- Cash benefits, such as full and partial unemployment benefits, early retirement benefits paid to 
older workers who retire before reaching the standard retirement age due to unemployment or job reduction caused by economic measures, allowances to targeted groups in the labor force who take part in training schemes intended to develop their potential for employment, redundancy compensation, and other periodic or lump-sum payments to the unemployed, particularly the long-term unemployed

- Benefits in kind, such as mobility and resettlement payments, vocational training provided to persons without a job or retraining provided to persons at risk of losing their job, and accommodation, food, or clothes provided to unemployed persons and their families.

Excludes: general programs or schemes directed toward increasing labor mobility, reducing the rate of unemployment or promoting the employment of disadvantaged or other groups characterized by high unemployment (70412); cash benefits and benefits in kind paid to unemployed persons on reaching the standard retirement age (71020).

\section{HOUSING}

\section{Housing (IS)}

- Provision of social protection in the form of benefits in kind to help households meet the cost of housing (recipients of these benefits are means-tested)

- Administration, operation, or support of such social protection schemes

- Benefits in kind, such as payments made on a temporary or long-term basis to help tenants with rent costs, payments to alleviate the current housing costs of owner-occupiers (i.e., to help with paying mortgages or interest), and provision of low-cost or social housing.

\section{SOCIAL EXCLUSION N.E.C.}

\section{Social exclusion n.e.c. (IS)}

- Provision of social protection in the form of cash benefits and benefits in kind to persons who are socially excluded or at risk of social exclusion (such as persons who are destitute, low-income earners, immigrants, indigenous people, refugees, alcohol and substance abusers, victims of criminal violence, etc.)

- Administration and operation of such social protection schemes
- Cash benefits, such as income support and other cash payments to the destitute and vulnerable persons to help alleviate poverty or assist in difficult situations

- Benefits in kind, such as short-term and longterm shelter and board provided to destitute and vulnerable persons, rehabilitation of alcohol and substance abusers, and services and goods to help vulnerable persons, such as counseling, day shelter, help with carrying out daily tasks, food, clothing, fuel, etc.

\section{R\&D SOCIAL PROTECTION}

Definitions of basic research, applied research, and experimental development are given under (7014) and (7015).

\section{R\&D Social protection (CS)}

- Administration and operation of government agencies engaged in applied research and experimental development related to social protection

- Grants, loans, and subsidies to support applied research and experimental development related to social protection undertaken by nongovernment bodies, such as research institutes and universities.

Excludes: basic research (70140).

\section{SOCIAL PROTECTION N.E.C.}

\section{Social protection n.e.c. (CS)}

- Administration, operation, or support of activities such as formulation, administration, coordination, and monitoring of overall social protection policies, plans, programs, and budgets; preparation and enforcement of legislation and standards for the provision of social protection; production and dissemination of general information, technical documentation, and statistics on social protection.

Includes: provision of social protection in the form of cash benefits and benefits in kind to victims of fires, floods, earthquakes, and other peacetime disasters; purchase and storage of food, equipment, and other supplies for emergency use in the case of peacetime disasters; other social protection affairs and services that cannot be assigned to (7101), (7102), (7103), (7104), (7105), (7106), (7107), or (7108). 


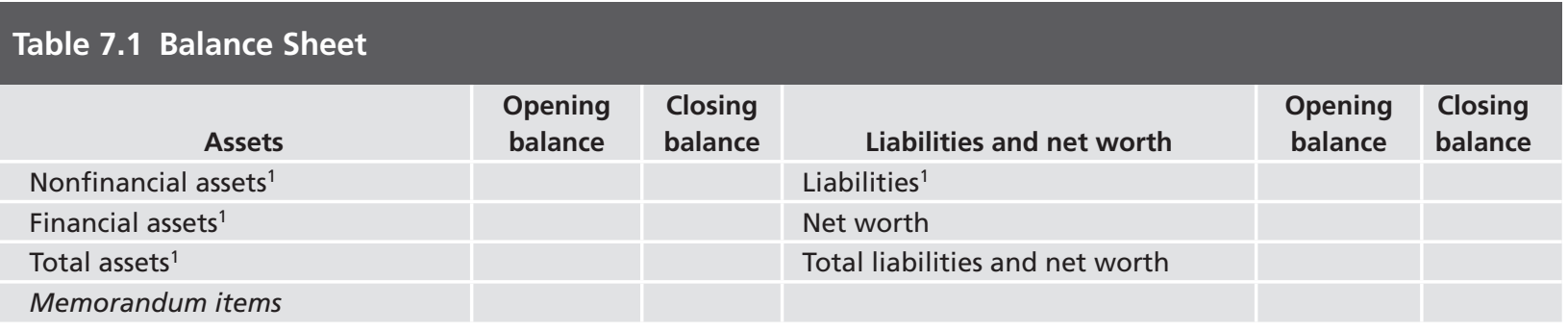

${ }^{1}$ Classified by categories of assets and liabilities as needed.

benefits associated with the resources. Only if such resources have a legal owner, either on an individual or collective basis, are they recognized in macroeconomic statistics.

- The economic owner of resources, such as goods and services, natural resources, financial assets, and liabilities, is the institutional unit entitled to claim the benefits associated with the use of these resources by virtue of accepting the associated risks.

7.6 As defined in paragraph 3.42, an asset is a store of value representing a benefit or series of benefits accruing to the economic owner by holding or using the resource over a period of time. It is a means of carrying forward value from one reporting period to another. Only economic assets are recorded in the macroeconomic statistical systems (i.e., included within the asset boundary), and they appear in the balance sheet of the unit that is the economic owner of the asset. Economic assets are those resources (i) over which economic ownership rights are enforced by institutional units, individually or collectively, and (ii) from which economic benefits may be derived by their owners by holding them or using them over a period of time (see paragraph 4.43).

7.7 Every economic asset provides benefits by functioning as a store of value. In addition:

- Some benefits are derived by using assets, such as buildings or machinery, in the production of goods and services.

- Some benefits consist of property income, such as interest, dividends, and rent receivable by the owners of financial assets, land, and other nonproduced assets.

7.8 When ownership rights are established and enforced, the resource is an economic asset regardless of who receives the benefits. For example, a government may own land in a national park with the intention that its benefits accrue directly to the community at large.

7.9 To be an economic asset, a resource must also be able to supply economic benefits given the technology, scientific knowledge, economic infrastructure, available resources, and relative prices existing at a given time or expected in the foreseeable future. Thus, a known deposit of minerals is an economic asset only if it is already commercially exploitable or is expected to become commercially exploitable in the foreseeable future.

7.10 Some resources are not economic assets if ownership rights over them have not been established or are not enforced. For example, it may not be feasible to establish ownership rights over the atmosphere and certain other naturally occurring assets. In other cases, ownership rights may be established, but it may not be feasible to enforce them, such as governmentowned land that is so remote or inaccessible that the government cannot exercise effective control over it or the government chooses not to enforce its ownership rights. In such cases, it can be a matter of judgment as to whether the degree of control exercised by the government is sufficient for the land to be classified as an economic asset. Nonetheless, even if ownership rights can be enforced, if the assets are not capable of bringing any economic benefits to their owners, they should be excluded.

7.11 Governments use assets to produce goods and services much like corporations. For example, office buildings, together with the services of government employees, office equipment, and other goods and services, are used to produce collective or individual services, such as general administrative services. In addition, however, governments often own assets whose services are consumed directly by the general 
public and assets that need to be preserved because of their historic or cultural importance. Thus, when the asset boundary is applied to the general government sector, it often incorporates a wider range of assets than is normally owned by a private organization. That is, government units frequently own:

- General-purpose assets, which are assets that other units would be likely to possess and use in similar ways, such as schools, road-building equipment, fire engines, office buildings, furniture, and computers

- Infrastructure assets, which are immovable nonfinancial assets that generally do not have alternative uses and whose benefits accrue to the community at large; examples are streets, highways, lighting systems, bridges, communication networks, canals, and dikes

- Heritage assets, which are assets that a government intends to preserve indefinitely because they have unique historic, cultural, educational, artistic, or architectural significance.

7.12 In some cases, governments can create economic assets by exercising their sovereign powers or other powers delegated to them. For example, a government may have the authority to assert ownership rights over naturally occurring assets that otherwise would not be subject to ownership, such as the electromagnetic spectrum and natural resources in international waters subject to designation as an exclusive economic zone. ${ }^{3}$ These assets are economic assets only if the government uses its authority to establish and enforce ownership rights.

7.13 Only actual (outstanding) liabilities (and their corresponding assets) are included in the balance sheet. Contingent assets and liabilities are not recognized as financial assets and liabilities prior to the condition(s) being fulfilled. Explicit contingent liabilities are discussed in paragraphs 7.251-7.260.

- Amounts set aside in business accounting as provisions to provide for a unit's future liabilities, either certain or contingent, or for a unit's future expenditures, are not recognized in the macroeconomic statistical systems. However, amounts accrued and not yet due for payment (such as

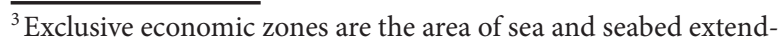
ing from the shore of a country claiming exclusive rights to them. employment-related pension "provisions") are liabilities.

- No liability is recognized on the balance sheet for government's implicit obligations to pay social security benefits, such as unemployment, old age pensions, and health care, in the future (see Appendix 2). However, it is recommended to include net implicit obligations for social security benefits as a memorandum item to the balance sheet (see paragraph 7.261).

- Lines of credit, letters of credit, and loan commitments assure funds will be made available in the future, but no financial asset (and liability) in the form of a loan is created until funds are actually advanced.

- Uncalled share capital is contingent until there is an obligation to pay the amount.

- Environmental liabilities, which are probable and measurable estimates of future environmental cleanup, closure, and disposal costs other than those included in costs of ownership transfer (see paragraphs 8.6-8.8), are not recognized. ${ }^{4}$

\section{Deriving Definitions for Assets and Liabilities}

7.14 This section defines liabilities and financial claims, from which it then derives the definitions of financial and nonfinancial assets.

7.15 As defined in paragraph 3.45 , a liability is established when one unit (the debtor) is obliged, under specific circumstances, to provide funds or other resources to another unit (the creditor). Normally, a liability is established through a legally binding contract that specifies the terms and conditions of the payment(s) to be made, and payment according to the contract is unconditional. Whenever a liability exists, the creditor has a corresponding financial claim on the debtor. A financial claim is an asset that typically entitles the owner of the asset (the creditor) to receive funds or other resources from another unit, under the terms of a liability. Like liabilities, financial claims are unconditional. Financial claims consist of

\footnotetext{
${ }^{4}$ An example is an agreement to perform cleanup (i.e., removal, containment, and disposal) of hazardous waste that resulted from government operations. Where terminal costs are part of costs of ownership transfer, these costs are written off through consumption of fixed capital over the whole life of the asset. Terminal costs are discussed in paragraphs 6.60 and 8.6.
} 
debt instruments (see paragraph 7.236), financial derivatives and employee stock options, and equity and investment fund shares.

- Debt instruments are financial instruments that typically are created when one unit provides funds or other resources (e.g., goods in the case of trade credit) to a second unit and the second unit agrees to provide a return in the future. Debt liabilities can also be created by the force of law, ${ }^{5}$ and by events that require future transfer of payments. ${ }^{6}$ For a liability to be considered debt it must exist and be outstanding.

- In contrast, financial derivatives are financial instruments of which the underlying contracts involve risk transfer. Thus, rather than supplying funds or other resources, a derivative contract shifts the exposure to the effect of a change in the value of an item between the parties, without a change in ownership of that item. Employee stock options share some of the risk elements of financial derivatives, but are also designed to be a form of remuneration.

- Equity and investment fund shares issued by corporations and similar legal forms of organization are treated as liabilities of the issuing units even though the holders of the claims do not have a fixed or predetermined monetary claim on the corporation. Equity and investment fund shares do, however, entitle their owners to benefits in the form of dividends and other ownership distributions, and they often are held with the expectation of receiving holding gains. In the event the issuing unit is liquidated, shares and other equities become claims on the residual value of the unit after the claims of all creditors have been met. If a public corporation has formally issued shares or another form of equity, then the shares are a liability of that corporation and an asset of the government or other unit that owns them. If a public corporation has not issued any type of share, then the value of other equity is estimated (see paragraph 7.173).

- Monetary gold in the form of bullion is not a financial claim, because it is not the liability of any

\footnotetext{
${ }^{5}$ These liabilities could include those arising from taxes, penalties (including penalties arising from commercial contracts), and judicial awards at the time they are imposed.

${ }^{6}$ These include claims on nonlife insurance companies, claims for damages not involving nonlife insurance companies, and claims arising from lottery and gambling activity.
}

other unit. Monetary gold does, however, provide economic benefits by serving as a store of value and a means of international payment to settle financial claims and finance other types of transactions. As a result, monetary gold in the form of bullion is, by convention, treated as a financial asset. Monetary gold in the form of unallocated gold accounts is a financial claim and, therefore, a liability of another unit in the form of currency and deposits (see paragraph 7.139).

7.16 Financial assets consist of financial claims plus gold bullion held by monetary authorities ${ }^{7}$ as a reserve asset.

7.17 Nonfinancial assets are economic assets other than financial assets. The main categories of nonfinancial assets are: produced assets (such as fixed assets, inventories, and valuables) and nonproduced assets (such as natural resources, contracts, leases, and licenses, and goodwill and marketing assets). Nonfinancial assets are stores of value and provide benefits either through their use in the production of goods and services or in the form of property income. Unlike financial claims, nonfinancial assets have no counterpart liability-that is, the owner of the nonfinancial asset does not have a claim on another institutional unit. Nonfinancial assets may come into existence as the output from a production process, or in other ways, such as natural occurrences.

7.18 Produced assets are classified as fixed assets, inventories, or valuables:

- Fixed assets are produced assets that are used repeatedly or continuously in production processes for more than one year. Fixed assets are discussed in paragraphs 7.35-7.74.

- Inventories are produced assets consisting of goods and services, which came into existence in the current period or in an earlier period, and that are held for sale, use in production, or other use at a later date. Inventories are discussed in paragraphs 7.75-7.86.

- Valuables are produced assets of considerable value that are not used primarily for purposes of production or consumption, but are held primarily

\footnotetext{
${ }^{7}$ Government units typically do not fulfill functions of monetary authorities and thus would not hold financial assets in the form of gold bullion.
} 
as stores of value over time. Valuables are discussed in paragraphs 7.87-7.89.

7.19 Naturally occurring assets and constructs of society are both referred to as nonproduced assets (see paragraph 7.90). Naturally occurring assets include land, subsoil mineral deposits, fish in open but territorial waters, and the radio spectrum when ownership rights are enforced. Constructs of society that are assets include some contracts, leases, and licenses, as well as goodwill and marketing assets.

\section{Valuation of Assets and Liabilities}

7.20 As discussed in paragraph 3.113 , stock positions of assets and liabilities should be valued at market value-that is, as if they were acquired in market transactions on the balance sheet reporting date (reference date). Therefore, the value of an asset at any given time is its current market value, which is the amount that would have to be paid to acquire the asset on the reporting date, taking into account its age, condition, and other relevant factors. This amount depends on the economic benefits that the owner of the asset can derive by holding or using it. The remaining benefits expected to be received from most assets diminish with the passage of time, which will reduce the value of the asset. The remaining benefits of some assets, such as valuables, may increase with the passage of time. The value of the remaining benefits may also increase or decrease because of changes in economic conditions.

7.21 In addition to current market value, the nominal value (see paragraph 3.115) of financial instruments is also useful for some purposes. This value is typically established by reference to the terms of a contract between the debtor and creditor. The nominal value of a debt instrument reflects the value of the debt at creation plus any subsequent economic flows, such as transactions (e.g., accrual of interest or repayment of principal), exchange rate and other valuation changes other than market price changes, ${ }^{8}$ and other volume changes.

7.22 The current market value for nonfinancial assets (except land) includes all costs of ownership transfer and for financial assets excludes these costs. For more details, see paragraphs 8.6-8.8.

\footnotetext{
${ }^{8}$ Accumulated revaluations arising from market price changes reconcile nominal value with market value.
}

7.23 The value of financial assets and liabilities denominated in foreign currencies should be converted to the domestic currency as discussed in paragraph 3.119.

7.24 Ideally, observable market prices should be used to value all assets and liabilities in a balance sheet. However, in estimating the current market price for balance sheet valuation, a price averaged over all transactions in a market can be used if the market is one on which the items in question are regularly, actively, and freely traded. When there are no observable prices because the items in question have not been purchased or sold on the market in the recent past, an attempt has to be made to estimate what the prices would be were the assets to be acquired on the market on the date to which the balance sheet relates. Such estimates may be obtained by (i) accumulating and revaluing transactions, or (ii) estimating the present value of future returns. These two methods, together with values observed in markets, are discussed in paragraphs 7.26-7.33.

7.25 The following paragraphs describe possible methods of estimating current market prices. Additional guidance on the valuation of specific types of assets and liabilities is included in the relevant parts of the section that describes the classification of assets and liabilities. Because the valuation of liabilities is the same as the valuation of the corresponding financial assets, in most cases, the remainder of this chapter will refer only to financial assets, but such references should be read as including liabilities equally. GFS compilers are typically not expected to independently derive the market values of assets and liabilities; they should evaluate what is available and how that information could be used in the GFS balance sheet.

\section{Value Observed in Markets}

7.26 The ideal source of price observations for valuing balance sheet items is a market, like the stock exchange, in which each asset traded is completely homogeneous, is often traded in considerable volume, and has its market price listed at regular intervals. Such markets yield data on prices that can be multiplied by indicators of quantity in order to compute the total market value of different classes of assets held by sectors and of different classes of their liabilities.

7.27 For securities quoted on a stock exchange, for example, it is feasible to gather the prices of individual assets and of broad classes of assets and, in addition, 
to determine the global valuation of all the existing securities of a given type. Debt securities traded (or tradable) in organized and other financial marketssuch as bills, bonds, debentures, negotiable certificates of deposits, asset-backed securities, etc.- - should be valued at market value and, in the case of liabilities, at nominal value as well. ${ }^{9}$ In some countries, another example of a market in which assets may be traded in sufficient numbers to provide useful price information is the market for existing dwellings.

7.28 If assets of the same kind are being produced and sold on the market, an existing asset may be valued at the current market price of a newly produced asset adjusted for consumption of fixed capital in the case of fixed assets, and any other differences between the existing asset and a newly produced asset. This adjustment for consumption of fixed capital should be calculated on the basis of the asset prices prevailing on the balance sheet reference date rather than the actual amounts previously recorded as an expense. ${ }^{10}$

7.29 In addition to providing direct observations on the prices of assets actually traded there, information from such markets may also be used to price similar assets that are not traded. For example, information from the stock exchange also may be used to price unlisted shares by analogy with similar, listed shares, making some allowance for the inferior marketability of the unlisted shares. Similarly, independent appraisals of assets for insurance or other purposes generally are based on observed prices for items that are close substitutes, although not identical, and this approach can be used for balance sheet valuation.

7.30 Debt instruments other than debt securities (as well as the corresponding financial assets in the form of debt instruments) are normally not traded and, therefore, lack generally observable market values. This means that these values have to be estimated by using the nominal value as a proxy (see paragraph 7.122). ${ }^{11}$

- Nontraded debt instruments: Debt instruments (as well as the corresponding financial assets in the form of debt instruments) not generally traded

\footnotetext{
${ }^{9}$ Nominal and market valuation are discussed in paragraphs 3.113-3.117. For a numerical examples on the calculation of interest and nominal value, see Boxes 2.3-2.5 in the PSDS Guide.

${ }^{10}$ Amounts previously recorded as expense are based on the average prices of the asset over the reporting period.

${ }^{11}$ See the PSDS Guide, Chapter 2.
}

(or tradable) in organized or other financial markets-namely, loans, currency and deposits, and other accounts payable/receivable-should be valued at nominal value. The nominal value of a debt instrument could be less than the originally advanced amount if there have been repayments of principal, debt forgiveness, or other economic flows (such as arising from indexation) that affect the value of the amount outstanding. The nominal value of a debt instrument could be more than originally advanced because of, for example, the accrual of interest or other economic flows.

- Debt instruments that do not accrue interest: For debt instruments (as well as the corresponding financial assets in the form of debt instruments) that do not accrue interest-for example, most trade credit and advances-the nominal value is the amount owed by the debtor to the creditor at the balance sheet date. If there is an unusually long time before payment is due on an outstanding debt liability on which no interest accrues, the value of the principal should be reduced by an amount that reflects the time to maturity and an appropriate existing contractual rate, such as for similar debt instruments (see also paragraph 3.118).

- Repayment specified in terms of commodities or other goods: For some instruments, such as a loan, repayment may be specified in a contract in terms of commodities or other goods deliverable in installments over a period of time. At inception, the value of the debt (as well as the corresponding financial assets in the form of debt instruments) is equal to the principal advanced. When payments are made in the form of the good or commodity, the value of the principal outstanding will be reduced by the market value of the good or commodity at the time the payment is made.

- Extinguishing a trade credit under barter arrangements: The value of the commodities, other goods, or services to be provided for extinguishing a trade credit liability (and the corresponding financial asset) under barter arrangements is established at the creation of the debt-that is, when the exchange of value occurred. However, as noted earlier, if there is an unusually long time before payment, the value of the principal should be reduced by an amount that reflects the time to 
maturity and an appropriate existing contractual rate, and interest should accrue until actual payment is made.

- Nontraded debt instruments with uncertain nominal values: For nontraded debt instruments (as well as the corresponding financial assets in the form of debt instruments) where the nominal value is uncertain, the nominal value can be calculated by discounting future interest and principal payments at an appropriate existing contractual rate of interest.

\section{Value Obtained by Accumulating and Revaluing Transactions}

7.31 In the absence of observable market prices, the balance sheet value of an asset may be obtained by accumulating and revaluing transactions. The values of most nonfinancial assets change, reflecting changes in market prices. At the same time, initial acquisition costs are reduced by consumption of fixed capital ${ }^{12}$ (in the case of fixed assets) or amortization or depletion $^{13}$ (in the case of other nonfinancial assets) over the expected life of the asset. In principle, the value of such a nonfinancial asset at a given point in its life is given by the current acquisition price of an equivalent new asset minus the accumulated consumption of fixed capital, amortization, or depletion. This valuation is referred to as the written-down replacement cost. When reliable, directly observed market prices for used assets are not available, applying this method gives a reasonable approximation of what the market price would be, were the asset offered for sale. For example, the principle could be applied as follows for these assets:

- In the absence of observed market values, most fixed assets are recorded in the balance sheet at their written-down replacement cost.

- Intangible nonproduced assets, such as goodwill and marketing assets, are typically valued at their initial acquisition costs minus an allowance for amortization. For this method, a pattern of decline must be chosen, which may be based on tax laws and accounting conventions.

- It may be possible to value subsoil and other naturally occurring assets at their initial acquisition

\footnotetext{
${ }^{12}$ See Box 6.1 for guidance on the calculation of consumption of fixed capital.

${ }^{13}$ See paragraph 10.52 .
}

costs (appropriately revalued using a relevant specific or commodity price index) minus an allowance for depletion.

7.32 The perpetual inventory method (PIM) is commonly used to estimate the written-down replacement cost of a category of assets, especially tangible fixed assets. With this method, the value of the stock is based on estimates of acquisitions and disposals that have been accumulated (after deduction of the accumulated consumption of fixed capital, amortization, or depletion) and revalued over a long enough period to cover the acquisition of all assets in the category. The PIM may be viewed as the macro equivalence of an asset register: the PIM does these calculations for large groups of assets, while an asset register does them for individual assets or asset types. ${ }^{14}$

\section{Present Value of Future Returns}

7.33 In some cases, current market prices may be approximated by the present value ${ }^{15}$ of the future economic benefits expected from a given asset. This method may be feasible for a number of financial assets, naturally occurring assets, and intangible assets. For example, timber and subsoil assets are assets whose benefits are normally receivable well in the future and/or spread over several years. Current prices can also be approximated by net present value when there are costs of bringing assets to the market. The economic benefit and costs can be discounted to estimate the net present value of the asset.

\section{Classification of Assets and Liabilities}

\section{Nonfinancial Assets (61) ${ }^{16}$}

7.34 At the first level of classification, there are four categories of nonfinancial assets. The first three categories are produced assets-fixed assets (611), inventories (612), and valuables (613) - and the fourth consists of all nonproduced assets (614). The summary

\footnotetext{
${ }^{14}$ For details on the PIM, see Organisation for Economic and Cooperation and Development, Measuring Capital-OECD Manual: Measurement of Capital Stocks, Consumption of Fixed Capital and Capital Services (Paris, 2009).

${ }^{15}$ Present value is the value today of a future payment or stream of payments discounted at some appropriate compounded interest rate. It is also referred to as the "time value of money" or "discounted cash flow."

${ }^{16}$ The numbers in parentheses after each classification category are the GFS classification codes. Appendix 8 provides all classification codes used in GFS.
} 


\begin{tabular}{|l|c|}
\hline Table 7.2 & Summary Classification of \\
Nonfinancial Assets
\end{tabular}

classification of nonfinancial assets is shown in Table 7.2; more detailed classifications of these categories are provided in the discussions of the various types of fixed assets, where relevant. ${ }^{17}$

\section{Fixed assets (611)}

7.35 Fixed assets (611) are produced assets that are used repeatedly or continuously in production processes for more than one year. The distinguishing feature of a fixed asset is not that it is durable in some physical sense, but that it may be used repeatedly or continuously in production over a long period of time, which is taken to be more than one year (by convention). Some goods, such as coal used as fuel, may be highly durable physically but cannot be fixed assets

\footnotetext{
${ }^{17}$ The classification of assets and liabilities in this chapter is supplemented by description of transactions in Chapters 8 and 9, while other economic flows related to these assets and liabilities are described in Chapter 10.
}

because they can be used only once. Fixed assets are further classified as buildings and structures (6111), machinery and equipment (6112), other fixed assets (6113), and weapons systems (6114).

7.36 In general, in the absence of observable market prices for used assets, the written-down replacement cost is used as a proxy for the current market value of fixed assets. In the remainder of this section, it is noted when a particular type of fixed asset is likely to be more accurately valued by another method.

7.37 The production of some fixed assets may span two or more reporting periods. These nonfinancial assets should be reflected on the balance sheet, in principle, when economic ownership changes, as evidenced by the transfer of risks and benefits associated with the asset. For high-value fixed assets such as ships, heavy machinery, and other equipment, ownership changes are recorded at the time agreed between the parties; for example, it could be a progressive change in line with stage payments, or in full on delivery. When a contract of sale is agreed in advance for the construction of buildings and structures, incomplete structures are being acquired in each period through progress payments and classified as fixed assets on the purchaser unit's balance sheet (i.e., the structure is being sold by the construction contractor to the purchaser in stages as the latter takes legal possession of the structure). When progress payments exceed the value of the incomplete asset, the excess should be recorded as a trade advance that will be exhausted as work proceeds. In the absence of a contract of sale, the incomplete structure is recorded as work in progress, and completed structures are recorded as finished goods, on the balance sheet of the unit doing the construction until ownership of the asset changes. Fixed assets being constructed on own account are treated as fixed assets rather than inventories of work in progress. These general principles also apply to the production of cultivated assets (see paragraph 7.62).

7.38 Fixed assets acquired under a financial leasemost likely machinery and equipment-are treated as if purchased and owned by the user or lessee (the economic owner) rather than the lessor (the legal owner). The acquisition is treated as being financed by a financial claim, classified as a loan. For example, if a bank purchases an airplane and then leases it to the national airline, the airplane is recorded as an asset of 
the airline and a loan is recorded as a liability of the airline and an asset of the bank. Financial leases are discussed in detail in paragraphs A4.10-A4.15.

7.39 A further consideration to be taken into account in determining ownership concerns fixed assets built under a public-private partnership (PPP) or a build, own, operate, and transfer (BOOT) scheme, sometimes also described as a private finance initiative (PFI), or some other similar shorthand. The statistical treatment is based on the economic ownership of the asset involved (see paragraph 7.5). PPPs are discussed in detail in paragraphs A4.58-A4.65. Also, immovable fixed assets, such as buildings and other structures within the economic territory, are deemed, by convention, to be owned by resident units (see paragraph 2.13).

7.40 Small/hand tools are excluded from the fixed asset boundary. Costs incurred on these inexpensive durable goods are recorded as use of goods and services (22) when such expenses are incurred regularly and are small compared with the costs incurred for the acquisition of machinery and equipment. But there can be circumstances when such small/hand tools are recorded as fixed assets (see paragraph 6.43).

\section{Buildings and structures (6111)}

7.41 Buildings and structures (6111) consist of dwellings (61111), buildings other than dwellings (61112), other structures (61113), and land improvements (61114), as shown in Table 7.3. The value of buildings and structures includes the costs of site clearance and preparation and the value of all fixtures, facilities, and equipment that are integral parts of the structures.

7.42 Public monuments in the form of buildings and structures are included here. Public monuments are identifiable because of particular historical, national, regional, local, religious, or symbolic significance. They are accessible to the general public,

\begin{tabular}{|l|l|}
\hline Table 7.3 & $\begin{array}{l}\text { Classification of Buildings and } \\
\text { Structures }\end{array}$ \\
\hline 6111 & Buildings and structures \\
61111 & Dwellings \\
61112 & Buildings other than dwellings \\
61113 & Other structures \\
61114 & Land improvements \\
\hline
\end{tabular}

and visitors are often charged for admission to the monuments or their vicinity. Public sector units typically use public monuments to produce cultural or entertainment-type services. In principle, public monuments should be included in dwellings, buildings other than dwellings, and other structures, as appropriate; in practice, it may be desirable to classify them with other structures when such a breakdown is not available. Consumption of fixed capital on new monuments, or on major improvements to existing monuments, should be calculated on the assumption of appropriately long service lives.

7.43 Public monuments can be valued directly, however, only when their significance has been recognized by someone other than the owner, typically by a sale or a formal appraisal. Newly constructed public monuments are valued at written-down replacement cost. Other than newly constructed monuments should be valued at the most recent sale price, updated, if need be, by a general price index. If no sale price is available, then an alternative valuation, such as an insurance appraisal or replacement cost (see paragraph 7.31), should be used.

\section{Dwellings (61111)}

7.44 Dwellings (61111) are buildings, or designated parts of buildings, that are used entirely or primarily as residences, including any associated structures, such as garages, and all permanent fixtures customarily installed in residences. Houseboats, barges, mobile homes, and caravans that are used as principal residences are also included, as are public monuments identified primarily as dwellings. Dwellings acquired by government for military personnel are included in this category because they are used in the same way as dwellings acquired by civilians. Incomplete dwellings are included to the extent that the ultimate user is deemed to have taken economic ownership, because the construction is on own account, the ultimate user assumed the risks and benefits of the asset, or as evidenced by the existence of a contract of sale or purchase.

7.45 For dwellings, there may be adequate information available from the sale of both new and existing buildings in equivalent private markets to assist in making balance sheet estimates of comparable price movements in the total value of public sector dwellings. However, these house prices depend to a 
considerable extent on location and may include land values. The geographical pattern of sales in the period may not cover all areas adequately, in which case a technique such as a PIM will have to be used (see paragraph 7.32). This technique will probably also apply to many other public buildings and structures since their characteristics are often specific to the structure concerned.

\section{Buildings other than dwellings (61112)}

7.46 Buildings other than dwellings (61112) include whole buildings or parts of buildings not designated as dwellings. Fixtures, facilities, and equipment that are integral parts of the structures are included. For new buildings, costs of site clearance and preparation are included.

7.47 Examples of types of buildings included in this category are office buildings, schools, hospitals, buildings for public entertainment, warehouses and industrial buildings, commercial buildings, hotels, and restaurants. Public monuments identified primarily as nonresidential buildings are also included. Prisons, schools, and hospitals are regarded as buildings other than dwellings despite the fact that they may shelter institutional households. Buildings and structures acquired for military purposes are included to the extent that they are used repeatedly, or continuously, in processes of production for more than one year.

\section{Other structures (61113)}

7.48 Other structures (61113) consist of all structures other than buildings. The costs of site clearance and preparation are also included. Public monuments are included if identification as dwellings or buildings other than dwellings is not possible. Also included are the construction of sea walls, dikes, flood barriers, etc. intended to improve the quality and quantity of land adjacent to them. The infrastructure necessary for aquaculture, such as fish farms and shellfish beds, is also included. Further examples are:

- Highways, streets, roads, bridges, elevated highways, tunnels, railways, subways, and airfield runways

- Sewers, waterways, harbors, dams, and other waterworks

- Shafts, tunnels, and other structures associated with mining mineral and energy resources
- Communication lines, power lines, long-distance pipelines, local pipelines, and cables

- Outdoor sport and recreation facilities

- Structures acquired for military purposes are included to the extent that they are used repeatedly, or continuously, in processes of production for more than one year.

\section{Land improvements (61114)}

7.49 Land improvements (61114) are the result of actions that lead to major improvements in the quantity, quality, or productivity of land, or prevent its deterioration. Activities such as land reclamation, land clearance, land contouring, and creation of wells and watering holes that are integral to the land in question are to be treated as resulting in land improvements. Seawalls, dikes, dams, and major irrigation systems that are in the vicinity of the land but not integral to it, which often affect land belonging to several owners and which are often carried out by government, are classified as other structures (61113).

7.50 Land improvements represent a category of fixed assets distinct from the nonproduced asset land (6141) as it existed before improvement. Unimproved land remains a nonproduced asset and as such is subject to holding gains and losses separately from price changes affecting the improvements. In cases where it is not possible to separate the value of the land before improvement and the value of those improvements, the asset should be allocated to the category that represents the greater part of the value.

7.51 The value of land improvements is shown as the written-down replacement cost of the improvements as originally carried out, suitably revalued to market prices. This is conceptually equal to the difference in value between the land concerned in an unimproved or natural state and its value after the improvements have been made, taking into account price changes. The costs of ownership transfer on all land are, by convention, included with land improvements. Consumption of fixed capital and the costs of ownership transfer are discussed in paragraphs 6.53-6.60.

\section{Machinery and equipment (6112)}

7.52 Machinery and equipment (6112) cover transport equipment, machinery for information, computer, and telecommunications (ICT) equipment, 
and machinery and equipment not elsewhere classified. Machinery and equipment forming an integral part of a building or other structure are included in the value of the building or structure rather than in machinery and equipment. Tools that are inexpensive and purchased at a relatively steady rate, such as hand tools, are not considered fixed assets unless they form a large share of the stock of machinery and equipment. As explained in paragraph 7.38, machinery and equipment under a financial lease are classified here because they are treated as being acquired by the user (lessee). Machinery and equipment acquired for military purposes other than weapons systems are classified under this category; weapons systems (6114) form a separate category (see paragraph 7.74).

7.53 Machinery and equipment are classified in two main categories: transport equipment (61121) and machinery and equipment other than transport equipment (61122), with a further breakdown of other machinery and equipment, as shown in Table 7.4.

\section{Transport equipment (61121)}

7.54 Transport equipment (61121) consists of equipment for moving people and objects, including motor vehicles, trailers and semitrailers, ships, railway locomotives and rolling stock, aircraft, motorcycles, and bicycles. Markets for existing automobiles, aircraft, and some other types of transportation equipment may be sufficiently representative to yield price observations that are superior to valuations at writtendown replacement cost.

\section{Machinery and equipment other than transport equipment (61122)}

7.55 This category consists of all machinery and equipment other than transport equipment. A dis-

\begin{tabular}{|c|c|} 
Table 7.4 & $\begin{array}{c}\text { Classification of Machinery and } \\
\text { Equipment }\end{array}$ \\
\hline 6112 & Machinery and equipment \\
61121 & $\begin{array}{l}\text { Transport equipment } \\
\text { Machinery and equipment other than } \\
61122\end{array}$ \\
\hline 611221 & $\begin{array}{l}\text { transport equipment } \\
\text { Information, computer, and } \\
\text { telecommunications (ICT) equipment } \\
\text { Machinery and equipment not } \\
\text { elsewhere classified }\end{array}$ \\
\hline 611222 & \\
\hline
\end{tabular}

tinction is made between information, computer, and telecommunications (ICT) equipment (611221) and machinery and equipment not elsewhere classified (611222).

\section{Information, computer, and telecommunications equipment (ICT) (611221)}

7.56 Information, computer, and telecommunications equipment (611221) consists of devices using electronic controls and also the electronic components forming part of these devices. Examples are products that form part of computing machinery and parts and accessories thereof, television and radio transmitters, television, video, and digital cameras, and telephone sets. In practice, this narrows the coverage of ICT equipment mostly to computer hardware and telecommunications equipment.

\section{Machinery and equipment not elsewhere classified (611222)}

7.57 This category includes all machinery and equipment not classified in any of the other machinery and equipment categories. ${ }^{18}$ Types of assets that would be included are general- and special-purpose machinery; office and accounting equipment; electrical machinery; medical appliances; precision and optical instruments; furniture; watches and clocks; musical instruments; and sports goods. It also includes paintings, sculptures, other works of art or antiques, and other collections of considerable value that are owned and displayed for the purpose of producing museum and similar services. Similar items owned primarily as stores of value that are not intended for use in production would be classified as valuables (see paragraphs 7.87-7.89). Also excluded from this category are inexpensive durable goods such as small/hand tools that are recorded as use of goods and services (22) (see paragraph 6.43).

\section{Other fixed assets (6113)}

7.58 Other fixed assets consist of cultivated biological resources (61131) and intellectual property products (61132), as shown in Table 7.5.

\footnotetext{
${ }^{18}$ All items under the United Nations' Central Product Classification (CPC), version 2.0, categories 43-48, are included here, except for categories 452 and 472, which are classified under Information, Computer, and Telecommunications (ICT) Equipment. For more details, see http://unstats.un.org/unsd/cr/registry/ cpc-2.asp.
} 


\section{Table 7.5 Classification of Other Fixed Assets}

\begin{tabular}{|c|c|}
\hline 6113 & Other fixed assets \\
\hline 61131 & Cultivated biological resources \\
\hline 611311 & $\begin{array}{l}\text { Animal resources yielding repeat } \\
\text { products }\end{array}$ \\
\hline 611312 & $\begin{array}{l}\text { Tree, crop, and plant resources yielding } \\
\text { repeat products }\end{array}$ \\
\hline 61132 & Intellectual property products \\
\hline 611321 & Research and development \\
\hline 611322 & Mineral exploration and evaluation \\
\hline 611323 & Computer software and databases \\
\hline 6113231 & Computer software \\
\hline 6113232 & Databases \\
\hline 611324 & $\begin{array}{l}\text { Entertainment, literary, and artistic } \\
\text { originals }\end{array}$ \\
\hline 611325 & Other intellectual property products \\
\hline
\end{tabular}

\section{Cultivated biological resources (61131)}

7.59 Cultivated biological resources (61131) cover animal resources yielding repeat products and tree, crop, and plant resources yielding repeat products whose natural growth and regeneration are under the direct control, responsibility, and management of institutional units.

7.60 Animal resources yielding repeat products (611311) include breeding stocks, dairy cattle, draft animals, sheep, or other animals used for wool production, animals used for transportation, racing, or entertainment, and aquatic resources yielding repeat products. Immature cultivated assets are excluded unless produced for own use. Animals raised for slaughter, including poultry, are not fixed assets but inventories.

7.61 Tree, crop, and plant resources yielding repeat products (611312) include trees (including vines and shrubs) cultivated for fruits and nuts, for sap and resin, and for bark and leaf products. Trees grown for timber that yield a finished product once only when they are ultimately felled are not fixed assets, but are included as inventories, just as grains or vegetables that produce only a single crop when they are harvested cannot be fixed assets.

7.62 In general, when the production of fixed assets takes a long time to complete, those assets for which production is not yet completed at the end of the reporting period are recorded as inventories in the form of work in progress. These general principles also apply to the production of cultivated assets, such as animals or trees that may take a long time to reach maturity. Two cases need to be distinguished from each other: the production of cultivated products by specialized producers, such as breeders or tree nurseries, and the own-account production of cultivated assets by their users:

- In the case of the specialist producers, animals or trees whose production is not yet complete and are not ready for sale or delivery are recorded as work in progress.

- However, when animals or trees intended to be used as fixed assets are produced on own account on farms or elsewhere, incomplete assets in the form of immature animals, trees, etc. not ready to be used in production are treated as the acquisition of fixed assets by the producing public sector unit in its capacity as eventual user and not as work in progress.

7.63 Only animals and plants cultivated under the direct control, responsibility, and management of institutional units are cultivated assets or inventories. Otherwise, they are nonproduced assets. Animals classified as cultivated biological resources usually can be valued on the basis of the current market prices for similar animals of a given age. Such information is less likely to be available for plants; more likely they will have to be valued at the written-down replacement cost.

\section{Intellectual property products (61132)}

7.64 Intellectual property products (61132) are the result of research, development, investigation, or innovation leading to knowledge that the developers can market or use to their own benefit in production because use of the knowledge is restricted by means of legal or other protection. The knowledge may be embodied in a free-standing product or may be embodied in another product. When the latter is the case, the product embodying the knowledge has an increased price relative to a similar product without this embodied knowledge. The knowledge remains an asset as long as its use can create some form of monopoly profits for its owner. When it is no longer protected or becomes outdated by later developments, it ceases to be an asset. Intellectual property products can be classified as:

- Research and development (611321)

- Mineral exploration and evaluation (611322) 
- Computer software and databases (611323)

- Entertainment, literary, and artistic originals (611324)

- Other intellectual property products (611325).

7.65 Some intellectual property products are used solely by the unit responsible for their development or by a single unit to whom the product is transferred. Mineral exploration and evaluation are an example. Other products, such as computer software and artistic originals, are used in two forms. The first is the original copy. This is frequently controlled by a single unit but exceptions exist, as explained in the remainder of this section. The original is used to make copies that are, in turn, supplied to other institutional units. The copies may be sold outright or made available under a license:

- A copy sold outright may be treated as a fixed asset if it satisfies the necessary conditions-that is, it will be used in production for a period in excess of one year.

- A copy made available under a license to use may also be treated as a fixed asset if it meets the necessary conditions-that is, if it is expected to be used in production for more than one year and the licensee assumes all the risks and rewards of ownership. A good indication, but not a necessary one, is if the license is purchased with a single payment for use over a multiyear period.

- If the acquisition of a copy with a license to use is purchased with regular payments over a multiyear contract and the licensee is judged to have acquired economic ownership of the copy, then it should be regarded as the acquisition of a fixed asset.

- If regular payments are made for a license to use without a long-term contract, then the payments are treated as payments for a service.

- If there is a large initial payment followed by a series of smaller payments in succeeding years, the initial payment is recorded as the net acquisition of a fixed asset and the succeeding payments are treated as payments for a service.

- If the license allows the licensee to reproduce the original and subsequently assume responsibility for the distribution, support, and maintenance of these copies, then this is described as a license to reproduce and should be regarded as the sale of part or whole of the original to the unit holding the license to reproduce.

7.66 Research and development (611321) consists of the value of expenditure on creative work undertaken on a systematic basis in order to increase the stock of knowledge, including knowledge of man, culture, and society, and use of this stock of knowledge to devise new applications. It does not extend to including human capital as assets within GFS and other macroeconomic statistics. The value of research and development should be determined in terms of the economic benefits it is expected to provide in the future. This value includes the provision of public services in the case of research and development acquired by government. In principle, research and development that does not provide an economic benefit to its owner does not constitute a fixed asset and should be treated as an expense. Only research and development that meets the criteria to be a nonfinancial asset should be included in this category. ${ }^{19}$

7.67 Unless the market value of the research and development is observed directly, it may, by convention, be valued at the sum of costs, including the cost of unsuccessful research and development. More specifically, research and development undertaken by government units, universities, nonprofit research institutes, etc. is nonmarket production and should be valued on the basis of the total costs incurred, excluding a return to capital used. Research and development expenditure carried out on contract is valued at the contract price. If carried out on own account, it is valued as cumulated costs. If it is carried out by a public corporation, the costs include a return to capital. These valuations need to be increased for changes in prices and reduced because of consumption of fixed capital over the life of the asset. With the inclusion of research and development in the asset boundary, patented resources are no longer considered as a form of nonproduced assets. ${ }^{20}$

\footnotetext{
${ }^{19}$ For further guidance on the practical measurement of research and development, see Organisation for Economic and Co-operation and Development, Handbook on Deriving Capital Measures of Intellectual Property Products (Paris, 2010).

${ }^{20}$ The patent agreement is to be seen as the legal agreement concerning the terms on which access by third parties to research and development is granted. The patent agreement is a form of license to use, which is treated as payments for service or the acquisition of assets. See discussions on contracts, leases, and licenses (61441) in paragraph 7.105 and in Appendix 4.
} 
7.68 Mineral exploration and evaluation (611322) consist of the value of expenditure on exploration for petroleum and natural gas and for nonpetroleum deposits and subsequent evaluation of the discoveries made. The information obtained from exploration influences the production activities of those who obtain it over a number of years. Mineral exploration and evaluation should be valued either on the basis of the amounts payable under contracts awarded to other institutional units for the purpose or on the basis of the costs incurred for exploration undertaken on own account. These costs should include a return to the fixed capital used in the exploration activity. In addition to the costs of actual test drilling and boring, mineral exploration includes any prelicense, license, acquisition, and appraisal costs, the costs of aerial and other surveys, and transportation and other costs incurred to make the exploration possible. The value of the resulting asset is not measured by the value of new deposits discovered by the exploration but by the value of the resources allocated to exploration during the reporting period. Exploration undertaken in the past whose value has not yet been fully written off should be revalued to the prices and costs of the current period.

7.69 Computer software and databases (611323) are grouped together because a computerized database cannot be developed independently of a database management system that is itself computer software. This category can be further divided into computer software (6113231) and databases (6113232).

7.70 Computer software (6113231) includes computer programs, program descriptions, and supporting materials for both systems and applications software that is expected to be used for more than one year. The software may be purchased from other units or developed on own account and may be intended only for own use or may be intended for sale by means of copies. Databases (6113232) consist of files of data organized in such a way as to permit resource-effective access and use of the data. These expenditures on the purchase, development, or extension of computer databases are assets when expected to be used in production for more than one year.

7.71 The value of computer software and databases (611323) should be based on the amount payable if acquired from another unit or on the costs of pro- duction (including a return to capital if produced by a public corporation) if produced on own account. Software and databases acquired in previous years and not yet fully written off should be revalued to current prices.

7.72 Entertainment, literary, and artistic originals (611324) are original films, sound recordings, manuscripts, tapes, and models in which drama performances, radio and television programming, musical performances, sporting events, and literary and artistic output are recorded or embodied. They should be valued at their current market price when they are actually traded. Otherwise, they should be valued either on the basis of their acquisition price or costs of production (including a return to capital if produced by a public corporation), revalued to the prices of the current period and written down, or on the basis of the present value of the expected future receipts.

7.73 Other intellectual property products (611325) consist of new information and specialized knowledge not elsewhere classified, the use of which is restricted to the units that have established ownership rights over the information or to other units licensed by the owners. The assets should be valued at their current written-down replacement cost or the present value of expected future receipts.

\section{Weapons systems (6114)}

7.74 Weapons systems (6114) include vehicles and other equipment, such as warships, submarines, military aircraft, tanks, missile carriers and launchers, etc. Weapons systems are treated as fixed assets. The military weapons systems comprising specialized vehicles and other equipment, such as warships, submarines, military aircraft, tanks, missile carriers and launchers, etc., are used continuously in the provision of defense services, even if their peacetime use is simply to provide deterrence. Therefore, military weapons systems should be classified as fixed assets and this classification of military weapons systems as fixed assets should be based on the same criteria as for other fixed assets-that is, produced assets that are themselves used repeatedly, or continuously, in processes of production for more than one year. Most single-use weapons they deliver, such as ammunition, missiles, rockets, bombs, etc., are treated as military inventories (61225) (see paragraphs 7.86 and 6.49). However, 
some single-use items, such as certain types of ballistic missiles with a highly destructive capability, may provide an ongoing service of deterrence against aggressors and therefore meet the general criteria for classification as fixed assets. Weapons systems are valued at their written-down replacement cost.

\section{Inventories (612)}

7.75 Inventories (612) are produced assets consisting of goods and services, which came into existence in the current period or in an earlier period, and that are held for sale, use in production, or other use at a later date. Inventories are classified as materials and supplies (61221), work in progress (61222), finished goods (61223), goods for resale (61224), and military inventories (61225), as shown in Table 7.6. Each of these types of inventories has a different economic function.

\subsection{Inventories consist of stocks of:}

- Goods that are still held by the units that produced them prior to their being further processed, sold, delivered to other units, or used in other ways

- Products acquired from other units that are intended to be used in the production of market and nonmarket goods and services by units, or for resale without further processing

- Strategic stocks that are goods held for strategic and emergency purposes, goods held by market regulatory organizations, and other goods of special importance to the nation, such as grain, military inventories, and petroleum.

7.77 Inventories may include services consisting of work in progress or finished products-for example, architectural drawings that are in the process of completion or are completed and waiting for the building to which they relate to be started.

7.78 Inventories should be valued at their current market prices on the balance sheet date rather than

\section{Table 7.6 Classification of Inventories}

\begin{tabular}{l|l}
612 & Inventories \\
61221 & Materials and supplies \\
61222 & Work in progress \\
61223 & Finished goods \\
61224 & Goods for resale \\
61225 & Military inventories
\end{tabular}

their acquisition prices. In principle, current market prices should be available for most types of inventories, but in practice, the values of inventories frequently are estimated by adjusting book or acquisition values of inventories with the aid of price indexes.

\section{Materials and supplies (61221)}

7.79 Materials and supplies (61221) consist of all goods held with the intention of using them as inputs to a production process. Public sector units may hold a variety of goods as materials and supplies, including office supplies, fuel, and foodstuffs. Every public sector unit may be expected to hold some materials and supplies, if only office supplies. Materials and supplies often can be valued on the basis of the current market prices for the same goods.

\section{Work in progress (61222)}

7.80 Work in progress (61222) consists of goods and services that are not yet sufficiently processed to be in a state in which it is normally supplied to other institutional units. General government units that primarily produce nonmarket services are likely to have little or no work in progress, as the production of most such services is completed in a short time span or continuously. Work in progress must be recorded for any output that is not complete at the end of the reporting period, such as construction. The only exceptions to recording incomplete work as work in progress are for partially completed projects for which the ultimate owner is deemed to have taken economic ownership in stages (see paragraph 7.37). Economic ownership conveys in stages when the production is for own use, the new owner assumes the risks and benefits associated with the incomplete asset, or when evidenced by specific clauses in a contract of sale or purchase. In these exceptions, the partially complete products are recorded as the acquisition of fixed assets rather than work in progress.

7.81 Work in progress can take a wide variety of different forms, ranging from growing crops to developing computer programs. Although work in progress is output that has not reached the state in which it is normally supplied to others, its ownership is nevertheless transferable, if necessary. ${ }^{21}$

\footnotetext{
${ }^{21}$ For example, it may be sold under exceptional circumstances, such as the liquidation of a public sector unit.
} 
7.82 Work in progress inventories are valued on the basis of the cost of production at current prices as of the balance sheet date. The value of standing timber and other cultivated crops may be estimated by discounting the future proceeds of selling the final product at current prices and the expenses of bringing the product to maturity.

\section{Finished goods (61223)}

7.83 Finished goods (61223) consist of goods that are the output of a production process, are still held by their producer, and are not expected to be processed further by the producer before being supplied to other units. Finished goods may be held only by the units that produce them. General government units will have finished goods only if they produce goods for sale or transfer to other units. Inventories of finished goods are valued at their current sales value (before adding any taxes, transport, or distribution charges) or at the cost to produce them currently (i.e., their current replacement prices).

\section{Goods for resale (61224)}

7.84 Goods for resale (61224) are goods acquired for the purpose of reselling or transferring to other units without being further processed. Goods for resale may be transported, stored, graded, sorted, washed, or packaged by their owners to present them for resale in ways that are attractive to their customers or beneficiaries, but they are not otherwise transformed. Any general government unit that sells goods for economically significant prices, such as a museum gift shop, is likely to possess an inventory of goods for resale. This category also includes goods purchased by general government units for provision free of charge or at prices that are not economically significant to other units. Goods acquired by government for distribution as social transfers in kind but that have not yet been so delivered are also included in goods for resale.

7.85 Inventories of goods intended for resale are valued at their current replacement prices.

\section{Military inventories (61225)}

7.86 Military inventories (61225) consist of single-use items, such as ammunition, missiles, rockets, bombs, etc., delivered by weapons or weapons systems. As noted in paragraph 7.74, in the discussion of weapons systems as fixed assets, most single-use items are treated as inventories, but some types of missiles with highly destructive capability may be treated as fixed assets. Military inventories are valued at their current replacement prices.

\section{Valuables (613)}

7.87 Valuables (613) are produced assets of considerable value that are not used primarily for purposes of production or consumption but are held as stores of value over time. They are expected to appreciate, or at least not to decline, in real value, and they do not deteriorate over time under normal conditions.

7.88 Included in valuables are:

- Nonmonetary gold and other precious stones and metals that are not intended to be used as materials and supplies in the processes of production

- Paintings, sculptures, and other objects recognized as works of art or antiques held primarily as stores of value over time

- Jewelry of significant value fashioned out of precious stones and metals, collections, and miscellaneous other valuables.

Many items fitting the description of a valuable that are owned by general government units will be classified as machinery and equipment not elsewhere classified (611222) because they are not held primarily as stores of value but used in production, such as by being displayed in government museums. (See also paragraph 7.57.)

7.89 To the extent that there are well-organized markets for valuables, they can be valued at current market prices, including any costs of ownership transfer, such as agents' fees or commissions. Otherwise, the amounts for which they are insured against fire, theft, and other risks may be appropriate.

\section{Nonproduced assets (614)}

7.90 Nonproduced assets consist of tangible, naturally occurring assets-natural resources-over which ownership rights are enforced, and intangible nonproduced assets (6144) that are constructs of society. Natural resources comprise land (6141), mineral and energy resources (6142), and other naturally occurring assets (6143). If ownership rights have not or cannot be enforced over naturally occurring resources, then they are not economic assets. 
7.91 All immovable nonproduced assets such as land and other natural resources within the economic territory are deemed, by convention, to be owned by resident units (see paragraph 2.13).

\section{Land (6141)}

7.92 Land (6141) consists of the ground, including the soil covering and any associated surface waters, over which ownership rights are enforced and from which economic benefits can be derived by their owners by holding or using them. The associated surface water includes any reservoirs, lakes, rivers, and other inland waters over which ownership rights can be exercised and that can, therefore, be the subject of transactions between units. However, water bodies from which water is regularly extracted, against payment, for use in production (including for irrigation) are included not in water associated with land but in water resources (61432).

7.93 Land excludes the following:

- Buildings and other structures constructed on the land or through it, such as roads, office buildings, and tunnels

- Land improvements and the costs of ownership transfer on land

- Cultivated components of vineyards, orchards, and other plantations of trees, animals, and crops

- Subsoil assets

- Noncultivated biological resources

- Water resources below the ground.

7.94 Land is valued at its current price that would be payable by a new owner, excluding the costs of ownership transfer. By convention, the costs of ownership transfer on land are recorded as the net investment in fixed assets as part of land improvements and are subject to consumption of fixed capital. The value of land can vary enormously depending on its location and the uses for which it is suitable or sanctioned. As a result, these factors must be taken into account when the current market price for the land is determined. In a number of instances, it may be difficult to separate the value of land from the value of structures erected on the land:

- One method of estimating the value of land separately is to calculate ratios of the value of the site to the value of the structure from valuation ap- praisals and to deduce the value of land from the replacement cost of the buildings or from the value on the market of the combined land and buildings.

- When the value of land cannot be separated from the building, structure, plantation, vineyard, etc., above it, the composite asset should be classified in the category representing the greater part of its value.

- Similarly, if the value of the land improvements (which include site clearance, preparation for the erection of buildings or planting of crops, and costs of ownership transfer) cannot be separated from the value of land in its natural state, the value of the land may be allocated to one category or the other, depending on which is assumed to represent the greater part of the value.

7.95 Land appears on the balance sheet of the legal owner except when the land is not separable from other assets that are subject to a financial lease. This may most often occur in connection with a financial lease over a building or plantation on the land, when the inseparable assets, including land, are on the balance sheet of the economic owner. ${ }^{22}$

7.96 By convention, where the legal owner of a building is not the legal owner of the land on which the building stands, but the purchase price of the building includes an upfront payment of rent on the land beneath, without any prospect of further payments being due in future, land is recorded on the balance sheet of the owner of the building on the land.

\section{Mineral and energy resources (6142)}

7.97 Mineral and energy resources (6142) consist of mineral and energy reserves located on or below the earth's surface that are economically exploitable, given current technology and relative prices. Ownership rights to the mineral and energy resources are usually separable from those to the land itself. The deposits may be located on or below the earth's surface, including deposits under the sea, but they must be economically exploitable. Mineral and energy resources are known reserves of oil, natural gas, coal, metallic ores (including ferrous, nonferrous, and precious metal ores), and nonmetallic mineral reserves (including

\footnotetext{
${ }^{22}$ See paragraphs $3.38-3.41$ and 7.5 , for a description of the distinction between legal and economic ownership.
} 
stone quarries, clay and sand pits, chemical and fertilizer mineral deposits, and deposits of salt, quartz, gypsum, natural gem stones, asphalt, bitumen, and peat). Mine shafts, wells, and other subsoil extraction facilities are fixed assets in the form of other structures (61113) rather than subsoil assets.

7.98 The value of the resources is usually estimated as the present value of the expected net returns resulting from their commercial exploitation, but if the ownership of subsoil assets changes frequently on markets, then it may be possible to obtain appropriate prices. In practice, it may be necessary to use the valuations that the owners of the assets place on them in their own accounts.

7.99 It is frequently the case that the enterprise extracting a resource is different from the owner of the resource. In many countries, for example, oil resources are the property of government. However, it is the extractor who determines how fast the resource will be depleted, and since the resource is not renewable on a human time scale, it appears as if there has been a change of economic ownership to the extractor even if this is not the legal position. Nor is it necessarily the case that the extractor will have the right to extract until the resource is exhausted. Because there is no wholly satisfactory way in which to show the value of the asset split between the legal owner and the extractor, the whole of the resource is shown on the balance sheet of the legal owner and the payments by the extractor to the owner shown as rent. (This treatment is, therefore, an extension of the concept of a resource lease applied in this case to a depletable asset, as described in paragraphs 5.130 and A4.16-A4.17.) ${ }^{23}$

\section{Other naturally occurring assets (6143)}

7.100 Other naturally occurring assets (6143) comprise noncultivated biological resources (61431), water resources (61432), and other natural resources (61433), as shown in Table 7.7.

7.101 Noncultivated biological resources (61431) consist of animals, birds, fish, and plants that yield both once-only and repeat products over which ownership rights are enforced but for which natural growth or regeneration is not under the direct control, responsibility, and management of any institutional

\footnotetext{
${ }^{23}$ See Appendix 4, Box A4.1, for a description of the criteria to distinguish between rent and asset sales of natural resources.
}

\begin{tabular}{|l|l|}
\hline Table 7.7 & $\begin{array}{c}\text { Classification of Other Naturally } \\
\text { Occurring Assets }\end{array}$ \\
\hline 6143 & Other naturally occurring assets \\
61431 & Noncultivated biological resources \\
61432 & Water resources \\
61433 & Other natural resources \\
614331 & $\begin{array}{l}\text { Radio spectrum } \\
\text { Natural resources not elsewhere } \\
614332\end{array}$ \\
& classified \\
\hline
\end{tabular}

units. Examples are virgin forests and fisheries that are commercially exploitable. Only those resources that have economic value that is not included in the value of the associated land are included. As observed prices are not likely to be available, such assets are usually valued at the present value of expected future returns (see paragraph 7.33).

7.102 Water resources (61432) consist of surface and groundwater resources used for extraction to the extent that their scarcity leads to the enforcement of ownership or use rights, market valuation, and some measure of economic control. As observed prices are not likely to be available, such assets are usually valued at the present value of expected future returns.

7.103 The category other natural resources (61433) includes the electromagnetic spectrum, which includes the range of radio frequencies used in the transmission of sound, data, and television. The value of the spectrum is usually determined as the present value of expected future returns. If a long-term contract to use the spectrum exists, its value could be used as a basis for estimating the total value of the asset. Given the tendency to implement environmental policy by means of market instruments, it may be that additional natural resources will come to be recognized as economic assets. (See also paragraphs A4.18-A4.40 and A4.48-A4.50 on the treatment of permits and licenses to use natural resources.)

\section{Intangible nonproduced assets (6144)}

7.104 Intangible nonproduced assets (6144) are constructs of society evidenced by legal or accounting actions. Such assets entitle their owners to engage in certain specific activities or to produce certain specific goods or services and to exclude other units from doing so except with the permission of the owner. The owners of the assets may be able to earn monopoly 


\begin{tabular}{|l|c|}
\hline Table 7.8 & $\begin{array}{c}\text { Classification of Intangible } \\
\text { Nonproduced Assets }\end{array}$ \\
\hline 6144 & Intangible nonproduced assets \\
61441 & Contracts, leases, and licenses \\
614411 & Marketable operating leases \\
614412 & Permits to use natural resources \\
614413 & Permits to undertake specific activities \\
614414 & Entitlement to future goods and \\
& services on an exclusive basis \\
61442 & Goodwill and marketing assets \\
\hline
\end{tabular}

profits by restricting the use of the assets to themselves. Two types of intangible nonproduced assets are distinguished: contracts, leases, and licenses (61441) and goodwill and marketing assets (61442), as shown in Table 7.8. Whenever possible, contracts, leases, and licenses, should be valued at current prices when they are actually traded on markets. Otherwise, it may be necessary to use estimates of the present value of expected future returns. Goodwill and marketing assets are typically valued at their initial acquisition costs minus allowances for amortization (see paragraph 10.55).

\section{Contracts, leases, and licenses (61441)}

7.105 Contracts, leases, and licenses (61441) are treated as assets only when both the following conditions are satisfied:

- The terms of the contract, lease, or license specify a price for the use of an asset or provision of a service that differs from the price that would prevail in the absence of the contract, lease, or license.

- One party to the contract must be able legally and practically to realize this price difference.

7.106 These kinds of contracts are regarded as assets only if the existence of the legal agreement confers benefits on the holder in excess of the price payable to the lessor, owner of the natural resource, or permit issuer, ${ }^{24}$ and the holder can realize these benefits legally and practically (i.e., if a market for the contract exists). It is recommended that in practice, contracts, leases, and licenses should be recorded only when the value of the asset is significant and if holders can actually exercise the right to realize the price difference

${ }^{24}$ Also see 2008 SNA, Chapter 17, part 5. by on-selling the asset. In this case, a suitable market price necessarily exists. The asset does not exist beyond the length of the contract agreement, and its value must be reduced accordingly as the remaining contract period shortens (see paragraph 10.53).

7.107 Contracts, leases, and licenses may be marketable operating leases (614411), permits to use natural resources (614412), permits to undertake specific activities (614413), and entitlement to future goods and services on an exclusive basis (614414). ${ }^{25}$

\section{Marketable operating leases (614411)}

7.108 Marketable operating leases (614411) are third-party property rights relating to fixed assets. The lease confers economic benefits to the holder in excess of the fees payable and the holder can realize these benefits legally and practically, through transferring them. An example is where a tenant of a building has a fixed rental but the building could fetch a higher rental in the absence of the lease. If, in these circumstances, the tenant is able both legally and practically to sublet the building, then the tenant has an asset of the type of a marketable operating lease.

\section{Permits to use natural resources (614412)}

7.109 Permits to use natural resources (614412) are third-party property rights relating to natural resources. An example is where an institutional unit holds a fishing quota and is able, again both legally and practically, to sell this to another unit. Payment for a mobile phone license constitutes the sale of an asset, not payment for rent, when the licensee acquires effective economic ownership rights over the use of the spectrum. To decide whether ownership is effectively transferred, the six criteria quoted in Box A4.1 are to be considered.

\section{Permits to undertake specific activities (614413)}

7.110 A permit to undertake a specific activity (614413) is an asset for the holder when: (i) the permits are limited in number and so allow the holders to earn monopoly profits, (ii) the monopoly profits do not come from the use of an asset belonging to the permit-issuer, and (iii) a permit holder is able both legally and practically to sell the permit to a third party.

\footnotetext{
${ }^{25}$ For a description of the recording of these permits issued by government see paragraphs A4.18-A4.52.
} 
Such permits are issued mainly by government but may also be issued by other units.

7.111 When governments restrict the number of cars entitled to operate as taxis or limit the number of casinos by issuing permits or licenses, they are in effect creating monopoly profits for the approved operators and recovering some of the profits as the "fee." For government, such proceeds are recorded as other taxes on the use of goods and on permission to use goods or perform activities (11452) (see paragraph 5.81). For the permit holder, the incentive to acquire such a license is that the licensee believes that it will thereby acquire the right to make monopoly profits at least equal to the cost of the license. This permission to create monopoly profits creates an asset for the holder if the licensee can realize these profits by onselling the asset-that is, the license is tradable. The value of this asset is determined by the value at which it can be sold or, if no such information is available, is estimated as the present value of the future stream of monopoly profits (see also paragraphs A4.42-A4.45).

\section{Entitlement to future goods and services on an exclusive basis (614414)}

7.112 Entitlement to future goods and services on an exclusive basis (614414) relates to the case where one party that has contracted to purchase goods or services at a fixed price at a time in the future is able to transfer the obligation of the second party to the contract to a third party. These entitlements relate to footballers' contracts and a publisher's exclusive right to publish new works by a named author or issue recordings by named musicians (see also paragraph A4.51). For example, when a football player contracted his or her services to a club, the latter has an asset with the ability to sell this contract to another club.

\section{Goodwill and marketing assets (61442)}

7.113 Potential purchasers of an enterprise are often prepared to pay a premium above the net value of its individually identified and valued assets and liabilities. This excess is described as goodwill and reflects the value of corporate structures and the value to the business of an assembled workforce and management, corporate culture, distribution networks, and customer base. It may not have value in isolation from other assets, but it enhances the value of those other assets. Looked at another way, it is the addition to the value of individual assets because they are used in combination with each other.

7.114 Goodwill cannot be separately identified and sold to another party. The value has to be derived by deducting the value of assets and liabilities classified elsewhere within the asset boundary of GFS from the sale value of the corporation. (In practice, since it is estimated as a residual, an estimate of goodwill will also reflect errors and omissions in the valuation of other assets and liabilities.)

7.115 As well as residual errors, the value of goodwill may include the value to the corporation of items known as marketing assets. Marketing assets consist of items such as brand names, mastheads, trademarks, logos, and domain names. A brand can be interpreted as far more than just a corporate name or logo. It is the overall impression a customer or potential customer gains from his or her experience with the company and its products. Interpreted in that wider sense it can also be seen to encompass some of the characteristics of goodwill, such as customer loyalty.

7.116 The value of goodwill and marketing assets is the difference between the value paid for an enterprise as a going concern and the sum of its assets minus the sum of its liabilities, each item of which has been separately identified and valued. Although goodwill is likely to be present in most corporations, for reasons of reliability of measurement it is recorded in GFS only when its value is evidenced by a market transaction, usually the sale of the whole corporation. In some exceptions, identified marketing assets may be sold individually and separately from the whole corporation, in which case their value should also be recorded under this item.

7.117 The balance sheet entry for goodwill and marketing assets is the written-down value of the entry that appears as a transaction in financial assets and liabilities when an enterprise is taken over or when a marketing asset is sold. ${ }^{26}$ These entries are not revalued.

\section{Financial Assets (62) and Liabilities (63)}

7.118 Financial assets and liabilities were defined in paragraphs 7.15-7.16. The classifications of financial assets and liabilities are based primarily on the

\footnotetext{
${ }^{26}$ As explained in paragraph 10.55 , the amortization of goodwill and marketing assets over their service or legal lives is an other economic flow.
} 
liquidity and legal characteristics of the instruments that describe the underlying creditor-debtor relationships. The liquidity of a financial instrument embraces characteristics such as negotiability, transferability, marketability, and convertibility.

7.119 Securities are debt and equity instruments that have the characteristic feature of negotiability. That is, their legal ownership is readily transferred from one unit to another unit by delivery or endorsement. While any financial instrument can potentially be traded, securities are designed to be traded, usually on organized exchanges or "over the counter." (The over-the-counter market involves parties negotiating directly with one another, rather than on a public exchange.) Negotiability is a matter of the legal form of the instrument. Some securities may be legally negotiable, but there is not, in fact, a liquid market where they can be readily bought or sold. Listed financial derivatives, such as warrants, are sometimes considered to be securities.

7.120 In addition to classifying financial assets and liabilities by the characteristics of the financial instrument, they can also be classified according to the residence of the other party to the instrument (the debtors for financial assets and the creditors for liabilities). ${ }^{27}$ Residence is defined in paragraphs $2.6-2.21$. The classifications of financial assets and liabilities by instrument are shown in Table 7.9.

7.121 Because a given financial instrument creates both a financial asset and a liability, the same descriptions of instruments can be used for both. For simplicity, the descriptions will refer only to financial assets unless there is a specific need to refer to liabilities.

7.122 As discussed in paragraphs 3.113 and 7.207.25 , in principle, all financial assets should be valued at market value. ${ }^{28}$ Because the creditor can dispose of the asset on the date of the balance sheet at its current market price, it is that price that is relevant for the balance sheet. In practice, valuing debt instruments ${ }^{29}$ at market value on the balance sheet date means that:

\footnotetext{
${ }^{27}$ A discussion of Islamic banking instruments and how they can be treated in terms of the classification of financial assets and liabilities can be found in the MFSM, Appendix 2.

${ }^{28}$ That value, however, may differ from an asset's nominal value, which is a measure of value from the viewpoint of the debtor: at any moment in time the nominal value is the amount that the debtor owes to the creditor. See paragraph 3.115.

${ }^{29}$ All liabilities except equity and investment fund shares, and financial derivatives and employee stock options are debt instruments.
}

- Debt securities are valued at market prices.

- Insurance, pension, and standardized guarantee schemes are valued according to principles that are equivalent to market valuation.

- All other debt instruments are valued at nominal prices, which are considered to be the best generally available estimates of their market prices.

7.123 Some financial assets and liabilities, most typically deposits, debt securities, loans, and other accounts payable/receivable, require the debtor to pay interest. The interest accrues continuously and increases the total amount that the debtor will be required to pay (see paragraph 6.64).

7.124 To calculate the overall balance (see paragraph 4.57) financial assets acquired by government units in support of their fiscal policies ${ }^{30}$ are classified differently from financial assets acquired for liquidity management. The distinction between financial assets acquired for public policy purposes and financial assets acquired for liquidity purposes is not included in the GFS classification of financial assets. This distinction rests on the judgment of the analyst of the particular purpose for employing financial assets. ${ }^{31}$

\section{Monetary gold and Special Drawing Rights (SDRs) $(6201,6221,6301,6321)$}

7.125 On the financial assets side, this category comprises monetary gold and SDRs, and on the liabilities side it comprises only SDRs (see paragraph 7.128). The counterparties to this financial asset and liability are nonresidents.

\section{Monetary gold $(62011,62211)^{32}$}

7.126 Monetary gold is gold to which the monetary authorities (or others who are subject to the effective control of the monetary authorities) have title and is held as a reserve asset. It comprises gold bullion (including gold held in allocated gold accounts)

\footnotetext{
${ }^{30}$ This is often referred to as "public policy lending" or "policy lending" and is treated akin to expenditure in the calculation of the overall balance.

${ }^{31}$ As explained in Box 6.3, under some circumstances, "capital or equity injections" are considered to be expense-that is, they do not result in a financial claim on the debtor.

${ }^{32}$ There is no liability in the form of monetary gold; the counterpart liability to monetary gold in the form of unallocated gold accounts with nonresidents that give title to claim the delivery of gold is classified under deposits. Gold bullion has no counterparty liability.
} 


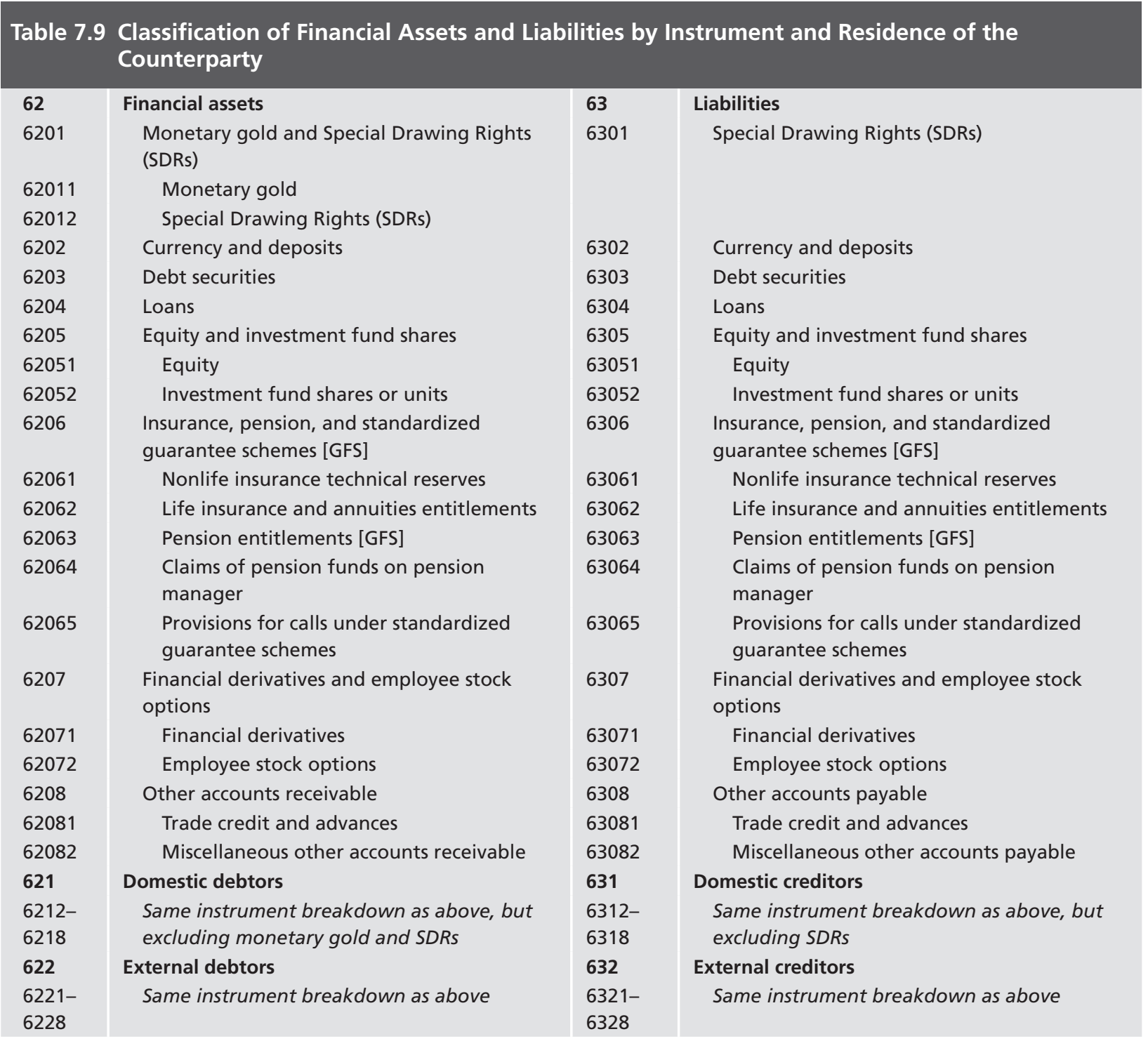

and unallocated gold accounts with nonresidents that give title to claim the delivery of gold. ${ }^{33}$ All monetary gold is included in reserve assets or is held by international financial organizations. Only gold that is held as a financial asset and as a component of reserve assets is classified as monetary gold. Therefore, except in limited institutional circumstances, ${ }^{34}$ gold bullion is a financial asset only for the central bank or central government. Deposits, loans, and securities denominated in gold are treated, respectively, as deposits, loans, and securities denominated in foreign currencies, and not

\footnotetext{
${ }^{33}$ See the BPM6, paragraphs 5.74-5.78, for a detailed discussion of gold bullion and gold accounts.

${ }^{34}$ For example, gold held by a commercial bank but under the control of the monetary authorities.
}

as monetary gold, unless held as unallocated gold accounts by monetary authorities as reserve assets.

7.127 Allocated gold accounts provide ownership of a specific piece of gold. The ownership of the gold remains with the entity placing it for safe custody. When held as reserve assets, allocated gold accounts are classified as monetary gold. Otherwise, allocated gold accounts are treated as representing the ownership of a nonfinancial asset. In contrast, unallocated gold accounts represent a claim against the account custodian to deliver gold. For these accounts, the account provider holds title to a reserve base of physical gold and issues claims to account holders denominated in gold. When held as reserve assets, unallocated gold accounts are classified as monetary gold. Unallocated 
accounts not held as reserve assets, and all unallocated gold account liabilities, are classified as deposits.

7.128 Gold bullion takes the form of coins, ingots, or bars with a purity of at least 995 parts per 1,000, including such gold held in allocated gold accounts. Gold bullion is usually traded on organized markets or through bilateral arrangements between central banks. Gold bullion held as a reserve asset is the only financial asset with no corresponding liability.

7.129 Any gold held by a government unit that does not satisfy the definition of monetary gold is not a financial asset and is included in nonmonetary gold as a nonfinancial asset, most likely valuables (613) but possibly inventories (612). ${ }^{35}$ In some cases, a central bank may own gold bullion that is not held as reserves, such as sometimes occurs when it acts as a monopoly reseller of mined gold. A gold swap is treated as a loan (see paragraph 7.161).

7.130 Monetary gold is valued at the price established in organized markets or when traded through bilateral arrangements between central banks.

\section{Special Drawing Rights (SDRs) (62012, 62212, 6301, 6321)}

7.131 Special Drawing Rights (SDRs) are international reserve assets created by the International Monetary Fund (IMF) and allocated to its members to supplement reserve assets. The Special Drawing Rights Department of the IMF allocates SDRs among member countries of the IMF (collectively known as the participants). The allocation of SDRs is a liability of the member country and interest accrues on this liability. ${ }^{36}$

7.132 SDR holdings represent each holder's unconditional right to obtain foreign exchange or other reserve assets from other IMF members. These financial assets represent claims on the participants in the IMF's SDR Department collectively and not on the IMF. A participant may sell some or all of its SDR holdings to another participant and receive other reserve assets, particularly foreign exchange, in return. Participants may also use SDRs to meet liabilities.

\footnotetext{
${ }^{35}$ Nonmonetary gold is a good and classified under nonfinancial assets as valuables, if held primarily as a store of value, and classified as inventories of materials and supplies, if used in a production process (such as jewelry or dentistry).

${ }^{36}$ The IMF has also designated a limited number of international financial institutions as holders of SDRs.
}

7.133 SDR allocations constitute a (debt) liability of the recipients (and part of the public sector's debt liabilities) and the SDR holdings are part of the public sector's financial assets. The allocation and holdings are recorded on a gross basis. The macroeconomic statistical guidelines do not specify on whose balance sheet SDR holdings and allocations should be recorded (e.g., the central bank or a general government entity such as the ministry of finance or treasury). This is because SDR allocations are made to IMF members that are participants in the SDR Department of the IMF, and it is for those members to follow domestic legal and institutional arrangements to determine the ownership and recording of SDR allocations and SDR holdings in the public sector. Given that financial claims on and liabilities to members in the SDR system are attributed on a cooperative basis, a residual partner category-other nonresidents-is used as the counterparty to SDR holdings and allocations.

7.134 In addition to SDRs as a type of financial instrument, SDRs may also be used as a unit of account in which other debt instruments can be expressed. The value of the SDR is determined daily by the IMF on the basis of a selected basket of currencies. To ensure consistency, the SDR rates against domestic currencies are obtainable from the IMF. Both the basket and the weights of the currencies that make up the SDR basket are revised from time to time.

\section{Currency and deposits (6202, 6212, 6222, $6302,6312,6322$ )}

7.135 Currency consists of notes and coins that are of fixed nominal values and are issued or authorized by the central bank or government. All sectors may hold currency as assets, but normally only central banks and government may issue currency. In some countries, commercial banks are able to issue currency under the authorization of the central bank or government. Currency constitutes a liability of the issuing units. Unissued currency held by a public sector unit is not treated as a financial asset of the public sector or a liability of the central bank. Gold and commemorative coins that are not in circulation as legal tender, or as monetary gold, are classified as nonfinancial assets in the form of valuables or inventories of materials and supplies, as appropriate, rather than currency.

7.136 A distinction should be drawn between domestic currency that is a liability of a resident unit 
and foreign currency that is the liability of nonresident units. (See paragraph 3.134 for the definitions of domestic and foreign currency.) Domestic currency has a fixed nominal value. The value of foreign currency is converted to the domestic currency at the exchange rate valid on the date to which the balance sheet relates. The rate used should be the midpoint between the buying and selling spot rates for currency transactions.

7.137 Deposits are all claims, represented by evidence of deposit, on the deposit-taking corporations (including the central bank) and, in some cases, general government or other institutional units. A deposit is usually a standard contract, open to the public at large, that allows the placement of a variable amount of money. Public sector units may hold a variety of deposits as assets, including deposits in foreign currencies. It is also possible for a government unit to incur liabilities in the form of deposits. For example, postal offices or other government units may accept deposits from the public, acting like a sort of rural financial institution as a secondary activity. Public financial corporations (e.g., the central bank) typically incur liabilities in the form of deposits, including to government units.

7.138 Claims on the IMF that are components of international reserves and are not evidenced by loans should be classified as deposits. (Claims on the IMF evidenced by loans should be included in loans.) Repayable margin payments in cash related to financial derivative contracts (see paragraph 7.219) can also be classified under deposits.

7.139 Unallocated accounts for precious metals, such as unallocated gold accounts, are also deposits, except for unallocated gold accounts held by monetary authorities for reserves purposes, for which the asset holding is included in monetary gold, with the counterpart liability being recorded as a deposit (as also mentioned in paragraph 7.15).

7.140 Deposits may be transferable or nontransferable. Transferable deposits comprise all deposits that are (i) exchangeable (without penalty or restriction) on demand at par, and (ii) directly usable for making third-party payments by check, draft, giro order, direct debit/credit, or other direct payment facility. Nontransferable deposits comprise all other financial claims, other than transferable deposits, represented by evidence of deposit. Examples of other deposits are sight deposits that permit immediate cash withdrawals but not direct third-party transfers, savings and fixed-term deposits, overnight and very short-term repurchase agreements that are included in the national measures of broad money, and foreign currency deposits that are blocked because of the rationing of foreign exchange as a matter of national policy.

7.141 It may be useful to further classify deposits according to whether they are denominated in the domestic currency or a foreign currency.

7.142 Deposits should be recorded at nominal value. They give rise to the same issues as loans with respect to nominal and fair values (see paragraph 7.163). Deposit assets at banks and other public deposit-taking corporations in liquidation also should be recorded at their nominal value until they are written off. If the difference between the nominal and fair values is significant, the fair value of such deposits could be shown as an additional memorandum item to the balance sheet. The same treatment is applicable for any other cases of impaired deposits (i.e., where the public deposit-taking corporation is not in liquidation but is insolvent).

\section{Debt securities $(6203,6213,6223,6303$, 6313,6323 )}

7.143 Debt securities are negotiable financial instruments serving as evidence of a debt. The security normally specifies a schedule for interest and principal payable. Examples of debt securities are:

- Bills

- Bonds and debentures, including bonds that are convertible into shares

- Loans that have become negotiable from one holder to another

- Nonparticipating preferred stocks or shares

- Asset-backed securities and collateralized debt obligations

- Similar instruments normally traded in the financial markets.

7.144 Bills are defined as securities (usually shortterm) that give holders the unconditional rights to receive stated fixed sums on a specified date. Bills are issued and usually traded in organized markets at discounts to face value that depend on the rate of 
interest and the time to maturity. Examples of bills are treasury bills, negotiable certificates of deposit, bankers' acceptances, promissory notes, and commercial paper.

7.145 A banker's acceptance is created when a financial corporation endorses, in return for a fee, a draft or bill of exchange and the unconditional promise to pay a specific amount at a specified date. International trade is often financed in this way. A banker's acceptance is classified under the category of debt securities. A banker's acceptance represents an unconditional claim on the part of the holder and an unconditional liability on the part of the accepting financial corporation; in turn, the financial corporation acquires an asset because it has a claim on its customer. A banker's acceptance is treated as a financial asset from the time of acceptance, even though funds may not be exchanged until a later stage. ${ }^{37}$

7.146 Bonds and debentures are securities that give the holders the unconditional right to fixed payments or contractually determined variable payments on a specified date or dates. The earning of interest is not dependent on earnings of the debtors. Bonds and debentures could have various characteristics and uses. For example, bonds may be issued to recognize a liability for government employee pensions (often called recognition bonds). Bonds can be issued at a deep discount or with no coupons (zero-coupon bonds).

7.147 Zero-coupon bonds are long-term securities that do not involve periodic payments during the life of the bond. Similar to short-term securities, zero-coupon bonds are sold at a discount, and a single payment, that includes accrued interest, is made at maturity. ${ }^{38}$ Deep-discount bonds are long-term securities that require periodic coupon payments during the life of the instrument, but the amount is substantially below the market rate of interest at issuance.

7.148 Instruments with embedded derivatives ${ }^{39}$ are not classified as financial derivatives. If a primary instrument, such as a security or loan, contains an em-

\footnotetext{
${ }^{37}$ Appendix 1 of the EDS Guide provides a glossary of financial instruments, including banker's acceptances.

${ }^{38}$ For a discussion of the accrual recording of interest on zerocoupon and deep-discounted bonds, see paragraphs 6.71-6.72 and the annex to Chapter 2 of the PSDS Guide.

${ }^{39} \mathrm{An}$ embedded derivative arises when a derivative feature is inserted in a standard financial instrument and is inseparable from the instrument.
}

bedded derivative, the instrument is valued and classified according to its primary characteristics-even though the value of that security or loan may well differ from the values of comparable securities and loans because of the embedded derivative. Examples are corporate bonds that are convertible into shares of the same corporation at the option of the bondholder and securities with options for repayment of principal in currencies that differ from those in which the securities were issued. If the conversion option is traded separately, then the option is treated as a separate instrument, classified as a financial derivative, and it is not debt.

7.149 Loans (see paragraph 7.157) that have become negotiable from one holder to another are to be reclassified (through other changes in the volume of assets) from loans to debt securities under certain circumstances. For such reclassification, there needs to be evidence of secondary market trading, including the existence of market makers, and frequent quotations of the instrument, such as provided by bid-offer spreads. ${ }^{40}$

7.150 Nonparticipating preferred stocks or shares are those that pay a fixed income but do not provide for participation in the distribution of the residual value of an incorporated enterprise on dissolution. These shares are classified as debt securities. Bonds that are convertible into equity should also be classified as debt securities prior to the time that they are converted.

7.151 Asset-backed securities and collateralized debt obligations are arrangements under which payments of interest and principal are backed by payments on specified assets or income streams. This process is also described as securitization (for more details, see paragraph A3.59-A3.66). Asset-backed securities are backed by various types of financial assets-for example, mortgages and credit card loans. A general government unit may issue debt securities backed by specific streams of earmarked revenue. This is not an asset-backed security, as in macroeconomic statistical systems, the ability to raise taxes or other government revenue is not recognized as a government asset that could be used for securitization. Nevertheless, the

\footnotetext{
${ }^{40} \mathrm{An}$ example is a syndicated loan, which is provided by a group of lenders and is structured, arranged, and administered by one or several commercial or investment banks. If parts of a syndicated loan become traded in secondary markets, the loan may meet the criteria to be reclassified as a security.
} 
earmarking of future revenue, such as receipts from toll roads, to service debt securities issued by a general government (or public sector) unit may resemble securitization.

7.152 Stripped securities are securities that have been transformed from a principal amount with coupon payments into a series of zero-coupon bonds, with a range of maturities matching the coupon payment date(s) and the redemption date of the principal amount(s). The function of stripping is that investor preferences for particular cash flows can be met in ways different from the mix of cash flows of the original security. There are two cases of stripped securities:

- When a third party acquires the original securities and uses them to back the issue of the stripped securities; then new funds have been raised and there is a new financial instrument.

- When no new funds are raised and the payments on the original securities are stripped and marketed separately by the issuer or through agents (such as strip dealers) acting with the issuer's consent; in this case, there is no new instrument.

7.153 Index-linked securities are instruments for which either the coupon payments (interest) or the principal or both are linked to another item, such as a price index, an interest rate, or the price of a commodity. Issues in the measurement of interest on index-linked securities are discussed in paragraphs 6.75-6.78.

7.154 Debt securities traded (or tradable) in organized and other financial markets-such as bills, bonds, debentures, negotiable certificates of deposits, asset-backed securities-should be valued at both market and nominal value. Debt securities are shown in the balance sheet at market value. The nominal value is used to determine gross debt at nominal value, which is shown as a memorandum item to the GFS balance sheet. For a traded debt security, nominal value can be determined from the value of the debt at creation and subsequent economic flows, while market value is based on the price at which it is traded in a financial market.

7.155 For debt securities that are tradable but for which the market price is not readily observable, the market value can be estimated by the discounted present value method provided an appropriate discount rate can be used (see paragraph 3.125). This and other methods of estimating market value are explained in the PSDS Guide, Box 2.2.

7.156 When securities are quoted on markets with a buy-sell spread, the midpoint should be used to value the instrument. The spread is an implicit service fee of the market platform or dealer payable by buyers and sellers.

\section{Loans (6204, 6214, 6224, 6304, 6314, 6324)}

7.157 A loan is a financial instrument that is created when a creditor lends funds directly to a debtor and receives a nonnegotiable document as evidence of the asset. ${ }^{41}$ This category includes overdrafts, mortgage loans, loans to finance trade credit and advances, repurchase agreements, financial assets and liabilities created by financial leases, and claims on or liabilities to the IMF in the form of loans. Trade credit and advances and similar accounts payable/receivable are not loans (see paragraph 7.225). Loans that have become marketable in secondary markets should be reclassified under debt securities (see paragraph 7.149). However, if traded only occasionally, the loan is not reclassified under debt securities.

7.158 A financial lease involves imputing a loan. A financial lease is a contract under which the lessor, as legal owner of an asset, conveys substantially all risks and rewards of ownership of the asset to the lessee. When goods are acquired under a financial lease, the lessee is deemed to be the owner, even though legally the leased good remains the property of the lessor. This is because the risks and rewards of ownership have been, de facto, transferred to the lessee. This change in ownership is deemed to have been financed by an imputed loan, which is an asset of the lessor and a liability of the lessee.

7.159 A securities repurchase agreement (repo) is an arrangement involving the sale of securities for cash, at a specified price, with a commitment to repurchase the same or similar securities at a fixed price either on a specified future date (often one or a few days hence) or with an open maturity. ${ }^{42}$ The economic nature of the transaction is that of a collateralized loan

\footnotetext{
${ }^{41} \mathrm{~A}$ loan is distinguished from a deposit on the basis of the representation in the documents that evidence them.

${ }^{42} \mathrm{An}$ open maturity exists when both parties have the option to agree daily to renew or terminate the agreement.
} 
(or a deposit ${ }^{43}$ ) because the risks and rewards of ownership of the securities remain with the original owner (security provider). Thus, the funds advanced by the security taker (cash provider) to the security provider (cash taker) are treated as a loan and the underlying securities remain on the balance sheet of the security provider, despite the legal change in ownership.

7.160 Securities lending is an arrangement whereby a security holder transfers securities to another party (security taker), subject to the stipulation that the same or similar securities be returned on a specified date or on demand. As with a securities repurchase agreement, the risks and rewards of ownership remain with the original owner. If the security taker provides cash as collateral, then the arrangement is a repo (see paragraph 7.159). If the security taker provides noncash collateral, then no stock position changed. In either case, the securities involved remain on the balance sheet of the original owner.

7.161 A gold swap involves an exchange of gold for foreign exchange deposits with an agreement that the transaction be reversed at an agreed future date at an agreed gold price. The gold taker (cash provider) should not record the gold on its balance sheet, while the gold provider (cash taker) should not remove the gold from its balance sheet. Gold swaps are similar to securities repurchase agreements, except that the collateral is gold, and should therefore be recorded as a collateralized loan or deposit. Gold loans occur in the same form as securities lending and should be treated in the same way.

7.162 An off-market swap is a swap contract ${ }^{44}$ that has a nonzero value at inception as a result of having reference rates priced differently from current market values-that is, "off-the-market." Such a swap results in a lump sum being paid, usually at inception, by one party to the other. The economic nature of an offmarket swap is equivalent to a combination of borrowing (i.e., the lump sum), in the form of a loan, and an on-market swap (financial derivative).$^{45}$

\footnotetext{
${ }^{43}$ Repurchase agreements that are included in the national definition of broad money should be classified as nontransferable deposits. All other securities repurchase agreements should be classified under loans.

${ }^{44}$ A swap contract involves the counterparties exchanging, in accordance with prearranged terms, cash flows based on the reference prices of the underlying items.

${ }^{45}$ For more details, see the PSDS Guide, paragraphs 4.127-4.131.
}

7.163 Loans are recorded at nominal value (i.e., the amount advanced plus interest accrued and not paid minus any repayments). The use of nominal values is partly influenced by pragmatic concerns about data availability. In addition, because loans are generally not intended for trading on the secondary market, estimating a market price can be subjective. Nominal value is also useful because it shows actual legal liability and the starting point of creditor recovery behavior. In some cases, loans may be traded, often at discount, or a fair value may exist or could be estimated. It is recognized that nominal value provides an incomplete view of the financial position of the creditor, particularly when the loans are nonperforming. In such cases, information on the nominal value, as well as the fair value, of nonperforming loan assets should be included as a memorandum item to the GFS balance sheet—see paragraph 7.262.

\section{Equity and investment fund shares (6205, $6215,6225,6305,6315,6325$ )}

7.164 Equity and investment fund shares have the distinguishing feature that the holders own a residual claim on the assets of the institutional unit that issued the instrument. Equity represents the owners' funds in the institutional unit. In contrast to debt, equity does not generally provide the owner with a right to a predetermined amount or an amount determined according to a fixed formula. Investment fund shares have a specialized role in financial intermediation as a kind of collective investment in other assets, and should be identified separately. When an institutional unit's net worth is calculated, equity and investment fund shares are, by convention, included in total liabilities (see paragraphs 7.228-7.233).

\section{Equity (62051, 62151, 62251, 63051, 63151, 63251)}

7.165 Equity consists of all instruments and records that acknowledge claims on the residual value of a corporation or quasi-corporation, after the claims of all creditors have been met. Equity is treated as a liability of the issuing institutional unit (a public corporation or other government unit).

7.166 Ownership of equity in legal entities is usually evidenced by shares, stocks, participations, depository receipts, or similar documents. Shares and stocks have the same meaning. Participating preferred 
shares are those that provide for participation in the residual value on the dissolution of an incorporated enterprise. Such shares are also equity securities, regardless of whether the income is fixed or determined according to a formula. (For nonparticipating preferred shares, see paragraph 7.150.) In addition to the purchase of shares, the value of equity can be affected by a range of factors, such as share premiums, accumulated reinvested or retained earnings, or revaluations. In addition, a direct investor may increase its equity in an affiliate by providing goods and services or assuming debt.

7.167 Depository receipts are securities that represent ownership of securities listed in other economies. Depository receipts listed on one exchange represent ownership of securities listed on another exchange, and ownership of the depository receipts is treated as if it represents direct ownership of the underlying securities. Depository receipts facilitate transactions in securities in economies other than their home listing. The underlying securities may be equity or debt securities.

7.168 Equity may be subdivided into listed shares, unlisted shares, and other equity. Both listed and unlisted shares are equity securities (securities are defined in paragraph 7.119). Listed shares are equity securities listed on an exchange and may be referred to as quoted shares. Unlisted shares are equity securities not listed on an exchange. Listed and unlisted shares tend to be issued by different types of corporations (unlisted shares are often issued by subsidiaries and smaller businesses) and typically have different regulatory requirements.

7.169 Other equity is equity that is not in the form of securities. This can include equity in quasicorporations, such as branches, trusts, limited liability and other partnerships, unincorporated funds, and notional units for ownership of real estate and other natural resources. The ownership of many international organizations is not in the form of shares and should be classified as other equity (although equity in the Bank for International Settlements is in the form of unlisted shares). Ownership of currency union central banks is included in other equity. ${ }^{46}$

7.170 Most general government units do not have liabilities in the form of equity and investment fund

\footnotetext{
${ }^{46}$ See the BPM6, paragraph A3.44.
}

shares. However, in two cases, it is possible to show a general government unit with liabilities for equity and investment fund shares. The first relates to some units (usually special purpose entities) that are established legally as public corporations but carry out only fiscal and quasi-fiscal activities-they are treated as part of general government (regardless of their legal status) because they are not considered to be separate institutional units, unless they are nonresident. Second, when a unit under the control of government is legally established as a corporation but functions as a nonmarket producer, such a unit is also part of general government, as explained in paragraph 2.41.

7.171 The general principles of valuation at market prices given in paragraphs 7.20-7.33 apply to equity. Equity can be readily valued at its current market prices when it is regularly traded on stock exchanges or other financial markets.

7.172 However, there may be no observable market prices for unlisted shares and other equity positions (e.g., for equity in direct investment enterprises, unlisted and delisted companies, listed but illiquid companies, joint ventures, and unincorporated enterprises).

7.173 When actual market values of equity are not available, an estimate is required. One approach is to use information from the stock market on a similar listed share, as described in paragraph 7.29. Alternative methods of approximating the market value of shareholders' equity are outlined in 2008 SNA, paragraphs 13.71-13.73, and include the following: recent transaction price, net asset value, present value/price to earnings ratios, book values reported by enterprises with macro-level adjustments by the statistics compilers, own funds at book value, and apportioning global value. The value of other equity is equal to the value of the unit's assets minus the value of its liabilities. So for unincorporated enterprises, such as quasicorporations, net worth is zero and the estimated value of other equity can be negative if the value of liabilities exceeds the value of the assets. ${ }^{47}$

\section{Investment fund shares or units (62052,} 62152, 62252, 63052, 63152, 63252)

7.174 Investment funds are collective investment undertakings through which investors pool funds for

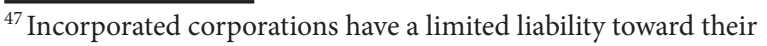
shareholders so that the minimum value of their equity is zero.
} 
investment in financial or nonfinancial assets. These funds issue shares (if a corporate structure is used) or units (if a trust structure is used). Investment funds include money market funds (MMF) and non-MMF investment funds. ${ }^{48}$ Investment fund shares or units refer to the shares issued by mutual funds and unit trusts, rather than the shares they may hold.

7.175 MMFs are investment funds that invest only or primarily in short-term money market securities, such as treasury bills, certificates of deposit, and commercial paper. MMF shares and units sometimes are functionally close to transferable deposits-for example, accounts with unrestricted check-writing privileges. If MMF shares are included in broad money in the reporting economy, they should be recorded as a separate item in the balance sheet to allow reconciliation with monetary statistics.

7.176 Investment funds invest in a range of assets, such as debt securities, equity, commodity-linked investments, real estate, shares in other investment funds, and structured assets.

7.177 Shares (or units) in money market funds or in other investment funds should be valued in a manner similar to the methods under equity:

- Listed shares should be valued using the market price of the share.

- Unlisted shares should be valued according to one of the methods described in paragraph 7.172 for unlisted equity and other equity.

Insurance, pension, and standardized guarantee schemes [GFS] $(6206,6216,6226$, $6306,6316,6326)$

7.178 Insurance, pension, and standardized guarantee schemes comprise:

- Nonlife insurance technical reserves

- Life insurance and annuities entitlements

- Pension entitlements [GFS]

- Claims of pension funds on pension manager

- Provisions for calls under standardized guarantee schemes.

7.179 These reserves, entitlements, and provisions for calls represent liabilities of a public sector unit as

\footnotetext{
${ }^{48}$ These are discussed further in the BPM6, paragraphs 4.73-4.75.
}

the insurer, pension fund, or issuer of standardized guarantees, and corresponding assets of the policyholders or beneficiaries. In the public sector, it is usually public financial corporations that engage in insurance schemes. General government units may incur liabilities for these reserves, entitlements, and provisions as operators of nonlife insurance schemes, nonautonomous or unfunded pension schemes, and standardized guarantee schemes. ${ }^{49}$

7.180 The value of a public sector unit's assets in the form of insurance, pension, and standardized guarantee schemes-as a policyholder-is determined by the amount of prepaid premiums plus estimates for claims established but not yet received by the public sector unit. The value of a public sector unit's liabilities in the form of each of these instruments is discussed under the relevant instrument.

7.181 In general, insurance companies and operators of pension funds and standardized guarantee schemes make actuarial estimates of their liabilities under these schemes. These estimates will be the usual source to compile statistics for this instrument.

7.182 The following paragraphs briefly define the types of reserves, entitlements, and provisions applicable to insurance, pension, and standardized guarantee schemes. ${ }^{50}$

Nonlife insurance technical reserves (62061, 62161, 62261, 63061, 63161, 63261)

7.183 Nonlife insurance ${ }^{51}$ technical reserves consist of (i) prepayments of net nonlife insurance premiums and (ii) reserves to meet outstanding nonlife insurance claims. In other words, nonlife insurance technical reserves consist of premiums paid but not

\footnotetext{
${ }^{49}$ It is unlikely that a general government unit would incur liabilities with respect to life insurance and annuities, unless it provides such schemes to its employees.

${ }^{50}$ These issues are discussed in detail in the 2008 SNA, paragraphs 17.76-17.224.

${ }^{51}$ Nonlife insurance covers all risks other than life insurance, such as accidents, sickness, fire, etc. A policy that provides a benefit in the case of death within a given period but in no other circumstances, usually called term insurance, is regarded as nonlife insurance because, as with other nonlife insurance, a claim is payable only if a specified contingency occurs and not otherwise. In practice, because of the way in which insurance corporations keep their accounts, it may not always be possible to separate term insurance from other life insurance. In these circumstances, term insurance may have to be treated in the same way as life insurance for practical reasons.
} 
yet earned (called unearned premiums) and claims incurred but not yet settled.

7.184 Prepayments of net nonlife insurance premiums arise because premiums are usually payable at the beginning of the period covered by the policy. However, on an accrual basis, the premiums are earned through the policy period, so that the initial payment involves a prepayment or advance. At any given time, part of the insurance premiums already paid has not yet been earned by the insurance enterprise because these prepaid premiums provide coverage against risks in the future. The value of the prepaid or unearned premiums should be determined proportionally. For example, if an annual policy with a premium of 120 currency units comes into force on April 1 and accounts are being prepared for a calendar year, the premium earned in the calendar year is 90 . The prepaid or unearned premium is the amount of the actual premium received that relates to the period past the reporting point. In the example just given, there will be an unearned premium of 30 at the end of December. This unearned premium is intended to provide coverage for the first three months of the next year.

7.185 Reserves to meet outstanding nonlife insurance claims are amounts arising from events that have occurred but for which the claims are still pending. They also include reserves for unexpired risks. The liability incurred by the insurer to meet outstanding claims represents the present value of the amounts expected to be paid out in settlement of claims, including disputed claims, as well as allowances for claims for incidents that have taken place but have not yet been reported.

7.186 Other reserves, such as equalization reserves, may be identified by insurers. However, these are recognized as liabilities (and corresponding assets) only when there is an event that gives rise to a liability. Otherwise, equalization reserves are internal accounting entries by the insurer that represent saving to cover irregularly occurring catastrophes, and thus do not represent any existing corresponding claims for policyholders.

\section{Life insurance and annuities entitlements} (62062, 62162, 62262, 63062, 63162, 63262)

7.187 Life insurance and annuities entitlements are financial claims policyholders have against an enterprise offering life insurance or providing annui- ties. This category consists of liabilities of life insurance companies and annuity providers for prepaid premiums and accrued liabilities to life insurance policyholders and beneficiaries of annuities. Life insurance and annuity entitlements are the obligation to provide benefits to policyholders, or to compensate beneficiaries upon the death of policyholders, ${ }^{52}$ and thus are kept separate from shareholders' funds. These entitlements are regarded as liabilities of the insurance companies and assets of the policyholders and beneficiaries. Annuities entitlements are the actuarial calculation of the present value of the obligations to pay future income until the death of the beneficiaries.

7.188 The amount to be recorded as the stock positions for life insurance and annuities entitlements is similar to that for nonlife insurance technical reserves in that it represents obligations to meet future claims already accrued. However, in the case of life insurance, the level of the entitlements is considerable and represents the present value of all expected future benefits. ${ }^{53}$

\section{Pension entitlements [GFS] ${ }^{54}(62063,62163$, $62263,63063,63163,63263)$}

7.189 As explained in paragraphs A2.5-A2.7, entitlements to social insurance benefits are divided between those relating to pensions and those relating to all other forms of benefits (i.e., nonpensions). The distinction between the two is important because the GFS recognizes liabilities for employment-related pensions, regardless of whether there are actually assets set aside to meet the entitlements, but recognizes reserves for employment-related nonpension benefits only when these reserves actually exist (see paragraph 7.195). Furthermore, a distinction is made between social security schemes and employmentrelated schemes. This section deals with entitlements to employment-related pension schemes.

7.190 Pension entitlements are financial claims that existing and future pensioners ${ }^{55}$ hold against

\footnotetext{
${ }^{52}$ This is distinct from term insurance, which is regarded as nonlife insurance (see footnote 51).

${ }^{53}$ In the commercial accounts of insurance corporations, some of these obligations will be described as provisions for bonuses and rebates. This is the result of the insurance industry's practice of smoothing benefits over time and retaining some benefits until the policy matures.

${ }^{54}$ [GFS] indicates that an item has the same name but different coverage in the 2008 SNA.

${ }^{55}$ Existing and future pensioners include past and current employees, as well as existing pensioners, but exclude future employees.
} 
either their employer or a fund designated by the employer, to pay pensions earned as part of a compensation agreement between the employer and employee. The nature of these claims, and the corresponding liabilities of the units operating the pension funds, depends on the type of benefit promised.

7.191 The two main types of pension schemes are defined-benefit schemes and defined-contribution schemes. ${ }^{56}$ In a defined-benefit scheme, the level of pension benefits promised by the employer to participating employees and other family members is determined by an actuarial formula based on participants' length of service and salary. In a definedcontribution scheme, the level of contributions to the fund is set, but the benefits that will be payable depend on the assets of the fund.

7.192 A pension fund for public sector employees can be managed on behalf of the public sector unit by a public or private insurance corporation, or it can be organized and managed by the public sector unit as an autonomous or nonautonomous pension fund. A nonautonomous pension fund is not a separate unit and the assets of the fund belong to the employer. The employees have a claim against the employer who operates the nonautonomous fund, and the employer has a liability equal to the present value of the promised benefits. For a description of the typology of social protection arrangements, see Appendix 2.

7.193 The liabilities of unfunded pension schemes should also be included in pension entitlements. By its nature, an unfunded employment-related pension scheme must be organized and managed by the employer, which may be a general government unit or a public corporation.

7.194 No liability is recognized in the primary accounts of macroeconomic statistical systems for benefits under social security schemes. ${ }^{57}$ The implicit obligation for future social security benefits are reported as a memorandum item to the balance sheet (see paragraph 7.261), regardless of the level of assets in a social security fund or other segregated accounts. Liabilities for the payment of social security benefits

\footnotetext{
${ }^{56}$ Defined-benefit schemes are sometimes referred to as "final salary schemes," while defined-contribution schemes are sometimes referred to as "money-purchase schemes."

${ }^{57}$ Social security schemes are defined in paragraphs $2.100-2.102$.
}

that were due to be paid but have not yet been paid are classified as other accounts receivable/payable (6308, 6318,6328 ). If a social security fund also administers an employment-related pension scheme, those pension obligations are included under pension entitlements, and not as implicit social security obligations.

7.195 As well as pensions, some employmentrelated schemes may have other related liabilities, such as for health benefits, which are included under entitlements to nonpension benefits. ${ }^{58}$ Liabilities for these nonpension entitlements are recorded in macroeconomic statistics only when and to the extent that they exist in the employer's accounts-that is, when reserves for these nonpension entitlements actually exist. For pragmatic reasons, such liabilities for nonpension entitlements may be included with those for pension entitlements.

7.196 In addition to its pension entitlement liabilities to its beneficiaries, a pension fund may sometimes have a claim on the employer, as the pension manager of the scheme. On the other hand, the pension manager may have a claim on the surplus of the pension fund. Such claims are excluded from pension entitlements and are classified as claims of pension funds on pension manager $(62064,62164,62264,63064,63164$, 63264) (see paragraphs 7.199-7.200).

7.197 Pension entitlements are valued as follows:

- The liability of a defined-benefit pension scheme (including nonautonomous pension funds and unfunded pension schemes) is the present value of the promised benefits.

- The liability of a defined-contribution pension fund is the current market value of the fund's net assets, which is determined according to the performance of the assets acquired with the pension contributions. ${ }^{59}$

7.198 Because the measurement of defined-benefit pension fund entitlements rests on various assumptions and methods, the nature of coverage and estimation should be described in metadata accompanying the balance sheet and other data reports.

\footnotetext{
${ }^{58}$ Funded schemes for social insurance other than pensions are not common.

${ }^{59}$ The basis on which pension entitlement is calculated is described in detail in the 2008 SNA, Chapter 17.
} 


\section{Claims of pension funds on pension manager (62064, 62164, 62264, 63064, 63164, 63264)}

7.199 An employer may contract with a third party to administer a pension fund for its employees. If the employer continues to determine the terms of the pension scheme and retains the responsibility for funding any deficit, as well as the right to retain any excess funding, the employer is referred to as the pension manager and the unit working under the direction of the pension manager as the pension administrator. If the agreement between the employer and the administrator is such that the employer passes the risks and responsibilities for any deficit in funding to the administrator in return for the right of the administrator to retain any excess, the latter becomes the pension manager as well as the administrator.

7.200 When the pension manager is a unit different from the administrator, and the responsibility for any deficits, or claims on any excess, rests with the pension manager, the following are recorded in the balance sheet of the pension manager:

- A liability for claims of pension funds on the pension manager, in the case of deficits

- A financial asset in the form of a claim on the pension fund, if the pension fund generates more investment income from the assets it holds than is necessary to cover the increase in pension entitlements

- A counterpart entry should be recorded in imputed employer's social contributions on a net basis (i.e., an expense to increase the liability and a reduction in the expense when the liability reduce or when government acquires an asset).

\section{Provisions for calls under standardized guarantee schemes (62065, 62165, 62265, 63065, 63165, 63265)}

7.201 Standardized guarantees are those kinds of guarantees that are issued in large numbers, usually for fairly small amounts, along identical lines. ${ }^{60} \mathrm{Op}$ erators of standardized guarantee schemes incur liabilities equal to the present value of the expected calls under outstanding guarantees, net of any recoveries

\footnotetext{
${ }^{60}$ In contrast, one-off guarantees are individual, and guarantors usually cannot reliably estimate the risk of calls. As a result, in most cases, one-off guarantees are considered a contingent liability (unless and until such guarantees are called). For a discussion of contingent liabilities, see paragraphs 7.251-7.260.
}

the guarantor expects to receive from the defaulting borrowers, a similar approach as for nonlife insurance. This liability is called provisions for calls under standardized guarantees.

7.202 There are three parties involved in these arrangements: the borrower (debtor), the lender (creditor), and the guarantor. Either the borrower or lender may contract with the guarantor to repay the lender if the borrower defaults. Examples are export credit guarantees, deposit guarantees, and student loan guarantees. Standardized guarantees are based on the same paradigm as that for nonlife insurance, and a similar treatment is adopted for these guarantees, as discussed in paragraphs A4.66-A4.80.

Financial derivatives and employee stock options $(6207,6217,6227,6307,6317,6327)$

7.203 Financial derivatives and employee stock options are financial assets and liabilities that have similar features, such as a strike price and some of the same risk elements. However, although both transfer risk, employee stock options are also designed to be a form of remuneration.

Financial derivatives (62071, 62171, 62271, $63071,63171,63271$ )

7.204 A financial derivative contract is a financial instrument that is linked to another specific financial instrument, indicator, or commodity and through which specific financial risks (e.g., interest rate risk, foreign exchange risk, equity and commodity price risks, and credit risk) can be traded in their own right in financial markets. Transactions and positions in financial derivatives are treated separately from the values of any underlying items to which they are linked. Financial derivatives are valued at market prices prevailing on balance sheet recording dates. If market price data are unavailable, other fair value methods (e.g., option models or present values) may be used to value them. Compilers are generally constrained to use the parties' own accounts.

7.205 The risk embodied in a financial derivative contract can be traded either by selling the contract itself, as is possible with options, or by creating a new contract embodying risk characteristics that match, in a countervailing manner, those of the existing contract. The latter practice, which is termed offsetability, occurs in forward markets. Offsetability means that it is often 
possible to eliminate the risk associated with a derivative by creating a new but reverse contract having characteristics that countervail the risk underlying the first derivative. Buying the new derivative is the functional equivalent of selling the first derivative because the result is the elimination of the underlying financial risk. The ability to countervail the underlying risk in the market is therefore considered the equivalent of tradability in demonstrating value. The outlay that would be required to replace the existing derivative contract represents its value; actual offsetting is not required.

7.206 In many cases, derivatives contracts are settled by payments of net amounts in cash, rather than by the delivery of the underlying items. Once a financial derivative reaches its settlement date, any unpaid overdue amount is reclassified as other accounts receivable/payable, as its value is fixed, and thus the nature of the claim becomes debt.

7.207 The following types of financial arrangements are not financial derivatives:

- A fixed-price contract for goods and services is not a financial derivative unless the contract is standardized so that the market risk therein can be traded in financial markets in its own right. For example, an option to purchase an aircraft from the manufacturer is not classified as a financial derivative; if the option to purchase is transferable, and is in fact transferred, the transaction is recorded under contracts, leases, and licenses, discussed in paragraph A4.52.

- Insurance and standardized guarantees are not financial derivatives. Insurance involves the collection of funds from policyholders to meet future claims arising from the occurrence of events specified in insurance policies. That is, insurance and standardized guarantees are used to manage event risk primarily by the pooling, not the trading, of risk (see paragraph 7.201). However, some guarantees other than standardized guarantees meet the definition of financial derivatives. Those guarantees protect, on a guarantee-by-guarantee basis, the lender against certain types of risk arising from a credit relationship by paying the guarantor a fee for a specified period-these are known as credit derivatives (see paragraph 7.218).

- Contingent assets and liabilities, such as one-off guarantees and letters of credit, are not financial assets (as discussed in paragraph 7.251).
- Instruments with embedded derivatives are not financial derivatives (see paragraph 7.148). If the owner of the primary instrument subsequently creates a new but reverse financial derivative contract to offset the risk of the embedded derivative, the creation of this new financial derivative contract is recorded as a separate transaction, which does not affect the recording of transactions and positions in the primary instrument. However, detachable warrants are treated as separate financial derivatives, because they can be detached and sold in financial markets.

- Timing delays that arise in the normal course of business and may entail exposure to price movements do not give rise to financial derivatives. Timing delays include normal settlement periods for spot transactions in financial markets.

7.208 There are two broad types of financial derivatives-options and forward-type contracts.

\section{Options}

7.209 In an option contract (option), the purchaser acquires from the seller a right to buy or sell (depending on whether the option is a call (buy) or a put (sell)) a specified underlying item at a strike price on or before a specified date. The purchaser of an option pays a premium to the writer of the option. In return, the buyer acquires the right but not the obligation to buy (call option) or sell (put option) a specified underlying item (real or financial) at an agreed-on contract price (the strike price) on or before a specified date. (On a derivatives exchange, the exchange itself may act as the counterparty to each contract.)

7.210 Options can be contrasted with forwardtype contracts in that:

- At inception, there is usually no up-front payment for a forward-type contract and the derivative contract begins with zero value, whereas there is usually a premium paid for an option that reflects the nonzero value of the contract.

- During the life of the contract, for a forward-type contract, either party can be creditor or debtor, and it may change, whereas for an option, the buyer is always the creditor and the writer is always the debtor. 
- At maturity, redemption is unconditional for a forward-type contract, whereas for an option it is determined by the buyer of the option.

7.211 Warrants are a form of financial derivative option giving the owner the right but not the obligation to purchase from the issuer of the warrant a fixed amount of an underlying asset, such as equities and bonds, at an agreed contract price for a specified period of time or on a specified date. Although similar to other traded options, a distinguishing factor is that the exercise of the warrants can create new securities, thus diluting the capital of existing bond- or shareholders, whereas traded options typically grant rights over assets that are already available.

\section{Forward-type contracts}

7.212 A forward-type contract (forward) is an unconditional contract by which two counterparties agree to exchange a specified quantity of an underlying item (real or financial) at an agreed-on contract price (the strike price) on a specified date. Forward-type contracts include futures and swaps (other than as discussed in paragraph 7.215). The term forward-type contract is used because the term forward is often used more narrowly in financial markets (often excluding swaps).

7.213 Futures are forward-type contracts traded on organized exchanges. The exchange facilitates trading by determining the standardized terms and conditions of the contract, acting as the counterparty to all trades, and requiring a margin to be deposited and paid to mitigate risk. Forward rate agreements and forward foreign exchange contracts are common types of forward-type contracts.

7.214 At the inception of a forward-type contract, risk exposures of equal market value are exchanged, so a contract typically has zero value at that time. As the price of the underlying item changes, the market value will change, although it may be restored to zero by periodic settlement during the life of the forward. The classification of a forward-type contract may change between asset and liability positions.

\section{Other issues associated with financial derivatives}

\section{Swap contracts}

7.215 A swap contract involves the counterparties exchanging, in accordance with prearranged terms, cash flows based on the reference prices of the underlying items. Swap contracts classified as forwardtype contracts include currency swaps, interest rate swaps, and cross-currency interest rate swaps. Under a swap contract, the obligations of each party may arise at different times-for example, an interest rate swap for which payments are quarterly for one party and annual for the other. In such cases, the quarterly amounts payable by one party prior to payment of the annual amount payable by the other party are recorded as transactions in the financial derivative contract. Other types of arrangements also called swaps but not meeting the foregoing definition include gold swaps (see paragraph 7.161 for a discussion of their treatment), central bank swap arrangements, ${ }^{61}$ and credit default swaps (see paragraph 7.218).

7.216 For foreign currency financial derivative swap contracts, such as currency swaps, it is necessary to distinguish between transactions in a financial derivative contract and transactions in the underlying currencies. At inception, the parties exchange the underlying financial instruments (usually classified as currency and deposits or loans). At the time of settlement, the difference in the values of the currencies swapped, as measured in the unit of account at the prevailing exchange rate, is allocated to a transaction in a financial derivative, with the values swapped recorded in the relevant item (usually currency and deposits, or loans).

7.217 As mentioned in paragraph 7.162, the economic nature of an off-market swap is equivalent to a combination of borrowing (i.e., the lump sum), in the form of a loan, and an on-market swap (financial derivative).

\section{Credit derivatives}

7.218 Credit derivatives are financial derivatives whose primary purpose is to trade credit risk. They are designed for trading in loan and security default risk. In contrast, the financial derivatives described in paragraphs 7.215-7.217 are mainly related to market risk, which pertains to changes in the market prices of securities, commodities, interest, and exchange rates. Credit derivatives take the form of both forward-type (total return swaps) and option-type contracts (credit default swaps). Under a credit default swap, premiums are paid in return for a cash payment in the event of a default

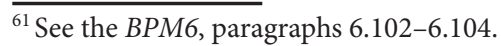


by the debtor of the underlying instrument. Like other financial derivatives, credit derivatives are frequently drawn up under standard master legal agreements and involve collateral and margining procedures, which allow for a means to make a market valuation.

\section{Margins}

7.219 Financial derivatives are often subject to margin calls. Margins are payments of cash or deposits of collateral that cover actual or potential obligations incurred. The required provision of margin reflects market concern over counterparty risk, especially in markets for futures and exchange-traded options. The classification of margins depends on whether they are repayable or nonrepayable:

- Repayable margin consists of cash or other collateral deposited to protect counterparties against default risk. Ownership of the margin remains with the unit that deposited it. Repayable margin payments in cash are classified as transactions and stock positions in deposits (particularly if the debtor's liabilities are included in broad money) or in other accounts receivable/payable. When a repayable margin deposit is made in an asset other than cash (such as securities), no transaction nor change in stock position is recorded because no change in economic ownership has occurred.

- Nonrepayable margin payments reduce the financial liability position in a derivative. In organized exchanges, nonrepayable margin (sometimes known as variation margin) is paid daily to meet liabilities recorded as a consequence of the daily marking of derivatives to market value. The entity that pays nonrepayable margin no longer retains ownership of the margin nor has the right to the risks and rewards of ownership. Nonrepayable margin payments are classified as transactions in financial derivatives.

7.220 These principles for the classification of margins also apply more generally to margin calls relating to positions in other financial assets.

\section{Employee stock options (62072, 62172, 62272, 63072, 63172, 63272)}

7.221 Employee stock options are options to buy the equity of a company, offered to employees of the company as a form of remuneration. Employee stock options have similar pricing behavior to financial de- rivatives, but they have a different nature-including arrangements for the granting and vesting dates-and purpose (i.e., to motivate employees to contribute to increasing the value of the company, rather than to trade risk). If a stock option granted to employees can be traded on financial markets without restriction, it is classified as a financial derivative.

7.222 In some cases, stock options may be provided to suppliers of goods and services to the enterprise. Although these are not employees of the enterprise, for convenience they are also recorded under employee stock options because their nature and motivation is similar. (Whereas the corresponding entry for stock options granted to employees is wages and salaries in kind (2112) as discussed in paragraph 6.17, the corresponding entry for stock options granted to suppliers is use of goods and services (22).)

7.223 Employee stock options should be valued at fair value at grant date ${ }^{62}$ using a market value of equivalent traded options (if available) or using an option pricing model (binomial or Black-Scholes) with suitable allowance for particular features of the options. ${ }^{63}$ After the vesting date, employee stock options are valued at market prices.

\section{Other accounts receivable/payable (6208, $6218,6228,6308,6318,6328$ )}

7.224 Other accounts receivable/payable consist of trade credit and advances and miscellaneous other items due to be paid or received. If an economic event requires a subsequent cash flow, for example, goods and services are sold on credit provided by the supplier and the length of time between the economic event and the time of the cash flow is bridged by an entry in other accounts receivable/payable.

7.225 Trade credit and advances (62081, 62181, 62281, 63081, 63181, 63281) include (i) trade credit extended directly to purchasers of goods and services and (ii) advances for work that is in progress or to be undertaken, such as progress payments made during

\footnotetext{
${ }^{62}$ The terms grant date, vesting date, and exercise date are defined in paragraph 9.77.

${ }^{63}$ The International Accounting Standards Board provides detailed recommendations on how employee stock options may be valued, and its recommendations are likely to be followed by corporations using employee stock options as a form of compensation for their employees. The value of the employee stock options varies between grant date and vesting date and then between the vesting date and exercise date, as the value of the shares covered changes.
} 
construction in advance for work being performed, or for prepayments of goods and services. Such credit arises both from normal delays in receiving payment and from deliberate extensions of vendor credit to finance sales. Trade credit extended by the seller of goods and services does not include loans, debt securities, or other liabilities that are provided by third parties to finance trade. If a government unit issues a promissory note or another type of security to consolidate the payment due on several trade credits, the note or security should be classified as a debt security. Trade credit and advances exclude trade credits that meet the definition of a loan. ${ }^{64}$

7.226 Miscellaneous other accounts receivable/ payable (62082, 62182, 62282, 63082, 63182, 63282) include accrued but unpaid taxes, dividends, payment for purchases and sales of securities paid or received before the instrument is issued, rent, wages and salaries, social contributions, social benefits, and similar items. They also include payments due under financial derivative contracts that are in arrears and payments of amounts that have not yet accrued, such as prepayments of taxes. Some of these prepayments, often called "deposits," should be recorded here rather than in currency and deposits. These "deposits" are repayable only when specific conditions are met. Examples of this type of "deposit" included under miscellaneous other accounts receivable/payable are deposits held by court or tax authorities pending resolution of a dispute, deposits payable in advance to cover breakages or nonpayment for the use of goods and services, and bail deposits. In principle, accrued but unpaid interest should be added to the principal of the underlying asset rather than included in this category. Taxes receivable and/or compensation of employees payable should be separately identified if the amounts are substantial.

\footnotetext{
${ }^{64} \mathrm{~A}$ supplier of goods or services may have a claim on a government unit in the form of a trade credit. When the supplier transfers this claim completely and irrevocably to a financial institution (notably a unit engaged in factoring activity), the original liability of the government unit recorded as trade credit in other accounts payable should be reclassified (by way of other changes in the volume of assets) as a loan when the following two conditions are both met: (i) the government unit has no longer any payment obligation to its supplier, and (ii) the financial institution has no direct or indirect recourse on the supplier (transferor of the claim) if the government unit does not meet its payment obligations in due time. Also, if a trade credit is restructured in such a way that it meets the definition of a loan, it should be reclassified as a loan.
}

7.227 Other accounts receivable/payable should be recorded at nominal value. By definition, other accounts receivable/payable are accrual concepts and do not exist in an accounting system that uses a pure cash basis of recording.

\section{Net Worth}

7.228 As defined in paragraph 7.1, net worth (6) of an institutional unit (or grouping of units) is the total value of its assets minus the total value of its liabilities. Net worth is a balancing item that stems from valuing assets and liabilities (including equity and investment fund shares) at their market prices on the balance sheet date. Net worth can be positive, negative, or zero. As with other balancing items in GFS, net worth cannot be measured independently of the other entries.

7.229 For most government units, the net worth is the economic value of the unit because they usually have no issued shares and other equity. In the case of quasi-corporations, net worth is zero, because the value of the owners' equity is assumed to be equal to its assets minus its liabilities. Even when general government units have liabilities in the form of equity (see paragraph 7.170), the net worth of such government units is zero, similar to that of quasi-corporations, if these shares are not traded or the value of the shares cannot be determined independently. For other corporations, net worth is a component of own funds. In macroeconomic statistics, own funds and net worth have a specific meaning, which may differ from the understanding of these terms within the context of accounting.

7.230 When an autonomous pension fund operates as a defined contribution scheme, the net worth will be zero, because by definition the claims on the pension fund are equal to the assets of the fund. However, a defined-benefit pension scheme operated by an insurance corporation or as an autonomous pension fund can have a net worth, positive or negative, if the assets of the fund exceed or fall short of the fund's liability for the pension benefits, unless there is a claim of the pension fund on the pension manager-in which instance the net worth is also zero (see paragraphs 7.199-7.200).

7.231 Own funds are defined as the difference between total assets (at market values) and total liabilities excluding shares and other equity (at market value). From the foregoing, it follows that the value 
Figure 7.1 Net Worth in a Macroeconomic Statistics Balance Sheet

\begin{tabular}{|l|l|}
\hline \multirow{4}{*}{$\begin{array}{l}\text { Assets (at market } \\
\text { value) }\end{array}$} & $\begin{array}{l}\text { Shares and other equity } \\
\text { (at market value) + net } \\
\text { worth = Own funds }\end{array}$ \\
\cline { 2 - 2 } & $\begin{array}{l}\text { Liabilities excluding } \\
\text { shares and other equity } \\
\text { (at market value) }\end{array}$ \\
\hline
\end{tabular}

of own funds is equal to the value of shares and other equity (at current market prices on the balance sheet date) plus net worth, as illustrated in Figure 7.1.

7.232 In the case of quasi-corporations, their imputed shareholders' equity is equal to their own funds. Public corporations are seen to have a net worth (which could be positive or negative) in addition to the value of the shareholders' equity, if shares are traded in the market or the value can be determined independently. This is because shares are included in the public corporation's balance sheet at their current market price on the balance sheet date.

7.233 If the current market value of equity and investment fund shares cannot be determined independently or they do not trade in the market, an alternative calculation is similar to the treatment of quasi-corporations (see paragraph 7.232). This calculates the value of equity and investment fund shares in such a way that the net worth of the public corporation is zero.

\section{Memorandum Items}

7.234 It may be desirable to record memorandum items to provide supplemental information about items (such as aggregates and balancing items) related to, but not included on, the balance sheet. Table 7.10 shows the memorandum items to the balance sheet proposed in the GFS framework (additional items and subitems may be added, as needed).

\section{Net Financial Worth (6M2)}

7.235 The net financial worth (6M2) of an institutional unit (or grouping of units) is the total value of its financial assets minus the total value of its liabilities. This balancing item is often cited because of the general government and public sectors' influence on the financial system and also because of the difficulties in valuing government-unique nonfinancial assets.

\begin{tabular}{|c|c|}
\hline $6 \mathrm{M} 2$ & Net financial worth \\
\hline $6 \mathrm{M} 3$ & Gross debt at market value \\
\hline $6 \mathrm{M} 4$ & Gross debt at nominal value \\
\hline $6 \mathrm{M} 35$ & Gross debt at face value \\
\hline $6 \mathrm{M} 36$ & Net debt at market value \\
\hline $6 \mathrm{M} 37$ & Net debt at nominal value \\
\hline $6 \mathrm{M} 38$ & Net debt at face value \\
\hline $6 \mathrm{M} 391$ & Concessional loans at nominal value \\
\hline $6 \mathrm{M} 392$ & $\begin{array}{l}\text { Implicit transfers resulting from loans at } \\
\text { concessional interest rates }\end{array}$ \\
\hline $6 \mathrm{M} 5$ & Arrears \\
\hline $6 \mathrm{M} 6$ & Explicit contingent liabilities ${ }^{1}$ \\
\hline $6 \mathrm{M} 61$ & Publicly guaranteed debt \\
\hline $6 \mathrm{M} 62$ & Other one-off guarantees \\
\hline $6 \mathrm{M} 63$ & $\begin{array}{l}\text { Explicit contingent liabilities not } \\
\text { elsewhere classified }\end{array}$ \\
\hline $6 \mathrm{M7}$ & $\begin{array}{l}\text { Net implicit obligations for future social } \\
\text { security benefits }{ }^{1}\end{array}$ \\
\hline $6 \mathrm{M} 8$ & Nonperforming loan assets at fair value \\
\hline $6 \mathrm{M} 81$ & $\begin{array}{l}\text { Nonperforming loan assets at nominal } \\
\text { value }\end{array}$ \\
\hline
\end{tabular}

${ }^{1}$ The contingent liabilities are shown in the Summary Statement of Explicit Contingent Liabilities and Net Implicit Obligations for Future Social Security Benefits (Table 4.6).

\section{Debt $^{65}$}

\section{Gross debt}

7.236 Total gross debt-often referred to as "total debt" or "total debt liabilities" - consists of all liabilities that are debt instruments. A debt instrument is defined as a financial claim that requires payment(s) of interest and/or principal by the debtor to the creditor at a date, or dates, in the future. The following instruments are debt instruments:

- Special Drawing Rights (SDRs)

- Currency and deposits

- Debt securities

- Loans

- Insurance, pension, and standardized guarantee schemes [GFS]

- Other accounts payable.

\footnotetext{
${ }^{65}$ For a detailed discussion on the compilation of public sector debt, see the PSDS Guide.
} 
7.237 From the foregoing list, it follows that all liabilities included in the GFS balance sheet are considered debt, except for liabilities in the form of equity and investment fund shares and financial derivatives and employee stock options. Equity and investment fund shares are not debt instruments because they entitle the holders to dividends and a claim on the residual value of the unit. Financial derivatives are not debt instruments because they do not supply funds or other resources, but rather shift the exposure to risks from one party to another.

7.238 As recommended in the PSDS Guide, debt instruments should be valued on the reference date at nominal value, and, for traded debt securities, at market value as well. Both valuation bases provide useful information about debt. If the nominal and market values of debt instruments are not available, gross debt is at face value. Deviations from these valuation principles should always be specified in the footnotes to the balance sheet.

7.239 These valuations of gross debt are discussed, in turn, in paragraphs 7.240-7.242. For more details on valuation, see paragraphs $3.107-3.129$.

\section{Gross debt at market value (6M3)}

7.240 Gross debt at market value (6M3) means that debt securities are valued at market prices; insurance, pension, and standardized guarantee schemes are valued according to principles that are equivalent to market valuation; and all other debt instruments are valued at nominal prices, which are considered to be the best generally available proxies of their market prices.

\section{Gross debt at nominal value (6M4)}

7.241 Gross debt at nominal value means that debt securities are valued at their nominal values. The nominal value of a debt instrument at any moment in time is the amount that the debtor owes to the creditor. This is a measure of value from the viewpoint of the debtor.

\section{Gross debt at face value (6M35)}

7.242 The face value of a debt instrument is the undiscounted amount of principal to be repaid at (or before) maturity and has been called nominal value in some cases. The use of face value as a proxy for nominal value in measuring the gross debt position can re- sult in an inconsistent approach across all instruments and is not recommended, unless nominal and market values are not available.

\section{Net debt}

7.243 Net debt is calculated as gross debt minus financial assets corresponding to debt instruments. ${ }^{66}$ Financial assets corresponding to debt instruments are:

- Monetary gold and Special Drawing Rights (SDRs)

- Currency and deposits

- Debt securities

- Loans

- Insurance, pension, and standardized guarantee schemes [GFS]

- Other accounts receivable.

7.244 Monetary gold, as defined in the 2008 SNA and this Manual, includes elements of a debt instrument (unallocated gold accounts) and a nondebt instrument (gold bullion). In principle, the gold bullion element of monetary gold should be excluded from the calculation of net debt. However, in practice, the total amount for monetary gold may have to be used in the net debt calculation because compilers of public sector debt statistics may not be able to exclude the gold bullion element.

7.245 Net debt can be calculated at market value (6M36), nominal value (6M37), and face value (6M38).

\section{Concessional loans}

7.246 Loans with concessional interest rates could be seen as providing a benefit to the borrower in the form of a transfer equal to the difference between the actual interest payable and the amounts that would

\footnotetext{
${ }^{66}$ This category calculates net debt as total debt liabilities minus all financial assets corresponding to debt instruments. For some purposes, it may be useful to net individual debt instruments against their corresponding financial assets. For other purposes, it may be useful to calculate debt net of highly liquid assets. However, in most cases, a one-on-one netting of a debt instrument against its corresponding financial asset may not be analytically useful because, typically, specific types of assets are not earmarked to repay specific types of liabilities. Debt net of highly liquid assets is, in most cases, equal to gross debt minus financial assets in the form of currency and deposits. However, in some cases, debt securities held for debt management purposes could be included as highly liquid financial assets.
} 
be payable if market-equivalent interest prevailed. If such a transfer were recognized, it would usually be recorded as current transfer/grant (depending on the type of recipient), and the interest recorded would be adjusted by the same amount. However, the means of incorporating the impact of concessional rates within macroeconomic statistics have not fully evolved, although various alternatives have been advanced. ${ }^{67}$ Accordingly, until the treatment is agreed, information on concessional debt should be provided through supplementary information in the form of two memorandum items. The first shows the stock of concessional loans at nominal value (6M391). The second shows an estimate of the value of the benefit transferred to the borrower-that is, the value of implicit transfers resulting from loans at concessional interest rates (6M392), calculated as described in footnote 67.

\section{Arrears (6M5)}

7.247 Arrears are defined as amounts that are both unpaid and past the due date for payment. In principle, amounts payable for any expense, acquisition of assets, or related to any liability may be in arrears. ${ }^{68}$ For debt liabilities, arrears arise when principal or interest payments are not made when due. For expense and the acquisition of nonfinancial assets, amounts payable may be in arrears from inception. For example, when amounts payable for compensation of employees are not made when due, the other accounts payable for compensation of employees are in arrears. Also, when a contract stipulates payment on delivery

\footnotetext{
${ }^{67}$ The one-off benefit at the point of loan origination can be calculated as being equal to the difference between the nominal value of the debt and its present value using a relevant market discount rate. This option has the advantage of considering all the possible sources of transfers in debt concessionality-maturity period, grace period, and frequency of payments, as well as the interest rate-and is consistent with nominal valuation of loans. Such an approach should be used for official lending involving an intention to convey a benefit and occurrence in a noncommercial setting (usually government-to-government). For example, in debt reorganization through the Paris Club, debt reduction in present value terms is calculated using a market-based discount rate, usually the OECD's Commercial Interest Reference Rate (CIRR). The difference between the nominal value of the applicable debt and its present value is the amount of capital transfer derived from the debt reorganization arrangements. For more details, see the PSDS Guide, paragraphs 4.83-4.86. For the treatment of concessional loans to employees, see paragraph 6.17 .

${ }^{68}$ In some cases, arrears arise for operational reasons (such as minor administrative delays) rather than from a reluctance or inability to pay. Nonetheless, in principle, such arrears should be recorded as arrears when outstanding at the reference date.
}

for goods and services or nonfinancial assets and such amounts payable are not settled on delivery, other accounts payable for these goods and services or nonfinancial assets are in arrears from inception.

7.248 When arrears in an existing liability occur, they should continue to be shown in the same instrument until the liability is extinguished. However, if the contract provides for a change in the characteristics of a financial instrument when it goes into arrears, this change should be recorded as a reclassification through other changes in the volume of assets and liabilities (see paragraphs 3.97, 9.21, and 10.84).

7.249 If under a cash accounting system, arrears are not recorded separately, compilers will need to collect supplementary information to estimate arrears. Information on arrears is useful for various kinds of policy analyses and solvency assessments and should be shown as a memorandum item in the balance sheet where significant. Information on arrears should continue to be collected from their creationthat is, when payments are not made-until they are extinguished, such as when debt arrears are repaid, rescheduled, or forgiven by the creditor, or when (say) wages and salaries in arrears are paid.

7.250 The nominal value of arrears is equal to the value of the payments-interest and principal in the case of liabilities-missed, and any subsequent economic flows, such as the accrual of additional interest on a liability in arrears, or the settlement of arrears. (See also paragraphs 9.22-9.23.)

\section{Explicit Contingent Liabilities (6M6) Overview}

7.251 Contingent liabilities create fiscal risks ${ }^{69}$ and may arise from deliberate public policy or from unforeseen events, such as a financial crisis. Contingent liabilities are obligations that do not arise unless a particular, discrete event(s) occurs in the future. A key difference between contingent liabilities and liabilities ${ }^{70}$ is that one or more conditions must be fulfilled before

\footnotetext{
${ }^{69}$ At the most general level, fiscal risks may be defined as any potential differences between actual and expected fiscal outcomes (e.g., fiscal balances and public sector debt). Contingent liabilities are a specific source of potential fiscal risk.

${ }^{70}$ Liabilities refer to those obligations recognized on a macroeconomic statistics balance sheet in the calculation of an institutional unit's net worth. Contingent liabilities are not included on the balance sheet (i.e., contingent liabilities are not taken into account in the calculation of a unit's net worth).
} 
a contingent liability is recognized as a liability. With contingent liabilities, there is typically uncertainty over whether a payment will be required, and its potential size. $^{71}$

7.252 A distinction is made between explicit and implicit contingent liabilities. Explicit contingent liabilities are defined as legal or contractual financial arrangements that give rise to conditional requirements to make payments of economic value. The requirements become effective if one or more stipulated conditions arise. By contrast, implicit contingent liabilities do not arise from a legal or contractual source but are recognized after a condition or event is realized. While the focus of GFS (and other macroeconomic statistical systems) is largely on explicit contingent liabilities, implicit contingent liabilities, such as the net implicit obligations for future social security benefits (see paragraph 7.261), are important factors in fiscal risk and vulnerability analyses. Other examples of implicit contingent liabilities include ensuring the solvency of the banking sector, covering the obligations of subnational governments (state and local governments) or the central bank in the event of a default, assuming unguaranteed debt of public sector units, and potential spending for natural disaster relief. ${ }^{72}$

7.253 Figure 7.2 provides an overview of liabilities and contingent liabilities in macroeconomic statistics. Explicit contingent liabilities can take a variety of forms, although guarantees are the most common. However, not all guarantees are contingent liabilities; as discussed earlier in this chapter, guarantees in the form of financial derivatives and provisions for calls under standardized guarantee schemes are liabilities on the balance sheet. On the other hand, one-off guarantees are contingent liabilities.

7.254 Explicit contingent liabilities comprise:

- Publicly guaranteed debt (6M61), which is oneoff guarantees in the form of loan and other debt instrument guarantees (see paragraphs 7.259-7.260)

\footnotetext{
${ }^{71}$ Uncertainty about the potential size of liabilities does not make them contingent liabilities.

${ }^{72}$ It is recommended in this Manual (and the PSDS Guide) to include as a separate memorandum item in the balance sheet the net obligations for future social security benefits-often the largest implicit contingency of government.
}

- Other one-off guarantees (6M62) for other than publicly guaranteed debt (see paragraphs 7.259-7.260)

- Explicit contingent liabilities not elsewhere classified (6M63), which are explicit contingent liabilities that are not in the form of guarantees-for example:

- Potential legal claims, which are claims stemming from pending court cases ${ }^{73}$

- Indemnities, which are commitments to accept the risk of loss or damage another party might suffer (e.g., indemnities against unforeseen tax liabilities arising in government contracts with other units)

- Uncalled capital, which is an obligation to provide additional capital, on demand, to an entity of which it is a shareholder (e.g., an international financial institution)

- Potential payments resulting from PPP arrangements.

7.255 Information on the stock positions of one-off guarantees is relevant for public financial policy and analysis-particularly the stock position of publicly guaranteed debt. It is recommended that publicly guaranteed debt (6M61) should be shown, at nominal value, as a memorandum item to the balance sheet. If significant, information on other one-off guarantees (6M62) and explicit contingent liabilities not elsewhere classified (6M63) should also be included as a memorandum item to the balance sheet, at nominal value. ${ }^{74}$ One-off guarantees are discussed in paragraphs 7.256-7.260.

\section{One-off guarantees}

7.256 One-off guarantees comprise those types of guarantees where the debt instrument is so particular that it is not possible to calculate the degree of risk

\footnotetext{
${ }^{73} \mathrm{~A}$ pending legal case may also be a contingent asset-for example, a case in which the government has claimed damages against another party.

${ }^{74}$ Limitations of this approach are that it offers no information on the likelihood of the contingency occurring and it may overstate the possible risk. For loan and other debt instrument guarantees, the maximum potential loss is likely to be less than their nominal value, because not all debts will default. There are several other approaches that address limitations to valuing explicit contingent liabilities; they are discussed in detail in Chapter 4 of the PSDS Guide and in Chapter 9 of the EDS Guide. The actual approach adopted will depend on the availability of information on the type of contingency. For this reason, it is particularly important to provide metadata on the method(s) used to value contingent liabilities.
} 


\section{Figure 7.2 Overview of Liabilities and Contingent Liabilities in Macroeconomic Statistics}

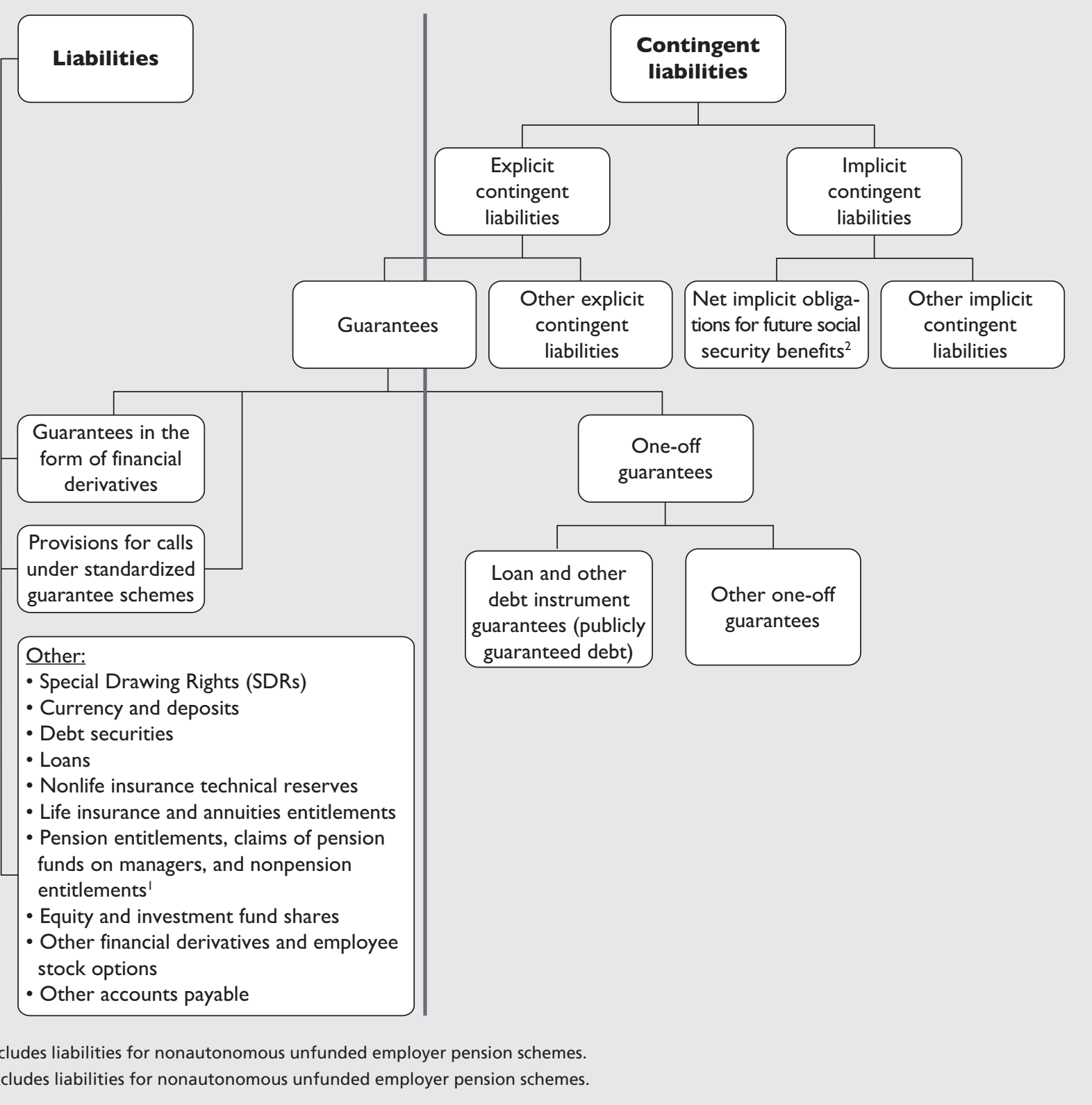

associated with the debt with any degree of accuracy. In contrast to standardized guarantees, one-off guarantees are individual, and guarantors are not able to make a reliable estimate of the risk of calls.

7.257 In most cases, a one-off guarantee is considered a contingent liability of the guarantor. Liabilities under one-off guarantees continue to be attributed to the debtor, not the guarantor, unless and until the guarantee is called.
7.258 In contrast, a one-off guarantee granted by government to a corporation in financial distress and with a very high likelihood to be called is treated as if the guarantee is called at inception. ${ }^{75}$ The activation

\footnotetext{
${ }^{75}$ Such treatment should be undertaken with caution, not least to avoid double-counting of the debt and inconsistencies with other macroeconomic statistics (which still record the claim to the original debtor). Eurostat uses the following practical guidance with regards to publicly guaranteed debt: if government, as a guarantor, makes a payment on an existing guaranteed debt in three consecutive years,
} 
of such a one-off guarantee is treated as debt assumption ${ }^{76}$ and this liability is part of the public sector unit's balance sheet.

7.259 One-off guarantees may be grouped into loan and other debt instrument guarantees and other one-off guarantees:

- Loan and other debt instrument guaranteesor one-off guarantees of payment-are commitments by one party to bear the risk of nonpayment by another party. Guarantors are required to make a payment only if the debtor defaults. Loans and other debt instrument guarantees constitute publicly guaranteed debt that is defined as debt liabilities of public and private sector units, the servicing of which is contractually guaranteed by public sector units.

- Other one-off guarantees include credit guarantees (such as lines of credit and loan commitments), contingent credit availability guarantees, and contingent credit facilities. Lines of credit and loan commitments provide a guarantee that undrawn funds will be available in the future, but no financial liability/asset exists until such funds are actually provided. Undrawn lines of credit and undisbursed loan commitments are contingent liabilities of the issuing institutions-generally, banks. Letters of credit are promises to make payment upon the presentation of pre-specified documents. Underwritten note issuance facilities provide a guarantee that a borrower will be able to issue short-term notes and that the underwriting institution(s) will take up any unsold portion of the notes. Only when funds are advanced by the underwriting institution(s) will a liability/asset be created. The unutilized portion is a contingent liability. Other note guarantee facilities providing contingent credit or back-up purchase facilities are revolving underwriting facilities, multiple options facilities, and global note facilities. Bank and nonbank financial institutions provide back-up purchase facilities. Again, the unutilized amounts of these facilities are contingent liabilities.

7.260 Loan and other debt instrument guarantees (publicly guaranteed debt) differ from the other types of one-off guarantees. This is because the guarantor

and this situation is expected to continue, then the debt is considered to be assumed, normally in its entirety (or for the proportion government is expected to repay, if there is evidence of that).

${ }^{76}$ Debt assumption is discussed in paragraphs A3.26-A3.31. guarantees the servicing of an existing debt of other public and private sector units. With the other oneoff guarantees, no financial liability/asset exists until funds are provided or advanced.

\section{Net Implicit Obligations for Future Social Security Benefits (6M7)}

7.261 As explained in paragraphs 7.194 and A2.39, no liability is recognized in macroeconomic statistical systems for social security benefits-such as retirement benefits (other than employment-related pensions) and health care benefits-payable in the future. ${ }^{77}$ These implicit obligations to pay social security benefits in the future are not contractual obligations and are therefore not recorded on the balance sheet (see paragraph 7.252). The present value of social security benefits that have already been earned according to the existing laws and regulations but are payable in the future should be calculated in a manner similar to the liabilities of an employment-related pension scheme. This amount minus the present value of social security scheme contributions provides an indication of the net implicit obligations that a government unit has for social security benefits payable in the future.

\section{Nonperforming Loan Assets at Fair Value (6M8)}

7.262 Nonperforming loans are those for which (i) payments of principal and/or interest are past due by three months (90 days) or more; or (ii) interest payments equal to three months (90 days) interest or more have been capitalized (reinvested to the principal amount) or payment has been delayed by agreement; or (iii) evidence exists to reclassify a loan as nonperforming even in the absence of a 90-day past due payment, such as when the debtor files for bankruptcy. The amount of nonperforming debt outstanding remains a legal liability of the debtor and interest should continue to accrue, unless the liability has been extinguished (e.g., by repayment or as a result of a bilateral arrangement between debtor and creditor).

\footnotetext{
${ }^{77}$ In contrast, social security benefits due for payment but not yet paid are included as other accounts payable in a public sector unit's balance sheet. Also included in the balance sheet (and thus excluded from implicit contingent liabilities) are public sector units' liabilities for unfunded nonautonomous pension schemes for their employees.
} 
7.263 As mentioned earlier in this chapter, loans are recorded at nominal value (i.e., the amount advanced plus interest accrued and not paid minus any repayments). It is recognized that nominal value provides an incomplete view of the financial position of the creditor, particularly when the loans are nonperforming. In such cases, information on the nominal value (6M81), as well as the fair value $(6 \mathrm{M} 8),{ }^{78}$ of nonperforming loan assets should be included as a memorandum item to the balance sheet.

\section{Classification of the Counterparty of Financial Assets and Liabilities by Institutional Sector}

7.264 The preceding section discussed the classifications of financial assets and liabilities based on the characteristics of the instrument underlying the claim. For a fuller understanding of financial assets and liabilities of the general government or the public sector, the counterparties to these financial relationships should also be considered. For example, a classification of liabilities according to the economic sectors providing the financing (i.e., the sources of funding) complements the classification by type of financial instrument. Information on debtor-creditor relationships between sectors and subsectors is essential for proper consolidation of GFS. A classification of financial assets and liabilities according to whether the counterparty is a public or private nonfinancial or financial corporation, respectively, will be necessary to compile accurate consolidated general government or public sector balance sheets.

7.265 Two parties are associated with all financial claims. As a result, it is possible to cross-classify the financial instruments of financial claims with the sector of the counterparty, making a distinction between resident and nonresident units. ${ }^{79}$ This supplemental classification is presented in Table 7.11, which should be compiled separately for financial assets and liabilities. ${ }^{80}$

\footnotetext{
${ }^{78}$ The concepts nominal value and fair value are described in paragraph 3.115 .

${ }^{79}$ Although gold bullion has no counterparty, by convention, the counterparty to the stock position in gold bullion is shown as "other nonresidents" in Table 7.11.

${ }^{80}$ See Chapter 2 of this Manual, and the 2008 SNA, Chapter 4, for a description of sector classification. Issues in the identification of counterparties of traded debt securities are discussed in the PSDS Guide, Chapter 7.
}

\section{Classification of Debt Liabilities and Financial Assets Corresponding to Debt Instruments by Maturity}

7.266 A supplementary classification of debt liabilities and financial assets corresponding to debt instruments by maturity and type of financial instrument provides information on the liquidity dimensions of debt. The maturity of a debt instrument refers to the time until the debt is extinguished according to the contract between the debtor and the creditor. A debt instrument's maturity can be either short-term or long-term:

- Short-term is defined as payable on demand or with a maturity of one year or less. This category includes arrears and interest on arrears.

- Long-term is defined as having a maturity of more than one year or no stated maturity (other than debt repayable on demand, which is considered short-term).

7.267 Maturity may relate to:

- Original maturity, which is the period from the issue date until the final contractually scheduled payment date, or

- Remaining maturity or residual maturity, which is the period from the reference date (balance sheet date) until the final contractually scheduled payment date.

7.268 This Manual recommends a three-way classification (see Table 7.12) that allows for deriving debt statistics on both original and remaining maturity bases:

- Short-term debt on an original maturity basis

- Long-term debt due for payment within one year or less

- Long-term debt due for payment in more than one year.

7.269 To derive short-term debt on a remaining maturity basis, the second bullet above can be combined with the first bullet above. To derive long-term debt on an original maturity basis, the second bullet above can be combined with the third bullet above. Other aggregates on an original or a remaining maturity basis can be derived directly from Table 7.12. The classification codes in Table 7.12 correspond to those in Table 7.9; only a suffix has been added to indicate the type of maturity. 
Table 7.11 Cross-Classification of Financial Assets and Liabilities by the Institutional Sector of the Counterparty

\begin{tabular}{|c|c|c|c|c|c|c|c|c|}
\hline & $\begin{array}{l}\text { Monetary } \\
\text { gold }{ }^{1} \text { and } \\
\text { SDRs }\end{array}$ & $\begin{array}{l}\text { Currency } \\
\text { and } \\
\text { deposits }\end{array}$ & $\begin{array}{c}\text { Debt } \\
\text { securities }\end{array}$ & Loans & $\begin{array}{l}\text { Equity and } \\
\text { investment } \\
\text { fund shares }\end{array}$ & $\begin{array}{l}\text { Insurance, } \\
\text { pension, and } \\
\text { standardized } \\
\text { guarantee } \\
\text { schemes [GFS] }\end{array}$ & $\begin{array}{l}\text { Financial } \\
\text { derivatives } \\
\text { and } \\
\text { employee } \\
\text { stock options }\end{array}$ & $\begin{array}{l}\text { Other } \\
\text { accounts } \\
\text { receivable/ } \\
\text { payable }\end{array}$ \\
\hline \multicolumn{9}{|l|}{ Financial assets: } \\
\hline \multicolumn{9}{|l|}{ Domestic debtors } \\
\hline \multicolumn{9}{|l|}{ General government ${ }^{2}$} \\
\hline \multicolumn{9}{|l|}{ Central bank } \\
\hline \multicolumn{9}{|l|}{$\begin{array}{l}\text { Deposit-taking } \\
\text { corporations except the } \\
\text { central bank }\end{array}$} \\
\hline \multicolumn{9}{|c|}{$\begin{array}{l}\text { Public deposit-taking } \\
\text { corporations except the } \\
\text { central bank }\end{array}$} \\
\hline \multicolumn{9}{|c|}{$\begin{array}{l}\text { Private deposit-taking } \\
\text { corporations except the } \\
\text { central bank }\end{array}$} \\
\hline \multicolumn{9}{|l|}{$\begin{array}{l}\text { Other financial } \\
\text { corporations }\end{array}$} \\
\hline \multicolumn{9}{|l|}{$\begin{array}{l}\text { Public other financial } \\
\text { corporations }\end{array}$} \\
\hline \multicolumn{9}{|l|}{$\begin{array}{l}\text { Private other financial } \\
\text { corporations }\end{array}$} \\
\hline \multicolumn{9}{|c|}{ Nonfinancial corporations } \\
\hline \multicolumn{9}{|l|}{$\begin{array}{l}\text { Public nonfinancial } \\
\text { corporations }\end{array}$} \\
\hline \multicolumn{9}{|l|}{$\begin{array}{l}\text { Private nonfinancial } \\
\text { corporations }\end{array}$} \\
\hline \multicolumn{9}{|c|}{$\begin{array}{l}\text { Households and nonprofit } \\
\text { institutions serving } \\
\text { households }\end{array}$} \\
\hline \multicolumn{9}{|l|}{ External debtors } \\
\hline \multicolumn{9}{|l|}{ General government } \\
\hline \multicolumn{9}{|l|}{$\begin{array}{l}\text { International } \\
\text { organizations }\end{array}$} \\
\hline \multicolumn{9}{|l|}{$\begin{array}{l}\text { Financial corporations } \\
\text { other than international } \\
\text { organizations }\end{array}$} \\
\hline \multicolumn{9}{|l|}{ Central banks } \\
\hline \multicolumn{9}{|c|}{$\begin{array}{l}\text { Financial corporations } \\
\text { not elsewhere classified }\end{array}$} \\
\hline \multicolumn{9}{|l|}{ Other nonresidents } \\
\hline \multicolumn{9}{|l|}{ Liabilities: } \\
\hline \multicolumn{9}{|l|}{ Domestic creditors } \\
\hline \multicolumn{9}{|l|}{$\begin{array}{l}\text { Same institutional } \\
\text { breakdown as above }\end{array}$} \\
\hline \multicolumn{9}{|l|}{ External creditors } \\
\hline $\begin{array}{l}\text { Same institutional } \\
\text { breakdown as above }\end{array}$ & & & & & & & & \\
\hline
\end{tabular}

${ }^{1}$ Gold bullion does not have a counterparty. By convention, in this table, the counterparty to the stock position in gold bullion is shown as other nonresidents.

2Zero if data cover the consolidated general government. Further breakdown/of which lines could allow for the identification of subsectors and individual units (see Table 3.1). 
Table 7.12 Classification of Debt Liabilities and Financial Assets Corresponding to Debt Instruments by Maturity and by Type of Debt Instrument

\section{Financial assets corresponding to debt instruments \\ Monetary gold and Special Drawing Rights (SDRs) \\ Currency and deposits \\ Debt securities \\ Loans \\ Insurance, pension, and standardized guarantee schemes [GFS] \\ Nonlife insurance technical reserves \\ Life insurance and annuities entitlements \\ Pension entitlements [GFS] \\ Claims of pension funds on pension manager \\ Provisions for calls under standardized \\ guarantee schemes \\ Other accounts receivable \\ Trade credit and advances \\ Miscellaneous other accounts receivable \\ Domestic \\ Same instrument breakdown as above, but excluding monetary gold and SDRs \\ External}

Same instrument breakdown as above

Debt instruments (= gross debt)

Special Drawing Rights (SDRs)

Currency and deposits

Debt securities

Loans

Insurance, pension, and standardized guarantee schemes [GFS]

Nonlife insurance technical reserves

Life insurance and annuities entitlements

Pension entitlements [GFS]

Claims of pension funds on pension manager

Provisions for calls under standardized

guarantee schemes

Other accounts payable

Trade credit and advances

Miscellaneous other accounts payable

Domestic

Same instrument breakdown as above, but excluding SDRs

\section{External}

\section{Same instrument breakdown as above}

Long-term by original maturity

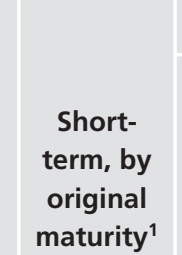

(a)

62.1

6201.1

6202.1

6203.1

6204.1

6206.1

62061.1

62062.

62063.1

62064.1

62065.1

6208.1

62081.1

62082.1

621.1

6212.1-

6218.1

622.1

6221.1-

6228.1

63.1

6301.1

6302.1

6303.1

6304.1

6306.1

63061.1

63062.

63063.

63064.1

63065.1

6308.1

63081.1

63082.1

631.1

6312.1-

6318.1

632.1

6321.1-

6328.1

\section{With}

payment due in one

year or les

(b)

62.2

6201.2

6202.2

6203.2

6204.2

6206.2

62061.2

62062.2

62063.2

62064.2

62065.2

6208.2

62081.2

62082.2

621.2

6212.2-

6218.2

622.2

6221.2-

6228.2

63.2

6301.2

6302.2

6303.2

6304.2

6306.2

63061.2

63062.2

63063.2

63064.2

63065.2

6308.2

63081.2

63082.2

631.2

6312.2-

6318.2

632.2

6321.2-

6328.2

\section{With payment}

due in more

than one year $=$ Long-term by remaining maturity (c)

62.3

6201.3

6202.3

6203.3

6204.3

6206.3

62061.3

62062.3

62063.3

62064.3

62065.3

6208.3

62081.3

62082.3

621.3

6212.3-

6218.3

622.3

6221.3-

6228.3

63.3

6301.3

6302.3

6303.3

6304.3

6306.3

63061.3

63062.3

63063.3

63064.3

63065.3

6308.3

63081.3

63082.3

631.3

6312.3-

6318.3

632.3

6321.3-

6328.3
Shortterm by remaining maturity

(b) + (c) (a) + (b)

$62.4 \quad 62.5$

$6201.4 \quad 6201.5$

$6202.4 \quad 6202.5$

$6203.4 \quad 6203.5$

$6204.4 \quad 6204.5$

$6206.4 \quad 6206.5$

$62061.4 \quad 62061.5$

$62062.4 \quad 62062.5$

$62063.4 \quad 62063.5$

$62064.4 \quad 62064.5$

$62065.4 \quad 62065.5$

$6208.4 \quad 6208.5$

$62081.4 \quad 62081.5$

$62082.4 \quad 62082.5$

$621.4 \quad 621.5$

6212.4- 6212.5-

$6218.4 \quad 6218.5$

$622.4 \quad 622.5$

6221.4- 6221.5-

$6228.4 \quad 6228.5$

$63.4 \quad 63.5$

$6301.4 \quad 6301.5$

$6302.4 \quad 6302.5$

\begin{tabular}{l|l}
6303.4 & 6303.5
\end{tabular}

$6304.4 \quad 6304.5$

\begin{tabular}{l|l}
6306.4 & 6306.5
\end{tabular}

\begin{tabular}{l|l}
63061.4 & 63061.5
\end{tabular}

\begin{tabular}{l|l}
63062.4 & 63062.5
\end{tabular}

$63063.4 \quad 63063.5$

$63064.4 \quad 63064.5$

$63065.4 \quad 63065.5$

\begin{tabular}{l|l}
6308.4 & 6308.5
\end{tabular}

$63081.4 \quad 63081.5$

$63082.4 \quad 63082.5$

$631.4 \quad 631.5$

6312.4- 6312.5-

$6318.4 \quad 6318.5$

$632.4 \quad 632.5$

6321.4- 6321.5-

\begin{tabular}{l|l}
6328.4 & 6328.5
\end{tabular}

${ }^{1}$ This category includes arrears and interest on arrears 
7.270 Measuring the value of outstanding long-term public sector debt (original maturity) falling due in one year or less may raise practical difficulties, in which instance, one proxy measure that may be used is the undiscounted value of principal payments on long-term public sector debt liabilities (original maturity basis) due to mature in one year or less. This proxy measure is incomplete in its coverage of interest payments falling due in the coming year but can be compiled using the principles for projecting payments in a debt-service schedule.
7.271 Statistics on a remaining maturity basis permit an assessment of liquidity risk by indicating when public sector debt payments will fall due. Information on payments becoming due in the short- to nearterm is particularly relevant for this analysis. Statistics on a remaining maturity basis are also used for debt management purposes. Statistics on an original maturity basis provide an indication of the borrower's credit-worthiness and the type of markets in which it is borrowing. 
- Consumption of fixed capital is an internal transaction that records the decrease in the value of fixed assets because they have been used repeatedly or continuously in production.

- Inventories can be acquired (additions) or disposed of (withdrawals) through internal transactions as well as transactions with other units. For example, withdrawals from inventories of materials and supplies for use in the production of general government services and transfers of completed production from work-in-progress inventories to inventories of finished goods are internal transactions. Recurrent losses and spoilage of goods held in inventories are also treated as internal transactions.

8.4 All transactions that increase a unit's holdings of nonfinancial assets are labeled acquisitions. With the exception of consumption of fixed capital, all transactions that decrease a unit's holdings of nonfinancial assets are labeled disposals. Thus, the results of transactions in a particular category of nonfinancial assets can be presented either as total acquisitions, total disposals, and consumption of fixed capital, or as net investment in nonfinancial assets. ${ }^{2}$ The net investment in a nonfinancial asset is its acquisitions minus disposals minus consumption of fixed capital. The gross investment in a nonfinancial asset is its acquisitions minus disposals (i.e., consumption of fixed capital is not taken into account). On a cash basis, the purchases minus the sales of nonfinancial assets are referred to as the net cash outflow from investment in nonfinancial assets.

8.5 The remainder of this chapter first describes costs of ownership transfer, valuation, time of recording, consumption of fixed capital, and netting of transactions that affect nonfinancial assets and then provides details on the classification of transactions that affect specific categories of nonfinancial assets.

\section{Costs of Ownership Transfer}

8.6 Costs of ownership transfer are the costs associated with acquiring and disposing of nonfinancial assets (other than inventories ${ }^{3}$ ) and consist of:

- All professional charges or commissions incurred by both units acquiring or disposing of an asset,

\footnotetext{
${ }^{2}$ The net investment in inventories is referred to as "changes in inventories." Net investment in nonfinancial assets can be positive or negative.

${ }^{3}$ Usually, there are no costs of ownership transfer on inventories.
}

such as fees paid to lawyers, architects, surveyors, engineers, and valuers, and commissions paid to estate agents and auctioneers

- Any trade and transport costs separately invoiced to the purchaser

- All taxes payable by the unit acquiring the asset on the transfer of ownership of the asset

- Any tax payable on the disposal of an asset

- Any delivery and installation or disinstallation costs not included in the price of the asset being acquired or disposed of

- Any terminal costs ${ }^{4}$ incurred at the end of an asset's life, such as those required to render the structure safe or to restore the environment in which it is situated.

8.7 The costs of ownership transfer on fixed assets, valuables, and nonproduced assets are treated as transactions in fixed assets. In particular, transactions in the:

- Costs of ownership transfer on fixed assets are recorded as transactions in the relevant fixed asset

- Costs of ownership transfer on valuables are recorded as transactions in valuables (313.1)

- Costs of ownership transfer on land are recorded, by convention, with land improvements (31114.1), a fixed asset

- Costs of ownership transfer on nonproduced assets other than land are recorded in fixed assets as transactions in costs of ownership transfer on nonproduced assets other than land (31133.1), as explained in paragraph 8.42; in the balance sheet, however, these costs of ownership transfer on nonproduced assets other than land are incorporated in the value of the asset to which they relate (see paragraph 3.111), even though the asset is nonproduced (i.e., there are no costs of ownership transfer on nonproduced assets other than land shown separately in the balance sheet).

\footnotetext{
${ }^{4}$ In the case of some significantly large and important assets, such as oil rigs and nuclear power stations, there may also be major costs associated with the decommissioning of the asset at the end of its productive life. For some land sites, such as those used for landfill, there may be large costs associated with rehabilitation of the site. These are referred to collectively as terminal costs.
} 
8.8 Costs of ownership transfer are attributed to the purchaser or seller of the asset according to which unit bears the responsibility of meeting the costs. These costs of ownership transfer should be written off as consumption of fixed capital, as discussed in paragraph 6.60. Interest and other financing charges incurred in connection with a transaction are not costs of ownership transfer.

\section{Valuation}

8.9 General principles for valuation of transactions in assets and liabilities are discussed in paragraphs 3.108-3.112. Acquisitions and disposals of fixed assets and valuables are valued at market prices (i.e., exchange value plus costs of ownership transfer). Fixed assets acquired through barter or transfer in kind are valued at a market price-equivalent. Fixed assets produced for own-account capital formation or for transfers in kind are valued at their estimated market prices before adding any taxes less subsidies, transport, or distribution margins, or by their costs of production when satisfactory estimates of market prices cannot be made. ${ }^{5}$

8.10 Additions to and withdrawals from inventories are valued at market prices applicable at the time of the addition or withdrawal, which in the case of withdrawals may be quite different from their value when acquired. ${ }^{6}$ No costs for installation or ownership transfer are added or subtracted for transactions in inventories.

8.11 Acquisitions and disposals of land are valued at their exchange value, and the costs of ownership transfer on land are included, by convention, with land improvements (311141.1). Acquisitions and disposals of nonproduced assets other than land are valued at their exchange value. The costs of ownership transfer on nonproduced assets other than land are recorded as a separate category of fixed assets, costs

\footnotetext{
${ }^{5}$ In GFS, it is assumed that market prices of fixed assets constructed by general government units will not be known, and these values are calculated as the sum of expense on compensation of employees, use of goods and services, and the consumption of fixed capital used for own-account production of these assets. This treatment also applies to the production of valuables and major improvements to land when carried out on own account.

${ }^{6}$ Holding gains on inventories are discussed in paragraphs $10.16-10.17$
}

of ownership transfer on nonproduced assets other than land (31133.1), as explained in paragraph 8.42.

8.12 General government units may acquire or dispose of nonfinancial assets on a nonmarket basis as an element of their fiscal policy, either by purchasing an asset for more than its market value or by selling an asset for less than its market value. By their nature, such transactions involve a transfer component. If the asset's market value can be determined, then the transaction should be valued at that amount and a second transaction should be recorded as an expense to account for the transfer. ${ }^{7}$ Usually, however, there is not an active market for the assets and it is difficult to estimate a market value. In this case, the value of the acquisition or disposal should be the amount of economic value exchanged, which could be in the form of ownership rights on physical objects (e.g., a dwelling) or intangible assets (e.g., a film original).

\section{Time of Recording}

8.13 As described in paragraph 3.62, on an accrual basis, transactions are recorded at the time economic value is created, transformed, exchanged, transferred, or extinguished. For transactions in nonfinancial assets, this time is when the economic ownership of the nonfinancial assets is obtained or relinquished. On a cash basis, transactions are recorded when cash payments are made.

8.14 Transactions (including by barter, payment in kind, or transfer in kind) ${ }^{8}$ in nonfinancial assets are, in principle, recorded the moment when economic ownership changes, which often may depend on the provisions in the sales contract. When change of ownership is not obvious, the time of recording by the transaction partners ${ }^{9}$ may be a good indication and, failing that, the moment when there is a change in physical possession or control.

8.15 The time of recording of the acquisition of a new nonfinancial asset depends on how the asset is acquired.

\footnotetext{
${ }^{7}$ The expense often will be a capital transfer to a market enterprise and classified as capital transfers not elsewhere classified (2822). It would be a capital grant if the recipient is a general government unit. For inventories, this type of transfer is a subsidy (see paragraph 6.91). ${ }^{8}$ These acquisitions and disposals are excluded from a pure cash basis of recording.

${ }^{9}$ To maintain symmetry in the macroeconomic system, the time of recording should be the same for both partners to the transaction.
} 
- If the asset is acquired from the producing unit as a finished good, then the timing is determined in the same manner as for the purchase of an existing asset-that is, when economic ownership changes hands. Typically, this time is not the time at which the asset was produced or the time at which it is put to use in production.

- When another unit produces buildings and structures under a contract of sale agreed in advance with the general government unit, and the production extends over more than one reporting period, then ownership of the structure is deemed to be transferred to the government unit as work proceeds; stage or progress payments may approximate the value of the transactions in fixed assets to be recorded. ${ }^{10}$ In the absence of a contract of sale, the incomplete production each period is added to work in progress of the contractor (see also paragraph 7.37).

- When production is carried out on own account, there is no formal transfer of ownership. The producing unit effectively takes possession progressively as production proceeds, so that the asset is acquired as each transaction involved in its production is recorded. For example, if a government unit constructs a building using its own workforce, then each use of goods and services and work performed by employees is classified as an acquisition of the fixed asset as work takes place.

8.16 Consumption of fixed capital, in principle, should be recorded continuously throughout each reporting period. In practice, consumption of fixed capital can be computed only after the end of the reporting period because its value depends on the average price of the asset over the entire reporting period (see paragraphs 6.53-6.61).

8.17 Fixed assets acquired or disposed of by means of a financial lease are deemed to be acquired or disposed of when the lease is signed or economic control of the asset otherwise changes hands.

\section{Consumption of Fixed Capital}

8.18 Consumption of fixed capital is an internal transaction that reflects the fact that an institutional

\footnotetext{
${ }^{10} \mathrm{~A}$ transaction in other accounts receivable/payable is recorded if the value of the stage payment exceeds the value of the work put in place. As work proceeds, an acquisition of fixed assets is recorded by the final owner until the other accounts receivable/ payable are exhausted.
}

unit used up a portion of each of its fixed assets through its productive activities during the reporting period and the value of those assets declined correspondingly. As a result, consumption of fixed capital (23), which is recorded as an expense, is also recorded as a transaction that reduces the value of the respective category of fixed asset, so that there is no impact on expenditure nor net lending/net borrowing (see paragraph 4.20). The recording of consumption of fixed capital is discussed in detail in paragraphs 6.53-6.61 and Box 6.1.

\section{Netting of Transactions}

8.19 It is recommended that transactions in nonfinancial assets other than inventories be presented as acquisitions, disposals, and consumption of fixed capital, as indicated in Table 8.1. The net investment in a category of nonfinancial assets is computed as acquisitions minus disposals minus consumption of fixed capital.

8.20 Acquisitions of, use of, and disposals of inventories should be netted because the separate data for acquisitions and disposals are not economically meaningful. In addition, as a matter of practice, it is often impossible to estimate individual transactions in inventories (see paragraphs 8.44-8.47). Inventories are not subject to consumption of fixed capital.

\section{Classification and Recording of Transactions in Nonfinancial Assets}

8.21 The classification of transactions in nonfinancial assets is shown in Table 8.1. The table summarizes transactions in nonfinancial assets as acquisitions, disposals, and consumption of fixed capital.

8.22 The classification of transactions in nonfinancial assets is identical to the classification of stock positions in nonfinancial assets employed in Chapter 7 (Table 7.2). Chapter 7 also provides full definitions of the assets included in each category, and those definitions are not repeated here. This chapter provides guidance applicable to transactions affecting all or most categories of nonfinancial assets. The remainder of this section provides guidance only on those transactions for which the general guidance may not be sufficient.

8.23 In addition to the classification of transactions in nonfinancial assets described in this chapter, the Classification of the Functions of Government (COFOG) can also be applied to the acquisitions 


\section{Table 8.1 Classification of Transactions in Nonfinancial Assets}

\begin{tabular}{|c|c|c|c|c|}
\hline & Acquisitions of & Disposals of & $\begin{array}{l}\text { Consumption of } \\
\text { fixed capital }^{1}\end{array}$ & $\begin{array}{c}\text { Net investment } \\
\text { in nonfinancial } \\
\text { assets }\end{array}$ \\
\hline Nonfinancial assets & 31.1 & 31.2 & $31.3=23$ & 31 \\
\hline Fixed assets & 311.1 & 311.2 & 311.3 & 311 \\
\hline Buildings and structures & 3111.1 & 3111.2 & 3111.3 & 3111 \\
\hline Dwellings & 31111.1 & 31111.2 & 31111.3 & 31111 \\
\hline Buildings other than dwellings & 31112.1 & 31112.2 & 31112.3 & 31112 \\
\hline Other structures & 31113.1 & 31113.2 & 31113.3 & 31113 \\
\hline Land improvements & 31114.1 & 31114.2 & 31114.3 & 31114 \\
\hline Machinery and equipment & 3112.1 & 3112.2 & 3112.3 & 3112 \\
\hline Transport equipment & 31121.1 & 31121.2 & 31121.3 & 31121 \\
\hline Other machinery and equipment & 31122.1 & 31122.2 & 31122.3 & 31122 \\
\hline $\begin{array}{l}\text { Information, computer, and } \\
\text { telecommunication (ICT) equipment }\end{array}$ & 311221.1 & 311221.2 & 311221.3 & 311221 \\
\hline $\begin{array}{l}\text { Machinery and equipment not } \\
\text { elsewhere classified }\end{array}$ & 311222.1 & 311222.2 & 311222.3 & 311222 \\
\hline Other fixed assets & 3113.1 & 3113.2 & 3113.3 & 3113 \\
\hline Cultivated biological resources & 31131.1 & 31131.2 & 31131.3 & 31131 \\
\hline $\begin{array}{l}\text { Animal resources yielding repeat } \\
\text { products }\end{array}$ & 311311.1 & 311311.2 & 311311.3 & 311311 \\
\hline $\begin{array}{l}\text { Tree, crop, and plant resources } \\
\text { yielding repeat products }\end{array}$ & 311312.1 & 311312.2 & 311312.3 & 311312 \\
\hline Intellectual property products & 31132.1 & 31132.2 & 31132.3 & 31132 \\
\hline Research and development & 311321.1 & 311321.2 & 311321.3 & 311321 \\
\hline Mineral exploration and evaluation & 311322.1 & 311322.2 & 311322.3 & 311322 \\
\hline Computer software and databases & 311323.1 & 311323.2 & 311323.3 & 311323 \\
\hline Computer software & 3113231.1 & 3113231.2 & 3113231.3 & 3113231 \\
\hline Databases & 3113232.1 & 3113232.2 & 3113232.3 & 3113232 \\
\hline $\begin{array}{l}\text { Entertainment, literary, and artistic } \\
\text { originals }\end{array}$ & 311324.1 & 311324.2 & 311324.3 & 311324 \\
\hline $\begin{array}{l}\text { Other intellectual and property } \\
\text { products }\end{array}$ & 311325.1 & 311325.2 & 311325.3 & 311325 \\
\hline $\begin{array}{l}\text { Costs of ownership transfer on } \\
\text { nonproduced assets other than land }\end{array}$ & 31133.1 & 31133.2 & 31133.3 & 31133 \\
\hline Weapons systems & 3114.1 & 3114.2 & 3114.3 & 3114 \\
\hline Inventories ${ }^{2}$ & & & & 312 \\
\hline Materials and supplies & & & & 31221 \\
\hline Work in progress & & & & 31222 \\
\hline Finished goods & & & & 31223 \\
\hline Goods for resale & & & & 31224 \\
\hline Military inventories & & & & 31225 \\
\hline Valuables & 313.1 & 313.2 & & 313 \\
\hline Nonproduced assets & 314.1 & 314.2 & & 314 \\
\hline Land & 3141.1 & 3141.2 & & 3141 \\
\hline Mineral and energy resources & 3142.1 & 3142.2 & & 3142 \\
\hline Other naturally occurring assets & 3143.1 & 3143.2 & & 3143 \\
\hline Noncultivated biological resources & 31431.1 & 31431.2 & & 31431 \\
\hline Water resources & 31432.1 & 31432.2 & & 31432 \\
\hline Other natural resources & 31433.1 & 31433.2 & & 31433 \\
\hline Radio spectra & 314331.1 & 314331.2 & & 314331 \\
\hline $\begin{array}{l}\text { Natural resources not elsewhere } \\
\text { classified }\end{array}$ & 314332.1 & 314332.2 & & 314332 \\
\hline
\end{tabular}




\section{Table 8.1 Classification of Transactions in Nonfinancial Assets (concluded)}

\begin{tabular}{|c|c|c|c|c|}
\hline & Acquisitions of & Disposals of & $\begin{array}{l}\text { Consumption of } \\
\text { fixed capital }^{1}\end{array}$ & $\begin{array}{c}\text { Net investment } \\
\text { in nonfinancial } \\
\text { assets }\end{array}$ \\
\hline Intangible nonproduced assets & 3144.1 & 3144.2 & & 3144 \\
\hline Contracts, leases, and licenses & 31441.1 & 31441.2 & & 31441 \\
\hline Marketable operating leases & 314411.1 & 314411.2 & & 314411 \\
\hline Permits to use natural resources & 314412.1 & 314412.2 & & 314412 \\
\hline Permits to undertake specific activities & 314413.1 & 314413.2 & & 314413 \\
\hline $\begin{array}{l}\text { Entitlement to future goods and } \\
\text { services on an exclusive basis }\end{array}$ & 314414.1 & 314414.2 & & 314414 \\
\hline Goodwill and marketing assets & 31442.1 & 31442.2 & & 31442 \\
\hline \multicolumn{5}{|l|}{ Memorandum items } \\
\hline Own-account capital formation & & & & $3 \mathrm{M} 1$ \\
\hline Compensation of employees & & & & 3M11 \\
\hline Use of goods and services & & & & $3 \mathrm{M} 12$ \\
\hline Consumption of fixed capital & & & & $3 \mathrm{M} 13$ \\
\hline $\begin{array}{l}\text { Other taxes on production minus other } \\
\text { subsidies on production }\end{array}$ & & & & $3 \mathrm{M} 14$ \\
\hline
\end{tabular}

${ }^{1}$ Consumption of fixed capital is not recorded for inventories. It is recorded for nonproduced assets only to the extent of costs of ownership transfer on nonproduced assets other than land (a fixed asset). For land, the costs of ownership transfer are included, by convention, with land improvements (a fixed asset).

${ }^{2}$ In GFS, only the net changes in inventories resulting from transactions are recorded, but gross acquisitions and disposals may be recorded, if needed.

minus disposals of these assets. COFOG is described in the annex to Chapter 6.

\section{Fixed Assets (311) 11}

8.24 The cost of acquisition of assets from third parties is determined by the market price of the transactions. Government or public sector units can also incur costs associated with the production or the maintenance of fixed assets. To determine the amount of these costs that should be recorded as the value of ownaccount production of fixed assets during the reporting period, a distinction between major improvements of assets and maintenance of assets is necessary. The section on Fixed Assets first describes how to distinguish transactions that should be recorded as acquisitions of fixed assets from transactions that should be recorded as expense related to maintenance. The recording of transactions in specific categories of assets follows.

\section{Major improvements versus maintenance and repair}

8.25 Major improvements (such as renovations, reconstructions, and enlargements) to existing assets that increase their productive capacity, extend their

\footnotetext{
${ }^{11}$ The numbers in parentheses after each classification category are the GFS classification codes. Appendix 8 provides all classification codes used in GFS.
}

service lives, or both, are classified as acquisitions of fixed assets. On the other hand, maintenance and repair of fixed assets constitute an expense classified as the use of goods and services (22) (as mentioned in paragraph 6.45). By definition, however, major improvements do not lead to the creation of new assets that can be separately identified and valued. Instead, the value of such an improvement is added to the value of the existing underlying asset.

8.26 Although the distinction is not clear-cut, major improvements to assets are distinguished from maintenance and repairs by the following features:

- The decision to renovate, reconstruct, or enlarge an asset is a deliberate investment decision that may be undertaken at any time and is not dictated by the condition of the asset. Major renovations of ships, buildings, or other structures are frequently undertaken well before the end of their normal service lives.

- The major renovations, reconstructions, or enlargements increase the performance or capacity of existing assets or significantly extend their previously expected service lives. Enlarging or extending an existing road, building, or structure constitutes a major change in this sense, but a complete refitting or restructuring of the interior of a building also qualifies. 
8.27 Maintenance and repairs are distinguished by two features:

- They are activities that owners or users of assets are obliged to undertake periodically in order to be able to utilize such assets over their expected service lives. They are current costs that cannot be avoided if the fixed assets are to continue to be used. The owner or user cannot afford to neglect maintenance and repairs as the expected service life may be drastically shortened otherwise.

- They do not change the fixed asset or its performance, but simply maintain it in good working order or restore it to its previous condition in the event of a breakdown. Defective parts are replaced by new parts of the same kind without changing the basic nature of the fixed asset.

\section{Buildings and structures (3111)}

8.28 In addition to the transactions reflecting the acquisition of newly constructed buildings and structures, acquisitions of buildings and structures include all amounts payable for site clearance and preparation and the cost of all fixtures, facilities, and equipment that are integral parts of buildings and structures.

8.29 Certain structures, such as buildings, roads, and bridges, may be produced for communal use by groups of households. After the construction is completed, the ownership of such structures may then be transferred to a general government unit that will assume responsibility for their maintenance. When the transfer occurs, an acquisition of a structure is recorded together with the receipt of a capital transfer in kind.

8.30 The construction of new public monuments, as well as major improvements to existing public monuments, constitutes an acquisition of buildings and structures, either as dwellings (31111), buildings other than dwellings (31112), or other structures (31113), as explained in paragraphs $7.42-7.43 .{ }^{12}$ However, when the special archaeological, historical, or cultural significance of a structure or site not already recorded in the balance sheet is first recognized, it is recorded as an other change in the volume of assets, as explained in paragraph 10.50 .

8.31 The costs of land improvements (31114) are recorded as transactions and, in subsequent periods,

${ }^{12}$ Consumption of fixed capital on new public monuments as well as major improvements to existing public monuments should be calculated on the assumption of appropriately long service lives. transactions in consumption of fixed capital (23) are recorded, based on the service life of the improvement. Any excess in the increase in the value of the land over the value of land improvements or any increase in price levels due to adjacent capital activity is recorded as holding gains. Other changes in the volume of assets (economic appearance) of the nonproduced asset land (5141) should be recorded when adjacent activities bring land into the asset boundary (see paragraph 10.52).

8.32 Acquisitions of tunnels and other structures associated with the mining of mineral deposits are classified as acquisitions of structures and not as improvements to land. These assets are used separately from the land through which they are drilled or bored. The costs of ownership transfer on land are included, by convention, with land improvements, and these costs are written off over the period the owner expects to own the land.

\section{Machinery and equipment (3112)}

8.33 The determination of which goods should be classified as machinery and equipment is normally straightforward. However, as explained in paragraphs 6.43 and 7.40, some flexibility may be needed in the recording of small/hand tools.

\section{Other fixed assets (3113) Cultivated biological resources (31131)}

8.34 As explained in paragraphs 7.59-7.63, cultivated biological resources comprise animal resources yielding repeat products (311311) and tree, crop, and plant resources yielding repeat products (311312). Acquisitions of cultivated biological resources include acquisitions from other units of plants and animals that are cultivated for the products they yield year after year and the value of similar plants and animals produced on own account. ${ }^{13}$ Disposals consist of animals and plants sold or otherwise disposed of, including animals sold for slaughter or slaughtered by their owners and plants cut down before the end of their service lives. Disposals do not include exceptional losses of animals and plants due to major outbreaks of disease, contamination, drought, famine, or other natural disasters, which are recorded as

\footnotetext{
${ }^{13}$ Plants and animals grown for a single use, such as animals grown for slaughter and trees grown for timber, are treated as inventories rather than fixed assets (see paragraphs 7.60-7.61).
} 
other changes in the volume of assets. Consumption of fixed capital on these resources includes incidental losses of animals and plants from natural causes, as well as the decline in an animal's or plant's value as it gets older.

8.35 The net investment in livestock that are cultivated for the products they yield year after year (e.g., dairy cattle) is equal to the total value of all mature animals and immature animals produced on own account or acquired by users of the livestock minus the value of their disposals minus consumption of fixed capital.

8.36 The net investment in plantations, orchards, etc. is equal to the value of the acquisitions of mature trees, shrubs, etc. (including immature trees, shrubs, etc. produced on own account) minus their disposals minus consumption of fixed capital. The value of immature trees, shrubs, etc. may be approximated, if necessary, by the value of accumulated costs incurred in their production.

\section{Intellectual property products (31132)}

8.37 As explained in paragraphs 7.64-7.73, intellectual property products comprise:

- Research and development (311321)

- Mineral exploration and evaluation (311322)

- Computer software and databases (311323)

- Entertainment, literary, and artistic originals (311324)

- Other intellectual and property products (311325).

8.38 The value of expenditure on research and development (311321) should be determined in terms of the economic benefits it is expected to provide in the future. It is treated as an asset except in cases where it is clear that the activity does not entail any economic benefits for its owner (see paragraphs 7.66-7.67).

8.39 As mentioned in paragraph 7.68, expenditure incurred on exploration is classified as the acquisition of mineral exploration and evaluation (311322). Mineral exploration expenditure includes the costs of actual test drillings and borings and all other costs incurred to make it possible to carry out the tests, such as prelicense, license, acquisition, and appraisal costs, the costs of aerial and other surveys, and transportation and other costs incurred to make the exploration possible. Consumption of fixed capital may be calculated for such assets by using average service lives similar to those used by mining or oil corporations in their own accounts.

8.40 Computer software and databases (311323) include acquisitions of computer software that comprise programs, program descriptions, and supporting materials for both systems and applications software that are expected to be used for more than one year. The net investment in nonfinancial assets in the form of computer software includes both the initial development and subsequent extensions of software, as well as acquisition of copies that are classified as assets. Software developed in-house is valued at its cost of production. This category also includes the purchase, development, or extension of large databases that the unit expects to use for more than one year. When a database is created, its value will generally have to be estimated by a sum-of-costs approach. These costs include the cost of preparing data in the appropriate format, staff time estimated on the basis of the amount of time spent in developing the database, and costs of items included as use of goods and services. ${ }^{14}$ Not included are the cost of the database management system and the cost of acquiring or producing the data. Transactions in databases sold should be valued at their market price, which includes the value of the information content. If the value of a software component in a database that is sold is available separately, it should be recorded as the sale of software.

8.41 The production of new entertainment, literary, and artistic originals (311324) is recorded at their current market price when they are actually traded. However, this asset category is often undertaken on own account. Subsequently, they may be sold outright or by means of licenses. When produced on own account, it may be difficult to establish their market value, which depends on the present value of the future benefits the owner expects to derive from their use. In the absence of information, it may be necessary to value the acquisition of the original by its cost of production.

\footnotetext{
${ }^{14}$ If the database is created in-house, compensation of employees and use of goods and services related to this own-account capital formation are excluded from compensation of employees (21) and use of goods and services (22).
} 
Costs of ownership transfer on nonproduced assets other than land (31133)

8.42 Transactions in the costs of ownership transfer on nonproduced assets ${ }^{15}$ other than land are treated as transactions in fixed assets because these costs are considered a produced asset. The costs of ownership transfer on nonproduced assets other than land are subject to consumption of fixed capital, which is also included in this category. However, in the balance sheet, these costs of ownership transfer, as well as the consumption of fixed capital on these costs, are reflected in the value of the respective nonproduced assets. The additional entries necessary for this treatment are discussed in paragraph 10.83. The treatment of costs of ownership transfer on nonproduced assets is illustrated in Figure 8.1.

\section{Weapons systems (3114)}

8.43 The acquisitions and disposals of weapons systems that meet the general definition of assets include vehicles and other equipment such as warships, submarines, military aircraft, tanks, missile carriers and launchers, etc. The acquisitions of most single-use weapons they deliver, such as ammunition, missiles, rockets, bombs, etc., are classified as transactions in military inventories and their use as withdrawals from military inventories. However, some single-use items, such as certain types of ballistic missile with a highly destructive capability, may be classified as fixed assets (see paragraph 7.74).

\section{Inventories (312)}

8.44 In principle, net investment in inventories (change in inventories) is measured by the value of the additions to inventories minus the value of withdrawals from inventories minus the value of any recurrent losses of goods held in inventories during the reporting period. ${ }^{16}$ In general, additions to and withdrawals from inventories should be recorded according to the same principles used for recording transactions in other nonfinancial assets. Additions to inventories are recorded when products are purchased, produced, or otherwise acquired, and withdrawals from inven-

\footnotetext{
${ }^{15}$ Transactions in nonproduced assets are discussed in paragraphs 8.49-8.58.

${ }^{16}$ These changes in inventories are as a result of transactions. The value of the stock of inventories may also change due to other economic flows.
}

tories are recorded when products are sold, used up in production, transferred to a different category of inventories, or otherwise relinquished.

8.45 In contrast to other nonfinancial assets, however, no costs of ownership transfer are included in the values of additions to or withdrawals from inventories, and no consumption of fixed capital is attributed to inventories, as indicated by the shaded area in Table 8.1. Further, only the net value of additions minus withdrawals of inventories is usually estimated rather than separate, gross values for additions and withdrawals, unlike for other nonfinancial assets. This estimate of the changes in inventories is used in the formula to determine an estimate of expense in the form of use of goods and services (22), as explained in paragraph 6.29.

8.46 To understand the various transactions in inventories, it is useful to distinguish between two functions performed by a unit: its function as a producer of goods and services and its function as an owner of assets. When a good is entered into inventories, it is acquired as an asset by the unit in its capacity as owner either by purchase (or barter) or by an internal transaction with itself as the producer. Conversely, a good leaving inventories represents the disposal of an asset by the owner either by sale or other use, by an internal transfer to the producer, or possibly as a result of recurrent losses (recurrent wastage, accidental damage, or pilfering).

8.47 Many transactions in inventories (i.e., additions to and withdrawals from) are purchases from or distributions to other units, but other acquisitions and disposals reflect internal transactions. All additions to and withdrawals from inventories, such as for use of goods or investment in fixed assets, should be valued at current market prices. Because of the continuous or frequent withdrawals from materials and supplies inventories and the additions to and withdrawals from work-in-progress inventories, information is usually not available to record these internal transactions accurately, and estimates may be necessary.

- When materials and supplies (31221) are transferred to a production process, a transaction is recorded for the withdrawal, which is balanced by an addition either to work-in-progress inventories (31222), use of goods and services (22), or, in the case of own-account capital formation, a 


\section{Figure 8.1 Illustrating the Treatment of Costs of Ownership Transfer on Nonproduced Assets}

Opening balance

Transactions relating to costs of ownership transfer on nonproduced assets

Costs of ownership transfer on land:

\begin{tabular}{|c|c|c|c|}
\hline $\begin{array}{l}\text { Fixed } \\
\text { asset }\end{array}$ & $\begin{array}{l}\text { Stock position } \\
\text { in land } \\
\text { improvements } \\
(6|1| 4)\end{array}$ & + & $\begin{array}{c}- \text { Acquisitions minus } \\
\text { disposals of land } \\
\text { improvements } \\
\text { (3III } 4 .|-3| I \mid 14.2) \\
\text { - Transactions in } \\
\text { cost of ownership } \\
\text { transfer on land } \\
(3|| 4 . \mid)\end{array}$ \\
\hline
\end{tabular}

Costs of ownership transfer on nonproduced assets other than land:

\section{Fixed}

assets

Nonproduced assets

\begin{tabular}{|c|c|c|}
\hline $\begin{array}{l}\text { Transactions in } \\
\text { costs of ownership } \\
\text { transfer on } \\
\text { nonproduced } \\
\text { assets other than } \\
\text { land } \\
(31133.1)\end{array}$ & - & $\begin{array}{l}\text { Consumption of } \\
\text { fixed capital on } \\
\text { costs of ownership } \\
\text { transfer on } \\
\text { nonproduced } \\
\text { assets other than } \\
\text { land } \\
(3 \mid 133.3)\end{array}$ \\
\hline
\end{tabular}

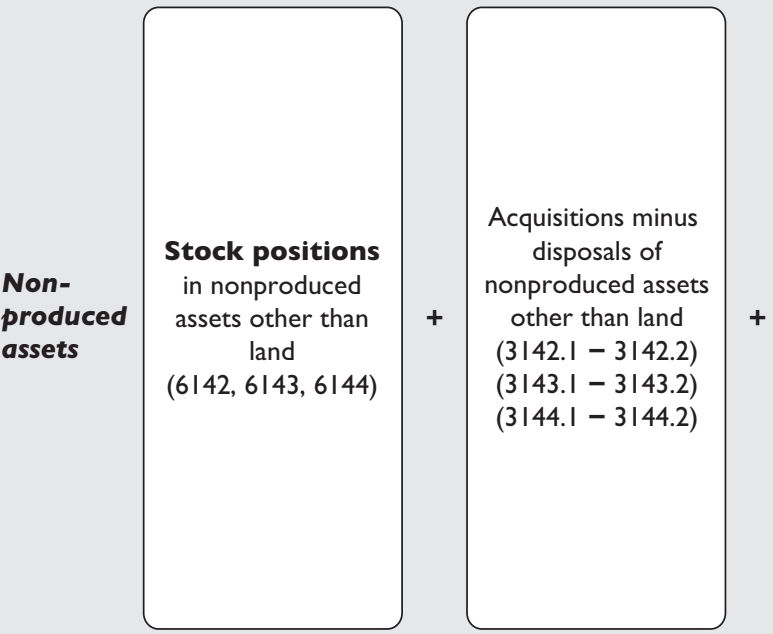

Holding gains and losses (revaluations) and other changes in the volume of assets relating to nonproduced assets

\begin{tabular}{|c|} 
Consumption of \\
fixed capital on \\
land improvements, \\
including on cost of \\
ownership transfer \\
on land \\
$(31114.3)$
\end{tabular}
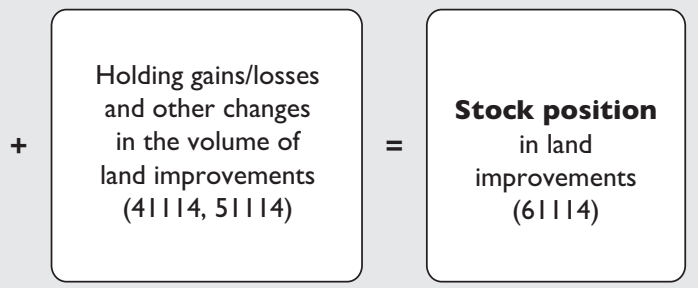

Stock position in lan

$(6 I 114)$

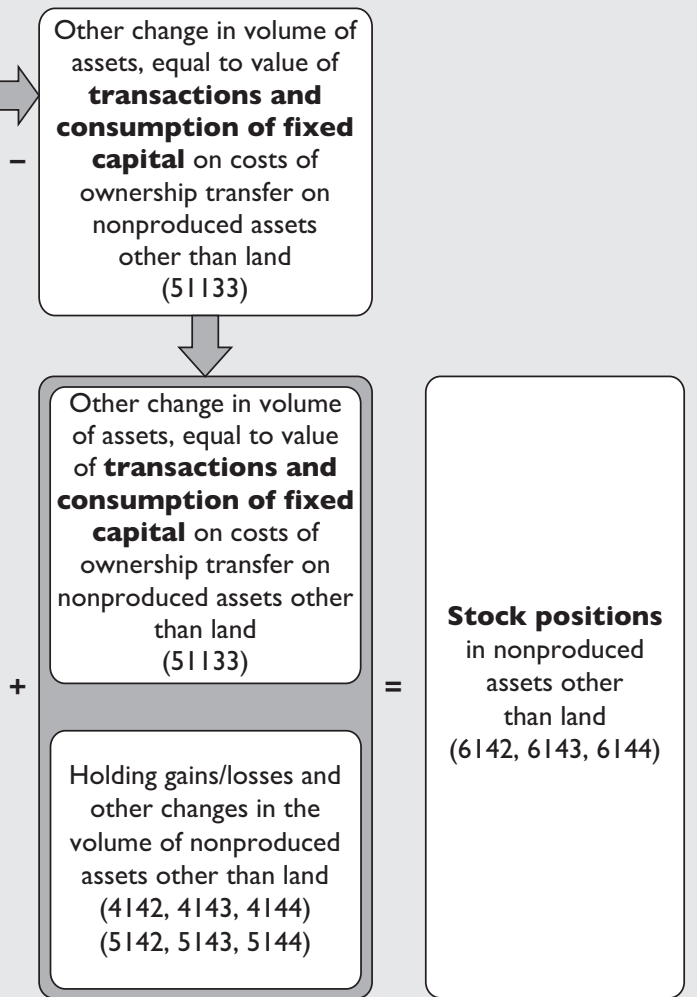

- Costs of ownership transfer on land are, by convention, included with land improvements. This applies to the transactions as well as the stock position of land improvements.

- There are no stock positions in costs of ownership transfer on nonproduced assets other than land shown separately in the balance sheet. These costs are included with the respective nonproduced assets in the balance sheet.

- Transactions in the costs of ownership transfer on nonproduced assets other than land are recorded as part of fixed assets.

- Costs of ownership transfer on nonproduced assets (and on produced assets other than inventories-which are not shown in this example) are subject to consumption of fixed capital over the period the owner expects to hold the asset.

- Costs of ownership transfer on nonproduced assets other than land and consumption of fixed capital on these costs are reclassified, through other changes in the volume of assets, to the respective nonproduced assets to maintain the integration of stock positions and flows. These reclassifications are considered to take place at the time of recording the transactions. The costs of ownership transfer on land, which are included with land improvements, are not reclassified to land and remain part of the stock of land improvements. 
specific fixed asset or possibly valuables (313). In other words, the balancing entry depends on the nature of the production process. The acquisition of gold, diamonds, etc. intended for use in production is recorded under materials and supplies (31221), but the acquisition of the same items to hold as a store of value is recorded under valuables (313).

- Transactions that add to work-in-progress inventories (31222) are, in principle, recorded continuously as production takes place. The counterpart transactions are reduction in other assets, such as materials and supplies, and the other costs incurred in production. ${ }^{17}$ When production is completed, all work in progress is reclassified as finished goods (31223). This reclassification is recorded as other changes in the volume of assets under the respective subcategories of inventories. Withdrawals of work-in-progress inventories (31222) should be valued at their cost of production, where all inputs are valued at their current market prices at the time of withdrawal rather than the prices paid for them. The difference between the prices payable for the inputs and their current market prices is a holding gain or loss. The ownership of work-in-progress inventories is transferable, if necessary. For example, it may be sold under exceptional circumstances, such as the liquidation of a public corporation.

- Work-in-progress inventories should be recorded for single-use cultivated biological resources. Any cultivation of resources with repeat yields, other than on own account or under an agreed contract with another unit, is also included in work-in-progress inventories. However, repeatyield resources, being cultivated on own account or under an agreed contract with another unit, are recorded as the acquisition of fixed assets.

- A good is finished when its producer has completed its intended production process and such inventories of finished goods (31223) may be held only by the units that produce them. When finished goods are sold or otherwise disposed of (e.g., as compensation of employees in kind or social benefits in kind), a transaction must be

${ }^{17}$ As explained in paragraph 6.27, an adjustment is made to use of goods and services (22) to account for those items used to produce nonfinancial assets, such as work-in-progress inventories. recorded to reduce inventories of finished goods (31223), which is balanced by an increase in use of goods and services (22). The distribution of finished goods as compensation of employees in kind or social benefits in kind is always recorded as use of goods and services (22) by the unit that produced these goods (see paragraph 6.39).

- Finished goods entering inventories are valued at the prices of those goods before adding any taxes, transport, or distribution margins, at the times the entries take place; finished goods withdrawn from inventories are valued at the prices before adding any taxes, transport, or distribution margins, at the time when their withdrawals take place. The difference between the "entering" and "withdrawal" values of finished goods is a holding gain or loss.

- When goods held as goods for resale (31224) are sold or otherwise disposed of, two transactions are recorded. First, reduce inventories of goods for resale (31224) and record a counterpart transaction in expense, recorded as use of goods and services (22) expense at the purchase price. Second, record (at the sale price) a sales of goods and services (142), which is balanced by either an increase in currency and deposits (3202) or other accounts receivable (3208). The difference between the value recorded as sales of goods and services and use of goods and services is reflected in the net operating balance (NOB). By convention, goods acquired by government for distribution as social transfers in kind or other transfers in kind but that have not yet been so delivered are also included in goods for resale. The distribution of such goods is recorded as a reduction in inventories of goods for resale (31224), and an increase in subsidies (25), grants (26), social benefits (27), or current transfers not elsewhere classified (2821).

- Goods for resale added to inventories are valued at their actual or estimated purchase prices, including any transportation charges paid to other units but not the costs of any transport services produced on own account by the unit taking delivery. In principle, goods acquired by barter are valued at their estimated purchasers' prices at the time of acquisition. However, because there are no taxes or margins on bartered goods, the purchaser's price is the same as the basic price. 
Goods for resale withdrawn from inventories are valued similarly at the purchase prices at which they can be replaced when they are withdrawn, which may differ from the prices that were paid to acquire them and the prices for which they were sold. ${ }^{18}$ Reductions in inventories are valued in this way whether the goods withdrawn are sold at a profit or at a loss, or even not sold at all as a result of physical deterioration, recurrent accidental damage, or pilfering.

- When military inventories (31225) are used or otherwise disposed of, their cost is recorded as use of goods and services (22) expense. A counterpart transaction is recorded as the withdrawal of military inventories (31225). Additions and withdrawals of military inventories are valued in a manner similar to finished goods or goods for resale, depending on how they were acquired.

- Recurrent losses of inventories resulting from physical deterioration, normal accidental damage, or pilfering should be treated as withdrawals in the same way as inventories withdrawn on purpose. In practice, determining the time of recording may be difficult because the time at which the inventories were stolen or spoiled may be unknown. Exceptional inventory losses are included as other changes in the volume of assets (see paragraph 10.70).

\section{Valuables (313)}

8.48 Acquisitions of valuables are valued at the prices payable plus any associated costs of ownership transfer incurred by the units acquiring the assets. Disposals are valued at the sales price minus any associated costs of ownership transfer incurred by the units disposing of the assets. Costs of ownership transfer may be significant for the services of appraisers, auctioneers, and dealers. Units fulfilling some functions of the monetary authority may have transactions in both monetary and nonmonetary gold, and care needs to be taken to classify them correctly and to record the other changes in the volume of assets needed to transfer gold from one category to the other.

\footnotetext{
${ }^{18}$ The difference between the price at which goods for resale is added to inventories and the price at which it is withdrawn is a holding gain or loss.
}

\section{Nonproduced Assets (314)}

8.49 Transactions reflecting a change in the ownership of nonproduced assets should be recorded in the same manner as transactions in existing fixed assets. The recording of the costs of ownership transfer on nonproduced assets other than land and the consumption of fixed capital on these costs are discussed in paragraphs 8.42 and 10.83 .

\section{Land (3141)}

8.50 Purchases and sales of land exclude the costs of ownership transfer on land for both buyers and sellers. These costs are, by convention, included in land improvements (31114). Actions that lead to major improvements in the quantity, quality, or productivity of land, or prevent its deterioration (such as land clearance, ${ }^{19}$ land contouring, creation of wells and watering holes that are integral to the land in question, etc.), are also treated as resulting in land improvements (31114), not the acquisition of land (3141). When a government unit acquires land that is physically located in a foreign country (for use as an embassy, base, or other territorial enclave), the transaction converts the land into part of the economic territory of the country of the acquiring government and, therefore, it enters the balance sheet by means of a transaction (i.e., the acquisition of a nonfinancial asset).

8.51 Buildings, or other structures, and plantations are often purchased or sold together with the land on which they are situated, without separate valuations being placed on the structures and the land. Even if it is not feasible to obtain separate valuations, as may be the case for existing structures, it may be possible to determine whether the land or the structure accounts for most of their combined value and to classify the transaction as the purchase of land or of a structure, depending upon which has the greater value. If it is not possible to determine whether the land or the structure is the more valuable, by convention, the transaction should be classified as the purchase of a structure (i.e., as the acquisition of a fixed asset in the form of buildings and structures (3111)). A similar convention holds for plantations. In most

\footnotetext{
${ }^{19}$ Costs relating to site clearance and preparation of land for purposes of construction are excluded; these are classified as the acquisition of buildings and other structures.
} 
cases, subsoil assets may be owned separately from the land and separate valuations should be estimated if possible. On the other hand, the law may stipulate that the ownership of the subsoil assets is inseparably linked to that of the land. For a financial lease of a building or plantation on the land when the assets are inseparable, see paragraph 7.95.

8.52 When governments acquire land (or other assets) under a compulsory sale by the owners, any difference between the market value of the assets acquired and any compensation provided is recorded as other changes in the volume of assets, in the form of an uncompensated seizure (see paragraph 10.62).

8.53 There is no consumption of fixed capital on land, but there are transactions in consumption of fixed capital on land improvements (31114) and costs of ownership transfer on land (which are included in land improvements).

\section{Mineral and energy resources (3142)}

8.54 Transactions in mineral and energy resources (3142) refer to acquisitions or disposals of deposits of mineral and energy resources in which the ownership of such assets passes from one institutional unit to another. Reductions in the value of known reserves of mineral and energy resources resulting from their depletion as a result of extracting the assets for purposes of production are not transactions but other changes in the volume of assets, as described in paragraph 10.52. Similarly, increases in the values resulting from discoveries are treated as other changes in the volume of assets. Decreases arising from reappraisals are also recorded as other changes in the volume of assets. The transactions in mineral and energy resources refer only to those mineral and energy resources over which ownership rights have been established.

\section{Other naturally occurring assets (3143)}

8.55 Transactions in noncultivated biological resources, water resources, and other natural resources relate to acquisitions or disposals of deposits of these resources in which the economic ownership of such assets passes from one institutional unit to another Similar to mineral and energy resources, depletion of noncultivated biological resources, water resources, or other natural resources, because a portion of the asset has been extracted, is recorded as other changes in the volume of assets, as described in paragraph 10.52 , and not as a transaction in nonfinancial assets.

\section{Intangible nonproduced assets (3144)}

8.56 As explained in paragraphs 7.104-7.117, intangible nonproduced assets consist of contracts, leases, and licenses (31441) and goodwill and marketing assets (31442).

8.57 Contracts, leases, and licenses may be marketable operating leases, licenses to use natural resources, permits to undertake specific activities and entitlement to future goods and services on an exclusive basis. The specific stocks and flows involved with contracts, leases, and licenses are discussed in Appendix 4.

8.58 As explained in paragraphs 7.113-7.117, goodwill is recorded in GFS only when its value is evidenced by a market transaction, usually the sale/ purchase of the whole corporation. The amortization of goodwill and marketing assets or other intangible nonproduced assets is an other economic flow rather than a transaction (see paragraph 10.55). 


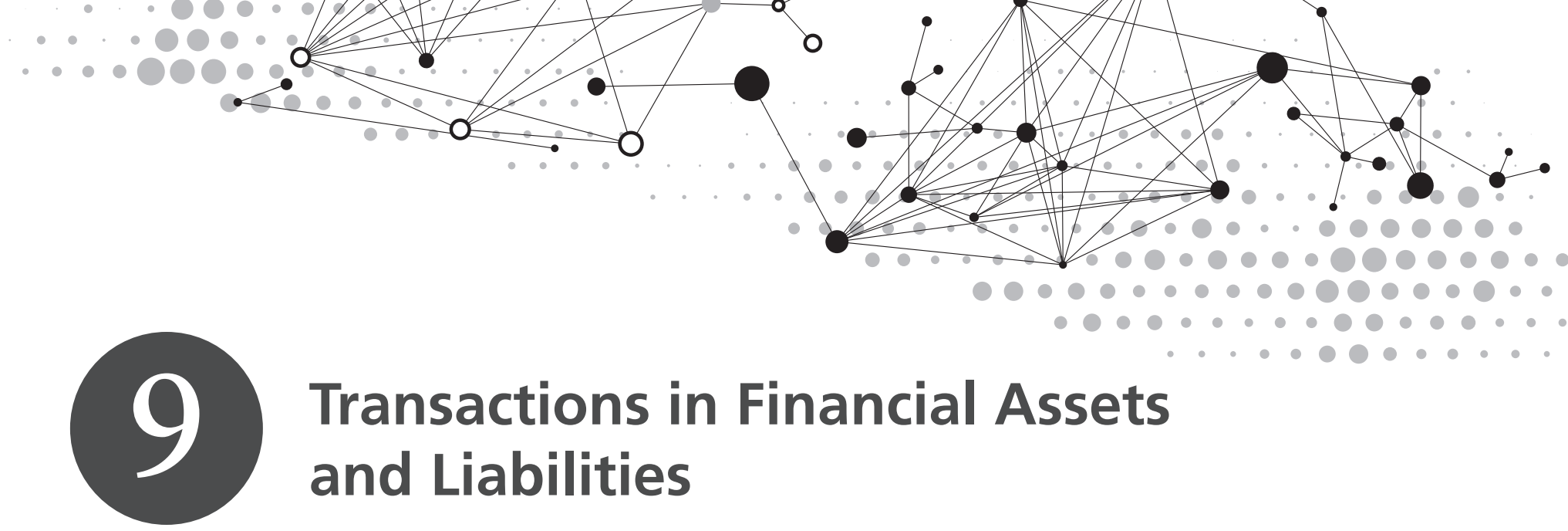

This chapter describes transactions in financial assets and liabilities and their classification.

\section{Introduction}

9.1 Chapter 7 describes the balance sheet and the assets and liabilities recorded on it. As an integrated framework, GFS also include the flows necessary to explain all changes between the balance sheet at the beginning of the period and the balance sheet at the end of the reporting period. As described in Chapter 3, there are two types of flows-transactions and other economic flows-both of which can affect stock positions of assets and liabilities. This chapter describes the transactions that affect stock positions of financial assets and liabilities, and Chapter 10 describes other economic flows.

9.2 The accounting identity given in paragraph 8.2 for nonfinancial assets also holds for financial assets and liabilities. ${ }^{1}$ The identity states that:

The value of a category of financial assets (liabilities) on the balance sheet at the beginning of the reporting period

plus

The total value of that category of financial assets (liabilities) acquired (incurred) in transactions during the reporting period

minus

The total value of that category of financial assets (liabilities) disposed of (extinguished) in transactions during the reporting period plus

The net value of other economic flows that affect that category of financial assets (liabilities)

\footnotetext{
${ }^{1}$ For ease of expression, assets will often be used as a reference to both assets and liabilities.
}

equals

The value of the category of financial assets (liabilities) on the balance sheet at the end of the reporting period.

This identity requires that transactions, other economic flows, and stock positions be recorded consistently with regard to classification, time of recording, and valuation. The accounting rules governing these factors are described in Chapter 3.

9.3 Transactions can change stock positions of financial assets or liabilities in different ways and all must be accounted for. The more important types of transactions follow:

- Transactions involving revenue, expense, the transfer of economic ownership of a good or nonfinancial asset, or the provision of a service or labor almost always entail a counterpart entry in transactions in financial assets and liabilities for means of payment or claims on future means of payment. Even many transactions in kind, such as barter transactions and remuneration in kind, could conceptually lead to counterpart transactions in financial assets (other accounts receivable) and/or liabilities (other accounts payable) when the timing of the exchange does not coincide. The sale of a good, service, or asset may have as its counterpart a change in currency or transferable deposit. Alternatively, the counterpart may be reflected as another type of financial asset or liability, such as other accounts receivable or payable.

- New financial claims are often created by transactions in which a creditor advances funds to a debtor. The creditor then acquires a financial asset and the debtor incurs a liability.

- Some transactions in financial assets and liabilities are simply exchanges of financial instruments. 
- Financial claims are normally terminated by transactions. In some cases, the debtor pays the creditor the funds stipulated by the financial instrument, thereby terminating the claim. In other cases, the debtor buys its own instrument in the market.

- Accrued interest is deemed to be reinvested in an additional quantity of the underlying financial instrument by means of a transaction.

- The trading and settlement of financial derivative contracts.

9.4 All transactions that increase a unit's holdings of assets are labeled acquisitions. All transactions that decrease a unit's holdings of assets are labeled disposals. Transactions that increase liabilities are referred to as the incurrence of a liability. Transactions that decrease liabilities are variously titled repayments, reductions, withdrawals, redemptions, liquidations, or extinguishments. Thus, the results of transactions in a particular category of financial assets can be presented either as total acquisitions and total disposals or as net acquisitions. Similarly, changes in liabilities can be presented as total incurrences and total reductions or as net incurrences. Transactions that change a category of financial assets are never combined with transactions that change the same category of liabilities. That is, in GFS, the net acquisition of loans is not presented as the increase in loans held as financial assets minus the increase of loans as liabilities (also see paragraph 9.17).

9.5 As explained in paragraph 4.17, the net operating balance minus the net investment in nonfinancial assets equals net lending $(+) /$ net borrowing (-). If the operating balance is not exhausted by the net investment in nonfinancial assets, the resulting surplus is called net lending $(+)$. Alternatively, if the net operating balance is not sufficient to cover the net accumulation of nonfinancial assets, the resulting deficit is called net borrowing (-). Transactions in financial assets and liabilities explain how net lending/net borrowing is financed by means of changes in holdings of financial assets and liabilities-that is, total financing. In other words, the net acquisition of financial assets minus the net incurrence of liabilities is conceptually equal to net lending/net borrowing.

9.6 The remainder of this chapter describes first the valuation, time of recording, netting, and con- solidation of transactions that affect financial assets and liabilities. It then provides details on transactions that affect specific categories of financial assets and liabilities. The classification of transactions in financial assets and liabilities by residence and sector of the counterparty is also discussed.

\section{Valuation}

9.7 The value of an acquisition or disposal of an existing financial asset or liability is its exchange valuethat is, the current market price. The value of a newly created financial claim is generally the amount advanced by a creditor to a debtor.

9.8 All service charges, fees, commissions, and similar payments for services provided in carrying out transactions and any taxes payable on transactions are excluded from transactions in financial assets and liabilities. They are expense transactions classified as use of goods and services (22). In particular, when new securities are marketed by underwriters or other intermediaries as agents for the unit issuing the securities, the securities should be valued at the price payable by the purchasers. The difference between that price and the amount receivable by the issuing unit is a payment for the services of the underwriters. When dealers have a margin between their buying and selling prices, the buyer and seller record transactions in financial assets and liabilities at the same midprice-that is, the midpoint between the buyer's price and the seller's price.

9.9 When a security is issued at a discount or premium relative to its contractual redemption value, the transaction should be valued at the amount actually payable for the asset and not the redemption value. Any interest that is prepaid jointly with the acquisition of a security should be treated as accrued interest that had been reinvested in an additional quantity of the security. In this case, the value of the acquisition is the sum of the amount paid for the security directly plus the amount prepaid for accrued interest. When issued at a premium, the difference between the redemption and issue price is amortized over the life of the instrument and reduces (rather than increases) the amount of interest accruing in each period.

9.10 In some cases, the value of a financial asset is determined by the value of the counterpart item to the transaction. For example, the initial value of a loan 
resulting from a financial lease is usually the value of the nonfinancial asset leased (if no initial down payments or fees are involved). The value of other accounts payable resulting from the purchase of goods or services is the value of the goods acquired or services received.

9.11 As mentioned in paragraph 3.119, the value of a transaction expressed in a foreign currency is converted to the domestic currency using the midpoint of the buying and selling exchange rates at the time of the transaction. ${ }^{2}$ If a transaction expressed in a foreign currency involves the creation of a financial asset or liability, such as other accounts receivable/payable, and is followed by a second transaction in the same foreign currency that extinguishes the financial asset or liability, then both transactions are valued at the exchange rates effective when each takes place.

9.12 Government units or public corporations may acquire or dispose of financial assets on a nonmarket basis as an element of their fiscal policy rather than as a part of their liquidity management. For example, they may lend money at a below-market interest rate or purchase shares of a corporation at an inflated price. It is generally accepted that concessional loans occur when units lend to other units and the contractual interest rate is intentionally set below the market interest rate that would otherwise apply. The degree of concessionality can also be enhanced with grace periods $s^{3}$ and frequencies of payments and maturity periods favorable to the debtor. Since the terms of a concessional loan are more favorable to the debtor than market conditions would otherwise permit, concessional loans effectively include a transfer from the creditor to the debtor. However, the means of incorporating the transfer impact within the SNA and other macroeconomic statistics have not been fully developed, although various alternatives have been advanced. Accordingly, until the appropriate treatment of concessional debt is agreed, information on concessional debt should be provided in supplementary tables, and in the memorandum items conces-

\footnotetext{
${ }^{2}$ The difference between buying or selling prices and midpoint prices represents a service charge and should conceptually be reported as sales of goods and services (142) or use of goods and services (22). The service charge may be estimated from the average trade margin spread between the buying and selling rates. If not significant or not practical to identify, it is recommended to disregard any service charge in GFS.

${ }^{3}$ The treatment of grace periods is discussed in paragraphs 6.69.
}

sional loans at nominal value (6M391) and implicit transfers resulting from loans at concessional interest rates (6M392), discussed in paragraph 7.246.

\section{Time of Recording}

9.13 On an accrual basis, transactions in financial assets and liabilities are recorded when economic ownership of the asset changes-that is, when the asset is created or liquidated-and when the addition or reduction in the amount of the financial instrument occurs, such as the accrual of interest and subsequent reduction when debt service payments are made. ${ }^{4}$ This time is usually clear when the transaction involves an exchange of existing financial assets or the simultaneous creation or extinction of a financial asset and a liability. In most cases, it will be when the contract is signed or when money or some other financial asset is paid by the creditor to the debtor or repaid by the debtor to the creditor.

9.14 In some cases, the parties to a transaction may perceive economic ownership to change on different dates because they acquire the documents evidencing the transaction at different times. This variation usually is caused by the process of check clearing or the length of time checks are in the mail. The amounts involved in such "float" may be substantial in the case of transferable deposits and other accounts receivable or payable. If there is disagreement on a transaction between two general government units or a government unit and a public corporation, the date on which the creditor receives the payment is the date of record because a financial claim exists up to the point that the payment is cleared and the creditor has control of the funds.

9.15 When a transaction in a financial asset or liability involves a nonfinancial component, the time of recording is determined by the nonfinancial component. For example, when a sale of goods or services gives rise to a trade credit, the transaction should be recorded when economic ownership of the goods is transferred or when the service is provided. When a financial lease is created, the loan implicit in the transaction is recorded when control of the fixed asset changes.

\footnotetext{
${ }^{4}$ On the pure cash basis of recording, transactions are recorded when cash is paid or received. See Chapter 3 for more details on the cash basis of recording.
} 
9.16 Some transactions, such as the accrual of interest expense and its treatment as borrowing of an additional amount of the financial instrument, take place continuously. In this case, the transaction in the associated financial asset or liability also takes place continuously.

\section{Netting and Consolidation of Flows Netting}

9.17 Transactions in financial assets and liabilities are presented in Table 9.1 as the net acquisition of each category of financial asset and the net incurrence of each category of liability. That is, in the GFS framework, only the net change in the holding of a type of asset is presented, not gross acquisitions and gross disposals, as with most nonfinancial assets. (Separate amounts for gross acquisitions and gross disposals may, of course, be presented if the underlying accounting records permit and the information is analytically meaningful.) When the same type of financial instrument is held both as a financial asset and a liability, transactions in financial assets are presented separately from transactions in liabilities rather than netting transactions in liabilities against transactions in financial assets.

\section{Consolidation}

9.18 As explained in paragraphs 3.152-3.168, consolidation is a method of presenting statistics for a set of units (or entities) as if they constituted a single unit. A consolidated set of accounts for a unit, or group of units, is produced by, first, an aggregation of all flows and stock positions within an agreed analytical framework, followed by the elimination, in principle, of all flows and stock positions that represent relationships among the units or entities being consolidated.

9.19 Transactions in financial assets are eliminated when the two parties to the transaction are units that are being consolidated. For example, if a local government unit purchases a security issued by the central government, both the acquisition of the financial asset and the incurrence of the liability would disappear in a presentation of statistics for the entire general government sector but not in a presentation of either the central or the local government subsector separately.

\section{Arrears}

9.20 As explained in paragraphs 7.247-7.250, arrears are defined as amounts that are both unpaid and past the due date for payment. In principle, amounts payable for any expense, for acquisition of nonfinancial assets, or related to any liability may become in arrears if the amounts are past due for payment (e.g., in the case of overdue debt service payments).

9.21 Some types of financial assets and liabilities, most notably debt securities, loans, financial derivatives, and other accounts receivable/payable, mature at scheduled dates, or series of dates, when the debtor is required to make specified payments to the creditor. If the payments are not made as scheduled, the debtor has effectively obtained additional financing by not making the scheduled payments. When arrears occur, no transactions should be imputed, but the arrears should continue to be shown in the same instrument until the liability is extinguished. However, if the contract provided for a change in the characteristics of a financial instrument when it goes into arrears, this change should be recorded as a reclassification in the form of other changes in the volume of the financial assets and liabilities (see paragraph 10.84). If the contract is renegotiated or the nature of the instrument changes from one instrument category to another (e.g., from bonds to equity), the resulting flow should be recorded as transactions in the repayment of the original liability and the creation of a new liability (see paragraph 3.97).

9.22 Nonetheless, interest accrues on liabilities in arrears (both principal and interest arrears) and is known as late interest. Late interest should accrue at the same interest rate as on the original debt instrument, unless the interest rate for arrears was stipulated in the original debt contract, in which case this stipulated interest rate should be used. The stipulated rate may include a penalty rate in addition to the interest rate on the original debt. For other liabilities in arrears, in the absence of other information, interest costs accrue on these arrears at the market rate of interest for overnight borrowing. Also, any additional charges relating to arrears (such as penalties) should be recorded as interest on arrears of the debtor at the time the charges accrue. If an item is purchased on credit and the debtor fails to pay within the period stated at the time the purchase was made, any extra charges incurred should be regarded as interest on arrears and accrue until the debt is extinguished. 


\begin{tabular}{|c|c|c|c|}
\hline 32 & Net acquisition of financial assets & 33 & Net incurrence of liabilities \\
\hline 3201 & Monetary gold and Special Drawing Rights (SDRs) & 3301 & Special Drawing Rights (SDRs) \\
\hline 2011 & Monetary gold & & \\
\hline 32012 & Special Drawing Rights (SDRs) & & \\
\hline 3202 & Currency and deposits & 3302 & Currency and deposits \\
\hline 3203 & Debt securities & 3303 & Debt securities \\
\hline 3204 & Loans & 3304 & Loans \\
\hline 3205 & Equity and investment fund shares & 3305 & Equity and investment fund shares \\
\hline 32051 & Equity & 33051 & Equity \\
\hline 32052 & Investment fund shares or units & 33052 & Investment fund shares or units \\
\hline 3206 & $\begin{array}{l}\text { Insurance, pension, and standardized guarantee } \\
\text { schemes [GFS] }\end{array}$ & 3306 & $\begin{array}{l}\text { Insurance, pension, and standardized guarantee } \\
\text { schemes [GFS] }\end{array}$ \\
\hline 32061 & Nonlife insurance technical reserves & 33061 & Nonlife insurance technical reserves \\
\hline 32062 & Life insurance and annuities entitlements & 33062 & Life insurance and annuities entitlements \\
\hline 32063 & Pension entitlements [GFS] & 33063 & Pension entitlements [GFS] \\
\hline 32064 & Claims of pension funds on pension manager & 33064 & Claims of pension funds on pension manager \\
\hline 32065 & $\begin{array}{l}\text { Provisions for calls under standardized } \\
\text { guarantee schemes }\end{array}$ & 33065 & $\begin{array}{l}\text { Provisions for calls under standardized } \\
\text { guarantee schemes }\end{array}$ \\
\hline 3207 & Financial derivatives and employee stock options & 3307 & Financial derivatives and employee stock options \\
\hline 32071 & Financial derivatives & 33071 & Financial derivatives \\
\hline 32072 & Employee stock options & 33072 & Employee stock options \\
\hline 3208 & Other accounts receivable & 3308 & Other accounts payable \\
\hline 32081 & Trade credit and advances & 33081 & Trade credit and advances \\
\hline 32082 & Miscellaneous other accounts receivable & 33082 & Miscellaneous other accounts payable \\
\hline 321 & Domestic debtors & 331 & Domestic creditors \\
\hline $\begin{array}{l}3211- \\
3218\end{array}$ & $\begin{array}{l}\text { Same instrument breakdown as above, but } \\
\text { excluding monetary gold }\end{array}$ & $\begin{array}{l}3312- \\
3318\end{array}$ & $\begin{array}{l}\text { Same instrument breakdown as above, but } \\
\text { excluding SDRs }\end{array}$ \\
\hline 322 & External debtors & 332 & External creditors \\
\hline $\begin{array}{l}3221- \\
3228\end{array}$ & Same instrument breakdown as above & $\begin{array}{l}3321- \\
3328\end{array}$ & Same instrument breakdown as above \\
\hline
\end{tabular}

9.23 When using the cash basis of recording, cash payments for the settlement of arrears should be recorded with a counterpart entry in the relevant categories of expense, net acquisition of nonfinancial assets, or net incurrence of liabilities. Recording arrears in this way recognizes the appropriate economic nature of these payments since they have not been recorded under the appropriate GFS categories in the past (see also paragraph 7.249).

\section{Classification of Transactions in Financial Assets and Liabilities by Type of Financial Instrument and Residence}

9.24 Table 9.1 presents the classification of transactions in financial assets by type of financial instrument and residence. This classification is consistent with the classification of the same financial assets and liabilities employed in Chapter 7 (Table 7.9). Chapter 7 also provides full definitions of the financial assets or liabilities included in each category, and those definitions are not repeated here. The remainder of this section provides guidance only on those transactions for which the general guidance may not be sufficient.

9.25 In principle, the classification of transactions in financial assets and liabilities by residence is based on the residence of the units that are a party to the transaction being recorded. The classification of stock positions in financial assets and liabilities in a unit's balance sheet (see paragraph 7.264) is based on the residence of the issuer of financial instruments (assets), and the residence of the holder of the financial instruments (liabilities). If a transaction in financial 
assets or liabilities between a resident and a nonresident unit involves an instrument originally issued by a resident, an entry in other changes in the volume of assets (reclassification) should be recorded to maintain the integrated GFS framework of flows and stock positions (see also paragraphs 9.85-9.87 and 10.79). In practice, available information may not permit the identification of the two parties to the transaction. Therefore, transactions recorded in the source data for external transactions in financial assets and liabilities may include those that take place not only between residents and nonresidents but also between two residents in nonresident financial assets and liabilities.

9.26 In addition to transactions in interest and principal on debt liabilities, general government and public sector units may undertake a range of complex debt-related transactions, such as assuming debt of other units, making payments on behalf of other units, debt rescheduling, debt forgiveness, debt defeasance, and financial leasing. The special features of these types of transactions are described in Appendix 3.

9.27 The classification of financial instruments in GFS, described in this chapter, does not include functional categories used in the Balance of Payment and International Investment Position, such as direct investment, portfolio investment, or international reserves. ${ }^{5}$

\section{Monetary Gold and Special Drawing Rights (SDRs) (3201, 3211, 3221, 3301, 3321)}

\section{Monetary gold (32011, 32211)}

9.28 Transactions in monetary gold are the exclusive responsibility of the monetary authorities, which will normally be the central bank (a public financial corporation). It is possible, however, for a unit of the general government sector to undertake some monetary functions, in which case it may have transactions in monetary gold. When transactions in financial assets are classified by residence of the counterparty, the counterpart liability to transactions in monetary gold

\footnotetext{
${ }^{5}$ For information on these categories, see the BPM6, Chapter 6. See also Appendix 7 for more information on the linkages between GFS and the Balance of Payments and International Investment Position.

${ }^{6}$ The numbers in parentheses after each classification category are the GFS classification codes. Appendix 8 provides all classification codes used in the GFS framework.
}

is shown as external because monetary gold can be held only as part of foreign reserves. ${ }^{7}$

9.29 Transactions in monetary gold can take place only between two monetary authorities or between a monetary authority and an international financial organization. If the monetary authority adds to its holdings of monetary gold by acquiring newly mined gold or existing gold offered on the private market, then the gold so acquired is said to have been monetized. No transaction in financial assets should be recorded. Instead, the acquisition of the gold should first be recorded as a transaction in nonfinancial assets, and then the reclassification of the gold as monetary gold should be recorded as an other economic flow. Demonetization of gold is recorded symmetrically (see paragraph 10.84).

9.30 Transactions in nonmonetary gold (including gold not held as reserves by the monetary authorities and all gold held by financial institutions other than the monetary authorities) are treated as acquisitions minus disposals of valuables (if the sole purpose is to provide a store of wealth) and otherwise as changes in inventories. Deposits, loans, and securities denominated in gold are treated as financial assets (not as gold) denominated in foreign currencies.

\section{Special Drawing Rights (SDRs) (32012,} $32112,32212,3301,3321)$

9.31 SDRs are held exclusively by participants of the IMF's SDR Department and prescribed holders, and are transferable among them. The creation of SDRs (referred to as allocations of SDRs) and the extinction of SDRs (cancellations of SDRs) are recorded as transactions. Transactions in SDRs also take place when a holder exercises its right to obtain foreign exchange or other reserve assets from other participants and prescribed holders and when SDRs are sold, loaned, or used to settle financial obligations.

9.32 At the time of the SDR allocation, the amounts recorded as SDR allocations (liabilities) and holdings (financial assets) are identical and on the same public sector unit's balance sheet. This public sector unitas official holder-may, subsequently, exchange some or all of its SDR holdings (financial asset) with other official holders for a freely usable currency(ies) or to

\footnotetext{
$\overline{{ }^{7} \text { See paragraphs } 7.126}-7.130$ for more details on monetary gold.
} 
meet its liabilities. Consequently, the SDR allocations and holdings on the balance sheet of that public sector unit would no longer be identical; the SDR holdings would be less than the allocations because they have been exchanged. As a result, interest payable on the SDR allocation of that public sector unit will be larger than interest receivable on its SDR holdings. Interest receivable on the SDR holdings exchanged will accrue to the new holder. These transactions in SDRs (and resulting stock positions) are recorded at their gross amounts.

\section{Currency and Deposits (3202, 3212, 3222, 3302, 3312, 3322)}

9.33 Because the market price of domestic currency and deposits is fixed in nominal terms, the net acquisition of domestic currency and deposits is equal to the stock held at the end of the reporting period minus the stock held at the beginning of the period, adjusted for any currency that was lost, stolen, or destroyed. Calculation of the net acquisition of foreign currencies and deposits must exclude the effects of changes in exchange rates, which are recorded as holding gains or losses (as also mentioned in paragraph 10.23).

9.34 Currency is treated as a liability of the unit that issued the currency. Consequently, when a unit puts new currency into circulation, a transaction is recorded that increases its liability for currency. Usually, the counterpart to the increase in liabilities is an increase in the unit's financial assets, most likely deposits. ${ }^{8}$ Transactions in gold and commemorative coins that do not circulate as legal tender are treated as transactions in inventories or valuables rather than currency (see paragraph 7.135). The cost of producing new currency is an expense transaction unrelated to the value of transactions in currency.

9.35 Transactions in unallocated accounts for precious metals (including gold) are classified under deposits (as explained in paragraph 7.15), except for transactions between two monetary authorities in unallocated gold accounts for reserves purposes. If a monetary authority acquires an unallocated gold ac-

\footnotetext{
${ }^{8}$ Seigniorage profits (i.e., the difference between the face value of currency issued and its costs of production, including the costs of base metals) for the issuer of currency are implicitly included under currency and deposits and are not treated as revenue.
}

count from a nonmonetary authority, the transaction is recorded as a transaction in currency and deposits and then reclassified as monetary gold (see paragraph 10.84). ${ }^{9}$

\section{Debt Securities (3203, 3213, 3223, 3303, 3313, 3323)}

9.36 Most transactions in bonds and other types of debt securities are covered by the general guidelines previously established. The accrual of interest on certain debt securities may deserve special attention and is summarized here (also see paragraphs 6.626.83). Interest is the amount debtors will have to pay their creditors over and above the repayment of the amounts advanced by the creditors. Interest accrues on a debt instrument for its entire life as determined by the conditions set at inception of the instrument. When payments are fixed in advance, accrued interest is determined using the original yield-to-maturity. A single, effective yield-established at the time of the security issuance-is used to calculate the amount of accrued interest in each period to maturity. This approach is known as the "debtor approach."

9.37 Most debt securities have a fixed or variable interest rate and may also be issued at a discount or, possibly, a premium. In such cases, the interest receivable by the holders of the debt securities has two components:

- The amount of money income receivable from coupon ${ }^{10}$ payments each period, plus

- The amount of interest accruing each period attributable to the difference between the redemption price and the issue price.

9.38 On a cash basis, interest expense is recorded at the time it is paid in cash, with a reduction in currency and deposits as the counterpart.

\section{Debt securities issued at par}

9.39 For debt securities for which the issue and redemption prices are the same (i.e., issued at par), total interest accrued over the whole life of the debt

\footnotetext{
${ }^{9}$ See also BPM6, paragraph 9.20.

${ }^{10} \mathrm{~A}$ coupon payment is a contractually agreed cash amount paid by the issuer of the debt security to the holder, at each coupon date. It is calculated from the coupon rate, face value of the debt security, and the number of payments per year, and may differ from the accrued interest if debt securities are issued at a discount or a premium.
} 
securities is given by the periodic coupon payments. If coupon payments are fixed, accrued interest can be calculated by allocating the coupon payment to the relevant period using a daily compound formula.

\section{Debt securities issued at a discount or premium}

9.40 Debt securities issued at a discount (or premium), such as short-term bills of exchange and discounted and zero-coupon bonds, are recorded at the time of issue at the issue price. ${ }^{11}$ The difference between the discounted issue price of such debt securities and their price at maturity (redemption price) is treated as interest accruing over the life of the debt security. For each reporting period, the holder of the debt security should record a transaction for the receipt of interest revenue arising from the difference between the issue and redemption prices and its reinvestment in an additional quantity of the debt security. The issuer of the debt security records the accrual of interest expense and an increase in its liability for debt securities. For debt securities issued at a premium, the difference between the issue price and the price at maturity should be amortized over the life of the instrument, reducing (rather than increasing) the amount of interest accruing in each period. On a cash basis, interest resulting from the discount should be recorded as an expense on redemption of the bond. Interest resulting from a premium should be recorded as a reduction in interest expense at the time of issue.

\section{Index-linked debt securities}

9.41 With an index-linked debt security, ${ }^{12}$ an indexation mechanism links the amount to be paid at maturity or coupon payments (or both) to an indicator agreed by the parties. The values of the indicators are not known in advance. For debt securities with indexation of the amount to be paid at maturity, these amounts may be known only at the time of redemption. As a result, total interest flows before redemption cannot be determined with certainty. To estimate the change in the value of the debt security due to interest accrued before the values of the reference indicators are known, some proxy measures need to be used.

\footnotetext{
${ }^{11}$ The issue price is the actual amount paid - that is, after the discount has been subtracted or premium added.

${ }^{12}$ It is possible for loans and other financial instruments to be index linked and the same transactions would be recorded.
}

In this regard, it is useful to distinguish the following three arrangements:

- Indexation of coupon payments only with no indexation of amount to be paid at maturity

- Indexation of the amount to be paid at maturity with no indexation of coupon payments

- Indexation of both the amount to be paid at maturity and coupon payments.

9.42 The principles describing the transactions for these index-linked debt securities revolve around determining the value of interest and are discussed in paragraphs 6.75-6.78.

\section{Debt securities with embedded derivatives}

9.43 For debt securities with embedded derivatives, ${ }^{13}$ such as call, put, or equity conversion options, the recording of accrued interest is the same as for securities that do not have such features. For all periods leading up to the exercise of the option, the interest accrued is unaffected by the presence of the option. When the embedded option is exercised, the securities are redeemed and the accrual of interest ceases.

\section{Loans (3204, 3214, 3224, $3304,3314,3324)$}

9.44 The terms of a loan contract frequently require periodic payments for all interest expense accrued since the previous periodic payment and a payment covering a portion of the original amount borrowed. On an accrual basis, interest accrues continuously over the reporting period and should be added to the principal; the payments of interest and principal are transactions in financial assets or liabilities (see paragraph 6.64). On a cash basis, periodic interest and principal payments are recorded as interest expense/ revenue and transactions in financial assets or liabilities, respectively, when cash payments are made-no interest is accrued (see paragraph 6.65).

9.45 When goods are acquired under a financial lease, a change of economic ownership from the lessor to the lessee is deemed to take place, even though the leased goods remain legally the property of the lessor. This change in economic ownership is

\footnotetext{
${ }^{13}$ As explained in paragraph 7.148, securities with an embedded derivative are classified entirely as debt securities. A separate financial derivate component is not recorded.
} 
financed by a loan transaction: the lessor and lessee record a loan equal to the market value of the asset, this loan being gradually paid off over the period of the lease. The implication of treating a financial lease as a loan is that interest accrues on the loan. The rate of interest on the imputed loan equates the present value of the total amount payable in installments over the life of the lease (including any value to be repaid at maturity) with the market value of the asset at the time the lease is initiated. The installment covers interest accrued during the period as well as the component of the repayment of the principal.

9.46 As described in paragraphs 7.159 and 7.161, repurchase agreements and gold swaps are treated as loans with no change of economic ownership for the underlying assets that legally were sold. Similarly, the winding up of the repurchase agreement or swap according to the initial terms of the agreement is treated as a liquidation of a loan. The economic nature of an off-market swap is equivalent to a combination of borrowing (the lump sum) in the form of a loan transaction and an on-market swap transaction (financial derivative) (see paragraph 7.162).

\section{Equity and Investment Fund Shares (3205, 3215, 3225, 3305, 3315, 3325) Equity (32051, 32151, 32251, 33051, 33151, 33251)}

9.47 The treatment of transactions in publicly traded shares is generally straightforward. Problems may be created, however, by the operations of quasicorporations and public corporations.

9.48 Additions to the funds and other resources of a quasi-corporation, including in-kind transfers of nonfinancial assets, are treated as purchases of equity by the owner of the quasi-corporation. This includes new finance made available for use by the enterprise in purchasing fixed assets, accumulating inventories, acquiring financial assets, or redeeming liabilities. Similarly, receipt by the owner of proceeds from sales of any of the quasi-corporation's assets, transfers in kind from the quasi-corporation, and withdrawals by the owner of accumulated retained earnings of the quasi-corporation are treated as reductions in equity by the owner. Liquidating dividends payable to shareholders when an enterprise becomes bankrupt (or is otherwise wound up) should also be recorded as withdrawal of equity.
9.49 For government units, regular transfers to corporations or quasi-corporations to cover persistent operating deficits are subsidies (251), but if payments from government are irregular and are made to cover accumulated losses or exceptional losses due to factors outside the control of the enterprise, they are treated as a capital transfer under capital transfers not elsewhere classified (2822). ${ }^{14}$ If government makes a transfer to a public corporation to finance all or part of the costs to finance its acquisition of nonfinancial assets, this also is recorded as equity unless there is no reasonable expectation of a sufficient rate of return on the investment, in which case the transfer is recorded as capital transfers not elsewhere classified (2822) (see Box 6.3). Regular withdrawals of the income from public corporations or quasi-corporations are property income under, respectively, dividends (1412) or withdrawals of income from quasi-corporations (1413). The exception occurs when dividends are disproportionately large relative to the recent level of dividends and earnings. Any dividends declared greatly in excess of the recent level of dividends and earnings should be treated as withdrawal of owners' equity (32051, 32151, $32251,33051,33151,33251)$ from the public corporation. This will be the case for distributions by public corporations to shareholders of proceeds from privatization receipts and other sales of assets and large and exceptional one-off payments based on accumulated reserves or holding gains.

9.50 Government units may acquire equity in a public corporation or quasi-corporation as a result of legislation or an administrative change creating the corporation or quasi-corporation. In some cases, this event will amount to a reclassification of existing assets and liabilities, which is recorded as an other economic flow that results in an addition of equity to the government unit's balance sheet. An advance of funds to create the new enterprise is a transaction reflecting the purchase of equity. As explained in paragraph 6.121, retained earnings of a foreign direct investment enterprise are treated as if they were distributed and remitted to foreign direct investors in proportion to their ownership of the equity of the enterprise and then reinvested by them by means of additions to equity.

\footnotetext{
${ }^{14}$ See Box 6.3 for more details.
} 
9.51 From time to time, corporations restructure their shares and may offer shareholders a new number of shares for each share previously held. These bonus shares are not, however, treated as transactions, but as a form of redenomination. If a public corporation buys its own shares, the transaction is classified as being a reduction in the equity liability, rather than an acquisition of an asset. Because a corporation cannot have a claim on itself, the liability is deemed to be extinguished, even if the shares are not canceled.

9.52 Membership dues and subscription fees payable to international organizations are treated as the acquisition of equity in cases when there is a possibility - even if unlikely_of repayment of the full amount. ${ }^{15}$ A capital contribution to an international organization or nonprofit institution is a capital transfer if it does not give rise to equity for the provider of the contribution (see paragraphs 6.94 and 6.124).

\section{Privatization/Nationalization}

9.53 Privatization generally is the disposal to private owners by a government unit of the controlling equity of a public corporation or quasi-corporation. Such a disposal is treated as a transaction in equity. ${ }^{16}$ If a public corporation or quasi-corporation sells some of its assets and provides part or all of the proceeds to its parent government unit, then the provision of the proceeds would also be a disposal of equity of the government unit. Brokers' commissions and other privatization costs are expense transactions just as all other costs of ownership transfer related to the acquisition or disposal of a financial asset.

9.54 Government units also can be privatized. If the assets disposed of as a single transaction constitute a complete institutional unit, the transaction should be classified as a sale of equity. The government is assumed to have converted the unit to a quasicorporation immediately prior to disposal by means of a reclassification of assets, which should be recorded as an other economic flow. If the assets disposed of do not constitute a complete institutional unit, then the

\footnotetext{
${ }^{15}$ In most cases, these membership dues and subscription fees should be recorded as an expense in use of goods and services (22) if there is an exchange of a payment for some form of a service or, if no exchange, as a current transfer not elsewhere classified (2821).

${ }^{16}$ The public corporation is reclassified to a private corporation through an entry in other changes in the volume of assets and liabilities, as explained in Chapter 10.
}

transactions should be classified as a disposal of the individual nonfinancial and/or financial assets.

9.55 Nationalization is generally the acquisition from private owners by a government unit of the controlling equity of a private corporation or quasicorporation. Such an acquisition is treated as a transaction in equity. In some exceptions, government units may acquire ownership of a private corporation or quasi-corporation by way of confiscation or appropriation. There is no payment to the owners (or the compensation is not commensurate with the fair value of the assets). This is not the result of a transaction by mutual agreement. The difference between the market value of the asset acquired and any compensation provided (a transaction) should be recorded as other changes in the volume of assets, in the form of an uncompensated seizure (see paragraph 10.62). ${ }^{17}$

Investment fund shares or units (32052, 32152, 32252, 33052, 33152, 33252)

9.56 Changes to the value of investment funds due to the issuance or repayment of shares or units are recorded as transactions. The increase (decrease) in the value of investment fund shares or units, other than from holding gains and losses, is recorded as distributed to the share- or unit holders and reinvested by the holders in the shares or units (see paragraph 5.121). This treatment is similar to the treatment of retained earnings of a foreign direct investment enterprise. Gains and losses arising from the value of an asset or fund to reflect its current market value are not recorded as transactions, but as holding gains or losses.

\section{Insurance, Pension, and Standardized Guarantee Schemes [GFS] (3206, 3216, 3226, 3306, 3316, 3326)}

9.57 General government units may incur liabilities for these reserves, entitlements, and provisions as operators of nonlife insurance and standardized guarantee schemes, nonautonomous pension funds, and unfunded pension schemes. General government units may acquire insurance technical reserves as financial assets in their capacity as holders of nonlife insurance policies. Public corporations can engage

\footnotetext{
${ }^{17}$ The same treatment would apply to the acquisition of land or any other nonfinancial asset under a compulsory sale.
} 
in all types of insurance activities. ${ }^{18}$ When operating standardized guarantee schemes, such as student loan guarantees, deposit guarantees, and export credit guarantees, general government units record transactions in liabilities for provision for calls under standardized guarantee schemes. These transactions in liabilities comprise:

- Prepayments of net fees: fees prepaid in the reporting period less previously prepaid fees earned for the reporting period

- Provisions for outstanding calls: expected calls less any expected asset recoveries on the standardized guarantees provided in the recording period less any calls settled in the recording period (see paragraphs A4.78-A4.80).

\section{Nonlife insurance technical reserves [GFS]} (32061, 32161, 32261, 33061, 33161, 33261)

9.58 In general, nonlife insurance premiums are paid in advance of the period covered by the policy. On an accrual basis, all such prepaid premiums are transactions that increase the insurance unit's liability and the policyholder's asset for insurance technical reserves. As the period covered by the premium progresses, the insurance unit continuously earns the premium, which requires a transaction to decrease its liability and the policyholder's asset for nonlife insurance technical reserves.

9.59 When events occur giving rise to a valid claim, a transaction is recorded that increases reserves against outstanding claims as a liability of the insurance unit and an asset of the beneficiaries. If payment of the claim is delayed for a substantial length of time or consists of periodic payments over several reporting periods, the value of the transaction corresponds to the present value of the expected payments.

9.60 The change in unearned premiums and reserves against outstanding claims is shown as a transaction in liabilities of the insurer and a transaction in assets of the policyholders. The relevant transactions in revenue and expense are discussed in paragraphs 5.149-5.151 and 6.125.

\footnotetext{
${ }^{18}$ It is assumed that general government units do not operate life insurance schemes and do not purchase life insurance policies. The treatment of insurance technical reserves created by life insurance activities of public corporations is similar to autonomous pension funds, but is not addressed separately here. Also see the 2008 SNA, Chapter 17, and the BPM6, Appendix 6c.
}

9.61 On a cash basis, premiums received and claims paid are shown as a transaction in revenue and expense of the insurer and the policyholders when payments are made.

\section{Life insurance and annuities entitlements} (32062, 32162, 32262, 33062, 33162, 33262)

9.62 As noted in paragraph 7.179, it is unlikely for general government units to incur liabilities or hold assets with respect to life insurance and annuities, unless they provide such schemes to their employees. Changes in life insurance and annuities entitlements are transactions in liabilities for the insurer and transactions in financial assets for the policyholders. In the case of annuities, the transactions constitute a stream of ongoing payments, rather than a lump sum that reduces the liability. The treatment of life insurance and annuities is elaborated in paragraph A4.69.

Pension entitlements [GFS] $(32063,32163$, 32263, 33063, 33163, 33263)

9.63 If a public sector unit operates a pension scheme, then it will have transactions in liabilities for pension entitlements.

9.64 For a defined-benefit scheme, actual and imputed social contributions receivable from employees, employers, or other institutional units on behalf of individuals or households with claims on the public sector unit for future pension benefits will increase the unit's liability for pension entitlements. The increase in the existing liability (because the future payments are discounted over fewer periods) is recorded as a transaction in pension entitlements with the corresponding entry being an expense in the form of imputed social contributions, as explained in paragraph 6.117. Payments to retired persons or their dependents and survivors in the form of periodic payments or lump sums reduce the liability, with a decrease in currency and deposits as the counterpart entry. On a cash basis, the benefits paid should be recorded as an expense in the form of employment-related social benefits [GFS] (273). ${ }^{19}$

\footnotetext{
${ }^{19}$ The cash treatment differs from the accrual treatment because there are no imputations for contributions and accumulated liabilities in a cash-based system. Furthermore, in a cash system, the benefits paid cannot be regarded as compensation of employees because they are paid to retired employees, not current employees-there is no exchange of labor involved at the time.
} 
9.65 For a defined-contribution scheme, transactions in pension liabilities for the pension fund are actual contributions receivable from employers on behalf of employees, from employees, and possibly from other individuals (formerly participating in a scheme, self-employed and unemployed persons, and retirees) plus contribution adjustments (property expense for investment income disbursement ${ }^{20}$ ) minus benefits payable. The same transactions in financial assets are recorded for the participants in the scheme. On a cash basis, transactions in liabilities of the insurance corporation are equal to social contributions and investment income received in cash minus benefit payments in cash.

9.66 On occasion, large one-off transactions (lump sums) may occur between a government and another institutional unit, often a public corporation, linked to pension reforms or to privatizations of public corporations. The goal may be to make the public corporation competitive and financially more attractive by removing existing pension liabilities from the balance sheet of the corporation. This goal is achieved by government assuming the liability in question in exchange for an asset or assets from the public corporation. If the value of the assets receivable is equal to the value of the liability assumed, the transaction is recorded as an exchange of assets and liabilities. However, the value of the asset(s) may not be the same value as the liability.

- If the value of the asset(s) receivable is less than the value of the liability incurred, an expense in the form of a capital transfer from government to the public corporation should be recorded for the difference. The assumer (government) records an increase in liabilities for pension entitlements, an increase in the relevant financial and/or nonfinancial assets, and an expense in the form of capital transfer to the public corporation (see paragraph 6.124). The public corporation records a decrease in liabilities for pension entitlements, a decrease in financial and/or nonfinancial assets, and revenue in the form of a capital transfer from government.

${ }^{20}$ Holding gains and losses generated by the investment of cumulated pension entitlements are not included in investment income.
- If the value of the asset(s) receivable is more than the value of the liability incurred, a capital transfer from the public corporation to the government is recorded for the difference (see paragraph 5.148). The public corporation records a decrease in liabilities for pension entitlements, a decrease in financial and/or nonfinancial assets, and an expense in the form of a capital transfer to government.

9.67 Where a government unit assumes pension liabilities, the pension obligations absorbed by the social security fund continue to be classified as pension entitlement liabilities. These obligations are gradually extinguished as the benefits are paid out. As noted in paragraph 7.261, net implicit obligations for future social security benefits are shown as a memorandum item to the balance sheet.

Claims of pension fund on pension manager (32064, 32164, 32264, 33064, 33164, 33264)

9.68 As explained in paragraph 7.199, an employer may contract with a third party to administer a pension fund for its employees. When the funding of a deficit of the pension fund is the responsibility of the employer or other sponsor (pension manager), then a claim of the pension fund on the manager accrues. Similarly, if the employer or sponsor (pension manager) has a right to claim surpluses of the pension fund, then a claim of the manager to the pension fund may accrue.

Provision for calls under standardized guarantee schemes $(32065,32165,32265$, 33065, 33165, 33265)

9.69 As explained in paragraphs 7.201-7.202, standardized guarantee schemes have much in common with nonlife insurance and are thus recorded in similar ways. The treatment of standardized guarantee schemes is elaborated in paragraphs A4.78-A4.80.

\section{Financial Derivatives and Employee Stock Options (3207, 3217, 3227, 3307, 3317, 3327)}

Financial derivatives (32071, 32171, 32271 , 33071, 33171, 33271)

9.70 Transactions involving financial derivatives may arise at inception, on secondary markets, with ongoing servicing (such as for margin payments), and at settlement. Transactions in derivatives preferably 
should be shown separately for assets and liabilities, whenever possible, but net settlements are acceptable when gross reporting is impractical. Any commission payable to brokers or other intermediaries for arranging a financial derivatives contract is treated as a payment for a service. In many cases, however, financial derivatives transactions involve implicit service charges, and it is usually not possible to estimate the service element. In such cases, the entire value of the transaction should be treated as a transaction in financial derivatives.

\subsection{At inception:}

- The creation of a forward-type contract (see paragraphs 7.212-7.214) does not generally require the recording of a transaction in a financial derivative because risk exposures of equal value are usually being exchanged. That is, there is usually zero exposure and zero value for both sides. In some cases, however, there may be a nonzero transaction value at issue, such as with off-market swaps. (In addition, there may be a service charge for the issue.)

- The purchaser of an option (see paragraph 7.209) pays a premium to the seller, which is the acquisition price of the instrument. Sometimes a premium is paid after the inception of the contract. In that case, the value of the premium is recorded at the inception of the contract in the same manner as if it had been paid then, but is shown as being financed by other accounts receivable/ payable between the writer and the purchaser.

9.72 Subsequent changes in the prices of derivatives are recorded as holding gains or losses, not as transactions, as explained in paragraph 10.42 .

9.73 Sales of options in secondary marketswhether exchanges or over the counter-are valued at market prices and recorded as transactions in financial derivatives.

9.74 When a contract requires ongoing servicing (such as an interest rate swap) and a cash payment is received, there is a decrease (increase) in a financial derivative asset (liability) if, at the time of the payment, the contract is in an asset (liability) position. If compilers are unable to implement this approach because of market practice, all cash receipts should be recorded as reductions in financial assets, and all cash payments should be recorded as decreases in liabilities.
9.75 Margins are payments of cash or deposits of collateral that cover actual or potential obligations incurred through financial derivatives-especially futures or exchange-traded options. As discussed in paragraph 7.219, repayable margins in cash are classified as transactions in deposits or other accounts receivable/payable, and nonrepayable margins are classified as transactions in financial derivatives.

9.76 At settlement, either a cash payment is made or an underlying item is delivered.

- When a financial derivative is settled in cash, a transaction equal to the cash value of the settlement is recorded for the derivative. In most instances, when a cash settlement payment is received, a reduction in a financial derivative asset is recorded. When a cash settlement payment is made, a reduction of a financial derivative liability is recorded.

- When an underlying item is delivered, two transactions are recorded:

- The transaction involving the underlying item is valued at the market price at the time. The entry for the underlying item is recorded under the relevant heading (goods, financial instrument, etc.).

- The transaction involving the derivative is valued as the difference, multiplied by the quantity, between the market price for the underlying item and the strike price specified in the derivative contract.

- When more than one contract is settled-in cash, at the same time, and with the same counterpartysome of the contracts being settled are in asset positions and some are in liability positions. In this situation, transactions involving assets should be recorded separately from those involving liabilities, wherever possible, but net settlements are acceptable when gross reporting is impractical.

\section{Employee stock options (32072, 32172, 32272, 33072, 33172, 33272)}

9.77 General government units are very unlikely to issue stock options. Only entities with issued share capital can create employee stock options, so they may arise for public corporations in unusual cases. An employee stock option is created on a given date 
(the "grant" date), providing that an employee may purchase a given number of shares of the employer's stock at a stated price (the "strike" price) either at a stated time (the "vesting" date) or within a period of time (the "exercise" period) immediately following the vesting date.

9.78 At the grant date, a transaction in employee stock options should be recorded as the corresponding entry to wages and salaries in kind (2112). The value of the employee stock options recorded as compensation should be spread over the period between the grant and vesting dates, if possible. Similarly, any increase in the value of the employee stock options between the grant and vesting date should be classified as compensation of employees. If this is not possible, for a pragmatic solution see paragraph 9.80 .

9.79 When the option is exercised, the transaction in the employee stock option is recorded at a value that reflects the difference between the market price of the equity and the price paid by the buyer for the equity. Any change in the value between vesting date and exercise date is not treated as compensation of employees but as a holding gain or loss (see paragraph 10.43).

9.80 In practice, it is most unlikely that estimates of the costs of employee stock options to the employers are revised between the grant date and the exercise date. For pragmatic reasons, therefore, the whole of the increase between grant date and exercise date is treated as a holding gain or loss (see paragraph 10.43). Cancellation of employee stock options is recorded as other changes in the volume of assets (see paragraph 10.57).

9.81 Employee stock options do not generally raise separate issues to those for financial derivatives, but one special case occurs when an employee of a subsidiary is issued options for stock in the parent company. Because the parent is not the employer, the subsidiary records a transaction acquiring the option from the parent before granting the stock option to the employee. See also paragraph 7.222 regarding stock options provided to suppliers of goods and services to an enterprise.

\section{Other Accounts Receivable/Payable (3208, $3218,3228,3308,3318,3328$ )}

9.82 Other accounts receivable/payable consist of trade credits and advances and miscellaneous other items due to be paid or received. Transactions in trade credits occur when credit is extended directly to purchasers of goods and services. Advances are recorded for amounts paid in advance of work being performed, or for prepayments of goods and services (see paragraph 7.225).

9.83 Miscellaneous other accounts receivable/ payable occur with respect to accrued but unpaid taxes, dividends, purchases and sales of securities, rent, wages and salaries, social contributions, social benefits, and similar transactions. Prepayments of taxes are also included in this category. Accrued but unpaid interest should be added to the principal of the underlying asset rather than included in this category.

9.84 This category is used to bridge the timing difference between the occurrence of economic events and the time the actual cash flows take place. It should not be used to record statistical discrepancies.

\section{Classification of Transactions in Financial Assets and Liabilities by Sector and Residence}

9.85 For a full understanding of financial flows and the role they play in government finance, it is often important to know not just what types of liabilities a general government unit uses to finance its activities and what types of financial assets it holds as investments. It is also important to know which sectors are providing the financing and what types of financial assets are held. In addition, it is often necessary to analyze financial flows between subsectors of the general government sector or the public sector. These flows of funds may be analyzed in a from-whom-towhom framework. ${ }^{21}$ Table 9.2 presents a classification of transactions in financial assets and liabilities based on the sector and residence of the two parties involved in the transactions.

9.86 An issuer of securities is usually not a party involved in a secondary market transaction in that security. However, when a transaction changes the residence or sector of the creditor, an entry in other

\footnotetext{
${ }^{21}$ See the PSDS Guide, Chapter 7, and Handbook on Securities Statistics, Part 2, for a detailed discussion of the from-whom-towhom approach.
} 


\begin{tabular}{|c|c|c|c|}
\hline 82 & Net acquisition of financial assets & 83 & Net incurrence of liabilities \\
\hline 821 & Domestic debtors & 831 & Domestic creditors \\
\hline 8211 & General government & 8311 & General government \\
\hline 8212 & Central bank & 8312 & Central bank \\
\hline 8213 & $\begin{array}{l}\text { Deposit-taking corporations except the } \\
\text { central bank }\end{array}$ & 8313 & $\begin{array}{l}\text { Deposit-taking corporations except the } \\
\text { central bank }\end{array}$ \\
\hline 82131 & $\begin{array}{l}\text { Public deposit-taking corporations except } \\
\text { the central bank }\end{array}$ & 83131 & $\begin{array}{l}\text { Public deposit-taking corporations except } \\
\text { the central bank }\end{array}$ \\
\hline 82132 & Private deposit-taking corporations & 83132 & Private deposit-taking corporations \\
\hline 8214 & Other financial corporations & 8314 & Other financial corporations \\
\hline 82141 & Other public financial corporations & 83141 & Other public financial corporations \\
\hline 82142 & Other private financial corporations & 83142 & Other private financial corporations \\
\hline 8215 & Nonfinancial corporations & 8315 & Nonfinancial corporations \\
\hline 82151 & Public nonfinancial corporations & 83151 & Public nonfinancial corporations \\
\hline 82152 & Private nonfinancial corporations & 83152 & Private nonfinancial corporations \\
\hline 8216 & $\begin{array}{l}\text { Households and nonprofit institutions serving } \\
\text { households }\end{array}$ & 8316 & $\begin{array}{l}\text { Households and nonprofit institutions serving } \\
\text { households }\end{array}$ \\
\hline 822 & External debtors & 832 & External creditors \\
\hline 8221 & General government & 8321 & General government \\
\hline 8227 & International organizations & 8327 & International organizations \\
\hline 8228 & $\begin{array}{l}\text { Financial corporations other than international } \\
\text { organizations }\end{array}$ & 8328 & $\begin{array}{l}\text { Financial corporations other than international } \\
\text { organizations }\end{array}$ \\
\hline 82281 & Central banks & 83281 & Central banks \\
\hline 82282 & $\begin{array}{l}\text { Financial corporations not elsewhere } \\
\text { classified }\end{array}$ & 83282 & $\begin{array}{l}\text { Financial corporations not elsewhere } \\
\text { classified }\end{array}$ \\
\hline 8229 & Other nonresidents & 8329 & Other nonresidents \\
\hline
\end{tabular}

changes in the volume of assets (reclassification) should be recorded to maintain the integrated GFS framework of stock positions and flows (see paragraphs 9.25 and 10.79).

9.87 The composition of the sectors listed in Table 9.2 is described in Chapter 2. All nonresident units are referred to collectively as the external sector ("rest of the world" sector in the 2008 SNA). In the GFS framework, it is important to know not only the total amount of financing receivable from nonresident units, but also the types of nonresident units supplying the financing. ${ }^{22}$ In GFS, therefore, the sec-

\footnotetext{
${ }^{22}$ Often, in cases of traded debt securities, this will show only the initial holders.
}

tor classification principles could also be applied to nonresident units. In particular, all foreign governments and international organizations are treated as separate sectors in Table 9.2.

\section{Classification of Debt Liabilities and Financial Assets Corresponding to Debt Instruments by Maturity}

9.88 A supplementary classification of the stock positions of debt liabilities and financial assets corresponding to debt instruments by maturity and type of financial instrument is of particular interest and is shown in Table 7.12. If analytically useful, the same classification structure could be applied for transactions in these debt liabilities and financial assets corresponding to debt instruments. 
increase net worth. In contrast, other economic flows related to reclassifications do not affect total net worth. These reclassifications change the value of two assets or two liabilities by the same amount but with opposite signs, or they change one asset and one liability by the same amount-for example, the reclassification of a loan when it becomes negotiable (see paragraph 7.149).

10.4 Other economic flows are classified by the type of asset or liability affected. The classification of assets and liabilities given in Chapter 7 is used for this purpose. In Table 10.2, total other economic flows are classified as being either holding gains and losses or other changes in the volume of assets. In addition, other economic flows can be classified by the type of event that caused the flow in as much detail as needed for fiscal analysis. The types of holding gains or specific types of other changes in the volume of assets could be introduced as an expansion of the table, if considered useful. For example, subcategories of other changes in volume of assets could identify whether the changes are due to the appearance, disappearance, or change in classification of assets and liabilities.

\section{Holding Gains \\ Holding Gains in General}

10.5 Holding gains result from price changes and can accrue on almost all economic assets held for any length of time during a reporting period. It does not matter whether an asset is held the entire period, acquired during the period and held until the end of the period, held at the beginning of the period and disposed of during the period, or acquired and disposed of within the same period. In each case, a holding gain is possible and must be recorded for the entire difference between the opening balance sheet date (or at time of acquisition) and closing balance sheet date (or time of disposal).

10.6 Holding gains may be unrealized or realized:

- An unrealized holding gain is one accruing on an asset that is still owned or a liability that is still outstanding at the end of the reporting period. The values of the assets and liabilities in the closing balance sheet incorporate the unrealized holding gains or losses.
- A holding gain is realized when an asset is sold, redeemed, used or otherwise disposed of, or a liability incorporating a holding gain or loss is repaid. The value of transactions includes the value of realized holding gains or losses. In other words, unrealized holding gains are realized when transactions take place.

10.7 The holding gain is recorded when the price change occurs, which may be at a different time from when the holding gain is realized. Thus, to capture the full value of the holding gains and losses that arose during the reporting period, both realized and unrealized gains and losses need to be covered.

10.8 Holding gains do not include a change in the value of an asset resulting from a change in the quantity or quality of the asset (which are other changes in the volume of assets) - in particular:

- The decline in the value of the fixed assets due to physical deterioration, normal rates of obsolescence, and normal accidental damage should be recorded as consumption of fixed capital (23) and not as a holding loss.

- Debt securities issued at a discount may increase in value progressively prior to redemption because of the accrual of interest. The increase in the market value of a bill or bond due to the accrual of interest should be recorded as a transaction in the asset and is not a holding gain.

10.9 It is not possible to calculate total holding gains using only balance sheet data since the stock positions do not reflect each of the economic events that may have occurred during a reporting period (see paragraphs 3.1-3.4). To measure holding gains directly, therefore, the calculation requires records to be maintained of all individual transactions and individual other changes in the volume of assets plus the price of each asset at the time of the opening and closing balance sheets. Observable market prices for nonfinancial assets are generally not as readily available as for financial assets and liabilities. If, in practice, not all of the requisite data are available, alternative estimation techniques must be employed to calculate holding gains.

10.10 A commonly used alternative method to estimate holding gains and losses is based on the identity that the ending balance sheet value for a 


\section{Table 10.2 Classification of Other Economic Flows}

\begin{tabular}{|c|c|c|c|}
\hline & $\begin{array}{l}\text { Holding gains } \\
\text { and losses }\end{array}$ & $\begin{array}{l}\text { Other changes in } \\
\text { the volume of assets }\end{array}$ & $\begin{array}{l}\text { Total other } \\
\text { economic flows }\end{array}$ \\
\hline $\begin{array}{l}\text { Change in net worth due to total other economic flows / } \\
\text { holding gains and losses / other changes in the volume of assets }\end{array}$ & 4 & 5 & 9 \\
\hline Nonfinancial assets & 41 & 51 & 91 \\
\hline Fixed assets & 411 & 511 & 911 \\
\hline Buildings and structures & 4111 & 5111 & 9111 \\
\hline Dwellings & 41111 & 51111 & 91111 \\
\hline Buildings other than dwellings & 41112 & 51112 & 91112 \\
\hline Other structures & 41113 & 51113 & 91113 \\
\hline Land improvements & 41114 & 51114 & 91114 \\
\hline Machinery and equipment & 4112 & 5112 & 9112 \\
\hline Transport equipment & 41121 & 51121 & 91121 \\
\hline Machinery and equipment other than transport equipment & 41122 & 51122 & 91122 \\
\hline Other fixed assets & 4113 & 5113 & 9113 \\
\hline Cultivated biological resources & 41131 & 51131 & 91131 \\
\hline Intellectual property products & 41132 & 51132 & 91132 \\
\hline Weapons systems & 4114 & 5114 & 9114 \\
\hline Inventories & 412 & 512 & 912 \\
\hline Materials and supplies & 41221 & 51221 & 91221 \\
\hline Work in progress & 41222 & 51222 & 91222 \\
\hline Finished goods & 41223 & 51223 & 91223 \\
\hline Goods for resale & 41224 & 51224 & 91224 \\
\hline Military inventories & 41225 & 51225 & 91225 \\
\hline Valuables & 413 & 513 & 913 \\
\hline Nonproduced assets & 414 & 514 & 914 \\
\hline Land & 4141 & 5141 & 9141 \\
\hline Mineral and energy resources & 4142 & 5142 & 9142 \\
\hline Other naturally occurring assets & 4143 & 5143 & 9143 \\
\hline Noncultivated biological resources & 41431 & 51431 & 91431 \\
\hline Water resources & 41432 & 51432 & 91432 \\
\hline Other natural resources & 41433 & 51433 & 91433 \\
\hline Intangible nonproduced assets & 4144 & 5144 & 9144 \\
\hline Contracts, leases, and licenses & 41441 & 51441 & 91441 \\
\hline Goodwill and marketing assets & 41442 & 51442 & 91442 \\
\hline Financial assets & 42 & 52 & 92 \\
\hline Monetary gold and Special Drawing Rights (SDRs) & 4201 & 5201 & 9201 \\
\hline Currency and deposits & 4202 & 5202 & 9202 \\
\hline Debt securities & 4203 & 5203 & 9203 \\
\hline Loans & 4204 & 5204 & 9204 \\
\hline Equity and investment fund shares & 4205 & 5205 & 9205 \\
\hline Equity & 42051 & 52051 & 92051 \\
\hline Investment fund shares or units & 42052 & 52052 & 92052 \\
\hline Insurance, pension, and standardized guarantee schemes [GFS] & 4206 & 5206 & 9206 \\
\hline Nonlife insurance technical reserves & 42061 & 52061 & 92061 \\
\hline Life insurance and annuities entitlements & 42062 & 52062 & 92062 \\
\hline Pension entitlements [GFS] & 42063 & 52063 & 92063 \\
\hline Claims of pension funds on pension manager & 42064 & 52064 & 92064 \\
\hline Provisions for calls under standardized guarantee schemes & 42065 & 52065 & 92065 \\
\hline Financial derivatives and employee stock options & 4207 & 5207 & 9207 \\
\hline Financial derivatives & 42071 & 52071 & 92071 \\
\hline Employee stock options & 42072 & 52072 & 92072 \\
\hline
\end{tabular}




\section{Table 10.2 Classification of Other Economic Flows (concluded)}

\begin{tabular}{|c|c|c|c|}
\hline & $\begin{array}{l}\text { Holding gains } \\
\text { and losses }\end{array}$ & $\begin{array}{l}\text { Other changes in } \\
\text { the volume of assets }\end{array}$ & $\begin{array}{l}\text { Total other } \\
\text { economic flows }\end{array}$ \\
\hline Other accounts receivable & 4208 & 5208 & 9208 \\
\hline Trade credit and advances & 42081 & 52081 & 92081 \\
\hline Miscellaneous other accounts receivable & 42082 & 52082 & 92082 \\
\hline Domestic debtors & 421 & 521 & 921 \\
\hline $\begin{array}{l}\text { Same instrument breakdown as above, but excluding } \\
\text { monetary gold }\end{array}$ & $4212-4218$ & $5212-5218$ & 9212-9218 \\
\hline External debtors & 422 & 522 & 922 \\
\hline Same instrument breakdown as above & $4221-4228$ & $5221-5228$ & $9221-9228$ \\
\hline Liabilities & 43 & 53 & 93 \\
\hline Special Drawing Rights (SDRs) & 4301 & 5301 & 9301 \\
\hline Currency and deposits & 4302 & 5302 & 9302 \\
\hline Debt securities & 4303 & 5303 & 9303 \\
\hline Loans & 4304 & 5304 & 9304 \\
\hline Equity and investment fund shares & 4305 & 5305 & 9305 \\
\hline Equity & 43051 & 53051 & 93051 \\
\hline Investment fund shares or units & 43052 & 53052 & 93052 \\
\hline Insurance, pension, and standardized guarantee schemes [GFS] & 4306 & 5306 & 9306 \\
\hline Nonlife insurance technical reserves & 43061 & 53061 & 93061 \\
\hline Life insurance and annuities entitlements & 43062 & 53062 & 93062 \\
\hline Pension entitlements [GFS] & 43063 & 53063 & 93063 \\
\hline Claims of pension funds on pension manager & 43064 & 53064 & 93064 \\
\hline Provisions for calls under standardized guarantee schemes & 43065 & 53065 & 93065 \\
\hline Financial derivatives and employee stock options & 4307 & 5307 & 9307 \\
\hline Financial derivatives & 43071 & 53071 & 93071 \\
\hline Employee stock options & 43072 & 53072 & 93072 \\
\hline Other accounts payable & 4308 & 5308 & 9308 \\
\hline Trade credit and advances & 43081 & 53081 & 93081 \\
\hline Miscellaneous other accounts payable & 43082 & 53082 & 93082 \\
\hline Domestic creditors & 431 & 531 & 931 \\
\hline Same instrument breakdown as above & $4312-4318$ & $5312-5318$ & 9312-9318 \\
\hline External creditors & 432 & 532 & 932 \\
\hline Same instrument breakdown as above & $4321-4328$ & $5321-5328$ & $9321-9328$ \\
\hline
\end{tabular}

category of assets must equal the opening balance sheet value plus the net value of transactions, other changes in the volume of assets, and holding gains that affect that category of assets or liabilities. If the information available on balance sheets, transactions, and other changes in the volume of assets is complete and accurate, then the net value of holding gains can be calculated to complete the identity. This formulation does not imply that the value of holding gains is a residual item-even if estimated this way, the results should always be carefully examined and evaluated.

10.11 For some analytic purposes, it may be desirable to divide the total value of holding gains accruing on a category of assets or liabilities into neutral and real holding gains.

- Neutral holding gains and losses over a period are the increase (decrease) in the value of an asset that would be required, in the absence of transactions and other changes in the volume of assets, to maintain command over the same amount of goods and services as at the beginning of the period. It is the value needed to preserve the real value of the asset.

- A real holding gain is defined as the value accruing to an asset as a result of a change in its price relative to the prices of goods and services in general. An increase in the relative price of an 
asset leads to a positive real holding gain, and a decrease in the relative price of an asset leads to a negative real gain. ${ }^{3}$

10.12 In concept, holding gains and losses occur continuously because prices change continuously. As a practical matter, holding gains for the entire reporting period are normally estimated at the end of the period.

\section{Holding Gains for Particular Types of Assets}

Fixed assets $(411)^{4}$

10.13 Estimating the holding gains on fixed assets is complicated by the fact that the value of a fixed asset changes as a result of consumption of fixed capital as well as price changes. Consumption of fixed capital, however, is valued in terms of the average prices prevailing during a reporting period. Thus, estimating the change in the price of a given fixed asset of a given age and condition is critical for estimating both consumption of fixed capital and holding gains.

10.14 Holding gains may occur on existing fixed assets because the market price of the asset itself changes over time. If market prices are not readily available, market-value equivalent prices should be used (see paragraph 7.31). When assets of the same kind are still being produced and sold on the market, an existing asset should be valued in the opening or closing balance sheet at the current acquisition price of a newly produced asset minus the accumulated consumption of fixed capital (i.e., at written-down replacement cost) up to that time.

10.15 When new assets of the same type are no longer being produced, the valuation of existing assets may pose difficult conceptual and practical problems. If broadly similar kinds of assets are still being produced, it may be reasonable to assume that the prices of the existing assets would have moved in the same way as those of new assets if they were still being produced. Such an assumption becomes questionable,

\footnotetext{
${ }^{3}$ Information on the calculation and interpretation of neutral and real holding gains is in the 2008 SNA, paragraphs 12.87-12.93.

${ }^{4}$ The numbers in parentheses after each classification category are the GFS classification codes. Appendix 8 provides all classification codes used in GFS.
}

however, when the characteristics of new assets are much improved by technical progress. ${ }^{5}$

\section{Inventories (412)}

10.16 The estimation of holding gains on inventories is needed for the calculation of use of goods and services (22) using the indirect method, as illustrated in Table 6.3. However, estimation may be difficult because of a lack of data on transactions or other changes in the volume of inventories:

- Many transactions in inventories are internal transactions, and the prices prevailing at the time they occur may not be adequately recorded.

- Withdrawals from inventories include an allowance for recurrent losses that are part of the normal operations of a production process.

- Other changes in the volume of assets are likely to consist of goods destroyed by natural disasters, major fires, and other exceptional events. Estimating the prices and quantities involved in these events may be difficult.

10.17 Thus, holding gains on inventories exclude both exceptional and recurrent losses on inventories. Certain types of inventories (e.g., stationery) have stable prices and are held over reasonably short periods of time, in which case the holding gains or losses are normally minimal. In other cases, such as strategic stocks, more sophisticated methods have to be applied. As records on transactions and other changes in the volume of assets may not be available, it becomes necessary to try to deduce the value of changes in inventories from the value and quantities of the opening and closing inventories using methods that attempt to partition the difference between the values of the opening and closing stock positions of assets into transactions and holding gains. Such methods are only as good as the assumptions on which they are based. ${ }^{6}$ In general, if assumptions are made, they should cover as short a period as possible. When there are high rates of inflation, estimating holding gains accurately in this way becomes more important.

\footnotetext{
${ }^{5}$ See Organisation for Economic Co-operation and Development, Measuring Capital-OECD Manual: Measurement of Capital Stocks, Consumption of Fixed Capital and Capital Services (Paris, 2009), for more details.

${ }^{6}$ Also see the 2008 SNA, paragraph 12.99 .
} 


\section{Valuables (413)}

10.18 The nature of valuables is that they are held as a store of value in the expectation that their value will increase over time. Any increase/decrease in value of an individual valuable is treated as a holding gain/loss.

\section{Nonfinancial assets disposed of during the reporting period}

10.19 There are no remaining costs of ownership transfer included in the value of the asset when it is sold to a new owner, as the amount the old owner receives is equal to the amount the new owner pays except for any costs of ownership transfer incurred by the new owner. This is because consumption of fixed capital is calculated on the value of the asset excluding the costs of ownership transfer over the whole of its life, and the consumption of fixed capital in respect of the costs of ownership transfer is calculated only over the period that the owner expects to hold the asset (see paragraph 6.60).

10.20 When a nonfinancial asset is disposed of in a market-related transaction ${ }^{7}$ at a value that is different from the balance sheet value of the asset immediately prior to disposal, a revaluation should be recorded to reflect the current market value of the asset in the balance sheet. This applies to all nonfinancial assets but not to scrap. ${ }^{8}$

\section{Monetary gold and Special Drawing Rights (SDRs) (4201, 4221, 4301, 4321)}

10.21 The price of gold is usually quoted in dollars; therefore, monetary gold (including unallocated gold accounts) is subject to holding gains and losses because of changes in the exchange rate as well as in the price of gold itself.

10.22 The value of the SDR is based on a basket of key currencies; therefore, the value of SDRs is always subject to holding gains and losses. From time to time, new allocations of SDRs may be made; when this occurs, the allocation is recorded as a transaction.

\footnotetext{
${ }^{7}$ If there is a transfer element to the transaction, the economic value of the transfer should be recorded as a separate transaction (see paragraph 3.122).

${ }^{8}$ In cases where the scrap value does not coincide with the residual balance sheet value of the asset immediately before disposal, an adjustment is to be made to the value of the asset via the other changes in the volume of assets account.
}

\section{Financial assets and liabilities with fixed monetary values}

10.23 Not all financial assets and liabilities have market prices. Currency, deposits, most loans, and other accounts receivable/payable, such as trade credit and advances, are recorded at nominal value. As a result, holding gains resulting from market price changes on these assets are always zero in terms of the currency in which they are denominated. When these financial assets are denominated in a foreign currency or held as unallocated gold accounts (or similar accounts in other precious metals), their value in domestic currency terms can change because of a change in the exchange rate or a change in the value of the precious metal.

\section{Debt securities $(4203,4213,4223,4303$, 4313, 4323)}

10.24 Debt securities typically have market prices that change over time. Changes in the value of the stock of debt securities between balance sheet dates arise from transactions in debt securities (i.e., acquisitions, disposals, and the accrual of interest), other changes in the volume of assets (such as write-offs), and revaluations (e.g., changes in the market rate of interest, exchange rate, expectation of creditworthiness, etc.).

10.25 When debt securities, especially deepdiscount and zero-coupon bonds, are issued at a discount, then, in the absence of other changes, the price will gradually rise over the life of the bond until it reaches the maturity value. This gradual increase in the market price of a bond that is attributable to the accumulation of accrued interest is a transaction, not a holding gain. The converse treatment applies to bonds issued at a premium.

10.26 The values of debt securities may change when the market rates of interest and/or exchange rates change. With the exception of broad-based index-linked securities (see paragraph 6.77), changes in the values of debt securities that are attributable to changes in market rates of interest and exchange rates (for debt securities denominated in another currency) are holding gains. An increase in interest rates causes a decrease in the market value of the fixed-rate debt securities, which is a holding gain for the debtor and a holding loss for the creditor, and conversely for a decrease in interest rates. 
10.27 Prices of bonds may also change because of a change in the creditworthiness of the issuer or guarantor. Such changes give rise to holding gains.

10.28 As explained in paragraphs 6.76-6.77, when the amount to be paid at maturity or when the coupon payments and the amount to be paid at maturity are indexed to a narrow index (e.g., a gold index) that includes a holding gain motive, any deviation of the underlying index from the originally expected path leads to holding gains or losses.

10.29 Holding gains or losses may accrue on bills in the same way as for bonds. However, because bills are short-term debt securities with much shorter times to maturity, the holding gains generated by interest rate changes are often much smaller than on bonds with the same face values.

\section{Equity and investment fund shares (4205,} 4215, 4225, 4305, 4315, 4325)

10.30 General government units may have financial assets or liabilities in the form of equity and investment fund shares. For example, a general government unit may own all or part of the equity of a public corporation or the equity of a quasi-corporation. As with any other asset, a change in the monetary value of these financial assets resulting from price changes is a holding gain or loss.

10.31 Several events can affect the valuation of shares and other equity. For purposes of explanation, a distinction is made between:

- Shares issued by incorporated corporations that are listed (publicly traded) and unlisted shares whose value can be otherwise independently determined

- Unlisted shares issued by incorporated corporations whose value cannot be independently determined and other equity of unincorporated enterprises, such as quasi-corporations.

10.32 If the shares of a public corporation are publicly traded or their value can be independently determined, then the holding gains or losses of the government unit or other public corporation that owns the shares are determined by reference to the market price per share or the independently determined price per share. Several factors may affect the market price per share, such as market perceptions on the profitability of the corporation and when shares go ex-dividend. Valuation changes in shares are recorded as holding gains and losses.

10.33 As explained in paragraph 7.229, net worth is zero for quasi-corporations ${ }^{9}$ and for public corporations for which the value of shares cannot be independently determined (most likely because the controlling government unit owns all of the shares). In these cases, the total value of the implicit equity of the quasi-corporation or shares of the corporation is equal to the total value of its assets minus the total value of its liabilities other than equity. As a result, a holding gain equal to the change in the total value of this measure of the equity needs to be recorded, taking into account all retained earnings, and other additions to and withdrawals from equity that may have occurred.

10.34 As mentioned in paragraphs 5.121 and 6.119, reinvested earnings on investment fund shares or of a foreign direct investment enterprise are treated as a type of property income and not holding gains.

Insurance, pension, and standardized guarantee schemes (4206, 4216, 4226, 4306, 4316, 4326)

10.35 When the reserves for nonlife insurance and standardized guarantee schemes are denominated in domestic currency, there are generally no holding gains and losses, just as there are none for currency or deposits and loans. In some exceptions, if an amount for a claim outstanding has been agreed upon and it has been agreed that it will be indexed pending payment, then there may be a holding gain or loss recorded for it.

10.36 Liabilities for pension entitlements include liabilities for the future payment of pensions and other retirement benefits of defined-benefit schemes. The value of these liabilities can change for several reasons, one of which is the passage of time. The liability is computed as the present value of the future benefits, and it will increase each period because there is one fewer period over which it is discounted. In GFS, this increase is treated as a property expense for investment income disbursements (2813) (see paragraphs 6.113-6.118).

10.37 In GFS, a holding gain is recorded with respect to the liability for a defined-benefit pension

\footnotetext{
${ }_{9}^{9}$ Because quasi-corporations do not issue shares, market prices do not apply to them.
} 
scheme when there is a change in the value of the liability because of a change in the interest rate used to discount the future benefits. The liability should be reviewed periodically and revalued as necessary for changes in market interest rates.

10.38 At first sight, it would seem that there are no other economic flows involved for a defined-benefit pension scheme since the two components recorded as the pension contributions and property expense for investment income disbursements are matched by equal-value increases in entitlements. However, because the nature of a defined-benefit pension scheme is that the level of benefit entitlements is determined by a formula, there are other factors that may intervene to affect changes in the level of entitlements. These factors include a price escalation clause, changes in the formula used to determine benefits, and demographic assumptions about lifespan.

10.39 The factors that change the level of entitlements (i.e., changes in the formula used to determine the benefits and demographic assumptions) should be recorded as other changes in the volume of assets (see paragraph 10.73); the adjustments from changes in the price escalation formula are recorded as holding gains or losses.

10.40 The impact of promotions, merit increases, and other real salary increases on entitlements is a special case. ${ }^{10}$ Many defined-benefit pension schemes use a formula to set benefits based on either the final salary or average salary as a key determinant. Therefore, this implies that any promotion or other real increase in salaries means that the total pension entitlements accrued to date are increased to take account of the new salary level. This is a significant benefit for the individual and has consequences for the employer's pension liabilities. It is recommended that a simple and adequate solution would be to treat the impact of promotions for the unit as a whole as a price change and record this change as a holding gain. If the projected benefit obligation method is used to value pension entitlements, an adjustment in the form of other changes in the volume of assets is needed if the enterprise makes a structural change in the way promotions and merit increases are awarded (see paragraph 10.72).

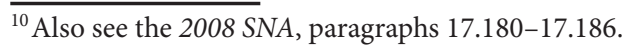

10.41 An equal-valued holding gain should be recorded with respect to the liability for a definedcontribution pension scheme whenever a holding gain is recorded with respect to the assets of the fund. The investment of accumulated pension entitlements of a defined-contribution pension scheme leads to holding gains (and possibly losses). These come about through the management of investment in assets held by the fund. The holding gains appear under entries for the relevant assets for the pension fund, with a matching entry for the increase in the liability of the pension fund toward the policyholders (households).

Financial derivatives and employee stock options (4207, 4217, 4227, 4307, 4317, 4327)

10.42 Financial derivatives have quoted prices or have prices that can be derived from the underlying item that is the subject of the derivative. Thus, financial derivatives register holding gains and losses.

10.43 Employee stock options can also register holding gains and losses. In principle, any change in value between the grant date and vesting date should be recorded as compensation of employees, while any change in the value between vesting date and exercise date is treated as a holding gain or loss. In practice, and for pragmatic reasons, the whole of the increase between grant date and exercise date is treated as a holding gain or loss (see paragraph 9.80). An increase in value of the share price above the strike price is a holding loss for the employer.

\section{Financial assets denominated in foreign currencies}

10.44 The value of a financial asset denominated in a foreign currency is its current value in the foreign currency converted into the domestic currency at the current exchange rate. Therefore, holding gains may occur not only because the price of the asset in the foreign currency changes but also because exchange rates change.

\section{Debt instruments that do not accrue interest}

10.45 There may be an unusually long time ${ }^{11}$ before payment is due on an outstanding debt liability

\footnotetext{
${ }^{11}$ What constitutes an unusually long time in this context will depend on the circumstances. For example, for any given time period, the higher the level of interest rates or the longer the delay in payment, the greater is the opportunity cost of delayed payment.
} 
(or the corresponding financial asset in the form of a debt instrument) on which no interest accrues (see paragraph 7.30). If so, the value of the principal should be reduced by an amount that reflects the time to maturity and an appropriate existing contractual rate, such as for similar debt instruments. Once the value of the principal is reduced through a revaluation, interest should accrue until actual payment is made, at the rate used to discount the principal.

\section{Other Changes in the Volume of Assets}

10.46 Other changes in the volume of assets cover a wide variety of events. For the purpose of description, these events are divided into three groups: ${ }^{12}$

- Events that involve the appearance or disappearance of existing resources as economic assets. In other words, certain assets enter and leave the GFS balance sheet through events other than by transactions

- The effects of external events-exceptional and unexpected-on the economic benefits derivable from assets (and corresponding liabilities)

- Changes in classification.

10.47 Many other volume changes occur at specific times and should be recorded when the event occurs. Some other volume changes occur continuously or at frequent intervals, such as the depletion of subsoil and other naturally occurring assets or environmental damage to assets. These changes should be recorded in the same manner as holding gains.

\section{Appearance or Disappearance of Existing Economic Assets}

10.48 For a resource to be an economic asset, ownership rights over it must be enforced and it must be capable of providing economic benefits. If a resource that is known to exist but is not classified as an economic asset becomes an economic asset because of a change in relative prices, technology, or some other event, an entry in other changes in the volume of assets should be recorded to recognize the asset's value and add it to the balance sheet. Conversely, an economic asset may need to be removed from the balance sheet because it is no longer capable of supplying economic benefits or

${ }^{12}$ The distinctions made here are only for purposes of description; the GFS classifications do not specify this breakdown. because the owner is no longer willing or capable of exercising ownership rights over the asset.

10.49 The recording of events relating to the appearance and disappearance of assets can be grouped according to the main type of asset under consideration based on whether they relate to:

- The economic recognition of produced assets

- Entry and exit from the asset boundary of natural resources

- Contracts, leases, and licenses

- Changes in goodwill and marketing assets, or

- Financial assets (and liabilities).

10.50 Usually, two types of assets can appear under the economic recognition of produced assets: public monuments and valuables. These are existing goods that may not already have been recorded in the balance sheets as public monuments or valuables for any of several reasons; they may date from a time before the reporting period covered by the accounts, they may have been originally recorded as expense for use of goods, or they may be structures that have already been written off.

- Public monuments are included with dwellings, buildings other than dwellings, or other structures, as appropriate, in the classification of fixed assets (see paragraphs 7.42-7.43). When the special archaeological, historical, or cultural significance of a structure or site not already recorded in the balance sheet is first recognized, it is classified as an economic appearance and recorded as other changes in the volume of assets. For example, such recognition might be accorded to an existing structure or site that is fully written off and thus no longer recorded in the balance sheet. Alternatively, a structure or site that is already within the asset boundary, but is new or only partially written off, may be assessed as having the status of a public monument. If the monument was previously written off, then its recognition as a public monument is recorded as an economic appearance of an asset. If it was previously classified as another type of asset, it is recorded as a reclassification of an asset (see paragraphs 10.80-10.84) and if at the same time a new valuation is placed on the monument, this increase in value is recorded as an economic appearance. 
- Valuables, such as precious stones, antiques, and other art objects, for which the high value or artistic significance has not already been recorded in the balance sheet, should be recognized as an economic appearance. Hitherto, the object may have been of little value and not considered an asset. For example, the item might have been considered an ordinary good whose purchase was recorded as an expense, classified in use of goods and services (22). Recognition of its worth as a store of value leads to its entrance into the balance sheet as a valuable. The recognition of the value of a previously unvalued item is often necessitated by a sale (e.g., at auction). The sale is recorded as a transaction under the disposal of nonfinancial assets only after the asset first entered into the balance sheet of the seller through an entry in other changes in the volume of assets.

10.51 Conversely, a nonfinancial asset that no longer has economic value because of a change in technology, relative prices, or other event must be removed from the balance sheet. For example, the commercial exploitation of mineral reserves, land, forests, fish stocks, aquifers, and other naturally occurring assets may become unfeasible. If so, then a negative entry in other changes in the volume of assets would be recorded to remove the asset from the balance sheet.

10.52 It may be difficult to determine the exact time at which a natural asset should be added to the balance sheet, and to determine the value that should be attributed to it at that time. Often, the date at which the first substantial commercial exploitation begins or the signing of a contract to permit commercial exploitation is used to establish the time of recording. Several events may result in natural resources to enter or exit the asset boundary:

- Discoveries/extractions and upward/downward reappraisals of subsoil resources-The value of these resources may increase in the balance sheet by the discovery of new exploitable deposits, whether as a result of systematic scientific explorations or surveys, or by chance. Economic appearance may also occur because a deposit of subsoil minerals has become economically exploitable as a result of technological progress or relative price changes.

- Conversely, the value of these resources may decrease in the balance sheet by the depletion of deposits of subsoil assets as a result of the physical extraction and use of the assets, or from downward reappraisals that reduce their exploitability because of changes in technology or relative prices.

- Natural growth/harvesting of noncultivated biological resources-The natural growth of noncultivated biological resources, such as natural forests and fish stocks, may take various forms: a stand of natural timber may grow taller, or fish in the estuaries may become more numerous. Although these resources are economic assets, growth of this kind is not under the direct control, responsibility, and management of an institutional unit and thus is not treated as a transaction in net investment in fixed assets. In principle, natural growth should be recorded gross, and the depletion of these resources should be recorded as economic disappearance, as described in the next bullet. This recording would be consistent with the gross recording of transactions in acquisitions and disposals described under the net investment in nonfinancial assets. In practice, however, many countries will record natural growth net because only the net physical measures are likely to be available. The net physical measure multiplied by the market price for a unit of the asset may be used in estimating the value of the volume change to be recorded.

- The depletion of natural forests, fish stocks in the open seas, and other noncultivated biological resources included in the asset boundary of general government or public sector units as a result of harvesting, forest clearance, or other use beyond sustainable levels of extraction constitutes an economic disappearance of assets and should be recorded as negative other changes in the volume of assets.

- Transfers of other natural resources to/out of economic activity-Not all land included in the geographic surface area of a country is necessarily within the asset boundary of GFS. Land may make its economic appearance when, for example, general economic development in nearby areas transforms the land from a wild or waste state to a state in which ownership rights can be enforced and the land can be put to economic use. ${ }^{13}$ Land may also make its economic

\footnotetext{
${ }^{13}$ For the treatment of land improvements, including land reclamation, see paragraphs 7.49-7.51.
} 
appearance (or enter the asset boundary) because of activity in the vicinity-for example, land that becomes more desirable because a new development is established nearby or an access road built. Any excess in the value of the land over the value of land improvements or any increase due to adjacent capital activity is recorded as economic appearance. For virgin forests, gathering firewood is not commercial exploitation, but large-scale harvesting of a virgin forest for timber is and brings the forest into the asset boundary. Similarly, drawing water from a natural spring does not bring an aquifer into the asset boundary of GFS, but a significant diversion of groundwater does. A move to charge for regular extraction from a body of surface water may also bring a water resource into the balance sheet.

- A government unit can create an economic asset by exerting ownership rights over a naturally occurring asset that had not previously been recognized as an asset, such as the electromagnetic spectrum or fish stocks in exclusive economic zones. When this occurs, the asset enters the balance sheet through other changes in the volume of assets.

- It is possible that some natural resources cease to be exploited because of changed technology or reduced demand for the resulting product, or for legislative reasons, such as the suspension of fishing to ensure the survival of fish stocks. When this change in use occurs, the asset is removed from the balance sheet through other changes in the volume of assets.

- Quality changes in natural resources due to changes in economic uses-In this case, the asset is already within the asset boundary. The change in quality of the asset due to changes in its economic use is regarded as the appearance of additional amounts of the asset. For example, the use of bare rural land changes when it becomes land underlying buildings and may result in a change in the balance sheet value that is effected through an other change in the volume of the asset.

- All degradation of land, water resources, and other natural assets caused by economic activity should be recorded as negative other changes in the volume of assets. The degradation may be the anticipated result from regular economic activity or less predictable erosion and other damage to land from deforestation or improper agricultural practices.

- The difference between a quality change and a price change is a matter of degree, and it may not always be clear whether other changes in the volume of assets or a holding gain is most appropriate. For example, activities adjacent to land may bring land into the asset boundary (recorded as another volume change), while the value of land in the vicinity may also increase due to a rise in general price levels of land (recorded as holding gains).

10.53 It is recommended to recognize assets in the form of contracts, leases, and licenses in the balance sheet of the holder only when the value of the asset can be realized (see paragraph 7.106). In this case, they are first recorded as other changes in the volume of assets and, subsequently, form the basis of a transaction (or series of transactions). The value of the contract, lease, or license that is treated as an asset is equal to the present value of the excess of the prevailing price over the contract price. The value will decline as the remaining contract period shortens. Changes in the value of the contract, lease, or license due to changes in the prevailing price are recorded as holding gains or losses (revaluations); changes due to the expiration of the time over which the contract, lease, or license is valid are recorded as other changes in volume of assets (i.e., to write off the cost of the asset). The rate at which the value is written down should be in accordance with internationally accepted accounting standards. The treatment of contracts, leases, and licenses is discussed more extensively in Appendix 4.

10.54 When an enterprise-whether a corporation, quasi-corporation, or unincorporated enterprise-is sold, the price payable may not equal the sum of all the assets minus the liabilities of the enterprise. The difference between the price payable and the sum of all the assets minus liabilities is called the purchased goodwill and marketing assets of the buyer. The value may be positive or negative (or zero). When the buyer includes this asset in the calculation of the net worth of the enterprise at the moment it is bought, net worth is exactly zero.

10.55 The value of purchased goodwill and marketing assets is calculated at the time of the sale, and entered in the books of the seller as an other 
change in the volume of assets. Subsequently, it is then exchanged as a transaction with the purchaser. Thereafter, the value of the purchased goodwill and marketing asset must be written down in the books of the purchaser via entries under other changes in the volume of assets. The rate at which it is written down should be in accordance with internationally accepted accounting standards. These standards are typically conservative in the amount that may appear on the balance sheet of an enterprise and should be subject to an "impairment test" whereby accountants can satisfy themselves that the remaining value is likely to be realizable in case of a further sale of the enterprise.

10.56 Goodwill that is not evidenced by a sale or purchase is not considered an economic asset in GFS. In some exceptions, a marketing asset may be subject to sale. When this is the case, entries should be made for the buyer and the seller along the lines of those made for purchased goodwill and marketing assets when the entire enterprise is sold.

10.57 Financial assets and liabilities may appear on or disappear from the balance sheet in several waysfor example:

- A creditor may determine that a financial claim can no longer be collected because of the debtor's bankruptcy or other factors. If so, the creditor writes off the debt and removes the claim from its balance sheet by means of an entry in other changes in the volume of assets. ${ }^{14}$

- Cancellations of employee stock options are recorded as other changes in the volume of assets.

10.58 The creation of SDRs (referred to as allocations of SDRs) and the extinction of SDRs (cancellations of

\footnotetext{
${ }^{14}$ Usually, debt is written off as uncollectible because of the bankruptcy or liquidation of the debtor; however, it may sometimes be written off for other reasons, such as a court order. The write-off may be full or partial; partial write-offs may arise, for example, under a court order, or if the liquidation of the debtor's assets allows some of the debt to be settled. Recognition that the debt is uncollectible should be distinguished from internal accounting provisions of the creditor for the possibility of default (such as adjustments to fair value of nonperforming loans). Although such provisions may be useful for analysis, they do not mean that the debt should no longer be recognized as existing and should therefore not be considered as written off. In contrast, as described in paragraphs 6.124 and A3.7-A3.9, a reduction in a financial claim by mutual agreement between the creditor and debtor is a transaction rather than an other change in the volume of assets.
}

SDRs) are treated as transactions, not other changes in the volume of assets. ${ }^{15}$

\section{The Effect of External Events on the Value of Assets}

10.59 There are three principal causes of the reduction in the value of an asset, or even its disappearance, that are not related to the nature of the asset but to conditions prevailing in the economy that impact either the value or ownership of assets. These are catastrophic losses, uncompensated seizures, and other changes in the volume of assets not elsewhere classified. Each is discussed in the remainder of this section.

\section{Catastrophic losses}

10.60 A catastrophic loss is the partial or complete destruction of a significantly large number of assets within any of the asset categories resulting from a large-scale, discrete, and recognizable event. Such events will generally be easy to identify. They are usually sudden or one-time events of large proportions. They include major earthquakes, volcanic eruptions, tidal waves, exceptionally severe hurricanes, droughts, and other natural disasters; acts of war, riots, and other political events; and technological accidents, such as major toxic spills or release of radioactive particles into the air. Included here are such major losses as deterioration in the quality of land caused by abnormal flooding or wind damage; destruction of cultivated assets by drought or outbreaks of disease; and destruction of buildings, equipment, or valuables in fires or earthquakes. An entry in other changes in the volume of assets is recorded to reduce or eliminate the value of any asset damaged or destroyed.

10.61 Although produced assets are the most likely candidates to be damaged or destroyed by a catastrophic loss, nonproduced assets and financial assets are also subject to damage or destruction. For example, major decreases in the value of land and other natural assets caused by abnormal flooding or wind damage and the accidental destruction of currency or bearer securities as a result of natural catastrophes or abnormal political events would be included.

\footnotetext{
$\overline{{ }^{15} \text { See paragraphs } 7.131}-7.134$ and 9.31 .
} 


\section{Uncompensated seizures}

10.62 Government units may take possession of the assets of other institutional units without full compensation for reasons other than the failure to pay taxes, fines, or similar levies. Such seizures of assets, legal or illegal, are not capital transfers because they do not take place by mutual agreement of the units involved. The difference between the market value of the assets seized and any compensation provided is recorded as an other change in the volume of assets, in the form of an uncompensated seizure. Foreclosures and repossessions of assets by creditors are transactions when the contractual agreement between debtor and creditor provides this avenue of recourse.

\section{Other volume changes not elsewhere classified}

10.63 The value of a fixed asset is continuously reduced by consumption of fixed capital until the asset is disposed of or has no remaining value. It is possible for the assumptions underlying the calculation of consumption of fixed capital to be inaccurate, in which case corrections to the value of the asset need to be made through other changes in the volume of assets. Similarly, if the assumption about the rate of shrinkage of inventories was inaccurate, this should also be corrected through an entry in other changes in the volume of assets. Financial assets and liabilities, such as those related to insurance, pension, and standardized guarantee schemes, can also be affected by volume changes. ${ }^{16}$

\section{Fixed assets (511)}

10.64 The calculation of the consumption of fixed capital reflects an assumption about normal rates of physical deterioration, obsolescence, and accidental damage. Each of these assumptions may prove to be faulty. In that case, an adjustment in the form of other changes in the volume of assets must be made.

10.65 Physical deterioration may include the effect of unforeseen environmental degradation on fixed assets. Entries must, therefore, be made through other changes in the volume of assets for the decline in the value of the fixed assets from, for example, the unforeseen effects of acidity in the air and acid rain on building surfaces or vehicle bodies.

\footnotetext{
${ }^{16}$ See paragraphs $10.39-10.40$ and A2.54.
}

10.66 The introduction of improved technology can render an asset obsolete or accelerate the rate of obsolescence. For example, improved models of the asset or of a new production process that no longer requires the asset may lead to unforeseen obsolescence. In consequence, the amount included in consumption of fixed assets for their expected obsolescence may have been underestimated, so an entry in other changes in the volume of assets should be recorded.

10.67 The amount included for normally expected damage-as included in the calculation of consumption of fixed capital - may fall short of the actual damage. Adjustments must therefore be made through other changes in the volume of assets for the decline in the value of the fixed assets due to these events. While these losses may be larger than normal, they are not on a scale sufficiently large to be considered catastrophic-they are therefore included in other volume changes not elsewhere classified.

10.68 As explained in paragraph 6.60, costs of ownership transfer should, in principle, be written off over the expected time the asset will be in the possession of the purchaser. If the asset is disposed of before the costs of ownership transfer are completely written off, the remainder should be recorded as an other change in the volume of assets.

10.69 Production facilities with long construction periods may cease to have an economic use before they are completed or are put into service. For example, a nuclear power plant or industrial site may never be put into service. When the decision to abandon is made, the value of the fixed asset (or in some cases, work-in-progress inventories) as recorded in the balance sheet should be written off through an other change in the volume of assets.

\section{Exceptional losses in inventories (512)}

10.70 Exceptional inventory losses from fire, robbery, insect and vermin infestation of grain stores, and unusually high levels of disease in livestock, etc. are included as other changes in the volume of assets. In this context, exceptional losses indicate that the losses are not only large in value but also irregular in occurrence. Even very large losses that occur regularly should be taken into account when calculating the net change in inventories, as explained in paragraph 8.47. The adjustment for unforeseen damage could be an 
increase in assets if the actual damage falls short of the amount covered by the allowance for losses.

\section{Life insurance and annuities entitlements (52062, 52162, 52262, 53062, 53162, 53262)}

10.71 For an annuity, the relationship between the expected net premiums and benefits is usually determined when the contract is entered into, taking account of mortality data available at that time. Any subsequent changes will affect the liability of the annuity provider toward the beneficiary, and the consequences should be recorded as other changes in the volume of assets.

\section{Pension entitlements (52063, 52163, $52263,53063,53163,53263)$}

10.72 In defined-benefit pension schemes, the level of benefits promised to participating employees is determined by a formula that is usually based on the participants' length of service and salary. Changes in pension entitlements that are imposed without negotiation are recorded as other changes in the volume of assets. ${ }^{17}$ That is because such changes are assumed to be imposed unilaterally by the employer and do not constitute a capital transfer negotiated by mutual agreement.

10.73 As explained in paragraph 10.38 , for a defined-benefit pension scheme, any changes in the value of the liability due to changes in the formula used to determine benefits and due to changes in demographic assumptions about the lifespan should be recorded as other changes in the volume of assets. If the projected benefit obligation method is used to value pension entitlements, an adjustment in the form of other changes in the volume of assets is needed if the enterprise makes a structural change in the way promotion and merit increases are awarded (see paragraph 10.40).

10.74 No such adjustments are needed for defined-contribution schemes where the benefits are determined solely in terms of the contributions and investment earnings of the scheme. ${ }^{18}$

\footnotetext{
${ }^{17}$ The cases where changes in pension entitlements are recorded as transactions are discussed in paragraphs 9.63-9.67. The distinction between transactions and other changes in the volume of assets remains theoretical, as it is recognized that the distinction between what is negotiated and what is imposed without negotiation will be difficult to determine in practice, with different situations prevailing in different countries.

${ }^{18}$ Also see the 2008 SNA, Chapter 17, Part 2.
}

\section{Provisions for calls under standardized guarantee schemes (52065, 52165, 52265, $53065,53165,53265)$}

10.75 Changes to provisions for calls under standardized guarantee schemes not resulting from transactions and holding gains and losses are shown as other changes in volume of assets. For example, such other changes in volume of assets occur whenever a significant change to the expected level of calls is recognized beyond any asset recovery (see paragraph A4.79).

\section{Changes in Classification}

10.76 The composition of the general government or public sector's balance sheet may change because there has been a reclassification of an entire institutional unit, the structure of a unit, or a group of assets and liabilities. A reclassification rearranges assets and liabilities without adding to or subtracting from total net worth.

\section{Changes in sector classification and structure}

10.77 An entire unit may be reclassified from the general government sector to another sector or to the general government sector from another sector without a change of ownership or control, normally because the unit either begins or ceases to sell its output for economically significant prices. When a unit is reclassified out of the general government sector, all of the unit's assets and liabilities are removed from the general government sector's balance sheet and the net value of those assets and liabilities is replaced by a financial asset, equity and investment fund shares, to reflect the continued ownership or control of the unit by a general government unit. The reverse will be true when a unit is reclassified into the general government sector. By contrast, when a public corporation is privatized, all of the unit's assets, liabilities, and net worth are reclassified from being that of a public corporation to a private corporation. ${ }^{19}$

10.78 A change in the structure of units is also recorded as an other change in the volume of assets-for example, when two general government units merge into a single unit, or a single unit splits into two units.

\footnotetext{
${ }^{19}$ In the balance sheet of the shareholder (such as government), the privatization transaction will lead to a reduction in the financial asset equity and investment fund shares.
} 
When two units are merged, all financial claims and liabilities that existed between them are eliminated. Symmetrically, when a unit splits into two or more units, new financial claims and liabilities may appear between the new units.

10.79 In cases where general government units issue negotiable securities that sell in secondary markets, the holders of the securities may change during the life of the security. In debt data classified by counterparties, this change in the debtor/creditor relationship should be recorded as a reclassification under other changes in the volume of assets (see also paragraphs 9.25 and 9.86). For example, a central government debt security may be sold originally to a bank and then subsequently sold by the bank to a local government unit. To show on the central government's balance sheet that the new holder of the security on the reporting date is the local government, entries in other changes in the volume of assets are recorded in the central government accounts, reducing the security liability to the bank and increasing the liability to the local government. ${ }^{20} \mathrm{No}$ transactions between the central government, bank, and the local government should be imputed to reclassify the holder of the securities.

\section{Changes in classification of assets and liabilities}

10.80 Depending on the degree of detail of the classifications of assets, there may be reclassifications of existing assets and liabilities from one category to another, usually when there is a change in the purpose for which an asset is used. The change in classification is recorded as other changes in the volume of assets with the same value for both entries. If the change in the use also means a change in its value, then a second entry in other changes in the volume of assets is recorded for the entrance into the asset boundary of the asset with the higher value. It is not recorded as a revaluation since the value increase is due to the change in use and is not due to price changes.

10.81 The use of a structure may be changed from a dwelling to a government office building or vice versa. If these types of structures are classified sepa-

\footnotetext{
${ }^{20}$ Because the local government has a claim on central government, without the central government being involved in the transaction, the same other volume change would be recorded on the local government's balance sheet to show that the central government is the creditor.
}

rately, then an entry in other changes in the volume of assets is recorded. The positive change in one asset category is balanced by a negative change in the other asset category. A conversion resulting solely from new investment in a building is not an other change in the volume of the asset but a transaction in fixed assets (see paragraph 8.28).

10.82 In all instances, work in progress needs to be reclassified to finished goods prior to sale, through an entry in other changes in the volume of assets. In principle, reclassification from one type of inventory to another or from fixed assets to inventories should not involve a change in value. If at the time of conversion, the previous value is different from the appropriate new value, an entry in other changes in the volume of assets should be recorded under economic appearance or disappearance as appropriate. If this is found to be happening systematically, the valuation techniques for inventories should be re-examined.

10.83 As explained in paragraph 8.42, transactions in the costs of ownership transfer of nonproduced assets other than land are classified as fixed assets and these costs are subject to consumption of fixed capital. To maintain the integration of stock positions and flows, the costs of ownership transfer of nonproduced assets other than land and the consumption of fixed capital relating to these costs are reclassified to the respective nonproduced assets through an entry in other changes in the volume of assets. ${ }^{21}$ This reclassification is considered to take place at the time of recording the transactions in cost of ownership transfer and consumption of fixed capital, respectively.

10.84 Some examples of changes in the classification of financial assets and liabilities are:

- When monetary gold held in the form of gold bullion becomes a reserve asset, it enters the financial assets in the balance sheet as a reclassification via other changes in the volume of assets from valuables to monetary gold. At the time it is acquired by a monetary authority, it is first classified as inventory or a valuable. ${ }^{22}$ The same

\footnotetext{
${ }^{21}$ Two entries are recorded in other changes in the volume of assets: a reduction in the fixed asset costs of ownership transfer on nonproduced assets other than land (31133) and an increase in the value(s) of the respective nonproduced assets.

${ }^{22} \mathrm{Gold}$ is reclassified to inventories if not primarily held as a store of value.
} 
recording is followed for allocated gold accounts that become part of monetary gold. When unallocated gold accounts become reserve assets, they are reclassified from currency and deposits to monetary gold, also through other changes in the volume of assets. Monetary gold may be sold to another monetary authority, but otherwise, any reduction in holdings follows a similar declassification path; the monetary gold is reclassified to be either a valuable or inventories (in the case of gold bullion) or currency and deposits (in the case of unallocated gold accounts). Subsequent transactions are recorded in terms of inventories or valuables or currency and deposits and not in terms of monetary gold.

- In cases when benefits under a defined-contribution pension scheme are converted to annuities, a reclassification should be recorded from pension entitlements to annuities entitlements.

- When loans become tradable in the conditions stated in paragraph 7.149, a reclassification should be recorded from loans to debt securities.

- If arrears arise and the contract provides for a change in the characteristics of a financial instrument when it goes into arrears, this change should be recorded as a reclassification in the other changes in the financial assets and liabilities account. The reclassification applies to situations where the original contract remains, but the terms within it changes (e.g., interest rates or repayment periods).

- If the amount payable under a derivative remains due for payment after the derivative matures, the amount due no longer represents a derivative because the value is fixed. It is therefore reclassified under other accounts receivable or payable. ${ }^{23}$

- Bonds that are convertible into equity are reclassified as equity and investment fund shares when the option is exercised.

- In cases where government units acquire equity in a public corporation or quasi-corporation as a result of legislation or an administrative change creating the corporation or quasi-corporation, this event will amount to a reclassification of the corporation's existing assets and liabilities that results in an addition of equity and investment fund shares to the balance sheets of government and the corporation (see paragraph 9.50).

\footnotetext{
${ }^{23}$ The creation and exhaustion of financial derivatives are transactions in financial assets (and liabilities), not other changes in the volume of assets.
} 


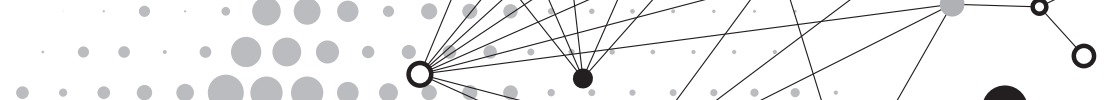

APPENDIX

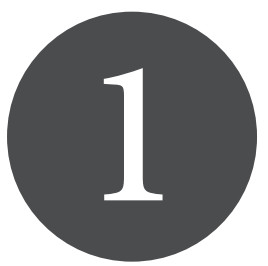

\section{Changes from the GFSM 2001 and GFSM 1986}

This appendix describes the changes in the Government Finance Statistics Manual 2014 (GFSM 2014) from the Government Finance Statistics Manual 2001 (GFSM 2001), and describes the differences with the traditional approach to fiscal reporting as depicted in A Government Finance Statistics Manual 1986 (GFSM 1986).

\section{Introduction}

A1.1 In the GFSM 2014, the guidelines in the GFSM 2001 have been revised to harmonize with the updates in other macroeconomic statistical manuals and guides, such as the overarching System of $\mathrm{Na}$ tional Accounts 2008 (2008 SNA), the sixth edition of the Balance of Payments and International Investment Position Manual (BPM6), and the Public Sector Debt Statistics: Guide for Compilers and Users (PSDS Guide).

A1.2 The GFSM 2014 addresses important international economic developments in recent years and takes into account improved recording and methodological treatments of various events. The changes incorporated can broadly be summarized as methodological changes agreed to in the update of the 2008 $S N A$, clarifications on existing methodological guidelines, presentational changes, and editorial changes.

A1.3 The remainder of this appendix first describes the changes in the GFSM 2014, compared to the GFSM 2001. Since many countries are still in various stages of migrating from presenting fiscal statistics in a traditional way, based on the GFSM 1986, the second part of this appendix also provides a description of the difference between the guidelines in this Manual and the GFSM 1986.

\section{Changes from the GFSM 2001}

A1.4 The GFSM 2014 retains the basic conceptual framework of its predecessor, the GFSM 2001. How- ever, this Manual introduces improved treatments for recent developments and specific events, elaborates on aspects of reporting that have proved to be complex, and takes into consideration new needs of compilers and users of GFS. The remainder of this section describes the main changes, grouped according to the chapters of the GFSM 2014, before describing changes in terminology introduced in this Manual. The discussion of the changes includes cross-references to the relevant paragraphs in the chapters.

\section{Chapter 1}

A1.5 A definition for fiscal policy, general government sector, and public sector is introduced in paragraph 1.2 .

A1.6 A section to describe the evolution of international statistical guidelines on government finance statistics, starting in the early 1970s, is presented in paragraphs 1.6-1.9. This section also broadly outlines the reasons for the update of the GFSM 2001.

A1.7 The section on the structure and features of the GFS framework introduces two supplementary statements-namely, the Statement of Total Changes in Net Worth and the Summary Statement of Explicit Contingent Liabilities and Net Implicit Obligations for Future Social Security Benefits (see paragraphs 1.181.19). These supplementary statements are added to the GFS framework due to their analytical usefulness for users of fiscal data.

A1.8 The valuation principle described in paragraph 1.29 indicates that current market prices are used to value economic flows and stock positions. This principle is clarified by indicating that marketvalue equivalents are used for assets and liabilities that are not traded in markets, or are traded infrequently.

A1.9 The important linkages between GFS and other macroeconomic datasets are introduced in 
paragraph 1.35, also recognizing the close relationship with accounting standards. Paragraph 1.39 highlights the importance of good dissemination practices as spelled out in the General Data Dissemination System, Special Data Dissemination Standard, and the Special Data Dissemination Standard Plus.

\section{Chapter 2}

A1.10 The delineation of general government and public sector institutional units is clarified. The chapter is reorganized to first delineate the domestic economy, and then it describes institutional units and the types of units that exist in macroeconomic statistics, before defining institutional sectors. These principles are then applied to delineate the general government and public sectors, and the practical application of the sector classification principles to selected cases is described.

A1.11 The concept of residence is elaborated on to align with guidance of 2008 SNA and BPM6 (see paragraph 2.6). The additional guidance includes defining and describing the treatment of notional resident units (see paragraph 2.13) and nonresident special purpose entities (see paragraph 2.15). Additional guidance on identifying international and regional organizations is presented in paragraphs $2.16-2.19$. The treatment of multiterritory regional enterprises (see paragraph 2.20) and currency union central banks (see paragraph $2.21)$ is explained.

A1.12 The rationale for working with the institutional unit in macroeconomic statistics is explained in paragraph 2.23. In addition, the concepts establishment and enterprise are defined and explained in paragraphs 2.24 and 2.25, respectively.

A1.13 The description of the types of institutional units is organized to make a distinction between persons or groups of persons in the form of households and legal or social entities (see paragraph 2.27). Households are defined and described in paragraphs 2.28-2.29, while legal or social entities are defined, and the types of legal or social entities described in more detail (see paragraphs 2.30-2.38).

A1.14 The section on applying the definition of institutional unit to government introduces a discussion on artificial subsidiaries and ancillary activities, and applies these concepts to resident SPEs and a government central borrowing authority (see paragraphs 2.42-2.45).
A1.15 The definition and identification of nonfinancial and financial corporations sectors are presented in detail (see paragraphs 2.52-2.57). The additional guidance is provided to clarify the distinction between these corporations and government units. This includes the introduction of three broad classes of financial corporations-namely, financial intermediaries, financial auxiliaries, and other financial corporations-and specifically explains financial intermediation.

A1.16 The delineation of general government and public corporations is clarified using the concept of market and nonmarket producers. The application of the concept economically significant prices to determine whether a unit is a market or nonmarket producer is elaborated on (see paragraphs 2.65-2.75).

A1.17 Guidance is provided on how to determine whether a nonprofit institution is under control of government. Indicators of control and how to apply these to establish control of government are provided in Box 2.1.

A1.18 An extensive discussion on the public corporations subsector is introduced in paragraph 2.104. The rationale for the extension of GFS to include data for public corporations is described in paragraph 2.105 , and the types of public corporations are presented in paragraphs $2.113-2.121$. Guidance is provided on how to determine whether a corporation is under control of government (see paragraphs 2.1072.112). Indicators of control and how to apply them to establish control of government over corporations are provided in Box 2.2.

A1.19 Using the concepts of residence, institutional units, control, and market versus nonmarket producers, a decision tree for sector classification of the public sector is introduced in paragraph 2.124 and Figure 2.4.

A1.20 A separate section describes the practical application of the sector classification principles to selected cases-these cases are the topics of frequently asked questions. Included are: the identification of quasi-corporations (see paragraph 2.125); distinguishing head offices and holding companies (see paragraph 2.128 ); restructuring agencies (see paragraph 2.129); financial protection schemes (see paragraph 2.132); special purpose entities (see paragraph 2.136); joint ventures (see paragraph 2.140); sinking funds (see paragraph 2.144); pension schemes (see paragraph 2.147); 
provident funds (see paragraph 2.148); sovereign wealth funds (see paragraph 2.152); market regulatory agencies (see paragraph 2.156); and development funds and/or infrastructure companies or entities (see paragraph 2.160).

A1.21 The annex to Chapter 2 of the GFSM 2001, describing social protection, is subsumed in Appendix 2 of the GFSM 2014. This appendix presents guidance on the identification and sectorization of entities involved in social protection, as well as guidance on the recording of the flows and stock positions related to their economic activities.

\section{Chapter 3}

A1.22 A distinction between monetary and nonmonetary transactions is introduced in paragraphs 3.8 and 3.19, respectively. This distinction also forms the basis for the distinction between transfers (capital and current transfers), exchanges, in-kind transactions, and internal transactions.

A1.23 A definition of stock positions is provided in paragraph 3.36. The concepts economic benefits and ownership are used to define economic assets, before a distinction is drawn between legal and economic ownership in paragraphs 3.38-3.39. These concepts are used to determine the asset boundary and define assets and liabilities (see paragraphs 3.42-3.50).

A1.24 The GFSM 2014 reinstates a more balanced approach between having both accrual and cash information in an integrated statistical framework. Therefore, starting in paragraph 3.61, alternative recording bases are discussed with a reference to using the accrual basis of recording in the Statement of Operations (see paragraph 3.69) and using the cash basis of recording in the Statement of Sources and Uses of Cash (see paragraphs 3.67 and 3.103).

A1.25 Additional guidance on the application of the accrual basis of recording principles is described from paragraph 3.76 onward. Guidance on the time of recording and measurement of taxes and other compulsory transfers is presented in paragraph 3.77.

A1.26 The time of recording dividends when using an accrual basis of recording is defined as when the equity or shares go ex-dividend (see paragraphs 3.87 and 5.112).

A1.27 When using an accrual basis of recording, the time of recording transactions in goods and services, nonfinancial assets, and many financial assets and liabilities is defined as the moment when economic ownership changes. Recognition is given to cases where change of ownership is not obvious and additional guidance for those cases is provided (see paragraphs 3.88-3.97).

A1.28 Guidance on the time of recording other economic flows is described in paragraphs 3.98-3.102.

A1.29 Guidance on using the cash basis of recording in the Statement of Sources and Uses of Cash is elaborated in paragraphs 3.103-3.106.

A1.30 Guidance on valuation is elaborated on and the section is structured to present descriptions of the general valuation rule (see paragraph 3.107), valuation of transactions (see paragraphs 3.108-3.112), valuation of stock positions including alternatives valuation methods (see paragraphs 3.113-3.117), valuation adjustments in special cases (see paragraphs 3.118-3.125), and valuation of other economic flows (see paragraphs 3.126-3.129).

A1.31 The GFSM 2014 introduces a discussion on currency, starting with a discussion on the unit of account for the compilation of GFS in paragraph 3.130. Guidance is provided on currency conversions for transactions and stock positions (see paragraphs 3.132-3.133) and the distinction between domestic and foreign currency (see paragraphs 3.134-3.136) and currency of denomination and currency of settlement (see paragraphs 3.137-3.139).

A1.32 Starting in paragraph 3.152, the GFSM 2014 presents a detailed discussion of consolidation. The concept is defined (see paragraphs 3.153-3.154), a distinction is made between intrasectoral and intersectoral consolidation (see paragraphs 3.155-3.157), and reasons for consolidation are discussed (see paragraphs 3.158-3.160), before conceptual guidelines for the process of consolidation are presented (see paragraphs 3.161-3.164). Paragraphs 3.165-3.166 present practical guidelines on implementing consolidation, while paragraphs 3.167-3.168 describe consolidation principles used in other datasets.

\section{Chapter 4}

A1.33 The analytic objectives of the GFS framework were expanded to include the ability to assess management and policy decisions, as well as sustainability and liquidity decisions (see paragraphs 4.3-4.5). 
A1.34 Paragraph 4.7 elaborates on the coverage of GFS, emphasizing that data should cover the nonmarket activities of the general government sector, as well as the market activities of the public sector.

A1.35 Two additional statements are included in the GFS framework, to further enhance the analytical usefulness of GFS (see paragraphs 4.13-4.15 and 4.46-4.49):

- Statement of Total Changes in Net Worth

- Summary Statement of Explicit Contingent Liabilities and Net Implicit Obligations for Future Social Security Benefits.

A1.36 The concept expenditure is reinstated as an aggregate in both the Statement of Operations and in the Statement of Sources and Uses of Cash (see paragraph 4.21, Table 4.1, and Table 4.2).

A1.37 The definition and identification of policy lending are elaborated on in Box 4.1.

A1.38 The composition of the item net change in the stock of cash, as presented in the Statement of Sources and Uses of Cash, is clarified-the item refers to the financial asset currency and deposits (3202), and should not include other financial instruments or overdrafts (see paragraph 4.33).

A1.39 The description of the Balance Sheet is expanded with a discussion on the use of the net worth concept in the case of public corporations (see paragraph 4.40).

A1.40 Box 4.1 in the GFSM 2001 is replaced with an annex to Chapter 4 of the GFSM 2014, Using GFS for Fiscal Analysis. The annex offers an overview of how analysts can use the data in GFS to build well-defined and internationally comparable fiscal indicators. Some of the indicators can be observed or derived directly from the GFS framework, while others can be derived using GFS together with additional data.

\section{Chapter 5}

A1.41 The rationale for defining revenue as an increase in net worth resulting from a transaction is added in paragraph 5.1 .

A1.42 The definition of grants (13) is revised to no longer refer to grants as noncompulsory transfers. The change accommodates cases where compulsory revenue sharing occurs between government units. The definition is also expanded to indicate that grants are transfers that do not meet the definition of a tax, subsidy, or social contribution (see paragraphs 5.5 and 5.101).

A1.43 Definitions of the respective categories of other revenue (14) are replaced by a definition of the main category other revenue (14), with only references to the subcategories it comprises (see paragraph 5.6).

A1.44 The section on defining revenue is enhanced with the inclusion of a discussion on the treatment of refunds and corrections, and with an explanation of the delineation between revenue and transactions in assets and liabilities (see paragraphs 5.7-5.8).

A1.45 The section on the time of recording and measurement of revenue is expanded to clearly indicate the time of recording when using the accrual basis of recording, as well as the cash basis of recording (see paragraphs 5.10-5.11). Further clarification is provided on applying an accrual basis of recording to revenue transactions (see paragraphs 5.12-5.17), as well as on the treatment of amounts assessed, but discovered to be uncollectable (see paragraph 5.20).

A1.46 The basis on which the classification of revenue should be made is presented in paragraph 5.21, while paragraph 5.22 describes the rationale for standardized summary classifications and the usefulness of adding subitems according to analytical use and need.

A1.47 Paragraphs 5.27-5.32 describe the treatment of tax refunds and tax relief. In this regard, the GFSM 2014 adopted the gross recording of payable tax credits, while nonpayable tax credits continue to be treated on a net basis.

A1.48 The tax category unallocable (1113), in the GFSM 2001, is renamed other taxes on income, profits, and capital gains (1113) in the GFSM 2014, and a breakdown of the category is introduced to separately identify these taxes receivable from general government units (11131) and unallocable taxes on income, profits, and capital gains (11132) (see paragraph 5.42 and Tables 5.1 and 5.2). This change allows the identification of those taxes receivable from other general government units that are subject to consolidation.

A1.49 The tax attribution rules are described in paragraphs 5.33-5.38. The tax attribution rules applicable to cases where the activities of the religious organizations are funded from earmarked taxes 
collected by general government are clarified in paragraph 5.39.

A1.50 The GFSM 2001 tax category for taxes on financial and capital transactions (1134) is moved from property taxes (113) to general taxes on goods and services (1141). In the GFSM 2014, this tax category retains its name, but with a different classification code-namely, taxes on financial and capital transactions (11414) (see paragraphs 5.52 and 5.61). This change aligns the GFSM 2014 with the 2008 SNA, which regards this tax as a tax on the sale rather than on the property itself. To maintain consistency with codes used in the GFSM 2001, the codes in taxes on property do not follow directly.

A1.51 A new definition for excises is introduced in paragraph 5.62.

A1.52 The concept profits on fiscal monopolies (1143) is clarified, and its application to public enterprises, lotteries, and other gambling activities is elaborated on (see paragraphs 5.63-5.68).

A1.53 The coverage of taxes on specific services is extended to include the implicit taxes that result from the central bank imposing a rate of interest other than the market rates (see paragraphs 5.70 and 6.89, Box 6.2).

A1.54 The coverage of taxes on use of goods and on permission to use goods or perform activities (1145) is clarified (see paragraph 5.72). Boundaries of this tax with administrative fees (paragraph 5.73), taxes on business activities (see paragraph 5.76), other tax categories (see paragraph 5.77), and the acquisition or use of an asset (see paragraph 5.78) are explained.

A1.55 Taxes on use of goods and on permission to use goods or perform activities (1145) are subdivided into motor vehicle taxes (11451) and other taxes on the use of goods and on the permission to use goods or perform activities (11452). For the latter, the GFSM 2014 introduces several subcategories of taxes to clarify their classification (see paragraph 5.81 and Table 5.4). Furthermore, the accrual recording of business licenses and taxes on pollution (such as emission trading schemes) is elaborated on (see paragraph 5.81).

A1.56 The implicit taxes or subsidies created by multiple exchange rate regimes are introduced in paragraph 5.89. Furthermore, it is clarified that lumpsum payments receivable by government from monetary authorities should be disaggregated according to the economic nature of the components of the payment (see paragraph 5.90).

A1.57 The concept social contributions (12) is clarified (see paragraph 5.94), specifically making a distinction between voluntary and compulsory contributions, describing the flexibility arrangement for the recording of social contributions used in the 2008 SNA (see paragraph 5.95), and presenting the boundary between social contributions and other categories of taxes (see paragraph 5.96).

A1.58 The treatment of grants is elaborated on, specifically describing the distinction between current and capital grants, grants in kind, and the time of recording in an accrual and cash basis of recording (see paragraph 5.103-5.105).

A1.59 The time of recording dividends when using an accrual basis of recording is clarified to be when the equity or shares go ex-dividend (see paragraphs 3.87, 5.112, and 6.109). In addition, it is clarified that legally constituted corporations, reclassified to be a general government unit, could also distribute dividends (see paragraph 5.113). The treatment of disproportionately large dividends is clarified (see paragraphs 5.115-5.116).

A1.60 The coverage of property income from investment income disbursements (1414) is expanded to include distributions to holders of investment fund shares or units (see paragraph 5.120).

A1.61 The concept rent (1415) is elaborated on to explain the distinction between a resource lease, the creation of an asset, contracts, leases, and licenses (31441), or the sale of the resource. Two types of resource rent, for land and subsoil assets, are described in detail and the boundary with the rental of produced assets is explained (see paragraphs 5.124-5.133).

A1.62 The GFSM 2014 assumes the 2008 SNA and BPM6 treatment of reinvested earnings on foreign direct investment (1416) (see paragraphs 5.134-5.135 and 6.121).

A1.63 The classification of administrative fees (1422) is clarified to include fees payable for voluntary participation in deposit insurance or other guarantee schemes that do not qualify to be a standardized guarantee scheme. For it to be administrative fees, the amount payable should be in proportion to the cost of producing the service (see paragraph 5.138). 
A1.64 The treatment of fines and penalties imposed for evasion of taxes and bails set by courts is clarified in fines, penalties, and forfeits (143) (see paragraphs 5.143-5.144).

A1.65 The GFSM 2001 revenue categories for voluntary transfers other than grants (144) and miscellaneous and unidentified revenue (145) are subsumed in two new categories-namely, transfers not elsewhere classified (144) and premiums, fees, and claims receivable related to nonlife insurance and standardized guarantee schemes (145) (see paragraphs 5.145 and 5.149). Revenue from subsidies (14411) receivable is introduced as a separate category of transfer not elsewhere classified (see paragraph 5.146), while the other transfers are distinguished as other current transfers not elsewhere classified (14412) (see paragraph 5.147) and capital transfers not elsewhere classified (1442) (see paragraph 5.148).

A1.66 The revenue category premiums, fees, and claims related to nonlife insurance and standardized guarantee schemes (145) (see paragraph 5.149) is introduced to allow for the appropriate recording of the revenue related to nonlife insurance and standardized guarantees. Subcategories provide for the identification of premiums receivable (14511), fees for standardized guarantees receivable (14512), current claims receivable (14513), and capital claims receivable (1452) (see paragraphs 5.150-5.151).

\section{Chapter 6}

A1.67 The rationale for defining expense as a decrease in net worth resulting from a transaction is added in paragraph 6.1 .

A1.68 The distinction between economic classification of expense and functional classification of expense is clarified in paragraphs 6.2 and 6.3, respectively.

A1.69 The section on defining expense is enhanced with the inclusion of a discussion on the treatment of refunds and corrections and the delineation between expense and transactions in assets and liabilities (see paragraphs 6.4-6.5).

A1.70 The section on the time of recording expense is expanded to clearly indicate the time of recording when using the accrual basis of recording, as well as the cash basis of recording. Furthermore, the time of recording of the acquisition and use of goods and services (22) is clarified (see paragraphs 6.6-6.7).
A1.71 The definition of compensation of employees is clarified to emphasize the individual employeremployee relationship, and the exchange of manual and intellectual labor services (see paragraph 6.9). Furthermore, the nature of wages and salaries in cash (see paragraph 6.13) and in kind (see paragraph 6.17) is elaborated on.

A1.72 Guidance on estimating imputed employers' social contributions (2122) is elaborated on. A clear distinction between nonpension and employmentrelated pension benefits is introduced (see paragraphs 6.23-6.26).

A1.73 The section on the use of goods and services (22) is reorganized to: define the concept (see paragraph 6.27); make a distinction between the time of recording use of goods and services when using an accrual and cash basis of recording (see paragraphs 6.28-6.31); describe the boundary between use of goods and services and compensation of employees (see paragraph 6.33); describe the boundary between use of goods and services and transfers (see paragraph 6.37); describe the boundary between use of goods and services and transactions in the acquisition of nonfinancial assets (see paragraph 6.43); and describe other boundaries related to use of goods and services (see paragraph 6.50).

A1.74 Conceptually, the coverage of use of goods and services (22) in the GFSM 2001 is changed to exclude weapons and weapons systems in the GFSM 2014 (see paragraphs 6.49). These are recognized as the acquisition of a specific category of nonfinancial assets in the GFSM 2014 (see paragraph 8.43).

A1.75 The relationship between inventory (612) and use of goods and services (22) is clarified in Table 6.3.

A1.76 The treatment in GFS of the implicit fees for financial services is explained (see paragraphs 6.52 and 6.81). These implicit fees include items such as financial intermediation services indirectly measured (FISIM), service fees implied by nonlife insurance premiums, and the implicit fees payable by governments to central banks for nonmarket services.

A1.77 The concept consumption of fixed capital (23) is elaborated on. The relation between consumption of fixed capital as recorded in the 2008 SNA and in GFS is explained (see paragraph 6.53). The relation 
between consumption of fixed capital and depreciation as used in government financial records is also explained (see paragraph 6.54). The calculation of consumption of fixed capital is described in Box 6.1. Furthermore, the treatment of costs of ownership transfer as a component of consumption of fixed capital is explained in paragraphs 6.60 and 8.42 .

A1.78 The description of interest (24) is clarified to show the relationship between interest as recorded in the 2008 SNA and interest as recorded in the GFSM 2014. It is suggested to identify the counterpart for interest transactions to allow for consolidation (see paragraph 6.62). A discussion on recording interest, when using a cash basis of recording, is introduced in paragraph 6.65. Recording interest in the case of grace periods and step-up interest arrangements is explained in paragraphs $6.69-6.70$. The recording of interest related to index-linked securities is explained in paragraphs 6.75-6.78. Furthermore, clarification is provided on the treatment of interest on debt securities with embedded derivatives, nonperforming loans, and arrears (see paragraphs 6.79-6.82).

A1.79 Recording subsidies (25) is clarified. The treatment of subsidies in cases when an institutional unit acts on behalf of another unit to redistribute the subsidies is explained in paragraph 6.84. It is also clarified that subsidies are receivable by all resident and nonresident producers, and that units such as general government units, nonprofits institutions serving households, and households can receive subsidies in their capacity as producers (see paragraph 6.86). The coverage of subsidies is extended to include the implicit subsidy that results from the central bank imposing a rate of interest other than the market rates (see paragraphs 5.70 and 6.89, Box 6.2). The discussion on subsidies also introduced the distinction between subsidies on products and subsidies on production to better align with this distinction in the 2008 SNA (see paragraphs 6.89-6.90).

A1.80 To further delineate subsidies, a list of items that do not constitute subsidies is included (see paragraph 6.91), and Box 6.3 elaborates on transactions with public corporations with specific reference to the classification of "capital injections" into public corporations.

A1.81 The definition of grants (26) is revised to no longer refer to grants as noncompulsory transfers. This change accommodates cases where compulsory revenue sharing occurs between government units. The definition is also expanded to indicate that grants are transfers that do not meet the definition of a tax, subsidy, or social contribution (see paragraph 6.92).

A1.82 The treatment of grants in kind is elaborated on, specifically describing the distinction between current and capital grants, and the time of recording in, respectively, an accrual and cash basis of recording (see paragraph 6.93-6.95).

A1.83 The circumstances under which social as sistance benefits (272) become payable are clarified to include contributions payable to social insurance schemes on behalf of households who cannot otherwise afford to participate in the scheme (see paragraph 6.102).

A1.84 The distinction between imputations for employment-related nonpension social benefits and employment-related pensions and other retirement benefits is clarified in paragraph 6.105 .

A1.85 The time of recording dividends (2811) when using an accrual basis of recording is clarified to be when the equity or shares go ex-dividend (see paragraphs 3.87, 5.112, and 6.109). The treatment of disproportionately large dividends is clarified (see paragraphs 5.116 and 6.110).

A1.86 The coverage of property expense for investment income disbursements (2813) is expanded to include distributions to holders of investment fund shares or units (see paragraph 6.113).

A1.87 It is clarified that rent (2814) includes amounts payable under resource leases on land, subsoil resources, and on other natural resources. The measurement of such amounts payable is clarified in the context of the corresponding revenue item (see paragraph 6.120).

A1.88 The GFSM 2014 assumes the 2008 SNA and BPM6 treatment of reinvested earnings on foreign direct investment (2815) (see paragraph 6.121).

A1.89 The GFSM 2001 expense categories for miscellaneous other expense (282) are subsumed in two new categories in the GFSM 2014-namely, transfers not elsewhere classified (282) and premiums, fees, and claims payable related to nonlife insurance and standardized guarantee schemes (283) (see paragraphs 6.122 and 6.125 , respectively). The transfers are 
distinguished as current transfers not elsewhere classified (2821) (see paragraph 6.123) and capital transfers not elsewhere classified (2822) (see paragraph 6.124).

A1.90 The expense category premiums, fees, and claims related to nonlife insurance and standardized guarantee schemes (283) is introduced to allow for the appropriate recording of the expense related to nonlife insurance and standardized guarantee schemes. Subcategories provide for the identification of premiums payable (28311), fees for standardized guarantees (28312), current claims payable (28313), and capital claims payable (2832) (see paragraph 6.125).

A1.91 The discussion on the Classification of Functions of Government (COFOG) in Chapter 6 of GFSM 2001 is moved to the annex to Chapter 6 in GFSM 2014.

A1.92 COFOG in GFS is limited to the expenditure of government, which differs from its application to all outlays of government as used in the OECD/UN classification (see paragraph 6.127 in the annex).

A1.93 The annex is reorganized to separately present: the structure of COFOG classifications (see paragraph 6.128); uses of COFOG (see paragraph 6.130); distinction between individual and collective goods and services (see paragraph 6.133); units of classification (see paragraph 6.140); problems in identifying functions of government (see paragraph 6.143); and the crossclassification of expenditure (see paragraph 6.148). No changes occurred in the functions themselves.

\section{Chapter 7}

A1.94 The usefulness of a set of balance sheets integrated with economic flows is elaborated on in paragraph 7.2.

A1.95 A distinction is drawn between legal and economic ownership in paragraphs 3.38-3.41 and 7.57.13. These concepts are used to determine the asset boundary and to provide an overview of assets and liabilities (see paragraphs 7.14-7.19).

A1.96 The asset boundary is clarified to not include contingent assets and liabilities (see paragraph 7.13), and financial claims are clarified to include: debt instruments; financial derivatives and employee stock options; equity and investment fund shares; and monetary gold in the form of unallocated gold accounts (see paragraph 7.15).
A1.97 The GFSM 2001 treatment of monetary gold and SDRs (6201/6301) as financial assets without a corresponding financial claim is revised. In the GFSM 2014, only monetary gold in the form of gold bullion is regarded as a financial asset without a corresponding financial claim. Also, recognizing that transactions in SDR holdings may be entered into by two domestic units, the exclusion of SDRs from domestic financial asset flows is eliminated (see paragraphs 7.15 and 7.125-7.134, respectively).

A1.98 The concept of produced versus nonproduced nonfinancial assets is introduced in paragraph 7.17-7.19.

A1.99 The valuation of assets and liabilities is elaborated on in paragraphs 7.20-7.25. The usefulness of nominal value of financial instruments is presented in paragraph 7.21, while the treatment of cost of ownership transfer is described in paragraph 7.22. Possible methods of estimating current market prices are described in paragraphs 7.25-7.33.

A1.100 Determining the time of change in ownership of fixed assets that are produced over two or more accounting periods, and those built under a publicprivate partnership, is elaborated on (see paragraphs 7.37 and 7.39 , respectively).

A1.101 The creation of notional units to own fixed assets in territories where they are not residents is explained in paragraphs 2.13 and 7.91 .

A1.102 Identifying public monuments and guidance on their recording are clarified in paragraph 7.42.

A1.103 The definition and identification of $d w e l l-$ ings (61111) are clarified and guidance on the valuation of dwellings is provided in paragraphs 7.44-7.45.

A1.104 Within buildings and structures, a category of fixed assets for land improvements (61114) is added. The cost of ownership transfer on all land is included with land improvements (see paragraphs 7.49-7.51).

A1.105 Subcategories are introduced for machinery and equipment other than transport equipment (61122) to separately identify information, computer, and telecommunications (ICT) equipment (see paragraphs 7.56-7.57) and machinery and equipment not elsewhere classified (see paragraph 7.57).

A1.106 The definition and identification of cultivated biological resources (61131) are clarified, and 
the time of recording when the production of these fixed assets takes a long time to complete is elaborated on. Subcategories are introduced to further clarify the composition of this item (see paragraphs 7.59-7.63 and Table 7.5).

A1.107 The definition and identification of intellectual property products (61132) are elaborated on. Subcategories separately identify research and development (611321), mineral exploration and evaluation (611322), computer software and databases (611323), entertainment, literary, and artistic originals (611324), and other intellectual property products (611325). The coverage of this item is expanded to include research and development products so that patented resources no longer appear as nonproduced assets. Furthermore, the coverage of computer software is expanded to include databases (see paragraphs 7.64-7.73).

A1.108 Weapons systems are introduced as a separate fixed asset category (see paragraph 7.74).

A1.109 In the GFSM 2014, categories of inventory (612) are aligned with the categories used in 2008 SNA. The category strategic stocks (6121) is eliminated as a separate category of inventory and is subsumed in goods for resale (61224), and a category for military inventories is added (see paragraphs 7.75-7.86).

A1.110 The definition of land (6141) is clarified and guidance is provided on the valuation of land (see paragraphs 7.92-7.96).

A1.111 The GFSM 2001 category subsoil assets is replaced by mineral and energy resources (6142). The ownership and recording of this category of asset are elaborated on in paragraphs 7.97-7.99.

A1.112 The classification of other naturally occurring assets (6143) is elaborated on. Subcategories for specific classes of other naturally occurring assets are introduced, and their definitions are clarified (see paragraphs 7.100-7.103 and Table 7.7).

A1.113 The category intangible nonproduced assets (6144) is clarified, and subcategories are introduced for contracts, leases, and licenses (61441) and goodwill and marketing assets (61442) (see paragraphs 7.104-7.117).

A1.114 Negotiability is introduced as a distinguishable feature of securities (see paragraph 7.119).
A1.115 Market value for valuing debt instruments is elaborated on by providing practical guidance on valuation (see paragraph 7.122).

A1.116 Monetary gold and Special Drawing Rights $(6201,6221,6301,6321)$ as financial instruments are elaborated on (see paragraphs 7.125-7.134).

A1.117 The coverage of currency and deposits $(6202 / 6302)$ is clarified and the valuation of this instrument explained (see paragraphs 7.135-7.142).

A1.118 A description of various types of debt securities (6203/6303) and their recording is introduced in paragraphs 7.143-7.156.

A1.119 The description of loans (6204/6304) is expanded to clarify financial leases (see paragraph 7.158), gold swaps (see paragraph 7.161), and offmarket swaps (see paragraph 7.162). The treatment of securities repurchase agreements is clarified as a collateralized loan (see paragraph 7.159). The valuation of loans and treatment of nonperforming loans are presented in paragraph 7.163.

A1.120 The category equity and investment fund shares (6205/6305) is elaborated on to distinguish various types of financial instruments (see paragraphs 7.164-7.177). Investment fund shares (62052/63053) have a specialized role in financial intermediation and are introduced as a separate category (see paragraphs 7.174-7.177).

A1.121 The category for the reserves of insurance, pension and standardized guarantee schemes (6206/6306) is clarified by introducing subcategories for: nonlife insurance technical reserves (see paragraphs 7.183-7.186); life insurance and annuities entitlements (see paragraphs 7.187-7.188); pension entitlements (see paragraphs 7.189-7.198); claims of pension funds on pension managers (see paragraphs 7.199-7.200); and provisions for calls under standardized guarantee schemes (see paragraphs 7.201-7.202).

A1.122 The coverage of insurance, pension, and standardized guarantee schemes (6206/6306) is expanded following recognition of standardized guarantees in a way similar to nonlife insurance and the recognition of claims of pension funds on pension managers (see paragraphs 7.201-7.202 and 7.1997.200 , respectively).

A1.123 The category financial derivatives and employee stock options (6207/6307) is clarified by defining 
the two concepts (see paragraphs 7.204 and 7.221, respectively), describing the types of financial derivatives (see paragraphs 7.209-7.218), and explaining the use of margins (see paragraphs 7.219-7.220).

A1.124 The main balancing item on the balance sheet, net worth (6), is clarified and the relationship with equity for public corporations explained (see paragraphs 7.228-7.233).

A1.125 The items recorded as memorandum items to the balance sheet are expanded to include: net financial worth (see paragraph 7.235), various valuations of gross and net debt (see paragraphs 7.236-7.245), concessional loans and the implicit transfers resulting from loans at concessional interest rates (see paragraph 7.246), arrears (see paragraphs 7.247-7.250), explicit contingent liabilities (see paragraphs 7.251-7.260), net implicit obligations for future social security benefits (see paragraph 7.261), and nonperforming loans (see paragraph 7.262).

A1.126 The classification of the counterparty of financial assets and liabilities by institutional sector is introduced in paragraphs 7.264-7.265 and Table 7.11.

A1.127 The classification of debt liabilities and their corresponding financial assets by maturity is introduced in paragraphs 7.266-7.271 and Table 7.12.

\section{Chapter 8}

A1.128 The concept of net investment in nonfinancial assets is introduced in paragraph 8.4 , and a distinction drawn with gross investment in nonfinancial assets (i.e., consumption of fixed capital is not taken into account).

A1.129 The treatment of costs of ownership transfer associated with acquiring and disposing of nonfinancial assets (other than inventory) is clarified (see paragraphs 8.6-8.8).

A1.130 The valuation of transactions in nonfinancial assets is elaborated to make a clear distinction between valuation of acquisitions and disposals of: fixed assets (see paragraph 8.9); inventories (see paragraph 8.10); land (see paragraph 8.11); and nonproduced assets other than land (see paragraph 8.11).

A1.131 Time of recording transactions in nonfinancial assets is clarified to be when economic ownership changes. Guidelines for alternatives to use when change of ownership is not obvious are provided (see paragraphs 8.13-8.17).
A1.132 The classification of transactions in nonfinancial assets is identical to the classifications of the same stock positions introduced in Chapter 7 (see paragraph 8.22 and Table 8.1).

A1.33 The treatment of public monuments as buildings and structures (3111) is clarified in paragraph 8.30.

A1.134 Transactions related to land improvements (31114) are introduced as a separate category of transactions in paragraph 8.31 .

A1.135 Transactions related to cultivated biological resources (31131) are clarified to include net investment in livestock that are cultivated for the products they yield, and net investment in plantations, orchards, etc. Guidance is provided on the valuation of these transactions (see paragraphs 8.34-8.36).

A1.136 Guidance on the transactions in intellectual property products (31132) is expanded to clarify the valuation of transactions related to research and development (311321) (see paragraph 8.38), mineral exploration and evaluation (311322) (see paragraph 8.39), computer software and databases (311323) (see paragraph 8.40), and entertainment, literary, and artistic originals (311324) (see paragraph 8.41).

A1.137 The treatment of costs of ownership transfer on nonproduced assets other than land (31133) is introduced in paragraph 8.42 . Figure 8.1 is included to illustrate the treatment of these costs in the GFS framework.

A1.138 The recording of transactions related to the acquisition and disposals of weapons systems (3114) is introduced in paragraph 8.43 .

A1.139 Transactions related to the additions and withdrawals of inventory (312) are elaborated on. A distinction is made between the owner of inventory acting as a producer of goods and services and acting as an owner of assets (see paragraphs 8.44-8.47).

A1.140 The nature and treatment of transactions in all the categories of nonproduced assets are elaborated on (see paragraphs 8.49-8.58).

\section{Chapter 9}

A1.141 An explanation of the relationship between transactions and the impact of these on financial assets/liabilities is introduced in paragraph 9.3. Similarly, the impact of net lending/net borrowing on the economy is explained in paragraph 9.5. 
A1.142 Concessional loans and their treatment in macroeconomic statistics are clarified in paragraph 9.12 .

A1.143 Arrears are defined in paragraph 9.20, and the recording of transactions related to arrears is described in paragraphs 9.21-9.23.

A1.144 The classification of transactions in financial assets and liabilities by instrument and residence of the counterparty is described in paragraphs 9.249.27. The classification by instrument that follows is the same as those described in the balance sheet (Chapter 7).

A1.145 Transactions related to monetary gold and special drawing rights $(3201 / 3301)$ are clarified in paragraphs 9.28-9.32.

A1.146 For debt securities (3203/3303), transactions related to interest and amortization are elaborated on (see paragraphs 9.36 -9.43).

A1.147 The impact of recording transactions between the owners of enterprises and the enterprise is clarified. Transactions such as dividends, transfers, membership dues and subscription fees payable to international organizations, and other operations, such as privatization and nationalization, are clarified in the description of transactions in equity (32051/33051) (see paragraphs 9.47-9.55).

A1.148 The recording of the change in value of investment fund shares or units, other than from holding gains and losses, is described in paragraph 9.56.

A1.149 For insurance, pension, and standardized guarantee schemes (3206/3306), the transactions influencing these reserves are elaborated on for each subcategory of the reserves (see paragraphs 9.57-9.69).

A1.150 The coverage of financial derivatives and employee stock options (3207/3307) is expanded to separately identify employee stock options. Transactions related to financial derivatives (32071/33071) are clarified. A distinction is introduced between transactions at inception, on secondary markets, with ongoing servicing, and at settlement (see paragraphs 9.71-9.76). Transactions related to employee stock options (32072/33072) are introduced in paragraph 9.77.

A1.151 The classification of transactions in financial assets and liabilities by sector and residence is introduced in paragraphs 9.85-9.87 and Table 9.2.
A1.152 The classification of transactions in debt liabilities and their corresponding financial assets by maturity is introduced in paragraph 9.88. If analytically useful, the same classification structure could be applied for transactions as what is depicted for stock positions in Table 7.12.

\section{Chapter 10}

A1.153 Other economic flows are described and the two components of other economic flowsnamely, holding gains and losses and other changes in the volume of assets-are defined in paragraph 10.1.

A1.154 The section on holding gains for particular types of nonfinancial assets is elaborated on. Specific guidance is added on: the difference between unrealized and realized holding gains (see paragraph 10.6); neutral and real holding gains (see paragraph 10.11); estimating the holding gains on fixed assets (see paragraphs 10.13-10.15) and inventories (see paragraphs 10.16-10.17); valuables (see paragraph 10.18); and nonfinancial assets disposed of during the reporting period (see paragraphs 10.19-10.20).

A1.155 The impact of various events on the valuation of financial instruments is elaborated on. Specific guidance is added on: monetary gold and SDRs (see paragraphs 10.21-10.22); financial assets and liabilities with fixed monetary values (see paragraph 10.23); debt securities (paragraphs 10.24-10.29); equity and investment fund shares (see paragraphs 10.30-10.34); insurance, pension, and standardized guarantee schemes (see paragraphs 10.35-10.41); and financial derivatives and employee stock options (see paragraphs 10.42-10.43).

A1.156 Paragraph 10.44 introduces holding gains and losses related to financial instruments denominated in foreign currencies, and debt instruments that do not accrue interest over an unusually long time are discussed in paragraph 10.45 .

A1.157 Paragraph 10.46 introduces three events that result in other changes in the volume of assetsnamely, the appearance or disappearance of existing resources as economic assets, the effects of external events, and changes in classifications.

A1.158 The appearance or disappearance of financial assets and liabilities from the balance sheet is elaborated on with specific reference to the appearance of public monuments and valuables (see paragraph 10.50). Circumstances under which natural 
assets, such as subsoil assets, noncultivated biological resources, other natural resources, or land, appear on the balance sheet are explained in paragraph 10.52.

A1.159 The effects of external events on the value of assets and liabilities are described in paragraph 10.59. Details on the recording of these events are provided and include catastrophic losses (see paragraph 10.60), uncompensated seizures (see paragraph 10.62), and other volume changes not elsewhere classified (see paragraph 10.63).

A1.160 Paragraph 10.83 introduces the reclassification of costs of ownership transfer on nonproduced assets other than land, and the consumption of fixed capital relating to these costs. The reclassification is necessary to maintain the integration of stock positions and flows.

A1.161 Paragraph 10.79 elaborates on the reclassifications of negotiable securities necessary due to secondary transactions.

A1.162 The reclassification of monetary gold held in the form of gold bullion when it becomes a reserve asset is introduced as an example of changes in the classification of financial assets and liabilities (see paragraph 10.84).

\section{Cross-Cutting Changes in Terminology}

A1.163 The following changes in terminology were made to further clarify the text of the Manual.

- References to GFS system are replaced with GFS framework - this allows a clear distinction with the 2008 SNA.

- In the context of GFS, references to accounting principles and periods are replaced by references to statistical guidelines and reporting periods-this allows a clear distinction with the use of the term accounting in source data compilation in the context of public sector accounting.

- References to flows are replaced by references to economic flows, while it is acknowledged that flows will often be used as a short form for economic flows.

- References to the balances of assets and liabilities as stocks are replaced by references to stock positions-this allows a clear distinction with the use of the word "stocks" referring to a specific type of financial instrument.
- References to net acquisition of nonfinancial assets are replaced with references to net investment in nonfinancial assets-the former term is often misinterpreted as including only the acquisition minus disposals of nonfinancial assets, while consumption of fixed capital should also be included in this concept. Similar to what is customary in the case of operating balances, references to net/ gross investment in nonfinancial assets can now be used to make a distinction for the including/ excluding of consumption of fixed capital.

- References to net lending/borrowing are replaced with references to net lending/net borrowing, to enhance the precision in terminology.

- References to the Statement of Government Operations are replaced with references to Statement of Operations-this allows the use of this statement for government units as well as public sector units.

- References to other nonrecurrent taxes on property (1135) in the GFSM 2001 are replaced with references to capital levies (1135) - this allows the terminology in GFS to align with 2008 SNA terminology.

- References to property income attributed to insurance policyholders are replaced with references to property income from investment income disbursements - this allows the terminology in GFS to align with 2008 SNA terminology.

- References to the expense for social contributions (212) are replaced by references to employers' social contributions (212) -this clarifies the economic nature of this item. Similarly, actual social contributions (2121) and imputed social contributions (2122) are replaced with actual employers' social contributions (2121) and imputed employers' social contributions (2122), respectively.

- References to the outlays of government are replaced with references to expenditure-this eliminates confusion with the use of outlays in the OECD/UN classification, which include expense, acquisition of nonfinancial assets, and transactions in financial assets and liabilities.

- References to nonresidential buildings (61112) are replaced with references to buildings other than dwellings (61112) - this allows the terminology in GFS to align with 2008 SNA terminology. 
- References to other machinery and equipment (61122) are replaced with references to machinery and equipment other than transport equipment (61122) - this allows the revised GFS category to align with historic data and to subsume the 2008 SNA categories of information, computer, and telecommunications equipment and other machinery and equipment.

- References to cultivated assets (61131) are replaced with references to cultivated biological resources (61131) - this allows the terminology in GFS to align with 2008 SNA terminology.

- References to subsoil assets (6142) are replaced with references to mineral and energy resources (6142) - this allows the terminology in GFS to align with 2008 SNA terminology.

- References to intangible fixed assets (61132) are replaced with references to intellectual property products (61132) - this allows the terminology in GFS to align with 2008 SNA terminology. The word "products" is included to make clear that it does not include third-party rights, which are nonproduced assets.

- References to securities other than shares (6203/6303) are replaced with debt securities (6203/6303) - this allows the terminology in GFS to align with 2008 SNA terminology.

- References to shares and other equity (6205/6305) are replaced with equity and investment fund shares (6205/6305) - this allows the terminology in GFS to align with 2008 SNA terminology.

- References to insurance technical reserves (6206/6306) are replaced with insurance, pension, and standardized guarantee schemes (6206/6306) this allows the terminology in GFS to align with 2008 SNA terminology.

- References to financial derivatives (6207/6307) are replaced with financial derivatives and employee stock options (6207/6307) - this allows the terminology in GFS to align with 2008 SNA terminology.

- References to entity when meaning a good, service, nonfinancial asset, etc. are replaced with references to resource-this eliminates the confusion with entities referred to in the context of institutional units.

\section{Changes from the GFSM 1986 Introduction}

A1.164 The integrated GFS framework described in the GFSM 2014 represents a substantial modernization and expansion of the framework described in A Manual on Government Finance Statistics, 1986 (GFSM 1986). Major changes have been made to definitions, classifications, balancing items, the coverage of units and economic events to be recorded in the GFS framework, and the timing at which economic events are to be recorded. The GFS framework is also more harmonized with other macroeconomic statistical frameworks than is the GFSM 1986. There are numerous detailed changes within each major topic, but an exhaustive listing of all such changes is beyond the scope of this appendix.

\section{Coverage of Units}

A1.165 The focus of the coverage of units in the GFS framework is the general government sector as defined in the 2008 SNA. Its definition is based on the concept of an institutional unit, which is described in Chapter 2. The general government sector consists of all resident government units and all resident nonprofit institutions that are controlled by government. The coverage of the GFSM 1986 is defined on a functional basis rather than a unit basis. It includes all units carrying out a function of government, but, in principle, only those transactions that are directly related to the functions of government are included. By implication, the transactions that do not represent the fulfillment of a fiscal policy are excluded. In particular, all transactions related to the functions of the monetary authority and other depository financial institutions are excluded.

A1.166 Supranational authorities are international organizations that have been endowed with the authority to raise taxes or other compulsory transfers within the territories of the countries that are members of the authority. Despite the fact that supranational authorities fulfill some of the functions of government within each member country, they are always considered nonresident institutional units. As a result, they are not included in the GFS framework for any country. In the GFSM 1986, transactions resulting from governmental functions carried out within a country by supranational organizations are included 
in the statistics for that country. It is possible, however, to compile statistics for supranational authorities using the GFS framework as if they constituted a separate country and to classify relevant categories of transactions by country.

\section{Time of Recording Economic Events}

A1.167 The time at which transactions and other economic flows are recorded is determined by the principles of accrual accounting in the GFS framework. That is, flows are recorded when economic value is created, transformed, exchanged, transferred, or extinguished. In the GFSM 1986, transactions are recorded when cash is received or paid. In general, flows are recorded at an earlier time under the accrual basis than under the cash basis.

A1.168 Recording flows on the accrual basis will automatically capture past-due obligations, such as arrears of debt principal, interest payments, or payments for goods and services. In the GFSM 1986, use of the cash basis means that arrears and changes in the level of arrears are not recorded.

A1.169 The accrual basis of recording permits the difference between the redemption value of a bond or similar security and its issue price to be recorded as interest as it is earned or incurred rather than when the security matures. In the GFSM 1986, the entire difference between the issue and redemption prices is recorded as interest when the security is redeemed.

\section{Coverage of Events}

A1.170 The coverage of events in the GFS framework is broader than in the GFSM 1986 because the revised framework includes all economic events that affect assets, liabilities, revenue, or expense, rather than just those represented by a cash transaction. For example, barter and grants of goods and services are included. The GFSM 1986 incorporates in-kind transactions only selectively and as memorandum items.

A1.171 The GFS framework includes other economic flows, which are all flows other than transactions that affect a unit's stock position of assets, liabilities, and net worth. Other economic flows must be included to fully reconcile the balance sheet at the beginning of an accounting period with the balance sheet at the end of the period. Examples of other economic flows are price changes and the destruction of assets. By definition, other economic flows are noncash events, which means that they are not part of the GFSM 1986.

\section{Valuation}

A1.172 Assets and liabilities are valued at current market prices in the GFS framework, including debt securities that may have a different nominal value. Several assets/liabilities are valued at nominal value as proxy for market value-for example, loans generally are not traded and therefore do not have market values. They are recorded at their nominal values. In the GFSM 1986, debt securities are always valued at the amount the government is obligated to pay when the debt matures, which may differ from both the nominal value and the current market value. The GFS framework includes a provision for recording the nominal value of debt securities as a memorandum item.

\section{Gross and Net Recording of Flows}

A1.173 The presentation of flows on a gross or net basis is, for the most part, the same in the GFS framework and the GFSM 1986. The major exception pertains to the sales and expenses of market establishments. Generally speaking, a market establishment is a part of a general government unit that is situated in a single location and whose primary activity is to produce and sell goods and services at economically significant prices. In concept, it is possible to compile complete accounting records with respect to an establishment's productive activity, including sales and the costs of production. In the GFS framework, the sales and costs of production of market establishments are presented on a gross basis as revenue and expense, respectively. In the GFSM 1986, the net value of sales less the costs of production is recorded as revenue if positive and as expenditure if negative.

\section{Integration of Flows and Stocks}

A1.174 The GFS framework is fully integratedthat is, the stock position at the end of a reporting period can be derived from the stock position at the beginning of the reporting period and the flows occurring during the period. As a result of this integration, all events that affect the financial performance, financial position, or liquidity situation of the general government sector are included. In the GFSM 1986 , the stock positions included are limited to debt 
liabilities. The changes in the stock position of debt liabilities cannot be reconciled with the flows recorded. Flows in the GFSM 1986 represent only cash flows and will not account for changes in stocks related to flows other than cash, such as discounts allowed, debt assumption, debt forgiveness, etc. Supplementary tables are included that indicate the additional data that would be needed to complete the reconciliation.

\section{Definitions and Classifications}

A1.175 Revenue in the GFS framework is an increase in net worth resulting from a transaction. Thus, revenue includes grants but excludes proceeds from disposals of nonfinancial assets. In the GFSM 1986, revenue is defined as the set of all nonrepayable receipts other than grants. Thus, revenue includes proceeds from disposals of nonfinancial assets.

A1.176 Similarly, expense in the GFS framework is a decrease in net worth resulting from a transaction. Purchases of nonfinancial assets do not affect net worth and are not considered expense transactions. The term "expense" replaces "expenditure" from the GFSM 1986 because it is more closely associated with the accrual basis of recording and indicates that transactions in nonfinancial assets are excluded. Expenditure is defined in the GFSM 1986 as the set of all nonrepayable payments and includes purchases of nonfinancial assets.

A1.177 The classifications of revenue are substantially different in the two manuals. Revenue in the GFSM 1986 is classified as tax, nontax, or capital revenue. Grants form a separate, nonrevenue category of receipts. In the GFS framework, revenue is subdivided into taxes, social contributions, grants, and other revenue. In more detail:

- Taxes exclude social contributions in the revised GFS framework, but include them in the GFSM 1986.

- Social contributions in the GFS framework include social security contributions, which are classified as taxes in the GFSM 1986, and other social contributions to social insurance schemes operated for the benefit of government employees, which are classified as nontax revenue in the GFSM 1986.

- Other revenue in the GFS framework includes most of the category of nontax revenue in the
GFSM 1986 plus capital transfers, which are classified as capital revenue in the GFSM 1986.

- Capital revenue in the GFSM 1986 consists of sales of nonfinancial assets and receipts of capital transfers. Sales of assets are not revenue in the GFS framework, but capital transfers are classified as revenue.

A1.178 Expense/expenditure is classified in two ways-by function and by economic type of transaction-in both the GFS framework and the GFSM 1986. The classification by function in both manuals is the Classification of Functions of Government (COFOG) published by the United Nations. The GFS framework incorporates the 2000 edition of COFOG.

A1.179 The classification of expense by economic type in the GFS framework is broadly similar to the corresponding classification in the GFSM 1986. The primary exception is that acquisitions of nonfinancial assets are not considered an expense in the GFS framework. Other changes include the following:

- Consumption of fixed capital is an expense in the GFS framework. As a noncash expense, it is excluded from the GFSM 1986.

- Transfer payments are classified by type of payment in the GFS framework. In the GFSM 1986, they are classified by the sector receiving the payment. The major types of transfer payments are subsidies, grants, social benefits, transfers not elsewhere classified, and premiums, fees, and claims related to nonlife insurance and standardized guarantee schemes.

A1.180 A new classification is dedicated to net investment in nonfinancial assets resulting from transactions because they are not classified as revenue or expense in the GFS framework. The classification follows the parallel classification in the 2008 SNA, which is based on the type of asset involved in the transaction. This classification includes consumption of fixed capital because it represents a decline in the value of fixed assets.

A1.181 "Lending minus repayments" is a category of transactions in the GFSM 1986 representing the net acquisition of financial assets for policy purposes, and is classified together with expenditure for the calculation of the overall deficit/surplus. In the GFS framework, these transactions are classified together with other transactions in financial assets. However, 
if supplementary information is available on policy lending, both the overall balance and policy lending can be calculated from GFS source data, as a fiscal indicator (see annex to Chapter 4, Table 4A.2).

\section{Balancing Items}

A1.182 Several new balancing items are introduced in the GFS framework, a consequence of the view that fiscal analysis must include a variety of considerations and that no single measure is sufficient for all purposes. In the GFSM 1986, the analytic framework is focused on a single balancing item, the overall deficit/surplus, although provision is made for other balancing items.

A1.183 The analytic framework of the integrated GFS features several balancing items. The Statement of Operations includes the following:

- The net operating balance, which is defined as revenue minus expense and represents the change in net worth resulting from transactions

- Net lending/net borrowing, which is defined as the net acquisition of financial assets minus the net incurrence of liabilities, or, alternatively, as the net operating balance minus the net investment in nonfinancial assets; it is also equal to the gross operating balance minus gross investment in nonfinancial assets.

A1.184 The Statement of Sources and Uses of Cash includes the cash surplus/deficit to indicate the balance of cash flows from government operations and the gross investment in nonfinancial assets. It is similar to the overall deficit/surplus of the GFSM 1986 except that net cash outflows from policy lending (lending minus repayment of policy-related transactions in financial assets or liabilities) are not subtracted.

A1.185 Another balancing item in the GFS framework is the overall balance, defined as net lending/ net borrowing adjusted through the rearrangement of transactions in assets and liabilities that are deemed to be for public policy purposes. Notably, policy lending is added to expense while privatization proceeds (including fixed asset sales) are included as transactions in financial items in calculating the overall fiscal balance. It is the equivalent of the overall deficit/surplus in the GFSM 1986, but determined using the accrual basis of recording.

A1.186 Other balancing items in the GFS framework include net worth, net financial worth, the change in net worth, the change in net financial worth (all related to the balance sheet), the change in net worth from other economic flows, the primary balance, and savings. There are no similar balancing items in the GFSM 1986.

\section{Harmonization with Other Statistical Systems}

A1.187 The GFS framework is harmonized with other international macroeconomic statistical systems. That is, the basic concepts, definitions, and conventions are the same to the extent possible, given the objective of the GFS framework to provide data that support fiscal analysis. The other statistical manuals with which the GFS framework has been harmonized are the 2008 SNA, the sixth edition of the IMF's Balance of Payments and International Investment Position Manual, and the IMF's Monetary and Financial Statistics Manual (in the process of being updated). In contrast, the GFSM 1986 follows the 1968 version of the SNA where possible, but the degree of harmonization is much less, primarily because of the use of the cash basis of recording in the GFSM 1986. Appendix 7 of this Manual provides additional information on linkages of the GFS framework with other macroeconomic statistics. 


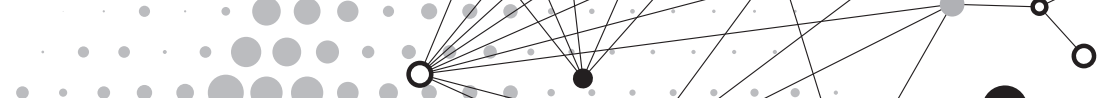

\section{Social Protection}

This appendix describes the various organizational structures used to provide social protection and the associated government finance statistics compiled for the general government or public sectors.

\section{Introduction}

A2.1 Social protection is the systematic intervention intended to relieve households and individuals of the burden of a defined set of social risks. ${ }^{1}$ Social risks are defined as events or circumstances that may adversely affect the welfare of households either by imposing additional demands on their resources or by reducing their income. Needs may occur due to sickness, unemployment, retirement, housing, education, or family circumstances. Many governments devote considerable economic resources to protect citizens and their employees against these risks.

A2.2 This appendix describes the nature of social protection, the boundary between social protection and private insurance, and the criteria used in the classification of social protection arrangements. A typology of social protection arrangements is presented. The typology has the purpose of identifying the type and sector attribution of social protection arrangements, in order to assist the compiler in the recording of flow and stock positions. Examples of the recording of specific flows related to various types of social protection arrangements are presented in tabular form. ${ }^{2}$

\footnotetext{
${ }^{1}$ The Classification of Functions of Government (COFOG) (see Annex to Chapter 6) has a category labeled social protection, but its scope differs from social protection described here, notably by excluding health care.

${ }^{2} \mathrm{~A}$ discussion of the issues involved in the organization and treatment of social protection schemes can also be found in the European Commission, European System of Integrated Social Protection Statistics (ESSPROS) Manual 2008 (Luxembourg, 2008).
}

\section{The Nature of Social Protection}

A2.3 Households benefit from social protection in different ways:

- Households could receive benefits when they meet certain eligibility criteria that originated from a social risk without making any contributions. These benefits are classified as an expense that leads to a redistribution of income through transfers.

- Households could make contributions and receive benefits as transfers receivable in the event of the occurrence of the specified social risks. Neither the contributions nor the benefits constitute an exchange as no direct exchange of economic value occurs. The payment of the social contribution entitles the contributor to some contingent future benefits. The finances of these arrangements function similarly to nonlife insurance schemes (see paragraph A4.70). Such social protection arrangements are essentially a process of redistribution across a wide section of the population, with many individuals contributing resources so that those in need may benefit. ${ }^{3}$ These social benefits are classified as an expense.

- Households (including employees, self-employed, and unemployed) could make contributions (actual and imputed) to a scheme to accumulate assets. They can withdraw from these accumulated assets in the event of the occurrence of the specified social risk. Examples are employmentrelated pensions and other retirement benefits, compulsory saving schemes, and other types of annuities. The finances of these arrangements function similarly to life insurance schemes (see paragraph A4.69). There is relatively little redistribution among the various households holding

\footnotetext{
${ }^{3}$ As described in paragraph 6.97 , the category social benefits [GFS] differs from social benefits as defined in the 2008 SNA.
} 
similar policies, and members of households are able to predict with a reasonable degree of certainty what they will receive and when. Therefore, contributions and payments of these benefits are transactions in financial assets and liabilities.

A2.4 Depending on the nature of the social protection arrangement, the unit that administers the arrangement could earn revenue (social contributions) and/or incur expense (social benefits) related to the social protection arrangement. Social contributions [GFS] (12) are actual or imputed revenue receivable by social insurance schemes to make provision for social insurance benefits payable (see paragraphs 5.945.100). As an expense, social benefits [GFS] (27) are current transfers receivable by households intended to provide for the needs that arise from social risks (see paragraphs 6.96-6.106). Alternatively, the unit that administers the arrangement could be involved in transactions in financial assets and liabilities, classified as insurance, pensions, and standardized guarantee schemes (see paragraphs 7.178-7.202).

A2.5 The social risks covered by social protection vary from country to country and from scheme to scheme. Generally, social protection may be divided into two classes-namely:

- Pensions and other retirement benefits

- All other social benefits, collectively described as nonpension social benefits.

A2.6 Pensions and other retirement benefits are payable when individuals cease employment upon retirement. Pensions may also be payable to other individuals-for example, a bereaved spouse or other dependents, or to someone suffering from a permanent disability. As indicated in Figure A2.1, pensions and other retirement benefits are provided to individuals via social assistance, social security, employmentrelated pension schemes, or private insurance.

A2.7 Nonpension social benefits include payments made to individuals when they are temporarily unemployed, suffering from a medical condition, or suffering from an event that prevents them from working for a period. The following list of typical nonpension social benefits illustrates their general nature:

- The beneficiaries, or their dependents, require medical, dental, and other treatments, or hos- pital, convalescent, or long-term care as a result of sickness, injuries, maternity needs, chronic invalidity, old age, etc. These social benefits are provided in kind in the form of treatment or care provided free or at prices that are not economically significant, or by reimbursing expense incurred by households or individuals.

- The beneficiaries have to support dependents of various kinds: spouses, children, elderly relatives, physically or mentally disabled persons, etc. These social benefits are usually payable in cash in the form of regular dependents' or family allowances.

- The beneficiaries suffer a reduction in income as a result of not being able to work full-time. These social benefits are usually payable regularly in cash for the duration of the condition or for a maximum period. In some instances, a lump sum may be provided additionally or instead of the regular payment. People may be prevented from working for various reasons, including involuntary unemployment, temporary layoffs, short-time working, sickness, accidental injury, the birth of a child, etc.

- The beneficiaries suffer a reduction in income because of the death of the main income earner. These social benefits are usually payable in cash, often in the form of regular allowances or, in some instances, a lump sum.

- The beneficiaries are provided with housing either free or at prices that are not economically significant, or by reimbursing some of the expense they incur.

- The beneficiaries are provided with allowances to cover education expenses incurred on behalf of themselves or their dependents; education services may occasionally be provided in kind (i.e., education services provided free or at prices that are not economically significant ${ }^{4}$ to those subject to social risks).

A2.8 Social benefits can be provided in cash or in kind. If provided in kind, the goods or services could be produced by the unit providing the benefits, they could be purchased by the unit providing

\footnotetext{
${ }^{4}$ In this case, the social benefit will cover only the difference between the normal price of such services and the price payable.
} 


\section{Figure A2.1 Boundary between Social Protection and Private Insurance}

\begin{tabular}{|c|c|c|c|c|c|}
\hline & \multicolumn{5}{|c|}{ Insurance } \\
\hline & \multicolumn{3}{|c|}{ Social Insurance } & \multicolumn{2}{|c|}{ Individual Insurance } \\
\hline \multicolumn{6}{|c|}{ Social Protection } \\
\hline \multirow[t]{2}{*}{ Social Assistance } & \multirow[t]{2}{*}{$\begin{array}{l}\text { Social Security } \\
\text { Schemes }\end{array}$} & \multicolumn{2}{|c|}{$\begin{array}{l}\text { Employment-Related Social } \\
\text { Insurance Schemes' }\end{array}$} & \multicolumn{2}{|c|}{ Private Insurance } \\
\hline & & $\begin{array}{l}\text { Nonpension } \\
\text { Schemes }\end{array}$ & $\begin{array}{l}\text { Pension } \\
\text { Schemes }\end{array}$ & $\begin{array}{c}\text { Nonlife Insurance } \\
\text { Schemes }\end{array}$ & $\begin{array}{l}\text { Life Insurance } \\
\text { Schemes }\end{array}$ \\
\hline Amounts & $\begin{array}{l}\text { Amounts } \\
\text { receivable: } \\
\text { - Social security } \\
\text { contributions } \\
\text { (revenue) }\end{array}$ & $\begin{array}{l}\text { Amounts } \\
\text { receivable: } \\
\text { - Other social } \\
\text { contributions } \\
\text { (revenue) }\end{array}$ & $\begin{array}{l}\text { Amounts } \\
\text { receivable: } \\
\text { - Incurrence of } \\
\text { liabilities through } \\
\text { actual and imputed } \\
\text { contributions }\end{array}$ & $\begin{array}{l} \\
\text { - Premiums } \\
\text { (revenue) }\end{array}$ & $\begin{array}{l}\text { Amounts } \\
\text { receivable: } \\
\text { - Incurrence of } \\
\text { liabilities through } \\
\text { actual } \\
\text { contributions }\end{array}$ \\
\hline Amounts payable: & Amounts payable: & Amounts payable: & Amounts payable: & Amounts payable: & Amounts payable: \\
\hline $\begin{array}{l}\text { - Social assistance } \\
\text { benefits (expense) }\end{array}$ & $\begin{array}{l}\text { - Social security } \\
\text { benefits (expense) }\end{array}$ & $\begin{array}{l}\text { - Employment- } \\
\text { related social } \\
\text { benefits (expense) }\end{array}$ & $\begin{array}{l}\text { - Reduction in } \\
\text { liabilities through } \\
\text { pensions paid }\end{array}$ & - Claims (expense) & $\begin{array}{l}\text { - Reduction in } \\
\text { liabilities through } \\
\text { pensions paid }\end{array}$ \\
\hline
\end{tabular}

${ }^{1}$ Including defined-contribution schemes, treated similar to life insurance.

the benefits from a market producer before distributing them to the household, or the households could purchase the goods and services and be reimbursed. Some benefits are provided indirectly, such as through tax allowances, exemptions, and deductions; benefits provided in this manner are not considered social benefits in GFS. However, if social benefits are made available via the tax system in the form of payable tax credits, these payable tax credits should be recorded on a gross basis and recorded as a social benefit payable by government (see paragraphs 5.29-5.32).

A2.9 In GFS, a social benefit expense is always a transfer payment because the benefits are provided without the recipients being required to provide something of equivalent value in return. Allowances provided as compensation of employees or loans provided by employers to employees are not social benefits. Transfers are defined and explained in more detail in paragraph 3.10 .

A2.10 Social benefits do not include transfers payable in response to events or circumstances that are not normally covered by social insurance schemes. Therefore, transfers made in response to unusual events, such as natural disasters or destruction dur- ing wars, should be recorded as transfers not elsewhere classified (282) in GFS (see paragraphs 6.122-6.126).

\section{Boundary between Social Protection and Private Insurance}

A2.11 Social benefits are provided by general government employers to their employees and their dependents, or other units, such as trade unions and nonprofit institutions serving households. Social benefits are always provided in collective arrangements. Consequently, individual insurance policies taken out on the private initiative of individuals or households solely in their own interest are excluded from social protection arrangements. When individuals take out insurance policies in their own names, on their own initiative, and independently of their employers or government, the claims receivable are not treated as social benefits, even if the policies are taken out against the same kinds of social risks as those listed in paragraphs A2.6-A2.7-these private initiatives are treated as private insurance.

A2.12 Individual saving arrangements that maintain the integrity of the participants' contributions and are restricted to protecting against social risks are private insurance schemes. Under such arrangements, 
the contributions of the participants and/or their employers are kept in a separate account and may be withdrawn under specified circumstances, such as retirement, unemployment, invalidity, and death.

A2.13 Social protection arrangements (covering social assistance and social insurance) must be organized collectively for groups of workers or be available by law to all workers or designated categories of workers, possibly including unemployed persons as well as employed. Social insurance includes private social insurance schemes arranged for selected groups of workers employed by a single employer, and social security schemes (see paragraph 2.101). ${ }^{5}$

A2.14 Many social insurance schemes (covering social security schemes and employment-related insurance schemes) are organized collectively for groups of workers so that those participating do not have to take out individual insurance policies in their own names. In such cases, there is no difficulty about distinguishing social insurance from private insurance taken out on an individual basis. However, some social insurance schemes may permit, or even require, participants to take out policies in their own names. In order for an individual policy to be treated as part of a social insurance scheme, the eventualities or circumstances against which the participants are insured must be of the kind listed in paragraphs A2.5-A2.7, and, in addition, one or more of the following conditions must be satisfied:

- Participation in the scheme is obligatory either by law for a specified category of persons, whether employed or unemployed, or under the terms and conditions of employment of an employee, or group of employees.

- The scheme is a collective one operated for the benefit of a designated group of persons, whether employees or unemployed, participation being restricted to members of that group.

- An employer makes a contribution (actual or imputed) to the scheme on behalf of an employee, regardless of whether the employee also makes a contribution.

A2.15 The premiums payable, and claims receivable, under individual policies taken out under a

\footnotetext{
${ }^{5}$ Social insurance schemes are a subset of social protection arrangements, and social security schemes are a subset of social insurance schemes.
}

social insurance scheme are recorded as social contributions and social benefits. Most individual policies that qualify as social insurance schemes are likely to be for pension provision, but it is possible that they may cover other eventualities-for example, to provide income if the policyholder is unable to work for a prolonged period because of ill health.

A2.16 Participation in insurance schemes, public or private, may be voluntary for the workers concerned, but it is more common for it to be obligatory. For example, participation in schemes organized by individual employers may be required by the terms and conditions of employment collectively agreed between employers and their employees. Participation in nationwide social security schemes organized by government units may be compulsory by law for the entire labor force, except perhaps for persons who are already covered by private schemes. Making a distinction in underlying source data between compulsory and voluntary social contributions is required when the total fiscal burden is calculated (see Table 4A.1). In contrast, social assistance is provided without any insurance involved (see paragraph A2.25).

\section{Classification Criteria for Social Protection Arrangements}

A2.17 As indicated in Figure A2.2, the following criteria are used in macroeconomic statistics to classify social protection arrangements:

- Contributory versus noncontributory-Contributory schemes require actual or imputed social contributions by the protected persons or by other parties on their behalf to obtain entitlement to the benefits. Noncontributory arrangements do not require the payment of contributions, but other eligibility requirements may apply.

- Compulsory versus voluntary-Compulsory schemes may be established by law and/or regulation or by agreement between employer and employees. In some cases, a scheme may be mixed, where some people are required to participate and others are allowed a choice. Participation in voluntary schemes is at free will.

- Cover the whole (or large segments of the) population or just government employees-Social protection is provided collectively to the general population (or a large segment of the general 


\section{Figure A2.2 Typology of Social Protection}

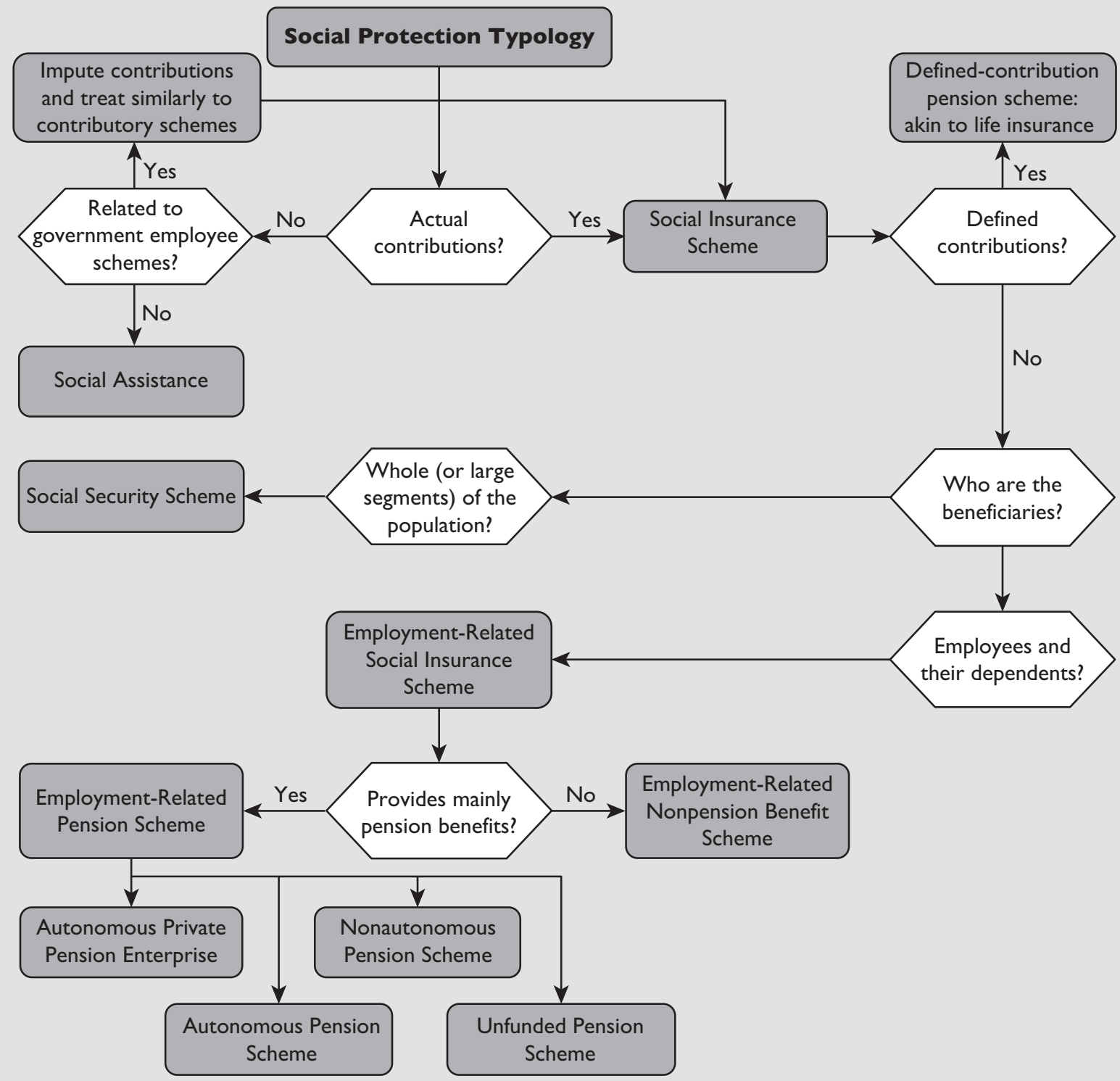

population), although possibly limited by eligibility criteria, while employment-related schemes provide benefits as part of the conditions of employment. ${ }^{6}$

- Provide pension and other retirement benefits, or other types of social benefits-Social protection arrangements distinguish between those that provide pensions and other retirement benefits,

${ }^{6}$ As indicated in paragraph A2.12, individual insurance or saving arrangements that maintain the integrity of the participant's contributions are not considered social insurance. and those that provide other types of nonpension benefits, such as medical, unemployment, disability, etc. This distinction determines the transactions recorded for the arrangement; for example, employment-related pension schemes are considered to give rise to liabilities in the form of pension entitlements recorded under the debt instrument insurance, pension, and standardized guarantee schemes.

- Autonomous versus nonautonomous-A social protection scheme is autonomous when a 
separate institutional unit exists ${ }^{7}$ that is directly held responsible, and accountable, for the decisions and actions the unit takes. Where a separate institutional unit does not exist, the arrangement would be considered nonautonomous and be classified with the unit that controls it.

- Defined-contribution versus defined-benefit schemes-A defined-contribution scheme is one where the benefits are determined by the actual contributions made to the scheme, and the investment income and holding gains and losses earned on these and previous contributions. Under a defined-benefit scheme, the ultimate benefit is calculated by means of a formula embodied in the terms of the social insurance scheme. These benefits are usually determined in terms of the undertakings made by the employer or operator of the scheme.

- Funded versus unfunded schemes-A social insurance scheme is funded if contributions are held in a segregated fund (reserve), from which future benefits will be payable. If a segregated fund is sufficient to finance the present value of the future benefits payable, the scheme is fully funded. If the segregated fund is insufficient to finance the net present value of the future benefits payable, it is underfunded. If the reserve is more than sufficient to finance the net present value of the future benefits payable, it is overfunded. For an unfunded scheme, contributions are not held in a segregated fund (reserve). By definition, unfunded schemes have no separate pool of reserves and cannot be a separate institutional unit.

\section{Typology of Social Protection Arrangements}

A2.18 The classification of social protection is based on the type of social protection arrangement governing the payment of the benefits. Social protection can be organized as social assistance or social insurance schemes, with the latter organized as social security schemes or employment-related social insurance schemes. The units involved in the organization and operation of social protection can be general government units, public corporations, nonprofit institutions serving households, or private corporations.

\footnotetext{
${ }^{7}$ The definition of an institutional unit and the criteria that an entity must fulfill to be an institutional unit are described in paragraph 2.22 .
}

A2.19 Using the various aspects of the classification criteria for social protection, as described earlier, Figure A2.2 provides a typology designed to assist compilers in identifying and classifying various social protection arrangements. Identifying the type of unit involved in social protection arrangements is an important step in determining the recording of flows and stock positions, which differs depending on the type of arrangement.

A2.20 The first level in the typology of social protection is based on whether payments of contributions are required to obtain entitlement to benefits. Where no contributions are required, social protection is provided as a social assistance arrangement (see paragraphs A2.25-A2.29). The requirement to make payments of social contributions by the protected persons or by other parties on their behalf to obtain entitlement to the benefits indicates the existence of a social insurance scheme (see paragraphs A2.30-A2.31). However, noncontributory employment-related social protection schemes provided by employers for the benefit of their employees are treated as if they were contributory schemes because contributions are imputed. The amounts necessary to obtain coverage against the specified social risks are imputed as social contributions, and another transaction imputes the employees' payment of the same amounts to the employer as social contributions (see paragraph A2.40).

A2.21 The next level in the typology of social protection is determined by whether the social insurance is arranged as a defined-contribution or definedbenefit scheme. Defined-contribution schemes will constitute either a compulsory savings arrangement or an employment-related pension scheme, and, as described in paragraph A2.12, these arrangements are treated similarly to life insurance. Paragraphs A2.55A2.59 describe the treatment of defined-contribution schemes.

A2.22 Within social insurance, the types of beneficiaries covered by the scheme determine the next level in the typology. When the beneficiaries are the general population, or a large segment of the general population, the scheme would be a social security scheme, as discussed in paragraphs A2.33-A2.39. If individuals or households are eligible to receive social benefits as a group of employees, it is an employment-related social insurance scheme, as discussed in paragraph A2.40. 
A2.23 The typology of employment-related social insurance schemes further distinguishes based on the types of benefits provided by the scheme: Employmentrelated pension schemes provide pension and other retirement benefits and are discussed in paragraphs A2.41-A2.59; employment-related nonpension social insurance schemes provide nonpension benefits and are discussed in paragraphs A2.64-A2.66. These benefits may be provided in cash or in kind, similar to the benefits as described in paragraph A2.27.

A2.24 Employment-related pension and other retirement benefit schemes can further be distinguished by whether they are funded or unfunded (see paragraph A2.17). While unfunded schemes are always considered nonautonomous, for funded schemes a further distinction is made between those that are nonautonomous (see paragraph A2.44) or autonomous (see paragraph A2.47).

\section{Social Assistance}

A2.25 Social assistance provides social protection benefits to all persons who are in need without any formal requirement to participate as evidenced by the payment of contributions. The eligibility to receive social benefits is not conditional on the payment of contributions by the protected persons or by other parties on their behalf. There may, however, be specific eligibility criteria, such as a "means test," where the expression indicates a maximum qualifying level of income or assets. The benefits payable by such an arrangement are social assistance benefits. Social assistance benefits (272) are transfers payable in cash or in kind to households to meet the same needs as social insurance benefits but are not made under a social insurance scheme (see paragraph A2.30).

A2.26 All social assistance is organized and operated by government units and NPISHs. The benefits are payable to households, out of the unit's general resources, according to the specified criteria. Eligibility is purely related to the criteria stipulated in the social protection arrangement.

A2.27 Social assistance benefits may be provided in cash or in kind. The classification of this expense is further discussed in paragraphs 6.101-6.102, and Table A2.1 illustrates the recording of flows related to social assistance. Social assistance benefits in kind are recorded when:

\section{Table A2.1 Illustrative Recording of Flows Related to Social Assistance}

\begin{tabular}{l|l|l|l|} 
Description & Credit
\end{tabular}

1.1 Government provides benefits payable to qualifying persons who have met the eligibility criteria of a social assistance arrangement

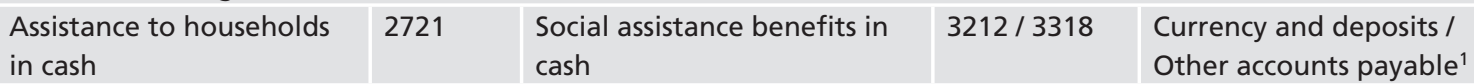

1.2 Government provides goods purchased from market producers to persons who have met the eligibility criteria of a social assistance arrangement

\begin{tabular}{l|l|l|l|l|}
\hline $\begin{array}{l}\text { Government acquires the } \\
\text { goods }\end{array}$ & 31224 & $\begin{array}{l}\text { Inventories (goods for } \\
\text { resale) }\end{array}$ & $3212 / 3318$ & $\begin{array}{l}\text { Currency and deposits / } \\
\text { Other accounts payable }\end{array}$ \\
\hline $\begin{array}{l}\text { Government provides } \\
\text { goods }\end{array}$ & 2722 & $\begin{array}{l}\text { Social assistance benefits in } \\
\text { kind }\end{array}$ & 31224 & $\begin{array}{l}\text { Inventories (goods for } \\
\text { resale) }\end{array}$
\end{tabular}

1.3 Government reimburses market providers or households for goods and services acquired from market entities in accordance with the conditions of a social assistance arrangement

\begin{tabular}{l|l|l|l|l}
$\begin{array}{l}\text { Government reimburses } \\
\text { providers or households }\end{array}$ & 2722 & $\begin{array}{l}\text { Social assistance benefits in } \\
\text { kind }\end{array}$ & $3212 / 3318$ & $\begin{array}{l}\text { Currency and deposits / } \\
\text { Other accounts payable }\end{array}$
\end{tabular}

1.4 Government produces and provides goods or services to the population in accordance with the condition of a social assistance arrangement

The operational costs incurred in the production of the goods and services are recorded as relevant
21, 22, 23 Compensation of employees, 3212 / 3318 use of goods and services, and consumption of fixed capital
Currency and deposits / Other accounts payable ${ }^{1}$

${ }^{1}$ In a cash reporting environment, the expense will be recorded at the time of the cash flow. In an accrual reporting environment, an other account payable should be recorded in cases where the payment is not made when the eligibility criteria have been met.

${ }^{2}$ The flow of inventories will be recorded only in an inventory accounting system. 
- Government provides directly to the households goods and services purchased from market producers.

- Market entities provide goods and services directly to households, with the government providing reimbursement either directly to the provider or to the household for expenses incurred. Although households are reimbursed in cash for eligible purchases of goods and services, the transaction should be recorded as social assistance benefits in kind. ${ }^{8}$

A2.28 A distinction should be made between social assistance benefits and certain other expense categories incurred by government-notably:

- When a government unit produces the goods and services provided to households as social assistance benefits, they are not recorded as social benefits but rather by type of expense incurred in producing these goods and services: compensation of employees (21), use of goods and services (22), and consumption of fixed capital (23). ${ }^{9}$

- If a government unit reimburses corporations for the cost of goods and services provided to targeted social assistance beneficiaries, the transfers are recorded as social assistance benefits in kind. These transfers to corporations should be distinguished from subsidies (25), which are transfers to enterprises intended to reduce prices or increase the provision of goods and services for the general population.

- Social assistance benefits do not include transfers payable in response to events or circumstances that are not normally covered by social insurance schemes (see paragraph A2.10).

A2.29 Typically, social assistance benefits will be recorded on an accrual basis as an expense when all eligibility criteria have been met and the benefits become payable. Although some benefits, such as disability or maternity payments, may be payable over several reporting periods, no liability for the future

\footnotetext{
${ }^{8}$ The economic substance of the transactions is recorded as if the government purchased the goods and distributed them to the beneficiaries. The intermediate step of acquisition and disposal of inventories of goods is netted out in the calculation of change in inventories.

${ }^{9}$ This treatment differs from the treatment in the 2008 SNA. See Appendix 7, Box A7.1, for an explanation of the difference in the treatment of goods produced by government and transferred in kind.
}

payments of social assistance benefits should be recorded on the balance sheet of government. Other accounts payable will be recognized only in cases where a benefit accrued but remained unpaid at the end of a reporting period. ${ }^{10}$ However, to increase transparency and allow an analysis of the sustainability of social assistance policies, an estimate of the present value of social assistance benefits that have already been earned, according to the existing laws and regulations, but are payable in the future, could be calculated in a manner similar to the liabilities of an employmentrelated insurance scheme.

\section{Social Insurance Schemes}

A2.30 Social insurance schemes provide social protection and require formal participation by the beneficiaries, evidenced by the payment of contributions (actual or imputed). These schemes are organized in such a way that a third party, usually an employer or the government, encourages or obliges individuals to participate in a scheme that provides benefits for a number of identified circumstances, including pensions in retirement. Social insurance schemes have much in common with direct insurance (see paragraph A4.68) and may be run by insurance corporations. The payment of contributions (corresponding to premiums in the case of direct insurance) and benefits (corresponding to claims in the case of direct insurance) is recorded according to the nature of the scheme. Participation is usually linked to employment, and contributions are payable either by the participants, an employer, or both. Therefore, a social insurance scheme is an insurance scheme for which the following two conditions are satisfied:

- The benefits receivable are conditional on participation in the scheme and constitute social benefits.

\footnotetext{
${ }^{10}$ For example, assume person A has met the eligibility criteria for unemployment payments in period $\mathrm{t} 1$, and is entitled to receive benefits for six periods. Because of administrative delays, no benefit payment was made in the first period-therefore, an other account payable at the end of that period, equal to the value of payment for one period only, should be recorded. Similarly, if another payment is not made in the second period, the account payable will increase with the value of benefits for another one month. The full amount of benefits to be receivable over the six periods should not be recognized as an upfront payable, but rather be accrued continuously over the period of eligibility.
} 
- At least one of the following three conditions is met:

- Participation in the scheme is obligatory either by law or under the terms and conditions of employment of an employee, or group of employees.

- The scheme is a collective one operated for the benefit of a designated group of workers, whether employed or unemployed, participation being restricted to members of that group.

- An employer makes a contribution (actual or imputed) to the scheme on behalf of an employee, regardless of whether the employee also makes a contribution.

A2.31 A social insurance contribution is the amount payable to a social insurance scheme in order for a designated beneficiary to be entitled to receive the social benefits covered by the scheme. A social insurance benefit is a social benefit payable because the beneficiary participates in a social insurance scheme and the identified circumstances have occurred.

A2.32 As indicated in paragraph A2.22, the types of beneficiaries covered by the social insurance scheme determine the next level in the typology of this scheme (see Figure A2.2). The individuals or households eligible to receive social insurance benefits are either a group of employees, the general population, or a large segment of the general population. Social security schemes are social insurance schemes that cover the community as a whole, or large sections of the community, and are imposed and controlled by government units. In contrast, as indicated in paragraph A2.40, social insurance schemes in which employers provide social insurance benefits only to their employees, former employees, or their beneficiaries are referred to as other employmentrelated social insurance schemes. Where the same scheme covers the general population and government employees, the scheme is treated as a social security scheme. However, if the conditions for participation and benefits payable, as determined by the employment contract, differ from those of the social security scheme for nongovernment employee participants, an employment-related scheme exists and the flows and stock positions of the two schemes should be distinguished within the social security fund (see paragraph 2.102).

\section{Social security schemes}

A2.33 Social security schemes are social insurance schemes covering the community as a whole, or large sections of the community, and are imposed and controlled by government units. These schemes cover a wide variety of programs, providing benefits in cash or in kind for old age, invalidity or death, survivors, sickness and maternity, work injury, unemployment, family allowance, health care, etc. There is not necessarily a direct link between the amount of the contribution payable by an individual and the benefits receivable.

A2.34 Social security schemes that are organized separately from the other activities of government units, hold their assets and liabilities separately from the latter, and engage in financial transactions on their own account qualify as institutional units. These institutional units are described as social security funds. A social security fund is a particular kind of government unit that is devoted to the operation of one or more social security schemes. These special types of government units are identified separately in a subsector to allow for the alternative methods of constructing subsectors of the general government sector (see paragraph 2.78). The existence of a social security fund depends on its organization as a separate institutional unit, not on other characteristics of the scheme, such as types of benefits provided or sources of finance.

A2.35 Not all social security schemes are operated by social security funds. Where a separate social security fund does not exist, the transactions of the social security scheme would be reported as an integral part of the transactions of the government unit that controls operations of the social security scheme. Social security schemes can therefore be operated by government units that are not social security funds. Consequently, statistics for the social security funds subsector may not include all social security schemes. If a social security scheme is not a separate institutional unit, however, there may be separate accounts to manage the scheme's finances, which would permit compiling supplementary statistics on social security activities with broader coverage than that of the social security subsector.

A2.36 By definition, social security schemes are contributory-participants in the scheme are required to make regular contributions to be eligible to 
receive benefits for themselves or their dependents. The primary receipts of social security schemes are social security contributions. As shown in Table 5.1 in Chapter 5, social security contributions are classified according to their source, which may be employers or households. Participation in social security schemes can be compulsory or voluntary. Further breakdown in the classification of these social contributions would allow a distinction between contributions receivable in cash and in kind, and between compulsory and voluntary contributions. In addition to social contributions, social security schemes may receive grants from general government resources and may earn property income from the investment of their assets.

A2.37 Social security benefits [GFS] (271) payable are current transfers and are classified as one of the social benefits categories. These can further be classified as being payable in cash or in kind (see Table 6.1). Social security benefits in kind can be provided to beneficiaries in the same ways as social assistance benefits in kind (see paragraphs A2.27-A2.28). Table A2.2 illustrates the recording of some of the flows related to social security schemes.

A2.38 Social security schemes are characterized by a degree of contingent reciprocity. Social security contributions secure entitlements to benefits that are contingent on the event underlying the social risk occurring. Nonetheless, the amount and timing of receipts of benefits by beneficiaries (if any) are subject to various eligibility criteria without necessarily a direct relationship between the amount of the contribution payable by an individual and the benefits receivable. Therefore, the link between benefits and contributions is not considered sufficiently strong to give rise to a financial claim on the part of contributors. The potential individual claims of contributors (and therefore the corresponding government obligations) are regarded as contingent. Also, because social security benefits can be changed at will by the government or legislature as part of its overall economic policy, there is uncertainty about the eventual payment or level of payment of these social benefits. ${ }^{11}$ As a result, in GFS,

\footnotetext{
${ }^{11}$ The amounts of social security contributions receivable and benefits payable may be deliberately changed in order to achieve objectives of government policy. The change may have no direct connection with the functions of social security. For example, the contributions and benefits may be raised or lowered in order to influence the level of aggregate demand in the economy, or to ensure fiscal sustainability.
}

no liabilities are associated with the potential future claims on social security schemes. An expense is recorded only when payment of the benefits is due.

A2.39 However, a high expectation exists that social security benefits earned according to the existing laws will be payable in the future. Therefore, an estimate equal to the net implicit obligations for future social security benefits should be presented as a memorandum item to the Balance Sheet, and details of it presented as a supplementary statement, the Summary Statement of Explicit Contingent Liabilities and Net Implicit Obligations for Future Social Security Benefits (see paragraphs 4.47 and 7.261).

\section{Other employment-related social insurance schemes}

A2.40 Other employment-related social insurance schemes derive from an employer-employee relationship in the provision of pension entitlement and other social benefit to employees as part of the conditions of employment. By definition, these schemes are contributory and, for government or public sector units, protect only their own employees and dependents. The provision of social insurance benefits by government to its own employees is considered to be part of an actual or implicit contract between the government, as employer, and the employees, to compensate them for the provision of their labor services. Therefore, employment-related social insurance schemes give rise to requited expense transactions for government when the social contributions became payable. To accurately reflect the accrued costs of employment, the actual and imputed social insurance contributions should be recorded as employers' social contributions (212) in the expense category for compensation of employees (21) (see Table 6.1).

\section{Employment-related pensions and other retirement benefit schemes}

A2.41 Employment-related social insurance schemes that provide pensions and other retirement benefits can be organized as a funded or unfunded social insurance scheme. Table A2.3 illustrates the recording of some of the flows of employment-related pensions.

A2.42 There are three types of employment-related pension schemes:

- A nonautonomous pension scheme that is therefore regarded as an integral part of the employer 


\section{Table A2.2 Illustrative Recording of Flows Related to Social Security Schemes}

\begin{tabular}{|c|c|c|c|c|c|}
\hline & Description & Debit & & Credit & \\
\hline \multicolumn{6}{|c|}{ ontributo } \\
\hline & $\begin{array}{l}\text { Social security contributions } \\
\text { receivable from employees, self- } \\
\text { employed, and unemployed }\end{array}$ & $3212 / 3218$ & $\begin{array}{l}\text { Currency and deposits / } \\
\text { Other accounts } \\
\text { receivable }^{1}\end{array}$ & $1211 / 1213$ & $\begin{array}{l}\text { Social security } \\
\text { contributions: Employee } \\
\text { contributions/self- } \\
\text { employed, and unemployed }\end{array}$ \\
\hline & $\begin{array}{l}\text { Social security contributions } \\
\text { receivable from employers }\end{array}$ & $3212 / 3218$ & $\begin{array}{l}\text { Currency and deposits / } \\
\text { Other accounts } \\
\text { receivable }^{1}\end{array}$ & 1212 & $\begin{array}{l}\text { Social security } \\
\text { contributions: Employer } \\
\text { contributions }\end{array}$ \\
\hline \multicolumn{6}{|c|}{$2.2 \mathrm{Th}$} \\
\hline & $\begin{array}{l}\text { Government contributions as } \\
\text { employer become payable }\end{array}$ & 2121 & $\begin{array}{l}\text { Actual employers' } \\
\text { social contributions }\end{array}$ & $3212 / 3318$ & $\begin{array}{l}\text { Currency and deposits / } \\
\text { Other accounts payable }\end{array}$ \\
\hline \multirow[t]{2}{*}{2.3} & \multicolumn{5}{|c|}{$\begin{array}{l}\text { The government social security scheme provides social security benefits to the eligible beneficiaries in accordance } \\
\text { with the conditions of the scheme }\end{array}$} \\
\hline & $\begin{array}{l}\text { Social security scheme benefits } \\
\text { become payable }\end{array}$ & 2711 & $\begin{array}{l}\text { Social security benefits } \\
\text { in cash }\end{array}$ & $3212 / 3318$ & $\begin{array}{l}\text { Currency and deposits / } \\
\text { Other accounts payable }\end{array}$ \\
\hline \multirow[t]{3}{*}{2.4} & The government social security sc & heme provid & soods purchased from & market produ & ers to qualifying beneficiaries \\
\hline & $\begin{array}{l}\text { Social security scheme acquires } \\
\text { the goods }\end{array}$ & 31224 & $\begin{array}{l}\text { Inventories (goods for } \\
\text { resale) }\end{array}$ & $3212 / 3318$ & $\begin{array}{l}\text { Currency and deposits / } \\
\text { Other accounts payable }\end{array}$ \\
\hline & $\begin{array}{l}\text { Social security scheme provides } \\
\text { goods to households }\end{array}$ & 2712 & $\begin{array}{l}\text { Social security benefits } \\
\text { in kind }\end{array}$ & 31224 & $\begin{array}{l}\text { Inventories (goods for } \\
\text { resale) }\end{array}$ \\
\hline \multirow[t]{2}{*}{2.5} & $\begin{array}{l}\text { The government social security s } \\
\text { by market entities to eligible ben }\end{array}$ & $\begin{array}{l}\text { me reimb } \\
\text { ciaries in a }\end{array}$ & $\begin{array}{l}\text { rses market providers o } \\
\text { cordance with the cono }\end{array}$ & $\begin{array}{l}\text { ouseholds } \\
\text { ons of the s }\end{array}$ & $\begin{array}{l}\text { goods and services provided } \\
\text { eme }\end{array}$ \\
\hline & $\begin{array}{l}\text { Social security scheme reimburses } \\
\text { providers or households }\end{array}$ & 2712 & $\begin{array}{l}\text { Social security benefits } \\
\text { in kind }\end{array}$ & $3212 / 3318$ & $\begin{array}{l}\text { Currency and deposits / } \\
\text { Other accounts payable } 1\end{array}$ \\
\hline \multirow[t]{2}{*}{2.6} & $\begin{array}{l}\text { The government social security sc } \\
\text { with the conditions of the scheme }\end{array}$ & ne prod & es and provides goods & vices to & population in accordance \\
\hline & $\begin{array}{l}\text { No social security benefits } \\
\text { are recorded in GFS-the } \\
\text { operational costs incurred in the } \\
\text { production of the goods and } \\
\text { services are recorded as relevant }\end{array}$ & $21,22,23$ & $\begin{array}{l}\text { Compensation of } \\
\text { employees, use of } \\
\text { goods and services, } \\
\text { and consumption of } \\
\text { fixed capital }\end{array}$ & $3212 / 3318$ & $\begin{array}{l}\text { Currency and deposits / } \\
\text { Other accounts payable }{ }^{1}\end{array}$ \\
\hline
\end{tabular}

Note: The net implicit obligation for future social security benefits should be recorded as a memorandum item (see paragraph 7.261).

${ }^{1}$ In a cash reporting environment, the revenue/expense will be recorded at the time of the cash flow. In an accrual reporting environment, an other account receivable/payable should be recorded in cases where the payment is not made when the eligibility criteria have been met. ${ }^{2}$ The flow of inventories will be recorded only in an inventory accounting system. In a cash reporting environment, social benefits in kind will not be recorded. The purchases of goods and services distributed as social benefits in kind will be included in purchases of goods and services (22).

- A separate institutional unit that operates a pension scheme that is therefore regarded as an autonomous pension fund

- A scheme managed by an insurance enterprise on behalf of the employer regarded as a financial corporation.

A2.43 The manner in which the employmentrelated pension scheme is organized determines the recording of the associated transactions. Insurance enterprises and autonomous pension funds are units of the financial corporations sector, while nonautonomous pension funds and unfunded employmentrelated social insurance schemes are units of the general government sector.

\section{Nonautonomous employment-related pension schemes}

A2.44 Nonautonomous social insurance schemes are operated by the employer, and these schemes are usually unfunded schemes because they are organized by the employer without assigning specific accounts or otherwise creating special reserves for the payment of benefits. Instead, the benefits are payable from the employer's general resources.

A2.45 A nonautonomous pension fund for public sector employees does not meet the criteria to be considered an institutional unit, and is therefore deemed to be included in the unit that operates the scheme. This is also the case when the employer has established 
Table A2.3 Illustrative Recording of Flows Related to Employment-Related Pension Schemes
Description
Debit
Credit

3.1 The government makes pension contributions on behalf of its employees to an autonomous pension fund maintained by an insurance company (i.e., it is part of the private financial corporation sector)
Government pays social
2121
Actual employers' social
$3212 / 3318$
Currency and deposits /
contributions as component of
contributions
Other accounts payable ${ }^{1}$

compensation of employees

3.2 The government makes pension contributions on behalf of its employees to an autonomous pension fund set up by government as a separate institutional unit (i.e., it is part of the public financial corporation sector)
Government pays social
2121
Actual employers' social
$3212 / 3318$
contributions
Currency and deposits /
contributions as component of
Other accounts payable ${ }^{1}$

3.3 The government operates a funded nonautonomous pension fund for its employees (i.e., a separate reserve is maintained in the government account but it is not an institutional unit)

\begin{tabular}{|c|c|c|c|c|}
\hline $\begin{array}{l}\text { Government pays social } \\
\text { contributions as component of } \\
\text { compensation of employees }\end{array}$ & 2121 & $\begin{array}{l}\text { Actual employers' social } \\
\text { contributions }\end{array}$ & 3212 / 3318 & $\begin{array}{l}\text { Currency and deposits / } \\
\text { Other accounts payable }{ }^{1}\end{array}$ \\
\hline $\begin{array}{l}\text { Receipts of social contributions by } \\
\text { the pension fund account giving } \\
\text { rise to a liability }\end{array}$ & $3212 / 3218$ & $\begin{array}{l}\text { Currency and deposits / } \\
\text { Other accounts } \\
\text { receivable }^{1}\end{array}$ & 3316 & $\begin{array}{l}\text { Insurance, pension, and } \\
\text { standardized guarantee } \\
\text { schemes }\end{array}$ \\
\hline $\begin{array}{l}\text { Government, as owner of } \\
\text { the pension fund account, } \\
\text { receives property income on the } \\
\text { investments of the pension fund }\end{array}$ & $3212 / 3218$ & $\begin{array}{l}\text { Currency and deposits / } \\
\text { Other accounts } \\
\text { receivable }^{1}\end{array}$ & $1411 / 1412$ & $\begin{array}{l}\text { Interest } \\
\text { Dividends }\end{array}$ \\
\hline $\begin{array}{l}\text { Government attributes the } \\
\text { property income to the policy } \\
\text { holders }^{2}\end{array}$ & 2813 & $\begin{array}{l}\text { Property expense for } \\
\text { investment income } \\
\text { disbursements }\end{array}$ & 3316 & $\begin{array}{l}\text { Insurance, pension, and } \\
\text { standardized guarantee } \\
\text { schemes }\end{array}$ \\
\hline $\begin{array}{l}\text { Government provides pension } \\
\text { benefit payments to eligible } \\
\text { beneficiaries }\end{array}$ & 3316 & $\begin{array}{l}\text { Insurance, pension, and } \\
\text { standardized guarantee } \\
\text { schemes }\end{array}$ & 3212 / 3318 & $\begin{array}{l}\text { Currency and deposits / } \\
\text { Other accounts payable }{ }^{1}\end{array}$ \\
\hline
\end{tabular}

3.4 Government operates an unfunded nonautonomous pension fund for its employees (i.e., there are no actual contributions and no separate reserve is maintained in the government account)

\begin{tabular}{|c|c|c|c|c|}
\hline $\begin{array}{l}\text { Government provides pension } \\
\text { benefit payments to eligible } \\
\text { beneficiaries: cash basis of recording }\end{array}$ & 2731 & $\begin{array}{l}\text { Employment-related } \\
\text { social benefits in cash }\end{array}$ & 3212 & Currency and deposits \\
\hline $\begin{array}{l}\text { Imputed social contributions as } \\
\text { component of compensation } \\
\text { of employees: accrual basis of } \\
\text { recording }\end{array}$ & 2122 & $\begin{array}{l}\text { Imputed employers' } \\
\text { social contributions }\end{array}$ & 3316 & $\begin{array}{l}\text { Insurance, pension, and } \\
\text { standardized guarantee } \\
\text { schemes }\end{array}$ \\
\hline $\begin{array}{l}\text { overnment provides pension benefit } \\
\text { ayments to eligible beneficiaries: } \\
\text { ccrual basis of recording }\end{array}$ & 3316 & $\begin{array}{l}\text { Insurance, pension, and } \\
\text { standardized guarantee } \\
\text { schemes }\end{array}$ & $3212 / 3318$ & $\begin{array}{l}\text { Currency and deposits / } \\
\text { Other accounts payable }\end{array}$ \\
\hline $\begin{array}{l}\text { overnment recognizes the } \\
\text { ncrease in liability for benefit } \\
\text { ntitlements due to time passing }\end{array}$ & 2813 & $\begin{array}{l}\text { Property expense for } \\
\text { investment income } \\
\text { disbursements }\end{array}$ & 3316 & $\begin{array}{l}\text { Insurance, pension, and } \\
\text { standardized guarantee } \\
\text { schemes }\end{array}$ \\
\hline \multicolumn{5}{|c|}{ All defined-benefit schemes can also be subject to other economic flows } \\
\hline $\begin{array}{l}\text { Pension liabilities increase due to } \\
\text { unilateral changes in conditions } \\
\text { of the scheme }\end{array}$ & 5 & $\begin{array}{l}\text { Other changes in the } \\
\text { volume of assets and } \\
\text { liabilities }\end{array}$ & 5316 & $\begin{array}{l}\text { Insurance, pension, and } \\
\text { standardized guarantee } \\
\text { schemes }\end{array}$ \\
\hline $\begin{array}{l}\text { ension liabilities increase due to } \\
\text { hanges in interest rates used to } \\
\text { alculate the present value of the } \\
\text { ability }\end{array}$ & 4 & Holding gains/losses & 4316 & $\begin{array}{l}\text { Insurance, pension, and } \\
\text { standardized guarantee } \\
\text { schemes }\end{array}$ \\
\hline
\end{tabular}

${ }^{1}$ In a cash reporting environment, the revenue/expense will be recorded at the time of the cash flow. In an accrual reporting environment, an other account receivable/payable should be recorded in cases where the payment is not made when the eligibility criteria have been met. ${ }^{2}$ These disbursements will primarily be reinvested in the fund as social contributions, while the portion that will meet the cost of operating the fund should be recorded as the purchases of a financial service from the pension fund. 
segregated reserves, but the organization and operations of the scheme do not meet the criteria to be an institutional unit (see paragraph 2.22). The economic flows and stock positions of nonautonomous employment-related pension funds are integrated with those of the controlling employer. All of the assets, liabilities, transactions, and other economic events of the pension fund are combined with the corresponding items of the employer operating the scheme, which may be a general government unit or a public corporation. The treatment of the assets, liabilities, transactions, and other economic events related to the nonautonomous pension fund is similar to that of an autonomous pension fund. However, in this case, the contributions payable as a component of compensation of employees, the receipt of the contributions by the pension scheme, and the associated liabilities are recorded by the same level of government. These flows are not eliminated in consolidation because households are regarded as, respectively, the recipient and payer. These flows should be rerouted as described in paragraph 3.28.

A2.46 In accordance with the accrual basis of recording, the amount that would be required to cover the accrual of the social benefits must be imputed. This will also ensure that the full cost of employment is accounted for by recording the imputed social contributions, with a counterpart entry that creates the associated liability for these pension benefits. This imputation recognizes the economic flows during the period in which the underlying economic event takes place. It also improves transparency because it records the cost of providing the social benefits to its employees and flags the risks associated with the future demands on resources. When these pension benefits are paid, the payment is recorded as a reduction in liabilities. ${ }^{12}$

\section{Autonomous employment-related pension schemes}

A2.47 To be regarded as autonomous, the entity responsible for the employment-related pension scheme must have the characteristics of an institutional unit (see paragraph 2.22). These institutional units are considered to provide financial services (i.e., insurance/ pensions) to the household sector, and are therefore

${ }^{12}$ When using the cash basis of recording, the only flow recorded for these unfunded pension schemes is the employment-related social benefits expense, with a counterpart entry as a decrease in currency and deposits. The expense is recorded when cash payments are made. classified in the financial corporations sector. They are classified as either private or public financial corporations, depending on whether they are controlled by the private or public sectors (see Box 2.2).

A2.48 An employer may contract with a third party to administer the pension funds for its employees. The employment-related pension scheme is then managed through an insurance enterprise or an autonomous pension fund. The employer's primary responsibility with respect to the scheme is to pay the social contributions on behalf of its employees. The government unit records the payment as part of compensation of employees, under actual social contributions (see Table 6.1 and paragraph 6.21). No other transactions are recorded by the government unit as employer, as it has no direct liability for future provision of social benefits.

A2.49 However, in cases where the employer continues to determine the terms of the pension schemes and retains the responsibility for any deficit in funding, as well as the right to retain any excess funding, the employer is described as the pension manager and the unit working under the direction of the pension manager is described as the pension administrator. If the agreement between the employer and the third party is such that the employer passes the risks and responsibilities for any deficit in funding to the third party in return for the right of the third party to retain any excess, the third party becomes the pension manager as well as the administrator.

A2.50 When the pension manager is a unit different from the administrator, and the responsibility for any deficit, or claims on any excess, rests with the pension manager, the claim of the pension fund on the pension manager should be shown under the liability, claims of pension funds on pension managers (63064). By contrast, if the pension fund makes more investment income from the pension entitlements it holds than necessary to cover the increase in entitlements, the difference is payable to the pension manager of the scheme. The pension manager records this claim on the pension administrator as a financial asset, claims of pension funds on pension managers (62064). ${ }^{13}$

\footnotetext{
${ }^{13}$ Although this financial asset effectively represents a claim of the pension manager on the pension fund, the same line item title is used for both the asset and liability accounts.
} 
A2.51 If government controls the financial corporation that manages the employment-related pension scheme for government employees, the corporation will be part of the public financial sector, and the relevant flows and stock positions would be recorded when compiling GFS for the public sector. The receipt of social contributions by this insurance enterprise or pension fund gives rise to a liability, classified in the financial instrument insurance, pensions, and standardized guarantee schemes (6306), and more specifically in pension entitlements (63063). The liability originates from the obligation to pay future pension benefits-any subsequent payment of the benefits will be recorded as a reduction in this liability. Although the social contributions are payable directly by the employer to the financial corporation, they are recorded in GFS as if payable by the employer to households as compensation of employees: households in turn pay the contributions to the financial corporation. Because of this rerouting, these transactions should not be eliminated in consolidation of the public sector (see paragraph 3.28).

A2.52 For the financial corporation, revenue from the investment of the financial reserves should be classified as the relevant category of property income. However, since these resources are considered to give rise to an asset of the policyholders, such income should be attributed to policyholders. An expense is recorded, classified as property expense for investment income disbursements (2813), with a counterpart entry that increases the liability to reflect the policyholders' increase in claims for pension entitlements.

A2.53 Autonomous employment-related pension schemes can be organized as a defined-benefit pension scheme or a defined-contribution pension scheme.

\section{Defined-benefit pension schemes}

A2.54 A defined-benefit pension scheme is one where the benefits payable to an employee on retirement are determined by the use of a formula, either alone or as a minimum amount payable. The level of benefits promised to participating employees is determined by a formula embodied in the terms of the social insurance scheme. These terms are usually based on factors such as the participants' length of service and salary. ${ }^{14}$ The calculation of imputed contributions and net present value of future benefits requires advanced actuarial techniques, beyond the responsibility of GFS compilers. The present value of future benefit entitlements increases each period because there is one fewer period over which it is discounted. This increase should be a transaction in property expense for investment income disbursements (2813) (see paragraph 6.113). Furthermore, a holding gain should be recorded with respect to the liability in order to reflect any change in the value of the liability because of a change in the interest rate used to discount the future benefits. A change in the liability resulting from a change in the benefit structure should always be treated as an other volume change, because it does not constitute a transaction but represents a unilateral change brought about by the employer.

\section{Defined-contribution pension schemes}

\section{A2.55 A defined-contribution pension scheme} is one where the benefits payable to an employee on retirement are defined exclusively in terms of the level of the funds built up from the contributions made over the employee's working life and the increases in value that result from the investment of these funds by the manager of the scheme. The risk of the scheme to provide an adequate retirement income is thus borne by the employee, and the benefits that will be payable depend on the assets of the fund. ${ }^{15}$ For a definedcontribution pension scheme, a pension fund is always deemed to exist.

A2.56 Contributions to a defined-contribution pension scheme are invested on behalf of the employees as future beneficiaries. The investment income on the cumulated assets of the pension fund is recorded as revenue for the fund, classified according to the nature of the respective property income revenue (usually including interest (1411), dividends (1412), or

\footnotetext{
${ }^{14}$ There are four sources of changes in pension entitlements in a defined-benefit pension scheme: (i) the current service increaseit is the increase in entitlement associated with the wages and salaries earned in the current period; (ii) the past service increase-it is the increase in the value of the entitlement due to the fact that for all participants in the scheme, retirement (and death) is one year nearer; (iii) a decrease due to the payment of benefits to retirees of the scheme; and (iv) other factors-that is, factors that are related to other changes in the volume of assets. ${ }^{15}$ Defined-contribution schemes are also referred to as moneypurchase schemes.
} 
rent (1415)). The investment income is also recorded as being distributed to the beneficiaries (classified as property expense for investment income disbursements (2813)), who are deemed to reinvest the income in the pension fund as contributions. Therefore, the investment income payable on defined-contribution entitlements is equal to the investment income on the financial investments plus any net operating surplus earned by renting land or buildings owned by the fund.

A2.57 The value of the pension entitlement liability of a defined-contribution pension scheme is the market value of the financial assets held by the pension fund on behalf of the future beneficiaries. Any changes in the market value of these investments of the pension fund would include holding gains and losses. These holding gains and losses should be recorded as changes in the value of the relevant assets of the institutional unit administering the pension fund. In addition, these holding gains or losses should also be attributed to the policyholders. Therefore, a matching entry for the holding gain or losses in the liability of the pension fund toward households should be recorded.

A2.58 For a defined-contribution pension scheme, the risks and costs associated with the scheme are borne by the beneficiaries. There are no imputed contributions for defined-contribution pension schemes, unless the employer operates the scheme directly. In that case, the value of the costs of operating the scheme is treated as an imputed contribution payable to the employee as part of compensation of employees. This amount is recorded by the employer as the sale of a financial service to the employees, classified as imputed sales of goods and services (1424) (see paragraph 5.140). When the fund is operated by a unit other than the employer, the operating costs are financed from investment income retained by the fund to meet its costs and generate a profit. Therefore, in keeping with the recording of insurance, the investment income generated is treated as being attributed in full to the beneficiaries in the household sector who use part of the income to purchase a financial service from the fund, and reinvest the remainder with the fund.

A2.59 As indicated in paragraphs A2.3 and A2.21, defined-contribution schemes are similar to life insur- ance schemes. ${ }^{16}$ However, a scheme that may be defined in terms similar to a defined-contribution scheme, but with a guaranteed minimum benefit specified, or other hybrid schemes, should be treated as defined-benefit pension schemes in macroeconomic statistics.

\section{Government assumption of employment- related pension obligations of other institutional units}

A2.60 On occasion, large one-off transactions (lump-sum transactions) may occur between a government and another institutional unit, often a public corporation, linked to pension reforms or to privatization of the public corporations. The goal may be to make the corporation competitive, or financially more attractive, by removing existing pension liabilities from its balance sheet. This goal is achieved by government assuming the liability in exchange for an asset or assets from the other institutional unit. When the value of the asset(s) receivable is the same as the value of the liability assumed, the transaction is recorded as a transaction in financial assets and liabilities for both units involved.

A2.61 However, if the value of the asset(s) receivable by government is less than the value of the liability assumed, an expense in the form of a capital transfer from government to the corporation is recorded for the difference. The assumer (government) records an increase in liabilities for pension entitlements, an increase in the relevant financial and/or nonfinancial assets, and an expense in the form of capital transfer to the corporation (see paragraph 6.91). The corporation records a decrease in liabilities for pension entitlements, a decrease in financial and/or nonfinancial assets, and revenue in the form of a capital transfer from government.

A2.62 If the value of the asset(s) receivable is more than the value of the liability incurred, a capital transfer receivable from the corporation to the government is recorded for the difference (see paragraph 5.148). The corporation records a decrease in liabilities for pension entitlements, a decrease in financial and/or nonfinancial assets, and an expense in the form of a capital transfer to government.

\footnotetext{
${ }^{16}$ The treatment of the flows and stock positions of these schemes is similar to the treatment of compulsory savings schemes.
} 
A2.63 Even if the arrangement transforms the pension liability, so that it is to be administered as part of a social security fund, the initial assumption of the pension obligation should be recorded as in the foregoing paragraphs. The pension obligations absorbed by the social security fund continue to be classified as pension entitlement liabilities. These obligations are gradually extinguished as the benefits are paid out.

\section{Employment-related nonpension social insurance schemes}

A2.64 Employment-related nonpension social insurance schemes can be operated by the government or by autonomous nongovernment entities. In either case, the actual or imputed employers' contributions are included as an expense in the compensation of employees, under social contributions. For funded schemes, the actual contributions made to the scheme are classified under actual employers' social contributions. For unfunded schemes, the amount that would be required to purchase equivalent social benefits must be imputed by the employer, and should be classified under imputed employers' social contributions. Where a scheme is operated by the government, a simultaneous transaction equal to the actual or imputed social contributions is recorded as revenue from the household sector back to government, and classified under other social contributions by employees. The social benefits provided by the government are classified as an expense under employment-related social benefits. Table A2.4 illustrates the recording of some of these flows of employmentrelated nonpension social insurance schemes.

A2.65 Some employers provide nonpension social benefits directly to their employees, former employees, or dependents without involving an insurance enterprise or autonomous pension fund, and with- out creating a special fund or segregated reserve for the purpose. Employees may be considered as being protected against various specified social risks, even though no reserves are built up to provide for future entitlement to social security benefits. An expense for employers' social contributions should therefore be imputed for such employees (see paragraph 6.22), equal in value to the amount of social contributions revenue needed to obtain the de facto entitlements to the accrued social benefits. These amounts take into account any actual contributions made by the employer or employee. The amounts depend not only on the levels of the benefits currently payable but also on the impact on future employer's liabilities of demographic and actuarial factors, such as expected changes in the numbers, age distribution, and life expectancies of their present and previous employees. Therefore, the values that should be imputed for the contributions ought, in principle, to be based on the same kind of actuarial considerations that determine the levels of premiums charged by insurance enterprises.

A2.66 In practice, however, it may be difficult to estimate such imputed contributions. The government unit may make estimates itself, perhaps on the basis of the contributions payable into similar funded schemes, in order to calculate its likely liabilities in the future. Otherwise, the only practical alternative may be to use the unfunded nonpension benefits payable by government during the same reporting period as an estimate of the imputed remuneration that would be needed to cover the imputed contributions. This is a second best option as the value of the imputed contributions may diverge from the unfunded nonpension benefits actually paid in the same period, due to factors such as the changing composition and age structure of the government labor force. 


\section{Table A2.4 Illustrative Recording of Flows Related to Employment-Related Nonpension Social} Insurance Schemes

\section{Description}

Debit

Credit

4.1 Social insurance contributions receivable from employers and employees Social insurance contributions 3212 / 3218 Currency and deposits / receivable from employees Social insurance contributions receivable from employers Other accounts receivable ${ }^{1}$ Currency and deposits / 1222 Other accounts receivable ${ }^{1}$

Other social contributions: Employee contributions Other social contributions: Employer contributions

4.2 The government as employer makes contributions to social insurance schemes on behalf of its employees
Government contributions as 2121
Actual employers' social
$3212 / 3318$
Currency and deposits / employer becomes payable contributions Other accounts payable ${ }^{1}$

4.3 Government as employer imputes contributions to the social insurance scheme where no or insufficient contributions to obtain entitlement to benefits were made
Imputed contributions
2122
Imputed employers' social
contributions
1223
Imputed contributions

4.4 Employer social insurance scheme provides benefits to government employees

\begin{tabular}{|c|c|c|c|c|}
\hline $\begin{array}{l}\text { mployer social insurance } \\
\text { cheme pays benefits in cash }\end{array}$ & 27 & $\begin{array}{l}\text { Employment-related social } \\
\text { benefits in cash }\end{array}$ & 32 & $\begin{array}{l}\text { Currency and deposits / } \\
\text { Other accounts payable }\end{array}$ \\
\hline
\end{tabular}

4.5 Employer social insurance scheme provides goods purchased from market producers to employees in accordance with the conditions of the scheme
Employer social insurance
31224
Inventories (goods for resale) $)^{2}$
Employer social insurance
2732
Employment-related social
$3212 / 3318$
Currency and deposits /
benefits in kind Other accounts payable ${ }^{1}$ Inventories (goods for resale) ${ }^{2}$ households

4.6 Employer social insurance scheme reimburses market providers or households for goods and services provided by market entities in accordance with the conditions of the scheme
Employer social insurance
2732
Employment-related social
$3212 / 3318$
Currency and deposits / scheme reimburses providers benefits in kind Other accounts payable ${ }^{1}$ or households

4.7 Government produces and provides goods or services to their employees in accordance with an employer's social insurance scheme

\begin{tabular}{l|l|l|l|}
\hline $\begin{array}{l}\text { No employer social insurance } \\
\text { benefits are recorded in } \\
\text { GFS-the operational costs }\end{array}$ & $21,22,23$ & $\begin{array}{l}\text { Compensation of } \\
\text { employees, use of } \\
\text { incurred in the production } \\
\text { of the goods and services are } \\
\text { recorded as relevant }\end{array}$ & $\begin{array}{l}\text { goods and services, and } \\
\text { consumption of fixed } \\
\text { capital }\end{array}$ \\
\hline
\end{tabular}

Note: The net implicit obligation for future social security benefits should be recorded as a memorandum item (see paragraph 7.261).

${ }^{1}$ In a cash reporting environment, the revenue/expense will be recorded at the time of the cash flow. In an accrual reporting environment, an other account receivable/payable should be recorded in cases where the payment is not made when the eligibility criteria have been met.

${ }^{2}$ The flow of inventories will be recorded only in an inventory accounting system. 
- 00000

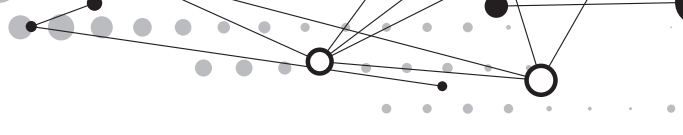

\section{Debt and Related Operations}

This appendix provides guidance on selected issues that may arise in the recording of flows and stock positions related to public sector debt.

\section{Introduction}

A3.1 In the recording of debt ${ }^{1}$ of the general government or public sectors, complex methodological issues can arise with regard to flows (i.e., transactions and other economic flows) and stock positions associated with the debt liabilities. Some of the most common issues are discussed in detail, with examples of their treatment, in Chapter 4 of the PSDS Guide. This appendix provides a summary of the same issues and their treatment.

\section{Debt Reorganization}

A3.2 Debt reorganization (also referred to as debt restructuring) is defined as an arrangement involving both the creditor and the debtor (and sometimes third parties) that alters the terms established for servicing an existing debt. Governments are often involved in debt reorganization, as debtor, creditor, or guarantor.

A3.3 Debt reorganization usually involves relief for the debtor from the original terms and conditions of debt obligations. This may be in response to liquidity constraints, where the debtor does not have the cash to meet debt service payments due, or sustainability issues, where the debtor is unlikely to be able to meet its debt obligations in the medium term.

A3.4 A failure by a debtor to honor its debt obligations (e.g., default) does not constitute debt reorganization because it does not involve an arrangement between the creditor and the debtor. Similarly, a creditor can reduce the value of its debt claims on the debtor in its own accounts through debt writeoffs-unilateral actions that arise, for example, when the creditor regards a claim as unrecover-

\footnotetext{
${ }^{1}$ Gross debt and net debt are defined in paragraphs 7.236-7.245.
}

able, perhaps because of bankruptcy of the debtor, and, as a result, no longer carries the claim on its balance sheet. Again, this is not considered debt reorganization.

A3.5 The four main types of debt reorganization are:

- Debt forgiveness, which is a reduction in the amount of, or the extinguishing of, a debt obligation by the creditor via a contractual arrangement with the debtor.

- Debt rescheduling or refinancing (or debt exchange), which is a change in the terms and conditions of the amount owed, which may result in a reduction in debt burden in present value terms.

- Debt conversion and debt prepayment (or debt buybacks for cash), where the creditor exchanges the debt claim for something of economic value, other than another debt claim, on the same debtor; examples of debt conversion are debt-forequity swaps, debt-for-real-estate swaps, debtfor-development swaps, and debt-for-nature swaps. $^{2}$

- Debt assumption when a third party is also involved.

A3.6 A debt reorganization package may involve more than one of the types just mentioned; for example, most debt reorganization packages involving debt forgiveness also result in a rescheduling of the part of the debt that is not forgiven or cancelled.

\section{Debt Forgiveness}

A3.7 Debt forgiveness (or debt cancellation) is defined as the voluntary cancellation of all or part of a

\footnotetext{
${ }^{2}$ Some agreements described as debt swaps are equivalent to debt forgiveness from the creditor together with a commitment from the debtor country to undertake a number of development, environmental, etc., expenses. These transactions should be considered under debt forgiveness, as counterpart funds are not provided to the creditor.
} 
debt obligation within a contractual arrangement between a creditor and a debtor. With debt forgiveness, there is a mutual agreement between the parties involved and an intention to convey a benefit. In contrast, with debt write-off, there is no such agreement or intention-it is a unilateral recognition by the creditor that the amount is unlikely to be collected (see paragraphs A3.32-A3.34). ${ }^{3}$ Debt forgiven may include all or part of the principal outstanding, inclusive of any accrued interest arrears (interest that fell due for payment in the past) and any other interest costs that have accrued. Debt forgiveness includes forgiveness of some, or all, of the principal amount of a credit-linked note arising from an event affecting the entity on which the embedded credit derivative was written. Also included is forgiveness of principal that arises when the debt contract stipulates that the debt will be forgiven if a specified event occurs, such as forgiveness in the case of a type of catastrophe. Debt forgiveness does not arise from the cancellation of future interest payments that have not yet fallen due and have not yet accrued.

A3.8 Debt forgiveness is always recorded as a capital grant or transfer from the creditor to the debtor, which extinguishes the financial claim and the corresponding debt liability. A government or public sector unit may be involved in debt forgiveness as a creditor or a debtor. Market prices are the basis for valuing debt forgiveness, except for loans, where nominal value is used.

A3.9 Although no transactions are recorded for debt forgiveness under the cash basis of recording, the stock positions relating to the debt liability and the corresponding financial asset would reflect the debt forgiveness.

\section{Debt Rescheduling and Refinancing}

A3.10 Debt rescheduling and refinancing involve a change in an existing debt contract and its replacement by a new debt contract, generally with extended debt service payments. ${ }^{4}$ Debt rescheduling involves rearrangements on the same type of instrument, with

\footnotetext{
${ }^{3}$ Debt forgiveness is unlikely to arise between commercial entities.

${ }^{4}$ If the original terms of the contract provide that the maturity or interest rate terms, or both, change as a result of, for example, a default or decline in credit rating, then this involves a reclassification. In practice, these reclassification entries cancel out within
}

the same principal value and the same creditor as with the old debt. Debt refinancing entails a different debt instrument, generally at a different value, and possibly with a different creditor. ${ }^{5}$ For example, a creditor may choose to apply the terms of a Paris Club (see PSDSG, paragraphs 10.125-10.134) agreement either through a debt rescheduling option (changing the terms and conditions of its existing claims on the debtor) or through refinancing (making a new loan to the debtor that is used to repay the existing debt).

\section{Debt rescheduling}

A3.11 Debt rescheduling is a bilateral arrangement between the debtor and the creditor that constitutes a formal postponement of debt service payments and the application of new and generally extended maturities. The new terms normally include one or more of the following elements: extending repayment periods, reductions in the contracted interest rate, adding or extending grace periods for the payment of interest and principal, fixing the exchange rate at favorable levels for foreign currency debt, and rescheduling the payment of arrears, if any. In the specific case of zerocoupon securities, a reduction in the principal amount to be paid at redemption to an amount that still exceeds the principal amount outstanding at the time the arrangement becomes effective could be classified as either an effective change in the contractual rate of interest or a reduction in principal with the contractual rate unchanged. Such a reduction in the principal payment to be made at maturity should be recorded as debt forgiveness, or debt rescheduling if the bilateral agreement explicitly acknowledges a change in the contractual rate of interest. Paris Club creditors provide debt relief to debtor countries in the form of rescheduling, which is debt relief by postponement or, in the case of concessional rescheduling, reduction in debt service obligations during a defined period (flow treatment) or as of a set date (stock treatment).

\footnotetext{
the same instrument category unless the original and new terms have a different principal, different instrument classification, or different maturity classification. In contrast, if the original terms of a debt (typically a loan or debt security, but also other debt instruments) are changed through renegotiation by the parties, this is treated as transactions in the repayment of the original debt and the creation of a new debt liability.

${ }^{5}$ From the debtor perspective, debt refinancing may involve borrowing from a third party to repay a creditor. The definition of debt refinancing used here is a narrower concept reflecting transactions between the debtor and same creditor only.
} 
A3.12 With debt rescheduling, the applicable existing debt is recorded as being repaid and a new debt instrument (or instruments) created with new terms and conditions. This treatment does not apply, however, to interest arrears that are rescheduled when the conditions in the existing debt contract remain unchanged. In such a case, the existing debt contract is not considered as rescheduled, only the interest arrears. A new debt instrument is recorded for the rescheduled interest arrears.

A3.13 The debt rescheduling transaction is recorded at the time agreed to by both parties (the contractually agreed time), and at the value of the new debt (which, under a debt rescheduling, is the same value as that of the old debt). If no date is set, the time at which the creditor records the change of terms is decisive. If the rescheduling of obligations due beyond the current period is linked to the fulfillment of certain conditions, when the obligations fall due (such as multiyear Paris Club rescheduling), entries are recorded only in the period when the specified conditions are met.

\section{Debt refinancing}

A3.14 Debt refinancing involves the replacement of an existing debt instrument or instruments, including any arrears, with a new debt instrument or instruments. It can involve the exchange of the same type of debt instrument (such as a loan for a loan) or different types of debt instruments (such as a loan for a bond). For example, a public sector unit may convert various export credit debts into a single loan, or exchange existing bonds for new bonds through exchange offers given by its creditor (rather than a change in terms and conditions).

A3.15 The treatment of debt refinancing transactions is similar to debt rescheduling. The debt being refinanced is extinguished and replaced with a new financial instrument, or instruments. The old debt is extinguished at the value of the new debt instrument, except for nonmarketable debt (e.g., a loan) owed to official creditors.

A3.16 If the refinancing involves a direct debt exchange, such as a loan-for-bond swap, the debtor records a reduction in liabilities under the appropriate debt instrument and an increase in liabilities to show the creation of the new obligation. The transaction is recorded at the value of the new debt (reflecting the current market value of the debt), and the difference between the value of the old and new debt instruments is recorded as a holding gain or loss. However, if the debt is owed to official creditors and is nonmarketable, the old debt is extinguished at its original value with the difference in value with the new instrument recorded as debt forgiveness (see paragraphs A3.7A3.9). Where there is no established market price for the new bond, an appropriate proxy is used. For example, if the bond is similar to other bonds being traded, the market price of a traded bond would be an appropriate proxy for the value of the new bond. If the debt being swapped was recently acquired by the creditor, the acquisition price would be an appropriate proxy. Alternatively, if the interest rate on the new bond is below the prevailing interest rate, the discounted value of the bond, using the prevailing interest rate, could serve as a proxy. If such information is not available, the face value of the bond being issued may be used as a proxy. See also debt-for-equity conversion in paragraph A3.21).

A3.17 The balance sheet reflects the changes in the stock positions as a result of the transactions extinguishing the old debt instrument and creating the new debt instrument along with any valuation changes. For example, a loan-for-bond exchange will generally result in a reduction in the liabilities of the debtor (reduction in the claim of the creditor on the debtor) because the loan is recorded at nominal value, while the bond is recorded at market value, which may be lower.

A3.18 If the proceeds from the new debt are used to partially pay off the old (existing) debt, the remaining old debt is recorded being extinguished and a new debt instrument is created (equal to the value of the remaining old debt extinguished), unless the old debt is paid off through a separate transaction.

A3.19 If the terms of any new borrowings are concessional, the creditor could be seen as providing a transfer to the debtor. Debt concessionality is discussed in paragraphs A3.39-A3.41.

\section{Debt Conversion and Debt Prepayment Debt conversion}

A3.20 Debt conversion (swap) is an exchange of debt-typically at a discount-for a nondebt claim (such as equity), or for counterpart funds that can be used to finance a particular project or policy. In essence, public sector debt is extinguished and a nondebt liability created in a debt conversion. 
A3.21 A common example of debt conversion is debt-for-equity swaps. ${ }^{6}$ Determining the value of the equity may be difficult if the equity is not actively traded on a market, as is likely to be the case if the unit that issued the equity is a controlled public corporation. If the equity is not traded, its valuation should be based on one of the methods set out in paragraph 7.173.

A3.22 Further examples of debt conversions are other types of debt swaps (such as external debt obligations for exports or "debt-for-exports") or debt obligations for counterpart assets that are provided by the debtor to the creditor for the creditor to use for a specified purpose, such as wildlife protection, health, education, and environmental conservation (debt-for-sustainable-development).

A3.23 Direct and indirect debt conversions should be distinguished. A direct swap leads directly to the acquisition of a nondebt claim on the debtor (such as a debt-for-equity swap). An indirect debt conversion involves another claim on the economy, such as a deposit, that is subsequently used to purchase equity.

\section{Debt prepayment}

A3.24 Debt prepayment consists of a repurchase, or early payment, of debt at conditions that are agreed between the debtor and the creditor. The debt is extinguished in return for a cash payment agreed between the debtor and the creditor. The transaction is recorded at the value of the debt prepaid. Debt prepayment could be driven by the debtor's need to reduce the cost of its debt portfolio by taking advantage of favorable economic performance or market conditions to repurchase debt.

A3.25 If the debt is owed to official creditors and is nonmarketable (e.g., a loan), an element of debt forgiveness could be involved (i.e., if the prepayment occurs within an agreement between the parties with an intention to convey a benefit). As explained in the section on debt forgiveness (see paragraph A3.8), a capital transfer or capital grant from the creditor to the debtor is recorded for debt forgiveness, which reduces the value of the outstanding liability/claim.

${ }^{6}$ Often, a third party is involved in a debt-for-equity swap, buying the claims from the creditor and receiving equity in a public corporation (the debtor).

\section{Debt Assumption and Debt Payments on Behalf of Others}

\section{Debt assumption}

A3.26 Debt assumption is a trilateral agreement between a creditor, a former debtor, and a new debtor (typically a government unit), under which the new debtor assumes the former debtor's outstanding liability to the creditor, and is liable for repayment of debt. Calling a guarantee is an example of debt assumption. If the original debtor defaults on its debt obligations, the creditor may invoke the contract conditions permitting the guarantee from the guarantor to be called. The guarantor unit must either repay the debt or assume responsibility for the debt as the primary debtor (i.e., the liability of the original debtor is extinguished). A public sector unit can be the debtor that is defaulting or the guarantor. A government can also, through agreement, offer to provide funds to pay off the debt obligation of another government unit owed to a third party. ${ }^{7}$

A3.27 The statistical treatment of debt assumption depends on (i) whether the new debtor acquires an effective financial claim on the original debtor, and (ii) if there is no effective financial claim, the relationship between the new debtor and the original debtor and whether the original debtor is bankrupt or no longer a going concern. ${ }^{8}$ This implies three possibilities (see Figure A3.1):

- The debt assumer (new debtor) acquires an effective financial claim on the original debtor. The debt assumer records an increase in debt liabilities to the original creditor, and an increase in financial assets, such as in the form of loans, with the original debtor as the counterparty. The original debtor records a decrease in the original debt liability to the creditor and an increase in liabilities, such as in the form of a loan, to the debt assumer. The value of the debt assumer's claim on the original debtor is the present value

\footnotetext{
${ }^{7}$ For example, a central government unit offering to provide funds to pay off the debt of a local government unit owed to a bank.

${ }^{8}$ An "effective financial claim" is understood to be a claim that is supported by a contract between the new debtor and the original debtor, or (especially in the case of governments) an agreement, with a reasonable expectation to be honored, that the original debtor will reimburse the new debtor. A "going concern" is understood to be an entity in business, or operating for the foreseeable future.
} 


\section{Figure A3.1 Decision Tree for the Statistical Treatment of Debt Assumption}

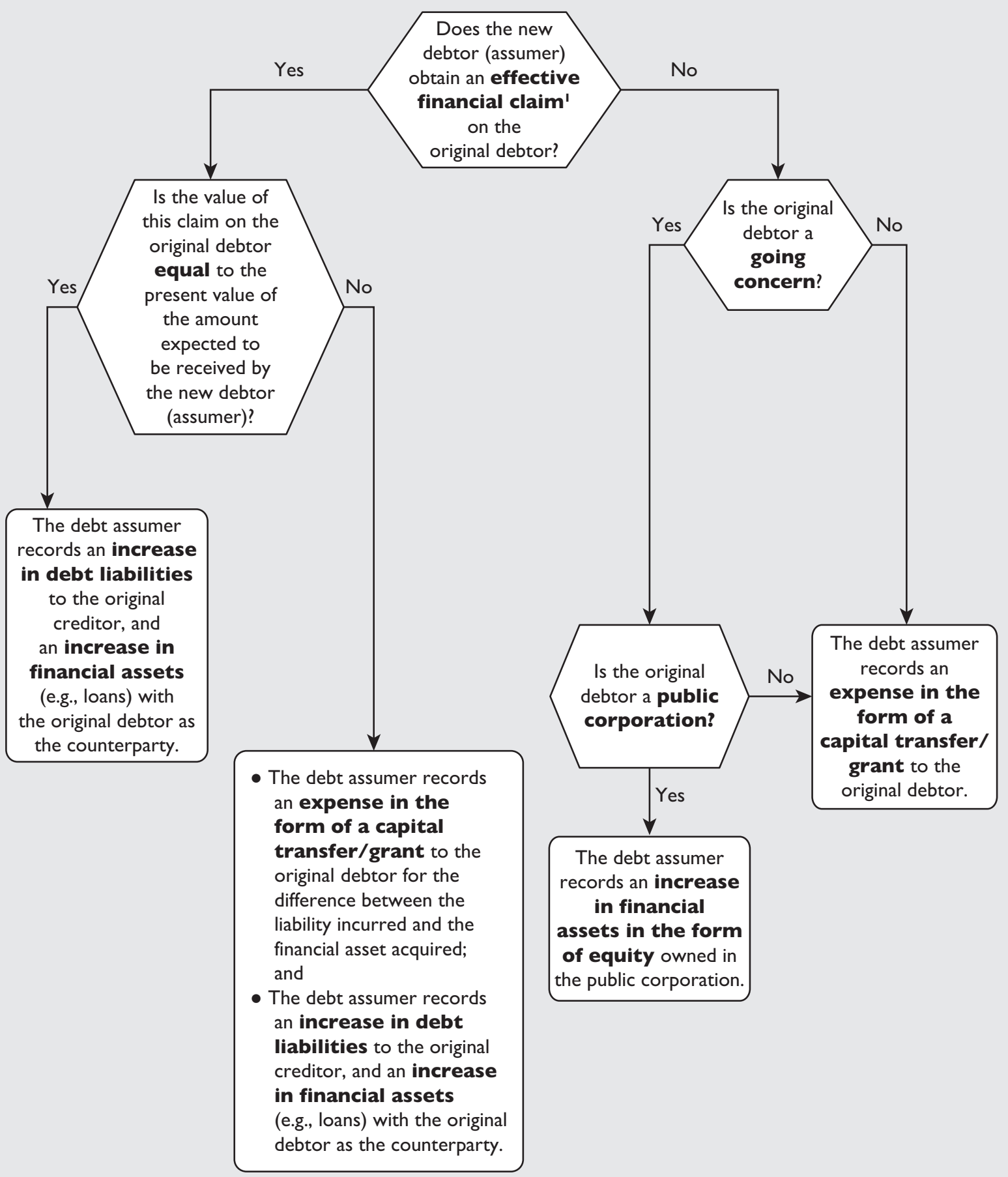

${ }^{1}$ An "effective financial claim" is understood to be a claim that is supported by a contract between the new debtor and the original debtor, or (especially in the case of governments) an agreement, with a reasonable expectation to be honored, that the original debtor will reimburse the new debtor. 
of the amount expected to be received by the assumer. If this amount is equal to the liability assumed, no further entries are required.

If the amount expected to be recovered is less than the liability assumed, the debt assumer records an expense in the form of capital transfer/grant to the original debtor for the difference between the liability incurred and the financial asset acquired in the form of loans. For the debt assumer, gross debt increases by the amount of debt assumed.

- The debt assumer (new debtor) does not acquire an effective financial claim on the original debtor. This may be the case when the original debtor is bankrupt or no longer a going concern, or when the debt assumer seeks to convey a benefit to the original debtor. The debt assumer records an expense in the form of a capital transfer/grant to the original debtor, and an increase in debt liabilities to the original creditor. The original debtor records revenue in the form of a capital transfer/grant, which extinguishes the debt liability on its balance sheet.

The exception to this case is when the original debtor is a public corporation that continues to be a going concern, which is discussed next.

- The debt assumer (new debtor) does not acquire an effective financial claim and the original debtor is a public corporation that continues to be a going concern. The debt assumption amounts to an increase in the equity owned by the debt assumer in the public corporation (original debtor). The debt assumer records an increase in debt liabilities to the original creditor, and an increase in financial assets in the form of equity and investment fund shares. The public corporation records a decrease in the debt liability to the original creditor, and an increase in nondebt liabilities in the form of equity and investment funds shares.

A3.28 A special case is where debt assumption involves the transfer of nonfinancial assets (such as fixed assets or land) from, for example, a public corporation (original debtor) to the debt assumer (new debtor). In this case, the debt assumer records an increase in debt liabilities to the original creditor and the acquisition of a nonfinancial asset(s). If the market value of the nonfinancial asset(s) is equal to the value of the liability assumed, no further entries are required. A capital transfer/grant between the debt assumer and original debtor is recorded for any difference between the value of the liability assumed and the market value of the nonfinancial assets.

A3.29 Although no transactions are recorded for debt assumption under the cash basis of recording, the stock positions would change due to the debt assumption. Any subsequent payments in cash relating to the assumed debt would be recorded as interest, and/or transactions in financial assets other than cash and liabilities, as relevant.

\section{Debt payments on behalf of others}

A3.30 Rather than assuming a debt, a public sector unit may decide to repay that debt or make a specific payment on behalf of another institutional unit (original debtor), without a guarantee being called or the debt being taken over. In this case, the debt stays recorded solely on the balance sheet of the other institutional unit, the only legal debtor. While this activity is similar to debt assumption, as the existing debt remains with unaltered terms, debt payment on behalf of others is not considered debt reorganization. Such a situation may occur where a debtor is experiencing temporary liquidity difficulties rather than permanent solvency problems. ${ }^{9}$

A3.31 The treatment of debt payments on behalf of others depends on whether the public sector unit paying the debt acquires an effective financial claim on the debtor.

- If the paying unit obtains an effective financial claim on the original debtor, the paying unit records an increase in financial assets (e.g., loans) and a decrease in currency and deposits. The recipient (debtor) records a decrease in the original debt liability and an increase in another liability-which may be debt or nondebt-to the paying unit. If the claim of the paying unit on the debtor is in the form of a debt instrument, gross debt and net debt of the paying unit and recipient (debtor) do not change. However, if the claim of the paying unit on the debtor is in the form of a nondebt instrument-for example, equity:

- For the paying unit, gross debt remains unchanged, but net debt increases (due to the

\footnotetext{
${ }^{9}$ Debt payments on behalf of others are different from the case where debt may be considered to be assumed at inception when a guarantee has a very high likelihood to be called, as described in paragraph 7.258.
} 
reduction in its financial assets in the form of currency and deposits).

- For the recipient (debtor), gross debt and net debt decrease (due to the reduction in the debt liability).

- If the paying unit does not obtain an effective financial claim on the original debtor, the paying unit records an expense in the form of a capital transfer-classified according to the nature of the recipient-and a decrease in financial assets in the form of currency and deposits. The receiving unit (debtor) records a revenue in the form of a capital transfer-classified according to the nature of the paying unit-and a decrease in the original debt liability.

\section{Other Debt-Related Issues}

\section{Debt Write-Offs and Write-Downs}

A3.32 Debt write-offs or write-downs refer to unilateral reductions by a creditor of the amount owed to it. This usually occurs when a creditor concludes that a debt obligation has no value or a reduced value because part or all of the debt is not going to be repaid (frequently because the debtor is insolvent). For example, a public corporation that borrowed from the general government unit may be insolvent. As a result, the general government unit's claim loses some, or all, of its value and is written down or written off on the balance sheet of the government unit (creditor). ${ }^{10}$ In contrast, a unilateral write-off by a debtor, or debt repudiation, is not recognized in the macroeconomic statistical systems.

A3.33 Unlike debt forgiveness (see paragraphs A3.7-A3.9), which is a mutual agreement and, therefore, a transaction, a debt write-off or write-down is a unilateral action and, therefore, recorded as other changes in the volume of assets. The financial asset is removed from the balance sheet of the creditor and the corresponding liability should be removed from the balance sheet of the debtor, also through other changes in the volume of assets, to maintain consistency in the macroeconomic statistics. ${ }^{11}$

\footnotetext{
${ }^{10}$ If a bankruptcy still allows some of the debt to be settled, it is possible that the creditor writes off only a part of the claim.

${ }^{11}$ Provisions by the creditor for bad debts or expected losses (sometimes referred to as "write-down") are not recorded in macroeconomic statistics.
}

A3.34 Although no transactions are recorded for a debt write-off or write-down under the cash basis of recording, the stock positions relating to these operations would be reduced, reflecting the debt write-off or write-down.

\section{New Money Facilities}

A3.35 In some arrangements that assist the debtor to overcome temporary financing difficulties, new money facilities are agreed with the creditor to repay maturing debt obligations. The two debt instruments involved-the maturing debt obligation and the new money facility-are treated separately.

A3.36 The creditor records a reduction in the original claim on the debtor and an increase in a new claim on the debtor. Similarly, the debtor records a reduction in the original liability to the creditor and an increase in a new liability to the creditor. If the terms of the new borrowings are concessional, the creditor could be seen as providing a transfer to the debtor. (Debt concessionality is discussed in paragraphs A3.39-A3.41.)

\section{Debt Defeasance}

A3.37 With defeasance, a debtor unit removes liabilities from its balance sheet by pairing them with financial assets, the income and value of which are sufficient to ensure that all debt-service payments are met. Defeasance may be carried out by placing the assets and liabilities in a separate account within the institutional unit concerned or by transferring them to another unit. In either case, the macroeconomic statistical systems do not recognize defeasance as affecting the outstanding debt of the debtor. Thus, no transactions with respect to defeasance are recorded in the GFS framework, as long as there has been no change in the legal obligations of the debtor. When the assets and liabilities are transferred to a separate account within the unit, both assets and liabilities should be reported on a gross basis. If a separate entity resident in the same economy is created to hold the assets and liabilities, that new unit should be treated as an ancillary entity and consolidated with the defeasing unit.

A3.38 The sectorization of restructuring agencies (also referred to as "defeasance structures") is discussed in paragraphs 2.129-2.131. 


\section{Debt Concessionality}

A3.39 There is no consistent definition or measure of debt concessionality in macroeconomic statistics. However, it is generally accepted that concessional loans occur when units lend to other units and the contractual interest rate is intentionally set below the market interest rate that would otherwise apply. The degree of concessionality can be enhanced with grace periods, ${ }^{12}$ and frequencies of payments and maturity periods favorable to the debtor.

A3.40 Since the terms of a concessional loan are more favorable to the debtor than market conditions would otherwise permit, concessional loans effectively include a transfer from the creditor to the debtor. However, the means of incorporating the transfer impact within macroeconomic statistics have not been fully developed, although various alternatives have been advanced. Accordingly, until the appropriate treatment of concessional debt is agreed, information on concessional debt should be provided in a memorandum item to the balance sheet (see paragraph 7.246) and/or in supplementary tables.

A3.41 The case of Paris Club debt concessionality is discussed in Chapter 4 of the PSDS Guide.

\section{Debt Arising from Bailout Operations}

A3.42 A bailout refers to a rescue from financial distress. It is often used when a government unit provides either short-term financial assistance to a corporation to help it survive a period of financial difficulty, or a more permanent injection of financial resources to help recapitalize the corporation. A bailout may, in effect, constitute nationalization if the government acquires control of the corporation it is bailing out. Bailouts of financial institutions are a case in point. They are likely to involve highly publicized, one-time transactions often involving large amounts and are, therefore, easy to identify.

A3.43 Analysts generally refer to "capital injections" made by government into corporations when some significant financial support is provided to capitalize or recapitalize the corporation in financial distress. The 2008 SNA uses "capital injections" to mean

\footnotetext{
${ }^{12}$ The grace period is the period from the disbursement of the loan until the first payment due by the debtor.
}

a direct intervention that is recorded in macroeconomic statistics either as a capital transfer, a loan, an acquisition of equity, or a combination of these. Direct intervention by general government units may take various forms-for example:

- Providing recapitalization through an injection of financial resources ("capital injection") or the assumption of a failed corporation's liabilities.

- Providing loans and/or acquiring equity in the corporations in distress (i.e., "requited recapitalization") on favorable terms, or not.

- Purchasing assets from the financially distressed corporation at prices greater than their true market value.

A3.44 Indirectly, general government may intervene by extending the range of guarantees it is prepared to offer.

A3.45 Broadly, two main issues arise with bailout operations:

- The first issue is the sectorization of the entity or unit created to finance or manage the sales of assets and/or liabilities of the distressed corporation. The sectorization is important, in particular, for determining whether its transactions, other economic flows, and stock positions (debt liabilities and other assets and liabilities) are within the general government sector or public corporations sector.

- The second issue is the appropriate statistical treatment of "capital injections."

\section{The sectorization issue}

A3.46 A government might create a restructuring agency (or "defeasance structure") in the form of a special purpose entity (SPE), or other type of public body, to finance or to manage the defeasance of impaired assets or repayment of liabilities of the distressed corporation. ${ }^{13}$ As is the case with all entities in macroeconomic statistics, the sectorization of a restructuring agency should reflect the underlying economic nature of the entity. Thus, the sectorization rules, as outlined in Chapter 2, should be applied to

\footnotetext{
${ }^{13}$ In the case of banks with impaired assets, such entities are commonly referred to as "bad banks."
} 
determine whether such an entity or unit should be treated as part of the general government sector or public financial corporations sector:

- If a public institutional unit is created by government solely to assume management of the assets or liabilities of the distressed corporation, and is not a market producer, the unit should be classified in the general government sector because it is not involved in financial intermediation.

- If the new unit has other functions and the management of the assets or liabilities of the distressed corporation is a temporary task, its classification as a government unit or a public financial corporation is made according to the rules described in the section on restructuring agencies in paragraphs 2.129-2.131.

\section{Statistical treatment of "capital injections"}

A3.47 The assistance provided by government (or another public sector unit) to the unit suffering financial distress is usually recorded as a loan, a capital transfer, or an equity injection. Figure A3.2 provides a decision tree for the statistical treatment of "capital injections."

A3.48 When a public sector unit (investor unit), such as a government unit, intervenes by means of a capital injection that is legally in the form of a loan to the corporation in distress, the statistical treatment depends on whether the investor unit obtains an effective financial claim on the corporation, as described in paragraph A3.27.

A3.49 When a public sector unit, such as government, intervenes by means of a capital injection other than a loan to the corporation in distress, the statistical treatment depends on whether a realistic return ${ }^{14}$ can be expected on this investment:

- If the public sector unit (investor unit) can expect a realistic return on the investment, the investor unit records an increase in financial assets in the form of equity and investment fund shares, and a decrease in financial assets (e.g., currency and deposits) or an increase in liabilities, depending on how the acquisition of equity is financed.

\footnotetext{
${ }^{14} \mathrm{~A}$ realistic rate of return on funds is indicated by the intention to earn a rate of return that is sufficient to generate dividends or holding gains at a later date, and that is a claim on the residual value of the corporation.
}

The corporation in financial distress records an increase in financial assets (e.g., currency and deposits), and an increase in nondebt liabilities in the form of equity and investment fund shares.

- The portion of the investment on which no realistic return can be expected-which may be the entire investment-is treated as a capital transfer.

A3.50 A capital injection in the form of a capital transfer (full or partial) is recorded when the funds are provided:

- Without receiving anything of equal value in exchange

- Without a reasonable expectation of a realistic rate of return

- To compensate for the impairment of assets or capital as a result of large operating deficits accumulated over two or more years, and exceptional losses due to factors outside the control of the enterprise.

A3.51 The unit providing the assistance records expense in the form of a capital transfer and a decrease in financial assets (e.g., currency and deposits) or an increase in liabilities, depending how this capital transfer is financed. The recipient records revenue in the form of a capital transfer and an increase in financial assets in the form of currency and deposits.

A3.52 In determining the magnitude of the capital transfers, the following points need to be taken into account:

- If the government buys assets from the corporation to be assisted, the amount paid may be more than the true market price of the assets.

- The purchase of assets should be recorded at the current market price, and, except for loans, a capital transfer should be recorded for the difference between the market price and the actual amount paid.

- Governments often buy loans from financial institutions during a bailout. Unless a loan becomes tradable and is traded at an established market value, it is always recorded in balance sheets at nominal value. Only if a market for the loans develops and the loans are regularly traded, they are reclassified as securities (see paragraphs 7.157 and 7.163) and also recorded at market value. 


\section{Figure A3.2 Decision Tree for the Statistical Treatment of "Capital Injections"}

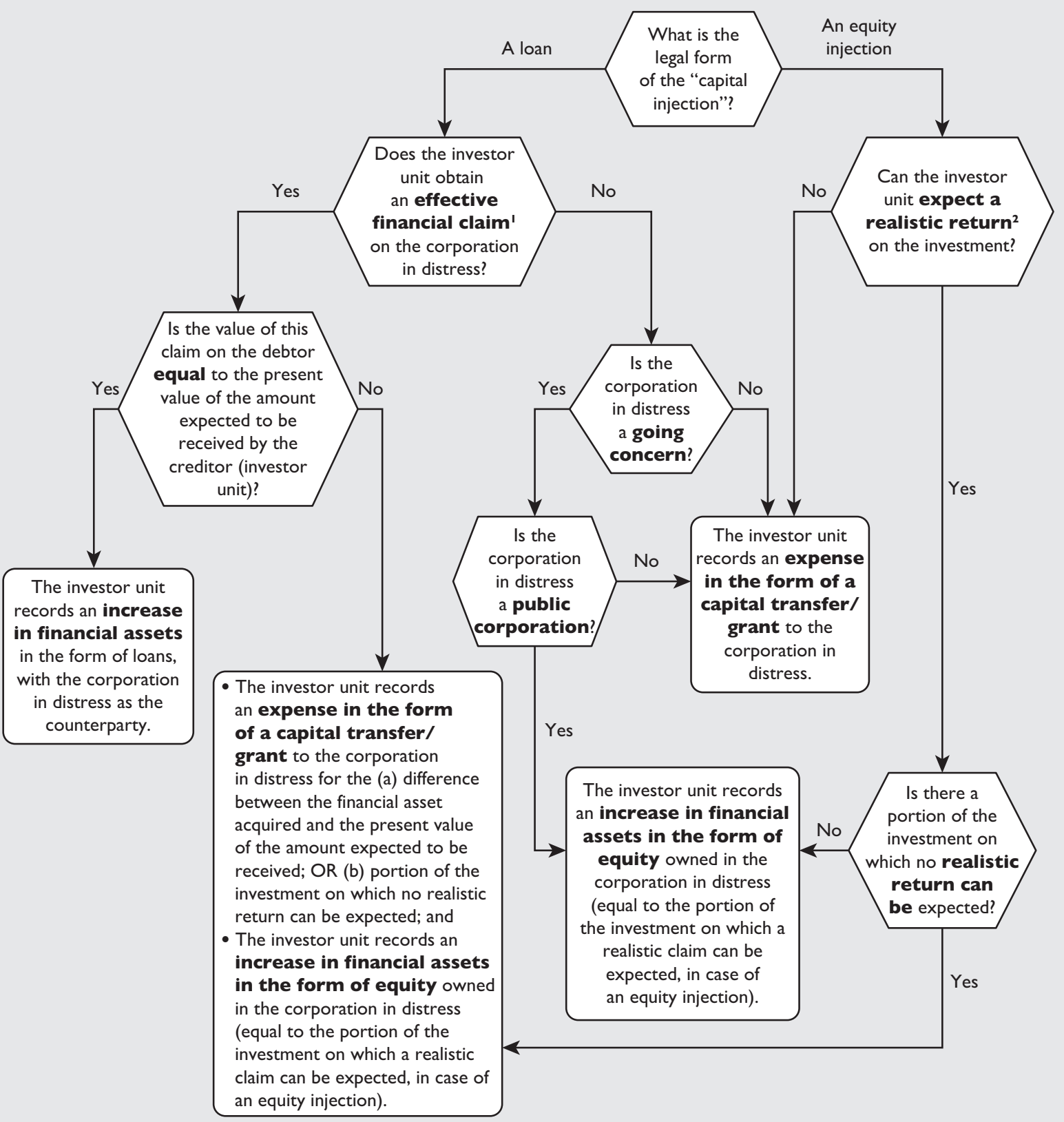

${ }^{1}$ An "effective financial claim" is understood to be a claim that is supported by a contract between the new debtor and the original debtor, or (especially in the case of governments) an agreement, with a reasonable expectation to be honored, that the original debtor will reimburse the new debtor.

${ }^{2} \mathrm{~A}$ realistic rate of return on funds is indicated by the intention to earn a rate of return that is sufficient to generate dividends or holding gains at a later date, and that is a claim on the residual value of the corporation. 
- When government buys a loan that has a fair value much less than its nominal value, no capital transfer for the difference in value is recorded as loans are recorded at nominal value on the balance sheet. Any difference between the price paid and the nominal value is recorded as a valuation change (see BPM6 paragraph 9.33). However, if there is reliable information that some loans are irrecoverable, their value is reduced to zero in the balance sheet (with an "other volume change") and a capital transfer is recorded equal to the value paid by the government to the corporation. If some or all of these loans subsequently become recoverable, this is shown as a revaluation in the government's balance sheet.

- If government extends a guarantee as part of a bailout, the guarantees should be recorded according to whether this is a one-off guarantee or part of a standardized guarantee scheme (see paragraphs 7.254-7.260 for details on the statistical treatment of guarantees).

A3.53 Additional factors should be taken into account for borderline cases, such as the following:

- If the capital injection is covering large operating deficits accumulated over two or more years or exceptional losses due to factors outside the control of the enterprise, the capital injection is, by definition, a capital transfer.

- If capital injection is made to a quasi-corporation that has negative equity (see Box 6.3), the capital injection is always a capital transfer.

- If the capital injection is undertaken for specific purposes relating to public policy in order to compensate a bank in financial distress for anticipated defaults/bad assets/losses within its balance sheet, the capital injection is a capital transfer, unless a realistic return can be expected, in which instance an equity investment is recorded.

- If there are private shareholders providing a significant share (in proportion to their existing shareholding) of equity during the injection, then the capital injection is an equity investment since the assumption is that private investors would be seeking a return on their investment.

\section{Debt of Special Purpose Entities}

A3.54 Special purpose entities (SPEs) are described in paragraphs $2.136-2.139$. For GFS, the appropriate units and institutional sectorization of the SPE must be determined. If the SPE is part of the public sector, its debt should be part of the debt of the public sector or relevant subsector.

A3.55 As noted in paragraphs 2.41-2.45, governments may establish public corporations that sell goods or services exclusively to government, without tendering for a government contract in competition with the private sector. Such a public corporation is called an artificial subsidiary and should be classified as part of the general government sector (its parent unit). Often, such government artificial subsidiaries are set up as SPEs. These units, which are legally corporations, should be classified as part of the general government sector and their debt liabilities are thus part of general government debt.

A3.56 A government may conduct fiscal activities through an entity that is resident abroad. For example, a government may fund its outlays by issuing securities abroad through an SPE. This SPE is not part of the general government sector in either home or host economy. Such entities are not treated in the same way as embassies and other territorial enclaves because they operate under the laws of the host economy. Governments may be direct investors in these units/entities. However, special imputations of transactions and stock positions between the government and the SPE abroad must be used to ensure that any fiscal operations undertaken through nonresident entities are reflected in the transactions and stock positions of the home government concerned. ${ }^{15}$ As a result, the government will show an actual, or imputed, debt to its SPE arising from any debts the SPE incurs on behalf of the government.

A3.57 When an SPE entity resident in one economy borrows on behalf of the government of another economy, and the borrowing is for fiscal purposes, the statistical treatment in the accounts of that government is as follows:

\footnotetext{
${ }^{15}$ The reason for having a special approach for government entities is that, unlike in the private sector, the nonresident entity undertakes functions at the behest of general government for public policy, not commercial purposes. Without this approach, a misleading picture of government expenditure and debt could arise.
} 
- At the time of borrowing-A transaction creating a debt liability of the government to the borrowing entity is imputed equal to the amount borrowed. The counterpart entry is an increase in the government's equity in the borrowing entity.

- At the time funds or assets acquired with the funds (as applicable) are transferred to the government-A transaction for the flow of funds or assets is recorded, matched by a reduction of the government's equity in the borrowing entity by the same amount.

- At the time expenses are incurred, or assets are transferred by the borrowing entity to a third party (i.e., are not transferred to the government), where applicable-A current or capital transfer between the government and the entity is imputed, with the matching entry of a reduction in the value of the government's equity.

A3.58 These entries are made symmetrically for both the government and the borrowing entity. The entries do not affect the transactions or stock positions between the borrowing entity and its creditors or other third parties, which are recorded as they occur, with no imputations.

\section{Debt Arising from Securitization}

A3.59 Securitization occurs when a unit, named the originator, conveys the ownership rights over financial or nonfinancial assets, or the right to receive specific future flows, to another unit, named the securitization unit. In return, the securitization unit pays an amount to the originator from its own source of financing. The securitization unit obtains its own financing by issuing debt securities using the assets or rights to future flows transferred by the originator as collateral. ${ }^{16}$ When asset-backed securities are issued by a public sector unit, they form part of public sector debt.

A3.60 Securitization results in debt securities for which coupon or principal payments (or both) are backed by specific financial or nonfinancial assets or future revenue streams. A variety of assets or future

\footnotetext{
${ }^{16}$ For a detailed discussion of securitization, see Handbook on Securities Statistics, Bank for International Settlements, European Central Bank, and International Monetary Fund, May 2009, as well as the 2008 SNA, paragraphs 22.131-22.133. The Handbook also considers that securitization can occur when there is no securitization unit or transfer of assets.
}

revenue streams may be used for securitization, including residential and commercial mortgage loans, consumer loans, government loans, and credit derivatives. A general government unit may issue debt securities backed by specific earmarked revenue. In macroeconomic statistical systems, the ability to raise taxes or other government revenue is not recognized as a government asset that could be used for securitization. ${ }^{17}$ Nevertheless, the earmarking of future revenue, such as receipts from toll roads, to service debt securities issued by a general government (or public sector) unit may resemble securitization (see paragraphs A3.64 and A3.66).

A3.61 Securitization schemes vary within and across debt securities markets. At the broadest level, a distinction is made about whether a securitization unit is involved. In securitization schemes where debt securities are issued by a securitization unit, the issuing institutional unit is a financial intermediary in the financial corporations sector. The securitization unit is often an SPE. However, as described in paragraph 2.137, resident SPEs functioning in only a passive manner relative to general government and carrying out fiscal activities are not treated as separate institutional units in the macroeconomic statistical systems. Such SPEs are treated as part of the general government sector regardless of their legal status-therefore:

- If a securitization unit is involved, four types of schemes may be distinguished from a macroeconomic statistics perspective:

- True-sale securitization, ${ }^{18}$ which is schemes involving a true transfer (sale) of assets-from a macroeconomic statistics perspective ${ }^{19}$ - from the original asset owner's balance sheet to that of the securitization unit

\footnotetext{
${ }^{17}$ For example, future tax revenue has not yet accrued, presumably because the event that leads to the tax liability has not yet taken place, and consequently no asset exists on the government balance sheet.

18 "Type 2" schemes in the Handbook on Securities Statistics and the "first case" of securitization in the 2008 SNA.

${ }^{19}$ To be treated as a sale, the asset must already appear on the balance sheet of the public sector unit (e.g., central government) and there must be a full change of ownership to the securitization unit, as evidenced by the transfer of the risks and rewards linked to the asset. The following must be considered: (i) The purchase price should equal the current market price, otherwise it is not a sale; and (ii) if the originator (e.g., central government) guarantees repayment of any debt related to the asset acquired by the securitization unit, it is unlikely that all of the risks associated with the asset have been transferred and there is, therefore, no sale.
} 
- No true-sale securitization, ${ }^{20}$ which is schemes that do not involve a true transfer of assetsfrom a macroeconomic statistics perspectivefrom the original asset owner's balance sheet to that of the securitization unit (see footnote 19)

- No asset securitization, ${ }^{21}$ which is schemes involving securitization of future revenue streams that are not recognized as assets in macroeconomic statistics

- Synthetic securitization with a securitization unit, ${ }^{22}$ which is schemes involving the transfer of credit risk only (but not the transfer of assets), through a securitization unit.

- If no securitization unit is involved, two types of securitization are possible:

- On-balance sheet securitization, ${ }^{23}$ which is schemes in which the original asset owner issues new debt securities and there is no transfer of assets

- Synthetic securitization without a securitization unit, ${ }^{24}$ which is schemes involving the transfer of credit risk only (but not the transfer of assets), through the direct issue of debt securities by the original asset owner.

A3.62 True-sale securitization involves debt securities issued by a securitization unit where the underlying assets have been transferred from the original asset owner's (i.e., the originator's) balance sheet to that of the securitization unit. The securitization unit uses the proceeds from selling the debt securities to investors to finance the acquisition of the assets. The revenue stream from the pool of assets (typically, interest payments and principal repayments on the loans) is used to make the coupon payments and principal repayments on the debt securities issued. In case of a true-sale securitization by a public sector unit, the original asset owner's gross debt remains unchanged. The gross debt of the securitization unit increases as a result of the securities issued. If this unit is a public financial corporation, its debt is part of public sector debt. A resident securitization "unit" controlled by a government unit that is an SPE but

\footnotetext{
${ }^{20}$ Derived from the "first case" of securitization in the 2008 SNA.

${ }^{21}$ The "second case" of securitization in the 2008 SNA.

22 "Type 3" schemes in the Handbook on Securities Statistics.

23 "Type 1" schemes in the Handbook on Securities Statistics.

24 "Type 3" schemes in the Handbook on Securities Statistics.
}

does not meet the requirements of an institutional unit is treated as part of general government regardless of its legal status. Such an SPE's debt is part of general government's debt (see also paragraph A3.61).

A3.63 If no true sale had taken place from a macroeconomic statistics perspective (see footnote 19), the amount received from the securitization unit by the public sector unit as the originator is treated as borrowing, usually in the form of a loan. ${ }^{25}$ The debt securities issued by the securitization unit are part of public sector debt, if the securitization unit is part of the public sector.

A3.64 No asset securitization involves securitization of future revenue streams. As mentioned in paragraph A3.60, the ability to raise taxes or other government revenue is not recognized as a government asset that could be used for true-sale securitization. In most cases, it is not the rights to the future revenue that are used as collateral, but the obligation of the public sector unit to use a sufficient amount of the future income to repay the borrowing in full. If more income is earned than is needed to repay the borrowing, the excess is retained by the public sector unit. So, if "rights" to future government revenue are transferred to a securitization unit, the amount received from the securitization unit by the public sector unit, arising from the proceeds of the debt securities issue, is treated as borrowing, usually in the form of a loan. ${ }^{26}$ The revenue stream continues to accrue to government and government uses these proceeds to repay the loan from the securitization unit. The debt securities issued by the securitization unit are part of public sector debt if the securitization unit is part of the public sector.

A3.65 Synthetic securitization involves transfer of the credit risk related to a pool of assets without transfer of the assets themselves, either through a securitization unit or through the direct issuing of debt securities by the original asset owner.

- Synthetic securitization with a securitization unit: The owner of a pool of assets buys credit default

\footnotetext{
${ }^{25}$ When both the originator and the securitization unit are in the public sector, this loan will be eliminated from public sector debt through consolidation.

${ }^{26}$ When both the originator and the securitization unit are in the public sector, this loan will be eliminated from public sector debt through consolidation.
} 
swaps (CDS) (protection buyer) from the securitization unit (protection seller) for a premium to obtain protection against possible default losses on the pool of assets. ${ }^{27}$ The protection seller issues a debt instrument. The proceeds from the issue of debt securities by the securitization unit are invested in low-risk, low-return financial assets (such as deposits), and the income accrued on this investment, together with the premium from the CDS, finances coupon payments on the debt securities due by the securitization unit to the investors. On maturity, the holders of the debt securities are reimbursed, provided there has been no default on the pool of assets. If there is a default, the protection buyer is compensated by the protection seller for the default losses related to the pool of assets, while the holders of the debt securities (investors) suffer losses for the same value, a realized holding gain for the protection seller.

The debt securities issued by the securitization unit are part of public sector debt if the securitization unit is part of the public sector.

- Synthetic securitization without a securitization unit: The owner of the asset issues credit-linked notes (CLN). CLN are debt securities that are backed by reference assets (such as loans and bonds), with an embedded CDS allowing credit risk to be transferred from the issuer to investors. There is usually a higher interest rate to compensate the investors for taking on higher risks. Credit protection for the pool of assets is sold by the investors to the protection buyer (or issuer of the CLN) by buying the CLN. Repayment of principal and interest on the notes is conditional on performance of the pool of assets. If no default occurs during the life of the note, the full redemption value of the note is paid to investors at maturity. If a default occurs, investors receive the redemption value of the note minus the value of the default losses.

With synthetic securitization without a securitization unit, the debt securities (CLN) issued by a public sector unit are part of that unit's debt.

A3.66 On-balance sheet securitization involves debt securities backed by a future revenue stream

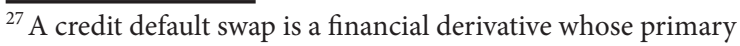
purpose is to trade credit default risk. generated by the assets. The assets remain on the balance sheet of the debt securities issuer (the original asset owner), typically as a separate portfolio. There is no securitization unit involved. The issue of debt securities provides the original asset owner with funds and the debt securities form part of the original asset owner's debt.

\section{Debt Arising from Off-Market Swaps}

A3.67 In macroeconomic statistics, swaps give rise to financial derivatives, which are nondebt instruments (see paragraph 7.215). However, off-market swaps have a debt component.

A3.68 An off-market swap is a swap contract that has a nonzero value at inception as a result of having reference rates priced differently from current market values-that is, "off-the-market." Such a swap results in a lump sum being paid, usually at inception, by one party to the other. The economic nature of an offmarket swap is a combination of borrowing (i.e., the lump sum), in the form of a loan, and an on-market swap (financial derivative). The loan component of an off-market swap is debt and, if a public sector unit receives the lump-sum payment, this will be part of public sector debt. Examples of swaps contracts that may involve off-market reference rates include interest rate and currency swaps.

A3.69 Because the economic nature of an off-market swap is equivalent to a combination of a loan and a financial derivative, two stock positions are recorded in the balance sheet:

- A loan-a debt instrument-which is equal to the nonzero value of the swap at inception and with a maturity date equivalent to the expiration date of the swap

- A financial derivative (swap) component-a nondebt instrument-that has a market value of zero at inception.

A3.70 The loan position is a liability of the party that receives the lump sum, while the derivative position may appear either on the financial asset or liability side, depending on market prices on the balance sheet date.

A3.71 Future streams of flows relating to these stock positions are also partitioned between those relating to the loan and financial derivative component, respectively. 


\section{On-Lending of Borrowed Funds}

A3.72 On-lending of borrowed funds refers to a resident institutional unit, A (usually central government), borrowing from another institutional unit(s), $\mathrm{B}$ (usually a nonresident unit), and then on-lending the proceeds from this borrowing to a third institutional unit(s), C (usually state or local governments, or public corporation (s)), where it is understood that unit A obtains an effective financial claim on unit C. On-lending of borrowed funds is motivated by several factors-for example:

- Institutional unit A may be able to borrow from unit $B$ at more favorable terms than unit $C$ could borrow from unit $B$

- Institutional unit C's borrowing powers are limited by factors such as foreign exchange regulations; only unit A can borrow from nonresidents.

A3.73 On-lending results in (at least) two separate financial claims. These claims should not be offset against each other in government finance and public sector debt statistics; institutional unit B has a debt claim on unit(s) A, and unit(s) A has a debt claim on unit $\mathrm{C}$, which may be consolidated (see paragraph A3.76). Depending on the residence of institutional unit(s) B and C, respectively, these debt liabilities (and the corresponding financial claims) are classified as domestic or external.

A3.74 The statistical treatment of the two claims to be recorded if the resident institutional unit (A), which on-lends the borrowed funds to unit(s) $\mathrm{C}$, obtains an effective financial claim on unit(s) $\mathrm{C}$, depends on:

- The residence of the creditor(s) from which unit A is borrowing (i.e., unit(s) B)

- The residence of unit(s) C to which unit A is onlending the borrowed funds (see Table A3.1).

A3.75 The classification of the debt liability of institutional unit A to unit(s) B depends on the type of instrument(s) involved: typically, such borrowing is in the form of loans and/or debt securities. In such cases, institutional unit A's debt liabilities in the form of loans and/or debt securities increase (credit) as a result of the borrowing from unit(s) B, with a corresponding increase (debit) in unit A's financial assets in the form of currency and deposits. These events result in an increase in the gross debt position of unit $\mathrm{A}$, but no change in its net debt position.

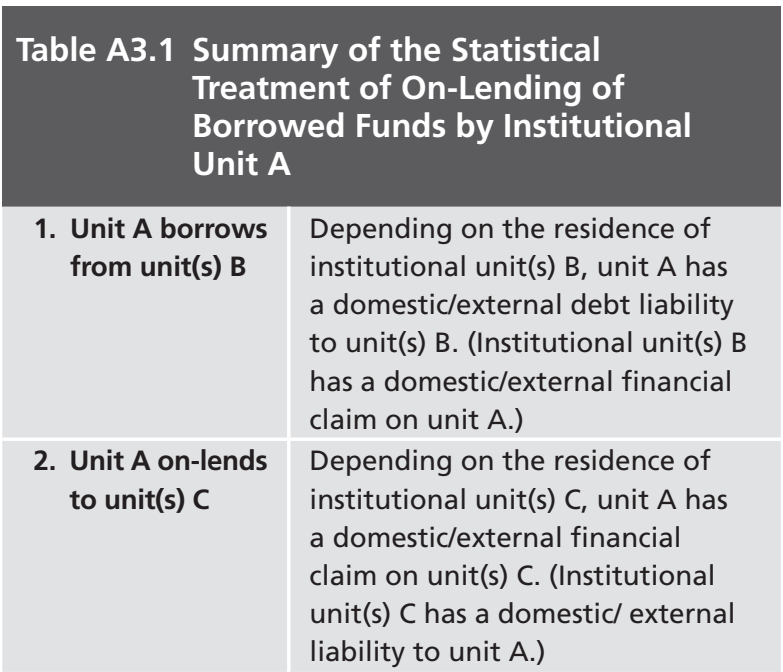

A3.76 The debt liability of institutional unit(s) C to unit A, as a result of the on-lending of the borrowed funds, is typically in the form of a loan. In other words, institutional unit C's debt liabilities increase (credit) as a result of the borrowing from unit A, with a corresponding increase (debit) in unit C's financial assets in the form of currency and deposits. Institutional unit A's financial assets (e.g., loans) will increase (debit) as a result of the on-lending to unit $\mathrm{C}$ and its financial assets in the form of currency and deposits will decrease (credit). If institutional unit(s) $\mathrm{C}$ is classified to the same sector, subsector, or group of units as unit $\mathrm{A}$, this debt liability (and corresponding financial claim) is eliminated in consolidation.

A3.77 The amortization of each of the debt liabilities (and corresponding financial assets) is recorded in the books of the unit in whose balance sheet the debt liability appears. Thus, if institutional unit A has a debt liability to unit $B$, the amortization of this (usually external) liability (debit) is recorded in the books of unit $\mathrm{A}$, even if these borrowed funds were on-lent to unit $\mathrm{C}$.

A3.78 Similarly, the amortization of institutional unit C's (usually domestic) debt liability (debit) to unit A is recorded in the books of unit C. Unit A would record a decrease (credit) in its (domestic) financial claims on unit $\mathrm{C}$. The amortization of institutional unit C's debt liability to unit A improves unit C's gross debt position, while its net debt position remains the same. 


\section{Stock Positions and Related Flows with the IMF}

A3.79 This section briefly describes the stock positions and flows in countries' financial assets and liabilities arising from membership in the International Monetary Fund (IMF), as they relate to public sector debt statistics. Debt data compilers first have to determine in which public sector unit(s) to record the stock positions and related flows with the IMF. Stock positions and flows in financial assets and liabilities of member countries with the IMF are usually recorded in the accounts of the public sector unit as determined by the legal and institutional arrangements in the member country.

A3.80 The IMF conducts its dealings with a member through the fiscal agency and the depository:

- Each member country designates a fiscal agency to conduct financial transactions with the IMF on behalf of the member. ${ }^{28}$

- Each member is also required to designate its central bank as a depository for the IMF's holdings of the member's currency. ${ }^{29}$ In most member countries, the central bank is both the fiscal agency and the depository.

A3.81 The next sections discuss member countries' quotas in the IMF, their reserve positions in the IMF, remuneration (interest) receivable from the IMF, the account that is used for administrative payments (the "No. 2 Account"), and their Special Drawing Rights (SDRs) allocations and holdings.

\section{Quotas}

A3.82 Member countries are assigned a quota on joining the IMF. A quota is the capital subscription, expressed in SDRs, that each member must pay the IMF on joining and consists of two components:

- Reserve asset component-A member is required to pay 25 percent of its quota in SDRs or in currencies specified by the IMF. This 25 percent portion is a component of the member's reserve assets and is known as the "reserve tranche." In the public sector unit's accounts, subscribing this

\footnotetext{
${ }^{28}$ The fiscal agency may be the member's treasury (ministry of finance), central bank, official monetary agency, stabilization fund, or other similar agency. The IMF can deal only with, or through, the designated fiscal agency.

${ }^{29}$ If the member has no central bank, it shall designate such other institution as may be acceptable to the IMF.
}

portion is shown as a transaction involving an increase in external financial assets in the form of currency and deposits-that is, the reserve tranche position, which is a liquid claim on the IMF (debit), offset by an equal reduction in existing external financial assets ${ }^{30}$ (credit).

- Domestic currency component-The remaining 75 percent of the quota is payable in the member's own currency at the designated depository. The payment is made either in domestic currency (IMF No. 1 Account) or if the member country so chooses, by issuance of a promissory note (in the IMF Securities Account). The No. 1 Account is used for the IMF's operational transactions (e.g., purchases and repurchases), and small transfers may be made from this account to the No. 2 Account, which is used for the payment of local administrative expenses incurred by the IMF in the member's currency. ${ }^{31}$ The promissory notes are encashable by the IMF on demand. The domestic portion of the quota payment is not recorded in the public sector unit's accounts, because it is considered in economic terms to be of a contingent nature. No interest is payable on either the deposit account or the note.

A3.83 There are periodic reviews of the size of member quotas. Recording transactions that reflect a change in a member's quota is the same as the recording that takes place when the quota is initially paid.

\section{Reserve position in the IMF}

A3.84 A member country's reserve position in the IMF equals the sum of the reserve tranche plus any indebtedness of the IMF (under bilateral loan agreements, notes, or participation in standing borrowing agreements such as the General Agreements to Borrow and New Agreements to Borrow) in the General Resources Account that is readily available to the member country (for further details, see BMP6, paragraph 6.85). The reserve tranche represents the member's unconditional drawing right on the IMF, created by the foreign exchange portion of the quota subscription, plus increases (decreases) through the

\footnotetext{
${ }^{30}$ The type of instrument varies.

${ }^{31}$ When the IMF uses funds from the No. 2 Account to pay for the acquisition of goods and services, the member country shows a reduction in this account and an offset transaction in the use of goods and services.
} 
IMF's sale (repurchase) of the member's currency to meet the demand for use of IMF resources by other members in need of balance of payments financing. A member's reserve position in the IMF constitutes part of its reserve assets (external financial assets).

A3.85 To utilize its reserve tranche in the IMF, a member must present a declaration of a balance of payments need and purchase foreign exchange from the IMF with its own currency. The domestic currency, equal to the value of the foreign exchange, is paid into the IMF's No. 1 Account with the member's depository or through the issuance to the IMF of a noninterest-bearing promissory note recorded in the IMF's Securities Account. The transaction is recorded in the public sector unit's accounts as a reduction in the member's external financial assets in the form of currency and deposits (i.e., the reserve tranche position in the IMF), which is offset by an increase in the member's external financial assets (i.e., foreign exchange).

\section{Credit and loans from the IMF}

A3.86 A member may make use of IMF credit or concessional loans under the trusts administered by the IMF (for financing for low-income countries) to acquire additional foreign exchange from the IMF. The use of IMF credit and concessional loans results in the same outcome-that is, the member entering into these agreements has access to foreign exchange in return for agreeing to meet a set of conditions. Both IMF credit and concessional loans are classified in the public sector unit's accounts as external liabilities in the form of loans, although the two types of arrangements are executed in different ways:

- When a member country uses IMF credit, it "purchases" foreign exchange from the IMF in return for its domestic currency deposited in the IMF No. 1 Account (or backed by the issuance of a promissory note). Use of IMF credit is shown as the member's loan liability (denominated in SDRs) in the accounts of the public sector unit, reflecting the economic nature of the transaction. Liabilities under IMF credit arrangements are extinguished when the member uses foreign exchange to "repurchase" its domestic currency.

- The concessional loans, also denominated in SDRs, result in the member borrowing foreign exchange with a commitment to repay. Such loans do not affect the IMF No. 1 Account. Repayments must be made in SDRs or freely useable currencies.

A3.87 If the value of the member's domestic currency changes in relation to the SDR, "maintenance of value payments" are made once a year in the No. 1, No. 2, and Securities Accounts in domestic currency to maintain a constant SDR liability. Because the liability is denominated in SDRs, the maintenance of value payments are not entered as transactions in the central bank's accounts, but as holding gains/losses (revaluations) when the domestic currency is used as the unit of account.

A3.88 When the central bank passes on proceeds from IMF borrowing to a general government unit:

- The central bank has a domestic financial claim (loan) on the general government unit and the general government unit has a domestic debt liability to repay (principal and interest).

- The central bank has an external debt liability to repay, and may use the debt service payments received from the general government unit to do so.

\section{Remuneration}

A3.89 The IMF pays its members "remuneration" quarterly (in SDRs) on the basis of their reserve tranche position, except for a small portion related to prior quota payments in gold that are interest-free resources to the IMF. This remuneration should be recorded on an accrual basis as interest income (revenue) of the public sector unit, which is realized as an increase in its external financial assets in the form of currency and deposits.

\section{IMF No. 2 Account}

A3.90 As discussed in paragraph A3.82, the IMF No. 2 Account is used by the IMF for administrative payments and is reflected as a liability in the public sector unit's accounts. Transactions involving the No. 2 Account are recorded as increases or decreases in this liability and are offset by the source of funds (in the case of an increase) or the use of funds (in the case of a decrease). When the IMF transfers funds from the No. 1 Account to the No. 2 Account, the public sector unit's accounts will show an increase in its reserve tranche (i.e., currency and deposits). The 
increase reflects the reduction in IMF holdings of the member's currency in the No. 1 Account and is offset by an increase in the member's liabilities relating to currency and deposits.

\section{Special Drawing Rights (SDRs)}

A3.91 The SDR is an international reserve asset created by the IMF in 1969. The SDR is administered by the IMF's SDR Department, which is required by the IMF's Articles of Agreement to keep its accounts strictly separate from those of the General Department. Members participating in the SDR Department incur the financial asset or liability position unto itself. Given that financial claims on and liabilities to members in the SDR system are attributed on a cooperative basis, a residual partner category-other nonresidents-is used as the counterparty to SDR holdings and allocations. ${ }^{32}$

A3.92 SDR allocations received by a country are recorded as a liability in the form of SDRs (part of gross debt of the public sector unit) with a corresponding entry for SDR holdings as a financial asset. The calculation of a public sector unit's net debt takes into account SDR holdings and SDR allocations. Interest income on SDR holdings (revenue) and interest expense on SDR allocations are accrued on a gross basis to the outstanding financial asset and liability, respectively.

A3.93 The SDR allocation is debt of the recipient (i.e., the participant in the SDR Department), and forms part of public sector debt. The SDR holdings are part of the public sector's financial assets. However, the international statistical systems do not specify on which balance sheet SDR holdings and allocations should be recorded (e.g., the central bank or a general

\footnotetext{
${ }^{32}$ See paragraph 7.264 for a discussion of the classification of the
} counterparty by institutional sector. government entity such as the ministry of finance or treasury). This is because SDR allocations are made to IMF members that are participants in the SDR Department of the IMF, and it is for those members to follow domestic legal and institutional arrangements to determine the ownership and recording of SDR allocations and SDR holdings in the public sector.

A3.94 For GFS and public sector debt statistics, it is particularly relevant in which public sector unit's accounts the SDR holdings and allocations are recorded. If the SDR allocation is recorded on the government's balance sheet, the allocation is part of general government debt. If the SDR allocation is on the central bank's balance sheet, the allocation is not part of general government debt but still part of public sector debt.

A3.95 SDRs are held exclusively by participants, the IMF, through the General Resources Account, and prescribed holders, ${ }^{33}$ and are transferable among them. At the time of the SDR allocation, the amounts recorded as SDR allocations (liabilities) and holdings (financial assets) are identical and on the same public sector unit's balance sheet. This public sector unitas official holder-may, subsequently, exchange some or all of its SDR holdings (financial asset) with other official holders for freely usable currency(ies). In this case, the SDR allocations and holdings on the balance sheet of the public sector unit are no longer identical; the SDR holdings are less than the allocations because they have been converted into freely usable currencies (i.e., currency and deposits). As a result, interest payable on the SDR allocation of public sector unit will be larger than interest receivable on its SDR holdings. Interest receivable on the SDR holdings exchanged will accrue to the new holder.

\footnotetext{
${ }^{33}$ The IMF has prescribed a limited number of international financial institutions as holders of SDRs.
} 


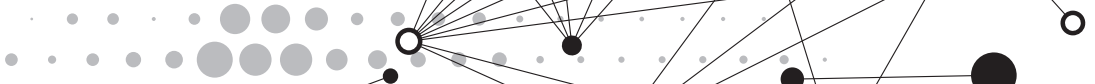

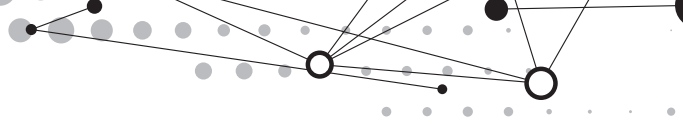

O

APPENDIX

\section{Some Cross-Cutting Issues}

This appendix applies government finance statistics principles to illustrate the recording of: leases, licenses, permits, and contracts; public-private partnerships; and insurance and standardized guarantee schemes.

\section{Introduction}

A4.1 Some cross-cutting issues relate to the recording of the impact of specific events on revenue, expense, and flows and stock positions of assets and liabilities. Aspects of recording these events are described in various chapters of this Manual. However, bringing all of these together enhances the clarity of recording these events. This appendix deals with three such issues: ${ }^{1}$

- Leases, licenses, permits, and contracts

- Public-private partnerships (PPPs)

- Insurance and standardized guarantee schemes.

\section{Leases, Licenses, Permits, and Other Contracts Introduction}

A4.2 Many transactions are specified in terms of a contract between two institutional units. The majority of contracts are such that one unit provides a good, service, or asset to the other unit for an agreed payment at an agreed time (possibly immediately after agreeing on the price). Such contracts may be written and legally binding or may be informal or even only implicit. However, these contracts are simply agreements about the terms under which goods, services, and assets are provided to the recipient along with the ownership of the item. In particular, these contracts can help to determine the point at which the transactions should be recorded in GFS in accordance with the accrual principles described in paragraphs 3.69-3.75.

\footnotetext{
${ }^{1}$ While social protection and debt operations can also be regarded as cross-cutting issues, these issues are described separately in Appendixes 2 and 3.
}

A4.3 For certain types of contracts and legal agreements, variously described as leases and licenses (or permits), the terms of the agreement may affect not only the time of recording of transactions but also the classification of transactions and the ownership of the item subject to the agreement. The purpose of this section is to provide guidance on how transactions entered into under these more complex arrangements should be recorded in GFS.

\section{Leases}

A4.4 Three types of leases are recognized in macroeconomic statistics: operating leases, financial leases, and resource leases. Each of these leases relates to the use of a nonfinancial asset. Fundamental to the distinction between the different types of leases is the difference between legal and economic ownership. The legal owner of resources is the institutional unit entitled by law and sustainable under the law to claim the benefits associated with the asset. By contrast, the economic owner of resources is entitled to claim the benefits associated with the use of the asset in the course of an economic activity by virtue of accepting the associated risks. This distinction between legal and economic ownership is elaborated upon in paragraphs 3.37-3.41 and 7.5. The legal owner is often the economic owner as well. When they are different, the legal owner has divested itself of the majority of risks in return for agreed payments from the economic owner. Thus:

- In the case of operating leases and resource leases, there is no change of economic ownership: the legal owner continues to be the economic owner. Resource leases are agreements for the use of natural resources, such as land and radio spectrum. Operating leases are agreements for the use of all other nonfinancial assets.

- In the case of financial leases, there is a difference between economic ownership and legal 
ownership of the asset. Financial leases can apply to all nonfinancial assets, including natural resources under some circumstances.

A4.5 The following paragraphs discuss the treatment of operating leases, financial leases, and resource leases in detail.

\section{Operating leases}

A4.6 Operating leasing is the activity of renting out produced assets under arrangements that provide use of a tangible asset to the lessee, but do not involve the transfer of the bulk of risks and rewards of ownership to the lessee. The legal and economic owner is called the lessor. One indication that an operating lease exists is that the responsibility for repair and maintenance of the asset lies with the legal owner. Under an operating lease, the asset remains on the balance sheet of the lessor.

A4.7 Amounts payable under an operating lease for the use of the asset are referred to as rentals and are recorded as payments for a service. In principle, any fixed asset may be subject to an operating lease. The character of operating leases may most easily be described in relation to fixed assets since operating leases often concern vehicles, office equipment (e.g., photocopiers), construction equipment, buildings, etc. The service provided by the lessor to the lessee goes beyond the mere provision of the asset. It includes other elements, such as the convenience for the lessee that the lessor takes responsibility for the maintenance and security of the asset-an important point from the user's view. In the case of equipment, the lessor, or owner, normally maintains a stock of equipment in good working order that can be hired on demand or at short notice. The lessor is normally a specialist in the operation of the equipment, a factor that may be important in the case of highly specialized equipment, where the lessee may not have the necessary expertise or facilities to maintain the equipment properly. The lessor may also undertake to replace the equipment in the event of a serious or prolonged breakdown. In the case of a building, the lessor is responsible for the structural integrity of the building, and would usually be responsible in the case of damage-for example, due to a natural disaster. The lessor is usually also responsible for ensuring that elevators, heating, and ventilation systems function adequately.
A4.8 Operating leases often aim at meeting the needs of users who require certain types of equipment only intermittently. Many operating leases are for short periods, although the lessee may renew the rental when the period expires and the same user may hire the same piece of equipment on several occasions. Because of the evolution of increasingly complicated types of machinery, especially in the electronics field, the servicing and backup facilities provided by a lessor are important factors that may influence a user to rent. Other factors that may persuade users to rent over long periods rather than purchase are considerations regarding the lessor's balance sheet, cash flow, or tax liability.

A4.9 The service provided under an operating lease should be recorded as use of goods and services (22) for the lessee and sales of goods and services (142) for the lessor. Consumption of fixed capital (23) on the fixed asset involved is recorded in the accounts of the lessor.

\section{Financial leases}

A4.10 A financial lease is a contract under which the lessor, as legal owner of an asset, conveys substantially all risks and rewards of ownership of the asset to the lessee. The economic nature of the arrangement is such that the lessor is deemed to provide a loan to allow the lessee to acquire the majority of risk and rewards of ownership, but the lessor retains legal title (ownership) as collateral for the loan. In other words, the lessee becomes the economic owner of the asset. Under a financial lease, the lessor records a loan to the lessee with which the lessee acquires the asset. Thereafter, the leased asset is shown on the balance sheet of the lessee and not of the lessor; the corresponding loan is shown as an asset of the lessor and a liability of the lessee.

A4.11 Financial leases are distinguished from other types of leases because substantially all risks and rewards of ownership are transferred from the legal owner of the nonfinancial asset (the lessor) to the user of the nonfinancial asset (the lessee). The following provisions in the lease contract would normally lead to a lease being classified as a financial lease:

- The lease contract transfers legal ownership of the asset to the lessee at the end of the lease term, or

- The lease contract gives the lessee the option to acquire legal ownership of the asset at the end of 
the lease term at a price that is sufficiently low that the exercise of the option is reasonably certain, or

- The lease term is for the major part of the economic life of the asset, or

- At inception, the present value of the lease payment amounts to substantially all of the value of the asset, or

- If the lessee can cancel the lease, the losses of the lessor are borne by the lessee, or

- Gains or losses in the residual value of the asset accrue to the lessee, or

- The lessee has the ability to continue the lease for a secondary period for a payment substantially lower than market value.

A4.12 These provisions in the lease contract may not be conclusive that substantially all of the risks have been conveyed. For example, if the asset is conveyed to the lessee at the end of the lease at its fair value at that time, the lessor holds substantial risks of ownership. The lease is then considered to be an operating lease. Financial leases are also called "finance leases" or "capital leases," highlighting that the motivation (paragraphs A4.10-A4.11) is to finance the acquisition of a nonfinancial asset. Internationally accepted accounting practices generally recognize financial leases in the same manner as in GFS. ${ }^{2}$ A treatment akin to financial leases is also adopted for some public-private partnerships ${ }^{3}$ (PPPs) (see paragraphs A4.58-A4.65 and the 2008 SNA, paragraphs 22.154-22.163).

A4.13 The statistical treatment of financial leases is designed to capture the economic reality of such arrangements, by treating assets under a financial lease as if they were purchased and owned by the user. The lessee (economic owner) records the acquisition of the asset that is financed by an imputed loan. The loan is redeemed through payments during the contract (consisting of interest and original principal el-

\footnotetext{
${ }^{2}$ At the time of publication of this Manual, the treatment of financial and operating leases is under review by international accounting standard setters.

${ }^{3}$ For example, a build, own, operate, transfer scheme could be established to assign the risks and rewards of ownership to the government, and the private partner would be treated as the provider of a financial lease.
}

ements) and any residual payment at the end of the contract (or alternatively, by the return of the good to the lessor). If the lessor is a financial intermediary, part of the payment is also treated as a service charge (see paragraph 6.81).

A4.14 It is common, but not necessary, for a financial lease to cover the whole economic life of the asset. Regardless of whether the lease is for the whole economic life of the asset or for less, the value of the imputed loan, at inception, corresponds to the market value of the asset, and is valued at nominal value throughout its life, in the same way as other loans. The value of the loan consists of the present value of the future payments due to the legal owner plus the value of the asset at the end of the lease, as specified in the lease agreement.

A4.15 At the inception of the lease, the value of the asset appearing on the balance sheet of the lessee should be equal to the value of the loan owed to the lessor at that time. At the end of the lease term, the asset may be returned to the lessor to cancel the loan, or a new arrangement, including the outright purchase of the asset, may be reached between the lessor and lessee. If the lease is for less than the expected economic life of the asset, the lease usually specifies the value to the lessor at the end of the lease or the terms under which the lease can be renewed. Any variation in the price of the asset from the value specified in the lease agreement is borne by the lessee.

\section{Resource leases}

A4.16 A resource lease is an agreement whereby the legal owner of a natural resource that macroeconomic statistics treat as having an infinite life makes it available to a lessee in return for a regular payment recorded as property income and described as rent. In the case of resource leases, there is no change of economic ownership and, therefore, the resource continues to be recorded on the balance sheet of the lessor, even though it is used by the lessee. Payments due under a resource lease are recorded as revenue or expense in the form of rent (1415 or 2814). By convention, no consumption of fixed capital is applied to natural resources. Depletion of a natural resource is instead recorded as an other change in the volume of assets (see paragraph 10.52). 


\section{Figure A4.1 Illustrating the Treatment of Licenses and Permits to Use a Natural Resource}

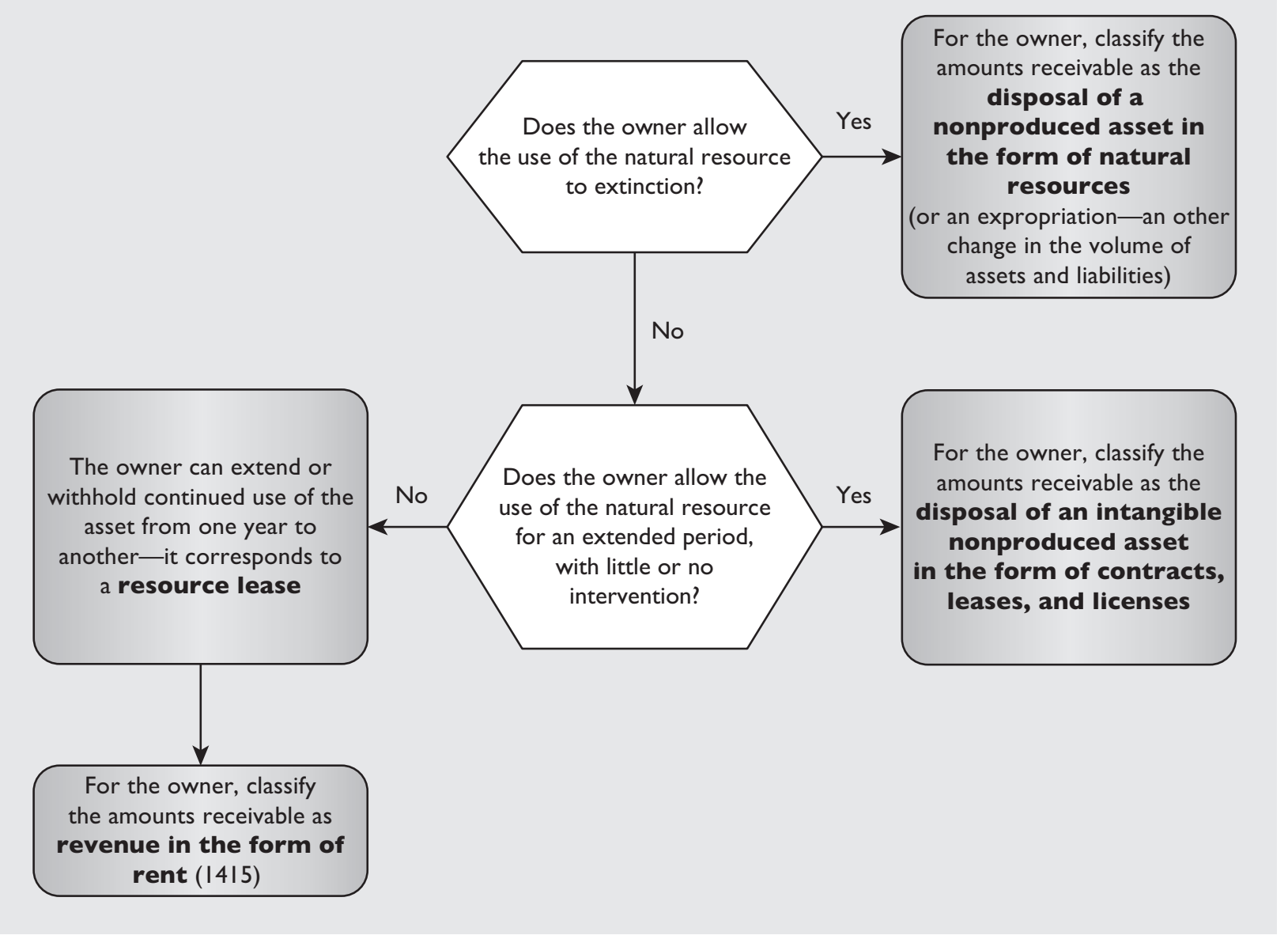

A4.17 Land is the classic case of an asset subject to a resource lease, but all other natural resources are also treated this way. An exception, when a long-term lease of land may be recorded as the sale of land, is described in paragraph A4.26. ${ }^{4}$

\section{Licenses and Permits to Use a Natural Resource}

A4.18 In many countries, licenses and permits to use natural resources are issued by government because government claims ownership of the resources on behalf of the community. However, government

${ }^{4}$ Further discussions of natural resources in the next section also indicate other cases where the use of a resource should be taken as the sale of the resource. could also issue these licenses and permits if the resources are privately owned.

A4.19 As illustrated in Figure A4.1, there are three different sets of conditions that may apply to the use of a natural resource:

- The owner may permit the resource to be used to extinction. This option results in the sale (or possibly an expropriation) of the nonproduced resource asset itself.

- The owner may permit the resource to be used for an extended period of time in such a way that, in effect, the user controls the use of the resource during this time with little if any intervention from the legal owner. This permit leads to the creation of an intangible nonproduced asset classified as contracts, leases, and licenses 
(31441) for the user, distinct from the resource itself; however, the value of the resource and the value of the nonproduced asset in the form of contracts, leases, and licenses are linked. An inverse relationship will exist between the value of the resource itself and the value of the intangible asset. $^{5}$

- The owner can extend or withhold permission to continued use of the asset from one year to the next. This option corresponds to a resource lease on which rent is payable/receivable (see paragraphs A4.16-A4.17).

A4.20 The differences in treatment between the various options are not clear-cut. ${ }^{6}$ There is no single, universal, and clear-cut criterion to distinguish between rent and asset sales, so a range of criteria should be considered in making the decision (see Box A4.1).

A4.21 The considerations listed in Box A4.1 can be seen as a more specific parallel to the distinction of economic ownership from legal ownership used in distinguishing between operating and financial leases described earlier. The conditions for treatment of the payment as the acquisition of an asset or rent are indicative rather than prescriptive. A decision on the appropriate treatment when some of the conditions are not met will necessitate consideration of how to record those transactions. For example, if, on balance, the decision is to treat the payment as rent, but a large upfront payment was made, this should be treated as a prepayment, recorded on an accrual basis. However, if the recipient is not willing to consider a refund if the contract is suspended, this is indicative of the sale of an intangible nonproduced asset rather than the payment of rent.

A4.22 The application of these principles to the main types of natural resources is described in the following text.

\footnotetext{
${ }^{5}$ The encumbered value of the resource is based on the present value of future rental payments taking the existence of the lease into account. The value of the resource increases as the contract winds down, while the value of the contract decreases over the same period. Also see Box A4.3.

${ }^{6}$ Also see this issue articulated in the context of the case of mobile phone licenses in SNA News and Notes, Volume 14, United Nations, 2002.
}

\section{Radio spectrum}

A4.23 Payment for a mobile phone license constitutes the sale of an asset rather than a payment for rent when the licensee acquires effective economic ownership rights over the use of the spectrum. ${ }^{7}$

A4.24 If the sale of such a license constitutes the sale of an asset, two possible treatments may apply: the sale of the spectrum itself or the sale of a permit to use the spectrum.

- When the life spans of the license and of the spectrum coincide, the payment for a license is treated as the sale of the spectrum itself (other natural resources: radio spectrum (314331)). The latter situation applies always when licenses are granted indefinitely.

- When the life span of the license is different from the life span of the spectrum, the payment for a license is treated as the sale of an intangible nonproduced asset classified as permits to use natural resources (314412) by the legal owner (licensor) to the economic owner (licensee).

A4.25 When the license agreement is treated as the sale of an intangible asset, in its own right, its value is established at the time of its sale. The value of the license declines with the remaining period of validity to a value of zero when the license expires. Symmetrically, the value of the spectrum to the lessor falls when the license acquires a value and progressively increases as the license expires. This reflects the potential for a further sale of the right to use the spectrum for another period. ${ }^{8}$

\section{Land}

A4.26 Land may be sold outright (i.e., when the legal ownership is transferred from one institutional unit to another $)^{9}$ or may be subject to a resource lease (e.g., tenant farmers usually pay regular rent to their landlord). A resource lease on land may instead be considered as a sale of the land (3141) if the

\footnotetext{
${ }^{7}$ To decide whether ownership is effectively transferred, the six criteria presented in Box A4.1 are to be considered.

${ }^{8}$ This recording ensures a neutral effect on the net worth of the overall economy during the life of the license.

${ }^{9}$ As described in paragraph 2.13, land may not be recorded as being sold to a nonresident unit. In such cases, a notional resident unit is created that holds title to the land; the nonresident unit then owns the equity in the notional resident unit.
} 


\section{Box A4.1 Criteria to Determine Whether a License Represents an Asset Sale or Rent}

Several criteria need to be considered:

- Costs and benefits assumed by licensee-The greater the extent of the risks and benefits associated with the right to use an asset incurred by the licensee, the more likely the classification of a transaction as the sale of an asset as opposed to rent. Pre-agreement on the value of payments (whether by lump sum or by installments) effectively transfers all economic risks and benefits to the licensee and points, therefore, to the sale of an asset. If, on the other hand, the value of payment is contingent on the results from using the license, risks and benefits are only partially transferred to the licensee and the situation is more readily characterized as payment of rent. In the case of mobile phone licenses, the total amount payable is often pre-agreed. An additional indication of the degree to which commercial risks have been passed to the licensee is to examine the hypothetical case where a licensee goes bankrupt. If, in such a case, the licensor reimburses none of the upfront payment made by the licensee, this would constitute a strong case against a characterization of the transaction as rent, as apparently the licensee has incurred all the risks involved.

- Upfront payment or installment-As with other indicators, the mode of payment is in itself not conclusive for a characterization as a transaction in assets or rent payment. Generally, the means of paying for a license is a financial issue and not a relevant factor in determining whether it is an asset. However, business practice shows that upfront payments of rent for long periods (15-25 years in the case of mobile phone licenses) are unusual and this favors an interpretation as sale of an asset.

- Length of the license-Licenses granted for long periods suggest the transaction should be treated as the sale of an asset, and for shorter periods treated as payments for rent. The timeframe involved in mobile phone licensing (15-25 years) is considered rather unusual as a period for which to conclude a fixed payment of rent and therefore a further indication favoring an interpretation as sale of an asset.

- Actual or de facto transferability - The possibility to sell the license is a strong indication of ownership and if transferability exists, this is considered a strong condition to characterize the licensing act as the sale of third-party property rights. In practice, mobile phone licenses are often transferable either directly (by the corporation selling the license to another corporation) or indirectly (through the corporation being acquired through a takeover).

- Cancellation possibility - The stronger the restrictions on the issuer's capacity to cancel the license at its discretion, the stronger the case for treatment as a sale of an asset. Conversely, when licenses can easily be cancelled at the discretion of the issuer, ownership over benefits and risks has not been fully transferred to the licensee and the transaction qualifies more readily as rent.

- Conception in the business world and international accounting standards- Businesses, in accordance with international accounting standards, often treat a license to use the spectrum as an asset. Again, in itself this does not lead to treatment as an asset in the national accounts, and there are other areas where companies choose to present figures in their accounts in ways that are not consistent with the national accounts. But the treatment of the acquisition of mobile phone licenses as capital investment in company accounts provides an added incentive to treat them in a similar way in the national accounts.

Not all or a majority of these considerations have to be satisfied to characterize the license as a sale of an asset. However, to qualify as rent (1415 or 2814) of a natural resource asset (rather than the sale of an asset), at least some of the following conditions should hold:

- The contract is of short-term duration, or renegotiable at short-term intervals. Such contracts do not provide the lessee with a benefit when market prices for the leased asset go up in the way that a fixed, long-term contract would. Such benefits are holding gains that typically accrue to owners of assets.

- The contract is nontransferable. Nontransferability is a strong but not a sufficient criterion for the treatment of license payments as rent, because, although it precludes the lessee from cashing in on holding gains, it does not preclude the lessee from reaping comparable economic benefits (e.g., using the license in a business).

- The contract contains detailed stipulations on how the lessee should make use of the asset. Such stipulations are often seen in cases of rent of land, in which the owner wishes to retain control over the usage of the land. In the case of licenses, examples of such stipulations would be that the contract states what regions or types of customers should be served, or that it sets limits on the prices that the lessee may charge.

- The contract includes conditions that give the lessor the unilateral right to terminate the lease without compensation-for instance, for underuse of the underlying asset by the lessee.

- The contract requires payments over the duration of the contract, rather than a large, upfront payment. Although this condition is essentially financial in character and thus cannot be decisive on the type of the lease, it may indicate a degree of control for the lessor to direct the use of the nonproduced asset. The case for a treatment as rent is further supported if the payments are related to the revenue the lessee derives from the license. 
lease satisfies most or all of the criteria to be considered a sale of an asset in Box A4.1. When the land is leased in other circumstances, the payments are recorded as rent (1415 or 2814) under a resource lease agreement.

A4.27 In some jurisdictions, the land under buildings remains in the legal ownership of a landlord other than the owner of the buildings. If regular payments are made to the landlord, these are recorded as rent (1415 or 2814). However, it is sometimes the case that, even though the land legally belongs to another unit, the right to occupy it for an extended period is payable in a single upfront payment often when the building is acquired. In such a case the payment is recorded as the acquisition of a nonproduced asset, classified as land (3141) if the value of the land can be established separately from that of the building. If not, the composite asset should be classified in the category representing the greater part of the value (see paragraphs 7.94 and 8.51 ). In such a case, when the building changes ownership, the purchase price includes an element representing the present value of future rent payments. Therefore, the land is recorded as if the ownership is transferred along with the building above the land. If, at the end of the land lease, a further payment is liable for extension of the lease for another long-term period, this should be recorded as an acquisition of another nonproduced asset, as described earlier.

\section{Timber}

A4.28 For timber, four possibilities are distinguished: the sale of a natural resource asset, the sale of a permit, rent of a natural resource asset, or sale of forests that are produced assets.

- Sale of a natural resource asset-If government gives a unit permission to clear an area of natural forest, or to fell at its discretion without any restriction in perpetuity, the payments made to government (the owner) constitute the sale of the natural resource asset, classified as noncultivated biological resources (31431). ${ }^{10}$

- Sale of a permit-When licenses or permits issued to use the natural resource, such as timber,

\footnotetext{
${ }^{10}$ The sale of forested land may be recorded as the sale of the tim-
} ber and the land separately, depending on the intended use of each. satisfy the criteria to be a separate asset, the assets are classified as contracts, leases, and licenses (31441).

- Rent of a natural resource asset-It is common for timber felling to be allowed, subject to strict limits with a fee payable per unit volume of timber felled (stumpage). The limits are usually such that the harvest of timber is sustainable and so the payments are recorded as rent (1415 or 2814) in the case of a natural forest. The option to have a lease permitting felling at the lessee's discretion but subject to the restoration of the land, in an acceptable forested state, at some time in the future is improbable.

- Sale of goods and services-When cultivated forests are produced assets in the form of inventories, the extraction of timber is treated as the sale of goods and services (142).

A4.29 Illegal logging is prevalent in some countries. In such cases, the quantity of timber extracted should be recorded as other changes in the volume of assets (i.e., uncompensated seizure).

\section{Fish}

A4.30 Natural stocks of fish with an economic value are an asset, and the same considerations apply to them as to other natural resources. ${ }^{11}$ Two possibilities exist for commercial fishing:

- Fishing quotas are permits that may be allocated in perpetuity or for extended periods to particular institutional units-for example, where fishing is an established way of life and there may be little alternative economic employment. In such circumstances, the quotas may be transferable and, if so, there may be a well-developed market for them. Fishing quotas may, therefore, be considered as transferable permits to use a natural resource. Such permits are assets in macroeconomic statistics and classified as permits to use natural resources (614412) in the balance sheet.

\footnotetext{
${ }^{11}$ It is not realistic to consider that permission would be given to exhaust fish stocks, but illegal fishing may either reduce the stock position below the point of sustainability or exhaust it altogether. In these cases, an other volume change in the stock position should be recorded.
} 
- An alternative regime is to issue a permit for a strictly limited period of time, less than a year, to a nominated institutional unit, often a nonresident. This is a common practice in some islands in the South Pacific, for example. In these cases, the revenue from the licenses should be recorded as rent (1415) because it is a resource lease.

A4.31 A license for recreational fishing has long been considered, by convention, as payment of a tax under other taxes on the use of goods and on permission to use goods or perform activities (11452). This treatment is not changed by the wider considerations for commercial fishing.

\section{Water}

A4.32 A natural body of water with an economic value can be sold in its entirety either as part of the land that surrounds it or as a separate entity.

A4.33 As is the case for fish, it is unlikely that economic ownership would be ceded under a long lease with no preconditions on the quantity and state in which a similar amount of water should be returned to the owner. However, it is possible that surface water could be leased under a long lease for recreational purposes, for example. The treatment of such leases should be the same as for land (see paragraphs A4.26-A4.27).

A4.34 Regular payments for the extraction of water from natural water bodies (as opposed to the delivery of it) should be treated as rent (1415 or 2814). However, extraction of water as a produced commodity (e.g., purchases from a reservoir) should be recorded as the sale of goods and services.

\section{Mineral and energy resources}

A4.35 Mineral and energy resources differ from land, timber, and fish in that, although they also constitute a natural resource, they cannot be used sustainably. All extraction necessarily reduces the amount of the resource available for the future. This consideration necessitates a different set of recommendations for how transactions relating to their use should be recorded.

- When a unit, such as government, owning a mineral or energy resource cedes all rights over it to another unit, this constitutes the sale of the resource classified as mineral and energy resources (3142). Like land, mineral resources can be owned only by resident units; if necessary, a notional resident unit must be established to preserve this convention.

- When a unit extracts a mineral or energy resource under an agreement where the payments made each year are dependent on the amount extracted, the payments (sometimes described as royalties) are recorded as rent (1415 or 2814). The depletion of the resource itself is recorded as other changes in the volume of assets. ${ }^{12}$

\section{Sharing Assets}

A4.36 There are two ways in which assets may be shared, and the two cases require different treatments:

- The asset may be wholly legally owned by two or more units, each at different points in time.

- Alternatively, the risks of and benefits from the asset may be shared by two or more units at a single point in time.

A4.37 In macroeconomic statistics, even though the asset may be owned by different units at different times, when a balance sheet is drawn up, the whole of the value of the asset is attributed to one unit.

- For an asset subject to an operating lease, there is no ambiguity. The legal owner is also the economic owner and is the unit that shows the asset on its balance sheet.

- An asset subject to a financial lease is shown on the balance sheet of the economic owner. This is consistent with the views that the value of the asset represents the stream of future benefits coming from the asset and the economic owner is the unit entitled to receive these benefits in return for accepting the risks associated with using the asset in production.

- For an asset subject to a resource lease, the value is shown on the balance sheet of the legal owner.

\footnotetext{
${ }^{12}$ The reasons for recommending the simple recording of payments each year from the extractor to the owner as rent and changes in the size and value of the resource as other changes in the volume of assets of the legal owner are given in the 2008 SNA, paragraph 17.343.
} 
A4.38 When licenses to use natural resources such as radio spectrum, land, timber, and fish satisfy the criteria to be classified as intangible assets under permits to use natural resources (314412), they are part of the subclass of nonfinancial assets in the form of contracts, leases, and licenses (31441) and are shown on the balance sheet of the licensee.

A4.39 Sharing the risks and rewards of an asset between different units at a point in time is unusual. The most common occurrence is that a single unit undertakes the activity in which the asset is used and that unit shares the returns among the owners in the form of distributed property income. However, occasionally it is possible that such a single unit does not exist and it is not meaningful to try to create it statistically. This is most common when the participating units are resident in different economies, as may be the case with an airline, or in the case of some unincorporated joint ventures. The terms under which unincorporated joint ventures are established are diverse, but one form allows that all members share the assets equally. In such cases, macroeconomic statistics record the assets shared between the owners in proportion to their ownership shares.

A4.40 In some joint ventures that are recognized as institutional units, one party may contribute an asset as its share of the costs. If this happens, an injection of equity equal to the value of the asset should be recorded along with the acquisition of the asset in question by the joint venture.

\section{Permits to Undertake a Specific Activity}

A4.41 In addition to leases and licenses to use an asset as described in the previous sections, permission may be granted by government to engage in a particular activity, independently of any assets involved in the activity. Permission to extract minerals in return for the payment of rent, for example, is not covered by this type of permit because the permit derives from the government's ownership of the assets. The permits that give permission to engage in a particular activity are designed to limit the number of individual units entitled to engage in the activity. Such permits may be issued by government or by private institutional units and different treatments apply to the two cases. This section deals only with permits issued by government. Permits issued by units other than government are not discussed here because their treatment does not affect the government accounts. ${ }^{13}$

\section{Permits issued by government}

A4.42 When governments restrict, for example, the number of cars entitled to operate as taxis or limit the number of casinos permitted by issuing licenses, they are, in effect, creating monopoly profits for the approved operators and recovering some of these profits as the "permission fee." Such fees are recorded as other taxes on the use of goods and on permission to use goods or perform activities (11452). This principle applies to all cases where government issues licenses to limit the number of units operating in a particular field where the limit is fixed arbitrarily and is not dependent only on qualifying criteria.

A4.43 In principle, if the license is valid for several reporting periods, the payment should be recorded on an accrual basis with an entry in other accounts receivable (3208) or other accounts payable (3308) for the amount of the license fee covering future reporting periods. However, if government does not recognize a liability to repay the licensee in the case of a cancellation, the whole of the fee payable should be recorded as a single tax payment at the time it is paid.

A4.44 The incentive to acquire such a license is the licensees' expectation that they acquire the right to make monopoly profits at least equal to the amount payable for the license. For the license holder, this stream of future income is treated as an asset if the licensee can realize this by on-selling the asset. The asset first appears in the accounts of the licensee as an other change in the volume of assets. Subsequent increases and decreases in its value are recorded as holding gains or losses. These types of assets are described as permits to undertake a specific activity (614413). The value of the asset is determined by the value at which it can be sold or, if no such information is available, is estimated at the present value of the future stream of monopoly profits.

A4.45 If the payment for the license is being recorded on an accrual basis, the licensee has in the

\footnotetext{
${ }^{13}$ See the 2008 SNA, paragraphs $17.360-17.362$. Similarly, contracts for time share arrangements are not discussed in this Manual (see the 2008 SNA, paragraphs 17.344-17.348).
} 
balance sheet an asset under other accounts receivable equal to the value of the license fee covering future reporting periods and an asset recorded as permits to undertake specific activities (614413) for the value of the license covering the excess of the monopoly profits over the cost. If the license is on-sold, the price paid by the new owner reflects both the value of the right to receive a refund from the government if the license is cancelled and the present value of the future stream of monopoly profits. If the license was recorded as a single reporting period tax payment, the value of the asset for the licensee is the value at which it can be sold or, if no such information is available, is estimated as the present value of the future stream of monopoly profits. Box A4.2 outlines the statistical treatment of permits issued by government using four examples.

\section{Conditions for government permits recognized as assets}

A4.46 A permit issued by government to undertake a specific activity may be treated as an asset (permits to undertake specific activities (614413)) only when all the following conditions are satisfied:

- The activity concerned does not utilize an asset belonging to government; if it does, the permission to use the asset is treated as an operating lease, a financial lease, a resource lease, or possibly the acquisition of an asset representing permission to use the asset at the discretion of the licensee over an extended period.

- The permit holder must be legally and practically able to sell the permit to a third party.

- The number of permits is limited, thereby allowing the holder to make monopoly profits when undertaking the activity concerned.

- The permit is not issued subject to a qualifying criterion. Revenue raised from the issuance of permits that are subject to qualifying criteria are treated as either taxes on the use of goods and on permission to use goods, or perform activities (11452) or payments for services under administrative fees (1422).

A4.47 Even if all these conditions are satisfied, if in practice the permits are not on-sold, it is not rel- evant to record the permits as assets. If any of the conditions is not satisfied, the payments are treated as taxes on the use of goods and on permission to use goods or perform activities (11452) - that is, without the creation of an asset in the form of permits to undertake specific activities (614413). (There may be an account payable in cases when the permit holders make payments that will accrue over more than one reporting period.)

\section{Permits to use natural resources as sinks}

A4.48 Governments may issue emission permits as a means of controlling total emissions. These permits do not involve the use of a natural asset (there is no economic value placed on the atmosphere so it cannot be considered an economic asset). However, it is inherent in the concept that these permits will be tradable and that there will be an active market for them.

A4.49 The payments for emission permits issued by government are treated as taxes on the use of goods and on permission to use goods or perform activities (11452), at the time the emissions occur. The timing difference between the payments received by government for the permits and the time the emission occurs gives rise to a transaction in financial liabilities classified as other accounts payable (3308) for government and a financial asset classified as other accounts receivable (3208) for the holder. The difference between the prepaid tax value of the permit and the market value of the permit represents a marketable contract (nonproduced nonfinancial asset) for the holder. The creation and disappearance of the nonproduced nonfinancial asset are recorded as an other change in volume of assets.

A4.50 The case of payments for discharging water may be considered as an example of the different possible ways of treating the payments:

- If a payment to discharge water is a fine imposed by government intended to inhibit discharge, the fine should be treated as revenue for government classified as fines, penalties, and forfeits (143). If such a fine is imposed on government or public sector units by another institutional unit, the fine is included in expense, classified as current transfers not elsewhere classified (2821). 


\section{Box A4.2 Statistical Treatment of Permits Issued by Government: Examples}

Suppose unit A contracts with government to buy a permit to operate a casino for three years at a total cost of 12 . A expects to make monopoly profits of 7 per year because the permit excludes other casinos from operating. The government may or may not be prepared to make a refund if $A$ relinquishes the permit. A may utilize the permit for the three years for which it is valid or may sell it to unit B at the end of year 1 . The recordings under these four possibilities are examined as follows.

\section{Case 1: Government does not offer a refund and A keeps the permit for three years}

At the start of year 1, A pays tax of 12 and through an other change in the volume of assets recognizes an asset worth 21 initially. Government records only tax revenue of 12. Assuming no market price changes or discount factor, by the end of the year the value of the asset has reduced by 7 as an other volume change, because one of the three years for which the permit was initially valid has expired. At this point the asset is contributing 14 to A's net worth. By the end of the second year A writes off an additional 7 as an other volume change, leaving a contribution to net worth of 7 . By the end of the third year the asset is worth zero.

\section{Case 2: Government does not offer a refund and A sells the permit to B after one year}

At the start of year 1, A pays tax of 12 and through an other change in the volume of assets recognizes an asset worth 21 initially. Government records only tax revenue of 12. Assuming no market price changes or discount factor, by the end of the year the value of the asset has reduced by 7 as an other volume change, because one of the three years for which the permit was initially valid has expired. At this point, the value of the asset is 14 . However, B is prepared to pay only 13 for the asset and A accepts this offer. A therefore reduces the value of the asset by 1 through a holding loss (revaluation change), before selling it for 13. B acquires the asset for 13 and, assuming no further market price changes, its value reduces by 6.5 in the other change in volume of assets account in each of the two following years.

\section{Case 3: Government offers a possibility to refund and A keeps the permit for three years}

At the start of year 1, A makes a payment of 12 to government, which is recorded as a payment of tax of 4 for the year. The remainder of the amount is a prepayment of a tax and, therefore, at the end of the year government has an otheraccount payable to $A$ of 8 . The value of the permit to $A$ is only the excess of the monopoly profit over the total amount that A will have to pay to government. At the start of year 1, A recognizes an asset with a value of 9 (the difference between 7 and 4 for three years) through an other change in the volume of assets. Assuming no market price changes or discount factor, by the end of year 1 this permit asset is worth only 6 . At the end of that year, A's net worth includes an other account receivable from government of 8 and the remaining value of the permit of 6 . The total value of A's assets is 14 as in case 1. During the second year, A's other account receivable from government reduces by 4 which is used to pay the accrued tax in year 2. In that year, the value of the permit also reduces by 3 from 6 to 3 . At the end of the second year, A's net worth includes an other account receivable from government of 4 and, assuming no further market price changes, a permit worth 3, bringing A's total assets to 7 as in case 1 . At the end of year 3, A's other account receivable and the value of the permit are reduced to zero.

\section{Case 4: Government offers a possibility to refund and A sells the permit to B after one year}

At the start of year 1, A makes a payment of 12 to government which is recorded as a payment of tax of 4 for the year. The remainder of the amount is a prepayment of a tax and, therefore, at the end of the year government has an other account payable to $A$ of 8 . The value of the permit to $A$ is only the excess of the monopoly profit over the other account payable. At the start of year 1, A recognizes an asset with a value of 9 (the difference between 7 and 4 for three years) through an other change in the volume of assets. Assuming no market price changes or discount factor, by the end of the year, this permit asset is worth only 6 . At the end of the year, A's net worth includes an other account receivable from government of 8 and the remaining value of the permit of 6 . The total value of A's assets is 14 , as in case 1 . However, $B$ is prepared to pay only 13 for the asset and A accepts this offer. As in case 2, A has to reduce the value of the permit by 1 through a holding loss (revaluation change) before selling the asset to $B$ for 13 . The other account receivable from government of 8 is transferred to B and the asset (permit) is sold for 5 . B's net worth is unchanged because B has paid A 13 but received the other account receivable of 8 and an asset (permit) valued at 5 in return. In year 2, B's other account receivable is reduced by 4 due to the tax payment of 4 that accrued and, assuming no further market price changes, the permit declines in value from 5 to 2.5. At the end of year 3, B's other account receivable and the value of the permit are reduced to zero. 
- If a limited number of permits are issued with the intent to restrict discharges, the payment should be treated as taxes on the use of goods and on permission to use goods or perform activities (11452) if the medium into which the water is discharged is not regarded as an asset in macroeconomic statistics.

- If the medium into which the water is discharged is an asset and the necessary conditions are met concerning the terms on which the discharge is permitted, then the payment for the permit should be treated in the same way as the payment for a license to use the radio spectrum for mobile phones. If the payment is linked to remedial action, the payment is a payment for a service, unless the amount levied is out of proportion to the costs involved in subsequent water treatment, in which case the payment should be treated as other taxes on the use of goods and on permission to use goods or perform activities (11452).

\section{Contracts for future production}

A4.51 Although human capital is not recognized as an economic asset, there are cases where a contract that entitles the holder to limit the ability of a named individual to work for others may be regarded as an asset. Prolific and lucrative contracts may be for sports players where, for example, one football club can "sell" a player to another. In fact, the club is not selling the person, but rather the exclusive rights to have that person working for it. Similar contracts exist for the rights to publish literary works or musical performances. Such contracts are treated as assets, classified as entitlement to future goods and services on an exclusive basis (614414) within the asset class of contracts, leases, and licenses.

A4.52 Similar contracts may exist for the production of nonfinancial assets in future. An examination of the practice of purchasing the options of future aircraft production revealed, however, that in this case there is no transferable asset and a change of mind on the part of the potential purchaser or failure to deliver on the part of the supplier is settled by a change in the arrangements between the two parties and does not lead to the sale of the option to a third party. If an instance arises where the option to purchase nonfi- nancial assets is treated in the same way as a contract for a named individual's performance, the same classification would apply.

\section{Leases as Assets}

A4.53 As stated in paragraph A4.2, contracts underlie many transactions recorded in macroeconomic statistics and it is important to understand what the implications are for the time of recording and classification of transactions arising from a contract. Permits or licenses to use natural resources may constitute an asset, as may permits to undertake specific activities and contracts for future production.

A4.54 As indicated in paragraphs 7.105-7.106, a contract may be considered an asset when it is transferable to a third party (i.e., a unit other than the two specified in the original contract) - for example, a marketable operating lease acquiring a value as an asset. An example is given in Box A4.3. Assets reflecting such third-party property rights are always transitory: they exist only for the length of the lease and where there is a difference between the encumbered and unencumbered values.

A4.55 Permits to use natural resources and contracts for future production may also give rise to these types of third-party property rights assets. Similarly, permits to undertake specific activities may give rise to these types of assets even though the original payment, if payable to government, was treated as a tax. Financial leases do not give rise to these types of assets. If the value of the asset being leased increases by more than the payments due under the financial lease, the lessee may have the option of selling the asset, repaying the loan, and keeping the difference.

A4.56 In the case of marketable operating leases, the lease may be treated as an asset only when the two following conditions are satisfied:

- The lease specifies a predetermined price for the use of an asset that differs from the price the asset could be leased for at the current time.

- The lessee is able legally and practically to realize this price difference by subcontracting the lease to a third party.

A4.57 In practice, it is recommended that such assets should be recorded only when the value of the asset is significant and the lessee can actually exercise the right to realize the price difference. 


\section{Box A4.3 Practical Example of Leases as Assets}

Suppose a lease on an apartment agreed some time ago specifies the rental at 100 per month but its current market rent is 120 per month. From the lessor's point of view, the apartment is "encumbered" by the existing lease; that is, it carries a penalty (in this case of 20 per month) because of the existence of the lease. The encumbered value of the apartment is based on the present value of future rental payments taking the existence of the lease into account; that is, the future income stream is 100 for the remaining period of the lease and 120 thereafter (ignoring any allowance for inflation). The unencumbered value of the apartment is a present value based on an income stream of 120 per month from the current period forward. The value to be entered in the landlord's balance sheet is the encumbered value, which is also all the landlord (lessor) can hope to realize if he sold the apartment while the tenant has the right to maintain the lease. To realize the unencumbered value, the lessor would have to pay the tenant the difference between the unencumbered value and the encumbered value to be free of the lease. This amount, the encumbrance, can in some circumstances be treated as an asset of the tenant. The circumstances are that it is both legally possible and is practicable for the tenant to sublet the apartment to a third party. Because of the difficulty of identifying when such assets may exist, it is recommended that in practice these assets be recorded only when there is evidence that they have been realized.

The encumbered value of the apartment may be higher than the unencumbered value if rentals have fallen since the lease was agreed. In this case, it is the landlord who benefits from the discrepancy between the contract price and the market price because the value of the apartment in his balance sheet is still the encumbered value. If the tenant wishes to cancel the lease, he may have to pay the landlord the difference between the encumbered value and the unencumbered value. Only in the exceptional case where the tenant pays a third party to assume the lease at the price specified in the lease does this payment represent an asset of negative value to the tenant. Once the lease expires or is cancelled, the value of the apartment returns to its unencumbered value.

\section{Public-Private Partnerships Introduction}

A4.58 Public-private partnerships (PPPs) are longterm contracts between two units, whereby one unit acquires or builds an asset or set of assets, operates it for a period, and then hands the asset over to a second unit. Governments engage in PPPs for a variety of reasons, including the expectation that private management may lead to more efficient production and that access to a broader range of financial sources can be obtained. Such arrangements are usually between a private corporation and government, but other combinations are possible, with a public corporation as either party or a private nonprofit institution as the second unit. For ease of reference, the second unit will be referred to as the private corporation. These schemes are referred to by different names depending on the type of contracts that are in place. Examples are: private finance initiatives (PFIs); design, build, operate, and transfer schemes (DBOT); build, own, and transfer schemes (BOTs); or build, own, operate, and transfer schemes (BOOTs). For ease of reference, the remainder of this section will refer to PPPs.

A4.59 The nature of activities that PPPs are involved with varies greatly. Generally, the private corporations construct and operate assets of a kind that are usu- ally the responsibility of the general government or public corporations. These commonly include roads, bridges, water supply and sewerage treatment works, hospitals, prison facilities, electricity generation and distribution facilities, and pipelines.

A4.60 The private corporation expects to recover its costs and to earn an adequate rate of return on its investment. The government may make periodic payments during the contract period, ${ }^{14}$ or, alternatively, the private corporation may sell the services to the public (e.g., a toll road), or a combination of the two. The price is often regulated by the government and set at a level that will allow the private corporation to recover its costs and earn a return on its investment (benchmark price). If the regulated price is set at a level below such a benchmark price, the government will have to compensate the private partner, usually through subsidies or other transfers. There can be many variations in PPP contracts regarding aspects such as the disposition of the assets at the end of the contract, the required operation and maintenance of the assets during the contract, and the price, quality, and volume of services produced. At the end of the contract period, the

\footnotetext{
${ }^{14}$ The contract period refers to the length of the contractual agreement between the parties involved in the PPP.
} 


\section{Box A4.4 Determining the Economic Ownership of PPP-Related Assets}

The economic owner of the assets related to a PPP is determined by assessing which unit bears the majority of the risks and which unit is expected to receive a majority of the rewards of the asset.

The factors that need to be considered in assessing economic ownership of PPP-related assets include those associated with acquiring the asset and those associated with using the asset.

Some of the risks associated with acquiring the asset are:

- The degree to which the government controls the design, quality, size, and maintenance of the assets

- Construction risk, which includes the possibility of additional costs resulting from late delivery, not meeting specifications, or building codes, and environmental and other risks requiring payments to third parties.

Some of the risks associated with operating the asset are:

- Supply risk, which covers the degree to which the government is able to control the services produced, the units to which the services are provided, and the prices of the services produced

- Demand risk, which includes the possibility that the demand for the services, either from government or from the public at large in the case of a paying service, is higher or lower than expected

- Residual value and obsolescence risk, which includes the risk that the value of the asset will differ from any price agreed for the transfer of the asset to government at the end of the contract period

- Availability risk, which includes the possibility of additional costs or the incurrence of penalties because the volume and/or quality of the services do not meet the standards specified in the contract.

The relative importance of each factor is likely to vary with each PPP. It is not possible to state prescriptive rules that will be applicable to every situation. The provisions of each PPP arrangement must be evaluated to decide which unit is the economic owner.

government may gain legal and economic ownership of the assets, possibly without payment.

A4.61 The decision about economic ownership of the asset and whether to record PPP-related assets and liabilities in the government's or the private corporation's balance sheet is not straightforward. The private corporation is responsible for acquiring/constructing the fixed assets, although the acquisition/construction is often supported by the backing of the government. The contract often allows government to specify the design, quality, capacity use, and maintenance of the asset in accordance with government standards. Typically, the assets have service lives much longer than the contract period so that, for this reason alone, the government will control the assets, bear the risks, and receive the rewards for a major portion of the assets' service lives. Thus, it is frequently not obvious whether the private corporation or the government controls the assets over their service lives or which party bears the majority of the risks and benefits from the majority of the rewards. ${ }^{15}$

15 "Majority" should be assessed from an economic point of view. A single risk and reward may imply the "majority" in some cases, while in other cases, a number of separate risks and rewards combined may do so.

\section{Determining Economic Ownership of PPP-Related Assets}

A4.62 The statistical treatment depends on the economic ownership of the asset(s) involved. In macroeconomic statistics, a distinction is made between legal ownership and economic ownership (see paragraphs 3.38-3.41) based on risks and benefits. With a PPP, the legal and economic owner may be different parties. Box A4.4 summarizes the associated risks to be considered.

A4.63 The macroeconomic statistics approach is broadly consistent with considerations listed by the International Public Sector Accounting Standards Board (IPSASB) for the recognition and measurement of a service concession asset. ${ }^{16}$ While it is not possible to prescribe rules applicable to every PPP type of arrangement, the considerations presented in Box A4.4 should guide the decision on which party is the economic owner of the asset(s) during and at the end of the PPP contract period. The International

\footnotetext{
${ }^{16}$ IPSAS 32 spells out some guidelines for recognizing and measuring assets and liabilities relating to service concession assets (i.e., PPP-related assets).
} 


\section{Box A4.5 Practical Applications of the Economic Ownership Concept}

To operationalize the criteria for economic ownership-that is, whether the majority of risks and rewards accrue to government or to the private corporation-countries have followed different approaches.

Under Eurostat's guidelines to its member states, a sufficient condition for a PPP to be excluded from government's accounts has been that the private corporation bears the construction risk in the project and either the availability or the demand risks in using the asset in production. In 2010, Eurostat clarified how other elements, in addition to these three principal risk categories, should be analyzed to determine the distribution of risks between the public and private sectors - notably: the existence and scope of grantor guarantees; majority financing by the grantor of capital cost during the construction phase; and financial aspects of termination clauses (see Manual on Government Deficit and Debt Implementation of ESA 95, 2012 Edition, section VI.5).

Some countries are following internationally accepted accounting standards (e.g., IPSAS) applicable to financial leases (see paragraphs A4.10-A4.15). If a PPP contract is deemed to be a financial lease, an asset and liability are recorded on the public sector unit's balance sheet, interest and depreciation are recorded as operating expenses, and amortization is recorded as a transaction in financial assets and liabilities. IPSASs treat a lease as a financial lease to the extent that the following criteria are met: (i) the contract period covers most of the useful life of the asset; (ii) the asset is transferred to the lessee (the public sector unit in this case) at the end of the contract; (iii) the lessee can purchase the asset at a bargain price at the end of the contract; (iv) the present value of payments prescribed in the contract is close to the fair market value of the asset; and (v) the asset is useful mainly to the lessee.

Public Sector Accounting Standards (IPSASs) considerations of control of the asset include aspects of risks and rewards, and should, in principle, lead to the same conclusions on economic ownership. Box A4.5 presents a brief discussion on how some countries apply, in practice, the concept of economic ownership related to PPPs.

\section{Statistical Treatment}

A4.64 The following description of the statistical treatment of PPPs is based on the guidelines prescribed in the 2008 SNA. ${ }^{17}$ If the government is considered the economic owner of the asset(s) during the contract period but does not make any explicit payment at the beginning of the contract, a transaction must be imputed to cover the acquisition of the asset(s). The recording of these depends on the specific contract provisions, how they are interpreted, and possibly other factors. Most frequently, these contracts will be recorded as the acquisition of the asset through an imputed financial lease because of the similarity with actual financial leases. In other cases, for example, a loan that equals the market value of the asset at acquisition could be imputed, the actual government payments to the private corporation could be partitioned,

\footnotetext{
${ }^{17}$ The PSDS Guide presents examples of the recording of financial leases (see Box 4.11) and the recording of debt and flows arising from PPPs (see Box 4.16).
}

so that a portion of each payment represents the repayment of the loan (see paragraphs A4.10-A4.15), and the remainder could represent an expense for use of goods or services, subsidies, etc., in accordance with the contract.

A4.65 If the private corporation is considered the economic owner of the asset(s) during the contract period, any debt associated with the acquisition of the asset(s) should be attributed to the private corporation. Normally, the government obtains legal and economic ownership of the assets at the end of the contract without any significant payment. However, two approaches are possible to account for the acquisition of the asset(s) by government:

- Over the contract period, government gradually builds up a financial claim (e.g., other accounts receivable) and the private corporation gradually accrues a corresponding liability (e.g., other accounts payable), such that both values are equal to the residual value of the assets at the end of the contract period. At the end of the contract period, government records the acquisition of the asset, with a reduction in the financial claim (other accounts receivable) as the counterpart entry. The other unit records the disposal of the asset, with a reduction in the liability (other accounts payable) as the counterpart entry. Implementing this approach may be difficult because it requires new 
transactions to be constructed using assumptions about expected asset values and interest rates.

- An alternative approach is to record the change of legal and economic ownership from the private unit to government as a capital transfer at the end of the contract period. At the end of the contract period, government records revenue in the form of a capital transfer that finances the acquisition of the asset and the private unit records an expense in the form of a capital transfer payable to government, financed by the disposal of the asset. The capital transfer approach does not reflect the underlying economic reality as well as the first alternative, but data limitations, uncertainty about the expected residual value of the assets, and contract provisions allowing various options to be exercised by either party make recording a capital transfer in GFS acceptable on pragmatic grounds.

\section{Insurance and Standardized Guarantee Schemes Introduction}

A4.66 An insurance policy is an agreement between an insurer and another institutional unit, the policyholder. Under the agreement, the policyholder makes a payment (premium) to the insurance corporation, which makes a payment (claim) to the policyholder if or when a specified event occurs. The policyholder protects itself against certain forms of risk. By pooling the risks, the insurer aims to receive more from the receipt of premiums than it has to pay out as claims to the insured.

A4.67 This section describes types of insurance and standardized guarantee schemes. It first defines some terminology and then provides statistical guidance on the recording of the relevant flows and stock positions related to nonlife insurance and standardized guarantee schemes.

\section{Types of Insurance and Standardized Guarantee Schemes}

A4.68 The most common form of insurance is called direct insurance, whereby the policy is issued by an insurer to another type of institutional unit. ${ }^{18}$ There are two types of direct insurance-namely, life and nonlife insurance. Both types of insurance involve pooling risks. Insurers receive many (relatively)

\footnotetext{
${ }^{18}$ Another form of insurance is provided by one insurer to another insurer, which is referred to as reinsurance.
}

small regular payments of premiums from policyholders and pay much larger sums to claimants when the contingencies covered by the policy occur. During the interval between the receipt of premiums and the payment of claims, the insurance corporation earns income from investing the premiums received. This investment income affects the levels of premiums and benefits set by the insurer.

A4.69 Life insurance is an activity whereby a policyholder makes regular payments to an insurer, in return for which the insurer guarantees to provide the policyholder (or in some cases another nominated person) with an agreed sum, or an annuity, at a given date or earlier if the policyholder dies beforehand. For life insurance, an important relationship exists between premiums and benefits during the policy period. For policyholders, the benefits receivable are expected to be at least as great as the premiums payable, and this type of insurance can be seen as a form of saving. The insurer combines this aspect of a single policy with the actuarial calculations about the insured population concerning life expectancy (including the risks of fatal accidents) when determining the relationship between the levels of premiums and benefits. Life insurance mainly redistributes premiums payable over a period of time as benefits payable later to the policyholders or his/her beneficiaries. Essentially, life insurance premiums and benefits are transactions in financial assets and liabilities and not transactions in revenue and expense. Public sector units' involvement in life insurance is most often provided in the context of social protection in the form of employmentrelated pension schemes and other social protection schemes, such as compulsory saving schemes. The GFS treatment of these types of schemes is elaborated in Appendix 2.

A4.70 Nonlife insurance is an activity similar to life insurance except that it covers all other risks, accidents, sickness, fire, etc. For nonlife insurance, the risks are spread over all policyholders, and the number of claimants is typically much smaller than the number of policyholders. Nonlife insurance includes policies that provide a benefit in the case of death within a given period but in no other circumstances, usually called term insurance. With nonlife insurance, a claim is payable only if a specified contingency occurs and not otherwise. This type of insurance consists of redistribution in the current period 
between all policyholders and a few claimants. While public corporations may be involved in various types of insurance schemes, general government units are usually not involved in nonlife insurance other than social insurance, as discussed in Appendix 2.

A4.71 Standardized guarantees are those kinds of guarantees that are issued in large numbers, usually for fairly small amounts, along identical lines. There are three parties involved in these arrangements, the borrower (debtor), the lender (creditor), and the guarantor. Either the borrower or lender may contract with the guarantor to repay the creditor if the debtor defaults. Similar to nonlife insurance, it is not possible to determine the likelihood of any particular debtor defaulting. Nevertheless, because the guarantees are very similar and numerous, it is possible to estimate the general likelihood of defaults the guarantor will have to cover. It is standard practice to estimate how many out of a batch of similar debts will default. ${ }^{19}$ Therefore, standardized guarantees are based on the same paradigm as that for nonlife insurance, and a similar treatment is adopted for these guarantees. Standardized guarantees are distinguished from oneoff guarantees based on two criteria:

- They are characterized by often repeated transactions with similar features and pooling of risks.

- Guarantors are able to estimate the average loss based on available statistics by using probabilityweighted concepts.

A4.72 Standardized guarantees may be provided by a financial institution, including, but not limited to, insurance corporations. It is possible (but unlikely) that nonfinancial corporations provide these kinds of guarantees. However, government units are often involved as the guarantor in standardized guarantee schemes. The most common examples are export credit guarantees, deposit insurance schemes, ${ }^{20}$ and student loan guarantees. Specifically, when a government unit provides standardized guarantees without fees or at such low rates that the fees are significantly less than

\footnotetext{
${ }^{19}$ This default risk establishes the liability arising from standardized guarantees.

${ }^{20}$ If participation in such a deposit insurance or other guarantees is compulsory-that is, if beneficiaries cannot opt out of the scheme and the payment is clearly out of proportion to the service provided-it will not constitute a standardized guarantee scheme, but should be recorded as taxes on use of goods and on permission to use goods or perform activities (1145) as described in paragraphs 5.73-5.76.
}

the calls and administrative costs, the unit should be treated as a nonmarket producer within the general government. If government recognizes the probability of having to finance some of the calls under the guarantee scheme to the extent of including a provision in its accounts, a transfer of this size from government to the units concerned and a liability of this amount (under provisions for calls under standardized guarantee schemes) should be recorded. If a standardized guarantee scheme is operated by a corporation or quasi-corporation on behalf of government, any transfers to cover recurrent losses are classified as subsidies (see paragraph 6.89) and any transfers to cover large operating deficits accumulating over two or more years or exceptional losses due to factors outside the control of the corporation/quasi-corporation are recorded as capital transfers (see paragraphs 6.91-6.124).

\section{Defining Terminology Used in Insurance}

A4.73 Defining some of the terms peculiar to the insurance industry is helpful in clarifying the discussion on the statistical treatment of insurance and standardized guarantees. The term "premiums" is used for payment to the insurer, while the term "fees" is used to describe the payment to the guarantor in the case of standardized guarantees. Payments by the insurer are called "claims" in the case of nonlife insurance policies and "benefits" in the case of life insurance policies. In the case of standardized guarantees, "calls" relate to expected defaults on the guarantees.

A4.74 The actual premium (fee) is the amount payable to the insurer (guarantor) to secure insurance coverage for a specific event over a stated time period. Coverage is frequently provided for one year at a time, with the premium payable at the outset, though coverage may be provided for shorter (or longer) periods and the premium (fee) may be payable in installments-for example, monthly.

A4.75 The premium earned is the part of the actual premium that relates to coverage provided in the reporting period. For example, if a new annual policy with a premium of 120 units comes into force on April 1, and GFS are being prepared for a calendar year, the premium earned in the calendar year is 90 . The unearned premium is the amount of the actual premium received that relates to the period past the reporting period. In the example just given, at the end of the reporting period there will be an unearned 
premium of 30, intended to provide coverage for the first three months of the next reporting period.

A4.76 Net premiums are defined as actual premiums plus premium supplements minus the insurance service charge payable by the policyholders. Premiums are usually payable regularly, often at the start of an insurance period, whereas claims fall due later, in the case of life insurance, often many years later. The amounts accumulating between the periods the premiums were payable and when a claim becomes payable create a liability (reserves) for the insurer. These amounts are at the disposal of the insurer to invest in assets and earn income from it. The income allows the insurance corporation to charge lower premiums than would be the case otherwise. The property income earned in this way is attributed to the policyholders and is subsequently recorded as premium supplements from the policyholders.

A4.77 A claim (benefit or call) is the amount payable to the policyholder by the insurer in respect of an event covered by the policy occurring in the period for which the policy is valid. Claims generally become due when the event occurs, even if the payment is made some time later. An exception is made in cases where making a claim is possible only long after the event has happened. ${ }^{21}$ In such a case, the claim is recorded at the time the insurance company accepts the liability. Claims that become due are described as claims incurred. In some contested cases, the time between the occurrence of the event giving rise to the claim and the settlement of the claim may be several years. Claims on an accrual basis are recognized as due when an event takes place that gives rise to a valid claim, regardless of whether paid, settled, or reported during that period.

\section{Statistical Treatment of Nonlife Insurance and Standardized Guarantees}

A4.78 Under a nonlife insurance policy (or standardized guarantee), the insurer (or guarantor) accepts a premium (or fee) from a client and holds it in reserve (liability) until a claim (or call) is made or the period of the insurance expires. In the meantime, the insurer (guarantor) invests the amounts available due to pre-

\footnotetext{
${ }^{21}$ For example, an important series of claims were recognized only when exposure to asbestos was established as a cause of serious illness and was judged to give rise to claims under an insurance policy valid at the time of the exposure.
}

payments of premiums, reserves held against outstanding claims, and actuarial reserves held against outstanding risks. These assets generate investment income. The property income represents income forgone by the client, and so is treated as property expense attributed to the policyholders. It is therefore rerouted and subsequently recorded as an implicit supplement to the actual premiums. The insurer (guarantor) sets the level of the actual premiums (fees) to be such that the sum of the actual premiums plus the property income earned on assets, minus the expected outstanding claims will leave a margin that the insurer can retain. As an insurer or guarantor, the general government or public sector unit incurs liabilities equal to the present value of the expected claims or calls on outstanding guarantees, net of any recoveries. ${ }^{22}$ The statistical treatment of nonlife insurance and standardized guarantee schemes in GFS will depend on whether the general government or public sector unit acts as the insurer (guarantor), or whether they are policyholders.

\section{Flows and stock positions recorded by public sector units as nonlife insurers or guarantors}

A4.79 General government units are not likely to operate an insurance scheme, but if they do and if they maintain separate reserves, they would record transactions related to the nonlife insurance in the same way as other insurers. On the other hand, general government units are often involved as the guarantor in standardized guarantee schemes. For general government or public sector institutional units acting as an insurer or guarantor of standardized guarantees, recording these events would require recording the following entries in GFS:

- Actual premiums (fees) receivable-The amount of actual premiums (fees) receivable represents premiums earned and prepayment of premiums. $^{23}$ The portion of actual premiums (fees) receivable representing premiums (fees) earned for the reporting period represents revenue, classified as premiums (14511) or fees for standardized guarantees (14512), respectively. Prepaid

\footnotetext{
${ }^{22}$ These recoveries could include recoveries from the insured, reinsurance, defaulting borrowers, or third parties.

${ }^{23}$ An implicit service charge is implied by nonlife premiums. However, these charges can be calculated only in the context of an analysis of the whole of the economy. Therefore, the implicit service charge is not recognized in GFS.
} 
premiums (fees) represent a transaction in financial asset and liabilities, and are recorded as an increase in liabilities for nonlife insurance technical reserves (33061) or provisions for calls under standardized guarantee schemes (33065).

- Property income earned on the investment of reserves-Usually, the reserves related to insurance or standardized guarantees are invested in financial assets and the revenue generated by these investments is generally in the form of interest (1411) or dividends (1412). Sometimes, however, the reserves may be used to generate net operating surpluses either in a separate establishment or as a secondary activity. The most common example is rent (1415) generated from real estate assets.

- Property income attributed to policyholdersProperty income generated by the investment of reserves is deemed to be an implicit premium supplement. ${ }^{24}$ Therefore, the insurer or guarantor should attribute the property income to the policyholders ${ }^{25}$ by recording an expense, classified as property expense for investment income disbursements (2813). The counterpart entry to this expense is a transaction resulting in an increase in liabilities for nonlife insurance technical reserves (33061) or provisions for calls under standardized guarantee schemes (33065).

- Claims (calls) payable-An expense for expected claims (calls) should be recognized in premiums, fees, and current claims (2831) or capital claims (2832), as relevant, and with a counterpart entry as an increase in the liability related to nonlife insurance technical reserves (33061) or provisions for calls under standardized guarantee schemes (33065). For standardized guarantee schemes, the expense recorded is the expected level of calls (minus any expected asset recoveries) on the standardized guarantees provided in the recording period. When claims (calls) are paid, transactions are recorded reducing liabilities

\footnotetext{
${ }^{24}$ The attribution should, in principle, be made according to the proportion of reserves (stock of reserves) attributed to the different classes of insurance and policyholders. In practice, the usual method is to distribute the investment income in proportion to the actual premiums.

${ }^{25}$ In the case of standardized guarantees, the institutional unit that benefits from the guarantee may not be the same as the unit paying the fee for the guarantee. In this case, the property income is distributed to the unit paying the fee. The distributed property income is treated as a supplementary fee.
}

related to nonlife insurance technical reserves or provisions for calls under standardized guarantees with a corresponding reduction in assets or an increase in other liabilities.

- Holdings gains and losses-In some exceptions, if an amount for a claim outstanding has been agreed upon and it has been agreed that it will be indexed pending payment, there may be a holding gain or loss recorded for it.

- Other changes in volume of assets and liabilitiesChanges to provisions for calls under standardized guarantee schemes not resulting from transactions and holding gains and losses are shown as other changes in volume of assets-for example, whenever a significant change to the expected level of calls is recognized, beyond any asset recovery.

\section{Flows and stock positions recorded by public sector units as nonlife policyholders and holders of standardized guarantees}

A4.80 The recording of flows and stock positions related to standardized guarantees differs from the recording of one-off guarantees (see paragraph 7.256). For general government or public sector institutional units as nonlife insurance policyholders, or holders of standardized guarantees, the recording of their activities would require the following entries in GFS:

- Actual premiums (fees) payable - The amount of actual premiums payable represents premiums incurred, prepayment of premiums, and an implicit services charge payable. Because the implicit service charge can be calculated only in the context of an analysis of the whole of the economy, it is not recognized in GFS as an expense. The portion of actual premiums payable representing premiums incurred for the reporting period is an expense, classified as premiums (28311) or fees for standardized guarantees (28312), respectively. Prepaid premiums represent a transaction in financial assets and liabilities, and should be recorded as an increase in the financial assets in the form of nonlife insurance technical reserves (32061) or provisions for calls under standardized guarantee schemes (32065).

- Property income attributed to policyholders-As explained in paragraph A4.78, property income generated by insurers (guarantors) on the investment of reserves is deemed to be an implicit 
premium supplement, attributed to the policyholders. Conceptually, general government or public sector institutional units as policyholders might potentially record property income revenue, classified as property income from investment income disbursements (1414). The counterpart entry to this revenue is an increase in the financial asset for nonlife insurance technical reserves (32061) or provisions for calls under standardized guarantee schemes (32065). However, the revenue related to this item is not always known to GFS compilers. Therefore, this revenue is not recorded in GFS and remains an adjustment item between GFS and national accounts.

- Claims receivable-Claims become due when the event that gives rise to a valid claim occurs, regardless of whether paid, settled, or reported during the reporting period. The policyholder recognizes revenue for the claim at the time an event giving rise to a claim occurred, or in the case of a standardized guarantee, at the time a call can be made in terms of the contract. These claims receivable should be recognized as revenue classified as premiums, fees, and current claims (1451) or capital claims (1452), as relevant, and with a counterpart entry as an increase in a financial asset in the form of nonlife insurance technical reserves (32061) or provisions for calls under standardized guarantee schemes (32065). Upon actual payment of the claims, a decrease is recorded in the relevant insurance reserve, with a corresponding increase in cash or other financial assets. 
APPENDIX

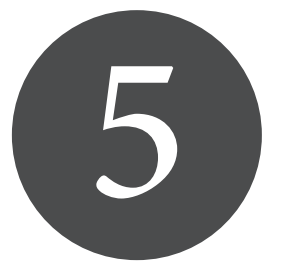

\section{Regional Arrangements}

This appendix describes various regional arrangements for monetary and economic cooperation and the implications of these arrangements for government finance statistics.

\section{Introduction}

A5.1 This appendix addresses the main issues for GFS that arise from regional arrangements. Regional arrangements involve coordination of institutional units in several countries for a particular monetary or economic purpose. These arrangements are often supported by regional organizations that operate across borders that need harmonized macroeconomic statistics to monitor economic development and the progress toward meeting the goals of the regional arrangement. The statistical issues that may arise in compiling harmonized data tend to be the same as those addressed in the GFS framework: definitions, coverage, time of recording, frequency, classifications, and presentation formats. An effective way of achieving this harmonization is by using a common methodology, such as the GFSM 2014.

A5.2 Where regional arrangements create regional organizations by means of an intergovernmental legal arrangement (e.g., a treaty), these institutions are classified as an international/regional organization if they satisfy the criteria to be an institutional unit and satisfy the criteria to be an international organization. ${ }^{1}$ Regional organizations are created for many purposes, including supporting, guiding, and even governing aspects of the economic relationships or integration processes among the region's economies. Regional organizations can be financial (e.g., regional central or development banks) or nonfinancial (e.g., administrative or economic organizations).

\footnotetext{
${ }^{1}$ International organizations are discussed in paragraphs 2.16-2.21.
}

A5.3 Regional arrangements tend to strengthen economic relations among the governments of the participating countries and between the regional organizations and the governments of the participating countries. As these economic relations can lead to significant flows and stock positions, it is important to have guidelines on their recording in GFS.

A5.4 This appendix presents the major types of regional arrangements, and points out the main GFS issues observed in each case. The appendix then examines using GFS under regional arrangements and, finally, it analyzes the requirements for harmonization to promote optimal coordination of policies and consistency in data.

\section{Types of Regional Arrangements}

A5.5 In the course of the last decades, numerous regional arrangements have been set up with various degrees of cooperation and integration between the participating countries. Such regional arrangements include:

- Customs unions, which have common tariff and other trade policies with nonmember economies

- Economic unions, which harmonize certain economic policies to foster greater economic integration

- Monetary and currency unions, which provide for a single monetary policy and the use of a single currency across an area.

\section{Custom Unions}

A5.6 A custom union is a form of regional arrangement whereby agreement exists on a common tariff (custom duties) vis-à-vis the other economies, while the movement of goods within the arrangement tends to be duty-free, although it may exclude exemptions 
in certain sectors. ${ }^{2}$ This type of arrangement is different from bilateral cooperation agreements between two countries in commercial areas that have little impact, if any, on GFS. ${ }^{3}$

A5.7 In compiling GFS for members of a customs union, the main issue is the recording of custom duties in the accounts of the member governments participating in the union. Duties on imports from countries outside the customs union are usually collected on a mutually agreed basis at custom union entry points. As these entry points may be concentrated in one or a small group of members of the customs union, revenue-sharing formulas among member countries are implemented. Recording customs duties in the GFS of individual members of the customs union is thus affected by the institutional and administrative organization of the customs union.

A5.8 The following paragraphs set out four possible types of regional arrangements: ${ }^{4}$

- A designated agency levies, ${ }^{5}$ collects, and distributes the proceeds from the duties.

- A designated agency levies and distributes duties, but member governments collect duties on behalf of the designated agency.

- Member governments have collective rights (i.e., the right is shared by everyone in the group) to levy, collect, and distribute the duties.

- Member governments have collective rights to levy the duties, but only one member collects and distributes the duties.

\footnotetext{
${ }^{2}$ Examples of such arrangements are: the Mercosur, which comprises Argentina, Bolivia, Brazil, Paraguay, Uruguay, and Venezuela; and the Southern African Customs Union, which comprises Botswana, Lesotho, Namibia, South Africa, and Swaziland. ${ }^{3}$ Bilateral trade agreements may also be observed between a regional arrangement and third countries or between regional arrangements. "Free trade agreements" generally fall under this category.

${ }^{4}$ There could be other, less formal or less complete arrangements. In the case of Mercosur countries, for instance, duties have so far been recorded for each individual country as taxes on international trade and transactions, as goods from third countries transiting from one union member to another are regarded as imports and exports among different custom union members. In 2010, Mercosur members agreed on a customs code that will allow the final confirmation of a genuine customs union and the redistribution of customs duties among members.

${ }^{5}$ To levy a tax implies that the agency has the authority to impose the tax, either as principal or through the delegated authority of a principal, and the agency has final discretion to set and vary the rate of the tax.
}

A5.9 In all four scenarios where there are economic arrangements involving a small group of economies, it is recommended that the governments involved agree on common, appropriate recording procedures to avoid bilateral asymmetries. ${ }^{6}$ The required information should be readily available from customs services. If a portion of the amount of customs duties is retained as collection fees (regardless of how the amount is calculated by the collecting agency or government), these fees should be recorded gross of the grants expense when the customs pool is distributed to the members. The retained amount should be recorded as incidental sales by nonmarket establishments (1423) in the accounts of the collecting agency or government, and use of goods and services (22) in the accounts of the member government receiving the grants.

A5.10 Tax attribution rules (see paragraphs 5.335.38) should be used to determine the attribution of customs duties revenue and the transfers associated with sharing the revenue pool among the members. The recording of such customs duties and grant transfers for four types of arrangements are discussed in paragraphs A5.11-A5.18.

\section{A designated agency levies, collects, and distributes the proceeds from the duties}

A5.11 In this case, the designated agency has the right to levy and collect the customs duties and distribute the proceeds. If the designated agency is recognized as an institutional unit, it may satisfy the criteria to be an international organization (see paragraphs 2.16-2.21), in which case all the transactions described should be between this international organization and the member governments. Otherwise it would be a resident of one member country, in which case all the transactions described should be between that government and all the other member governments. If the designated agency is not a separate institutional unit, it should be classified with the government unit that controls it.

\footnotetext{
${ }^{6}$ Member countries of the Central American Common Market (CACM) (Costa Rica, El Salvador, Guatemala, Honduras, Nicaragua) apply a common external tariff for products manufactured and imported from outside of the CACM. However, each CACM member is allowed to determine any product exceptions.
} 
A5.12 The customs duty revenue is attributed to the designated agency and should be recorded as customs and other import duties (1151) at the time the underlying economic event occurs (e.g., imports of goods or services) that gives rise to the customs duties, along with a counterpart entry increasing currency and deposits (3202) or other accounts receivable (3208).

A5.13 A revenue-sharing agreement may determine that the designated agency is to distribute the revenue pool to the participating national governments on the basis of an underlying economic event (e.g., imports of goods or services). In this case, revenue in the form of a grant (13), with a counterpart entry in other accounts receivable (3208), is recorded in the accounts of the member countries at the time the underlying economic event occurs. In the accounts of the designated agency, an equal amount of expense in the form of a grant (26) with a counterpart entry in other accounts payable (3308) should be recorded. Depending on the sector classification of the designated agency, the grant revenue should be recorded as either current grants from international organizations (1321) or current grants from foreign governments (1311), while the grant expense should be classified as grants to foreign governments (261) or grants to other general government units (263). The size of the grant depends on the nature of the revenue-sharing agreement. However, these revenue distributions may display an element of income redistribution among the members of a regional arrangement. That is, the distributions are not based on underlying economic events but are rather made to an agreed and negotiated formula. In this case, the grant should be recorded at the time the member economy acquires an unconditional claim on the designated agency. At the time of distribution, the member economies extinguish the other accounts receivable (3208), with a corresponding increase in the financial asset currency and deposits (3202). Conversely, the designated agency would record a decrease in other accounts payable (3308) and a decrease in the financial asset currency and deposits (3202).

\section{A designated agency levies and distributes duties but member governments collect duties on behalf of the designated agency}

A5.14 If national governments act as collecting agents on behalf of the designated agency for the cus- toms duties from importers in their own economy, the collecting national government should record only transactions in financial assets and liabilities when the economic event occurs. A liability in the form of other accounts payable (3308) to the designated agency should be recorded, with a counterpart entry in currency and deposits (3202) or other accounts receivable (3208). Because the customs duty revenue is attributed to the designated agency, they should record a financial claim on the member collecting the customs duties, in the form of other accounts receivable (3208) as the revenue in the form of customs duties accrues. When the collecting national government makes the payment to the designated agency, this member government records a reduction in financial assets in the form of currency and deposits (3202), with a counterpart entry to extinguish the liability in the form other accounts payable (3308).

A5.15 Distributions of the revenue pool by the designated agency are treated as described in paragraph A5.13.

\section{Member governments have collective rights to levy, collect, and distribute the duties}

A5.16 If member governments have collective rights to levy the customs duties under the customs union agreement, the custom duty revenue is attributed to the member governments according to the underlying economic activity that gives rise to the customs duties. The total customs duty revenue attributed to each member government is in proportion to the respective underlying economic activity that gives rise to the customs duties. Each member government records customs duties due on their imports on an accrual basis (i.e., when the underlying economic event occurred), regardless of how the revenue pool is to be shared or where the customs duties are collected. Should the customs union agreement provide for any member government to receive a larger share of the customs pool than is evidenced by the underlying economic activities, a grant revenue (131)/expense (261) should be recorded between member governments at the time the unconditional claims are established, with a corresponding entry in other accounts receivable (3208)/payable (3308).

A5.17 It is possible that the ports of entry for the customs union are situated in one or a small group of member economies. If so, there could be a 
discrepancy between the customs duty revenue collected by a member state and that member's share of the customs pool. In these circumstances, an increase in liabilities in the form of an other accounts payable (3308) is recorded for the collecting government at the time that such a claim can be established, with the corresponding increase in financial assets in the form of currency and deposits (3202) for the collecting government. The differences between the customs revenue collected by each of the customs union members and the total of each member's share of the customs pool should sum to zero across the customs union, as the customs revenue collected by the customs union equals the revenue to be shared among member governments.

\section{Member governments have collective rights to levy the duty, but only one member collects and distributes the duties}

A5.18 If member governments have collective rights to levy the duty, the tax revenue is attributed to the member governments according to the underlying economic activity that gives rise to the customs duties. If one of the member governments collects all the customs revenue, the recording is as described in paragraphs A5.16-A5.17. In this case, however, only the collecting government will record an increase in liabilities in the form of other accounts payable (3308), as all other economies will have claims in the form of other accounts receivable (3208) on the collecting economy for their share of the customs revenue.

\section{Economic Unions}

\section{Introduction}

A5.19 For statistical purposes, an economic union is a union to which two or more economies belong. Economic unions are established by means of an intergovernmental legal agreement among sovereign countries or jurisdictions with the intention of fostering greater economic integration. In an economic union, some of the legal and economic characteristics associated with a national economic territory are shared among the different countries or jurisdictions. These elements include: (i) the free movement of goods and services within the economic union and a common tax regime for imports from nonmember economies (free trade zone); (ii) the free movement of financial resources within the economic union; and (iii) the free movement of (individual and legal) persons within the economic union. ${ }^{7}$ Also, in an economic union, specific regional organizations are created to support the functioning of the economic union. Some form of cooperation and coordination in fiscal and monetary policy usually exists within an economic union.

A5.20 This type of regional arrangement represents greater cooperation than in a customs union agreement (which may have been a first step) because the members agree to harmonize a significant part of the conditions in which economic activity is undertaken over the whole union territory. The main example is the European Union (EU). The EU takes the form of common legislation in some areas, most notably in competition or product norms. Harmonization of taxes is also being envisaged in some areas. The aim of such unions is to unify markets by enlarging their size, improving efficiency, and developing specialization. Economic unions usually achieve a large, if not total, freedom of circulation for goods, services, capital, and individuals by removing the obstacles to such movements.

A5.21 Economic unions may also cover common policies in other fields. These may take a range of forms, from simple coordinated policy measures to a strongly harmonized framework and even to a centralized, direct management by supranational bodies having an autonomous budget and strict policy rules.

A5.22 An economic union requires specific entities endowed with the authority to manage an autonomous budget. These entities may have more or less autonomy to perform their tasks, in accordance with the institutional arrangements agreed between the members of the union.

A5.23 There may be significant grants payable and receivable between member states of an economic union to support certain economic activities or to develop the region. Nevertheless, the size of common budgets observed in existing economic unions is much smaller than member states' budgets. The flows involved are a small portion of total revenue and expense of the individual member states. ${ }^{8}$ All requirements related to fiscal policy are generally seen as

\footnotetext{
${ }^{7}$ As noted in paragraph 2.11, an economy and, by extension, an economic union can include physical or legal (special) zones to which, to some extent, separate laws are applied.

${ }^{8}$ In the European Union, the common budget amounted to about 1 percent of GDP of the union at the time of drafting this Manual.
} 
cooperation/coordination arrangements rather than effective common fiscal policies.

\section{Residence in an economic union}

A5.24 The economic territory of an economic union consists of the economic territory of the member countries or jurisdictions, and the regional institutions that comprise the same, or a subset of the same, economies and are set up to manage the functioning of the economic union.

A5.25 Being a resident of an economy of an economic union implies being a resident of the economic union. Regional organizations that operate within the boundaries of the economic union territory are also residents of the union. However, regional organizations whose membership of economies is not the same as, nor a subset of, those in the economic union should be regarded as nonresidents of the economic union. ${ }^{9}$

\section{Recording some specific transactions related to regional organizations}

A5.26 The common budget of the union that is managed by a regional organization may be funded by different types of sources. The main sources are taxes and grants. For example, in the EU, the majority of EU budget resources is based on gross national income (GNI) and value-added tax revenues of individual countries.

A5.27 Direct levies for the account of the common budget-in practice often collected by member governments-are recorded as taxes of the common budget in accordance with the tax attribution principle (see paragraphs 5.33-5.40). Such revenue cannot be considered as part of government revenue of the member economy because they are collected by the member economy on behalf of the union. In accordance with the accrual basis of recording, the collection of the taxes will give rise to other accounts payable (3308) for the collecting member government, and other accounts receivable (3208) in the accounts of the regional organization, at the time the taxes accrue to the international organization. These tax flows must be recorded gross of any collection fees. If there are specific provisions related to collection fees (based on actual expenses, a forfeited amount, or a percentage), the latter should be considered as revenue generated

\footnotetext{
${ }^{9}$ See paragraphs 2.6-2.21 for a description of the use of the residence criteria in GFS.
}

by incidental sales by nonmarket establishments (1423) in the accounts of the member government, and an expense for use of goods and services (22) in the accounts of the regional organization.

A5.28 The union agencies may also be financed directly by contributions from the members, according to agreed criteria. Such contributions may be agreed portions of certain taxes and fees. These taxes and other revenues are attributed to the member governments and are not collected on behalf of the union, but for their own account. Therefore, the respective member governments record the full collectable amount as taxes and other revenues in their accounts, and a subsequent grant payable to the regional organization.

A5.29 Expense of the regional organization covers its administrative and operating costs, but also costs associated with executing common policies for the benefit of the members of the union. Administrative and operating costs impact mainly the economy where the regional organization is physically located. These amounts are usually not significant and, where a common budget is developed, they represent a small portion of total expense of the regional organization. Of these, a small part could possibly be transactions with the host government and should be recorded in the government accounts of the member in accordance with the economic nature of the transaction.

A5.30 Expense associated with executing common policies for the benefit of the members of the economic union impacts specific categories of beneficiaries in the respective member countries. To accurately record these transactions, the ultimate beneficiary and nature of the expense should be identified regardless of the practical and/or institutional arrangements for channeling the amounts payable from union agencies to these economic beneficiaries.

- Where such expenses from the union budget managed by the regional organization cover costs directly benefiting the recipient member government units (in the context of a given programe.g., projects for infrastructures, research and development), revenue in the form of grants from international organizations (132) should be recorded in the member government accounts when all conditions have been met.

- Where member government units act as agents on behalf of the union, all transactions conducted 
on behalf of the union should, over time, be neutral on the member government revenue and expense. ${ }^{10}$ For example, if the member government receives amounts from the regional organization to distribute on behalf of the union to beneficiaries, only transactions in financial assets and liabilities should be recorded in the member government accounts. The national government records the incurrence of a liability for amounts received, classified as other accounts payable (3308) that are distributable to other economic beneficiaries. The actual distribution to the ultimate beneficiary reduces this account payable by the government unit. For the beneficiary, these amounts should be recorded as the appropriate category of revenue receivable-usually some kind of transfer receivable such as grants (13), subsidies (14411), or transfers not elsewhere classified (144). The regional organization would record the amounts payable in the corresponding categories of expense such as grants (26), subsidies (25), or transfers not elsewhere classified (282).

- Amounts distributable by government, acting as an agent for the union, may take the form of reimbursements claimed by the final beneficiary. These claims are usually on the basis of documents evidencing spending by the beneficiaries. Any amounts distributed by government on the basis of such claims by the beneficiaries give rise to a financial claim of government on the regional organization, notably other accounts receivable (3208), while the regional organization incurs a liability, other accounts payable (3308). Where the member government is acting on behalf of nongovernment units, it is possible that the member government anticipates repayments from the common union budget. Such anticipated repayments are also recorded as transactions in financial assets and liabilities, notably other accounts receivable/payable (3208/3308) between the government and the regional organization.

- When governments' claims on the regional organization for amounts reimbursed on the regional organization's behalf are not fully redeemed by the regional organization, the member government's recording depends on the circumstances:

\footnotetext{
${ }^{10}$ In some cases, by agreement, a part of the expense, in the context of programs managed at the union level, may be financed by the member government; for this portion of the expense the impact on the member government finances will not be neutral.
}

- The member government could decide to cover the expense made by final beneficiaries from the member government budget sources. The expense is recorded with a counterpart entry in the reduction of the claims on the regional organization. Such an expense should be classified according to the economic nature of the transfer-usually some type of transfer payable such as grants (26), subsidies (25), or transfers not elsewhere classified (282). The time of recording the expense is determined by the time of the government decision to cover the expense.

- The regional organization could indicate that a reimbursement by the member country should not have been made. The member government could recover the funds from the beneficiaries, or record the amount as expense of the member country.

A5.31 Full coverage of data for an economic union requires that these data include data from member countries as well as from the union agencies. Furthermore, to consolidate the accounts of the union-that is, eliminating all the flows and stock positions among member countries and the union agencies-sectors of the counterparties should be available for data on transactions, stock positions, and other economic flows. Compiling union accounts will allow an analysis of the whole union's flows and stock positions. This will also allow monitoring of the contributions of individual members to the union and measure the impact of the union on each member economy through redistribution mechanisms.

\section{Monetary and Currency Unions}

A5.32 A monetary union exists where there is the presence of a single monetary policy among economies, established by an intergovernmental legal agreement. In a monetary union, the decision-making related to monetary policy is transferred to a centralized body. There are different models-for instance, a single central bank for the whole union (possibly having only branches in the national economies) ${ }^{11}$ or a federal-like system where national central banks

\footnotetext{
${ }^{11}$ This arrangement is applied in the case of the West African Economic and Monetary Union (WAEMU) and the Economic and Monetary Community of Central Africa (CEMAC). WAEMU includes Benin, Burkina Faso, Côte d'Ivoire, Guinea-Bissau, Mali, Niger, Senegal, and Togo. CEMAC includes Cameroon, the Central African Republic, Chad, the Republic of Congo, Equatorial Guinea, and Gabon.
} 
still exist, keeping some specific activities not directly linked to monetary policy. ${ }^{12}$

A5.33 However, the core characteristic of a monetary union is that the monetary policy is exclusively conducted at the union level. There is a single set of intervention rates, and the national central banks (or branches) may in no way autonomously adjust the monetary policy to national conditions. They may, however, perform some specific tasks in the implementation process of the monetary policy, such as the management of collaterals that may be required for access to central bank liquidity and the delivery of banknotes in the different economies. ${ }^{13}$

A5.34 If a monetary union replaces national currencies with a common currency, they form a currency union. For statistical purposes, a currency union is defined as a union to which two or more economies belong and that has a regional central decision-making body, commonly a currency union central bank, endowed with the legal authority to conduct a single monetary policy and issue the single currency of the union.

A5.35 Monetary and currency unions do not raise specific issues for GFS, even in cases where a single, common central bank is a substitute for a domestic central bank in the context of the relationships between central bank and government. The currency union central bank is an institutional unit in its own right, owning assets and incurring liabilities, and is nonresident of any currency union member economy but resident in the currency union (see paragraph 2.21). Distributions of profits of such regional central banks should be classified as income on the financial asset to which member economies' subscriptions are attributed.

\section{Using the GFSM Statistical Framework under Regional Arrangements}

A5.36 Participation in regional economic arrangements may require some cooperation and coordination of fiscal policies. However, it is only in the context of monetary unions where such cooperation and coordination are generally viewed as an indispensable element for ensuring its optimal functioning.

\footnotetext{
${ }^{12}$ This arrangement is applied in the case of the European Monetary Union with the "Euro system" made up of the national central banks of the EU member states.

${ }^{13}$ See the BPM6, Appendix 3.
}

A5.37 In a monetary union, there is one single monetary policy that interacts with fiscal policies primarily carried out at the national level of each member country. At the same time, fiscal conditions may impact monetary policies.

A5.38 Therefore, to conduct proper monetary policies, monitor macroeconomic imbalances in member economies, and consolidate accounts for the union, fiscal statistics should be compiled in a consistent manner for all members of the union. Consistency in compiling fiscal data will allow the accurate measurement of differences in aggregates such as the tax burden, the share of government expense to GDP, the respective weight of different types of taxes in the total tax burden, the composition of expense, the implementation of budgetary rules, etc.

A5.39 Where coordinated fiscal policies are agreed in a union, the scope of such fiscal cooperation/ coordination has consequences for the statistical reporting framework. Fiscal targets may be defined and monitored at the union level. Examples of such key variables are the level of gross/net debt, operating balance, net lending/net borrowing, or, in the case of the cash basis of recording, the cash surplus/deficit. Quantitative targets (or "reference values") may be set at the union level, and these targets may be expressed as nominal amounts or ratios to gross domestic product. ${ }^{14}$

A5.40 Coordinated fiscal policies may also call for more disaggregated data. For instance, the calculation of primary balances requires that data on interest income and expense are available. Similarly, eliminating the influence of the business cycle on the level of revenue and expenditure by calculating the structural balance may require additional information (see annex to Chapter 4). In addition, measuring the outcome of specific economic objectives may require data on very detailed types of expenses, such as those related to social development goals or the government employee wage bill. The statistical framework for a union should be designed with a sufficient degree of detail, and should be applied by all members in a fully consistent manner, in order to capture the relevant information

\footnotetext{
${ }^{14}$ In the case of the West African Economic and Monetary Union (WAEMU), these quantitative targets, called "convergence criteria," are important for the multilateral surveillance exercised by the WAEMU Commission to ensure the convergence of the economic performance and policies of the member countries.
} 
needed to monitor the progress with the implementation of fiscal coordination objectives.

\section{Harmonization Requirements for GFS in Economic or Monetary Unions}

A5.41 The harmonization of GFS in the context of economic and monetary unions is important. It may be useful to introduce guidelines additional to the GFSM for economic and monetary unions. Additional guidelines could provide "rulings" or "fiscal policy rules" on specific transactions, aggregates, or balancing items that may occur in the member countries of the regional arrangement. It may also be useful to further clarify existing guidelines on concepts and definitions where it is observed that countries in a union interpret these guidelines differently, or application of these guidelines poses practical problems for members. Some examples of harmonizing regional arrangements are presented in Box A5.1.

A5.42 A common reason for fiscal data not being comparable across countries is the delineation of the general government sector. In most countries, there are borderline cases relating to units selling goods or service as their principal activity with various levels of financial support from government units (in the form of subsidies, grants, and other current transfers). Agreement on precise guidelines for the classification and sectorization of such units is an important factor in ensuring comparable data. When in doubt about these classifications, an appropriate dispute resolution mechanism should exist. In this context, the concept of economically significant prices might be clarified with a practical perspective. It is also recommended to publish institutional lists of general government and public sector units of individual countries to show transparently which units are included in the general government and public sectors.
A5.43 Another possible reason for data not being comparable across countries is the time of recording of economic events. In many countries, government units still apply the cash basis of accounting. International statistical guidelines and accounting standards have adopted the accrual basis of recording. Although an increasing number of governments have adopted accrual recording, many countries still use various mixes of source data based on cash- and accrual-based accounts. The differences in time lags between the economic events and the associated cash flows could distort the assessment of fiscal stance during a given year if a cash basis of accounting is mainly used. It is, therefore, preferable that fiscal targets include both cash and accrual measures. If no accrual source data are available, the countries in a union should agree on the methodology used to estimate the adjustments to convert cash data into accrual data. In practice, the adjustments required are especially relevant for taxes, social contributions, and interest.

A5.44 Attaining comparability in the measurement of gross and net debt across all countries in an economic or monetary union may be difficult in practice. In this Manual and the PSDS Guide, all debt instruments issued by government units are considered to be part of the coverage of debt (see paragraphs 7.236-7.245). Where the definition of gross and net debt in a union departs from international agreed definitions of debt, the data should be clearly labeled, and any departure from the required coverage and standard definition should be disclosed to the users of the data. Debt instruments excluded from the union definition of debt could be shown in memorandum items to allow comparability between data of the union members and other countries and to avoid the problem of "hidden" liabilities. 


\section{Box A5.1 Regional Arrangements in the Harmonizing of GFS}

\section{Customs Union of Belarus, Kazakhstan, and Russian Federation}

The Customs Union between Belarus, Kazakhstan, and Russia came into existence in 2010. Common trade controls and external tariffs exist, and two regional organizations make decisions related to the union. These agencies are financed by transfers from member countries. Customs duties collected at the first point of entry are redistributed to members via special accounts of members in the respective treasuries and the central banks. While no specific harmonization effort for fiscal data was implemented, the importance of consistency in recording trade data and valuations, and recording collection and redistributions related to customs collections is being considered by the member countries.

\section{Eastern Caribbean Currency Union}

In 2012, a proposal to migrate from the existing reporting format (based on the GFSM 1986) to a presentation highlighting the integration of stocks and flow as recommended by the GFSM 2001 was endorsed by the Eastern Caribbean Central Bank and the member countries.

\section{European Union}

The excessive deficit procedure, defined by the Maastricht Treaty (article 104) and in force in the European Union since 1994 , is a well-known regional arrangement in the compilation of fiscal data. The conceptual references for the debt and deficit aggregates are based on the European System of Accounts (ESA). The compilation practices and reporting requirements are legally binding in the European Union; regulations adopted by the European Commission form the basis for reporting. Eurostat issued the Manual on Government Deficit and Debt to aid member states in the application of ESA principles. This Manual addresses the most common statistical issues raised in the EU.

\section{Mercosur}

At the 40th meeting of Mercosur economy ministers and central bank chairmen in December 1998, the need to have statistical data based on a common methodology in Mercosur was acknowledged. This common methodology materialized in 2000, as a result of the member countries' decision to coordinate their macroeconomic policies with joint convergence targets. The preparation of harmonized statistics was agreed on, starting with six indicators: nominal fiscal balance of the national government, primary fiscal balance of the national government, net debt of the national government, net debt of the consolidated public sector, change of net debt of the consolidated public sector, price level, and the construction of a new indicator of the structural fiscal balance. Further efforts have been made since then in order to harmonize the Mercosur statistics according to international standards.

\section{South African Development Community (SADC)}

In 2010, participants from member countries of SADC endorsed a proposal by the SADC Secretariat to adopt the GFSM 2001 presentation of fiscal statistics, beginning in 2012. Preliminary work on converting the historical SADC fiscal database (based on the GFSM 1986) was completed, and countries made a commitment to begin compiling a Statement of Sources and Uses of Cash and a financial balance sheet.

\section{West African Economic and Monetary Union (WAEMU) and Economic and Monetary Community of} Central Africa (CEMAC)

In June 2009, the Council of Ministers of WAEMU adopted five regulations (directives) related to public finance management. One of the directives is related to the common reporting format of government fiscal operations known as Tableau des operations financières de l'État (TOFE). The TOFE directive is based on the GFSM 2001 methodology. The long-term objective of this directive is for member countries to produce comparable general government data for both flows and stocks. In December 2001, similar directives, including a TOFE directive, were adopted by the Council of Ministers of the CEMAC. In both monetary unions, a transition period was determined to fully implement the directives. (At the time of publishing this Manual, CEMAC was undertaking a revision of its public finance directives, one of which is related to common reporting formats for government fiscal operations.) 


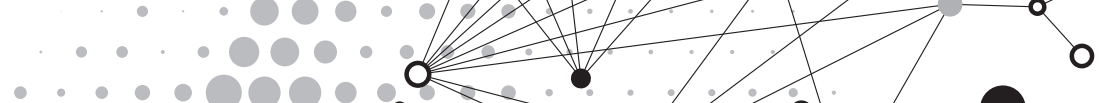

APPENDIX

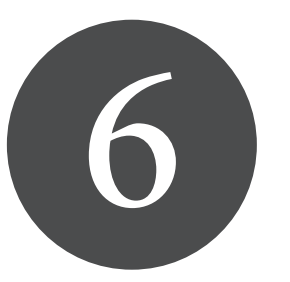

\section{GFS and International Public Sector Accounting Standards}

This appendix provides a generalized description of the relationship between the government finance statistics reporting guidelines and the International Public Sector Accounting Standards.

\section{Introduction}

A6.1 This Manual recognizes the close relationship between guidelines for reporting GFS and accrualsbased public sector accounting standards. Many of the accounting rules, concepts, and procedures used in macroeconomic statistics are based on those used in public sector accounting. International developments in statistical methodology and accounting standards for the public sector have been coordinated over recent years, to improve government reporting and fiscal transparency. A government's preparation of fiscal statistics that meet the guidelines set out in this Manual is facilitated by application of highquality accrual accounting standards, such as International Public Sector Accounting Standards (IPSASs). This is because a comprehensive accruals accounting system greatly improves the source data necessary for compilation of GFS. Governments should be aware of the scope that exists for them to design their Chart of Accounts so that data capture works efficiently for the dual purpose of generating GFS and accounting information.

A6.2 The Task Force on Harmonization of Public Sector Accounting, created in 2003, was the first formal initiative at the international level with the objective to harmonize statistical guidelines and accounting standards. The Task Force's major outputs were: (i) guidance in the area of public sector statistics that informed the update of the 2008 SNA, and (ii) a research report that systematically documented similarities and differences between the two reporting systems. International organizations and the International Public Sector Accounting Standards Board
(IPSASB) continue efforts to align guidelines as far as possible, while identifying and reconciling unavoidable differences that may continue to exist.

A6.3 Because both IPSASs and statistical reporting guidelines are dynamic and change over time, this appendix focuses only on the basic principles that explain why the two reporting frameworks differ. Detailed information on specific differences can be found on the IPSASB's website and through reference to individual IPSASs and detailed chapters of the GFSM 2014.

A6.4 This appendix focuses specifically on the links between GFS and IPSASs, because IPSASs are international standards and recognized as best practice for public sector financial reporting. IPSASs form a comprehensive set of full accruals accounting standards. Public sector accounting standards developed in many national jurisdictions are based on IPSASs. This means that comparison with IPSASs provides a clear, comprehensive basis for a GFS reporting guidelines comparison with accounting standards, while leaving scope for those who apply other, non-IPSASbased, full accruals accounting standards to adjust this overview for their own national differences.

\section{Comparison of IPSASs and GFS Reporting Guidelines}

A6.5 There is considerable overlap between IPSASs and GFS reporting guidelines. This section provides a generalized description of the relationship between IPSASs and the GFS reporting guidelines, focusing on the conceptual differences that explain why the two reporting frameworks differ in certain areas. It provides a summary of how to reconcile these two very similar yet-in important ways-different sets of information. If suitable adjustments are made to address the differences described here, IPSAS-based 
financial reporting information can be used as a highquality source for the data necessary for GFS reports. Independent audit of IPSAS-based financial reports enhances their reliability for GFS purposes.

A6.6 The description in this appendix is the same as the one included in Section 2 of the IPSASB Consultation Paper, IPSASs and Government Finance Statistics Reporting Guidelines. ${ }^{1}$ Readers are referred to the GFSM 2014 or the latest edition of the Handbook of International Public Sector Accounting Pronouncements for more detailed explanations of the applicable reporting guidelines and standards.

A6.7 The information provided here is at a high level, and focuses on identification of differences between the two frameworks. It is not designed to provide detailed current information about either IPSASs or GFS reporting guidelines. Detailed information on specific topics can be found through reference to individual IPSASs, the 2008 SNA, the ESA 2010, and the GFSM 2014. Both IPSASs and GFS reporting guidelines are dynamic and change over time. IPSASs, for example, have annual improvements, which typically impact on a number of different standards. The IPSASB's Conceptual Framework Project may also result in changes to IPSASs. For the most current IPSASs and detailed information on them, it is important to refer to the Standards themselves.

A6.8 Differences between IPSASs and GFS reporting guidelines are of two main types: (i) underlying conceptual differences, and (ii) presentation and terminology differences.

\section{Conceptual Differences between IPSASs and GFS Reporting Guidelines}

A6.9 The conceptual differences between IPSASs and GFS reporting guidelines are discussed under the following headings:

- Objectives

- Reporting entity

- Recognition criteria for some assets, liabilities, revenue, and expense

- Valuation (measurement) differences for certain types of assets and liabilities

- Revaluations and other volume changes.

\footnotetext{
${ }^{1}$ See www.ifac.org/publications-resources/ipsass-and-governmentfinance-statistics-reporting-guidelines.
}

A6.10 Box A6.1 compares IPSASs and GFS reporting guidelines in these areas.

\section{Objectives}

A6.11 GFS reporting guidelines and IPSASs have different objectives for the two sets of financial information produced. GFS reports are used to: (i) analyze fiscal policy options, make policy, and evaluate the impact of fiscal policies, (ii) determine the impact on the economy, and (iii) compare outcomes nationally and internationally. The focus is on evaluating the impact of the general government and public sector on the economy, and the influence of government on other sectors of the economy. The GFS reporting framework was developed specifically for public sector input to other macroeconomic accounts, although a range of countries adopt GFS reporting for their fiscal reporting, and for measuring compliance with fiscal rules. By contrast, IPSAS-based financial statements are used to: (i) evaluate financial performance and position, (ii) hold management accountable, and (iii) inform decision-making.

A6.12 Although the two sets of financial information necessary to meet these different objectives have many similarities, the different objectives do result in some fundamental differences in how and what information is reported. For example, in GFS reports, one distinction for transactions in financial assets and liabilities is whether the counterparty of the transactions is a resident or nonresident. In contrast, IPSAS-based financial statements report these transactions according to whether they are current or noncurrent assets or liabilities, with classification also in terms of their maturities and supplementary information provided on risks.

\section{Reporting entity}

A6.13 One of the fundamental differences between GFS reporting guidelines and IPSASs relates to the definition of the reporting entity and the process of consolidation (collectively often referred to as "identification of the reporting entity boundary"). Under GFS reporting guidelines, as described in Chapter 2 of the GFSM 2014 and in Chapter 4 of the 2008 SNA, institutional units are aggregated and consolidated into statistical sectors and subsectors. The focus of statistical reporting is primarily on consolidated sectors and subsectors. Although it is theoretically possible to 


\section{Box A6.1 Summary Comparison of GFS and IPSASs}

There is considerable commonality between IPSAS and GFS reporting guidelines. There are also some important conceptual differences within each area. Presentation and terminology differences are described in paragraph A6.34.

Government Finance Statistics

IPSASs

\section{Objectives}

Evaluate economic impact: Government finance statistics are used to (i) analyze and evaluate the outcomes of fiscal policy decisions, (ii) determine the impact on the economy, and (iii) compare national and international outcomes. The GFS reporting framework was developed specifically for public sector input to other macroeconomic datasets.

\section{Reporting entity}

Institutional units and sectors: The statistical reporting unit is an institutional unit, defined as an entity that is capable, in its own right, of owning assets, incurring liabilities, and engaging in economic activities in its own name. The reporting entity may be an institutional unit, but the primary focus is on a group of institutional units (consolidated sector or subsector). Control and the nature of economic activities determine consolidation and the scope of the reporting entity. The general government sector does not include institutional units primarily engaged in market activities.

\section{Recognition criteria}

The key difference relates to some liabilities.

Economic events recognized: GFS recognize economic events on the accrual basis of recording when economic value is created, transformed, exchanged, transferred, or extinguished. To maintain symmetry for both parties to the transaction, some provisions recognized in IPSAS reporting may not be recognized under GFS reporting. While not recognized, those provisions may instead be disclosed as GFS memorandum items, as is the case, for example, with exposures to explicit one-off guarantees and provisions for doubtful debts.

\section{Valuation (measurement)}

Current market prices: Current market prices are used for all flows and stocks of assets/liabilities, but allowance is made for the use of alternative valuation methods where an active market does not exist.
Past events with probable outflows recognized: IPSASs recognize liabilities, including provisions, when a past economic event has taken place; the amount can be reliably estimated; and future outflows are probable.

These factors allow, in certain cases, recognition of items that do not involve a counterparty recognizing a symmetrical amount. For example, so long as criteria are met, IPSASs require recognition of restructuring provisions.
Fair value, historic cost, and other bases: Fair value, historic cost, or other bases are used for the measurement of assets and liabilities. Similar assets and liabilities must be valued consistently and the bases disclosed. Where an entity reports an item using historic cost, IPSASs often encourage disclosure of fair value if there is a material difference between the reported cost and the item's fair value. Often IPSASs also allow entities to choose between fair value and historic cost.

\section{Revaluations and other volume changes}

Record all revaluations and changes in volume in the Statement of Other Economic Flows: Separating all these "other economic flows" is viewed as useful for fiscal analysis, on the basis that revaluations and changes in volume do not represent fiscal policy decisions directly within the control of government. GFS distinguishes between value changes and volume changes.
Realized and unrealized gains and losses: Some gains or losses due to revaluations or changes in volume of assets are reported in the Statement of Financial Performance, while others are reported directly in the Statement of Changes in Net Assets/Equity. Some other gains and losses-for example, market value changes for property, plant, and equipment carried at historic cost-are not reported at all. 
create GFS reports for individual institutional units, separate statistical reports for individual units are usually not disseminated. Each individual entity in the economy is analyzed with respect to its ability to hold assets and liabilities and exercise full economic ownership over them, to determine if it can be considered an institutional unit.

A6.14 Those government-controlled units that are primarily engaged in nonmarket (including redistributive) activities are included within the general government sector. Although all resident governmentcontrolled entities, including public corporations engaged in market activities, are included within the public sector, nonmarket activities determine the delineation of the general government sector, as a distinct subsector within the public sector. The general government sector does not include institutional units primarily engaged in market activities. The general government sector presents consolidated data, which means that transactions and stock positions between general government sector units are eliminated.

A6.15 In IPSASs, the "reporting entity" is a government or other public sector organization, program, or identifiable activity that prepares general purpose financial reports (GPFRs). Within a jurisdiction, reports may be prepared on either a compulsory or voluntary basis. A key characteristic of a reporting entity is that there are users who depend on GPFRs for information about the entity. A reporting entity may be a "group reporting entity."

A6.16 A group reporting entity consists of two or more separate entities that present GPFRs as if they are a single entity. A group reporting entity is identified where one entity has the authority and capacity to direct the activities of one or more other entities so as to benefit from the activities of those entities. It may also be exposed to a financial burden or loss that may arise as a result of the activities of entities whose activities it has the authority and capacity to direct. If these conditions are met, then the entity is described as a "controlling entity," with control defined according to the principle of exercisable power to govern the financial and operating policies of another entity so as to benefit from its activities.

A6.17 The requirement to consolidate entities differs in IPSASs and GFS. Under IPSAS 6, Consolidated and Separate Financial Statements, consolidated fi- nancial statements are the financial statements of a group of entities presented as those of a single entity. This means that a controlling entity will consolidate the financial statements of all of its controlled entities, irrespective of whether they are: (i) resident units, (ii) market/nonmarket entities, or (iii) the IPSAS equivalent of a market entity-that is, a "government business enterprise" (GBE). This contrasts with the general government sector consolidation approach, described earlier, where nonresident and resident market institutional units are included as a single line showing net investment, rather than fully consolidated into the general government sector.

A6.18 Nevertheless, IPSASs provide for the disclosure of financial information about the general government sector. IPSAS 22, Disclosure of Financial Information about the General Government Sector, specifically sets aside the application of IPSAS 6 while retaining the application of all other IPSASs. This allows-though does not require-an aggregate presentation that does not consolidate controlled interests in entities in other sectors.

A6.19 IPSASs also have a requirement (see IPSAS 18 , Segment Reporting) that a reporting entity provides disaggregated financial information about each of its segments. The information provided includes segment assets, liabilities, revenue, and expense. Segments are usually defined either in terms of geographical regions or services. GFS include data on expenditure by function of government.

\section{Recognition criteria}

A6.20 GFS reporting guidelines and IPSASs both aim to recognize economic events in the period in which they occur. Neither GFS reporting guidelines nor IPSASs allow the application of precaution or prudence to justify the reporting of provisions that anticipate future possible events. However, they differ in their recognition criteria for certain liabilities, because GFS treats uncertainty about future economic outflows differently from IPSASs. The effect of this difference is that IPSASs require more items to be recognized as liabilities than does GFS.

A6.21 In macroeconomic statistics, a liability is not recognized until a claim by the counterparty exists. Maintaining symmetry in the macroeconomic statistical system is a fundamental principle. Therefore, 
GFS guidance is that probable exposures such as contingencies and one-off guarantees should be disclosed in memorandum items, until such time as these are called. Some liabilities for government employee benefit payments and certain guarantee schemes are not contingencies, but instead are recognized as liabilities. IPSASs require that where there is a present obligation and an outflow will probably occur, the amount should be estimated and, if it can be reliably estimated, should be recognized as a liability in the statement of financial position (balance sheet).

A6.22 The key area of difference is that of "provisions," which IPSASs define as liabilities of uncertain timing or amount (see IPSAS 19, Provisions, Contingent Liabilities and Contingent Assets, paragraph 18). Provisions include obligations for which there is no counterparty-for example, provisions for restructuring and environmental restoration. Provisions may also involve an estimate of economic outflow for a group of obligations (e.g., warranties), on the basis that it is probable that the entity will have to meet a claim by a proportion of the overall group.

A6.23 This difference with respect to liability recognition will have consequential differences for expense and asset recognition. For example, recognition of a provision for restructuring will, under IPSASs, require recognition of a related expense, because there is no compensating increase in asset value. Recognition of a provision for eventual site restoration during construction of a landfill will, under IPSASs, be capitalized, adding to the overall investment in the asset. Under IPSASs, it is also possible for an increase or decrease in the amount of a provision to occur due to an improved estimate. An increase could result in expense recognition, while a decrease could result in revenue recognition. GFS would not recognize either these changes in assets/liabilities or the resulting revenue/expense until a point in the process where another party can be identified as receiving value.

A6.24 GFS and IPSASs apply the same broad recognition criteria to assets, with the result that, with a few exceptions such as assets arising from oil and gas exploration, the same financial and nonfinancial assets are recognized. Revenue related to asset recognition is generally also reported at the same point. But other differences, such as asset measurement differences, can affect the asset value recognized and there- fore the amount of revenue recognized. The timing of revenue recognition may differ due to differences between when GFS and IPSASs consider either that related obligations have been discharged or that related conditions have been removed.

\section{Valuation (measurement) bases}

A6.25 The valuation principles in GFS and IPSASs provide scope for the majority of assets and liabilities to be valued on the same basis-that is, at current market values, except where IPSASs require the use of historic cost or some other measurement basis. Both GFS and IPSASs allow proxies for current market value. For example, depreciated replacement cost can be used as a proxy for the current value of specialized assets, if no market price information is available.

A6.26 The general valuation principle of GFS is to use current market prices for all assets, liabilities, and related value changes-that is, for all stocks and flows. As explained in Chapter 3 of the GFSM 2014, where an active market does not exist, the GFS reporting guidelines recommend the use of nominal values for financial instruments, and an estimate of the value of other assets/liabilities. These estimates could be based on: (i) prices of similar products in similar markets, (ii) the costs of production of similar assets at the reporting date, or (iii) the discounted present value of expected future returns on the asset. (See also paragraphs 3.107-3.129 for a complete discussion of the valuation principles of GFS.)

A6.27 IPSASs allow, but generally do not require, the use of "fair value" for many, but not all, assets, liabilities, and related value changes. IPSASs define "fair value" as the amount for which an asset could be exchanged, or a liability settled, between knowledgeable, willing parties in an arm's-length transaction. This is similar to the basis for market price used in GFS IPSASs also allow assets and liabilities to be valued at historic cost.

A6.28 Under IPSASs, financial liabilities (with some exceptions) and financial assets that are (i) heldto-maturity investments, (ii) loans and receivables, or (iii) investments in equity instruments that cannot be measured at fair value because fair value cannot be determined reliably are measured at either cost or amortized cost, usually minus impairment losses (see IPSAS 29, Financial Instruments: Recognition and 
Measurement). Other marketable financial instruments are measured at fair value. Employee-related liabilities and long-term provisions other than financial instruments are measured at net present value, which may approximate market price. Property, plant, and equipment (PP\&E) and intangible assets can be valued either at fair value or at depreciated historic cost. Inventory is valued at cost, with a requirement to reduce to net realizable value, if the inventory's net realizable value falls below cost. IPSASs allow investment properties to be measured at fair value, except for those for which a fair value is not reliably determinable on a continuing basis (see IPSAS 16, Investment Property, paragraph 62). Biological assets are valued at fair value minus costs to sell, provided that fair value can be reliably measured.

A6.29 Where an item is reported at its historic cost, IPSASs often encourage or require disclosure of fair value, if there is a material difference between the item's historic cost and its fair value. For example, this is the case for property, plant, and equipment, intangible assets, and investment properties. In these three cases, the use of historic cost is optional under IPSASs. This means that governments can choose to value such assets at fair value. If an entity chooses fair value, then an initial valuation is made at cost, followed by subsequent measurements at fair value. Fair value measurement is not necessarily done annually. Interim measurements will be at the fair value determined at the most recent revaluation minus accumulated depreciation or amortization. While the choice of fair value should, theoretically, align IPSAS measurement with GFS measurement, other factors can, in practice, result in differences. Statisticians' measurement practices can involve sampling, indexing to inflation, and other estimation techniques that can generate different values from those produced by financial accountants.

A6.30 IPSASs require disclosure of the valuation basis for assets and liabilities. This means that IPSAS information makes clear whether a current market price has been used to value assets and liabilities. If historic cost has been used to value assets or liabilities, then the IPSAS source data will need to be adjusted from historic cost to current market price before it can be used for GFS. The adjustment will be straightforward where IPSASs already require disclosure of a market price valuation, which may be the case for some types of assets and liabilities where fair value is materially different from cost.

\section{Treatment of revaluations and other volume changes}

A6.31 GFS differentiates between transactions (economic flows by mutual agreement) and other economic flows. GFS records all holding gains and losses (revaluations) and other changes in the volume of assets and liabilities in the Statement of Other Economic Flows, which separates them from transactions. This distinction is useful for fiscal analysis. Other economic flows represent economic value gained or lost due to events that are not directly under the control of the government.

A6.32 IPSASs require the majority of changes in value to be recorded in the Statement of Financial Performance. Gains and losses recorded in the Statement of Financial Performance are then included in the total net amount that flows from the Statement of Financial Performance into the Statement of Changes in Net Assets/Equity. As a result, the Statement of Changes in Net Assets/Equity reports the total impact of all recognized value changes. Some unrealized gains and losses are not allowed to be recorded in the Statement of Financial Performance and must, instead, be recorded directly in the Statement of Changes in Net Assets/Equity. The main items are foreign exchange gains and losses related to foreign subsidiaries, and revaluations of property, plant, and equipment.

A6.33 Traditionally, the distinction between realized and unrealized gains/losses was viewed as the main difference between items recorded in the Statement of Financial Performance versus those excluded from this statement and, instead, recorded only in the Statement of Changes in Net Assets/Equity. The Statement of Financial Performance was viewed as showing realized gains/losses, while the Statement of Changes in Net Assets/Equity showed unrealized gains/losses. However, IPSASs now require many unrealized value changes to be included in the Statement of Financial Performance. For example, value changes due to unrealized revaluations of employee liabilities and impairments are included in the Statement of Financial Performance. The two main exceptions recorded in the Statement of Changes in Net Assets/Equity (foreign exchange fluctuations and revaluations of property, plant, and equipment, and intangible assets) are both unrealized, but they are also viewed as potentially obscuring an entity's financial performance, partly because they are viewed as outside of management's control, and 
partly because gains in one year may be reversed in subsequent years.

\section{Presentation and Terminology Differences}

A6.34 Presentation and terminology differences between IPSASs and GFS reporting guidelines also exist. As a result, the GFS and IPSAS financial statements and disclosures look different, even though the information reported is largely the same, apart from the recognition and measurement differences discussed elsewhere in this paper. This subsection describes the main presentation and terminology differences between GFS guidance and IPSAS requirements.

A6.35 The main presentation and terminology differences are as follows:

- Different names for the IPSAS equivalents of the GFS statements.

- The types of classification structures included in the balance sheet (statement of financial position), operating statement (statement of financial performance), and cash flow statement for the two reporting frameworks differ, which, in some cases, also necessitate differences in terminology.

- GFS sets out a minimum level of detail for a comprehensive list of standard line items that all entities must report in their GFS statements, while IPSASs establish a minimum set of standard line items, while providing principles and guidance on further line items that a reporting entity may need to report.

- The way in which additional information about the data is disclosed differs in the two frameworks.

- The definition and/or value of key statement totals (such as total assets, net worth, total revenue, and surplus/deficit) may differ.

A6.36 Each of these main differences is discussed in paragraphs A6.37-A6.46.

\section{Different names for statements}

A6.37 The IPSAS equivalents to the GFS statements have different names (see IPSAS 1, Presentation of Financial Statements). The IPSAS equivalent to the GFS Balance Sheet is a "Statement of Financial Position," although "Balance Sheet" and "Statement of Assets and Liabilities" are acceptable alternatives under IPSASs. The IPSAS equivalent to the GFS Statement of
Operations is a "Statement of Financial Performance," although "Income Statement," "Statement of Revenues and Expenses," "Operating Statement," and "Profit and Loss Statement" are acceptable alternatives under IPSASs. The GFS Statement of Other Economic Flows is partly captured in the IPSAS "Statement of Changes in Net Assets/Equity" and partly in the IPSAS "Statement of Financial Performance." The IPSAS equivalent to the GFS Statement of Sources and Uses of Cash is called a "Cash Flow Statement."

A6.38 IPSAS financial statements may also include a "Comparison of Budget and Actual Amounts," for which there is no GFS equivalent. This information must be provided by all entities that publish an approved budget (see IPSAS 1, Presentation of Financial Statements and IPSAS 24, Presentation of Budget Information in Financial Statements). It is presented either as a separate financial statement or as additional columns in the financial statements. A separate statement must be used when the budget is on a different basis from the actual reported results. For example, if the budget is prepared on a cash basis, while the results reported in financial statements are prepared on an accrual basis, the Comparison of Budget and Actual Amounts Statement is separate. If they are prepared on the same basis, the budgeted amounts can be fully integrated into the financial statements through the use of additional columns, and a separate statement is not necessary.

\section{Classification structures}

A6.39 The GFS reporting guidelines classify and group items in its statements differently from IPSASs. At the highest level, the terminology used for classifications is the same-for example, assets, liabilities, revenue, and expense. However, within these items there are conceptual differences and differences in the structure of subclassifications. The differences reflect the different objectives of the two information sets. For example, IPSASs require that assets and liabilities be presented as current or noncurrent, or that a liquidity structure be followed. This is important for assessing an entity's liquidity and solvency. GFS does not make this distinction in its core statements, but allows a supplementary table on the maturity structure of government's financial assets and liabilities to be compiled. However, GFS requires that assets be presented as financial or nonfinancial, which IPSASs do not require. 
A6.40 For GFS, standardized economic and functional classifications serve the specific objectives of: (i) comparability of the accounts of various government entities and subsectors, and (ii) international comparability. These classifications are devised to evaluate the impact of the general government and public sector on the economy as a whole, and to identify government's involvement with other sectors. For example, financial assets and liabilities are classified and presented according to whether they are domestic or foreign instruments, to allow an assessment of the government's interaction with the rest of the world. Such a classification is important because fiscal policy decisions on domestic versus foreign instruments are based on different criteria, and also because this classification allows the derivation of a government's impact on the balance of payments of the country. IPSASs do not require this distinction. The standardized GFS presentation also allows the calculation and comparison of analytical measures of fiscal policy, such as the primary balance, tax incidence ratio, expenditure by function, etc.

A6.41 Counterparty information is collected for both GFS and IPSAS reporting. The GFS economic classification requires counterparty information for flows and stocks (balance sheet) to be reported as standard line items. These identify items for consolidation, and establish the linkages with other sectors of the economy. IPSASs generally do not require counterparty information to be reported on the face of the financial statements or their related notes. However, IPSASs do require counterparty information to be collected: (i) by a parent entity to identify intra-group transactions, so that the entity can eliminate those in preparing the consolidated financial statements, and (ii) by a subsidiary to identify transactions with the parent entity and other entities that are under common control, so that information about those transactions can be disclosed in the notes. Counterparty information can also be important for risk-related note disclosures and related party disclosures.

\section{Minimum level of detail}

A6.42 GFS requires a minimum level of detail to be reported according to a comprehensive list of standard items. The level of detail is presented in standardized items to facilitate consistency over time, comparability, and consolidation of data across units and sectors. However, preparers may choose to provide additional detail.

A6.43 IPSASs also require some minimum items to be reported. However, presentation is less prescriptive compared to GFS reporting, with preparers required to make decisions about what items are shown, with reference to the purposes and understandability of statements, information relevance, and the principle that material items should be presented separately in the financial statements (see IPSAS 1). For example, preparers may choose between a presentation based on nature or function.

\section{Disclosure of additional information}

A6.44 To facilitate the correct interpretation of their GFS reports, compilers are encouraged to present information on the sources, methods, and procedures of the statistics as metadata or footnotes to statistical reports. In particular, information that may have an impact on assessing the statistics should be disclosed in the statistical reports. GFS also uses standard categories of memorandum items to report on items that are not reported in the body of the statements.

A6.45 IPSASs require that information that may have a significant impact for users be disclosed in notes to the financial statements. Notes include a summary of significant accounting policies. They also include further detailed information about individual items reported on the face of a statement-for example, (i) a breakdown of property, plant, and equipment into classes, (ii) information about items that are not recognized but nonetheless important (e.g., contingencies), and (iii) risk information related to financial instruments.

A6.46 GFS information is usually presented as a time series of data, so that comparative data for multiple years are presented at the same time. The periodicity of these data could be monthly, quarterly, or annually. IPSASs require only annual reporting, but allow more frequent reporting. Consistent GFS time series may be very long, decades for some countries. Following from this, corrections to data will be required to be made in the period in which errors occurred, irrespective of when the need for such corrections is determined. Financial statements presented according to IPSASs require comparative information for only one previous year, though the number of years involved in calculating adjustments 
of prior year figures for policy changes and errors is not specified.

\section{Mapping from IPSAS financial statement aggregates to GFS aggregates Total assets and total liabilities}

A6.47 Some broad classification differences exist between the classification of assets and liabilities in GFS and IPSASs.

- GFS classify assets and liabilities in terms of whether they are financial or nonfinancial. IPSASs do not require assets and liabilities to be grouped in these terms, nor do they require summary totals for financial and nonfinancial assets. However, they do require financial and nonfinancial assets and liabilities to be separately disclosed, which means that there is sufficient information in an IPSAS statement of financial position (balance sheet) to determine totals for financial and nonfinancial assets and liabilities.

- GFS classify financial assets and liabilities into domestic and foreign. IPSASs do not use this classification, although some of these disclosures may be included in an entity's risk management disclosures related to financial instruments.

- GFS classify assets and liabilities according to standardized GFS characteristics and purposes, which can differ from the classifications required by IPSASs. For example, in IPSASs, the classification of property is determined by whether it is an investment property, while GFS distinguishes property according to whether it is a produced/ nonproduced asset and whether it is a dwelling, other building, other structure, or land improvement. IPSASs classify financial instruments into whether they are for trade or to be held until maturity, whether liabilities are employee liabilities, and whether provisions relating to environmental restoration all differ from the GFS classification.

\section{Net worth}

A6.48 The GFS concept of net worth plus equity (also referred to as own funds) is equal to IPSASs' net assets/equity:

- In GFS, net worth for a specific period is defined as total assets minus total liabilities. The balance sheet opening net worth + operating balance + changes in all assets and liabilities due to other economic flows $=$ balance sheet closing net worth.

- According to IPSASs, net assets/equity is calculated as the opening net assets/equity + surplus/ deficit + items shown directly on changes in equity statement $=$ closing net assets/equity. Net assets/equity is also equal to the net of all assets minus liabilities, excluding equity.

A6.49 These differences in the calculation of the net balancing item primarily result from the differences between how GFS and IPSASs allocate items to their respective statements (GFS showing other economic flows separately). In addition, it should be noted that, in the GFS net worth concept, equity is treated symmetrically as part of financial assets and liabilities-that is, equity investments within assets, and any equity of the government entity held by nongovernment units-usually rare for government entities-within liabilities. In contrast, the IPSAS net assets/equity concept includes equity that GFS treats as a liability, whereas investments in another entity's equity are recognized as financial assets.

A6.50 In addition to these presentational differences, the values of these items can also differ due to valuation and recognition differences.

\section{Revenue and expense}

A6.51 Although the GFS and IPSAS accrual concepts of revenue and expense are different, they can be reconciled as follows:

- GFS revenue + other economic inflows = IPSAS revenue + economic inflows recognized directly in Statement of Changes in Net Assets/Equity

- GFS expense + other economic outflows = IPSAS expense + outflows recognized directly in Statement of Changes in Net Assets/Equity.

A6.52 IPSASs refer to materiality as a classification criterion for revenue and expense. In this context, GFS requires reporting on standard items. In addition to the economic classification (as shown), the GFSM 2014 and the SNA/ESA also have a Classification of Functions of Government (COFOG).

A6.53 Under IPSASs and GFS, cash flows resulting from acquisitions or disposals of assets are recognized in the Cash Flow Statements. However, in the accrual-based accounts, the time of recording asset 
revaluations and the statement in which changes in valuations are recorded may differ. Under IPSASs, assets may be recorded at historical cost or fair value, depending on their nature. Any gain or loss on disposal is a realized holding gain or loss recorded in revenue and expense at the time of disposal. As such, these gains/losses are shown as part of the surplus/ deficit that is recognized in the Statement of Financial Performance. Under GFS, assets are valued at current market prices and any holding gains or losses are recognized as they occur. These valuation changes are reflected in the Statement of Other Economic Flows. For assets disposed of at prices different from the valuation of the asset, it is deemed that such an other economic flow occurred right before disposal, so that at disposal there is no gain or loss reflected in the Statement of Operations. Therefore, the amounts of revenue/expense recognized will differ from that recorded under IPSASs.

\section{Consumption of fixed capital (assets)}

A6.54 In theory, the GFS concept of consumption of fixed capital differs from the IPSAS concept of "depreciation." The IPSAS concept of "depreciation" involves allocating changes in an asset's historic cost or current value to the reporting period in which the asset is used, as a measure of the asset's consumption. The GFS concept of consumption of fixed capital is based on a current value concept-described in the 2008 SNA (paragraph 6.240) as the decline, during the course of the accounting period, in the current value of the stock of fixed assets owned and used by a producer as a result of physical deterioration, normal obsolescence, or normal accidental damage. Consumption of fixed capital is a forward-looking measure that is determined by the benefits that institutional units expect to derive in the future from using the asset in production over the remainder of its service life. In practice, consumption of fixed capital is usually calculated according to aggregated asset groups using a model approach.

A6.55 In practice, depreciation would approximate GFS consumption of fixed capital, if similar valuation methods and service lives are assumed for assets, and IPSAS-based asset values are close to replacement values through revaluations. Where IPSAS asset values are based on historic cost values, depreciation would usually represent an underestimate of consumption of fixed capital. The difference will be large for governments that have a large stock of fixed assets, as many governments do.

\section{Operating balance}

A6.56 The GFS net operating balance is calculated in the same way as the IPSAS "surplus/deficit." Both are calculated as revenue minus expense. However, the value of these two balancing items is likely to differ, because there may be differences between items included in the GFS revenue and expense and those included in IPSAS revenue and expense. This difference can be mainly attributed to the conceptual difference in the treatment of other economic flows. 


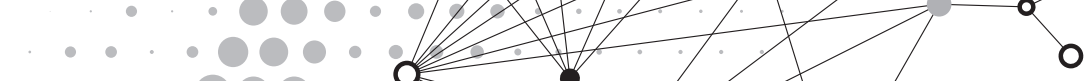

\section{GFS and Other Macroeconomic Statistics}

This appendix describes the relationships between government finance statistics and national accounts, balance of payments and international investment position, monetary and financial statistics, and the System of Environmental-Economic Accounting (SEEA) Central Framework. This appendix is intended to provide an overview of the major similarities and differences between government finance statistics and other major datasets, as well as an indication of how to reconcile the data in cases where there are differences in presentation. The text of this appendix is not intended to take preference over the methodological guidance provided elsewhere in this Manual.

\section{Introduction}

A7.1 It is important for compilers and users of GFS data to understand how GFS relate to the other macroeconomic datasets. More specifically, an understanding of the linkages fosters consistency in the respective datasets and supports whole-of-economy analysis.

A7.2 The institutional arrangements for compiling and producing macroeconomic statistics differ from country to country. These could range from a single entity being responsible for the compilation of source data and the final GFS to several national agencies being involved in the compilation of various components of the data. Agencies such as ministries of finance (MOFs), national statistics offices (NSOs), central banks (CBs), and other government agencies may be involved. The MOFs are often involved in compiling budget data from accounting and other administrative records to monitor implementation of the government budget. NSOs are often responsible for compiling, producing, and disseminating macroeconomic statistics in line with the $2008 S N A^{1}$

\footnotetext{
${ }^{1}$ In this appendix, most references to the SNA concern the general content of the volume rather than the citation of a specific portion of the text. The expression "in the SNA" is used to refer to the national accounts compiled in accordance with the 2008 SNA as a body of thought.
}

principles. They may use source data from MOFs that are based on national classifications and make necessary adjustments according to the requirement of the statistical guidelines. CBs are primarily involved in compiling monetary and financial data to allow them to monitor financial conditions and the implementation of monetary policies. All these data should be based on consistent methodological guidance, and where multiple agencies are involved in compiling macroeconomic data compilation, it is essential that these national agencies coordinate efforts to best ensure consistency in data outputs. ${ }^{2}$

A7.3 A clear understanding of the linkages between datasets will assist countries in producing comparable and consistent statistics needed for economic analysis and policy decisions. The primary purpose of GFS is to provide a comprehensive conceptual and statistical reporting framework for analyzing and evaluating fiscal policy. In addition, detailed GFS also provide a measurement of the impact of government on other sectors of the economy. Therefore, these fiscal data serve as input for other datasets, while other datasets may be used to derive and/or verify GFS data. Harmonization in practice allows compilers to share source data, where appropriate, and also fosters coherent developments in the source data systems.

A7.4 The remainder of this appendix provides an overview of the important similarities and differences between the GFS and other major datasets. It describes the similarities related to coverage and accounting rules and then provides a comparison of the analytical framework of GFS with that of the national accounts, balance of payments and international investment position, and the monetary and financial statistics. Last, the appendix describes how the GFS

\footnotetext{
${ }^{2}$ See Dziobek and Tanase, Institutional Cooperation between Central Banks and the Statistical Offices for Producing Macroeconomic Statistics, IFC Bulletin No 28, August 2008.
} 
framework relates to the System of EnvironmentalEconomic Accounting (SEEA) Central Framework. Where there are differences in presentation, the appendix provides an indication of how to reconcile the data.

\section{Overview of Similarities and Differences}

A7.5 This Manual is harmonized with the 2008 SNA, which provides the conceptual basis for national accounts. The BPM6 serves as the standard framework for statistics on the transactions and positions between an economy and the rest of the world. The Monetary and Financial Statistics Manual (MFSM) provides guidelines on compiling statistics for the financial corporations sector. These manuals are also harmonized with the 2008 SNA. ${ }^{3}$

A7.6 Broadly, the principles and concepts are defined in a consistent manner in all these statistical manuals. The delineation between resident and nonresident entities, sectorization of the domestic economy, and definitions and classifications of financial instruments are the same. The accounting rules used are the same with respect to basis of recording and valuation. While the accrual basis of recording flows and stock positions is used consistently in all data-sets, GFS also include the compilation of a Statement of Sources and Uses of Cash. With a few exceptions, as described in the detailed comparisons, the flows and stock positions of GFS are defined and valued in the same way.

A7.7 For analytical reasons, the structure and presentation of the GFS framework in Chapter 4 and the GFS treatment of a few activities differ from the framework and presentation of the data of the general government sector in the 2008 SNA and other datasets. While all the datasets have balancing items, the aggregation and consolidation rules are not exactly the same.

A7.8 GFS focus on measuring the impact of economic events on the finances of government, and the impact of government activities on the economy through taxing, spending, borrowing, and lending. The SNA focuses on the linkages between sectors of the economy, and the economic processes of produc-

\footnotetext{
${ }^{3}$ Revision of the MFSM, 2000 edition, to align with the 2008 SNA, is pending at the time of publication of this Manual.
}

tion, income generation and distribution, consumption of goods and services, and accumulation. The balance of payments summarizes economic transactions between residents and nonresidents during a specific period, while the international investment position shows the value of the financial assets and liabilities stock positions between the residents of an economy and nonresidents at a reporting date. Monetary statistics focus on assessing monetary conditions and the impact of monetary policy decision on the money and capital markets. These differences in focus require that the recording of government activities in GFS occasionally differ from the recording of those activities in the other macroeconomic datasets. However, such differences are the exception to the general principle, as consistent application of conceptual standards applies across related datasets. Where there are differences in presentation, reconciliation of the differences should routinely be made to ensure consistency in the macroeconomic data.

\section{Coverage and Accounting Rules}

A7.9 The identification of institutional units and their sectorization are conceptually the same in all macroeconomic datasets. Where analytically useful, certain datasets may require that the primary sectors be further divided into subsectors according to need. For example, GFS present data for the subsectors of the general government as separate datasets, while monetary statistics present data for subsectors of the financial corporations. As described in paragraph 2.58, the general government sector in GFS is defined identically to the general government sector in the national accounts, balance of payments, and monetary statistics. Although the public sector is not one of the five primary sectors in the SNA, it is recognized as an additional grouping. ${ }^{4}$ The residence concept used to delineate resident and nonresident entities and the sectors used in identifying counterpart transactions are the same across all datasets. Compilers of macroeconomic data should therefore ensure that the actual coverage used in their statistics is identical.

A7.10 Most of the accounting rules employed in these macroeconomic frameworks are identical. In

\footnotetext{
${ }^{4}$ The definition of public sector as defined in the 2008 SNA, Chapter 22, Section B, is identical to the definition in paragraph 2.63 of this Manual.
} 
particular, the rules for time of recording, the valuation of flows and stock positions, and the rules governing the gross or net recording of flows and stock positions are identical.

A7.11 The principal difference between GFS and the SNA regarding accounting rules concerns consolidation (see paragraph 3.167 of this Manual). In principle, GFS requires the elimination of all intra- and intersector flows and stock positions between units of the same sector and subsectors. Consolidation can be applied to the statistics of any group of units, including subsectors of the general government sector, the entire public sector, or any other grouping depending on analytical interest.

A7.12 As a matter of principle, consolidation is not used in the SNA, although it is acknowledged that consolidation may be useful for the general government sector (see the 2008 SNA, paragraphs 2.69, 3.197, and 22.79). Even when used in the national accounts, transactions appearing in different accounts are never consolidated so that balancing items are not affected. For example, in national accounts, interest receivable by one government unit that is payable by another government unit is shown as both revenue and expense in the accounts of the general government sector. In contrast, full consolidation is used in GFS. Such interest is recorded neither as an expense nor as revenue in the data for the consolidated general government sector as a whole, although such interest could appear in the subsector accounts of general government if the two parties involved are in different subsectors of the general government. Because SNA statistics are not consolidated, the GFS compiler should preserve the unconsolidated statistics for use by the national accounts compiler.

\section{Comparison of the Analytical Frameworks of GFS and the SNA}

A7.13 Both GFS and the SNA can be described as the systematic recording and presentation of flows and stock positions, with the flows comprising transactions and other economic flows. While the recording of flows and stock positions are generally the same in the two datasets, the accounts in which these are recorded differ because of the unique objectives of the two datasets. In general, both datasets have the same interest in the activities of general government and public sectors, although the arrangement of the data differs and the actual flows recorded differ in some instances. These differences could be summarized as follows (see Table A7.1):

- The GFS framework primarily records the operations of the general government or public sector according to revenue, expense, and transactions in nonfinancial and financial assets, and liabilities. These transactions and other economic flows are integrated with balance sheets. The SNA records general governments' transactions according to their involvement in the measurement of production, generation, distribution and use of income, and capital and financial account transactions. These transactions and other economic flows are also integrated with balance sheets.

- The SNA reconciles the current accounts, accumulation accounts, and balance sheet positions across all institutional sectors, whereas GFS undertake such reconciliations only for the general government and public sectors.

- The two datasets differ in recording practices. GFS are based on the principle of double-entry recording, similar to business accounting, but the SNA is based on the principle of quadrupleentry accounting, because most transactions involve two institutional units. Each institutional unit involved in a transaction must record the transactions according to the double-entry system for the accounts to be in balance.

- The focus of the SNA is on various kinds of economic processes. Therefore, where the recording of a single transaction is sufficient in GFS, multiple entries may be required in the SNA to correctly reflect all the relevant economic processes.

\section{Comparison of the Accounts in GFS and the SNA}

A7.14 The GFS analytic framework consists of four statements (see Chapter 4). The Statement of Operations is a presentation of all transactions recorded in the GFS framework. Other economic flows are presented in the Statement of Other Economic Flows, ${ }^{5}$ and the stock positions are presented in the Balance Sheet.

\footnotetext{
${ }^{5}$ For analytical reasons, the Statement of Other Economic Flows could also be presented as separate statements to record Holding Gains and Losses and Other Changes in Volume of Assets and Liabilities.
} 


\section{Table A7.1 Main Differences between GFS and the SNA}

\begin{tabular}{|c|c|}
\hline Indicator & Differences identified \\
\hline Analytical framework & $\begin{array}{l}\text { GFS are mainly presented in four statements, including a cash-flow statement. } \\
\text { In the SNA, transactions are presented in a sequence of seven accounts (see Figure A7.1), other } \\
\text { economic flows are presented in two accounts, and stock positions are presented in the Balance } \\
\text { Sheet. There is no equivalent to the GFS cash-flow statement. }\end{array}$ \\
\hline Focus & $\begin{array}{l}\text { GFS focus on measuring the impact of economic events on the finances of government. } \\
\text { The SNA focuses on measuring economic processes and their impact on the various sectors of } \\
\text { the economy. }\end{array}$ \\
\hline Consolidation & $\begin{array}{l}\text { In principle, GFS eliminate all intra- and intersector flows and stock positions between units of } \\
\text { the same sector and subsectors. } \\
\text { In the SNA, consolidation is not used as a matter of principle, although it is acknowledged that } \\
\text { consolidation may be useful for the general government sector. }\end{array}$ \\
\hline $\begin{array}{l}\text { Unfunded } \\
\text { employment-related } \\
\text { pension funds }\end{array}$ & $\begin{array}{l}\text { GFS require that a liability be recognized for all unfunded employment-related pension } \\
\text { obligations. } \\
\text { SNA allows some pension obligations to be excluded from the core accounts and reported } \\
\text { in supplementary tables. The SNA recognizes all social contribution revenue and expense, } \\
\text { and records an adjustment item for the change in liabilities, while GFS recognize social } \\
\text { contributions and benefits as either revenue and expense or transactions in liabilities. }\end{array}$ \\
\hline $\begin{array}{l}\text { FISIM, insurance } \\
\text { services, and } \\
\text { fees related to } \\
\text { standardized } \\
\text { guarantees }\end{array}$ & $\begin{array}{l}\text { In GFS, the services fees related to interest, nonlife insurance premiums, and fees for } \\
\text { standardized guarantees are not separately identified because they can be estimated only } \\
\text { indirectly by considering data for all sectors of the economy, such as in the national accounts. } \\
\text { In the SNA, the values for FISIM, insurance services, and standardized guarantees are derived by } \\
\text { partitioning interest, nonlife insurance premiums, and fees for standardized guarantees. }\end{array}$ \\
\hline $\begin{array}{l}\text { Transfers in kind- } \\
\text { goods and services } \\
\text { produced by } \\
\text { government }\end{array}$ & $\begin{array}{l}\text { In GFS, goods and services produced by government and transferred in kind are recorded as } \\
\text { imputed sales only when provided to employees as wages in kind. In all other cases, only the } \\
\text { cost of producing these goods and services is recognized in the respective expense categories. } \\
\text { In the SNA, all goods and services produced by government and transferred in kind are recorded } \\
\text { as a transfer and an imputed sale of goods and services. }\end{array}$ \\
\hline $\begin{array}{l}\text { Internal transactions } \\
\text { in respect of own- } \\
\text { account capital } \\
\text { formation }\end{array}$ & $\begin{array}{l}\text { In GFS, compensation of employees, use of goods and services, and consumption of fixed } \\
\text { capital incurred in own-account capital formation are excluded from expense and are recorded } \\
\text { as a component of the cost of the acquisition of the nonfinancial asset. } \\
\text { In the SNA, the full costs of compensation of employees, use of goods and services, and } \\
\text { consumption of fixed capital are recorded as well as the acquisition of the nonfinancial asset. }\end{array}$ \\
\hline
\end{tabular}

Finally, the Statement of Sources and Uses of Cash provides information on liquidity.

A7.15 In the SNA, transactions are presented in a sequence of seven accounts (see Figure A7.1), other economic flows are presented in two accounts, and stock positions are presented in the Balance Sheet. There is no SNA equivalent to the GFS Statement of Sources and Uses of Cash.

A7.16 Each flow in the SNA relates to a particular kind of economic process or activity, such as production, or the generation, distribution, redistribution or use of income, and accumulation. Each of the current accounts shows the resources available to the institu- tional units and the uses of these resources. These accounts are balanced by introducing a balancing item defined residually as the difference between the total resources recorded on one side of the account and the total uses recorded on the other side. The balancing item from one account is carried forward as the first item in the following account, on the opposite side, thereby making the set of accounts an articulated whole.

A7.17 In the SNA, the sequence of transaction accounts is grouped into current and accumulation accounts. The current accounts record the production of goods and services, and the generation, distribution, redistribution, and use of income. The accumulation 


\section{Figure A7.1 Diagram of the Sequence of SNA Accounts}

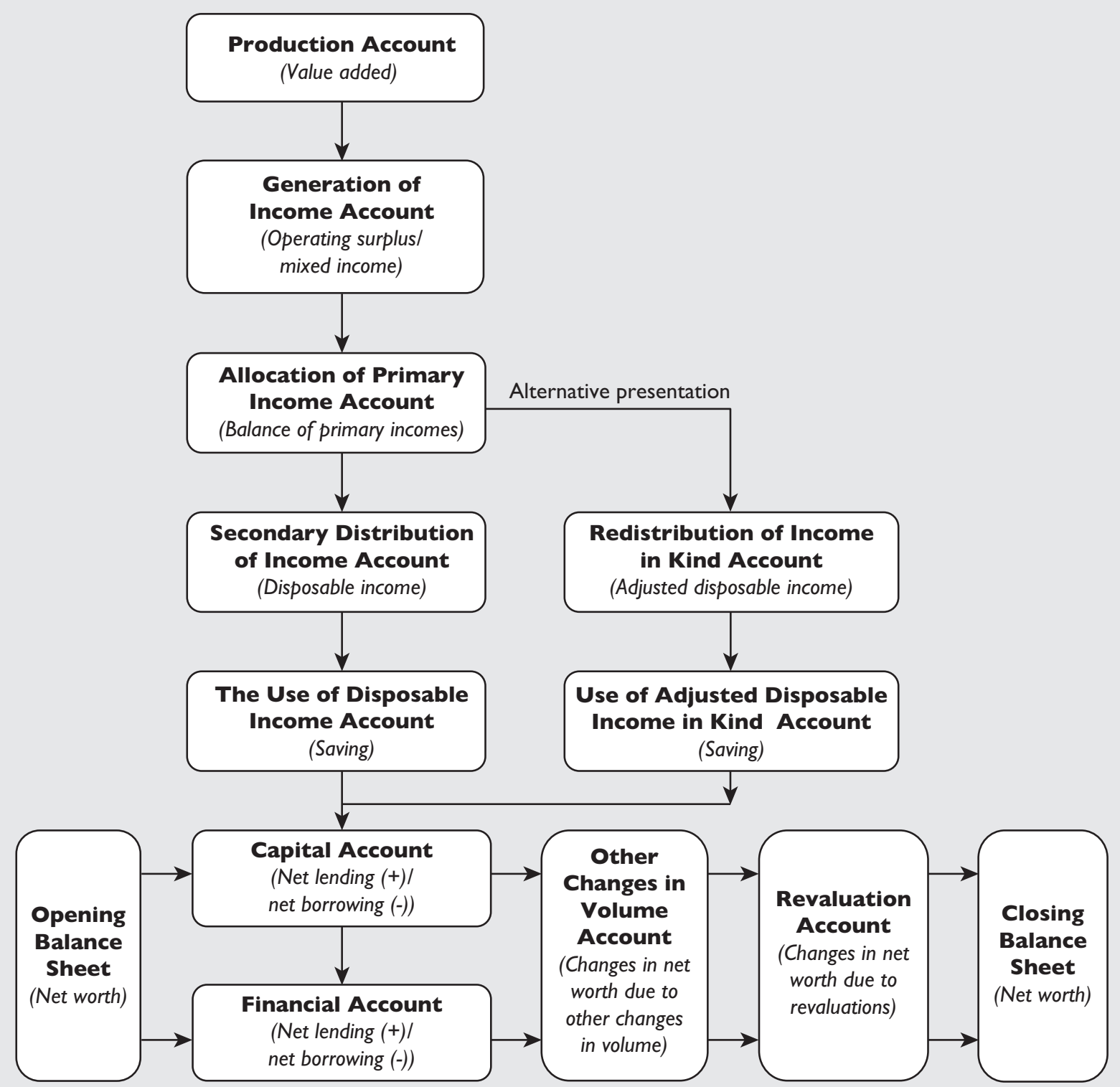

Note: Balancing items are shown in italics.

accounts record capital transfers, the acquisition and disposal of assets and liabilities, and other economic flows related to assets and liabilities. Despite the large number of accounts in the SNA, there is broad correspondence between the structures of the GFS and SNA datasets. ${ }^{6}$

\footnotetext{
${ }^{6}$ Explicit provision is made in the SNA for flexibility in the presentation of stock positions and flows. The accounts described here comprise the basic presentation described in Chapters 6 through 13 of the 2008 SNA.
}

A7.18 As illustrated in Table A7.2, the GFS Statement of Operations can be divided into three sectionsnamely:

- Transactions affecting net worth

- Transactions in nonfinancial assets

- Transactions in financial assets and liabilities.

The GFS transactions affecting net worth (revenue and expense) are shown as transactions in the current 


\begin{tabular}{|c|c|c|c|}
\hline \multicolumn{2}{|c|}{ GFS Statement of Operations } & \multicolumn{2}{|c|}{ SNA Sequence of Accounts } \\
\hline Main aggregates & Balances & SNA current accounts & $\begin{array}{l}\text { Balances and main } \\
\text { aggregates }\end{array}$ \\
\hline Revenue, Expense ${ }^{2}$ & $\begin{array}{l}\text { Net operating balance (or } \\
\text { change in net worth due } \\
\text { to transactions) }\end{array}$ & $\begin{array}{l}\text { Production account } \\
\text { Generation of income account } \\
\text { Allocation of primary income account } \\
\text { Secondary distribution of income } \\
\text { account } \\
\text { Use of disposable income account }{ }^{1}\end{array}$ & $\begin{array}{l}\text { Value added / GDP } \\
\text { Operating surplus and } \\
\text { mixed income } \\
\text { Balance of primary } \\
\text { income / GNI } \\
\text { Disposable income / NDI } \\
\text { Saving / National saving }\end{array}$ \\
\hline \multicolumn{4}{|c|}{$\begin{array}{l}\text { Conceptually, net operating balance differs from saving with the value of capital transfers and taxes on capital } \\
\text { transactions, and capitalized expense. Additional differences in calculated values may arise due to differences in } \\
\text { treatment of some employment-related pension schemes. }\end{array}$} \\
\hline & & SNA accumulation accounts & $\begin{array}{l}\text { Balances and main } \\
\text { aggregates }\end{array}$ \\
\hline $\begin{array}{l}\text { Operating balance }{ }^{2} \\
\text { minus net investment in } \\
\text { nonfinancial assets }\end{array}$ & $\begin{array}{l}\text { Net lending }(+) / \text { net } \\
\text { borrowing }(-)\end{array}$ & Capital account ${ }^{2}$ & $\begin{array}{l}\text { Net lending }(+) / \text { net } \\
\text { borrowing }(-)\end{array}$ \\
\hline \multicolumn{4}{|c|}{$\begin{array}{l}\text { Conceptually, net lending (+)/net borrowing (-) in GFS is the same as in the SNA. In practice calculated values may differ } \\
\text { due to difference in treatment of some employment-related pension schemes. }\end{array}$} \\
\hline $\begin{array}{l}\text { Net acquisition of } \\
\text { financial assets minus net } \\
\text { incurrence of liabilities }\end{array}$ & $\begin{array}{l}\text { Change in financial } \\
\text { worth due to transactions } \\
=\text { net lending }(+) / \text { net } \\
\text { borrowing }(-)\end{array}$ & Financial account & $\begin{array}{l}\text { Net lending }(+) / \text { net } \\
\text { borrowing (-) }\end{array}$ \\
\hline
\end{tabular}

${ }^{1}$ The use of the disposable income account is replaced by the use of the adjusted disposable income account by an alternative sequence of accounts in which the secondary distribution of income account is augmented with the redistribution of income in kind account (see Chapters 8 and 9 of the 2008 SNA for additional details on these accounts).

${ }^{2}$ Capital transfers as recorded in the SNA capital account are included in GFS as revenue and expense.

accounts of the SNA with one exception: capital transfers are shown in the capital account of the SNA, one of the accumulation accounts. All of the GFS transactions in nonfinancial assets presented in the second section of the Statement of Operations are shown in the capital account of the SNA, while the GFS transactions in financial assets and liabilities correspond to the transactions shown in the financial account of the SNA.

A7.19 Because each of the SNA accounts has its own balancing item, there are more balancing items in the SNA than in GFS. However, some of the SNA balancing items can be derived from GFS. The different placement of capital transfers means that the GFS balancing item for the first section of the Statement of Operations, the net operating balance, differs from saving, the final balancing item in the sequence of current accounts in the SNA. The net operating balance of GFS minus capital transfers is comparable to saving as calculated in the SNA. Net capital transfers are recorded as an aggregate in the capital account of the SNA. Conceptually, net lending/net borrowing, the balancing item in GFS, is equivalent to the net lending/net borrowing calculated in the capital and financial accounts of the SNA. However, the difference in the treatment of certain activities, such as some employment-related pension arrangements (see paragraph A7.46-A7.47), means that the value of net lending/net borrowing in GFS may differ from the SNA. These differences are reconcilable.

A7.20 The GFS Statement of Other Economic Flows covers all other economic flows, classified by type of asset or liability affected and according to whether the flow is a holding gain or an other change in the 
volume of assets. In the SNA, the same distinction between holding gains and other changes in the volume of assets is made. In the SNA, these accounts are the revaluation account, in which effects of price changes in values of assets and liabilities are recorded, and the other changes in volume of assets account, in which changes in the amounts of the assets and liabilities as a result of factors other than transactions and revaluations are recorded. ${ }^{7}$

A7.21 The coverage of the GFS Balance Sheet is identical to the coverage of the Balance Sheet in the SNA, except for some employment-related pension entitlements. Due to different institutional arrangements in countries, some flexibility is given in the SNA, but not in GFS, regarding the recording of pension entitlements for unfunded pension schemes sponsored by government. Some of these pension entitlements may be recorded within the main sequence of the SNA accounts (also referred to as the core accounts) and others may be reported in supplementary tables.

\section{Linkages between GFS and the SNA}

A7.22 Despite the structural consistencies, the different objectives of GFS and the SNA require that a few transactions and other economic flows recorded in the various statements and accounts be recorded and presented differently. This section reviews and summarizes the relevant linkages between the two datasets. In order to facilitate references to the respective datasets, the items are referred to by their names and the relevant SNA and GFS classification codes. ${ }^{8}$ Tables A7.3 and A7.4 indicate how the GFS revenue and expense categories link with the SNA classifications, and Table A7.5 identifies the correspondence of GFS and SNA transactions in nonfinancial assets, with corresponding classification codes. The SNA also provides volume measures (including of government components), an important

\footnotetext{
7 "Revaluations" and "holding gains" are used interchangeably in the 2008 SNA.

${ }^{8}$ The SNA classification codes for transactions and other flows have the form of a letter: $\mathrm{D}$ for distributive transactions, $\mathrm{F}$ for financial assets and liabilities, $\mathrm{K}$ for other changes in assets accounts, or $\mathrm{P}$ for transactions in products, each followed by a number. The SNA codes for the balance sheet are AN for nonfinancial assets and AF for financial assets and liabilities. The SNA coding system uses the letter B for balancing items. The GFS coding system is presented in Appendix 8.
}

type of measure for fiscal analysis that makes the SNA complementary to GFS.

\section{Current accounts}

A7.23 The current accounts of the SNA record the production of goods and services, the generation of income by production, the subsequent distribution and redistribution of income among institutional units, and the use of income for purposes of consumption or saving. This section describes the GFS linkages with each of these current accounts.

\section{The production account}

A7.24 The production account records the transactions relating to the activity of producing goods and services as defined in the SNA. The balancing item, gross value added, is defined as the value of output minus the value of intermediate consumption. The production measure of gross domestic product is defined as gross value added plus any taxes minus subsidies on products not already included in the value of output. Output is the value of goods and services produced during an accounting period. Intermediate consumption comprises the cost of goods and services used in production. Value added is a measure of the contribution to gross domestic product made by an individual producer, industry, or sector. For general government, the production account represents the general government's contribution to the domestic production.

A7.25 Value added can be presented gross or net of consumption of fixed capital. Net value added is the value of output minus the values of both intermediate consumption and consumption of fixed capital. Intermediate consumption of goods and services (P2) and consumption of fixed capital (P51c) are included as uses, while the output (P1) of all goods and services produced by a general government unit is a resource. Total output is divided into market output (P11), output for own final use (P12), ${ }^{9}$ and other nonmarket output (P13).

A7.26 Output is not recorded as such in GFS. Nevertheless, the total output of the general government sector can be determined as the sum of the output of

\footnotetext{
${ }^{9}$ Output for own final use in the SNA consists of products retained by the producer for its own use as final consumption or capital formation. Therefore, own-account capital formation, as referred to in GFS, is a narrower definition than the SNA concept of output for own final use.
} 


\section{Table A7.3 Correspondence of GFS and SNA Revenue Transaction Categories}

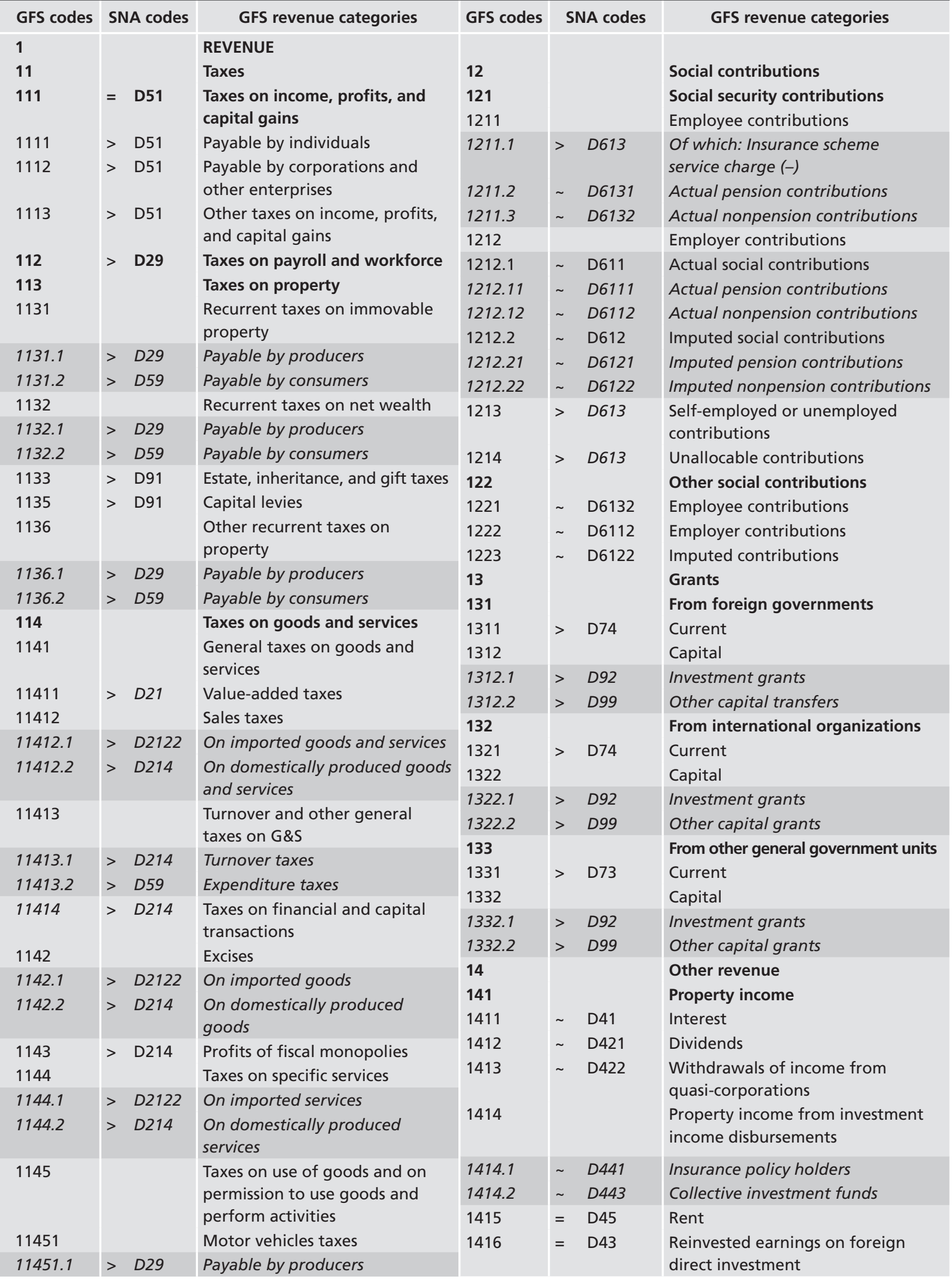




\section{Table A7.3 Correspondence of GFS and SNA Revenue Transaction Categories (concluded)}

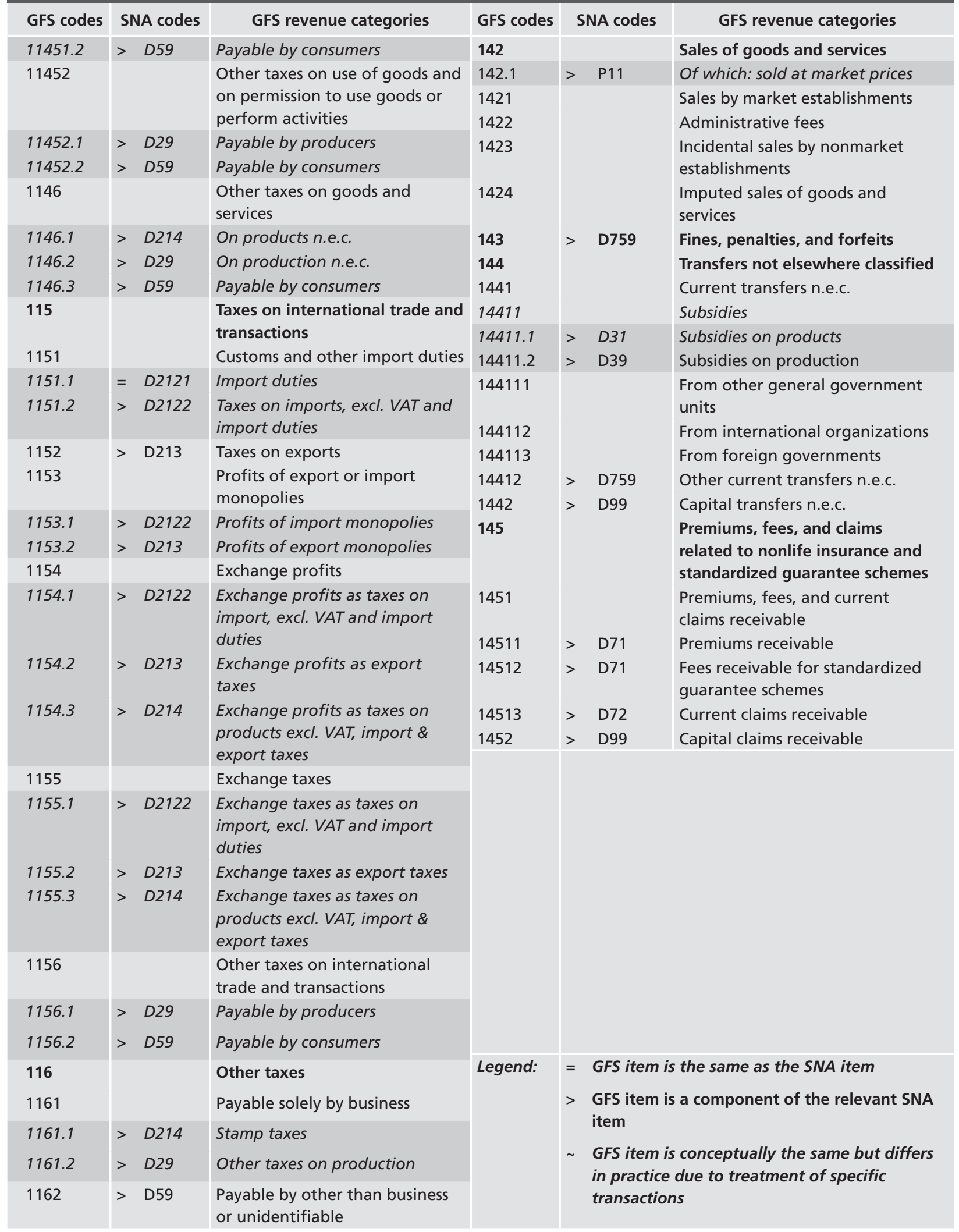

Note: Nonstandard GFS items required for the SNA indicated in darker shaded rows. n.e.c. $=$ not elsewhere classified; VAT $=$ value-added taxes. 
nonmarket establishments and the output of market establishments. The output of the two types of establishments is derived quite differently:

- The output of market establishments is equal to the sales of those establishments (GFS revenue item sales by market establishments (1421)) plus changes in their inventories of work in progress (31222) and finished goods (31223). Thus, to establish a direct link with the SNA, GFS data on the changes in inventories need to be divided into separate data for market and nonmarket establishments.

- The output of nonmarket establishments cannot be determined from sales statistics because most of it is distributed without charge or sold at prices that are not economically significant. Instead, the output of nonmarket establishments is defined to be equal to the sum of their production costs: compensation of employees (21), use of goods and services (22), consumption of fixed capital (23), other taxes on production paid, and other subsidies on production received (as a negative value).

Therefore, in order to calculate the output of nonmarket establishments from GFS data, it is necessary to divide the total values of each of the relevant expense categories into expenses incurred by market establishments and expenses incurred by nonmarket establishments. ${ }^{10}$

A7.27 In the national accounts, the total output of the general government sector is allocated among three components: market output, output for own final use, and other nonmarket output.

- Output for own final use is the value of goods and services produced for own final use or nonfinancial assets constructed for own use by general government units. The latter data are available directly from the details of GFS expenditure as memorandum item $3 \mathrm{M} 1$ in Table 8.1. In the SNA, provision is made to value this output at market prices if the assets constructed on own account are also offered for sale on the market. In the GFS framework, it is assumed that assets constructed on own account by the general govern-

\footnotetext{
${ }^{10}$ Market establishments included in the general government sector are usually a small fraction of the general government total output.
}

ment sector are not offered for sale on the market so that valuation should be based on the cost of production.

- Market output and other nonmarket output are not directly available from GFS, and do not necessarily correspond to the output of market and nonmarket establishments because nonmarket establishments can produce market output, and vice versa.

- The value of market output is calculated as the sum of the entire output of market establishments, actual sales of nonmarket establishments at market prices $^{11}$ (part of GFS revenue item incidental sales by nonmarket establishments (1423)), and other output that is imputed to have been sold (part of GFS revenue item imputed sales by nonmarket establishments (1424)). Imputed sales are in-kind transactions that are valued at market prices (see Box A7.1).

- The value of other nonmarket output can be calculated residually as the total output of the general government sector minus output for own final use and market output.

A7.28 Intermediate consumption consists of the goods and services consumed as inputs by a process of production, excluding fixed assets whose consumption is recorded as consumption of fixed capital. For general government or public sector units, intermediate consumption includes the following GFS items:

- Use of goods and services (GFS expense item 22) minus the portion of goods purchased for resale that was actually sold during the reporting period (reduction in GFS item 31224 due to sales)

- Goods and services used in own-account capital formation (GFS memorandum item 3M12)

- Consumption of financial intermediation services indirectly measured (FISIM), which is already taken into account in interest revenue and expense of GFS (GFS items 1411 and 24, respectively)

\footnotetext{
${ }^{11}$ Sales of nonmarket goods or services at prices that are not economically significant remain a part of the value of nonmarket output (see the 2008 SNA, paragraph 6.132).
} 
Table A7.4 Correspondence of GFS and SNA Expense Transaction Categories

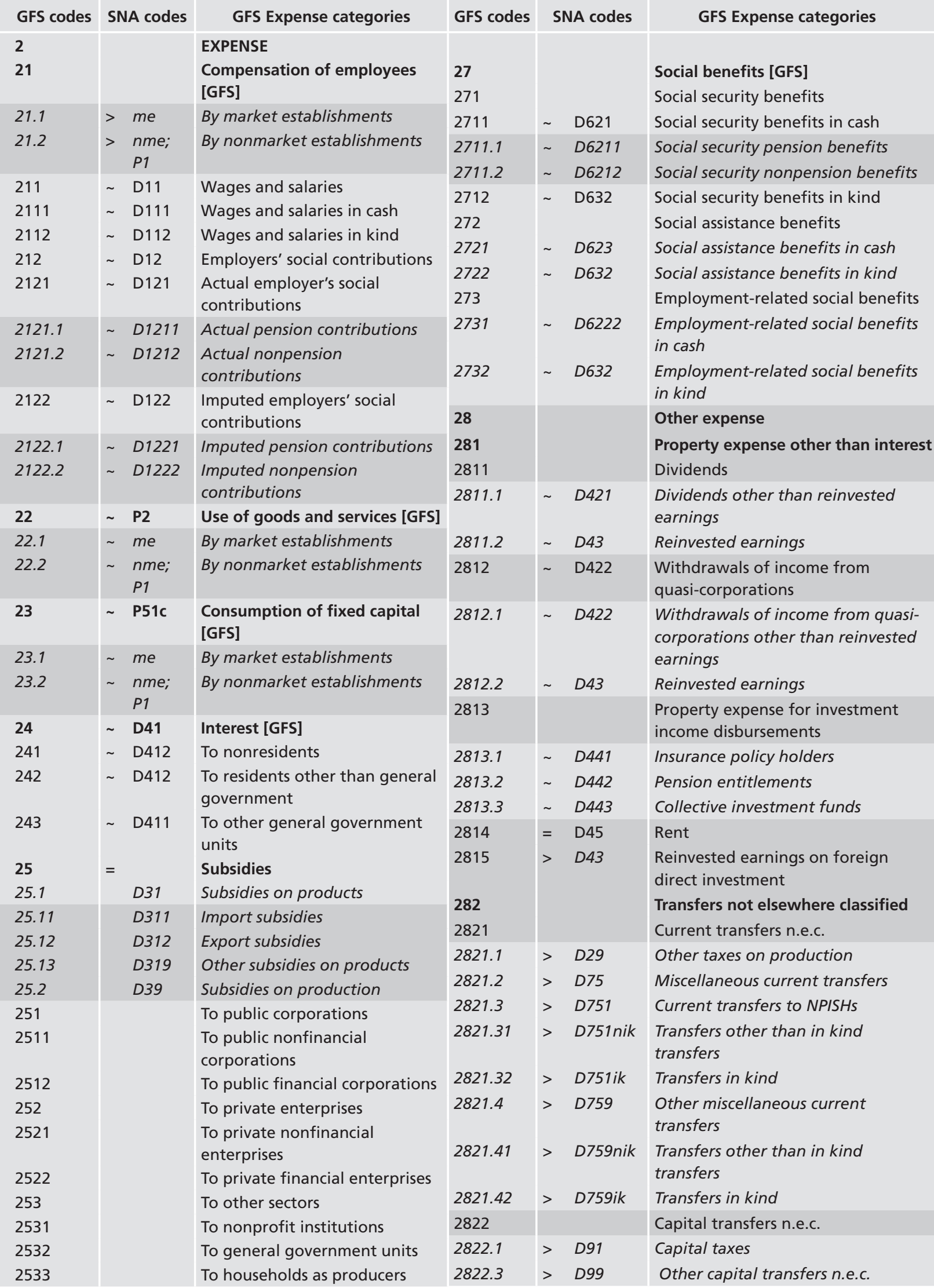


Table A7.4 Correspondence of GFS and SNA Expense Transaction Categories (concluded)

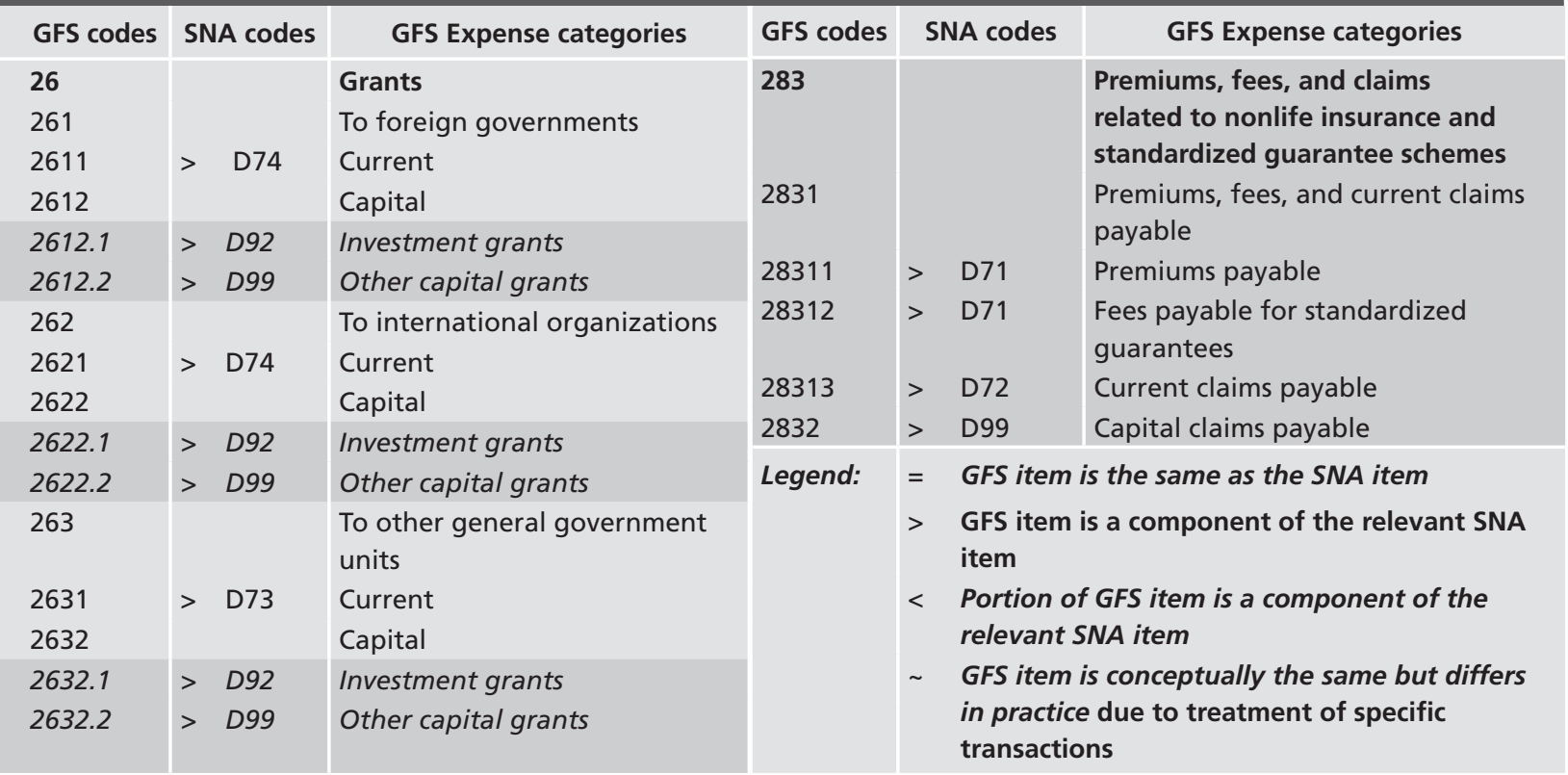

Note: Nonstandard GFS items required for SNA, indicated in darker shaded rows.

n.e.c. $=$ not elsewhere classified .

- Consumption of insurance services and service charge/fee related to standardized guarantees that are components of premiums, fees, and current claims related to nonlife insurance and standardized guarantee schemes (GFS items 1451 and 2831).

A7.29 For SNA purposes, the values for FISIM, insurance services, and standardized guarantees schemes are derived by partitioning interest, nonlife insurance premiums, and fees for standardized guarantees (see paragraphs 6.81 and 6.125). In concept, the value of these services should be treated as a use of goods and services expense for the consumer and revenue from the sale of a service for the financial intermediary providing the service. However, in GFS, these partitions are not made because they can be estimated from data for the entire economy. Instead, in GFS, the entire values of the transactions are recorded as interest, nonlife insurance premiums, or fees for standardized guarantees, respectively. ${ }^{12}$

A7.30 Consumption of fixed capital (P51) in the SNA is identical to the concept in GFS. However, the amounts of consumption of fixed capital may differ because of the differing treatment of own-account

\footnotetext{
${ }^{12}$ See the 2008 SNA, paragraphs A3.24-A3.27, for additional details on the estimation of these services.
}

capital formation. Consumption of fixed capital as recorded in the national accounts should be equal to the consumption of fixed capital [GFS] (23) plus the consumption of fixed capital recorded as a component of own-account capital formation in GFS (GFS memorandum item $3 \mathrm{M} 13$ ).

\section{The distribution of income accounts}

A7.31 The distribution of income accounts are decomposed into three main accounts. These separated accounts each have different balancing items that have meaningful interpretations of income and comprise:

- Primary distribution of income account, comprising the generation of income account and the allocation of primary income account

- Secondary distribution of income account

- Redistribution of income in kind account.

\section{The primary distribution of income account}

A7.32 The primary distribution of income account shows how GDP is distributed to labor, capital, government, and, where necessary, flows to and from the rest of the world. The primary distribution of income is always presented in two subaccounts-namely, the generation of income account and the allocation of primary income account. 


\section{Box A7.1 In-Kind Transactions}

Although GFS and the SNA recognize in-kind transactions, recording these may differ in the two datasets, specifically in the case of goods and services produced by general government. Due to the SNA's focus on economic processes, such transactions may be recorded at various stages in the SNA, while in general they are recorded only once in GFS. Imputed sales, as recorded in GFS, are called nonmonetary transactions in the SNA.

GFS and the SNA record such an imputed sale in the case of:

- Goods and services produced by the general government sector and provided to employees as wages in kindTreated as compensation of employees paid in cash followed by a sale to the employees (GFS item 1424). The compensation is recorded in the generation of income account as compensation of employees, as wages and salaries (D11), and the output is recorded as household final consumption expenditure. In GFS, goods and services produced by the general government sector and provided to employees as wages in kind are treated similarly to the SNA treatment. The government is deemed to be acting in two capacities: as an employer and as a general producer of goods and services. In order to indicate the total amount paid as compensation of employees, it is necessary to treat the amount payable in kind as if it had been paid in cash as wages and salaries and then the employees had used the cash to purchase the goods and services.

The SNA records transactions in imputed sales that are not recorded in GFS in the following cases:

- Goods and services produced by the general government sector and provided as social benefits in kind in accordance with employment-related social benefits-Treated in the SNA as if there had been a transfer to the beneficiaries in cash followed by a sale of the output to the beneficiaries. Thus, the goods and services are recorded in the SNA as final consumption expenditure of the households while the transfer is recorded as a social benefit (recorded in the secondary distribution of income account as social benefits other than social transfers in kind (D62 in SNA), under other social insurance benefits (D622 in SNA). This item is divided further into pension benefits (D6221 in SNA) and nonpension benefits (D6222 in SNA). In GFS, goods and services produced by general government units and provided as social benefits are recorded in GFS as costs of production in the various GFS expense categories, such as compensation of employees and use of goods and services, and consumption of fixed capital, and not as social benefits.

- Goods and services produced by the general government sector and provided as grants in kind to other governments and international organizations-Treated in the SNA as if there had been a transfer in cash followed by a sale of the output to the recipients of the goods and services. The output is shown as exports (P6 in SNA) in the case of grants to foreign governments and international organizations and either government final consumption expenditure or gross fixed capital formation (P51 in SNA) in the case of grants to other domestic general government units. The transfer is shown in the secondary distribution of income account as other current transfers (D7), either as current transfers within general government (D73 in SNA) or current international cooperation (D74 in SNA), or in the capital account as capital transfers, as investment grants (D92 in SNA) or other capital transfers (D99 in SNA). In GFS, such grants in kind are recorded as grants to foreign governments (GFS expense item 261) or grants to international organizations (GFS expense item 262).

- Goods and services produced by the general government sector and provided as transfers in kind to nonprofit institutions serving households or to individuals or households as compensation for damage to property or personal injury or as the settlement of an insurance claim-Treated as a transfer in cash and a sale of market output. The transfer is recorded in the secondary distribution of income account of the SNA as other current transfers, as nonlife insurance claims (D72) or miscellaneous current transfers (D75), and the output is recorded as final consumption expenditure of the households sector or the nonprofit institutions serving households sector. In GFS, these goods and services provided in kind are recorded as other transfers (GFS expense item 282).

\section{The generation of income account}

A7.33 The generation of income account shows from the point of view of resident institutional units or sectors, in their capacity as producers, how the value added generates income for labor, capital, and government. The account starts with value added as a resource and then includes as uses:
- Compensation of employees (D1)

- Other taxes on production ${ }^{13}(\mathrm{D} 29)$ payable

\footnotetext{
${ }^{13}$ Other taxes on production consist of all taxes except taxes on products that enterprises incur as a result of engaging in production. A tax on products is a tax that is payable per unit of some good or service. (See the 2008 SNA, paragraphs 7.88-7.97.)
} 
- Other subsidies on production (D39) receivable as a negative use.

A7.34 The balancing item of the generation of income account is the operating surplus (B2), which can be presented gross or net of consumption of fixed capital. It measures the surplus accruing from production before deducting any explicit or implicit income: interest charges, rent, or other property incomes payable on financial assets, land, or other natural resources held to carry on the production process.

A7.35 Compensation of employees in the SNA corresponds to the sum of the GFS expense item compensation of employees [GFS] (21) and the amount of compensation of employees recorded as a component of own-account capital formation (GFS memorandum item 3M11).

A7.36 The taxes and subsidies that are included in the valuation of the output of nonmarket establishments consist of other taxes on production payable by general government units to other government units and other subsidies on production receivable by general government units from other government units, both national and foreign. These amounts are likely to be rare and/or small in magnitude. Taxes payable by one level of government to another level of government are classified in GFS as transfers not elsewhere classified (282) in the subcategory current (2821). Subsidies on production (D39) receivable are a portion of the subsidies (14411) classified under transfers not elsewhere classified (144). ${ }^{14}$ In GFS, these items, involving general government units, would be eliminated in consolidation when statistics for the general government or public sector are compiled.

\section{The allocation of primary income account}

A7.37 The allocation of primary income account focuses on resident institutional units or sectors in their capacity as recipients of primary incomes. It shows where the items payable in the generation of income account are receivable, and also includes the amounts of property income receivable and payable by institutional unit or sectors. It contains the operating surplus or mixed income as a resource and records for each sector, property income receivable and payable, compensation of employees receivable, and

\footnotetext{
${ }^{14}$ While a general government unit, public and private corporations, NPISH, or households may be recipients of subsidies, these are payable by government units only.
}

taxes minus subsidies on production and imports receivable. The balancing item is the balance of primary income (B5), which represents the sector's contribution to the national income. The balance of primary income or national income can be presented gross or net of consumption of fixed capital.

A7.38 For the general government sector, the account records the following resources:

- Taxes on production and imports (D2), which are divided into taxes on products (D21) and other taxes on production (D29)

- Subsidies as a negative resource (D3)

- Property income as both a resource and a use (D4).

A7.39 In the SNA, taxes are classified according to their role in economic activities as:

- Taxes on production and imports (D2) in the production account, generation of income account, and allocation of primary income account

- Current taxes on income, wealth, etc. (D5) in the secondary distribution of income account

- Capital taxes (D91) in the capital account.

A7.40 GFS include a detailed classification of taxes based on common practices in tax administration. The result is that some tax categories in GFS, such as motor vehicle taxes, need to be allocated between two of the SNA tax categories according to whether they are payable by producers or final consumers. This allocation is required in the SNA and, in the absence of a split in GFS or source data, national accounts compilers will need to employ various methods to identify the payer (i.e., a producer or final consumer).

A7.41 A breakdown of these taxes is shown in Table A7.3, which indicates, among other things, the linkages between the GFS and the SNA tax categories. The table shows which GFS tax categories directly correspond to the SNA tax category, which SNA tax category consists of two or more GFS subcategories, and which GFS tax item requires further breakdowns to allow linkage to the SNA categories.

A7.42 Subsidies (D3) in the SNA are the equivalent of subsidies in GFS (GFS revenue item 14411 and GFS expense item 25), but the classification of the type of subsidies is quite different in the two datasets. In the SNA, the subsidies are divided into subsidies on products (D31) and other subsidies on production (D39). The subsidies on products are divided further into 
subsidies on imports (D311), exports (D312), and other subsidies on products (D319). In GFS, to allow consolidation of the public sector, subsidies are classified by recipients. To allow correspondence between the SNA and GFS, a building block approach can be used to identify all subsidies according to whether they are on production or products, as well as identification of the recipients.

A7.43 There are several types of property income included as resources in the allocation of primary income account:

- Dividends (D421) in the SNA are the equivalent of dividends recorded in GFS (GFS revenue item 1412 and GFS expense item 2811, respectively).

- Withdrawals of income from quasi-corporations (D422) in the SNA are the equivalent of these withdrawals recorded in GFS (GFS revenue item 1413 and GFS expense item 2812).

- Rent (D45) in the SNA is the equivalent of rent recorded in GFS (GFS revenue item 1415 and GFS expense item 2814).

- Interest (D41) in the SNA is the equivalent of interest in GFS (GFS revenue item 1411 and GFS expense item 24), adjusted for FISIM (see paragraph A7.29).

- Reinvested earnings on direct foreign investment (D43) in the SNA are the equivalent of reinvested earnings recorded in GFS (GFS revenue item 1416 and GFS expense item 2815).

- Imputed property income on investment income disbursements (D44), such as income attributable to insurance policy holders, etc., in the SNA is conceptually the equivalent of property income/ expense related to investment income disbursements (GFS revenue item 1414 and GFS expense item 2813). However, for government sector units as holders of insurance policies, the revenue related to this item is likely to be unknown, and would probably be calculated only in the context of the whole of the economy. It therefore remains an adjustment item between GFS and national accounts. This imputed property income is also recorded as payable by the beneficiaries to the operator of the scheme as a household contribution supplement (D6141) in the secondary distribution of income account. In the case of pension schemes for general government, this imputed transaction primarily relates to employment-related nonautonomous pension schemes. If these pension schemes are au- tonomous, the transactions affect only households and the financial corporations sector. In GFS, an imputed property expense on existing pension entitlements, recorded under GFS expense item 2813, is equal to the increase in the liability of a definedbenefit pension scheme resulting from the passage of time. Thus, the imputed household pension contribution supplements, recorded in the secondary distribution of income account in the SNA, should be recorded in GFS as incurrence of pension liabilities (GFS transactions in liabilities item 33063) and not as revenue from social contributions (GFS revenue item 12). The SNA values can be derived from the detailed records of the pension schemes.

\section{The secondary distribution of income account}

A7.44 The secondary distribution of income account covers redistribution of income through current transfers (other than social transfers in kind made by government and NPISHs to households). ${ }^{15}$ In addition to carrying forward the balance of primary income, this account records:

- Current taxes on income, wealth, etc. (D5 in SNA) as a resource for government, divided further into taxes on income (D51 in SNA) and other current taxes (D59 in SNA)

- Net social contributions (D61 in SNA) as a resource for government

- Social benefits other than transfers in kind (D62 in SNA) as a use for government

- Other current transfers (D7 in SNA), both as a resource and a use.

A7.45 The net social contributions (D61) are the actual and imputed contributions made by households to social insurance schemes. The net contributions exclude fees charged by the administrators of the schemes, which should be recorded as an expense for households for services rendered. The net social contributions are divided into four subcategories in the SNA, with each of the net social contribution subcategories further divided into pension and nonpension contributions. The subcategories for net social contributions are:

- Employers' actual social contributions (D611)

- Employers' imputed social contributions (D612)

\footnotetext{
${ }^{15}$ Social transfers in kind are recorded in the redistribution of income in kind account.
} 
- Households' actual social contributions (D613)

- Households' social contributions supplements (D614).

A7.46 The amount recorded for net social contributions receivable by units operating social insurance schemes can be different in the GFS and SNA datasets due to differences in the treatment of contributions to employment-related pension schemes. In the SNA, amounts payable to the operator of the scheme as social contributions (D6111, D6121, and D6131) are included in the secondary distribution of income, with a subsequent adjustment for the change in pension entitlements to record the incurrence of pension liabilities (F63 in SNA). GFS record social contributions payable to employment-related schemes providing pensions and other retirement benefits directly as transactions increasing the scheme's liabilities for pension entitlements (GFS item 33063) by the operator of the scheme. ${ }^{16}$ In the SNA, all social benefits payable, including pensions and other retirement benefits, are recorded either in the secondary distribution of income account as social benefits other than social transfers in kind (D62), or in the redistribution of income account as social transfers in kind (D63). In addition, all pensions and other retirement social benefits payable are recorded as a reduction in pension entitlements (F63).

A7.47 Unlike the SNA, transfer expense in GFS excludes government employee pension and retirement benefits payable. These benefits are reported only as a transaction reducing liabilities for pension entitlements (GFS liability item 33063). As a result, GFS does not need the item for adjustment for change in pension entitlements. Also, unlike in the SNA, benefits in the form of goods and services produced by general government units are not recorded as social benefits in GFS, but in the various GFS expense categories corresponding to the costs of producing these goods and services, such as compensation of employees, and use of goods and services, etc.

A7.48 As stated in Box A7.1, goods and services produced by the general government sector and provided as social benefits in kind, grants in kind, or transfers in kind are recorded in the SNA as the production of output and a transfer to the beneficiaries. These transfers are recorded in the secondary

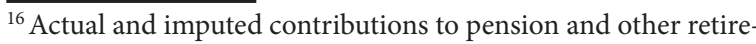
ment benefit schemes are therefore excluded from GFS revenue from social contributions (GFS revenue category 12).
}

distribution of income account, as if received in cash by the beneficiaries, accompanied by a sale of the output to the beneficiaries.

A7.49 Other current transfers (D7) in the SNA are a disparate collection of entries that are found in various categories in GFS:

- Net nonlife insurance premiums (D71) is the equivalent of net nonlife insurance premiums (GFS revenue item 14511 and GFS expense item 28311), adjusted for the imputation of the sale or purchase of insurance services, as described in paragraph A7.29.

- Nonlife insurance claims (D72) are the equivalent of the current nonlife insurance claims in GFS (GFS revenue item 14513and GFS expense items 28313).

- Current transfers within general government (D73) and current international cooperation (D74) in the SNA are recorded in GFS as current grants receivable (GFS revenue categories 1311, 1321 , or 1331) or payable (GFS expense categories 2611, 2621, or 2631) except for goods and services produced by general government units and distributed in kind (see Box A7.1).

- Miscellaneous current transfers (D75) in the SNA are recorded in GFS as fines, penalties, and forfeits (GFS revenue item 143), other current transfers not elsewhere classified (GFS revenue item 14412), current transfers not elsewhere classified (GFS expense item 2821), adjusted with transfers of goods and services produced by general government units and distributed in kind (see Box A7.1).

A7.50 The balancing item of the secondary distribution of income account is disposable income. For households, this income can be used for final consumption expenditure and saving. For nonfinancial and financial corporations, disposable income is income not distributed to owners of equity minus taxes payable on income. The disposable income can be presented gross or net of consumption of fixed capital.

\section{The redistribution of income in kind account}

A7.51 The redistribution of income in kind account records social benefits in kind and transfers of individual nonmarket goods and services from the government sector to the household sector using the goods or services. Because of the nature of the transactions 
concerned, this account is significant only for government, households, and NPISHs. The account records two elements of the redistribution process. The first is nonmarket production by government and NPISHs of individual services, and the second is the purchase by government and NPISHs of goods and services for transfer to households free of charge or at prices that are not economically significant. The redistribution of income in kind account records social transfers in kind as resources for households and as uses of government and NPISHs. The balancing item of the redistribution of income in kind account is adjusted disposable income.

A7.52 The Classification of Functions of Government (COFOG) can be used to assist in deriving the government individual consumption expenditure (P31 in SNA). Government's social benefits in kind should be equal to the nonmarket produced social transfers in kind (D631 in SNA). See Table A7.4 for a presentation of the corresponding GFS expense items. Government collective consumption (P32 in $\mathrm{SNA}$ ) is equal to its actual final consumption (P4 in SNA).

\section{The use of disposable income account}

A7.53 The use of income accounts exists in two variants, the use of disposable income account and the use of adjusted disposable income account. Both accounts show for the three sectors that undertake final consumption-namely, the household sector, the NPISH sector, and the general government sector-how disposable income or adjusted disposable income is allocated between final consumption and saving. It measures that part of income, domestically or abroad, that is not used for final consumption. Savings can be shown on a gross or a net basis (depending on whether consumption of fixed capital is included).

A7.54 In the SNA, gross saving is the balancing item before capital transactions and can be derived by excluding from the net lending/net borrowing the capital transfers receivable/payable, gross capital formation and acquisitions minus disposals of nonfinancial nonproduced assets. Gross saving can also be derived as disposable income minus final consumption. Since net lending/net borrowing in the SNA and GFS is conceptually the same, for the general government or public sector, gross saving can be derived from GFS, as follows:
Net lending/net borrowing

Minus: Capital grants/transfers receivable

Plus: Capital grants/transfers payable

Plus: Net acquisition of nonfinancial assets.

To get from net saving to gross saving, consumption of fixed capital needs to be added.

A7.55 The use of disposable income account and the use of adjusted disposable income account calculate saving as a balancing item. The two measures of saving are the same, but calculated differently.

- The use of disposable income account calculates saving using:

- Disposable income as a resource

- Final consumption expenditure as a use

- An adjustment item showing the adjustment for the change in pension entitlements.

- The use of adjusted disposable income account calculates saving as a balancing item using:

- Adjusted disposable income as a resource

- Actual final consumption as a use

- An adjustment item showing the adjustment for the change in pension entitlements.

A7.56 Final consumption is a key component of the use of disposable income account and gross domestic product. The concept is implemented in the SNA in two ways: final consumption expenditure (P3) and actual final consumption (P4). The difference between them is social transfers in kind (D63), which represents the final consumption of goods and services purchased by general government units but actually consumed by households.

A7.57 Final consumption expenditure is not an element of GFS. Final consumption expenditure can be calculated using linkages with GFS data established earlier. It can be calculated as:

Total output minus output related to own-account capital formation; ${ }^{17}$

Plus: Purchases of goods and services that are transferred to households without further transformation; ${ }^{18}$

\footnotetext{
${ }^{17}$ As illustrated in Tables A7.3 and A7.4, this corresponds to the sum of the following GFS categories:

$1421+21.2+22.2+23.2+$ FISIM

${ }^{18}$ As illustrated in Tables A7.3 and A7.4, this corresponds to the sum of the following GFS categories: $2712+2722+2732+2821.32+2821.42$.
} 
Minus: Actual and imputed sales of goods and services (GFS revenue item 142); ${ }^{19}$

Minus: Changes in inventories of work in progress and finished goods (GFS items 31222 and 31223).

A7.58 In GFS, purchases of goods and services that are transferred to final consumers without further transformation are classified as social security benefits in kind (GFS expense item 2712), social assistance benefits in kind (GFS expense item 2722), employmentrelated social benefits in kind (GFS expense item 2732), or the in-kind portion of current transfers not elsewhere classified (GFS expense item 2821), depending on the nature and the organization of the distribution.

A7.59 The GFS expense categories for social benefits in kind include reimbursements to households for purchases of goods and services receivable as social benefits in kind, and direct purchases by general government units of goods and services from market producers and provided as social benefits in kind. In addition, the GFS item for transfers not elsewhere classified (2821) may include purchases of goods and services from market producers that are distributed directly to households for final consumption other than social benefits. Goods and services produced by government themselves and subsequently used as transfers in kind are not reported as in-kind transactions in GFS, but are included in the SNA concept for social transfers in kind (D63).

A7.60 Because the SNA separately measures production and distribution of goods and services, transactions in kind are normally recorded in the accounts as if they are monetary transfers followed by the beneficiary spending the transfer to obtain the goods and services concerned. Therefore, social transfers in kind (D63) consist of final consumption expenditure undertaken by government and NPISHs on behalf of households. For this reason they are described as individual goods and services. Information on these individual goods and services may be obtainable from the crossclassification of the COFOG and economic type of expense in Table 6A.2. The annex to Chapter 6 lists the services that are considered individual.

\footnotetext{
${ }^{19}$ When an existing good is sold, the amount receivable from its sale is recorded as negative final consumption expenditure if the initial outlay on the good was classified as final consumption expenditure.
}

A7.61 In the SNA, an adjustment is made in the use of disposable income account, as well as in the use of adjustment disposable income account for the change in pension entitlements (D.8). This adjustment for the change in pension entitlements is equal to:

The total value of the actual social contributions payable to funded pension schemes,

Plus: The total value of the imputed social contributions payable to employment-related pension schemes,

Plus: The total value of social contribution supplements,

Minus: The value of the associated service charges;

Minus: The total value of the pensions paid out as pension benefits by the pension schemes.

The different treatment of pension schemes eliminates the need for this adjustment item in the GFS framework (see paragraph 5.95).

\section{The accumulation accounts}

A7.62 Saving is the balancing item of the last of the current account in the SNA and the starting point for the accumulation accounts. The first group of accumulation accounts, comprising the capital and financial accounts, covers transactions in assets or liabilities and changes in net worth due to capital transfers. A second group of accumulation accounts, comprising the other changes in volume of assets account and revaluation account, relates to changes in assets and liabilities caused by factors other than transactions.

\section{The capital account}

A7.63 The capital account records transactions linked to the acquisition of nonfinancial assets and capital transfers. The account starts with net saving, the final balancing item of the current accounts, and records transactions in nonfinancial assets and capital transfers. The balancing item is either net lending $(+)$, which measures the net amount available to finance other sectors, or net borrowing (-) which corresponds to the net financing from other sectors.

A7.64 Most of the entries in the capital account of the SNA can be derived from the corresponding entries in GFS. For example, the gross fixed capital 
formation (P51g) minus the consumption of fixed capital (P51c) is the net investment in fixed assets in GFS (GFS item 311). As indicated in Table A7.5, the 2008 SNA classification of categories of nonfinancial assets has been fully incorporated in GFS. However, in the SNA, fixed assets are also classified into:

- Acquisition of new fixed assets (item 311.1/ P5111 in Table A7.5)

- Acquisition of existing fixed assets (item 311.1/ P5112 in Table A7.5)

- Disposal of existing fixed assets (item 311.2/ P5113 in Table A7.5).

This distinction between new and existing assets is not available from GFS, and would require supplementary information from source data systems.

A7.65 Consumption of fixed capital in the SNA (P51c) equals the sum of the expense item of the same name in GFS (GFS expense item 23) and the consumption of fixed capital that was capitalized as part of own-account capital formation (GFS item 3M13).

A7.66 Changes in inventories (P52), acquisitions minus disposals of valuables (P53), and acquisitions minus disposals of nonproduced assets (NP) are the same as the net investment in the corresponding items in GFS (GFS items 312, 313, and 314, respectively).

A7.67 In the SNA, capital transfers receivable and payable (D9) are recorded as capital taxes (D91), investment grants (D92), and other capital transfers (D99). These transfers are included in GFS as follows:

- Capital taxes (D91) receivable by the general government sector can directly be related to GFS revenue recorded in estate, inheritance, and gift taxes (GFS revenue item 1133) and other nonrecurrent taxes on property (GFS revenue item 1135). Where these taxes are payable by one level of government to another, they are included in the expense item capital transfers not elsewhere classified (2822) of the payee.

- Investment grants (D92) consist of all capital transfers made by governments to other resident or nonresident institutional units to finance all or part of the costs of their acquiring fixed assets. These investment grants receivable/payable are a component of capital grants receivable (GFS revenue items 1312, 1322, or 1332), and a compo- nent of capital grants payable (GFS expense items 2612, 2622, and 2632).

- Other capital transfers (D99) consist of all capital transfers except capital taxes and investment grants. One notable category included here is capital transfers related to debt cancellation by mutual agreement. In GFS, these are a component of capital grants (GFS revenue items 1312, 1322 , or 1332 or GFS expense items 2612, 2622, and 2632), capital transfers not elsewhere classified (GFS revenue item 1442 and GFS expense item 2822), and capital claims related to nonlife insurance (GFS revenue item 1452 and GFS expense item 2832).

\section{The financial account}

A7.68 The financial account in the SNA records transactions in financial assets and liabilities, classified by instruments. It therefore records the net acquisition of financial assets, and the net incurrence of liabilities. The balancing item, net lending $(+) /$ net borrowing (-), is in principle equal to the net lending $(+) /$ net borrowing $(-)$ in the capital account, although measured differently.

A7.69 Conceptually, the transactions recorded in the financial account of the SNA are identical to the transactions in financial assets and liabilities recorded in GFS (see Table A7.6). At the general government or public sector level the value of transactions in financial assets and liabilities could differ due to the different approach to consolidation (see paragraph A7.11). Some investment income disbursements (see paragraph A7.43) would likely be unknown to government, and would be calculated only in the context of the whole of the economy and therefore remain an adjustment item between GFS and national accounts. Amounts recorded as transactions in insurance, pension, and standardized guarantee schemes may also differ due to the option in the SNA to treat some employment-related liabilities in supplementary rather than the main tables (see paragraph 5.95).

\section{The other changes in the volume of assets accounts}

A7.70 The other changes in the volume of assets account in the SNA records the same economic events as those recorded in GFS (GFS items $5^{\star * *}$ ); the total value of changes should therefore be consistent in 
the two datasets. In both datasets, the other changes in volume of assets are recorded for each type of assets and liabilities. In addition, the SNA also classifies these changes according to specific events that give rise to the change in the volume of the assets or liabilities. Data are separately recorded for economic appearance of assets (K1), economic disappearance of nonproduced nonfinancial assets (K2), catastrophic losses (K3), uncompensated seizures (K4), other changes in volume not elsewhere classified (K5), and changes in classification (K6). Source data for recording these events should therefore provide for identification of the relevant assets and liabilities, but also identify the underlying event that caused the change in the volume.

\section{The revaluation account}

A7.71 The revaluation account in the SNA records the same holding gains or losses as those recorded in GFS (GFS items $4^{* * *}$ ). The total value of nominal holding gains for the general government or public sector should therefore be the same in the two datasets. In addition, the SNA recommends that nominal holding gains and losses be further subdivided between neutral and real holding gains and losses. GFS do not make this distinction:

- Neutral holding gains and losses (B1031) over a period are the increase (decrease) in the value of an asset that would be required, in the absence of transactions and other changes in the volume of assets, to maintain command over the same amount of goods and services as at the beginning of the period. The value is obtained by applying, during the same periods of time, an index of the change in the general price level to the initial value of all assets or liabilities. The result of this operation is called neutral holding gains and losses because all assets and liabilities are revalued so as to preserve exactly their purchasing power.

- Real holding gains and losses (B1032) record the difference between nominal holding gains and losses and neutral holding gains and losses.

\section{The balance sheet}

A7.72 The opening and closing balance sheets for the general government or public sector are conceptually the same in the SNA and GFS. Both datasets display assets on the left-hand side, and liabilities and net worth on the right-hand side. The changes in the
Balance Sheet in the SNA are the sum of the entries in the four accumulation accounts corresponding to the respective asset or liability. Similarly, in GFS the changes in the Balance Sheet for each category of assets and liabilities are equal to the sum of transactions, holding gains and losses, and other changes in volume. The classification of assets and liabilities in the two frameworks are fully consistent. However, at the general government or public sector level the value of stock positions in financial assets and liabilities could differ due to the different approach to consolidation (see paragraph A7.11). In practice amounts recorded as stock positions may also differ in two cases:

- Liabilities in respect of employment-related pension schemes may differ, due to the option in the SNA to treat some employment-related liabilities in supplementary tables (see paragraph 5.95).

- Assets and liabilities subject to investment income disbursements may differ in cases where these amounts are unknown to government, and therefore excluded from GFS, and would be calculated only in the context of the whole of the economy (see paragraph A7.43). ${ }^{20}$

\section{Comparison of the Analytical Frameworks of GFS and the Balance of Payments and the International Investment Position}

A7.73 The BPM6 serves as the standard framework for statistics on the flows and stock positions between an economy and the rest of the world. Since the BPM6 is harmonized with the 2008 SNA, it is also harmonized with the other macroeconomic datasets, including GFS. Because of conceptual linkages, compilers of the international accounts and GFS should consult to ensure the consistent application of definitions of coverage and concepts, and accounting rules.

\section{Comparison of the Accounts in GFS and Balance of Payments and the International Investment Position}

A7.74 The structure of the international statistical framework is similar to the structure used in the GFS framework, and comprises (i) the balance

\footnotetext{
${ }^{20}$ The SNA also provides volume measures (including of government components) - an important type of information for fiscal analysis that makes the SNA complementary to GFS.
} 


\section{Table A7.5 Correspondence of GFS and SNA Transactions in Nonfinancial Asset Categories}

\begin{tabular}{|c|c|c|c|}
\hline GFS codes & & SNA codes & Nonfinancial asset categories \\
\hline $\begin{array}{l}31 \\
311\end{array}$ & $=$ & P511 & $\begin{array}{l}\text { Nonfinancial assets } \\
\text { Fixed assets }\end{array}$ \\
\hline $3 M 1$ & $>$ & P1 & Of which: Own-account capital formation \\
\hline $3 M 11$ & $>$ & D1 & Own-account capital formation, compensation of employees \\
\hline $3 M 111$ & $>$ & D11 & Wages and salaries \\
\hline $3 M 112$ & $>$ & D12 & Employers' social contributions \\
\hline $3 M 1121$ & $>$ & D121 & Employers' actual social contributions \\
\hline $3 M 11211$ & $>$ & D1211 & Employers' actual pension contributions \\
\hline $3 M 11211$ & $>$ & D1212 & Employers' actual nonpension contributions \\
\hline $3 M 1122$ & $>$ & D122 & Employers' imputed social contributions \\
\hline $3 M 11221$ & $>$ & D1221 & Employers' imputed pension contributions \\
\hline $3 M 11222$ & $>$ & D1222 & Employers' imputed non-pension contributions \\
\hline $3 M 12$ & $>$ & $P 2$ & Own-account capital formation, intermediate consumption \\
\hline $3 M 13$ & $>$ & P51c & Own-account capital formation, consumption of fixed capital \\
\hline 311.1 & $<$ & P5111 & Acquisition of new fixed assets \\
\hline 311.1 & $<$ & P5112 & Acquisition of existing fixed assets \\
\hline 311.2 & $<$ & P5113 & Disposals of existing fixed assets \\
\hline 3111 & & & Buildings and structures \\
\hline 31111 & & & Dwellings \\
\hline 31112 & & & Buildings other than dwellings \\
\hline 31113 & & & Other structures \\
\hline 31114 & & & Land improvements \\
\hline 3112 & & & Machinery and equipment \\
\hline 31121 & & & Transport equipment \\
\hline 31122 & & & Machinery and equipment other than transport equipment \\
\hline 311221 & & & ICT equipment \\
\hline 311222 & & & Machinery and equipment not elsewhere classified \\
\hline 3113 & & & Other fixed assets \\
\hline 31131 & & & Cultivated biological resources \\
\hline 31132 & & & Intellectual property products \\
\hline 31133 & $=$ & P512 & Costs of ownership transfer of nonproduced assets (other than land) \\
\hline 31134 & & & Weapons systems \\
\hline 312 & $=$ & P52 & Inventories \\
\hline 31221 & & & Materials and supplies \\
\hline 31222 & & & Work-in-process \\
\hline 31222.1 & & me & Of which: Market establishments \\
\hline 312221 & & & Work-in-process on cultivated biological assets \\
\hline 312222 & & & Other work-in-process \\
\hline 31223 & & & Finished goods \\
\hline 31223.1 & & me & Of which: Market establishments \\
\hline 31224 & & & Goods for resale \\
\hline 31225 & & & Military inventories \\
\hline 313 & $=$ & P53 & Valuables \\
\hline 314 & & NP & Nonproduced assets \\
\hline 3141 & $>$ & NP1 & Land \\
\hline 3142 & $>$ & NP1 & Mineral and energy resources \\
\hline 3143 & $>$ & NP1 & Other naturally occurring assets \\
\hline 3144 & & & Intangible nonproduced assets \\
\hline 31441 & $=$ & NP2 & Contracts, leases, and licenses \\
\hline 31442 & $=$ & NP3 & Goodwill and marketing assets \\
\hline Legend: & $\begin{array}{l}= \\
> \\
< \\
\sim\end{array}$ & $\begin{array}{l}\text { GFS item is } \\
\text { GFS item is } \\
\text { Portion of } \\
\text { GFS item is }\end{array}$ & $\begin{array}{l}\text { component of the relevant SNA item } \\
\text { S item is a component of the relevant SNA item } \\
\text { onceptually the same but differs in practice due to treatment of specif }\end{array}$ \\
\hline
\end{tabular}

Note: Nonstandard GFS items required for the SNA indicated in darker shaded rows. 
of payments, which summarizes economic transactions between residents and nonresidents during a specific time period; (ii) the other changes in financial assets and liabilities, which show flows due to economic events other than transactions between residents and nonresidents, and include valuation changes; and (iii) the international investment position (IIP), which shows the value of the financial asset and liability stock positions between the residents of an economy and nonresidents at a reporting date. The difference between the opening and closing stock positions of the IIP is explained by the sum of transactions and other changes in financial assets and liabilities.

\section{Linkages between GFS and Balance of Payments and the International Investment Position}

A7.75 The BPM6 framework provides a sequence of accounts, each encompassing a separate economic process or phenomenon and a balancing item. The remainder of this section describes how the various international accounts correspond to GFS.

\section{The balance of payments}

A7.76 The balance of payments summarizes economic transactions between residents and nonresidents during a specific time period. The different accounts within the balance of payments are distinguished according to the nature of the economic resources provided and received, and comprise the following:

- The current account shows flows of goods and services, primary income, and secondary income between residents and nonresidents.

- The capital account shows flows for transactions in nonproduced nonfinancial assets, and capital transfers between residents and nonresidents.

- The financial account shows net acquisition and disposal of financial assets and liabilities.

- The sum of the balances on the current and capital accounts represents the net lending (surplus) or net borrowing (deficit) by the resident economy with the rest of the world. This is conceptually equal to the net balance of the financial account. It is also conceptually equal to the sum of net lending/borrowing for all the resident sectors.

\section{The current account}

A7.77 The current account shows flows of goods and services, primary income, and secondary income between residents and nonresidents. The balance on this account, known as the current account balance, shows the difference between the sum of exports and income receivable and the sum of imports and income payable. The current account balance represents the saving-investment gap for the economy.

\section{The goods and services account}

A7.78 The goods and services account shows transactions in items that are outcomes of production activities. The focus of the account is the point at which goods and services ${ }^{21}$ are exchanged between a resident and a nonresident. Production is an activity in which an enterprise uses inputs (intermediate inputs, labor, produced and nonproduced assets) in order to transform them to an output that can be supplied to other units.

A7.79 The GFS Statement of Operations has a linkage to the goods and services account to the extent that general government/public sector units enter into transactions with nonresidents, involving goods and services, either as a producer/seller or user of these goods or services. GFS will usually not separately identify these transactions, which limits opportunities for reconciliation between the goods and service account and GFS. However, in some cases, supplementary information in the underlying source data may identify such transactions-either because of their nature, large volumes, or large values of the transactions. Specifically, where produced assets are exchanged, contractual arrangements may be publicly available and should be consistently treated in the goods and services account of the balance of payments and GFS.

A7.80 The goods and services account requires that goods and services be classified according to the nature of the good or service. One of these specifically requires the separate disclosure of government goods and services not included elsewhere, which cover:

- Goods and services supplied by and to enclaves, such as embassies, military bases, and international organizations

\footnotetext{
${ }^{21}$ Goods as used in this context include both consumer goods and produced nonfinancial assets.
} 


\section{Table A7.6 Correspondence of GFS and SNA Financial Assets and Liabilities}

GFSM harmonized with other datasets

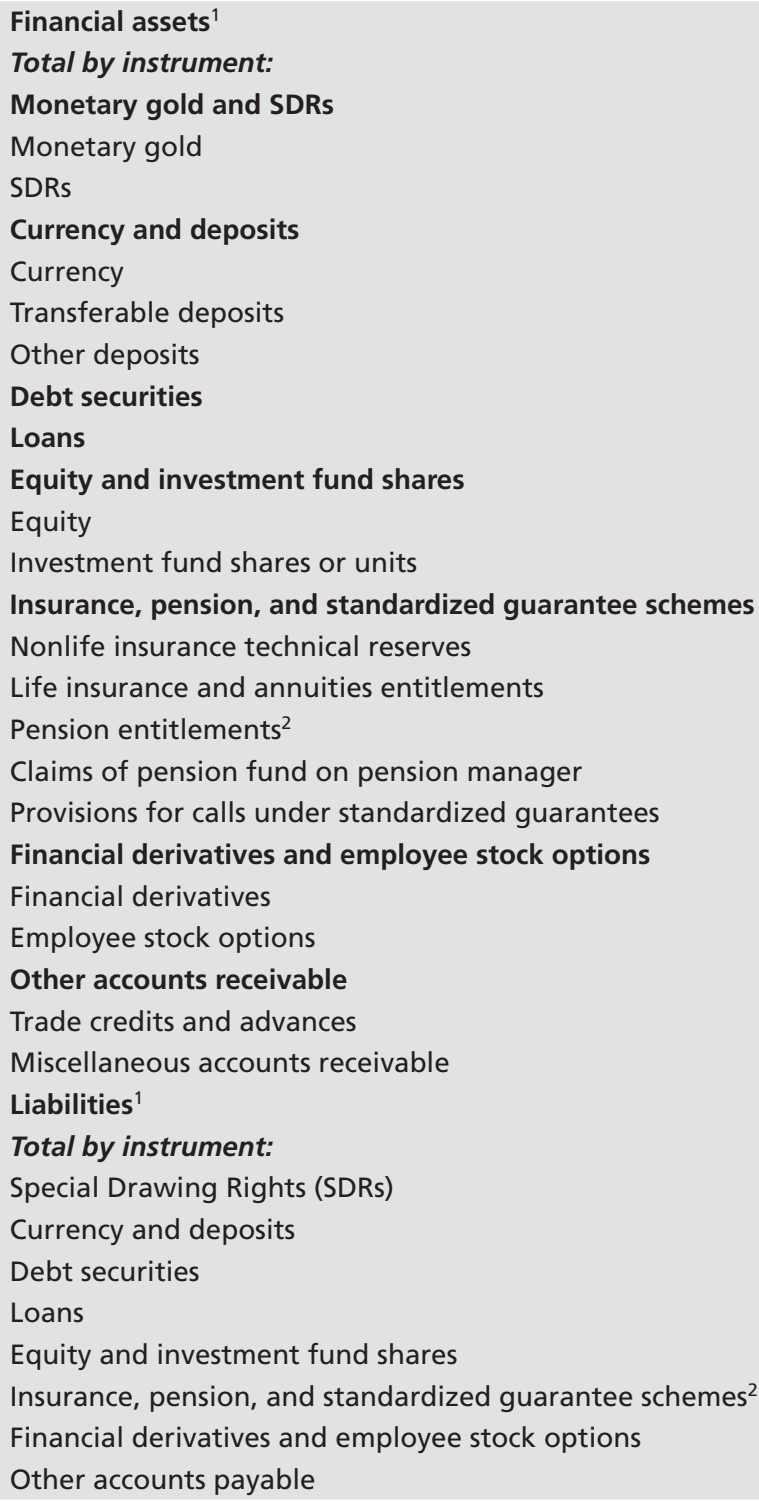

\begin{tabular}{|c|c|c|c|}
\hline \multicolumn{2}{|c|}{ GFS codes } & \multicolumn{2}{|c|}{2008 SNA codes } \\
\hline Transaction & $\begin{array}{c}\text { Stock } \\
\text { position }\end{array}$ & Transaction & $\begin{array}{c}\text { Stock } \\
\text { position }\end{array}$ \\
\hline 32 & 62 & & \\
\hline 3201 & 6201 & F1 & AF1 \\
\hline 32011 & 62011 & F11 & AF11 \\
\hline 32012 & 62012 & F12 & AF12 \\
\hline 3202 & 6202 & F2 & AF2 \\
\hline 32021 & 62021 & F21 & AF21 \\
\hline 32022 & 62022 & F22 & AF22 \\
\hline 32023 & 62023 & F29 & AF29 \\
\hline 3203 & 6203 & F3 & AF3 \\
\hline 3204 & 6204 & F4 & AF4 \\
\hline 3205 & 6205 & F5 & AF5 \\
\hline 32051 & 62051 & F51 & AF51 \\
\hline 32052 & 62052 & F52 & AF52 \\
\hline 3206 & 6206 & F6 & AF6 \\
\hline 32061 & 62061 & F61 & AF61 \\
\hline 32062 & 62062 & F62 & AF62 \\
\hline 32063 & 62063 & F63 \& F65 & AF63 \& AF65 \\
\hline 32064 & 62064 & F64 & AF64 \\
\hline 32065 & 62065 & F66 & AF66 \\
\hline 3207 & 6207 & F7 & AF7 \\
\hline 32071 & 62071 & F71 & AF71 \\
\hline 32072 & 62072 & F72 & AF72 \\
\hline 3208 & 6208 & F8 & AF8 \\
\hline 32081 & 62081 & F81 & AF81 \\
\hline 32082 & 62082 & F82 & AF82 \\
\hline 33 & 63 & & \\
\hline 3301 & 6301 & F12 & AF12 \\
\hline 3302 & 6302 & $\mathrm{~F} 2$ & AF2 \\
\hline 3303 & 6303 & F3 & AF3 \\
\hline 3304 & 6304 & F4 & AF4 \\
\hline 3305 & 6305 & F5 & AF5 \\
\hline 3306 & 6306 & F6 & AF6 \\
\hline 3307 & 6307 & F7 & AF7 \\
\hline 3308 & 6308 & F8 & AF8 \\
\hline
\end{tabular}

'Both financial assets and liabilities are classified further into domestic and external in the same subcategories except that: liabilities and domestic assets exclude monetary gold from flows and stock positions; and domestic assets and domestic liabilities exclude SDRs from stock positions.

${ }^{2}$ To the extent that nonpension entitlement reserves exist, such liabilities are included with those for pension entitlements for pragmatic reasons (see paragraph 7.195).

- Goods and services acquired from the host economy by diplomats, consular staff, and military personnel located abroad and their dependents

- Services supplied by and to governments and not included in other categories of services.

A7.81 Government and international organization enclaves are not residents of the territory in which they are physically located. Therefore, their transactions with residents of that territory or location are international transactions. However, all expenditure on goods and services by locally engaged staff of the enclave is excluded from international transactions. In addition, government supply of licenses and permits to nonresidents that are classified as fees and some activities related to technical assistance provided by one country to another are included in goods and 
services. ${ }^{22}$ The GFS classifications do not specifically require the identification of transactions in goods and services with nonresidents. However, where these transactions can be identified and classifications are built into the underlying general government sector accounting system, the information should be provided to balance of payments compilers. The value of transactions in goods and services entered into with nonresidents in GFS may differ from the international statistics that follow the SNA treatment of insurance services and standardized guarantee fees (see paragraph A7.29).

\section{The primary income account}

A7.82 The primary income account shows primary income flows between resident and nonresident institutional units. Primary income represents the return that accrues to an institutional unit for its contribution to the production process or for the provision of financial assets and renting natural resources to other institutional units.

A7.83 The international accounts distinguish the following types of primary income:

- Compensation of employees

- Investment income

- Dividends

- Reinvested earnings

- Interest

- Investment income attributable to policyholders in insurance, standardized guarantees, and pension funds

- Other primary income

- Rent

- Taxes on production and imports

- Subsidies.

A7.84 The consistency in data between the GFS and primary income account can be established only to the extent that sufficient supplementary details are separately identified in GFS, or the underlying source data. The following linkages exist between the primary income account and GFS:

- Compensation of employees: To the extent that the resident government employs nonresident

\footnotetext{
${ }^{22}$ See the BPM6, paragraphs 10.173-10.181. The criteria for the identification of these fees are the same as in the SNA and GFS.
}

individuals, compensation of employees of government would include amounts payable to nonresidents that should be recorded in the primary income account of the balance of payments. Because government employment usually has some residence criteria as a precondition, these amounts are often not very large. However, in the case of territorial enclaves, all compensation of employees payable by government to residents of the host country should be included in the primary income account. The GFS classifications do not specifically require the identification of compensation of employees to nonresidents. However, when such payments are identified in the underlying source data system, the information should be reported consistently in the GFS and primary income account.

- Investment income: The contribution of the general government sector to investment income is mainly derived from the nonresident portion of the GFS items interest (GFS revenue item 1411 and GFS expense item 24) and dividends (GFS revenue item 1412 and GFS expense item 2811). It can therefore be linked with the GFS accounts, if underlying source data distinguish between receivables and payables from/to residents and nonresidents. While the categories of investment income are conceptually the same for GFS and the international accounts, the value of transactions with nonresidents in GFS may differ from the international statistics due to the treatment of FISIM (see paragraph A7.29). Where general government sector units control insurance, standardized guarantees or pension schemes, they attribute investment income to policyholders in these schemes. These policyholders may include nonresidents, in which case the relevant portion of the property expense for investment income disbursement (GFS expense item 2813) should be consistent with the corresponding item recorded in the primary income account. Where a general government unit or public corporation has foreign direct investments in nonresident special purpose entities (SPEs), or foreign branches of public corporations, reinvested earnings, as reported in the primary income account, should be recorded separately in GFS (GFS revenue item 1416). Similarly, where public corporations have foreign direct investors or investment fund shares/units, reinvested earnings should be 
included in the primary income accounts, and should be consistent with amounts reported in GFS (GFS expense item 2815).

- Other primary income: In calculating other primary income, linkages with the GFS data arise from the transactions with nonresidents related to subsidies (GFS revenue item 14411 and GFS expense item 25) and rent (GFS revenue item 1415 and GFS expense item 2814). Where information on such payments or receipts is provided in the underlying source data, these data should be consistent with the primary income account. The taxes on production and on imports reported in the balance of payments primary income account constitute the portion of these taxes collected from nonresidents and are the same tax categories as the corresponding item in the SNA (D2 in SNA). Taxes on production and on imports are the sum of several detailed GFS tax categories:

- Recurrent taxes on immovable property (GFS item 1131)

- Recurrent taxes on net wealth (GFS item 1132)

- Other recurrent taxes on property (GFS item 1136)

- General taxes on goods and services (GFS item 1141)

- Excises (GFS item 1142)

- Profits of fiscal monopolies (GFS item 1143)

- Taxes on specific services (GFS item 1144)

- Taxes on use of goods and on permission to use goods or perform activities-Payable by producers (GFS item 1145)

- Other taxes-Payable by business (GFS item 1161).

A7.85 To allow consistency checks with the primary income account in the balance of payments, these GFS tax categories need to be divided between amounts receivable from residents and nonresidents. These subcategories are normally not available from GFS, and would be useful only for deriving credits in the primary income account. While certain taxes on production and imports are easier to divide between residents and nonresidents, others are more difficult. Also, the portion attributable to nonresidents may vary from one tax category to the next and from one year to the next.

\section{The secondary income account}

A7.86 The secondary income account in the balance of payments shows current transfers between residents and nonresidents. This account shows redistribution of income; that is, when resources for current purposes are provided by one party without anything of economic value being supplied as a direct return to that party. Various types of current transfers are recorded in this account to show their role in the process of income distribution between economies. The extent to which governments are involved in these transfers will determine the linkages between the GFS Statement of Operations and this account.

A7.87 The standard components of the secondary income account make a distinction at the first level between current transfers receivable/payable by general government and by other sectors, comprising the financial corporations, nonfinancial corporations, households, and NPISHs. For the general government, these transfers include the transfers in respect of:

- Current taxes on income, wealth, etc.

- Social contributions

- Social benefits

- Net nonlife insurance premiums

- Nonlife insurance claims

- Current international cooperation

- Miscellaneous current transfers.

A7.88 To the extent that the current transfers of general government are identifiable and reported in GFS as being from or to nonresidents, these data should be consistently reported in the secondary income account of the balance of payments.

- Current taxes on income, wealth, etc. reported in the secondary income account make up the nonresident portion of the same tax categories as in the 2008 SNA (D5 in SNA). Current taxes on income, wealth, etc. are the sum of several detailed tax categories as reported in GFS, and comprise taxes on income, profits and capital gains (GFS item 111) and several other tax categories mainly payable by final consumers (see paragraph A7.40).

- Social contributions (D61 in SNA) receivable from nonresidents by general government sector units or social benefits payable to nonresidents 
(D62 and D63 in SNA) may be different from the corresponding GFS items (see paragraphs A7.45-A7.47).

- Current international cooperation is separately reported in the GFS Statement of Operations and should be reported consistently in the secondary income account. Grants payable to foreign government and international organizations (GFS item 2611 and 2621 respectively) and grants receivable from foreign governments and international organizations (GFS item 1311 and 1321 respectively) are usually the most important linkage between the GFS and the secondary income account.

- Other miscellaneous current transfers (D75 in SNA $)^{23}$ comprise various items of current transfers receivable and payable (see paragraph A7.49).

- Current transfers of government sector units related to nonlife insurance premiums and claims and miscellaneous current transfers would require a distinction of those receivable or payable to resident and nonresidents.

\section{The capital account}

A7.89 The capital account in the international accounts shows transactions between residents and nonresidents related to capital transfers receivable and payable and the acquisition and disposal of nonproduced nonfinancial assets. It records acquisitions and disposal of nonproduced nonfinancial assets, such as land sold to embassies and sales of leases and licenses, as well as capital transfers-that is, the provision of resources for capital purposes by one party without anything of economic value being supplied in direct return to that party.

A7.90 Nonproduced nonfinancial assets consist of five items: land, mineral and energy resources, and other naturally occurring assets, contracts, leases, and licenses, and marketing assets and goodwill (GFS items $3141,3142,3143,31441$, and 31442, respectively). There is full consistency in the macroeconomic statistical framework with regards to the items of nonproduced nonfinancial assets that exist. Where general government sector units acquire or dispose of these assets in transactions with nonresidents, supplementary information would be required from the GFS

\footnotetext{
${ }^{23}$ The detailed corresponding GFS categories are shown in Tables A7.3 and A7.4.
}

transactions to allow compilation or consistency checks with the international accounts.

A7.91 It should be noted that the capital account in the balance of payments does not show produced nonfinancial assets, as is the case in the SNA and GFS. It shows only transactions in nonproduced nonfinancial assets. Transactions in produced nonfinancial assets are included in the goods and services account, which does not distinguish whether those goods or services are destined for capital or current purposes.

A7.92 Conceptually capital transfers are the same as the capital transfers recorded in the SNA and GFS. Governments are often involved in these transfers, which should be reported in a consistent way in GFS and the capital account of the balance of payments. These capital transfers consist of compulsory transfers to governments, transfers under court orders, and voluntary transfers. There may also be imputed capital transfers as a result of governments' use of special purpose entities resident in other economies, for fiscal purposes (see paragraph 2.138 and paragraphs 8.248.26 of the BPM6). The capital account of the balance of payments includes the following main types of capital transfers:

- Debt forgiveness: When government/public sector entities are involved in debt forgiveness (see paragraphs A3.7-A3.9), either as a recipient or grantor, the event is usually well known and it should be identifiable in the GFS accounts. In the balance of payments capital account, debt forgiveness received from nonresidents is reflected as revenue in capital grants received from either foreign governments, international organizations, or included in capital transfers not elsewhere classified, when received from other nonresident entities. The corresponding entries in GFS are recorded in GFS items 1312, 1322, or 1442 respectively. A corresponding reduction in the appropriate foreign debt instrument will be recorded. When the government sector unit is the provider of debt relief to a nonresident, an expense is reflected as capital grants to foreign governments or international organizations, or is included in capital transfers not elsewhere classified, when provided to other nonresident entities. The GFS expense is recorded in GFS items 2612, 2622 , or 2822 , respectively. A corresponding 
reduction in the appropriate foreign financial asset is recorded.

- Exceptionally large nonlife insurance claims: Where these claims are receivable/payable by government sector units, they are recorded as capital claims (GFS revenue item 1452 or GFS expense item 2832, respectively). Due to the extraordinary nature of this item, it is usually well known and visible in the GFS data, and will allow inclusion in the international accounts.

- Investment grants in the balance of payments: These are capital transfers in cash or in kind made by governments or international organizations to other institutional units to finance all or part of the cost of their acquiring fixed assets. Government/public sector units can be the grantor or recipient of these investment grants. These transfers are recorded in GFS capital grants, as described earlier.

- One-off guarantees and other debt assumption: When government/public sector units and nonresidents are involved in these transactions (see paragraph 7.256-7.260), it should be consistently treated in the capital account and GFS.

- Capital taxes (defined in paragraph 5.51): Those capital taxes recorded in the capital account of the balance of payment comprise the same tax categories as the corresponding item in the SNA (D91 in SNA), but represent only the portion of these taxes collected from nonresidents (see paragraph A7.67). Consistency for this item in the capital account and GFS requires a breakdown of these taxes in supplementary GFS data between amounts receivable from residents and nonresidents.

- Other capital transfers: These consist of major nonrecurrent payments in compensation for extensive damage or serious injuries not covered by insurance policies. Where government/public sector units are the recipient of this type of transfer from nonresidents, it is recorded as part of capital grants receivable from either foreign governments, international organizations, or included as capital transfers not elsewhere classified, when received from other nonresident entities (GFS revenue items 1312, 1322, or 1442, respectively). When the government/public sector unit is the grantor of this type of transfer to a nonresident, an expense is reflected as capital grants to foreign governments, international organizations, or as capital transfers not elsewhere classified, when provided to other entities (GFS expense items 2612, 2622, or 2822, respectively). Consistency for this item in the capital account and GFS also requires a further breakdown of the transfers to identify amounts receivable or payable to nonresidents.

\section{The financial account}

A7.93 The financial account of the balance of payments records transactions that involve financial assets and liabilities that take place between residents and nonresidents. Financial account transactions appear in the balance of payments and, because of their effect on the stock of assets and liabilities, also in the integrated IIP statement. The net balance on the financial account is conceptually equal to the sum of the balances on the current and capital accounts (net lending (+)/net borrowing (-)). The financial account therefore measures how the net lending to or net borrowing from nonresidents is financed.

A7.94 The international accounts use functional categories as the primary classification for each of the financial transactions, other changes in assets and liabilities, and stock positions. ${ }^{24}$ Five functional categories of investment are distinguished in the international accounts:

- Direct investment

- Portfolio investment

- Financial derivatives (other than reserves) and employee stock options

- Other investment

- Reserve assets.

This functional classification takes into consideration some aspects of the relationship between the parties and the motivation for investment (see the $B P M 6$, Chapter 6). In addition, data in the financial account are also presented according to the financial asset or liability instrument employed, the sector or the resident counterpart to the transaction, and maturity. Although the classification of financial assets and liabilities as presented in GFS does not follow

\footnotetext{
${ }^{24}$ The term functional classification is used in a different context in the classification of the functions of government.
} 
a functional classification, it is fully consistent with the instrument breakdown and sector classification as used in the international accounts. As regards financial assets and liabilities the GFS framework distinguishes between transactions with residents and nonresidents. GFS follow the same criteria for determining residence as the international accounts. Conceptually, therefore, the GFS data are consistent with the data for general government as presented in the financial account of the balance of payments. ${ }^{25}$

\section{The other changes in financial assets and liabilities account}

A7.95 In the international accounts, the other changes in financial assets and liabilities account shows changes in financial positions that arise for reasons other than transactions between residents and nonresidents. These changes are also called other flows, and, similar to GFS, they include holding gains and losses, and other volume change in financial assets and liabilities (including reclassifications). Because of the importance of different currencies in the IIP, revaluations (holding gains and losses) are broken down between changes due to exchange rates and other price changes. As described in earlier paragraphs, the classification of assets and liabilities by financial instruments is conceptually fully consistent in the GFS and international accounts. It should result in consistency in the data reported for these other flows in the two datasets, except in the case of liabilities for pension entitlements that may differ.

\section{The international investment position}

A7.96 The international investment position (IIP) is a statistical statement that shows at a point in time the value of: financial assets of residents of an economy that are claims on nonresidents and gold bullion held as reserve assets, and the liabilities of residents of an economy to nonresidents. The difference between the assets and liabilities is the net position in the IIP and represents either a net claim on or a net liability to the rest of the world. The IIP represents a subset of the assets and liabilities included in a country's balance sheet. In addition to the IIP, this balance sheet incor-

\footnotetext{
${ }^{25}$ The international accounts identify general government, but do not present data for the subsectors of the general government, as is the case in GFS.
}

porates nonfinancial assets as well as financial assets and liability positions between residents.

A7.97 As is the case for the financial account, the highest level of classification used in the IIP is the functional classification (see paragraph A7.94). Because of the growing importance of the balance sheet approach to analyze sustainability and vulnerability, the recording in the IIP of information by currency composition is part of the standard presentation, while remaining maturity is encouraged.

A7.98 General government's financial asset/liability positions with nonresidents, as reported in the GFS balance sheet, follow the same accounting rules and classification by instruments as the IIP. Additional reporting requirements on remaining maturity breakdowns and currency breakdowns, as recommended in the PSDS Guide and GFS, are also fully consistent.

\section{Comparison of the Analytical Frameworks of GFS and the Monetary and Financial Statistics}

A7.99 The MFSM is part of international macroeconomic statistical guidelines and can therefore be seen as extending and elaborating on the 2008 SNA. The MFSM framework is consistent with the 1993 SNA with respect to principles and concepts, like the delineation of resident and nonresident entities, sectorization of the economy, classification of the various categories of financial assets and liabilities, time of recording, valuation, and data aggregation. On consolidation, the MFSM follows GFS in consolidating sectoral balance sheets. The main principles and concepts of the MFSM also accord with those in the BPM6 and this Manual.

\section{Comparing the Accounts in GFS and Monetary and Financial Statistics}

A7.100 The purpose of the MFSM is to provide guidelines for the compilation and the presentation of monetary and financial statistics. Monetary statistics consist of a comprehensive set of stock and flow data on the financial and nonfinancial assets and liabilities of an economy's financial corporations sector. The organization and presentation of monetary statistics follow a hierarchical approach based on two general data frameworks - sectoral balance sheets and surveys. Stock position data reported by individual 
institutional units are aggregated into sectoral balance sheets, which contain the comprehensive data for the financial corporations subsectors. At a second level, the data in the sectoral balance sheets are consolidated into surveys.

A7.101 Financial statistics, on the other hand, consist of a comprehensive set of flows and stock position data on financial assets and liabilities of all sectors of an economy. These data are organized and presented in formats designed to show financial flows among the sectors of an economy and corresponding financial asset and liability positions. Also included in monetary and financial statistics are the flow of funds data, presented in a matrix format. A detailed flow of funds accounting cross-classifies financial assets acquired by each sector, by instrument with the counterpart debtor sector. It also cross-classifies liabilities incurred by each sector by instrument and counterpart creditor sector. Therefore, this matrix shows the financial transactions among all subsectors of an economy and the rest of the world. Such a presentation is particularly useful to analyze the allocation of financial resources and users in an economy.

\section{Linkages between GFS and Monetary and Financial Statistics}

A7.102 Linkages between GFS and the monetary and financial statistics (MFS) result from the financial relations between government and financial corporations. As clients (and in addition to holding currency), governments hold deposit assets with financial corporations and contract liabilities by borrowing from and selling debt securities to the corporations. As investors, governments generally are often the sole owner of public financial corporations or hold equity in other financial corporations. These financial relationships result in either a net claim of government on the financial corporations or a net claim of these corporations on government. The net asset/liability position between the general/central government sector and the financial corporations sector should be consistent, and reconcilable in the two datasets. The extent to which these data are similar is often a good indicator of the consistency in macroeconomic statistics in a country.

A7.103 Differences in the amounts reported as net claims between the government sector and the financial corporations sector could be used to check the accuracy and consistency of the respective datasets. Where the two sets of data are materially different, the reasons for the differences must be ascertained, and documentation on the size and reasons for the discrepancy should be provided to users of the data. Good statistical practice is for the compilers to investigate and try to resolve differences. Reasons for differences can often be found in:

- Coverage-In many cases, governments have numerous accounts held in several financial institutions. The institutional coverage of general/central government should be the same in both datasets. A common case exists where certain government institutions have accounts with financial institutions and MFS cover these accounts, but the accounts of these institutions are not covered in GFS because these GFS data are confined to budgetary accounts, thereby not covering the data of the extrabudgetary units. Differences may also arise if government has accounts with a financial institution, but this financial institution is not covered in the monetary and financial statistics.

- Sectorization-Some of the statistical institutional units may not be appropriately and consistently identified and classified as general government or public sector units or the sector classification of the subsectors may be different in the two datasets. For example, an institutional unit that manages and organizes externally financed projects and foreign grants may not be appropriately designated as a government account in financial corporations' records.

- Classification and coverage of financial instruments-The classification of financial instruments included in financial assets and liabilities may differ, or an instrument may not be consistently classified in the two datasets. For example, differences may arise when an instrument such as accounts receivable/payable is not treated the same way in the data, or when a loan is incorrectly reported as equity investment in one of the datasets.

- Time of recording-Complementary periods used in government accounting may result in transactions being recorded at a time other than when economic ownership changed hands.

- Accrual versus cash recording-Although conceptually both datasets should be recorded on an accrual basis, GFS compilers often use cash-based 
data as a proxy for data compiled on an accrual basis, or make adjustments to cash data to approximate accrual data. The financial corporations sector is often more advanced in implementing accrual accounting. Often, certain items may not be correctly accrued to the time when the economic event occurred-for example, they may be using different methods to accrue discount or premiums on bonds.

- Valuation-While conceptually both datasets should follow the same valuation principles for assets and liabilities, national practices may differ. Where valuation differences in source data exist, differences may occur between GFS and monetary and financial statistics, unless valuation adjustments are made when the respective datasets are prepared.

- Dematerializing of debt instruments-Where governments issue tradable securities, they often have no knowledge or record of transactions in the secondary market, so the sector holding such securities can usually be determined either by surveying the ultimate purchaser of such securities or by using data from a centralized securities depository. However, quite often these instruments are held by nominees of the financial corporations sector, which may complicate the identification of the owners of claims of the government. The complexity of determining ownership of tradable instruments may further introduce inconsistency in the data.

A7.104 Due to the financial asset/liability positions held between general/central government and the financial corporations sector, some additional revenue and expense flows occur between these sectors. Further consistency checks can be performed on these revenue and expense transactions where the level of detail in the source data permits them. These relate specifically to receivables/payables in respect of interest, dividends, other property income, subsidies, and capital transfers between the general/central government sector and the financial corporations sector.

\section{Comparison of the Analytical Framework of GFS and the System of Environmental-Economic Accounting Central Framework}

A7.105 The System of Environmental-Economic Accounting (SEEA) Central Framework is the international statistical standard for environmental- economic accounting. The SEEA Central Framework contains the internationally agreed standard concepts, definitions, classifications, and accounting rules and tables for producing internationally comparable statistics on the environment and its relationship with the economy. The SEEA Central Framework is a multipurpose conceptual framework that presents the stock positions and changes in these stock positions (flows) of environmental assets.

\section{Comparing the Accounts in GFS and SEEA Central Framework}

A7.106 The SEEA Central Framework follows a similar accounting structure to the 2008 SNA and this Manual, and uses consistent concepts, definitions, and classifications to facilitate the integration of environmental and other macroeconomic statistics. Consequently, the SEEA Central Framework allows for the integration of environmental information (often measured in physical terms) with economic information (often measured in monetary terms) in a single framework. However, given the specific analytical focus of the SEEA Central Framework on the environment and its linkages with the economy, as well as its focus on the measurement of flows and stock positions in physical and monetary terms, there are some limited differences between the SEEA Central Framework and the 2008 SNA. ${ }^{26}$ To the extent that SEEA Central Framework is consistent with the 2008 SNA, it is also consistent with this Manual.

\section{The Nature of Environmental Protection Activities and Accounting}

A7.107 Environmental protection activities are those activities whose primary purpose is the prevention, reduction, and elimination of pollution and other forms of degradation of the environment. These activities include, but are not limited to, the prevention, reduction, or treatment of waste and wastewater; the prevention, reduction, or elimination of air emissions; the treatment and disposal of contaminated soil and groundwater; the prevention or reduction of noise and vibration levels; the protection of biodiversity and landscapes, including their ecological functions; monitoring of the quality of the natural environment (air, water, soil, groundwater); research

\footnotetext{
${ }^{26}$ See SEEA Central Framework, paragraphs 1.39-1.52
} 
and development on environmental protection; and the general administration, training, and teaching activities oriented toward environmental protection.

A7.108 Resource management activities are those activities whose primary purpose is preserving and maintaining the stock of natural resources and hence safeguarding against depletion. These activities include, but are not limited to, reducing the withdrawals of natural resources (including through the recovery, reuse, recycling, and substitution of natural resources); restoring natural resource stocks (increases or recharges of natural resource stocks); the general management of natural resources (including monitoring, control, surveillance, and data collection); and the production of goods and services used to manage or conserve natural resources.

A7.109 To account for environmental protection and resource management activities the SEEA Central Framework comprises the following types of tables and accounts:

- Supply and use tables in physical and monetary terms showing flows of natural inputs, products, and residuals

- Asset accounts for individual environmental assets in physical and monetary terms showing the stock of environmental assets at the beginning and end of each accounting period and the changes in the stock

- A sequence of economic accounts that highlights depletion-adjusted economic aggregates

- Functional accounts that record transactions and other information about economic activities undertaken for environmental purposes.

The analysis of these data can also be extended by linking the tables and accounts to relevant employment, demographic, and social information.

A7.110 The SEEA Central Framework relies on basic environment statistics, such as statistics on natural resources-for example water, energy, forest, flows of materials and pollutants-which are usually collected for specific purposes. The SEEA Central Framework adds value to individual information components by bringing them together to inform integrated policies, evaluate trade-offs between different policies, and evaluate their impacts across domains of the economy, the environment, and society.

\section{Linkages between GFS and SEEA Central Framework}

A7.111 There is a wide range of transactions and stocks positions related to the environment that are recorded in the GFS framework. The type of transaction often flows from governments' role of owner of natural resources, such as land and subsoil assets, user of these resources, or other ways in which governments influence the use of these resources by other sectors, such as governments' control over the use of the atmosphere as a sink for pollution. Of particular interest in this regard are flows of taxes and subsidies related to the environment.

A7.112 Many of the mechanisms by which economic behavior is influenced toward meeting environmental policy objectives involve payments to government, most commonly in the form of taxes, permits, and rent; and payments by government in the form of subsidies and other transfers. These transactions are recorded in the GFS framework but are generally not separately identifiable as relating to the environment. In order to allow comparisons of GFS and the SEEA Central Framework, such data would need to be provided separately in the underlying source data of GFS.

A7.113 Similar to GFS, the SEEA Central Framework records only taxes and subsidies for which an actual transaction takes place between institutional units. In some cases there is interest in the value of socalled implicit subsidies-for example, via tax exemptions or preferential tax rates. However, as there are no transactions recorded in relation to these amounts they are not recorded in either dataset.

A7.114 The remainder of this section discusses payments to government related to the environment, and payments by government related to the environment. ${ }^{27}$

\section{Environmental payments to government Environmental taxes}

A7.115 The decision as to whether a payment regarded as a tax is environmental is based on consideration of the tax base. An environmental tax is a tax whose tax base is a physical unit (or a proxy of it) of something that has a proven, specific, negative impact on the environment. In practice, this definition is applied by looking at all of the various taxes levied in a

\footnotetext{
${ }^{27}$ See SEEA Central Framework, section 4.4, for a detailed description on accounting for transactions related to the environment.
} 
country and making an assessment as to whether the tax base in each circumstance is something that has a negative environmental impact.

A7.116 Since the application of this definition may vary across countries, for the purposes of international comparison of environmental taxes, lists of relevant taxes bases that satisfy this definition have been developed by the Organisation for Economic Co-operation and Development and Eurostat.

A7.117 The consideration of the tax base in the determination of the environmental status of a tax is an exception to the general approach to defining the environmental status on the basis of the purpose of the transaction. However, in the case of taxes, generally the taxpayer does not know in advance as to what the tax payment might be used for by the government. Nor are the reasons for levying a tax as stated by the legislator a reliable basis for international comparisons. The primary purpose of taxation may sometimes be to create incentives to reduce environmental pressures, or to raise revenue for the purpose of financing environmental protection. However, in many cases, the specific reason may not be stated and often the primary purpose of taxation is the raising of funds to pay for general social services, such as health and education.

A7.118 In cases where the use of the tax revenue is known, these taxes are considered "earmarked taxes." Those taxes that are earmarked for environmental protection are relevant in the calculation of environmental protection expenditure.

A7.119 There are four broad categories into which environmental taxes are generally grouped. These are:

- Energy taxes-This category includes taxes on energy products used for both transport and stationary purposes. Taxes on fuel used for transport purposes should be shown as a separate subcategory of energy taxes. Energy products for stationary use include fuel oils, natural gas, coal, and electricity. Taxes on carbon are included under energy taxes rather than under pollution taxes. If they are identifiable, carbon taxes should be reported as a separate subcategory within energy taxes. A special type of carbon taxes is payments for tradable emission permits. The treatment of payments for these permits is discussed later in this section.
- Transport taxes-This category mainly includes taxes related to the ownership and use of motor vehicles. Taxes on other transport equipment (e.g., planes) and related transport services (e.g., duty on charter or scheduled flights) are also included here as are taxes related to the use of roads. The transport taxes may be "one-off" taxes related to imports or sales of the equipment or recurrent taxes, such as an annual road tax. Taxes on petrol, diesel, and other transport fuels are included under energy taxes.

- Pollution taxes-This category includes taxes on measured or estimated emissions to air and water, and the generation of solid waste. An exception is taxes on carbon, which are included under energy taxes, as discussed earlier. Taxes on sulphur are included here.

- Resource taxes-This category typically includes taxes on water abstraction, extraction of raw materials, and other resources (e.g., sand and gravel). Consistent with the general scope of environmental taxes, payments to government for the use of land or natural resources are treated as rent and therefore are excluded from resource taxes.

\section{Treatment of value-added taxes}

A7.120 Generally, value-added taxes (VAT) are excluded from the definition of environmental taxes because they are considered to have no influence on relative prices in the same way that other taxes on environmental tax bases do (i.e., VAT is levied on a broad range of goods and services regardless of their impact on the environment). This lack of direct influence is also reflected in the deductible nature of VAT for many taxpayers. There is one relatively specific exception to this general treatment. In principle, where VAT is calculated on a price that includes a duty or tax already determined to be an environmental tax, the relevant amount of nondeductible VAT (equal to the VAT rate multiplied by the amount of the environmental tax excluding the part that is deductible by the taxpayer) can also be considered to be part of environmental taxes and classified based on the nature of the underlying tax base. Such a situation may occur when VAT on petrol/gasoline is calculated, including the fuel duty paid on hydrocarbon oils. In practice, the ability to separately identify this amount of VAT may require additional information. 


\section{Other payments to government}

A7.121 Only those payments that are considered to be taxes according to the definitions of GFS and the SNA are within the scope of environmental taxes in the SEEA. At the same time, there may also be particular interest in identifying and recording other payments to government that are also related to the environment, such as payments of rent, some sales of goods and services, and some fines and penalties. In determining the environmental status of these payments, focus should remain on the basis for the payment rather than on either the name used to describe the payment or the purpose for which the revenue raised may be used. The following paragraphs describe these other environment-related types of payments to government. To allow comparisons of GFS and SEEA Central Framework, data on these environment-related payments to government would need to be provided separately in the underlying source data of GFS, or added as subitems of the GFS categories.

\section{Rent}

A7.122 There are certain environmental assets, particularly mineral and energy resources, that are owned by government, and payments to government by extractors are often required. These payments are treated as rent. Payments of rent in respect of mineral and energy resources are commonly referred to as royalties, and in resource-endowed countries these payments may represent an important component of total government revenue. These are often also referred to as resource leases (see paragraph A4.16).

\section{Sales of goods and services}

A7.123 In a number of situations the government could undertake a range of activities that provide goods and services to households and businesses that are environmental in nature. Such provision of goods and services constitutes production by government units, and payments made by users are often referred to as "fees." A common situation is the payments made to general government units that operate waste collection schemes for the disposal of waste. Whether these payments are purchases of goods and services or taxes can be difficult to assess, since it must be determined as to whether the purchaser has received a commensurate service from the government in return for the payment. The general guidance in the paragraphs 5.73-5.75 should be followed to make the distinction.

\section{Fines and penalties}

A7.124 Fines and penalties are distinguished from taxes as being compulsory payments imposed on institutional units by courts of law or quasi-judicial bodies. These payments to governments are treated as fines, penalties and forfeits (GFS item 143). It may well be that some fines and penalties are related to illegal environmental activities-for example, fines for polluting water bodies. The recording of environmentrelated fines and penalties also arises in the case of the use of environmental assets as sinks.

\section{Environmental transfers by nongovernment institutional units}

A7.125 Where information on these flows is of interest, the amounts to be recorded as environmental should follow the same principles as applied in the case of government flows-that is, transfers paid to other institutional units should be based on whether the primary purpose of the payer is environmental protection or resource management. Within GFS further breakdown or "of which" lines may be added to the classification structure to specifically identify these flows.

A7.126 A particular instance of transfers between institutional units concerns flows between international organizations and national governments and other resident institutional units. In certain countries these flows may be significant. In line with the general principles outlined here, transfers paid by international organizations to institutional units within a country should be considered to be environmental if the primary intent of the international organization is that the money is spent for environmental protection or resource management purposes. Supplementary breakdowns in grants from foreign governments or international organizations (GFS item 131 and 132) could provide for this data need.

\section{Permits to use environmental assets}

A7.127 A common and important mechanism for managing the interaction between the economy and the environment is the use of permits and licenses to access, extract, or use environmental assets. In some cases, the permits and licenses may relate to the physical removal of environmental assets, such as in the 
case of fishing licenses, and in other cases they may relate to the use of the environment as a sink for emissions. For a discussion of licenses and permits to use natural resources, see A4.18-A4.50.

\section{Environmental payments by governments}

A7.128 Payments by government related to environmental issues are recorded in a number of places in GFS and the SNA. The treatment largely depends on how the payments relate to production and consumption and whether they are considered to be current or capital in nature.

A7.129 All of the payments considered in this section are transfers (see paragraph 3.10). Consequently, this section does not include payments by government for the purchase of goods and services related to the environment.

\section{Environmental subsidies and similar transfers}

A7.130 An environmental subsidy or similar transfer is a transfer that is intended to support activities that protect the environment or reduce the use and extraction of natural resources. It includes those transfers defined in GFS as subsidies (25), social benefits (27), grants (26), and transfers not elsewhere classified (282).

A7.131 Subsidies or other transfers should be treated as environmental when the primary intent or purpose of the government is that resources be used for either environmental protection or resource management purposes. The determination of primary purpose should not be based on whether the use of the resources by the recipient of the transfer results in positive outcomes for the environment. While it is reasonable to consider that the purpose of the government in making the transfer and the purpose of the recipient are the same, it may not be the case that the expenditure of the transferred resources results in beneficial environmental outcomes even if this was the intent. For detailed descriptions of the classification of these transfers, refer to Chapter 6.

A7.132 In principle, a decision as to whether the primary purpose of a transfer is environmental should be made for each individual transfer. Then, once a decision on the primary purpose has been made, the total value of the transfer is treated as being for that primary purpose.

A7.133 In practice, information on transfers by government is usually contained in budget and other government expenditure data. Generally, these data do not show individual transactions and more commonly show information by type of government program, thus including a large number of individual transfers. It is usually the case that such programs have multiple purposes, and hence determining the number and value of individual transfers that have a primary purpose of environmental protection or resource management may require additional information.

A7.134 In these situations, it may be necessary to estimate the share of the value of transfers for a given government program that reflects the value of individual transfers within the program that have environmental protection or resource management as their primary purpose. 


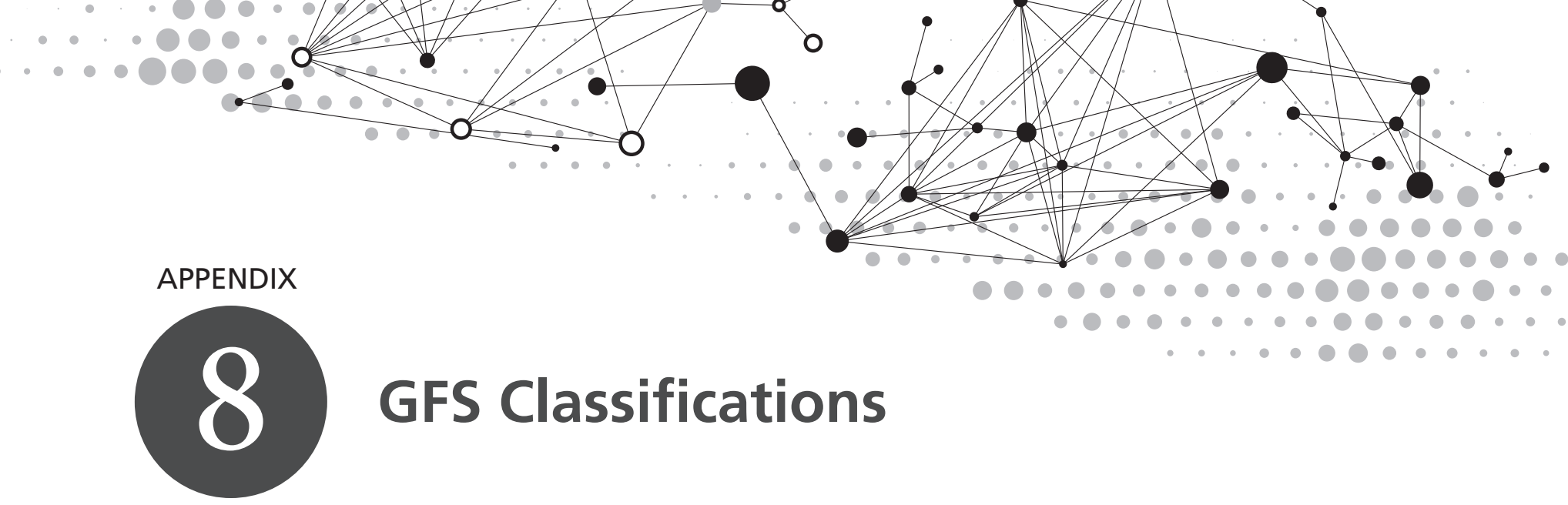

This appendix provides all of the classification codes used in the GFS framework.

A8.1 Classification codes are used in the GFS system to identify types of transactions, other economic flows, and stock positions of assets and liabilities. This appendix presents in one place all of the codes that were presented in Chapters 5 through 10. The overall organization of the codes is shown in Figure A8.1.

A8.2 Codes beginning with 1 refer to revenue; codes beginning with 2 refer to expense; and codes beginning with 3 refer to transactions in nonfinancial assets, financial assets, and liabilities. For financial assets and liabilities, the code 3 signifies transactions that have been classified by financial instrument.

A8.3 The first digit of the classification code for a specific type of other economic flow is 4 or 5 : codes beginning with 4 refer to holding gains and losses, while codes beginning with 5 refer to other changes in the volume of assets and liabilities. The first digit for total other economic flows is 9. For a stock position in a type of asset or liability, the first digit of the classification code is 6 .

A8.4 Codes for transactions, other economic flows, and stock positions in assets and liabilities also identify types of assets and liabilities. Hence, the second and subsequent digits of each code are identical for each type of asset or liability. That is, 311 refers to transactions in fixed assets, 411 to holding gains in fixed assets, 511 to other changes in the volume of fixed assets, 911 to total other economic flows in fixed assets, and 611 to the stock position of fixed assets.

A8.5 Expense transactions and transactions in nonfinancial assets (i.e., expenditure) can also be classified using the Classification of Functions of Government (COFOG), as described in the annex to Chapter 6. All COFOG classification codes begin with 7 .

A8.6 Transactions and stock positions in financial assets and liabilities can be classified according to the residence and institutional sector of the other party to the financial instrument, as well as according to the type of financial instrument. When classified by residence and institutional sector of the counterparty, the classification codes for transactions begin with 8 and the classification codes for stock positions begin with 68 . The counterparty to the transactions is not necessarily the same as the counterparty to the stock positions. While the parties are the same at the inception of the instrument, they may differ for transactions in that instrument. As explained in paragraph 9.25, in principle, the classification of general government units' transactions in financial assets and liabilities by residence is based on the residence of the units that were a party to the transaction being recorded, whereas the classification of stock positions in financial assets and liabilities in a government unit's balance sheet is based on the residence of the issuer of financial instruments (assets), and the residence of the holder of the financial instruments (liabilities). If a transaction in financial assets or liabilities is between a resident and a nonresident unit that involves an instrument originally issued by a resident, an entry in other changes in the volume of assets (reclassification) is recorded to maintain the integrated GFS framework of flows and stock positions.

A8.7 In this appendix, the classification codes are presented in Tables A8.1-A8.6, which illustrate the standard presentation of these items in GFS. In practical applications, this standard presentation could be used to select subsets of data for various presentational formats. It may also be possible and desirable to use more detailed classifications. Such an expansion can be accomplished by adding another digit to any given classification code. For example, the classification code for the stock of transport equipment is 61121. If types of transport equipment were to be classified separately, the codes 611211,611212 , and so forth could be used. 


\section{Figure A8.1 The Classification Coding System for GFS}

\begin{tabular}{|c|c|}
\hline \multicolumn{2}{|c|}{ Flows } \\
\hline Transactions & Other economic flows \\
\hline
\end{tabular}
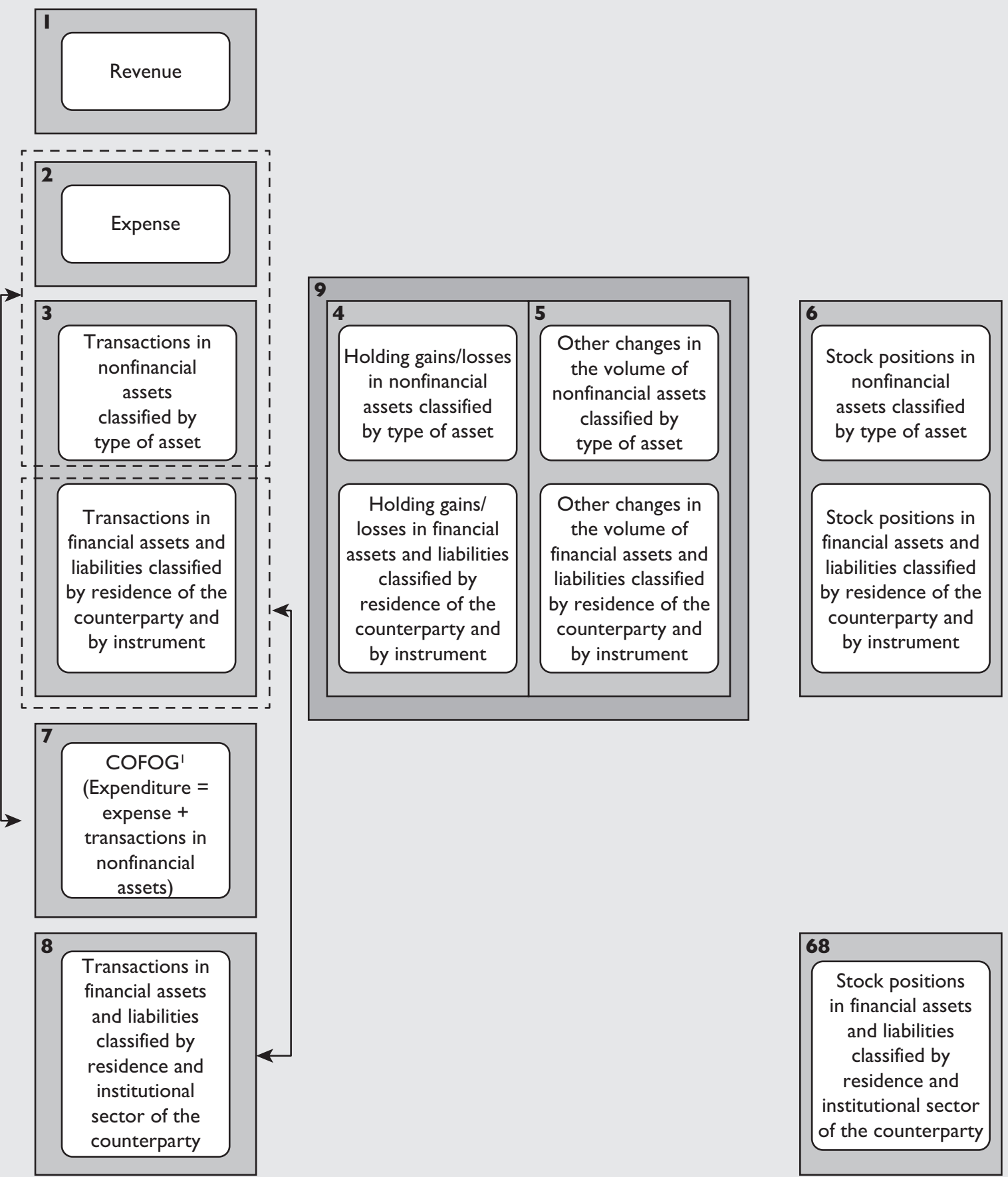

${ }^{1}$ Classification of the Functions of Government 


\section{Table A8.1 Classification of Revenue}

\begin{tabular}{|c|c|c|c|}
\hline 1 & Revenue & 122 & Other social contributions [GFS] \\
\hline 11 & Taxes & 1221 & Employee contributions [GFS] \\
\hline 111 & Taxes on income, profits, and capital gains & 1222 & Employer contributions [GFS] \\
\hline 1111 & Payable by individuals & 1223 & Imputed contributions [GFS] \\
\hline 1112 & Payable by corporations and other enterprises & 13 & Grants \\
\hline 1113 & Other taxes on income, profits, and capital gains & 131 & From foreign governments \\
\hline 11131 & Payable by general government & 1311 & Current \\
\hline 11132 & Unallocable taxes on income, profits, and & 1312 & Capital \\
\hline & capital gains & 132 & From international organizations \\
\hline 112 & Taxes on payroll and workforce & 1321 & Current \\
\hline 113 & Taxes on property & 1322 & Capital \\
\hline $\begin{array}{l}1131 \\
1132\end{array}$ & Recurrent taxes on immovable property & 133 & From other general government units \\
\hline 1132 & $\begin{array}{l}\text { Recurrent taxes on net wealth } \\
\text { Estate, inheritance, and gift taxes }\end{array}$ & 1331 & Current \\
\hline 1135 & Capital levies & 1332 & Capital \\
\hline 1136 & Other recurrent taxes on property & 14 & Other revenue \\
\hline 114 & Taxes on goods and services & 141 & Property income [GFS] \\
\hline 1141 & General taxes on goods and services & 1411 & Interest [GFS] \\
\hline 11411 & Value-added taxes & 14111 & From nonresidents \\
\hline 11412 & Sales taxes & 14112 & From residents other than general \\
\hline 11413 & $\begin{array}{l}\text { Turnover and other general taxes on goods } \\
\text { and services }\end{array}$ & 14113 & $\begin{array}{l}\text { government } \\
\text { From other general government }\end{array}$ \\
\hline 11414 & Taxes on financial and capital transactions & & units \\
\hline 1142 & Excise & 1412 & Dividends \\
\hline 1143 & Profits of fiscal monopolies & 14121 & From nonresidents \\
\hline 1144 & Taxes on specific services & 14122 & From residents \\
\hline 1145 & $\begin{array}{l}\text { Taxes on use of goods and on permission to use } \\
\text { goods or perform activities }\end{array}$ & 1413 & $\begin{array}{l}\text { Withdrawals of income from } \\
\text { quasi-corporations }\end{array}$ \\
\hline 11451 & Motor vehicle taxes & 1414 & Property income from investment \\
\hline 11452 & $\begin{array}{l}\text { Other taxes on use of goods and on permission } \\
\text { to use goods or perform activities }\end{array}$ & 1415 & $\begin{array}{l}\text { income disbursements } \\
\text { Rent }\end{array}$ \\
\hline 114521 & Business and professional licenses & 1416 & Reinvested earnings on foreign direct \\
\hline 114522 & Pollution taxes & & investment \\
\hline 114523 & Radio and television licenses & 142 & Sales of goods and services \\
\hline 114524 & Licenses and permits for households & 1421 & Sales by market establishments \\
\hline 114525 & $\begin{array}{l}\text { Other taxes on use of goods and on } \\
\text { permission to use goods or perform activities } \\
\text { not elsewhere classified }\end{array}$ & $\begin{array}{l}1422 \\
1423\end{array}$ & $\begin{array}{l}\text { Administrative fees } \\
\text { Incidental sales by nonmarket } \\
\text { establishments }\end{array}$ \\
\hline 1146 & Other taxes on goods and services & 1424 & Imputed sales of goods and services \\
\hline 115 & Taxes on international trade and transactions & 143 & Fines, penalties, and forfeits \\
\hline 1151 & Customs and other import duties & 144 & Transfers not elsewhere classified \\
\hline 1152 & Taxes on exports & 1441 & Current transfers not elsewhere \\
\hline 1153 & Profits of export or import monopolies & & classified \\
\hline 1154 & Exchange profits & 14411 & Subsidies \\
\hline 1155 & Exchange taxes & 14412 & Other current transfers not \\
\hline 1156 & $\begin{array}{l}\text { Other taxes on international trade and } \\
\text { transactions }\end{array}$ & 1442 & $\begin{array}{l}\text { elsewhere classified } \\
\text { Capital transfers not elsewhere classified }\end{array}$ \\
\hline 116 & Other taxes & 145 & Premiums, fees, and claims related to \\
\hline 1161 & Payable solely by business & & nonlife insurance and standardized \\
\hline 1162 & Payable by other than business or unidentifiable & & guarantee schemes \\
\hline 12 & Social contributions [GFS] & 1451 & Premiums, fees, and current claims \\
\hline 121 & Social security contributions [GFS] & & receivable \\
\hline 1211 & Employee contributions [GFS] & 14511 & Premiums receivable \\
\hline 1212 & Employer contributions [GFS] & 14512 & Fees receivable for standardized \\
\hline 1213 & $\begin{array}{l}\text { Self-employed or nonemployed contributions } \\
\text { [GFS] }\end{array}$ & 14513 & $\begin{array}{l}\text { guarantee schemes } \\
\text { Current claims receivable }\end{array}$ \\
\hline 1214 & Unallocable contributions [GFS] & 1452 & Capital claims receivable \\
\hline
\end{tabular}

Note: Further breakdown/" of which" lines may be analytically useful and could be presented as indicated in the detailed tables in Chapter 5 . 


\section{Table A8.2 Classification of Expense}

\begin{tabular}{|c|c|c|c|}
\hline 2 & Expense & 27 & Social benefits [GFS] \\
\hline 21 & Compensation of employees [GFS] & 271 & Social security benefits [GFS] \\
\hline 211 & Wages and salaries [GFS] & 2711 & Social security benefits in cash [GFS] \\
\hline 2111 & Wages and salaries in cash [GFS] & 2712 & Social security benefits in kind [GFS] \\
\hline 2112 & Wages and salaries in kind [GFS] & 272 & Social assistance benefits [GFS] \\
\hline 212 & Employers' social contributions [GFS] & 2721 & Social assistance benefits in cash [GFS] \\
\hline 2121 & Actual employers' social contributions [GFS] & 2722 & Social assistance benefits in kind [GFS] \\
\hline 2122 & Imputed employers' social contributions [GFS] & 273 & Employment-related social benefits [GFS] \\
\hline $\begin{array}{l}22 \\
23\end{array}$ & $\begin{array}{l}\text { Use of goods and services } \\
\text { Consumption of fixed capital [GFS] }\end{array}$ & 2731 & $\begin{array}{l}\text { Employment-related social benefits in } \\
\text { cash [GFS] }\end{array}$ \\
\hline $\begin{array}{l}24 \\
241\end{array}$ & $\begin{array}{l}\text { Interest [GFS] } \\
\quad \text { To nonresidents [GFS] }\end{array}$ & 2732 & $\begin{array}{l}\text { Employment-related social benefits in } \\
\text { kind [GFS] }\end{array}$ \\
\hline 242 & To residents other than general government & 28 & Other expense \\
\hline & [GFS] & 281 & Property expense other than interest \\
\hline 243 & To other general government units [GFS] & 2811 & Dividends \\
\hline 25 & Subsidies & 28111 & To nonresidents \\
\hline $\begin{array}{l}251 \\
2511\end{array}$ & To public corporations & 28112 & To residents \\
\hline $\begin{array}{l}2511 \\
2512\end{array}$ & $\begin{array}{l}\text { Public nonfinancial corporations } \\
\text { Public financial corporations }\end{array}$ & 2812 & Withdrawals of income from \\
\hline 252 & To private enterprises & & quasi-corporations \\
\hline 2521 & Private nonfinancial enterprises & 2813 & $\begin{array}{l}\text { Property expense for investment income } \\
\text { disbursements }\end{array}$ \\
\hline 2522 & Private financial enterprises & & disbursements \\
\hline 253 & To other sectors & 2814 & Rent \\
\hline 26 & Grants & 2815 & Reinvested earnings on foreign direct \\
\hline 261 & To foreign governments & & investment \\
\hline 2611 & Current & 282 & Transfers not elsewhere classified \\
\hline 2612 & Capital & 2821 & Current transfers not elsewhere classified \\
\hline 262 & To international organizations & 2822 & Capital transfers not elsewhere classified \\
\hline 2621 & Current & 283 & Premiums, fees, and claims related to nonlife \\
\hline 2622 & Capital & & insurance and standardized guarantee schemes \\
\hline 263 & To other general government units & 2831 & Premiums, fees, and current claims payable \\
\hline 2631 & Current & 28311 & Premiums payable \\
\hline \multirow[t]{3}{*}{2632} & Capital & 28312 & $\begin{array}{l}\text { Fees payable for standardized guarantee } \\
\text { schemes }\end{array}$ \\
\hline & & 28313 & Current claims payable \\
\hline & & 2832 & Capital claims payable \\
\hline
\end{tabular}

Note: Further breakdown/"of which lines" may be analytically useful and could be presented as indicated in the detailed tables in Chapter 6 . 
Table A8.3 Classifications of Flows and Stock Positions in Assets and Liabilities

\begin{tabular}{|c|c|c|c|c|c|}
\hline & $\begin{array}{l}\text { Classification } \\
\text { of transactions } \\
\text { in assets and } \\
\text { liabilities }^{1}\end{array}$ & $\begin{array}{l}\text { Classification } \\
\text { of holding } \\
\text { gains and } \\
\text { losses in } \\
\text { assets and } \\
\text { liabilities }\end{array}$ & $\begin{array}{c}\text { Classification } \\
\text { of other } \\
\text { changes in } \\
\text { the volume } \\
\text { of assets and } \\
\text { liabilities }\end{array}$ & $\begin{array}{l}\text { Classification } \\
\text { of total other } \\
\text { economic } \\
\text { flows in } \\
\text { assets and } \\
\text { liabilities }\end{array}$ & $\begin{array}{c}\text { Classification } \\
\text { of stock } \\
\text { positions in } \\
\text { assets and } \\
\text { liabilities }\end{array}$ \\
\hline Net worth and its changes & 3 & 4 & 5 & 9 & 6 \\
\hline Nonfinancial assets & 31 & 41 & 51 & 91 & 61 \\
\hline Fixed assets & 311 & 411 & 511 & 911 & 611 \\
\hline Buildings and structures & 3111 & 4111 & 5111 & 9111 & 6111 \\
\hline Dwellings & 31111 & 41111 & 51111 & 91111 & 61111 \\
\hline Buildings other than dwellings & 31112 & 41112 & 51112 & 91112 & 61112 \\
\hline Other structures & 31113 & 41113 & 51113 & 91113 & 61113 \\
\hline Land improvements & 31114 & 41114 & 51114 & 91114 & 61114 \\
\hline Machinery and equipment & 3112 & 4112 & 5112 & 9112 & 6112 \\
\hline Transport equipment & 31121 & 41121 & 51121 & 91121 & 61121 \\
\hline $\begin{array}{l}\text { Machinery and equipment other } \\
\text { than transport equipment }\end{array}$ & 31122 & 41122 & 51122 & 91122 & 61122 \\
\hline $\begin{array}{l}\text { Information, computer, and } \\
\text { telecommunications (ICT) } \\
\text { equipment }\end{array}$ & 311221 & 411221 & 511221 & 911221 & 611221 \\
\hline $\begin{array}{l}\text { Machinery and equipment not } \\
\text { elsewhere classified }\end{array}$ & 311222 & 411222 & 511222 & 911222 & 611222 \\
\hline Other fixed assets & 3113 & 4113 & 5113 & 9113 & 6113 \\
\hline Cultivated biological resources & 31131 & 41131 & 51131 & 91131 & 61131 \\
\hline $\begin{array}{l}\text { Animal resources yielding } \\
\text { repeat products }\end{array}$ & 311311 & 411311 & 511311 & 911311 & 611311 \\
\hline $\begin{array}{l}\text { Tree, crop, and plant resources } \\
\text { yielding repeat products }\end{array}$ & 311312 & 411312 & 511312 & 911312 & 611312 \\
\hline Intellectual property products & 31132 & 41132 & 51132 & 91132 & 61132 \\
\hline Research and development & 311321 & 411321 & 511321 & 911321 & 611321 \\
\hline $\begin{array}{l}\text { Mineral exploration and } \\
\text { evaluation }\end{array}$ & 311322 & 411322 & 511322 & 911322 & 611322 \\
\hline $\begin{array}{l}\text { Computer software and } \\
\text { databases }\end{array}$ & 311323 & 411323 & 511323 & 911323 & 611323 \\
\hline Computer software & 3113231 & 4113231 & 5113231 & 9113231 & 6113231 \\
\hline Databases & 3113232 & 4113232 & 5113232 & 9113232 & 6113232 \\
\hline $\begin{array}{l}\text { Entertainment, literary, and } \\
\text { artistic originals }\end{array}$ & 311324 & 411324 & 511324 & 911324 & 611324 \\
\hline $\begin{array}{l}\text { Other intellectual property } \\
\text { products }\end{array}$ & 311325 & 411325 & 511325 & 911325 & 611325 \\
\hline $\begin{array}{l}\text { Cost of ownership transfer on } \\
\text { nonproduced assets other than land }\end{array}$ & 31133 & & 51133 & 91133 & \\
\hline Weapons systems & 3114 & 4114 & 5114 & 9114 & 6114 \\
\hline Inventories & 312 & 412 & 512 & 912 & 612 \\
\hline Materials and supplies & 31221 & 41221 & 51221 & 91221 & 61221 \\
\hline Work in progress & 31222 & 41222 & 51222 & 91222 & 61222 \\
\hline Finished goods & 31223 & 41223 & 51223 & 91223 & 61223 \\
\hline Goods for resale & 31224 & 41224 & 51224 & 91224 & 61224 \\
\hline Military inventories & 31225 & 41225 & 51225 & 91225 & 61225 \\
\hline Valuables & 313 & 413 & 513 & 913 & 613 \\
\hline
\end{tabular}


Table A8.3 Classifications of Flows and Stock Positions in Assets and Liabilities (continued)

\begin{tabular}{|c|c|c|c|c|c|}
\hline & $\begin{array}{l}\text { Classification } \\
\text { of transactions } \\
\text { in assets and } \\
\text { liabilities }^{1}\end{array}$ & $\begin{array}{l}\text { Classification } \\
\text { of holding } \\
\text { gains and } \\
\text { losses in } \\
\text { assets and } \\
\text { liabilities }\end{array}$ & $\begin{array}{c}\text { Classification } \\
\text { of other } \\
\text { changes in } \\
\text { the volume } \\
\text { of assets and } \\
\text { liabilities }\end{array}$ & $\begin{array}{l}\text { Classification } \\
\text { of total other } \\
\text { economic } \\
\text { flows in } \\
\text { assets and } \\
\text { liabilities }\end{array}$ & $\begin{array}{c}\text { Classification } \\
\text { of stock } \\
\text { positions in } \\
\text { assets and } \\
\text { liabilities }\end{array}$ \\
\hline Nonproduced assets & 314 & 414 & 514 & 914 & 614 \\
\hline Land & 3141 & 4141 & 5141 & 9141 & 6141 \\
\hline Mineral and energy resources & 3142 & 4142 & 5142 & 9142 & 6142 \\
\hline Other naturally occurring assets & 3143 & 4143 & 5143 & 9143 & 6143 \\
\hline Noncultivated biological resources & 31431 & 41431 & 51431 & 91431 & 61431 \\
\hline Water resources & 31432 & 41432 & 51432 & 91432 & 61432 \\
\hline Other natural resources & 31433 & 41433 & 51433 & 91433 & 61433 \\
\hline Radio spectrum & 314331 & 414331 & 514331 & 914331 & 614331 \\
\hline $\begin{array}{l}\text { Natural resources not } \\
\text { elsewhere classified }\end{array}$ & 314332 & 414332 & 514332 & 914332 & 614332 \\
\hline Intangible nonproduced assets & 3144 & 4144 & 5144 & 9144 & 6144 \\
\hline Contracts, leases, and licenses & 31441 & 41441 & 51441 & 91441 & 61441 \\
\hline Marketable operating leases & 314411 & 414411 & 514411 & 914411 & 614411 \\
\hline Permits to use natural resources & 314412 & 414412 & 514412 & 914412 & 614412 \\
\hline $\begin{array}{l}\text { Permits to undertake specific } \\
\text { activities }\end{array}$ & 314413 & 414413 & 514413 & 914413 & 614413 \\
\hline $\begin{array}{l}\text { Entitlement to future goods and } \\
\text { services on an exclusive basis }\end{array}$ & 314414 & 414414 & 514414 & 914414 & 614414 \\
\hline Goodwill and marketing assets & 31442 & 41442 & 51442 & 91442 & 61442 \\
\hline Financial assets & 32 & 42 & 52 & 92 & 62 \\
\hline $\begin{array}{l}\text { Monetary gold and Special Drawing } \\
\text { Rights (SDRs) }\end{array}$ & 3201 & 4201 & 5201 & 9201 & 6201 \\
\hline Monetary gold & 32011 & 42011 & 52011 & 92011 & 62011 \\
\hline Special Drawing Rights & 32012 & 42012 & 52012 & 92012 & 62012 \\
\hline Currency and deposits & 3202 & 4202 & 5202 & 9202 & 6202 \\
\hline Debt securities & 3203 & 4203 & 5203 & 9203 & 6203 \\
\hline Loans & 3204 & 4204 & 5204 & 9204 & 6204 \\
\hline Equity and investment fund shares & 3205 & 4205 & 5205 & 9205 & 6205 \\
\hline Equity & 32051 & 42051 & 52051 & 92051 & 62051 \\
\hline Investment fund shares or units & 32052 & 42052 & 52052 & 92052 & 62052 \\
\hline $\begin{array}{l}\text { Insurance, pension, and standardized } \\
\text { guarantee schemes [GFS] }\end{array}$ & 3206 & 4206 & 5206 & 9206 & 6206 \\
\hline Nonlife insurance technical reserves & 32061 & 42061 & 52061 & 92061 & 62061 \\
\hline $\begin{array}{l}\text { Life insurance and annuities } \\
\text { entitlements }\end{array}$ & 32062 & 42062 & 52062 & 92062 & 62062 \\
\hline Pension entitlements [GFS] & 32063 & 42063 & 52063 & 92063 & 62063 \\
\hline $\begin{array}{l}\text { Claims of pension funds on pension } \\
\text { manager }\end{array}$ & 32064 & 42064 & 52064 & 92064 & 62064 \\
\hline $\begin{array}{l}\text { Provisions for calls under } \\
\text { standardized guarantee schemes }\end{array}$ & 32065 & 42065 & 52065 & 92065 & 62065 \\
\hline $\begin{array}{l}\text { Financial derivatives and employee } \\
\text { stock options }\end{array}$ & 3207 & 4207 & 5207 & 9207 & 6207 \\
\hline Financial derivatives & 32071 & 42071 & 52071 & 92071 & 62071 \\
\hline Employee stock options & 32072 & 42072 & 52072 & 92072 & 62072 \\
\hline Other accounts receivable & 3208 & 4208 & 5208 & 9208 & 6208 \\
\hline Trade credit and advances & 32081 & 42081 & 52081 & 92081 & 62081 \\
\hline $\begin{array}{l}\text { Miscellaneous other accounts } \\
\text { receivable }\end{array}$ & 32082 & 42082 & 52082 & 92082 & 62082 \\
\hline
\end{tabular}




\section{Table A8.3 Classifications of Flows and Stock Positions in Assets and Liabilities (continued)}

\begin{tabular}{|c|c|c|c|c|c|}
\hline & $\begin{array}{l}\text { Classification } \\
\text { of transactions } \\
\text { in assets and } \\
\text { liabilities }^{1}\end{array}$ & $\begin{array}{l}\text { Classification } \\
\text { of holding } \\
\text { gains and } \\
\text { losses in } \\
\text { assets and } \\
\text { liabilities }\end{array}$ & $\begin{array}{l}\text { Classification } \\
\text { of other } \\
\text { changes in } \\
\text { the volume } \\
\text { of assets and } \\
\text { liabilities }\end{array}$ & $\begin{array}{l}\text { Classification } \\
\text { of total other } \\
\text { economic } \\
\text { flows in } \\
\text { assets and } \\
\text { liabilities }\end{array}$ & $\begin{array}{c}\text { Classification } \\
\text { of stock } \\
\text { positions in } \\
\text { assets and } \\
\text { liabilities }\end{array}$ \\
\hline Domestic & 321 & 421 & 521 & 921 & 621 \\
\hline $\begin{array}{l}\text { Same instrument breakdown as } \\
\text { above, but excluding monetary gold } \\
\text { for all flows and stock positions and } \\
\text { SDRs for stock positions }\end{array}$ & $3211-3218$ & $4211-4218$ & $5211-5218$ & $9211-9218$ & $6212-6218$ \\
\hline External & 322 & 422 & 522 & 922 & 622 \\
\hline Same instrument breakdown as above & $3221-3228$ & $4221-4228$ & $5221-5228$ & $9221-9228$ & $6221-6228$ \\
\hline Liabilities & 33 & 43 & 53 & 93 & 63 \\
\hline Special Drawing Rights (SDRs) & 3301 & 4301 & 5301 & 9301 & 6301 \\
\hline Currency and deposits & 3302 & 4302 & 5302 & 9302 & 6302 \\
\hline Debt securities & 3303 & 4303 & 5303 & 9303 & 6303 \\
\hline Loans & 3304 & 4304 & 5304 & 9304 & 6304 \\
\hline Equity and investment fund shares & 3305 & 4305 & 5305 & 9305 & 6305 \\
\hline Equity & 33051 & 43051 & 53051 & 93051 & 63051 \\
\hline Investment fund shares or units & 33052 & 43052 & 53052 & 93052 & 63052 \\
\hline $\begin{array}{l}\text { Insurance, pension, and standardized } \\
\text { guarantee schemes [GFS] }\end{array}$ & 3306 & 4306 & 5306 & 9306 & 6306 \\
\hline Nonlife insurance technical reserves & 33061 & 43061 & 53061 & 93061 & 63061 \\
\hline $\begin{array}{l}\text { Life insurance and annuities } \\
\text { entitlements }\end{array}$ & 33062 & 43062 & 53062 & 93062 & 63062 \\
\hline Pension entitlements [GFS] & 33063 & 43063 & 53063 & 93063 & 63063 \\
\hline $\begin{array}{l}\text { Claims of pension funds on pension } \\
\text { manager }\end{array}$ & 33064 & 43064 & 53064 & 93064 & 63064 \\
\hline $\begin{array}{l}\text { Provisions for calls under } \\
\text { standardized guarantee schemes }\end{array}$ & 33065 & 43065 & 53065 & 93065 & 63065 \\
\hline $\begin{array}{l}\text { Financial derivatives and employee } \\
\text { stock options }\end{array}$ & 3307 & 4307 & 5307 & 9307 & 6307 \\
\hline Financial derivatives & 33071 & 43071 & 53071 & 93071 & 63071 \\
\hline Employee stock options & 33072 & 43072 & 53072 & 93072 & 63072 \\
\hline Other accounts payable & 3308 & 4308 & 5308 & 9308 & 6308 \\
\hline Trade credit and advances & 33081 & 43081 & 53081 & 93081 & 63081 \\
\hline $\begin{array}{l}\text { Miscellaneous other accounts } \\
\text { payable }\end{array}$ & 33082 & 43082 & 53082 & 93082 & 63082 \\
\hline Domestic & 331 & 431 & 531 & 931 & 631 \\
\hline $\begin{array}{l}\text { Same instrument breakdown as } \\
\text { above, but excluding SDRs }\end{array}$ & $3312-3318$ & $4312-4318$ & $5312-5318$ & $9312-9318$ & $6312-6318$ \\
\hline External & 332 & 432 & 532 & 932 & 632 \\
\hline Same instrument breakdown as above & $3321-3328$ & $4321-4328$ & $5321-5328$ & $9321-9328$ & $6321-6328$ \\
\hline \multicolumn{6}{|l|}{ Memorandum items } \\
\hline $\begin{array}{l}\text { Own-account capital formation } \\
\text { Compensation of employees } \\
\text { Use of goods and services } \\
\text { Consumption of fixed capital } \\
\text { Other taxes on production minus } \\
\text { other subsidies on production }\end{array}$ & $\begin{array}{l}3 \mathrm{M} 1 \\
3 \mathrm{M} 11 \\
3 \mathrm{M} 12 \\
3 \mathrm{M} 13 \\
3 \mathrm{M} 14\end{array}$ & & & & \\
\hline
\end{tabular}


Table A8.3 Classifications of Flows and Stock Positions in Assets and Liabilities (concluded)

Net financial worth

Gross debt:

Gross debt at market value

Gross debt at nominal value

Gross debt at face value

Net debt:

Net debt at market value

Net debt at nominal value

Net debt at face value

Concessional loans:

Concessional loans at nominal value Implicit transfers resulting from loans at concessional interest rates

Arrears

Explicit contingent liabilities:

Publicly guaranteed debt

Other one-off guarantees

Net implicit obligations for future social security benefits

Nonperforming loan assets

Nonperforming loan assets at fair

value

Nonperforming loan assets at nominal value

\section{Classification Classification}

of other of total other

changes in economic

the volume flows in

of assets and assets and

liabilities liabilities

$\begin{array}{lll}5 \mathrm{M} 2 & 9 \mathrm{M} 2 & 6 \mathrm{M} 2\end{array}$

$3 \mathrm{M} 2$

$3 \mathrm{M} 3$
$3 \mathrm{M} 4$
$3 \mathrm{M} 35$

3 M36

3 M37

$3 \mathrm{M} 38$

in assets and

and liabilities

$4 \mathrm{M} 2$

$5 \mathrm{M} 2$

$9 \mathrm{M} 3$

$4 \mathrm{M} 3$

$5 \mathrm{M} 3$

$6 \mathrm{M} 3$

$4 \mathrm{M} 4$

$5 \mathrm{M} 4$

$9 \mathrm{M} 4$

$6 \mathrm{M} 4$

6M35

$6 \mathrm{M} 36$

\begin{tabular}{l|l|l|l|}
\hline $4 M 36$ & $5 M 36$ & $9 M 36$ & $6 M 36$ \\
$4 M 37$ & $5 M 37$ & $9 M 37$ & $6 M 37$
\end{tabular}

\begin{tabular}{|l|l|l}
$6 \mathrm{M} 38$ \\
\hline
\end{tabular}

(20)

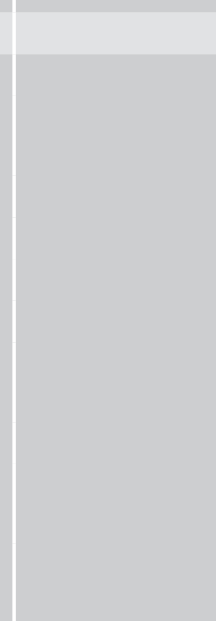

6M38

6М391

6M392

6M5

6M6

6M61

$6 \mathrm{M} 62$

6M7

$6 \mathrm{M} 8$

6M81

${ }^{1}$ Transactions in each category of nonfinancial assets may be further distinguished as acquisitions, disposals, and consumption of fixed capital (see Table 8.1). 


\section{Table A8.4 Classifications of the Counterparty of Transactions and Stock Positions in Financial Assets and Liabilities by Institutional Sector}

\begin{tabular}{|c|c|c|}
\hline Change in net financial worth due to transactions / net financial worth & 8 & $68(=6)$ \\
\hline Financial assets & $82(=32)$ & $682(=62)$ \\
\hline Domestic debtors & $821(=321)$ & $6821(=621)$ \\
\hline General government & 8211 & 68211 \\
\hline Central bank & 8212 & 68212 \\
\hline Deposit-taking corporations except the central bank & 8213 & 68213 \\
\hline Public deposit-taking corporations except the central bank & 82131 & 682131 \\
\hline Private deposit-taking corporations & 82132 & 682132 \\
\hline Other financial corporations & 8214 & 68214 \\
\hline Other public financial corporations & 82141 & 682141 \\
\hline Other private financial corporations & 82142 & 682142 \\
\hline Nonfinancial corporations & 8215 & 68215 \\
\hline Public nonfinancial corporations & 82151 & 682151 \\
\hline Private nonfinancial corporations & 82152 & 682152 \\
\hline Households and nonprofit institutions serving households & 8216 & 68216 \\
\hline External debtors & $822(=322)$ & $6822(=622)$ \\
\hline General government & 8221 & 68221 \\
\hline International organizations & 8227 & 68227 \\
\hline Financial corporations other than international organizations & 8228 & 68228 \\
\hline Central banks & 82281 & 682281 \\
\hline Financial corporations not elsewhere classified & 82282 & 682282 \\
\hline Other nonresidents & 8229 & 68229 \\
\hline Liabilities & $83(=33)$ & $683(=63)$ \\
\hline Domestic creditors & $831(=331)$ & $6831(=631)$ \\
\hline General government & 8311 & 68311 \\
\hline Central bank & 8312 & 68312 \\
\hline Deposit-taking corporations except the central bank & 8313 & 68313 \\
\hline Public deposit-taking corporations except the central bank & 83131 & 683131 \\
\hline Private deposit-taking corporations & 83132 & 683132 \\
\hline Other financial corporations & 8314 & 68314 \\
\hline Other public financial corporations & 83141 & 683141 \\
\hline Other private financial corporations & 83142 & 683142 \\
\hline Nonfinancial corporations & 8315 & 68315 \\
\hline Public nonfinancial corporations & 83151 & 683151 \\
\hline Private nonfinancial corporations & 83152 & 683152 \\
\hline Households and nonprofit institutions serving households & 8316 & 68316 \\
\hline External creditors & $832(=332)$ & $6832(=632)$ \\
\hline General government & 8321 & 68321 \\
\hline International organizations & 8327 & 68327 \\
\hline Financial corporations other than international organizations & 8328 & 68328 \\
\hline Central banks & 83281 & 683281 \\
\hline Financial corporations not elsewhere classified & 83282 & 683282 \\
\hline Other nonresidents & 8329 & 68329 \\
\hline
\end{tabular}

\section{Classification of transactions in} financial assets and liabilities ${ }^{1}$

\section{Change in net financial worth due to transactions / net financial worth}

Central bank

Deposit-taking corporations except the central bank

Public deposit-taking corporations except the central bank

Other public financial corporations

Public nonfinancial corporations

Private nonfinancial corporations

xternal debtors

General government

International organizations

Central banks

Financial corporations not elsewhere classified

bilities

Domestic creditors

General government

Public deposit-taking corporations except the central bank

Private deposit-taking corporation

Other public financial corporations

Public nonfinancial corporations

Private nonfinancial corporations

General government

nternational organization

Central banks

Other nonresidents
Classification of stock positions in

financial assets and liabilities $^{1}$

68 (-6)

$6821(=621)$

68211

682132

68214

68215

682152

$6822(=622)$

68221

68227

68228

68228

683 (=63)

68313

683142

68315

$6832(=632)$

68321

68327

68329

Note: Transactions in monetary gold are classified according to the counterparty involved. Although gold bullion has no counterparty, by convention, the counterparty to the stock position in gold bullion is shown as "other nonresidents" in this table.

${ }^{1}$ The counterparty to the transactions is not necessarily the same as the counterparty to the stock positions. While the parties are the same at the inception of the instrument, they may differ for transactions in that instrument. As explained in paragraph 9.25 , in principle, the classification of general government units' transactions in financial assets and liabilities by residence is based on the residence of the units that were a party to the transaction being recorded, whereas the classification of stock positions in financial assets and liabilities in a government unit's balance sheet is based on the residence of the issuer of financial instruments (assets), and the residence of the holder of the financial instruments (liabilities). If a transaction in financial assets or liabilities is between a resident and a nonresident unit that involves an instrument originally issued by a resident, an entry in other changes in the volume of assets (reclassification) is recorded to maintain the integrated GFS framework of stock positions and flows. 
Table A8.5 Classification of Debt Liabilities and Financial Assets Corresponding to Debt Instruments by Maturity and by Type of Debt Instrument

\begin{tabular}{|c|c|c|c|c|c|}
\hline & \multirow[b]{2}{*}{$\begin{array}{l}\text { Short-term, } \\
\text { by original } \\
\text { maturity }{ }^{1} \\
\text { (a) }\end{array}$} & \multicolumn{3}{|c|}{ Long-term by original maturity } & \multirow[b]{2}{*}{$\begin{array}{l}\text { Short- } \\
\text { term by } \\
\text { remaining } \\
\text { maturity } \\
\text { (a) + (b) }\end{array}$} \\
\hline & & $\begin{array}{c}\text { With } \\
\text { payment } \\
\text { due in one } \\
\text { year or less } \\
\text { (b) }\end{array}$ & $\begin{array}{l}\text { With } \\
\text { payment } \\
\text { due in } \\
\text { more than } \\
\text { one year } \\
\text { = Long- } \\
\text { term by } \\
\text { remaining } \\
\text { maturity } \\
\text { (c) }\end{array}$ & $\begin{array}{l}\text { Total } \\
\text { (b) }+ \text { (c) }\end{array}$ & \\
\hline Financial assets corresponding to debt instruments & 62.1 & 62.2 & 62.3 & 62.4 & 62.5 \\
\hline Monetary gold and Special Drawing Rights (SDRs) & 6201.1 & 6201.2 & 6201.3 & 6201.4 & 6201.5 \\
\hline Monetary gold & 62011.1 & 62011.2 & 62011.3 & 62011.4 & 62011.5 \\
\hline Special Drawing Rights & 62012.1 & 62012.2 & 62012.3 & 62012.4 & 62012.5 \\
\hline Currency and deposits & 6202.1 & 6202.2 & 6202.3 & 6202.4 & 6202.5 \\
\hline Debt securities & 6203.1 & 6203.2 & 6203.3 & 6203.4 & 6203.5 \\
\hline Loans & 6204.1 & 6204.2 & 6204.3 & 6204.4 & 6204.5 \\
\hline $\begin{array}{l}\text { Insurance, pension, and standardized guarantee } \\
\text { schemes [GFS] }\end{array}$ & 6206.1 & 6206.2 & 6206.3 & 6206.4 & 6206.5 \\
\hline Nonlife insurance technical reserves & 62061.1 & 62061.2 & 62061.3 & 62061.4 & 62061.5 \\
\hline Life insurance and annuities entitlements & 62062.1 & 62062.2 & 62062.3 & 62062.4 & 62062.5 \\
\hline Pension entitlements [GFS] & 62063.1 & 62063.2 & 62063.3 & 62063.4 & 62063.5 \\
\hline Claims of pension funds on pension manager & 62064.1 & 62064.2 & 62064.3 & 62064.4 & 62064.5 \\
\hline $\begin{array}{l}\text { Provisions for calls under standardized } \\
\text { guarantee schemes }\end{array}$ & 62065.1 & 62065.2 & 62065.3 & 62065.4 & 62065.5 \\
\hline Other accounts receivable & 6208.1 & 6208.2 & 6208.3 & 6208.4 & 6208.5 \\
\hline Trade credit and advances & 62081.1 & 62081.2 & 62081.3 & 62081.4 & 62081.5 \\
\hline Miscellaneous other accounts receivable & 62082.1 & 62082.2 & 62082.3 & 62082.4 & 62082.5 \\
\hline Domestic & 621.1 & 621.2 & 621.3 & 621.4 & 621.5 \\
\hline Same instrument breakdown as above, but & 6212.1- & $6212.2-$ & 6212.3- & 6212.4- & 6212.5- \\
\hline excluding monetary gold and SDRs & 6218.1 & 6218.2 & 6218.3 & 6218.4 & 6218.5 \\
\hline External & 622.1 & 622.2 & 622.3 & 622.4 & 622.5 \\
\hline Same instrument breakdown as above & $\begin{array}{l}6221.1- \\
6228.1\end{array}$ & $\begin{array}{l}6221.2- \\
6228.2\end{array}$ & $\begin{array}{l}6221.3- \\
6228.3\end{array}$ & $\begin{array}{l}6221.4- \\
6228.4\end{array}$ & $\begin{array}{l}6221.5- \\
6228.5\end{array}$ \\
\hline Debt instruments (= gross debt) & 63.1 & 63.2 & 63.3 & 63.4 & 63.5 \\
\hline Special Drawing Rights (SDRs) & 6301.1 & 6301.2 & 6301.3 & 6301.4 & 6301.5 \\
\hline Currency and deposits & 6302.1 & 6302.2 & 6302.3 & 6302.4 & 6302.5 \\
\hline Debt securities & 6303.1 & 6303.2 & 6303.3 & 6303.4 & 6303.5 \\
\hline Loans & 6304.1 & 6304.2 & 6304.3 & 6304.4 & 6304.5 \\
\hline $\begin{array}{l}\text { Insurance, pension, and standardized guarantee } \\
\text { schemes [GFS] }\end{array}$ & 6306.1 & 6306.2 & 6306.3 & 6306.4 & 6306.5 \\
\hline Nonlife insurance technical reserves & 63061.1 & 63061.2 & 63061.3 & 63061.4 & 63061.5 \\
\hline Life insurance and annuities entitlements & 63062.1 & 63062.2 & 63062.3 & 63062.4 & 63062.5 \\
\hline Pension entitlements [GFS] & 63063.1 & 63063.2 & 63063.3 & 63063.4 & 63063.5 \\
\hline Claims of pension funds on pension manager & 63064.1 & 63064.2 & 63064.3 & 63064.4 & 63064.5 \\
\hline $\begin{array}{l}\text { Provisions for calls under standardized } \\
\text { guarantee schemes }\end{array}$ & 63065.1 & 63065.2 & 63065.3 & 63065.4 & 63065.5 \\
\hline Other accounts payable & 6308.1 & 6308.2 & 6308.3 & 6308.4 & 6308.5 \\
\hline Trade credit and advances & 63081.1 & 63081.2 & 63081.3 & 63081.4 & 63081.5 \\
\hline Miscellaneous other accounts payable & 63082.1 & 63082.2 & 63082.3 & 63082.4 & 63082.5 \\
\hline Domestic & 631.1 & 631.2 & 631.3 & 631.4 & 631.5 \\
\hline Same instrument breakdown as above, but & 6312.1- & 6312.2- & 6312.3- & 6312.4- & 6312.5- \\
\hline excluding SDRs & 6318.1 & 6318.2 & 6318.3 & 6318.4 & 6318.5 \\
\hline External & 632.1 & 632.2 & 632.3 & 632.4 & 632.5 \\
\hline Same instrument breakdown as above & $\begin{array}{l}6321.1- \\
6328.1\end{array}$ & $\begin{array}{l}6321.2- \\
6328.2\end{array}$ & $\begin{array}{l}6321.3- \\
6328.3\end{array}$ & $\begin{array}{l}6321.4- \\
6328.4\end{array}$ & $\begin{array}{l}6321.5- \\
6328.5\end{array}$ \\
\hline
\end{tabular}

${ }^{1} T$ This category includes arrears and interest on arrears. 


\section{Table A8.6 Classification of Expenditure by Functions of Government According to Divisions and Groups}

\begin{tabular}{|l|l|}
\hline 7 & Total expenditure \\
$\mathbf{7 0 1}$ & General public services \\
7011 & $\begin{array}{l}\text { Executive and legislative organs, financial and } \\
\text { fiscal affairs, external affairs }\end{array}$ \\
\hline 7012 & Foreign economic aid \\
7013 & General services \\
7014 & Basic research \\
7015 & R\&D General public services \\
7016 & General public services n.e.c. \\
7017 & Public debt transactions \\
7018 & Transfers of a general character between different \\
& levels of government
\end{tabular}

702

7021

7022

7023

7024

7025

\section{3}

7031

7032

7033

7034

7035

7036

704

7041

7042

7043

7044

7045

7046

7047

7048

7049

705

7051

7052

7053

7054

7055

7056
706

7061

7062

7063

7064

7065

7066

707

7071

7072

7073

7074

7075

7076

708

7081

7082

7083

7084

7085

7086

709

7091

7092

7093

7094

7095

7096

7097

7098

710

7101

7102

7103

7104

7105

7106

7107

7108

7109
Housing and community amenities

Housing development

Community development

Water supply

Street lighting

R\&D Housing and community amenities

Housing and community amenities n.e.c.

Health

Medical products, appliances, and equipment

Outpatient services

Hospital services

Public health services

R\&D Health

Health n.e.c.

Recreation, culture, and religion

Recreational and sporting services

Cultural services

Broadcasting and publishing services

Religious and other community services

R\&D Recreation, culture, and religion

Recreation, culture, and religion n.e.c.

\section{Education}

Pre-primary and primary education

Secondary education

Postsecondary nontertiary education

Tertiary education

Education not definable by level

Subsidiary services to education

R\&D Education

Education n.e.c.

Social protection

Sickness and disability

Old age

Survivors

Family and children

Unemployment

Housing

Social exclusion n.e.c.

R\&D Social protection

Social protection n.e.c.

Note: $R \& D=$ research and development; n.e.c. $=$ not elsewhere classified. 

Bills

Bonds and debentures

Book value

Budgetary central

government

Buildings other than

dwellings

Capital account in the international accounts

Capital claims payable

Capital claims receivable

Capital grants

Capital levies

Capital taxes

Capital transfers

Capital transfers not elsewhere classified

Captive financial institutions and money lenders

Cash basis of recording

Catastrophic loss
Bills are defined as securities (usually short-term) that give holders the unconditional rights to receive stated fixed sums on a specified date. 7.144

Bonds and debentures are securities that give the holders the unconditional right to fixed payments or contractually determined variable payments on a specified date or dates.

Book value generally refers to the value recorded in the entities' records... 3.115

The budgetary central government is often a single unit of the central government that encompasses the fundamental activities of the national executive, legislative, and judiciary powers

Buildings other than dwellings include whole buildings or parts of buildings not designated as dwellings. Fixtures, facilities, and equipment that are integral parts of the structures are included

The capital account in the international accounts shows transactions between residents and nonresidents related to capital transfers receivable and payable and the acquisition and disposal of nonproduced nonfinancial assets......A7.89 Capital claims payable comprise exceptionally large insurance settlements payable in the wake of a catastrophic event or disaster

Capital claims receivable comprise exceptionally large insurance settlements receivable in the wake of a catastrophic event or disaster 5.151

Capital grants are capital transfers receivable by government units, from other resident or nonresident government units or international organizations, that do not meet the definition of a tax, subsidy, or a social contribution.

Capital levies cover taxes on the values of the assets or net worth owned by institutional units levied at irregular and very infrequent intervals of time ..... 5.52

Capital taxes are taxes levied at irregular and very infrequent intervals on the values of the assets or net worth owned by institutional units or on the values of assets transferred between institutional units as a result of legacies, gifts, or other transfers .5 .52

Capital transfers are transfers in which the ownership of an asset (other than cash or inventories) changes from one party to another or that oblige one or both parties to acquire or dispose of an asset (other than cash or inventories) ........3.16

Capital transfers not elsewhere classified are gifts and transfers of a capital nature (other than grants) from individuals, private nonprofit institutions, nongovernmental foundations, or corporations

5.148

Captive financial institutions and money lenders are institutional units providing financial services other than insurance, where most of their assets or liabilities are not available on open financial markets. .2 .54

In the cash basis of recording, flows are recorded when cash is received or disbursed. 3.67

A catastrophic loss is the partial or complete destruction of a significantly large number of assets within any of the asset categories resulting from a large-scale, discrete, and recognizable event 10.60 
Center of predominant economic interest

\section{Central bank}

Central government subsector

Change in net worth due to holding gains or losses

Change in net worth due to other changes in the volume of assets and liabilities

Change in net worth due to other economic flows

Claim (benefit or call)

Collective service

Commitments basis of recording

Compensation of employees

\section{Computer software}

Consolidation

Consumption of fixed capital

\section{Contingent liabilities}

An institutional unit has a center of predominant economic interest in an economic territory when there exists, within the economic territory, some location, dwelling, place of production, or other premises on which, or from which, the unit engages and intends to continue engaging, either indefinitely or over a finite but long period of time, in economic activities and transactions on a significant scale.

The central bank is the national financial institution that exercises control over key aspects of the financial system....

The central government subsector consists of the institutional unit(s) of the central government plus those nonmarket NPIs that are controlled by the central government. The political authority of the central government extends over the entire territory of the country

Change in net worth due to holding gains or losses is defined as the sum of the positive or negative holding gains and holding losses on all assets and liabilities

Change in net worth due to other changes in the volume of assets and liabilities is defined as the sum of the positive and negative other changes in the volume of assets and liabilities.

Change in net worth due to other economic flows is defined as the sum of the change in net worth due to holding gains or losses and the change in net worth due to other changes in the volume of assets. $4.36,10.2$

A claim (benefit or call) is the amount payable to the policyholder by the insurer in respect of an event covered by the policy occurring in the period for which the policy is valid A4.77

A collective service is a service provided simultaneously to all members of the community or to all members of a particular section of the community, such as all households living in a particular region.

In the commitments basis of recording, flows are recorded when an institutional unit has committed itself to a transaction .3 .65

Compensation of employees is the total remuneration, in cash or in kind, payable to an individual in an employer-employee relationship in return for work performed by the latter during the reporting period

Computer software includes computer programs, program descriptions, and supporting materials for both systems and applications software that are expected to be used for more than one year.... .7 .70

Consolidation is a method of presenting statistics for a set of units (or entities) as if they constituted a single unit.....

$3.153,9.18$

Consumption of fixed capital is the decline, during the course of the reporting period, in the current value of the stock of fixed assets owned and used by a government unit as a result of physical deterioration, normal obsolescence, or normal accidental damage

Contingent liabilities are obligations that do not arise unless a particular, discrete event(s) occurs in the future. $4.47,7.251$ 
Contracts, leases, and licenses

Control of a corporation

Control of an NPI

Corporations

Costs of ownership transfer

Credit derivatives

Credit entry

Cultivated biological resources

Currency

Currency union

Current account

Current grants

Current transfers

Custom union

Databases
Contracts, leases, and licenses are treated as assets only when both the following conditions are satisfied: (i) the terms of the contract, lease, or license specify a price for the use of an asset or provision of a service that differs from the price that would prevail in the absence of the contract, lease, or license, and (ii) one party to the contract must be able legally and practically to realize this price difference 7.105

Control of a corporation is defined as the ability to determine general corporate policy of the corporation 2.107, Box 2.2

Control of an NPI is defined as the ability to determine the general policy or program of the NPI Box 2.1

Corporations are defined as entities that are capable of generating a profit or other financial gain for their owners, are recognized by law as separate legal entities from their owners, and are set up for purposes of engaging in market production

Costs of ownership transfer are the costs associated with acquiring and disposing of nonfinancial assets (other than inventories)..... .8 .6

Credit derivatives are financial derivatives whose primary purpose is to trade credit risk 7.218

A credit entry is a decrease in an asset, an increase in a liability, or an increase in net worth

Cultivated biological resources cover animal resources yielding repeat products and tree, crop, and plant resources yielding repeat products whose natural growth and regeneration are under the direct control, responsibility, and management of institutional units

Currency consists of notes and coins that are of fixed nominal values and are issued or authorized by the central bank or government 7.135

A currency union is defined as a union to which two or more economies belong and that has a regional central decision-making body, commonly a currency union central bank, endowed with the legal authority to conduct a single monetary policy and issue the single currency of the union

A5.34

The current account shows flows of goods and services, primary income, and secondary income between residents and nonresidents A7.78

Current grants are current transfers receivable by government units, from other resident or nonresident government units or international organizations, and that do not meet the definition of a tax, subsidy, or a social contribution 5.103

Current transfers consist of all transfers that are not capital transfers 3.17

A custom union is a form of regional arrangement whereby agreement exists on a common tariff (custom duties) vis-à-vis the other economies while the movement of goods within the arrangement tends to be duty-free A5.6

Databases consist of files of data organized in such a way as to permit resourceeffective access and use of the data. .7 .70 


\section{Debit entry}

Debt assumption

Debt conversion (swap)

Debt forgiveness (or debt cancellation)

Debt payments on behalf of others

\section{Debt prepayment}

Debt refinancing

Debt reorganization (also referred to as debt restructuring)

Debt rescheduling

Debt securities

Debt write-offs or write-downs

Deep-discount bonds

Defeasance

Defined-benefit pension scheme

Defined-contribution pension scheme
A debit entry is an increase in an asset, a decrease in a liability, or a decrease in net worth

Debt assumption is a trilateral agreement between a creditor, a former debtor, and a new debtor (typically a government unit), under which the new debtor assumes the former debtor's outstanding liability to the creditor, and is liable for repayment of debt...... A3.26

Debt conversion (swap) is an exchange of debt-typically at a discount-for a nondebt claim (such as equity), or for counterpart funds that can be used to finance a particular project or policy.

A3.20

Debt forgiveness (or debt cancellation) is defined as the voluntary cancellation of all or part of a debt obligation within a contractual arrangement between a creditor and a debtor.

Rather than assuming a debt, a public sector unit may decide to repay that debt or make a specific payment on behalf of another institutional unit (original debtor), without a guarantee being called or the debt being taken over....A3.30

Debt prepayment consists of a repurchase, or early payment, of debt at conditions that are agreed between the debtor and the creditor A3.24

Debt refinancing involves the replacement of an existing debt instrument or instruments, including any arrears, with a new debt instrument or instruments.

Debt reorganization (also referred to as debt restructuring) is defined as an arrangement involving both the creditor and the debtor (and sometimes third parties) that alters the terms established for servicing an existing debt ......A3.2

Debt rescheduling is a bilateral arrangement between the debtor and the creditor that constitutes a formal postponement of debt service payments and the application of new and generally extended maturities

Debt securities are negotiable financial instruments serving as evidence of a debt.

Debt write-offs or write-downs refer to unilateral reductions by a creditor, of the amount owed to it.

Deep-discount bonds are long-term securities that require periodic coupon payments during the life of the instrument, but the amount is substantially below the market rate of interest at issuance

With defeasance, a debtor unit removes liabilities from its balance sheet by pairing them with financial assets, the income and value of which are sufficient to ensure that all debt-service payments are met. A3.37

A defined-benefit pension scheme is one where the benefits payable to an employee on retirement are determined by the use of a formula, either alone or as a minimum amount payable

A defined-contribution pension scheme is one where the benefits payable to an employee on retirement are defined exclusively in terms of the level of the funds built up from the contributions made over the employee's working life and the increases in value that result from the investment of these funds by the manager of the scheme. A2.55 


\section{Depository receipts}

Deposits

Distributable income

Dividends

Domestic currency

Due-for-payment basis of recording

Dwellings

Economic assets

Economic classification of expense

Economic flows

Economic owner

Economic territory

Economic unions

Economically significant prices

Economy
Depository receipts are securities that represent ownership of securities listed in other economies 7.167

Deposits are all claims, represented by evidence of deposit, on the deposittaking corporations (including the central bank) and, in some cases, general government or other institutional units

Distributable income of a corporation is equal to entrepreneurial income, plus all current transfers receivable, minus all current transfers payable and minus the adjustment for the change in pension entitlements relating to the pension scheme of that corporation

Dividends are the distributed earnings allocated to government or public sector units, as the owners of equity, for placing funds at the disposal of corporations. $5.111,6.109$

Domestic currency is that which is legal tender in the economy and issued by the monetary authority for that economy-that is, either that of an individual economy or, in a currency union, that of the common currency area to which the economy belongs.

In the due-for-payment basis of recording, flows that give rise to cash payments are recorded at the latest times they can be paid without incurring additional charges or penalties or, if sooner, when the cash payment is made. 3.66

Dwellings are buildings, or designated parts of buildings, that are used entirely or primarily as residences, including any associated structures, such as garages, and all permanent fixtures customarily installed in residences .7 .44

Economic assets are resources over which ownership rights are enforced and from which economic benefits may flow to the owners. $3.43,4.43$

The economic classification of expense identifies the types of expense incurred according to the economic process involved

Economic flows reflect the creation, transformation, exchange, transfer, or extinction of economic value; they involve changes in the volume, composition, or value of a unit's assets, liabilities, and net worth 3.4

The economic owner of resources such as goods and services, natural resources, financial assets, and liabilities is the institutional unit entitled to claim the benefits associated with the use of these resources by virtue of accepting the associated risks

$3.39,7.5$

Economic territory, in its broadest sense, can be any geographic area or jurisdiction for which statistics are required

2.8

Economic unions are established by means of an intergovernmental legal agreement among sovereign countries or jurisdictions with the intention of fostering greater economic integration

A5.19

Economically significant prices are prices that have a significant effect on the amounts that producers are willing to supply and on the amounts purchasers wish to buy 2.66

An economy consists of a set of resident institutional units 2.6 


\author{
Embedded derivative \\ Employee stock options \\ Employers' social \\ contributions \\ Employment-related social \\ benefits
}

\section{Enterprise}

Entertainment, literary, and artistic originals

Entitlement to future goods and services on an exclusive basis

\section{Environmental protection activities}

Environmental tax

Equity

\section{Establishment}

Estate, inheritance, and gift taxes

Exchange
An embedded derivative arises when a derivative feature is inserted in a standard financial instrument and is inseparable from the instrument. 7.148 Employee stock options are options to buy the equity of a company, offered to employees of the company as a form of remuneration

Employers' social contributions are social contributions payable by employers, to social security funds, employment-related pension funds, or other employment-related social insurance schemes to obtain entitlement to social benefits for their employees

Employment-related social benefits are social benefits payable in cash or in kind by government or public sector units to their employees or employees of other government or public sector units participating in the scheme (or to survivors and dependents of the employees who are eligible for such payments)

An enterprise is the view of an institutional unit as a producer of goods and services 2.25

Entertainment, literary, and artistic originals are original films, sound recordings, manuscripts, tapes, and models in which drama performances, radio and television programming, musical performances, sporting events, and literary and artistic output are recorded or embodied.

Entitlement to future goods and services on an exclusive basis relates to the case where one party that has contracted to purchase goods or services at a fixed price at a time in the future is able to transfer the obligation of the second party to the contract to a third party

Environmental protection activities are those activities whose primary purpose is the prevention, reduction, and elimination of pollution and other forms of degradation of the environment.

A7.107

An environmental tax is a tax whose tax base is a physical unit (or a proxy of it) of something that has a proven, specific, negative impact on the environment

Equity consists of all instruments and records that acknowledge claims on the residual value of a corporation or quasi-corporation, after the claims of all creditors have been met

An establishment is an enterprise, or part of an enterprise, that is situated in a single location and in which only a single productive activity is carried out or in which the principal productive activity accounts for most of the value added.....

Estate, inheritance, and gift taxes cover taxes on transfers of property at death and on gifts, including gifts made between living members of the same family to avoid, or minimize, the payment of inheritance taxes

An exchange is a transaction in which one unit provides a good, service, asset, or labor to a second unit and receives a good, service, asset, or labor of the same value in return. 3.9 
Excises

Expenditure

Expense

Explicit contingent liabilities

Extrabudgetary

Face value

Fair value

Financial account of the balance of payments

Financial assets

Financial auxiliaries

Financial claim

Financial corporations

Financial corporations sector

Financial intermediaries
Excises are taxes levied as a product-specific unit tax on a predefined limited range of goods. .5 .62

Expenditure is the sum of expense and the net investment in nonfinancial assets.

Expense is a decrease in net worth resulting from a transaction $4.24,6.1$

Explicit contingent liabilities are defined as legal or contractual financial arrangements that give rise to conditional requirements to make payments of economic value 7.252

General government entities with individual budgets not fully covered by the main (or general) budget are considered extrabudgetary

2.82

Face value of a debt instrument is the undiscounted amount of principal to be repaid at (or before) maturity $3.115,7.242$

Fair value is a market-equivalent value defined as the amount for which an asset could be exchanged, or a liability settled, between knowledgeable, willing parties in an arm's-length transaction

3.115

The financial account of the balance of payments records transactions that involve financial assets and liabilities that take place between residents and nonresidents

A7.93

Financial assets consist of financial claims and gold bullion held by monetary authorities as a reserve asset 3.48

Financial auxiliaries consist of financial corporations that are principally engaged in activities associated with transactions in financial assets and liabilities or with providing the regulatory context for these transactions but in circumstances that do not involve the auxiliary taking ownership of the financial assets and liabilities being transacted .2 .54

A financial claim is an asset that typically entitles the owner of the asset (the creditor) to receive funds or other resources from another unit, under the terms of a liability $3.47,7.15$

Financial corporations are corporations that are principally engaged in providing financial services, including insurance and pension fund services, to other institutional units

2.115

The financial corporations sector consists of resident corporations that are principally engaged in providing financial services, including insurance and pension fund services, to other institutional units 2.53

Financial derivative contract A financial derivative contract is a financial instrument that is linked to another specific financial instrument or indicator or commodity and through which specific financial risks (e.g., interest rate risk, foreign exchange risk, equity and commodity price risks, and credit risk) can be traded in their own right in financial markets

7.204

Financial intermediaries are institutional units that incur liabilities on their own account for the purpose of acquiring financial assets by engaging in financial transactions on the market. 2.54 
Financial lease

Fines and penalties

Finished goods

Fiscal policy

Fixed assets

Forfeits

Forward-type contract

Functional classification of expense

General government sector

General taxes on goods and services

Gold bullion

Gold swap

Goods and services account

Goods for resale

Government units
A financial lease is a contract under which the lessor, as legal owner of an asset, conveys substantially all risks and rewards of ownership of the asset to the lessee. 7.158, A4.10

Fines and penalties are compulsory current transfers imposed on units by courts of law or quasi-judicial bodies for violations of laws or administrative rules 5.142

Finished goods consist of goods that are the output of a production process, are still held by their producer, and are not expected to be processed further by the producer before being supplied to other units .7 .83

Fiscal policy is the use of the level and composition of the general government and public sectors' spending and revenue-and the related accumulation of government assets and liabilities-to achieve such goals as the stabilization of the economy, the reallocation of resources, and the redistribution of income

Fixed assets are produced assets that are used repeatedly or continuously in production processes for more than one year. $7.18,7.35$

Forfeits are amounts that were deposited with a general government unit pending a legal or administrative proceeding and that have been transferred to the general government unit as part of the resolution of that proceeding....... 5.142

A forward-type contract (forward) is an unconditional contract by which two counterparties agree to exchange a specified quantity of an underlying item (real or financial) at an agreed-on contract price (the strike price) on a specified date

The functional classification of expense provides information on the purpose for which an expense was incurred.

The general government sector consists of resident institutional units that fulfill the functions of government as their primary activity. $1.2,2.58,2.76$

General taxes on goods and services are levied on the production, leasing, delivery, sale, purchase, or other change of ownership of a wide range of goods and the rendering of a wide range of services

Gold bullion takes the form of coins, ingots, or bars with a purity of at least 995 parts per 1,000, including such gold held in allocated gold accounts

A gold swap involves an exchange of gold for foreign exchange deposits with an agreement that the transaction be reversed at an agreed future date at an agreed gold price 7.161

The goods and services account shows transactions in items that are outcomes of production activities.

Goods for resale are goods acquired for the purpose of reselling or transferring to other units without being further processed.

Government units are unique kinds of legal entities established by political processes that have legislative, judicial, or executive authority over other institutional units within a given area 2.38 
Grants

Gross debt at market value

Gross debt at nominal value

Gross value added or gross domestic product (GDP)

Historic cost

Holding gain or loss

Household

Households sector

Implicit contingent liabilities

Imputed employers' social contributions

Index-linked securities

Individual consumption good or service

Information, computer, and telecommunications equipment

Institutional sector

Institutional unit

Intangible nonproduced assets
Grants are transfers receivable by government units, from other resident or nonresident government units or international organizations, and that do not meet the definition of a tax, subsidy, or social contribution. $5.5,5.101$

Gross debt at market value means that debt securities are valued at market prices; insurance, pension, and standardized guarantee schemes are valued according to principles that are equivalent to market valuation; and all other debt instruments are valued at nominal prices, which are considered to be the best generally available proxies of their market prices 7.240

Gross debt at nominal value means that debt securities are valued at their nominal values. The nominal value of a debt instrument at any moment in time is the amount that the debtor owes to the creditor

7.241

Gross value added is defined as the value of output minus the value of intermediate consumption

Historic cost, in its strict sense, reflects the cost at the time of acquisition, but sometimes it may also reflect occasional revaluations 3.115

A holding gain or loss is a change in the monetary value of an asset or liability resulting from changes in the level and structure of prices, excluding qualitative or quantitative changes in the asset or liability $3.33,10.1$

A household is a group of persons who share the same living accommodation, who pool some, or all, of their income and wealth, and who consume certain types of goods and services collectively, mainly housing and food................2.28

The households sector consists of all resident households .2 .60

Implicit contingent liabilities do not arise from a legal or contractual source but are recognized after a condition or event is realized 7.252

Imputed employers' social contributions are the amounts calculated and added to actual contributions, sufficient to exactly match the increases in employees' social benefit entitlements

Index-linked securities are instruments for which either the coupon payments (interest) or the principal or both are linked to another item, such as a price index, an interest rate, or the price of a commodity. 7.153

An individual consumption good or service is one that is acquired by a household and used to satisfy the needs or wants of members of that household

Information, computer, and telecommunications (ICT) equipment consists of devices using electronic controls and also the electronic components forming part of these devices 7.56

An institutional sector groups together similar kinds of institutional units according to their economic objectives, functions, and behavior 2.50

An institutional unit is an economic entity that is capable, in its own right, of owning assets, incurring liabilities, and engaging in economic activities and in transactions with other entities

Intangible nonproduced assets are constructs of society evidenced by legal or accounting actions 7.104 


\section{Intellectual property products}

Interest

Intermediate consumption

International investment position

Intersectoral consolidation

Intrasectoral consolidation

Inventories

Investment funds

Joint operating

arrangements

Joint venture

Land

Land improvements

Legal or social entity

Legal owner

Liability
Intellectual property products are the result of research, development, investigation, or innovation leading to knowledge that the developers can market or use to their own benefit in production because use of the knowledge is restricted by means of legal or other protection .7 .64 Interest is a form of investment income that is receivable by the owners of certain kinds of financial assets (SDRs, deposits, debt securities, loans, and other accounts receivable) for putting these financial assets and other resources at the disposal of another institutional unit. 5.108 Intermediate consumption consists of the goods and services consumed as inputs by a process of production, excluding fixed assets whose consumption is recorded as consumption of fixed capital

The international investment position (IIP) is a statistical statement that shows at a point in time the value of: financial assets of residents of an economy that are claims on nonresidents and gold bullion held as reserve assets; and the liabilities of residents of an economy to nonresidents A7.96

Intersectoral consolidation is consolidation between subsectors of the public sector to produce consolidated statistics for a particular grouping of public sector units. 3.156

Intrasectoral consolidation is consolidation within a particular subsector to produce consolidated statistics for that particular subsector 3.155

Inventories are produced assets consisting of goods and services, which came into existence in the current period or in an earlier period, and that are held for sale, use in production, or other use at a later date $7.18,7.75$ Investment funds are collective investment undertakings through which investors pool funds for investment in financial or nonfinancial assets. 7.174

Joint operating arrangements can be in the form of jointly controlled operations or jointly controlled assets.

A joint venture involves the establishment of a corporation, partnership, or other institutional unit in which, legally, each party has joint control over the activities of the joint venture unit 2.141

Land consists of the ground, including the soil covering and any associated surface waters, over which ownership rights are enforced and from which economic benefits can be derived by their owners by holding or using them

Land improvements are the result of actions that lead to major improvements in the quantity, quality, or productivity of land, or prevent its deterioration

A legal or social entity is one whose existence is recognized by law or society independently of the persons or other entities that may own or control it.

The legal owner of resources such as goods and services, natural resources, financial assets, and liabilities is the institutional unit entitled by law and sustainable under the law to claim the benefits associated with the resource $3.38,7.5$ A liability is established when one unit (the debtor) is obliged, under specific circumstances, to provide funds or other resources to another unit (the creditor) $3.45,4.45,7.15$ 


\section{Life insurance}

Life insurance and annuities entitlements

Listed shares

Loan

Loans and other debt instrument guarantees

Local government units

Machinery and equipment

Margins

Market establishment

Market prices

Market prices for transactions

Market producer

Market regulatory agencies

Marketable operating leases

Marketing assets

Materials and supplies
Life insurance is an activity whereby a policyholder makes regular payments to an insurer in return for which the insurer guarantees to provide the policyholder (or in some cases another nominated person) with an agreed sum, or an annuity, at a given date or earlier if the policyholder dies beforehand.

Life insurance and annuities entitlements are financial claims policyholders have against an enterprise offering life insurance or providing annuities. ..7.187

Listed shares are equity securities listed on an exchange and may be referred to as quoted shares. (Unlisted shares are equity securities not listed on an exchange).

7.168

A loan is a financial instrument that is created when a creditor lends funds directly to a debtor and receives a nonnegotiable document as evidence of the asset. 7.157

Loans and other debt instrument guarantees are commitments by one party to bear the risk of nonpayment by another party 7.259 Local government units are institutional units whose fiscal, legislative, and executive authority extends over the smallest geographical areas distinguished for administrative and political purposes .2 .95

Machinery and equipment cover transport equipment, machinery for information, computer, and telecommunications (ICT) equipment, and machinery and equipment not elsewhere classified.

Margins are payments of cash or deposits of collateral that cover actual or potential obligations incurred $7.219,9.75$

A market establishment is an establishment that charges economically significant prices .2 .75

Market prices refer to current exchange value - that is, the value at which goods, services, labor, or assets are exchanged or else could be exchanged for cash (currency or transferable deposits) 3.107

Market prices for transactions are defined as amounts of money that willing buyers pay to acquire something from willing sellers; the exchanges are made between independent parties and on the basis of commercial considerations only, sometimes called "at arm's length" 3.108

A market producer is an institutional unit that provides all or most of its output to others at prices that are economically significant.

Market regulatory agencies act on behalf of a government (or a regional organization with governments as its members) and influence the market for specific goods or services directly and/or indirectly 2.156

Marketable operating leases are third-party property rights relating to fixed assets 7.108

Marketing assets consist of items such as brand names, mastheads, trademarks, logos, and domain names...

Materials and supplies consist of all goods held with the intention of using them as inputs to a production process. .7 .79 


\section{Maturity of a debt instrument}

Military inventories

Mineral and energy

resources

Mineral exploration and
evaluation

Monetary gold

Monetary transaction

Monetary union

Motor vehicle taxes

Net debt

Net financial worth

Net investment in inventories (change in inventories)

\section{Net premiums}

Net value added

Net worth

Neutral holding gain

Nominal value
The maturity of a debt instrument refers to the time until the debt is extinguished according to the contract between the debtor and the creditor 7.266

Military inventories consist of single-use items, such as ammunition, missiles, rockets, bombs, etc., delivered by weapons or weapons systems .7 .86

Mineral and energy resources consist of mineral and energy reserves located on or below the earth's surface that are economically exploitable, given current technology and relative prices 7.97

Mineral exploration and evaluation consists of the value of expenditure on exploration for petroleum and natural gas and for nonpetroleum deposits and subsequent evaluation of the discoveries made .7 .68

Monetary gold is gold to which the monetary authorities (or others who are subject to the effective control of the monetary authorities) have title and is held as a reserve asset.

A monetary transaction is one in which one institutional unit makes a payment (receives a payment) or incurs a liability (acquires an asset) to (from) another institutional unit stated in units of currency 3.8

A monetary union exists where there is the presence of a single monetary policy among economies, established by an intergovernmental legal agreement..... A5.32

Motor vehicle taxes include taxes on the use of motor vehicles or permission to use motor vehicles

Net debt is calculated as gross debt minus financial assets corresponding to debt instruments

The net financial worth of an institutional unit (or grouping of units) is the total value of its financial assets minus the total value of its liabilities. $4.41,7.235$

Net investment in inventories (change in inventories) is measured by the value of the additions to inventories minus the value of withdrawals from inventories minus the value of any recurrent losses of goods held in inventories during the reporting period

Net premiums are defined as actual premiums plus premium supplements minus the insurance service charge payable by the policyholders

Net value added is the value of output minus the values of both intermediate consumption and consumption of fixed capital

The net worth of an institutional unit (or grouping of units) is the total value of its assets minus the total value of its liabilities. $4.39,7.1$

Neutral holding gains and losses over a period are the increase (decrease) in the value of an asset that would be required, in the absence of transactions and other changes in the volume of assets, to maintain command over the same amount of goods and services as at the beginning of the period

$10.11, \mathrm{~A} 7.71$

Nominal value at any moment in time is the amount that the debtor owes to the creditor. 3.115 


\section{Noncultivated biological resources}

Nonfinancial assets

Nonfinancial corporations

Nonfinancial corporations sector

Nonlife insurance

Nonlife insurance technical reserves

Nonmarket producer

Nonmonetary transactions

Nonparticipating preferred stocks or shares

Nonpension social benefits

Nonperforming loans

Nonprofit institutions

Nonprofit institutions serving households

Notional resident unit
Noncultivated biological resources consist of animals, birds, fish, and plants that yield both once-only and repeat products over which ownership rights are enforced but for which natural growth or regeneration is not under the direct control, responsibility, and management of any institutional units. 7.101

Nonfinancial assets are economic assets other than financial assets .3 .50

Nonfinancial corporations are corporations whose principal activity is the production of market goods or nonfinancial services

The nonfinancial corporations sector consists of resident institutional units that are principally engaged in the production of market goods or nonfinancial services.

.2 .52

Nonlife insurance is an activity similar to life insurance except that it covers all other risks, accidents, sickness, fire, etc.

Nonlife insurance technical reserves consist of (i) prepayments of net nonlife insurance premiums and (ii) reserves to meet outstanding nonlife insurance claims

7.183

A nonmarket producer provides all or most of its output to others for free or at prices that are not economically significant

Nonmonetary transactions are transactions that are not initially stated in units of currency

Nonparticipating preferred stocks or shares are those that pay a fixed income but do not provide for participation in the distribution of the residual value of an incorporated enterprise on dissolution.

7.150

Nonpension social benefits include payments made to individuals when they are temporarily unemployed, suffering from a medical condition, or suffering from an event that prevents them from working for a period

Nonperforming loans are those for which (i) payments of principal and/or interest are past due by three months (90 days) or more; or (ii) interest payments equal to three months (90 days) interest or more have been capitalized (reinvested to the principal amount) or payment has been delayed by agreement; or (iii) evidence exists to reclassify a loan as nonperforming even in the absence of a 90-day past due payment, such as when the debtor files for bankruptcy 7.262

Nonprofit institutions (NPIs) are legal or social entities created for the purpose of producing or distributing goods and services, but they cannot be a source of income, profit, or other financial gain for the institutional units that establish, control, or finance them 2.36

The nonprofit institutions serving households (NPISHs) sector consists of resident nonmarket nonprofit institutions (NPIs) that are not controlled by government 2.61

A notional resident unit is a unit identified for statistical purposes to be the resident owner of immovable assets legally owned by nonresidents 2.13 
Off-market swap

\section{On-balance sheet securitization}

\section{One-off guarantees}

On-lending

Operating leasing

Option contract

\section{Original maturity}

Other accounts receivable/ payable

Other changes in the volume of assets

Other current transfers not elsewhere classified

Other economic flows

Other employment-related social insurance schemes

\author{
Other equity \\ Other intellectual property \\ products
}

Other public financial corporations
An off-market swap is a swap contract that has a nonzero value at inception as a result of having reference rates priced differently from current market valuesthat is, "off-the-market" 7.162, A3.68

On-balance sheet securitization involves debt securities backed by a future revenue stream generated by the assets. The assets remain on the balance sheet of the debt securities issuer (the original asset owner), typically as a separate portfolio. There is no securitization unit involved A3.66

One-off guarantees comprise those types of guarantees where the debt instrument is so particular that it is not possible to calculate the degree of risk associated with the debt with any degree of accuracy. 7.256

On-lending of borrowed funds refers to a resident institutional unit, A (usually central government), borrowing from another institutional unit(s), B (usually a nonresident unit), and then on-lending the proceeds from this borrowing to a third institutional unit(s), C (usually state or local governments, or a public corporation(s)), where it is understood that unit A obtains an effective financial claim on unit $\mathrm{C}$ A3.72

Operating leasing is the activity of renting out produced assets under arrangements that provide use of a tangible asset to the lessee, but do not involve the transfer of the bulk of risks and rewards of ownership to the lessee. A4.6 In an option contract (option), the purchaser acquires from the seller a right to buy or sell (depending on whether the option is a call (buy) or a put (sell)) a specified underlying item at a strike price on or before a specified date 7.209

Original maturity is the period from the issue date until the final contractually scheduled payment date. 7.267

Other accounts receivable/payable consist of trade credit and advances and miscellaneous other items due to be paid or received

Other changes in the volume of assets are any changes in the value of an asset or liability that do not result from a transaction or a holding gain/loss .........3.35, 10.1

Other current transfers not elsewhere classified are gifts and transfers of a current nature (other than grants or subsidies) from individuals, private nonprofit institutions, nongovernmental foundations, or corporations

Other economic flows are changes in the volume or value of assets or liabilities that do not result from transactions

Other employment-related social insurance schemes derive from an employeremployee relationship in the provision of pension entitlement and other social benefit to employees as part of the conditions of employment

Other equity is equity that is not in the form of securities

Other intellectual property products consist of new information and specialized knowledge not elsewhere classified.

Other public financial corporations comprise all resident financial corporations, except public deposit-taking corporations, controlled by general government units or other public corporations 2.121 
Other recurrent taxes on property

Other revenue

Other social contributions

Other structures

Other subsidies on

production

Other taxes

Other taxes on goods and services

Other taxes on use of goods and on permission to use goods or perform activities

\section{Own funds}

Partitioning

Pension entitlements

Pensions and other retirement benefits

Permit to undertake a specific activity

Permits to use natural resources

Premium earned
Other recurrent taxes on property include all recurrent taxes on property other than immovable property or net wealth..... .5 .53

Other revenue is all revenue receivable excluding taxes, social contributions, and grants $.5 .6,5.106$

Other social contributions are actual and imputed contributions receivable by social insurance schemes operated by employers on behalf of their employees 5.98

Other structures consist of all structures other than buildings .7 .48

Other subsidies on production are subsidies that enterprises receive as a consequence of engaging in production but that are not related to specific products.

Other taxes cover revenue from taxes levied predominantly on a base or bases not elsewhere classified, and unidentified taxes.

Other taxes on goods and services includes taxes on the extraction of minerals, fossil fuels, and other exhaustible resources from deposits owned privately or by another government and any other taxes on goods or services not included in categories 1141 through 1145 .5 .82

Other taxes on use of goods and on permission to use goods or perform activities include business and professional licenses that consist of taxes paid by enterprises in order to obtain a license to carry on a particular kind of business or profession and taxes payable by individuals to perform certain activities

Own funds are defined as the difference between total assets (at market values) and total liabilities excluding shares and other equity (at market value)..........7.231

Partitioning records a transaction that is a single transaction from the perspective of the parties involved as two or more differently classified transactions 3.29

Pension entitlements are financial claims that existing and future pensioners hold against either their employer or a fund designated by the employer, to pay pensions earned as part of a compensation agreement between the employer and employee

Pensions and other retirement benefits are payable when individuals cease employment upon retirement A2.6

A permit to undertake a specific activity is an asset for the holder when: (i) the permits are limited in number and so allow the holders to earn monopoly profits, (ii) the monopoly profits do not come from the use of an asset belonging to the permit-issuer, and (iii) a permit holder is able both legally and practically to sell the permit to a third party

7.110

Permits to use natural resources are third-party property rights relating to natural resources.

The premium earned is the part of the actual premium that relates to coverage provided in the reporting period. A4.75 
Premiums, fees, and claims payable related to nonlife insurance and standardized guarantee schemes

Premiums, fees, and claims receivable related to nonlife insurance and standardized guarantee schemes

Premiums, fees, and current claims payable

Premiums, fees, and current claims receivable

Present value

Primary income account

Production measure of gross domestic product

Profits of fiscal monopolies

Property expense

Property expense for investment income disbursements

Property income

Property income from invest- Property income from investment income disbursements includes property ment income disbursements

Provident funds

Public corporations subsector

Premiums, fees, and claims payable related to nonlife insurance and standardized guarantee schemes include nonlife insurance premiums payable to insurance schemes/corporations to secure entitlement to insurance against risks, claims payable by insurance schemes to beneficiaries, and fees payable to obtain standardized guarantees.

Premiums, fees, and claims receivable related to nonlife insurance and standardized guarantee schemes comprise nonlife insurance premiums receivable by insurance schemes to provide entitlement to insurance against risks; claims receivable from insurance schemes by beneficiaries; and fees receivable for the issuance of standardized guarantees

Premiums, fees, and current claims payable comprise nonlife insurance premiums expense and fees payable for the issuance of standardized guarantees, as well as insurance settlement expense that is not exceptional.

Premiums, fees, and current claims receivable comprise nonlife insurance premium revenue and fees receivable for the issuance of standardized guarantees, as well as insurance settlement revenue that is not exceptional

Present value is the value today of a future payment or stream of payments discounted at some appropriate compounded interest rate

The primary income account shows primary income flows between resident and nonresident institutional units

The production measure of gross domestic product is defined as gross value added plus any taxes minus subsidies on products not already included in the value of output

Profits of fiscal monopolies cover that part of the profits of fiscal monopolies that is transferred to the government. Fiscal monopolies are public corporations, public quasi-corporations, or government-owned unincorporated enterprises that have been granted a legal monopoly over the production or distribution of a particular kind of good or service in order to raise revenue and not in order to further the interests of public economic or social policy

Property expense is the expense payable to the owners of financial assets or natural resources when they put them at the disposal of another unit 6.108

Property expense for investment income disbursements includes property income attributed to insurance policyholders, pension entitlements, and holders of investment fund shares

Property income is the revenue receivable in return for putting financial assets and natural resources at the disposal of another unit income attributed to insurance policyholders and holders of investment fund shares.

Provident funds are compulsory saving schemes that maintain the integrity of the contributions for individual participants

The public corporations subsector consists of all resident corporations controlled by government units or by other public corporations... 2.104 
Public deposit-taking corporations

Public deposit-taking corporations except the central bank

Public financial corporations subsector

Public monuments

Public nonfinancial corporations subsector

Public-private partnerships (PPPs)

Public sector

Quasi-corporation

Quasi-fiscal operations

Real holding gain

Realized holding gain

Reassignment

Recurrent taxes on immovable property

Recurrent taxes on net wealth
Public deposit-taking corporations are financial corporations controlled by general government units or other public corporations whose principal activity is financial intermediation and who have liabilities in the form of deposits or financial instruments that are close substitutes for deposits

Public deposit-taking corporations except the central bank consist of all resident depository corporations, except the central bank, that are controlled by general government units or other public corporations

2.120

All resident financial corporations controlled by general government units or other public corporations are part of the public financial corporations subsector.

Public monuments are identifiable because of particular historical, national, regional, local, religious, or symbolic significance

All resident nonfinancial corporations controlled by general government units or other public corporations are part of the public nonfinancial corporations subsector

Public-private partnerships (PPPs) are long-term contracts between two units, whereby one unit acquires or builds an asset or set of assets, operates it for a period, and then hands the asset over to a second unit.

A 4.58

The public sector consists of all resident institutional units controlled directly, or indirectly, by resident government units-that is, all units of the general government sector and resident public corporations $1.2,2.63$

A quasi-corporation is (i) either an unincorporated enterprise owned by a resident institutional unit that has sufficient information to compile a complete set of accounts and is operated as if it were a separate corporation and whose relationship to its owner is effectively that of a corporation to its shareholders, or (ii) an unincorporated enterprise owned by a nonresident institutional unit that is deemed to be a resident institutional unit because it engages in a significant amount of production in the economic territory over a long or indefinite period of time .2 .33

Quasi-fiscal operations are government operations carried out by institutional units other than general government units. 2.4

A real holding gain is defined as the value accruing to an asset as a result of a change in its price relative to the prices of goods and services in general.......10.11

A holding gain is realized when an asset is sold, redeemed, used, or otherwise disposed of, or a liability incorporating a holding gain or loss is repaid 10.6

Reassignment records a transaction arranged by a third party on behalf of others as taking place directly by the two principal parties involved

Recurrent taxes on immovable property cover taxes levied regularly on the use or ownership of immovable property, which includes land, buildings, and other structures .5 .49

Recurrent taxes on net wealth cover taxes levied regularly on net wealth .........5.50 
Regional arrangements

Reinvested earnings

Remaining maturity or residual maturity

Rent (expense)

Rent (revenue)

Rerouting

Research and development

Residence

Resource lease

Resource management activities

Restructuring agencies

Revenue

Sales of goods and services

Sales taxes

Securities

Securities lending
Regional arrangements involve coordination of institutional units in several countries for a particular monetary or economic purpose

Reinvested earnings are the direct investor's share of the retained earnings of the direct investment enterprise $5.134,6.121$

Remaining maturity or residual maturity is the period from the reference date (balance sheet date) until the final contractually scheduled payment date.....7.267 Rent is the expense payable to the owners of a natural resource (the lessor or landlord) for putting the natural resource at the disposal of another institutional unit (a lessee or tenant) for use of the natural resource in production 6.120

Rent is the revenue receivable by the owners of a natural resource (the lessor or landlord) for putting the natural resource at the disposal of another institutional unit (a lessee or tenant) for use of the natural resource in production

Rerouting records a transaction as taking place through channels that differ from the actual ones, or as taking place in an economic sense when no actual transactions take place.

Research and development consists of the value of expenditure on creative work undertaken on a systematic basis in order to increase the stock of knowledge, including knowledge of man, culture, and society, and use of this stock of knowledge to devise new applications. . .7 .66$

The residence of each institutional unit is the economic territory with which it has the strongest connection (i.e., its center of predominant economic interest) .....2.7

A resource lease is an agreement whereby the legal owner of a natural resource that macroeconomic statistics treat as having an infinite life makes it available to a lessee in return for a regular payment recorded as property income and described as rent.

Resource management activities are those activities whose primary purpose is preserving and maintaining the stock of natural resources and hence safeguarding against depletion.

A7.108

Restructuring agencies are entities set up to sell corporations and other assets, and for the reorganization of companies

Revenue is an increase in net worth resulting from a transaction

Sales of goods and services consist of the sales by market establishments, administrative fees charged for services, incidental sales by nonmarket establishments, and imputed sales of goods and services.

Sales taxes are all general taxes levied on sales at one stage only, whether at manufacturing or production stages or on wholesale or retail trade

Securities are debt and equity instruments that have the characteristic feature of negotiability.

Securities lending is an arrangement whereby a security holder transfers securities to another party (security taker), subject to the stipulation that the same or similar securities be returned on a specified date or on demand..

.7 .160 
Securities repurchase agreement (repo)

\section{Securitization}

Sinking fund

Social assistance

Social assistance benefits

Social benefits

Social contributions

Social insurance contribution

Social insurance schemes

\section{Social protection}

Social risks

Social security benefits

Social security contributions

Social security fund
A securities repurchase agreement (repo) is an arrangement involving the sale of securities for cash, at a specified price, with a commitment to repurchase the same or similar securities at a fixed price either on a specified future date (often one or a few days hence) or with an open maturity

Securitization occurs when a unit, named the originator, conveys the ownership rights over financial or nonfinancial assets, or the right to receive specific future flows, to another unit, named the securitization unit. In return, the securitization unit pays an amount to the originator from its own source of financing. The securitization unit obtains its own financing by issuing debt securities using the assets or rights to future flows transferred by the originator as collateral A3.59

A sinking fund is a separate account, which may be an institutional unit, made up of segregated contributions provided by the unit(s) that makes use of the fund (the "parent" unit) for the gradual redemption of the parent unit's debt. A sinking fund may also be established to provide for major repairs or replacements

2.144

Social assistance provides social protection benefits to all persons who are in need without any formal requirement to participate as evidenced by the payment of contributions

Social assistance benefits are transfers payable in cash or in kind to households to meet the same needs as social insurance benefits but are not made under a social insurance scheme 6.101, A2.25

Social benefits are current transfers receivable by households intended to provide for the needs that arise from social risks A2.4

Social contributions are actual, or imputed, revenue receivable by social insurance schemes to make provision for social insurance benefits payable ... 5.4, 5.94, A2.4

benefits covered by the scheme

A2.31

Social insurance schemes provide social protection and require formal participation by the beneficiaries, evidenced by the payment of contributions (actual or imputed) $2.101, \mathrm{~A} 2.30$

Social protection is the systematic intervention intended to relieve households and individuals of the burden of a defined set of social risks. A2.1

Social risks are events or circumstances that may adversely affect the welfare of the households concerned either by imposing additional demands on their resources or by reducing their income $2.46,6.96$, A2.1

Social security benefits are social benefits expense payable in cash or in kind to households by social security schemes.

Social security contributions are actual revenue receivable by social security schemes organized and operated by government units, for the benefit of the contributors to the scheme 5.97

A social security fund is a particular kind of government unit that is devoted to the operation of one or more social security schemes. 2.100, A2.34 
Social security schemes

Sovereign wealth funds

Special Drawing Rights

Standardized guarantees

State governments

Stock position

Stripped securities

Subsidies

Subsidy on products

Swap contract

Synthetic securitization

Tax credit

Tax expenditures

Tax refunds

Tax relief measures

Taxes
Social security schemes are social insurance schemes covering the community as a whole, or large sections of the community, and are imposed and controlled by government units

2.101, A2.33

Created and owned by the general government for macroeconomic purposes, sovereign wealth funds hold, manage, or administer assets to achieve financial objectives, and employ a set of investment strategies that include investing in foreign financial assets 2.152

Special Drawing Rights (SDRs) are international reserve assets created by the International Monetary Fund (IMF) and allocated to its members to supplement reserve assets.

7.131

Standardized guarantees are those kinds of guarantees that are issued in large numbers, usually for fairly small amounts, along identical lines 7.201, A4.71

State governments consist of institutional units exercising some of the functions of government at a level below that of central government and above that of the government institutional units existing at a local level

A stock position is the total holdings of assets and/or liabilities at a point in time... 3.36

Stripped securities are securities that have been transformed from a principal amount with coupon payments into a series of zero-coupon bonds, with a range of maturities matching the coupon payment date(s) and the redemption date of the principal amount(s)

Subsidies are current unrequited transfers that government units make to enterprises on the basis of the level of their production activities or the quantities or values of the goods or services they produce, sell, export, or import .... 5.146, 6.84

A subsidy on products is a subsidy payable per unit of a good or service 6.89

A swap contract involves the counterparties exchanging, in accordance with prearranged terms, cash flows based on the reference prices of the underlying items.

$7.162,7.215$

Synthetic securitization involves transfer of the credit risk related to a pool of assets without transfer of the assets themselves, either through a securitization unit or through the direct issuing of debt securities by the original asset owner..........A3.65 A tax credit is an amount subtracted directly from the tax liability due by the beneficiary household or corporation after the liability has been computed ..........5.29

Tax expenditures are concessions or exemptions from a "normal" tax structure that reduce government revenue collection.

Tax refunds are adjustments for overestimation of taxes payable or the return of amounts to taxpayers due to overpayments.

Tax relief measures are incentives that reduce the amount of tax owed by an institutional unit. 5.28

Taxes are compulsory, unrequited amounts receivable by government units from institutional units $5.2,5.23$ 
Taxes on capital gains

Taxes on financial and capital transactions

Taxes on goods and services

Taxes on income, profits, and capital gains

Taxes on individual or household income

Taxes on international trade and transactions

Taxes on payroll or workforce

Taxes on property

Taxes on specific services

Taxes on the income of corporations

Taxes on use of goods and on permission to use goods or perform activities

Taxes on winnings from lotteries or gambling

Total gross debt

\section{Transaction}

Transfer
Taxes on capital gains consist of taxes on the capital gains (including capital gain distributions of investment funds) of persons or corporations that become payable during the current reporting period, irrespective of the periods over which the gains have accrued

Taxes on financial and capital transactions are taxes levied on the change in ownership of property, except those classified as gifts, inheritance, or estate transactions.

.5 .61

Taxes on goods and services are taxes that become payable as a result of the production, sale, transfer, leasing, or delivery of goods and rendering of services, or as a result of their use for own consumption, or own capital formation

.5 .55

Taxes on income, profits, and capital gains consist of taxes assessed on the actual or presumed incomes of institutional units

Taxes on individual or household income consist of personal income taxes, including those deducted by employers (pay-as-you-earn taxes), and surtaxes

Taxes on international trade and transactions are taxes that become payable when goods cross the national or customs frontiers of the economic territory, or when transactions in services exchange between residents and nonresidents .5 .83

Taxes on payroll or workforce are taxes payable by enterprises assessed either as a proportion of the wages and salaries paid or as a fixed amount per person employed .5 .45

Taxes on property are taxes payable on the use, ownership, or transfer of wealth .5 .46

Taxes on specific services are levied on payments for specific services .5 .69

Taxes on the income of corporations consist of corporate income taxes, corporate profits taxes, corporate surtaxes, etc.

Taxes on use of goods and on permission to use goods or perform activities are fees levied for the issuance of a license or permit that are not commensurate with the cost of the control function of government

5.72

Taxes on winnings from lotteries or gambling are taxes payable on the amounts receivable by winners

Total gross debt-often referred to as "total debt" or "total debt liabilities"consists of all liabilities that are debt instruments. A debt instrument is defined as a financial claim that requires payment(s) of interest and/or principal by the debtor to the creditor at a date, or dates, in the future

7.236

A transaction is an economic flow that is an interaction between institutional units by mutual agreement or through the operation of the law, or an action within an institutional unit that is analytically useful to treat like a transaction, often because the unit is operating in two different capacities

3.5

A transfer is a transaction in which one institutional unit provides a good, service, or asset to another unit without receiving from the latter any good, service, or asset in return as a direct counterpart 3.10 
Transfers not elsewhere classified (payable)

Transfers not elsewhere classified (receivable)

\section{Transport equipment}

True-sale securitization

Turnover and other general taxes on goods and services

Unallocated gold accounts

Unearned premium

Unrealized holding gain

Valuables

Valuation of stock positions

Value of goodwill and marketing assets

Value-added taxes

Wages and salaries

Wages and salaries in cash

Wages and salaries in kind

Water resources
Transfers not elsewhere classified payable include a number of gifts and transfers to individuals, private nonprofit institutions, nongovernmental foundations, corporations, or government units that are not included in other categories of transfers, and serving quite different purposes

Transfers not elsewhere classified receivable include subsidies, as well as gifts and transfers from individuals, private nonprofit institutions, nongovernmental foundations, corporations, or sources other than governments and international organizations. 5.145

Transport equipment consists of equipment for moving people and objects ...7.54

True-sale securitization involves debt securities issued by a securitization unit where the underlying assets have been transferred from the original asset owner's (i.e., the originator's) balance sheet to that of the securitization unit A3.62

Turnover and other general taxes on goods and services are multistage cumulative taxes and taxes where elements of consumption taxes are combined with multistage taxes

Unallocated gold accounts represent a claim against the account custodian to deliver gold

The unearned premium is the amount of the actual premium received that relates to the period past the reporting period

A4.75

An unrealized holding gain is one accruing on an asset that is still owned or a liability that is still outstanding at the end of the reporting period 10.6

Valuables are produced assets of considerable value that are not used primarily for purposes of production or consumption, but are held primarily as stores of value over time

$7.18,7.87$

Stock positions should be valued at market value-that is, as if they were acquired in market transactions on the balance sheet reporting date (reference date).

The value of goodwill and marketing assets is the difference between the value paid for an enterprise as a going concern and the sum of its assets minus the sum of its liabilities, each item of which has been separately identified and valued 7.116 Value-added taxes (VAT) are taxes on goods or services collected in stages by enterprises but ultimately charged in full to the final purchasers 5.58

Wages and salaries are compensation of employees payable in cash and/or in kind, except for social contributions payable by employers

Wages and salaries in cash are the amounts payable in cash, or any other financial instruments used as means of payments, to employees in return for work performed

Wages and salaries in kind are amounts payable in the form of goods, services, interest forgone, and shares issued to employees in return for work performed

Water resources consist of surface and groundwater resources used for extraction to the extent that their scarcity leads to the enforcement of ownership or use rights, market valuation, and some measure of economic control. 7.102 
Weapons systems

quasi-corporations

Work in progress

Written-down replacement cost

Zero-coupon bonds
Weapons systems include vehicles and other equipment such as warships, submarines, military aircraft, tanks, missile carriers and launchers, etc. .7 .74

Withdrawals of income from quasi-corporations consist of that part of distributable income that the owner withdraws from the quasi-corporation.................5.118

Work in progress consists of goods and services that are not yet sufficiently processed to be in a state in which it is normally supplied to other institutional units 7.80

Written-down replacement cost is the current acquisition price of an equivalent new asset minus the accumulated consumption of fixed capital, amortization, or depletion. 3.115

Zero-coupon bonds are long-term securities that do not involve periodic payments during the life of the bond ..7.147 
This page intentionally left blank 


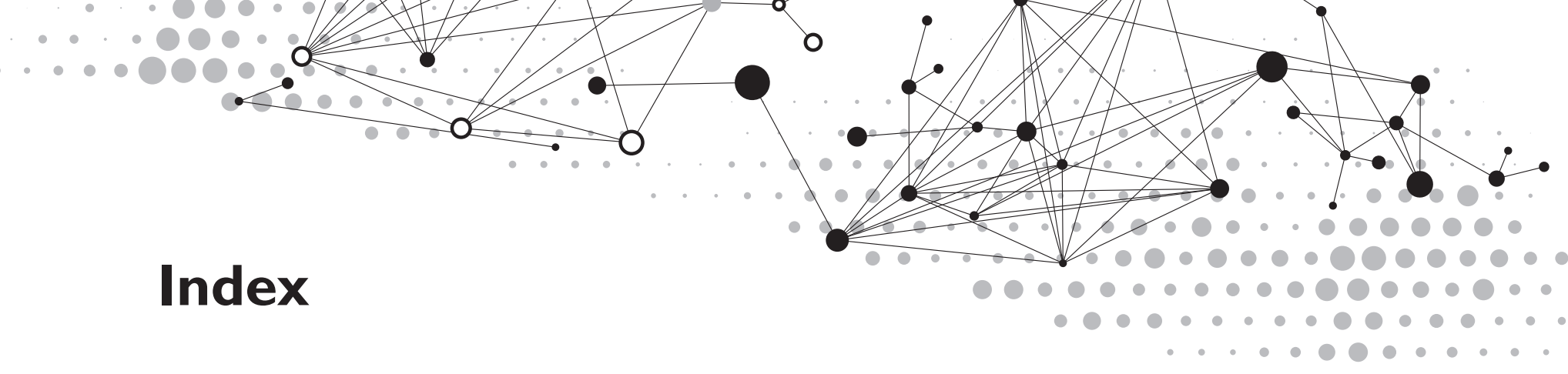

Numbers in references refer to paragraphs in chapters, boxes, tables, or appendices.

A

Above-the-line transactions, 4.53, Table 4A.1

Accounting rules

choice of gross and net presentations, 3.143-3.151

credit entries, 3.55

currency conversion, 3.132-3.133

currency denomination and currency settlement, 3.137-3.139

data reporting guidelines and standards, 3.52, 3.53

debit entries, 3.55

double-entry recording of economic events, 3.54

harmonization of macroeconomic datasets, A7.9-A7.12, A7.98, A7.105

international standards for, government finance statistics framework and, A6.1-A6.56

reporting periods, 3.52

treatment of domestic and foreign currency, 3.134-3.136

unit of account, 3.51, 3.130-3.131

valuation, 3.113

See also Analytic framework of government finance statistics; Consolidation; Time of recording economic flows; Type of accounting system

Accounts payable, See Other accounts payable/receivable

Accrual basis of recording economic events

advantages of, 3.69-3.74, 4.2

compensation of employees, 6.10

definition of, 3.62, 5.10

dividends, 3.87 employment-related pensions and other retirement benefits, 6.106

expense transactions, 6.6

implementation of government

finance statistics framework,

1.37-1.38, 3.75

imputed social contributions, A2.46

income taxes, 5.43

interest, 5.108-5.109, 6.64, 9.44, A3.89

licenses, A4.43

premiums, fees and current claims,

$5.150,7.184,9.58$

prepayments, A4.21

refunds, 5.27

rent, 5.123

revenue transactions, 5.14, 5.17

sales of goods, 5.141

social assistance benefits, A2.29

taxes on pollution, 5.81

taxes on property, 5.47

time of recording transactions, 3.60,

$3.62-3.64,5.13,8.13,9.13$

use in government finance frame-

work, 1.27-1.28, 3.70, A5.43,

Box A6.1

Accumulation accounts, A7.18,

A7.62-A7.71, Table A7.2

Administrative fees, 5.73-5.75, 5.138

Aggregates

analytical value of, 3.140, 4.53-4.54

definition of, 3.141

of revenue for fiscal analysis, 5.9

reasons for consolidation, 3.155 ,

3.158

to create balancing items, 3.142

Amortized value, 3.115

Analytic framework of government

finance statistics, Figure 4.1

analytic objectives of, 1.41, 4.4-4.5 balancing items and, 1.32-1.33

components of, 4.8. See also specific component

GFSM 1986 and, 4.6-4.7

purpose of, 4.3

supplementary statements, 4, 13.

See also specific statements

Ancillary activities, 2.45, 2.72, A3.37

Animal resources, 7.60, 7.62-7.63,

8.34-8.35

Annuity entitlements, 7.187-7.188, 9.62, A4.69

other changes in volume of assets, 10.71

Aquaculture, 7.48

Arrears

as balance sheet memorandum item, 7.247-7.250

as step in migration path, 1.38

as transactions in financial assets and liabilities, 9.20-9.23

changes in classification of, 10.84

definition of, 3.71, 7.247, 9.20,

Table 4A.1

interest rate in calculating, 6.80

statistical recording of, 7.248-2.250, 7.266

time of recording repayment of debts in, 3.97

under financial derivative contracts, 7.226

valuation of, 7.250

Artificial subsidiaries of government, 2.42-2.44, 2.162, A3.55

Asset-backed securities

definition of 7.151

included in debt instruments, 7.143, A3.59

valuation of, 7.27, 7.154 
Asset management companies. See Restructuring agencies

Assets

analytic framework, 1.34

appearance or disappearance of, $10.48-10.58$

classification of, 4.43-4.44, 7.34, Table A8.3

definition of, 3.42-3.43, 7.6, 7.14-7.19

economic, 3.43, 4.43, 7.5-7.10

effect of external events on value of, $10.59-10.75$

financial, 3.43, 3.48

leases as, A4.53-A4.57, Box A4.3

liquidity-related, 4.31

nationalization of, 9.55, Box 4.1

net presentation of, 3.143-3.151

nonfinancial, $3.43,3.50$

other changes in the volume of, $3.35,4.10$

other economic flows of, 3.31

ownership concepts and, 3.38-3.41, $7.5-7.13$

permits recognized as, A4.46-A4.52

policy-related, Box 4.1, 4.30

privatization, 9.53-9.54

reclassification of institutional unit resulting in change in value of, 10.76-10.79

reclassification of, 3.101-3.102, $10.80-10.84$

rent versus sale of, A4.21, Box A4.1 shared, A4.36-A4.40

stock positions of, 3.1, 3.36

time of recording, 3.88-3.97

valuation of, 1.29, 3.107, $3.111-3.117,7.20-7.33$

See also Financial assets and liabilities; Fixed assets; Nonproduced assets

\section{B}

Bad banks. See Restructuring agencies Bailout operations, A3.42-A3.53

Bail, 5.144, 7.226

Balance of Payments and International Investment Position Manual (BPM6), 1.8, 1.35, 2.89, A3.52, A7.5 government finance statistics framework and, A7.73-A7.98

Balance sheet, Table 4.4, Table 7.1 accounting principles, 3.56 appearance or disappearance of existing economic assets from $10.48-10.58$

arrears in, 7.247-7.250

as condition to be a separate institutional unit, 2.126

classification of assets in, 4.43-4.44

classification of counterparties to financial relationships in, 7.264-7.265, Table 7.11

classification of debt liabilities and corresponding financial assets by maturity, 7.266-7.271, Table 7.12

classification of financial assets and liabilities in, 4.43-4.45, 7.118-7.227

classification of fixed assets in, 7.34-7.74, Tables 7.2-7.5

classification of nonfinancial assets in, 7.34-7.117, Table 7.2

classification of nonproduced assets in, 7.90-7.117, Table 7.2

concessional loans in, 7.246, A3.40 contingent assets and liabilities in, 7.13. See also balance sheet memorandum items

cost of ownership transfer, 8.42, Figure 8.1

definition of, 1.17, 3.56, 4.39, 7.1 deriving definitions of assets and liabilities for, 3.43, 7.6, 7.14-7.19 explicit contingent liabilities in, $7.13,7.251-7.260$

fiscal indicators available from, 7.2, 4.54

fundamental identity of, 3.54

gross debt in, 7.236-7.242

implicit obligations for future social security benefits in, 7.13, 7.261, 9.67

in analytic framework of GFSM 2014, 4.3, 4.6, 4.8, Figure 4.1, A7.21, A7.72

in government finance statistics framework, 1.30. See also balance sheet in analytic framework of GFSM 2014

in implementation of the GFS framework, 1.38

integration of, 1.20, 3.2, 7.2, 8.2, 9.2, A7.13

memorandum items, 3.49, 4.47, 7.142, 7.234-7.263, Table 7.10 net debt in, 7.243-7.245

net financial worth in, 7.235

net worth calculation in, 4.39,

7.228-7.333, A6.48, Figure 7.1,

Table 4.4

nonperforming loan assets in, $7.262-7.263$

ownership and asset boundary in, 7.5-7.13

purpose of, 7.2

recording of net worth in, 7.1

recording of PPP-related assets in, A4.61

recording of shared assets in, A4.37 recording of stock positions in, 3.36 time of recording/compilation, 3.57, $7.1,7.37$

valuation of assets and liabilities for,

$3.107,3.113,7.20-7.33,7.122$

Balancing items

analytical significance of, 4.39,

4.53-4.55

consolidation and, 3.166

definition of, 3.142

in government finance statistics framework, 1.1, 1.11, 1.32, 3.151, 7.228

See also Financial Net Worth and

Net worth

Banker's acceptance, 7.145

Barter transactions, 3.19, 3.22, 3.88,

$3.112,3.125,4.23-4.24,4.35$ 7.30

Below-the-line transactions, 4.53 , Table 4A.1

Bills

as discounted financial instruments, $6.71,9.40$

banker's acceptance of, 7.145

definition of, 7.144

holding gains or losses on, 10.29

types of, 7.144

valuation of, 7.27, 7.154

Biological resources

cultivated, 7.58-7.63, 8.34-8.36,

Table 7.5

noncultivated, $7.101,8.55,10.52$

Bonds

consolidation of, 3.152

definition of, 7.146-7.147

discounted, 6.71, 9.40

holding gains or losses on, 10.27 
reclassified as equity, 3.97, 7.150, 9.21, 10.84

refinancing through, A3.14-A3.16 valuation of, 3.115-3.117, 7.27

Book value, 3.115, 6.146, 7.173

Brass plate companies, 2.15

Bridge banks. See Restructuring agencies

Budgetary and extrabudgetary government units, 2.41-2.42, 2.80-2.83, 2.87, 2.93, Figure 2.3

Build, own, operate, and transfer schemes, 7.39, A4.12, A4.58

Build, own and transfer schemes, A 4.58

Buildings and structures classification of, 7.41-7.51, Table 7.3 never put into service, 10.69 owned by nonresidents, 2.13 recording of transactions in, $8.28-8.32$

time of recording, $7.37,8.15$ valuation of, 7.41, 7.45

See also Monuments

C

Capital account, A7.18-A7.19, A7.63-A7.67, A7.76, A7.89-A7.92, Figure A7.1, Table A7.2

Capital claims payable, 6.125, A4.79, A7.67, A7.92, Table 6.11

receivable, 5.151, A4.80, A7.67, A7.92, Table 5.12

Capital formation. See Own-account capital formation

Capital gains taxes. See Taxes on capital gains

Capital grants, 5.103, 6.94

Capital injections, 2.130, A3.43, A3.47-A3.53, Box 6.3, Figure A3.2

Capital levies, 5.52

Capital spending, Table 4A.1

Capital taxes, 5.25, 5.51, 6.124, A7.39, A7.67, Table 4A.1

Capital transfers acquisition of PPP assets through, A4.65

capital injections as, 2.130, 9.66, A3.47, A3.49-A.53, Figure A3.1 current transfers and, 3.15, 3.18 debt assumption/forgiveness/ payment on behalf of others as A2.61-A2.62, A3.8, A3.25-A3.31 defining characteristics of, 3.15-3.16 equity versus, 9.52

in kind, 8.29

not elsewhere classified, 5.148, 6.124, Table 5.11, Table 6.10 other economic flows versus, 10.62 , 10.72

subsidies versus, 6.85, 6.91, 8.12, 9.49

Captive financial institutions, 2.44, $2.54,2.56,2.121,2.128$

Cash balance, Table 4A.1

Cash basis of recording, 4.2

definition of, 3.67

in Statement of Sources and Uses of Cash, 3.103-3.106, 4.34, 5.11, 6.7

limitations of, 3.70-3.72

time of recording transactions, 3.60, 3.67

Cash transfers, 3.16, 3.18

Catastrophic loss of assets, 1.16, 3.128, $10.60-10.61$

Central bank(s)

as financial intermediary, 2.55-2.56

as public financial corporation, 2.118-2.119, Figure 2.3

currency issued by, 7.135

dividends of, 5.114-5.116

gold as financial asset of, 7.126-7.130, 9.28

implicit subsidies/taxes of, 5.26, 5.70, 6.89, Box 6.2

implicit taxes from multiple exchange rates, 5.88

in monetary and currency unions, 2.21, 7.169, A5.32-A5.35

representative office as territorial enclave, 2.9

SDR allocations and holdings of, 7.133, A3.80, A3.87, A3.94

Central borrowing authority, 2.44

Central government public sector, 2.122

Central government subsector definition, 2.85

institutional units of, 2.87-2.89

intrasectoral consolidation of, 3.155

recording monetary authority functions of, 2.89 responsibilities of, 2.85

significance of statistics from, 2.86

Chambers of commerce, 2.37, 6.42

Changes in net worth

as fiscal indicator, 4.40

due to holding gains or losses, 4.37

due to other changes in the volume of assets and liabilities, 4.38

due to other economic flows, 3.54 , $4.36,10.2$

due to transactions, $1.15,1.33$

in Statement of Total Changes in Net Worth, 1.18, 4.14, 4.46, Table 4.5

Charities, 2.61, 6.123

Classification of Functions of Government (COFOG), 1.43

classification challenges in, 6.143-6.146

classification of administrative expenditures in, 6.144

classification of consumption of fixed capital in, 6.146-6.147

classification of shared expenditures in, 6.143

classification of subsidies in, 6.145

cross-classification of expenditures in, 6.148-6.149, Table 6A.2

definition of, 6.126

government finance statistical framework and, 6.127

individual versus collective goods and services distinguished in, 6.133-6.139

purpose of, 6.126 structure, 6.128-6.129, Table 6A.1 units of classification, 6.140-6.142 uses of, 6.130-6.132

COFOG. See Classification of Functions of Government

Collateralized debt obligations, 7.143, 7.151

Collective goods and services, 6.133-6.139

Commitments basis of recording, $3.61,3.70-3.71$

time of recording transactions, 3.65

Compensation of employees

arrears of, 7.247

as exchange type of transaction, 3.9

classified as expense, 4.24, 6.2, 6.9-6.11, Table 6.2 
coverage in GFS versus 2008 SNA, 1.24

definition of, 6.9

employee benefits purchased by employee, 6.14

employer-employee relationship and, 6.9, 6.33-6.34, A2.40

employers' social contributions, 6.19-6.26

expenses for use of goods and services versus, 6.33-6.36

imputed, 5.100, 5.140, 6.22

in accrual basis of recording, 6.10

in cash basis of recording, 6.10

in government finance statistics framework, 1.24

in kind, 5.140, 8.47, 9.78

reimbursements, $6.15,6.36$

social contributions. See Social contributions and Employers' social contributions

wages and salaries, $6.12-6.18$

Computer software and databases, 7.64-7.65, 7.69-7.71, 8.40,

Table 7.5

Concessional lending (loans), A3.39-A3.41

as memorandum items, 7.246, 9.12, Table A8.3

by central banks, $5.70,6.89$, Box 6.2 description of, $3.123,9.12$, Table 4A.2 examples of, 3.123

from International Monetary Fund, A3.86-A3.88

loans at nominal value, 9.12 recorded as supplementary information, 3.123, 7.246, 9.12 to government employees, 6.17

Consolidation

balancing items and, 3.166 data discrepancies in process of, 3.165 definition of, $2.23,3.153,9.18$ implementation of, 3.165-3.166 in financial statements according to accounting standards, 3.168, A6.13, A6.17

in System of National Accounts 2008, $2.22,3.53,3.167$

intersectoral, 3.156, 3.157

intrasectoral, 3.155, 3.157

major transactions subject to, $3.162-3.164,5.22,6.8,6.20$ of transactions in financial assets, 3.163-3.164, 9.19

principles/conceptual guidelines of, 3.161

process of, 3.152, 9.18

purpose/reasons for, 3.152 , $3.158-3.160$

types of consolidation, 3.154

types of transaction not subject to, 3.161

Constructs of society, 7.19, 7.90, 7.104

Consumers' associations, 2.61

Consumption of fixed capital

as expense, $4.24,6.53,8.18$

as part of production cost, $2.74,6.2$

calculation of, 6.55-6.56, 6.59, Box 6.1

cash flows and, 6.61

change in volume of assets versus, 6.58

classification of, Table 6.4

cost of ownership transfer as, 6.60,

Figure 8.1

decline in value of fixed assets due

to deterioration as, $8.18,10.8$

definition of, 6.53

depreciation versus, 6.54, A6.54

excluded events, 6.58

gross operating balance and, 4.20

in calculation of holding gains, 10.8, 10.13-10.14

in Classification of Functions of Government, 6.146-6.147

in government finance statistics framework, 4.20, A6.54

in System of National Accounts 2008, 6.53

losses of fixed assets as, 6.57 time recording of, $3.90,6.61,8.16$

Contingent liabilities

as memorandum items, 7.251-7.261, Table 7.10, Table A8.3

classification of explicit, 7.254, Table 4.6

definition of, 4.47, 7.251, Table 4A.1 explicit versus implicit, 7.252

guarantees and, 7.253, 7.256

in macroeconomic statistics, 7.253, Figure 7.2

liabilities and, 7.251

recording of, 4.15, A2.38

statements in government finance statistics framework, 1.19,

4.13-4.15, 4.47, Table 4.6
See also Summary Statement of Explicit Continent Liabilities and Net Obligations for Future Social Security Benefits

Contractors, 6.33

Contracts, leases, and licenses as assets/nonfinancial assets, 7.17, 7.105-7.106, 8.56-8.57, A4.53-A4.57, Box A4.3, Table 7.2 financial derivatives versus, 7.207 for use of natural resources, A4.19, Figure A4.1

recording changes in value of, 10.49 , 10.53, Table 10.2

recording transactions in, A4.2-A4.3 types of, 7.107, 8.57, Table 7.8.

See also specific type

See also Leases

Conversion, currency, 3.130, 3.132-3.133

Conversion, debt, A3.5, A3.20-A3.23

Corporations

defining characteristics of, as institutional unit, $2.31-2.35$

distributable income of, 5.111-5.116

financial, 2.53-2.57, Figure 2.2

government control of, 2.107, Box 2.2 imputation system of taxing, 5.44

income taxes, 5.41-5.44

market producers as, 2.65-2.69

nonfinancial, 2.52, Figure 2.2

quasi, 2.125

restructuring. See Restructuring agencies

See also Public corporations

Counterparty information and classification, 2.6, 2.23, 3.165, 7.264-7.265, A6.41, Table 3.1, Table 7.11, Table A 8.4

Credit derivatives, 7.207, 7.218

Credit guarantees, 7.259, 9.57, A4.72

Cultivated biological resources, 7.58-7.63, 8.34-8.36, Table 7.5

Cultural clubs, 2.61

Currency

classification of, 7.135-7.136, 9.33-9.34 consolidated statistical presentation, 3.164

conversion, 3.119, 3.132-3.133, 7.23, $7.136,9.11$

definition of, 4.33, 7.135

domestic versus foreign, 3.134-3.136, $6.78,7.136$ 
holding gains and losses on, 10.23 monetary/nonmonetary transac-

tions expressed in, 3.8, 3.19

of denomination, 3.131, 3.137-3.139

of settlement, 3.131, 3.137-3.139

production/issuance of, $6.48,9.34$

swap contracts, 7.215

union, A5.34

unit of account, 3.130

volume changes, 10.61

Currency boards, 2.17, 2.118

Currency union central bank, 2.21, 7.169, A5.35. See also Monetary and currency unions

Current accounts, A7.13, A7.23-A7.61, A7.77-A7.88, Table A7.2

Current grants, 5.103-5.104, 6.94, A5.13

Current transfers, 3.15, 3.17-3.18

not elsewhere classified, 5.147, 6.123

Customs duties, 5.84

collection and allocation in customs union, A5.7-A5.18

Customs unions

administrative structures for collection of duties in, A5.8

as international/regional organization, 2.17, A5.5

definition of, A5.6

recording of collection fees in, A5.9 recording of customs duties in, A5.7-A5.18

See also Regional organizations

Cyclically adjusted balances, 4.58 , Table 4A.2

D

Debentures, 7.146

Debit entry, 3.54-3.55

Debt

arising from off-market swaps, A3.67-A3.71

arising from securitization, A3.59-A3.66

arrears of, 3.71, 6.80, 7.247-7.250, $9.20-9.23$

assumption, 5.148, A3.26-A3.29

bailout operations and, A3.42-A3.53 cancellation, 5.148, 6.91, 6.124, A3.7 classification by counterparty, 10.79 classification by maturity, 7.266-7.271, 9.88 classification codes, Table A8.5

comparability across member states in economic or monetary union, A5.44

concessional debt, 3.123, 7.246, 9.12

defeasance, A3.37-A3.38

definition, A7.236

fiscal indicators, 1.3, 1.13, Table 4A.1

forgiveness, 4.35, A3.7-A3.9

gross and net, 3.150, 4.54-4.55, 7.236-7.245, Table 7.10

guarantees. See Contingent liabilities nonperforming. See Nonperforming loans

of special purpose entities, A3.54-A3.58

on-lending of, A3.72-A3.78

payment on behalf of others, A3.30-A3.31

securities. See Debt securities sinking fund for redemption of, 2.144

statistics, 1.8, 3.137

time of recording, 3.93, 3.97, 9.13

valuation, 1.29, 3.113-3.117,

$7.27-7.30$

with the IMF, A3.79-A3.95

write-offs/write-downs, 10.57,

A3.32-A3.34

See also Debt instruments; Debt reorganization; Debt securities

Debt instruments, 7.15

classification of, 7.236-7.237,

Table A8.5

definition of, 7.236

dematerializing of, A7.103

financial assets corresponding to, 7.243

grace periods 6.69

included in financial claims, 3.47, 7.15

maturity of, 7.266, 9.88, Table 7.12, Table A8.5

new money facility, A3.35-A3.36

nominal value of, 7.21

types of, 7.236

valuation of, 7.26-7.30, 7.122, 7.238

on which no interest accrues, 3.118 , 10.45

See also Debt; Debt reorganization; Debt securities
Debt reorganization

by assumption or payments on behalf of others, A3.5, A3.26-A3.31, Figure A3.1

by conversion or prepayment, A3.5, A3.20-A3.25

by forgiveness, A3.5, A3.7-A3.9

by rescheduling or refinancing,

A3.5, A3.10-A3.19

definition of, A3.2

reason for, A3.3

types of, A3.4-A3.6

Debt securities

accrual of interest on, 9.36, 10.8

arrears on, 9.21

changes in classification, 10.84

changes in value due to interest or exchange rate changes, 10.26

classification of, 7.143-7.156, 9.36-9.43

consolidated statistical presentation, $3.163-3.164$

definition of, 7.143

gross presentation of, 3.150

index-linked, 6.75-6.78, 9.41-9.42, 10.28

interest on, 6.62-6.83

issued at discount or premium, 9.40, $10.8,10.25$

issued at par, 9.39

recording holding gains and losses on, 10.24-10.29

securitization of, A3.59-A3.66 time of recording transactions in, 3.93

valuation of, 1.29, 3.117, 7.27, 7.154-7.156

with embedded derivatives, 7.148 , 9.43

Deep-discount bonds, 6.72, 7.146-7.147

Defeasance, 2.129, 9.26, A3.37-A3.38, A3.46

Deposit guarantee/insurance schemes, 2.132-2.135, 7.202, 9.57. See also Financial protection schemes

Depository receipts, 7.166-7.167

Deposits

classification of, 7.137-7.142, 9.33-9.35

definition of, 4.33, 7.137

denominated in gold, 7.126

mineral, 4.10, 5.129-5.130, 6.55, 7.9, $7.19,7.68,7.97,8.32,8.54,10.52$ 
prepayments versus, 7.226

transferable versus nontransferable, 7.140

valuation, $7.142,10.23$

Deposit-taking corporations, 2.54-2.56, 7.137

public sector, 2.117-2.120, Figure 2.3, Table 7.11

Depreciation, 6.54, 6.146, A6.29, A6.54-A6.55

Derivatives, embedded, 7.148, 7.207 debt securities with, 6.79, 9.43

Derivatives, financial changes in classification of, 10.84 classification of, 4.28, 9.70-9.76 contracts requiring ongoing servicing, 9.74

credit derivatives, 7.218

debt component of off-market swaps, A3.67-A3.71

debt instruments versus, 7.15, 7.119

definition of, 7.204

forward-type contracts, 7.210, $7.212-7.214$

holding gains or losses on, 10.42 interest versus settlement payments, 6.63

margins, 7.219-7.220, 9.75

offsetability, 7.205

option contracts, 7.209-7.211

sales in secondary markets, 9.73

settlement, 9.76

swap contracts, 7.215-7.217

types of financial derivatives, 7.208

valuation of, 7.204, 9.73

Derived measures, 3.140-3.142, 3.161

Design, build, operate, and transfer schemes, A4.58

Development funds, 2.160-2.162

Development spending, Table 4A.2

Diplomatic, 2.9

Direct taxes, 5.9, Table 4A.1

Discounted debt securities, 6.71-6.73, 9.40

Dissemination of data, good practices in, $1.39,3.52$

Distributable income, 5.116, 5.118, $5.134,6.111,6.121$

Dividends

classification of, 5.107, 5.113, 6.108, 9.49, Table 5.9, Table 6.9

definition of, 5.111, 6.109 disproportionately large ("super"), 5.64-5.66, 5.115-5.116, 6.110, 9.49

distributed to investment fund shareholders, 5.121

distribution of profits versus, 5.114 economic benefits, 3.37, 7.7

income tax on, 5.41, 5.44

interim payment, 5.117

lump-sum payments, 5.90

schedule and size of, 5.115-5.117, 6.110

time of recording transactions, 3.87, $5.112,6.109$

Domestic bank financing, Table 4A.1

Domestic financing, Table 4A.1

Domestic nonbank financing, Table 4A.1

Domestic versus foreign currency, 3.134-3.136

Double-entry, 3.54, 3.56, A7.13

Due-for-payment basis of recording, $3.61,3.66,3.70-3.71,3.73$

Dwellings, 7.44-7.45, Table 7.3

E

Economic assets, 3.35, 3.37, 3.43, 3.50, $4.25,4.38,4.43,7.6-7.10,7.12$, $10.5,10.48$

Economic benefits derived from assets, 3.37

Economic flows. See flows

Economic ownership, 2.143, 3.38-3.41, $3.60,3.62,3.88,3.93,3.100,7.5$, 7.37, 7.109, 9.13-9.14, 9.45, A4.4, A4.16, A4.21, A4.23, A4.33, A4.62-A4.65, Box A4.4, Box A4.5

Economic territory

definition and scope of, 2.8-2.12

land and buildings in extraterritorial enclaves, 2.13

of economic union, A5.24

of international organizations, 2.16

residence criteria and, 2.2, 2.7

Economic unions

budget authority in, A5.22

common budget versus member state budgets in, A5.23

definition of, A5.5, A5.19

economic territory of, A5.24

expenses of, A5.29-A5.30

goals of, A5.20 grants payable/receivable, A5.23

harmonization for government finance statistics, A5.31, A5.41-A5.44, Box A5.1

legal and economic characteristics of, A5.19

member government units acting as agents of, A5.30

recording transactions related to, A5.26-A5.31

residence of, 2.17, A5.24-A5.25

revenues of common budget in, A5.20, A5.26-A5.28

scope of policy harmonization in, A5.21

See also Regional organizations

Economically significant prices, 2.32-2.33, 2.37, 2.65-2.75, 2.114 , 10.77

Electromagnetic spectrum, 7.12, 7.103, $10.52, \mathrm{~A} 4.23$

Employee stock options

cancellation of, 10.57

classification of, 7.221, 9.77-9.81

definition of, 7.221

financial claims/instruments as, $3.47,4.28,7.15$

granted to suppliers, 7.222

holding gains or losses on, 10.43

issued by parent company to employee in subsidiaries, 9.81

valuation of, 7.223

Employer-based social insurance schemes, 5.98-5.100

Employer-employee relationship, 6.9, 6.33-6.34, A2.40

Employment-related pensions, 2.102 , 2.147, 4.48, 4.50, 5.94, 6.21, 6.26, 7.189-7.198, A2.21, A2.24, A2.41-A2.43, Figure A2.1, Figure A2.2

Employment-related social benefits, 4.48, 6.16, 6.97, 6.104-6.106, 7.195, A2.22-A2.24, Table 6.8, Figure A2.1

Employment-related social insurance, A2.18, A2.23, A2.40, Figure A2.1, Figure A2.2

Enterprise(s), 2.25

Entertainment, literary, and artistic originals, 7.64, 7.72, 8.37, 8.41, Table 7.5 
Entitlements

employment-related pension, 2.102, 5.95, 5.116, 7.189, 9.63, 10.36, $10.41,10.72$

life insurance and annuities, 9.62, 10.71

payments as transfer transactions, 3.12

social benefit, 6.22 , A2.38

to future goods and services, 7.112, A4.51-A4.52

Environmental-economic accounting, A7.105-A7.134

Environmental groups, 2.61

Environmental taxes, A7.115-A7.121, Tables 5.2-5.5

Equity

as assets of general government, $2.48,2.59$

capital injections resulting in, A3.47-A3.49, Figure A3.2, A3.53, A 4.40

classification of, 7.166-7.170, 9.47-9.55

consolidation of, 3.164

conversions, 7.150, 9.43, 10.84

debt assumption resulting in, A3.28,

Figure A3.1

debt-for-equity swaps, A3.5, A3.21, A3.23

defining features of, 7.164, 7.165

evidence of ownership, 7.166

financial claims/instruments, 3.49, 4.28, 7.15, Box 6.3

holding gains or losses on, $10.30-10.33$

liabilities of general government, 2.47

membership fees as, 6.42

net worth versus, 4.40, 7.173,

7.228-7.229, A6.48, Figure 7.1

nonprofit institutional units, 2.37

notional resident units, 2.13

own funds versus, 7.231-7.232

policy lending, 4.30, Box 4.1

property income on, 5.90, 5.111, 6.109

reclassification of assets into, 10.77, 10.84

recorded according to accounting standards, A6.32-A6.33,

A6.48-A6.49 special purpose entities, A3.56-A3.57

valuation of, 7.166, 7.171-7.173, 7.233

withdrawals of, 5.90, 5.115, 6.112

Establishment(s), 2.24, 2.34, 2.75, 2.98, 2.124, 2.127

Estate taxes, 5.51

European Union, A5.20, Box A5.1

Exchange rates

changes in value of securities due to changes in, 10.1, 10.26

government finance accounting rules, 3.132-3.133

holding gains or losses from changes in, 3.33, 10.44, A7.95

multiple rate regimes, 5.89

role in credit derivatives, 7.218

subsidies in official system of, 6.89

taxes on exchange transactions and profits, 5.88-5.91

use of, in recording currency swaps, 7.216

valuation of transactions expressed in foreign currency, 3.119, 9.11, 9.33

Exchanges

as determinant of market prices, 3.108 as monetary transaction, 3.9

combined with transfers, 3.11, 3.123 of financial assets and liabilities, 3.44, 5.8, 6.5, 7.119, 9.3, A3.5

Excise taxes, 5.55, 5.57, 5.62, 5.71, $5.84,5.96$

Ex-dividend shares, 3.87, 5.112, 6.109, 10.32

Expenditure, 3.7, 4.21, 4.53, 5.28, 6.32, Table 4.1, Table 4.2, Table 4A.1

Expense

accounting rules for recording, $3.55-3.56$

accrued expense versus cash flow expense, 4.35

classification of, 1.21, 6.1-6.3, 6.8, 6.126, Table 4.2, Table 4.2, Table 6.1, Table A8.2, Table A8.6. See also Classification of Functions of Government (COFOG)

collection fees as, 5.35

consolidation of, $3.162,3.165$

definition of, 4.16, 4.24, 6.1

excluded transactions, 4.24, 5.44, 6.5 fiscal indicators using, 4.53, 4.55, 4.57, Table 4A.1, Table 4A.2

gross/net recording of, 3.143-3.151

in government finance statistics

framework, 1.33, 4.16, Figure 4.1

major types of, 4.24

of regional organizations, A5.29-

A5.30

payable tax credits as, 5.31

refunds of, 6.4

time of recording of, 3.77-3.92, $3.104,6.6-6.7$

valuation of, 3.107-3.112

See also respective categories of expense such as Compensation of employees; Interest expense; Property expense

Export taxes, 5.85. See also Taxes on exports

Extrabudgetary units, 2.41-2.44, 2.80, 2.82-2.83, 2.87, 2.93, Figure 2.3

F

Face value, 3.115, 3.117, 7.144, A3.16 gross debt at, 7.238, 7.242, Table 7.10

Fair value, 3.115, 7.142, 7.163, 7.204, 7.223, 7.262, 9.55, A3.52, A4.12, A6.27-A6.30, Box A6.1, Table 7.10

Fees and licenses classification of revenue from, 5.138 for business operations, 5.81, A4.42 for financial protection schemes, 2.135

for goods and services, 5.136, 6.30 not commensurate with the control function of government, 5.72

other taxes on use of goods and permission to use goods or perform activities, 5.81

standardized guarantee schemes, $5.149,6.125,9.57$

taxes versus, 5.73-5.75

Financial account, A7.68-A7.69, A7.93-A7.94, Figure A7.1, Table A7.2

Financial assets and liabilities accounting identity, 9.2 arrears of, 9.20-9.23

changes in classification of, 9.35, 10.84

changes in volume of, $10.57,10.63$ 
classification according to counterparties, 7.264-7.265, 9.86-9.87, Table 9.2

classification by maturity, 7.266-7.271, Table 7.12

classification of, 4.26-4.31, 7.118-7.124, 7.264-7.265, 9.249.27, Table 4.1, Table 4.2, Table 7.9, Table 7.11, Table 9.1

consolidation of transactions in, 9.18-9.19

currency and deposits, 7.135-7.142, 9.33-9.35

debt securities, 7.143-7.156, 9.36-9.43

definition and scope of, 3.43-3.48, $7.15-7.16$

employee stock options, 7.203, 7.221-7.223, 9.77-9.81

equity, 7.164-7.173, 9.47-9.55

financial derivatives contracts, 7.203-7.220, 9.70-9.76

holding gains and losses for, with fixed monetary values, 10.23

insurance, pension, and standardized guarantee schemes, 7.178-7.202, 9.57-9.69

investment fund shares, 7.164, 7.174-7.177, 9.56

liquidity, $2.55,4.31,7.118,7.124,7.266$

loans, 7.157-7.163, 9.44-9.46

monetary gold, 7.126-7.130, 9.28-9.30

net debt calculation, 7.243

net lending/net borrowing equal to transactions in, 9.5

net presentation of transaction in, 9.17, Table 9.1

other accounts receivable/payable, 7.224-7.227, 9.82-9.84

public policy-related, 4.29-4.30, Box 4.1

recording of transactions in Statement of Operations, 4.26-4.31 special drawing rights, 7.131-7.134, 9.31-9.32

time of recording transactions in, 3.93-3.97, 9.13-9.16

types of financial instruments included in, 9.24-9.27. See also the respective type of instruments types of transactions in, 9.3-9.4 valuation of transactions in, 9.7-9.12
Financial auxiliaries, 2.54, 2.121

Financial claims

definition of, 3.47, 7.15. See also specific type of claims

termination of, 9.3

Financial corporations

bailout operations, A3.42-A3.53

institutional sector for, 2.50, 2.53-2.57, Figure 2.1, Figure 2.2

pension funds, autonomous, A2.47-A2.52

public sector, 2.115-2.121, Figure 2.2, Figure 2.3

restructuring agencies as, $2.130-2.131$ types of/classes of, 2.54

Financial derivatives. See Derivatives, financial

Financial intermediaries central bank as, 2.118

definition of, 2.54

functions of, 2.54

interest expense payable to, 6.81

subsectors of, 2.55

Financial intermediation services indirectly measured (FISIM), 5.108, 6.52, 6.62, 6.81, A7.28, A7.29, Table 5.8, Table 6.5, Table A7.1

Financial leases, A4.4, A4.10-A4.15, A 4.55

definition of, 7.158, A4.10

fixed assets acquired under, 7.38

operating leases versus, 6.50, A4.37 time of recording, 8.17

Financial net worth. See Net financial worth

Financial protection/deposit insurance schemes, 2.132-2.135, 5.74 5.138, A4.72

Financial services fees, 6.52. See also Financial intermediation services indirectly measured (FISIM)

Financing indicators, Table 4A.1

Financing transactions, in Statement of Operations, 4.26-4.31, Table 4.1, Table 4.2. See also Transactions in financial assets and liabilities

Fines and penalties classification of, as expense, 6.123 classification of, as revenue, 5.6, 5.143-5.144

definition of, 5.142

on taxes, $5.24,5.143$ related to environmental-economic activities, A7.124

time of recording, 3.85, 5.144

Finished goods, 7.83, 8.47, Table 7.6

Fiscal analysis

role of GFSM 2014 in, 1.3

use of government finance statistics framework for, 1.10-1.13, 4.51-4.60, Table 4A.1, Table 4A.2 See also Analytic framework of government finance statistics

Fiscal balance analysis, 4.53, Table 4A.1

Fiscal burden, 5.9, Table 4A.1

Fiscal impulse, Table 4A.2

Fiscal policy

definition of, 1.2

government entities in execution of, 2.1

role of central government subsector in, 2.86

role of GFSM 2014 in analysis of, 1.2

Fiscal stabilization funds, 2.160-2.162

Fishing quotes/permits/licenses, A4.30-A4.31

Fixed assets, 7.35-7.74

acquired under financial lease, 7.38, 8.17

biological resources. See Cultivated biological resources

buildings and structures, 7.41-7.51, 8.28-8.32, Table 7.3

classification of other, 7.58-7.73, Table 7.5

classification of, 7.35, Table 7.2 component of produced assets, 7.18 constructed on own account, 7.37, 8.9 costs of ownership transfer, 6.60 , $8.7,8.42,10.68$, Figure 8.1

cultivated biological resources, 7.58$7.63,8.34-8.36,8.47$, Table 7.5

definition of, $7.18,7.35$

deterioration of, 10.65

holding gains and losses on, 10.13

intellectual property products, 6.46-6.47, 7.64-7.73, 8.37-8.41, Table 7.5

machinery and equipment, 6.43, 6.49, 7.52-7.57, 8.33, Table 7.4 maintenance and repair expenses, $6.45,8.25-8.27$

other changes in volume of, 10.63-10.69 
ownership of, 7.37-7.39

recording of transactions in, 8.24-8.43

revalued stock position for PIM,

Box 6.1

time of recording of phased production of, 7.37

valuation, $7.36,8.9,8.24$

weapons systems, $6.49,7.74,8.43$

Fixed capital consumption. See Consumption of fixed capital

Float, 9.14

Flows

basis of recording, 1.27-1.28, 3.60, 3.67

classification of, 1.21, Table A8.3

consolidation, 9.18-9.19

definition of, 3.4

double-entry recording of, 3.54

expressed in foreign currencies, 3.119-3.129

illustrative recording of flows related to nonlife insurance or standardized guarantees, A4.79-A4.80

illustrative recording of flows related to social protection, Table, A2.1,

Table A2.2, Table A2.3, Table A2.4

in government finance statistics framework, 1.15, 1.21, 1.27, $1.31,3.1$

in regional arrangements, A5.3 in structure of analytic framework, 3.1, 4.8, Table 4.1

integration of stock positions and, $1.31,3.2$

netting of, 3.143-3.151, 9.17

of special purpose entities, 2.138-2.139

time of recording. See Time of recording economic flows

types of, 1.15, 3.4, Figure 4.1

unit of account, 3.51, 3.130-3.131

valuation of, 1.29, 3.107, 3.115-3.129

See also Other economic flows;

Transactions

Foreign direct investment, reinvested

earnings, 5.134-135, 6.121, 9.50, 10.34

Foreign financing, Table 4A.1

Forfeits, 5.142-5.144

Forgiveness, debt, 3.16, 4.35, 7.30, A3.5, A3.7-A3.9
Forward-type contracts, 7.208, 7.210, 7.212-7.214, 7.218, 9.71

Free trade zones, 2.11, A5.6, A5.19

Functional classification of government, $1.21,6.3$, Table 6A.1

COFOG system for, 6.126-6.132

detailed functions of government, 6.150

economic function cross-classified with, 6.148-6.149, Table 6A.2

See also Classification of Functions of Government (COFOG)

Futures contracts, 7.213

G

Gambling winnings, 3.46, 5.41-5.42, $5.63,5.66-5.68$

General government sector

comprise of, 2.58-2.59

coverage of the GFS framework, $1.26,2.4,4.7$

decision tree for classification of entities in, 2.124, Figure 2.4

definition and scope of, 1.2, 2.58, $2.76,4.7$

delineation with public corporations, 2.64, A5.42, A6.14

economic functions of, 2.38

institutional units of, 2.58, 2.64

international comparison of subsector statistics, 2.77, A5.42

plus central bank, as public sector grouping, 2.122

reclassification of assets and liabilities of, $10.80-10.84$

reclassification of units to or from, $10.76-10.79$

relation to other institutional sectors, 2.122, Figure 2.1, Figure 2.2

residence of units of, 2.14

scope of government finance statistics framework for reporting on, 1.26

subsectors of, 2.62, 2.76-2.103, 3.153

transfer transactions typical in, 3.10 types of expense in, 6.1

types of revenue in, 5.1

types of transactions in financial assets and liabilities in, 9.85 uses of government finance statistics framework in analysis of, $1.10-1.13$
General taxes on goods and services, 5.57-5.61, Table 5.3

Geographical area, 2.8, 2.90, 2.95

GFSM 2014. See Government Finance Statistics Manual 2014

Gift taxes, 3.81, 5.51

Gold

allocated accounts, 7.126-7.128, 10.84

as financial asset, $3.43,3.48$

as financial claim, 3.47, 7.15

as financial instrument, 4.28

as remuneration to IMF member countries, A3.89

bullion, 3.43, 7.15-7.16, 7.126, 7.128

changes in classification of, 10.84 deposits, 7.139, 9.35

holding gains and losses, 3.127, $5.90,10.21,10.23$

international investment position, A7.96

monetary, classification of, 3.47, 7.126-7.130, 7.244, 9.28-9.29

nonmonetary, $7.88,7.135,8.47-8.48$, 9.30, 9.34

reclassification of, 10.84

recorded as foreign currency, 3.135

swaps, 7.161, 9.46

unallocated accounts, 7.127, 7.139

Golden shares, Box 2.2

Goods for resale, 6.29, 6.44, 7.75, 7.84-7.85, 8.47, Table 7.6

Goodwill and marketing assets, 7.17, 7.31, 7.104, 7.113-7.117, $8.56,8.58,10.49,10.54-10.56$, Table 7.8

Government

asset ownership/use of, 7.11-7.12 definition and scope of, 2.1

employees of, 6.9

entities of, 2.1. See also General Government Sector; Government units; Public corporations

final consumption expenditure, A7.55-A7.60, Table 4A.1

residence of entities of, 2.14

Government finance statistics framework, 1.1

advantages of accrual basis of recording in, 3.70

aggregates in, 3.141 
Balance of Payments and International Investment Position Manual and, A7.73-A7.98

balance sheets in, 1.30, 7.1-7.3

balancing items in, 1.32-1.34, 3.140

basis of recording economic events in, $1.27-1.28,3.61-3.75,4.3$

classification codes, A8.1-A8.7, Figure A8.1, Table A8.1, Table A8.2, Table A8.3, Table A8.4, Table A8.5, Table A8.6

classification of, 3.7

COFOG and, 6.126-6.127

coverage of, 1.26, 2.1-2.4, 3.53

differences in institutional and economic structures of countries and, 1.5, 1.36-1.39, A7.2

fiscal indicators available from, 4.51-4.60, Table 4A.1, Table 4A.2 harmonization of, 1.13, 1.22, 1.35, A5.1

implementation of, $1.5,1.36-1.39$

integration of, 3.2

International Public Sector Accounting Standards and, A6.1-A6.56, Box A6.1

Monetary and Financial Statistics Manual and, A7.99-A7.104

Objectives of accounting versus, A6.11-A6.12

purpose of, 4.1, 4.5, A7.3

structure and features of, 1.14-1.24, $4.8-4.15$

System of Environmental-Economic Accounting Central Framework and, A7.105-A7.134

System of National Accounts 2008 and, 1.22-1.24, 3.6, A7.13-A7.72, Tables A7.1-A7.5

uses of, 1.10-1.13, 4.51, A5.36-A5.40 valuation in, 1.29, 3.107-3.117, A6.25-A6.30

See also Analytic framework of government finance statistics

Government Finance Statistics Manual 1986 (GFSM 1986), 1.6-1.7, 1.35, $4.2,4.6$

GFSM 2014 and, 1.25-1.34, A1.164-A1.186

Government Finance Statistics Manual 2001 (GFSM 2001), 1.7-1.8, A1.1-A 1.162
Government Finance Statistics Manual 2014 (GFSM 2014)

additions and changes from previous editions in, 1.8-1.9, 1.25-1.345,

A1.1-A1.162

evolution of, 1.6-1.9

harmonization, 1.1, 1.8-1.9, 1.35,

A1.1, A1.187

preparation of, 1.8-1.9

purpose of, 1.1-1.5

revision process, 1.8

structure of, 1.40-1.44

supplemental practical guidelines, 1.1

See also Government finance statistics framework

Government Finance Statistics Yearbook, $1.6,4.51$

Government-owned enterprises

as government units, 2.47

examples of, 2.1

nonresident, 2.20, 2.57

See also Public corporations

Government production activities, 1.22

Government units

accountable to two levels of government, 2.79, 2.99, Box 2.1

ancillary activities supplied to, 2.45 , 2.72

artificial subsidiaries, 2.42-2.44, 2.162

as legal or social entities, 2.30, 2.47

as nonmarket producers, $2.32,2.37$, $2.41,2.58-2.59$

as recipients of subsidies, 6.86

budgetary and extrabudgetary, $2.80-2.82$

classification of revenue from sales of goods and services by, 5.136 , 5.141

definition of, 2.38

dividend payments to or from, 5.113 economic functions of, 2.38

establishments as, 2.24

geographic location of, 2.40

identification of, 2.39-2.47, 2.64-2.75

in control of public corporations, 2.107-2.112, Box 2.2

market producers versus, 2.24, 2.35, 2.64-2.75, 2.48, 2.63-2.64, 2.104

See also Public corporations net worth of, 7.229 privatization of, 9.54 public sector, 2.4, 2.63, Figure 2.3

relationships between, 2.47

rent from lands/subsoil assets owned

by, $5.126-5.130$

residence of, 2.14

sector classification of, 1.2, 2.38,

$2.76-2.84$

social protection programs and,

$2.46,2.100-2.101$

tax attribution principles, 5.33-5.40

taxes payable by, 5.42

types of expense, 3.1, 6.1-6.2

types of revenue in, 3.13, 5.1

See also General government sector Grants

as transfer transactions, 3.10

between general government units, $2.82,2.95,5.102,6.93$

capital, 5.103, 6.94

claims settlement and, 5.105

classification of, 5.5, 5.101-5.104, 6.92-6.94, Table 5.7, Table 6.7

consolidated statistical presentation, $3.153,3.162,5.5,5.102$

current, 5.103, 6.94

definition of, 5.5, 5.101, 6.92

distributed in regional arrangements, A5.8-A5.18, A5.23

in kind, 5.104, 6.92, 6.95

sources/recipients of, 5.102, 6.93

time of recording of, 3.86, 5.16, 5.105

valuation of, 3.108, 3.123, 5.104

Gross capital formation, A7.54,

Table 4A.1

Gross debt

analysis of, 4.55

as memorandum item to balance sheet, 7.236-7.242, Table 7.10

at market value, 7.240

at nominal value, 7.241

definition of, 7.236, Table 4A.1

face value, 7.241

valuation of, $7.154,7.239-7.242$

Gross debt sustainability, 4.55,

Table 4A.1

Gross financing needs, Table 4A.2

Gross fixed capital formation,

Table 4A.1

Gross investment in nonfinancial assets, 8.4, Table 4.1, Table 4.2, Table 4A.1 
Gross operating balance, 4.20 ,

Table 4.1, Table 4A.1

Gross saving, A7.54, Table 4A.1

Guarantees

classification of, 3.49

contingent liabilities and, 7.253,

Figure 7.2

control established through, Box 2.2

in the GFS framework, 3.49, 4.15,

Table 4.6

one-off, 7.255-7.260

risks associated with, 1.4, 1.19, 2.71

standardized schemes. See Standardized guarantee schemes

H

Historic cost, 3.115

Holding companies, 2.128

Holding gains and losses

as economic benefit, 3.37

calculation of holding gains,

$10.9-10.10$

changes in net worth due to, 4.37

changes in value excluded from classification as, 10.8

classification codes, 10.4, Table A8.3

consumption of fixed capital in esti-

mation of, $6.68,10.13-10.14$

continuous accrual of, 3.34. See also

Time of recording

definition of, 3.33, 4.10, 10.1

in the GFS framework, 4.10, 4.46,

10.2, Table 4.5, Table 10.1

measuring, 10.9-10.10

net presentation of, 3.149

neutral and real, 10.11

on debt instruments that do not accrue interest, 10.45

on debt securities, 10.24-10.29

on employee stock options, 10.43

on equity, $10.30-10.33$

on financial assets denominated in

foreign currencies, 10.44

on financial assets with fixed monetary values, 10.23

on financial derivatives, 10.42

on fixed assets, 10.13-10.15

on insurance, pension, and stan-

dardized guarantee schemes,

10.35-10.41

on inventories, 10.16-10.17 on investment fund shares, 10.34

on monetary gold, 10.21

on nonfinancial assets, 10.19-10.20

on special drawing rights, 10.22

on valuables, 10.18

realized and unrealized, 10.6-10.7,

A6.31-A6.33

recording of, 10.5

time of recording, 3.33-3.34,

3.99-3.100, 3.127, 10.7, 10.12

valuation of, $3.127,10.9-10.10$

Hospital buildings, 7.47

Hospitals

as institutional household, 2.28

as nonprofit institutions, $2.37,2.97$, 5.139

as market producers, $2.114,2.127$

Household(s)

as types of institutional units, 2.27

definition of, 2.28

economic sector, 2.60, Figure 2.2

income taxes, 5.41

multiperson, 2.29

nonprofit institutions serving. See

Nonprofit institutions serving

households

relation to other sectors, Figure 2.1

subsidies to, in capacity as produc-

ers, 6.86

I

Implementation of GFSM 2014

challenges using accrual basis accounting in, 3.75

consideration of local circumstances in, $1.36-1.37$

consolidation process, $3.165-3.166$

good data dissemination practices in, 1.39

institutional and legal structures of government and, 1.5

in monetary unions, A5.38-A5.40

sequence of, 1.38

Implicit transfers resulting from loans at concessional interest rates, $7.246,9.12$, Table 7.10

Import duties, 3.81, 5.84, A5.12, Table 5.5

Incidental sales, 5.139, A5.9, A5.27, Table 5.10

Income accounts, A7.31-A7.61, A7.82-A7.88
Income taxes

classification and recording of, 5.42-5.44, Table 5.2

definition and scope of, 5.41

refunds, 3.145

time of recording, 3.82-3.83, 5.12, $5.15,5.43$

withheld from employees, 6.12

Index-linked debt/securities/loans, 6.75-6.83, 7.153, 9.41-9.42, 10.26

Indirect taxes, 5.9, Table 4A.1

Individual goods and services, 6.133-6.139, A7.60

Information, computer, and telecommunication equipment, 7.52 , 7.56, Table 7.4

Infrastructure companies/funds, $2.160-2,162$

Infrastructure construction/assets, $7.11,7.48$

Inheritance taxes, 5.51

In kind transactions, 3.19-3.21

barter, 3.22

difference in GFS and SNA treatment of, Box A7.1

employee compensation. See Remuneration

grants, 5.5, 5.104-5.105, 6.94

payments other than remuneration, 3.24

remuneration, 3.23, 5.140, 6.35 . See also Wages and salaries, social benefits, 2.101, 6.39-6.40, 6.100-6.101, 6.104, A7.48

transfers, 3.16, 3.25

types of, 3.21

valuation, 3.121-3.123

wages and salaries, 6.17-6.18, Table 6.2

Institutional sectors

definition of, 2.50

financial corporations, $2.53-2.57$

general government, 2.58-2.59

households, 2.60

institutional units and relationship

to, 2.51, Figure 2.1

nonfinancial corporations, 2.52

nonprofit institutions serving

households, 2.61

subsectors of, 2.62

types of, 2.50 
Institutional units

ancillary activities of, 2.45

application of definition, 2.39-48

artificial subsidiary, 2.42

central borrowing authority as, 2.44

changes in classification of, 10.7610.79

characteristics of, 2.22-2.25

classification of specific types of, 2.125-2.162

classification of, 2.50, 2.63, 2.124, Figures 2.1 and 2.4. See also Sector classification

consolidated statistical presentation, 3.153-157

control of, 2.47

corporations as, $2.31-2.35$

criteria to be, 2.22

definition, 1.14, 2.22

enterprises and, 2.25

establishments and, 2.24

government units as, 2.38

households as, 2.28-2.29, 2.60

identification of, 2.26

in financial corporations sector, 2.53-2.57, 2.115-2.121

in general government sector, 2.58 , $2.76-2.103$

in government finance statistics framework, 2.3, 2.23, 4.7

in nonfinancial corporations sector, $2.52,2.114$

in public sector, 2.63

location of, 2.12

nonprofit institutions serving

households as, 2.36-2.37, 2.61

notional resident units, 2.13

of central government, 2.85-2.89

of local government, 2.95-2.99

of state government, 2.80-2.83, $2.90-2.94$

public corporations as, 2.48

residence of, 2.6-2.14

social protection and, 2.46,

Appendix 2

special purpose entities as, 2.15 , $2.43,2.136-2.139$

transactions between, 3.5

types of, 2.27-2.38. See also specific type
Insurance

claims, 5.148, 5.150-5.151, 7.15, A4.77, A7.84

classification of property income disbursements, 5.120

classification of, 9.57-9.62

conceptual basis of, A4.66

consolidated statistical presentation, 3.164

deposit. See Financial protection/ deposit insurance schemes

exceptionally large settlements receivable/payable, 5.151, 6.125

expenses attributed to policyholders, 6.113-6.114

financial corporations in, 2.53-2.55

financial derivatives versus, 7.207

financial intermediation, 2.55

life, 5.120, 7.187-7.188, 9.62, A4.69

nonlife insurance premiums as transfer transactions, 3.12, 3.14

nonlife, 7.183-7.186, 9.58-9.61, A4.70, A4.78-A4.80

policy, nature of, A4.66

premiums, 5.149-5.150, 6.125, A4.74A4.76, Table 5.12, Table 6.11

private, versus, A2.11-A2.16, Figure A2.1

public financial corporations, 2.115, 2.121

recording of nonlife insurance premiums as transactions, 9.58-9.61

reserves/assets/liabilities/entitlements related to, 5.120, 7.178, 9.57

service fees for, 6.52

SNA treatment versus GFS treatment of, A7.29, A7.43, A7.69, Table A7.1 social protection versus,

A2.11-A2.16, Figure A2.1

social. See Social insurance

taxes on, 5.92

terminology of, A4.73-A4.77

time of recording, 3.89

types of, A4.67-A4.70

valuation of, 5.20, 7.122

See also Insurance, pension, and standardized guarantee schemes

Insurance, pension, and standardized guarantee schemes

as debt instrument, 7.236, 7.243, Table 7.12 changes in volume of, 10.63-10.75

classification of, 4.28, 9.57-9.69

classification of, 7.178-7.202

consolidation of, 3.164

difference in GFS and SNA treatment of, 5.95, A7.69

holding gains or losses on, 10.3510.41

social protection arrangements. See Social protection

valuation of, 7.122, 7.240

See also Insurance; Pension schemes; Standardized guarantee schemes

Intangible nonproduced assets,

3.50, 7.31, 7.90, 7.104-7.117,

8.56-8.58, Table, 7.8

Intellectual property products

classification of, 6.46-6.47, 8.37, 7.64, Table 7.5

computer software and databases, 7.69-7.71, 8.40

definition of, 7.64

entertainment, literary and artistic, $7.72,8.41$

mineral exploration and evaluation, $6.47,7.68$

original products and copies, 7.65

other, 7.73

recording transactions in, 6.46-6.47, 8.37-8.41

research and development, 7.66-7.67, 8.38

See also Research and development expenses

Interest

accrual recording of, $3.70,3.90$, $6.64,7.123$

arrears, $6.80,7.247,9.22$

as exchange type of transaction, 3.9

as used in primary balance/fiscal analysis, 4.55, Table 4A.1

cash recording of, 6.65

classification as expense, 4.24, 5.110, 6.62, 6.83, Table 5.8, Table 6.5

classification as revenue, 5.108-5.110, Table 5.8

consolidated statistical presentation, $3.152,3.162$

debtor approach to calculating, 6.66-6.68

definition of, 5.108, 6.62 
financial intermediation services indirectly measured (FISIM) and, $6.62,6.81$

grace periods and, 6.69

gross versus net presentation of, 3.143-3.144

imputed, 5.108, 6.17

on debt instruments that do not accrue, $7.30,10.45$

on debt securities issued at par, 9.39

on debt securities with embedded

derivatives, 6.79, 9.43

on debt securities, $7.143,9.36-9.38$

on discounted instruments,

$6.71-6.72,7.144-7.147,9.9,9.40$

on index-linked instruments, 6.75-6.78, 9.41

on loans issued at premium, 6.73

on loans recorded at nominal value,

$7.163,9.44$

on nonperforming loans, 7.262

on overdue taxes, $5.24,6.82$

on Special Drawing Rights, 7.131, 9.32

payable to financial intermediaries, 6.81

step-up interest, 6.70

time of recording, 3.70, 3.90, 3.133, $5.108,6.64,9.16$

valuation of, $3.108-3.112,3.118$, $3.123,5.109-5.110$

Interest rates

changes in value of securities due to changes in, 10.26

concessional, 2.104, 3.123, 7.246, 9.12

for arrears, 9.22

implicit tax/subsidy of central bank, $5.70,6.89$, Box 6.2

step-up, 6.70

swap contracts, 7.215-7.216

Intermediation, 2.54. See also Financial intermediaries

International investment position, 9.27, A7.74, A7.96-A7.98

International Monetary Fund as international organization, 2.16 Code on Good Practice on Fiscal Transparency, 3.52, 4.51

credits and loans from, A3.86-A3.88 General Data Dissemination System, $1.39,3.52$
No. 1 Account, A3.82

No. 2 Account, A3.90

quotas, A3.82-A3.83

recording of stock positions and

flows arising from membership

in, 7.131-7.134, 9.31-9.32, A3.79-

A3.95

remuneration from, A3.89

reserve position in, A3.84-A3.85

Special Data Dissemination Standard

Plus, 1.39, 3.52

Special Data Dissemination Standard, $1.39,3.52$

Special Drawing Rights, 7.131-7.134, 7.138, 9.31-9.32, A3.82, A3.87, A3.91-A3.95

International organizations

defining characteristics of, 2.16

economic territory of, 2.16

grants from/to, 5.101-5.104, 6.92-6.93, Table 5.7, Table 6.7

membership fees and subscriptions to, 9.52

ownership of, 7.169

residence of, 2.16-2.21

See also Regional arrangements

International Public Sector Accounting Standards (IPSASs), 1.9, 4.46

relationship with, A4.63, A6.1-A6.56, Box A6.1

Inventories

as produced assets, 7.18

classification of, 3.50, 3.91, 6.6, 7.75-7.86, 8.45-8.46, Table 7.6

commemorative coins as, $7.135,9.34$

costs of ownership transfer on, 6.60, 8.45

definition of, 7.18, 7.75

exceptional losses in, 10.70

excluded from capital transfers, 3.16

finished goods, 7.83, 8.47

gold as, 7.129, 9.30

goods for resale, $7.84-7.85,8.47$

holding gains on, $10.16-10.17$

materials and supplies, 7.79, 8.47

military, 7.86, 8.43, 8.47

net investment in, 8.4, 8.44

net presentation of changes in, $3.147,8.19-8.20$

other change in volume of, 10.63 , $10.70,10.82,10.84$ plants and animals as, 7.60-7.61, 8.34

reclassification of, 10.82, 10.84

recording of transactions related to, $3.91,6.6,6.44,8.3,8.44-8.47$

time of recording, 3.90-3.91, 6.6, 8.44

transfers of inventory, 6.37, 6.40

use of goods and services and, 6.6, $6.29,6.44$, Table 6.3

valuation of, $7.78,8.10,8.44$

work in progress, $7.80-7.82,8.47$

Investment funds

as financial claim, 7.15

as financial intermediary, 2.55

classification of, 7.164, 7.174-7.177, 9.56

consolidated statistical presentation, 3.164

definition of, 7.174

development or infrastructure companies as, $2.160-2.162$

expense for disbursements of income from, 6.113

income disbursements, 5.120-5.121

recording changes in value of, 5.121, $6.119,10.34$

sector classification of, 2.121, 2.160

share or units of, 7.174

valuation of, 7.233

\section{J}

Joint accountability of units, 2.79

Joint operating arrangements, 2.143

Joint ownership of assets, 2.29, A4.39

Joint-stock companies, 2.32

Joint ventures, 2.140-2.143, A4.40

L

Land

asset boundary of land, 7.7-7.10

classification of, 3.50, 7.19, 7.93, 7.95-7.96

consumption of fixed capital on, 8.53

costs of ownership transfer, 3.111, 7.22, 8.7, 8.53, Figure 8.1

definition of, 7.92 economic territory and, 2.9-2.10 holding gains and losses on, 8.31 nonresident ownership of, 2.13, 7.91 
other changes in volume of, 8.31 , $10.51-10.52,10.60$

recording transaction, $8.50-8.53$ rent receivable/payable on, 5.122 ,

5.126-5.128, 5.132, 6.51, 6.120 resource lease on, 5.125, A4.17,

A4.26-A4.27

structures on, 8.51

taxes on, $5.49,5.52,5.53$

valuation of, 7.94, 8.11

See also Land improvements

Land improvements

classification of, 7.49-7.50, 8.50,

Table 7.3

consumption of fixed capital on,

$7.51,8.31,8.53$

definition of, 7.49

land and, 7.50

recording transactions in, 7.94, 8.7, 8.31

valuation of, 7.51

Late interest, 9.22

Leases

as assets, A4.53-A4.57, Box A4.3

types of, A4.4-A4.17. See also specific type, Financial leases; Operating

leases; and Resource leases

See also Contracts, leases, and licenses

Legal and social entities, 2.30-2.38

Legal ownership, 3.38-3.41, 5.141, 7.4-

$7.5,7.96,7.158, \mathrm{~A} 4.4, \mathrm{~A} 4.37, \mathrm{~A} 4.62$

Letters of credit, 7.13, 7.207, 7.259

Liabilities

classification of, 1.21, 4.27-4.30, 7.118-7.227, Table 7.9

consolidation of, 3.163

contingent liabilities versus, 7.13

definition of, $3.45,4.45,7.15$

financial claims and, 3.47, 7.15

holding gains and losses, 3.33 ,

$3.100,4.37$

in calculation of net worth, 1.17, 7.1

in government finance framework,

$1.15,1.30,4.22$, Figure 4.1

net presentation of, 3.148

nonfinancial, 3.44

other changes in the volume of, 3.35, 4.38

other economic flows, 3.31 , 3.126-3.129

reclassification of, 3.101-3.102, $10.80-10.84$ recording of transactions in, 1.34, $3.4,4.26-4.31$

relation with debt, 7.236-7.237

sources of, 3.45-3.46

time of recording transactions in, $3.60,3.93-3.97$

types of liabilities, 3.45-3.46

valuation of, 3.111, 3.113-3.115, $7.20-7.33$

See also Financial assets and liabilities and Contingent liabilities

Licenses

as asset sale versus rent, 5.124, 7.109, A4.21, Box A4.1

business, 5.81

compulsory, 5.138

original copies, 7.65

to make use of natural resources, 5.54, 5.78, A4.18-A4.35, Figure A4.1

to use goods, or to perform specific activities, 5.55, 5.72-5.75, 5.81, A4.36-A4.50, Box A4.2, Table 5.4

to use motor vehicles, $5.55,5.72-5.75$, 5.80

See also Contracts, leases, and licenses; Fees and licenses

Life insurance, 7.178-7.179, 7.187-7.188, 9.62, 10.71, A4.69

nonlife versus, 7.183

Lines of credit, 7.13, 7.259

Liquidation corporations. See Restructuring agencies

Liquidity management, 3.67, 4.29, 4.31, Box 4.1, 7.123, 9.12

Loans

arrears of, 3.71, 7.247, 9.21

as debt instrument, 7.236, 7.243

classification of, 7.157-7.162, 9.44-9.46

concessional, 2.162, 3.123, 5.108, 6.17, 7.246, 9.12, A3.39-A3.41, Box 6.2

consolidated statistical presentation, 3.163

control of corporations through, Box 2.2

definition of, 7.157

from International Monetary Fund, A3.86-A3.88

guarantees, 7.259

index-linked, 9.41. See also Indexlinked debt net presentation of, $3.148,9.4$

nonperforming, 7.262-7.263

on-lending of borrowed funds,

A3.72-A3.78, Table A3.1

other changes in volume of, 10.57 reclassification of, 7.149, 7.157, 10.84

time of recording disbursement of, 3.93

to employees, 5.108, 6.17, A2.9

valuation of, 7.163, 9.23, A3.8

Local government

definition of, 2.95

extrabudgetary units of, 2.82-2.83

functions of, 2.95-2.97

general government sector and,

2.58, 2.62, Figures 2.2 and 2.3

institutional units of, 2.80, 2.99

nonmarket NPIs of, 2.83

social security funds of, 2.78

Lotteries, 5.63, 5.66-5.69, 5.114

Lottery winnings, 5.41-5.42

\section{M}

Machinery and equipment, 6.37, 6.43, 6.49, 7.7, 7.35, 7.37-7.38, $7.52-7.57,7.88,8.33$, Table 7.4

Maintenance and repairs classification as expense, 6.45 defining features of, 8.27 major improvements versus, $8.25-8.26$

Major improvements to fixed assets. See Maintenance and repairs

Margins, 7.219-7.220, 9.75

Maritime territories, 2.9

Marketable operating leases, 7.107, 7.108, 8.57, A4.56, Table 7.8

Market producers

characteristics of, 2.32, 2.66-2.69, 2.73

classification of revenue from sales of goods and services by, 5.136-5.138

corporations as, $2.31,2.33$

definition of, 2.65

establishments as, 2.24, 2.76, 2.75

identification of, 2.64-2.75

in government finance framework, 2.4

nonmarket producers versus, 2.64-2.75, Figure 2.4. See also Nonmarket producers 
nonprofit institutions as, 2.37

regional enterprises as, 2.20

transfers of goods and services purchased from, 6.40, 6.91, 6.123, A2.27, A7.59

Marketing boards, 5.65, 5.86-5.87. See also Market regulatory agencies Market prices approximated by/equivalents of,

$3.112,3.114,7.30-7.33$

definition of, 3.107

estimation methods, $3.112,3.125$

exchange values versus, 3.122-3.123

for stock positions, 3.113-3.114

for transactions, 3.108-3.112, 8.9-8.12

holding gains and, 10.9

in government finance statistics framework, 1.29

valuation of assets and liabilities, 7.20-7.33. See also Valuation of each financial instrument

Market regulatory agencies, 2.156-2.159

Materials and supplies, 3.26, 3.91, 3.147, $6.29,7.79,8.3,8.47$, Table 7.6

Means test, 5.94, A2.25

Membership dues, 6.42, 6.123, 9.52, A3.79

Memorandum items, balance sheet, 7.234-7.263, Table 7.10

Military

bases, 2.9-2.10, 2.13, 7.48

dwellings for personnel, 7.44, 7.47 equipment, $6.49,7.52$

inventories, 7.86, 8.47, Table 7.6

See also Weapons Systems

Mineral and energy resources, 3.50, 7.97-7.99, 8.54, A4.35, A7.122

Mineral exploration and evaluation, 6.47, 7.64-7.65, 7.68, 8.37, 8.39, Table 7.5

Monetary and currency unions, 2.17, A5.5, A5.32-A5.35, A5.41-A5.44, Box A5.1

Monetary and Financial Statistics Manual, 1.8, A1.187, A7.5, A7.99-A7.104

Monetary transactions definition of, 3.8 exchanges, 3.9

in government finance statistics framework, 1.28, 3.64

transfers, $3.10-3.18$
Money market funds, 2.55, 2.121, $7.174,7.177$

Monopolies

permits and licenses creating, 7.111 profits of, 5.86-5.87

rerouting profits of, 3.28

taxes on, 5.55, 5.63-5.68, 5.86-5.87, 5.114, Table

Monuments, 7.42-7.43, 7.47-7.48, $8.30,10.50$

Motor vehicle taxes, 5.79-5.80, A7.40, Table 5.4

Mutual funds, 2.54, 7.174

$\mathbf{N}$

National accounts, $1.23,2.23,3.74$, $3.106,3.131,3.165,3.167,4.18$, $5.120,1.151,6.52,6.81,6.125$, 6.139, A7.13-A7.72. See also System of National Accounts 2008

Nationalization, 9.55, A3.42, Box 4.1

Natural disasters, 5.146, 6.37, 6.58, $6.91,10.16,10.60-10.61$, A2.10

Natural resources

as nonfinancial assets, 3.50

as nonproduced assets, 7.17, 7.19

classification of, 7.90-7.103

depletion of, 10.52

entering or exiting asset boundary, $10.49-10.52$

environmental-economic accounting, A7.108-A7.110, A7.122

fiscal analysis in countries with, 4.59, 5.9, Table 4A.2

leases, A4.16-A4.17, A4.53-A4.55

licenses and permits to make use of, 5.78, 7.109, A4.18-A4.35, -, A4.48, Box A4.1, Figure A4.1, Table 7.8 ownership by nonresidents, 2.13 ownership, 3.38-3.39, 7.5 permits to use. See Permits rent from/for, 5.122-5.129, 6.120 revenue from, 5.9, Table 4A.2

taxes on exploitation of, 5.54, 5.74, $5.78,5.82$

See also Rent; specific category of resource

Net acquisition of financial assets, $1.34,3.151,4.16,9.5,9.17,9.23$ Tables 4.1 and 9.1

Net cash outflow from investment in nonfinancial assets, 8.4 , Table 4.2
Net debt, 4.54-4.55, 7.243-7.245, Table 4A.1, Table 7.10

Net financial worth

as balance sheet memorandum item, 7.235

as indicator of sustainability, 4.41, Table 4A.1

definition of, 4.41, 7.235

in government finance statistics framework, Figure 4.1

Net incurrence of liabilities, 1.34, $1.15,3.151,4.16,9.5,9.17,9.23$, Tables 4.1 and 9.1

Net interest expense, 3.144, Table 4A.1

Net investment in nonfinancial assets definition of, 4.16, 8.4, Table 4.1, Table 4.2, Table 4A.1

in government finance statistics framework, 1.34

inventories, 8.44

Net lending/net borrowing as fiscal indicator, 4.19, 4.53, Tables 4A.1 and 4A.2 as fiscal targets in regional arrangements, A5.39 as indicator of fiscal balance, 4.53 calculation of, $4.17,9.5$ compared with SNA concept, A7.19 definition of, 4.17, Table 4.1

impact of capital grants in kind on, 5.104

impact of consumption of fixed capital on, 8.18

in government finance statistics framework, 1.11, 1.34

in gross saving calculation, A7.54 lending minus repayments versus, 4.30

nonresource balances and, 4.59 overall balance and, 4.57 primary balance and, 4.55

Net operating balance as fiscal indicator, 4.18, Table 4A.1 as proxy for distributable income, 5.116

calculation of, 1.33, 3.142, 4.17 compared with SNA concept, 4.18 definition of, 4.17-4.18 gross operating balance versus, 4.20 in government finance statistics framework, 1.11, 1.33, 1.34, 4.17, Figure, 4.1, Table 4.1 
IPSAS surplus/deficit versus, A6.56 savings in national accounts versus, 4.18, A7.19

Net worth

as sustainability indicator, 4.3 , 4.39-4.40, 4.54, Table 4A.1

balance sheet calculation, 3.142 , 4.39, 7.228-7.333, Figure 7.1, Table 4.4, Table 7.1

definition of, 4.39, 7.1, 7.228

in government finance statistics framework, 1.30, 1.33, Figure 4.1 IPSASs' net asset/equity versus, A6.48

of unincorporated enterprises, $7.173,7.232$

own funds versus, 7.231, Figure 7.1 See also Changes in net worth

Nominal value

arrears measured at, 7.250

as proxy for market values, 7.30

calculation of, 7.21

concessional loans at, 7.246, 9.11

definition of, 3.115

face value versus, 3.115

fair value of nonperforming loans versus, 7.263

gross debt at, 7.241

of loans, 7.263

publicly guaranteed debt at, 7.255

Nonfinancial assets

accounting identity, 8.2

appearance/disappearance of, $10.48-10.51$

categories of, 7.17

characteristics of, 7.17

choice of net or gross presentation, 3.146-3.147

classification in Statement of Operations, 4.25

classification of, 7.34, 8.3-8.4 8.21-8.23, Table 7.2, Table 8.1. See also each category of nonfinancial assets

consolidated statistical presentation, 3.162

costs of ownership transfer, 6.60 , $8.6-8.8$

definition of, 7.17

fixed, 7.35-7.74, 8.24-8.43

goods and services expenses versus acquisition of, 6.43-6.49 gross investment in, 8.4, Table 4A.1

gross presentation of, 3.146

holding gains and losses on,

$10.19-10.20$

in expenditure, 4.21

in government finance statistics framework, 1.33, 1.34, Figure 4.1 inventories, 7.75-7.86, 8.44-8.47

loss of economic value, 10.51

net investment in, 1.34, 4.16, 8.4

net presentation of some categories of, 3.146-3.147

netting of transactions in, 8.19-8.20

nonproduced, 7.90-7.117, 8.49-8.58

time of recording transactions in,

$3.88-3.92,8.13-8.17$

types of, 7.17

valuables, 7.87-7.89, 8.48

valuation of, 7.20-7.22, 8.9-8.12

Nonfinancial corporations

economic sector, 2.35, 2.52,

Figure 2.1

public sector, 2.114, Figure 2.2

Nonfinancial public sector, 2.122

Nonlife insurance

claims on, 3.46

classification of protection schemes for, 2.132

definition, A4.70

general government and public sector as operators or holders, 9.57

insurers, public sector units as, A4.79 life insurance versus, 7.183

policyholders, public sector units as, A4.80

premium, fees, and claims payable related to, 6.125 , Table 6.11

premiums and claims as transfers, $3.12,3.14$

premiums, fees, and claims receivable related to, 5.6, 5.149-5.151,

Table 5.12

service fees, 6.52

social security versus, Figure A2.1

statistical treatment of, A4.78-A4.80

technical reserves, 7.178, 7.183-7.186, 9.58-9.61, 10.35

Nonmarket producers, 2.37, 2.43, 2.65, $2.70,2.75,2.124$

Nonmarketable financial instruments, 3.129

Nonmonetary transactions definition of, 3.19

difference in treatment in SNA of, Box A7.1

economic significance of, 3.19

in government finance statistics framework, 1.28, 3.64

internal, 3.26

two-party, 3.21-3.25

types of, 3.20

Nonperforming loans, 7.262-7.263

Nonproduced assets

classification of, 3.50, 4.25, 7.17, 7.90-7.117, 8.49-8.57

costs of ownership transfer, 8.7, $8.42,10.83$, Figure 8.1

definition of, 7.19

economic benefits of, 7.7

in government finance statistics framework, 4.25, Table 4.2,

Table 4.3

intangible, 7.104-7.117, 8.56-8.58

land, 7.92-7.96, 8.50-8.53

mineral and energy resources, $7.97-7.99,8.54$

other naturally occurring assets, 7.101-7.103, 8.55

ownership, 7.90-7.91

types of, 7.90. See also specific type valuation of transactions in, 8.11

Nonprofit institutional units

accountable to two levels of government, 2.79, Box 2.1

as market or nonmarket producers, 2.37

as public corporations, 2.112

control of, Box 2.1

corporations versus, 2.32

defining characteristics of, 2.36-2.37

definition, 2.36

in financial corporations sector, $2.53,2.57$

in general government sector, 1.2, $2.58,2.64,2.83$

in nonfinancial corporations sector, 2.52

relation to sectors of the economy, Figure 2.1

See also Nonprofit institutions serving households

Nonprofit institutions serving households, 2.61, 6.86, Figures 2.1, 2.2, and 2.4 
Nonresource

net lending/net borrowing, 4.59,

Table 4A.2

operating balance, Table 4A.2

primary net lending/net borrowing,

Table 4A.2

primary operating balance,

Table 4A.2

Notional resident unit, 2.13, 7.169, A4.26

O

Obsolescence, 3.125, 6.53, 6.56, 10.8, 10.66, A6.54

Off-market swap, 7.162, A3.67-A3.71

Offshore financial operations, 2.11

One-off guarantees, 7.253-7.260, Figure 7.2, Tables 4.6 and 7.10

bailouts and, A3.52

financial assets/liabilities versus, 7.207, 7.251

IPSASs' treatment of, A6.21, Box A6.1

standardized guarantees versus, 7.201, A4.80

On-lending of borrowed funds, A3.72-A3.78, Table A3.1

Operating leases, 3.90, 7.108, 8.57, A4.4, A4.6-A4.9, A4.37, Table 7.8 financial lease versus, 6.50, A4.12 leases as assets versus, A4.54-A4.56 rent versus, 5.131-5.132

Option contracts, 7.209-7.211

Other accounts receivable/payable, 3 as debt instruments, 7.236, 7.243 classification of, 7.224-7.227, 9.3, 9.82-9.84

consolidation of, 3.163

definition, 7.224

holding gains and losses, 10.23

in government finance statistics framework, 4.28, Table 4A.1

other volume changes in, 10.84

recorded by collecting agents, 5.38 , 5.40

time of recording, 3.56, 3.63, 3.66, 3.72 , 3.94-3.96, 3.118, 4.16, 5.13, 6.10

use in overestimated revenue corrections, 5.20

valuation of, 7.30, 9.10

Other changes in volume of assets/ liabilities appearance or disappearance of assets recorded as, $10.48-10.56$

changes in classification, 3.97 , 10.76-10.84

classification codes, A8.3, Table A8.3

definition of, $3.35,10.1$

external events recorded as, $10.59-10.62$

in financial instruments, $10.71-10.75$

in fixed assets, 10.64-10.68

in government finance statistics framework, 4.10, A7.70, Table 4.3

in inventory, 10.70

in Statement of Other Economic

Flows, 4.38

net presentation of, 3.149

reclassifications, 3.97, 10.76-10.84

time of recording, 3.101, 10.47

types of, 10.46

valuation of, 3.128-3.129

volume changes not elsewhere classified, 10.63-10.75

Other current transfers not elsewhere classified described, 5.147, Table 5.11

Other economic flows

classification of changes in net worth due to, 10.2-10.4,

Table 10.1, Table 10.2

definition of, 3.31

in government finance statistics framework, 1.15-1.16, 1.20, 4.8, 4.14, Figure 4.1

IPSASs value changes versus, A6.31-A6.33, Box A6.1

recording effects of, 3.55

time of recording, 3.98-3.102

transactions versus, 3.31

types of, 3.32, 10.1

valuation of, 3.126-3.129

See also Holding gains and losses; Other changes in volume of assets/liabilities; Statement of Other Economic Flows

Other revenue, 4.23, 5.3, 5.6, 5.106 See also each category of other revenue

Other taxes, 5.93

classification in 2008 SNA versus government finance statistics, 5.25

on goods and services, $5.55,5.82$ on income, profits, and capital gains, 5.42, Table 5.2

on international trade and transactions, 5.92, Table 5.5 on production, 2.74, A7.41, Table A7.3 on use of goods and permission to use goods or perform activities, 5.81, Table 5.4

Other volume changes not elsewhere classified, 10.63-10.76

Overall deficit/surplus, 1.32-1.34

Overall fiscal balance, 1.34, 4.29, 4.57, 7.124, Table 4A.2

Overall primary balance, Table 4A.2

Own-account capital formation in government finance statistics framework, 1.22, 1.24

market producer evaluation and, 2.73

recorded as acquisition of nonfinancial asset, 6.6, 6.9, 6.12, 6.27, 6.43, Table 8.1

Ownership

as feature of institutional units, 2.22 asset boundary and, 7.5-7.13

costs of transfer of, 6.60, 8.6-8.8, 8.42 , Figure 8.1

economic, 3.38, 3.39, 7.5, A4.4

government claims of, 3.40

in classification of leases, A4.4

in public-private partnerships, A4.61-A4.63, Box A4.4, Box A4.5 legal, 3.38, 7.5, A4.4

nonresident, 2.13

of corporations, versus control, 2.32, Box 2.2

of government units, 2.47, 2.79

of immovable assets, 2.13

of nonproduced assets, 7.90-7.91

of nonprofit institutional units, versus control, Box 2.1

transformation of assets in transfer of, 3.41

Own funds

as indicator of net worth of public corporations, 4.40, 7.229

as proxy for market value of equity, $7.173,7.232-7.233$

bonus shares as reclassification of, 5.111

definition of, 7.231

shares and other equity versus, 7.231, Figure 7.1 


\section{$\mathbf{P}$}

Partitioning of transactions, 3.11, 3.29, $3.118,3.124$, A7.29, Table A7.1

Partnerships, 2.32, 2.141, 7.169. See also Joint ventures; Publicprivate partnerships

Payroll taxes, 5.23, 5.25, 5.45, 5.76, 5.96

Pension entitlements

assumption of, 5.148, 6.124, 9.66-9.67, A2.60-A2.63

changes in classification of, 10.84 classification of, 7.189-7.198, 9.63-9.67

definition of, 7.190

holding gains or losses on liabilities for, 10.36-10.41

in calculation of distributable income, 5.116

in government finance statistics framework, 2.102

other changes in volume of assets for, 10.72-10.74

property expense attributed to, 6.113 sources of changes in, A2.54 treatment in 2008 SNA versus government finance statistics, 5.95, 6.97

valuation, 7.197

Pension funds

administrators, A2.48-A2.51

as financial corporations sector, 2.53-2.55, 2.115, A2.43, A2.47-A2.52

as financial intermediaries, 2.54-2.55

as public financial corporations, 2.102 claims of, on pension manager, 7.196, 7.199-7.200, 9.68, A2.50 cost of operations, 5.140, A2.58 employers' contributions to, $6.19-6.21,6.25$

expense recorded to attribute income, 6.113, 6.116-6.118

large one-off transfers from government to, 9.66-9.67, A2.60-A2.63 net worth of, 7.230

provident funds versus, 2.150

social security contributions versus contributions to, 5.95

Pension schemes as general government liability, $7.179,9.57,9.63$ autonomous versus nonautonomous,

A2.17, A2.24, A2.42-A2.53

boundary with social security, Table A2.1

classification, 2.147, A2.18, 7.191, A2.41-A2.43

compulsory versus voluntary, A2.17 consolidated statistical presentation, 3.164

contributions to employmentrelated, $6.19-6.26$

contributory versus noncontributory, A2.17

defined-benefit, 6.116-6.117, 7.191, 9.64, 10.36-10.41, 10.72-10.73, A2.54

defined-contribution versus defined benefit, A2.17

defined-contribution, 6.116, 6.118, $7.191,9.65,10.74$, A2.55-A2.59

employment-related, A2.22-A2.24, A2.41-A2.59

excluded from social security funds, 2.102

funded versus unfunded, 5.95, 7.193, A2.17, A2.24

holding gains and losses of, 10.41

imputed sale for services of operator of, 5.140

in government finance statistics framework, A7.21

net worth of, 7.230

other changes in the volume of, 10.72-10.74

other economic flows of, 10.38 10.40

reclassification of, 10.84

recording flows related to employment-related, A2.41-A2.63, Table A2.3 reserves for, 7.179, 7.189 social security schemes versus, 2.102, 4.48, 4.50, 5.95, 6.106, 7.194, A2.5-A2.7

treatment in 2008 SNA versus government finance statistics, 1.22, $4.19,5.95$

types of, 6.116, 7.191, A2.42 valuation of liabilities of, 7.181, 7.197-7.198, A2.57-A2.58

See also Pension entitlements; Pension funds
Permits

as assets, A4.3, 7.106, A4.46-A4.47, A4.54-A4.55, Table 7.8

boundary with administrative fees, 5.73-75, 5.138, 7.111

recording transactions in, issued by government, A4.42-A4.45, Box A4.2

rent versus, 5.124-5.130

to undertake certain activities, 7.110, A4.41-A4.52

to use environmental assets, A7.127 to use goods or perform activities, $5.72,5.81$

to use natural resources as sinks, A4.48-A4.50

to use natural resources, 7.109, A4.18-A4.35, A4.54-A4.55, Figure A4.1

Perpetual inventory method, 7.32, 7.45, Box 6.1

Personal attributes as assets, 3.43

Policy lending, 4.29-4.30, 4.57, 7.124, Box 4.1, Table 4A.2

Political parties, 2.61

Poll taxes, 5.93

Pollution

emissions permits, A4.48-A4.50 environmental protection and, A7.107, A7.119

subsidies to reduce, 6.90 taxes on, 5.81, Table 5.4

Preferred stocks or shares, 7.143, $7.150,7.166$

Premium, fees, and claims payable related to nonlife insurance and standardized guarantee schemes, 6.125, Table 6.11

Premium, fees, and claims receivable related to nonlife insurance and standardized guarantee schemes, 5.149-5.151, Table 5.12

Present value of future returns, 7.33

Prices, economically significant, 2.66-2.68. See also Economically significant prices

Primary balance, 4.55, A5.40, A6.40, Table 4A.1

Prison buildings, 7.47

Private corporations as market producers, 2.68 distinguishing head offices of, 2.128 
holding companies, 2.128

joint ventures with public sector units, $2.140-2.143$

nationalization of, 9.55

nonresident government controlled corporations, $2.14,2.111$

receiving aid from government, 2.114

relation to other sectors of the economy, Figure 2.1, Figure 2.2

subsidies to, $6.84,6.87$

See also Public-private partnerships

Private finance initiative, 7.39, A4.58

Privatization, 4.57, 9.53-9.54

Produced assets, 3.50, 4.16, 5.125, $5.131,7.17-7.18,7.34$

Production account, 6.53, A7.24-A7.30, Figure A7.1

Production costs, 2.37, 2.69, 2.73-2.74

Professional and trade associations, $2.37,2.61$

Property expense

definition of, 6.108

for dividends, 6.109-6.110

for investment income disbursements, 6.113-6.119, 10.36

for reinvested earnings on foreign direct investment, 6.121

for rent, 6.120

for withdrawals from income of quasi-corporations, 6.111-6.112

forms of, 6.108

See also specific type

Property income

definition of, 5.107

forms of, 5.107, Table 5.8

from dividends, 5.111-5.117

from interest, 5.108-5.110

from investment income disbursements, 5.120-5.121

from reinvested earnings on foreign direct investment, 5.134-5.135

from rent, 5.122-5.133

from withdrawn from income of quasi-corporations, 5.118-5.119

See also specific type

Property sales as exchange type of transaction, 3.9

Property taxes, 3.84, 5.46-5.54, 5.77

Provident funds, 2.148-2.151

Public corporations

as instruments of public or fiscal policy, 2.104 changes in net worth of, 4.40

characteristics of, $2.35,2.48$, 2.104-2.105

classification of equity transactions in, 9.47-9.51, Box 6.3

classification of revenue from sales of goods and services by, 5.137

classification of equity of, 7.15, $7.165-7.173,7.232$

consolidated statistical presentation, $3.153,5.42$

control of, 2.35, 2.107-2.112, Box 2.2

coverage of government finance

statistics framework, 1.2, 1.4, 2.1, $2.4,4.7$

decision tree for classification of subsector entities, 2.124,

Figure 2.4

detailed classification of counterparty information, Table 3.1

dividends of, 5.111-5117, 6.109-6.110 economic sector classification of, $2.59,2.64,2.104$

economic significance of, 2.104-2.105 evaluating economically significant prices of, 2.66-2.75

identification of, 2.64-2.75

in financial corporations sector, 2.57

in nonfinancial corporations sector, 2.52

monopoly powers of, 6.63

net worth of, 7.229, 7.232-7.233, 10.33

nonprofit institutions as, $2.37,5.67$

privatization of, 9.53

purposes of, 2.105

quasi-fiscal operations of, 2.4, 2.104

reclassification of, 10.77, 10.84

residence of, 2.14

restructuring of share distribution, 9.51

revenue source of, 5.1

subscriptions of, 6.42

subsector components, 2.104

subsidies, 5.146, 6.87

taxes collected by, 5.38

taxes payable by, 5.42

transfer, 3.10, 5.148, 6.124

types of, 2.113-2.121

Publicly guaranteed debt, 7.254-7.260, Figure 7.2, Table 4.6, Table 7.10

Public monuments, 7.42-7.43, $7.47-7.48,8.30,10.50$
Public policy-related assets and liabilities, 4.29-4.30, 4.57, Box 4.1

Public-private partnerships alternative names for, A4.58 contractual relationships in, 2.140, A4.60

definition of, A4.58

economic ownership in, 3.40, 7.39, A4.61-A4.63, Box A4.4, Box A4.5

ownership of fixed assets built under, 7.39

reasons for, A4.58-A4.59

statistical treatment of, A4.64-A4.65

Public sector

accounting standards, 1.35, A6.1A6.56

consolidated statistical presentation, 3.153-3.156, 3.164

coverage of government finance statistics framework, $1.2,1.4,1.26$,

$2.1,2.4,4.7$

decision tree for classification of entities in, 2.124, Figure 2.4

definition of, 1.2, 2.63

financial corporations subsector, $2.115-2.121$

groupings of institutional units, 2.122-2.123, Figure 2.2

institutional units of, 2.63

main components of, 2.63, Figure 2.3

nonfinancial corporations subsector, 2.114

relation to other institutional sectors, 2.62, Figure 2.2

scope of government finance statistics framework for reporting on, 1.26

subsector of, 2.63, Figure 2.3

uses of government finance statistics framework in analysis of, $1.10-1.12$

See also Public Corporations Public Sector Debt Statistics: A Guide for Compilers and Users, 1.8

Purchase of goods and services accrual recording versus cash recording, 4.35

as exchange type of transaction, $3.4,3.9$

change in inventory and, 6.6, 6.29, Table 6.3 
distributed without transformation, $6.40,6.27$

valuation of, 6.41

See also Use of goods and services

\section{Q}

Quasi-corporations

as public corporations, 2.112

central government, 2.88

classification of equity transactions in, 9.47-9.50

classification of, equity of, 7.165-7.169

definition of, 2.33

enterprises as, 2.25

establishments as, 2.24, 2.75

identifying, 2.34, 2.125-2.127

local government, 2.98

nationalization of, 9.55

net worth of, 7.173, 7.229, 7.232

privatization of, 9.53

state government, 2.94

time of recording withdrawals from, 3.87

transfers to, 6.98, 6.91, 6.123, 6.124,

9.49, Box 6.3

withdrawals from income of,

5.118-5.119, 6.108, 6.111-6.112, 9.49

Quasi-fiscal activities, 2.137, 3.10, 4.7, 7.170

Quasi-fiscal operations, 2.4, 2.104,

Table 4A.2

$\mathbf{R}$

Radio spectrum, 7.19, A4.4, A4.23-A4.25, A4.38, Table 7.7

Reassignment of transactions, 3.30

Reclassification

of assets or liabilities, 3.101-3.102, $10.50,10.80-10.84$

of institutional unit, 10.76-10.79

Recurrent taxes, 5.49-5.50, 5.53, 5.77, A7.119

Refinancing, A3.5, A3.14-A3.19

Refunds/recoveries of overpayments, 3.59, 3.104, 3.110, 3.143, 3.145, $5.7,5.27,6.4$

Regional arrangements central bank of, 2.21 classification of financial positions in member states and, 2.19 customs unions, A5.5, A5.6-A5.18 debt measurement in, A5.44 definition, A5.1

delineation of general government sectors in member states of, A5.42

economic unions, A5.5, A5.19-A5.31

harmonization for government finance statistics, A5.41-A5.44, Box A5.1

implications for government finance statistics, A5.1, A5.3, A5.36-A5.40

monetary and currency unions, A5.5, A5.32-A5.35

organizations, 2.17-2.19, A5.2

purpose of, A5.2

regional enterprises and, 2.20

supranational authorities, 2.18

time of recording economic flows in, A5.43

types of, A5.5

Regulatory agencies, 2.156-2.159

Reimbursement of job-related expenses, 6.15, 6.35-6.36

Reimbursement of social security benefits, 6.101, A7.59

Reinvested earnings, 5.134-135, 6.121, 10.34

Relief and aid agencies, 2.61, 6.38, 7.252

Religious organizations, $2.61,5.39-5.40$

Remuneration in kind, 3.21, 3.23, $5.108,6.17-6.18,6.35,9.3$

Rent

asset sale versus, 5.78, A4.21, Box A4.1

definition of, 5.122, 6.120

environmental-economic accounting, A7.122

excluded payments, 5.124

land taxes and, 5.128

on land, 5.126-5.128, A4.26-A4.27

on subsoil assets, 5.129-5.130, 7.99

permits to use natural resources,

7.109, A4.19-A4.35, Figure A4.1

radio spectrum, A4.23-A2.25

receivable by notional resident units, 2.13

recording income from, 5.123

rental of produced assets versus, 5.131-5.132, 7.96

resource lease, A4.16-A4.17

resource revenue and, 5.122,

Table 4A.2

taxes versus, 5.54, 5.133

time or recording $3.89,5.123,6.120$ types of, 5.125

use of goods and services versus, 6.51

Rental

of fixed assets, 6.50, 7.108

of produced assets, 5.131-5.132, 5.137, 5.141, A4.6-A4.9

receivable by notional resident units, 2.13

Replacement cost, 3.115, 7.31-7.32, $7.36,10.14, \mathrm{~A} 6.25$

Reporting periods, 3.52

Repos (repurchase agreement), 7.140, 7.157, 7.159, 9.46

Rerouting of transactions, 2.131, 3.28, $5.68, \mathrm{~A} 2.51$

Rescheduling, debt, 9.26, A3.5, A3.10-A3.13

Research and development, 6.46, 7.64, 7.66-7.67, 8.38, Table 7.5

Research institutions, 2.37, 2.61

Reserve tranche, IMF, A3.82, A3.84-A3.85, A3.89

Residence

classification of transactions in financial assets and liabilities by, 4.44, 7.120, 9.24-9.25, 9.85-9.87, Table 7.9, Table 9.1, Table 9.2

definition of, 2.7

in economic union, A5.24-A5.25

notional resident units, 2.13

of currency union central banks, 2.21

of general government units, 2.14

of institutional units, 2.12

of international organizations, $2.16-2.21$

of public corporations, 2.14

of regional enterprises, 2.20

of special or legal zones, 2.11

of special purpose entities, $2.15,2.138$

of territorial enclaves, 2.10

significance of concept of, 2.6

to determine economic territory, $2.2,2.7-2.9,2.124$

Resident artificial subsidiaries of government, 2.42-2.44, 2.162

Resource expense/revenue, Table 4A.2 Resource leases, 5.122, 6.120, 7.99, A4.4, A4.16-A4.17, A4.37

Restructuring agencies, 2.129-2.131, A3.46

Revenue

accounting rules for recording, 3.55 , $3.61-3.68,5.10,5.11$ 
attribution, 5.33-5.40

classification of, 1.21, 5.21-5.22,

Table 5.1, Table A8.1. See also specific type

definition of, 4.16, 4.23, 5.1

estimating, 3.78-3.80, 5.17-5.20

fiscal analysis, 5.9

for common budget of economic unions, A5.26-A5.28

gross versus net presentation of, 3.144-3.145, 3.147

in government finance statistics framework, 1.2, 1.15, 1.33, 4.16, 4.53, Figure 4.1

other, 5.6, 5.106

refunds, 3.59, 3.104, 3.110, 3.143,

$3.145,5.7,5.7,5.27$

Revenue Statistics, 5.26

time of recording and measurement of, 3.77-3.88, 5.10-5.16

transactions excluded from recording as, 5.8

types of, 4.23, 5.1. See also specific type

S

Sales of goods and services, 2.75, 3.144,

3.162, 5.1, 5.6, 5.136-5.141, 8.47, A2.58, A4.9, A7.123

taxes on use of goods versus, 5.73-5.75

See also specific type of sales

Sales taxes, 5.55, 5.59

School buildings, 7.47

Schools, 2.37, 2.114, 5.139, 5.148, 7.11, 7.47

Sector classification/Sectorization bailout operations and, A3.45A3.46, 2.125-2.162

consistency/inconsistency of, A7.6, A7.9, A7.99, A7.103

general government, 2.64. See also General government sector harmonization of, in regional arrangements, A5.42

of special purpose entities, 2.1362.139, A3.54

practical application of principles, 2.125-2.162

public sector, 2.63. See also Public sector

use of decision tree for, 2.124

Securities

as financial instrument, 4.28 asset-backed, 7.151

classification of, 7.143-7.153, 9.36-9.43

consolidation of, $3.163,3.165,9.19$

definition of, 7.119

embedded derivatives, 6.79

equity, $7.166,7.168$

grace periods of, 6.69

gross presentation of, 3.150

in policy lending, 4.30

index-linked, 6.75, 7.153

lending, 7.160

negotiability of, 7.119

repurchase agreement, 7.159

step-up interest of, 6.70

stripped, 7.152

taxes on, 5.61

time of recording transactions in, 3.93, 3.96, 9.13-9.16

types of, 7.143-7.153. See also specific types

valuation $3.111,3.113-3.115$, 3.117, 7.26-7.27, 7.122, 7.154-7.156, $9.8,9.9$

Securitization, debt arising from, 7.151, A3.59-A3.66

Seizure of assets, uncompensated, 3.31, $8.52,9.55,10.62$, A 4.29

Self-employment, 6.33

Services, time of recording transactions in, 3.88-3.92

Severance payments to employees, $6.16,6.104$

Severance taxes, 5.133

Shared assets, A4.36-A4.40

Shell companies, 2.15

Sinking funds, 2.144-2.146

Social assistance

definition of, 6.101, A2.25

eligibility to receive, 6.101, A2.25-A2.26

government reimbursement to corporations for provision of, A2.28

in kind, 6.39, A2.27

in typology of social protection arrangements, A2.18, A2.20, Figure A2.2

liability for future payments of, A2.29 payable tax credits as, 5.31 purpose of, A2.25

recording of flows related to, 3.10, 6.101-6.102, A2.27-A2.29, Table A2.1 scope of, 2.147, A2.5-A2.6

social insurance versus, Figure A2.1 types of, 6.102-6.103

Social benefits as transfer payment expense, A2.9

classification of expense for, 4.24, 6.16, 6.98, A2.4, Table 6.8.

See also specific types

definition of, 6.96, A2.4

delivery methods, cash versus in kind, A2.8

employment-related, 6.104-6.106

goods and services distributed as, 6.39-6.40

nonpension, A2.7

private insurance versus, A2.11-A2.16

purpose of, 6.96

social assistance, 6.101-6.102

transfers not eligible for classification as, 6.97, A2.10

See also Social assistance benefits; Social security benefits

Social contributions

as revenue, $4.23,5.4$

as transfer transactions, 3.10, 3.14

classification of, 4.23, 5.94-5.95,

Table 5.6

definition of, 5.4, 5.94, A2.4

employers', as expense, 6.19-6.26

fiscal burden of, 4.55, Table 4A.1

imputed, 5.100, 6.25-6.26, 6.105

taxes versus, 5.96

time of recording and measurement of, 3.77-3.82, 5.17-5.20

to social insurance schemes, $5.98-5.100$

to social security schemes, 5.97

transactions not eligible for classification as, 5.95

voluntary and compulsory, 5.94, 5.96, A2.16-A2.17

Social insurance schemes

contributions and benefits, 5.4, 5.94, $5.98,6.1,6.19$, A2.15, A2.31

defined-contribution versus defined-benefit, A2.17, A2.21, A2.54-A2.59

definition of, 2.101, A2.30

eligibility to participate in, 2.101 , A2.30

employee contributions as revenue, 5.99 
employers' contributions as expense, 6.19-6.26

employers' contributions as revenue, 5.99-5.100

employment-related, A2.22-A2.24, A2.40-A2.58, A2.64-A2.66, Table A2.3, Table A2.4

funded versus unfunded, A2.17 imputed contributions to, 5.100

in typology of social protection arrangements, A2.18, A2.20-A2.23, A2.32, Figure A2.2 individual insurance versus,

Figure A2.1

noncontributory, 6.26

programs covered by, 2.101

purpose of, A2.14, A2.30

See also Pension schemes, employment-related

Social protection arrangements administrative arrangements, A2.4 as institutional units, 2.46, 2.62, $2.100-2.103$

autonomous versus nonautonomous, A2.17

beneficiaries, population versus employees, A2.17

benefits to households, A2.3, A2.8

benefits/contributions as transfer transactions, 3.10

classification criteria for, A2.17 compulsory versus voluntary, A2.17 contributory versus noncontributory, A2.17

defined contribution versus defined benefit, A2.17

funded versus unfunded, A2.17

nature of, $\mathrm{A} 2.3$

pension versus nonpension, A2.17

private insurance and, A2.11-A2.16, Figure A2.1

purpose of, A2.1

types of, 6.98, A2.5-A2.7

typology of, A2.18-A2.24,

Figure A2.2

Social risks, 2.46, 5.4, 6.96, A2.1

Social security schemes

accounting rules, 3.144-3.145, 3.161

as general government subsector, 2.78, 2.100-2.103, A2.34

as social benefits expense,

$6.99-6.100$ benefits as transfer transactions, $3.10,3.14,3.17,6.99-6.100$

benefits in kind, 6.100, A2.37

classification of flows related to,

A2.34-A2.39, Table A2.2

classification of liabilities of, 7.194

compulsory versus voluntary, A2.16

contributions, 5.97, 6.19-6.26,

A2.36

definition of, A2.33

fund, 2.58, 2.62, 2.78, 2.100, 9.67,

A2.34-A2.35, Figure 2.3

in typology of social protection arrangements, A2.22, Figure A2.2

net implicit obligations for future

benefits, $4.13,4.15,4.47-4.48$,

4.50, 7.13, 7.261, A2.39, Table 4.6

pensions provided by, 2.147

presentation of statistics by level of government, 2.78

provident funds versus, 2.149-2.151

reporting contingent liabilities, 1.18, A2.38-A2.39

rerouting of transactions of, 3.28

scheme, 2.101-2.102

social insurance schemes and,

A2.32, Figure A2.1

tax on payroll versus, 5.23, 5.45

unilateral changes in, 4.49

See also Social contributions; Social insurance; Summary Statement of Explicit Continent Liabilities and Net Obligations for Future Social Security Benefits

Social spending, Table 4A.1

Sovereign statistics, 2.123

Sovereign wealth funds, 2.152-2.155

Special Drawing Rights, A3.82, A3.87

as debt instrument, 7.236, 7.243

classification as foreign currency, 3.136

classification of, 7.131-7.134, 9.31-9.32, A3.91-A3.95

creation or extinction of, 10.58

holding gains and losses on, $10.21-10.22$

unit of account, 3.1307.134

Special purpose entities

artificial subsidiaries of government as, 2.43

as institutional units, 2.137-2.138

classifying debt of, A3.54-A3.58 defining characteristics of, 2.136

equity of, 7.170

functions of, 2.137

nonresident foreign direct investment of, 5.134

recording of flows and stock positions, $2.138-2.139$

residence of, 2.15, 2.138-2.139

sector classification of, 2.137-2.139

Sports clubs, 2.61, 2.97, 6.17, 7.48

Sports players, A4.51

Stamp taxes, 5.93

Standardized guarantee schemes as debt instrument, 7.236, 7.243, 7.253 , Figure 7.2

classification of transfers in, A4.72

classification of, 7.178, 7.201-7.202

conceptual basis of, A4.71

consolidation of, 3.164

definition of, 7.201, A4.71

financial protection schemes provided by, 2.135

guarantee holders, public sector units as, A4.80

guarantors, public sector units as, A4.79

holding gains and losses, 10.35

premium, fees, and claims payable related to, $6.107,6.125$, Table 6.11

premiums, fees, and claims receivable related to, 5.6, 5.149-5.151,

Table 5.12

property expense for investment income disbursement, 6.113-6.115

providers of, A4.72

provisions for calls under, 3.49 , 7.201-7.202, 9.57, 9.69, 10.75

recording of flows and stock positions, A4.78-A4.80

terminology of, A4.73-A4.77

types of insurance, A4.68-A4.72

valuation of, 7.122, 7.180-7.181

See also Insurance, pension, and standardized guarantee schemes

State government

authorities and responsibilities of, 2.91

characteristics of, 2.90

definition of, 2.90

institutional units of, 2.80-2.83, 2.91-2.94 
institutional units subject to dual control, 2.79, 2.99

international comparison of data for, 2.77

relation to other institutional sectors, Figure 2.2, Figure 2.3

Statement of Operations accrual reporting of, 3.64, 3.107 analytic balances of, 4.17-4.20 classification of transactions in, 4.22 , Table 4.1

components of, $4.16,4.22$, Table 4.1

definition and purpose of, 3.64, 4.9

expense recorded in, 4.24, 6.6

financing transactions recorded in, 4.26-4.31

fiscal indicators derived in, 4.17-4.21, 4.53

implementation of governments finance statistics framework, 1.38

in analytic framework of GFSM 2014, 1.15, A7.18

in structure of analytic framework, 4.8, Figure 4.1

IPSASs statements versus, A6.37 purpose of, 1.15

revenue recorded in, 4.23, 5.10

Statement of Sources and Uses of Cash and, 4.12, 4.35

Statement of Total Changes in Net Worth and, 1.18, 4.46

System of National Accounts and, 7.14, Table A7.2

transactions in nonfinancial assets recorded in, 4.25

Statement of Other Economic Flows accrual reporting of, 3.64, 3.107 classification of changes in net worth in, 4.36-4.38, 10.2, Table 4.3, Table 10.1

definition and purpose of, 1.16, $3.64,4.10$

holding gains and losses recorded in, 4.37

in analytic framework of GFSM 2014, 1.16, 4.8, A7.20

in structure of analytic framework, 4.8, Figure 4.1

IPSASs statements versus, A6.31, A6.37, A6.53

other changes in volume of assets/ liabilities recorded in, 4.38 purpose of, 4.36

Statement of Total Changes in Net

Worth and, 1.18, 4.46

valuation of flows in, 3.107

Statement of Sources and Uses of Cash cash basis of recording in, 3.67 , $3.103,4.34$

classification of cash flows in, 4.32, Table 4.2

government borrowing in, 3.105

implementation of government finance statistics framework, $1.15,1.38$

in structure of analytic framework, 4.8 purpose of, 1.15, 3.68, 3.103, 4.32 recording of consumption of fixed capital, 6.61

recording of expense transactions, $3.104,6.7$

recording of grants in kind, 6.95 recording of purchase of goods and services, 6.31

recording of revenue in, 3.104, 5.11

Statement of Operations and, 3.106, $4.12,4.35$

valuation in, 3.107

Statement of Total Changes in Net Worth

definition and purpose of, 4.14, 4.46

in analytic framework of GFSM 2014, 1.18, 4.13, Table 4.5

Statistical units, 2.2-2.3. See also Institutional units

Statistics compilation method/ principles, $1.1,1.25-1.35$

Stock positions

balance sheet, 1.17, 1.30, 3.56, 7.1

classification of, Table A8.3, 7.34-7.232. See also specific categories

definition of, 3.1, 3.36

economic benefits, 3.37

in government finance statistics framework, 1.15, 1.21, 3.36

in structure of analytic framework, 4.8, Table 4.1

integration of economic flows and, $1.20,1.31,3.2$

net/gross presentation of, 3.143-3.151 valuation of, 3.107, 3.113-3.117, $7.20-7.33$

Stripped securities, 7.152
Structural balances, 4.58, A5.40,

Table 4A.2

Structural primary balances, Table 4A.2

Subscription fees, 2.37, 2.53, 6.42, $6.123,9.52, \mathrm{~A} 3.82$

Subsidies

as transfer transactions, 3.10, 3.17, 6.85

capital transfers versus, 9.49

central bank interest rate policies as, 5.26, 5.70, 6.89, Box 6.2

classification of, as expense, 1.23, $4.24,6.84-6.91$, Table 6.6

classification of, as revenue, 5.146, Table 5.11

definition of, 5.146, 6.84

environmental, A7.130-A7.134

expense incurred by non-government unit, 6.84

foreign trade, 6.89

general government units as recipient of, 6.86

in Classification of Functions of Government, 6.145

in exchange rate regimes, 5.26, 5.89, 6.89

in government finance statistics framework, 1.23

losses of government trading organizations as, 6.89

on production, 6.90

on products, 6.89

purpose of, 6.84

tax credits as, 5.31, 6.89

to households, $6.86,6.91$

to nonprofit institutions serving households, 6.86

transfers not qualifying as, 6.91

treatment in calculation of economically significant/market prices, $2.69,2.74,3.110,5.136$

Subsoil assets, 5.54, 5.129-5.130, 7.93, 7.97-7.99, 8.32, 8.51, 10.52. See also Mineral and energy resources; Mineral exploration and evaluation

Summary Statement of Explicit Continent Liabilities and Net Obligations for Future Social Security Benefits

classification of revenue and expenses in, 4.48-4.50, Table 4.6

in analytic framework of GFSM

$2014,1.19,4.13$

purpose of, $4.15,4.47$ 
Super-dividends, 5.115-5.116, 6.110

Supranational authorities, 2.18, 5.37

Sustainability

calculation of primary balance for analysis of, 4.55, Table 4A.1

changes in net worth as indicator for, $1.10,1.33,2.106,3.167,4.3$, $4.18,4.39-4.40$

debt sustainability, 4.55

net financial worth as indicator for, 4.41

net operating balance as a summary measure of, 4.18

Swap contracts, 7.215-7.217, A3.20-A3.23, A3.67-A3.71

System of Environmental-Economic Accounting Central Framework, A7.105-A7.134

System of National Accounts 2008 consolidation principles in, 3.167 consumption of fixed capital in, 6.53 coverage of social contributions in, 5.95

government finance statistics framework and, 1.8, 1.22-1.24, 1.35, 3.6, 4.6, A7.5-A7.72, Table A7.1, Table A7.2, Table A7.3, Table A7.4, Table A7.5 treatment of economic activities in, 3.6

treatment of tax revenue in, 5.25

$\mathrm{T}$

Tax burden, 1.3, Table 4A.1, A5.38

Taxes

accounting presentation, 3.143, 3.145 administrative fees versus, 5.73-5.75 amnesties, 5.19

as revenue transactions, 3.5 ,

$3.10-3.13,4.23,5.1-5.2$

attribution/assignment principles, $3.30,5.33-5.40$

burden, fiscal analysis of, 4.55, 5.9, Table 4.1

business and professional licenses, 5.81

capital levies, 5.52

capital, 5.51

cash basis recording, 3.104

central governments' right to impose, 2.85

characteristics of, 5.2

classification of, 5.21-5.26, Table 5.1 consolidation, 3.161-3.162

credits as subsidies, 5.31, 6.89

credits, 5.29-5.32

definition of, $5.2,5.23$

direct versus indirect, Table 4A.1

earmarked taxes, 2.41, 2.79, 2.146, 5.39

environmental, A7.115-A7.121

exchange profits, $5.88-5.90$

exchange, 5.91

excise, 5.62

expenditures, 5.28

fines and penalties on overdue, 5.24, 5.143

general taxes on goods and services, 5.57-5.61, Table 5.3

gross versus net presentation of, 3.143-3.145

harmonization of, A5.20

implicit taxes of central banks, 5.70, Box 6.2

imposed by force of law, 3.5

imputation system of corporate income, 5.44

in common budget of economic unions, A5.26-A5.28

in cross country comparisons, 1.13

in System of National Accounts 2008, 5.25

interest payable on overdue, 5.24, 6.82

local governments' right to impose, 2.95

multistage, 5.60

net presentation of, 3.143-3.145

of government employees, 3.161

on business activities, 5.76

on capital gains, 5.41

on emissions, 5.81, A4.48-A4.49

on estates, 5.51

on exports, 5.85

on extraction of exhaustible resources, 5.82

on financial and capital transactions, 5.61

on foreign exchange transactions and profits, 5.88-5.91

on gifts, 5.51

on goods and services, 5.55-5.56. See also specific type

on goods and services, general, 5.57-5.61, Table 5.3

on imports, 5.84 on income, profit, and capital gains,

5.41-5.44, Table 5.2

on income of corporations, 5.41

on income of individuals or house-

holds, 5.41

on inheritance, 5.51

on international trade and transactions, 5.83-5.92, Table 5.5

on motor vehicles, $5.79,5.80$

on net wealth, 5.50

on ownership of assets or net worth, levied irregularly, 5.52

on ownership of immovable property, 5.49

on ownership of property other than immovable property, levied regularly, 5.53

on payroll and workforce, 5.45

on permission to perform activities, $5.72,5.79$, Table 5.4

on permission to use goods or perform activities, 5.72, 5.79, Table 5.4

on pollution, 5.81

on production, 2.74, A7.41, Table A7.3

on profits of export or import monopolies, 5.86-5.87

on profits of fiscal monopolies, $5.63-5.68$

on property, $3.84,5.46-5.54,5.77$

on recreational activities

on religious organizations, $5.39-5.40$

on specific services, 5.69-5.71

on use of goods and permission to use goods or perform activities, $5.72,5.79$, Table 5.4

on winnings from lotteries or gambling, 5.41

other taxes category, 5.93

other taxes on goods and services, 5.82

other taxes on international trade and transactions, 5.92

other taxes on use of goods and on permission to use goods or perform activities, 5.81

payment in kind of, 3.24

payments classified as transactions, $3.5,3.10,3.12-3.13$

payroll and workforce, 5.45

penalties/fines on overdue, $5.24,5.143$

permits as A4.42 
refunds, 3.145, 5.7, 5.27

regional organizations and, 2.18

relief measures, 5.28-5.31

rent and, 5.128, 5.133

sales, 5.59

severance, 5.133

social contributions versus, 5.96

state governments' right to impose, 2.91

time of recording and measurement of, 3.57-3.60, 3.62, 3.76-3.86, $5.10-5.20$

value-added, 5.58

withheld from employees, 3.161, 6.12

Territorial enclaves, 2.9-2.10, 2.13, 2.16, 8.50, A3.56, A7.84

Territorial waters, 2.9, 3.40, 7.19

Timber resources, 5.82, 5.127, 7.61, $7.82,8.34,10.52, \mathrm{~A} 4.28-\mathrm{A} 4.29$

Time of recording economic flows accounting bases, choices, 1.27, 3.57-3.60, 3.68

advantages of accrual accounting, $3.68-3.74$

appearance or disappearance of existing assets, 10.52

challenges in, 3.58-3.59, 3.75, 5.14 consumption of fixed capital, 3.90, 8.16

dividends, 3.87, 5.112, 6.109

expense transactions, 6.6-6.7

fines and penalties, 3.85, 5.144

grants, 3.86, 5.105

holding gains and losses, 3.99-3.100, 10.7

in accrual basis accounting, $3.62-3.64,3.76-3.102$

in cash basis accounting, 3.67, 3.69, 3.70, 3.71, 3.72, 3.103-3.106

in commitments basis accounting, $3.65,3.69,3.71$

in due-for-payment basis account-

ing, 3.66, 3.69, 3.70, 3.71, 3.73

in government finance statistics

framework, integration of 3.57

in regional arrangements, A5.43

income taxes, $3.83,5.15$

inventories, 3.91, 8.47

operating leases, 3.90

other changes in the volume of

assets, 3.98, 3.101-3.102

other economic flows, 3.98-3.102 production of fixed assets, 7.37

reclassifications, $3.102,10.83$

revenue transactions, $5.10-5.20$

sales of goods and services, 5.141

taxes and compulsory transfers/social contributions, 3.77-3.86, 5.12

taxes on ownership of property, 3.84

transactions in services, 3.89

transactions in financial assets and liabilities, 3.93-3.97, 9.2, 9.13-9.16

transactions in goods, services, and nonfinancial assets, 3.88-3.92

transactions in nonfinancial assets, $8.2,8.13-8.17$

transactions with nonfinancial component, 9.15

use of goods and services, 3.92, 6.7, 6.28

withdrawals of income from quasicorporations, 3.87

Tools, 6.15, 6.35, 6.43, 7.40, 7.52, 8.33

Total change in net worth, Table 4A.1. See also Changes in net worth

Total expenditure or outlays, Table 4A.1. See also Expenditure

Total financing, Table 4A.1. See also Financing

Total transfer payments excluding grants, Table 4A.1

Trade, international

associations, 2.37, 2.61, 6.42

government trade organizations, 6.89

sales of monopolies in, 5.86-5.87

subsidies, 6.89

taxes on, 5.83-5.92, Table 5.5

zones, 2.11

Trade credit and advances, 3.72, 3.95, 7.225, Table 4A.1

Transactions

barter as, 3.22

characteristics of transactions, $3.7-3.30$

classification of, 1.15, 1.21, 3.7, $5.21-5.22,6.8,6.148-6.150$, 8.21-8.23, 9.24-9.27, Table 5.1, Table 6.1, Table 6A.1, Table 6A.2, Table 8.1, Table 9.1

counterparty classifications, 2.23 , 3.165, Table 3.1, Table 9.2,

Table A8.4

currency conversion for recording, $3.132-3.133$ definition of, $3.5,4.9$

double-entry of, 3.54

exchanges as, 3.9

imputed, 3.28

in government finance statistics framework, 1.15, 1.20, 1.26-

$1.28,1.32-1.34,3.6-3.7,4.22$,

Figure 4.1, Table 4.1, Table 4.2

in kind, 3.23-3.25

integration of, 1.20, 1.31, 3.36

internal/intra-unit, 3.26

monetary, 3.8-3.18

nonmonetary, 1.28, 3.19-3.26

partitioning of, 3.29

rearrangements of, for recording, $3.27-3.30$

reassignment of, 3.30

rerouting of, 3.28

time of recording of. See Time of recording economic flows

transfers as, 3.10-3.18

two-party nonmonetary transactions, 3.21-3.25

valuation of. See Valuation

See also specific type of transactions

Transfer pricing, 3.122

Transfers

as monetary transaction, 3.10

as nonmonetary transaction, 3.19

capital versus current, 3.15-3.18, $4.23,5.145,5.147-5.148,6.122$, 6.123-6.124

compulsory transfers, 3.85

conditional, 3.86

consolidation of, 3.155

definition of, 3.10

exchanges combined with, 3.11-3.12

fines and penalties as, 5.142

grants as, 5.5, 5.101-5.105, 6.92-6.95, Table 5.7, Table 6.7

in-kind, 3.25

nonlife insurance premiums and claims, 3.14

not elsewhere classified, 5.6, 5.145-5.148, 6.122-6.124, Table 5.11, Table 6.10

of goods and services, 6.37-6.42 social benefits as, 6.96-6.106 subsidies, 5.146, 6.84-6.91,

Table 5.11, Table 6.6

taxes, 3.13

time of recording, 3.77-3.86

types of, 3.12-3.15 
use of goods and services versus, $6.37-6.42$

valuation of, $3.112,3.121$

voluntary transfers, 3.86

Transport equipment, 7.54, Table 7.4

Tree, crop, and plant resources, 7.59, 7.61-7.63, 8.34-8.36, Table 7.5

Turnover and other general taxes on goods and services, 5.60, Table 5.3

\section{U}

Underwriting facilities, 7.259

Unions, trade and labor, 2.61, A2.11

Unit of account, 3.51, 3.130-3.131

Use of goods and services acquisition of nonfinancial assets versus, 6.43-6.49, 7.40, 7.57

as charges for collection fees, 5.35 as expense, 4.24 , Table 6.1 compensation of employees versus, $6.9,6.15,6.18,6.33-6.36$

definition, 6.27

distributed as social benefits, $6.39-6.40$

excluded from, 6.27

fees and charges related to, $5.136-5.138,6.30$

fees for financial services and, 6.52, 6.81

gross recording of, 6.30

in calculation of production costs, $2.74,5.136$

in own-account capital formation, $6.27,8.15$

in production of coins or notes, 6.48 in research and development, 6.46 indirect estimation of, 6.29

internal or intra-unit transactions in, 3.26

inventories and, 6.29, 6.44, Table 6.3

major renovations versus, 6.45 , $8.25-8.27$

military, 6.49

mineral exploration and evaluation, 6.47

prepayments for, 6.69

reimbursement to employee as, 6.15 rent versus, 6.51

rentals and financial leases versus, 6.50 taxes on, $3.84,5.35,5.55,5.72-5.82$ time of recording, 3.92, 6.28, 6.31 transfers of goods and services versus, 6.37-6.42, 6.97
V

Valuables

as payments in kind, 3.24

catastrophic losses, 10.60

classification of, 3.50, 4.25, 4.44, $6.43,7.17$

consumption of fixed capital on, 6.55 costs of ownership transfer, 8.7, 8.48 definition of, 7.18, 7.87

economic appearance or disappearance of, 10.50

holding gains on, 10.18

reclassification of, 10.84

types of, $7.88,7.129$

valuation of, $7.20,7.89,8.9,8.48$

Valuation

accumulating and revaluing transaction, 7.31-7.32

as reason for consolidation discrepancies, 3.165

effect of external events on, 10.59

estimation of, 3.125

general rule for, 3.107

gross debt, 7.239-7.242

in government finance statistics framework, 1.29

in Statement of Operations, 3.107

in Statement of Sources and Used of Cash, 3.107

IPSASs versus GFS, A6.25-A6.30

observed in markets, 7.26

of arrears, 3.71, 7.250

of assets and liabilities, 7.20-7.33

of barter, 3.112, 3.125

of changes in volume of assets, 3.128-3.129

of concessional loans, 3.123

of consumption of fixed capital, Box 6.1

of debt instruments, 7.238

of debt securities, 7.154-7.156

of deposits, 7.142

of derived measures, 3.140-3.143

of dwellings, 7.45

of employee stock options, 7.223

of equity, 7.166, 7.171-7.173

of financial derivatives, 7.204

of fixed assets, 7.36, 8.9

of grants in kind, 5.104

of holding gains and losses, 3.127

of inventories, 7.78, 8.10

of land, 7.94

of loans, 7.163 of nonperforming loans, 7.262-7.263

of other changes in the volume of assets

of other economic flows, 3.126

of public monuments, 7.43

of stock positions, 3.2, 3.113-3.117

of transaction after partitioning, 3.124

of transactions and stock positions expressed in foreign currency, 3.119

of transactions in financial assets and liabilities, 3.11, 9.7-9.12

of transactions in nonfinancial assets, $8.9-8.12$

of transactions with a contractual quotation period, 3.120

of transactions with transfer pricing, 3.122

of transactions, 3.108-3.112, 8.9-8.12

of transfers in kind, 3.112, 3.121, 3.123

of valuables, $7.89,8.48$

present value of future returns, 7.33

when payment made after long delay, 3.118

Value-added taxes, 5.27, 5.58,

Table 5.3, A7.120

W

Wages and salaries definition, 6.12, Table 6.2

in cash, 6.13-6.16

in kind, 6.17-6.18

reimbursements of costs not counted as, 6.15

social benefits not counted as, 6.16

War, 6.58, 6.91, 10.60-10.61

Water resources, 7.12, 7.102, A4.32-A4.34, A7.119

taxes on, $5.62,5.71$

Weapons systems, 6.49, 7.52, 7.74, 8.43

Work in progress, 3.91, 6.29, 6.44, 7.37, 7.62, 7.80, 7.82. 8.47, Table 7.6

Write-offs, debt, 4.35, 10.24, 10.57, A3.4, A3.7, A3.32-A3.34

$\mathbf{Z}$

Zakat taxes, 5.39-5.40

Zero-coupon bonds, 3.70, 3.115, 4.35, $6.71,7.147,9.40,10.25$ 